COMPEDNIUM OF LOW-COST PACIFIC SALMON

AND STEELHEAD TROUT PRODUCTION FACILITIES

AND PRACTICES IN THE PACIFIC NORTHWEST

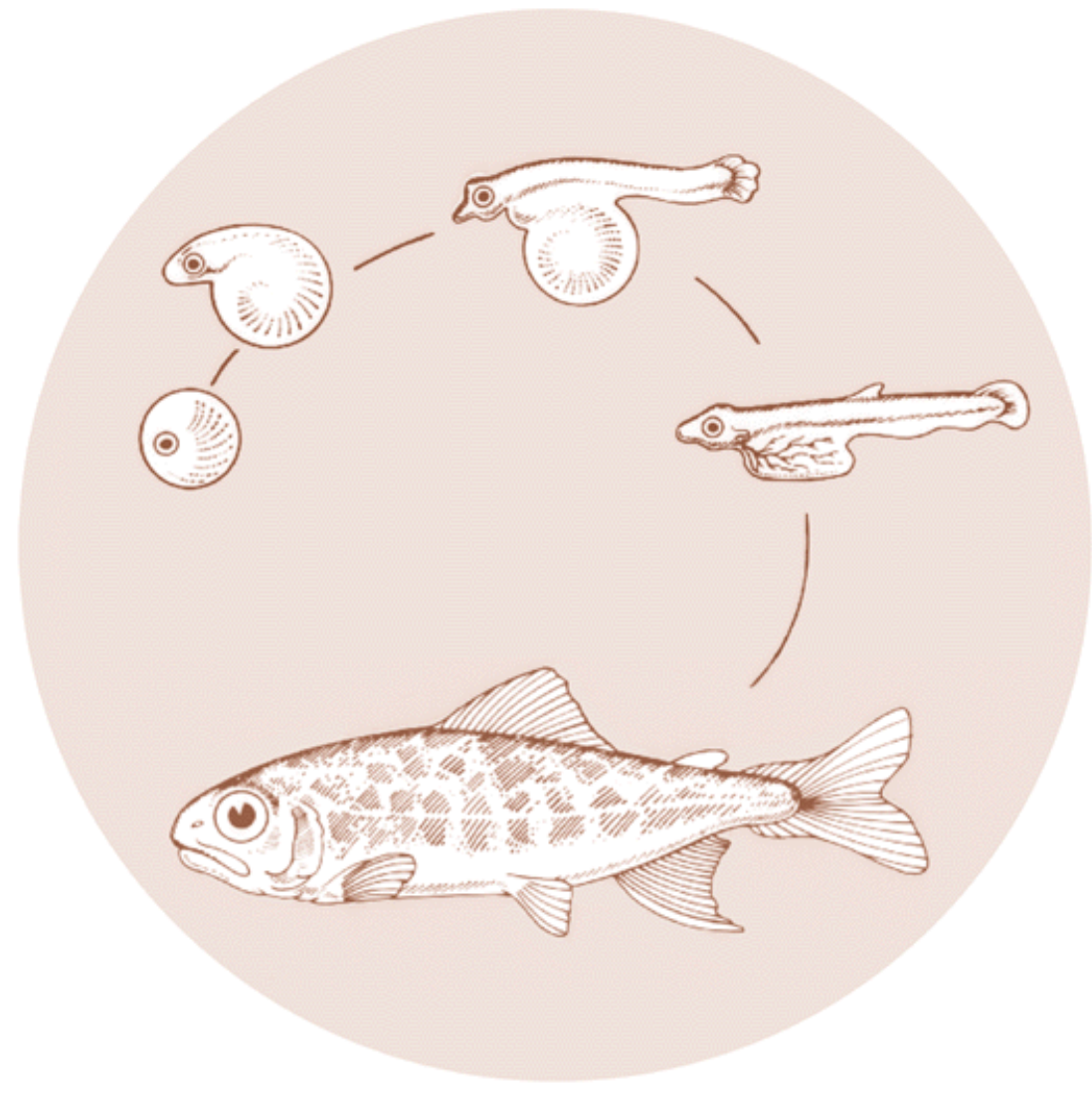

DOE/BP-365 
This report was funded by the Bonneville Power Administration (BPA), U.S. Department of Energy, as part of BPA's program to protect, mitigate, and enhance fish and wildlife affected by the development and operation of hydroelectric facilities on the Columbia River and its tributaries. The views of this report are the author's and do not necessarily represent the views of BPA.

This document should be cited as follows:

Harry Senn, J. Mack, L. Rothfus, Fish Management Consultants, Compendium of Low-Cost Pacific Salmon and Steelhead Trout Production Facilities and Practices in the Pacific Northwest, 1984, to Bonneville Power Administration, Portland, OR, Contract DE-AC79-83BP12745, Project 83-353, 513 electronic pages (BPA Report DOE/BP-365)

This report and other BPA Fish and Wildlife Publications are available on the Internet at:

\section{http://www.efw.bpa.gov/cgi-bin/efw/FW/publications.cgi}

For other information on electronic documents or other printed media, contact or write to:

Bonneville Power Administration Environment, Fish and Wildlife Division

P.O. Box 3621

905 N.E. 11th Avenue

Portland, OR 97208-3621

Please include title, author, and DOE/BP number in the request. 


\title{
COMPENDIUM OF LOW-COST PACIFIC SALMON AND STEELHEAD TROUT PRODUCTION FACILITIES AND PRACTICES IN THE PACIFIC NORTHWEST
}

Prepared by:

Harry Senn

John Mack

Lloyd Rothfus

Fish Management Consultants

\author{
Prepared for: \\ U.S. Department of Energy \\ Bonneville Power Administration \\ Environment, Fish and Wildlife \\ PO Box 3621 \\ Portland, Oregon 97208 \\ Project No. 83-353 \\ Contract No. DE-AC79-83BP12745
}

September 1984 
TABLE OF CONTENTS

INTRODUCTION

Page

$\begin{array}{cl}\text { CHAPTER } 1 & \text { WATER QUALITY } \\ \text { PART I. } & \text { TEMPERATURE } \\ \text { PART II. } & \text { DISSOLVED GASES } \\ \text { PART III. } & \text { WATER HARDNESS } \\ \text { PART IV. } & \text { TURBIDITY } \\ \text { PART V. } & \text { TOXIC MATERIALS } \\ \text { PART VI. } & \text { PATHOGENS }\end{array}$

CHAPTER 2 WATER COLLECTION, DELIVERY, AND QUALITY IMPROVEMENTS 12

PART I. WATER COLLECTION SYSTEMS

A. SURFACE WATERS

1. Stream and Lake Bank Intakes

2. Instream Diversion Dam with Screen Intake Structure 14

3. Instream Rock Filter Intakes 15

4. Miscellaneous Submerged Screen Intakes 15

B. SPRING WATERS 19

C. WELL WATERS 19

D. INFILTRATION SYSTEMS 22

$\begin{array}{lll}\text { PART II. } & \text { WATER DELIVERY SYSTEMS } & 24\end{array}$

A. PUMPS 24

1. Piston Pump 24

2. Gear Pump 24

3. Rubber Vane Pump 24

4. Axial Flow Propeller Pump 24

5. Centrifugal Pump 24

6. Air Lift Pump 24

B. GRAVITY 26

1. Pipelines 26

2. Open Channels 28

C. SIPHON 29

PART III. $\quad$ WATER QUALITY IMPROVEMENTS 30

A. DEBRIS REMOVAL 31

1. Coarse and Fine Screens 31

2. Inclined Plane Screen 32

3. Rotary Drum Fine Screen 33

4. Water Settling Basins 33

3. Other Debris Removal Methods 34 
B. GAS STABILIZATION 35

1. Tower/Media or Packed Column 37

2. Aspirator $\quad 39$

3. Paddle Aerators 40

4. Spray Aerators 41

5. Floating Aerator 42

6. Vacuum Degassing $\quad 42$

7. Multicone Aerator 44

8. Dissolved Gas Measurementation 45

C. WATER STERILIZATION 46

D. TEMPERATURE CONTROL TECHNIQUES 47

CHAPTER 3 ADULT COLLECTION, HOLDING, AND SPAWNING 49

PART I A ADULT COLLECTION $\quad 49$

A. BARRIERS 49

1. Single and Double Racks 49

2. Electric Fence 53

3. Velocity Barrier 55

4. Vertical Barrier Dam 56

B. FISHWAYS 58

1. Pool-and-Weir $\quad 59$

2. Denil-Type or Alaskan Steep Pass 60

3. Plastic Pool-an\&Weir 62

4. Rock Blasted Fishway 62

5. Wood Pool-and-Weir Fishway 63

C. HAND METHODS 63

$\begin{array}{ll}\text { 1. Nets } & 63\end{array}$

2. Snagging and Gaffing 64

3. Hook-and-Line Capture 67

4 . Electro-shocking 67

D. ARTIFICIAL IMPRIN TING 67

PART II. ADULT HOLDING FACILITIES $\quad 68$

A. BIOLOGICAL REQUIREMENTS 69

B. HOLDING PONDS

1. Long-Term Dirt Holding Pond 72

2. Long-Term Graveled Holding Pond 73

3. Long-Term Asphalt Holding Pond 73

4. Short-Term Concrete Holding Pond 74

5. Short-Term Shot-Crete Holding Pond 74

C. INFOR.IIL ADLLT HOLDING FACILITIES AND TECHNIQUES 75

1. Portable Tanks and Net Pens 75

2. Live Boxes ij

3. Traps and Juvenile Rearing Ponds 76

4. Compartment Holding Techniques 76

3. Tethering 78

PART III. $\quad$ SPAWNING

B. MATURATION CONTROL 
C. SPAWNING METHODS 81

D. ANESTHETICS $\quad 82$

E. TOOLS USED IN SPAWNING 83

CHAPTER $4 \quad$ INCUBATION 86

PART I. $\quad$ BIOLOGICAL REQUIREMENTS OF EGG INCUBATION

PART II. $\quad$ INCUBATION UNITS $\quad 88$

A. VERTICAL INCUBATORS 88

1. Vertical-Cabinet Incubator 88

2. NOPAD Incubator 91

B. TROUGH INCUBATORS 93

1. Deep-Trough Incubator 93

2. Shallow-Trough Incubator 95

c. POND INCUBATION 97

D. BOX INCUBATORS 99

1. False Bottom, or Deep-Matrix, Incubator 101

2. Baffled, or Shallow-Matrix, Incubator 104

3. Montana Hatching Box 106

4. Free-Style Incubation Box 107

E. CYLINDRICAL INCUBATORS 109

1. Jar Incubator 109

2. Jug and Bucket Incubators 111

3. Barrel Incubators 113

F. CHANNELS AND INSTREAM INCUBATION 114

1. Spawning Channel 114

2. Incubation Channel 117

3. Keeper Channel (Japanese style) 118

4. Planting of Eggs 119

$\begin{array}{lll}\text { PART III. INCUBATION TOOLS AND EQUIPMENT } & 120\end{array}$

A. EGG SORTERS 120

1. Hand Picking 121

2. Floatation Method 122

3. Mechanical Pickers (optical density method) 123

4. Bounce Method (Buzzell sorter) 123

B. EGG COUNTERS AND ENUMERATION MIETHODS 124

1. Nechanical Counters 124

2. Paddle Counter 124

3. Estimation Tools and Methods 124

C. SUBSTRATES 125

1. Gravel Substrate 126

$\begin{array}{ll}\text { 2. Plastic Netting } & 127\end{array}$

3. Plastic Saddles 128

4. Plastic Bio-Rings 128

PART IV. SU.IMARY 129

CHAPTER 5 REARING 133

PART I. BIOLOGICAL REQUIREMENTS 133

\begin{tabular}{ll} 
PART II. & REARING FACILITIES \\
\hline
\end{tabular} 
$\begin{array}{ll}\text { A. TROUGHS AND TANKS } & 137\end{array}$

1. Capilano Rearing Trough 138

B. RACEWAYS 139

1. Concrete Raceway 141

2. Earthen Raceways 142

3. Wooden Raceways 144

4. Metal Raceways 146

5. Fiberglass Reinforced Plastic Raceways 147

C. CIRCULAR PONDS 147

1. Concrete Circular Pond 149

2. Earthen Circular Pond 150

3. Plastic Circular Pond 151

4. Plastic-Sheet Circular Pond 152

5. Wooden Circular Pond 153

6. Circular Painted Sheet-Steel Pond 154

D. LARGE REARING PONDS 154

1. Large Dirt Pond 157

2. Large Gravel-Surfaced Pond 158

3. Large Asphalt-Surfaced Pond 159

4. Large Concrete-Surfaced Pond 160

5. Large Shot-crete-Surfaced Pond 160

6. Large Plastic Sheet-Surfaced Pond 161

E. NET PENS AND NET ENCLOSURES 161

1. Net Pens 162

2. Net Enclosures 164

F. REARING CHANNELS 168

G. SUMMARY - REARING FACILITIES 168

$\begin{array}{lll}\text { PXRT III. } & \text { FISH FOOD } & 168\end{array}$

$\begin{array}{lll}\text { PART IV. } & \text { SUPPORT EQUIPMENT } & 171\end{array}$

A. FEEDERS 171

1. Hand Feeding 171

2. Stationary Mechanical Fry Feeders 172

3. Stationary Pond Feeders 174

4. Demand Feeders 175

5. Mobile Feeders 175

B. POND SCREENS 176

1. Perforated Plate 177

2. Slotted Plate 178

3. Hardware Cloth 180

4. Aluminum Tude 181

5. Rotary Drum Screen 183

6. Belt Screens 184

C. PUMPS $18 j$

1. Trash Pump 183

2. High Pressure Pump 185

3. Vacuum Pump 186

4. Fish Transfer Pump 187

D. DIP-NETS XND SEINES 188 
E. POND CARE AND CLEANING 189

1. Pond Brooms 189

2. Paint As An Algacide 191

3. Herbicides 191

4. Chemical Applicators 192

5. Cleaning Large Ponds 192

F. POPULATION ENUMERATION 193

G. $\quad$ SIZING DEVICES 194

H. DISCHARGE WATER FACILITIES 195

CHAPTER 6 TRANSPORTATION OF SPERM, EGGS, AND LIVE FISH 199

PART I. SPERM AND EGG THANSPORTA'I'ION 199

A. GAMETE SHIPMENT 199

B. EGG SHIPMENT 200

PART II. LIVE FISH TRANSPORTATION 2ou

A. BIOLOGICAL REQUIREMENTS 201

B. ON-STATION FISH TRANSPORTATION EQUIP.IENT 202

1. Pipes and Tubes 202

2. Flumes 205

3. Pumps, Brails and Lifts 205

4. Crowders 206

3. Small Containers 20i

C. OFF-STATION FISH TRANSPORTATION EQUIP.IIENT 207

1. Portable Tanks 208

2. Tank Trucks and Tank Trailers 211

3. Floating Live Box 214

4. Tube Transfers 214

5. Collapsible Roll Poly 215

6. Cans, Buckets, and Backpacks 216

CHAPTER 7 PRODUCTION SUPPORT FACILITIES AND EQUIPMENT 218

$\begin{array}{llr}\text { PART I. } & \text { BUILDINGS } & 218\end{array}$

$\begin{array}{lll}\text { PART II. } & \text { FOOD STORAGE } & 222\end{array}$

$\begin{array}{lll}\text { PART III. } & \text { ROADS } & 224\end{array}$

$\begin{array}{lll}\text { PART IV. } & \text { SECURITY AND ALARM SYSTEMS } & 225\end{array}$

A. WATER ALARMS 227

1. Water Intakes 228

2. Incubation Units 228

3. Rearing Ponds 228

B. ADULT FISH SECURITY 229

1. Fences 229

2. Buildings 229

3. Lights 230

4. Guards 230

C. JUVENILE FISH SECURITY 230

1. Canopies and Covers 230

2. Fencing 232

3. St ringers 233 


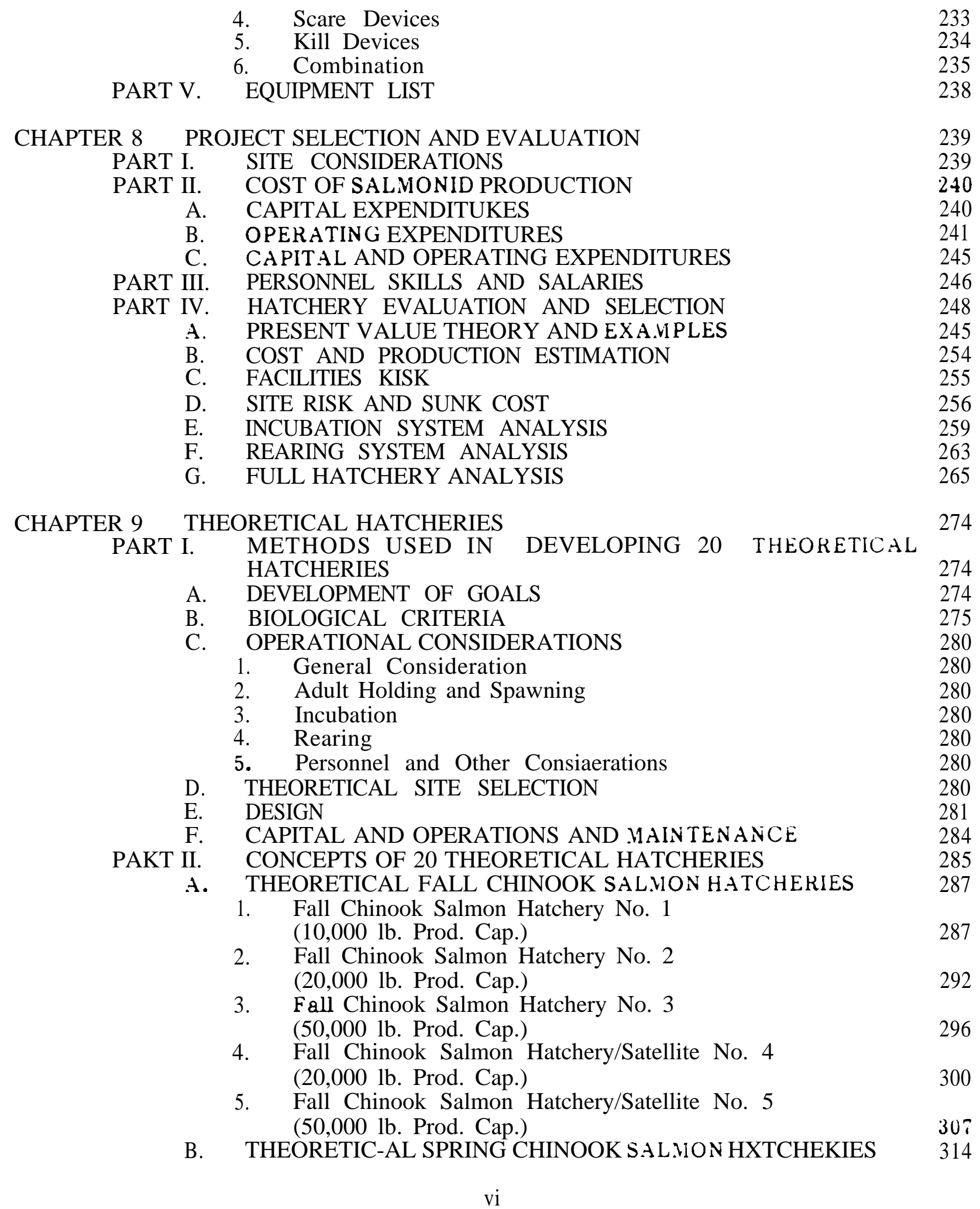


1. $\quad$ Spring Chinook Salmon Hatchery No. 1

(10,000 lb. Prod. Cap.) 314

2. $\quad$ Spring Chinook Salmon Hatchery No. 2 (20,000 lb. Prod. Cap.) 319

3. Spring Chinook Salmon Hatchery No. 3 (50,000 lb. Prod. Cap.) 323

4. Spring Chinook Salmon Hatchery/Satellite No. 4 (20,000 lb. Prod. Cap.)

5. Spring Chinook Salmon Hatchery/Satellite No. 5 (50,000 lb. Prod. Cap.)

C. THEORETICAL FALL CHINOOK/COHO SALMON HATCHERIES 348

1. Fall Chinook/Coho Salmon Hatchery No. 1 (10,000 lb. Prod. Cap.)

2. Fall Chinook/Coho Salmon Hatchery No. 2
(20,000 lb. Prod. Cap.)

3. Fall Chinook/Coho Salmon Hatchery No. 3 (50,000 lb. Prod. Cap.)

D. THEORETICAL COHO SALMON HATCHERIES

1. Coho Salmon Hatchery/Satellite No. 1

364 (20,000 lb. Prod. Cap.)

2. Coho Salmon Hatchery/Satellite No. 2 (50,000 lb. Prod. Cap.)

E. THEORETICAL STEELHEAD TROUT HATCHERIES 381

1. Steelhead Trout Hatchery No. 1 (10,000 lb. Prod. Cop.)

2. Steelhead Trout Hatchery No. 2 (20,000 1b. Prod. Cap.)

3. Steelhead Trout Hatchery No. 3 (50,000 lb. Prod. Cap.)

4. Steelhead Trout Hatchery/Satellite No. 4 (20,000 lb. Prod. Cap.)

395

5. Steelhead Trout Hatchery/Satellite No. 5 (50,000 lb. Prod. Cap.)

404

SUMMARY AND DISCUSSION

CHAPTER 10 PERMITS: FISH FACILITY DEVELOPMENT AND OPERATION 418

PART I. FACILITY DEVELOP.UENT PER.IIIS

A. FEDERAL GOVERNMENT 418

$\begin{array}{ll}\text { B. STATE GOVERNMENT } & 419\end{array}$

C. INDIAN TRIBAL GOVEKNMENT 423

PAHT II. FACILITY OPER ATIONS PERMITS

A. FEDERAL GOVERNMENT $\quad 425$

B. STATE GOVERN.MENT 425

C. INDIAN TRIBAL GOVERN:MENT 426

BIBLIOGRAPHY AND LITERATURE CITED 127

APPENDIX 1 TERMINOLOGY AND AGENCY ABBREVIATIONS 436

vii 
$\begin{array}{lll}\text { APPENDIX } 2 \quad \text { VENDORS } & 440\end{array}$

APPENDIX $3 \quad$ SALMON-STEELHEAD TROUT PRODUCTION FACILITIES VISITED 455

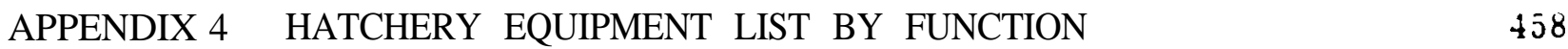

APPENDIX 5 HATCHERY PERSONNEL JOB DESCRIPTIONS 463

APPENDIX 6 METHODS USED TO DETERMINE FISH COMPLEMENT AND REARING SPACE FOR PROTOTYPE STATIONS

PXKT I. VIETHODS OF ESTIMATING THE NUMBERS OF ADULTS, EGGS, OR ALEVINS REQUIRED TO ACHIEVE PRODUCTION GOALS

PART II. METHOUS USED TO DETERMINE. REARING SPACE KEQUIRED IN LARGE PONDS TO MEET PRODLCTION GOALS

INDEX 


\section{LIST OF TABLES}

\section{CHAPTER 1 WATER QUALITY}

Table 1. Alaska Department of Fish and Game water quality standards for salmonid aquaculture.

Table 2. Dissolved oxygen in parts per million for fresh water, in equilibrium with air.

CHAPTER 2 WATER COLLECTION, DELIVERY, AND QUALITY IMPROVEMENTS

Table 1. Monthly production pumping costs at various lifts.

Table 2. Approximate costs of Duried pipelines.

Table 3. Recommended maximum approach velocity and minimum screen mesh size for salmonids on intake systems in the Columbia River.

Table 4. Dissolved gas limitations for hatchery water supplies.

CHAPTER 3 ADULT COLLECTION, HOLDING, AND SPAWNING 39

Table 1. A comparison of fishway characteristics

Table 2. Space and flow criteria for long-term holding of adult salmon and steelhead trout in 50F water and suggested spacing for rack pickets.

CHAPTER 4 INCUBATION

Table 1. Temperature unit requirements for salmon and steelhead trout eggs and alevins at $50 \mathrm{~F}$.

Table 2. Number of salmon and steelhead trout eggs and alevins that can be incubated under ideal conditions using $10 \mathrm{gpm}$ of water at 50F. Data based on present usage at 80 sites visited.

Table 3. Salmonid incubation capacities and water flow requirements in gpm by type of incubator unit.

Table 4. Comparison of capital costs and floor space requirements versus potential production for 16 different salmonid incubators.

Table 5. Summary analysis of salmonid incubator units to compare practical features and aid in the selection process.

Table 1. Hatchery pond loadings expressed in pounds of fish per gpm of inflow.

Table 2. Rearing criteria for salmonids in pounds of fish per cubic foot of rearing water for ponds less than 4,000 $\mathrm{ft}^{3}$ capacity ${ }^{3}$ ) and assuming water temperatures are within normal recommended ranges for the species. 
Table 3. A comparison of relative costs and life expectancy of salmonid rearing units.

Table 4. Conversion rates of salmonids from first feeding size $(3000 / 1 \mathrm{~b})$ to various release sizes using the Oregon moist pellet (OMP) diet. Source: Moore - Clark Co., Inc. (personal communication). 171

CHAPTER 6 TRANSPORTATION OF SPERM, EGGS, AND LIVE FISH

Table 1. Estimated cost per mile of fish transport equipment.

Table 2. Estimated costs of a 50-mile fish haul (100-mile rouno-trip) expressed in cost per pound of fish per gallon of tank water for three tank sizes.

CHAPTER 7 PRODUCTION SUPPORT FACILITIES AND EQUIPMENT

Taole 1. A comparison of metal, wood, and masonry buildings.

Table 2.

Building costs by material and building types.

Table 3.

The advantages and disadvantages of various road surfaces.

225

Table 4. Estimated road construction and annual maintenance costs by surface type and width for 100 feet of roadway, including 2-foot shoulders.

Table 5. Four types of audible water alarm switches and where they are used in a hatchery facility.

\section{CHAPTER 8 PROJECT SELECTION AND EVALUATION}

Taole 1. Considerations in facility site selection.

Table 2. Estimated total cost/lb of producing juvenile salmon at WDF hatcheries in 1983. (From Washington State Senate Natural Resources Committee).

Table 3. Annual man hours for fish culture and maintenance activities by the hatchery culturists at the WDF Klickitat Salmon Hatchery. From Clayton, (1968).

Taple 4. Salaries for various hatchery classes. All figures shown have been rounded to some extent. Source: W ashington State Department of Fisheries.

Table 5. An example of worksheet for compiling data inputs for an H.E.K. analysis of a planned salmon enhancement project. 256

Tasle 6. Example of a scoring system for hatchery components.

Table 7a. An example of sunk cost computation for hypothetical hatchery.

Taole 7b. Present value of total costs for hypothetical hatchery in sunk cost example.

Table 8 Computation of efficiency ratios for alternative fry incubation systems.

Taole 9 Computations of efficiency ratios for alternative rearing systems.

Table 10 . A 50,500 pound-2 million egg hatchery with high costs.

Table 11. A 50,500 pound-2 million egg hatchery with medium costs.

Table 12. A 50,500 pound-2 million egg hatchery with low costs.

Table 13. A 10,500 pound-1 million egg hatchery with high costs.

Table 14. A 10,500 pound-1 million egg hatchery with medium costs. 
Table 15. A 10,500 pound-1 million egg hatchery with low costs.

Table 16. An example of computations of hatchery efficiency ratio for a $50,500 \mathrm{lb}$. high cost unit.

Table 17. Hatchery efficiency ratios for six hypothetical production combinations.

\section{CHAPTER 9 THEORETICAL HATCHERIES}

Table 1. Broad production goals for 20 theoretical hatcheries.

Table 2. General Diological criteria used to program theoretical salmonid hatcheries in the Columbia River Basin.

Table 3. Numbers of adults, eggs, and juveniles needed for a 10,000-10 smolt release.

Table 4. Anticipated growth for fall chinook salmon and steelhead trout in water temperatures approximating 5UF.

Table 5. Programmed growth rates for juvenile spring chinook and coho salmon by time for theoretical hatcheries,

Table 6. Minimum recommended space $\left(\mathrm{ft}^{3}\right)$ for adult holding by station capacity.

Table 7. Recommended number and type of incubation units by station capacity. (Deeps and shallow refer to trough incubators, see Chapter 4.)

Table 8. Minimum recommended rearing space $\left(\mathrm{ft}^{3}\right)$ by rearing unit size by station capacity.

Table 9. Minimum recommended water flows (gpm) oy water type and station capacity.

Table 10. Facility development for Fall Chinook Salmon Hatchery Nio. 1 $(10,000 \mathrm{lbs}$, on-station release.)

Table 1 1. Facility development costs for Fall Chinook Salinon Hatchery Na. 1.

Tade 12. Estimated annual operational costs and labor requirements for

Table 13. Facility development for Fall Chinook Salmon Hatchery No. 2 (20,000 lbs, onstation release.)

Table 14. Facility development costs for Fall Chinook Salmon Hatchery No. 2.

Table 15. Estimated annual operational costs and laoor requirements for Fall Chinook Salmon Hatchery So. 2.

Table 16. Facility development for Fall Chinook Salmon Hatchery No. 3 (50,000 lbs, onstation releases).

Table 17. Facility development costs for Fall Cninook Salmon riatehery No. 3.

Table 18. Estimatea annual operational cost and labor requiremients for Fall Chinook Salmon Hatchery No. 3.

Table 19. Facility development for Fall Chinook Salmon Hutchery So. 4

Table 20. Facility development costs for Fall Chinook Salmon Hatchers.

Table 21. Estimated annual operational costs and lavor requirentents 10 r Fall Chinook Salinon Hatchery So. 4. 
Table 22. Facility development for Fall Chinook Salmon Hatchery No. 5 $(50,000 \mathrm{lbs}$, on- and offstation releases).

Table 23. Facility development costs for Fall Chinook Salmon Hatchery No. 5.

Table 24. Estimated annual operational cost and labor requirements for Fall Chinook Salmon Hatchery No. 5.

Table 25. Facility development for Spring Chinook Salmon Hatchery No. 1 $(10,000 \mathrm{lbs}$, onstation release).

Tade 26. Facility development costs for Spring Chinook Salmon Hatchery No. 1.

Table 27. Estimated annual operational costs and labor requirements for Spring Chinook Salmon Hatchery No. 1.

Table 28. Facility development for Spring Chinook Salmon Hatchery No. 2 $(20,000 \mathrm{lbs}$, on-station release).

Table 29. Facility development costs for Spring Chinook Salmon Hatchery No. 2.

Table 30. Estimated annual operational costs and labor requirements for Spring Chinook Salmon Hatchery No. 2.

Table 31. Facility development for Spring Chinook Salmon Hatchery No. 3 $(50,000 \mathrm{lbs}$, onstation release).

Table 32. Facility development costs for Spring Chinook Salmon Hatchery No. 3.

Table 33. Estimated annual operational costs and labor requirements for Spring Chinook Salmon Hatchery No. 3.

Table 34. Facility development for Spring Chinook Salmon Hatchery No. 4 (20,000 lbs, on- and offstation release).

Table 35. Facility development costs for Spring Chinook Salmon Hatchery No. 4.

Table 36. Estimated annual operational costs and labor requirements for Spring Chinook Salmon Hatchery No. 4.

Table 37. Facility development for Spring Chinook Salmon Hatchery No. 5 (50,000 lbs, on- and off-station releases).

Table 38. Facility development costs for Spring Chinook Salmon Hatchery No. 5.

Table 39. Estimated annual operational costs and labor requirements for Spring Chinook Salmon Hatchery No. 5.

Table 40. Facility development for Fall Chinook/Coho Salmon Hatchery No. 1 (10,000 lbs, on-station releases).

Table 41. Facility development costs for Fall Chinook/Coho Salmon Hatchery No. 1.

Table 42. Estimated annual operational costs and labor requirements for Fall Chinook/Coho Salmon Hatchery No. 1.

Table 43. Facility development for Fall Chinook/Coho Hatchery No. 2 (20,000 lbs, onstation release).

Table 44. Facility development costs for Fall Chinook/Coho Salmon Hatchery No. 2.

Table 45. Estimated annual operational costs and labor requirements for Fall Chinook/Coho Salmon Hatchery No. 2. 
Table 46. Facility development for Fall Chinook/Coho Hatchery No. 3 $(50,000 \mathrm{lbs}$, on-station release).

Table 47. Facility development costs for Fall Chinook/Coho Salmon Hatchery No. 3.

Table 48. Estimated annual operational costs and labor requirements for Fall Chinook/Coho Salmon Hatchery No. 3.

Table 49. Facility development for Coho Salmon Hatchery No. 1. (20,000 lbs, on- and off-station releases).

Table 50. Facility development capital costs for Coho Salmon Hatchery No. 1.

Table 51. Estimated annual operational costs and labor requirements for
Coho Salmon Hatchery No. 1 with on-station and off-station production.

Table 52. Facility development for Coho Salmon Hatchery h'o. 2 Ibs, on- and off-station releases).

Table 53. Facility development capital costs for Coho Salmon Hatchery No. 2.

Table 54. Estimated annual operational costs and labor requirements for Coho Salmon Hatchery No. 2 with on-station and off-station production.

Table 55. Facility development for Steelhead Trout Hatchery No. 1 (10,000 $\mathrm{lbs}$, on-station releases).

Table 56. Facility development costs for Steelhead Trout Hatchery No. 1.386

Table 57. Estimated annual operational costs and labor requirements for Steelhead Trout Hatchery No. 1.

Table 58. Facility development for Steelhead Trout Hatchery No. 2 (20,000 lbs, on-station releases).

Table 59. Facility development capital costs for Steelhead Trout Hatchery No. 2.

Table 60. Estimated annual operational costs and labor requirements for Steelhead Trout Hatchery No. 2.

Table 61. Facility development for Steelhead Trout Hatchery No. 3 (50,000 lbs, on-station releases).

Table 62. Facility development capital costs for Steelhead Trout Hatchery No. 3.

Table 63. Estimated annual operational costs and labor requirements for Steelhead Trout Hatchery No. 3.

Table 64. Facility development for Steelhead Trout Hatchery So. 4 (20,000 lbs, on- and off-station releases).

Table 65. Facility development costs for Steelhead Trout Hatchery No. 4. 402

Table 66. Estimated annual operational costs and labor requirements for Steelhead Trout Hatchery No. 4.

Table 67. Facility development for Steelhead Trout Hatchery No. 5 (50,000 lbs, on- and off-station releases).

Table 68. Facility development costs for Steelhead Trout Hatchery No. 5.

Table 69. Estimated annual operational costs and labor requirements for Steelhead Trout Hatchery No. 5. 
Table 70. Summary of the estimated facility development cost for 20 theoretical salmon and steelbead trout hatcheries for the Columbia River Basin.

Table 71. Summary of the estimated annual operational and maintenance cost for 20 theoretical salmon and steelhead trout hatcheries for the Columbia River Basin.

CHAPTER 10 PERMITS: FISH FACILITY DEVELOPMENT AND OPERATION

Table 1. Facility development permits required and regulating agencies for fish hatcheries in the State of Oregon.

Table 2. Facility development permits required and regulating agencies for fish hatcheries in the State of Washington.

Table 3. Facility development permits required and regulating agencies for fish hatcheries in the State of Idaho. 


\section{LIST OF FIGURES}

CHAPTER 2 WATER COLLECTION, DELIVERY, AND QUALITY IMPROVEMENTS

Figure 1. Inclined plane screen at the Gnat Creek Fish Hatchery.

Figure 2. Rock-filled gabions ready for use at the Clatsop County Rearing Pond, Oregon.

Figure 3. "Horizontal-vertical screening facility located in a diversion channel off the main stream. Water flows through the horizontal and vertical sections of the screen and is available for use in the irrigation channel or other water use facility downstream. Fish and debris are guided to the bypass culvert which discharges back to the main stream. (Adapted from $\mathrm{P}$. A. Slaney, 1977)" Courtesy of Canada Department of Fisheries and Oceans and British Columbia Ministry of Environment, Vancouver, B.C.

Figure 4. "Intake screens for pumps with capacities less than 2050 litres per second (i.e., one cubic foot per second, 450 L.s. or 375 IHP. gal. per minute). Adapted from Department of Fisheries of Canada (DWG No. 4-3-4 1965)" Courtesy of Canada Department of Fisheries and Oceans and British Columbia Ministry of Environment, Vancouver, B.C.

Figure 5. Typical spring water intake structure. Courtesy of the $\mathrm{N}$ isqually Indian Tribe.

Figure 6. An incubation and rearing channel developed in British Columbia which uses an infiltration water system (UFO).

Figure 7. A North Star micro-filter at the Puyallup Salmon Hatchery (WDF).

Figure 8. A packed column gas stabilization system consisting of a single cylindrical tower of aluminum pipe and filled with bio-rings Dworshak NFH, Idaho (LSF HS).

Figure 9. Multi-units of cylindrical towers constructed of alurninum pipe and filled with bio-rings.

Figure 10. A floating aerator in use at Allison Springs Rearing Pond (WDF).

Figure 11. A floating aerator used in a pollution abatement settling pond at the Big Creek Fish Hatchery (OF $W$ ).

Figure 12. A multicone aerator at the Beaver Creek Steelhead Hatchery (WDG).

CHAPTER 3 ADULT COLLECTION, HOLDING, AND SPAWNING

Figure 1. Single wooden fish rack at Cascade Fish Hatchery (OFW). Upstream face on left. 
Figure 2. "V" trap tunnel at Big Creek Fish Hatchery (OFW). Looking upstream.

Figure 3. Broom-stick weir in British Columbia (DFO).

Figure 4. Metal pole weir at Red River Rearing Pond (IFG). Looking downstream.

Figure 5. Small temporary weir (A) Four-pod horse, (B) 2-x 4-foot picket section. Looking downstream.

Figure 6. Pink salmon gilled in a pole rack.

Figure 7. Electric fence and fishway at the Quinault NFH. (Wooden planks over fishway can be dangerous if slippery or if deterioration occurs.)

Figure 8. Concrete velocity barrier at Klaskanine Fish Hatchery (OF $W^{\circ}$ ).

Figure 9. Cross-section of a concrete vertical barrier dam.

Figure 10. Pool-and-weir fishway in operation.

Figure 11. Empty pool-and-weir fishway showing general construction details.

Figure 12. General outline and operational characteristics of Denil fishway. Reprinted courtesy of Kerr, Hood, Leidal and Assoc. Ltd., and D.B. Lister and Assoc. Ltd., Stream Improvement Guide, p. 33. March 1980. Vancouver, B.C.

Figure 13. Typical hatchery adult pond seine.

Figure 14. PVC pipe used as pole for snagging at the Humptulips Salmon Hatchery ( $W D F)$.

Figure 15. Terminal hooks used for snagging: (A) weighted, (B) not weighted.

Figure 16. Terminal attachment of gaff hook to long pole.

Figure 17. Gaff hooks on pole (A) improper angle on hook, (B) recommended angle.

Figure 18. Backpack electro-shocker, Bear Cove, Alaska.

Figure 19. Spray system to refract light and prevent fish jumping at Wells Salmon and Trout Hatchery ( $K \mathcal{} \cdot \mathcal{L}$ and $W D G$ ).

Figure 20. Adult holding pond with neoprene apron along sides to prevent injury to jumping fish at Bonneville Salmon Hatchery (OFW).

Figure 21. Adult live box constructed of wood and vinyl-coated wire mesh.

Figure 22. Condominium unit for adult holding: (A) cover to several condo units, (B) single condo.

Figure 23. Tube holding apparatus.

Figure 24. Sketch of a relatively low-cost adult holding and spawning facility.

Figure 25. A relatively low-cost spawning area at the George Adams Salmon Hatchery ( $W D F$ ). For lower cost operation, we recommend plywood or plastic totes for fish storage.

Figure 26. Truck van used as storage and work area at the Squaxin Tribal Hatchery on Elsey Creek.

Figure 27. A typical fish club.

Figure 28. Spawn-taking equipment: (A) bleeding rack, (B) stand for holding spawning pan. 
Figure 29. Tools used for egg taking: (A) bleeding rack with fish, (B) spawning pan with eggs, (C) stand for j-gallon pail which holds spawning pan and eggs.

Figure 30. A Zak spawning knife.

Figure 31. Totes for adult fish storage: (A) wooden, (B) plastic.

Figure 1. Vertical-cabinet incubators, 16 trays high 90

Figure 2. Vertical-cabinet tray (A), with inner tray (B). 91

Figure 3. NOPAD aluminum incubator.

Figure 4. Deeptrough incubator illustrating: (A) trays, (B) perforated plate, (C) compartment for eggs only, (D) basket for eggs.

Figure 5. Aluminum shallow-trough incubators stored outside Yakima Trout Hatchery (WDG).

Figure 6. Wire egg baskets used in shallow-trough incubators.

Figure 7. Shallow-trough incubators stacked five-high (Quinault Tribal Hatchery).

Figure 8. Typical metal-frame pond tray for dropthrough or alevin retention.

Figure 9. Pond tray constructed of wood and nylon netting (Swecker Salmon Farm).

Figure 10. Pond tray-incubation unit at Oregon Aqua Foods,

Figure 11. A deepmatrix box installation to incubate 10 million salmon eggs at McKernan Salmon Hatchery ( $W \cup F) . \quad 100$

Figure 12. Heavy-duty plastic cargo box used as a box incubator. 101

Figure 13. Typical large deep-matrix box.

Figure 14. Typical small deepmatrix box.

Figure 15. Shallow-matrix incubator.

Figure 16. Shallow-matrix incubator at Skokomish Tribal Hatchery. 105

Figure 17. Montane hatching box at Niagra Springs Steelhead Hatchery (IFG)

Figure 18. Freestyle incubator. 107

Figure 19. Free-style incubators set in tandem within pond. 108

Figure 20. Dlustration of a typical cylindrical incubator.

Figure 21. Hatching jar used at the Dworshak National Fish Hatchery (USF WS).

Figure 22. Jar incubators in series at Dworshak National Fish Hatchery (USFWS).

Figure 23. One-gallon jug incubator noting: (A) inlet, (B) outlet, (C) perforated bottom plate.

Figure 24. Operation set-up for l-gallon jug incubators at Medvejie Creek, Sitka, Alaska.

Figure 25. Three-gallon bucket incubator noting: (A) sieve to hold eggs, (B) main water delivery pipe, (C) tube to bottom of bucket.

Figure 26. Typical low-cost side channel development in British Columbia for salmon spawning. 
Figure 27. Salmon spawning channel at Wells Dam, Columbia River ( DDF ) 115

Figure 28. Salmon spawning channel constructed at Priest Rapids Dam, Columbia River (WDF).

Figure 29. Low-cost eyed-egg channel, at Satsop Springs, (WDF).

Figure 30. Japanese keeper channel (Chehalis River Hatchery, British Columbia)

Figure 31. Tools used in egg picking: (A) bulb pickers, (B) siphon.

Figure 32. Tools used in egg picking: (A, C) skimmers, (B) tweezers.

Figure 33. Mechanical egg counter used at many $\mathrm{OFW}$ hatcheries.

Figure 34. Paddle egg counter of 100-egg capacity.

Figure 35. Spring scale and perforated scoop for weighing eggs.

Figure 36. Typical gravel composition used in egg boxes and keeper channels.

Figure 37. Plastic substrate materials used in incubators: (A) saddles, (B) 1-inch bio-rings, (C) 1.25-inch bio-rings.

\section{CHAPTER 5 REARING}

Figure 1. Fiberglass troughs used to rear fish at the Cowlitz Trout Hatchery ( $W D G)$.

Figure 2. Capilano rearing trough upside down to show construction (DFO).

Figure 3. Inlet water system on a 10-foot raceway at the Naselle Salmon Hatchery ( $W D F)$.

Figure 4. Outlet drain of a rearing pond showing how water flow is directed along floor of pond with $(A)$ baffle, $(B)$ second stand pipe.

Figure 5. Typical concrete raceway at the Abernathy Salmon Cultural Development Center (USF WS).

Figure 6. Earthen raceway at Garrison Springs Hatchery ( $\mathrm{UDF}$ ).

Figure 7. Water supply to earthen pond at Rapid River Salmon Facility (IFG).

Figure 8. Crosssection of a wooden raceway.

Figure 9. Wooden raceway at Nelson Springs, Yakima.( $\left.\boldsymbol{H}^{-} \mathrm{DG}\right)$.

Figure 10. Sheet-steel raceways at Priest Rapids Salmon Hatchery (WDF and Grant County PUD)

Figure 11. Fiberglass raceway at the Puyallup Salmon Hatchery (WDF).

Figure 12. Concrete circular ponds at the South Tacoma Steelhead Hatchery ( $W D G)$.

Figure 13. Dirt circular pond at Mariculture Northwest Hatchery, Rochester, Washington.

Figure 14. Plastic circular ponds at Quinsam River Salmon Hatchery,

B.C. (DFO).
Figure 15. Plasticsheet circular swimming pool used as a rearing pond.

Figure 16. Sheet-steel ponds at Naches Trout Hatchery ( $\boldsymbol{H}_{\mathrm{L}} \mathrm{DG}$ ).

Figure 17. Water supply manifold for large pond at the Naselle Salmon Hatchery (WDF).

Figure 18. Screened riser drain pipes at George Adams Salmon Hatchery (W DF). 
Figure 19. Dirt rearing pond with Neilsen automatic feeders in place at the Rapia River Hatchery (IFG).

Figure 20. Asphalt-lined pond at Elokomin Salmon hatchery ( $W D F$ ). $15 y$

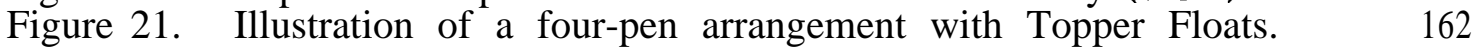

Figure 22. Illustration of a single net pen with pole flotation. 163

Figure 23. Styrofoam floats and a four-pan rearing complex - Clatsop County Pond, Astoria, Oregon. 164

Figure 24. A net pen complex in Lake .lerwin, Lewis River ( $W$ DG and Pacific Power and Light). PP \& L Photo.

Figure 25. Typical locations where net enclosures can be used. Also shows general construction features

Figure 26. Coffee can feeder attached to long pole.

Figure 27. Hand scoop feeder made from a one-gallon plastic jug.

Figure 28. Neilsen mechanical fry feeder at the Beaver Creek Steelhead Hatchery ( $H D G$ ). (A) food hopper, (B) fry in trough.

Figure 29. Neilsen pond feeders at Big Creek Fish Hatchery (OF W).

Figure 30. Stationary automatic fish feeders on 6-foot wide raceways at the Rapid River Fish Hatchery (IFG).

Figure 31. Illustration of a demand fish feeder.

Figure 32. Demand feeder on pond wall at Hagerman National Fish Hatchery (USF WS), Idaho.

Figure 33. Hobile fish feeder mounted on a trailer at Puyailup Salmon Hatchery ( $H$ DF).

Figure 34. Pickupmounted blower feeder (IF ( )).

Figure 35 . Typical perforated plate.

Figure 36. Slotted plate screen for dual purpose use. (A) large slots duwil

Figure 37 when rearing larger fish, (B) small slots down for smaller iish.

Figure 38. Aluminum tubing screens (IF (i).

Figure 40. Rotary drum screen powered by internal paddles.

Figure 41. Trash pump at Tulalip Tribal Hatchery, Washington.

Figure 42. High pressure pump at Big Creek Fish Hatchery (OFW). 180

Figure 43. Pole seine for juvenile fish.

Figure 44. Standard dip nets for juvenile fish.

Figure 45. Typical pond seine for juvenile fish showing construction details.

Figure 46 Warren Water Broom. Note variety of brush accessories.

1 b8

$18 y$

Figure 47. Warren Water Broom with handle.

Figure 48. Copper-base paint on pond used to retard algae at the Puntledge River Fish Hatchery (DFO).

Figure 49. Typical hand-held chemical dispenser.

Figure 50. A modern backpack chemical dispenser. 
Figure 54. Concrete settling basin at the Big Creek Fish Hatchery (OF W). (A) sludge, (B) ramp.

Figure 55. Floating aerator for pollution abatement settling basin at the Big Creek Fish Hatchery (OF $\left.W^{\circ}\right)$.

CHAPTER 6 TRANSPORTATION OF SPERM., EGGS, AND LIVE FISH

Figure 1. Stored sections of 10-inch aluminum pipe used for fish transfers.

Figure 2. Four-inch aluminum pipe being used to transfer juvenile salmon at the Washougal Salmon Hatchery (WDF).

Figure 3. Tube transfers used at the Chehalis River Hatchery in British Columbia, Canada (DFO).

Figure 4. PVC pipe used to transfer adult salmon at Priest Rapids Salmon Hatchery (WDF).

Figure 5. Flume used to transfer salmon and steelhead trout at the Rapid River Hatchery (IFG).

Figure 6. A 6-inch fish pump mounted on a trailer; (A) dryer used to separate fish and water, (B) discharge tube, (C) inlet.

Figure 7. Brail used in an adult salmon and steelhead transfer system at Priest Rapids Salmon Hatchery (WDF); (A) transfer brail, (B) tank on truck.

Figure 8. Mechanical fish crowder at the Hoodsport Salmon Hatchery (WDF); (A) crowder, (B) bars on crowder.

Figure 9. One-hundred gallon portable fish transport tank (DEO).

Figure 10. Three 300-gallon fish transport tanks mounted on a flatbed truck (Tulalip Tribal Hatchery).

Figure 11. Typical portable fish-transport tank with overhead spray and oxygen injection.

Figure 12. Sketch of a water circulation system for the portable fishtransport tank in Fig. 11.

Figure 13. Sketch of an air/oxygen circulation system for the portable fish-transport tank in Fig. 11.

Figure 14. Tank truck and tank trailer fish transport system (IFG).

Figure 15. Approximate loading rates of fish-transport tanks in pounds of fish per gallon and by fish size, species, and racial group (with water temperature at constant $48 \mathrm{~F}$ ).

Figure 16. Floating live-box transport system.

Figure 17. Tube transport system.

CHAPTER 7 PRODUCTION SUPPORT FACILITIES AND EQUIPMENT

Figure 1. Vancouver Trout Hatchery with majestic multi-purpose wood building (WDG).

Figure 2. Rocky Reach Hatchery with multi-purpose metal ouilding (Chelan County PUD and WDF). This building has $960 \mathrm{ff}^{2}$ and the construction cost in 1983 was $\$ 29,100.00$. If we assume construction cost at $75 \%$ of total cost, this building costs 38,800 or $\$ 40.42 / \mathrm{ft}^{2}$ (Steve Hays personal communication). 
Figure 3. Fifty-thousand pound capacity fabricated freezer at the Puyallup Salmon Hatchery (WDF).

Figure 4. A refrigerated trailer being used for fish food storage at the private Clear Springs Fish Hatchery, Idaho.

Figure 5. Permanent canopy using netting for predatory bird control at the Dworshak National Fish Hatchery (USF WS).

Figure 6. A pond-level canopy without the centerline wire support at the Elokomin Salmon Hatchery (WDF).

Figure 7. A three-wire electric fence at the Shelton Trout Hatchery (WDG).

Figure 8. Wire-mesh fence to prevent predation by wading birds at the Washougal Salmon Hatchery ( $W D F$ ).

Figure 9. An overhead stringer system for bird control at the Hagerman Fish Hatchery (IFG).

Figure 10. A view from below of the overhead wire stringers in Fig. 7 showing the springs used to keep wires taut.

Figure 11. Pond-level stringers to prevent American merganser predation at Klaskanine Fish Hatchery (OF W).

Figure 12. Stringers of red polyline form a canopy to discourage fish predation at the Elokomin Salmon Hatchery ( $\mathrm{H} \cup \mathrm{F}$ ).

Figure 13. The flashing colored-light setup used to scare fish-eating

Figure 14. An automatic propane exploder used to scare predatory birds at the Big Creek Fish Hatchery (OF W).

Figure 1. Components of capital expenditures in hatchery construction. 241

Figure 2. Composition of the annual operating costs for hatchery " $A$ " $\left(\mathrm{OF} \mathrm{W}^{\prime}\right)$ with $50 \%$ pumped water and $200 \mathrm{ft}$ of lift (average of fiscal 1984 and 1985 budget projections).

Figure 3. Composition of the annual operating costs for hatchery "B" (OF $\left.W^{\circ}\right)$ with $100 \%$ pumped water and $20 \mathrm{ft}$ of lift (average of fiscal 1984 and 1985 budget projections).

Figure 4. Composition of the annual operating costs for hatchery " $\mathrm{C}$ " (eight OFW hatcheries) with gravity flow (average of fiscal 1984 and 1985 budget projections).

Figure 5. Annual man hours of fish culture, maintenance, and leave by month at the WDF Klickitat Salmon Hatchery. From Clayton, (1968).

CHAPTER 9 THEORETICAL HATCHERIES

Figure 1. Surface water temperature curves for rearing fall chinook salmon and steelhead trout (upper), and spring chinook and coho salmon (lower), at theoretical hatcheries. Source: 5-year average at wells Salmon Hatchery, WDF (upper), and two years of records at Entiat NFH, USF WS (lower).

Figure 2. $\quad$ Schematic of Fall Chinook Salmon Hatchery No. 1. 288

Figure 3. Water-use strategies for Fall Chinook Salmon Hatchery No. 1. 291 
Figure 4. Space-use requirements for Fall Chinook Salmon Hatchery No. 1.

Figure 5. Schematic of Fall Chinook Salmon Hatchery No. 2.

Figure 6. Schematic of Fall Chinook Salmon Hatchery No. 3.

Figure 7a. Schematic of Fall Chinook Salmon Hatchery No. 4 - On-station facilities

Figure ib. Schematic of Fall Chinook Salmon Hatchery No. 4 - Satellite facilities,

Figure 8. Rearing and holding space requirements by time for Fall

Figure 9a. Schematic of Fall Chinook Salmon Hatchery No. 5 On-Station Facilities.

Figure 9b. Schematic of Fall Chinook Salmon Hatchery No. j - Satellite Facilities

Figure 10. Schematic of Spring Chinook Salmon Hatchery So. 1.

Figure 11. Water-use strategies for Spring Chinook Salmon Hatchery No. 1.

Figure 12. Space-use requirements for Spring Chinook Salmon Hatchery No. 1.

Figure 13. Schematic of Spring Chinook Salmon Hatchery So. 2.

Figure 14. Schematic of Spring Chinook Salmon Hatchery So. 3.

Figure 15. Vicinity map of the production facilities and release sites for Spring Chinook Salmon Hatchery No. 4.

Figure 16a. Schematic of Spring Chinook Salmon Hatchery So. 4 On-station facilities.

Figure 16b. Schematic of Spring Chinook Salmon Hatchery No. \& Satellite facilities.

Figure 17. Water-use strategies for Spring Chinook Hatchery No. 4 On-station.

Figure 18. Space-use requirements for Spring Chinook Hatchery So. 4 Onstation.

Figure 19. Facility programming by time for Spring Chinook Hatchery No. 4 - on and off-station.

Figure 20. Vicinity map of the production facilities and release sites for

Figure 2la. Schematic of Spring Chinook Salmon Hatehery ho. 5 Onstation facilities.

Figure 21 b. Schematic of Spring Chinook Salmon Hatchery No. 5 Off-station rearing pond at stream "C" (Note: Pond at stream "B" not shown.)

Figure 2lc. Schematic of Spring Chinook Salmon Hatchery No. 5 - Pen rearing complex.

Figure 22. Water-use strategies for Spring Chinook Salmon tiatchery No. 5 - On-station.

Figure 23. Space-use requirements for Spring Chinook Salmon Hatchery No. 5 - On-station.

Figure 2-I. Schematic of Fall Chinook/Coho Salmon Hatchery So. 1.

Figure 25. Schematic of Fall Chinook/Coho Salmon Hatchery No. 2. 
Figure 26. Water-use requirements for Fall Chinook/Coho Salmon Hatchery No. 2.

Figure 27. Space-use requirements for Fall Chinook/Coho Salmon Hatchery No. 2. 358

Figure 28. Facility product ion programming by time for Fall Chinook/Coho Salmon Hatchery No. 2. 359

Figure 29. Schematic of Fall Chinook/Coho Salmon Hatcherv No. 3. 361

Figure 30. Vicinity map of the production and release sites for Coho Salmon Hatchery No. 1. - on and off station facilities. 366

Figure 31a. Schematic of Coho Salmon Hatchery No. 1 - On-station facilities 367

Figure 31b. Schematic of Coho Salmon Hatchery No. 1 - Off-station pond. 368

Figure 32. Vicinity map of the production and release sites for Coho Salmon Hatchery No. 2.

Figure 33a. Schematic of Coho Salmon Hatchery No. 2 - On-station facilities.

Figure 33b. Schematic of Coho Salmon Hatchery No. 2 - Off-station pond. 375

Figure 34. Water-use strategies for Coho Salmon Hatchery No. 2 on-station.

Figure 35. Space-use requirements for Coho Salmon Hatchery Nio. 2 on-station.

Figure 36. Schematic of Steelhead Trout Hatchery No. 1. 382

Figure 37. Water-use strategies for Steelhead Trout Hatchery No. 1. 383

Figure 38. Space-use requirements for Steelhead Trout Hatchery No. 1. 384

Figure 39. Schematics of Steelhead Trout Hatchery ho. 2. 388

Figure 40. Schematics of Steelhead Trout Hatchery So. 3. $3 y 2$

Figure 41. Vicinity map of production and release sites for Steelhead Trout Hatchery No. 4. 397

Figure 42. Schematic of Steelhead Trout Hatchery No. 4 - on-station. 398

Figure 43. Water-use strategies for Steelhead Trout Hatchery io. 4 on-station.

Figure 44. Space-use requirements for Steelhead Trout Hatchery No. 4 on-station.

Figure 45. Facility production programming by time for Steelhead Trout Hatchery No. 4 - on and off-station.

Figure 46. Vicinity map of production and release sites for Steelhead Trout Hatchery No. 5.

Figure 47a. Schematic of Steelhead Trout Hatchery So. 5 - On-station facilities.

Figure 47b. Schematic of Steelhead Trout Hatchery No. 5 - Off-station pond.

Figure 48. Water-use strategies for Steelhead Trout Hatchery ho. 5 -
on-station.

Figure 48. Water-use strategies for Steelhead Trout Hatchery ho. 5 -
on-station.

Figure 49. Facility production programming by time for Steelhead Trout Hatchery No. 5 - on-station. 


\section{PREFACE}

Over 200 fish culture experts provided information for this document. While too numerous to mention each individual by name, their affiliations are acknowledged in Appendix 1 and 3 or within this report.

To the Bonneville Power Administration, we express our appreciation for the contributions from Gregory Drais, Dr. Gerald Bouck, Thomas Berggren, Sharon Blair, Vetta Uraine, and others To the National Marine Fisheries Service we show our appreciation to Mr. Einar Wold for his editorial review.

Lastly, we recognize the contributions from those individuals who worked directly with ourselves in producing this document. These include:

\author{
Russel Jones \\ Gary Logan \\ Brian Earp \\ Ernest Jeffries \\ Ross Antipa \\ Stephen B. Mathews \\ Melvin Eby \\ Jack Kawaguchi \\ Ray Johnson \\ Richard Pressey \\ Don Kauffman \\ Inkslinge r's, Inc.
}

\author{
Engineering \\ British Columbia Fish Culture \\ Nutrition \\ General Fish Culture \\ Water Quality \\ Economics \\ Construction \\ Drafting \\ Biology/Permits \\ Foreign Fish Culture \\ Editorial \\ Secretarial Service
}

BY
Harry Senn - John Mack - Lloyd Rothfus
Fish Management Consultants

xxiv 


\title{
COMPENDIUM OF LOW-COST PACIFIC SALMON AND STEELHEAD TROUT PRODUCTION FACILITIES IN THE PACIFIC NORTHWEST
}

\author{
INTRODUCTION
}

The proposal for a study to identify low-cost fish production facilities originated with the contributors to the Pacific Northwest Power Planning Council Fish and Wildlife Management Plan. Fish Managment Consultants (F.MC) modified that approach and prepared a proposal for Bonneville Power Administration (BPA) consideration. Together, we developed a study which has resulted in this Compendium of Low-Cost Salmon and Steelhead Trout Production Facilities for the Columbia River Basin.

The purpose of the study was to research low capital-cost salmon and steelhead trout production facilities and identify those that conform with management goals for the Columbia Basin. The species considered were chinook salmon (Oncorhynchus tshawytscha), coho salmon (O. kisutch), sockeye salmon (O. nerka), and steelhead trout (Salmo gairdneri). The objectives were:

-4. Produce a compendium of low-capital propagation facilities, including any descriptions and schematics required for clarification.

B. Identify the unit cost, the available vendors, sources of detailed information, and specific locations where the unit or system can be reviewed.

C. Identify cost-saving operational techniques and tools.

D. Illustrate how each low-capital propagation facility reviewed can or cannot be incorporated into the goals of the Columbia River Basin.

E. Provide a listing of factors for consideration in site selection evaluation.

F. Using low-capital propagation facilities, provide prototype designs for average physical and climatological conditions for twenty facilities, including costs and manpower requirements and skills.

The study was deemed necessary because natural production in the Columbia Basin is critically low in certain areas. Large centralized hatcheries have not been managed to address this problem and, in fact, are partly responsible for it.

The first Columbia River salmon hatchery was built by the Washington Fish Propagating Company on the Clackamas River in Oregon's Willamette Valley in 1876 (Wohle and Smith, 1979). Nearly 100 salmon and steelhead trout hatcheries have since been 
Introduction

constructed in the Basin. Most were built during the middle portion of the century, when largescale hydro-electric development occurred, at a time when Fisheries Science was a relatively new field. The fish agencies were confronted with the problems of insufficient skills and inadequate technology to properly assess the effect of dam building on fish. Compensation for losses usually involved the construction of a hatchery to replace the production lost through inundation of natural habitat. But production from these facilities was mainly directed toward massive onstation releases, with little attention given to the effect on natural production. The ultimate result was the production of large numbers of hatchery fish which benefited the sport and commercial fisheries, but which depressed many natural stocks mixed within the fisheries and harvested at the same rate. Management goals set to harvest hatchery stocks, as we now know, could only lead to lowered levels of natural production. This perspective on what has occurred, not only On the Columbia but on other streams of the coastal states, is presented not as criticism, but rather as a reality that simply resulted from a lack of knowledge. The fact that natural production in many streams is below optimum levels necessitates the implementation of management techniques to restore these pastures to production capacity.

Within the Columbia Basin, tribal, state, and federal biologists are making concerted efforts to provide a more balanced management plan. The consensus is that there is a massive potential for natural production that is not utilized (Northwest Power Planning Council, 1982). In order to harness this potential, new and innovative artificial production methods must be implemented to aid natural production. High construction costs, dwindling sources of guality water supplies, and the large number of affected streams require that smaller, more efficient, low-cost facilities oe used to help restore the natural stocks. There is considerable information available on low-cost fish production techniques and facilities, but much of this has oeen developed by individual agencies and hatchery managers, and it has not Deen widely disseminated within the fisheries community. For the last decade, the salmonid enhancement program in British Columbia has included many small projects directed at problems discussed above (Glover, 1983). Recent publications by Leitritz and Lewis, (1980); Piper et al., (1982); Alaska Department of Fish and Game, (1983); and .HcNeil and Baily (1975); are good reference materials on hatchery operations, but they do not include all the available types of fish facilities or sufficient cost information.

We believe this document will serve as an important tool in fish culture. It is a comprehensive listing of the facilities, techniques, and equipment used in artificial production in the Pacific Northwest. In most cases, it was necessary to describe both high- and low-cost facilities in order to make comparisons. Further, what is low cost to one agency or manager may not be to others, and it depends to a considerable extent on program objectives, location, and available funds. We believe that sufficient information has been detailed to assist hatchery managers and administrators in making facility choices that will help restore fish runs at the lowest possible cost. If the report serves that purpose, the efforts of the authors, contributors, and the BPX will have been worthwhile.

The compilation of material for the report was initiated by establishing lines of communication with all the fisheries agencies and tribal communities involved with Columbia River salmon and steelhead trout fisheries. A preliminary report outline, 


\section{Introduction}

including chapter contents and a report format, were submitted to each agency and tribal representative for their review and comment. Their responses were incorporated as appropriate, and the final report outline and format was developed by BPA and F.MC.

Data were compiled through a literature search, site visitations, and personal communications with knowledgeable hatchery personnel. Over 80 state, federal, and tribal facilities in Oregon, Washington, Idaho, and British Columbia were visited (Appendix 3). and additional information was obtained from Alask Ranchers, and Norway. Also, approximately 150 hatchery administrators, managers, biologists, and technicians were consulted.

Over 250 venaors of fish culture-related materials and equipment were solicited, and those responses that were applicable are noted in Appendix 2. BPA and F.MC agreed that vendor contacts would be limited only to Pacific Northwest iirms and those outsiae this area that are known bv the fisheries agencies as frequent suppliers. Neither BPA nor F $M C$ endorses the products distriouted by the venaors, and they are noted herein for informational purposes only. Throughout the report the advantages aria disadvantages o: particular equipment items are noted. These were developed from communications witn hatchery managers and from the personal knowledge of F.IC members and associates Comments under disadvantages are not intended to impugn a vendor or nis product. Rather, the comments should always be read as intended: "as comparec to otner options."

Construction cost estimates are based in 1983 dollars for average construction conditions, including a 50 mile remoteness factor for labor and material supply scurces. These estimates alsn include a 25 percent cost surcharge for engineering and cunstruction contingencies. These data were obtained from cost estimating manuals, contacts witn manufacturers and suppliers, and frorn documented price data on recent hatchery construction projects. Equipment costs are also based on 1983 doliars F.O.B. at the factory and were supplied by vendors.

Our discussion of the fish facilities and their component systems, for the most part, is presented in a format that describes the unit, details advantages and disadvantages, and shows costs, vendors, and where the unit can be seen. This format was chosen because it allows ready comparison of units, identification of sources of further information, \&lid possible vendors. This format was modified in instances where comparisons vere not possible and it was not used for equipment. Vendors; named as suppliers of a proouct represent a sample only, and Appendix 2 should be consulted for otner suppliers. $W$ here multiple measurements of objects are given in the text, we have used trie sequence of width $\mathrm{x}$ length $\mathrm{x}$ depth (or height).

Although we tried to be objective, we realize that many of the advantages and disadvantages noted may be questioned, since, in many instances, we found differences of opinion on individual units both between and within fisheries agencies. Obviously personal preference exists within agencies, and this has affected facility selection and construction costs.

In the appenasces, in addition to the lists of vendors and production fucilities visited, we have included a glossary of commonly-used technical terms and aboreviutions for the 
Introduction

various fishery agencies, a representative check-list of tools and equipment frequently used at a fish cultural facility, job descriptions for hatchery personnel required at low-cost facilities, and finally, examples of the methods we used to determine rearing space for prototype stations 


\title{
CHAPTER 1
}

\author{
WATER QUALITY
}

\begin{abstract}
Water quality is the single most important factor in selecting a hatchery site. The potential success of a proposed facility usually can be predetermined through a careful analysis of the water supply. Because water quality is so critical to good fish husbandry, we are including a discussion of its more important aspects and their relationship to fish culture. In this chapter, we illustrate acceptable water quality standards in terms of: 1) temperature, 2) dissolved gases, 3) turbidity, 4) toxic materials, and 5) pathogens. Succeeding chapters describe water quality requirements for each life stage and how these requirements are affected by facility design and operational techniques. Water quality needs will be an important consideration in the presentation of prototype facility design illustrated in Chapter 9 of this report. The treatment of hatchery effluent water will also be discussed in the latter Chapter.
\end{abstract}

Numerous manuals are readily available for more detailed information on fish and water quality, but we recommend a recent one prepared by Piper, et al. (1982).

Most fisheries agencies involved in salmonid aquaculture have adopted the water quality criteria used by the Alaska Department of Fish and Game (Table 1) for evaluating potential fish hatchery water supplies. A water supply that meets or exceeds these standards will provide an excellent environment for the culture of salmonid fishes.

In the absence of technical data, the existence of healthy fish in all life stages would provide empirical evidence of suitable water quality.

\section{PART I. TEMPERATURE}

Temperature is very important in the selection of a water source. It can: 1) determine growth and development rates, 2) limit disease problems, 3) maximize operational flexibility, 4) aid the smoltification process, and 5) acclimatize fish to the receiving waters.

Generally, salmonids rear best at temperatures between $46 \mathrm{~F}$ and $55 \mathrm{~F}$. With lower temperatures, development and growth may be too slow to achieve program objectives, while temperatures between $55 \mathrm{~F}$ and $70 \mathrm{~F}$ may encourage certain diseases. Based on the results at the Spring Creek NFH, the fall chinook do well at constant temperatures around 50F. Eggs subjected to prolonged periods at temperatures above 55-60F incur higher losses, while adults held at temperatures above $70 \mathrm{~F}$ may perish.

Water temperature is very important in maximizing facility use. Piper (ibid.) states that "as the water temperature increases, the loading factor decreases $5 \%$ for each degree (F) 


\section{Chapter 1}

Table 1. Alaska Department of Fish and Game water quality standards for salmonid aquaculture. (1)

Water Qualities

Alkalinity

Aluminum

A mmonia (un-ionized)

Arsenic

Barium

Cadmium

Carbon Dioxide

Chloride

Chlorine

Chromium

Copper

Dissolved Oxygen

Fluorine

Hydrogen Sulfide

Iron

Lead

Magnesium

Manganese

Mercury

Nickel

Nitrate (NO3)

Nitrate (NO2)

Nitrogen (N 2)

Petroleum (oil)

$\mathrm{pH}$

Potassium

Salinity

Selenium

Silver

Zinc

Sodium

Sulfate $\left(\mathrm{SO}_{4}-2\right)$

Temperature

Total Dissolved Solids

Total Settleable Solids
Standards

undetermined

$<0.01 \mathrm{mg} / \mathrm{liter}$

$<0.0125 \mathrm{mg} / \mathrm{liter}$

$<0.05 \mathrm{mg} /$ liter

$<5.0 \mathrm{mg} / \mathrm{liter}$

$<0.0005 \mathrm{mg} /$ liter $(100 \mathrm{mg} /$ liter alkalinity)

$<0.005 \mathrm{mg} /$ liter ( $>100 \mathrm{mg} /$ liter alkalinity)

$<1.0 \mathrm{mg} /$ liter

$<4.0 \mathrm{mg} / \mathrm{liter}$

$<0.003 \mathrm{mg} /$ liter

$<0.03 \mathrm{mg} /$ liter

$<0.006 \mathrm{mg} / \mathrm{liter}(100 \mathrm{mg} / \mathrm{liter}$ alkalinity)

$<0.03 \mathrm{mg} / \mathrm{liter}(>100 \mathrm{mg} /$ liter alkalinity)

$>7.0 \mathrm{mg} / \mathrm{liter}$

$<0.5 \mathrm{mg} / \mathrm{liter}$

$<0.003 \mathrm{mg} / \mathrm{liter}$

$<0.1 \mathrm{mg} / \mathrm{liter}$

$<0.02 \mathrm{mg} /$ liter

$<15 \mathrm{mg} / \mathrm{liter}$

$<0.01 \mathrm{mg} /$ liter

$<0.0002 \mathrm{mg} /$ liter

$<0.01 \mathrm{mg} /$ liter

$<1.0 \mathrm{mg} / \mathrm{liter}$

$<0.1 \mathrm{mg} /$ liter

$<110 \%$ total gas pressure

( $<103 \%$ nitrogen gas)

$<0.001 \mathrm{mg} / \mathrm{liter}$

$<6.5-8.0$

$<5.0 \mathrm{mg} / \mathrm{liter}$

$<5.0$ parts per thousand

$<0.01 \mathrm{mg} / \mathrm{liter}$

$<0.003 \mathrm{mg} /$ liter (fresh water)

$<0.0003 \mathrm{mg} /$ liter (salt water)

$<0.005 \mathrm{mg} / \mathrm{liter}$

$<75.0 \mathrm{mg} /$ liter

$<50.0 \mathrm{mg} /$ liter

$<0^{\circ}-15^{\circ} \mathrm{c}$

$<400.0 \mathrm{mg} /$ liter

$<80.0 \mathrm{mg} /$ liter (25 JTU)

Note: Synergistic and antagonistic chemical reactions must be considered when evaluating a water source against these criteria.

(1) Source: Fish Cultural Manual, Alaska Department of Fish and Game, FRED Div., June 1983. p.16. 
hater Quality

rise in temperature. Conversely, as the water temperature decreases, the loading factor will increase." If density is not a limiting factor, a $50 \%$ increase in the production nould be gained by using $50 \mathrm{~F}$ water instead of $60 \mathrm{~F}$ water. Thus, potential advantages can be guired oy the timely augmenting of warm spring and well-water supplies present in the Columbia River Basin with cooler river water, particularly at the time of release when the poundage being held is at its greatest.

We know that temperatures above $55 \mathrm{~F}$ retard smoltification in steelhead trout. Recent record returns of steelhead trout to WDG mid-Columbia Kiver stations are attributed mainly to the acclimatization of the juveniles before release into the Columbia River. Studies at the WDF Klickitat Salmon Hatchery demonstrated that coho salmon reared in warm spring water survived much better when acclimatized to the colder river water before release.

For a production program, we recommend a water supply with a range of useable temperatures. For example, a constant $50-55 \mathrm{~F}$ ground-water supply and a surface source with seasonably fluctuating temperatures of $40-60 \mathrm{~F}$.

\section{PART II. DISSOLVED GASES}

The two most abundant atmospheric gases are oxygen and nitrogen. In a quality water supply, oxygen should be near saturation, while nitrogen can be at any level less than saturation. High elevation and high temperature reduce the amount of gases water can retain. Table 2 gives dissolved oxygen levels for various temperatures and elevations.

The total dissolved gas pressure of the water supply is important because of a phenomenon 'nown as gas bubble disease. Fish living in water supersaturated with dissolved gases can suffer from the formation of gas bubbles in their body tissues. Susceptibility varies with the species and size. Generally, chinook salmon are more susceptible than coho salmon or steelhead trout, and fry or fingerlings are the most susceptible life stages. It is recommended that the total dissolved gas pressure of the water supply remain below $103 \&$ to eliminate problems with gas bubble disease in young salmonids, however we refer you to Chapter 2, Part III B on gas stabilization and more detailed notes on atmospheric gases.

Table 2. Dissolved oxygen in parts per million for fresh water, in equilibrium with air.(1)

$\begin{array}{cr}\text { Water temperature, } & \mathrm{F} 0 \\ 40 & 13.0 \\ 50 & 11.3 \\ 60 & 10.0 \\ 70 & 9.0\end{array}$

\begin{tabular}{crr}
$\begin{array}{c}\text { Elevation in feet } \\
1,000\end{array}$ & $\underline{2,000}$ & $\underline{3,000}$ \\
\hline 12.5 & 12.1 & 11.6 \\
10.9 & 10.5 & 10.1 \\
9.6 & 9.3 & 8.9 \\
8.7 & 8.4 & 8.0
\end{tabular}

(1)Condensed From Leitritz, E. and R. Lewis. 1980 
Chapter 1

\section{PART IIL WATER HARDNESS}

Total water hardness, acidity, and alkalinity may be a concern in the Columbia River Basin. Piper (ibid.) describes a desirable range for $\mathrm{pH}$ of 6.5-9.0 and water hardness $\left(\mathrm{CaCO}_{3}\right.$ - equivalent concentration) of $120-400 \mathrm{ppm}$. Total hardness in the upper range, however, may cause problems during the incubation process. This was one of several variables suspected of causing problems in incubating chinook salmon at Ringold Springs Rearing Pond near Pasco, Washington and in coho salmon at Rocky Ford Creek Hatchery, Ephrata, Washington. The total hardness was $380 \mathrm{ppm}$ at Ringold Springs Rearing Pond. More recently, total hardness is suspected to have been the cause of problems with eggs incubated in the groundwater supply at the Priest Rapids Salmon Hatchery just upstream from Ringold Springs.

\section{PART IV. TURBIDITY}

Suspended solids, or silt, in a water supply has the potential to smother incubating eggs and alevins in the tender stages when they cannot be moved. Eyed eggs, however, will stay viable without water during short periods while the silty water supply is bypassed. Salmonids rarely suffer from muddy water unless it is for a prolonged period and occurs during the early feeding stages. Gill tissue irritation is a common result of excessive turbidity. Piper (ibid.) states, "In general, tubidities less than 2,000 parts per million are acceptable for fish culture." Chapter 2 will address silt removal from water supplies.

\section{PART V. TOXIC MATERIALS}

Particular attention must be given to the potential pollution from toxic materials in the water supply or from the use of materials or equipment that create toxic conditions. Csually, the heavy metals, particularly zinc and copper, are the most common cause of mortality or sub-lethal adverse effects on salmonids. This is not as likely to occur in the highly buffered waters present in many Columbia River Basin water sources. But in poorly buffered water, a galvanized intake screen or a short galvanized or copper pipefitting can provide a concentration of ions that will cause high mortality to salmonids during the incubation stage.

Contamination from toxic materials originates from a variety of sources, such as used containers, uncured concrete, paint, or contaminated feed.

Some Columbia River Basin water sources may be exposed to herbicide or pesticide contamination. These chemicals are commonly utilized in agriculture and find their way into surface or groundwater supplies. At present, there is an identified pesticide contaminating groundwater in a section of the Yakima River valley. 
Water Quality

\section{PART VI. PATHOGENS}

It is well recognized that diseases may adversely affect the success of salmon and steelhead trout hatcheries. This is most often identified with poor fish culture practices; however, it is not widely known that many disease problems can be prevented by proper selection of a water supply.

Many salmon and steelhead hatcheries in the Columbia Basin have had a history of disease problems related to their water source. Examples are:

Hatchery

WDF-Klickitat Salmon Hatchery

HDG, WDF - Ringold Springs

Rearing and Steelhead Pond

WDF - Priest Rapids

Salmon Hatchery

USFWS - Leavenworth National Fish Hatchery

WDF - Rocky Reach Hatchery

Trout Lodge - Rocky Ford Creek

USF wS - Spring Creek National Fish Hatchery

WDG, WDF - Wells Salmon and Trout Hatchery
Disease

Sunburn of chinook salmon due to very clear spring water and lack of shade.

Parasitic trematodes invading the fish eye due to pond water conditions which favor the snail's intermediate host.

Soft-shell egg disease due to high levels of bacteria in water supply.

IHN virus present in water supply or in adult salmon.

Columnaris and furunculosis carried by suckers and other fish in the Columbia River water supply.

Redmouth disease from carp and trout in the water supply.

Gill disease due to malfunctioning water reuse system (high metabolic load).

Columnaris and gill disease of adult salmon and steelhead due to temperature and contamination of Columbia River water.

At many of the above stations, the disease-caused losses became a limiting factor to successful hatchery operation during some years. As a rule it is far more cost-effective to prevent fish diseases than treat them.

An analysis of hatchery water sources to determine potential disease problems and their control should include the following:

Presence of carriers of bacteria and virus

Are there fish living in the water supply?

Generally, the higher the biomass and the more diverse the species, the greater the chance for disease carriers. 


\section{Chapter 1}

Presence of parasite hosts

Are there invertebrates, birds or animals present which are known to be hosts for parasites?

Invertebrates such as snails and copepods frequently are hosts for parasites which infect fish Gulls and piscivorous mammals also commonly shed infective parasitic forms into water supplies.

Toxic algae blooms

Does the water supply have a history of toxic algae?

This problem frequently occurs in warm-water fish or pond culture, and will cause rapid mortalities.

Reconditioning of water

Does the hatchery propose to recycle or recondition the water?

Often malfunctioning reconditioning systems will result in diseases being rapidly spread throughout the hatchery.

Clarity of water

Is the water extremely clear or turbid?

Clear water may allow sunburn, while excessively turbid water exacerbates gill irritation.

Quality variations

Has the water source been sampled a number of times under various conditions?

Sometimes a water source which is normally adequate will periodically become unacceptable; gas supersaturation is a common example.

\section{Disinfection}

How feasible is it to disinfect the water supply?

Spring sources may be quite easily disinfected, while with river or lake sources this is often not feasible.

Organic material concentration

What is the level of organic contaminants?

Many mildly pathogenic fungi and bacteria attack fish reared in water with elevated levels of organic contaminants.

Bioassay test

Has a group of healthy fish been reared in the water supply as a test?

Live fish will often provide the best means to test a proposed water supply if problems are suspected.

\section{Minimizing stress}

Will juvenile or adult fish need to be transported long distances or require excessive handling in order to operate the hatchery?

Stress is often the primary cause of disease. It is far better for adult fish to migrate to the hatchery, rather than be trapped and transported. 
Human health

Is the site located upstream of a human domestic water diversion? Some fish diseases and some chemicals utilized in the hatchery may be harmful to humans. The hatchery should be located so as not to compromise human safety.

Water control for disease treatment and sanitation

Can the water flow be shut off for disease treatment?

Many hatchery ponds cannot be drained to enable effective disease treatment.

Seldom will a water source be totally adequate for all fish disease prevention criteria. However, each potential supply source should be evaluated for disease prevention along with other necessary criteria. If the water source is suitable for most needs, the deficiencies should be evaluated to determine if they can be minimized through engineering or management approaches. The most cost-effective and pathologically sound water supply will prove to be the best investment for a successful hatchery program. 


\section{CHAPTER 2}

\section{WATER COLLECTION，DELIVERY，AND QUALITY IMPROVEMENTS}

This Chapter describes the facilities and equipment utilized in providing water for fish cultural needs, and discusses various ways to treat the water supply to meet the quality criteria set forth in Chapter 1. For a typical fish hatchery, the water system is one of the major costs and can approach $50 \%$ of the total project. Facilities and equipment for water collection, conditioning, delivery, control, and drain systems detailed have been successfully utilized in Northwest salmon and steelhead trout fish cultural operations. Permits are commonly required for these construction activities (see Chapter 10).

\section{PART I. WATER COLLECTION SYSTEMS}

This Section discusses the various facilities and equipment in use to collect surface runoff, spring, and ground waters for fish cultural needs. Surface waters are considered as streams and lakes generally supplied from rain, or run-off from melting snow or glaciers. Spring waters are those surfacing from below ground, and ground waters are those collected from wells or from excavations that produce a continual flow.

\section{A. SURFACE WATERS}

The collection of surface waters requires a reliable system to protect hatchery fish from loss of water. Most Northwest streams have large fluctuations in flows, with the resulting bank erosion, turbidity, gravel deposition, and large amounts of floating debris. Cold winters can also cause stream icing conditions on the water surface as well as the stream bottom. Therefore, to insure a continuous water supply, a complex intake may be required according to the size and goals of the facility, and the adversity of the stream conditions. Unfortunately, maintenance-free intakes have not been developed to handle all stream flow conditions, so operators must be equipped to maintain water flows to the hatchery at all times. Adverse weather conditions usually maximize water supply problems. Lake water surface intakes also have a number of the above noted undesirable characteristics, but generally are not of the same magnitude because the larger body of water dampens the intensities of flows, sediments, and debris.

Various water intake facilities and methods are explained and analysed below.

1. Stream and Lake Bank Intakes This intake is a concrete Dox structure located on the bank of a stream or lake at a level that permits free entry of water for eitner pumping or gravity flow diversion into a pipeline or open ditch, but it should not be built in an area of back eddy. Low-cost facilities generally provide for double screening of the incoming water; first through a trash rack with large openings, and then through a small-mesh screen system. The two screens prevent large trash, 
Water Collection, Delivery, and Quality Improvements

leaves, debris, sediments, wild fish, etc. from entering the diversion and should be parallel to the flow of the stream to assist in keeping them clean. The structure should also have the capability for the installation of stop logs to shut down the water system for maintenance and cleaning. The actual intake in the concrete box can have vertical or inclined screens depending upon the needs of the system.

On streams where low-flow conditions do not afford sufficient depth for the required water diversion, small dams may be required to raise stream water elevations. These small dams may be a permanent concrete sill, a semi-permanent rock-filled dam, a temporary stream gravel dam, or a temporary rack with wood facing spanning the stream width. Regardless of which type of system is used to raise the water level, there should be provision for lowering the water to allow the forebay to be cleaned.

\section{Advantages:}

- Highly reliable for diverting water under varying stream flow and lake water conditions

0 Structure can be overtopped without serious damages or danger to the water supply

Simple construction

$0 \quad$ Small water diversions can utilize small pre-cast concrete intake boxes

$\underline{\text { Disadvantages: }}$

- Structure creates higher upstream water levels and may require flood and flowage easements in sensitive areas

- Requires daily inspection and the maintenance requirement can be hourly during adverse weather and water conditions

- Sand, silt, and muddy water pass through the diversion causing operation problems in incubation and rearing

0 Requires periodic cleanout of sediments from inside the intake as well as the waterway leading to the intake

- If a water diversion dam is required, upstream fish passage for native fish may be needed

- Screens are subject to freezing with reduction of water to fish facilities

\section{Cost:}

Capital costs can vary from $\$ 1,000$ for a 3-4 cfs capacity concrete pre-cast water diversion box, as installed at the Red River Salmon Rearing Pond with a bulldozed temporary gravel check dam, to $\$ 100,000$ for $60-75$ cfs capacity concrete intakes for the Bonneville Fish Hatchery and Quinault National Fish Hatchery with concrete dams and fishways. Life expectancy is 50 years for all three structures. 


\section{Chapter 2}

\section{Information Sources:}

Idaho Fish and Game Red River Salmon Rearing pond and Pahsimeroi Steelhead Collection Facility

Oregon Fish and Wildlife Bonneville Fish Hatchery

U.S. Fish and Wildlife Service Quinault NFH and Winthrop NFH, Washington

2. Instream Diversion Dam with Screen Intake Structure This type of intake requires a concrete dam with an overflow section capable of passing 100-vear floods. On all or a portion of the overflow section's downstream side, inclined plane screens are installed to pass water into a diversion flume, pipeline, or open ditch. Inclined plane screens are sloped with the water flow providing self-cleaning of the screen surfaces (Fig. 1). The screen slopes vary with each installation depending on the designer's criteria. At the Tulalip Tribal Hatchery in Washington, Tulalip Creek screens were installed on a 1 on 1 slope, while Hatchery Creek screens at the Quinault National Fish Hatchery, Washington, were installed on a 1 on 3 slope. Both installations have excellent self-cleaning performances and easily divert all of the normal stream flows.

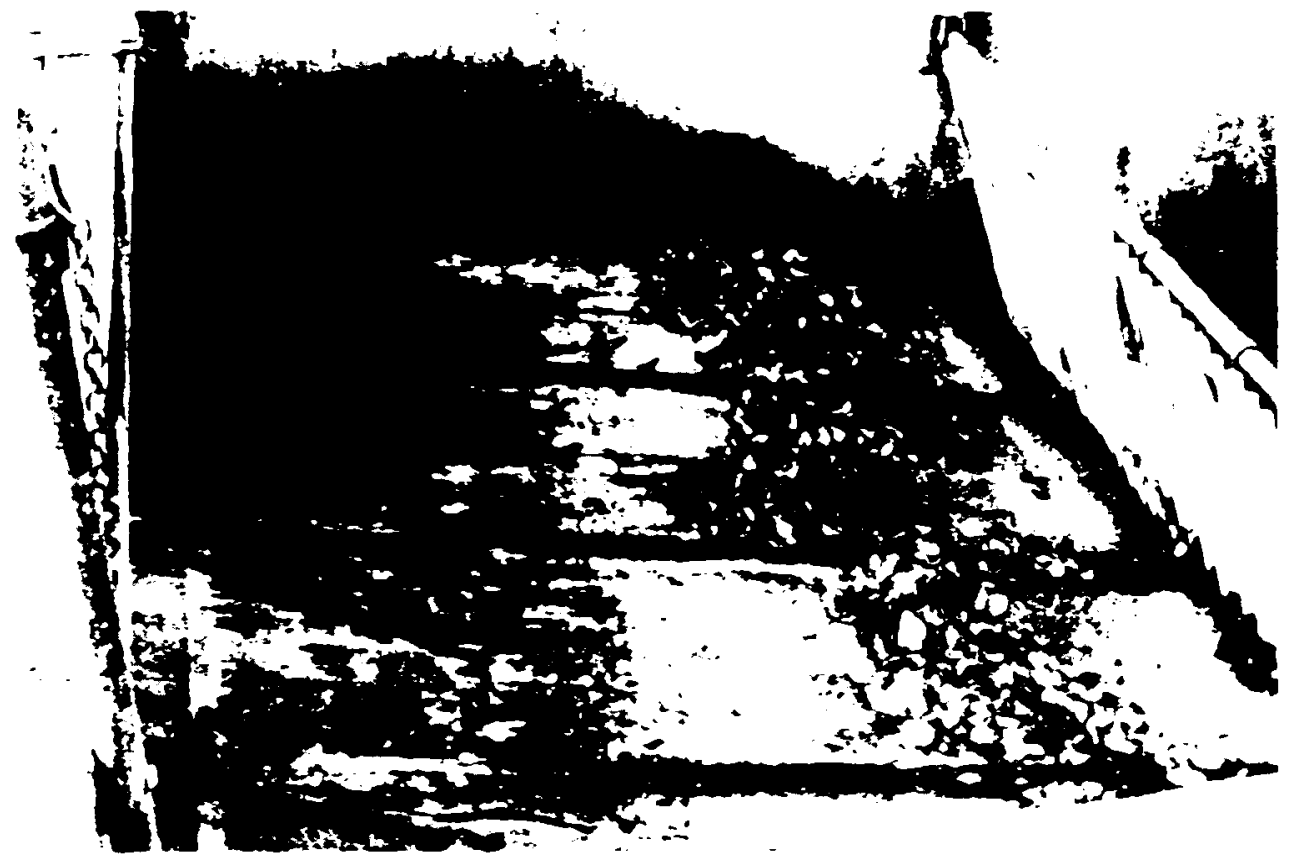

Figure 1. Inclined plane screen at the Gnat Creek Fish Hatchery

Advantages:

(OFW). Note leaves washed down by the water.

- Highly reliable for diverting water under varying stream flow conditions

- Structure can be overtopped without serious damages or danger to the water supply

- Self-cleaning capability 
Water Collection, Delivery, and Quality Improvements

Disadvantages:

- Requires daily inspection and the maintenance requirement can be hourly during adverse weather and water conditions

- Sand, silt, and muddy water pass through the diversion causing operation problems in incubating and rearing

- Requires periodic cleanout of sediments from inside the diversion flume

- Depending on location, may require passage facilities for native fish

- Structure creates higher upstream water levels and may require flood and/or flowage easements in sensitive areas

- Screens are subject to freeze-up with reduction of water to fish facilities, Temporary screen removal, portable heaters or heat lamps on the screens, or the introduction of warm well water on the screen surface are solutions to the freeze-up problem

- Inclined plane screening systems lose about 2 feet of available head between the dam and the diversion flume

\section{Cost:}

The capital cost of the 8-foot high West Fork Tulalip Creek diversion dam at the Tulalip Tribal Hatchery, Washington, with screened intakes was $\$ 119,000$, and the system diverts $14.5 \mathrm{cfs}$. The capital construction cost of the 5-foot high Hatchery Creek diversion dam at the Quinault NFH, Washington, with screen intakes was $\$ 40,000$, and diverts $12 \mathrm{cfs}$. Costs for this type of structure vary greatly depending on dam height and the stream width. Life expectancy of these structures is 50 years,

Information Sources:

Tulalip Tribal Salmon Hatchery, Washington

U.S. Fish and Wildlife Service Quinault NFH, Washington

3. Instream Rock Filter Intakes Considerable funds and manpower have been invested in improving water quality by filtering stream water through rock and gravel (Fig. 2). Most have developed problems, however, and few are presently in use. Filtration methods have included the use of perforated pipe or well screens carefully buried in trenches and backfilled with washed, graded gravel. Intakes centered in rock-filled wire gabion baskets, and intakes located along stream banks behind rock filter walls have also been tried. In operation, filters tend to soon become plugged. Backwash systems using water or compressed air have been installed but were unsuccessful in cleaning the systems. An additional problem has been the difficulty in preventing the passage of fish through the filters from the water supply systems. The rock filtering processes remain available but we do not recommend them. Information sources are the OFW Elkhorn Fish Hatchery and WDF Humptulips Salmon Hatchery.

4. Miscellaneous Submerged Screen Intakes The low-cost submerged screen intakes described below are from the Canada Department of Fisheries and Oceans, (1980). These type of intakes should be considered for secure water areas of lakes 
Chapter 2

and spring-fed ponds where damage potentials are minimal. Note that these intakes all have approximately $10 \mathrm{ft} 2$ of screen area to screen $1 \mathrm{cfs}$ of water. Intakes are required to be accessible for cleaning at regular intervals. All intakes are easy to build and can be constructed and installed for under $\$ 1,000$ each. Life expectancy is 10 years for the wood and 25 years for the metal intake parts. We also refer you to Swan et al., (1980) for the various types of surface intake screens used on pump stations located in the Columbia River watershed upstream of Pasco, Washington. A direct quote from the Canadian publication follows:

"Multiple well screens connected to a submerged pipeline on a lake bottom have been used to screen water for a municipal supply. The screens are normally positioned approximately 3 metres from the bottom of the lake to prevent silt and debris from entering the water system.

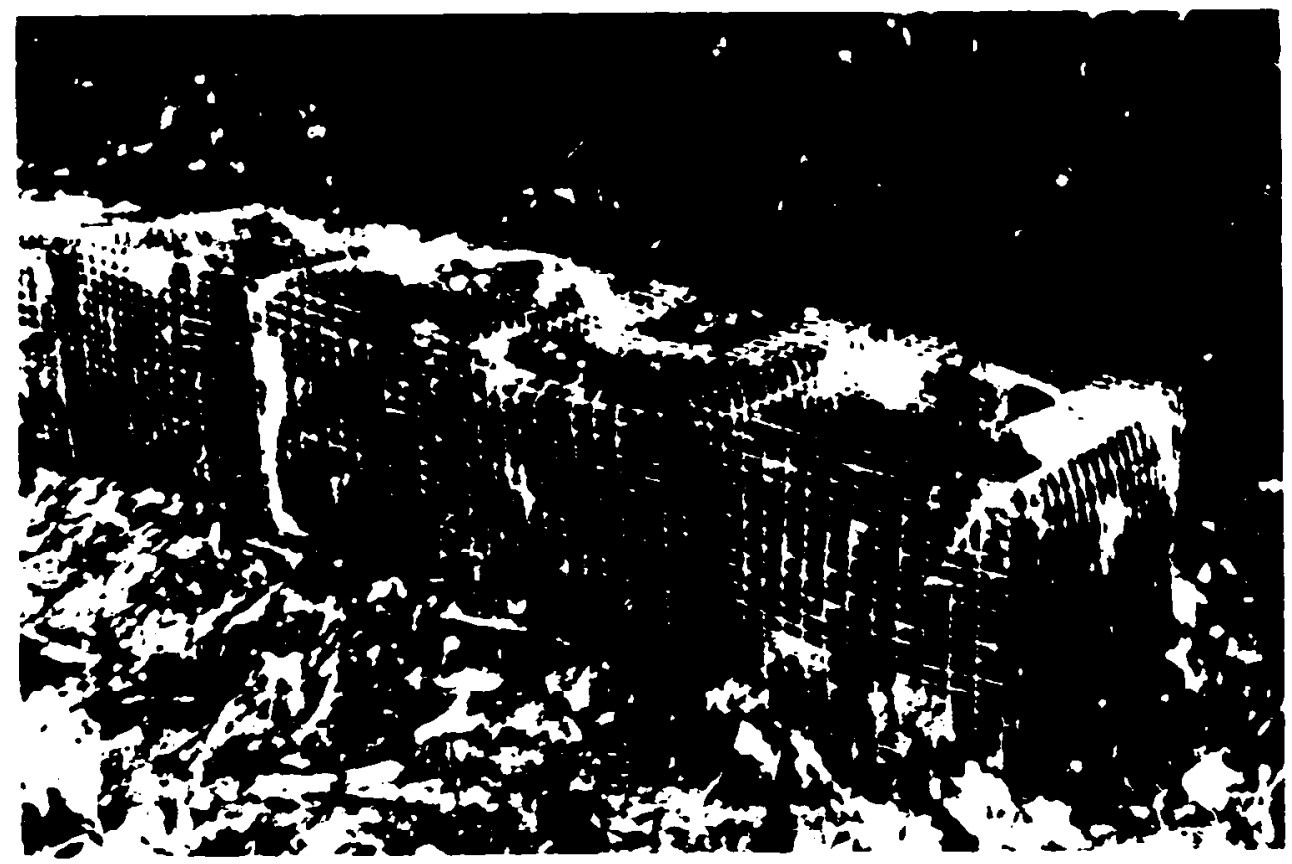

Figure 2. Rock-filled gabions ready for use at the Clatsop County Rearing Pond, Oregon.

A floating water intake can be fabricated utilizing two simple pontoons with a section of well screen supported between them. A flexible polyethylene pipeline can be connected from one end of the well screen to the shore. This type of intake can be used in either lakes or rivers, and is often ideal for supplying water to a fish egg incubation facility or temporary supply for rearing ponds.

A temporary intake may be constructed by connecting a flexible pipe to a well screen, which is raised above the bottom by simple support legs welded to each end of the screen (Fig. 3). This type of assembly may be installed 
Water Collection, Delivery, and Quality Improvements

in pools of streams, impoundments behind beaver dams, small lakes, or in other stable, clean water sources.

A screened intake can be made from a drum or welded rectangular frame covered with woven wire mesh (Pig. 4). This intake can be used in a stream or lake, supported below the water surface from floats."

\section{Information Sources:}

Canada Department of Fisheries and Oceans B.C. Ministry of Environment, Vancouver, B.C.

Washington Department of Fisheries, Grays River Hatchery

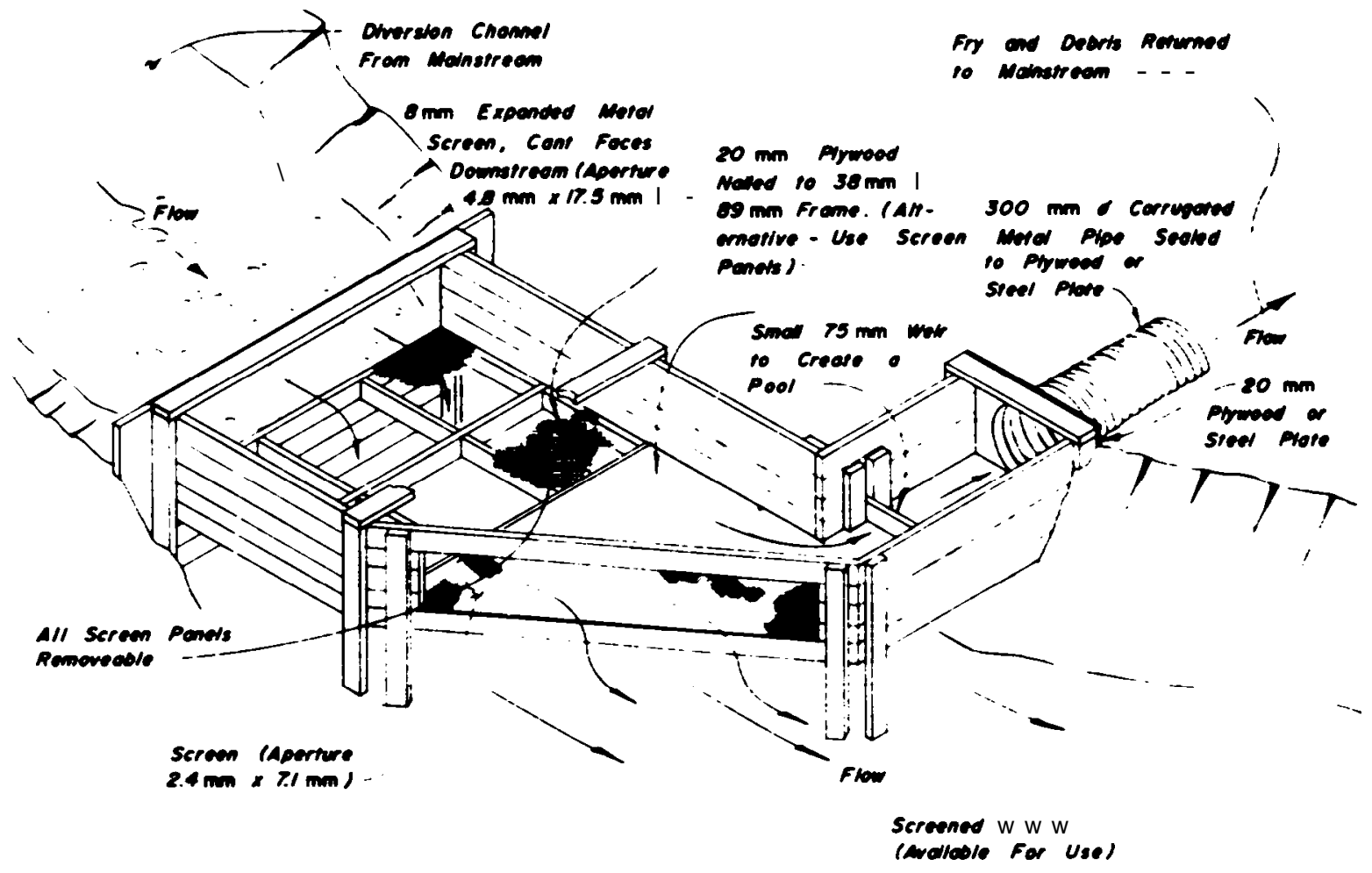

Figure 3. "Horizontal-vertical screening facility located in a diversion channel off the main stream. Water flows through the horizontal and vertical sections of the screen and is available for use in the irrigation channel or other water use facility downstream. Fish and debris are guided to the bypass culvert which discharges back to the main stream. (Adapted from P. A. Slaney, 1977)" Courtesy of Canada Department of Fisheries and Oceans and British Columbia Ministry of Environment, Vancouver, B.C. 
Chapter 2

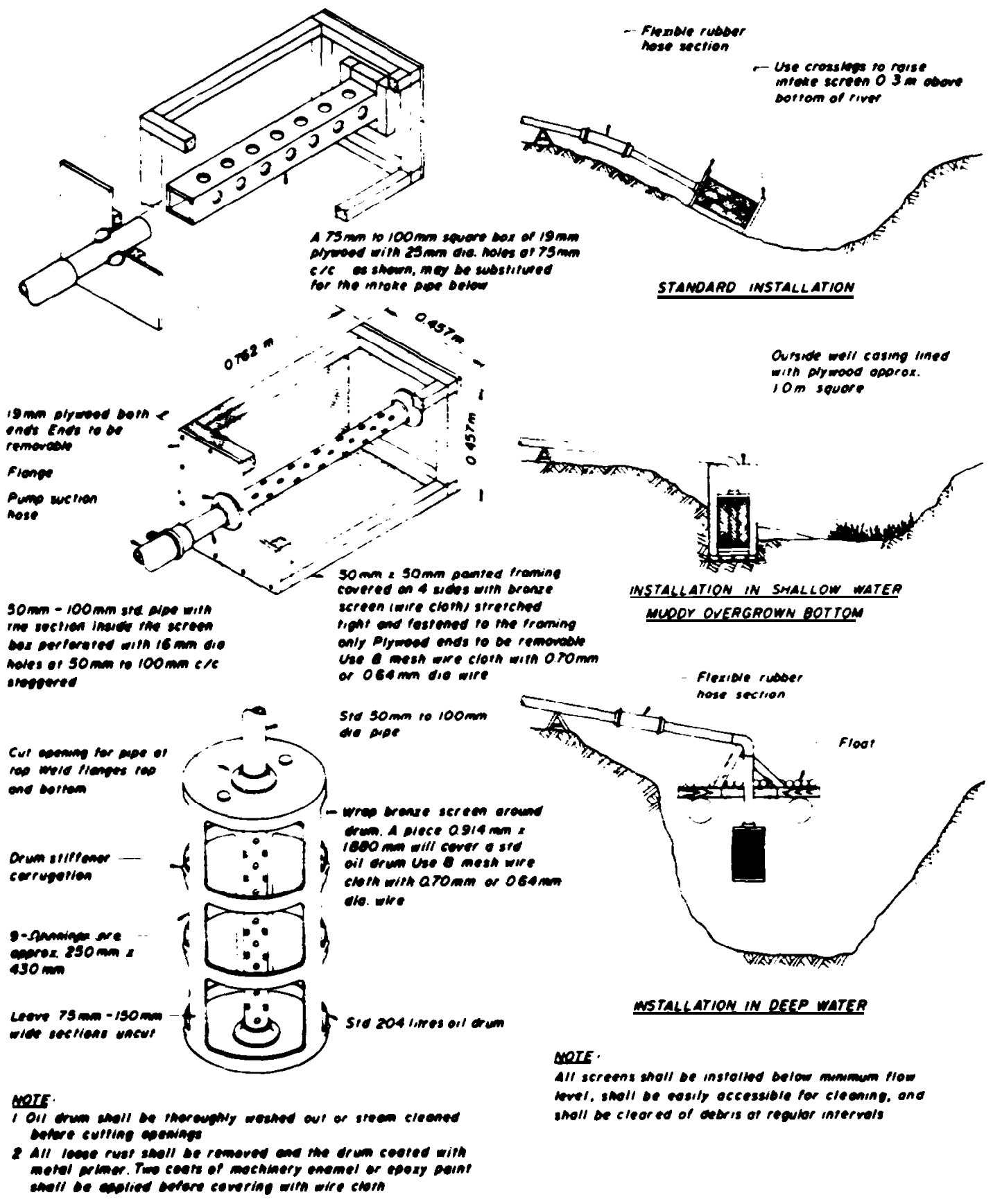

Figure 4. "Intake screens for pumps with capacities less than 2050 litres per second (i.e., one cubic foot per second, 450 U.S. or 375 IMP. gal per minute). Adapted from Department of Fisheries of Canada (DWG No. 4-3-4 1965)" Courtesy of Canada Department of Fisheries and Oceans and British Columbia Ministry of Environment, Vancouver, B.C. 
Water Collection, Delivery, and Quality Improvements

\section{B. SPRING WATERS}

Spring water collection is much easier than surface waters because of constant water flows and the general absence of sediment, debris, and ice. Spring water is commonly collected through an intake constructed within a cut-off wall dam that serves as an impoundment. These impoundments are sometimes covered to protect water quality. Open impoundments can have problems of algae and vegetation growth, wild fish, snail infestations, contamination from animals, and a temperature loss in severe climates. Fenced enclosures are also used to prevent animals and people from entering and degrading spring water areas.

The cut-off wall dams usually are installed 2 to 3 feet below ground level and extend 2 to 3 feet above ground levels. The wall can be constructed of concrete, sheet steel piling, Wakefield wood piling, or a combination of the above materials. The warer intake is through an opening in the dam with a vertical or upstream sloping screen in the upstream face of the dam. Inclined plane screens sloping downstream from the dam can also be installed, as for the proposed Nisqually Tribal Salmon Hatchery near Olympia, Washington (Fig. 5). A roof cover over the spring impoundment is either metal or wood construction supported on concrete footings. Operations require daily inspections to clean screens as necessary.

\section{Cost:}

A 35-foot long spring intake structure with cut-off wall dam costs about $\$ 6,000$, and has a 50-year life expectancy. The same structure with the Nisqually-type inclined plane screen intake costs $\$ 8,000$, and also has a 50-year life expectancy. Concrete or concrete block footings with a metal roof over the spring will cost $\$ 16 / \mathrm{ft}^{2}$, and have a 25 -year life expectancy. A wooden roof will cost $\$ 12 / \mathrm{ft}^{2}$, and have a lo-year life expectancy. For a low-cost cover, floating wood frames covered with 4 mil black plastic sheeting would cost approximately $\$ 0.20 / \mathrm{ft}^{2}$ plus labor.

Information Sources:

U.S. Fish and Wildlife Service Spring Creek NFH and Carson NFH, Washington Idaho Fish Game Niagara Springs Steelhead Hatchery Washington Department Fisheries Klickitat Salmon Hatchery

Washington Department of Game Ringold Steelhead Hatchery and Goldendale Fish Hatchery

\section{WELL WATERS}

Well water is generally excellent for hatchery operations and is usually disease-free, clear, clean, and at a constant temperature. This water is useful for incubation or tempering surface waters for rearing and adult holding. It is advisable, however, to determine the chemical qualities of the water before any great expenditure is mude (set Chapter 1, Table 1). 
Chapter 2
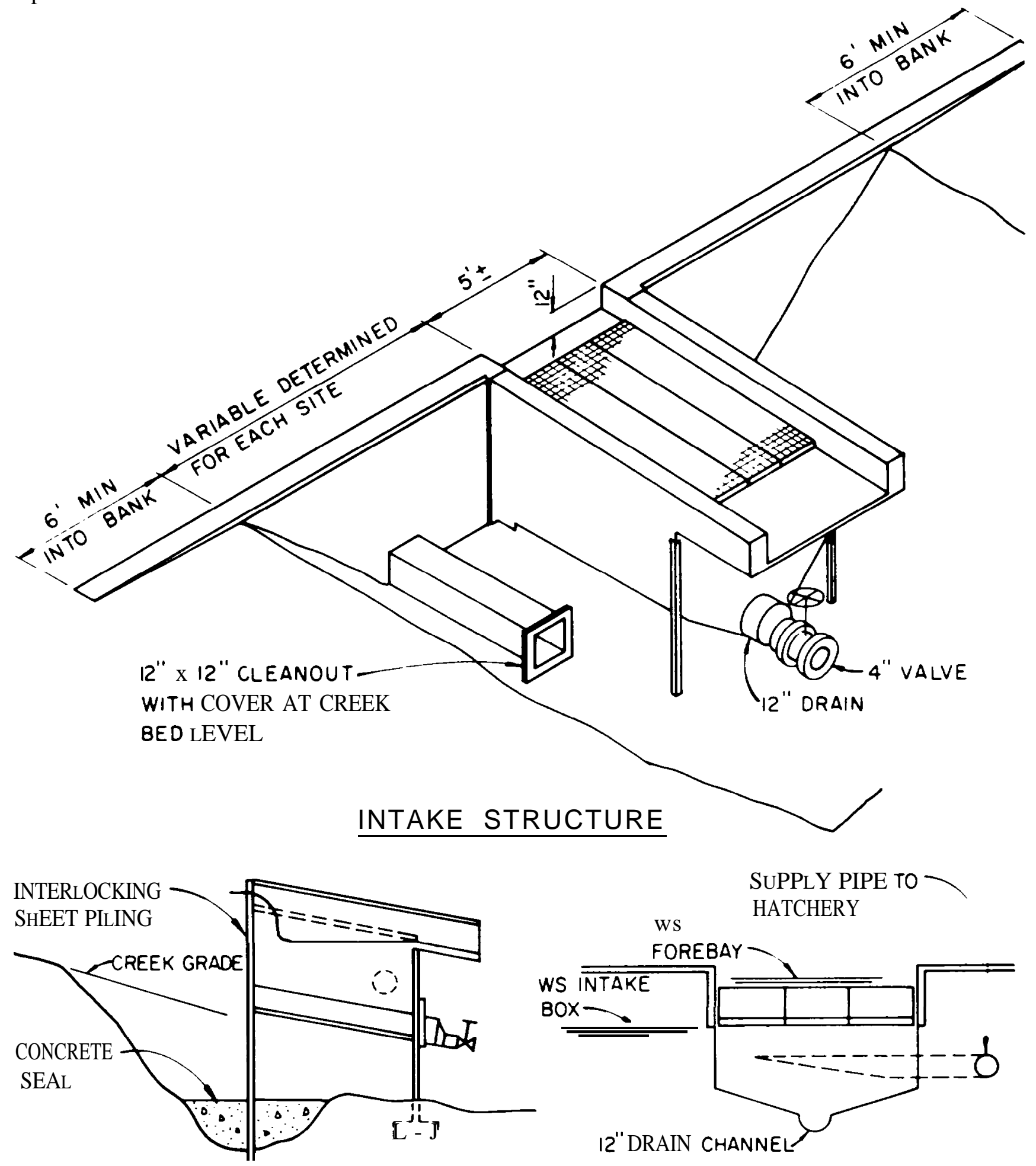

SUPPLY PIPE TO HATCHERY

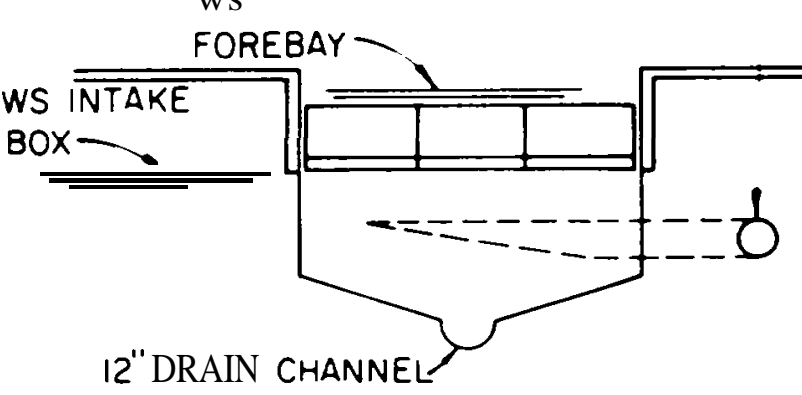

Figure 5. Typical spring water intake structure. Courtesy of the Nisqually Indian Tribe. 
Water Collection, Delivery, and Quality Improvements

Wells are usually developed with cable tool, mud rotary, or air rotary drilling rigs. Rainey wells are not applicable to this report because of the high development cost. Shallow, large diameter cistern-type wells can be dug by hand. Pump bowl diameters increase as pumping capacity increases, therefore, well diameters are sized for the pump and the estimated quantity of water available for pumping. An increase in well diameter will not produce appreciably more water. Pumps for wells are chosen from test pumping data, where well water quantity versus ground water level drawdown depth from ground surface to the pumping water level are physically measured.

Frequently, well pumps have been oversized because of the desire to pump all available water indicated by test pump data. Test pump data are obtained from 24 to 40 hours of test pumping, while the permanent production pumps run continuously for several months as required by operations. The production water levels associated with pumping usually stabilize at greater depths with less water available for pumping. Our recommendation is to choose pumps sized for $80 \%$ of the test pumping water quantities. When well pumps are oversized, well water levels can fall below pump suction and cause surging. Surging causes air to be pumped together with water, and leads to pump bowl cavitation and an overdraft on the water aquifer that brings sediment into the casing. The overdraft can also cause pump bowl wear and eventual well failure.

Well pumps should be selected with overall efficiencies of energy input to water output of not less than 75\%. Northwest production well pumps are normally powered by electric motors. Deep well turbine pumps are generally used for high capacity production wells. Recently, high quality submersible pumps with attached submersible electric motors have been developed. This submersible equipment provides improved security against vandalism, the ability to safely locate wells in flood zones that can be inundated with seasonal high water, and eliminates the need to lubricate pump shaft bearings located between the pump and motor.

Deep well vertical turbine pumps are available with pump shaft lubrication by either oil or water. Water lubrication is recommended to keep oils out of the fish culture operations.

cost:

a. Well drilling and furnishing and installing well casing pipe costs about $\$ 6.50$ per inch of well diameter par foot of well depth.

b. Well test pumping of less than 50 gpm with cable tool bailor costs about $\$ 40$ per hour. A variable speed pump with pumping capacities to $200 \mathrm{gpm}$ costs about $\$ 60$ per hour. A variable speed pump with pumping capacities of $200 \mathrm{gpm}$ to 1,000 gpm costs about $\$ 100$ per hour.

c. Electric powered permanent production pumps cost $\$ 500$ per HP for pumps rated over $40 \mathrm{HP}$, and about $\$ 1,000$ per HP for pumps rated under $10 \mathrm{HP}$.

d. A 12-inch diameter well that is 300 feet deep and equipped with a $50 \mathrm{HP}$ pump capable of pumping $700 \mathrm{gpm}$, costs about $\$ 50,000$. This cost does not include bringing electrical service to the well site, but does include pump panel switches, starters, heaters, and other controls. 


\section{Chapter 2}

e. Life expectancy of the well is 25 years. To maintain pump efficiencies, the pump should be overhauled every 10 years.

f. Well production pumping costs at $\$ 0.04$ per kilowatt-hour of electricity are shown under "Pumps" in the next section (II A), Table 1. Electrical demand charges of an additional $\$ 5$ to $\$ 25$ per month, depending on pump motor horsepower, are not included.

\section{Information Sources:}

U.S. Fish and Wildlife Service Leavenworth NFH, Washington, and Kooskia NFH, Idaho

Oregon Fish and Wildlife Gnat Creek and Bonneville Fish hatcheries

Washington Department of Fisheries Priest Rapids Salmon Hatchery

Washington Department of Game and Department of Fisheries Wells Salmon and Trout Hatchery

\section{INFILTRATION SYSTEMS}

Infiltration systems are used in developing ground water supplies in areas where a high ground water table is present and large water quantities are stored. This type of condition exists in floodplains where gravel deposits allow upstream water to continuously supply and permeate these deposits. Infiltration water is useful for fish culture because the water is not only clear and debris free, but most importantly, the water temperatures usually lag stream temperatures by about six weeks. Therefore, one can expect 2 to $4 \mathrm{~F}$ warmer water in winter and 2 to $4 \mathrm{~F}$ cooler infiltrated water in summer, compared with adjacent stream water temperatures during these critical water temperature periods.

This water is easily developed by excavating to depths below the water table. These excavations can be open trenches, channels, or backfilled trenches with perforated pipe draintile with gravity flow to a pump site or a channel. lnfiltrated ground water, as with all ground water supplies, may contain supersaturated nitrogen. This supersaturated condition may be continuous or seasonal, particularly when this water is warmer than the surface waters (see Chapter 1).

An early application of using infiltrated water was Satsop Springs (WDF) near Elma, Washington. A number of installations in British Columbia utilize infiltrated waters for spawning, incubation, and rearing channels (Fig. 6). These channels are $1 / 2$ to 1 mile long and 20 to 50 feet wide, with 12 to 18 inches of gravel substrate. The DFO indicated that construction costs were about $\$ 140,000$ per mile of channel. However, construction is simple and many were built very economically using volunteer labor and equipment. Spawning and incubating gravels should be mechanically cleaned at two- to four-year intervals for optimizing the system.

The USFWS Winthrop National Fish Hatchery has developed 6 cfs of infiltrated water from about 200 feet of trenching at a cost of $\$ 40 /$ in $\mathrm{ft}$ of backfilled trench with perforated pipe, and $\$ 10,000$ for the pump sump and pumping system. Life expectancy is 25 years. 
Water Collection, Delivery, and Quality Improvements

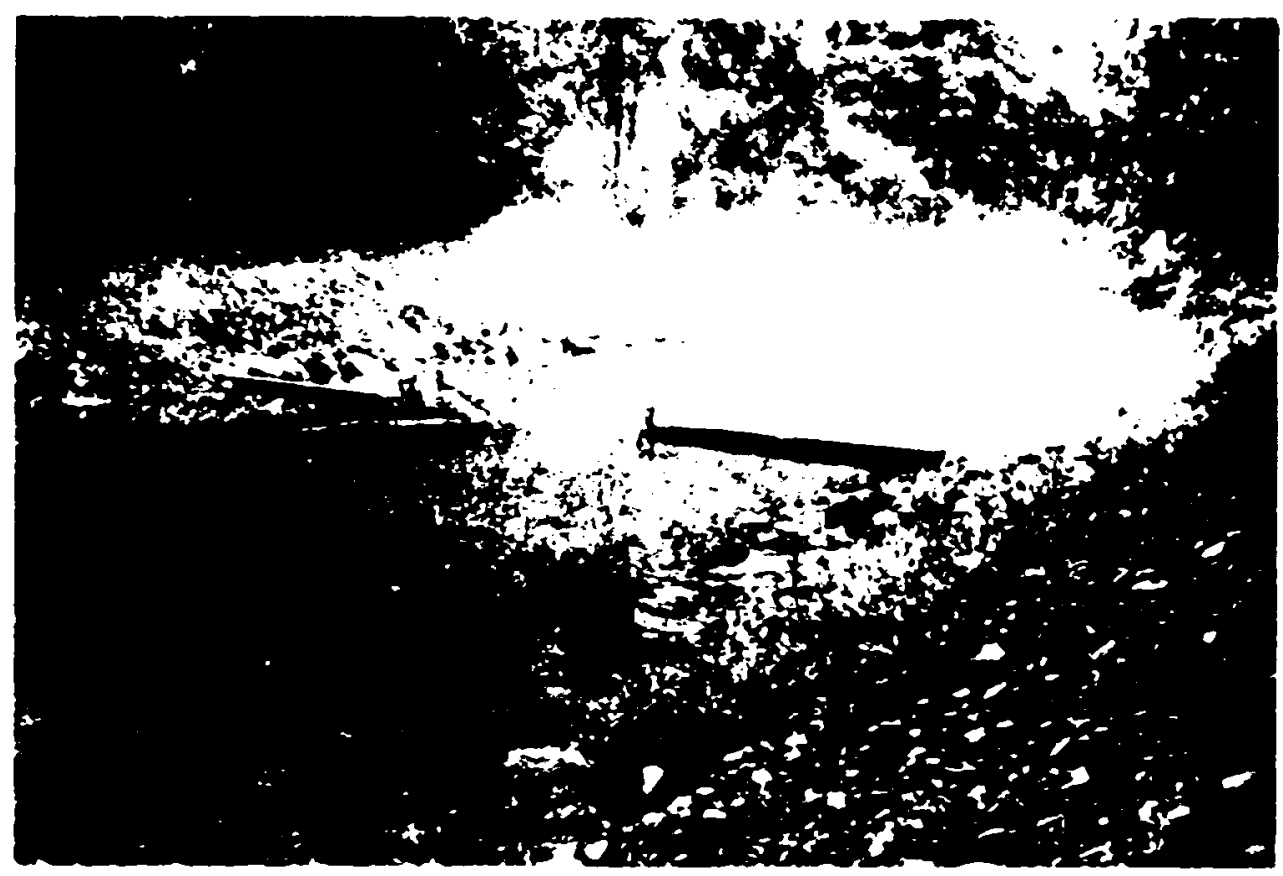

Figure 6. An incubation and rearing channel developed in British Columbia which uses an infiltration water system (DFO).

At many large dams, good quantities of infiltrated water are available from their downstream toe drains and can be collected for fish culture uses. Toe drain waters from the U.S. Corps of Engineers' Chief Joseph Dam have been studied and recommended as useable for the prime water supply source for a fish hatchery (Koch and Cochran, 1977). Chelan County PUD's Rocky Reach Dam toe drain water presently supplies 4 cfs of quality water to WDF's Rocky Reach Hatchery. Both of the dams are on the Columbia River upstream of Wenatchee, Washington.

\section{Information Sources:}

Worth Creek-Harrison River Side Channel, British Columbia

Little Mountain-Chehalis River, Chehalis Indian Reserve Side Channel, British Columbia

North Vancouver Outdoor School Mini Hatchery, British Columbia Rod and Gun Club-Puntledge River Side Channel, British Columbia U.S. Fish and Wildlife Service Winthrop NFH, Washington

Washington Department of Fisheries Rocky Reach Hatchery 
Chapter 2

\section{PART IL WATER DELIVERY SYSTEMS}

These systems involve the use of pumps, siphons, and gravity for water delivery through channels and/or pipelines from collection sources to the fish culture facilities, and then drain back to the receiving waters.

\section{A. PUMPS}

Pumps are mechanical devices for raising water to higher elevations or to higher pressures when the flow is constricted by a closed pipe system. Pumps require a rotating power source, usually an electric motor for fixed rpm, or a fueled engine for independent and variable speed operation. Following are several types of pumps:

1. Piston Pump A piston is moved back and forth in a cylinder with water passing through a valve as in an old style domestic pump or in boiler feed pumps.

2. Gear Pump Two gears in mesh turning in a close-tolerance case take liquid in on open teeth and squeeze liquid out as teeth close in mesh.

3. Rubber Vane Pump A rubber vane impeller in an eccentric case takes liquid in as vanes open and discharges as vanes close past eccentric.

4. Axial Flow Propeller Pump This pump, used in fisheries work, has a propeller type impeller rotating in a close-tolerance enclosure connected to the vertical discharge pipe up to a delivery elbow. Above the elbow is the electric motor driving the propeller by a long shaft supported in the center of the vertical delivery pipe. This type of pump is designed for low-heads of 10 to 20 feet with large flow capaity. A 12-inch pump with 15-foot head will deliver 2,000 gpm at $72 \%$ efficiency with a $15 \mathrm{HP}$ motor. The axial flow propellor pump is less expensive than centrifugals and is less efficient.

5. Centrifugal Pump Centrifugal type pumps come in a variety of classifications but all have a rotating impeller enclosed in a close-tolerance case. Centrifugal force from rotation of the impeller forces water to the outside of the case where it is discharged. As the water leaves the case, a vacuum causes new liquid to enter at the center of the impeller. Centrifugal pump types include self-priming, ditch, open impeller, closed impeller, multiple stage, high pressure, centrifugal driven, jet, and submersible. Modern development of seals, motors, and wiring has allowed the submersible centrifugal pump to become widely used for fisheries water supplies from wells, river intakes, and infiltration water sources.

6. Air Lift Pump These pumps are sometimes used in lakes for bottom to surface circulation. A solid wall or perforated pipe is suspended vertically from the surface to the lower lake levels. Air is introduced in the pipe, creating a flow of water to the surface as the air rises. Again, caution should be applied in the introduction of air to prevent supersaturation. Avoid dispensing air in the lower elevations of deep water. 
Water Collection, Delivery, and Quality Improvements

Fish hatchery water pumps are either propeller or centrifigal types that have the following characteristics:

Propeller

1. Low head to 20-foot lift

2. High capacity to $20,000 \mathrm{gpm}$

3. Efficiencies in low $70 \%$ ranges

4. Ability to pump sand and silt without excessive propeller damages

5. Costs less than centrifugal pumps

6. Available for trailer mounting if portability is required

\section{$\underline{\text { Centrifugal }}$}

1. Low to high head lifts

2. Low to high capacity water deliveries

3. Efficiencies in high $70 \%$ ranges

4. Sand and silt in water damages impellers

5. More costly than propeller pumps

6. Pump shafts longer than 20 feet require prelubrication (not applicable to submersibles)

\section{Advantages:}

- Initial capital construction outlay less costly than gravity flow pipelines with remotely located river intakes

- Multiple pumps can be sized and used for varying water quantities

- Pumping intake locations are usually much closer to the hatchery and can be more easily observed for security and maintenance

- Auxilary power unit can be located in close proximity to the power control centers for power distribution

\section{Disadvantages:}

- Power cost and pump repairs are continuing costs of the system not found in a gravity system

- Standby generator for minimum pumping flow, or reservoir storage is required for use during power outages

- Heavy equipment needed to remove and replace pumps

- $\quad$ Platform and pump installation subject to flood and debris damages

- Flow diversion can be required during low flow periods

\section{Cost:}

Costs are dependent on pump platform support installation, pump capacity, pump lift, pump motor horsepower, and equipment quality. Electrical pumping costs are a major operational expenditure. Table 1 illustrates production pumping costs at different heads, assuming \$0.04/kilowatt-hour for electricity. Equipment failure could be devastating to fish life, therefore, high quality, highly efficient pumping equipment is recommended for the water delivery systems. Life expectancy of pumps is 25 years with pump overhaul at ten-year intervals. 
Chapter 2

Table 1. Monthly production pumping costs at various lifts.(1)

\begin{tabular}{|c|c|c|c|c|}
\hline$\underline{\text { Production }}$ & 50' Lift & $\underline{100^{\prime} \mathrm{Lift}}$ & $150^{\prime} \mathrm{Lift}$ & $\underline{200^{\prime} \text { Lift }}$ \\
\hline $\begin{array}{c}50 \mathrm{gpm} \\
100\end{array}$ & $\begin{array}{r}\$ 18.14 \\
36.00\end{array}$ & $\begin{array}{r}\$ 36.00 \\
7279\end{array}$ & $\$ 54.43$ & $\$ 72.29$ \\
\hline 150 & 72.29 & 144.58 & 216.86 & 289.15 \\
\hline 200 & 108.29 & 216.86 & 325.44 & 434.62 \\
\hline
\end{tabular}

(1) Based on $\$ 0.04$ per kilowatt-hour. Does not include kilowatt demand charges; usually $\$ 1.00 /$ mo/kilowatt.

Information Sources:

U.S. Fish and Wildlife Service Dworshak NFH, Idaho and Warm Springs NFH, Oregon Washington Department of Fisheries Lewis River, Upper Kalama, Lower Kalama, Cowlitz, and washougal Salmon hatcheries

Pump suppliers are found in the phone directory yellow pages, such as Byron Jackson, Paco, Pearless, Johnson, and H.D. Fowler Pump companies

\section{B. GRAVITY}

Columbia River fish hatcheries commonly utilize buried gravity flow pipelines for fish cultural water supplies. These installations are considered the most reliable, risk free, and the preferred method for a fish hatchery water delivery system. On station, the water supply is further distributed and drained through combinations of buried pipelines, exposed pipelines, pipe manifolds, supply and drain troughs, water supply head and drain boxes, stop logs, gate valves, butterfly valves, and slide gates. Water supply troughs and head boxes are also the preferred method over manifold pipe systems for supplying water to stacks of vertical incubators, as individual water adjustments are more easily made without affecting flows in any of the other units using the same water supply.

1. Pipelines The importance of a reliable, uninterrupted water supply demands that high quality pipelines be installed, and that the lines be installed so that air will not be trapped, causing loss of flow or gas supersaturation. A quality pipeline is constructed of durable material, possesses good water flow characteristics, is watertight with no joint leakage, and is not difficult to install.

Pipelines 12 inches in diameter, or larger, with good performance records are made of reinforced concrete; ductile iron; concrete cylinder; welded steel; cement asbestos; aluminized-coated, welded-seam, corrugated steel; and wood staves. PVC plastic, black steel and ductile iron pipes for small diameter lines under 12 inches also have good performance records. 
Water Collection, Delivery, and Quality Improvements

\section{Advantages:}

0 Most reliable system for water delivery

0 Minimal maintenance required as related to other facilities

- Minimal water transportation losses

- Minimal exposure to accidental chemical spill or contamination

- Pipelines, when buried, are secure and have minimal problems with floods

- Non-ferrous materials (listed above) avoid decompositon from electrolysis

- Wood stave pipe leaks are easily repaired while under pressure

$\underline{\text { Disadvantages: }}$

- $\quad$ Buried pipeline leakage difficult to detect and to locate

- Wood stave pipe requires line to be maintained filled with water to prevent shrinking in cross section and leaking

- Welded steel, corrugated metal, black steel, and PVC plastic pipes cannot be installed around curves or bends without special sections

- Entrained air can supersaturate water

cost:

Costs are itemized (Table 2) for furnishing and installing the various buried pipelines, including special sections, air valves on high points, blow-off valves on low points of pipeline alignment, and a large blow-off valve on the terminal end of the line.

Table 2. Approximate costs of buried pipelines. (1)

Pipelines 12-inch

diameter and larger
Pipelines under 12-inch diameter

$\begin{array}{lr}\text { Reinforced concrete } & \$ 5.00 \\ \text { Ductile iron } & 5.00 \\ \text { Concrete cylinder } & 5.00 \\ \text { Welded steel } & 5.00 \\ \text { Wood stave } & 4.30 \\ \text { Corrugated steel } & 2.50 \\ \text { Cement asbestos } & 5.00\end{array}$

PVC

Ductile iron

Black steel
$\$ 3.00$

(1) The above costs are per inch of pipe diameter per linear foot of pipe. Therefore, a 12-inch diameter reinforced concrete pipe will cost 12 × $\$ 5.00$ or $\$ 60.00$ per linear foot. All pipelines have 50-year life expectancies.

\section{Information Sources:}

Reinforced concrete pipe - Concrete Products of Moses Lake, Moses Lake, h.4 Ductile iron pipe - Pacific States Cast Iron Pipe Co., Portland, OR Concrete cylinder pipe - Ameron Pipe Division NW, Portland, OK Welded steel pipe - Beal Pipe and Tank Corp., Portland, OR 


\section{Chapter 2}

Wood stave pipe - National Tank and Pipe Co., Clackamas, OR Corrugated steel pipe - Waterworks Supply Co., Portland, OR

PVC pipe - Hinds Supply Co., Portland, OR

Black steel pipe - Hinds Supply Co., Portland, OR

2. Open Channels Open channels may be unlined, or lined with concrete or culvert pipes cut into half-flumes to minimize water loss in areas of pervious soil materials. Culvert pipe flumes are also used in steep terrain where ditch maintenance would be difficult or impossible. Ditches are constructed to various sizes and shapes depending on the water capacity requirement and ditch gradient. For normal ground conditions, 3 feet of water depth in a ditch with a 3 -foot bottom width, and $1 \mathrm{l} / 2$ to 1 bank slopes, will deliver about $60 \mathrm{cfs}$ when excavated to a $0.03 \%$ ditch grade. Steeper ditch grades will cause erosion of an unlined ditch and must be avoided.

\section{Advantages:}

- Highly reliable for water delivery

- Provides significant storage capacity for water interruptions

- Low cost

- Easy to construct

\section{Disadvantages:}

- High maintenance cost, with need for ditch cleaning every other year

- High potential for water transportation losses. This could be critical during low flow periods

- High exposure to accidental spill or contamination

- Uniform ditch gradient requires following ground contours and may necessitate long ditch lengths

- Inverted siphon crossings may be required for passing under roadways and streams

- Corrugated flume sections may be required in difficult terrain

- Ditching in wetswampy areas requires specialized equipment

- May be problems in freezing weather

\section{Cost:}

An unlined open channel ditch costs about \$4/linear foot.

A ditch lined with 2 inches of concrete costs about $\$ 22 /$ inear foot.

\section{Infor mation Sources:}

Idaho Fish and Game Pahsimeroi Steelhead Collection Facility and Chinook Salmon Facility U.S. Fish and Wildlife Service Winthrop NFH, Washington

Washington Department of Game Ringold Springs Steelhead Pond

Washington Department of Fisheries Ringold Springs Rearing Pond 
Water Collection, Delivery, and Quality Improvements

\section{c. SIPHON}

This section will examine two types of siphons. A true siphon and an inverted siphon. Both systems have fish cultural applications; however, we caution their use because of their questionable reliability (see Disadvantages). A third type, the intermittent siphon, does not appear to have fisheries uses, and is used in automatically flushing public toilets where continuous water flows are not required or desired.

The true siphon is a device for transferring water through a water-tight pipeline from a higher elevation water source to a lower elevation discharge point over an obstruction that is at a higher elevation than the water source.

Because internal pipe pressures and external atmospheric air pressures try to equalize, water will flow through the pipe system if air obstructions are cleared. A siphon will also cease to function if the obstruction is higher than 34 feet above the water source. To make the siphon operate, a vacuum pump with a dome is needed at the high point in the pipeline to remove all air from the line. Air removal is periodically required to insure that the suction side of the siphon remains below atmospheric pressure. As air collects at the pipeline's high point, the air rises into the dome and is removed from the system by the vacuum pump. If only a small pocket of air is allowed in the dome, under vacuum conditions this air will expand into larger bubbles and can reduce pipeline flow. If the bubble is not removed, additional air brought in with the water flow will expand the bubble until pipe flow shuts down.

Inverted siphons are used for irrigation projects, and are also applicable for fish hatchery open channel delivery systems, where road or stream crossings are necessary. The open channel diverts the water into an inverted siphon pipeline that crosses under the roadway or stream, and returns the water to the channel on the opposite side at the same water surface elevation, less pipeline entrance, exit, and friction losses.

\section{True Siphon Advantages:}

- Water can be lifted over obstructions higher than intake water surface elevations without pumping

- Site specific conditions may locate pipeline alignments and/or excavations for cost effectiveness over gravity flow pipeline alignments

- Vacuum pump can be located at the hatchery or other convenient location with a small air-tight line to the siphon's high point dome. This line can be laid in the same ditch utilized by the siphon pipeline

True Siphon Disadvantages:

- A siphon system is not as reliable as a gravity flow system and requires maintenance, surveillance for air problems, and an alarm system for water shut down

- A vacuum system at the high point is required to activate pipe siphon flow

- Initial siphoning startup and restarts are slow

- Supplemental water supply is required for back up 
Chapter 2

- Both ends of the siphon must be water sealed, or shut-off with a tight valve on the delivery end, for siphoning startup

- During long power outages an auxillary power source, or manually operated mechanism, is needed to operate the priming system

- A 33- to 34-foot high loop in the vacuum line is needed to eliminate water entering the vacuum line and pump because vacuum pumps do not operate when water flooded

Inverted Siphon Advantages:

- Highly reliable

- Low maintenance

- Easily installed

- Low cost

Inverted Siphon Disadvantages:

- Requires periodic silt flushing through a cleanout-blowoff system to maintain flow capacities

cost:

True siphon special equipment costs will vary from $\$ 1,000$ to $\$ 10,000$, depending on vacuum pump size, pump location, and cost for bringing in electrical power. One-third horsepower vacuum pumps can be purchased for about $\$ 200$, while larger 3 HP pumps cost about $\$ 1,300$ each. Life expectancy for the pump is 10 years, and 50 years for the other special equipment.

Inverted siphon pipeline costs per foot can be found in the preceding section, "Pipelines". Pipeline life expectancy is 50 years.

Information Sources:

Air-Oil Products Corporation of Portland, OR is supplier for Gast vacuum pumps U.S. Fish and Wildlife Service Quinault NFH, Washington

Washington Department of Fisheries Willapa, Hood Canal, and Dungeness Salmon hatcheries

\section{PART III. WATER QUALITY IMPROVEMENTS}

The importance of a quality water supply for fish culture is noted in Chapter I. In many cases it is virtually impossible to find a water source that meets all the desired requirements, and some water supplies require special treatment to prevent the entrance of undesirable elements into the hatchery. Techniques are available to improve water quality. Methods and facilities to remove debris, settleable solids, wild fish, undesirable biological organisms, and to optimize dissolved gas levels and water temperatures are discussed in this chapter. 
Water Collection, Delivery, and Quality Improvements

\section{A. DEBRIS REMOVAL}

Common debris found in surface water that requires removal is silt, sand, leaves, sticks, ice and heavy bedload. These materials may cause physical harm to the fish or plug the water supply system; causing a disastrous loss of fish and considerable expense to effect repairs to the supply system. Water intake systems are designed to prevent the entrance of debris and bedload into the system, but finer materials, including settleable solids and colloidal materials, generally must be dealt with at some point beyond the intake. The discussion that follows considers the types of facilities required to remove debris before the water enters the hatchery incubators or ponds.

1. Coarse and Fine Screens Trash racks are usually located on the outer edge of the intake facility. They are generally constructed of wooden 2 x 4 's equally spaced, 3/8- x 2-inch equally spaced metal bars, or large-mesh wire screens. These racks prevent the larger debris and heavy bedload material from entering the water intake facility.

The material used for the interior screens may be heavy-duty hardware cloth, either steel or stainless steel; perforated or slotted plates, either aluminum or stainless steel; or closely spaced aluminum or steel rods. These can be used at the intake directly behind the coarse screens or trash rack, or in the water system at a more convenient downstream location. They remove the finer materials from the water and prevent the entrance of wild fish into the hatchery.

The regulatory agencies have fish screening requirements to protect wild fish from entering water intakes, and the general approach velocity and screen mesh size by size of fish are noted in Table 3.

Table 3. Recommended maximum approach velocity and minimum screen mesh size for salmonids on intake systems in the Columbia River. (Source: Swan, 1980).

\begin{tabular}{|c|c|c|}
\hline Fish type & Approach velocity & Screen mesl \\
\hline Salmonid fry & $0.5 \mathrm{feet} / \mathrm{sec}$ & 0.14 inches \\
\hline Salmonid fingerlings & 1.0 & 0.25 \\
\hline
\end{tabular}

Some fisheries agencies have used a heavy-duty wedge wire grating in select locations for a combination trash deflector and fine screen system. Grating bars are $\mathrm{V}$-shaped with the 3/16-inch wide top face to the outside. The $\mathrm{V}$ bars are spaced with a 0.1 18-inch clear opening at the top face and are supported on 1/2-inch diameter bars on 4-inch centers, which are supported by $1 / 2 \times 1-1 / 2$-inch bars on 9-inch centers. This grating has a good performance record but the cost per square foot is high.

\section{Advantages:}

- See above description discussion 
Chapter 2

Disadvantages:

- Requires regular cleaning or brushing

- Units are usually remote from main facility

- Requires almost continuous attention during storms, floods, and freezing conditions

- Fine sands and silts pass through these screens

Information Sources:

Washington Department of Fisheries Grays River Salmon Hatchery for the wedge wire grating intake

Tulalip Tribal Salmon Hatchery, WA for the wedge wire grating intake

Most all Northwest salmon and steelhead hatcheries for trash rack and fine screened intakes

Pacific Wire Works, Inc.

\section{Cost:}

Hardware cloth screens cost about $\$ 14 / \mathrm{ft}^{2}$; life expectancy is ten years.

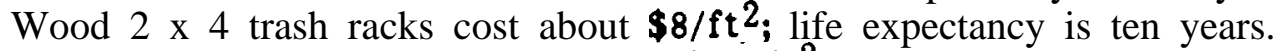

Metal flat bar trash racks cost about $\$ 45 / \mathrm{ft}^{2}$; life expectancy is 50 years.

Wedge wire grating (stainless steel) costs about $\mathbf{\$ 5 3 / \mathbf { f t } ^ { 2 }}$; life expectancy is 50 years.

2. Inclined Plane Screen The inclined plane screen for screening hatchery water supplies can either function as a fine screen or a combined coarse and fine screen. This screen has been previously noted in this Chapter (Part I, A-2, Instream Diversion Dam with Screen Intake Structure), and is popular because of excellent performance including (almost) self-cleaning of the screen surfaces by the water action (Figs. 1 and 5 ).

This unit is installed in a box structure sloping downstream in the direction of the water flow. Screened water falls through the screen and the debris and wild fish fall off the screen's lower end and are returned to the stream. The water chamber under the screen connects to the water supply system. The screen is framed with structural steel members, and the screening material can be hardware cloth, perforated plate, or wedge wire grating media. 'The type of material used will depend on the size of the stream, severity of flooding, amount of water used, etc.

\section{Advantages:}

- Low maintenance

- Highly effective

- Partially self-cleaning with excess water

- Can be designed for an adjustable slope angle with the horizontal

- The screen can be cleaned by back flushing if designed with this capability

- Wild fish pass downstream 
Water Collection, Delivery, and Quality Improvements

$\underline{\text { Disadvantages: }}$

- $\quad$ Passes silt and sand

- Requires regular observation and debris removal if necessary

- Can freeze if water supply is low during extremely cold weather

\section{Cost:}

Following cost estimates are only for the structural steel-framed screens: Hardware cloth screens cost about $\mathbf{\$ 2 4 / \mathbf { f t } ^ { 2 }}$; life expectancy is 15 years. Perforated plate screens cost about $\$ 28 / \mathrm{ft}^{2}$; life expectancy is 15 years. Wedge wire grating costs about $\$ \mathbf{5 3} / \mathrm{ft}^{2}$; life expectancy is 50 years.

Information Sources:

U.S. Fish and Wildlife Service Eagle Creek NFH, Oregon, and Kooskia NFH, Idaho Washington Department of Fisheries George Adams and Grays River Salmon hatcheries

3. Rotary Drum Fine Screen Rotary drum screens are most commonly used at irrigation diversions to prevent wild fish from entering the diversion canals. They can also be used on fish pond outlets to retain fish or to screen hatchery water supplies. Hatchery water supplies generally take the screened water from inside the drum while the debris is carried over the top and washed off the downstream side of the drum by the water flow. A trash rack in front of this facility may be required. These screens, including advantages, disadvantages, costs, and vendors are described in detail in Chapter 5.

4. Water Settling Basins Water settling basins settle out stream bedloads of gravels, sand, and heavy silt from hatchery raw water supplies. The lighter fine silts, clays, and colloidal materials in suspension are extremely difficult to remove without specialized equipment, including sand or artificial media filters. Bedload settling occurs where water velocities lessen, and is observed in forebays of dams, intakes, pipelines, head boxes, and all types of incubation and rearing pond systems. Hatchery designs should provide for lessening of bedload impacts in the incoming hatchery water supplies and also provide for a means of removing these accumulations.

Sizing of settling basins depends on the specific gravities of the settleable solids and the percentage reduction desired. However, 1- to 2-minute retention time with a properly designed basin will provide substantial solids reduction. In the cases where settling basin lagoons are specifically built to settle out solid materials to provide better water quality to hatching and rearing facilities, water is usually introduced into the basin bottom as slowly as possible to minimize turbulence. The water is taken out at the rim, or far end near the surface, to obtain maximum settling. Access for mechanized equipment should be provided to periodically remove the set tleable solids. 


\section{Chapter 2}

In situations where pond space is available, hatchery operators should consider utilizing a portion of unused rearing or holding ponds for water settling to improve water quality (prior to incubation uses, etc).

Advantages:

- Easily constructed

- Low maintenance

- Provides effective settleable solid removal

- Collects settleable materials at one location for disposal

- Basins can provide some water storage for use during emergencies

$\underline{\text { Disadvantages: }}$

- Settling basins require regular cleaning and sediment disposal; alternative is to increase basin depth for operation storage to extend cleaning interval time periods

- By-pass system required for cleaning, maintenance, and cold weather freeze-up

- Cover may be necessary to eliminate wind blown contaminates

\section{Cost:}

See Chapter $\mathbf{5}$ for comparable $\mathrm{ft}^{3}$ costs for various large rearing ponds. Life expectancies are also similar to those noted for each large pond.

Information Sources:

U.S. Fish and Wildlife Service Little White NFH, Washington, Eagle Creek NFH, Gregon, and Kooskia NFH, Idaho

Oregon Fish and Wildlife Big Creek Fish Hatchery

Washington Department of Fisheries Skykomish Salmon Hatchery

5. Other Debris Removal Methods Several debris removal methods that we consider too costly for low-cost facilities or as ineffective, are noted below. Sources of information are provided for those who might want to explore these possibilities.

Micro-filters (Fig. 7) and sand filters are used to remove colloidal materials from water. The former can be observed at the WDF Naselle Salmon Hatchery or by contacting North Star. Unit cost is about $\$ 90,000$ for a system that will handle 1 cfs of water. The sand filter is used at the Dworshak National Fish Hatchery, Idaho, and supplied by Becker Industries, Clatskanie, OR.

Belt screens are widely used in industrial water intake systems and can be used for hatchery intakes or to retain fish in a pond, as used by WDF. Pacific Wire Works, Portland, Oregon or WDF can be contacted for further information. 
Water Collection, Delivery, and Quality Improvements

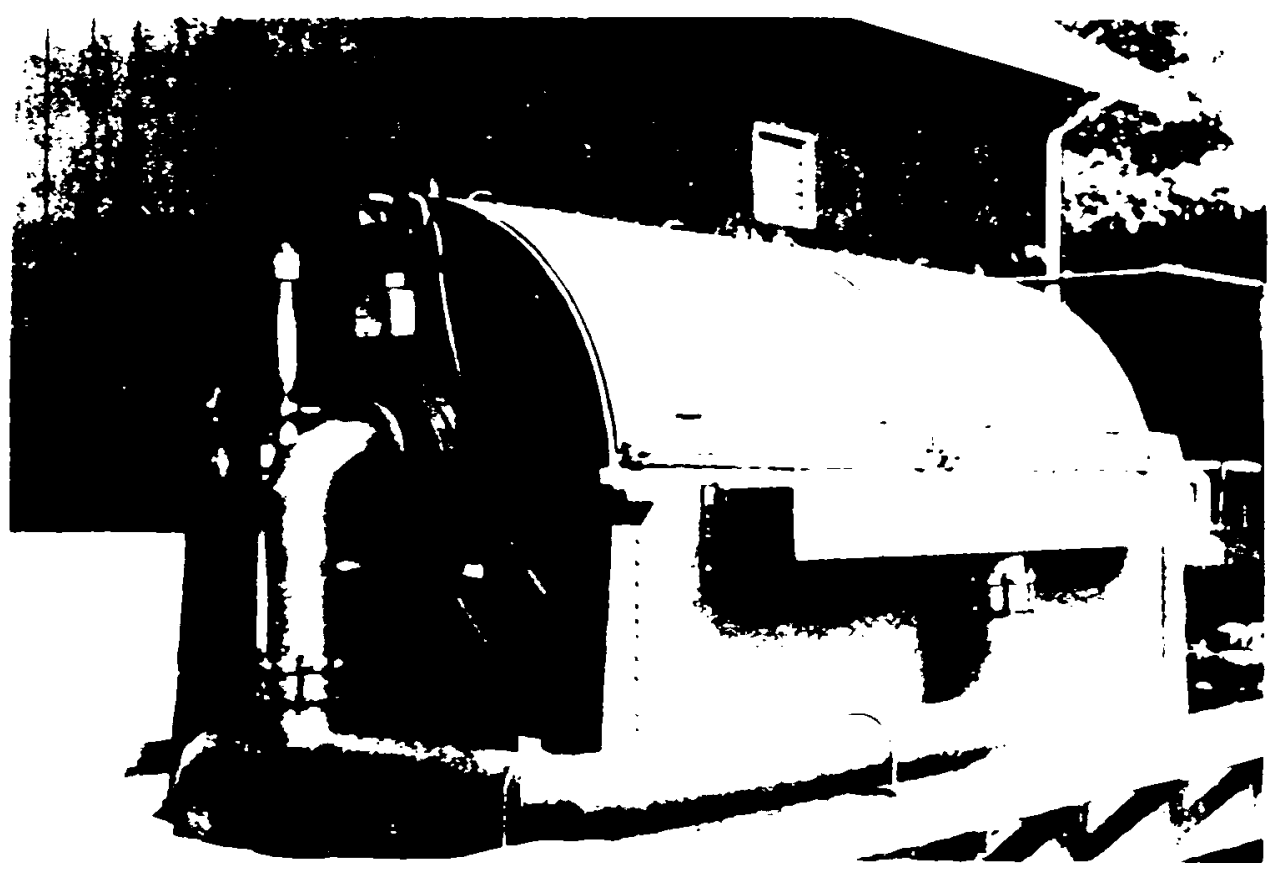

Figure 7. A North Star micro-filter at the Puyallup Salmon Hatchery ( $W D F)$.

Gabion screens are rectangular wire mesh baskets (Fig. 2), which, when filled with stones, can be used to stablize stream banks, develop instream pools, and screen water. Gabions are easily assembled, but are labor intensive, and are not recommended for screening of water supplies because of plugging, passing of wild fish, and the difficulties in backflush cleaning. Terra Aqua Conservation Co., Reno, $\mathrm{NV}$ is a supplier of the gabion wire.

\section{B. GAS STABILIZATION}

Gas stabilization systems in fish culture water supplies are used to equalize the dissolved gases in water with those in the atmosphere for the purpose of preventing gas bubble disease and to achieve maximum rearing capacity. Niater near saturation with dissolved oxygen (DO) is essential for fish life. A deficiency of DO can reduce the rearing capacity of a water supply, or extreme cases of depressed DO levels can cause acute mortaity. Vitroger, on the other hand, can cause mortality by gas bubble disease when in it supersaturated state. Fish rearing problems are caused by too little DO or too ir.uch dissolved nitrogen. Oxygen is readily absorbed into surface water by any action which: causes turbulence across the air-water interface, such as falling in a cascace, or b: winc: agitation. Therefore, a water supply from a stream with a steep gradient is usually $x \mathrm{t}$ near DO saturation and no treatment is necessary.

However, ground waters, defined as waters from springs or wells, sometines are ver! lon in DO, and usually supersaturated with dissolved nitrogen. These conditions are caused is both chemical and biological processes. DO in ground waters tends to combine cheirically 


\section{Chapter 2}

with other elements found in the ground, and bacterial growth may also utilize quantities of oxygen. Because both a readily available oxygen supply and agitation are not present in ground water sources, DO levels remain depressed. Dissolved nitrogen is relatively inert, both chemically and biologically, and levels of this gas remain high. Because cold water retains more gas than warm water, the geothermal warming of ground waters will usually cause nitrogen supersaturation.

Gas supersaturation can also occur in a number of other ways. In a fish hatchery system, supersaturation commonly occurs with the introduction of air into the water supply by the Venturi action of leaky pipes and/or pumps. As noted above, cold water retains more gas than warm water so the warming of a water supply causes supersaturation. For example, a steam plant discharging heated condensate water, and geothermal or seasonal warming in reservoirs leads to supersaturation. Therefore, it is important to recognize that supersaturated gas problems in water supplies can be continous, seasonal, or of an instantaneous nature.

Much experimental work has been done to determine the cause and effects of gas bubble disease in salmonids. The formation of gas bubbles in fish tissue is most closely correlated with the total dissolved gas pressure of the water. Therefore, it is necessars to monitor both oxygen and nitrogen dissolved gas levels to determine the probability of gas bubble disease occurrence. Nitrogen gas generally constitutes about $80 \%$ of the total dissolved gas pressure of water, and because of its quantity and relatively inert nature, it is the principal cause of gas bubble disease. Table 4 provides recommended operational limits with hatchery water supplies of varying dissolved gas saturations.

We therefore recommend that waters be stabilized prior to use in a fish hatchery if the DO is less than $90 \%$ saturation, or if the dissolved nitrogen is greater than $102 \%$ saturation. The gas stabilization equipment selected will have, as its principal function, the interface of air and water with maximum surface area, commensurate with cost, and is used to equalize the dissolved gas pressures in the liquid with those in the atmosphere. Xdding air or oxygen to water is often referred to as aeration. Removing nitrogen from water is referred to as degassing or sometimes called deaeration. Both require that the gas phase and the water phase be contacted to permit interphase diffusion to occur. The gas and water can be conveniently contacted with gas dispersed as bubbles. The gas-liquid can be mechanically agitated, as with an impeller, or as in the simplest design, agitation can be accomplished by the gas itself.

Early day hatchery water aeration schemes were simple and required no mechanical assistance, but frequently they could not approach DO saturation. To improve performance, energy must be expended. The energy input (horsepower/DO increment) is linear until about $90 \%$ saturation. Further DO increases require increasing aeration power input, and $100 \%$ saturation is practically impossible to attain under hatchery operating conditions. For example, Bouck, G.R., (personal communication) indicated that one unit of electrical energy may provide $90 \%$ DO saturation and fifteen units of electrical energy would be required to approach $100 \%$ DO saturation. Or water falling through a 4-foot high packed column may provide for $90 \%$ DO saturation, but an extremely high packed column is required to approach $100 \%$ DO saturation. 
Water Collection, Delivery, and Quality Improvements

Table 4. Dissolved gas limitations for hatchery water supplies.

$\underline{\text { Dissolved oxygen level }}$

Greater than $90 \%$ saturation

$70 \%$ to $90 \%$ saturation

Less than $70 \%$ saturation

Less than $30 \%$ saturation

$\underline{\text { Dissolved nitrogen level }}^{(1)}$

Less than $102 \%$ saturation(2)

Greater than $102 \%$ saturation

Greater than $107 \%$ saturation
Operations impact

Incubation and rearing at maximum loading densities

Rearing at $30 \%$ reduced loading densities

Not recommended; fish health impaired by prolonged exposure

Total fish mortality

Incubation and rearing at maximum loading densities $(2)$

Fish fatalities can occur; more critical for small fish

Total mortality of small fish; gas bubble disease occurs in larger fish

(1) Assuming that dissolved oxygen is at saturation level

(2) It is the opinion of Bouck (personal communication), that supersaturation should not be allowed during incubation as serious damage can occur with Alentic salmon and brown trout.

Gas stabilization units in use at Pacific Coast hatcheries agitate water in a number of ways to accomplish water contact with the atmosphere to increase DO or reduce dissolved nitrogen gas levels in their water supplies. All of these units require the use of energy to accomplish the water to air contact. The Packed Column Aerator is becoming popular for hatchery operations and appears to be the most cost effective system in use today. The gas stabilization systems now in use are described below.

1. Tower/Media or Packed Column A packed column is a cylindrical tower or pipe constructed of fiberglass, PVC, aluminum, or other rigid, durable material and filled with bio-rings or other bio-medias (Figs. 8 and 9). Tower dimensions are variable, but usually range from 4 to 12 feet high and approximately 8 to 48 inches in diameter. Bouck et al., (1981) reported that l-inch rings were most efficient, but rings commonly used are approximately 1.5 inches in diameter or larger. An aeration fan can be incorporated to force air into the tower bottom in order to increase water capacity through the system. Water must be free falling with no media submergence. As water is added to the top of the tower it gravitates down through the plastic media. Loading should not exceed 1 literiminicm ${ }^{2}$ of tower 
Chapter 2

cross section (250 gpm/ft $\left.{ }^{2}\right)$. Gas stabilization is accomplished by the rumbling water exposed to air. DO is increased and nitrogen is decreased in the same unit. Gases approach their air equilibrium value.

Fish Vianagement Consultants highly recommends pack column system as the very best aerator for fish culture operations. Owsley, (1979) said, "The packed column cannot guarantee nitrogen gas levels of 100 saturation, but to date the column is the most econo mical and efficient degasser available to the fish culturist."

\section{Xdvantages:}

0 Easily installed on new or existing operations

0 Economical to construct

0 Highly effective in stabilizing gas levels in water supplies

0 Very low operating and maintainence cost

$0 \quad$ No moving parts except for the optional air compressor

0 The minimal head required can be as little as 3 feet

Disadvantages:

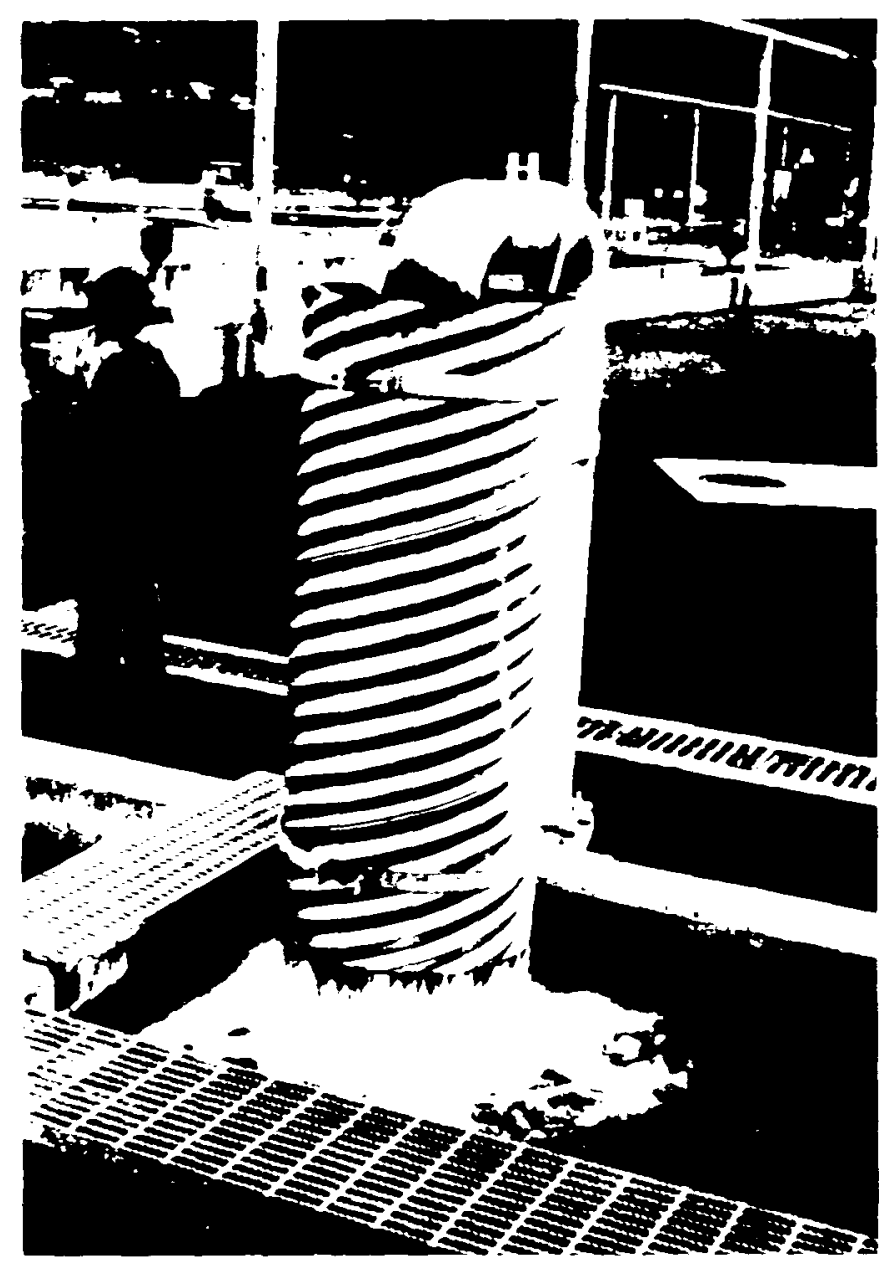

Figure 8. A preked column gas stabilization system consisting of a single cylindrical tower of aluminum pipe and filled with bio-rings. Dworshak NFH, Idaho (USFWS).

- Requires 3 to 15 feet of water head depending on water to be treated

- Falling water exposed to the atmosphere will lose or gain temperature units depending on air temperatures. Units that are covered or housed during extreme weather conditions or at all times will minimize water temperature gain or loss to less than $\mathrm{IF}$

- Does not necessarily provide adequate protection if overloaded with water, or if extremely sensitive organisms are involved

Cost:

A 12- x 4-foot Tower/Fan Aerator, capacity $700 \mathrm{gpm}$, costs about $\$ 6,250 /$ unit. 
Water Collection, Delivery, and Quality Improvements

A 5- x 1-foot Packed Column filled about 4.5 feet high with 1.5-inch bio-rings, capacity 100 to $150 \mathrm{gpm}$, costs about $\$ 200 /$ unit.

The above units have a 50-year life expectancy.

Information Sources:

U.S. Fish and Wildlife Service Dworshak NFH, Idaho, and Eagle Creek NFH, Oregon Washington Departments of Game and Fisheries Lyons Ferry Fish Hatchery

Tulalip Tribal Salmon Hatchery, Washington

Bio-ring plastic media and water distribution plates suppliers: Glitsch, Inc., Norton Co., or Koch Engineering Co.

Fiberglass Tower Shell suppliers: Justin Enterprises, Inc., Chemical Proof Corp., or Ershigs Inc.

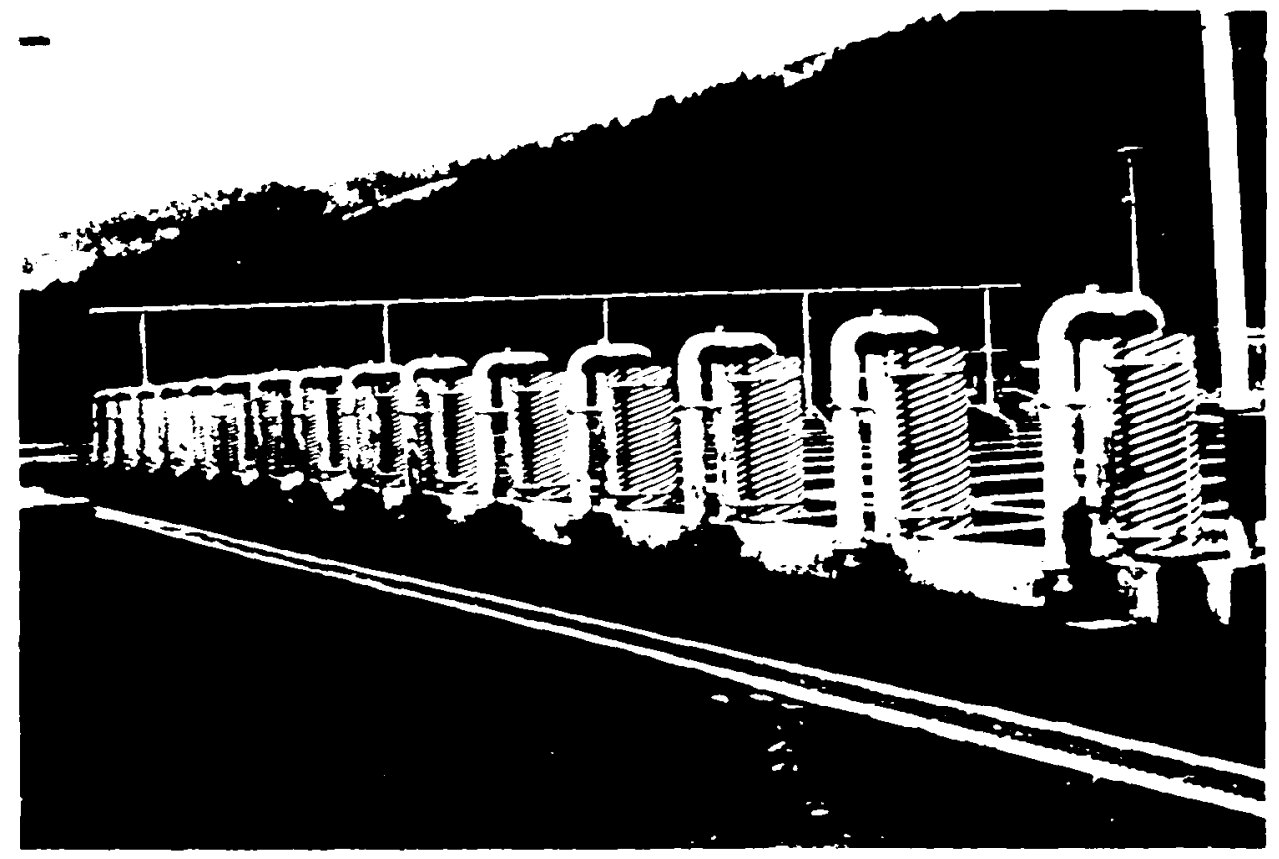

Figure 9. Multi-units of cvlindrical towers constructed of aluminum pipe and filled with bio-rings.

2. Aspirator An aspirator is defined as an apparatus using suction for moving a fluid or gas. The aspirator aerator utilizes water under pressure moving past a pipe open to the atmosphere, all inside a chamber, to create a vacuum in the air pipe. The vacuum draws in atmosperic air for mixing with the water and discharges from the chamber into a water tank.

Criteria developed by Burrows and Combs, (1968) at the Abernathy Salmon Cultural Development Center, requires that each aspirator be supplied with $125 \mathrm{gpm}$ at not less than 10 psi water pressure. Each aspirator is to have $4 \mathrm{ft}^{2}$ of tank surface area 


\section{Chapter 2}

and discharge into a minimum of S-foot tank water depth. The aspirator discharge pipe to be 6 inches above the tank water surface. Owsley, (1979) does not recommend this system to deaerate, or where water supplies are at or near dissolved nitrogen saturation, because aspirators tend to increase dissolved nitrogen in the water.

\section{Advantages:}

- Low cost

- Low maintenance-no moving parts

- Good water aeration

Disadvantages:

- Requires a pressurized water supply at the aspirator

- Requires a tank to contain the aeration operation

\section{Cost:}

The cost per aspirator is about $\$ 120$, including connection to a header pipe. Does not include costs for header, tank, or water to and from the facility. Life expectancy is 50 years.

\section{Information Sources:}

U.S. Fish and Wildlife Service Kooskia NFH, Idaho, and Leavenworth NFH, Washington

Oregon Fish and Wildlife Bonneville Fish Hatchery

U.S. Fish and Wildlife Service Abernathy Salmon Cultural Development Center, Washington

3. Paddle Aerators These are motor driven paddles mounted on a fixed elevation support system at the pond water surface of the aerator tank, or a floating support system on the aerator tank water surface. Dworshak National Fish Hatchery uses multiple $25 \mathrm{HP}$ aerators to each aerate $8,000 \mathrm{gpm}$ of water.

\section{Advantages:}

- Excellent water aeration

- Excellent water deaeration

\section{$\underline{\text { Disadvantages: }}$}

- $\quad$ Requires a standby power source during power outages

- Requires a tank to contain the operation

- Requires extremely high equipment maintenance and operating coats

- Constant tank water surface elevation required for a fixed elevation paddle aerator support system 
Water Collection, Delivery, and Quality Improvements

\section{Cost:}

A motor driven paddle aerator costs about $\$ 1250$ per HP. This does not include the aerator tank or costs of water delivery in and out of the system. For continuous use, heavy maintenance can be expected every three years, and with a good rehabilitation program this equipment could last 15 years.

\section{Information Sources:}

U.S. Fish and Wildlife Service Dworshak NFH, Idaho for the fixed elevation support system, and Kooskie NFH, Idaho for the floating support system

Pacific Water Works Supply Co.

Infilco-Degrémont, Inc.

4. Spray Aerators This system is similar to the aspirator detail discussed above except that the spray supply taps in the header pipe are on 12-inch centers. The aspirator attachment is deleted and is substituted with a small 3-inch plastic lawn sprinkler head screwed into the free end of the tapered pipe. The sprinkler head is secured in a face down position to sprinkle water directly on top of the aerator tank's water surface. Water pressure of $20 \mathrm{psi}$ in the header pipe sprays out 2 to 3 gpm at each sprinkler head. Increasing the water pressure will increase head spray output. Do not use metal sprinkler heads which contain heavy metals.

\section{Advantages:}

- Low cost

- Easily installed

- Low maintenance, no moving parts

- Good water aeration and deaeration

Disadvantages:

- Requires a pressurized water supply at the spray heads

0 Requires a tank to contain the aeration operation

- Require overhead housing for severe weather conditions because of heavy icing with the water spray

\section{Cost:}

The cost is $\$ 25$ per sprinkling head connection. Does not include costs for header, tank, housing, or water to and from the facility. Life expectancy is 50 years, but the sprinkler heads require replacement at two-year intervals.

\section{Information Sources:}

U.S. Fish and Wildlife Service Lahotan NFH, Nevada, and Dworshak NFH, Idaho. 
Chapter 2

5. Floating Aerator This system consists of a pump and motor mounted on a float that is anchored to the pond bottom or attached by shore lines. The aerator has a screened intake on its underside at about the 4-foot water depth, and lifts water above the pond surface to discharge back to the pond (Fig. 10). The discharge falls against plates in a turbulent manner to aerate the water. This equipment (Fig. 11) is primarily used to maintain pollution abatement pond wastes in an aerobic condition where water exchange rates are low, or it may be used in a small lake to improve the DO. It lifts about 400 gpm per horsepower.

\section{Advantages:}

- Easily installed

- Equipment is portable provided electric power is available where aerator is to operate

$0 \quad$ Retards icing of pond surfaces during cold temperatures

0 Used in emergencies at various hatcheries to aerate fish ponds during critical low dissolved oxygen periods

\section{Disadvantages:}

- Maintenance required for moving parts

$0 \quad$ Poor efficiency in aerating and de-aerating fish hatchery water supplies

\section{cost:}

The cost is about $\$ 1,500$ per HP for $3 \mathrm{HP}$ units and larger, and about $\$ 2,000 / \mathrm{HP}$ for smaller units. With good maintenance, this equipment has a ten-year life expectancy.

\section{Information Sources:}

U.S. Fish and Wildlife Service Eagle Creek NFH, Oregon (to aerate a pollution abatement pond)

Washington Department of Game Skamania Steelhead Hatchery (to aerate a pollution abatement pond)

H.D. Fowler Co., Inc.

Agri-Glass

6. Vacuum Degassing Vacuum degassing increases differential pressures in an airtight chamber between the air and the liquid's dissolved gases. Lowered air pressures reduce the liquids capability to maintain dissolved gases in solution. Air pressures are lowered by vacuum-type air pumps that maintain the chamber's air pressure significantly below atmospheric. A problem associated with this system is that the degassing removes all dissolved gases, including dissolved oxygen. Therefore, aeration of the degassed water is essential both before and possibly after vacuum degassing to obtain the dissolved oxygen saturation for fish cultural needs. buck, (personal communication) reports that operators of vacuum degassing systems have widely divergent opinions of its effectiveness for solving their gas 
Water Collection, Delivery, and Quality Improvements

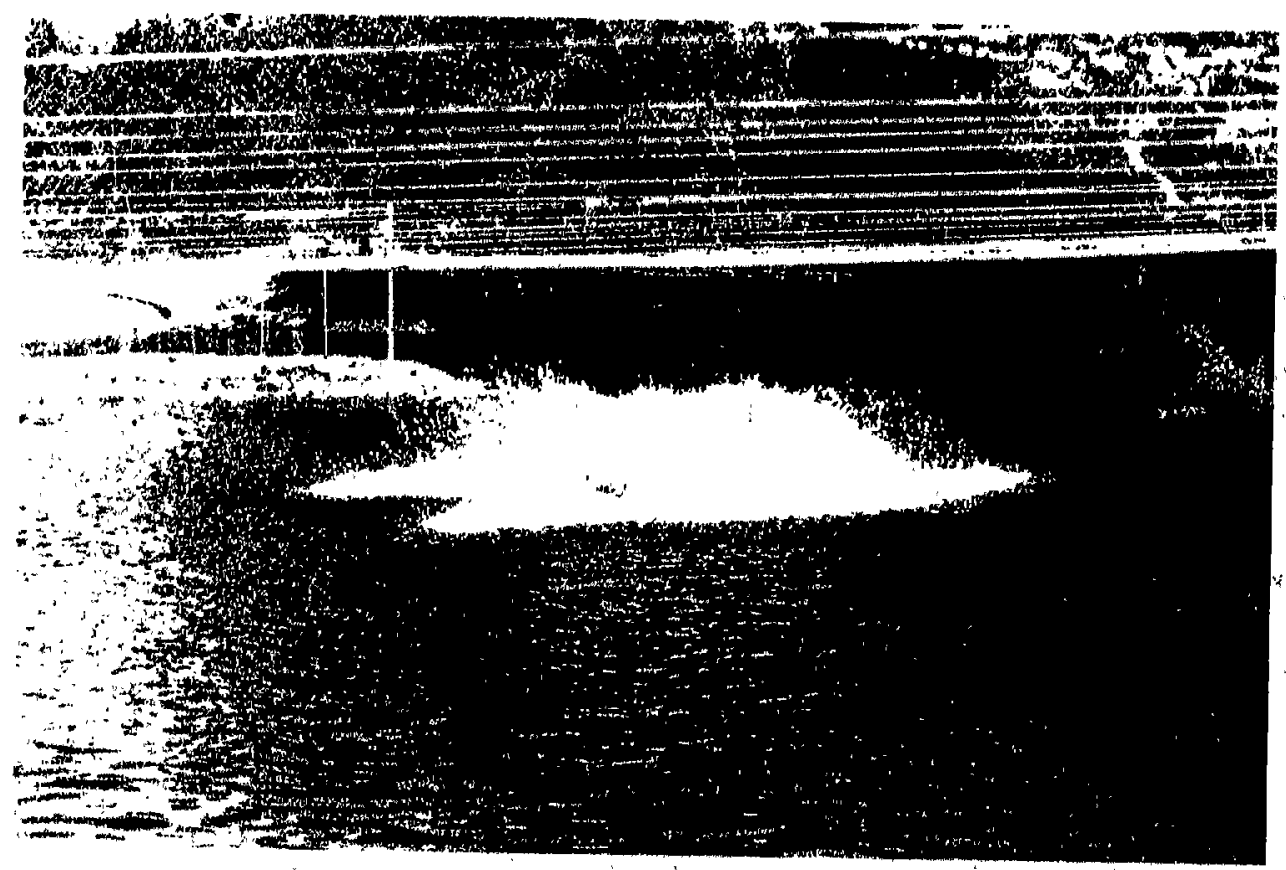

Figure 10. A floating aerator in use at Allison Springs Rearing $\mathrm{P}$ o $n \mathrm{n}$ (WDF).

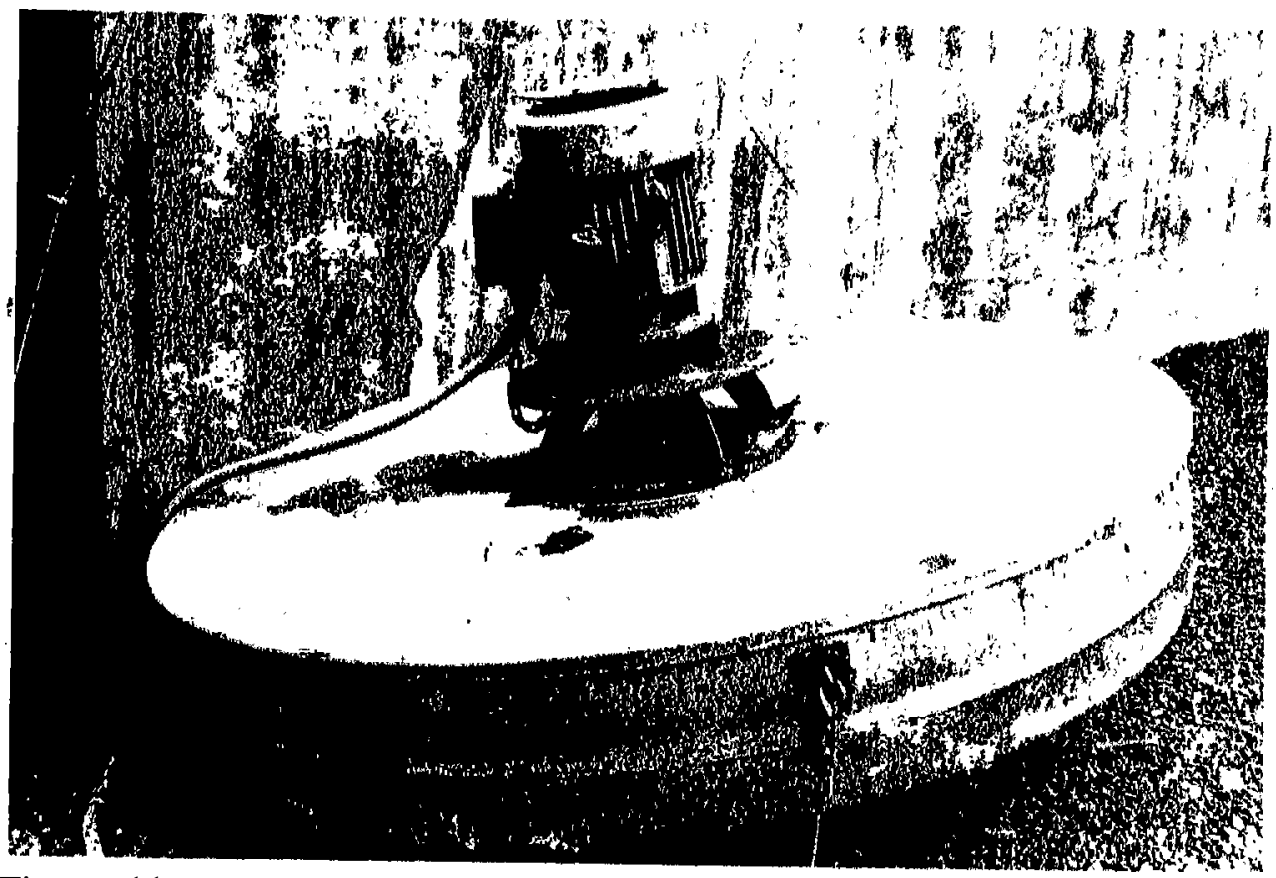

Figure 11. A 'floating aerator in use at a pollution abatement settling pond at the Big Creek Fish Hatchery (OFW). 


\section{Chapter 2}

saturation problems. Some biologists believe that vacuum degassing is necessary when chronic low level gas problems occur and certain species/life stages are cultured, i.e. Atlantic salmon fry, brown trout, and lake white fish. This equipment and system is expensive with high energy requirements, and therefore, is not considered a viable process for low-cost developments and operations.

\section{Cost:}

A vacuum degassing chamber with support equipment will cost about $\$ 200$ to $\$ 500$ per gpm of systems flow, and has a 25-year life expectancy.

\section{Information Sources:}

Michigan State Fish and Game Department Wolf Lake Fish Hatchery

U.S. Fish and Wildlife Service White River NFH, Vermont; La Crosse National Fishery Research Laboratory, Wisconsin; and National Fisheries Center, Leetown, West Virginia

7. Multicone Aerator The multicone aerator is an aspirating, multi-stage type aerator used in water and sewage treatment plants for the removal of dissolved gases or aeration of the water supply (Fig. 12). This equipment is constructed of cast aluminum for mounting to a bolt-on horizontal flange connection on the incoming water supply. The manufacturer indicates that the water flows up through the aerator's central inlet riser into the top inlet bowl of the primary cone and discharges into the primary aspirator chamber through multiple primary distribution orfices. The jet action of these many small streams of falling water, and the shaping of the aspirator chamber causes air to be brought in through the side of the primary cone. This aspirator air action with the falling water is repeated through three stages of vertically stacked cones, and then spills out in a waterfall into a basin or container for distribution.

This equipment is available in 100 to $2800 \mathrm{gpm}$ capacities. Equipment height varies from 63 inches for the small capacities to 76 inches for the larger sizes. Cone diameters vary from 15 inches on the small $100 \mathrm{gpm}$ unit to 76 inches for the largest $2800 \mathrm{gpm}$ size.

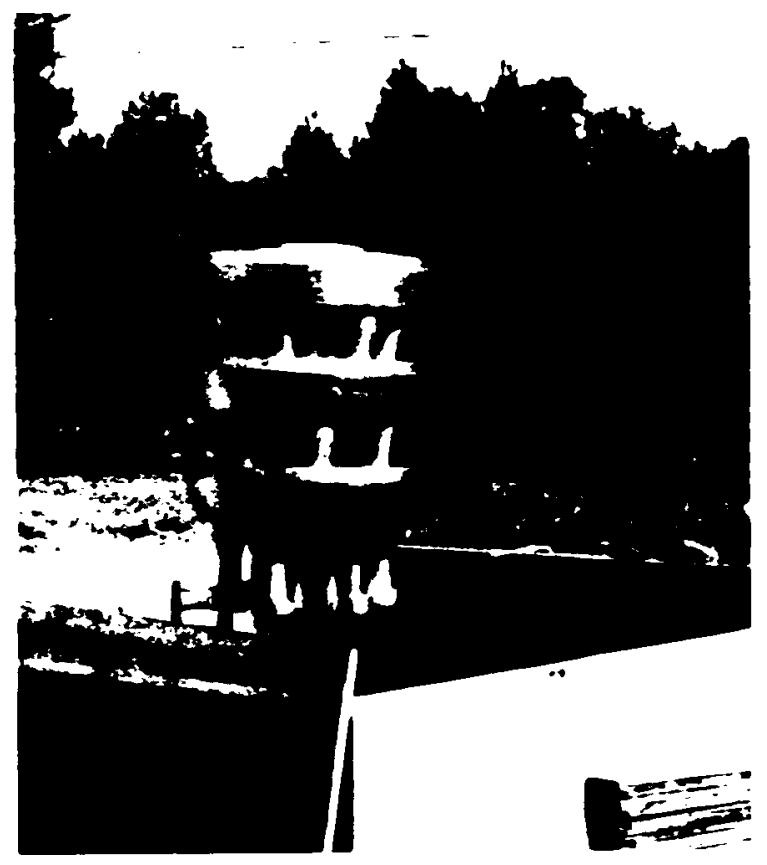

Figure 12. A multicone aerator at the Beaver Creek Steelhead Hatchery (WDG). 
Water Collection, Delivery, and Quality Improvements

Advantages:

$0 \quad$ Easily installed

- Low maintenance no moving parts

- Very good water aeration and deaeration

$0 \quad$ Low operating cost

Disadvantages:

- Relatively high cost equipment

Cost:

The cost of the $100 \mathrm{gpm}$ aerator is approximately $\$ 10,000$, the $1200 \mathrm{gpm}$ aerator is about $\$ 28,500$, and the $2800 \mathrm{gpm}$ unit is about $\$ 43,000$. Life expectancy for this equipment is 50 years.

Information Sources:

Washington Game Department Beaver Creek and Cowlitz Steelhead hatcheries Infilco Degremont, Inc.

Pacific Water Works Supply Co., Inc.

8. Dissolved Gas Measurementation There are numerous dissolved oxygen measuring instruments and chemical kits developed for monitoring hatchery water supplies, but relatively few instruments are available for dissolved nitrogen monitoring. Measuring of the dissolved gas levels are discussed below.

Dissolved Oxygen The DO levels in hatchery water supplies are easily measured with DO meters that provide for direct read-out of milliliters of DO per liter of water. Chemical titration kits are also often used by hatcherymen to measure the DO in water supplies. The titration kit system takes more time to make the measurement, but is more reliable. The problem with the meter is the periodic fouling of the sensor probes and a need for frequent calibration. We recommend that all hatcheries be equipped with DO measuring titration kits sold by Hach Chemical Co. of Loveland, CO., for about $\$ 150$. Direct read-out DO meters can also be purchased from the above company for $\$ 800$ and up.

Dissolved Nitrogen Analysis of dissolved gases, including nitrogen, in water traditionally has been difficult and required that the analysis be made in a laboratory. In recent years the Weiss "Saturometer" and the Bouck "Gasometer" were developed to more conveniently and easily measure gas saturation in water. Bouck, (1982) compares these two instruments and provides details for assembling the inexpensive Gasometer. Both instruments measure air pressure in the water similar to an air gauge that measures air pressure in an automobile tire. We do not advocate that all hatchery operators build or be trained in the use of this gas saturation measuring equipment. But 


\section{Chapter 2}

all operators should be knowledgeable and recognize that supersaturated nitrogen waters are highly lethal to fish, cause gas bubble disease, and the use Of such water must be avoided. If this condition is noted, a person qualified to analyze the water for nitrogen should be contacted. See Bouck, (1980) for cause and effect relationships for better understanding of gas bubble disease.

The cost of materials and supplies to assemble the Gasometer is less than $\$ 200$. Information sources on the assembly and use of gas saturation measuring equipment are USFWS Abernathy Salmon Cultural Development Center, WA and Dworshak National Fish Hatchery, ID; also the Bonneville Power Administration, Division of Fish and Wildlife, Portland, OR.

\section{WATER STERILIZATION}

Water sterilization systems are costly and relatively new to fish culture. They should be unnecessary for new hatchery developments in the Columbia River Basin if proper water source selection is made. Each method has specific use requirements which should be researched if treatment is necessary. Power outages, power surges, and other unforeseen events concern the culturist. Besides being costly, these systems have the possibility of equipment failures.

The methods that are available include electric grids, ozone, chlorine, and ultra violet light (UV). The electric grid has been tested (Combs, 1968) and used by the USFWS Abernathy Salmon Cultural Development Center. Combs reported that the principal factors affecting the power demand of a parallel-plate-type electrical grid are the quantity of water treated, the specific conductivity of the water, the voltage gradient, and the area of the plates. It could be used to control the cercariae of the trematodes (Sanguinicola sp and Nanophyetus salmincola).

Ozone is very effective against micro-organisms. The equipment is very costly and in 1977 the operational cost was \$0.043-0.049 for 1000 gallons of inflowing water at the USFWS Abernathy Salmon Cultural Development Center (Anderson, 1982). Ozone presents the risk of toxic overdose to the fish, is also very corrosive, and potentially dangerous to human health (Anderson, ibid.). The system would involve prefiltering, ozone contacting, and then deozonation; the latter by retention, aeration, activated carbon filtration, or a combination of these. Information sources are Dr. Gary Wedemeyer at the National Fish Research Center in Seattle, the WDG Cowlitz Trout Hatchery personnel, or A.R. Anderson at the USFWS Abernathy Salmon Cultural Development Center, Washington.

A water chlorination system is extremely corrosive, but has the advantage that electrical power is not required. Like ultra-violet light, it is effective on micro-organisms. The water system requires de-chlorination prior to use on fish. R.W. Beck and Assoc., Seattle, WA has incorporated this into the discharge system of the Medvejie Creek Hatchery at Si tka, Alaska. Oregon Aqua foods operates a chlorination system at their Springfield, Oregon facilities. Both are sources of current information. 
Water Collection, Delivery, and Quality Improvements

Ultra-violet light modules are available that handle 5 to $4,000 \mathrm{gpm}$. When treating the supply water U-V is reported to be effective on bacterial reduction at the $99 \%$ kill level and for the control of the virus causing IHN (infectious hematopoietic necrosis) (Wedemeyer, personal communication). Fortier of R.W. Beck and Associates (personal communication) related that the ultra-violet module they will install in the inflowing water at the Medvejie Creek Hatchery costs around \$30,000. This will treat about 2 cfs of water and we calculate it will cost $\$ 400$ per month for electrical power (based on

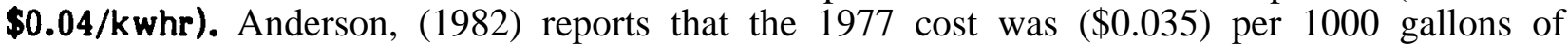
inflowing water. The replacement of the bulbs would be an additional cost. Clear water is a requirement for this unit to be efficient. Sources of information are USFWS Dworshak NFH; USFWS Abernathy Salmon Cultural Development Center; Department of Microbiology, Oregon State University; Syndel Laboratories Ltd.; and EMA Marketing, Inc.

\section{TEMPERATURE CONTROL TECHNIQUES}

As suggested in Chapter 1, water temperature considerations should begin with the source of supply. However, if the desired temperature ranges are not available, we believe that some temperature adjustments are economically feasible through the mixing of natural water sources, and to a limited extent, the use of heating and chilling systems.

Because the rearing of juveniles and the holding of adults take large volumes of water, direct heating or chilling is not considered a viable low-cost technique. Warming $1 \mathrm{cfs}$ of

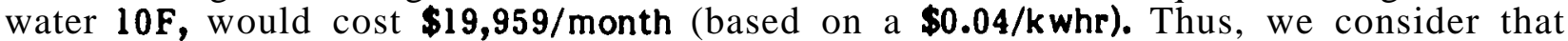
water temperature adjustments for rearing water should be limited to the use of natural sources such as springs, wells, or streams. The temperatures of off-station surface water sources, for example, that are used for acclimatization ponds, net pens, or net enclosures, usually are ideal for production and conditioning of fish prior to and during the smoltification process.

If temperature control for incubation is not possible at the site, one should explore the potential of using the waters of near-by facilities. Generally, we do not recommend alevin incubation with heated or chilled water because of the cost, however, because the eggs require extremely small amounts of water, a water heater or chiller may be feasible. A 16-40 gpm recirculating chiller system capable of reducing and maintaining water temperatures from $47 \mathrm{~F}$ to $\mathbf{3 7 F}$, and with $10 \%$ make-up water, costs between $\$ 6,000$ and $\$ 12,000$ (R.W. Reck and Associates, Seattle, personal communication). The 16 gpm will incubate 2.0 million coho eggs. The monthly energy consumption for a $16 \mathrm{gpm}$ system with a $10 \%$ makeup water, and chilling the water $1 \mathbf{0 . 8 F}$, would cost $\$ 80$ (based on

\section{$\$ 0.04 / \mathrm{kwhr})$.}

An $8 \mathrm{~F}$ differential in temperature (45F vs $37 \mathrm{~F}$ ) changes the hatching time on coho from 65 to 160 days, a delay of three months. With regard to egg incubation water, chilling has its greatest benefit with coho and spring chinook, while heating has its greatest application for accelerating steelhead trout and fall chinook. A potential problem occurs if the accelerated fish are placed in rearing waters where the temperatures are too cold for initial feeding. A heating system using $16 \mathrm{gpm}$, with $10 \%$ make-up water would have a $\$ 195$ monthly electrical billing if the water was heated 10.8F (SC). At the Eagle Creek $\mathrm{NFH}$, Oregon they use two swimming pool heaters that cost $\$ 250$ each and heat $50 \mathrm{gpm}$ 


\section{Chapter 2}

of water $3 \mathrm{~F}$ for a monthly electrical cost of $\$ 2,000$ (Jim Holway, personal communication). This system does not recirculate the water. Many techniques for water manipulations exist, and it is suggested that agencies be contacted for further information. Again, we caution that heating water may cause supersaturation of gases, and that the heating elements may have the potential of giving off toxic ions. 


\section{CHAPTER 3}

\section{ADULT COLLECTION, HOLDING, AND SPAWNING}

The capture of adult salmon and steelhead trout and the collection of their sex products marks the beginning of a new season for the fish culturist, and the success of the program depends upon effective capture, proper holding until ripe, and then careful spawning.

This Chapter introduces the various methods used to guide the fish to the hatchery from the native stream, or to block their upstream passage for subsequent capture; and further discusses hand methods of capture, and the use of imprinting as a tool to influence migration patterns.

We also discuss large formal holding ponds and compare their advantages, disadvantages and costs. Informal holding facilities most suitable for low-cost operations are described, as well as general spawning techniques, tools and facilities required, and the use of anesthetics and maturation control.

\section{PART I. ADULT COLLECTION}

Many different collection systems or methods are available to intercept the upstream migration of adult salmon and steelhead trout to obtain spawning stock. These can be either permanent or temporary structures, and range from simple instream weirs to formal concrete barriers and fishways that lead adults to permanent holding ponds; or relatively simple hand methods that work well for low-cost operations. All are discussed under barriers, fishways, and hand methods.

\section{A. BARRIERS}

All barriers discussed here can conflict to some extent with navigational and recreational uses of a stream. This situation must be considered early in the planning stage.

1. Single and Double Racks A rack is simply a fence installed across a stream to stop upstream migrations (Fig. 1). Racks are installed singly or in pairs. In the former case, an opening in the fence leads the fish into a trap. This opening is termed a "V" trap tunnel (Fig. 2), and once fish enter the trap they seldom find their way back through the tunnel. This fence, "V" tunnel, and trap arrangement is very effective for collecting small groups of spawning stocks; particularly on small streams.

A double rack system uses two racks spaced across the stream to form an adequate holding area. The lower rack has a "V" tunnel opening to lead fish into the holding impoundment. This is a popular method to collect and hold adult salmon, and in many cases, spawning is accomplished on the adjacent river bank. 


\section{Chapter 3}

Racks can be permanent or temporary, and the former usually are constructed of 2$\mathrm{x}$ 4-inch metal pickets supported by metal frames and counterforts anchored into a reinforced concrete apron spanning the entire stream. These facilities are usually used at large stations which handle many fish, and where the cost can be justified by the long life of the project. Temporary racks are constructed with 2- $x$ 4-inch lumber, but broomstick weirs (Fig. 3) or metal poles (Fig. 4) are more portable and are good low-cost materials. These are framed and secured to three- or four-legged horses set into the stream bed (Fig. 5). The horses are heavily weighted with rocks, concrete blocks, or cement bags to anchor them firmly to the stream bed. Tie-back cables secured to deadmen on the stream banks provide added rack stability. A walkway on top of the rack permits access to remove debris build-up on the upstream side. The spaces between the pickets vary between $3 / 4$ and $15 / 8$ inches according to species (see Table 2). It is essential that the spacing be correct. It should be as large as possible to pass small fish, water, and small debris, yet small enough to stop the desired fish species without gilling, as illustrated in Fig. 6.

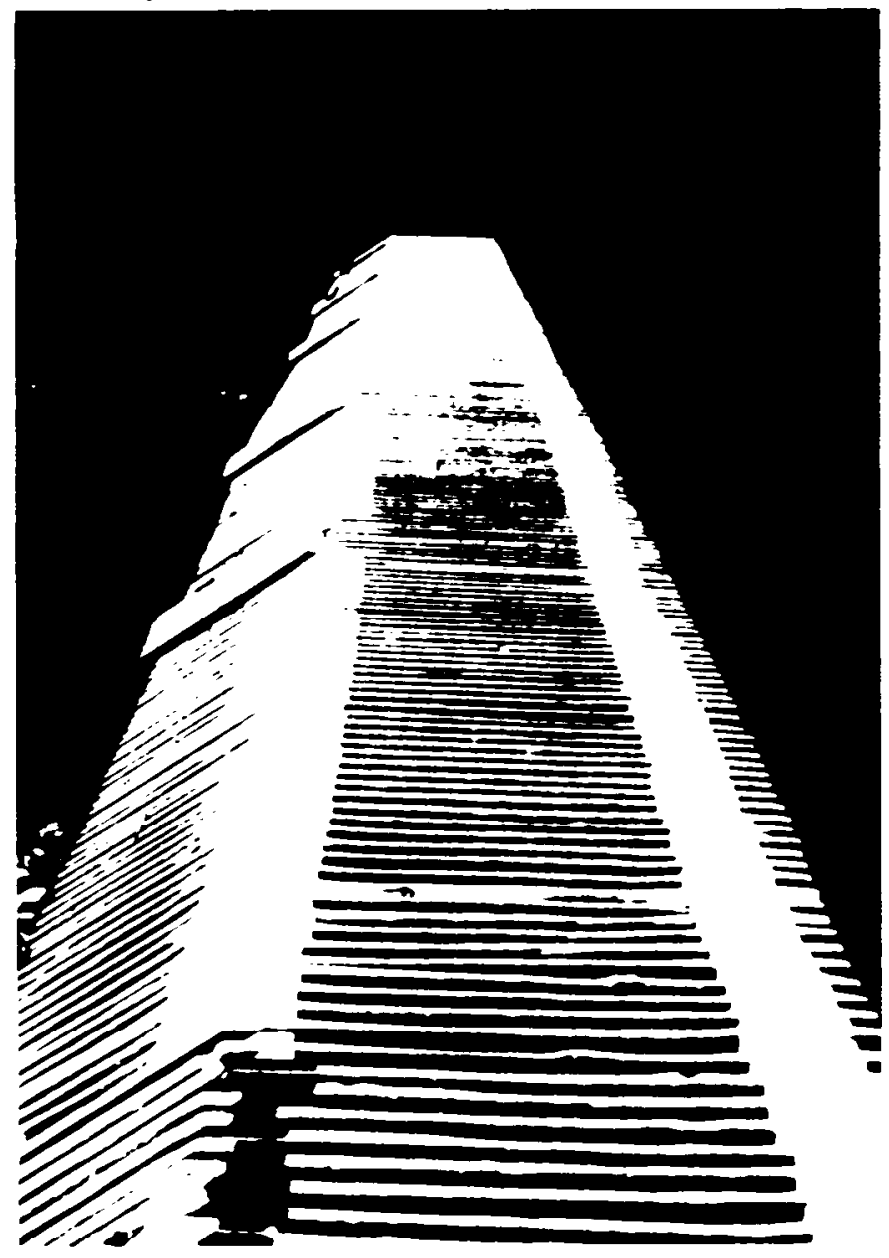

Advantages:

Figure 1. Single wooden fish rack at Cascade Fish Hatchery (OFW). Upstream

(Temporary rack) face on left.

Low eost

- Temporary; can be rapidly and easily installed by hatchery operators

- Spacing of rack pickets allows instream movement of smolts

(Permanent rack)

- Generally easier to clean, easier access, and can withstand flooding 
Adult Collection, Holding, and Spawning

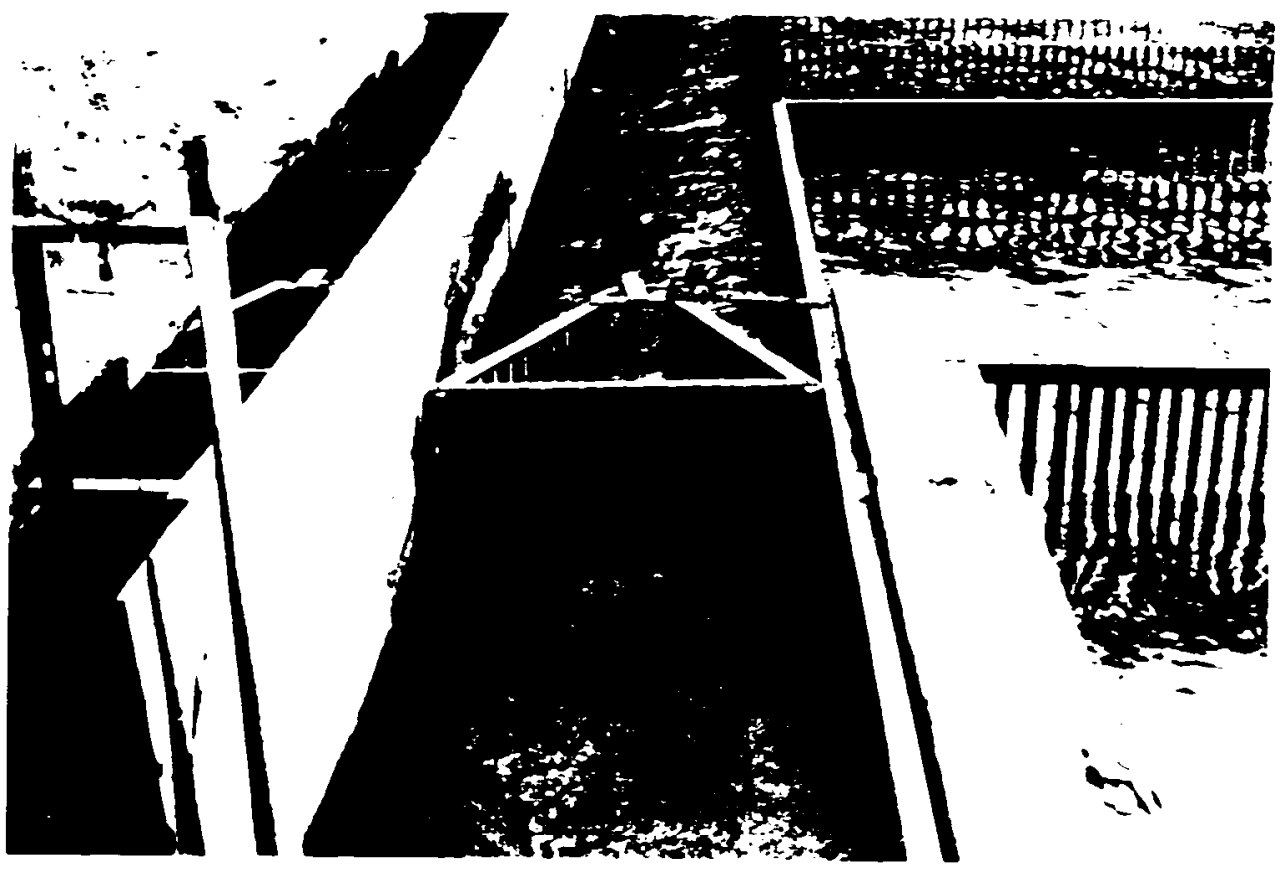

Figure 2. "V" trap tunnel at Big Creek Fish Hatchery $(\mathrm{OF} \backslash<)$. Looking upstream.

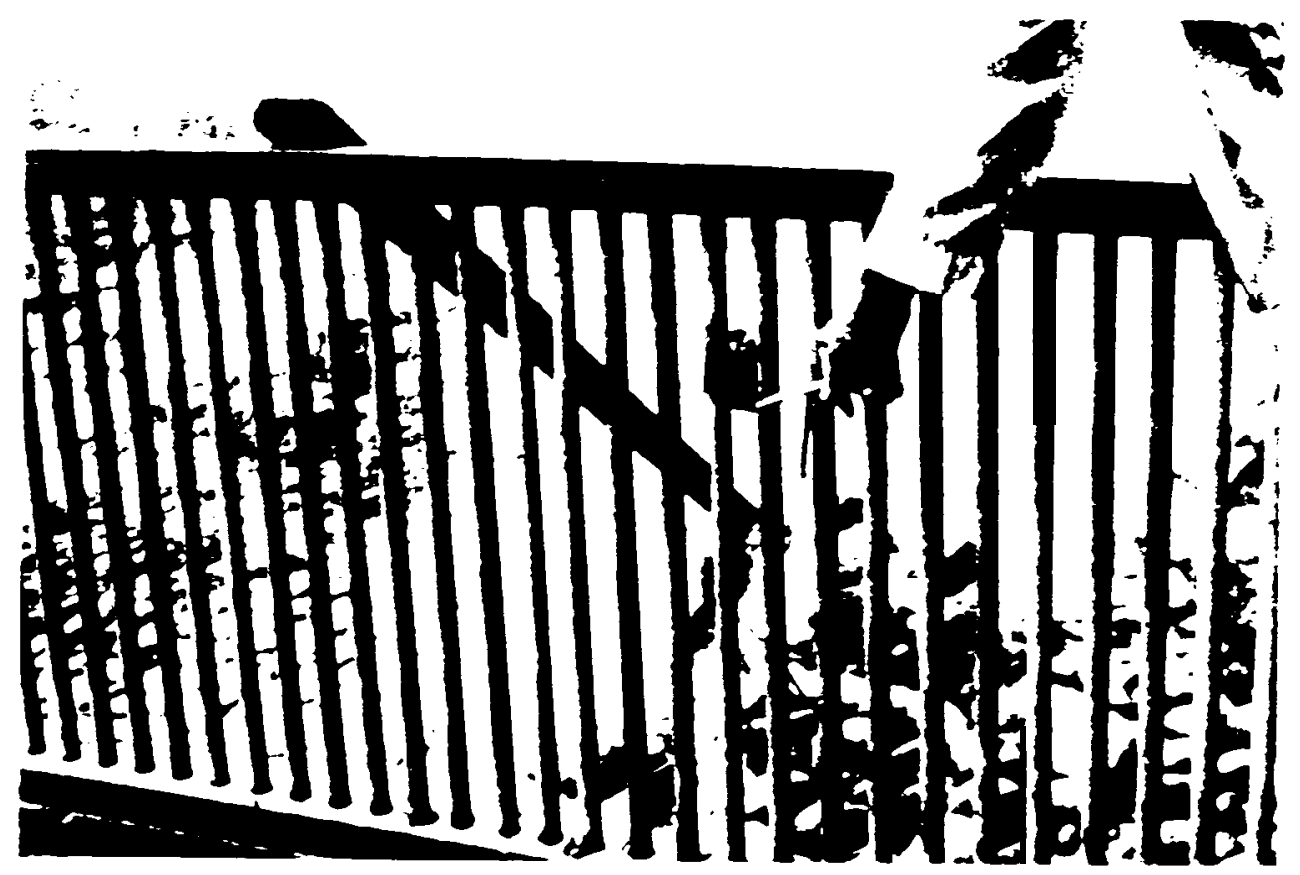

Figure 3. Broomstick weir in British Columbia (DFO). 
Chapter 3

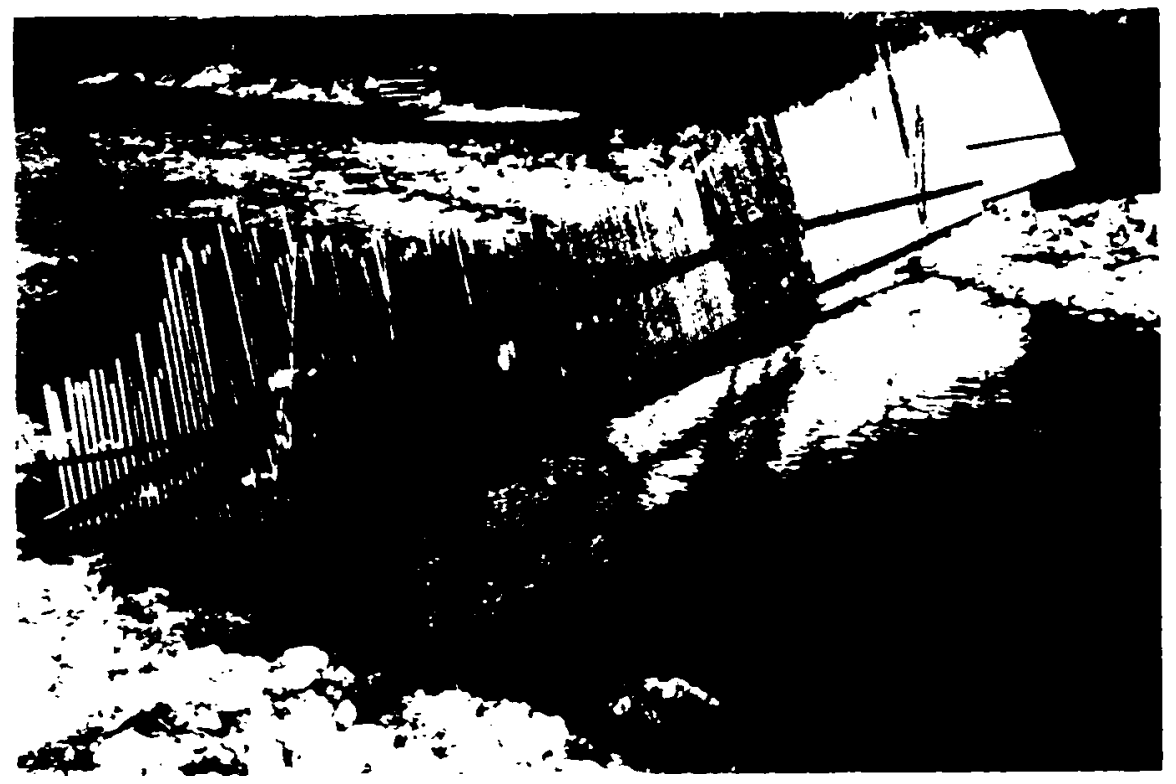

Figure 4. Metal pole weir at Red River Rearing Pond (IFG). Looking downstream.

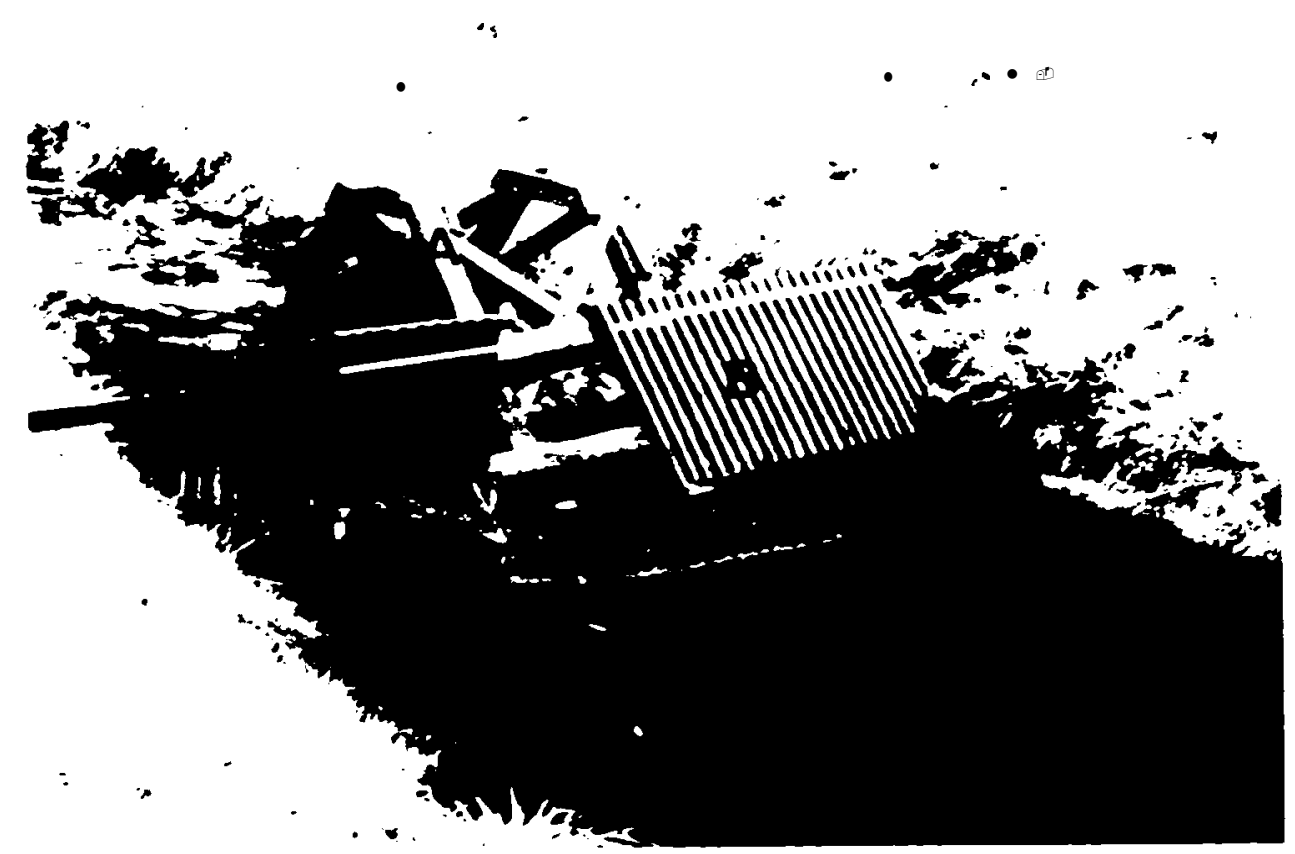

Figure 5. Small temporary weir (A) Four-pod horse, (B) 2- x 4-foot picket section. Looking downstream. 
Disadvantages:

(Temporary rack)

- Requires seasonal installation and removal, depending on fish species

- Subject to washout during high water or ice conditions

- Requires frequent cleaning and maintenance

(Permanent rack)

- May require provisions for fish passage

- Bedload may accumulate above, requiring periodic removal

$\underline{\operatorname{cost}}$ :

The estimates are based on the fabrication and installation of temporary racks by hatcherymen. Temporary rack 6 feet high: $\$ 75 /$ in $\mathrm{ft}$.

Temporary trap $(8 \times 12 \times 6$ feet

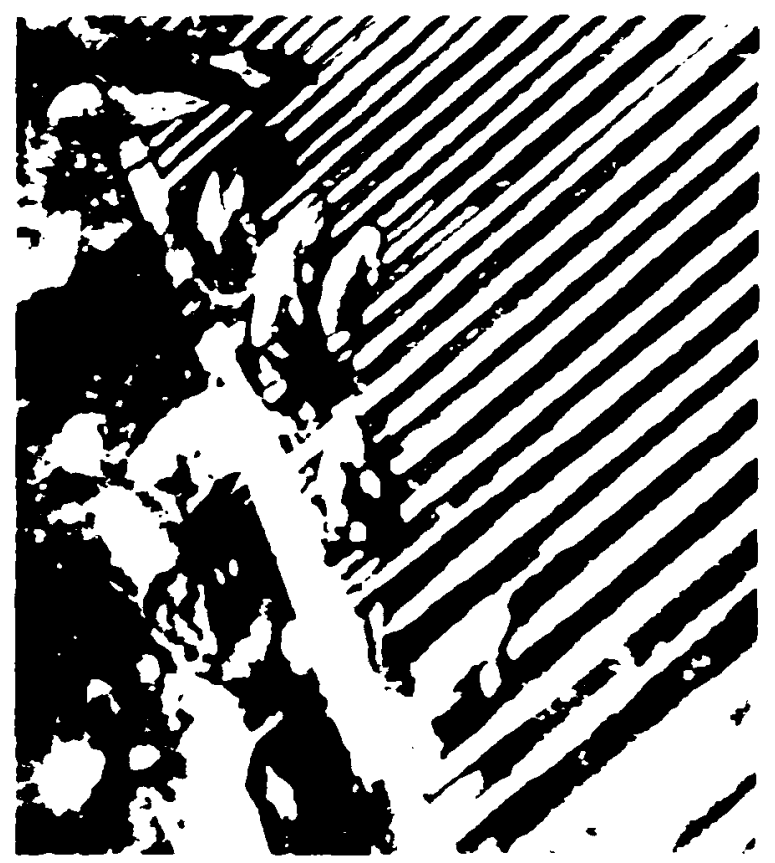

Figure 6. Pink salmon gilled in a pole rack. high): $\$ 2,000$.

"V" trap tunnel: $\$ 300$.

Permanent rack 6 feet high: $\$ 1,200 /$ in $\mathrm{ft}$.

Dismantling, salvaging, and storing temporary racks, traps, and "V" trap tunnel: $\$ 35 /$ in ft.

Re-installation of temporary rack: $\$ 40 /$ lin $\mathrm{ft}$.

Re-installation of trap: $\$ 800$.

Re-installation of "V" trap tunnel: \$100.

Life expectancy: 5 years for the temporary rack, and 20 years for the permanent rack.

\section{Information Sources:}

Oregon Fish Wildlife Cascade Salmon Hatchery

Washington Department of Fisheries Kalama River Rack

Idaho Fish and Game Department Red River Facility and Pahsimeroi Steelhead Collection Facility

2. Electric Fence The electric fence (Fig. 7) diverts adult salmon and steelhead trout by mildly shocking them when they enter a stream-width electric field between a set of suspended electrodes and a groundline. An adjacent fishway that is eventually found by the fish leads them upstream into a trap. When properly 


\section{Chapter 3}

operating, this system does not harm either the adult fish or downstream migrants. Operated by 110 volt, 60 cycle, single-phase alternating current, the'electrodes are spaced on 3-foot centers and are located 15 feet upstream and parallel to a ground line staked flush across the stream bottom. The factors which, influence the efficient operation of the eleetrical barrier are water velocity and voltage gradient. The water velocity within the electrical field should be $3 \mathrm{ft} /$ second or greater to wash the stunned fish downstream from the electrical field to prevent mortality. To provide a positive barrier, the minimum barrier voltage, should be 0.5 volts per inch with a field length of 10 feet, in which the voltage gradient may vary from 0.3 to 0.7 volts per inch. This barrier has satisfactorily operated in streams up to 200 feet wide and 8 feet deep. The electrical demand varies with the number of electrodes submerged' and the depth to which they are submerged. This averages approximately 10 watts per foot of electrode submergence. A 100-foot barrier's electric demand averages approximately 300 watts. Therefore, at $\$ 0.04 / \mathrm{KWH}$, electricity costs will be about $\$ 0.30 /$ day to operate.

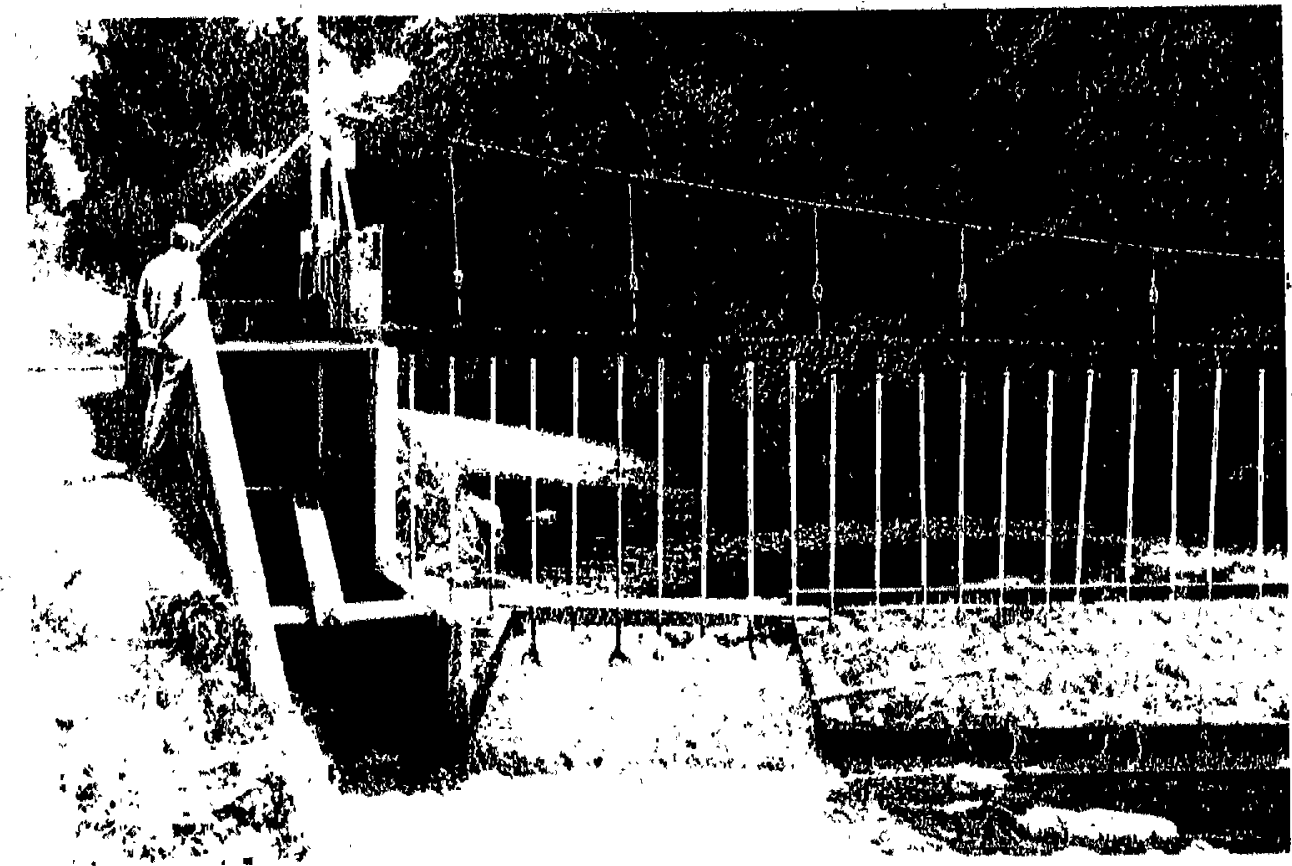

Figure 7. Electric fence and fishway at the Quinault NFH. (Wooden planks_over fishway can be dangerous if slippery o r i f deterioration occurs.)

Advantages:

Low construction cost compared to permanent racks

Easily installed and dismantled

Low maintenance and operating costs

Passes debris

Passes downstream migrating fish without harm

Positive barrier to adult fish even during flood stage 
Adult Collection, Holding, and Spawning

Disadvantages:

- The minimum water velocity of 3 feet per second or greater may require bank abutments to confine stream flow

- Concrete or wooden stream apron may be necessary to eliminate uneven bottom or large boulders that could trap stunned adults or cause uneven flow conditions and alter barrier field voltages

- Electrical power outages inactivate the barrier in the absence of standby emergency power

- Area must be fenced and posted to protect the general public

- Adult females penetrating the electrical field can receive sufficient shock to induce spinal curvature, which might cause problems for those that spawn naturally

\section{Cost:}

An electric fence without bank abutments or stream bottom apron, and with electric power on site is costed as follows:

Streams over 75 feet in width: approximately $\$ 165 /$ lin $\mathrm{ft}$.

Smaller streams 75 feet or less in width: approximately $\$ 275 / \mathrm{lin} \mathrm{ft}$.

Life expectancy is 25 years.

lnformation Sources:

U.S. Fish and Wildlife Service Quinault NFH, and Abernathy Salmon Cultural Development Center, Washington

Oregon Fish and Wildlife Bonneville Fish Hatchery

3. Velocity Barrier A velocity barrier can be described as a sill type structure installed across a stream and designed to hydraulically produce water velocities of 16 feet per second across the downstream apron. This velocity approaches the swimming abilities of salmon and steelhead trout and effectively stops them from moving upstream through the barrier (Fig. 8). They are used in conjunction with fishways to direct fish to holding ponds and are a high-cost unit.

\section{Advantages:}

- Low maintenance

- Minimal damage to fish as they attempt to swim past this barrier

- $\quad$ Passes debris

$\underline{\text { Disadvantages: }}$

- High-cost and not recommended for low-cost facilities

- Moderately difficult to construct in a flowing stream

- Barrier submerges during high flow and may allow fish to pass

- $\quad$ Structure usually requires upstream fish passage for native fish 


\section{Chapter 3}

- Structure creates slightly higher upstream water levels and may require easements for water backing up in sensitive areas

- Barrier may require removal of bedload build-up upstream of structure at twoor three-year intervals

- Navigation must be considered

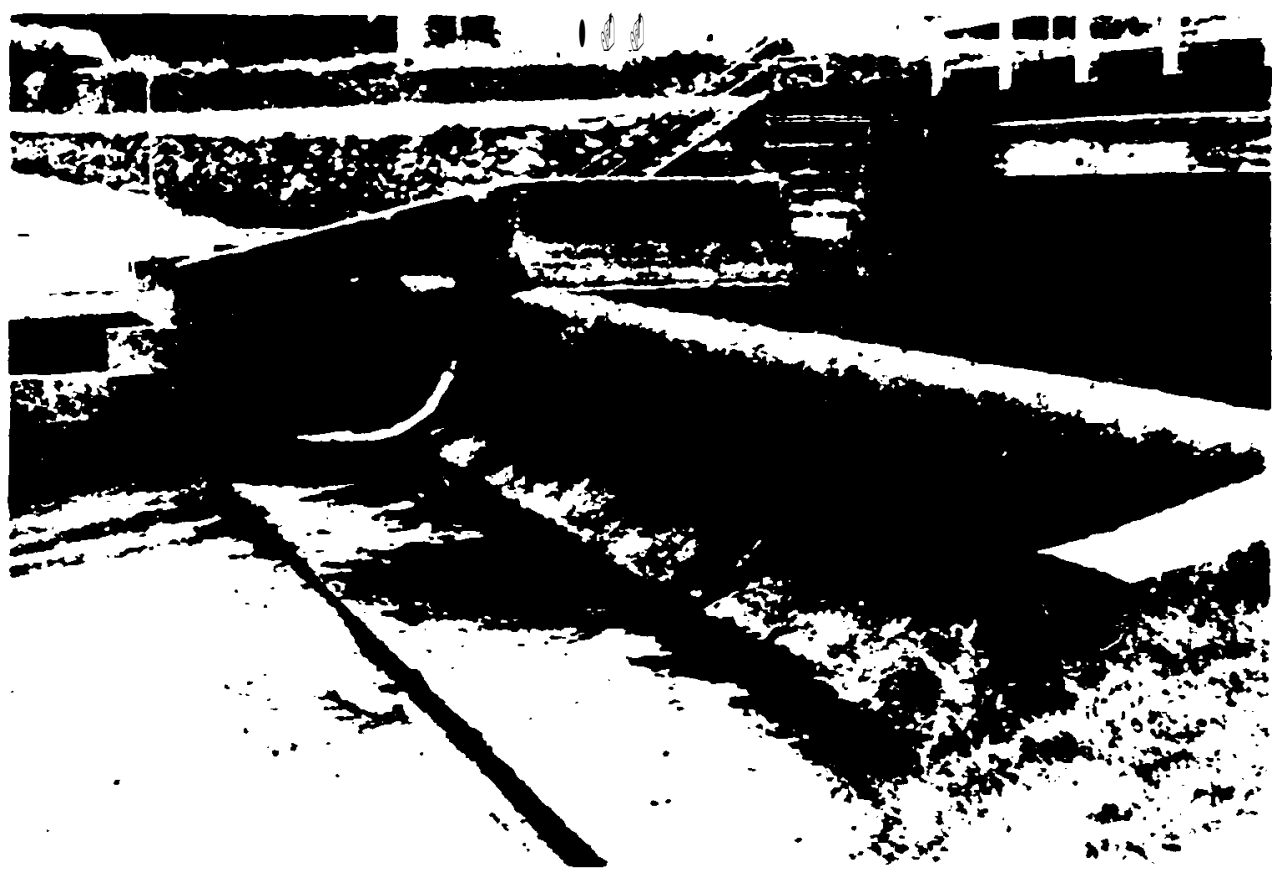

Figure 8. Concrete velocity barrier at Klaskanine Fish Hatchery (OF W).

\section{Cost:}

For a 30 -foot wide stream, the cost is $\$ 30,000$ or $\$ 1,000 /$ lin $\mathrm{ft}$. This includes a reinforced concrete sill, apron, and two bank abutments with rip-rap. The structure has a 50-year life expectancy.

\section{Information Sources:}

U.S. Fish and Wildlife Service Coleman NFH, California

Idaho Fish and Game Rapid River Hatchery

Washington Department of Fisheries Elokomin Salmon Hatchery

4. Vertical Barrier Dam The upstream migration of salmon and steelhead can be stopped by a vertical 6- to 8-foot water drop if the fish are prevented from sounding to enhance their jumping ability. Any one of a number of dams can produce the above waterfall. However, many of these structures injure fish when they continuously jump at the falling water and fall against the dam's hard surfaces. A recommended vertical barrier is an "Ambersen" type dam (named after the 
Adult Collection, Holding, and Spawning

designer). The Ambersen dam's face is sloped upstream, and jumping fish fall into water flowing across the downstream apron. This dam is constructed with concrete counterforts, stop logs, and a poured-in-place concrete leveling apron. Openings in the counterforts allow fish access across the entire apron width (Fig. 9). These structures are used in conjunction with fishways to lead fish to holding ponds, are high cost and not applicable for low-cost facilities.

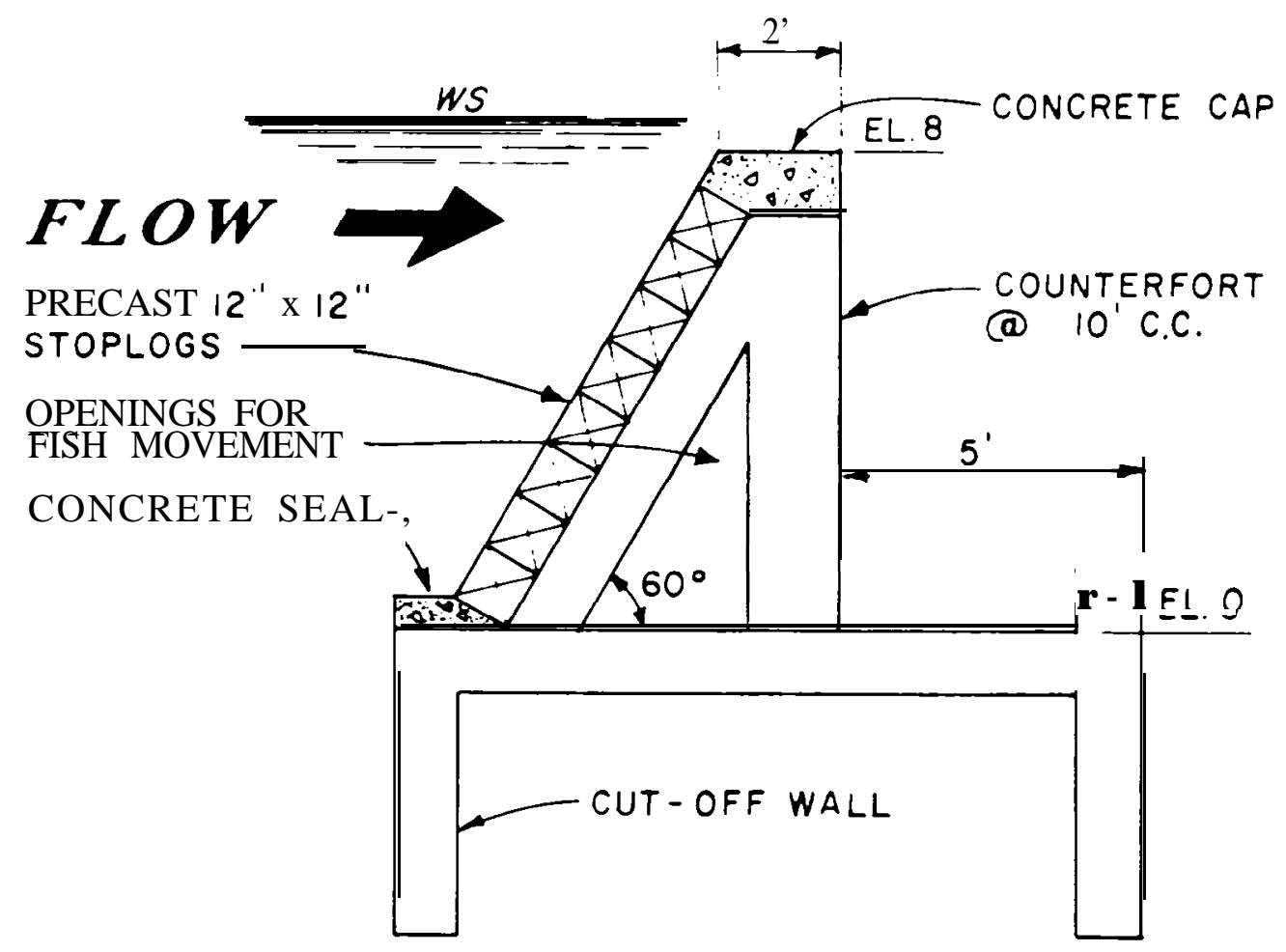

Figure 9. Cross-section of a concrete vertical barrier dam.

\section{Advantages:}

- Low maintenance

- Minimal damage to fish as they attempt to swim past this barrier

- $\quad$ Passes debris

Disadvantages:

- High cost

- Moderately difficult to construct in a flowing stream

- Upstream and downstream water elevation differences are minimized during high flows, enabling fish to move upstream

- Usually requires provision for upstream fish passage for native fish, which increases the cost 
Chapter 3

- Structure creates higher upstream water levels and may require flowage and/or flood easements in sensitive areas

- If necessary, bedload build-up above barrier may require removal at five- to ten-year intervals

\section{Cost:}

For a 30 -foot wide stream, the cost is $\$ 51,000$ or $\$ 1,700$ per linear $\mathrm{ft}$. This includes a reinforced concrete dam, apron, and two bank abutements with rip-rap. The structure has a 50-year life expectancy.

Information Sources:

Washington Department of Fisheries Kalama $\$ 2$ Salmon Hatchery

\section{B. FISHWAYS}

Fishways are used to pass fish over natural stream obstructions and man-made structures, but they can also be used at fish facilities to help collect fish for spawning purposes. The usual application is to lead the fish from the stream to the fishway, which in turn directs the fish to formal adult holding facilities. The fish are intercepted in the stream by velocity barriers, weirs, or electrical fences, as previously described, which lead them to the fishway entrance.

Tnree types of fishways are used in the Columbia Basin: the pool-and-weir, vertical slot baffle, and the Denil or its variation, the Alaskan Steep Pass. The three types are described in the publication "STREA.H ENHANCEMENT GUIDE" by KWL and Associates, and D. B. Lister and Associates (1980) as follows:

"The pool-and-weir type fishway consists of a series of vertical partitions installed at intervals down the length of a specially constructed channel or flume. Water flows over the top of the successive partitions, each 12" lower than its predecessor, creating a series of step-like pools which the mature fish can ascend with ease. Pool-and-weir fishways are most effective where water levels remain fairly constant. Where water levels fluctuate, regular adjustments are required at the upstream end to provide the optimum rate of flow."

"The Denil fishway is a second type and is essentially a short section of flume with baffles affixed to the sidewalls and floor. The energy of water passing through this structure is dissipated in turbulence caused by the baffles which leave a narrow zone of low velocity flow. Denil fishways can be installed at much steeper slopes and, for a given height of obstruction, they can be substantially shorter than other types. A modification of the Denil fishway, the Alaskan Steep Pass, is smaller, uses less water, reduces velocities more effectively, can be prefabricated from aluminum, and is easily installed." 
Adult Collection, Holding, and Spawning

"The vertical slot fishway is the third type and also creates a series of pools and drops. The water flow passes from pool to pool through narrow slots extending the full height of the vertical partitions. The vertical slot fishway is self-adjusting to flow levels. This fishway provides passage for fish through a range of changing volumes or levels of water in the stream, without requiring adjustments of stoplogs or baffles. This is a great advantage, in view of the extreme discharge fluctuations of many streams."

Perhaps the most famous fishways on the North American continent are the vertical baffle fishways located in the Fraser River canyon at Hell's Gate in British Columbia, Canada. Vertical baffle fishways are very costly and are not considered applicable for use in conjunction with low-cost adult holding facilities.

Fishways that might be applicable for low-cost fish facilities and could be used to transport fish from a stream to a pond are evaluated below and in Table 1. For cost comparison, a 6-foot vertical rise from the streams to the holding pond was assumed. The estimated costs do not include costs for facilities to direct fish into the fishway.

1. Pool-and-Weir The most commonly used fishway in the Columbia River Basin is a concrete pool-and-weir fishway. The fishway of study is 48 feet long, 6 feet wide, and 8 feet high; constructed on a 1 on 8 floor slope with 6- to 8-foot long pools (Figs. 10 and 11). These fishways also are found to be constructed on 1 on 6 and 1 on 10 floor slopes. Weirs are wood. stop logs 6 feet wide with a cut, or overflow width, depending on the available water supply. Each 12 -inch width of overflow weir flows about 3 efs of water at 12 inches of weir overflow water depth. The fish enter the holding facilities over a finger weir or through a "V" trap weir.

Advantages:

- Low maintenance

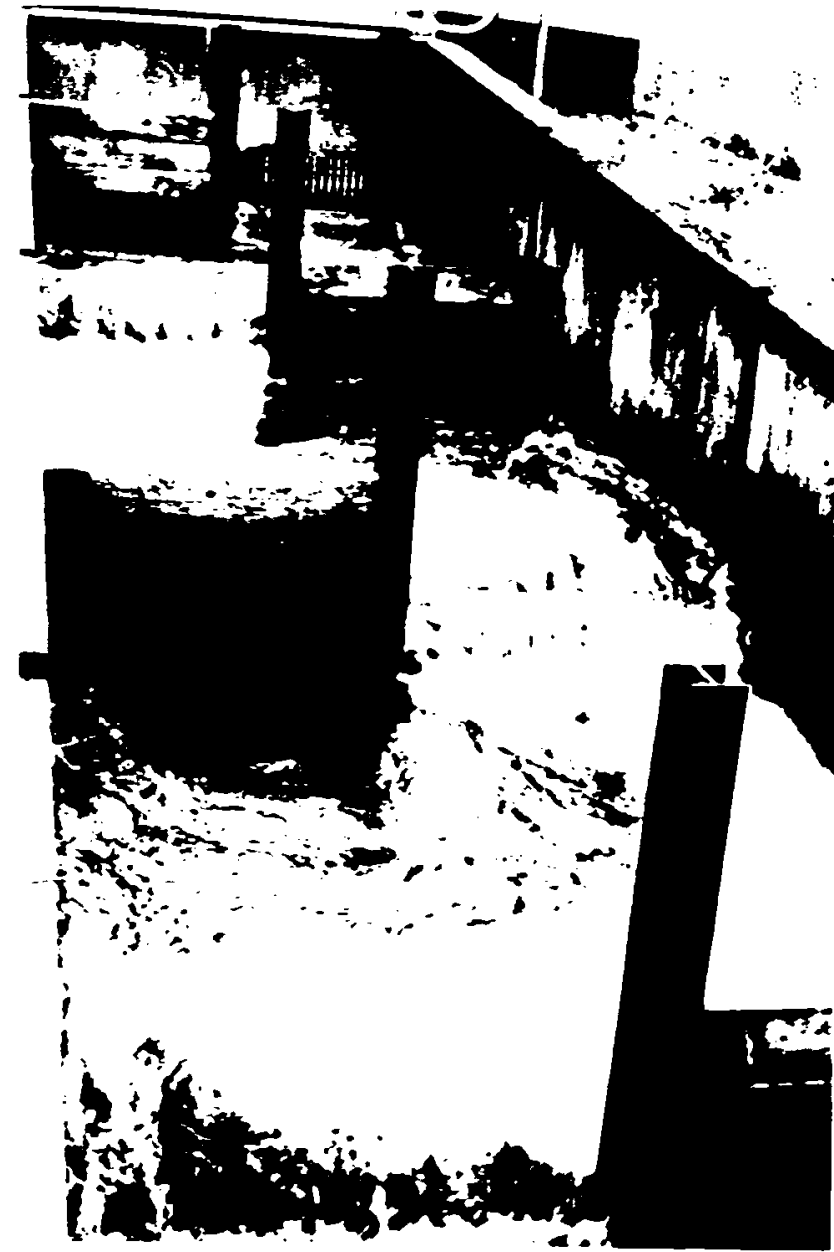

Figure 10. Pool-and-weir fishway in operation. 
- Requires small water flows for operations

- Easy to maintain flow when used at a hatchery

Disadvantages:

- High cost

- Does not adjust to varying water stages without weir adjustments

- Not difficult to construct except for the cofferdamdewatering required to pour the fishway stream entrance

\section{Cost:}

The cost for this fishway is $\$ 33,000$ or $\$ 5,500 / \mathrm{ft}$ of lift. This structure has a 50 -year life expectancy.

Information Sources:

U.S. Fish and Wildlife Service Sping Creek National Fish Hatchery, Washington

Washington Department of Game Skamania Steelhead Hatchery Oregon Fish and Wildlife Cascade Salmon Hatchery

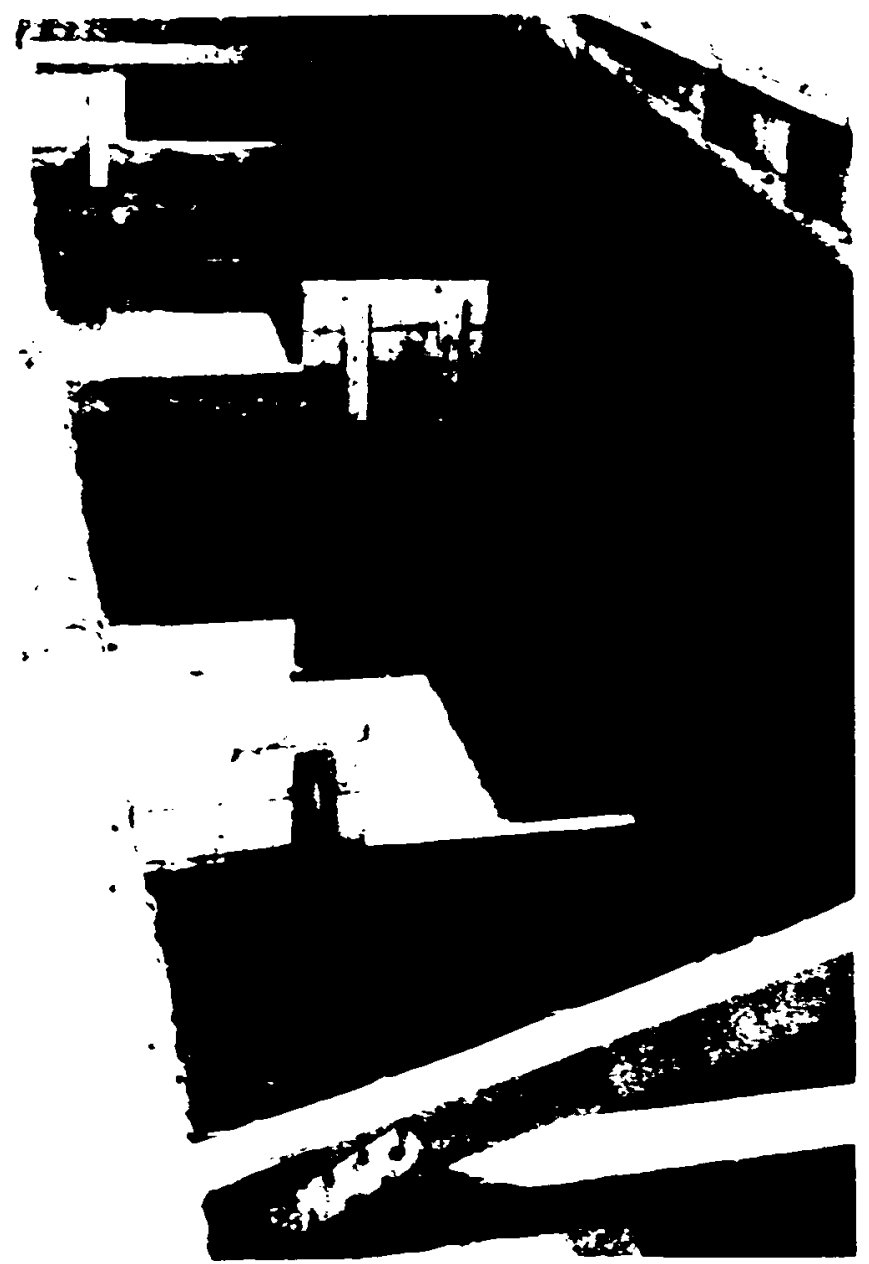

Figure 11. Empty pool-and-weir fishway showing general construction details.

2. Denil-Type or Alaskan Steep Pass As previousiy noted, the Denil fishway (Fig. 12) is verv similar in design and operation to the Alaskan Steep Pass fishway. The major differences are that the Denil is about 5 feet wide whiie the Alaskan Steep Pass is 2 to 4 feet wide. The Denil requries large water flows of 10 to $40 \mathrm{cfs}$ while the Alaskan Steep Pass requires flows of less than $10 \mathrm{cfs}$. In our example, both are 36 feet long and installed on a 1 on 6 slope. Because of width and height difference, the Denil is usually installed on-site while the Alaskan Steep Pass is prefabricated from aluminum plate and then installed on-site as a portable unit. Both produce low water velocities allowing for fish passage through the middle of the structure.

\section{Advantages:}

- Low maintenance

- Easy to install 
Aduit Collection, Holding, ariơ Spawning

- Passes debris and sediments

- Self-adjusts to varying upstream and downstream water stages

- Alaskan Steep Pass is portable and can be relocated as required

$\underline{\text { Disadvantages: }}$

- Resting pool for adults required after each 6-foot vertical fishway lift

$\underline{\operatorname{cost}}$ :

The cost of the Denil fishway is $\$ 36,000$ or $\$ 6,000 / \mathrm{ft}$ of lift, and the Alaskan Steep Pass is $\$ 30,000$ or $\$ 5,000 / \mathrm{ft}$ of lift. Life expectancy is 50 years for both fishways.

Information Sources:

State of Alaska Department of Fisheries

Washington Department of Fisheries Simpson Holding Pond for the steep pass ladder

Oregon Fish and Wildlife Lookingglass Creek fishway for the Denil fishway

Idaho Fish and Game Rapid River

Hatchery for the Denil fishway

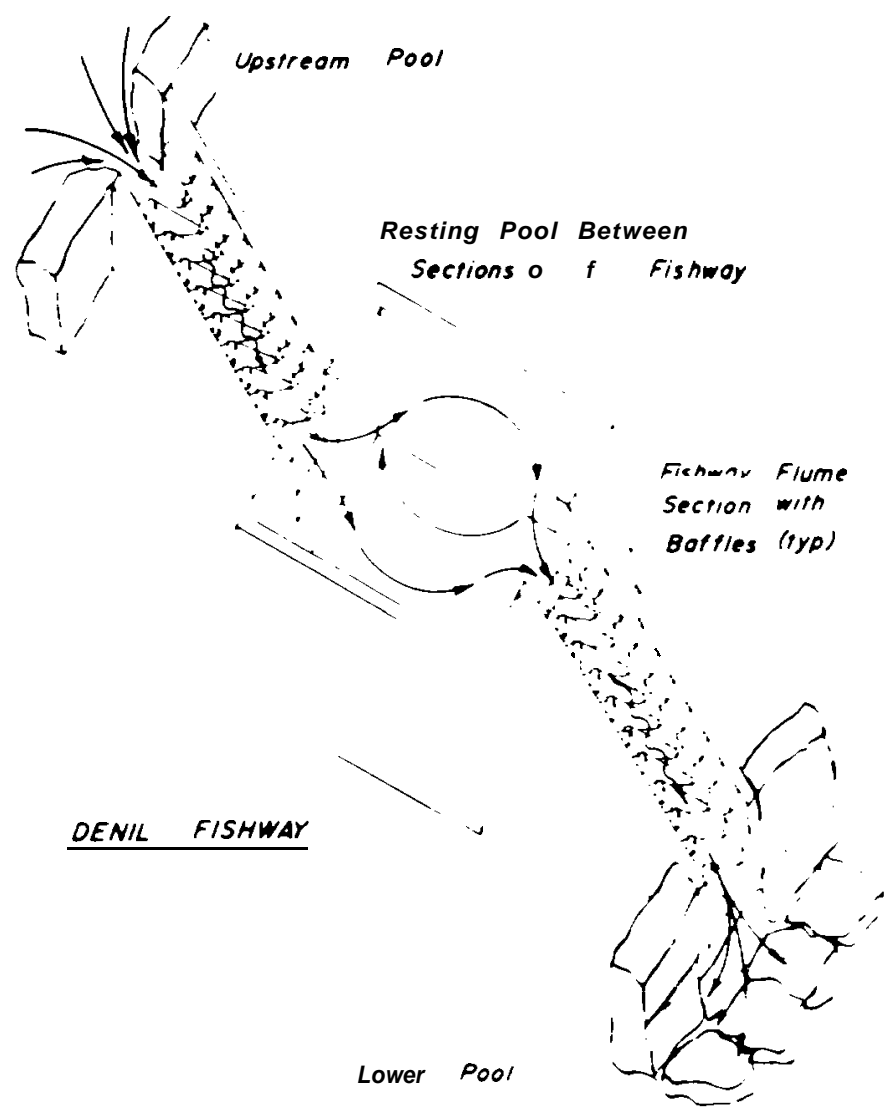

Figure 12. General outline and operational characteristics of Denil fishway. Reprinted courtesy of Kerr, Wood, Leidal and Assoc. Ltd., and D.B. Lister and Assoc. Ltd., Stream Improvement Guide, p. 33. March 1980. Vancouver, B.C.

Table 1. A comparison of fishway characteristics

$\begin{array}{lr}\text { Concrete pool-\&-weir } & \begin{array}{c}\text { Cost } / f t \\ \text { of lift }(1)\end{array} \\ \text { Denil } & \$ 5,500 \\ \text { Alaskan steep pass } & 6,000 \\ \text { Plastic pool \& weir } & 5,000 \\ \text { Rock channel pool \& weir } & 3,000 \\ \text { Wood pool \& weir } & 3,000 \\ & 1,667\end{array}$

Life expectancy 50 yrs.

50

50

20

25

10
Percent salvage for relocation-

33

100

100

0

80

(1) Based on a unit to lift fish six feet. 


\section{Chapter 3}

3. Plastic Pool-and-Weir This fishway is a $5 \times 48 \times 5$-foot deep channel of fiberglass-reinforced polyester plastics with a durable, opaque, external surface-coat to protect against ultraviolet light and provide a non-toxic environment for fish. The channel is equipped with six equally spaced fiberglass weirs, and a welded-wire cyclone-type fence on top of the channel's walls to contain the adult fish. This unit is prefabricated and then installed on-site with a 1 on 8 floor slope.

\section{Advantages:}

Low maintenance

Easily installed

Portable and can be relocated to another area as required

Requires small water flows for operations

\section{Disadvantages:}

- Has fixed weir heights and does not adjust to varying upstream water stages to maintain required channel flow

0 Adults moving through this fishway can easily jump over the channel walls unless a barrier type fence is used for containment

\section{Cost:}

The cost for this fishway is $\$ 18,000$ or $\$ 3,000$ per $\mathrm{ft}$ of lift. This structure has a 25-year life expectancy.

Information Sources:

Alaska Fish and Game

Chemical Proof Corporation

Corrosion Controllers, Inc.

4. Rock Blasted Fishway No standards are available. However an excavated channel augmented with wood or concrete sills capable of allowing fish passage is required. Channel bottom must be rock, hard pan or erosion resistant material.

\section{Advantages:}

- Econo mical

- Passes debris

- Operates over a wide range of flow

$\underline{\text { Disadvantages: }}$

- Extreme care required not to overblast and fracture excessive rock

- May only pass fish through small flow range 
Adult Collection, Holding, and Spawning

\section{Cost:}

The cost for this fishway is $\$ 18,000$ or $\$ 3,000 / \mathbf{f t}$ of lift. This structure has a 25 -year life expectancy.

Information Sources:

None known to be in operation for bringing adults into holding ponds. However, rock excavated-sill fishways are operating at several natural barriers installed by Oregon Fish and Wildlife on the North Fork Klaskanine, Minam, and Lostine rivers, and Plymtom Creek.

5. Wood Pool-and-Weir Fishway This Eishway is constructed with a 1 on 8 floor slope and framed with treated wood members similar to the framing system suggested for wood raceways in Chapter 5, and lined with marine plywood. Fishway dimensions are $4 \times 48$ x $4 \mathrm{ft}$ high with six equallyspaced pools separated by wood stoplog overflow weirs. Wire mesh fencing is necessary on wall tops to prevent adults from jumping out of the facility. It is important not to allow newly treated wood to be in direct contact with ladder flows as this may delay fish movement due to odors.

\section{Advantages:}

- Low cost

- Easily assembled and installed

- Small water flow requirements

- Small leakage is not a problem

$\underline{\text { Disadvantages: }}$

- High maintenance costs

- Fishway may require ballast to prevent floatation

\section{Cost:}

The cost for this fishway is $\$ 10,000$ or $\$ 1,667 / \mathrm{ft}$ of lift, and it has a lo-year life expectancy.

Information Sources:

Idaho Fish and Game Red River Rearing/Holding Area

Alaska Department of Fish and Game

Province of British Columbia, Ministry of Environment, Vancouver, B.C.

\section{HAND METHODS}

Usually adult fish collection facilities are provided at a hatchery, but in some instances a station is supplied with eggs from another source. Even though formal collection 


\section{Chapter 3}

facilities are available, it may be necessary to collect other selected stocks to meet program goals. An example would be the collection of adults native to a particular tributary to maintain the genetic integrity and enhance production. In these cases, informal collection techniques are available that may be particularly useful at "low-cost facilities". These methods, discussed below, usually require more labor, but generally the capital investment is minimal. If the fish are collected at or near maturity, adult holding facilities may not be required, resulting in further savings in capital costs and investment in both security type facilities and personnel.

1. Nets Gill nets and seines are commonly used to collect adult salmon for hatchery purposes. Gill nets are fished either set in a fixed position, or as drift nets and we recommend they only be used when fish are nearing sexual maturity. The former method captures fish migrating upstream while the latter method is used primarily on spawning beds. Both techniques generally necessitate transporting the adults to a holding facility at the hatchery because the fish usually are not completely sexually mature. When fish are nearing sexual maturity their firmly embedded scales protect them from injury, and with proper handling minimal losses will occur.

Seines are generally classified as beach or purse seines. The latter are used primarily in the marine environment, particularly in Alaska, and would have little practical application for collecting adults for spawning purposes in the Columbia Basin. Beach seines, the type of seine mainly used in hatchery work, are used extensively in hatchery holding ponds and can be used to collect adults from slow moving areas within streams. Generally they are used where fish are pooled prior to spawning. These nets have a heavily weighted lead-line to hug the bottom, and are usually set from a boat encircling a school of fish. Both gill nets and seines are available in a variety of standard sizes, but are often custom made to fit particular needs. A typical hatchery adult pond seine is illustrated in (Fig. 13). Further information can be obtained from fish agency personnel and the dealers noted in Appendix 2.

2. Snagging and Gaffing These are highly effective methods for collecting adults in smaller streams. Snagging works best when the fish are heavily schooled-up in pools. Figs. 14 and 15 illustrate equipment successfully used by the WDF. Usually the fish are "green" when captured and require transportation to holding facilities. At the WDF Humptulips Salmon Hatchery, the manager has taken 500,000 eggs in a single season in this manner.

Gaffing is used by some WDF hatchery managers to collect adults, particularly chinook. These are usually taken directly from the spawning beds, and a major advantage over some of the other collection methods is that the fish are almost always sexually mature and can be spawned immediately. Thus the costs of holding facilities and security measures are eliminated.

Gaffing requires good equipment (Figs. 16, 17) and clear water in order to see the fish. This method can be used to select stock and fish size; and one person can collect and spawn the adults. 
Adult Collection, Holding, and Spawning

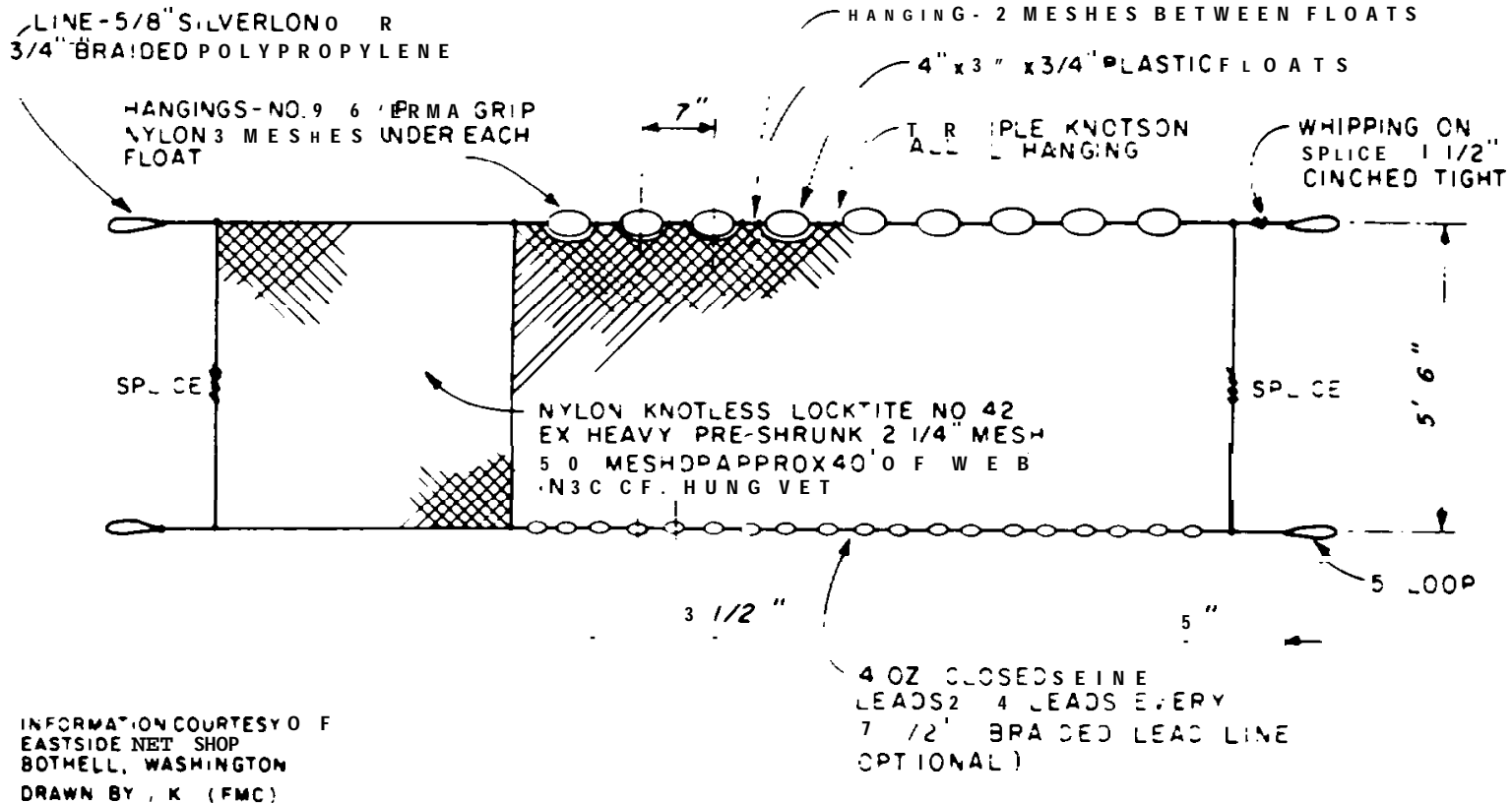

Figure 13. Typical hatchery adult pond seine.
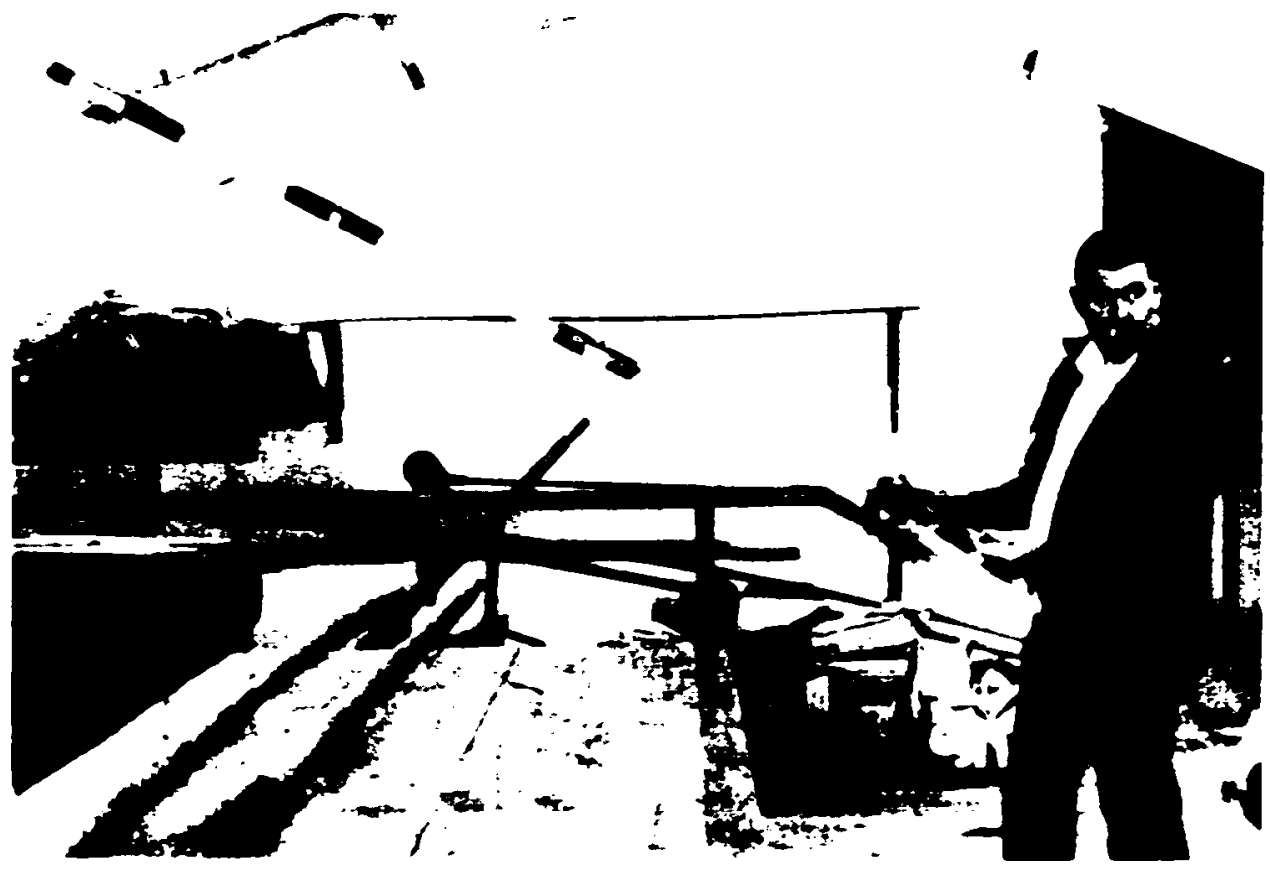

Figure 14. PVC pipe used as pole for snagging at the Humptulips Salmon Hatchery (WDF). 
Chapter 3

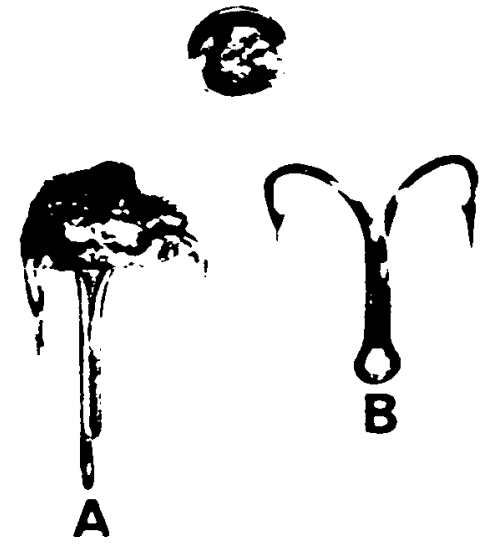

Figure 15. Terminal hooks used for snagging: (A) weighted, (B) not weighted.

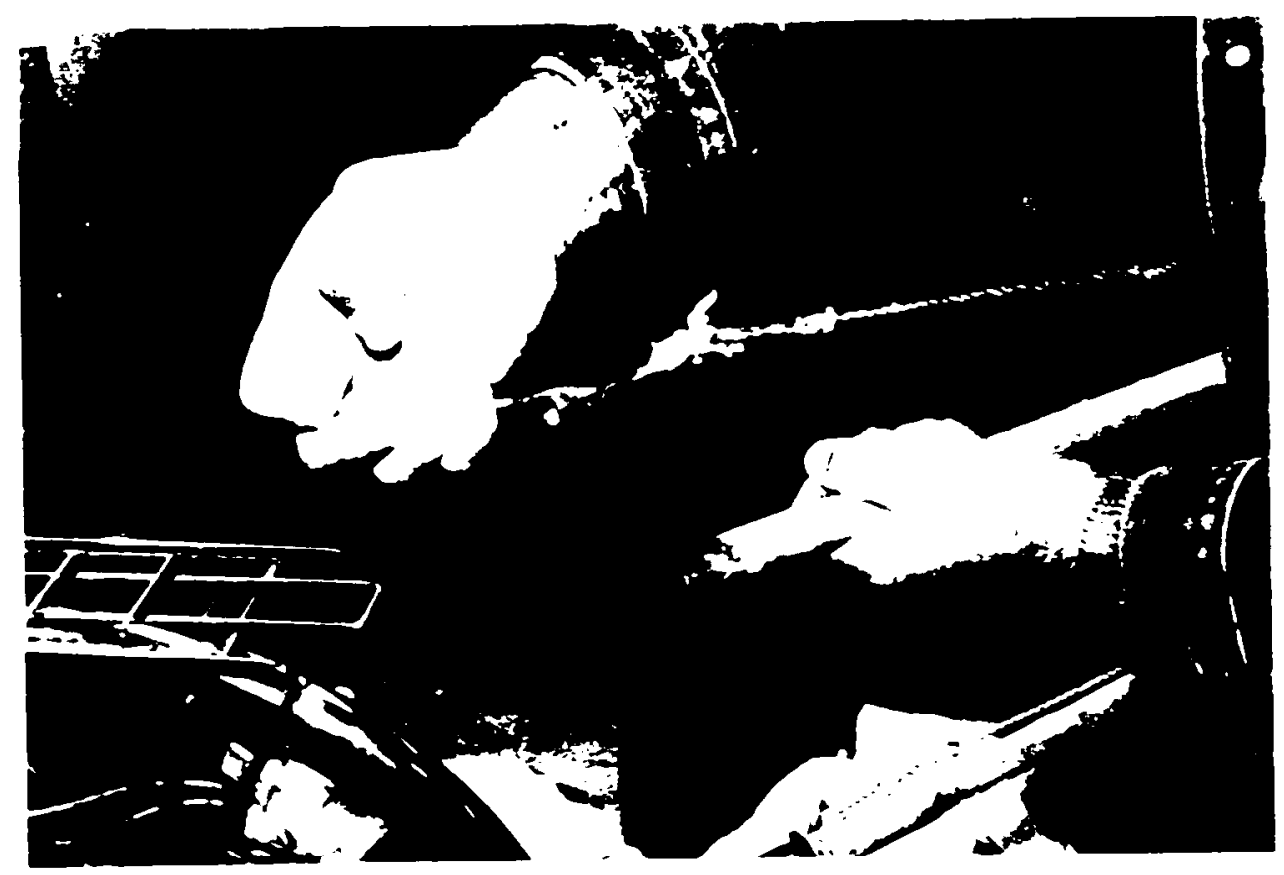

Figure 16. Terminal attachment of gaff hook to long pole. 
3. Hook-and-Line Capture The capture of adult fish with sport fishing gear is restricted almost exclusively to steelhead trout. It has been successfully used by DFO, and by WDG and their affiliated volunteer groups. Fish caught on sports gear are either tethered or placed in adult tubes (Fig. 17, Chapter 6) or floating pens (Fig. 16, Chapter 6); then transferred to transport trucks and hauled to hatchery ponds.

Hook-and-line capture is an excellent system for obtaining selected steelhead stocks for a new program, or to increase egg and fry survival for enhancement of a specific stream. It is relatively economical when used in conjunction with volunteer groups, and enhances good communications between management and user groups. The method is not practical for large egg taking programs.

4. Electro-shocking Electro-shocking is extensively used to capture adult pink, chum, chinook, and coho in shallow Alaska streams. Two culturists are required; one to operate the backpack electro-shocker (Fig. 18), and the other to dip the fish as they drift downstream. In Alaska it is common to obtain over one million eggs daily in this manner.

This method, like gaffing, works best on spawning riffles. The shocker is effective for capturing adult steelhead and coho from hiding places that would be inaccessible with other methods. It is also an advantage in a situation where returning adults enter a small hatchery stream but refuse to enter the adult trapping area. This trait applies to all species, but is particularly typical of chinook salmon. A compact, battery-operated shocker costs about $\$ 2,000$. Further equipment information can be obtained from Smith-Root Inc.., or the Alaska Department of Fish and Game.

\section{ARTIFICIAL IMPRINTING}

Artificial imprinting is a method of artificially altering the homing response of salmon or steelhead (Scholtz, et al., 1975) so that the returning adults can be attracted to specific sites. One important application of this method would be to attract adults into a side-stream trap or collection site, and thus avoid the need for high-cost collect ion structures. Other potential management applications might be attracting surpluses to underutilized spawning areas, decoying adult surpluses to facilitate their- harvest, or directing fish away from a potential overharvest area.

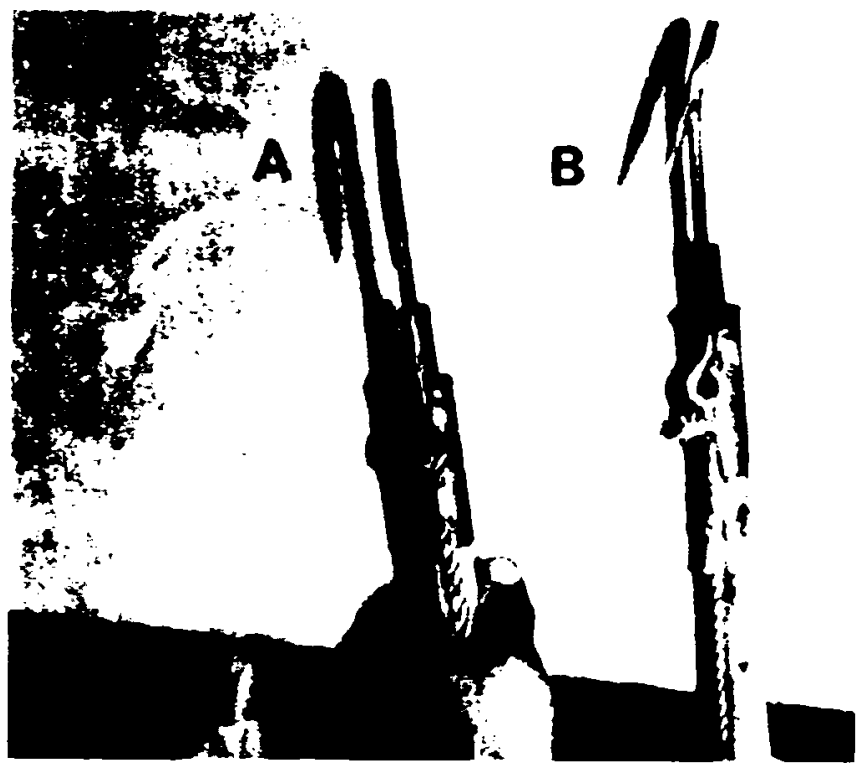

Figure 17. Gaff hooks on pole (A) improper angle on hook, (B) recommended angle. 


\section{Chapter 3}

Artificial imprinting has been successfully conducted on coho and steelhead by introducing the fish to morpholine during stages of smoltification. Morpholine is a synthetic chemical that does not occur in natural waters. It is highly soluble in water, stable in the natural environment, and can be detected by the fish in very low concentrations $\left(1 \times 10^{-6} \mathrm{mg} / \mathrm{l}\right)$. Operational exposure rate, maintained during imprinting and in the receiving waters to which returning adults are to be attracted, is $5 \times 10^{-5} \mathrm{mg} / \mathrm{l}$. This very dilute concentration makes this technique very inexpensive.

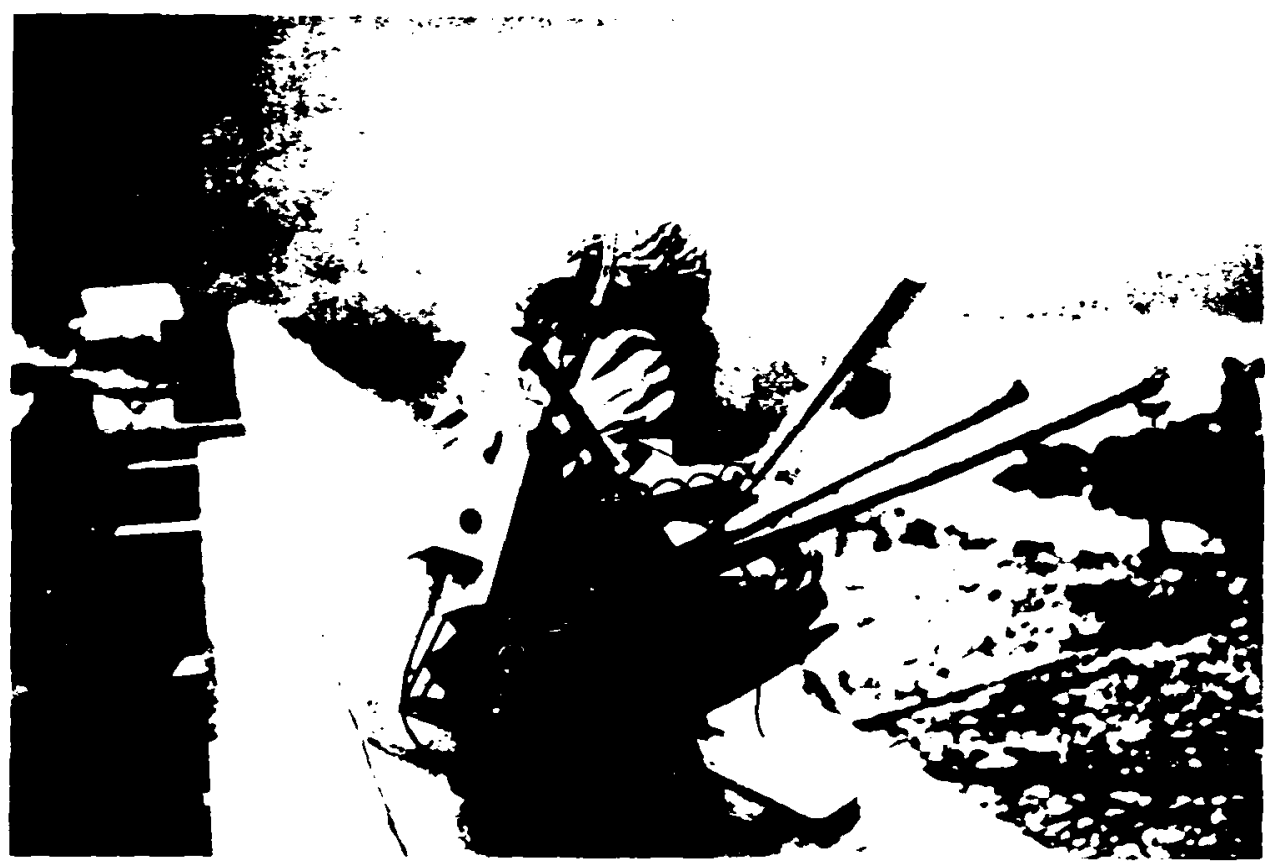

Figure 18. Backpack electro-shocker, Bear Cove, Alaska.

Morpholine may be purchased from chemical supply houses and further information can be obtained from the National Marine Fishery Service, Seattle. A second chemical successfully used, and similarly available, is phenethyl alcohol. Exposure concentrations required are slightly higher $\left(1 \times 10^{-3} \mathrm{mg} / \mathrm{l}\right)$.

\section{PART II. ADULT HOLDING FACILITIES}

This section describes the salmon and steelhead adult holding criteria, systems and techniques employed in Pacific Northwest fish culture operations. The function of a holding facility is to hold adults in a secure area until spawning. Adults can be successfully held in most water containers provided the fish have sufficient water flows with proper levels of temperature and dissolved oxygen. The container must not physically injure the fish, and proper operating procedures must be used. A number of hatcheries have holding ponds specifically constructed for adults, while many installations have ponds used for both holding and rearing. We recommend that holding ponds also be 
Adult Collection, Holding, and Spawning

used for rearing. Techniques of holding pond partitioning are valuable aids in efficientlv and effectively accomplishing holding and spawning operations in all ponds. These systems are further explained below in greater detail, including miscellaneous informal-type holding facilities and techniques.

\section{A. BIOLOGICAL REQUIREMENTS}

The necessary holding time varies by species from a few days to six months. Successful long-term holding (over 30 days) is difficult, because it can result in mortalities associated with fish diseases, especially where water quantity and quality is sub-standard. Vaccinating each adult for internal disease control and periodically treating the holding pond water source with chemicals for fish fungus growth control, are operational procedures used with varying degrees of success. Loss to poaching is also more probable with a longer holding period.

Because the size of fish being held varies greatly even within the same species, long-term holding criteria (Table 2) are recommended, based on units of fish weight. As a rule, at $50 \mathrm{~F}$ water temperature, one $\mathrm{ft}^{3}$ of holding space is required for each 2 pounds of fish; and $1 \mathrm{gpm}$ of water is required for each 15 pounds of adult fish. For each degree of water temperature below and above $50 \mathrm{~F}$, the poundage can be increased or decreased $5 \%$, respectively, without flow adjustment.

Table 2. Space and flow criteria for long-term holding of adult salmon and steelhead trout in $50 \mathrm{~F}$ water and suggested spacing for rack pickets. $(1)$

\begin{tabular}{|c|c|c|c|c|}
\hline Species & $\begin{array}{l}\text { Average } \\
\text { assumed } \\
\text { weight/fish } \\
\text { (pounds) }\end{array}$ & $\begin{array}{l}\text { Water flow per } \\
\text { fish (gpm) }\end{array}$ & $\begin{array}{l}\text { Pond space } \\
\text { per fish } \\
\text { (ft3) }\end{array}$ & $\begin{array}{l}\text { Suggested picket } \\
\text { spacing for traps } \\
\text { etc. } \\
\text { (inches) }\end{array}$ \\
\hline Spr. Ch. & 15 & 1.0 & $\overline{8}$ & $1015 / 8$ \\
\hline Fall $\mathrm{Ch} .(2)$ & 15 & 1.0 & 7 & $15 / 8$ \\
\hline Fall Ch.(3) & 18 & 1.0 & 8 & $15 / 8$ \\
\hline Coho & 8 & 0.5 & 4.0 & 1 \\
\hline Steelhd. & 8 & 2.0 & 2.5 & 1 \\
\hline Sockeye & 6 & 0.4 & 4.0 & $3 / 4$ \\
\hline
\end{tabular}

(1) From a pending publication of the Salmon and Steelhead Conservation and Enhancement Facility Design Group (Zook, 1984). A panel comprised of all Northwest fishery agencies, except Idaho; plus Indian tribal representation.

(2) Early spawners

(3) Late spawners

According to agency personnel, holding adult salmon and steelhead in temperatures in excess of $56 \mathrm{~F}$ during the last several weeks of ripening will cause poor quality eggs and should be avoided. 


\section{Chapter 3}

For short-term holding, the above density criteria can be exceeded, provided the aissolved oxygen level measured at the water discharge maintains 6-7 ppm. Coho, for example, held a week or two before spawning, have exceeded the long-term fish density criteria by a factor of three. As a rule, stream water temperatures fluctuate daily, and operators should be conservative in their loading of holding facilities.

\section{B. HOLDING PONDS}

Holding ponds with capacities for several hundred fish are constructed of various surfacing materials including dirt, gravel, concrete, asphalt, or shot-crete. Fish culturists are in substantial agreement that "long-term" holding ponds should be constructed with an upwelling water supply on the pond bottom and sloping banks around the pond periphery. The fish generally circle the upwelling water seeking openings for upstream migration and the sloping banks tend to eliminate fish jumping. Overhead water spray systems are also employed to refract light and thus reduce persistent fish jumping (Fig. 19).

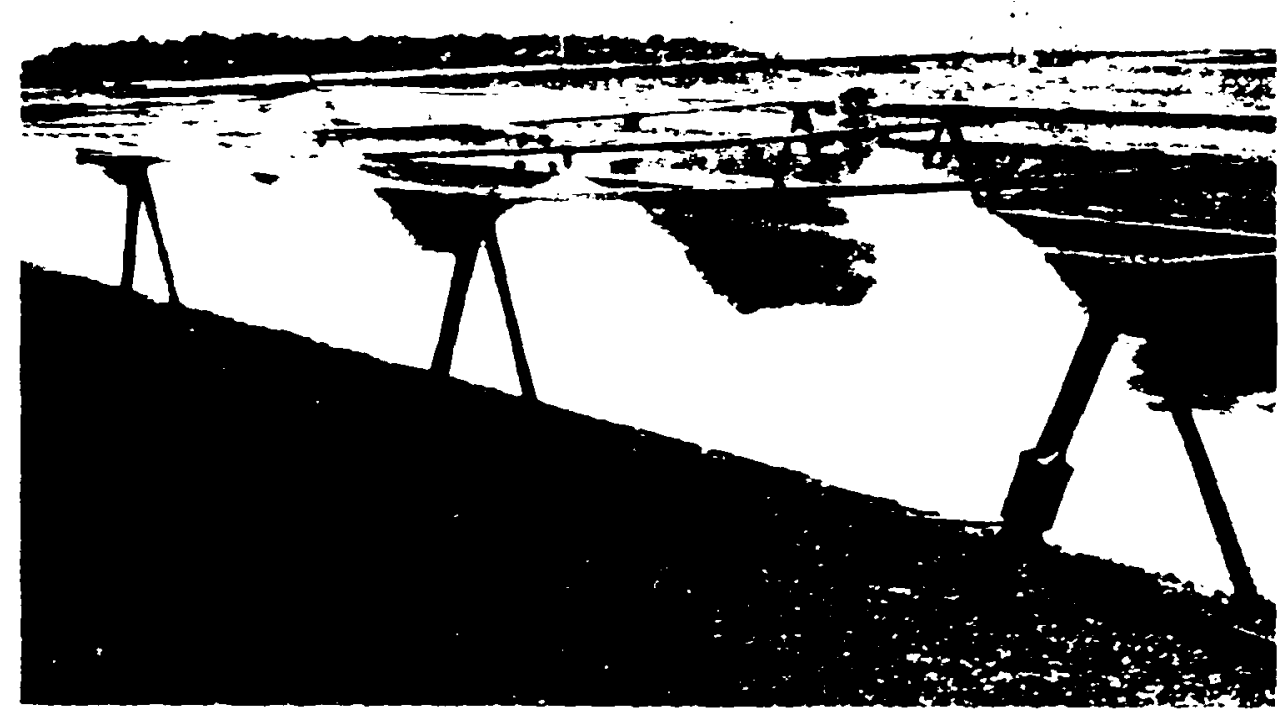

Figure 19. Spray system to refract light and prevent fish jumping at Wells Salmon and Trout Hatchery ( $W D F$ and $W D G$ ).

Short-term holding ponds also operate well with an upwelling water supply and sloping bank design. However, they usually have vertical walls and water is supplied at one eno and drained out the other. Fish jumping in the corners and along the vertical walls are frequently a problem, but this can be controlled by overhead spray systems (Fig. 19), floating rafts, and by placing plywood or other opaque materials over the troublesome areas. These light-diffusing materials also provide shaded areas for the fish to rest. Fencing and vertical walls are sometimes covered with a resilient material to prevent injury to jumping fish (Fig. 20). 


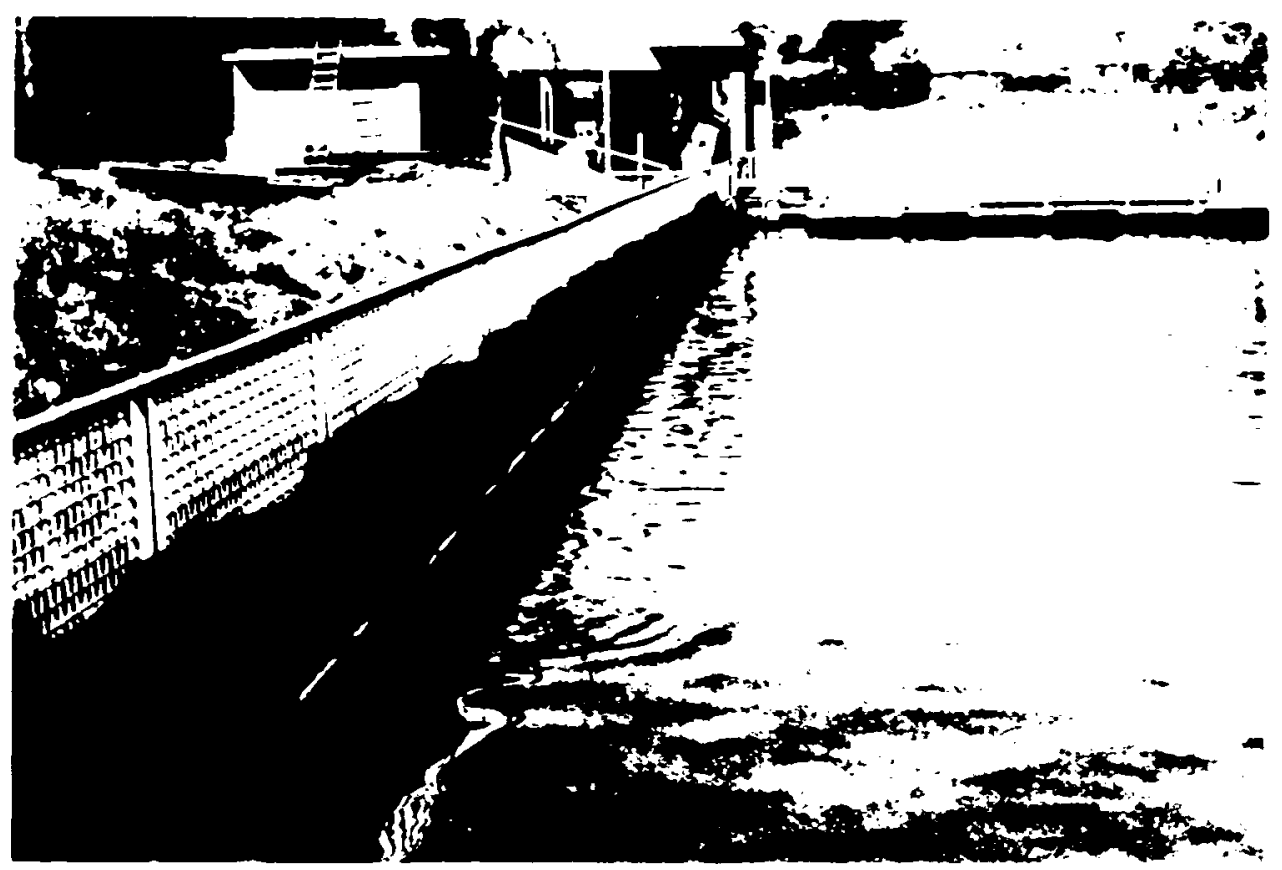

Figure 20. Adult holding pond with neoprene apron along sides to prevent injury to jumping fish at Bonneville Salmon Hatchery (OF W).

There are two methods, each associated with the theoretical behavior of adult fish, for collecting ripe fish held in holding facilities. The first method is based on the theory that these fish will move to the upstream end of the pond. Therefore, attraction water will lead them into an upstream trap for collection. The second method is based on the premise that if fish cannot move upstream, they will move downstream in search of a spawning area. Therefore, the ripe fish will drop back and can be collected at the downstream end of the pond. This method has been used successfully at the OFW Bonneville and Big Creek hatcheries, and is especially effective with fall chinook. In most adult holding ponds the fish are either seined or crowded into areas for sorting, testing, and spawning.

Adult long-term holding ponds are generally designed to provide for the following:

Minimum of pond water seepage

Stable pond sides and bottom

Clean water

Meet the biological criteria in Table 2

A pond drain sized to permit water levels to lower while maintaining the incoming water supply for operations

A drainage system (uplift relief) must be provided if a high ground water table is present

A system for anchoring pond partitioning materials

A method to easily move fish to the spawning area 


\section{Chapter 3}

Elimination of all sharp objects that could injure fish

Maintain all holding area openings to not exceed the maximum allowable spacing noted in Table 2.

Drainable for cleaning and disinfecting

Operation and maintenance accessibility

A $100 \mathrm{ft}^{2}$ covered open air spawning house equipped with overhead lighting, water, and a broom-finished concrete floor

Protection from poachers

Long- and short-term holding ponds surfaced with different materials are described below, along with their advantages, disadvantages, and costs. Water supply and drain systems are not included in this evaluation. For comparative purposes, each pond is dimensioned to contain approximately $4,000 \mathrm{ft}^{3}$ of water. Where pond dimensions are given, they represent a typical size to meet the $4,000 \mathrm{ft}^{3}$ water capacity.

1. Long-Term Dirt Holding Pond A rectangular dirt pond constructed with materials available from on-site excavations. Pond dimensions at the water surface are $40 \mathrm{ft}$ wide $\times 55 \mathrm{ft}$ long with an average depth of $5 \mathrm{ft}$, and with $3: 1$ bank slopes. An upwelling water supply is located in the upper end of the pond floor, and has two 24-inch screened outlet riser pipe-drains in the lower end (Fig. 18, Chapter 5).

\section{Advantages:}

- Simple construction

- Low construction cost

Disadvantages:

- Automatic crowders cannot be installed

- Requires bank vegetation control

- Pond difficult to clean if silt accumulates

- Working in the pond muddies the water

- Pond should be throughly cleaned, and if possible, disinfected if juveniles are to be reared

cost:

The estimated cost is $\$ 8,800$, or $\$ 2.20 / \mathrm{ft}^{3}$ of holding water; and the pond has a 50-year life expectancy.

Information Sources:

Idaho Fish and Game Red River Pond, Rapid River Hatchery, and Hayden Creek Research Station

Washington Department of Fisheries Washougal Salmon Hatchery 
Adult Collection, Holding, and Spawning

2. Long-Term Graveled Holding Pond This is a rectangular gravel-surfaced holding pond constructed identical to the dirt pond, except that the pond bottom is surfaced with 4 to 6 inches of round river gravel and the bank side slopes are surfaced with 2-inch minus crushed rock.

The gravel holding pond is very similar to the dirt holding pond regarding advantages and disadvantages. One advantage of the gravel bottom over dirt is that turbidity is lower when work is being done on the gravel surface.

\section{Cost:}

The estimated cost is $\$ 9,800$, or $\$ 2.45 / \mathrm{ft}^{3}$ of holding water; and the pond has a 50-year life expectancy.

\section{Information Sources:}

Washington Departments of Fisheries and Game

3. Long-Term Asphalt Holding Pond This rectangular, ssphaltsurfaced pond is constructed identical to the dirt holding pond, except that the bottom and banks are surfaced with a 3-inch asphalt lining made up of two 1-1/2-inch lifts over an under-drain of 8 -inch thick granular base material and a $\ddot{z}$-iiich thick sand leveling course (Fig. 20, Chapter 5). Bank slopes are also 3:11 and the water volume capacity is the same as the two previously described ponds. Bank slopes greater than this are optional; however, consideration should be given in the design to providing an inclined area sufficient to allow small tractors to enter.

\section{Advantages:}

- Easy to remove silt and disinfect if juveniles are to be reared.

- Easier and more efficient manpower operations with dividers

- Few bank vegetation problems

$\underline{\text { Disadvantages: }}$

- Necessary to eliminate all bank vegetation growth to maintain asphalt seal integrity

\section{Cost:}

The estimated cost is $\$ 13,600$, or $\$ 3.40 / \mathrm{ft}^{3}$ of holding water; and the life expectancy is 15 years.

Information Sources:

U.S. Fish and Wildlife Service Eagle Creek NFH, Oregon 


\section{Chapter 3}

4. Short-Term Concrete Holding Pond A rectangular concrete pond with vertical side and end walls. Its typical dimensions could be 15 x 54 x 8 feet deep. The water is supplied across the upper end of the pond width through a pipe manifold with a number of outlets, and drained out of the lower end. An aluminum tube-type screen with spacing applicable for the species (see Table 2) is installed to retain the adults.

Advantages:

- Low maintenance

- Automatic crowders can be incorporated

- Easy to clean silt and disinfect if juveniles are to be reared

- $\quad$ Easy to install dividers

$\underline{\text { Disadvantages: }}$

- High cost

- Pond needs cover or fencing to prevent fish from jumping out

\section{Cost:}

The estimated cost is $\$ 35,000$, or $\$ 8.75 / \mathrm{ft}^{3}$ of holding water. Life expectancy is 50 years.

Infor mation Sources:

Washington Department of Game Skamania Steelhead Hatchery

Oregon Fish and Wildlife Gnat Creek Fish Hatchery

Washington Department of Fisheries Kalama Salmon -Hatchery \#2 and Grays River Salmon Hatchery

5. Short-Term Shot-Crete Holding Pond This rectangular steel mesh reinforced shot-crete (sand, cement and water) holding pond is constructed identically to the preceding concrete holding pond, but surfaced with shot-crete.

Advantages:

- Same as for short-term concrete holding pond

$\underline{\text { Disadvantages: }}$

- Same as for short-term concrete holding pond, and also requires specialty construction contractor

\section{Cost:}

The cost is $\$ 32,000$, or $\$ 8.00 / \mathrm{ft}^{3}$ of holding water; the life expectancy is 50 years. 
Adult Collection, Holding, and Spawning

Information Sources:

Oregon Fish and Wildlife Klaskanine Fish Hatchery

\section{INFORMAL ADULT HOLDING FACILITIES AND TECHNIQUES}

When formal adult holding ponds do not exist, many other methods are available to accomplish the task. These include portable tanks and pens, live boxes, traps and rearing ponds, compartment holding, and tethering. All are discussed in this section.

1. Portable Tanks and Net Pens Any of the portable tanks and pens described in Chapter 4 can be used to hold adults at densities set forth in Table 2. Portable rearing facilities have little freeboard, and provisions are usually required to contain jumping fish. A seine or netting, properly installed, usually suffices. An opaque floating material also aids by providing a place for the fish to hide. Techniques described earlier in this chapter are applicable with these units.

A major advantage of portable facilities over formal ponds is that they can be quickly installed and removed. This is particularly advantageous for temporary programs or where smaller numbers of fish are involved.

Net pens are used to hold adults in marine waters, but are seldom used in freshwater areas. They may, however, afford one of the best low-cost methods for certain Columbia River programs. Suitable sites include within large rearing ponds, lakes and forebays, and backwater areas of rivers. One pen $20 \times 20 \times 5$ feet deep has the capability of holding 400-500 adult steelhead or coho and costs about $\$ 4,000$, including flotation. The various types are described in Chapter 5.

2. Live Boxes Live boxes are considered temporary holding facilities and are often used in conjunction with the spawning process. They are portable and easily handled by one or two people. Construction materials vary from heavy netting to vinyl-coated wire mesh (Fig. 21). Both are non-abrasive to the fish. A live box is especially useful when spawning steelhead. The selected males can be held and used several times. Live boxes are often used to hold immature adults to prevent excessive handling as the main population is sorted.

Floating live boxes (Fig. 16, Chapter 6) serve as excellent temporary holding facilities in ponds, or when fish are captured in remote river areas. They are flexible, can be easily transported to a remote site to hold fish, and then serve as a transport system (Chapter 6).

Material cost for a PVC-coated wire box $3 \times 5 \times 3$ feet deep would be $\$ 100.00$. Coated wire comes in 50- and 100-foot rolls up to 6 feet wide. Vendors have mesh sizes from 1/4-inch to 4 inches and four colors costing about $\$ 1.50$ a running foot. Contact agency personnel for further information and refer to Appendix 2 under Shepherd, C.E. Company, and Valentine Equipment Co. for vinyl-coated wire mesh. 


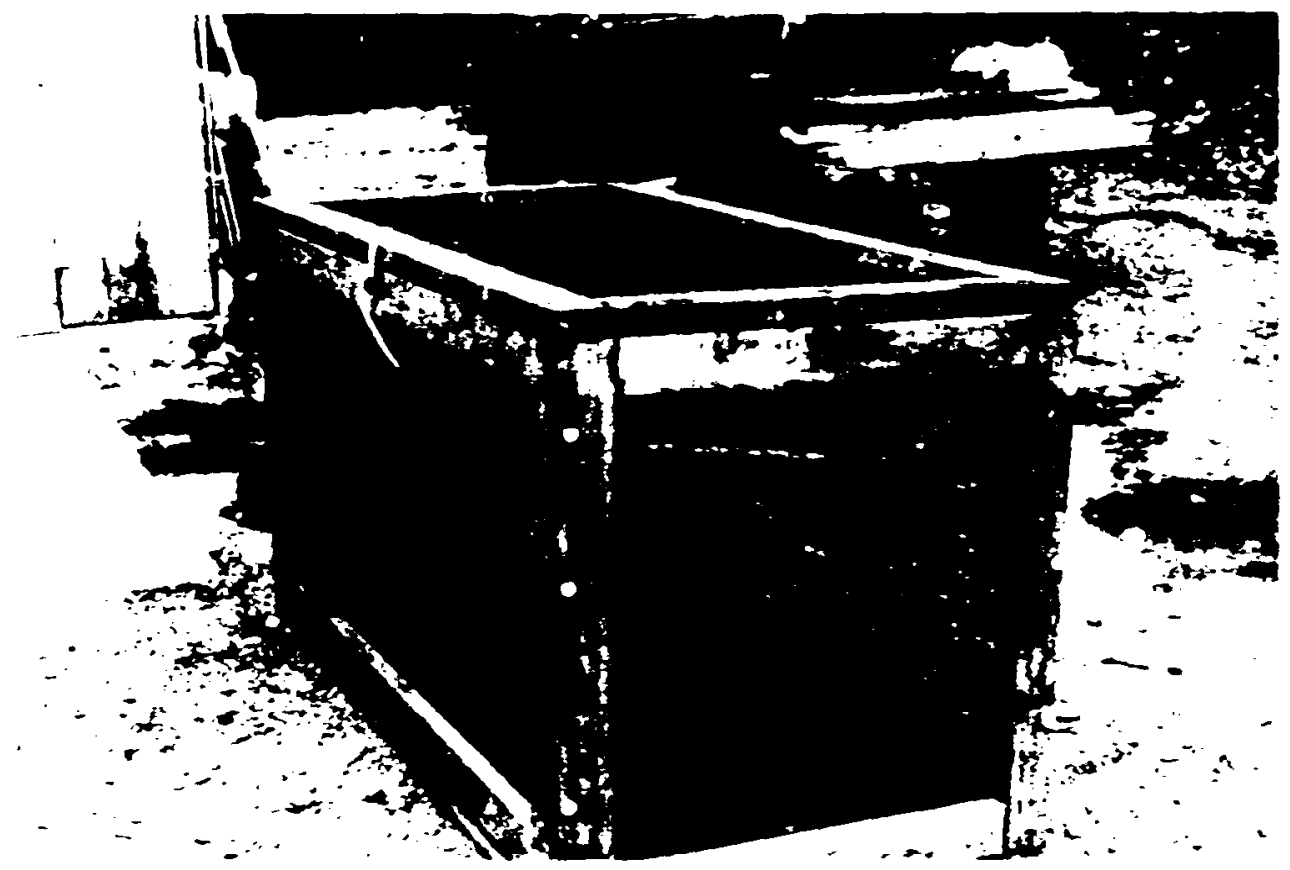

Figure 21. Adult live box constructed of wood and vinyl-coated wire mesh.

3. Traps and Juvenile Rearing Ponds If the number of adults to be held is small, partitions can be placed in existing traps, rearing units, or adult ponds. When using a trap, for example, a small, sectioned-off area allows selected fish to be held while others are passed upstream. The selected fish can be spawned on site or transported as appropriate. The WDF Simpson Salmon Hatchery uses this method on coho, and the WDG uses it at their South Tacoma Steelhead Hatchery.

Managers sometimes hold adult steelhead or salmon in a pond containing juvenile fish, which are retained below normal pond carrying capacities during the fall and winter months. Given this situation and a raceway $10 \times 100 \times 4$ feet deep, the lower 10 feet can be sectioned to provide $400 \mathrm{ft} 3$ of holding space. Fish have been held in these situations for several months.

4. Compartment Holding Techniques The Canada Department of Fisheries and Oceans uses two methods to hold individual steelhead to maintain genetic integrity. One is called condominium holding, (Fig. 22) and the other, tube holding (Fig. 23).

The condominiums are aluminum modules, each with a separate water supply to prevent the spread of disease.

The method of holding fish in tubes appears most applicable for low-cost facilities. Inexpensive PVC, ABS plastic, or acrylic pipe is used. The length and diameter of the tube should only be several inches greater than the dimensions of the fish. 
Adult Collection, Holding, and Spawning

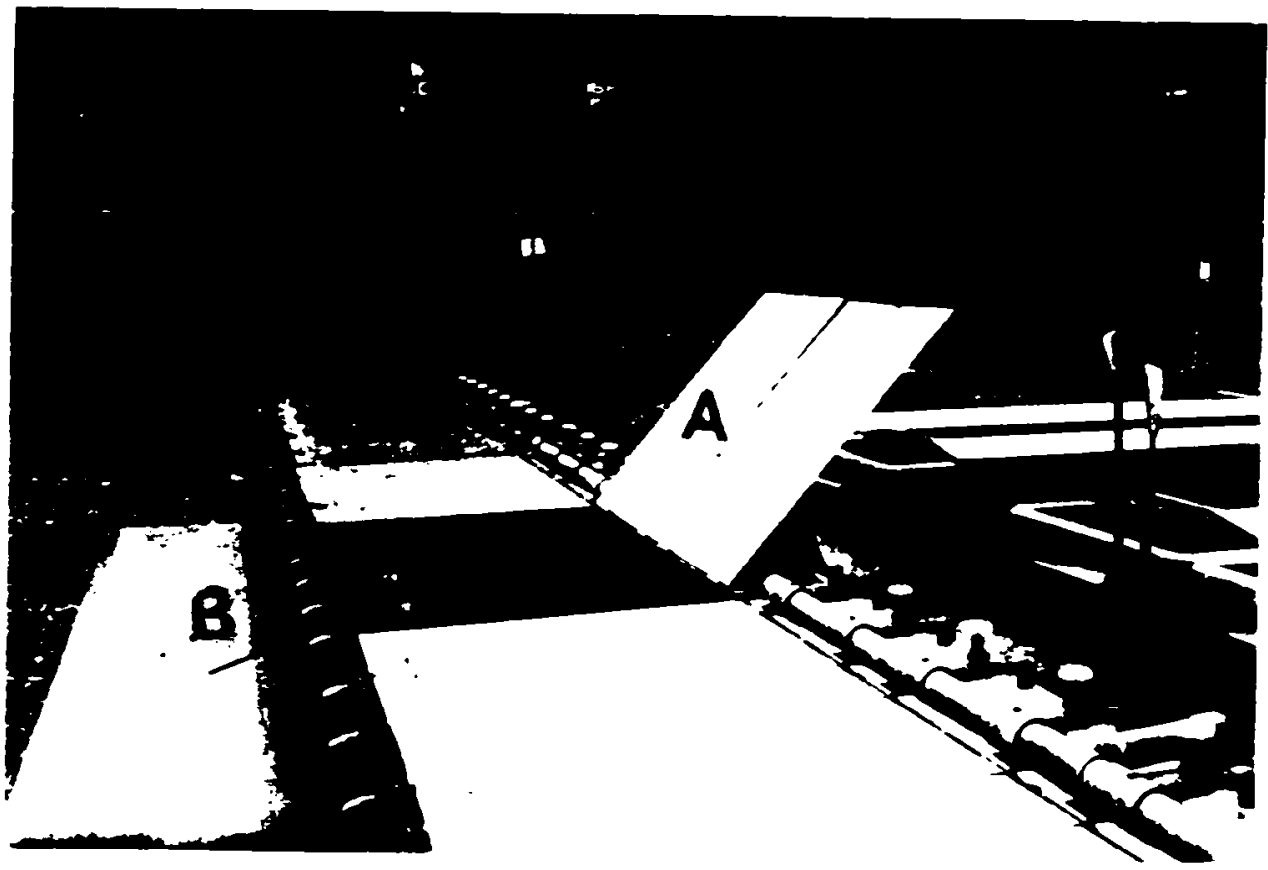

Figure 22. Condominium unit for adult holding: (A) cover to several condo units, (B) single condo.

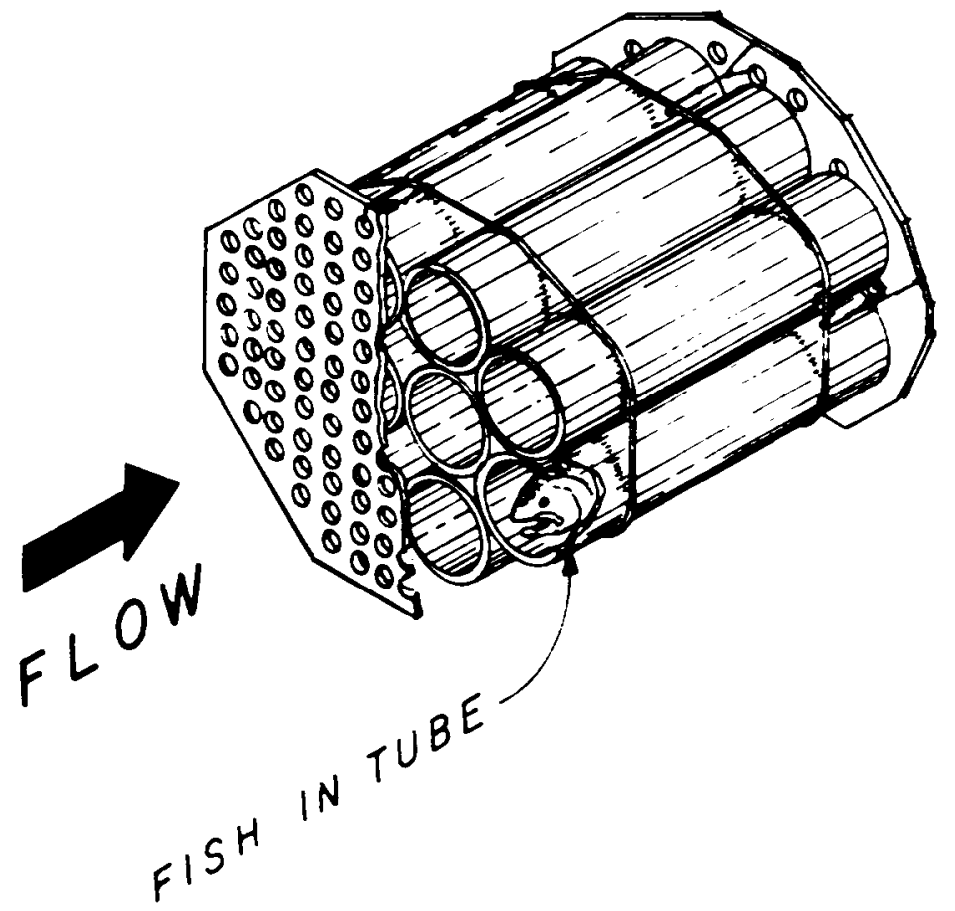

Figure 23. Tube holding apparatus. 


\section{Chapter 3}

Individual tubes are banded together and a perforated wood or acrylic diffuser is placed over the inlet and outlet ends. Heavy netting can be used in place of a wood or acrylic diffuser on the downstream end, for ease of access to the fish when checking for maturation. The bundle of tubes is placed in any trough or rearing pond that has a normal water flow. This system has worked well with pilot facilities, and DFO reports that egg-takes of $100,000-200,000$ are manageable and disease has not been a problem.

We recommend this tube method for holding small numbers of adult steelhead. When placed in a standard deep trough inside the incubation building, the fish will be secure and readily available when needed. With a water flow of $30 \mathrm{gpm}$, up to 15 adults could be held in this manner in each trough.

Instead of the modular tube holding apparatus as shown in Fig. 23, DFO sometimes uses a single tube to hold individual adults, Fig. 17, Chapter 6, which is similar in purpose to the tethering technique used by WDF.

5. Tethering Tethering or tying a fish to a fixed object for in-stream holding has been conducted during the gaffing operations in the Elwha River, Washington, for over a half century. A strong cord is passed through the gill arch and tied to the lower jaw of the fish. The cord is then attached to a fixed object such as a springy tree limb, or when this is not available, strong rubber tubing is placed in-line. For chinook salmon, tuna snubbers work well.

This system is especially advantageous in conjunction with the hook and line capture system used on steelhead, because the fish can be temporarily retained for later transportation. It is also used for both salmon and steelhead where quick recapture of a particular fish is necessary during the spawning process.

\section{PART III. SPAWNING}

The physical process of artificially spawning salmon and steelhead has changed little since hatchery systems began to evolve a hundred years ago. The facilities for performing the task, however, have become sophisticated, particularly in those situations where large numbers of adults must be handled in a given day. Tools and methods have improved as fish culturists have sought to improve efficiency. Finally, new techniques are being utilized which will accelerate or delay the maturation process, and hence may have a direct bearing on improving the efficiency of hatchery operations. These are discussed in this section as they apply to low-cost systems.

\section{A. FACILITIES}

The facilities required for spawning fish depend on the complexity of the program and the number of fish being handled. Where large numbers of fish must be congregated and separated by degree of maturity, elaborate systems with anesthetic tanks, conveyor belts, automatic crowders, holding ponds, and killing devices have been devised. While costly, they were developed as time and laborsaving techniques but they are not necessary for 
low-cost operations. We anticipate that a low-cost operation will handle fewer than one thousand fish per year, and that simple techniques are available to congregate, sort, and spawn the fish. Salmon and steelhead can be collected from in-stream traps and racks, and spawned directly on the site. Fish held between racks or in ponds can be congregated with seines, sorted, and the green fish returned to the pond. This necessitates sorting fish several times as they do not all reach sexual maturity at the same time, but if only a few fish are involved, it is a simple task. If larger numbers of fish are involved, then the technique illustrated in Fig. 24 is an efficient and relatively inexpensive spawning facility. Here, adults enter a pond from the river through a fishway and are held until maturity. Then the pond is sectioned with pickets to create several holding areas, where immature females and males can be held for later sorting and spawning. This technique requires less handling of the fish and therefore reduces egg losses. As the fish mature, they are congregated in a channel between the sections and crowded toward a spawning area. Here the fish are sorted and spawned or the excess fish returned to the river through a tube. The spawning area consists of a concrete slab with a shed roof to protect both the workers and buckets of gametes artificially spawned. This site also provides containers to hold the spawned fish, and is easily cleaned. Frequently, concrete bins are used to hold the carcasses, but simple plastic totes are suitable for most operations.

The facilities described above are relatively inexpensive, yet even these are sometimes unneccessary for small operations. Many examples of successful programs exist where fish are spawned directly from traps, or on gravel beaches. Generally, however, consideration is given to protecting the gametes from rain and freezing conditions. A low-cost facility to protect from these elements is illustrated in Fig. 25.

Because most salmon spawning is completed between late August and mid-November, freezing is more likely during steelhead spawning. The Japanese address freezing conditions by transporting freshly killed salmon from the holding area to buildings used for other purposes, such as the room where eggs are processed. Small portable buildings, or old truck vans (Fig. 26), would be examples of other low-cost working areas if required. Because the numbers of spawning steelhead would likely be less than 500, these procedures and buildings seem applicable.

If the facilities are located in areas where heavy rains prevail, the area where the spawning takes place should be protected, as mentioned earlier. A small shelter with an 8- x 12-foot concrete slab and frame type roof would suffice. The cost of any of these units would be less than $\$ 1,000$. A spawning shed as illustrated in Fig. 24 would cost $\$ 1,800$.

\section{B. MATURATION CONTROL}

The time span of fish spawning can be accelerated or prolonged. This is done by controlling the amount of light, or by injecting hormones to induce spawning. Simulating longer days accelerates ovulation in steelhead trout and prolongs it in salmon. The reverse is true if shorter days are simulated (Piper et $\mathbf{a l .}$, 1982).

Hormone injections, if given approximately one month prior to the normal spawning time, will accelerate ovulation by several weeks (Fitzpatrick et al, 1983). 


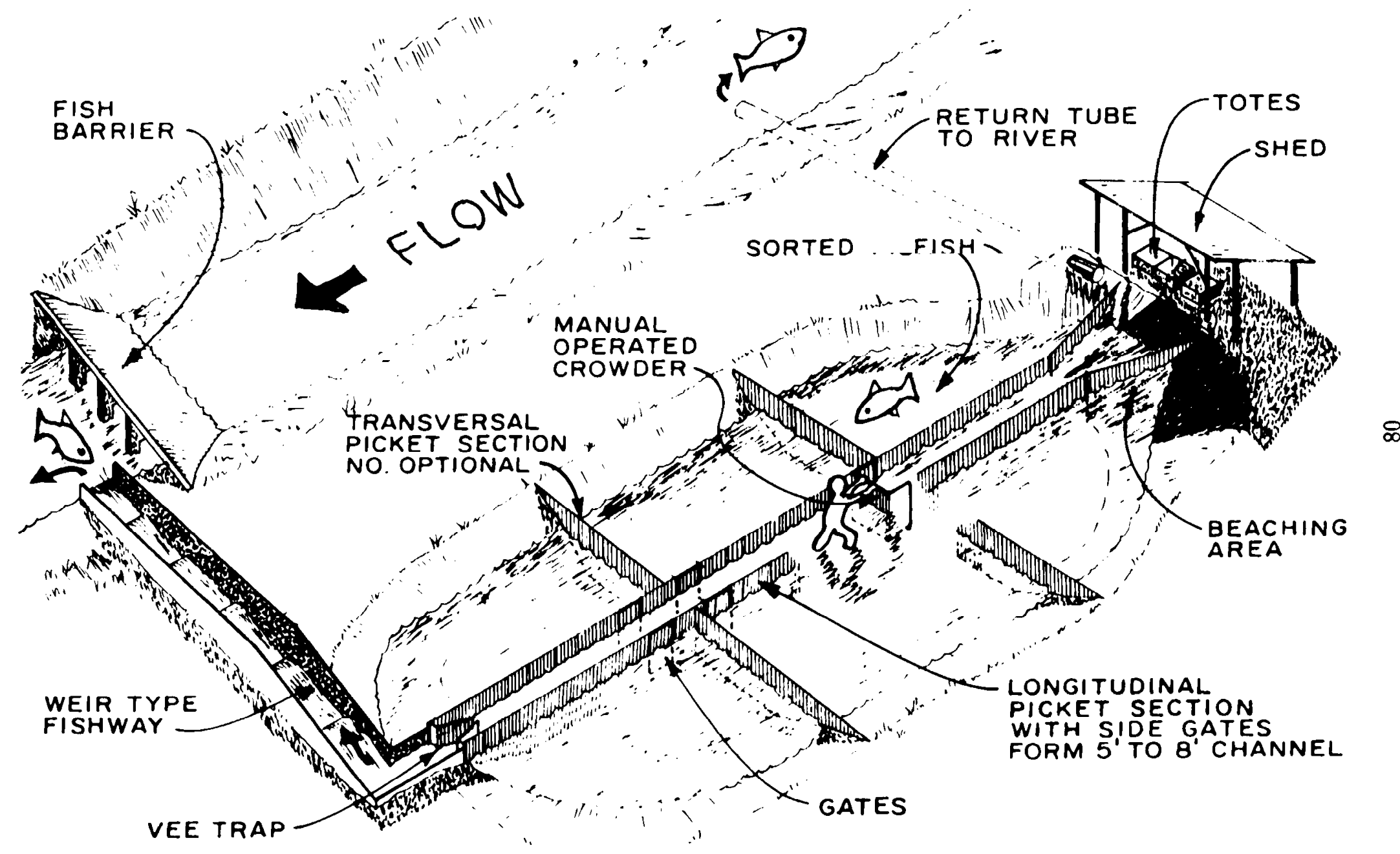

m

峞 Figure 24. Sketch of a relatively low-cost adult holding and spawning facility.

总 


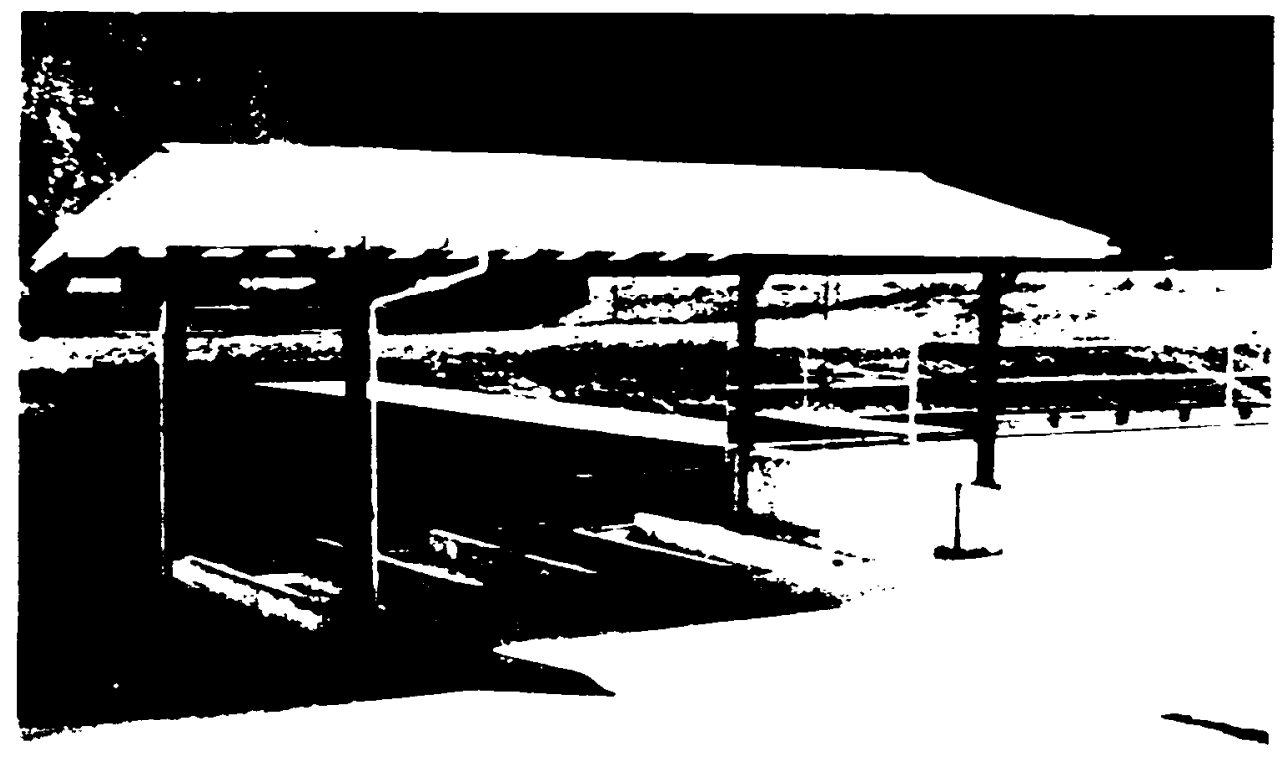

Figure 25. A relatively low-cost spawning area at the George Adams Salmon Hatchery (WDF). For lower cost operation, we recommend plywood or plastic totes for fish storage.

Some of the advantages of accelerated ovulation are:

Shorter holding period will result in lower pond mortality

Less time for security is required

The holding pond will be available sooner for the rearing program

Controlled induced spawning results in more fish spawned at a given time, and provides easier programming at the hatchery

The WDG has successfully demonstrated the value of both light control and hormone injection with their steelhead program at the Wells Trout Hatchery (Zook, personal communication). DFO personnel are most knowledgeable on hormone injection to induce spawning.

Few advantages have been determined for prolonging the spawning time. One that might be considered with salmon, is that if they must be held in high water temperatures, a delay to a later period when holding waters are cooler may enhance egg quality. This concept is presently being tested on chinook salmon in Australia (Johnson, 1983).

\section{SPAWNING METHODS}

Fish are spawned by hand stripping, incision, or air injection. Salmon females are generally always incised and the sperm is taken by hand stripping. Steelhead males and 


\section{Chapter 3}

females may not be killed before spawning, thus they are either hand stripped or sometimes, in the case of the females, the eggs are removed by injecting air just posterior to the pericardial cavity. Two to four psi of air pressure are used, forcing the eggs downward and out the vent. It is used only on steelhead, and is said by some to be superior to hand stripping, because the fish remain in better condition.

For more detailed information on spawning procedures, we recommend visitations to hatcheries or a review of the publications by Leitritz et al., (1976) and Piper et al., (1982).

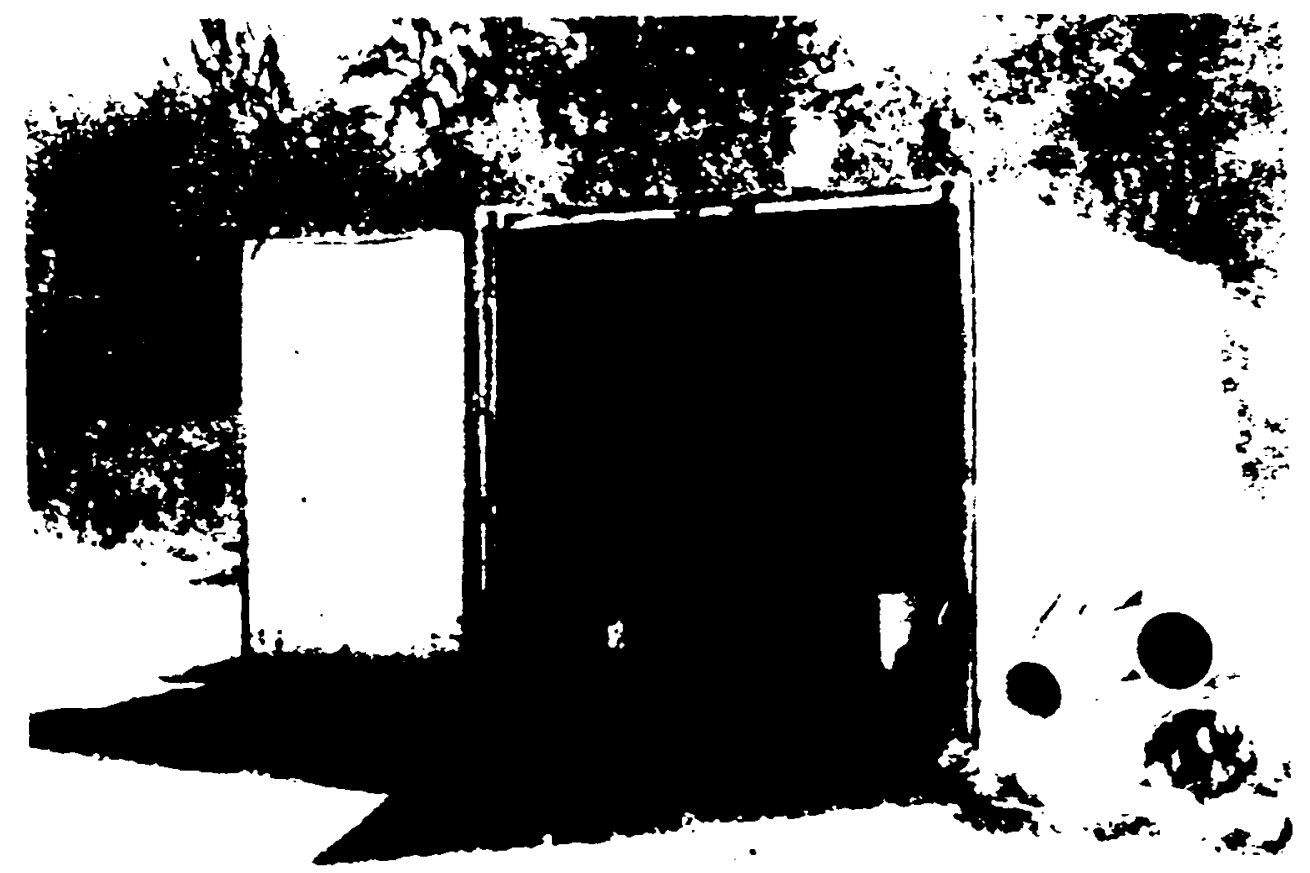

Figure 26. Truck van used as storage and work area at the Squaxin Tribal Hatchery on Elsey Creek.

\section{ANESTHETICS}

Anesthetics are used to relax fish at the time of spawning to make handling easier and reduce damage to the fish and their eggs. Few hatchery programs in the Columbia Basin use anesthetics, and we do not recommend the general use of it at low-cost facilities.

Numerous chemicals can be used, the more common being tricaine methane sulfonate (his 222) in a concentration of 1 gram to 7-10 gallons of water. All anesthetics should be tested to obtain the reaction of the fish before use. The sale or immediate release of fish after being anesthetized with chemicals is usually prohibited.

Carbon dioxide $\left(\mathrm{CO}_{2}\right)$ has been used at the WDF Cowlitz Salmon Hatchery as an anesthetic. The use of $\mathrm{CO} 2$ does not prohibit the sale or immediate release of live fish. It is more economical than MS 222 but is reported to be less desirable, as the fish, when handled, have an immediate quivering reaction. 
Adult Collection, Holding, and Spawning

\section{TOOLS USED IN SPAWNING}

The tools commonly used for the incision spawning process are; a woolen glove, a fish club (Fig. 27), a bleeding rack (Fig. 28), a spawning vessel (Fig. 29), a spawning knife (Fig. 30), and several carcass storage bins (Fig. 31). A clean water supply from a pump or supply system is desirable.

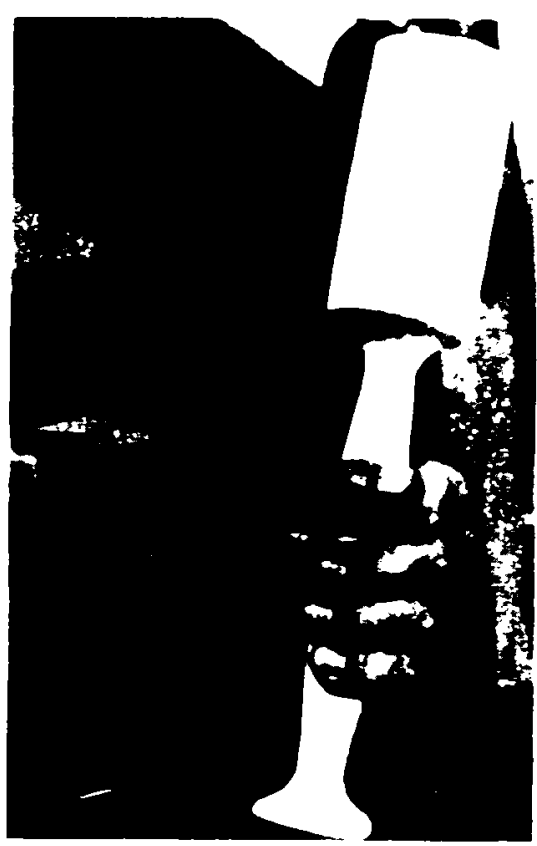

Figure 27. A typical fish club.

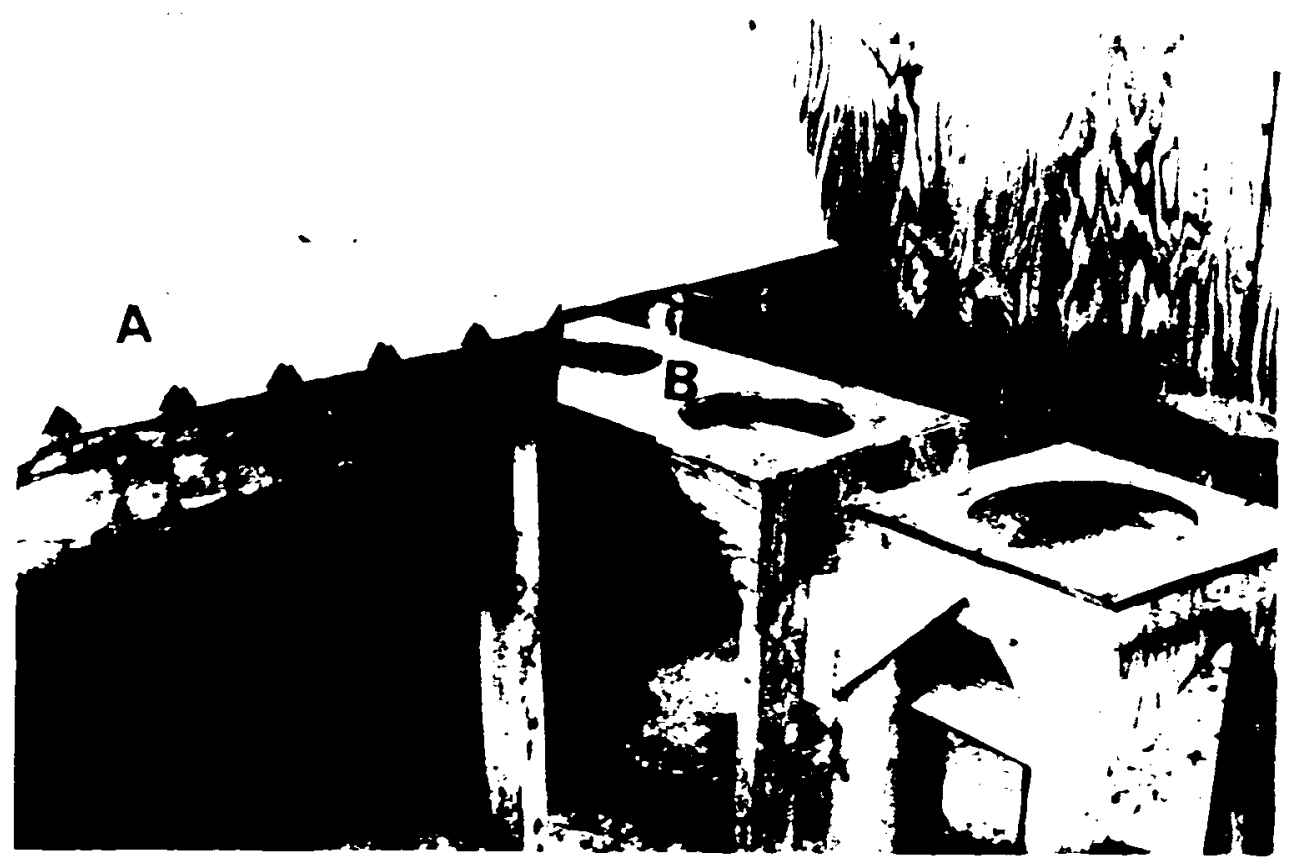

Figure 28. Spawn-taking equipment: (A) bleeding rack, (B) stand for holding spawning pan. 



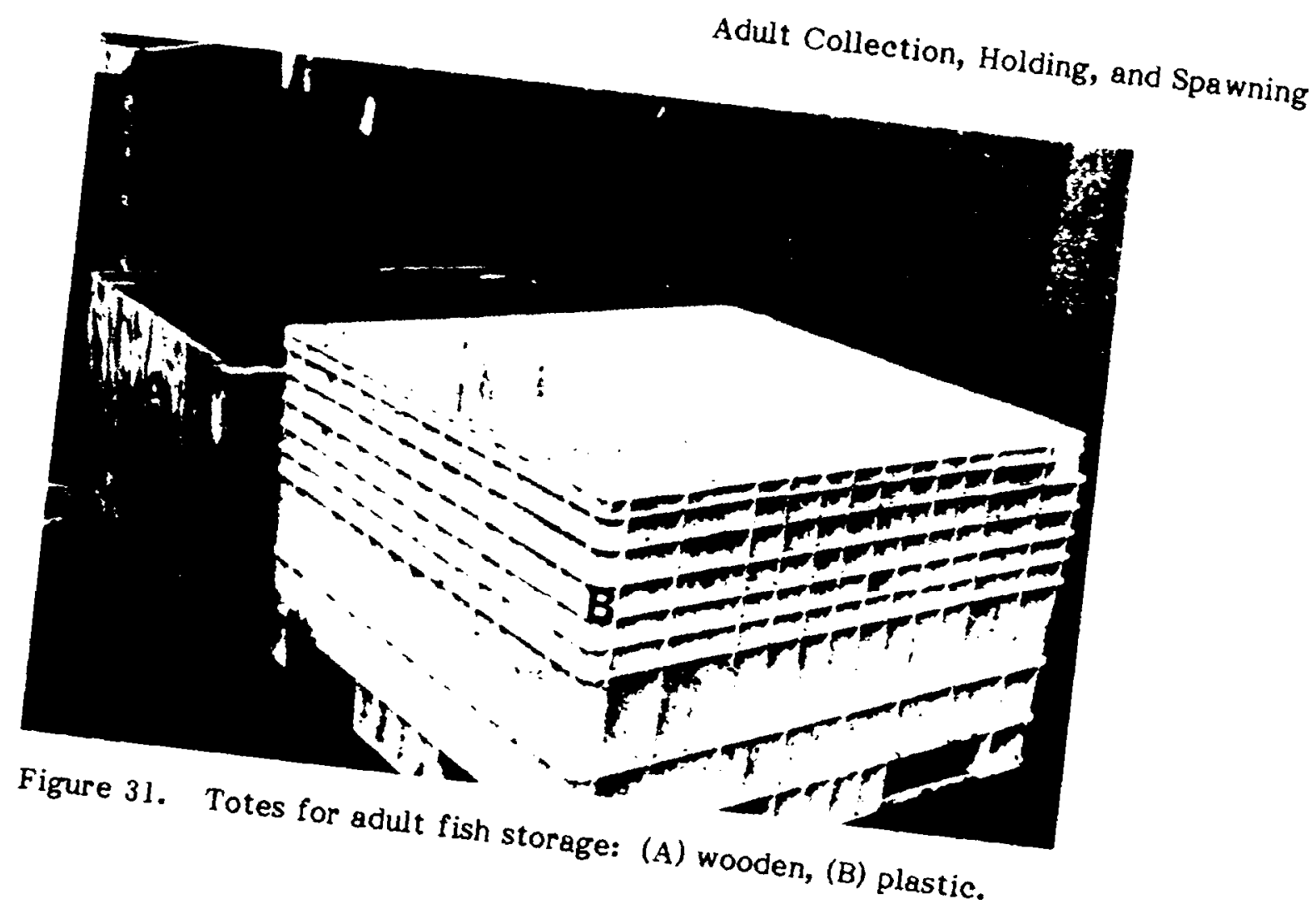




\title{
CHAPTER 4
}

\author{
INCUBATION
}

Numerous methods are available for incubating salmon and steelhead eggs, ranging from a simple bucket technique to the more sophisticated vertical incubators which require Buildings and extensive plumbing systems. Some methods are only used to eye eggs, others to only hatch eggs, while still others are used for both. 'The various methods have evolved as fish culturists sought to reduce labor costs and increase survival rates and improve fry quality. We have chosen to illustrate all the popular methods, including the more expensive techniques, because the ultimate choice in selecting a method depends on local conditions, program goals, cost, and to a large extent, on individual preference. Egg and alevin incusation can be a simple process where significant savings in capital and operations costs can be achieved witiout affecting the quality of the product. Numerous "low cost" techniques are available to incubate large numbers of eggs and alevins. A briei description of egg incubation biological requirements follows to facilitate the understanding of the incubation process and the methods described in this chapter. The material presented is general; greater detail can be obtained from salmon and trout fish cultural manuals.

\section{PART I. BIOLOGICAL REQUIREMENTS OF EGG INCUBATION}

Salmon and steelhead trout eggs become fertilized when the eggs and sperm are mixed together and water is added to insure even distribution of the sperm. The sperm penetrates the egg through a small opening in the shell called the micropyle. Viater is also assorbed through the micropyle and the porous outer shell. The water absorption process takes approximately 30 minutes and adds approximately 12 percent to the weight of the eggs. The fertilized eggs become increasingly fragile during the first 48 hours, and until the pigmented eyes of the embryo can be seen through the egg shell, they are easy to damage oy even a slight jar. When the eyes become visible, the development is called the "eyed egg stage", and healthy eggs are very resistant to mechanical damage and may be handled and shipped if desired. During this stage, but prior to hatching, the eggs are deliberately "shocked" so the dead and infertile eggs can be identified and removed. Eggs should never be exposed to direct sunlight and alevins do best when incubated in the dark.

The rate of egg and alevin development and fry quality is a function of water temperature, and the time required to reach various developmental stages is expressed in temperature units (TU). A TU is defined as one degree of temperature above freezing for 24 hours. Accordingly, at a 50F water temperature, $18 \mathrm{TU}$ are accumulated in one day. The TU requirements or developmental rate from egg fertilization to hatching and from hatching to yolk absorption at $50 \mathrm{~F}$ varies by species (Tade 1). 
Incubation

Table 1. Temperature unit requirements for salmon and steelhead trout eggs and alevins at 50F.(1)

\begin{tabular}{|c|c|c|}
\hline Species $(2)$ & To hatch & To first feeding \\
\hline Chinook & 900 & 1665 \\
\hline Coho & 850 & 1375 \\
\hline Sockeye & 1260 & 1900 \\
\hline Chum & 900 & 1550 \\
\hline Pink & 1370 & 2150 \\
\hline Steelhead & 570 & 975 \\
\hline
\end{tabular}

(1) Source: Combs and Burrows, 1957, University of Washington School of Fisheries, and State of Washington Departments of Game and Fisheries.

(2) Racial differences, if any, are judged to have no impact on program management.

Chinook coho and chum eggs require about $900 \mathrm{TU}$ from fertilization to hatching. The rule of thumb is 50 days at 50 degrees and the temperature units are derived as follows: $50 \mathrm{~F}-32 \mathrm{~F}=18$ units per day $\mathrm{x} 50$ days $=900 \mathrm{TU}$. Chinook at the same temperature require another $800 \mathrm{TU}$ from hatching to egg absorption, while coho require only $500 \mathrm{TU}$. Sockeye require $1260 \mathrm{TU}$ to hatch and another $640 \mathrm{TU}$ to feed, for a total of $1900 \mathrm{TU}$.

The requirements for steelhead are less than for salmon. At 50F, only 570 TU are required from fertilization to hatching and $405 \mathrm{TU}$ from hatching to egg absorption.

Although each species has a different TU requirement prior to complete yolk absorption, this requirement is not constant. Salmon take less TUs as the water temperature is decreased, while steelhead take proportionally more. The preferred incubation temperature for salmon and steelhead is from 45-55F. Temperatures above 56F may cause mortalities or affect the quality of surviving fry. High temperatures during early incubation are injurious. (Gearheard [WDG] and Parrish [IFG] personal communications.)

Often managers need to know the time required to reach the eyed stage when the eggs can be safely handled. Generally this takes about $1 / 2$ the TU necessary to reach hatching. Temperature also has a tremendous influence on egg and alevin incubation densities. While we found no documented data available, it is believed that for each degree below 50F the numbers can be increased by two to four percent. As the temperature increases above 50F, the carrying capacity of the system would decrease accordingly.

The volume of water required to incubate eggs is small compared to other life stages because the oxygen demand and waste products given off by the eggs are minimal. At 50F, $10 \mathrm{gpm}$ is sufficient to incubate one million salmon eggs (Table 2). It is common to use $50 \mathrm{gpm}$ for one million salmon alevins. Because steelhead eggs and alevins are approximately $2 / 3$ the size of salmon, 25 percent more steelhead are normally incubated in a given water supply or unit. 
Table 2. Number of salmon and steelhead trout eggs and alevins that can be incubated under ideal conditions using $10 \mathrm{gpm}$ of water at 50F. Data based on present usage at 80 sites visited.

Species
Chinook
Other Salmon
Steelhead

\begin{tabular}{lr} 
Eggs & Numbers \\
\hline & Alevins \\
$1,000,000$ & 150,000 \\
$1,200,000$ & 180,000 \\
$1,300,000$ & 200,000
\end{tabular}

The rate at which water moves through the incubator is also very critical for eggs and alevins. if it is too great and the eggs are disturbed, they can be killed. Excessive velocity will also erode the yolk sac on alevins, likely resulting in lesser quality fry. It also causes them to utilize yolk material for energy rather than growth. For alevins, as a general rule, the water velocity should not exceed $5 \mathrm{gpm} / \mathrm{ft}^{2}$ of incubating surface; and for eggs, velocity levels can be variable but must stay below the point where the eggs are disturped by rolling. Table 3 expresses these general levels Equally as important as the quantity and velocity of water are the design and operational procedures of all units which must achieve a uniform distribution of water flow past the eggs and alevins. Often, air bubbles, including supersaturated gases, entering with the water supply are trapped on screens or plates, grow in size and distort water-flow patterns. This causes losses by smothering.

The foregoing material on the incubation process demonstrates that both the egg and alevin incubation stages must be considered when selecting an incubation method. Far more eggs than alevins can be incubated in a given area and water supply, and the number can vary according to species and water quality. Further details on egg and alevin capacities of individual incubators and information on tools and equipment follow.

\section{PART II. INCUBATION UNITS}

Seven general egg incubation methods were chosen to separate, identify and describe the various incubation units involved. They include vertical incubators, trough incubators, pond incubators, box incubators, cylindrical incubators, channels for spawning and egg incubation, and instream planting. Egg and alevin capacities and water flow requirement by type and size of incubation unit are shown in Table 3.

\section{A. VERTICAL INCUBATORS}

Only two types of vertical incubators are available. They are the vertical cabinet and the NOPAD. Both are expensive to install and logically would not be classified as a low-cost method as compared to other available units. However, they do have certain advantages that merit their being considered for a low-cost facility, if only on a small scale.

1. Vertical-Cabinet Incubator This incubator consists of a cabinet designed to hold eight to ten trays in which the eggs and alevins are incubated. One cabinet 
stacked upon another is often preferred, giving a multiple-tray unit. This may require the use of a secondary water induction system that can be installed in the lower cabinet. In this case the draining of water from the top section is accomplished with a catch tray. Fig. 1 shows a series of two-high eight-tray cabinets, while Fig. 2 is a close-up photo of a single tray and the component parts.

Table 3. Salmonid incubation capacities and water flow requirements in gpm by type of incubator unit.

Type of incubator

Vertical

Cabinet (8-tray)

NOPAD (single tray)

Trough

Deep (10 compartments)

Pond

Shallow (7 compartments)

Box

Single tray(30X48 inches)

Deepmatrix 4 X8X4 feet $(3)$

2X8X1.25 feet

Shallow-matrix (Netarts) $4 \times 8 \times 1.3$ feet

Montana

Cylinder

Freestyle (single)

Modified jar

Gallon jug

5-gallon bucket

55-gallon drum

R-48 barrel
$\operatorname{Eggs}(1)$

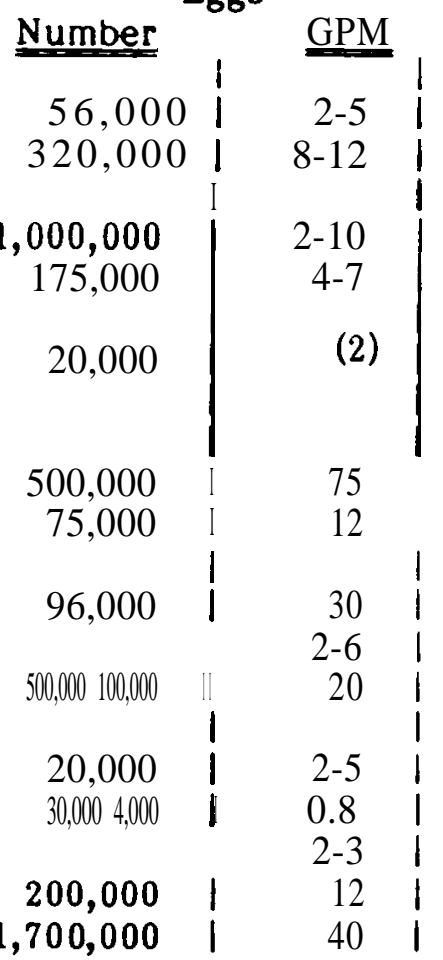

Alevins

\begin{tabular}{|c|c|}
\hline Number & GPU \\
\hline 40,000 & $2-5$ \\
\hline 160,000 & 12 \\
\hline 250,000 & $7-10$ \\
\hline 20,000 & $2-7$ \\
\hline same & same \\
\hline & 1 \\
\hline same & I same \\
\hline same & I same \\
\hline same & I s a me \\
\hline 75,000 & $3-b$ \\
\hline 150,000 & 20 \\
\hline same & $\mathrm{s} \mathrm{am} \mathrm{e}$ \\
\hline 2,000 & | $\quad 0.8$ \\
\hline 15,000 & $2-3$ \\
\hline 80,000 & 10 \\
\hline 725,000 & 40 \\
\hline
\end{tabular}

(1) The numbers are based on an average egg size of 1400 per pound and water temperature of $50 \mathrm{~F}$.

(2) No less than $8 \mathrm{gpm} / \mathrm{ft}^{2}$ of cross sectional area as measured by water depth $\mathrm{x}$ tray width.

(3) The measurement sequence is width $\mathrm{x}$ length $\mathrm{x}$ depth throughout this report.

Cabinet size in inches is 24.88 wide, 24.25 long, 31.5 high. The unit within the tray containing the eggs has an inside dimension of $13 \times 16 \times 2$ inches.

Loading levels vary by species. Common alevin levels per tray for complete incubation are: 7,000 coho, 5,000 chinook, and 8,000 steelhead. For eyed eggs, this capacity can be slightly greater. To improve fry quality, many WDF stations are now using folded heavy plastic netting within the trays as a standard procedure. 


\section{Chapter 4}

Also, it is common for managers to cover the cabinets with black plastic to prevent startling the alevins with external light sources.

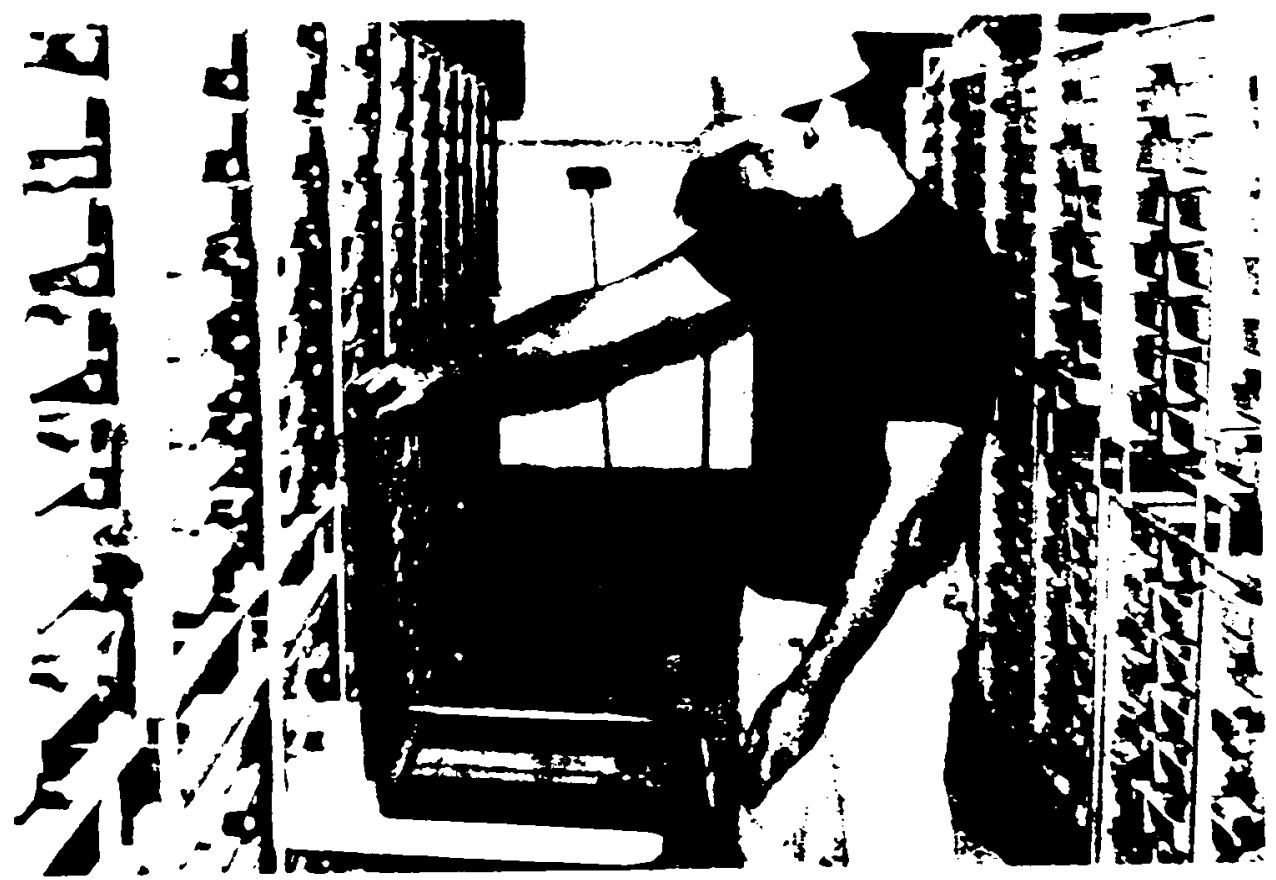

Figure 1. Vertical-cabinet incubators, 16 trays high

The amount of water necessary to incubate eggs and alevins in an eight-tray unit is generally 2-5 gpm depending on the developmental stage and water quality. As the water flows from one tray to another it upwells through the eggs.

\section{Advantages:}

Some aeration occurs between trays

A clean out is provided below each tray for removing silt

Small egg lots can be handled and kept separate

- The trays easily pull out for inspection of the eggs and alevins

- The maintenance cost is relatively low

- Fry quality is good for all species when substrate is used

- The water flow in the trays can be modified to isolate egg lots

\section{Disadvantages:}

- A building is generally used

- Handling small lots is time- consuming

- The floor space requirement is high for eyeing eggs because of the small tray size

- Wide aisles are required in order to pull the trays from the cabinets

- The plumbing system is complicated and expensive 
- Initial unit cost per egg is high

0 A separate trough is required for shocking eggs and removing mortalities

\section{Cost:}

An eight-tray cabinet costs approximately $\$ 700$. The life expectancy of the cabinets is 25 years plus, but the screens may require replacement every 15 years.

\section{Infor mation Sources:}

Fisheries agency and tribal biologists and hatchery managers

Heath Tecna Corporation

Tricor Plastics

FAL Productions, Inc.

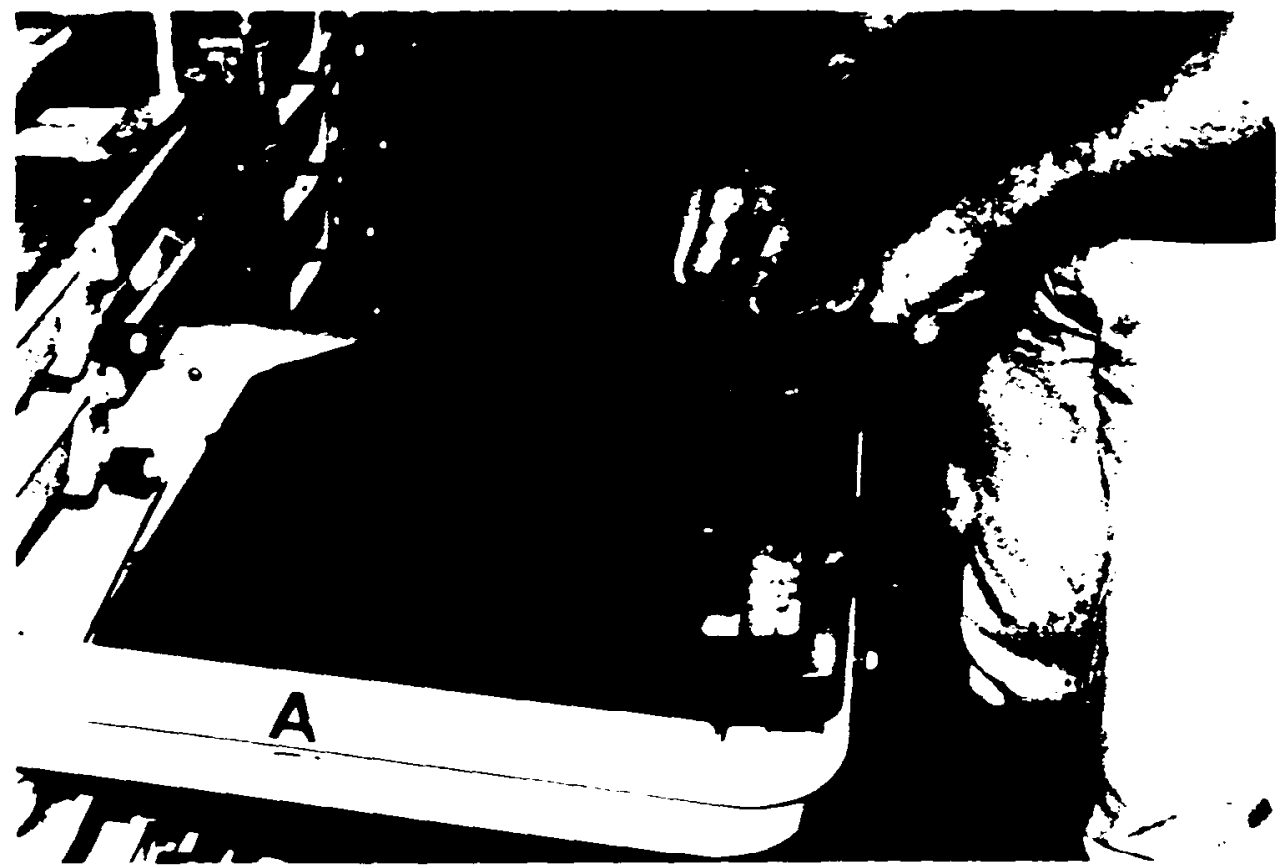

Figure 2. Vertical-cabinet tray (A), with inner tray (B).

2. NOPAD Incubator The NOPAD or Zenger incubator is manufactured from aluminum and designed to permit the stacking of individual units up to five high. A single unit is $4 \times 4 \times 1$ (Fig. 3 ).

When stacked, there is about 12 inches between each unit. Water upwells into the incubator after passing through a perforated plate, substrate and eggs, and finally a pressure plate which prevents the eggs from rolling. The plastic substrate is placed 4-inches deep on the perforated plate and the eggs are poured over the substrate. Plastic saddles or bio-rings are common substrates. 


\section{Chapter 4}

'Twice as many eggs can be incubated to the "eyed' stage in these units than can be carried through the complete hatching process. For the latter 160,000 chinook, coho or steelhead can be incubated in each unit. The water requirement at this loading density is 12 gpm per unit.

Advantages:

- Can be stacked in modules to conserve floor space

- Maintenance costs are low

- Less labor required compared to the cabinet incubator because the larger trays provide greater capacity

- Require less time to clean than a tray-type incubator for a given number of eggs

- Can be operated to permit volitional migration if desired

- A clean-out system to backflush silt is provided

Disadvantages:

- Building generally required

- When the incubators are stacked, access to the lower incubators is restricted

- Egg lots of less than SO-100,000 are not practical

- The plumbing system is complicated and costly

- Almost $\mathbf{5}$ feet of aisle space is required to remove empty units

\section{Cost:}

Approximately $\$ 800$ per incubator. The life expectancy is 25 years.

\section{Information Sources:}

Douglas Island Pink and Chum, Inc, Juneau, Alaska

Medvejie Central Incubation Facility, Sitka, Alaska

Tulalip Indian Tribe, Marysville, Washington

North Pacific Aquaculture Development Company, Juneau, Alaska Alaska Department of Fish and Game

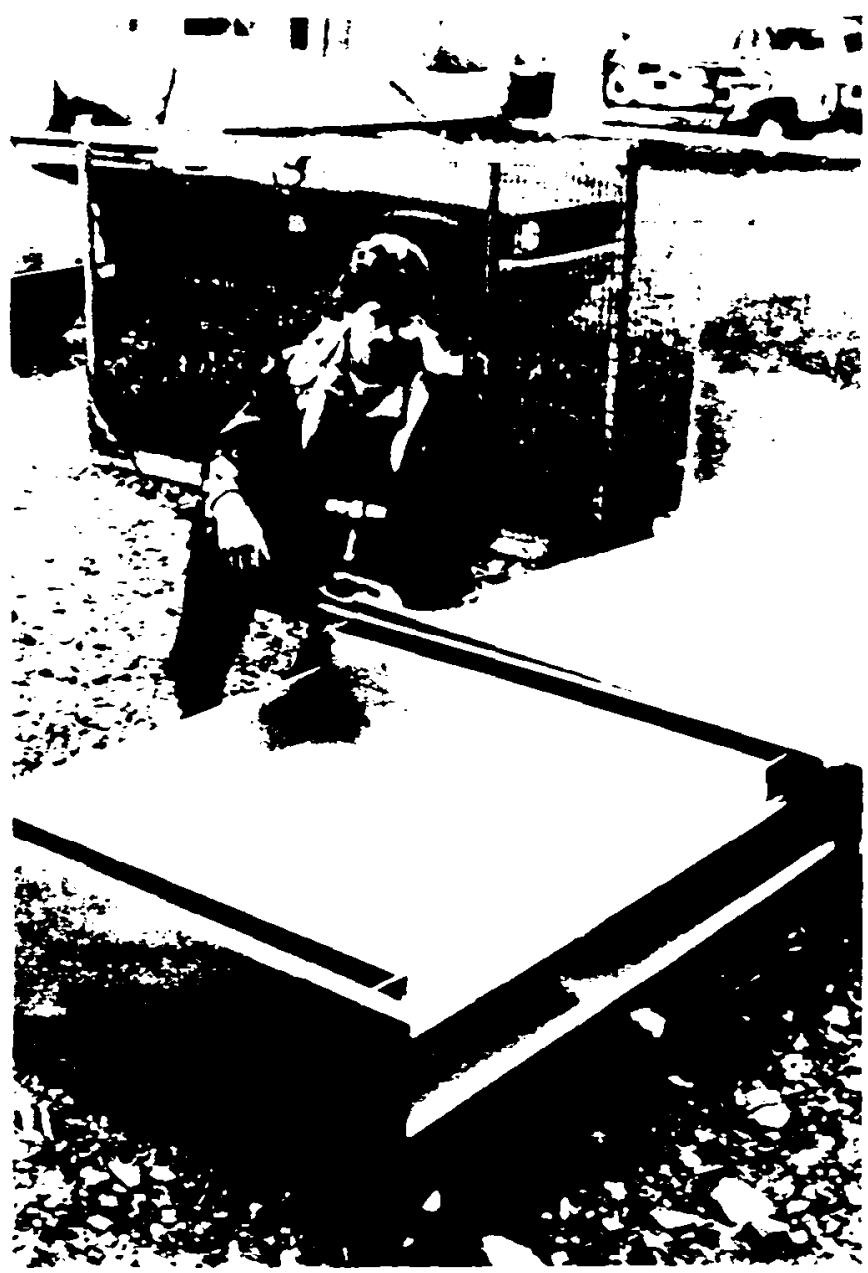

Figure 3. NOPAD aluminum incubator. 


\section{B. TROUGH INCUBATORS}

Trough incubators were one of the first egg incubation techniques used by fish culturists and are commonly used in modern fish hatcheries. The troughs have removable dividers so they can be used as rearing areas for fry. These units are usually described as "deeps" or "shallows"; those greater than 12 inches deep are called deeps. Otherwise the two troughs differ only in the way they are used.

Troughs were originally constructed of wood, but concrete was later employed, and today fiberglass and metal troughs are common. Various types and sizes of troughs are available as shelf items. There is great diversity in trough types between and within fish agencies, Indian tribes, and the private sector. The choice in most cases is usually dictated by individual preference, program goals, and cost.

1. Deep-Trough Incubator Figure 4 illustrates a deep trough that measures $1.33 \mathrm{x}$ $16 \times 1.30$ feet and contains ten compartments. This unit is excellent for egg incubation, but inefficient as an alevin incubator. They are a multiple-use unit, excellent as disinfectant and rearing tanks, and as a place to shock and sort eggs.

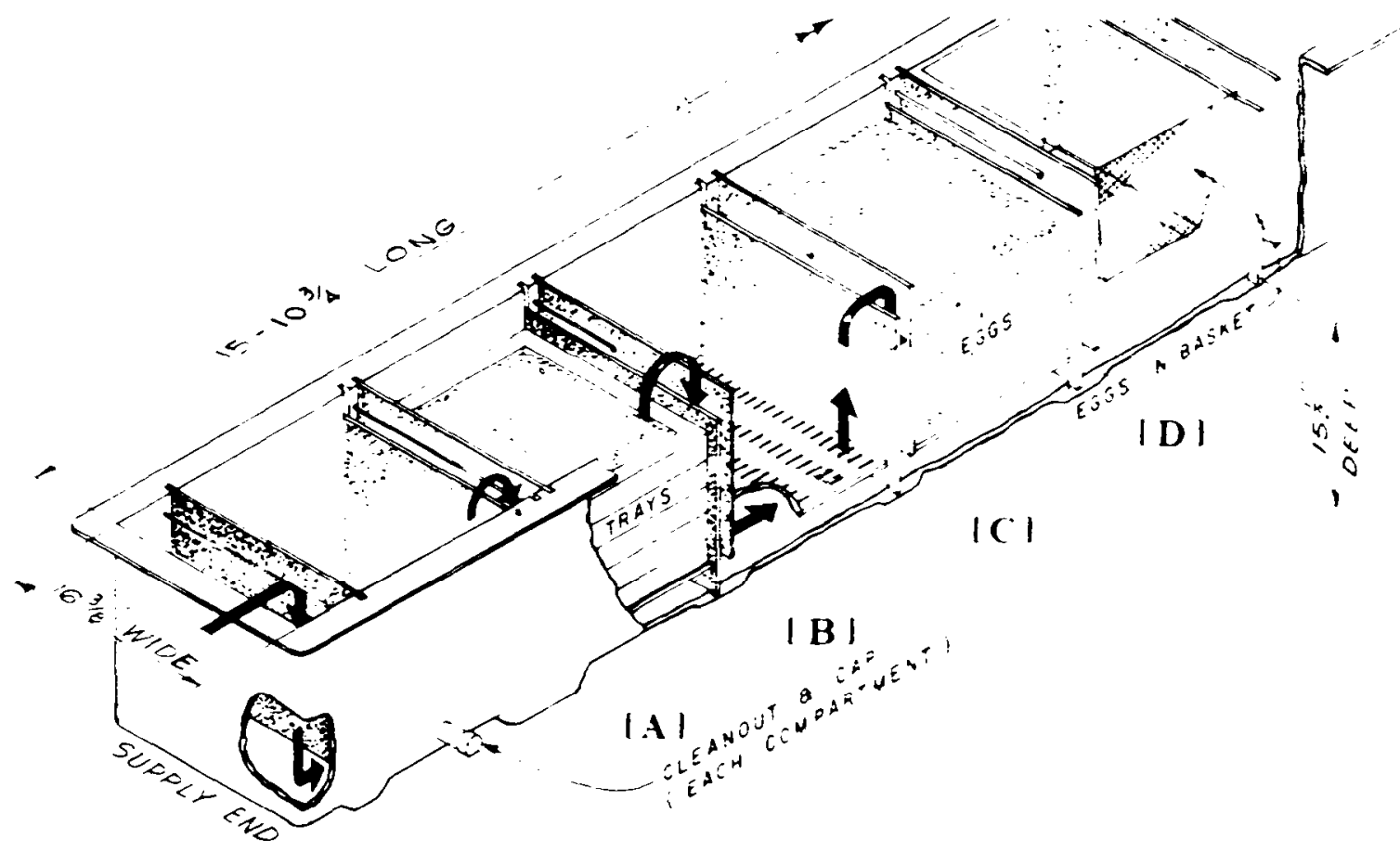

Figure 4. Deeptrough incubator illustrating: (A) trays, (B) perforated plate, (C) compartment for eggs only, (D) basket for eggs.

The water hydraulics in all troughs is similar, in that an upwelling flow is created in each compartment by the use of baffles (Fig. 4). In the unit illustrated, water entering the trough is directed by a baffle to the floor of the first compartment 


\section{Chapter 4}

where it upwells and exits the compartment over a second baffle. This flow pattern is repeated until the water leaves the trough through a drain pipe. The amount of flow depends on the area of the compartment. The unit illustrated in Fig. 4 generally requires 2-10 $\mathrm{gpm}$ for eggs and 7-10 gpm for alevins. Recent data suggests tha-t a flow in excess of $10 \mathrm{gpm}$ for alevins may be excessive and may tend to produce inferior fry.

Eggs can be incubated in the compartments by placing them directly on the perforated plate, or by placing the eggs in screen boxes or net bags and placing these in the compartments. We favor the first method because it is effective, requires less equipment and is less costly. Up to 100,000 salmon eggs can be eyed in each compartment of the unit illustrated.

To incubate alevins, eyed eggs are placed directly on trays with or without substrate. The trays are constructed with a 12-mesh screen bottom, and a heavy plastic netting is commonly used for substrate. Five trays, each containing 5,000 eggs, can be placed in a compartment. The total capacity of the unit illustrated is 250,000 salmon alevins.

\section{Advantages:}

One of the most economical methods to eye eggs

Most troughs are portable

Have several uses in a hatchery other than incubating eggs

If plumbed with bottom drains or clean-outs in each compartment, silty water can be managed

Plumbing system is less complicated and less expensive than vertical incubators

Can be stacked two high vertically to save floor space

Can be temporarily placed in dry rearing ponds and covered with temporary shelters

\section{Disadvantages:}

- Incubation densities of alevins per unit compared to floor space used are low because water flows must be reduced to maintain quality fry

0 Isolation of smaller egg lots is not practical because of plumbing cost

- Access to the alevins is more difficult than vertical cabinet incubators

- Building usually required

Cost:

The cost varies, depending on the vendor and material type. The estimated cost of the fiberglass unit illustrated in Fig. 4 is $\$ 900$, and it has a 25-year life.

\section{Infor mation Sources:}

Most hatchery managers

Sims Fiber Glass Co.

Ranger Boat Co. 
2. Shallow-Trough Incubator Shallow troughs vary in size but a common one measures $1 \times 15 \times 0.5$ feet (Fig. 5). Usually they have six or seven compartments and the eggs are incubated in specially-constructed wire baskets (Fig. 6). These are made about 1-inch smaller than the compartments.

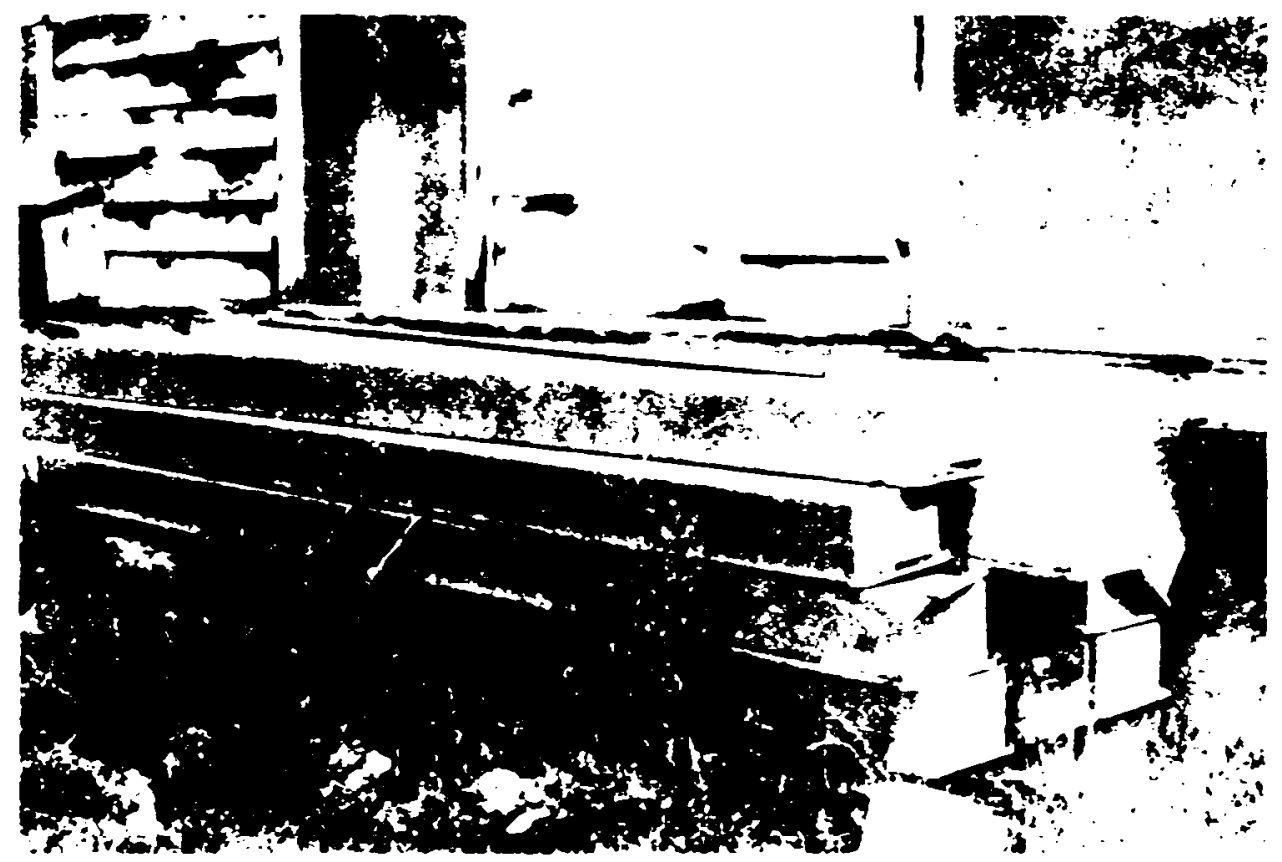

Figure 5. Aluminum shallow-trough incubators stored outside Yakima Trout Hatchery (WDG).

The eggs remain in the baskets until they hatch, after which the alevins drop through the baskets to complete the incubation process on the floor of the trough. Some agencies use trays as in deep troughs. Hydraulically, the water flow in a shallow trough is similar in principle to a deep trough. The compartments are separated by removable baffles which create an upwelling flow through the eggs. The water, however, does not pass through a perforated plate as in the deeps. Rather, the wire baskets and the eggs create the proper flow pattern within the compartment. A flow of 4-7 gpm is required during the egg stage and $7 \mathrm{gpm}$ is the maximum flow for alevins. Approximately 35,000 steelhead or 25,000 salmon eggs can be incubated in each compartment of the trough. The capacity to incubate alevins is limited to approximately 20,000 steelhead and 12,000 salmon in a trough. The troughs can be stacked as illustrated in Fig. 7 and are generally made of fiberglass. 
Chapter 4

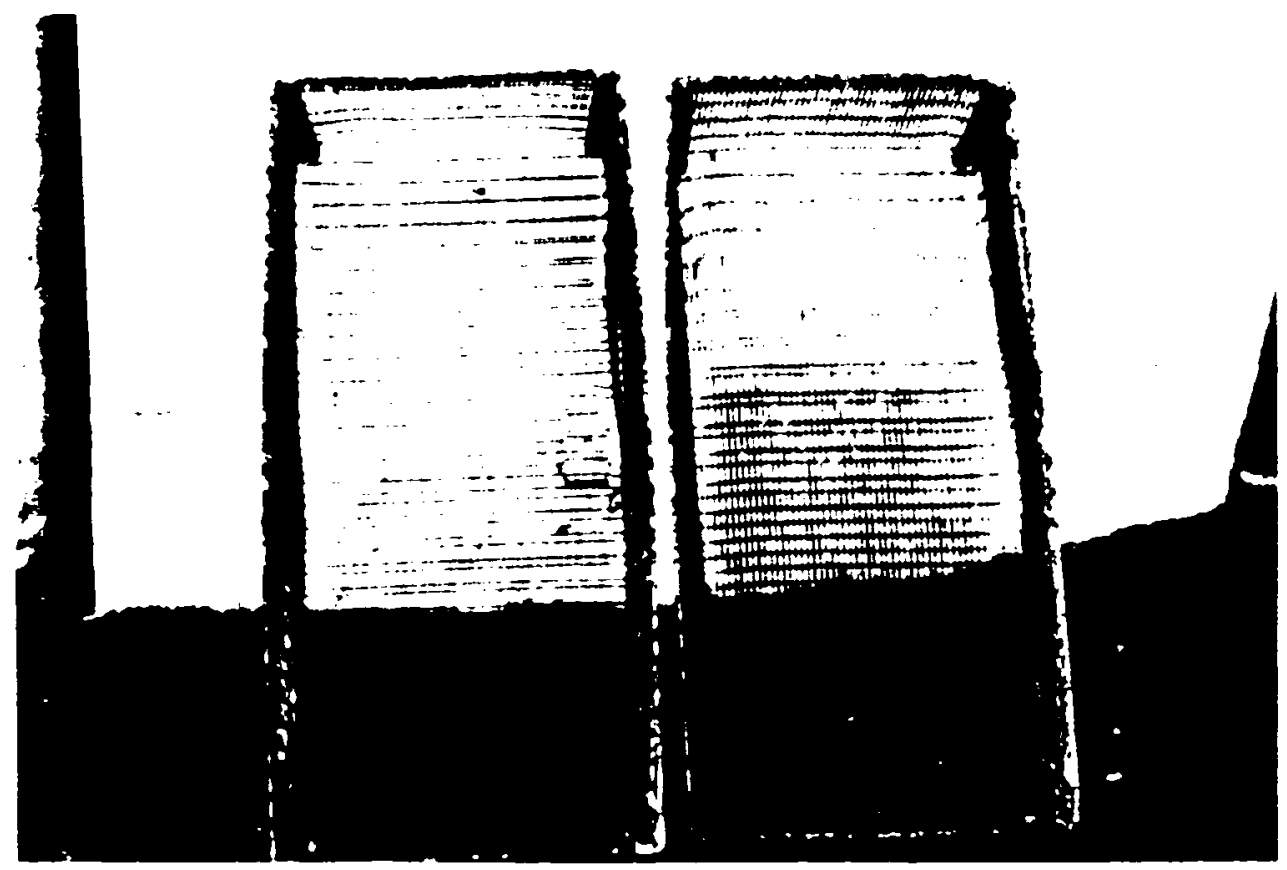

Figure 6. Wire egg baskets used in shallow-trough incubators.

\section{Advantages:}

Portable

Used for both incubation and rearing

Can be stacked

Can be positioned in rearing ponds empty of fish

The plumbing system is relatively simple and inexpensive

Easy to observe, handle, and treat eggs and alevins

Generally suitable for a small-scale operation

\section{$\underline{\text { Disadvantages: }}$}

- Not practical for a large-scale salmon production facility because of the low incubation capacity compared to the floor space required

- Only small lots can be fed in the troughs

- It is more difficult to shield the alevins from light than in the "deeps"

- The alevins tend to congregate at the upper end of each compartment and smother unless they are frequently re-distributed

- More expensive per $/ \mathrm{ft}^{3}$ of rearing area than deep troughs

- Difficult to remove heavy silt when trays are used 


\section{Cost:}

A 15-foot plastic trough costs approximately $\$ 300$. The wire baskets sell for $\$ 80$ each. Life of the trough is 25 years.

\section{Information Sources:}

Most hatchery managers

Sims Fiberglass Co.

Ranger Boat Co.

Heath Tecna Corp.

\section{POND INCUBATION}

Pond incubation is a method of incubating eggs in existing ponds where the water flow system is horizontal rather than upwelling, as used in most other methods. Its use evolved as fish culturists sought to make dual use of rearing areas, reduce the need for large incubation buildings, and improve the quality of fry. These points have been successfully demonstrated, though fry quality has improved in all incubation systems, particularly when substrates are used. We recommend that ponds not be designed solely for incubation purposes.

The pond method consists of using circular or rectangular rearing ponds that have a uniform flow distribution and pond trays on which to incubate the eggs. The trays resemble window screens (Fig. 8) but the frame is generally constructed of metal or 2-x 2-inch lumber and the screen has 10-14 openings to the inch. Larger openings are required if the fry are to be permitted to drop through and incubate in the pond. Nylon netting can also be used as the screen material (Fig. 9). The trays should extend the width of the pond to get the proper hydraulics. Thus the size of the trays depends on the pond size and individual preference. A 2.5-x 4-foot tray is convenient to handle.

The eggs are placed on the trays one egg deep; however, two layers are commonly incubated by the WDF. Depending on egg size, 2,000 salmon eggs can be incubated on each square foot of screen. The recommended densities for a pond should be no greater than initial rearing densities.

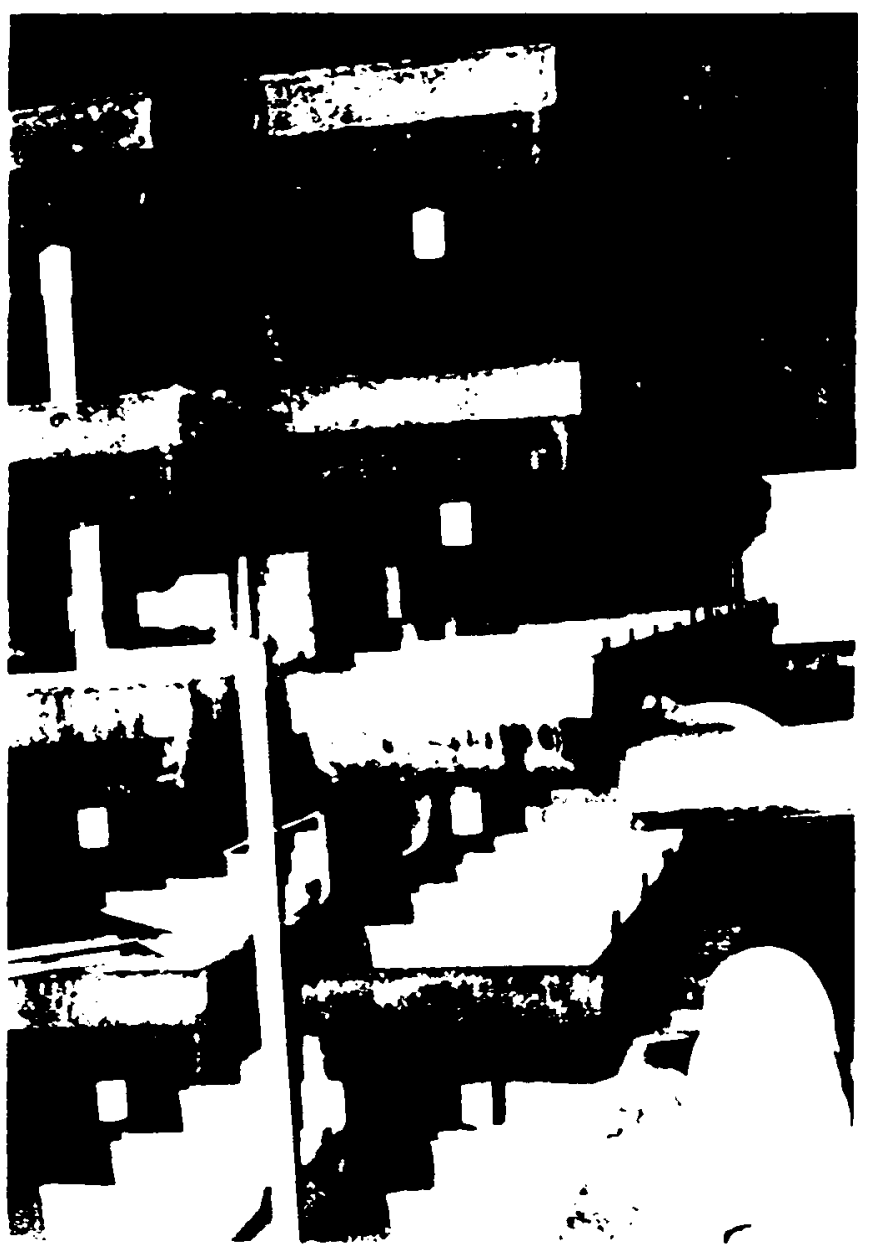

Figure 7. Shallow-trough incubators stacked five-high (Quinault Tribal Hatchery). 


\section{Chapter 4}

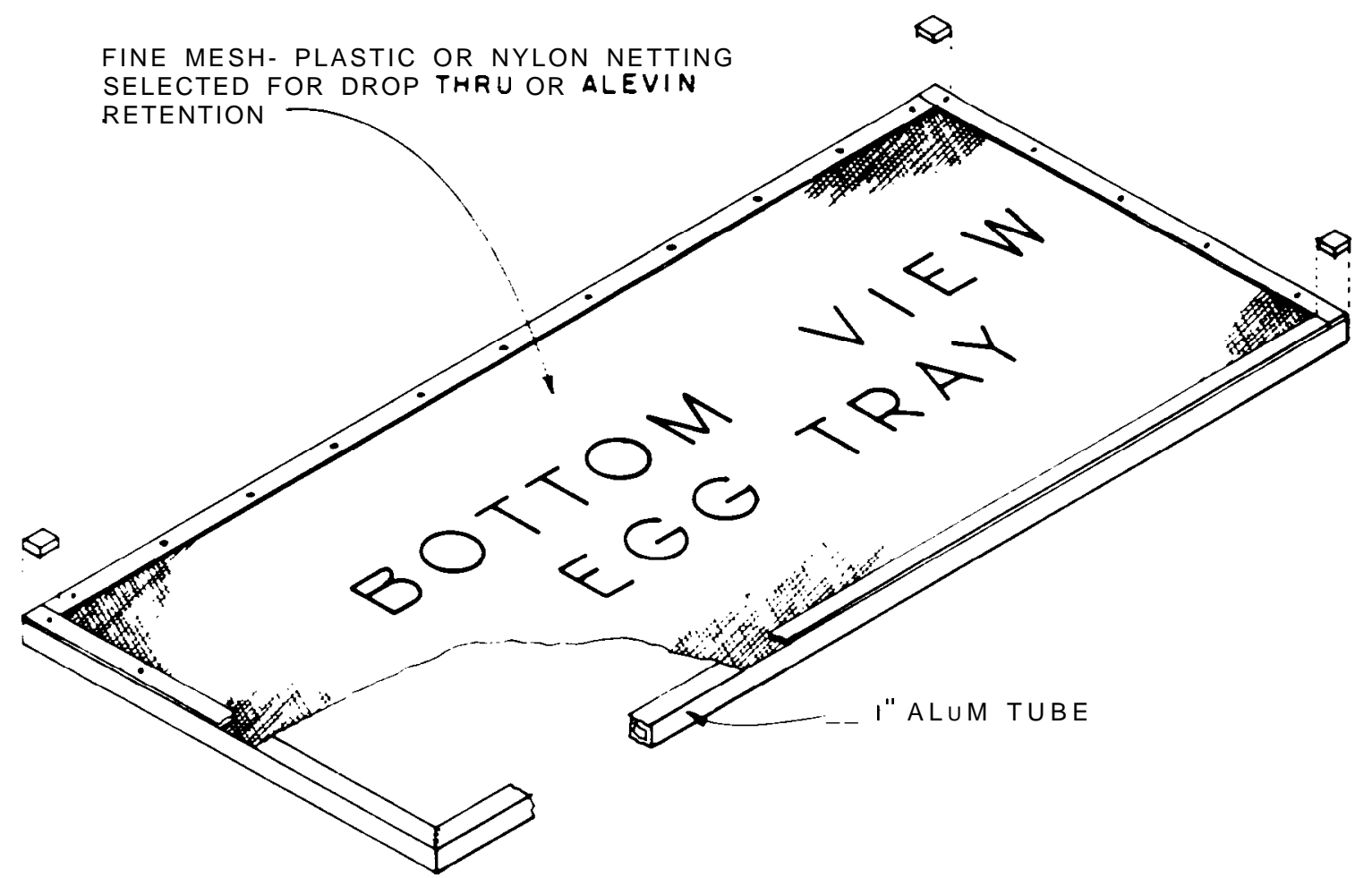

Figure 8. Typical metal-frame pond tray for drop-through or alevin retention.

The trays are stacked in the pond with a 0.5 to l-inch spacer between them. This provides an opening for water circulation and for the fry or alevins to leave the trays. A custom tray has been patented that uses a cabinet-and-traysystem which can be set in a pond as a unit (Fig. 10).

The water flow should be no less than $8 \mathrm{gpm} / \mathrm{ft}^{2}$ as computed by the water depth times the width of tray in the area of incubation. Maximum flows are of no concern, provided they do not move the eggs. Eggs and alevins are successfully incubated in ponds without a uniform flow distribution; however, lower egg densities are required. Clean water is mandatory for this method of egg incubation because the horizontal water flows allow silt to settle more readily than vertical flows. Since light must be prevented from entering the trays, a 4-mil black plastic sheeting is generally used to cover the trays and areas of alevin incubation. Incubation in circular ponds is successfully used by Swecker Salmon Farms near Rochester, Washington.

\section{Advantages:}

Large incubation buildings are unnecessary

Fry quality is acceptable

Labor cost is relatively low 
- Capital cost is low

- The trays are easily fabricated

$\underline{\text { Disadvantages: }}$

- Eggs tend to pile up and smother in poorly constructed trays

- The incubating eggs and alevins are not readily visible

- The survival rate is slightly less than in some other units

- Unless spring water is available, the units may require special care in freezing weather

- The ponds cannot be used for both incubation and rearing at the same time unless the trays are isolated in the pond by a screen

\section{Cost:}

A 2.5-x 4-foot tray with screen costs $\$ 20$ (wood) and $\$ 80$ (metal). Life expectancy is seven or eight years for wood frames and 15 years for metal.

Information Sources:

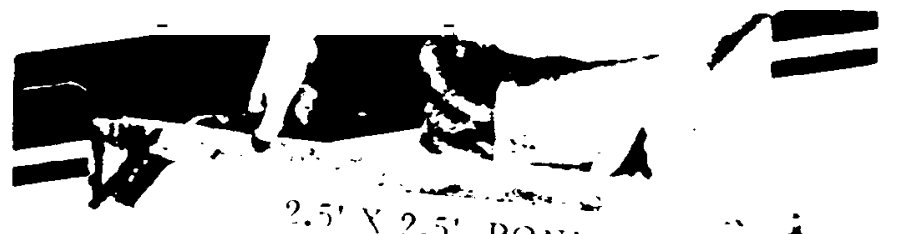

Washington Department of

Fisheries, Hoodsport Salmon Hatchery

Swecker Salmon Farm, Rochester, Washington

Oregon Aqua Foods, Springfield, Oregon

\section{BOX INCUBATORS}

A variety of box incubators have been developed and successfully used in the Pacific Northwest, British Columbia, and Alaska. They have become popular because of the low construction and installation costs, and their flexibility of use in meeting a variety of production and management goals. Boxes are frequently used as temporary streamside incubators to augment natural production and as satellite production stations where large numbers of high-quality fry are produced. The WDF and other agencies are presently using box incubators at conventional hatcheries (Fig. 11) for incubating large numbers of eggs and alevins for a very low capital investment. 
Chapter 4

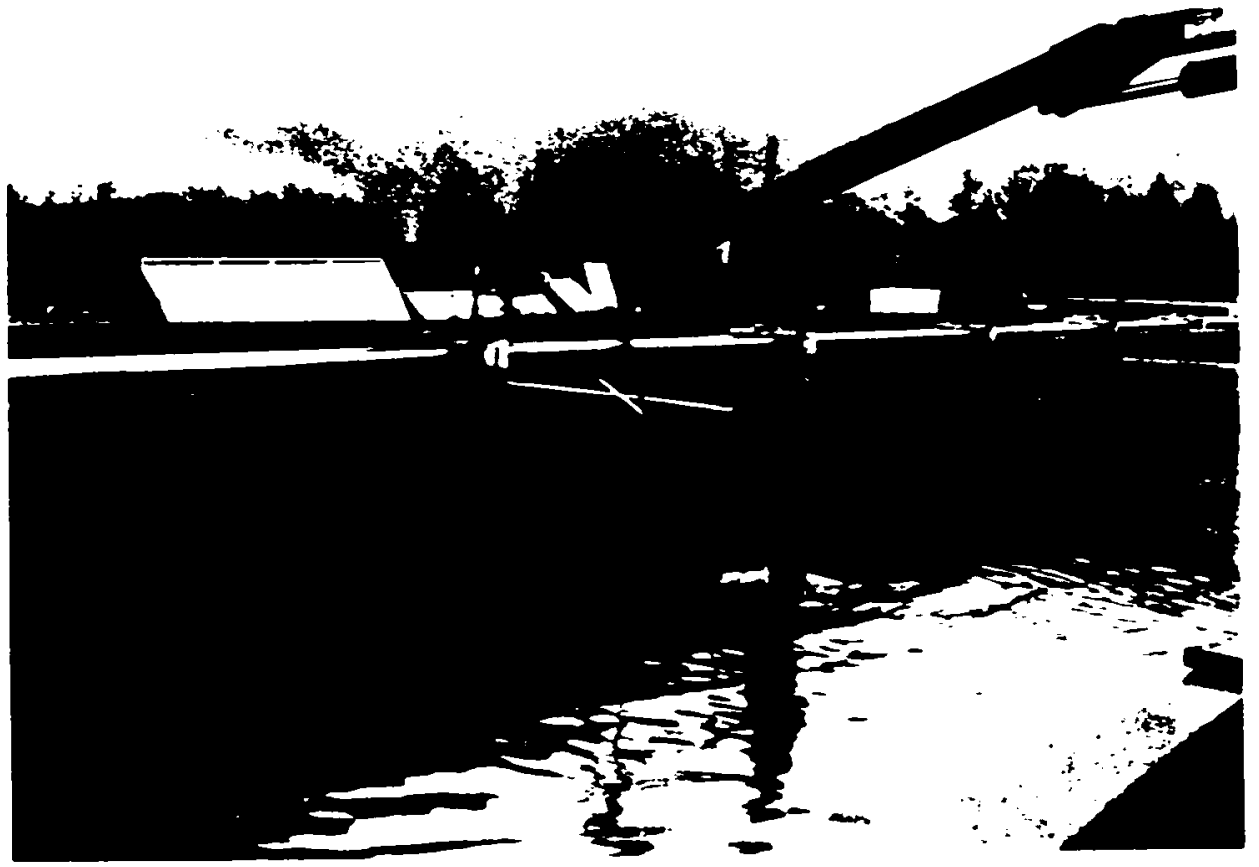

Figure 10. Pond tray-incubation unit at Oregon Aqua Foods.

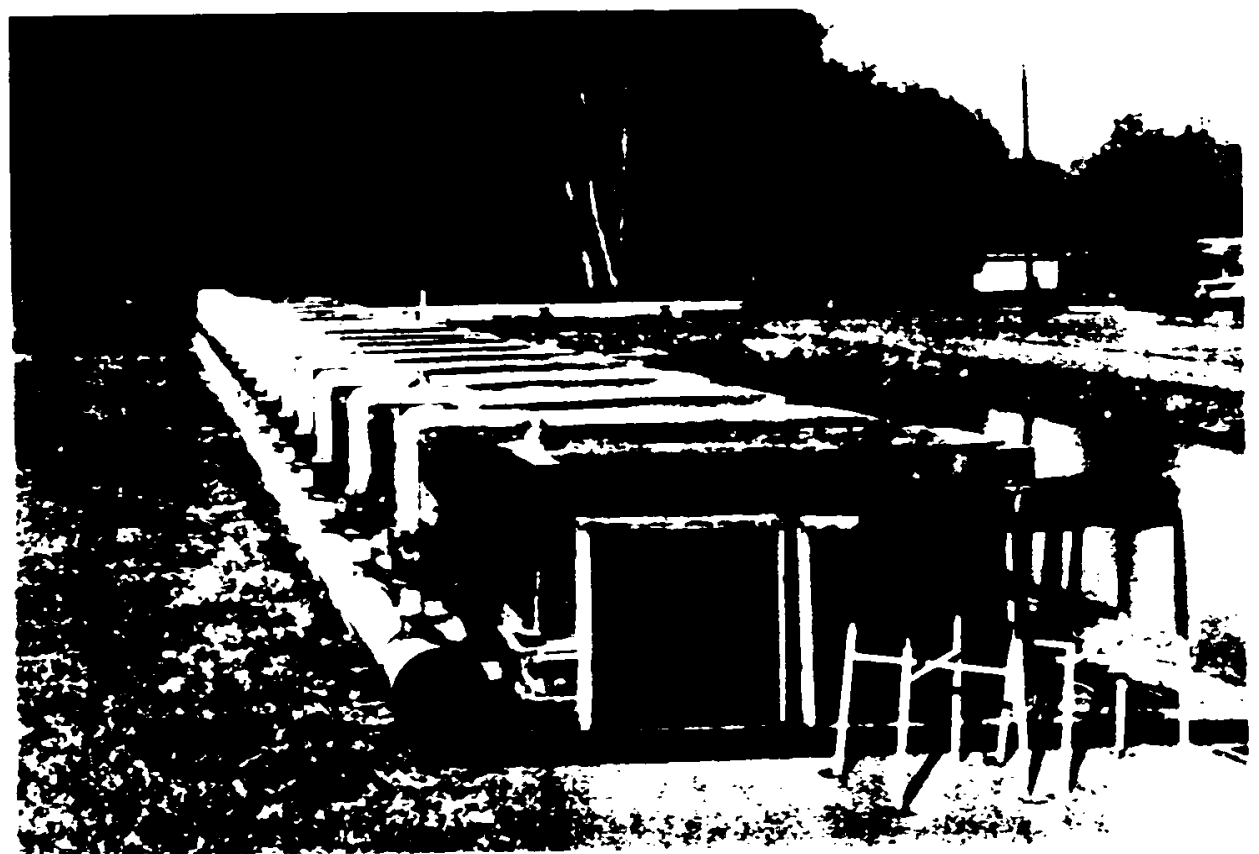

Figure 11. A deep-matrix box installation to incubate 10 million salmon eggs at McKernan Salmon Hatchery (WDF). 
The several types of incubation boxes described offer adaptability to a wide array of incubating requirements.

1. False Bottom, or Deep-Matrix, Incubator False bottom or deep-matrix incubators are boxes in which eggs or alevins incubate within a gravel or artificial substrate. Water is introduced at the bottom of the box in a manner that produces an evenly-distributed upwelling flow pattern. Deep-matrix incubators simulate natural salmon and trout incubation habitat, and they are capable of producing fry comparable in size and quality to wild fish.

Box incubators can be virtually any size desired and can be made from plywood, concrete, foam polyethylene, or fiberglass. One low-cost unit is a cargo box from the apple industry adapted for use as an incubation box (Fig. 12). Program goals, cost, and portability are major considerations in selecting materials.

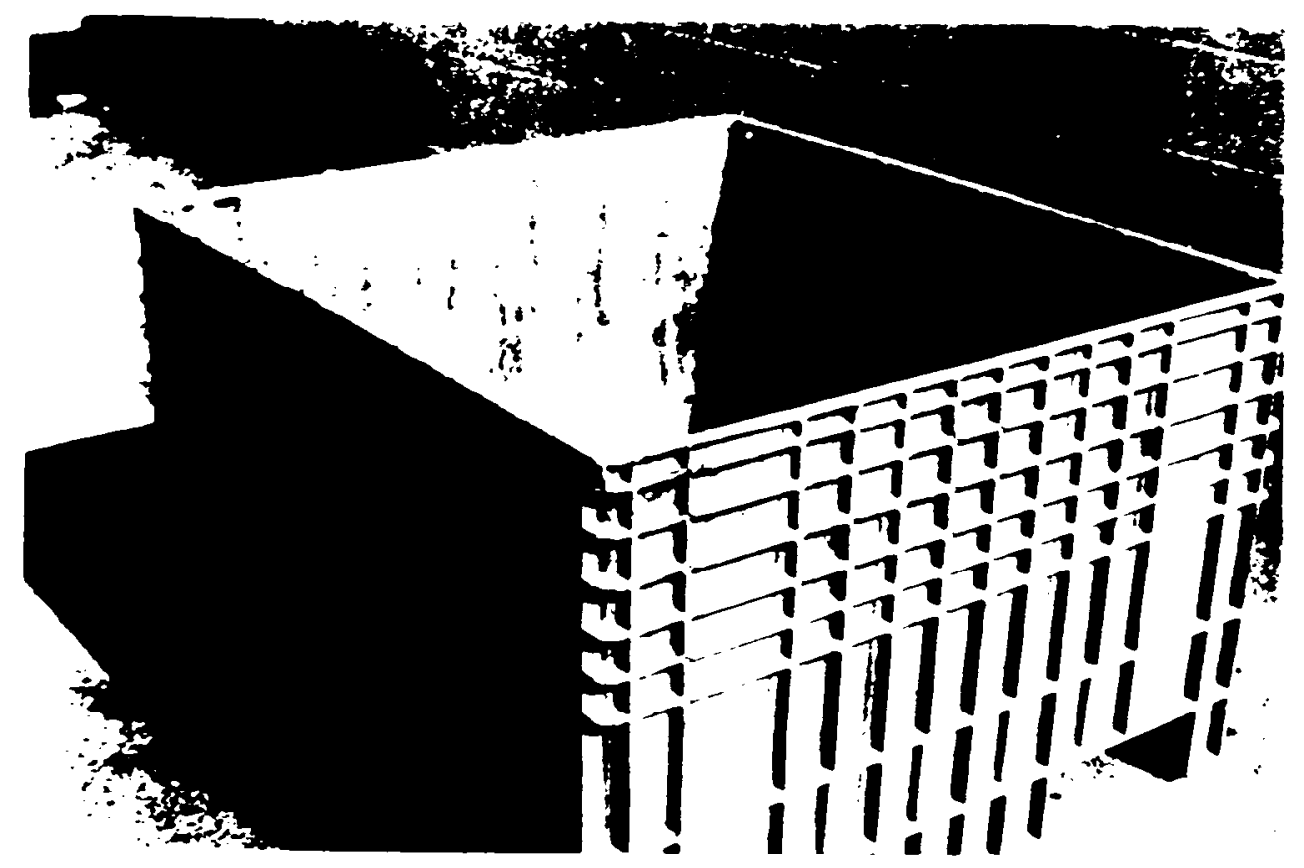

Figure 12. Heavy-duty plastic cargo box used as a box incubator.

In most boxes, water is delivered into a small header section and then flows downward beneath a false bottom. False bottom construction is usually of narrowlyspaced wooden pickets or aluminum angle, aluminum grating, or perforated aluminum sheets. In the incubation chamber a 2-to 4-inch layer of pea gravel is often placed over the false bottom and then filled to the desired level with 0.5-to 1.5-inch gravel. The pea gravel layer acts as a pressure plate to distribute uniform water flow and upwelling velocities throughout the box (Fig. 13). An optional water delivery system, more common in smaller units, uses a grid of perforated plastic pipes in lieu of the false bottom (Fig. 14). 
Chapter 4

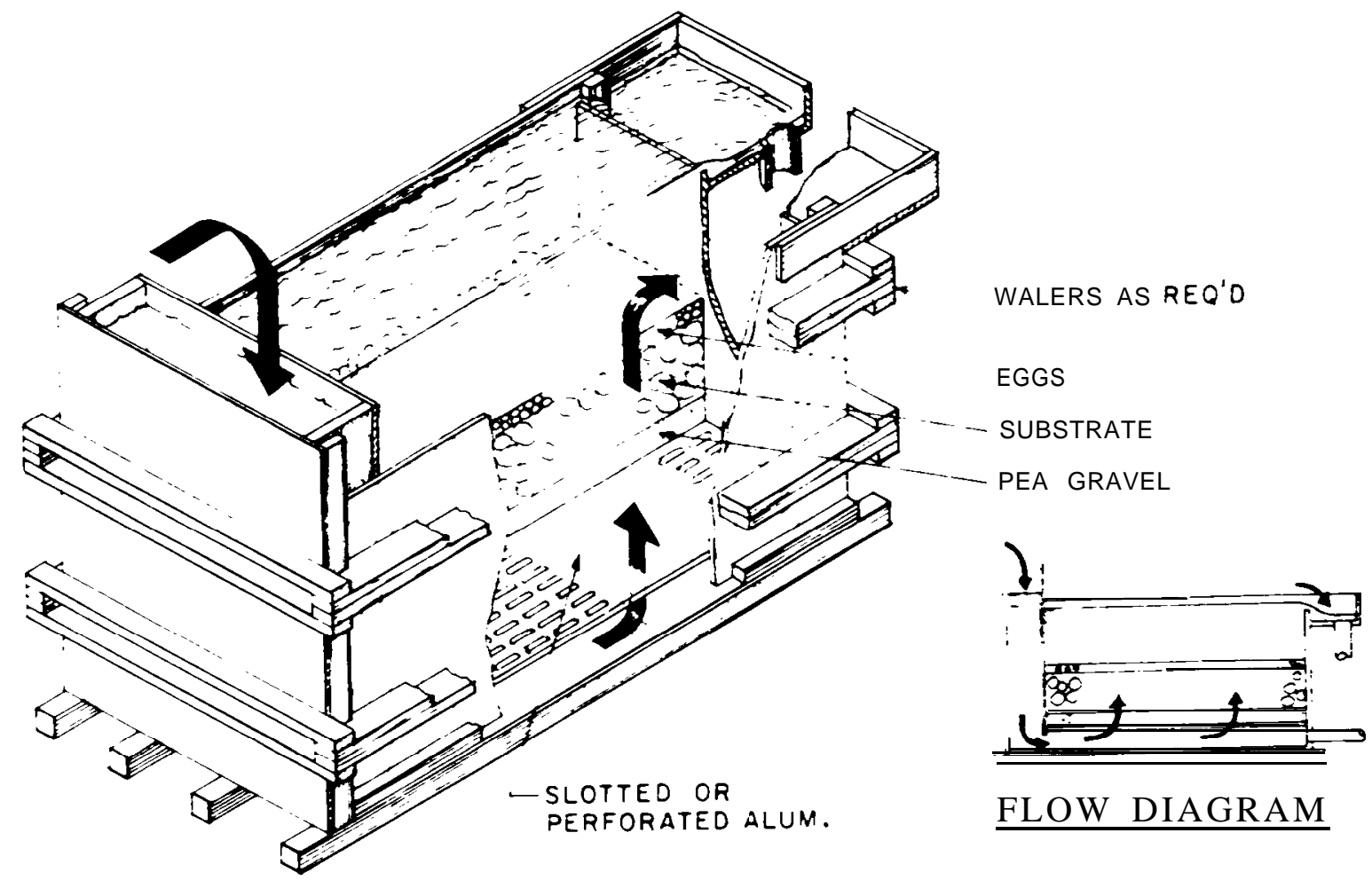

Figure 13. Typical large deep-matrix box.

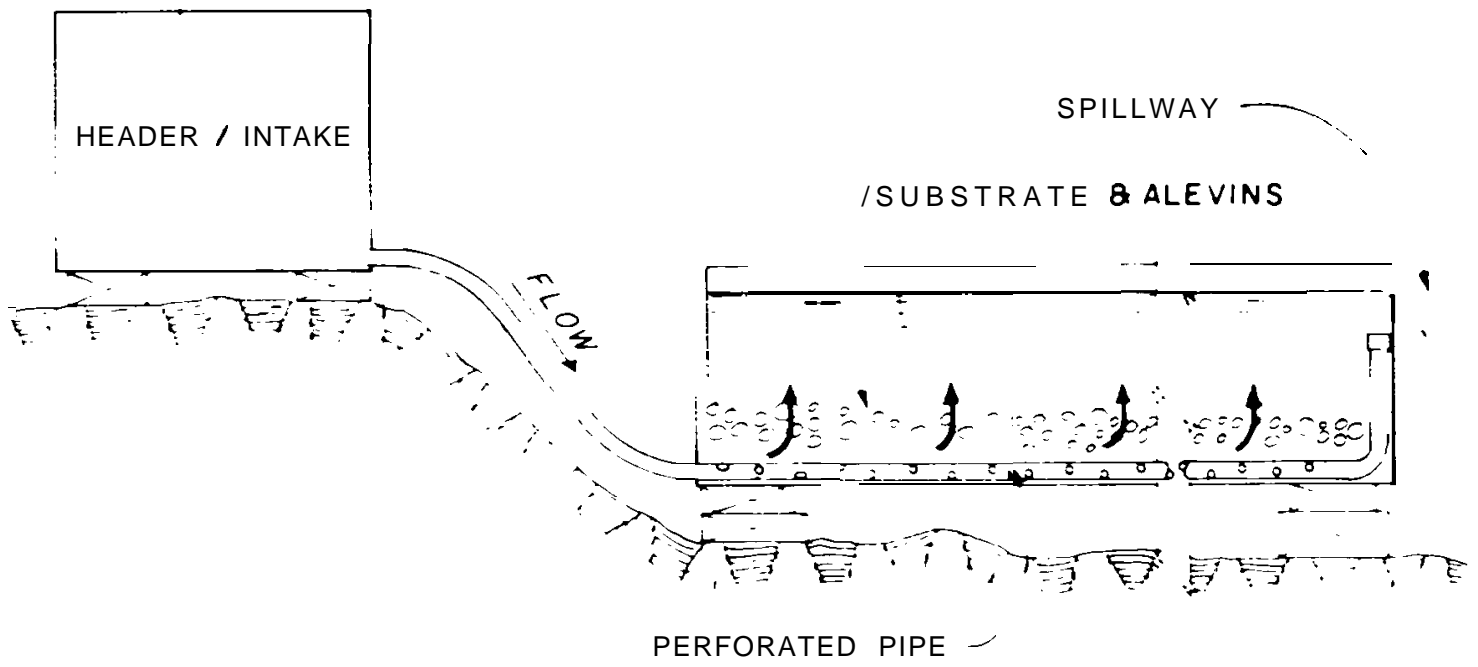

Figure 14. Typical small deepmatrix box.

Dimensions for perforations or spacings in a false bottom should be ng greater than $3 / 32$-inch to prevent the passage of alevins. Smaller spacings should be used for sockeye or steelhead. 
Gravel substrate has been most frequently used in box incubators, but two plastic alternatives, saddles and bio-rings, -have -been used successfully. They are more expensive, but are lighter and easier to handle than gravel during cleaning of the substrate.

In areas where freezing conditions are common, useful precautions include burying the boxes in or adjacent to the stream, insulating the walls and cover, and insulating the watersupply system. Also, units may be buried in a natural stream to increase hydraulic head; and bottomless, or pit incubators, have been buried to take advantage of natural upwelling. Either of these options require streams with very stable flows and maintenance is more difficult. All boxes must be securely covered for protection from predators and light.

Loading rates for box incubators are normally the numbers of eggs that can be carried completely through fry emergence, and will vary according to species. A 4-x 8-x 4-foot box with $75 \mathrm{gpm}$ could be stocked with 500,000 chinook, coho, or chum eggs, while the smaller $2-x$ 8-x 1.25-foot box with $12 \mathrm{gpm}$ incubates up to 75,000 eggs. If sockeye or steelhead eggs are used, the numbers can be increased 25 percent.

Alternate layers of gravel and eggs (either green or eyed) may be placed in the incubator, although the procedure presently used is to place the eggs on plastic screen trays positioned above the gravel so that observations may be made and dead eggs removed. After hatching, the alevins drop through the screen to the substrate. When using trays for egg incubation in this unit, the water supply need only enter and circulate above the substrate, thus keeping it clean until the alevins require the upwelling water.

The box incubator allows the fry to freely migrate into a stream or pond; however, the operator may delay them or divert them into a collection system.

Advantages:

- Low capital costs, and can be left unmanned if water supply is secure

- Easy to construct

- Flexibility of usage

- Production of high quality fry

- Does not require housing or support structures

- Plastic units can be moved by hand

- Can be used where space is limited

Disadvantages:

- No access to fry after hatching

- $\quad$ Risk of egg and alevin loss is higher when used in remote areas.

- Cleaning gravel substrate is laborious

- Fry may work through false bottom and perish in sump area 


\section{Chapter 4}

\section{Cost:}

One wooden box 4 × 8 x 4 feet costs $\$ 1200$ (includes perforated aluminum false bottom). Ten wooden trays 4 x 4 x l-inch deep costs $\$ 300$. One box. $2 \times 4 \times 1.25$ feet of wood costs $\$ 225$ (with perforated PVC pipe water supply bottom grid). Ten 2 $\mathrm{x} 4 \mathrm{x}$ l-inch deep wooden trays cost $\$ 150$. The plastic cargo box costs $\$ 130$ plus $\$ 200$ for plumbing. Wooden boxes have a ten-year life and plastic, a 15-year life.

\section{Information Sources:}

Skokomish Indian Tribe, Shelton, Washington

Washington Department of Fisheries

Canada Department of Fisheries and Oceans

Colossus Multi-Tainer Corp. (plastic box)

2. Baffled, or Shallow-Matrix, Incubator The shallow-matrix, or Netarts incubator is similar to a deep trough with two or more compartments (Fig. 15). Construction may be of high quality overlay plywood, fiberglass or concrete (Fig. 16). The incubators can be any desired size, but a common dimension is 4 x 8 x 1.3 feet with two compartments. Several units may be set up end-to end and share a common water source.

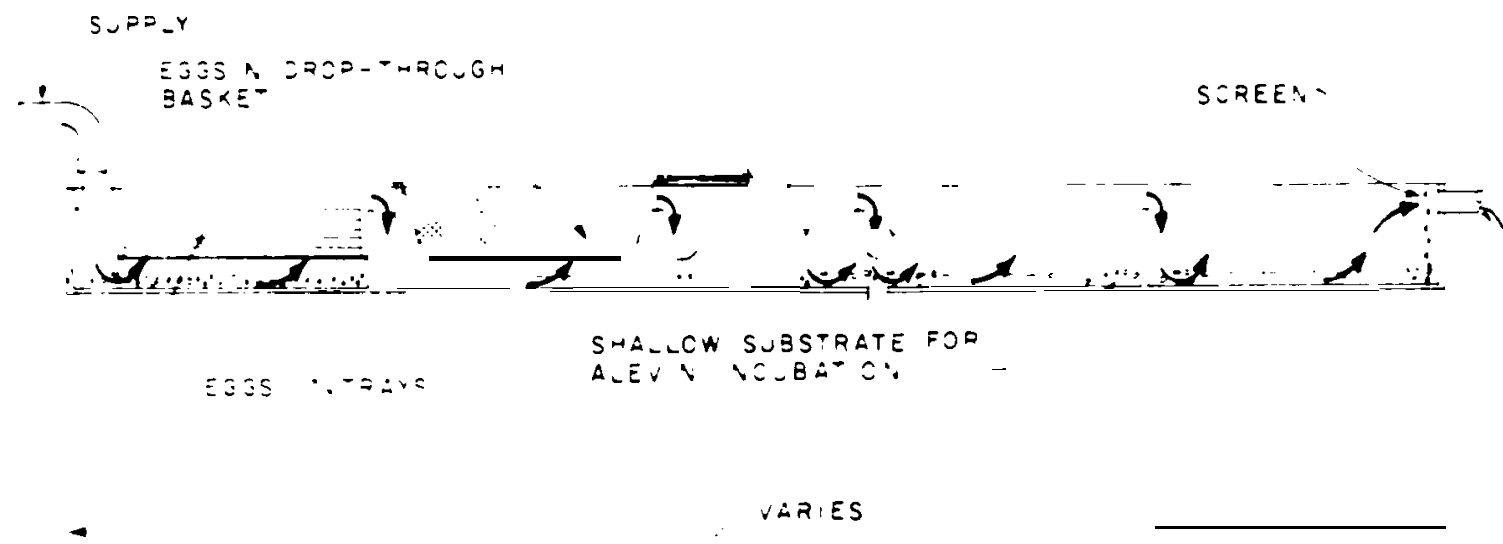

Figure 15. Shallow-matrix incubator.

Water enters one end of the box and is directed downward to the bottom of each compartment by baffles. A shallow layer of gravel substrate is used, usually about l-inch deep. Eggs are incubated on trays suspended above the substrate. Water upwells through the trays. After hatching, the alevins drop through the spacings in the trays to the substrate. The box should be covered for protection and the exclusion of light.

The density that alevins are incubated, per $4 \times 4$ foot compartment, ranges from 35,000 to 48,000 for chum, pink or coho. The Nisqually tribal biologist recommends the lower number (Svoboda, personal communication). About $30 \mathrm{gpm}$ of water are used during incubation. 


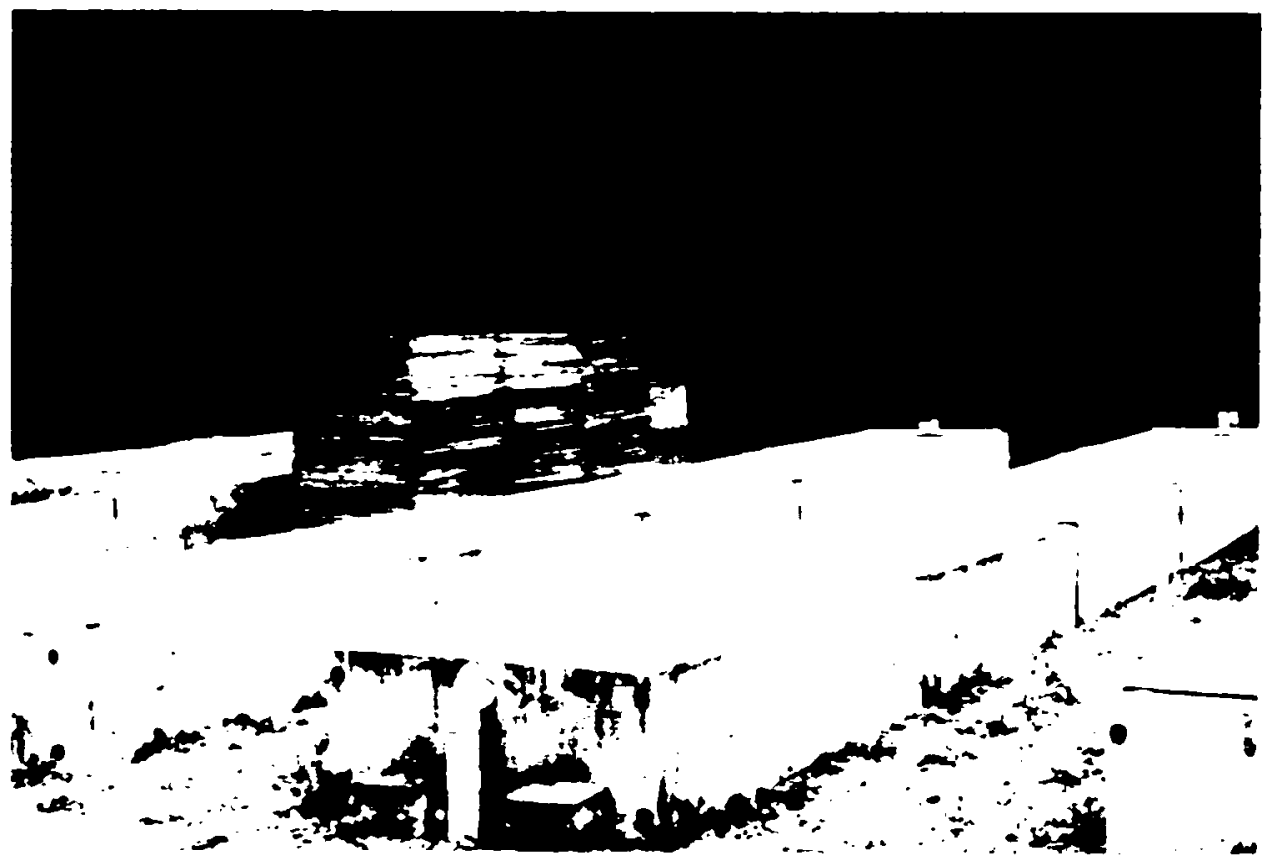

Figure 16. Shallow-matrix incubator at Skokomish Tribal Hatchery.

\section{Advantages:}

- Low capital costs

- Easy to construct

- Flexibility of usage

- Production of high quality fry

- Does not require housing or support structures

- Portability, if necessary can be moved by hand

- Can be used where space is limited

- Can be used for rearing

\section{$\underline{\text { Disadvantages: }}$}

- Risk of egg and alevin loss is higher when used in remote areas

- Requires more space than deep-matrix box

\section{Cost:}

A wooden unit $4 \times 8 \times 1.3$ feet costs approximately $\$ 350$, and has a ten-year life.

Information Sources:

Nisqually Indian Tribe

Skokomish Indian Tribe 


\section{Chapter 4}

3. Montana Hatching Box The Montana hatching box is used for egg and alevin incubation and is essentially one compartment of a deep trough set free as a separate unit. It is very similar in principle to the jar or bucket incubator describea later in this chapter. The box is built in various sizes, however, a typical unit is $1 \mathrm{x}$ 1 x 1.5 feet. They are constructed of waterproof plywood, fiberglass, or plywood with plexiglass on two sides. Substrate is not used in this box.

The water flows into a false bottom, up through a perforated plate, through the eggs and out the top. The unit observed at the Niagara Springs Steelhead Hatchery in Idaho (Fig. 17) uses manifold pipes to deliver water evenly below the perforated plate. On top of the plate Scotchbrite pad is used as a filter. Maximum water flows used were $6 \mathrm{gpm}$.

The number of steelhead eggs: that can be incubated is limited by the space in the incubator. The Niagara Springs Hatchery manager suggested 100,000 alevins for the unit described above. As the alevins absorb their yolk material, they may freely leave the incubator to be captured in rearing tanks or troughs.

\section{Advantages:}

- A tested and proven unit for steelhead incubation

- Portable; can be placed into rearing units

- Low cost

- Easy to construct

- Square units fit well in modules

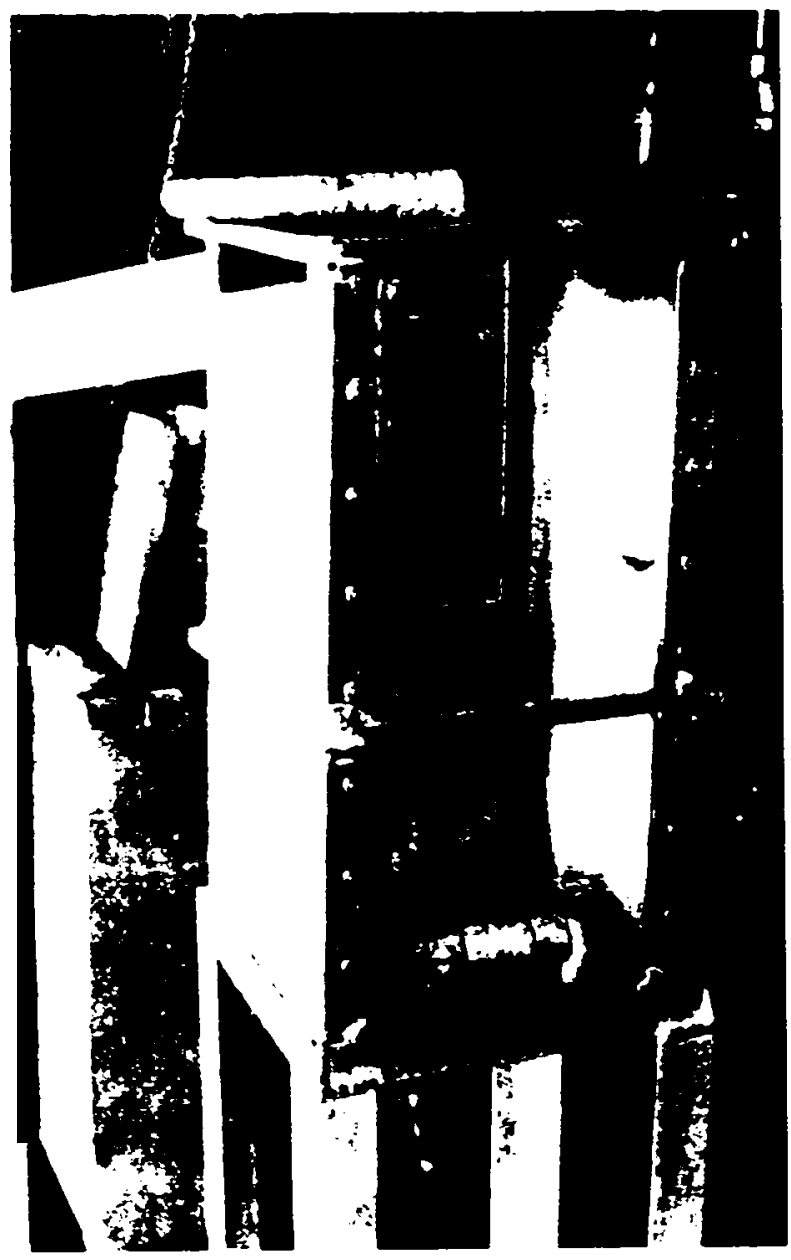

Figure 17. Montana hatching box at Niagra Springs Steelhead Hatchery (IFG)

\section{Disadvantages:}

0 Blue sac disease is reported at the lower preferred incubating temperature range 
Incubation

\section{Cost:}

The typical unit described has an estimated cost of labor and material of $\$ 200$ and has a ten-year life. There are no reported vendors.

\section{Information Sources:}

U. S. Fish and Wildlife Service

Idaho Fish and Game

4. Free-Style Incubation Box The freestyle incubator is a single plastic unit identical in principle to a module of a deep trough described earlier in this chapter. They are successfully used in Japan, and were recently introduced in the Pacific Northwest. Commonly manufactured from polyethylene or polypropylene plastic, the incubators measure about 2-x 2.5-x 2-feet deep (Fig. 18). They are used in tandem (Fig. 19) for egg incubation and singly for alevins. When used together, the water flows from one to the other.

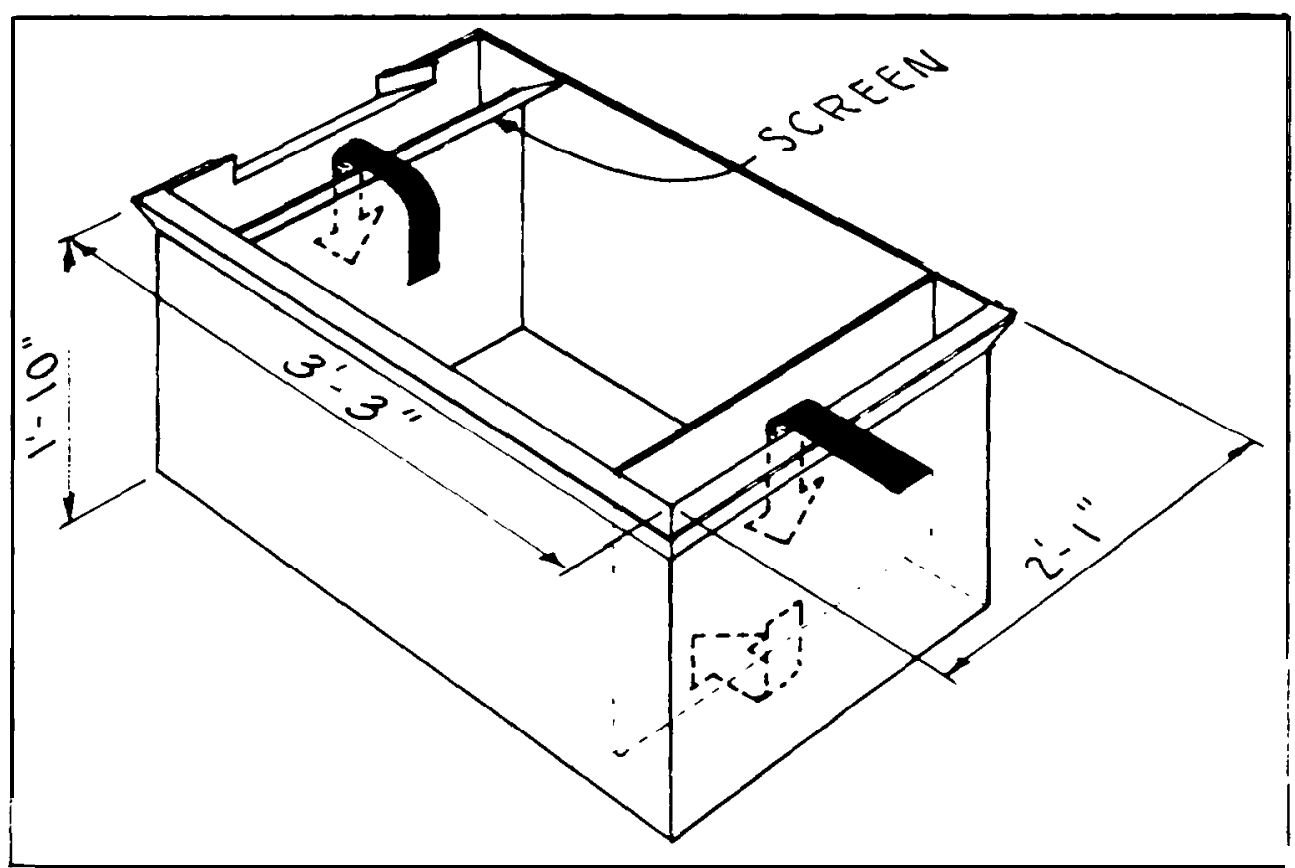

Figure 18. Free-style incubator.

Twenty gallons per minute is used for both egg and alevin incubation (Table 3). The recommended densities for salmon incubation are 500,000 eggs and 150,000 alevins per individual unit. As witil deep troughs, eggs can be incubated on trays or poured directly into the unit. When using trays, the alevins drop through to a substrate below. The latter method allows alevins to volitionally move to rearing areas. 
Chapter 4

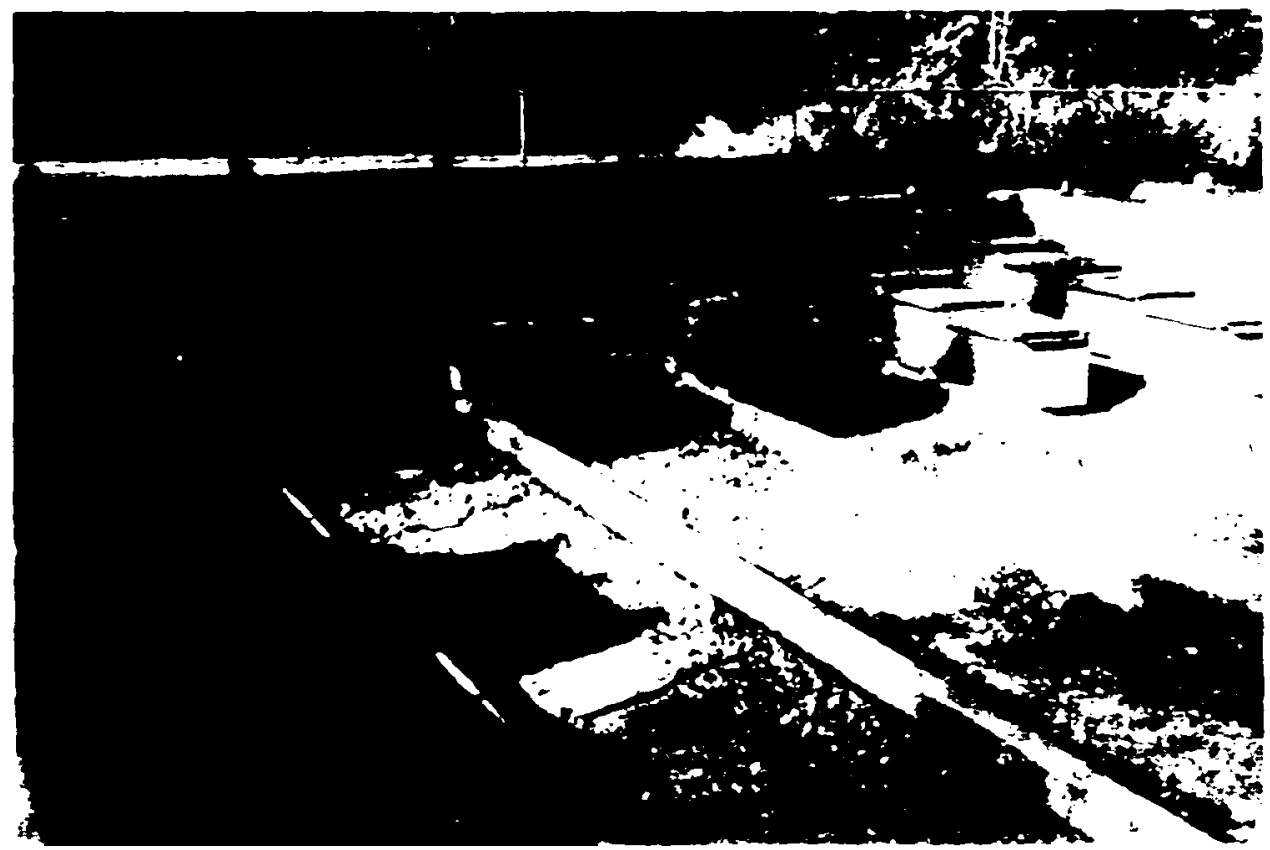

Figure 19. Free-style incubators set in tandem within pond.

Free-style incubators have not been tested sufficiently to recommend them for incubating alevins. The WDF indicates problems with water flow patterns and early emergence of fry. We suggest following the procedures illustrated in Fig. 20 for barrel incubators to eliminate or reduce both problems. A top pressure plate would eliminate early emigration. To start the feeding of all fry simultaneously, we recommend the same procedures used by Mariculture NW for barrel incubators, where plastic bio-rings in net bags are used for substrate. (See Section C Substrates.)

\section{Advantages:}

- Efficient for incubating large numbers of eggs

- Portable; can be readily set-up in rearing ponds

- Require little maintenance

- No building required

Disadvantages:

- $\quad$ Not practical for small egg lots

\section{Cost:}

One plastic unit costs approximately $\$ 600$, and has a life expectancy of 25 years. 
Incubation

Information Sources:

Washington Department of Fisheries George Adams and McKernan Salmon hatcheries Canada Department of Fisheries and Oceans

\section{E. CYLINDRICAL INCUBATORS}

Cylindrical incubators are made in various sizes and are practical for both small and large incubation programs (Fig. 20). They function on the same principle as the Montana and Free-style box incubators.

Simple models are made from stock plastic or metal containers; however, they can be manufactured from acrylic or PVC pipe, wood, or metal. For this reason the concept offers a variety of low-cost applications to incubate very small and very large numbers of eggs and alevins. Cylindrical incubators are described under the unit headings of jars, jugs and buckets, and barrels.

1. Jar incubator Hatching jars were developed to incubate small egg lots; a modified version is shown in Fig. 21. This unit has a 6-inch pipe set in the center of the 12-inch pipe. Water is forced down the larger pipe, then flows up through the smaller pipe, the incubating eggs and alevins. This jar is more efficient in preventing losses from occurring at the time of hatching than earlier designs.

Alevin density within the modified hatching jar should not exceed 20,000 salmon and 25,000 steelhead. Inflowing water used at the Dworshak NFH is 2-3 gpm on green eggs, $5 \mathrm{gpm}$ on eyed eggs, and $4 \mathrm{gpm}$ on alevins. The manager at this station believes that this unit handles silty water better than vertical cabinet incubators. Fig. 22 illustrates the jar incubators at Dworshak.

\section{Advantages:}

- Construction is simple

- Clear cylinders allow visual contact when necessary

- Units are portable and can be placed so the fry exit directly to rearing areas

- Practical for use in isolating egg takes from individual females or small egg lots

\section{$\underline{\text { Disadvantages: }}$}

Incubating large numbers of eggs in many small units is labor consuming

0 Smallersize fry and erosion of the yolk sac may occur

\section{Cost:}

Cost of labor and material is $\$ 100$. 
Chapter 4

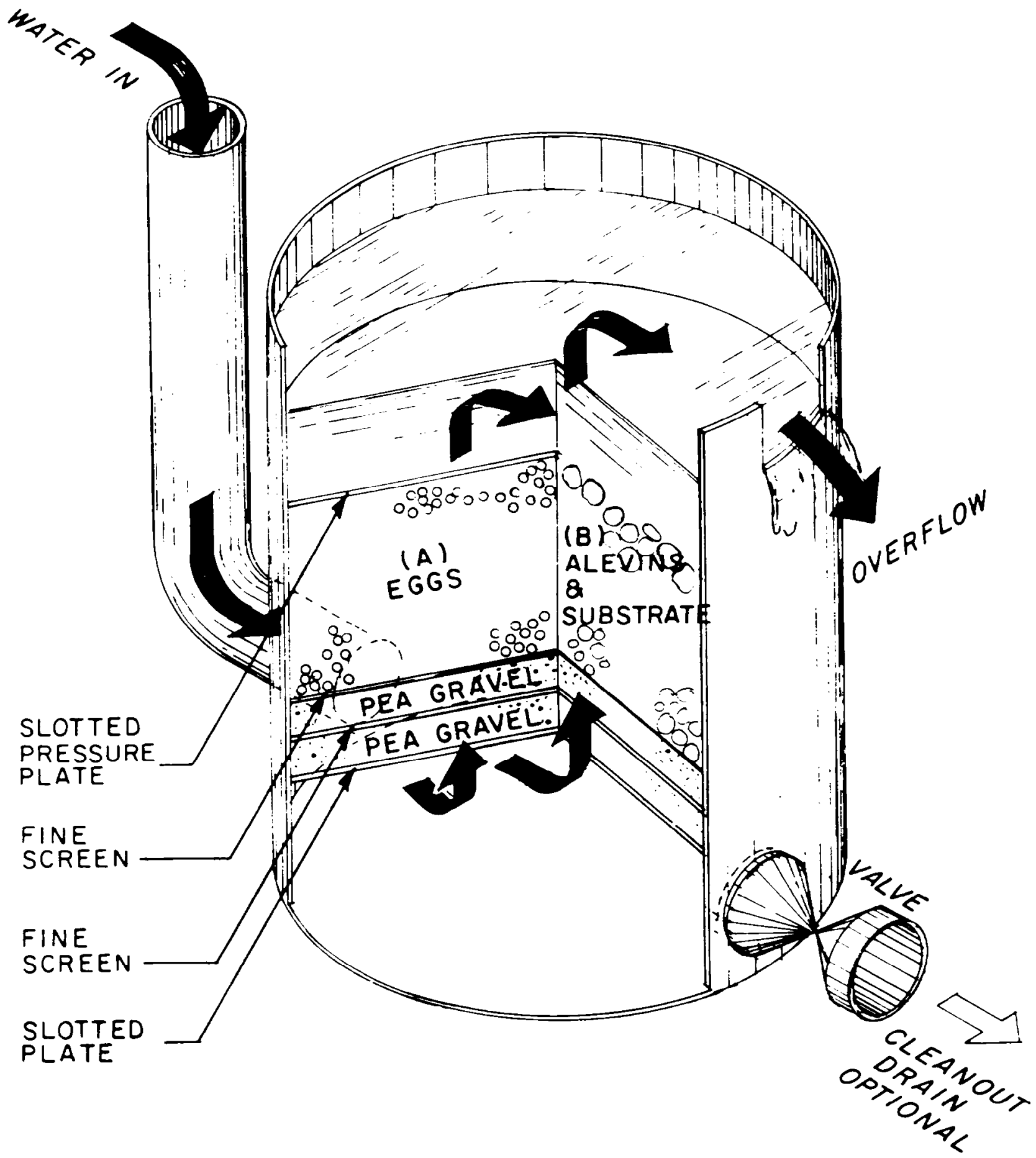

Figure 20.Illustration of a typical cylindrical incubator. 
Incubation

Information Sources:

Idaho Fish and Game

u. s. Fish and Wildlife Service, Dworshak NFH, Idaho, and Eagle Creek NFH, Oregon

2. Jug and Bucket Incubators A jug or bucket incubator is identical in principle to the jar incubator described above. The units are modifications of existing containers. A 1-gallon jug (Figs. 23, 24) or a 2-to 5-gallon plastic bucket (Fig. 25) are examples of some containers used.

A perforated plate is used to serve as a water diffuser and contain the eggs. The plate in Fig. 23 is made of perforated polyethylene sheeting cut to fit; however, perforated bucket lids have been used for this purpose. At the WDG Elokomin Trout Hatchery, the system was further simplified by directing the water from the top to the bottom of the bucket through a tube. No manifold was used and a house-hold sieve (Fig. 25) was used to contain the eggs. A diffuser plate is recommended and a Scotchbrite pad or 1 inch of pea gravel should be

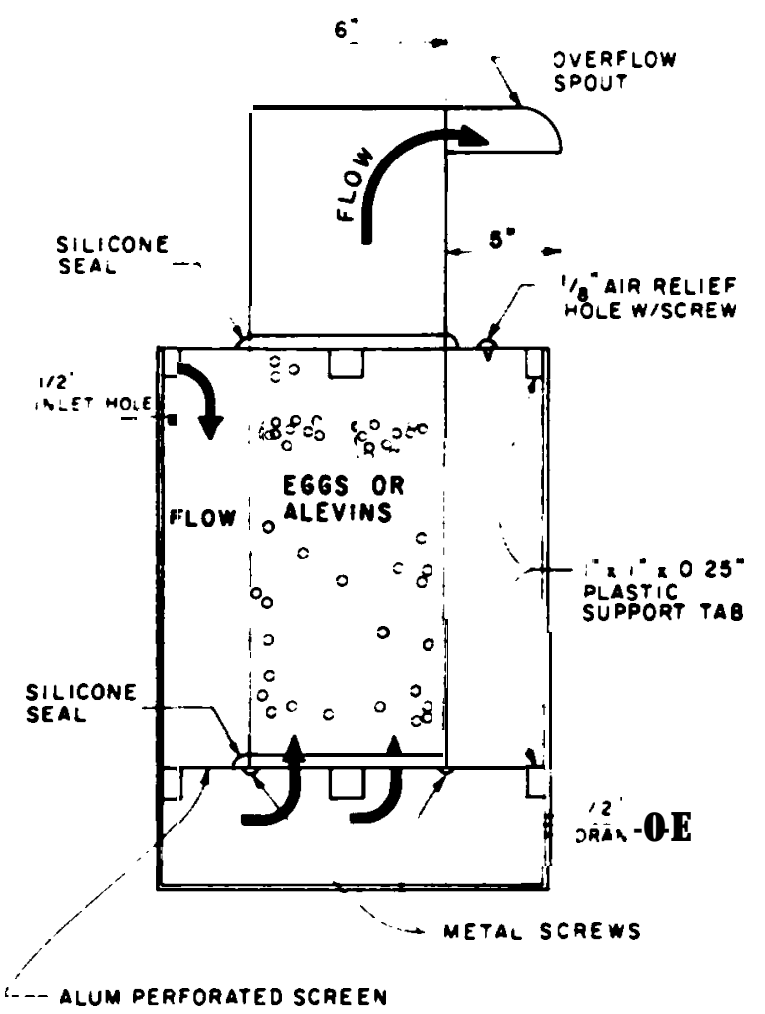

Figure 21. Hatching jar used at the Dworshak National Fish Hatchery (USF WS). placed on the plate to serve as a filter and diffuser (Fig.20). Substrate is recommended for alevin incubation. Any container can be constructed to allow the alevins to escape.

The steelhead egg capacity of a 1-gallon jug and a 5-gallon bucket is approximately 5,000 and 35,000 eggs, respectively. Selmon egg capacities would be about $\mathbf{3 / 4}$ this amount. Alevin capacities would be one-half of these amounts for each species. Water flows for alevin incubation should be $0.8 \mathrm{gpm}$ for the l-gallon and 2-3 gpm for the 5-gallon container.

\section{Advantages:}

- Easy to construct

- Containers available in various sizes

- Low cost

- Excellent for volunteer and classroom projects

- Portable; can be set next to or in a rearing unit

- Practical for use in isolating egg-takes from individual females or small egg lots 
Chapter 4

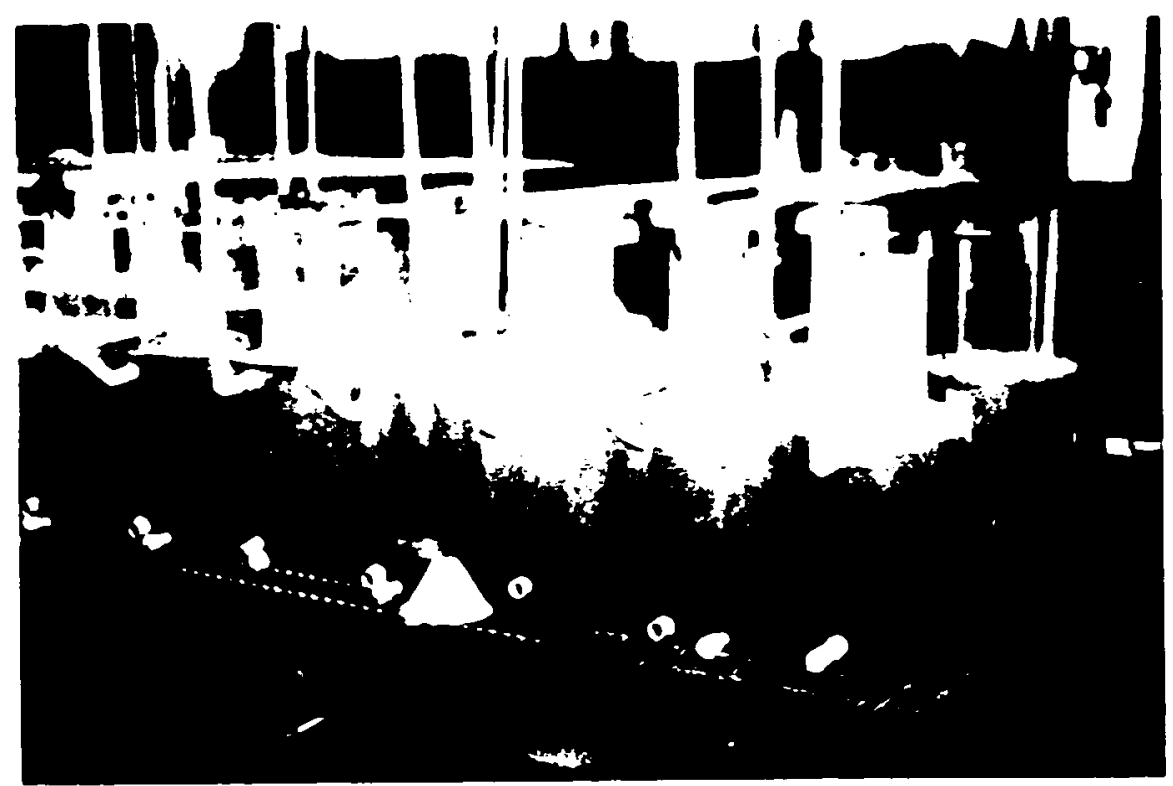

Figure 22. Jar incubators in series at Dworshak National Fish Hatchery (USF WS).

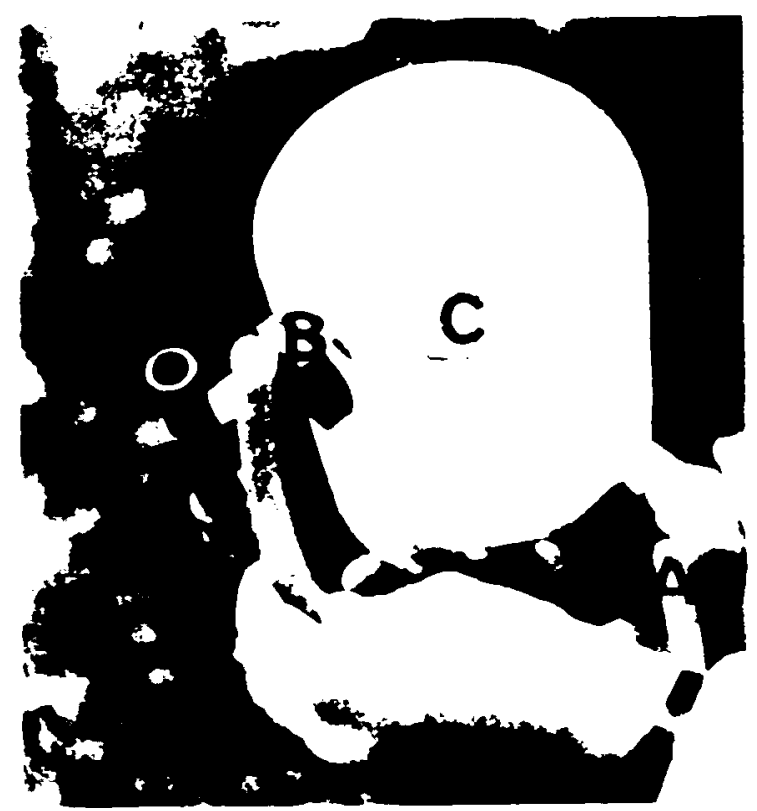

Yigure 23. One-gallon jug incubator noting: (A) inlet, (B) outlet, (r) Derforated bottom plate

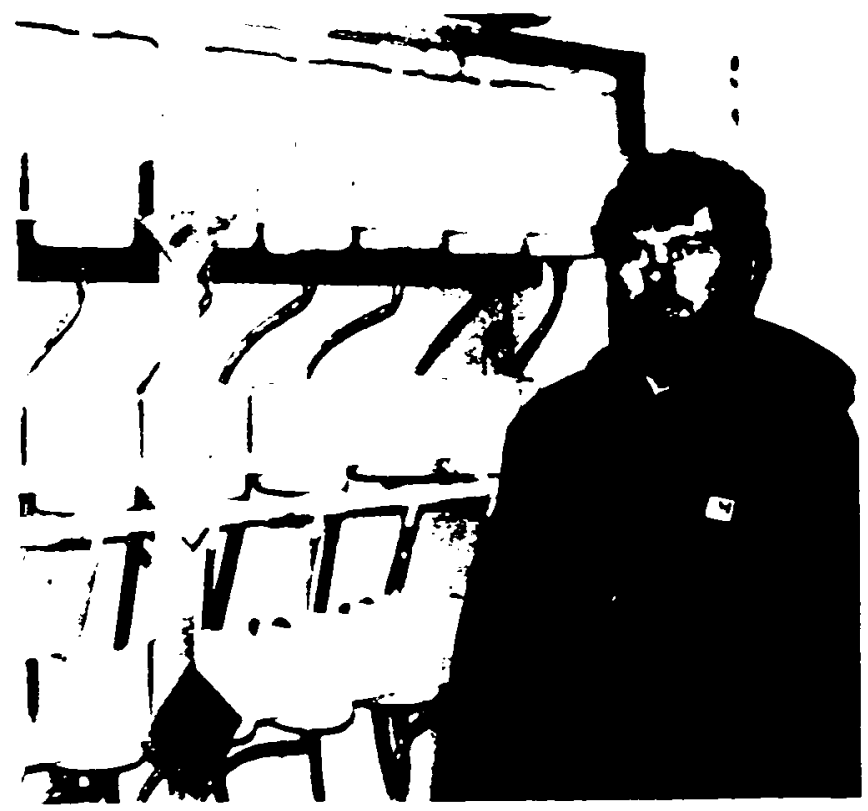

Figure 24. Operation set-up for 1-gallon jug incubators at Hedvejie Creek, -itria, Alaske. 


\section{Disadvantages:}

0 Visual observations are limited

0 Hound containers require more space than modular units

0 small egg lots are time-consuming

cost:

Estimated material cost is less than $\$ 20$ for a j-gallon unit

Information Sources:

Washington Department of Game

Northern Southeast Aquaculture

Association, Sitka, Alaska

U. S. Fish and Wildlife Service

Alaska Department of Fish and Game

3. Barrel Incubators The principle of barrel incubators is illustrated in Fig. 20. Any clean metal drum can be used, although AFG uses manufactured units that measure $29 \times 48$ inches and 48 x 48 inches and are called R29's and $\mathrm{R} 48^{\prime} \mathrm{s}$, respectively. Common commercial

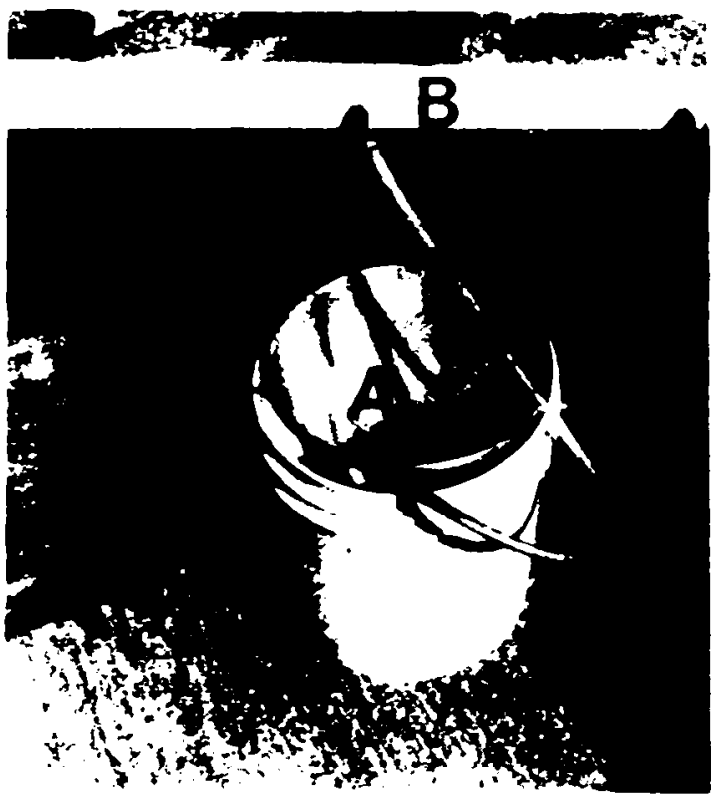

Figure 25. Three-gallon bucket incubator noting: (A) sieve to hold eggs, (B) main water delivery pipe, '(C) tube to bottom of bucket. barrels, 15-5 5 gallons, make excellent units which are used successfully by Mariculture NW of Rochester, Washington. Also, sections of adequate diameter plastic pipe will serve as well.

AFG culturists place 2 inches of plastic saddles upon the perforated aluminum manifold to act as a water diffuser, while Mariculture NW uses 8 inches of pea gravel for a water diffuser. A 12-mesh screen is placed on top of the saddles and is held in place by a stainless steel ferrule. Newly fertilized eggs are placed on top of the screen and are held in place by a perforated aluminum pressure plate.

Trays can be used to hatch eggs; however, it is most common to place eyed eggs in the barrels layered in plastic substrate. ADF prefers saddles, while Mariculture NW uses 1.25-inch bio-rings. The units can be constructed to allow the alevins to move freely to rearing areas and can serve as streamside incubators.

Alaska Department of Fish \& Game programs 600,000 salmon eggs for the R29's and $1,700,000$ for the R48's. A 55-gallon drum would hold about one-third of the R29's capacity.

Recommended alevin densities for chinook and coho are 80,000 in the 55-gallon drum, 250,000 in the R29, and 725,000 in the R48. 


\section{Chapter 4}

For alevins, the water inflow rate is $4 \mathrm{gpm} / \mathrm{ft}^{2}$ of perforated plate used. The $\mathrm{R} 48$ uses $40 \mathrm{gpm}$, and a 55-gallon drum 1 O-1 2 gpm.

\section{Advantages:}

- Many sizes of barrels are available

- Construction is simple

- Labor requirements in handling large egg lots are minimal

- Small units are portable and would not require a building unless there is danger from freezing

Disadvantages:

- Visual contact is minimal

- Require more floor space than rectangular units

- Building recommended for large units

\section{Cost:}

The approximate cost of each barrel unit is: 55-gallon drum $\$ 100$, and R48 $\$ 1800$.

Information:

Alaska Department of Fish and Game

Mariculture NW, Rochester, Washington

Indiana Fish and Game

\section{F. CHANNELS AND INSTREAM INCUBATION}

Natural incubation is often achieved by placing eggs into prepared channels with a controlled flow of water. Mature salmon may be allowed to spawn naturally, as in a spawning channel, or eggs may be manually buried in an incubation channel. Japanesestyle channels, or "Keeper Channels", are used in conjunction with production at some hatcheries. Eggs may also be planted directly into a natural streambed.

1. Spawning Channel Channels constructed adjacent to natural spawning streams provide optimum gravel bed and waterflow conditions for spawning and incubation. If a natural cycle of development is allowed, the egg and alevin survival rate is usually several times that of the native stream. Channels vary in size and specifications according to the amount of available land, water, program goals, and species. They also vary in complexity, from inexpensive side channels (Fig. 26) to massive concrete-lined structures (Figs. 27, 28). In Fig. 26 a side stream has been created and stablized to increase the spawning gravel area and provide more uniform stream flow.

While detailed engineering and design depend upon the site, species, and program goals, certain general criteria and basic requirements are consistent for all spawning channels. A clean water supply is particularly important. Transport of sediments 


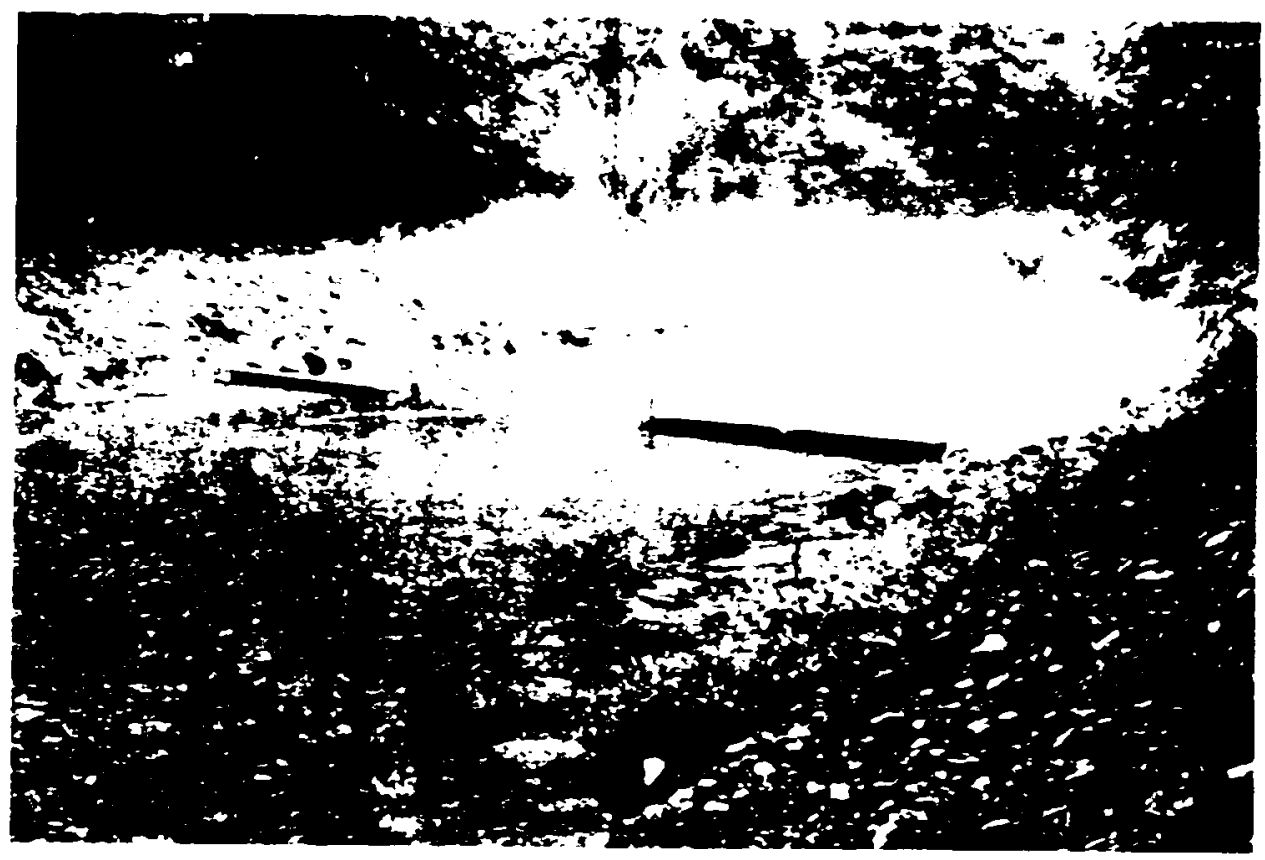

Figure 26. Typical low-cost side channel development in British Columbia for salmon spawning.

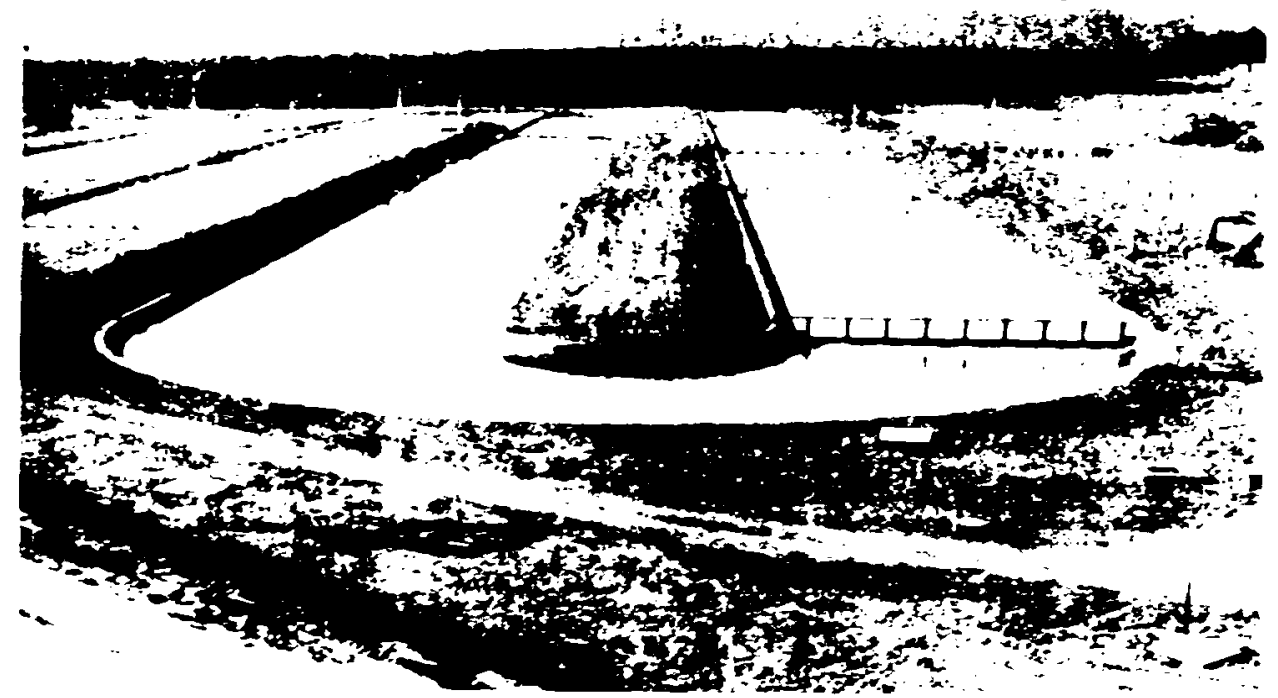

Figure 27. Salmon spawning channel at Wiells Dam, Columbia River (WDF). 


\section{Chapter 4}

into a channel reduces egg survival, increases maintenance, and can lead to costly' rehabilitation. Settling ponds are commonly used to help maintain clean grave! habitat. Gravel size typically ranges from 0.5 to 6 inches. The channel requires \& gradient of 0.2 to 0.5 percent to promote interchange between surface and intragravel water. Interchange of water can also be accomplished by varying the gravel depth, (usually 12-18 inches) or by burying impermeable byffles. luring spawning, the desirable water depth is 1.5 feet with 6 inches being minimum. Velocity should be between 1 and $3 \mathrm{fps}$, with 1.5 being most desired. Preferrec flows per foot of mean channel width are $2.2 \mathrm{cfs}$ for spawning, and $1.5 \mathrm{cfs}$ for incubation.

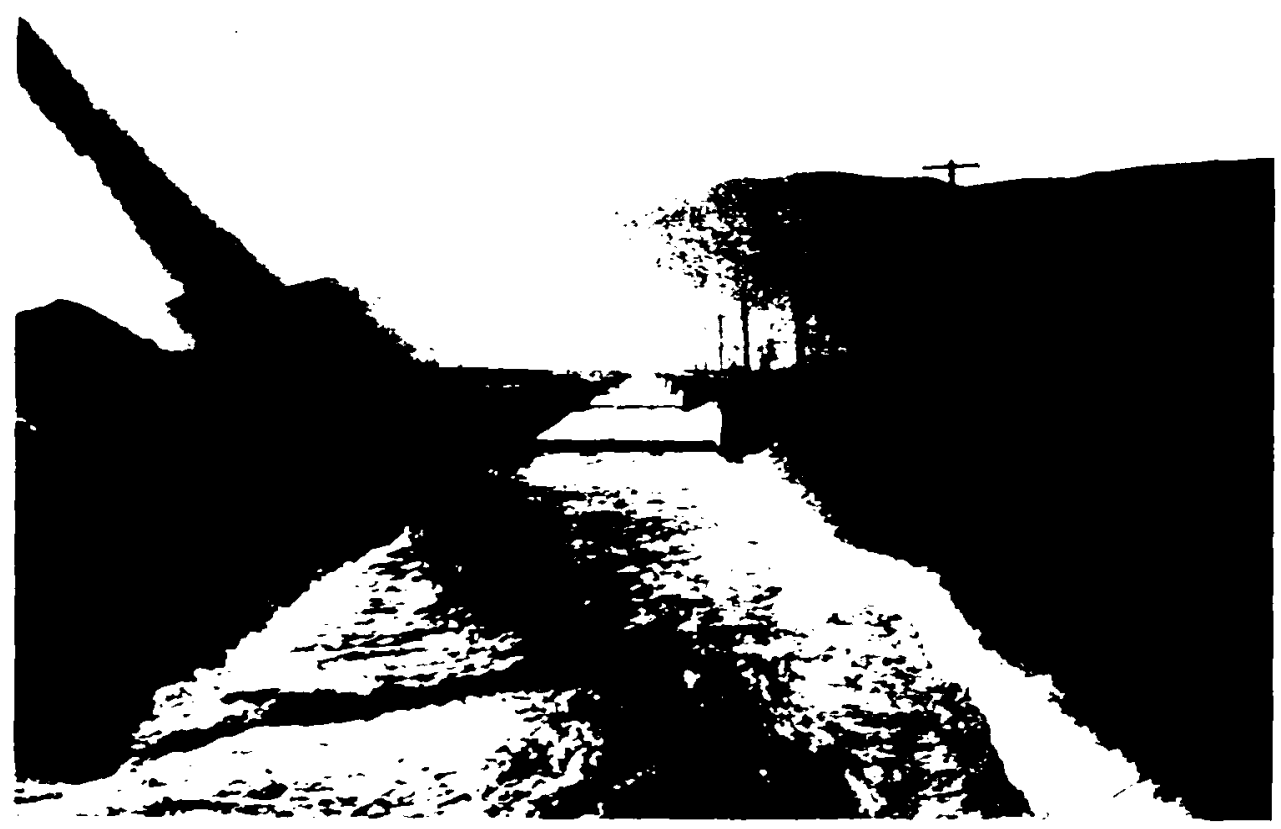

Figure 28. Salmon spawning channel constructed at Priest Rapids Dam, Columbia River (WDF).

\section{Advantages:}

- Increased survival over natural production because of controlled flow and clean habitat

- High quality fry in sync with wild populations

- Labor not needed for spawning adults and handling eggs

- Minimal need for support buildings

$0 \quad$ Provides natural mating and genetic responses

- Reasonable cost where physical conditions allow informality in development

Disadvantages:

- $\quad$ Large spacial requirement 
- Difficult to observe egg and alevin development, and to treat any problems

- Formal channels have large capital cost

- Survival rate lower than in "intensive" fish cultural facilities

0 Superimposition of eggs must be controlled

\section{Information Sources:}

Washington Department of Fisheries

International Pacific Salmon Fisheries Commission

Canada Department of Fisheries and Oceans

2. Incubation Channel Incubation channels (Fig. 29) differ from spawning channels in that eggs are buried artificially (usually by hand) rather than allowing the fish to spawn naturally.

Physical features are similar to those of spawning channels, except that stocking densities are higher. Densities of 500 eyed eggs $/ \mathrm{ft}^{2}$ of surface area yield high survival to the fry stage. Eyed eggs are most commonly used due to their substantially higher survival rate than newly fertilized eggs. Covered pond trays can be used to eye the eggs within the channel, provided water velocity is not prohibitive. Dead eggs can then be removed before burial. Alternative techniques would be to allow the alevins to drop through the egg tray and work their way into the substrate, or to pour the eggs evenly on top of the gravel shortly before hatching. If eggs cannot be eyed within the channel, space at another facility is required. Preferred flows are 1.0-1.5 cfs per foot of channel width. The incubation channel is effective for all salmonid species, but is more commonly used for those with no stream rearing requirement.

\section{Advantages:}

- Higher survival of quality fry than spawning channels

- Requires less space than spawning channels

- Increases survival over natural production because of controlled flow and clea habitat

$0 \quad$ Minimum need for support buildings

- Less capital cost than spawning channel

\section{Disadvantages:}

- Requires more space than most forms of incubation

- Requires a facility to eye eggs, if this cannot be done within the channel

0 Labor required for spawning adults, handling eggs, and enumerating production

Information Source:

Washington Department of Fisheries. 


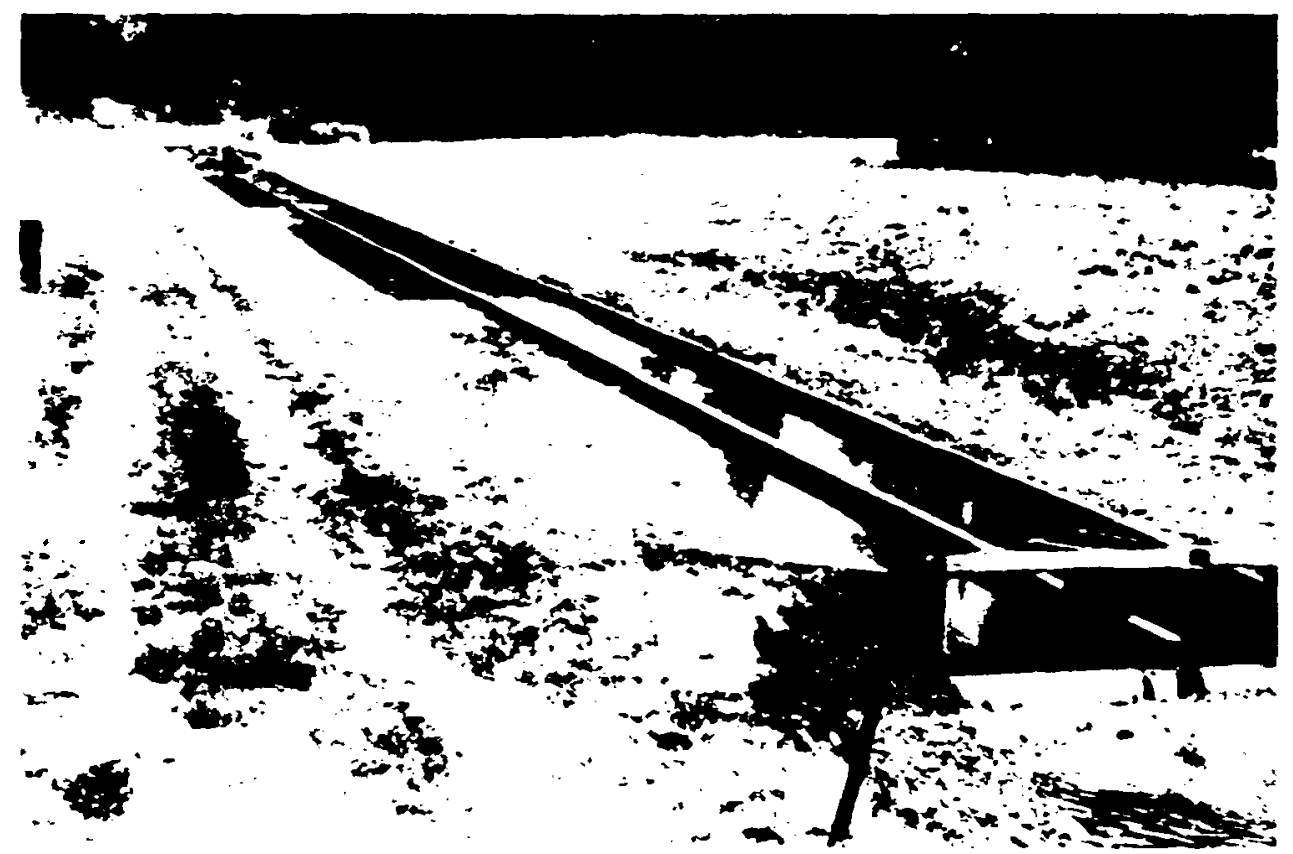

Figure 29. Low-cost eyed-egg channel, at Satsop Springs, (WDF).

3. Keeper Channel (Japanese style) The typical Japanese keeper channel is about 6 feet wide, 90 feet long, and 12 inches deep. They are usually constructed entirely of concrete, but the bottoms of some are earth. "The slope of the floor is approximately 0.2 percent with 0.5 -to 2 -inch gravel placed one rock deep (Fig. 30).

Eyed eggs are placed two deep on pond-width trays which have a screen bottom. The screen retains the eggs, but allows the alevins to drop through to the rock substrate below. Approximately 12,000 alevins are incubated per square yard of channel floor. When the alevins are ready to feed, they drop downstream to rearing areas.

The WDF and DFO have designed channels where water levels can be raised in order to create rearing ponds. The Japanese and DFO often cover the channels with a building. This protects the facility from freezing and allows light control. Light control is also accomplished by using boards or plastic materials.

The water volume supplied to each channel is about $60 \mathrm{gpm}$. Spring water or relatively silt-free water is a requirement. The water should flow evenly along the width of the channel at a depth of only 2 or 3 inches, barely covering the eggs, alevins, and the rock substrate.

The channels were designed for chum salmon incubation, however, DFO has successfully incubated eggs and alevins of steelhead and some species of salmon. 


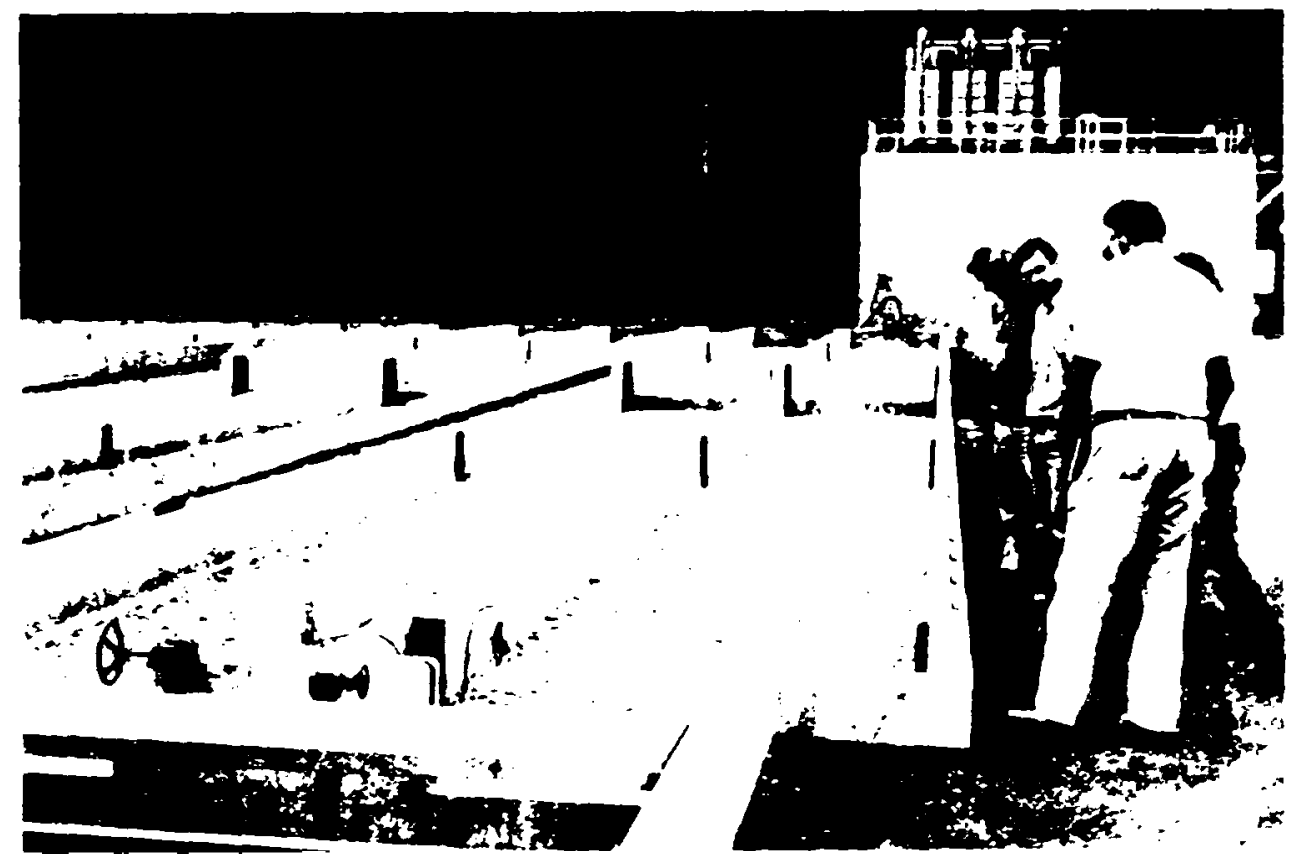

Figure 30. Japanese keeper channel (Chehalis River Hatchery, British Columbia)

\section{Advantages:}

- None can be listed over other incubation methods for the species considered

\section{Disadvantage:}

- Very costly

- Fry tend to migrate to head of channel, creating low dissolved oxygen conditions and high mortality

- Loading densities, gravel size, and depth of water very critical

- Water flow patterns must be monitored closely

\section{Infor mation Sources:}

Tulalip Indian Tribal Hatchery, Marysville, Washington

Washington Department of Fisheries McKernan Salmon Hatchery

Canada Department of Fisheries and Oceans

4. Planting of Eggs Salmonid eggs can be planted at either the green or eyed stages directly into redds dug by shovel in the stream gravel. A patented device, (Ova, Inc., Appendix 2) has also been successfully used to bury eggs by AFG. Egg plants will be most successful where flows are stable and suitable clean spawnïng gravel exists. Survival rates will be less than artificial production methods. 
Chapter 4

Another approach to egg planting is the use of perforated boxes, such as the Whitlock-Vibert box. This affords some protection to the developing eggs or alevins from either predators or shifts in the gravel beds. About 200 to 300 eyed eggs are placed in this translucent plastic box measuring approximately $6 \times 3.5 \times 2.5$ inches. Fry are able to emerge through slots or perforations in the walls of the box.

Modifications of the Whitlock - Vibert box have been made to accommodate larger numbers of eggs, such as the "sandwich box", considered for use by Grant County PUD, and the perforated drainfield pipe whose use was studied on the Chehalis River in western Washington State by Dr. E. Brannon, University of Washington.

\section{Advantages:}

- Low cost material investment

- $\quad$ Production of high quality fry

- Means to handle small egg lots for evaluation and bioassay

\section{Disadvantages:}

- Survival rates lower than other artificial production techniques

- Whitlock - Vibert boxes not efficient for handling large lots of eggs

Information Sources:

Alaska Department of Fish and Game

Canada Department of Fisheries and Oceans

Washington Department of Fisheries

Ova, Inc. - Wrangell, Alaska

Oregon Fish and Wildlife

Grant County Public Utility District, Ephrata, WA

University of Washington, School of Fisheries, Seattle, WA

\section{PART III. INCUBATION TOOLS AND EQUIPMENT}

Nearly every fish culturist has his own version of tools and equipment for handling salmon and steelhead eggs during the incubation period. Some of these he makes, while others are commercially manufactured. Both types, as well as techniques for their use, are discussed in this section under (A) egg sorters, (B) egg counters, and (C) substrates.

\section{A. EGG SORTERS}

The four common methods used to remove infertile eggs are hand picking, floating, mechanical sorting, and bouncing. All require that egg "shocking" be conducted before sorting to allow the infertile or dead eggs to be identified from the viable eggs. To do this, eyed eggs are sufficiently rough-handled to rupture the yolk membrane in the infertile eggs. As the yolk comes into contact with water it precipitates and turns white. Besides turning color, shocked infertile eggs have less resiliency and less specific gravity. 
Shocking does not harm viable eggs. This change in physical properties of the infertile eggs is the basis for all of the sorting procedures used.

1. Hand Picking Hand picking involves the removal of the opaque dead eggs, one at a time, directly from the incubator. The three commonly used pickers are the siphon and bulb (Fig. 31) and tweezer (Fig. 32). The first two are usually used with small eggs, while the tweezer is used to pick large eggs. They are similar in that they are inexpensive and easy to develop; they can be used to remove some dead eggs during the tender stage prior to shocking; they require a certain degree of operator skill; and an experienced person can remove 10-15,000 dead eggs in an 8-hour period.

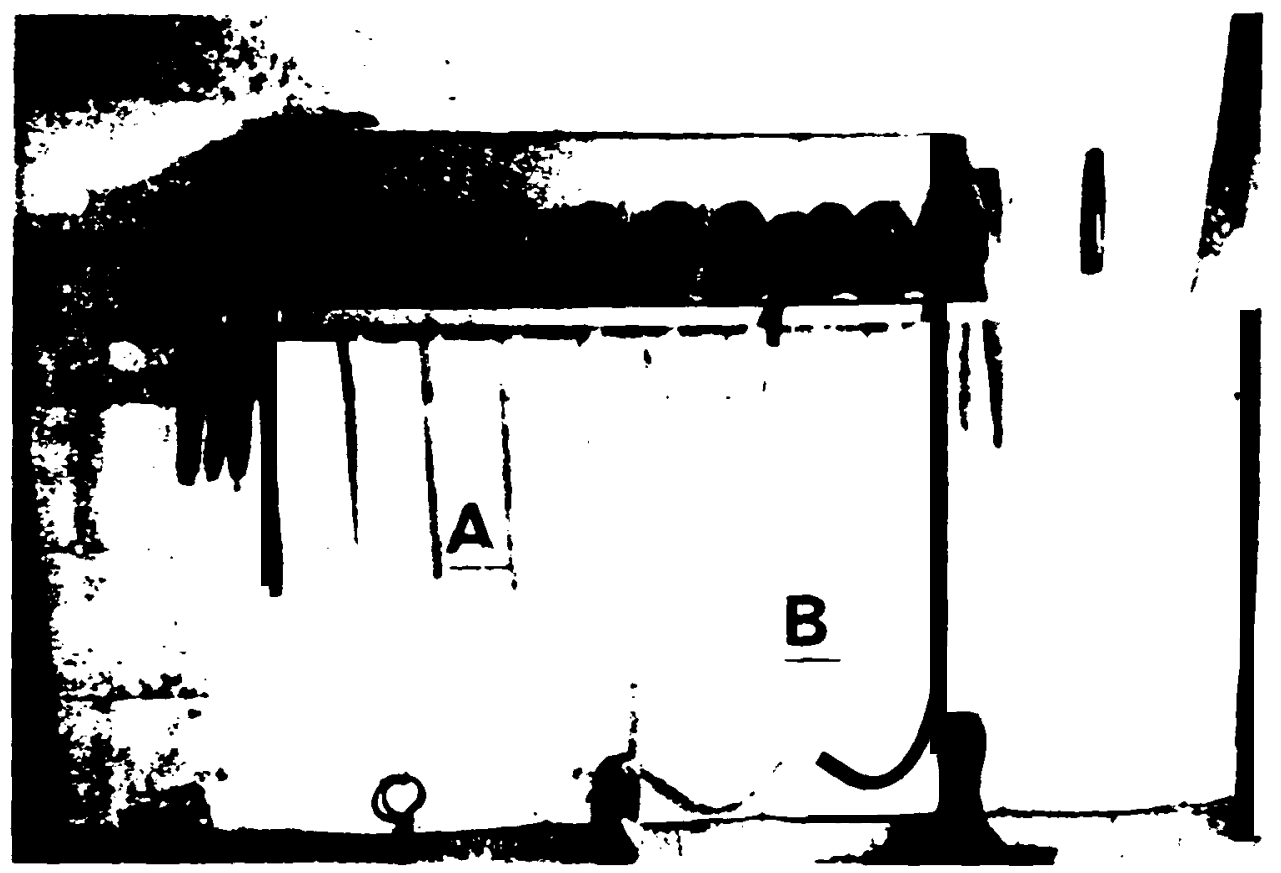

Figure 31. Tools used in egg picking: (A) bulb pickers, (B) siphon.

There are various types of siphon egg pickers. The simplest has only two parts; a length of flexible tubing and a 6-inch glass tube selected to the egg size for the picking end. Once the siphon is started, the glass tube is directed to an individual egg for removal. One hand of the operator controls the glass tube while the other pinches off the power of the siphon as required. The dead eggs lead through the tube and fall into a bucket below.

The bulb picker functions similarly to the siphon system. As the bulb is hand-squeezed and relaxed, the egg is sucked into the bulb and later dispelled with a squeeze of the bulb.

Fig. 32 (B) illustrates a wooden (cedar) tweezers. The wire loop on the end of each leg is sized to fit the egg. This tool is universally used and available in plastic or metal. 
Chapter 4

Advantages:

- $\quad$ They are cheap and easy to hold

- Ideal for picking small egg lots

- Usable during the tender stage

- Used in combination with all other methods

- $\quad$ Electric power not required

$\underline{\text { Disadvantages: }}$

- Time-consuming methods to pick large numbers of dead eggs

\section{Cost:}

Only a few dollars for any of the methods.

Infor mation Sources:

Contact steelhead hatchery managers for siphon and bulb pickers; salmon hatchery managers for wooden tweezers; Washington Department of Fisheries, Priest Rapids Salmon Hatchery

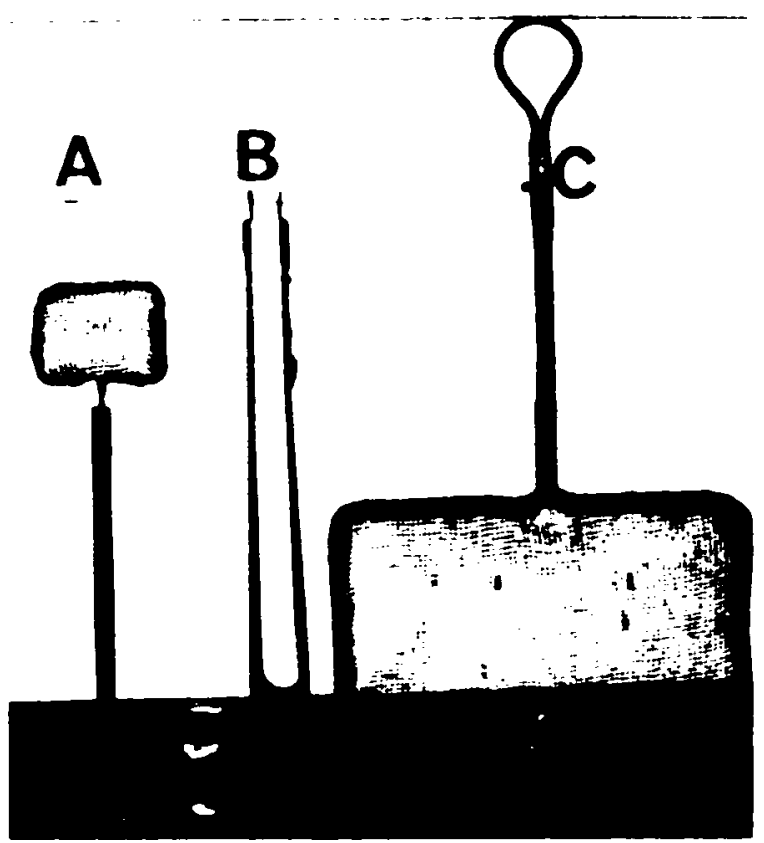

Figure 32. Tools used in egg picking: (A, C) skimmers, (B) tweezers. manager for plastic tweezers

Roe, Inc.

2. Ploatation Method This method is based on the fact that shocked infertile eggs have a specific density slightly less than shocked fertile eggs. By altering the specific gravity of water to a point where it is slightly greater than the dead eggs, but slightly less than the live eggs, the dead eggs will float. Sugar, table salt, and epsom salts are all used to alter the specific gravity, but the use of table salt is the most common. To change the specific gravity of water and keep it at the proper level is difficult, since fertile eggs have a specific gravity of 102 and water 100. Weithman and Anderson (1977) successfully tested these three solutions using a specific gravity of 1.075. Any watertight container can be used in this process but generally an incubation trough is employed. As the dead eggs float they are immediately skimmed off with small hand skimmers (Fig. 32). Care must be taken to remove the live eggs from the solution within minutes, as the solution can be lethal or cause weakness in the shell of viable eggs. In an 8-hour day, a person can remove dead eggs from a 500,000 egg lot.

\section{Advantages:}

- $\quad$ Special equipment or electric power is not required

- Very low cost 
Incubation

\section{Disadvantages:}

- The very narrow range in the specific gravity between dead and viable eggs make complete separation difficult

- Too long in the solution can be lethal or cause weakness to the egg shell on viable eggs, particularly if table salt is used

- It is difficult to regulate the specific gravity of the medium

\section{Cost:}

Several dollars of table salt would be sufficient for a million eggs. Sugar and epsom salts are slightly more expensive.

Infor mation Sources:

Most hatchery managers

3. Mechanical Pickers (optical density method) There are several optical egg pickers on the market and the newer ones can be adapted to count eggs. All the units are reasonably accurate, require a water and electrical supply, and can pick three to four times the number of eggs in a day as any of the methods previously discussed. Three brands commonly used in the Northwest are the Roescan, Jensorter, and Sustaf. The disadvantage of these and other brands is their high cost. Accordingly, they are not applicable for use at a low-cost facility. The Roescan and Jensorter cost $\$ 7,000$ each while the two models of the Sustaf cost $\$ 10,000$ and $\$ 13,000$ respectively. Further information is available from vendors in Appendix 2.

4. Bounce Method (Buzzell sorter) The Buzzell sorter consists primarily of two inclined boards and operates on the principle that shocked infertile or dead eggs have less resiliency than live eggs. Accordingly, when dead and live eggs fall a foot or two, the live eggs bounce many times further. To operate the sorter, eggs are rolled one layer deep down the upper board. When they fall from the upper to the lower board, they bounce, and the fertile and infertile eggs are separated by the distance bounced. Generally the eggs are sorted twice to achieve good results, but some units provide for two sortings of the same egg lot on a single pass. The sorter can be constructed of plywood, but the surface should be smooth. One person can sort approximately 500,000 to 700,000 eggs per day.

\section{Advantages:}

- Can be constructed in the home workshop, but is reportedly patented

- The units are portable

- The labor cost to operate the sorter is half that of hand picking and similar to flotation methods

- Electrical power is not required 
Chapter 4

Disadvantages:

- The last few remaining dead eggs may require hand picking

cost:

Material cost is $\$ 100$ for a plywood unit.

Information Sources:

Washington Department of Fisheries, Dungeness Salmon Hatchery

U. S. Fish and Wildlife Service, Quilcene NFH, Washington

Oregon Aqua Foods

\section{B. EGG COUNTERS AND ENUMERATION METHODS}

There are many ways to count or estimate egg numbers. Hechanical counters are usually the most accurate; however, they are subject to operator error. Estimations based on known numbers by weight or volume are adequate for most fish cultural programs since the degree of error usually falls within $5 \%$.

The three common egg enumeration methods described are mechanical counters, paddle counters, and the tools and equipment for estimating.

1. Mechanical Counters Several good electronic egg counters are available that count eggs at a rate of 5,000 per minute. Most units are adapatable to any physical layout and accurately determine egg numbers (Fig. 33).

Counters are used extensively by AFG and OFW. Cost ranges from $\$ 2,000$ to $\$ 5,000$. A recently developed model operates on 12-volt batteries. Local suppliers are Northwest Marine Technology, Inc., and Denny McLarry (contact through OFW).

2. Paddle Counter The paddle egg counter is used at most hatcheries (Fig. 34). By passing this unit through a basket of eggs, a sample of 100 are readily obtained. It is an excellent tool to accurately count large egg lots and works well on all species. One fish culturist can count 50,000 eggs per hour. A counter without a handle costs approximately $\$ 15.00$ (Demorest, Appendix 2).

3. Estimation Tools and Methods Estimating the number of eggs by weight or volume is reasonably accurate for large lots and is the least costly method. Only a few of the many ways are discussed here. To approximate total numbers by weight, a scale or balance (Fig. 35) is used to weigh four or five random samples of known numbers of eggs. Once a number per unit weight is established, the total number of eggs can be estimated after weighing the entire lot.

A slightly faster procedure is to count or use the above method to estimate the number of eggs per given volume, such as in a coffee can or a 5-gallon bucket. The total egg count is then equal to this figure multiplied by the number of cans or buckets of eggs comprising the entire lot. 


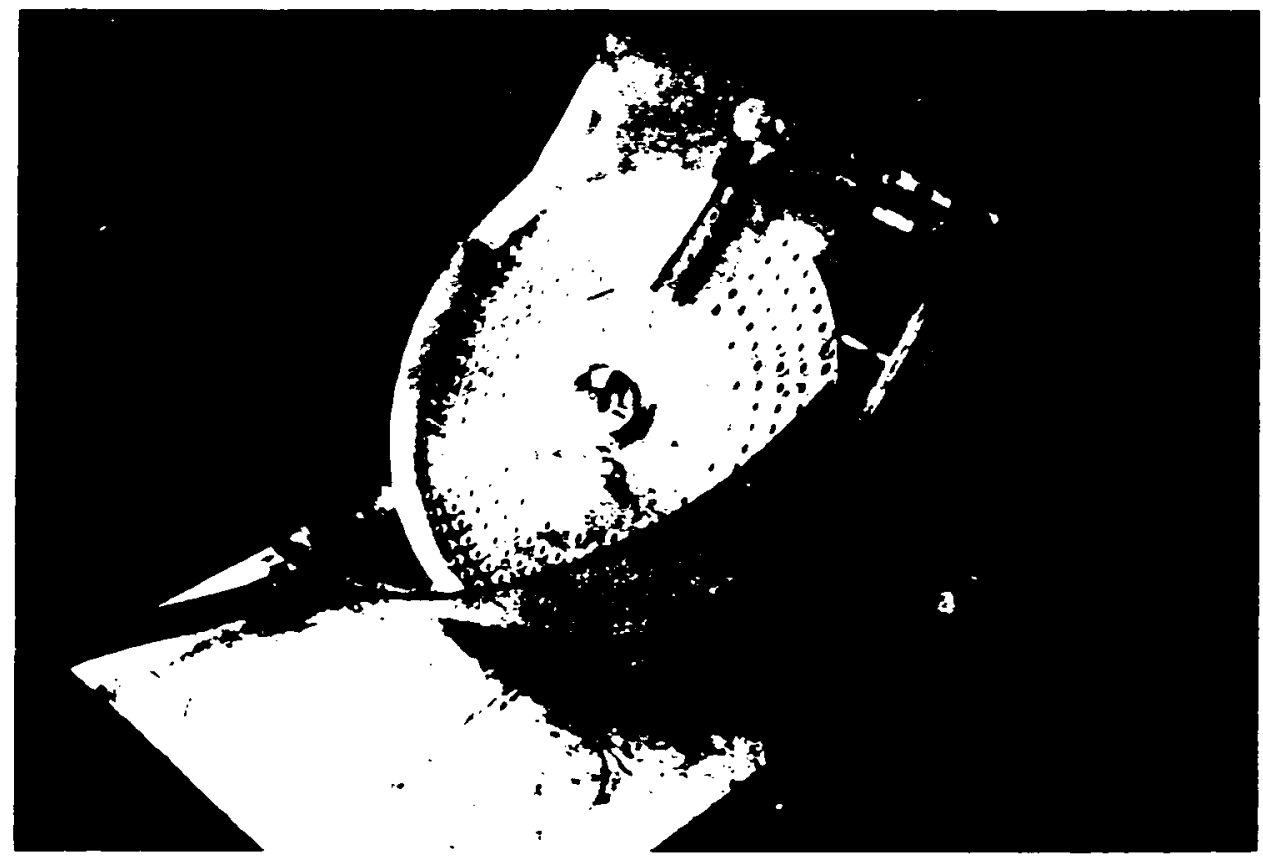

Figure 33. Mechanical egg counter used at many OFW hatcheries.

The water displacement method is another technique, and tables are available that show the number of eggs it takes to displace a given volume of water in a vessel. Also used is the ratio of the number of eggs per unit of length. Here, too, a table will allow the numbers to be estimated.

Hatchery personnel sometimes make gross egg estimates using the average number of eggs per female, or eggs held by an incubation unit of known capacity. These are reasonably accurate as an interim procedure; however, once the eggs are eyed and shocked a more accurate estimate is made.

\section{SUBSTRATES}

Substrate, or a medium in which alevins incubate, was originally conceived to be used for pink and chum salmon. Recently, fish culturists have begun to use it for incubating
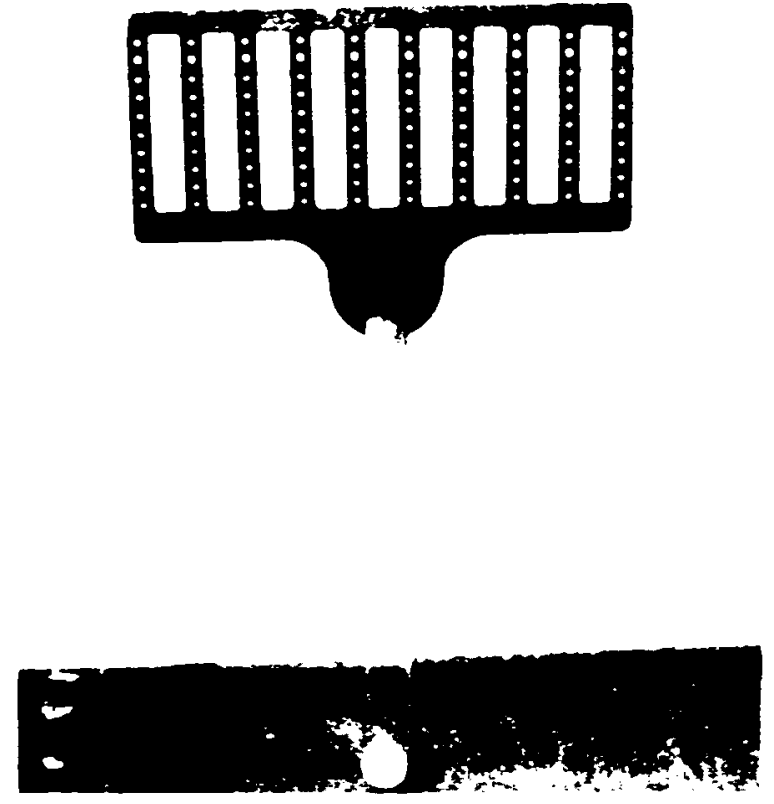

Figure 34 Paddle egg counter of 100-egg capacity. 


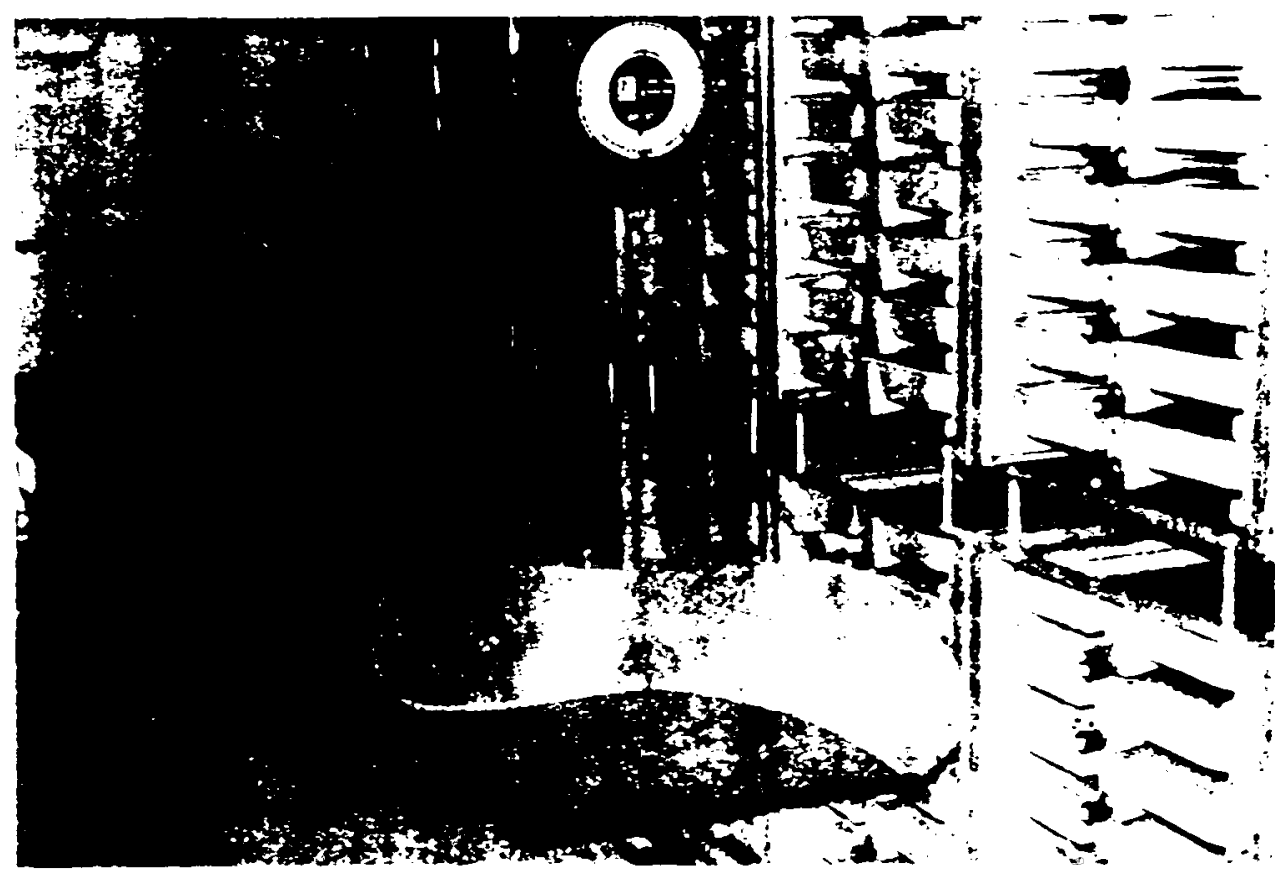

Figure 35. Spring scale and perforated scoop for weighing eggs.

chinook and coho, and to a lesser extent, steelhead trout. The reason for using substrate is to produce a higher quality fry and a better smolt. The former has been well-documented, but, the latter has not, especially in regards to a long-term reared fish. Regardless, most culturists agree that the improved fry quality has one definite benefit. That is, the extra cost and labor required to use substrate is offset by having less pond mortality during the early stages. Gains, if any, in the quality of smolts would be an additional benefit.

There are four substrates commonly used for incubation: gravel, plastic netting, plastic saddles, and plastic bio-rings. Fish culturists often differ in their selection of the substrate even for the same type of incubation unit. In cabinet incubation, all substrate types described seem to produce equal quality fry. This is substantiated by the recent work of Banks (1983). For other incubation units, a more careful choice of substrate should be considered. Cost, availability, personal preference, and ease of use are factors affecting choice.

1. Gravel Substrate Gravel substrate is most commonly used in egg-boxes, the Japanese keeper channel, egg-incubation channels, and spawning channels. A good gravel size for salmon egg-boxes and keeper-channels is $5 \%$ or less under 1 inch or over 2.5 inches, by weight, and the remainder ranging in size between these parameters. Steelhead are successfully incubated in Japanese keeper channels with this size gravel (Fig. 36). 


\section{Advantages:}

- The material is economical and readily available in the Columbia River basin

\section{Disadvantages:}

- It requires more physical effort to clean than other substrates

- The transportation of gravel to remote areas may be difficult

\section{Cost:}

The price is approximately $\$ 12$ /cubic yard at most sand and gravel companies.

\section{Information Sources:}

Washington Department of Fisheries Canada Department of Fisheries and Oceans

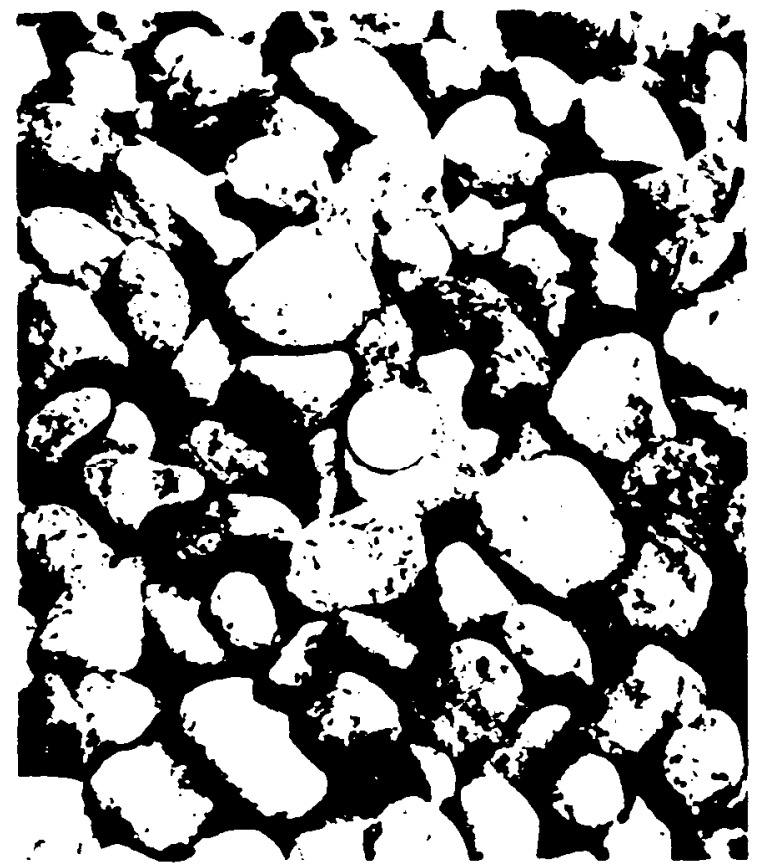

Figure 36. Typical gravel composition used in egg boxes and keeper channels.

2. Plastic Netting Polyethylene netting is used in vertical cabinet incubators and other tray-type incubators. The netting is a heavy gauge with mesh sizes of 0.75-1.25 inches. Each tray receives three folded layers tied to form a mat.

\section{Advantages:}

- Requires little space within the incubator

- The material is easily removed and separated from the fry

- Suitable for use in shallow tray incubators

\section{Disadvantages:}

0 The material is more difficult to clean than other artificial substrates because it cannot be run through a fish pump.

cost:

The material is $\$ 150$ per 48 -inch, 150 -foot roll. 


\section{Chapter 4}

Information Sources:

U.S. Fish and Wildlife Service

Abernathy Salmon Cultural Development Center, Longview, WA

Washington Department of Fisheries

Internet, Inc.

Memphis Net and Twine Co., Inc.

3. Plastic Saddles Plastic saddles, illustrated in Fig. 37, are constructed of poly-propylene and should be manufactured with a greater specific gravity than water. The width of the saddle commonly used is 1 inch. Saddles often are placed in 3/4-inch mesh net bags so they can be easily removed from the incubators. If the saddles have sharp edges, they are mixed with sand and turned in a cement mixer until acceptable. They can be used in most incubation units.

\section{Advantages:}

0 The material is light, easy to handle and transport and can be stored in bags

$0 \quad$ They can be washed and transported with a fish pump

- Saddles have more total void spaces than gravel per volume of material

Disadvantages:

0 The saddles tend to pack in the incubators

0 The material is expensive compared to gravel

$0 \quad$ More difficult to clean than bio-rings

0 The fry are more difficult to remove from saddles than bio-rings

\section{Cost:}

Approximately $\$ 16-\$ 30 / \mathrm{ft}^{3}$ or $\$ 640-\$ 1200$ per 4 x 8 -foot deep-matrix box (cost varies by vendor and is based on order of $100 \mathrm{ft}^{3}$ ).

\section{Infor mation Sources:}

Alaska Department of Fish and Game

Canada Department of Fisheries and Oceans

Glitsch, Inc.

Norton Company

4. Plastic Bio-Rings Plastic bio-rings (Fig. 37) can be used in most incubation units. A 1.5-inch diameter ring appears best for salmon while a l-inch ring would likely be best for steelhead. The rings should be ordered to sink in water.

For salmon alevins, fish culturists place bio-rings in loose bags made of I-inch mesh plastic netting. Mariculture Northwest places three bags of rings in a 50-gallon incubation barrel. They are removed from the incubator during the latter phases of yolk absorption or when the fry are ready to pond. The bags are easily removed with 
a short hook, leaving only fry. The rings can be stored in these bags. They can also be made up in long strings for easy removal.

\section{$\underline{\text { Advantages: }}$}

0 The same as those listed for saddles

o Bio-rings do not pack in the incubators

$\underline{\text { Disadvantages: }}$

$0 \quad$ Bio-rings are more expensive than gravel

\section{Cost:}

The lowest price obtained was $\$ 12.10 / \mathrm{ft}^{3}$ in $100 \mathrm{ft}^{3}$ lots for

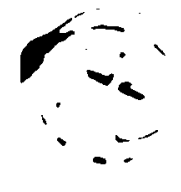

B

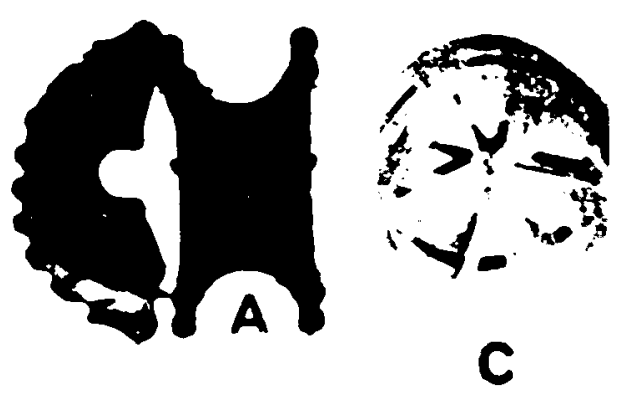

Figure 37. Plastic substrate materials used in incubators: (A) saddles, (B) 1-inch bio-rings, (C) $1.2 \%$ inch bio-rings.

Washington Department of Fisheries

Mariculture Northwest, Rochester, Washington Glitsch, Inc.

Norton Company

\section{PART IV. SUMMARY}

Table 4 summarizes information presented in this Chapter on the various types of salmonid incubators and compares their initial unit capital costs and floor space requirements in terms of egg and alevin production.

Table 5 grossly rates these same incubators on several practical features that are important in selecting a suitable incubation method. These features deal with their suitability for other uses, complexity of plumbing, ease of operation, and unit longevity. These tables show substantial differences in the relative cost, space requirements, and multipurpose functions of various units.

We feel that all the incubation units considered can be used successfully and, when differences between units are minor, we suggest that staff preference be considered. 
Chapter 4

Table 4. Comparison of capital costs and floor space requirements versus potential production for 16 different salmonid incubators.

Unit $\operatorname{cost}^{(1)}$ per
100,000

Type of incubator

Vertical

Cabinet (16 trays high)

NOPAD (5 units high)

Trough

Deep (2 units high and 2 wide)

Shallow (3 units high and 4 wide)

Pond

Wooden tray $2.5 \times 4 \mathrm{ft}$.

Metal tray $2.5 \times 4 \mathrm{ft}$.

Box

Deep-matrix

$4 \times 8 \times 4$ feet

$2 \times 8 \times 1.25$ feet

Shallow-matrix

$4 \times 8 \times 1.3$ feet

Montana

Free-style (single)

Cylinder

Modif ied jar

l-gallon jug (3 high)

5 -gallon bucket ( 2 high)

55-gallon drum

R-48 barrel $\underline{\text { Eggs }} \quad \underline{\text { Alevins }}$

$\$ 1250$

250

90

491

100

400

100

400

300

500

300

500

667

200

120

500

83

33

50

106

500

460

667

267

400

500

167

67

125

248
Production per square foot of floor space (3)

Eggs

Alevins

(in thousands)
10

62

7

54

13

23

3

outdoors

outdoors

13 or outdoors outdoors

13

outdoors

50

37.5

71 or outdoors 21
10

10

35

33

65
31

(1)Includes all costs, except external plumbing, necessary to make unit ready to operate, including trays or baskets.

(2) Calculations based on average egg size of 1400 per pound.

(3)Floor space includes aisles between rows of units but not end walkways. 
'lathle 5. Summary analysis of salmonid incubator units to compare practical features and aid in the selection process.

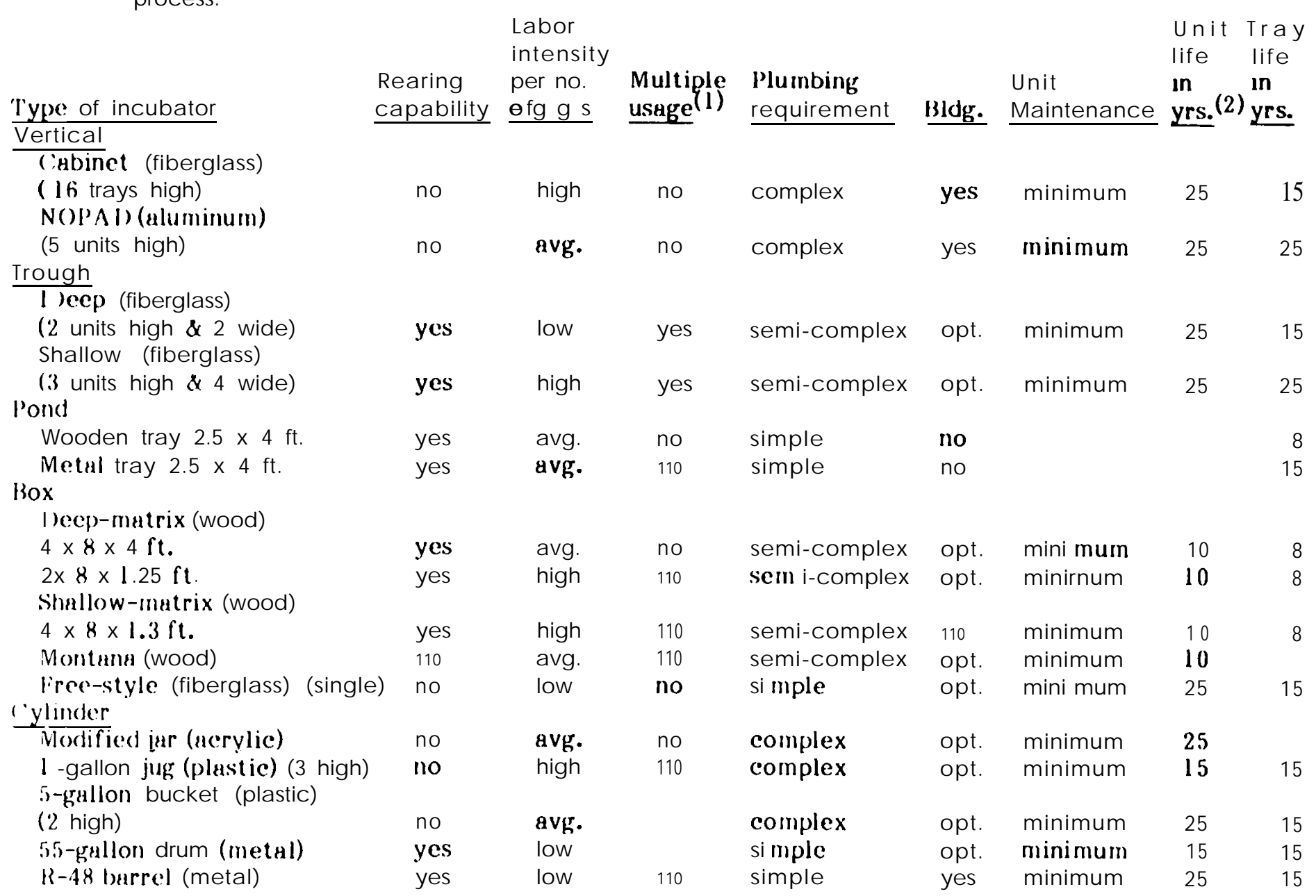

( I) ( $A n$ be used for egg shocking, picking and sorting, as disinfectant tanks, and for holding fish for marking or other exweriments.

(2) Maintenance for each type of incubator is deemed minimal or about the same, and not an important factor in selection. 'I'hose with longer unit life usually require less maintenance. 


\section{Chapter 4}

Based on our visits to numerous salmon rearing facilities in the Northwest, and knowing the ingenuity of the culturist, we expect that some will find exceptions to our ratings. Regardless, we feel that our work is reasonably representative of the actual conditions and practices that currently exist. 


\title{
CHAPTER 5
}

\author{
REARING
}

This Chapter includes biological requirements for rearing, descriptions of various rearing facilities, information on fish feeds, and support equipment. It was largely derived from direct contacts with fish culturists, visitations to Northwest facilities (Appendix 3), and from the aquaculture suppliers listed in Appendix 2. Further information was obtained from the Facility Design Work Group, consisting of Federal, State, and Tribal representatives in Washington and Oregon formed under the Salmon and Steelhead Conservation and Enhancement Act (SSCEA) of 1980 (PL 96-561).

\section{PART I. BIOLOGICAL REQUIREMENTS}

We have selected two criteria to determine the fish production capacity of a salmonid rearing facility. These are:

(1) The maximum pounds of fish to be reared with a water supply of l-gallon per minute (gpm) and adjusted for species, fish size, and water temperature (Table 1).

(2) The maximum pounds of fish to be reared in 1 cubic foot $\left(\mathrm{ft}^{3}\right)$ of rearing water and adjusted for fish size (Table 2).

We believe that choosing these two criteria will:

(1) Allow realistic prototype facilities to be designed and programmed by ourselves as in Chapter 9, and

(2) provide a guide for facility selection and realistic programming by the reader. Thus we have attempted to identify the specific levels of production for each criterion that is representative of current fish culture programs conducted by Northwest tribal and agency culturists.

We recognize that other biological factors have been used for design parameters, some of which include: oxygen consumption rates, accumulation of metabolic products (Haskell, 1955), production of un-ionized ammonia $\left(\mathrm{NH}_{3}\right)$ (Willoughby et al., 1972; Burrows, 1964; Trussel, 1972), disease considerations (Wedemeyer and hood, 1974), and historical conditions of existing stations (Banks et al., 1979). More recently, all Northwest agencies have been attempting to develop rearing criteria based on survival levels to adult.

To reduce risk, a new station is usually managed conservatively for the first few years until its performance characteristics are developed. This performance record is then used to adjust future production levels. A part of this performance record is how the species 


\section{Chapter 5}

Table 1. Hatchery pond loadings expressed in pounds of fish per gpm of inflow. (1)

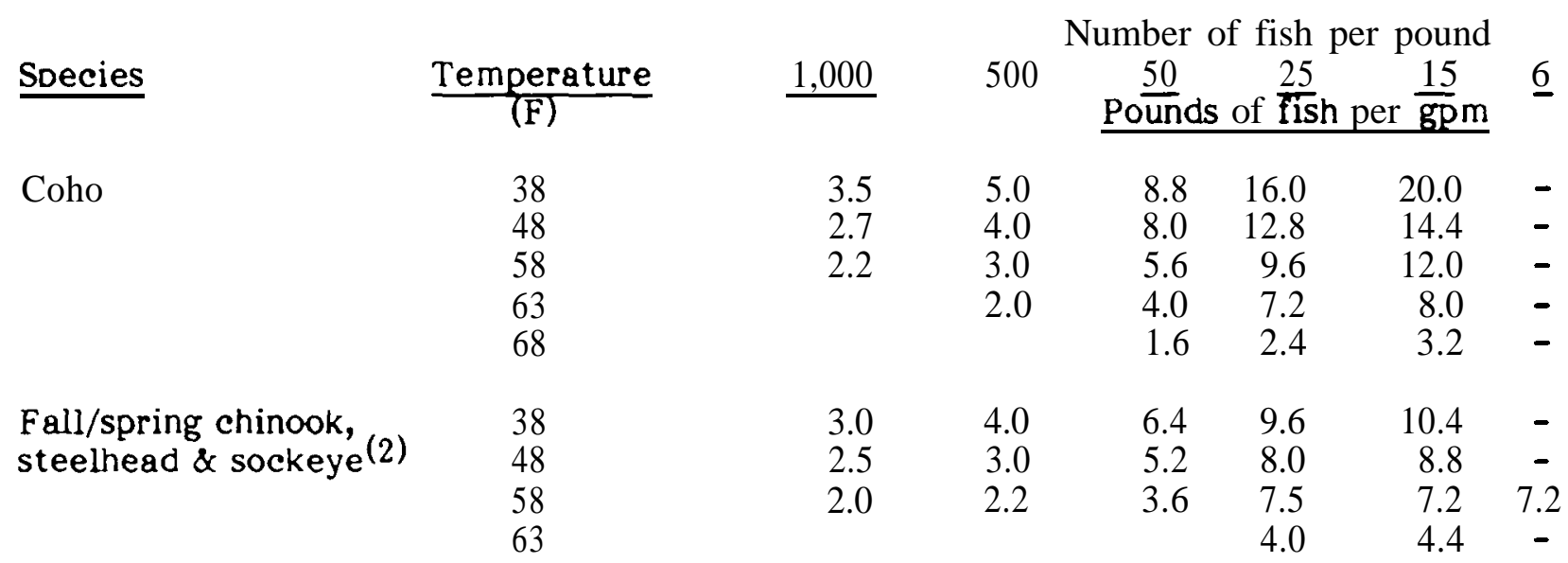

(1) Source: The basis for this table is primarily Wedemeyer and Wood (1974); however, it has been modified to show less pounds of fish per gpm with fish larger than 50 per pound (9 grams each). Modification was made after conferring with the Facility Design Work Group of SSCEA (Zook, 1984).

(2) The data for sockeye and steelhead were not presented by Wedemeyer and Wood, (1974). We arbritrarily assumed it to be similar to chinook after conferring with members of the SSCEA Facility Design Work Group. See Zook, (ibid).

Table 2. Rearing criteria for salmonids in pounds of fish per cubic foot of rearing water for ponds less than $4,000 \mathrm{ft}^{3}$ capacity(1) and assuming water temperatures are within normal recommended ranges for the species. $(2)$

Species

Number of fish per pound $12 \overline{\mathrm{M}}$ aximum pounds of fish/ $\overline{\mathrm{ft}}^{3} \quad \overline{15} \quad \underline{7}$

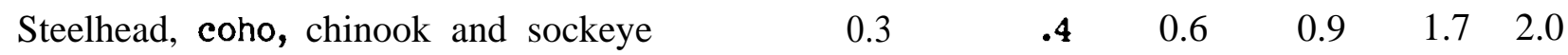

(1) The primary information source was Banks et al., (1979), however, for fish of a size larger than $100 / \mathrm{lb}$. (4.5 grams), we reduced the pounds $/ \mathrm{ft}^{3}$ of rearing space by approximately $20 \%$. Banks did not include sockeye in his material, but we will assume sockeye to be similiar to coho, chinook, and steelhead.

(2) The ft3 capacities are not affected by temperature as long as they are within the ranges recommended for the species. 
respond to conventional diets. Table 4, which follows in the Fish Food Section of this chapter, illustrates typical conversion rates of salmonids from first feeding to various release sizes and gives the manager a basis for comparison. For further discussion see Banks (ibid).

Recent studies by all Northwest agencies have suggested that rearing reduced numbers of salmonids in a given environment will produce a higher survival to adults and often result in a greater return for the dollar invested.

Zook (1984) showed that culturists in the Northwest often differ by $30 \%$ or more in the levels of a criterion used for rearing. In our opinion, this difference is to be expected in fish culture given the "state of the art" with all its variables. One can readily see, however, that if the functional criteria is for 30 percent more or less water or space for a given program the criteria is highly reflected in construction and design cost. Regardless of these differences, the least costly rearing facility will generally result if it is designed and constructed to approach the maximum recommended fish production levels established for each criterion. For example, the required amount of water (Table 1) should match the required amount of space (Table 2). Several approaches to address this concern exist, but the one we chose to use is to first determine the space requirement, and then program the required amount of water.

In a non-theoretical situation, where the desired amount of water may not be available, cost savings will result by reducing our original space conception.

Our recommended maximum pounds of smolts per cubic foot of rearing space (density) in ponds less than $4,000 \mathrm{ft}^{3}$ is illustrated in Table 2. For larger rearing ponds and for the purpose of this report, densities in Table 2 are reduced by one percent for each additional 1,000 cubic feet of rearing space, up to $50 \%$ (see Appendix 6). These density levels correspond generally with the current programming by agencies and tribes. This reduced level will decrease the possibility of disastrous loss by risking many fish in a single pona. When water is re-used (i.e. flows from one pond to another with larger fish), we have used an equivalent value of $60 \%$ of new water. This value is based on the practice of the USFWS and WDF who both use a new water equivalent of about $66 \%$. Table 2 provides information for pond design based on the volume of water in the rearing pond as related to fish size.

The "interchange rate" is a term often provided to the design team by the culturist that relates to the number of times a pond is filled each hour by the inflowing water. For example, an interchange rate of "2" means the pond will be filled twice during a 1-hour period. The rate can be calculated by multiplying the inflowing water in cubic feet per second (efs) by the seconds in an hour and then dividing by the cubic feet of rearing space in the pond. The formula is as follows:

$\frac{\text { rate of inflow (cfs) } x \text { (seconds in } 1 \text { hour) }}{\text { cubic feet of rearing space }}$

A pond containing $1,350 \mathrm{ft} 3$ of rearing space wth a water flow requirement of $338 \mathrm{gpm}$ $(0.75$ cfs), has an interchange rate of " 2 ". 


\section{Chapter 5}

$\frac{(0.75)(3600)}{1350}=2$

Interchange rates are often expressed incorrectly if the gallon per minute requirements are not carefully analyzed. If, for example, the rate is expressed to the design team as " 3 " and the space and flow requirements are the same as in the previous example, the facilities water flow will be over-designed by $50 \%$, because of the limitation with the pounds of fish that can be reared in a $\mathrm{ft}^{3}$. Most interchange rates fall between 1 and 2.5 . If we calculated for 15 per pound coho at $58 \mathrm{~F}$, the interchange rate would be 1.1 (based on tables provided) and 2,295 pounds of coho could be reared in the $1350 \mathrm{ft}^{3}$ pond using 191 gpm of water.

Because we have insufficient data to show that there are differences in production capabilities between raceway and circular troughs and ponds of equal size, we will assume them to be identical for the purpose of this report.

\section{PART II. REARING FACILITIES}

Fish rearing facilities are one of the most expensive components of a fish cultural station because of the space and water requirements that increase dramatically once incubation and early development stages are complete. Fortunately, many types of facilities are available and experimentation continues as fish culturists seek to reduce costs and improve fish quality. The options for multiple use must always be considered in selecting and costing a rearing facility. Some rearing facilities are also used for holding adults, housing incubation units, or as settling ponds to precondition incubation water. Generally, rearing ponds are designed to provide for the following:

A uniform water flow to minimize stagnant water areas and to flush metabolic wastes.

A screened water supply to prevent the entrance of debris and wild fish.

Stable sides and bottom.

Drainable for removing fish, cleaning and disinfecting.

Pond drain sized to permit the water to be lowered while maintaining the incoming supply during low-water operations.

A minimum of water seepage.

Access around the pond periphery for operations and maintenance.

Installation of predator control measures.

Protection from freezing weather, especially units above ground.

Rearing ponds are usually not classified by type of facility and rearing stage as most ponds can be used for all phases of rearing. But, for the purpose of discussion in this report, they are described as: troughs and tanks, raceways, circular ponds, large rearing ponds, and net pens and enclosures. A summary of the costs and usable life of the units described in the following sections is shown in Table 3. 


\section{A. TROUGHS AND TANKS}

Most troughs and tanks that have been used for the incubation stages of salmon and steelhead trout development have limited use in volume rearing. The initial feeding of salmon and steelhead trout at many hatcheries occurs in deep or shallow troughs, in concrete tanks which resemble deep troughs or small raceways, and in small circular tanks. Most fish culturists use the shallow troughs for steelhead trout and some agencies use both shallows and deeps and/or tanks for salmon. Small lots of steelhead are sometimes isolated in smaller units with separate water systems if virus disease is suspected, or if it is desired to keep genetically unique lots separate. In our opinion, these small tanks are generally not required for starting salmon. At many hatcheries, salmon feeding is initiated directly in larger ponds or the fish are congregated in a section of a raceway or pond until they are accustomed to taking food. This technique saves the cost of the starter units, building space if units are housed, and labor because larger numbers can be fed at one time. If the starter units for steelhead are deemed necessary for low-cost facilities, we recommend the portable troughs that can be stacked two to four units high to save floor space (Fig. 1). Rearing densities and flow rates for both shallow and deep troughs are shown in Chapter 4, Table 3.

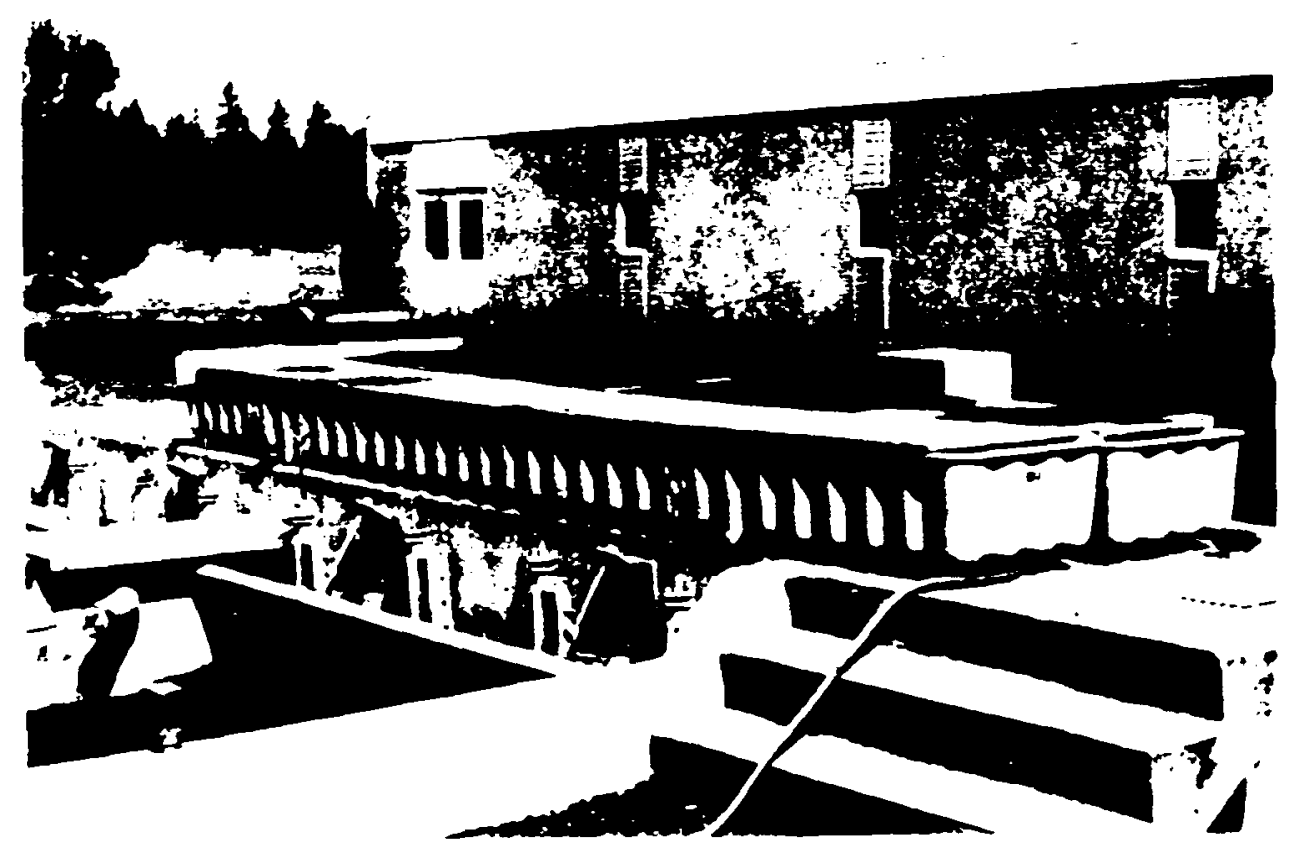

Figure 1. Fiberglass troughs used to rear fish at the Cowlitz Trout Hatchery ( $W D G$ ).

\section{General Trough Advantages:}

Small lots can be easily handled

Special lots can be kept separate or isolated

The initial feeding can be conducted under close observation 


\section{Chapter 5}

\section{General Trough Disadvantages:}

$0 \quad$ Time consuming to feed small lots and clean units

$0 \quad$ Kequire considerable in-house floor space if not stacked

0 If stacked, automatic feeders may be difficult to use

cost:

See Chapter 4 (Incubation) for details. A fiberglass shallow trough costs about $\$ 300$, and a fiberglass deep trough costs approximately $\$ 900$.

1. Capilano Rearing Trough The Capilano rearing trough was developed at the Capilano Hatchery, Vancouver, British Columbia. Constructed primarily of 12 -gauge sheet aluminum or fiberglass, they are parabolic in cross-section, and approximately $1.75 \times 21 \times 1.5$ feet (Fig. 2). They are very efficient for raising small lots of fish from the emergent -stage to approximately $90 \mathrm{fish} /$ pound. Consequently, these units have been popular for rearing steelhead trout fry, 90-day chinook smolts, chum fry to $450 /$ pound, and advanced coho fry for out-planting at 90-180 fish/pound. The spacial requirements for fish larger than $90 /$ pound tends to negate their use because they become very labor intensive. The Capilano trough has also been used for holding adults, and may be set up as an incubator by vertically baffling into compartments, loading with gravel, and thus creating several upwelling incubators in series. Estimated incubation production would be approximately 450,000-600,000 alevins based on 10-15 $\mathrm{gpm} / 100,000$ alevins. Unless one is dealing with small numbers, adult holding tends to be inefficient due to the limiting capacity. On average, one trough will hold 100 pounds of adult fish based on a loading rate of $2.0 \mathrm{lb} / \mathrm{ft}^{3}$. Flow rates are adjustable up to 30-40 gpm.

\section{Xdvantages:}

Easy to clean, and treat diseased stock

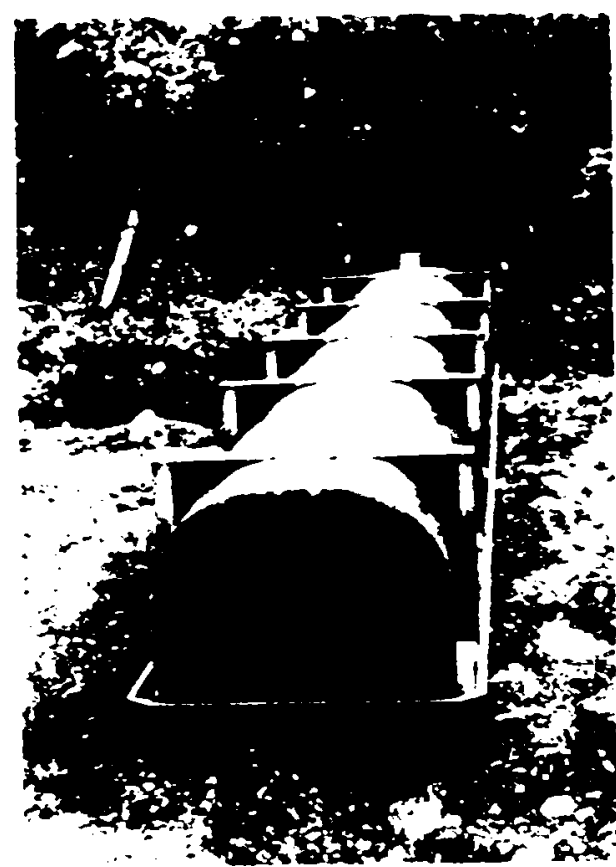

Figure 2. Capilano rearing trough upside down to show construction (DFO).

Good laminar flow patterns

Relatively high loading rates for fish up to $90 / \mathrm{b}$

Relatively maintenance free

Good usage when working with small remnant stocks destined for out-planting

Quality control of fish easily monitored visually and through routine sampling programs

- Relatively portable 
Rearing

$0 \quad$ Multiple usage, i.e. adult holding, fry rearing, and incubation

0 May be mounted above or adjacent to rearing raceways and used to stock raceways

$\underline{\text { Disadvantages: }}$

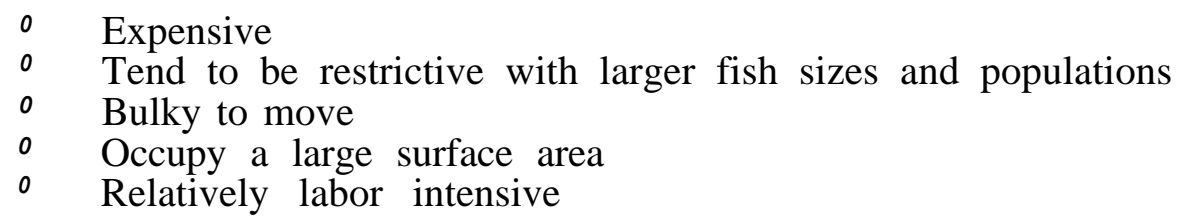

\section{Cost:}

The cost of one aluminum trough is about $\$ 1000$, or $\$ 18.14 / \mathrm{ft}^{3}$ of rearing volume. Life expectancy is 25 years. The fiberglass units cost more.

Information Sources:

Oregon Fish and Wildlife Lookingglass, Marion Forks, and Salmon River Fish hatcheries

Canada Department of Fisheries and Oceans

M \& W Fabricators

PROMETCO

\section{B. RACEWAYS}

The most common salmon and steelhead trout rearing facility in the Pacific Northwest is called a raceway. They are a rectangular water container used for all phases of rearing, and range from 3-20 feet in width, 20-150 feet or more in length, and have a water depth of 1-10 feet. Water enters at one end of the raceway and flows out the other. The various sizes evolved as fish agencies designed units to meet specific needs. Recently the fish agencies adopted a standard size of $10 \times 100 \times 3.5$ (mean water depth) which will be used at all hatcheries constructed under the Lower Snake River Compensation Plan.

Raceways are usually constructed with 6-12 inches of floor slope per hundred feet and built side by side so two ponds can utilize a common wall. Normally they are built in clusters of four, eight, twelve, or sixteen, and are referred to as a "Dank of raceways". The most efficient water utilization occurs when the units are installed in tandem, and in consideration of disease problems the smaller fish are reared upstream of the larger fish. Managers generally prefer single water usage (single pass), especially on fish of sinilar size.

Because of their configuration, raceways have a distinct advantage in that the water flow patterns can be designed for optimal fish health and production density.

For the inlet supply water we recommend a diffuser across the upper end of a raceway (Fig. 3). This creates a uniform water velocity and flow pattern throughout the pond and 


\section{Chapter 5}

eliminates "dead water" areas. For the drain or outlet structure we recommend the design illustrated in Fig. 4. The barrier (A), or the second standpipe (B), increases the water velocity along the bottom of the pond and creates a self-cleaning action in the area where most netabolic waste and unused food particles settle. This is especially beneficial if brush cleaning is used since most waste is pushed along the bottom. These inlet and outlet systems will optimize water quality and pond cleanliness.

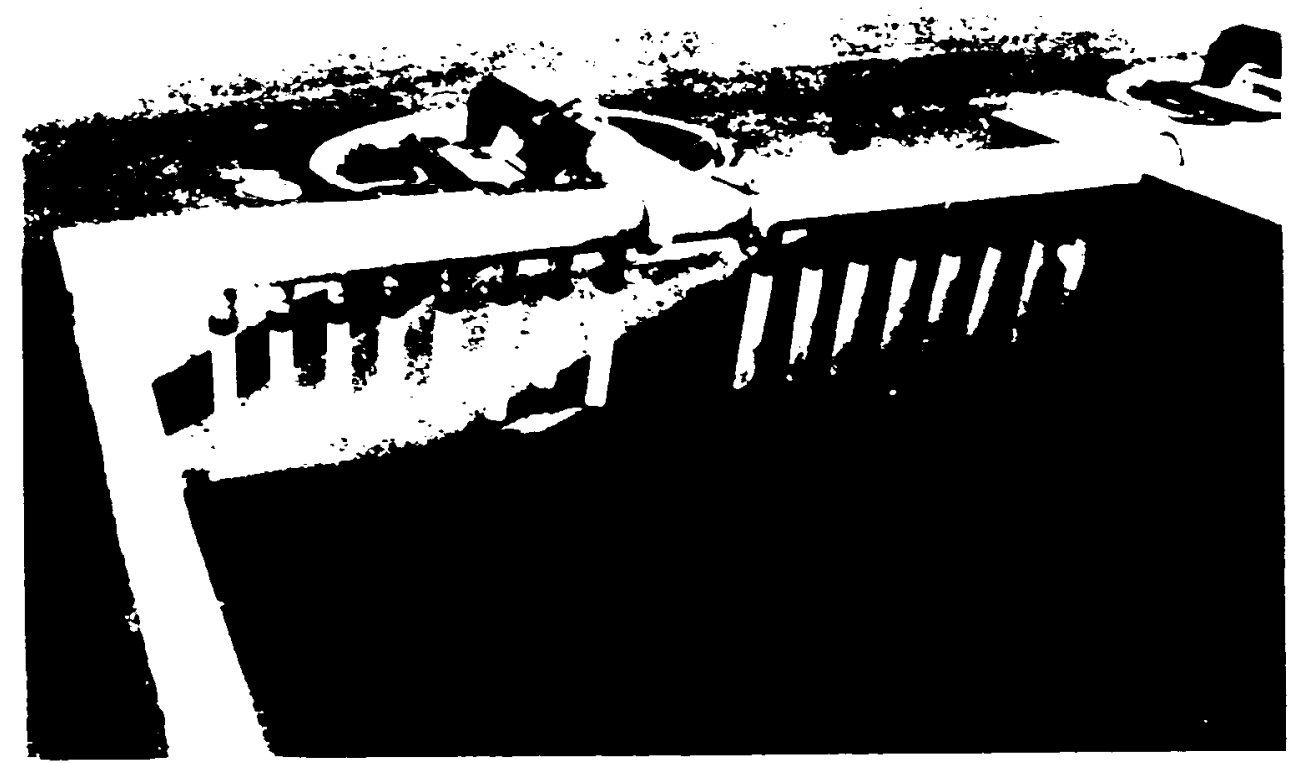

Figure 3. Inlet water system on a lo-foot raceway at the raselie Salmon Hatchery ( $W D F$ ).

Raceways can be fixed or movable units. The former are usually constructea of concrete or dirt, while the latter include wooden, metal, and fiberglass units. The metal and fiberglass structures can be purchased as shelf items. The general advantages and disadvantages of all raceways and specific details on types of units are discussed below. init details and costs do not include the water supply and drainage systems.

\section{General Raceway Advantages:}

- Water velocity patterns can be optimal through proper cesign

- Can be used for fry, fingerling, and smolt rearing

- Ponds can be sectioned to accomodate small lots of fish and different species

- Easier to clean; diagnose and treat fish for disease; and control and handle fish, than most rearing units

0 The design results in water-borne diseases moving rapidly through and out of the system

- Predator control measures are easy to incorporate

- If common walls are used, they are more cost efficient 


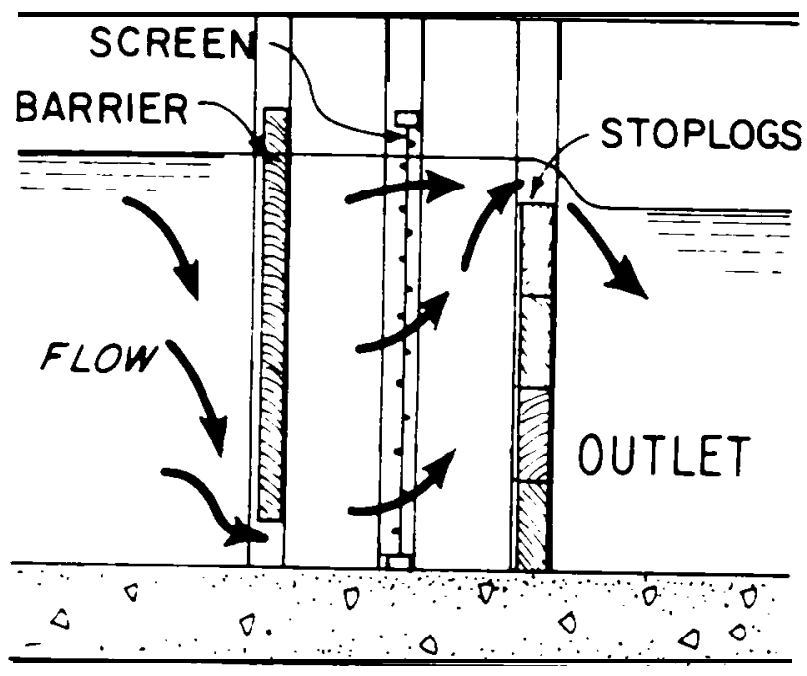

A.

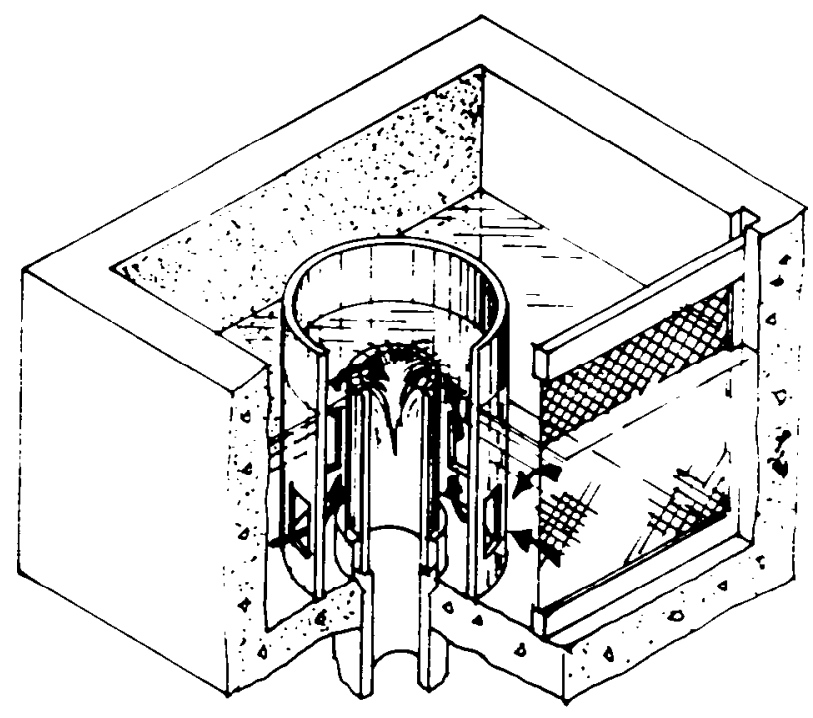

B.

Figure 4. Outlet drain of a rearing pond showing how water flow is directed along floor of pond with (A) baffle, (B) second stand pipe.

General Raceway Disadvantages:

- High space requirement when common walls are not used

- High unit development and manpower operating costs, particularly for small concrete units

- Sectioning of ponds generally requires vaccum cleaning unless short-term retention is programmed.

1. Concrete Raceway A typical USFWS-type reinforced concrete raceway is 8.75 $\mathrm{x} 80 \times 4$ feet and the walls and floor slab are 8 and 6 inches thick, respectively (Fig. 5). One cfs is the maximum designed water inflow and the mean water depth is maintained at 3 feet, providing $2000 \mathrm{ft}^{3}$ of rearing water.

Advantages:

- Low maintenance

- Long life expectancy

Disadvantages:

- Difficult to construct; requires plumb, straight walls for fish crowding, and has numerous embedded screen and flashboard guides

High cubic foot construction cost

Pond cleaning requires 1 hour per week per pond 
Chapter 5
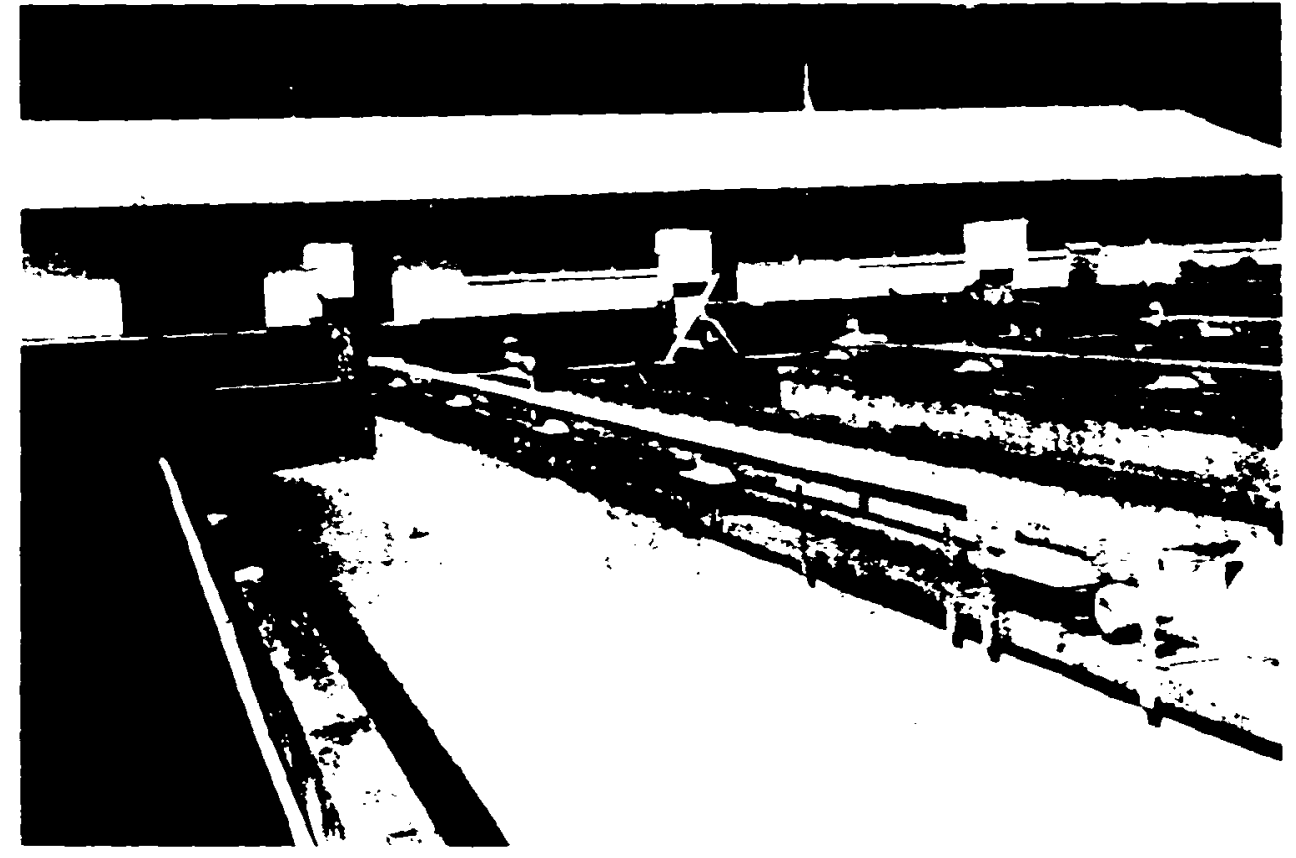

Figure 5. Typical concrete raceway at the Abernathy Salmon Cultural Development Center (USFWS).

Cost:

The capital cost is approximately $\$ 6.44 / \mathrm{ft}^{3}$ of rearing water, and the unit has a 50-year life expectancy.

Information Sources:

Federal and state fish hatchery managers

2. Earthen Raceways These ponds are usually constructed from materials available from on-site excavation, but sometimes material importing is necessary, particularly if surfacing is desired or if pond sealing is necessary. Gravel is usually used for surfacing and clay for sealing. Earthen raceways can be any size (Fig. 6) but a typical one is $20 \times 80$ feet and has a 3-foot water depth providing $2600 \mathrm{ft}^{3}$ of rearing area. The banks are constructed on a 3:1 slope or steeper. The water supply may be delivered through an upwelling facility at an elevation slightly higher than the pond surface (Fig. 7). However, we recommend a manifold system as illustrated in Fig. 17, which provides more favorable flow patterns. Pond drainage can be through a vertical riser pipe, or through a stop log facility with screening. 


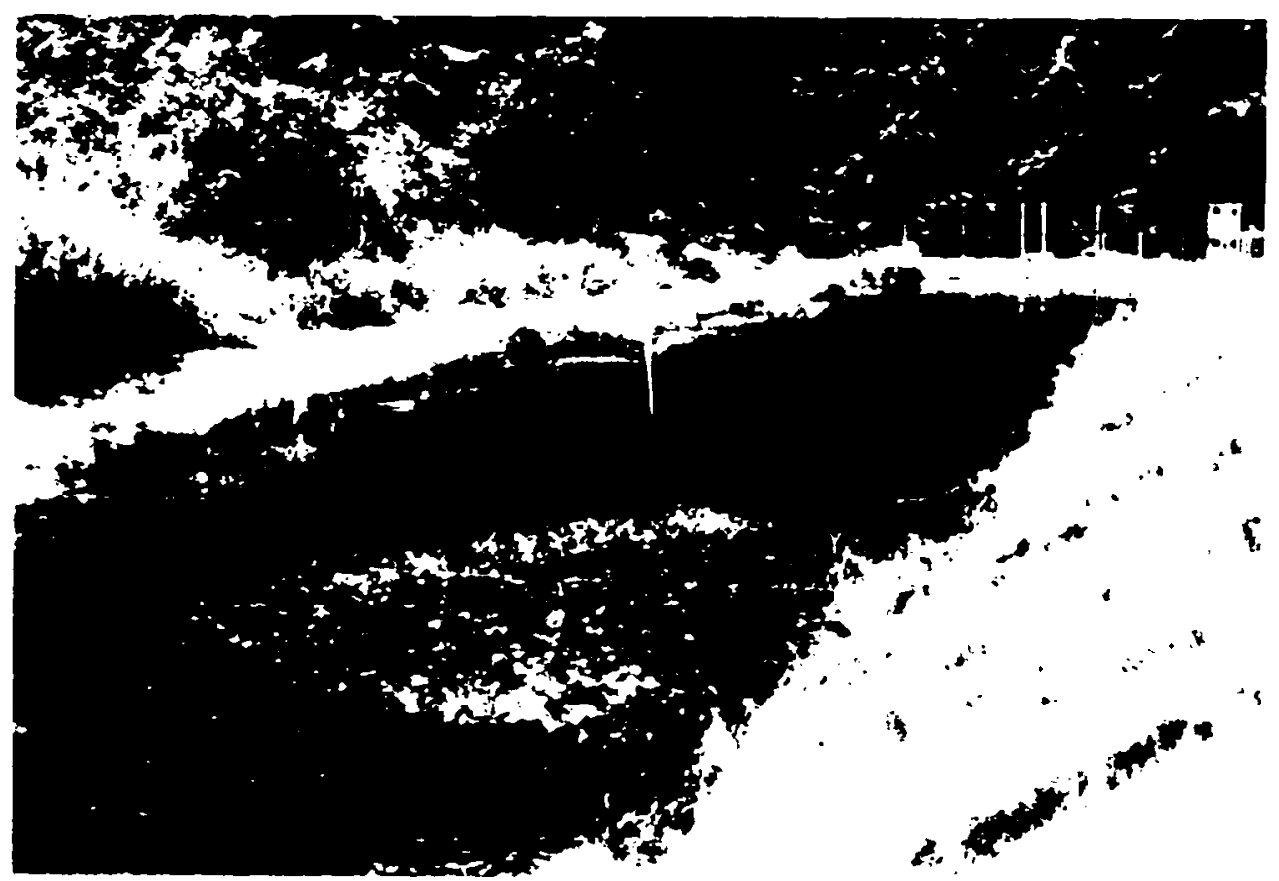

Figure 6. Earthen raceway at Garrison Springs Hatchery (WDF).
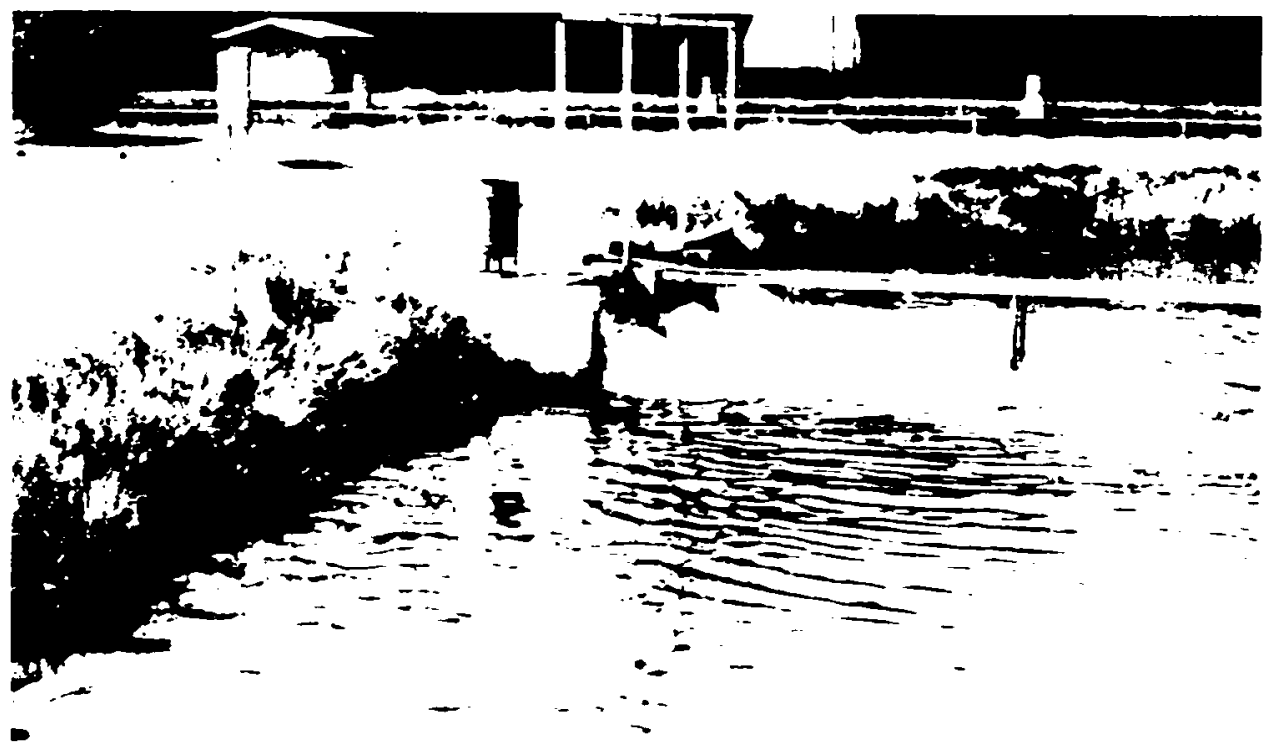

Figure 7. Nater supply to earthen pond at Rapid River Salmon Facility (IFG). 
Chapter 5

Advantages:

- Cleaning frequency requirements are less than with concrete ponds

- More economical and simple to construct

- More pond bottom area for nitrifying-bacteria to culture and convert ammonia to harmless nitrate ions

Disadvantages:

- Pond cleaning and fish collection and handling are more difficult because of the sloping pond sides and the lack of a hard bottom surface

- Ponds with sloping banks require about three times the land area as concrete raceways

- Bank vegetation control measures are required

- If good sanitation is not practiced, botulism can be a problem

\section{Cost:}

The capital cost is approximately $\$ 3.30 / \mathrm{ft}^{3}$ of rearing space for an unlined pond. A 4 -inch gravel surface would increase the cost to about $3.50 / \mathrm{ft}^{3}$. The units have a 50-year life expectancy.

Information Sources:

Washington Department of Fisheries Willapa and Nemah Salmon hatcheries British Columbia, Canada Corrections Service-Alouette River Unit Private trout growers

3. Wooden Raceways Wooden raceways can be constructed of 3/4-inch marine grade plywood sheathing or P-inch tongue and groove lumber, with construction grade treated lumber for supports (Figs, 8 and 9). The inside of the raceway may be lined with 1/8-inch butyl rubber or PVC sheeting for water seepage control. We recommend butyl rubber. Alternate construction is treated tongue and groove planks with the liner optional. The ponds can be built in various sizes, and construction costs for one the size of the concrete raceway described earlier are shown below.

\section{Advantages:}

- Simple construction and assembly

- Units on top of ground are easily dismantled and reassembled for use in another locale

\section{Disadvantages:}

- High maintenance cost

- Difficult to work in because of slippery floors

- Multiple units require more land area when a common wall cannot be utilized 


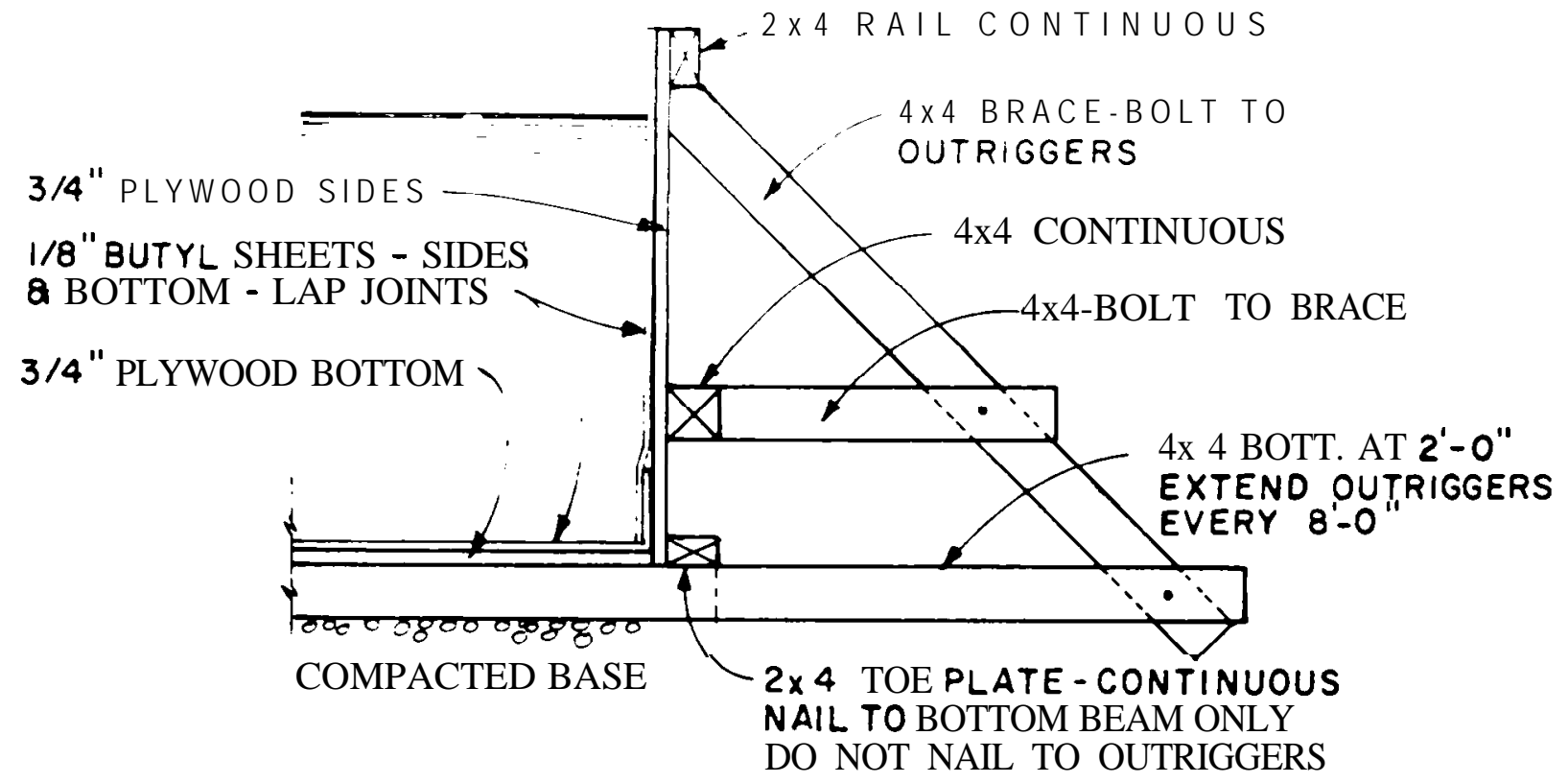

\section{WOODEN RACEWAY SECTION}

Figure 8. Cross-section of a wooden raceway.

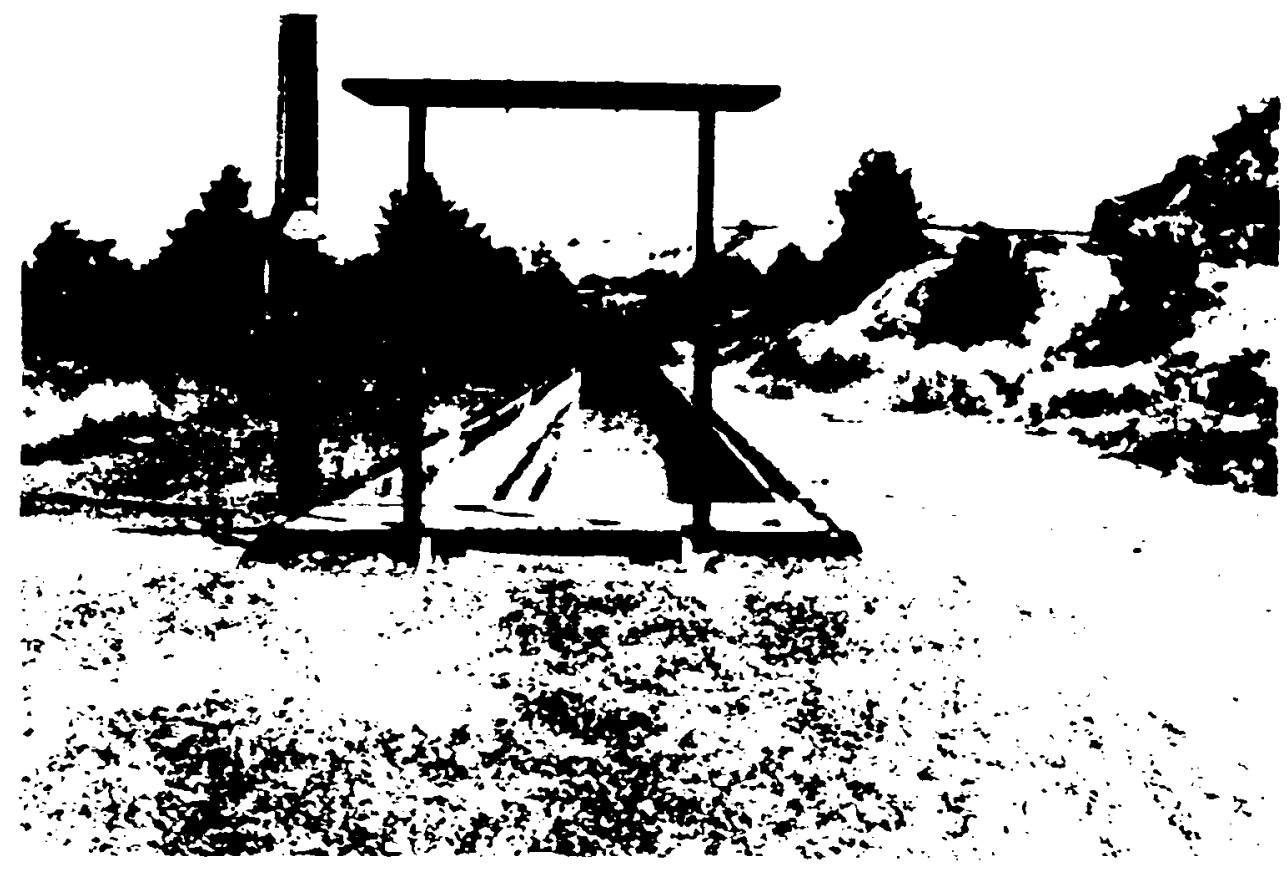

Figure 9. Wooden raceway at Nelson Springs, Yakima (WDG). 
Chapter 5

- Algae growth difficult to remove from sheet lining

- Liner can be punctured or slashed with a sharp object

\section{Cost:}

The capital cost is approximately $\$ 4.20 / \mathrm{ft}^{3}$ of rearing water, and they have a ten-year life expectancy.

Information Sources:

British Columbia, Canada Corrections Service-Alouette River Unit Washington Department of Game Naches River Pond

4. Metal Raceways Two materials are used for metal raceways, aluminum and galvanized sheet steel. The 16-gauge sheet steel raceways are available in many sizes as a kit package. The typical size used in the Columbia Basin is $8 \times 83 \times 3.5$ feet. This unit is lined with 20-mil PVC and the water is 3 feet deep (Fig. 10).

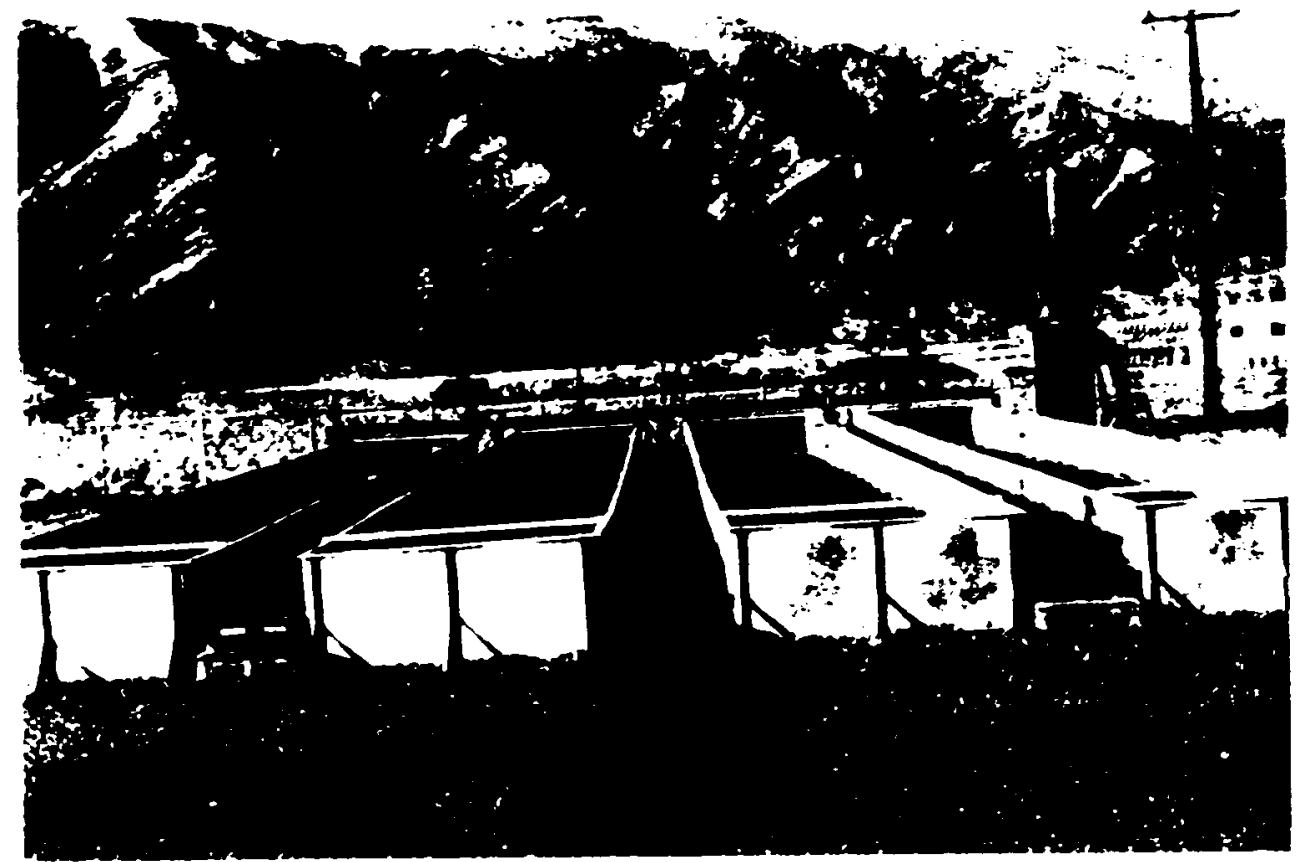

Figure 10. Sheet-steel raceways at Priest Rapids Salmon Hatchery (WDF and Grant County PUD)

The corrosive resistant aluminum alloy raceway is custom built and if the metal prices are depressed (as in 1983), they may be competitive in price (Pflug et al., 1983). The units are factory prefabricated in transportable lengths and field welded together. Liners are not used. The only one we identified was at the Neets Bay Hatchery near Ketchikan, Alaska. Custom work and updated prices can be obtained by contacting PRO.HETCO (Appendix 2). 


\section{Advantages:}

- Simple construction, can be assembled in two days with a two-man crew

- $\quad$ Pond is easily disassembled and moved

- Liner punctures can be repaired with an underwater pressure patch kit

- Pond can be dismantled and stored in a 10-x 15-foot space

- Low maintenance cost

\section{Disadvantages:}

- Algal type growth difficult to remove from sheet lining

- Liner can be punctured or slashed with a sharp object

- $\quad$ Difficult to work in pond because the liner is slippery

- Mlust be anchored to prevent wind displacement when pond is empty

\section{Cost:}

The capital cost is approximately $\$ \mathbf{\$ 6 0} / \mathrm{ft}^{3}$ of rearing water, and the life expectancy of the vinyl sheet liner is 20 years.

Information Sources:

Washington Department of Fisheries Ringold Salmon Hatchery

Chelan County Public Utility District No. 1, Rocky Reach Dam, ir.

Oregon Aqua Foods

ModuTank Inc.

PROMETCO (Aluminum raceways only)

5. Fiberglass Reinforced Plastic Raceways These units were observed at the $1 \mathrm{DF}$ Puyallup and Skykomish Salmon hatcheries (Fig. 11). The units are built in modular form, are easy to transport, install, and care for; but the cost is $\$ 15$ per $\mathrm{ft}^{3}$ of rearing volume and is 2-3 times that of metal raceways or circular plastic poncs. They are usually used above-ground. Plastic raceways are noted here because thes are available and further information can be obtained from vendors listed in Appendix 2.

\section{CIRCULAR PONDS}

Circular ponds and tanks are used for rearing salmon and steelhead trout by most fisheries agencies and are constructed of various materials including dirt, concrete, wood, and fiberglass reinforced plastics. They are constructed in various dimensions, usually not exceeding 30-foot diameters and 4 feet of water depth. Water is supplied in one or tw:o locations on the pond's outside periphery and is drained out from a center bottom opening. The water is supplied with a jetting force to aid in aeration and for energy to cause the water to circulate around the pond (Fig. 12). Pond bottoms are usually sloped to the center. The slope, in conjunction with the circulating water, provides for bottom cleaning action to move settleable solids to the center drain. 
Chapter 5

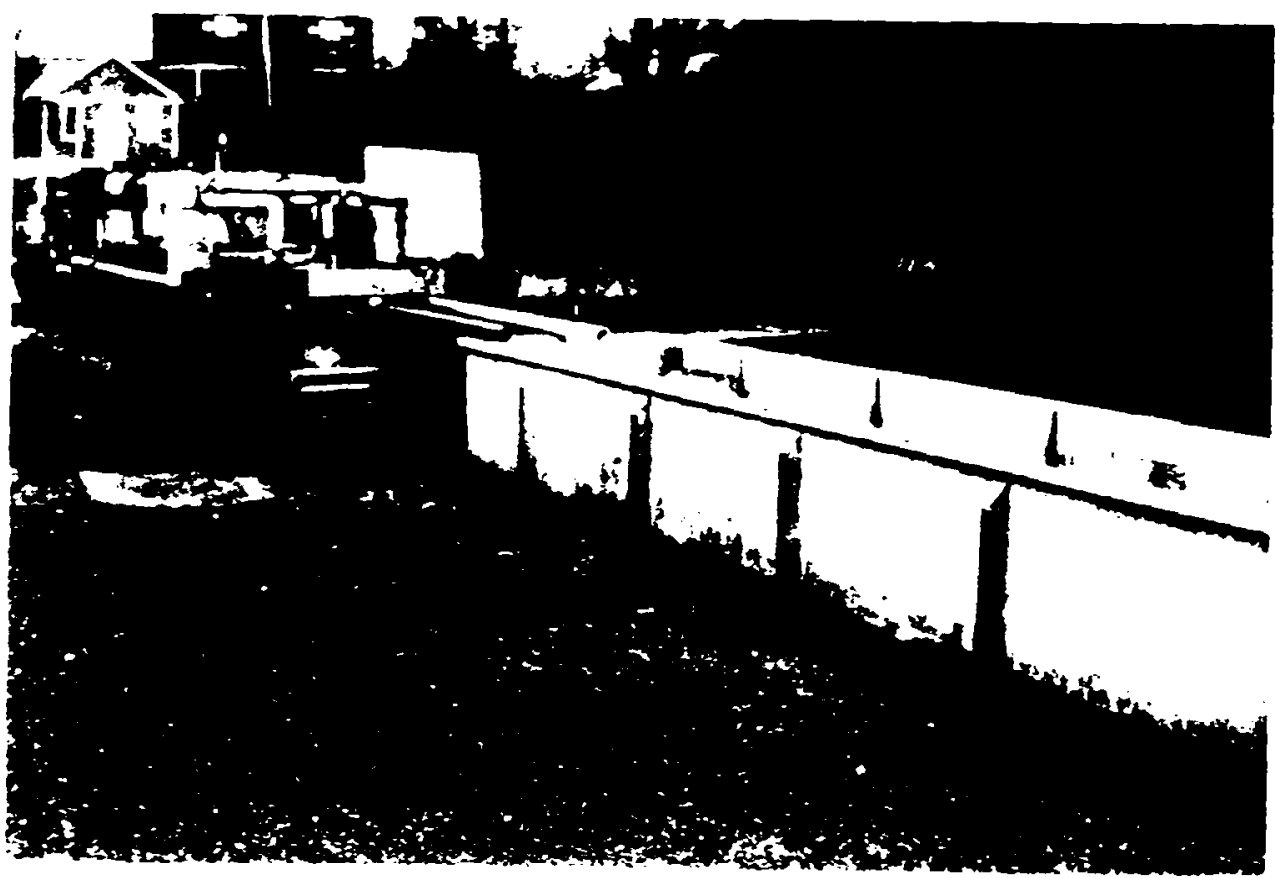

Figure 11. Fiberglass raceway at the Puyallup Salmon Hatchery (WDF).

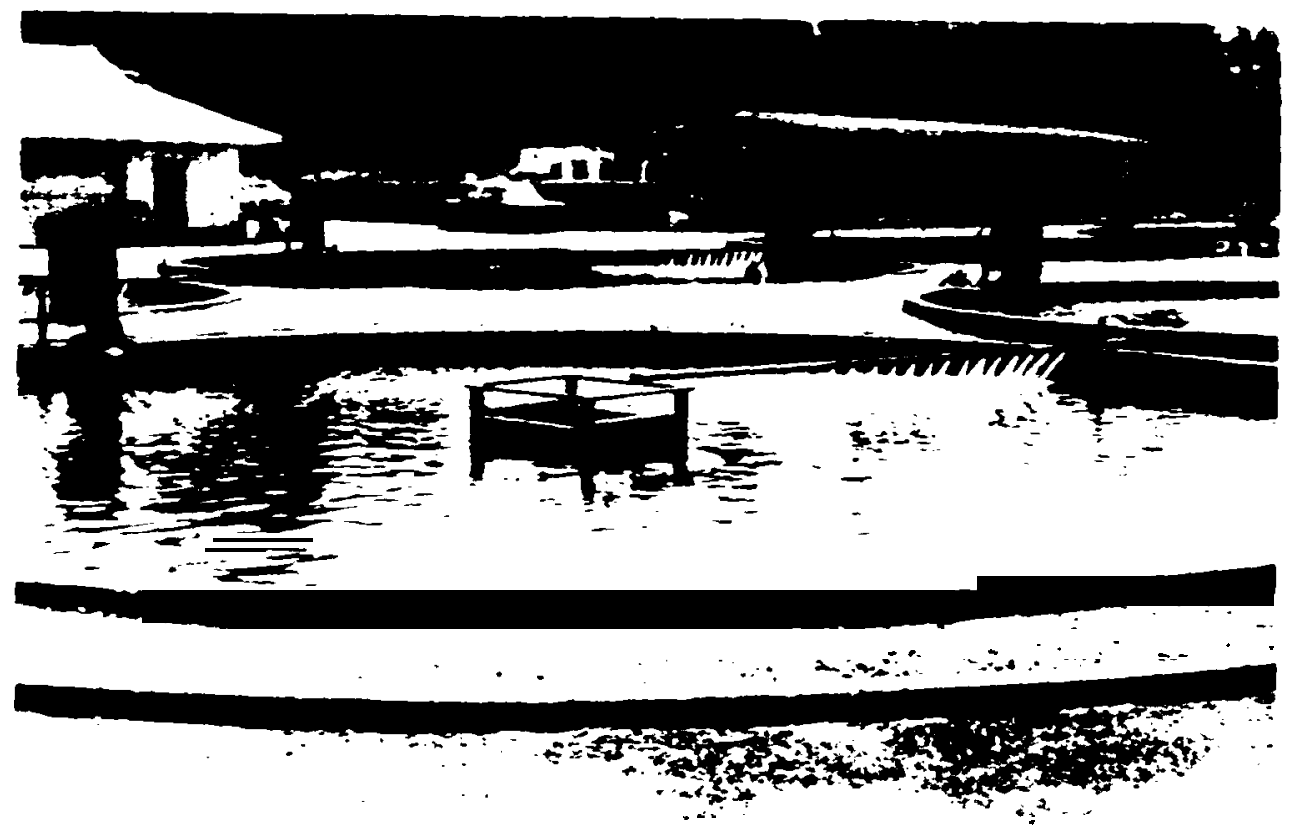

Figure 12. Concrete circular ponds at the South Tacoma Steelhead Hatchery (WDG). 
Circular ponds were one of the first rearing units developed for trout culture, and they apparently became popular across the United States because it was theorized that forcing the fish to swim in these ponds was more natural and produced a better quality fry. This theory has not been proven for salmon. In fact, WDF, and USFWS, who had built numerous rectangular rearing ponds with flow patterns similar to circular ponds, are converting these units to raceways because the latter are judged better for salmon production.

The general advantages and disadvantages of the various circular ponds and specific unit details are discussed below. The costs illustrated for the various units does not include the water supply and drainage systems. The units described are shown for comparative purposes, but we do not endorse circular pond use. The exceptions might be the plastic swimming-pool type pond, which is relatively inexpensive and portable; or for short-tern] early rearing, the small fiberglass tanks.

\section{General Circular Pond Advantages:}

- Generally good flow conditions and velocities that require fish to swim in all areas of pond except adjacent to the center screen

- Generally good cleaning action depending on water velocity and drain screen design

\section{General Circular Pond Disadvantages:}

- If a water borne disease or suspended solids are present in the water, they inay remain in the pond for an extended period and affect the fish

- Require additional space since they cannot be nested together as well as rectangular units

- Require additional piping to provide water and drain lines because of layout requirements

- Requires up to 10 feet of head or five pounds per square inch of pressure, for the incoming water supply jet action

- High unit development and manpower operating cost

- Access to the center screen is by wading or a special walkway must be instaliea

- Crowding fish and cleaning ponds is more difficult than in raceways

For comparative purposes, all the circular ponds discussed below contain $1,000 \mathrm{ft}^{3}$ of water.

1. Concrete Circular Pond These units are constructed of reinforced concrete and the walls are 4 feet high and 8 inches thick. The floor slab is 6 inches thick. A pond with a water volume of $1000 \mathrm{ft}^{3}$ would be about 20 feet in diameter, assuming a S-foot average water depth.

Advantages:

- Low maintenance 
Chapter 5

Disadvantages:

- Circular walls difficult to construct

cost:

The capital cost is approximately $\$ 9.40 / \mathrm{ft}^{3}$ of rearing water, and the pond has a 50-year life expectancy.

Information Sources:

U.S. Fish and Wildlife Service Spring Creek NFH, Washington

Washington Department of Game Chelan and Vancouver Trout hatcheries

Oregon Fish and Wildlife Marion Forks and Cole River Fish hatcheries

2. Earthen Circular Pond These ponds are constructed from materials available from on-site excavation. The pond water surface of this particular unit is 28 feet in diameter and the bank slope is $3: 1$, or steeper (Fig. 13).

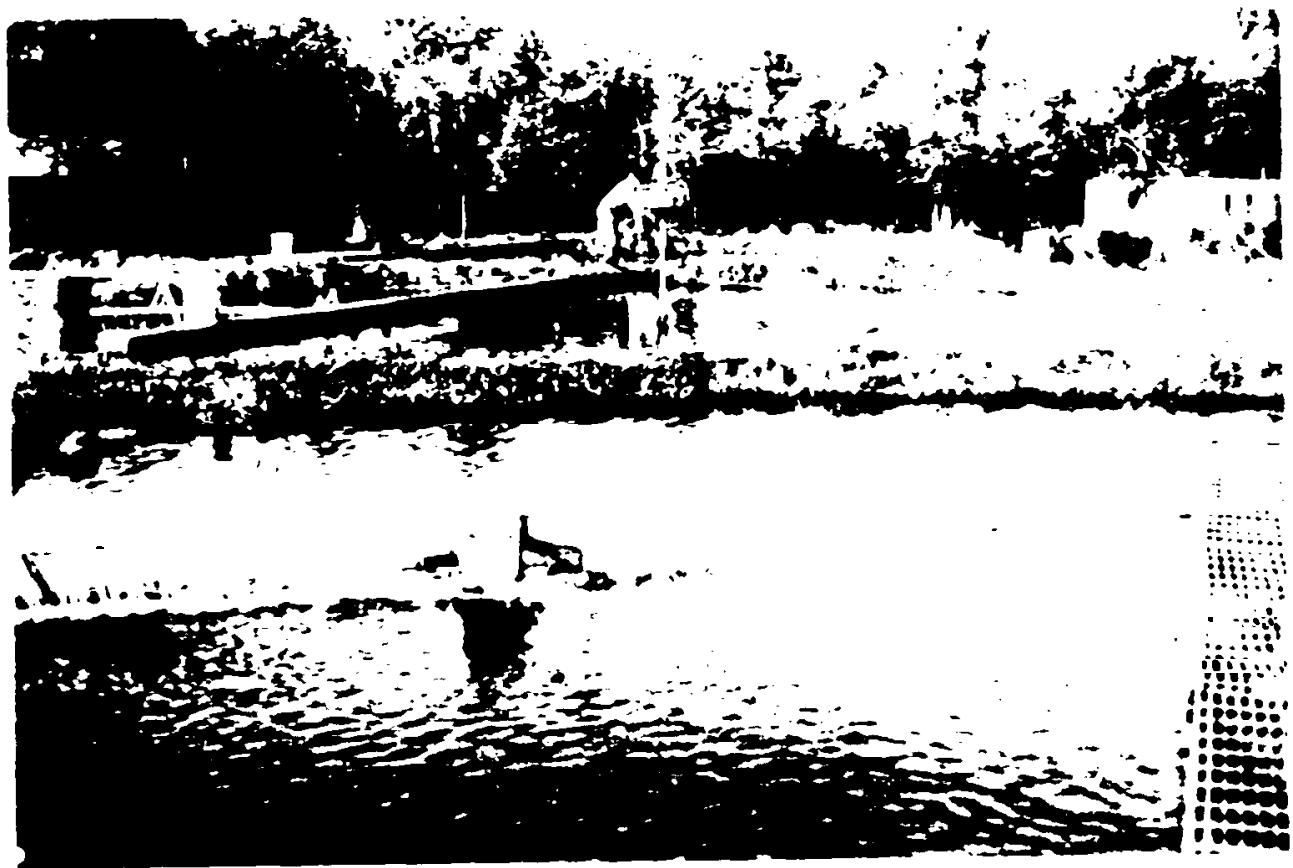

Figure 13. Dirt circular pond at Mariculture Northwest Hatchery, Rochester, Washington.

Advantages:

- Low construction cost

- Simple construction 


\section{$\underline{\text { Disadvantages: }}$}

- Pond cleaning and fish crowding difficult because of lack of a hard bottom surface, sloping pond sides, and circular shape

- Measures required to control bank vegetation

\section{Cost:}

The capital cost is approximately $\$ 3.60 / \mathrm{ft}^{3}$ of rearing water, and the pond has a 50-year life expectancy.

Information Sources:

Mariculture Northwest, Rochester, WA

3. Plastic Circular Pond This is a fiberglass reinforced polyester tank with a durable opaque surface coat for protection against ultraviolet light (Fig. 14). The materials should be non-toxic to fish, and the tank, generally used above-ground, should be supported on treated lumber joists and sills. They can be obtained as a one piece unit or as a modular unit in a larger size. The latter allows for easier shipment and lower cost (Antipa, 1982).

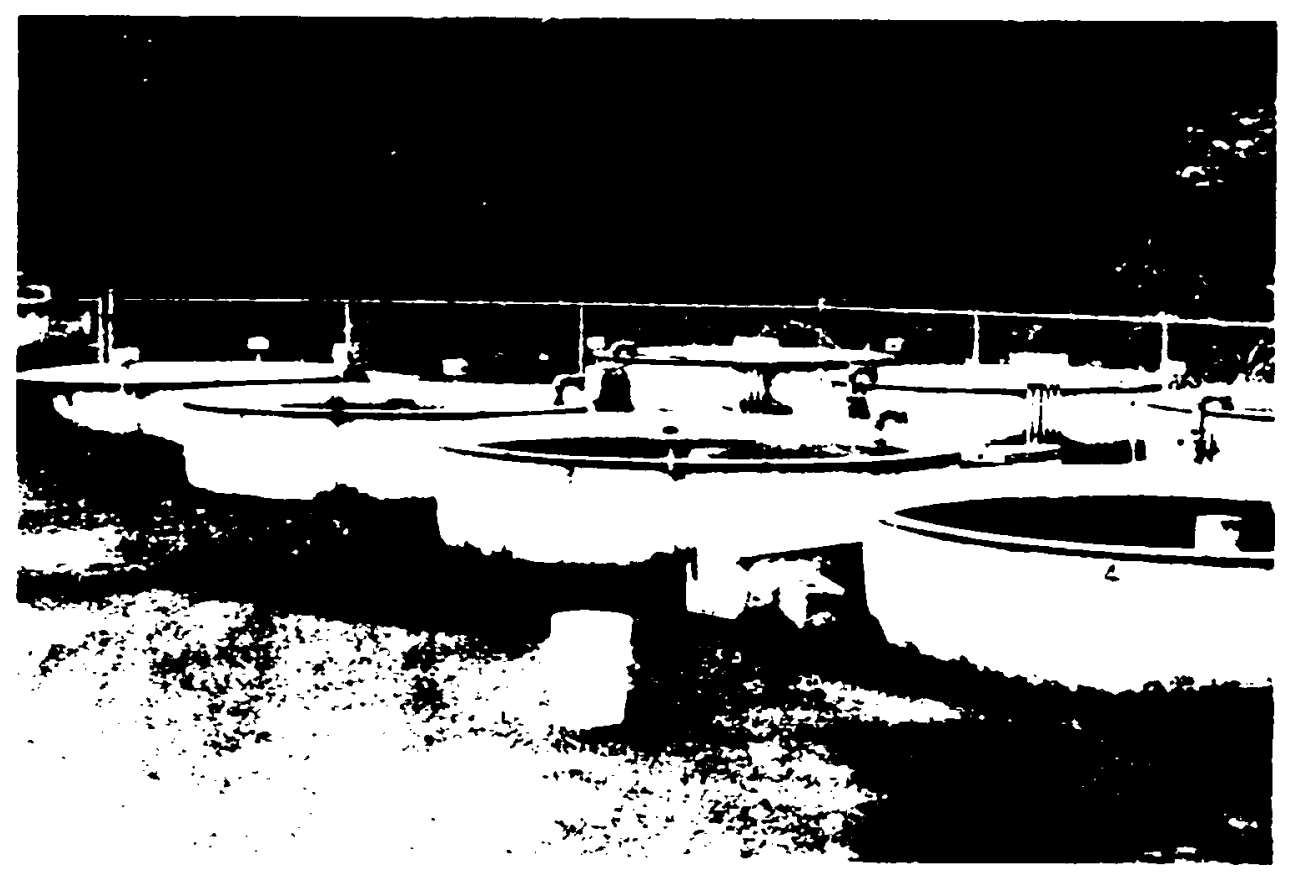

Figure 14. Plastic circular ponds at Quinsam River Salmon Hatchery, B.C. (DFO). 


\section{Chapter 5}

\section{Advantages:}

- Low maintenance

- Easy to erect

- Readily dismantled for relocation to another site

- Very smooth pond bottom and sides assists in cleaning

Disadvantages:

- Performance deflection tolerances should be specified when ordering because of the rather weak materials

- Fiberglass reinforced plastic products are relatively new and performance has not been totally established

- Pond anchors required to resist wind displacement when pond is empty

\section{Cost:}

The capital cost of a plastic tank $20 \mathrm{ft}$ in diameter and 4 feet deep is $\$ 13 / \mathrm{ft}^{3}$ of rearing water including center drain, exterior stand pipe for tank water level control, and treated lumber for the underside supports. Does not include costs for access walkways over the tank.

Information Sources:

Skokomish Tribal Hatchery, Washington

Chemical Proof Corporation

Corrosion Controls, Inc.

Red Ewald, Inc. (also handle modular tanks)

4. Plastic-Sheet Circular Pond This pond is available in a packaged kit sold as an sbove-ground swimming pool, and is constructed of galvanized structural steel members and lined with a 20-mil PVC plastic sheet (Fig. 15). The pond rests on a leveling pad of sand or gravel.

\section{Advantages:}

- Low cost of unit

- Simple construction and easy to erect in two days with a two-man crew

- Pond is easy to disassemble and move to another location

- Liner puncture can be repaired with underwater pressure patch kit

- Low maintenance

\section{Disadvantages:}

- Algal growth difficult to remove from sheet lining

- Liner can be punctured or slashed with a sharp object

- Must be maintained full of water to eliminate liner shrinkage

- Must be anchored to prevent wind displacement damage when pond is empty 


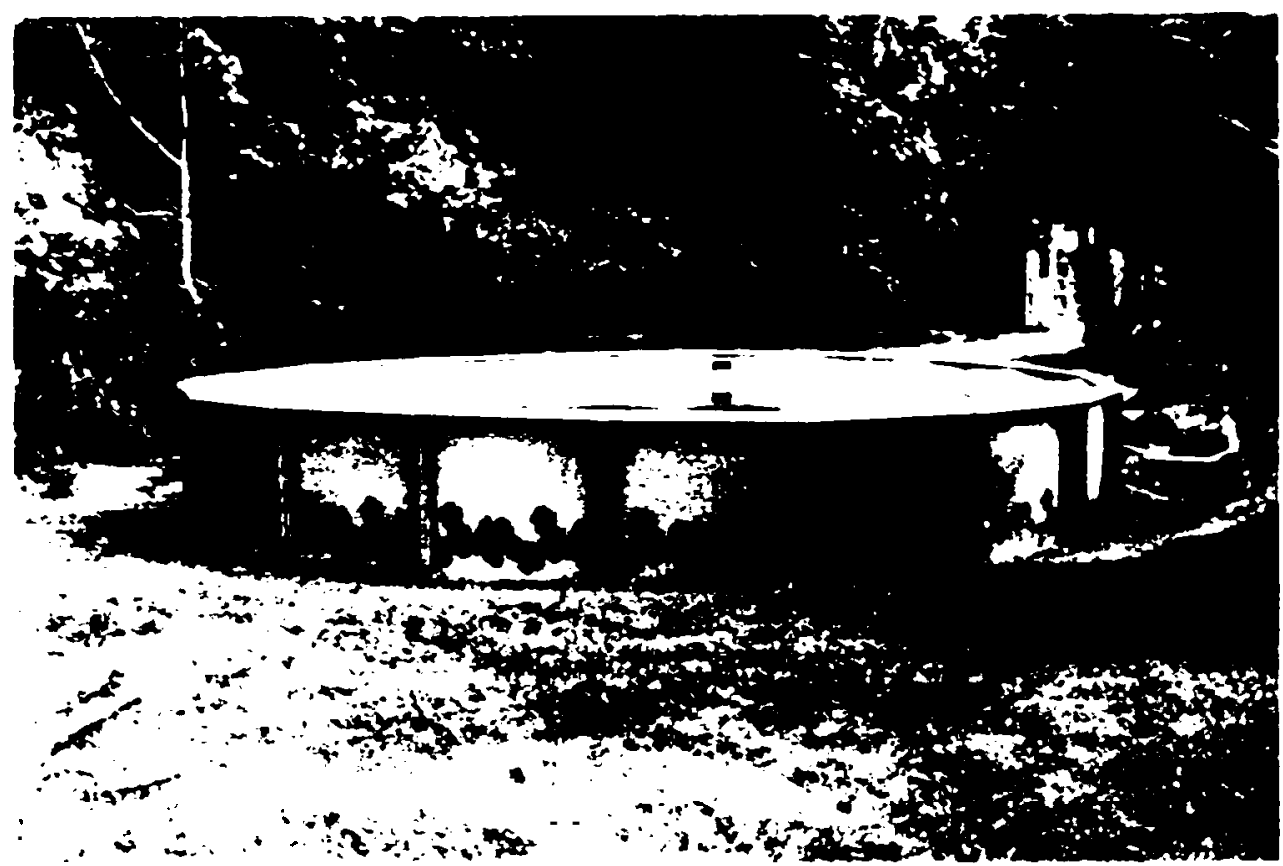

Figure 15. Plasticsheet circular swimming pool used as a rearing pond.

$\underline{\cos t:}$

The capital cost is approximately $\$ 3.12 / \mathbf{f t}^{3}$ of rearing water, and the life expectancy is 10 years for the liner and 15 years for the steel.

Information Sources:

Muckleshoot Indian Tribe, Auburn, WA

Northwest Indian Fisheries Commission, Olympia, WA

5. Wooden Circular Pond This pond is redwoodstave T\&G side and bottom construction. It is supported on redwood floor joists over wood sill supports.

Advantages:

- Low maintenance

- Easy to construct

- Readily dismantled for relocation to another site

Disadvantages:

High cost

- Requires pond maintained full of water to prevent wood shrinkage

- Pond floor slippery and difficult to work on 


\section{Chapter $\mathbf{5}$}

Cost:

The capital cost is approximately $\$ \mathbf{1 2 . 0 0} / \mathbf{f t}^{\mathbf{3}}$ of rearing water, and the pond has a 40-yearl i f e expectancy.

Information Sources:

Quinault Tribal Hatchery, Washington

National Tank \& Pipe Co.

6. Circular Painted Sheet-Steel Pond This pond (Fig. 16) was developed and constructed by WDG at their Naches and Yakima Trout hatcheries. The unit is 14 feet in diameter, 4 feet high, and the wall is constructed of 18-gauge steel. The floor slab is 4 -inch reinforced concrete and requires $2 \mathbf{y d}^{\mathbf{3}}$ of material. The wall is held to the floor by using tank bands and turnbuckles. A sealant is required between the steel and concrete.

\section{Advantages:}

- Low cost

$\underline{\text { Disadvantages: }}$

- Difficult to maintain tight seal between the steel wall and concrete floor

\section{Cost:}

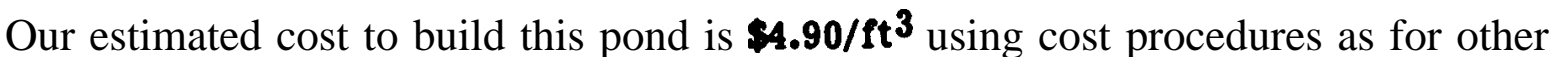
units; however, in 1984, the WDG build these ponds using their own forces for $\$ 1,200$, or $\$ \mathbf{2 . 6 0 / \mathbf { f t } ^ { 3 }}$. The unit has a 15-year life expectancy.

Information Source:

Washington Department of Game

\section{LARGE REARING PONDS}

Large rearing ponds are used by all the fishery agencies. The majority of these are dirt, but some are surfaced with river gravel, concrete, shot-crete, asphalt, and rubber or plastic impervious linings where pond water percolation losses are problems. These ponds can rear fish from the time fry respond to feeding to smolt release. Initially the large ponds were developed to provide additional fish rearing space at existing hatcheries. Then they were principally used for rearing during the advanced fingerling stages, and were often referred to us polishing, acclimation, or fish release ponds. Now $1 / 4$-acre and larger ponds are common, and their popularity has resulted from improvements in fish culture practices thut have greatly increased the capability to rear large numbers of salmonid juveniles in luige ponds. The elements providing for this progress are quality fish food, predution conl rol, mploved fish disease control, and reduced fish rearing densities. 
Manpower and initial construction costs are less for larger ponds than smaller units to produce an equivalent number of smolts. The use of mechanical fish feeders are cost and manpower effective in a large-pond rearing operation.

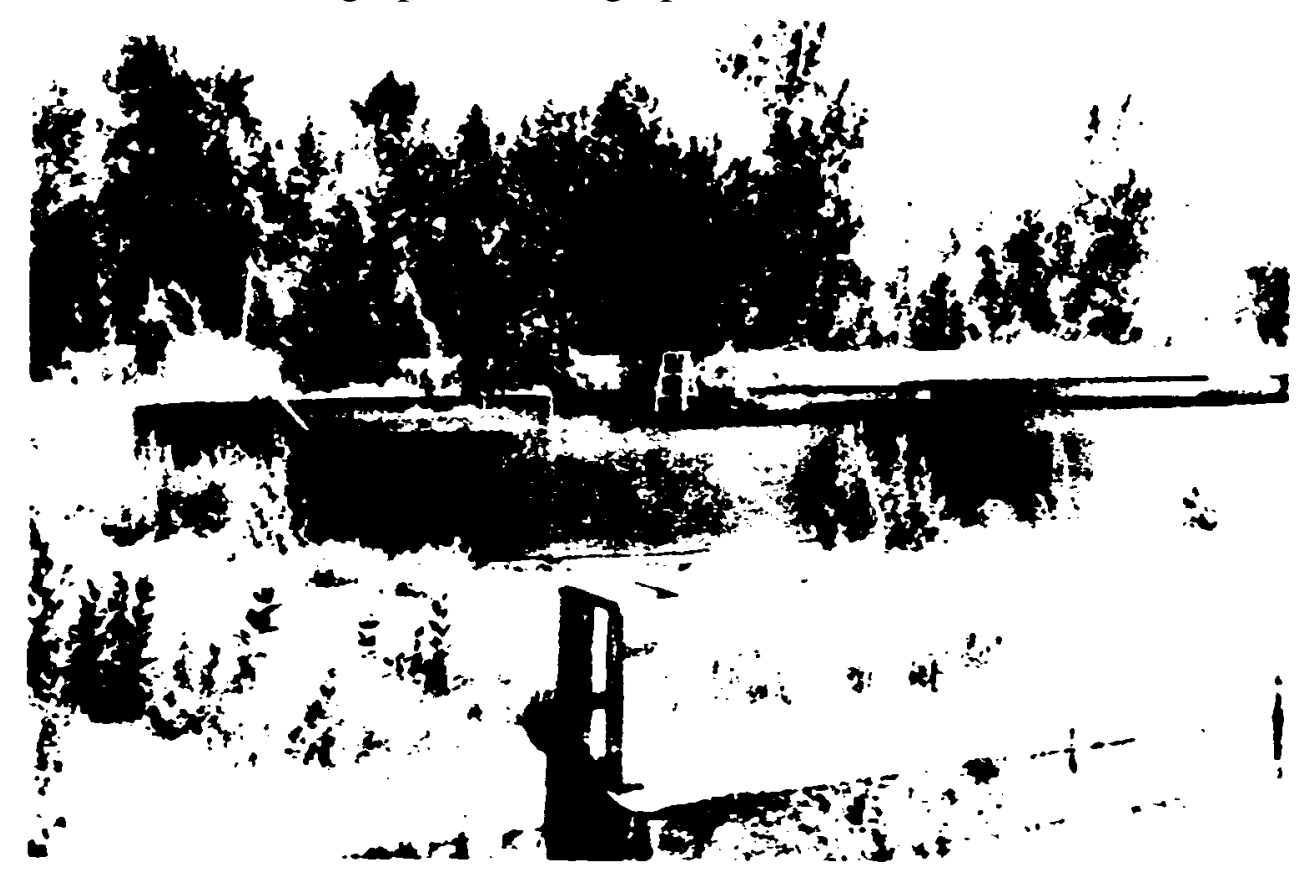

Figure 16. Sheet-steel ponds at Naches Trout Hatchery (WDG).

Because they are difficult to clean, particularly the unsurfaced ponds, the potential for disease, including botulism, requires that operators maintain good fish culture practices. These practices include controlling bank vegetation, removing dead fish and fish excrement from the bottom, and minimizing dead water areas by maintaining adequate water flow patterns and exchange rates.

Large ponds should have the following design considerations:

Water supply of sufficient quantity to provide for about one complete pond water change every two hours and minimize dead spots

Water supplied through a manifold system or overflow weir that evenly distributes the water inflow across the entire pond width (Fig. 17)

Pond should be no more than 80 feet wide if a pickup-mounted blower feeder is to be used

A predator control system

Surfaced access road around the pond periphery for operating and maintaining the pond

Drainable with a collection Incility to allow fish to be removed for transport, enumeration, and evaluation; 1 : designed to ullow free migrat ion from the pons Compartments within the p d or smaller outside poms available for cart

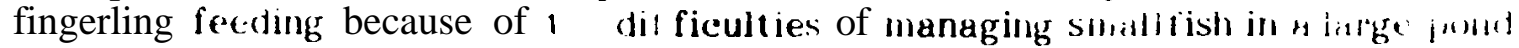


Chapter 5

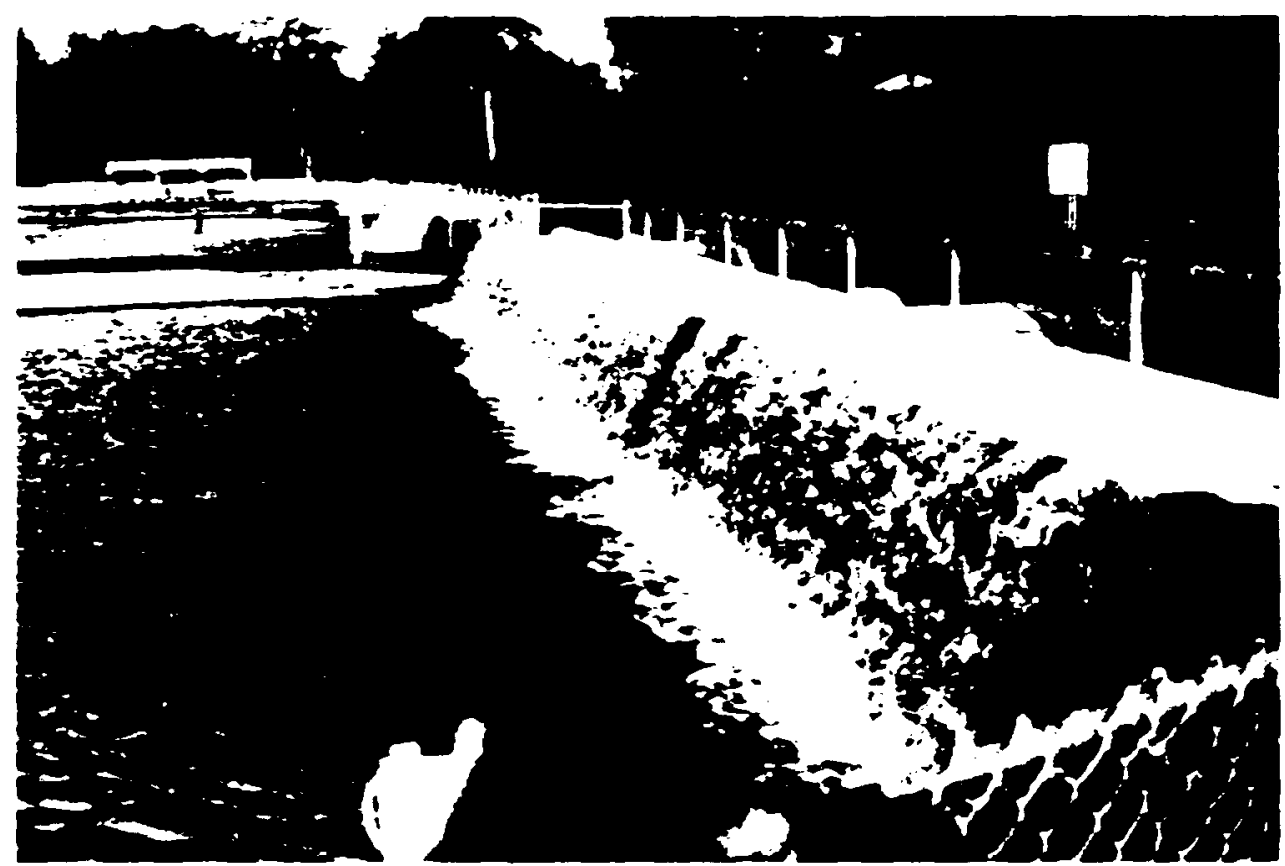

Figure 17. Water supply manifold for large pond at the Naselle Salmon Hatchery ( $W D F)$.

General Large Pond Advantages:

- Low unit capital development costs

- Low operating and maintenance costs

General Large Pond Disadvantages:

- Potential for botulism, particularly in unsurfaced ponds

- Large lots of fish exposed to a disease outbreak

- Disease treatment more difficult because of large water volume

- Bird and mammal predation can be a problem unless control measures installed

- Flexibility of rearing various species curtailed

- Capture of fish is more difficult than in small units

Large ponds with various surfacing materials are analyzed below. For ease of comparison all are identically sized at $80 \times 250$ feet with $3: 1$ bank slopes, 60,000 ft3 rearing volume, 3 feet of water depth at the upstream end and uniformly sloped to a 4.5-foot water depth at the drain end. The 3:1 bank slopes are used for pond comparisons only, and also allows for motorized equipment access in and out of the pond. Steeper bank slopes to 2:1 can be utilized if the operator desires to reduce the shallow water shoreline area, but a special ramped access road to the pond bottom is suggested for equipment use. Steeper bank slopes are also much more difficult to maintain. A water distribution manifold for $10 \mathrm{cfs}$ is provided at the upstream end (Fig. 17) and two 48-inch screened riser drain pipes are 
located at the downstream end (Fig. 18). A lo-foot wide perimeter graveled service road is included in the costs analysis. Water supply and drain systems are not included in the costs.

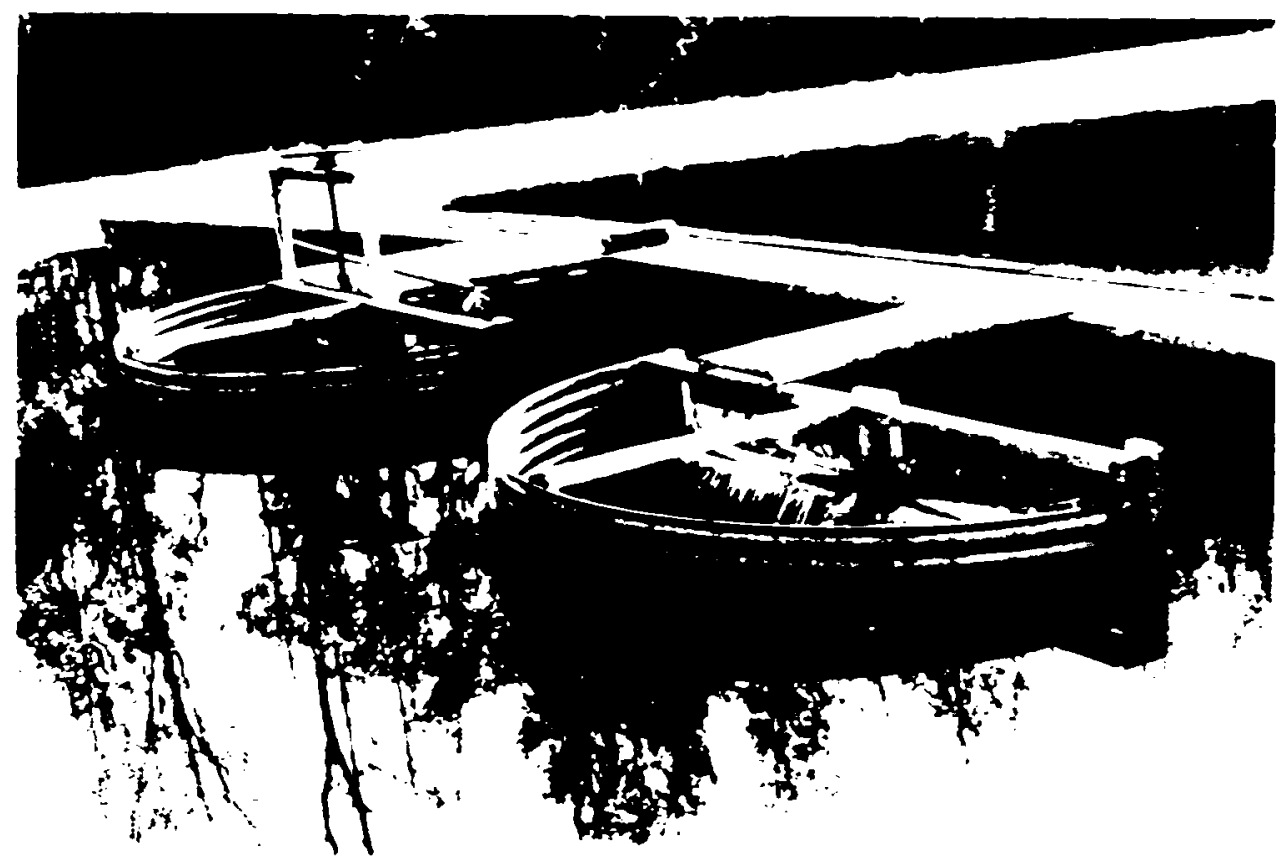

Figure 18. Screened riser drain pipes at George Adams Salmon Hatchery (W DF).

1. Large Dirt Pond A typical pond is constructed from materials available from on-site excavations (Fig. 19).

\section{Advantages:}

- Simple construction

Disadvantages:

- Difficult to handle fish because working in pond muddies the water

\section{Cost:}

The capital cost is approximately $\$ 1.40 / \mathrm{ft}^{3}$ of rearing water, and the life expectancy is 50 years.

Information Sources:

- Washington Department of Game Beaver Creek Steelhead Hatchery

- Washington Department of Fisheries Washougal Salmon hatchery 


\section{Chapter 5}

- Oregon Fish and Wildlife Cedar Creek Fish Hatchery

- Idaho Fish and Game Red River Rearing Pond

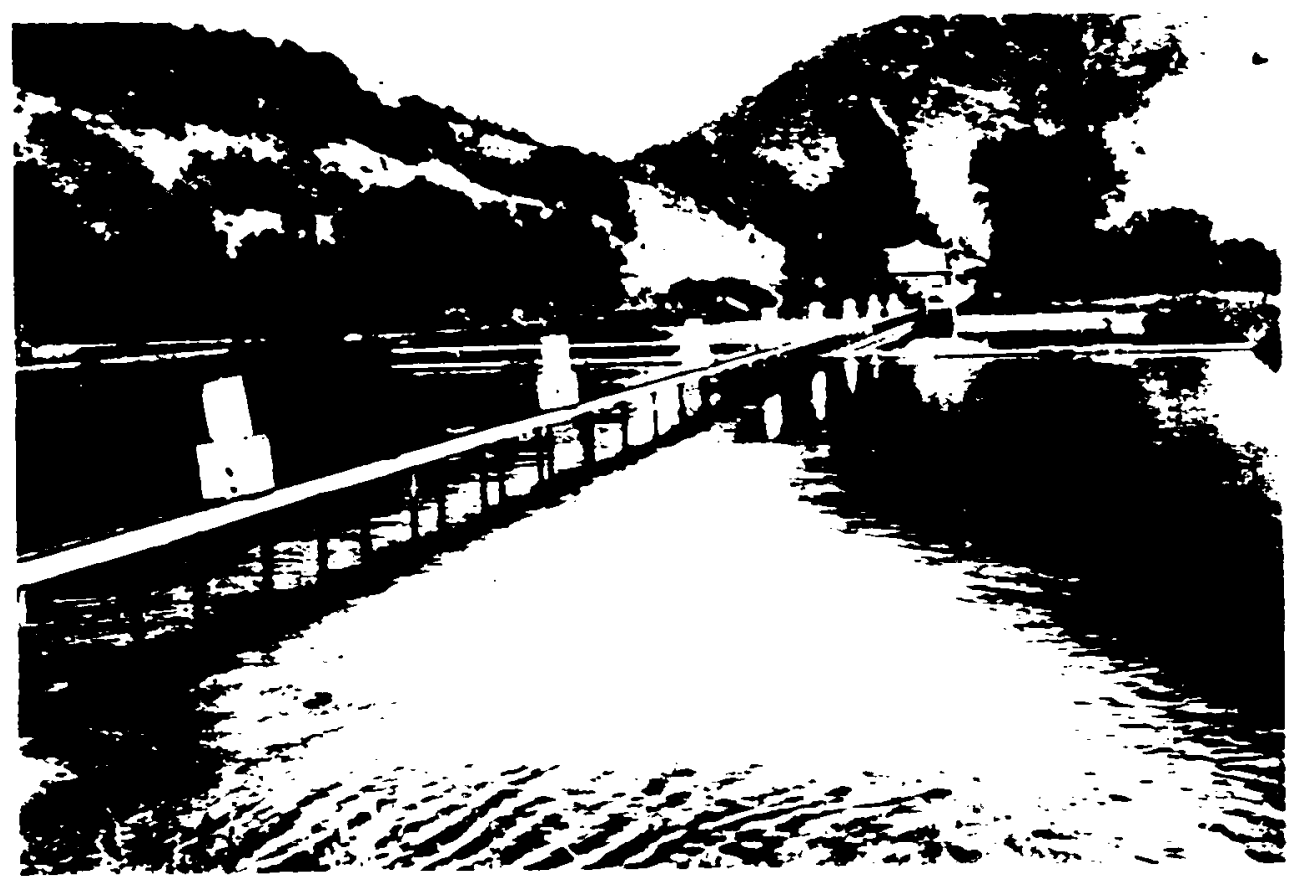

Figure 19. Dirt rearing pond with Neilsen automatic feeders in place at the Rapid River Hatchery (IFG).

2. Large Gravel-Surfaced Pond This is a pona typically constructed from materials available from on-site excavations, except that the bottom is surfaced with 4 to 6 inches of 4 -inch minus round river gravel, and 2 -inch minus crushed rock is placed on the side slopes.

\section{Advantages:}

- Simple construction

- Rock provides excellent surface area for nitrofying bacteria that convert ammonia to harmless nitrate ions.

$\underline{\text { Disadvantages: }}$

- Maintaining bank slope gravel could be an annual task

- Cleaning pond bottom during fish rearing is difficult

\section{$\underline{\text { Cost: }}$}

The capital cost is approximately $\$ 1.50 / \mathrm{ft}^{3}$ of rearing water, and the life expectancy is 50 years. 
Information Sources:

\section{U.S. Fish and Wildlife Service Carson NFH, Washington}

3. Large Asphalt-Surfaced Pond This pond is constructed from materials available from on-site excavations, but is surfaced with a 3-inch asphalt lining placed in two lifts 1-1/2 inches thick over an underdrain consisting of 8-inches of granular base material and a 2-inch thick sand leveling course (Fig. 20). Pipe drains may be placed in the base material. The surfacing includes the sloping sides and bottom. Some scientists will not endorse the use of asphalt because of the phenols present in the material but we found no adverse effects that have been documented.

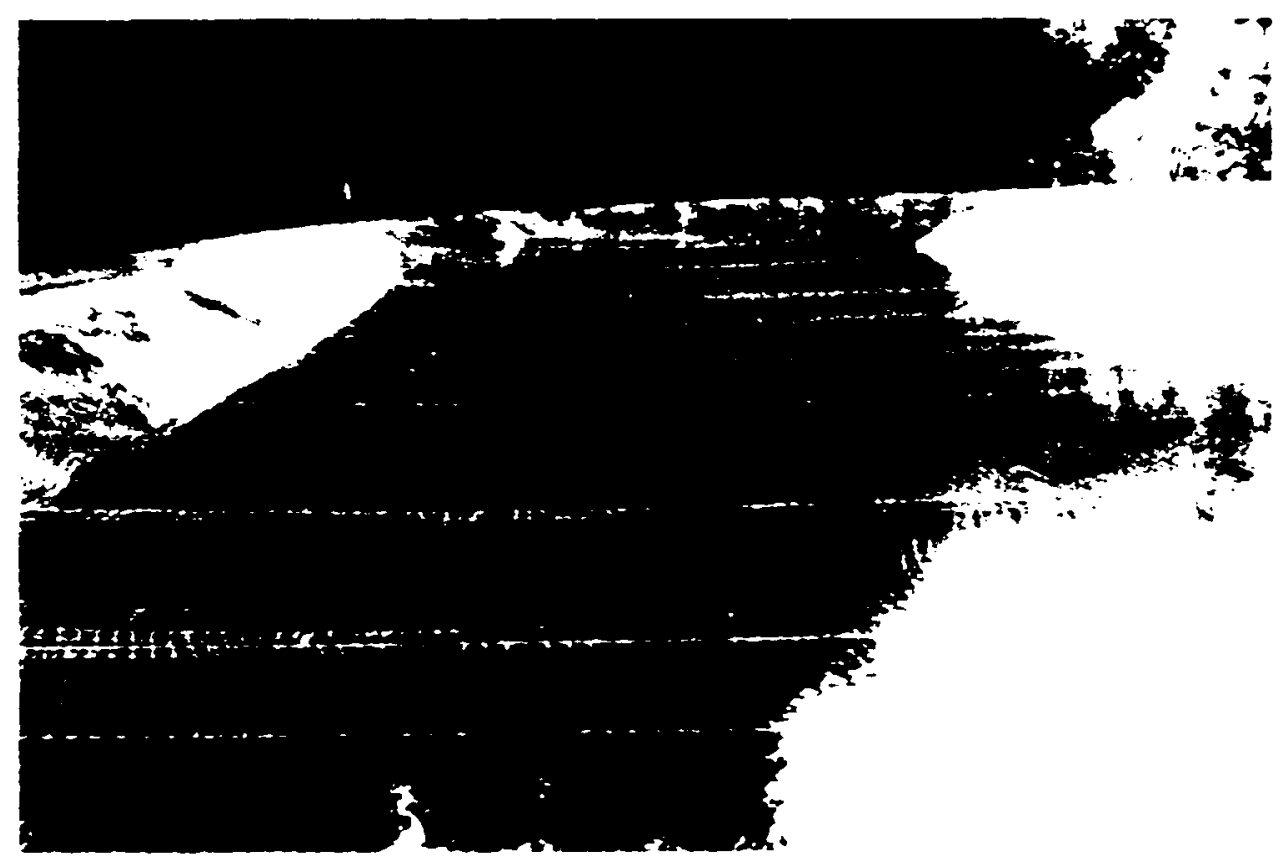

Figure 20. Asphalt-lined pond at Elokomin Salmon Hatchery (WDF).

Advantages:

- Surfacing increases the ability to clean the pond and capture fish

Disadvantages:

- Necessary to eliminate all bank vegetation growth to maintain asphalt seal integrity

- Bank slope becomes very slippery to work 


\section{Chapter 5}

cost:

The capital cost is approximately $\$ 1.95 / \mathrm{ft}^{3}$ of rearing water, and the life expectancy is 15 years for the asphalt with patch-work sealing required every five years.

Infor mation Sources:

Oregon Fish and Wildlife OxBow Fish Hatchery

Tulalip Tribal Salmon Hatchery, Washington

Nisqually Tribal Salmon Hatchery, Washington

Washington Department of Fisheries Elokomin Salmon Hatchery

4. Large Concrete-Surfaced Pond Like many other large ponds, this pond is also constructed from materials available from on-site excavations, but surfaced with a 4-inch reinforced concrete lining placed over a 6-inch thick granular base underdrain and leveling course. Additional drain pipes may be necessary in the granular base. The surfacing includes the pond ends, sloping sides, and bottom (Fig. 10, Chap. 4).

Advantages:

- Surfacing increases the ability to clean the pond and capture fish

Disadvantages:

- See general large pond disadvantages

Cost:

The capital cost is approximately $\$ \mathbf{2 . 5 0 / \mathrm { ft } ^ { 3 }}$ of rearing water, and the life expectancy is 50 years.

Information Sources:

Oregon Aqua Foods, Springfield, Oregon

Oregon Fish and Wildlife Wallowa Fish Hatchery

Washington Department of Fisheries Hoodsport Salmon Hatchery

5. Large Shot-crete-Surfaced Pond This pond is constructed from materials available from on-site excavations and surfaced with a 3-1/2-inch reinforced shot-crete lining placed over a 6-inch thick granular base underdrain and leveling course (Fig. 11, Chap. 7). The surfacing includes the pond bank slopes and bottom.

\section{Advantages:}

- Surfacing increases the ability to clean the pond and capture fish 
Rearing

Disadvantages:

- See general large pond disadvantages

- Speciality contractor required for shot-crete placement

Cost:

The capital cost is approximately $\$ 2.25 / \mathrm{ft}^{3}$ of rearing water. Life expectancy is 50 years.

Information Sources:

Oregon Fish and Wildlife Klaskanine Fish Hatchery

6. Large Plastic Sheet-Surfaced Pond This pond is constructed from materials available from on-site excavations and lined with a 1/16-inch butyl rubber, or PVC plastic sheet placed over a 6- to 8-inch sand leveling course on the pond bank slopes and bottom. The lining is used to prevent pond water percolation losses.

\section{Advantages:}

- Simple construction

- Surfacing increases the ability to clean the pond and capture fish

- Liner punctures can be repaired with an underwater pressure patch kit

\section{Disadvantages:}

- Algal growth difficult to remove from sheet lining

- Liner can be punctured or slashed with a sharp object

- Personnel working in pond can damage liner

- Sides become very slippery

\section{Cost:}

The capital cost is approximately $\$ 2.00 / \mathrm{ft}^{3}$ of rearing water, and the life expectancy is 15 years for the butyl rubber sheet.

\section{Information Sources:}

Oregon Fish and Wildlife East Fork Trask River Fish Hatchery (Butyl rubber liner) Washington Department of Game Cowlitz Trout Hatchery (PVC rubber liner) Washington Department of Fisheries Klickitat Salmon Hatchery (Butyl rubber liner)

\section{E. NET PENS AND NET ENCLOSURES}

Net pens and net enclosures are a very economical method to expand the rearing capacity of a hatchery. They do not require the cost of such hatchery components as the water intake and supply lines, outlet structures, or the pollution control system. 


\section{Chapter 5}

Survival rates of salmon and steelhead released from freshwater pens have been excellent. We discuss their applicability for rearing, advantages, disadvantages, and costs.

1. Net Pens For the purpose of this report, a net pen is defined as a floating structure whose sides and bottom are enclosed with knotless nylon netting. It is supported by a formal float structure, or logs, and used to rear juvenile salmon and trout. They are currently used in marine waters and freshwater lakes and reservoirs. In the Columbia River Basin, they could be used in the latter two locations and in backwater river areas where the effect of current is acceptable.

Set pens date back over 100 years in Europe, but they have only been used in the Pacific Xorthwest for the last 25 years. In the late-sixties, they were used to rear chinook in Lake Roosevelt, Lake Chelan, and Banks Lake; and currently, the Washington Department of Game rears steelhead trout in net pens at Lake lierwin (Lewis River), Skookumchuck Reservoir, and Lake Aberdeen. The Quinault Indian Tribe rears sockeye, steelhead, coho, and chinook in net pens placed in Lake Quinault. The tribal biologist and WDG personnel both consider net pen culture an economical way to expand existing fish facilities.

The most common shape of a net pen is rectangular, and because multiple groupings are easily designed, this configuration is recommended (Figs. 21, 22, 23). The pens can be built to any size, but since it is necessary to clean them periodically, and usually by hand, this should be considered in the design. The WDG uses a pen $16 \times 20$ $x 15$ feet at Lake Merwin (Fig. 24). Pens can be secured in position by anchors, or by tying to a dock or similar structure. Excessive flows will move the pens, and even if securely anchored, will tend to collapse the net. There is little written information on this subiect and other net pen users should be consulted.

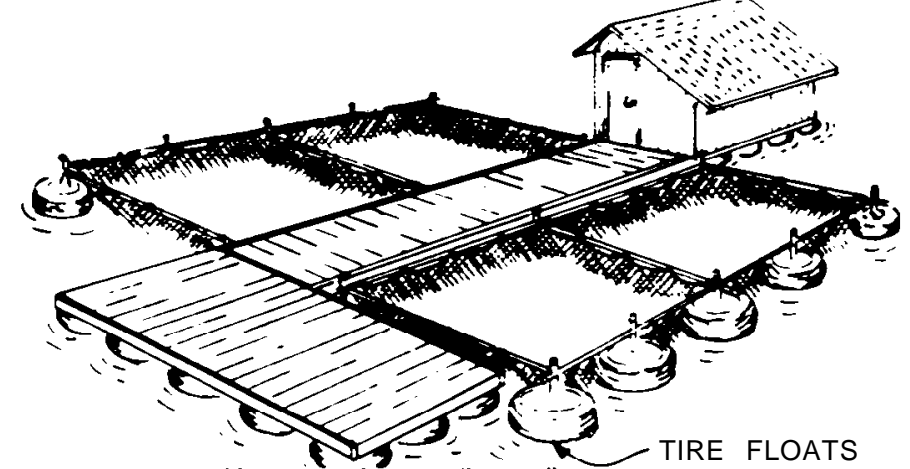

Figure 21. Illustration of a four-pen arrangement with Topper Floats.

A stable platform is usually used to support the pens; however, it is not a requirement. This provides a working space both to feed the fish and clean and repair the netting. The netting is usually knotless nylon or a similar material. Stretchedmeasure mesh sizes used vary with fish size and the recommended sizes are: 0.125 inch for fish 1,000 to 500 per pound, 0.25 inch for 500 to 50 per pound, and 0.5 inch for 50 to 10 per pound. Since smaller-mesh nets impede water flow and foul more quickly, the largest mesh size that will retain the smallest fish should be chosen. 
Predation problems can occur as with any rearing program. However, pens in freshwater present less problems than those in the marine environment. A 1-inch mesh bird net at water level will usually suffice unless otter are present (See Chapter 7).

Any size fish can be cultured in pens. Density levels are limited by the same factors described for other rearing procedures. A fish culturist should program maximum densities not to exceed $0.75-1.0 \mathrm{lb} / \mathrm{ft}^{3}$ of water for yearling coho and steelhead, assuming water conditions are very good. For yearling chinook or sockeye, 0.5 to 0.75 pounds may be attained. Fall chinook at $100 \mathrm{fish} / \mathrm{per}$ pound might best be reared at 0.25 to $0.4 \mathrm{lb} / \mathrm{ft}^{3}$.
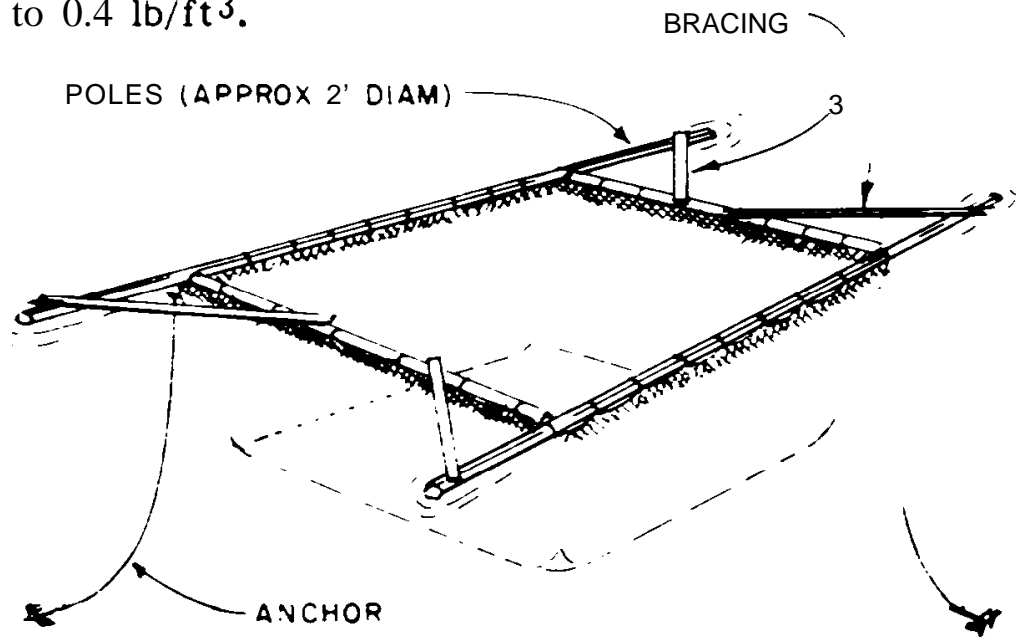

Figure 22. Illustration of a single net pen with pole flotation.

\section{Advantages:}

- Economical means to rear fish

- An excellent method to expand rearing space for steelhead and salmon with lon capital investment

- Net pens can be designed to fit the program

- Very suitable for community involvement

0 Supports are portable, but require equipment for moving

$0 \quad$ Nets can be made by culturists, volunteers, or purchased directly

- Intake and discharge systems, water supply lines, and electrical power sources are not required

Disadvantages:

- Algae fouling the net is common

$\therefore \quad$ Nets must be replaced every five to seven years

0 when large production programs are compared, the net pen facility is more labor intensive than net enclosures or rearing ponds

- Access to net pen complexes usually requires a boat 


\section{Chapter 5}

- Transporting fish from net pens to planting tanks or from planting tanks to net pens may be cumbersome

$0 \quad$ Freezing weather and high summer water temperatures may limit their use east of the Cascade mountains

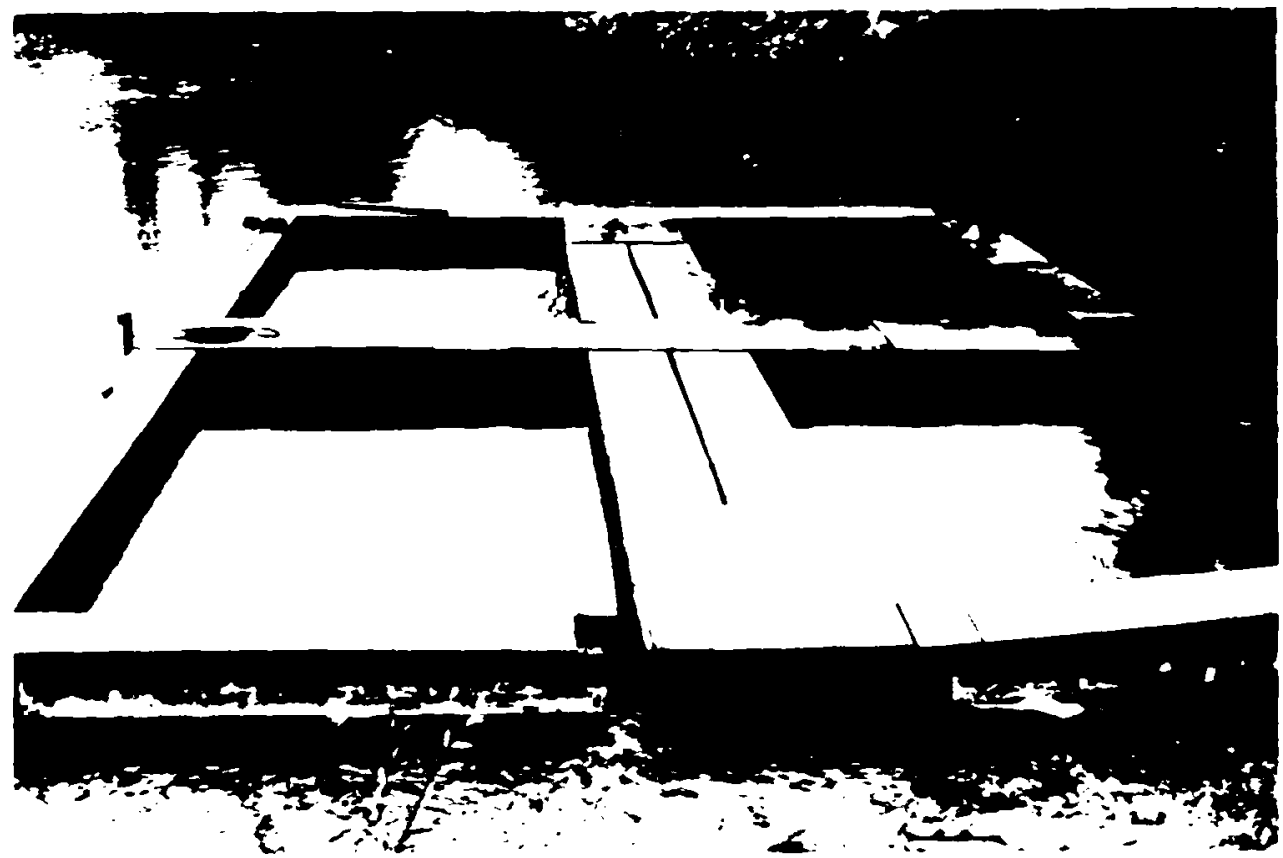

Figure 23. Styrofoam floats and a four-pen rearing complex cost:

Clatsop County Pond, Astoria, Oregon.

A net $20 \times 20 \times 10$ feet costs about \$1,000. A 20- x 20-foot aluminum frame with floats will add $\$ 2,000$ (Walkways not included). Special anchors are available up to 60 pounds each for $\$ 1.50 /$ pound. Several man days of labor would be required to place a pen. The cost per cubic foot of rearing space would range between $\$ 0.40$ and $\$ 1.50$. Net life is seven years, and floats, 20 years.

Information Sources:

Quinault Indian Tribe, washington

Washington Department of Game

Skretting

Pacific Power and Light, Portland Oregon

Topper Industries, Inc.

See vendors for nets (Appendix 2)

2. Net Enclosures A net enclosure is a fish-proof barrier made of netting that extends from the water's surface to the bottom, and is positioned with the shoreline to form a large rearing pond. It must be able to withstand the current and wind 
action. Fig. 25 illustrates typical locations where enclosures could be installed in the Columbia River Basin. Some of these concepts are used in the marine environment in the Scandinavian countries.

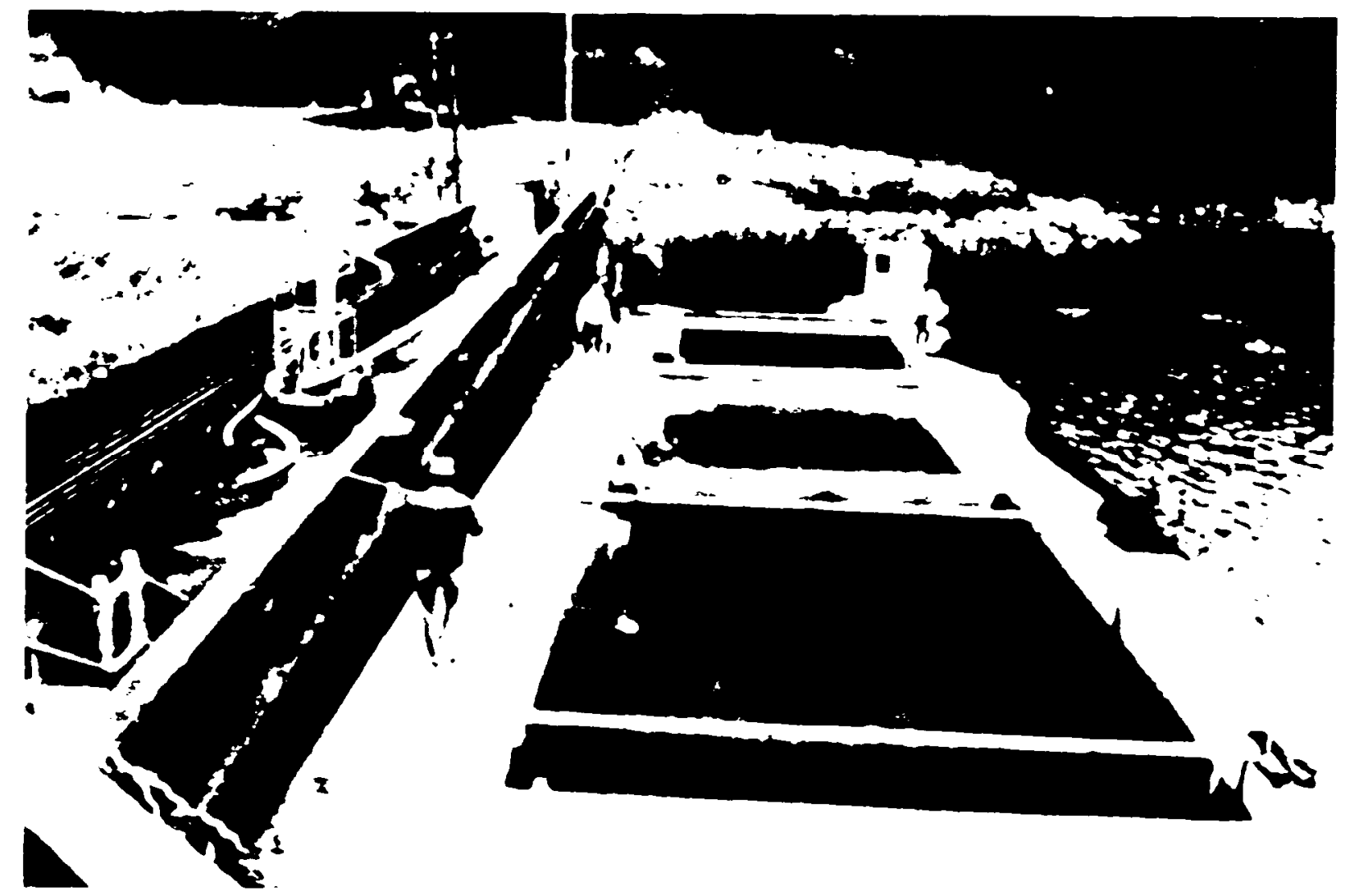

Figure 24. A net pen complex in Lake Merwin, Lewis River ( $\boldsymbol{W}$ DG and Pacific Power and Light). PP \& L Photo.

Basically, a net enclosure is similar to the large rearing pond concept, and our recommendation is that they be primarily used as acclimation ponds with two to three months maximum rearing time. Feeding is accomplished wih a blower feeder mounted on a barge or by hand feeding from a boat. The only major net enclosure in the northwest is a 20-acre (approximate) development at Olympia, Washington, from which up to 200,000 pounds of yearling fall chinook have been released in one year.

The features (Fig. 25) of a good enclosure, besides those illustrated, are: the bottom under the net should be relatively flat in order to provide a fish-tight seal; currents directed against the net should be less than 0.2 feet per second; the net should be protected from floating debris; the enclosure should be drainable, but is not absolutely necessary; there should be a good water interchange; easy access should be available; and in very large enclosures the program should allow most of the fish 


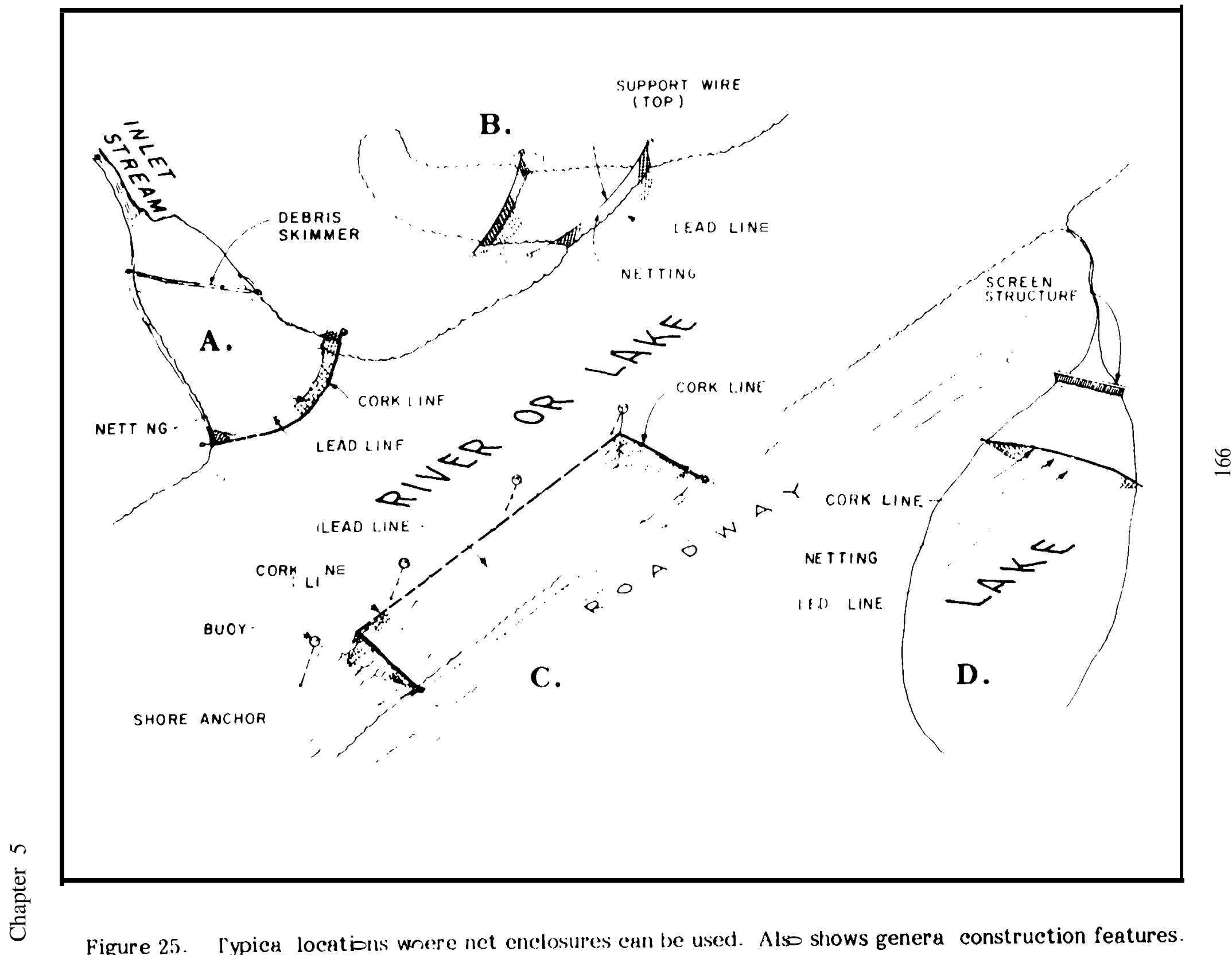


to be released directly from the enclosure to avoid the difficult task of crowding and capturing the migrants.

The lower edge of the net must be anchored to the bottom and the suggested method is with a heavy chain lead line. The upper edge of the net, or cork line, is supported by round Styrofoam $\operatorname{logs}$, and anchored buoys or wires stretched from point to point are required to maintain the net in position The enclosure is most manageable if the depth does not exceed 10 feet. At this depth 12 feet of netting should be considered, allowing slack for some current and wind action. The mesh size is the same as for net pens.

Net enclosures, like net pens, must have suitable environmental conditions. Freezing, warm water, flooding, and predation all must be considered.

The short-term rearing density in an enclosure is similar to a net pen, however, water interchange is difficult to assess. In this report we have assumed that rearing densities in an enclosure are approximately one-half that for net pens, or about 0.3 $\mathrm{lb} / \mathrm{ft}^{3}$ for fish under $25 / \mathrm{lb}$.

Interchange can be aided by directing currents with deflectors or low head pumps. The WDF chinook rearing enclosure has the influence of water deflected from a creek and has about $1,000,000 \mathrm{ft}^{3}$ of rearing area. Because the capital cost of rearing space is so economical, ultra conservative fish density levels should be used, Fall chinook are transferred to the WDF enclosure in September and released in late March as yearlings. The Department personnel mention that the fall chinook salmon is a difficult species to rear for extended periods, however, the program has been very successful.

\section{Advantages:}

- Extremely low cost to develop and requires no water intake or discharge systems

- On a large production scale, labor cost is very low, or comparable with large earthen ponds

- Numerous sites are available for the use of net enclosures

- Excellent for short-term holding to allow the fish to recuperate from the stress of hauling or allow imprinting to aid homing

- Water intake systems, pipelines, and electrical power are not required

\section{Disadvantages:}

- Attracts predatory birds; therefore a strong predation control program is necessary

- Boat or barge feeding is usually required on large areas

- The ponds have to be sited where fish can be released directly into a waterway, since the capture of juveniles is very difficult

- $\quad$ Flooding, freezing and warm water restrict their use

- Nets should be removed annually for maintenance and protection from the sun and unnecessary wear 


\section{Chapter 5}

- In areas that cannot be drained or lowered to remove all predator fish without using chemicals, excessive predation may be imposed on salmonids less than 4 or 5 inches long

Cost:

Total material cost for a net enclosure is about $\$ 8 /$ linear foot of net used. Stock knotless nylon netting 10 feet deep costs $\$ 3.00 /$ inear foot. Polyester netting, which has a little less stretch, costs $20 \%$ more; the chain to weight the net costs $\$ 2.00 /$ inear foot; and Styrofoam floats $\$ 2.00 /$ inear foot. Miscellaneous ropes and anchors may add another $\$ 1.00 /$ linear foot. Initial labor installation cost would likely be double material cost. On this basis, a $200,000 \mathrm{ft}^{3}$ rectangular enclosure with a maximum water depth of 8 feet, a mean depth of 4 feet, and a net size of 100 feet for each end, attached to the shoreside, 500 feet for the offshore outside, and 10 feet deep, would cost $\$ 16,800$ or $0.08 / \mathrm{ft}^{3}$. The use of smaller areas would increase the unit cost by several times. Net life is seven years.

\section{Information Sources:}

Washington Department of Fisheries, Olympia

See Appendix 2 for supplies

\section{F. REARING CHANNELS}

Rearing channels are used by the WDF, DFO, and others. They are noted here only as an option, but in most cases they are expensive to construct because of their large size, and are not applicable for low-cost facilities. Generally, the channels are about 30-50 feet wide, 400-2,000 feet long, and often built in sections. For all practical purposes, channels that we observed were essentially very large raceways sometimes built in tandem. Examples of large successful channel rearing projects are the Big Qualicum Hatchery (DFO) and Elwha Rearing Channels ( $H$ DF).

\section{G. SUMMARY - REARING FACILITIES}

Table 3 illustrates comparable costs and life expectancy of common salmonid rearing units. These costs do not include the water supplies, drains, or buildings if required.

\section{PART III. FISH FOOD}

Salmon and trout require a complete diet containing all essential elements for proper nutrition. Modern commercial feeds introduced in the early 1960's are complete and provide the nutritional requirements in convenient forms. The quality of commercial diets is good for the simple reason that strict quality control is maintained. Some of the "open" formula feeds, that is, those made to published formulas such as Abernathy and Oregon moist pellets (OMP), are frequently subject to inspection by the agencies buying the feed as to content and quality of ingredients. Quality control on "closed" feeds having unpublished formulas is performed by the manufacturers, but whether outside inspection is performed or not, the food quality is under constant scrutiny by the users. 
Table 3. A comparison of relative costs and life expectancy of salmonid rearing units.

\section{Rearing Unit}

Trough and Tanks (sizes in feet)

Fiberglass $1 \times 15 \times 0.5$

Fiberglass 1.33 x $16 \times 1.3$

Capilano Aluminum 1.75 x 21 x 1.5

Raceways

Concrete

Earthen

Wooden

Metal

Fiberglass Plastic
Cost per $\mathrm{ft}^{3}$

of rearing space

$\$ 40.00$

32.53

18.14

6.44

3.30

4.20

6.00

15.00

\subsection{0}

3.60

13.00

3.12

12.00

4.90

Painted sheet-steel

Large Rearing Pond

Dirt

Gravel

Asphalt

Concrete

Shot-Crete

Plastic Sheet
1.40

1.50

1.95

2.50

2.25

2.00

$0.40-1.50$

$0.08-0.36$

0.08

0.12
Life expectancy yne a $\mathrm{r} s$

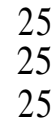

25

50

50

10

20 (Liner, 20)

25

50

50

25

10 (liner)

(steel, 15)

40

15

50

50

15

50

50

15 (liner)

(pond, 50)

7 (netting)

(floats, 20)

7 (netting)

(Measurements in feet)

(Costs are variable depending on

size and depth)

2 sides $100 \times$ one side $500 \times 4$

average depth; 200,000 $\mathrm{ft}^{3}$ area

2 sides $100 \times$ one side $100 \times 2$ average depth; 20,000 $\mathrm{ft}^{3}$ area 


\section{Chapter 5}

There are two types of commercial fish feeds: dry and semi-moist. Dry feeds have a moisture content of approximately $10 \%$ and do not require refrigerated storage. Dry feeds include the Abernathy salmon diet and several commercial brand-name diets. Semi-moist feeds, the most widely used being OMP, have a moisture content of approximately $30 \%$ or more, and require refrigerated storage. There are a few semi-moist pellets manufactured by special processes that permit their storage without refrigeration as long as the packages remain unbroken. These are becoming more widely used.

Both types of feed work well, but fill somewhat different needs. Generally, the more fastidious the species of fish, the easier it is to feed with OMP and the better the conversion rate. For instance, spring chinook salmon and summer-run steelhead trout are always difficult to feed, yet they take the O.MP without hesitation and thrive on it. Also, where the water is below $50 \mathrm{~F}$, and/or low in mineral content, it is easier to grow salmon on O.MP. Dry feeds work particularly well with trout and can be used on coho salmon when the water is above $\mathbf{5 0 \mathrm { F }}$. If sufficient information is not available, the choice of dry or semi-moist feed can best be determined by trial and error at each installation.

Conversion, i.e. the growth of fish relative to the amount of feed used, varies according to water quality, species, feeding techniques, fish quality, and others. However, a conversion rate of 1 : 1.5 , ie., 1 pound of fish flesh gain per 1.5 pounds of feed used, is a reasonably attainable goal. Under ideal conditions, conversions of close to 1 : 1 may be realized, but under poor circumstances it may be difficult to realize a $1: 1.5$ conversion. In a situation where conditions are highly variable, an improved conversion rate may be gained by using dry versus semi-moist feeds. However, under most adverse circumstances, OMP is likely to out-perform dry feeds. Because of its soft consistency it is more readily acceptable, and the higher moisture content and the presence of raw undenatured fish flesh has a positive effect on fish growth. Whenever there is a feeding problem, whether it is poor water quality or fastidious and difficult species of fish, O.ilP would definitely be the feed of choice. Since fish accept it so readily, feeding techniques also do not have to be nearly so rigidly controlled as with dry feeds. A guide to salmonid conversion rates using O.MP is shown in Table 4.

\section{Costs:}

Prices of feeds vary between types and sizes. Smaller pellet sizes of all fish feeds cost more because they contain higher levels of nutrients required by small fish, and the smaller particles are more difficult to manufacture. In general, dry feeds range between \$0.25-0.35/pound and O.MP between \$0.35-\$0.45/pound. These are 1984 F.O.B. prices at a food plant.

Information Sources:

Moore - Clark Co., Inc.

Rio-products, Inc.

Sterling H. Nelson \& Sons

Rangen, Inc. 
Table 4. Conversion rates of salmonids from first feeding size (3000/lb) to various release sizes using the Oregon moist pellet (OMP) diet. Source: Hoore - Clark Co., Inc. (personal communication).

Fish size at release in fish per pound

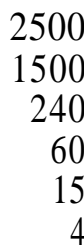

Pounds of OMP required to produce one pound of fish
1.2

1.3

1.4

1.6

1.8

2.0

Conversion rates computed by FMC for growth between the release sizes shown above are as follows:

$\begin{array}{rr}2500 \text { to } 1500 & 1.4 \\ 1500 \text { to } 240 & 1.4 \\ 240 \text { to } 60 & 1.7 \\ 60 \text { to } 15 & 1.9 \\ 15 \text { to } 4 & 2.1\end{array}$

\section{PART IV. SUPPORT EQUIPMENT}

\section{A. FEEDERS}

Five feeding systems are feasible for use at low-cost fish facilities. These are: (1) hanc feeding, (2) mechanical fry feeders, (3) stationary pond feeders that propel fish fooa, ( 4 ) demand feeders, and (5) mobile blower feeders. A stationary blower feeder is also available, but they are costly and of limited value for use at a low-cost facility. Feeders are supplied by many vendors and we recommend a careful analysis before inaiking $x$ decision.

Hand feeding is an acceptable procedure for all life stages and feeds, while the mechanical feeders were developed for specific uses, mostly for dry feeds. The mobile blower feeder works well with properly thawed moist pellets. Neilsen iletal Industries manufactures a stationary trough and pond feeder that is advertised as useable with moist feeds.

Factors to be considered when selecting a feeder include: (1) efficiency of the feeder, (2) manpower requirements for feeding, filling the hoppers, and cleaning and maintenance of the units; (3) type of ponds or troughs; (4) type of feed; (5) number and size of fish ponds; (6) storage space required; and (7) cost of the units.

1. Hand Feeding Hand feeding is the simplest method and feed can be distributeo literally by hand, with a spoon, from a can attached to a pole (Fig. 26), or with * 


\section{Chapter 5}

scoop (Fig. 27). The type of aid used depends on the size of the fish rearing unit. The advantages of hand feeding are that the equipment is inexpensive and the fish culturist will frequently observe the fish, noting problems and make adjustments in the amounts of feed to accommodate needs. A disadvantage is that the operator must be nearby if small fish are ponded, since they must be fed several times daily.

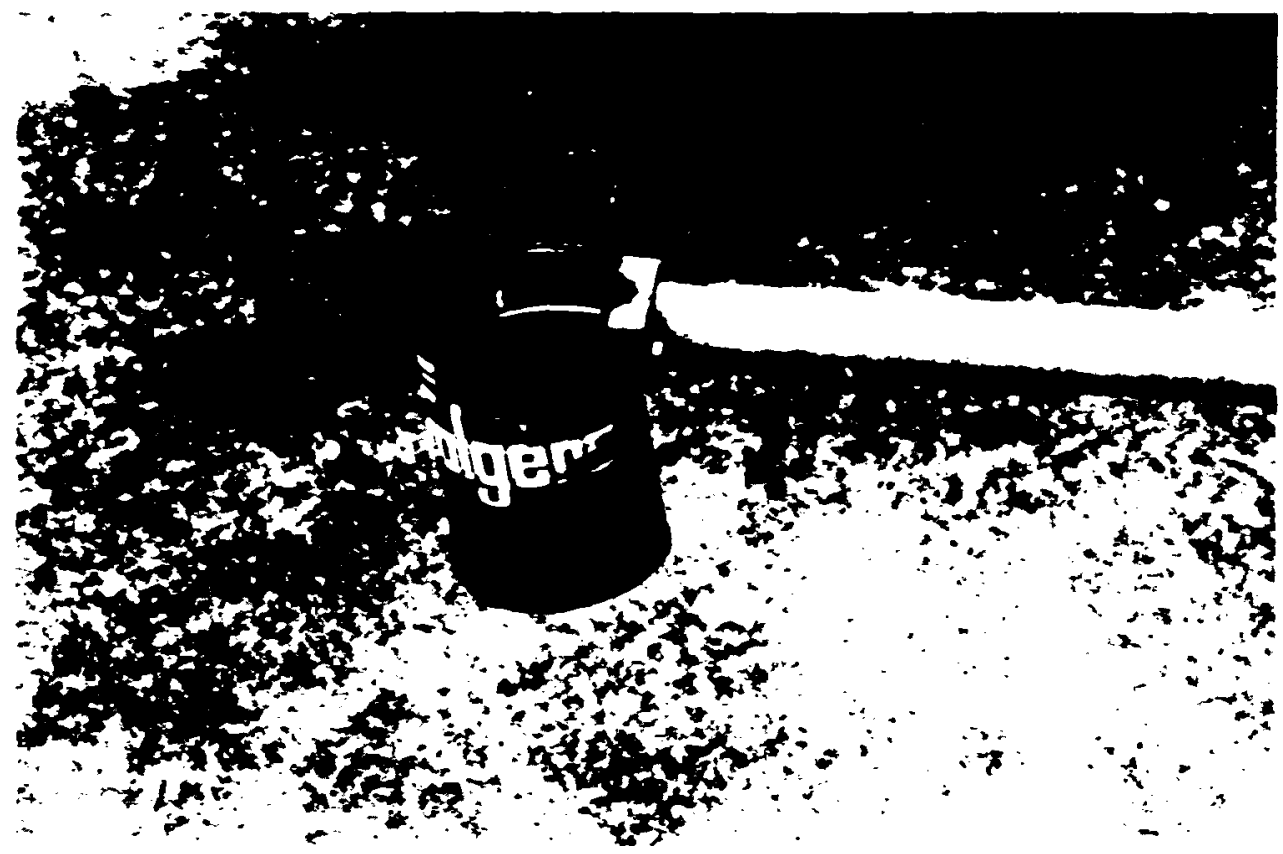

Figure 26. Coffee can feeder attached to long pole.

2. Stationary Mechanical Fry Feeders These feeders are usually suspended over troughs, small raceways, or small circular tanks. Food is distributed by shaking it on the water or by spreading it with a whirling blade as it falls from a hopper.

Skretting and Neilsen manufacture similar feeders for fry feeding. The Neilsen fry feeder is the most common mechanical fry feeder used in the Northwest. It is a long narrow unit, (Fig. 28), with several feeding slots. Feed is put into each hopper above the slot. The feeder can be suspended longitudinally over a trough or small raceway, or over a small circular tank. An electric timer is usually connected to the feeder which allows the slots to open as long and as often as required. The feed simply drops into the water. This unit allows frequent feeding of fry, but is not generally successful when used outside, as moisture causes food to build up around the slots. However, covers are available at extra cost. A 12-foot long feeder costs approximately $\$ 350$ for dry food and $\$ 550$ if moist food is used. They can be seen at many Columbia River hatcheries, particularly where steelhead and other trout are reared. 


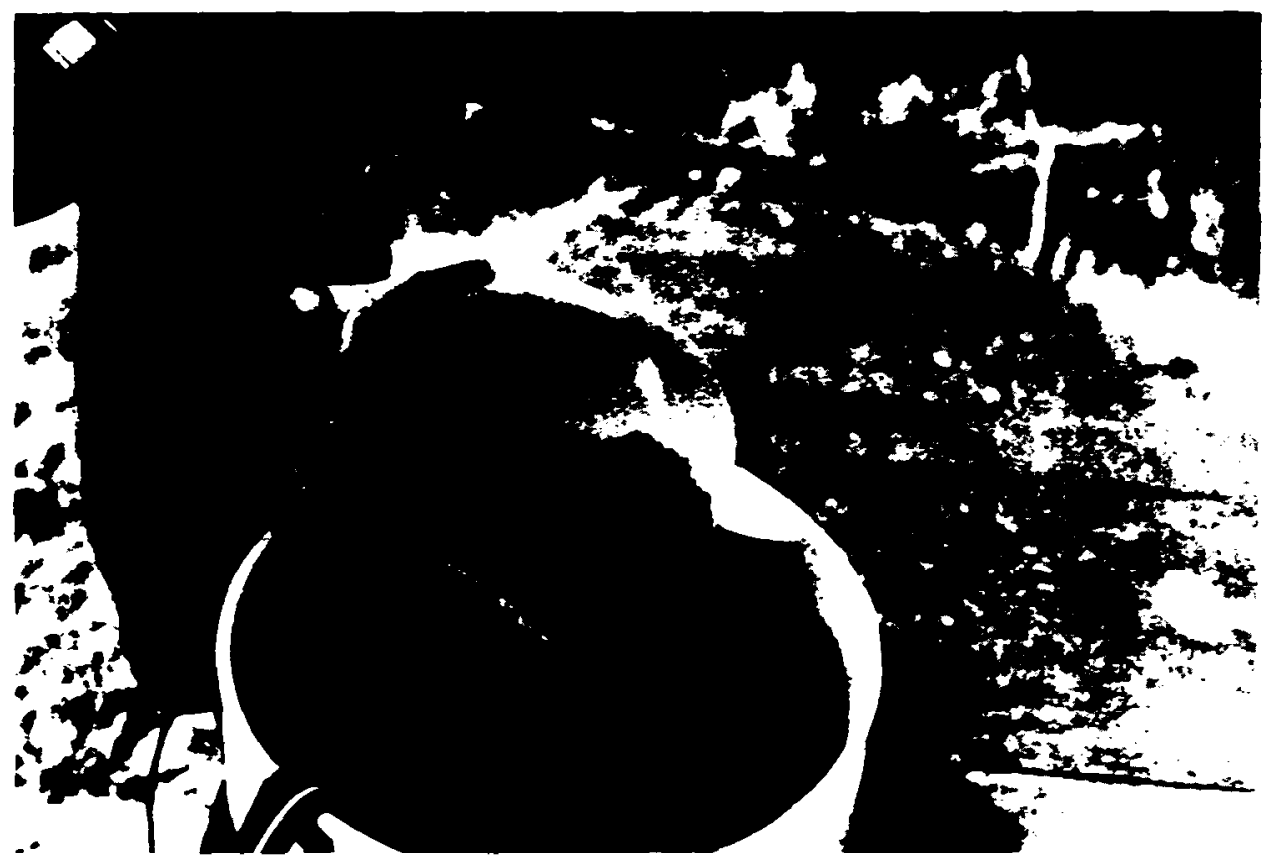

Figure 27. Hand scoop feeder made from a one-gallon plastic jug.

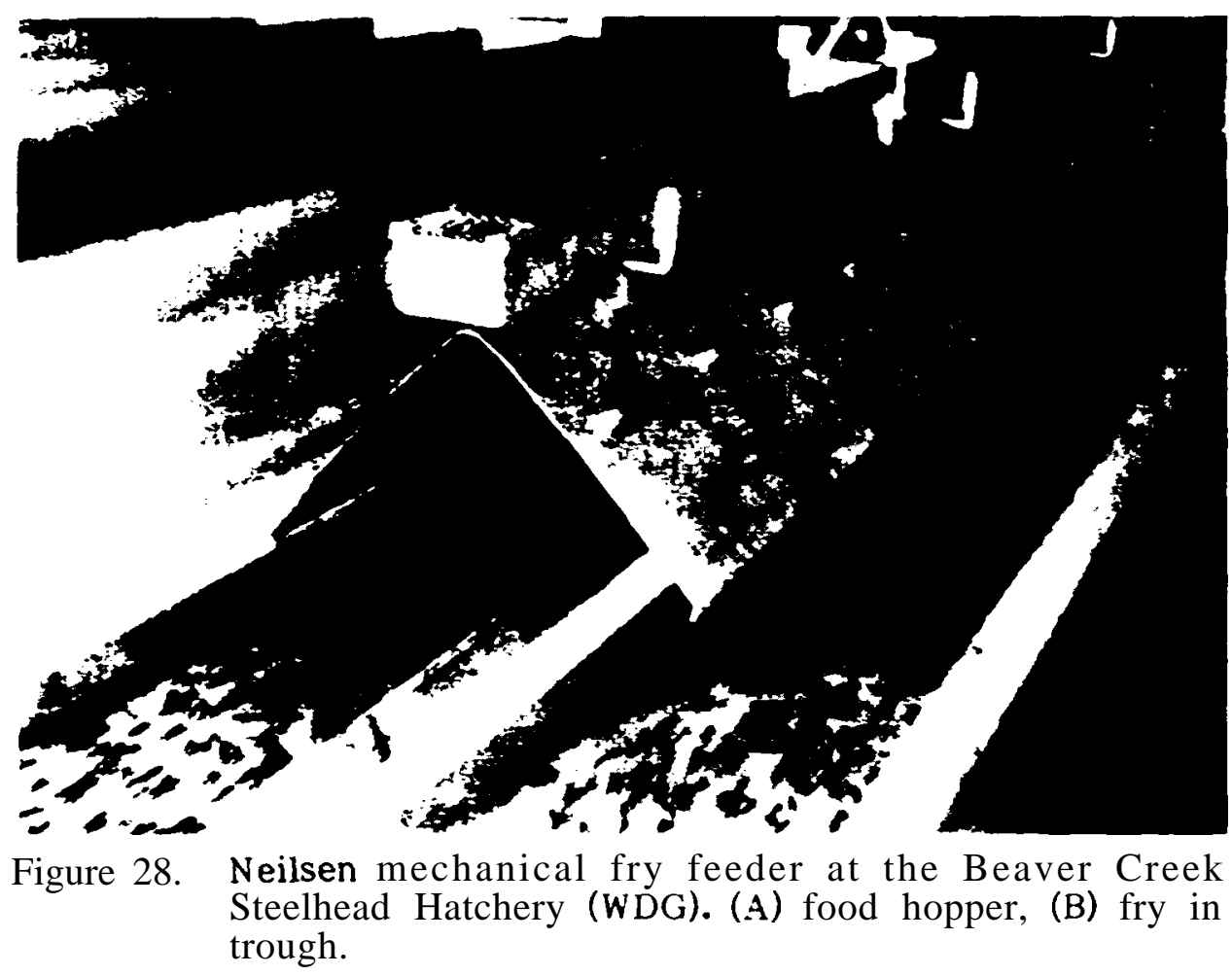


Chapter 5

3. Stationary Pond Feeders For larger fish, by far the most common unit is the Neilsen pond feeder illustrated in Fig. 29.

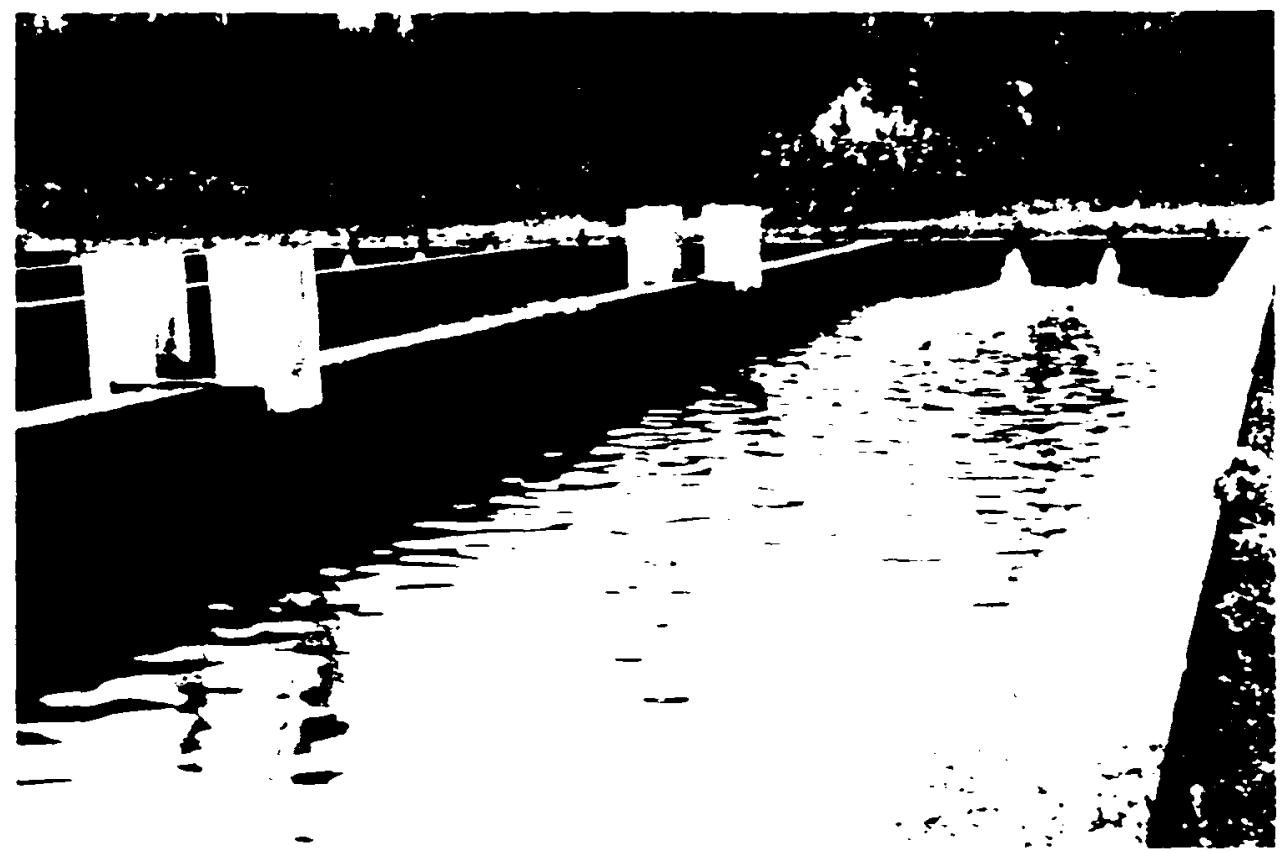

Figure 29. Neilsen pond feeders at Big Creek Fish Hatchery (OF w).

These units are stationary and feed automatically. The hopper (insulated ones available) holds about 100 pounds of pellets. The bottom is cone-shaped with a slide gate to allow pellets to fall out. Some units have agitator rods to make sure the pellets fall free. At the same time the slide gate opens, a small flat wheel turns directly below the hole. The vanes on the wheel pick up the pellets and throw them across the pond. The duration and the frequency that the pellets spill out is controlled by timers. This unit has been in use many years and is very reliable. Usually two to four units are placed on a 10- $x$ 80-foot pond. The only manpower required is to fill the hoppers and occasionally adjust the system. These units can be used in inclement weather, electricity must be available, and there is a fairly high initial cost for purchase and installation. The Neilsen Metal Industries, Inc. have both a dry and moist pellet feeder. With controls, they sell for around $\$ 1,000$ to $\$ 2,000$, respectively. The feeders and controls can be adapted to almost any fish and pond situation. For precise costs, Neilsens should be contacted.

Smaller battery operated feeders of this type are available or can be custom built. Costs range from $\$ 200$ to $\$ 400$. See Appendix 2 for Aquafarms, Skretting, or Boatcycle Co.

Helnie Manufacturing, Inc. produces a small feeder satisfactory for feeding fish in small rearing units. It is called the Allen Feeder and is used at the Rapid River Salmon Hatchery (IFG)(Fig. 30). THe 1984 cost was $\$ 119.00$ per unit. 


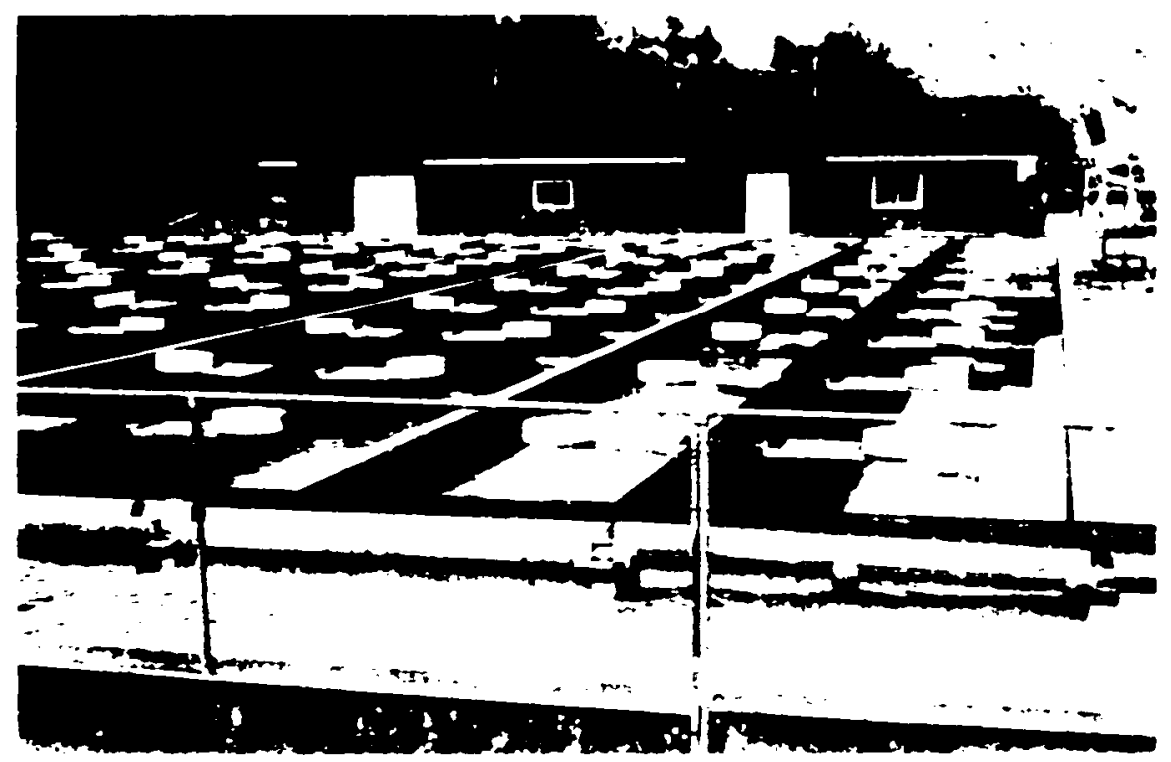

Figure 30. Stationary automatic fish feeders on 6-foot wide raceways at the Rapid River Fish Hatchery (IFG).

4. Demand Feeders These feeders allow the fish to feed themselves. They are inexpensive and consist of a hopper with a hole in the center of the bottom. A small rod extends down through the hole and into the water. The rod has a small red ball on the end (Fig. 31). When the fish hit the red ball, the rod movement loosens the food, which then falls into the water. These units can be suspended along the pond walls or placed on brackets which can be moved out over the pond (Fig. 32). Three units are usually installed in a 10- x 80-foot pond.

These units do not require electricity, reduce manpower requirements, and are relatively inexpensive. They do not handle moist pellets well, especially in moist climates, and there are reportedly questions about the efficiency of the units in providing food to all the fish, since it is distributed in a confined area. They apparently are more suitable for the feeding behavior of steelhead trout. A demand feeder holding 8 pounds costs $\$ 35$, while a 125 -pound capacity feeder costs $\$ 65$. See Appendix 2 for Babington Enterprises, Ken's Fish Hatchery, and others for feeder supplies.

5. Mobile Feeders A mobile feeder is an excellent choice for feeding fish in large rearing ponds. It consists of a food hopper, a blower, a gasoline engine to power the blower, and a pipe to direct the feed to the pond (Figs. 33 and 34).

The unit can be mounted in a boat or on a barge, large trailer, or pickup. To feed, the hopper is filled, the gasoline engine started, and the operator controls the feed 


\section{Chapter 5}

discharge gate in the pipe as he drives along the pond. Depending upon the size of the unit, food can be distributed up to 40 feet across the water.

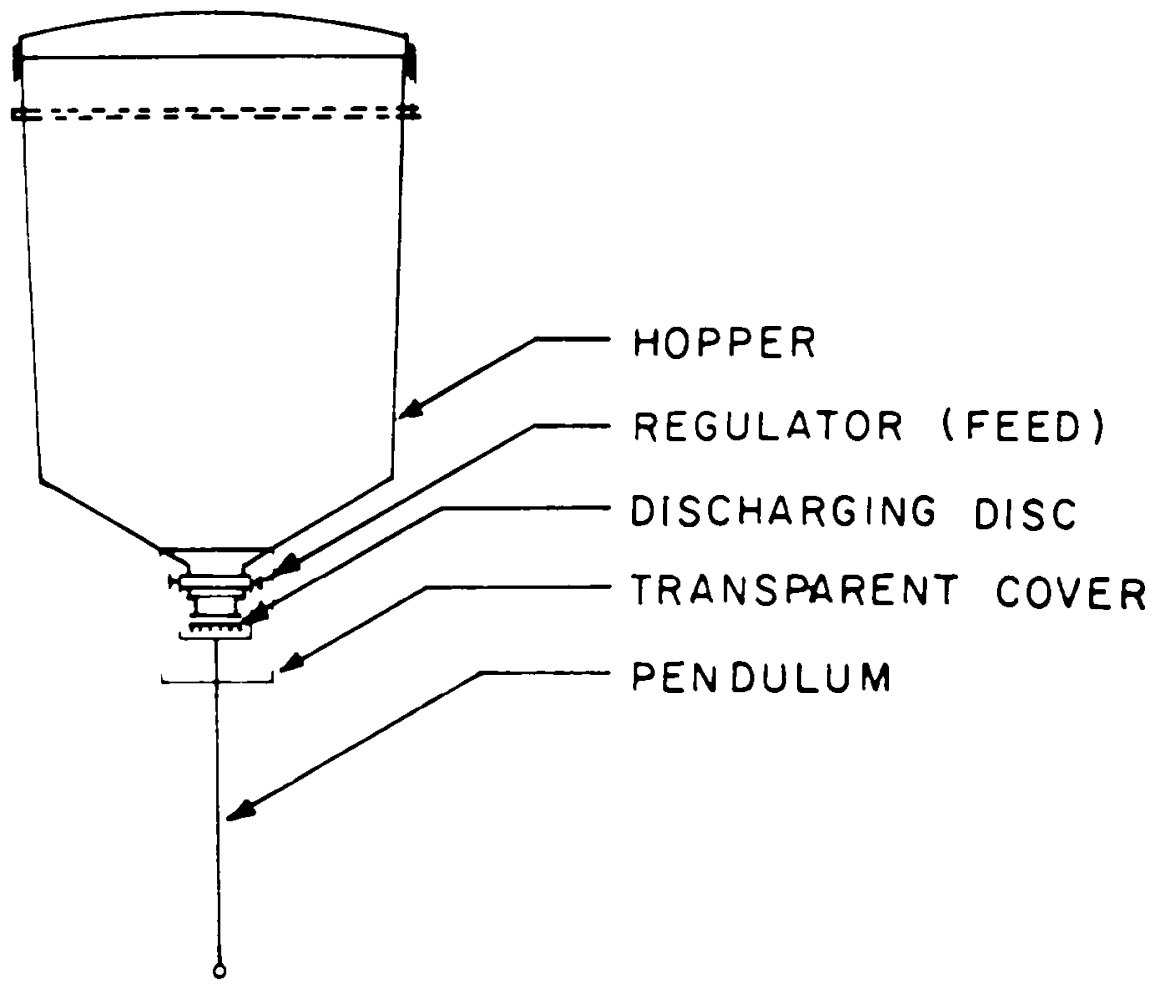

Figure 31. Illustration of a demand fish feeder.

These feeders are relatively simple and inexpensive to construct and maintain. They will handle both dry and moist pellets and can be adapted for feeding in raceways. For a large pond, this system precludes the installation of a large number of fixed mechanical feeders. They can be observed at most Columbia River hatcheries.

Host of the blower feeders now in use have been built by the hatchery personnel and the cost is dependent on the skill of the crew. See Appendix 2 for Herrington Manufacturing Co. for a mobile feeder that costs $\$ 6,000$ per unit.

\section{B. PONDSCREENS}

Pond screens are made from a variety of materials and are used to contain fish in desired locations. The screen material is usually mounted on metal or wooden frames. Vertical fixed screens are used for most purposes and are sized so that they can be manually handled for cleaning, repair, and replacement. Rotating screens, such as rotary drum and belt screens, are described in this section but we consider them too expensive for most low-cost facilities. 
Important considerations in selecting a screen type and mesh size are fish size, water velocity approaching the screen, and the amount of area to be screened in relationship to the water requirement. We recommend the following hole sizes for slotted screens (Source: Piper et al., 1982):
$1 / 16 \times 1 / 8$
$1 / 8 \times 1 / 4$
$1 / 4 \times 1 / 2$
$1 / 2 \times 3 / 4$
fry up to $1,000 / \mathrm{b}$
$1,000-200 / 1 \mathrm{~b}$
200-30/1b
$30 / \mathrm{lb}$ and larger

We found that managers installed $15-30 \mathrm{ft}^{2}$ of screen material for each cfs of discharge water. Generally, this requires that the screens be brushed once each day to prevent plugging. The common pond screens and materials used in rearing facilities and their applicetion are discussed:

\section{Perforated Plate Perforated} plate used by the Washington Department of Fisheries is $1 \mathrm{G}$-gauge aluminum with 3:1 6 -inch holes in staggered rows at $1 / 4$-inch centers, providing $52 \%$ of the plate open to pass water (Fig. 35). The perforated plate is available in 4- $\mathrm{x}$ 4-foot sheets and can be ordered with a plain edge border for better frame fastening. This material should be supported on 2-foot centers.

\section{Cost:}

A ready-to-use plate screen with support bar, ( $1-1 / 2 \times \mathrm{I} / 4$ inches) and an aluminum angle frame (1-1/2 x 1-1/2 inches $\times 3 / 16$-inch thick) costs $\$ 12.00 / \mathrm{ft}^{2}$ at the place of manufacture. Life expectancy is 10 years for the plate and 15 years for the frame. The hard waters east of the Cascade mountains sometimes cause corrosive action on aluminum. Special alloys to prevent this should be used.

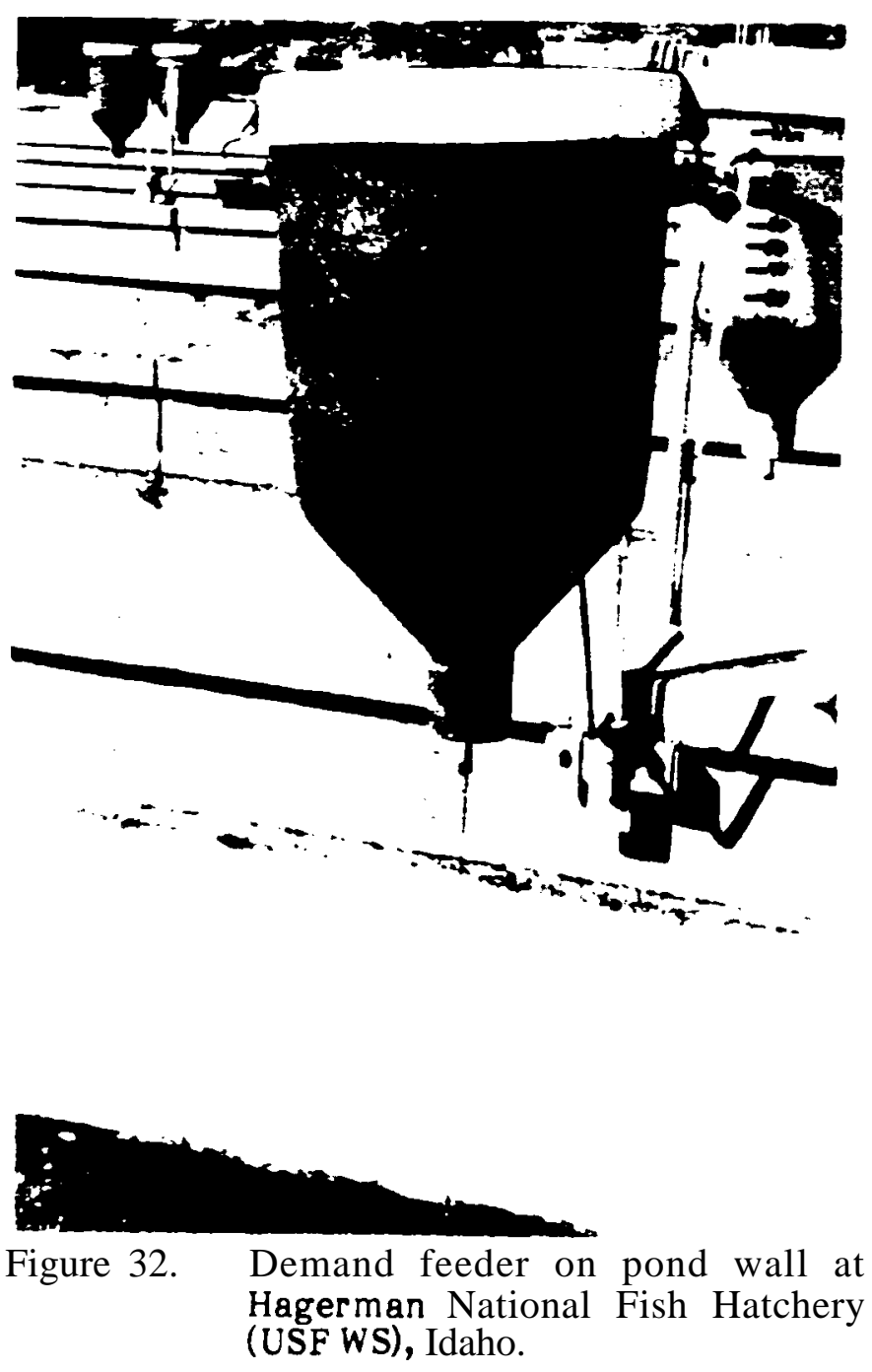




\section{Chapter 5}

Information Sources:

Western Wire Works (Plate)

Pacific Metal Co. (Frame)

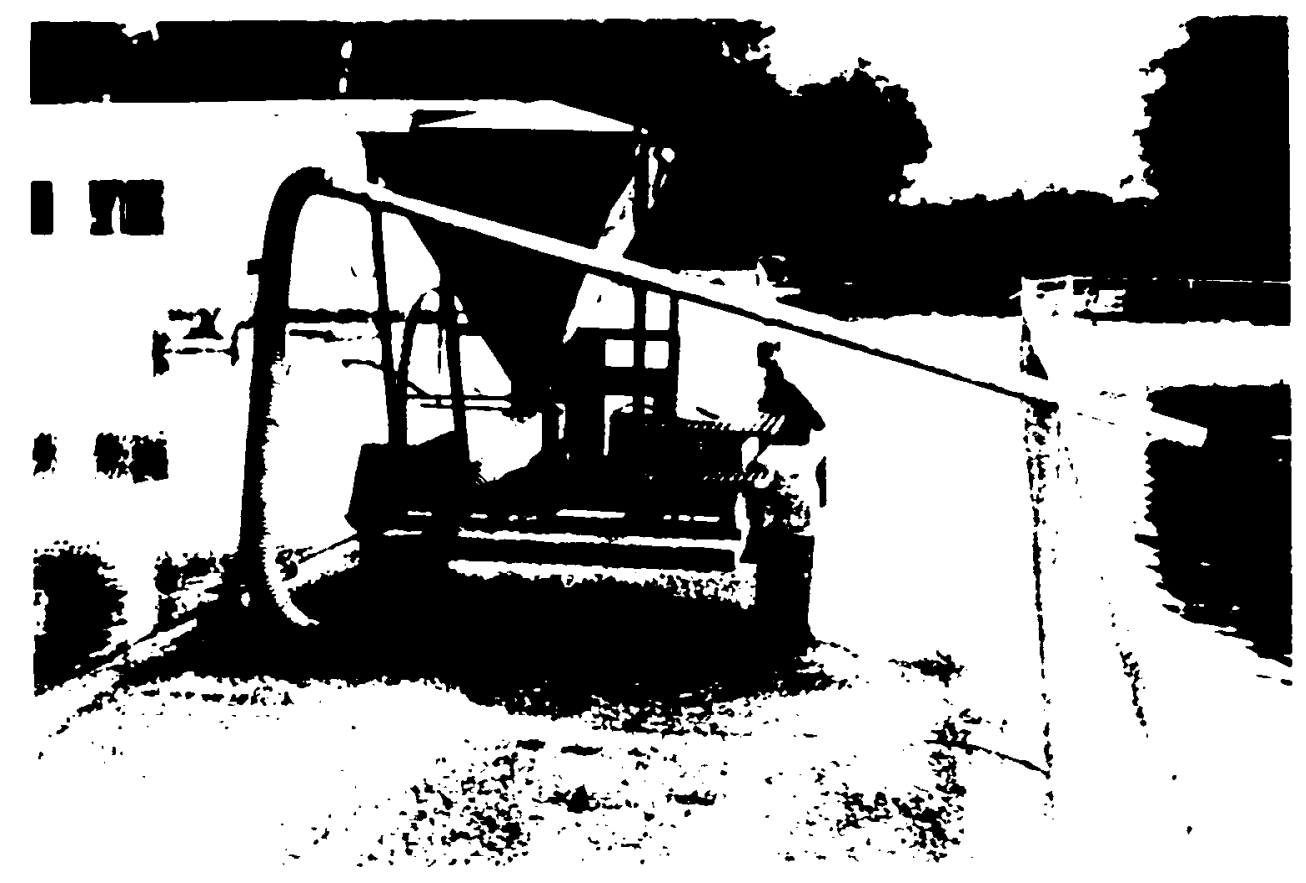

Figure 33. Mobile fish feeder mounted on a trailer at Puyallup Salmon Hatchery (WDF).

2. Slotted Plate There are several patterns and opening sizes available for slotted plate screens. One of the more common and popular all-purpose slotted plate is 14-gauge aluminum with $3 / 32$-inch slots 1 -inch long in a staggered pattern with $3 / 16$ inches between slots and $1 / 8$-inch between rows; providing $40 \%$ of the plate open to pass water (Fig. 36). The dual purpose screen shown in Fig. 36 can be used for both small and large fish, thus saving storage space and labor costs. In use, for small fish the small slots are under water; for larger fish the screen is rotated top to bottom and the large slots are in the water. Slotted screens are preferred by many operators because they are easier to clean than hardware mesh or round hole perforated plates. Stringy material, pine and fir needles, etc., all tend to pass through the slots without plugging.

\section{Cost:}

Sheets also come in 4- $x$ 4-foot size with a plain edge border. When fastened to a $1-1 / 2 \times 1-1 / 2 \times 3 / 16-i n c h$ thick aluminum angle frame the unit costs $\$ 14.00 / \mathrm{ft}^{2}$ at place of manufacture. Life expectancy is 10 years for the plate and 15 years for the frame. 


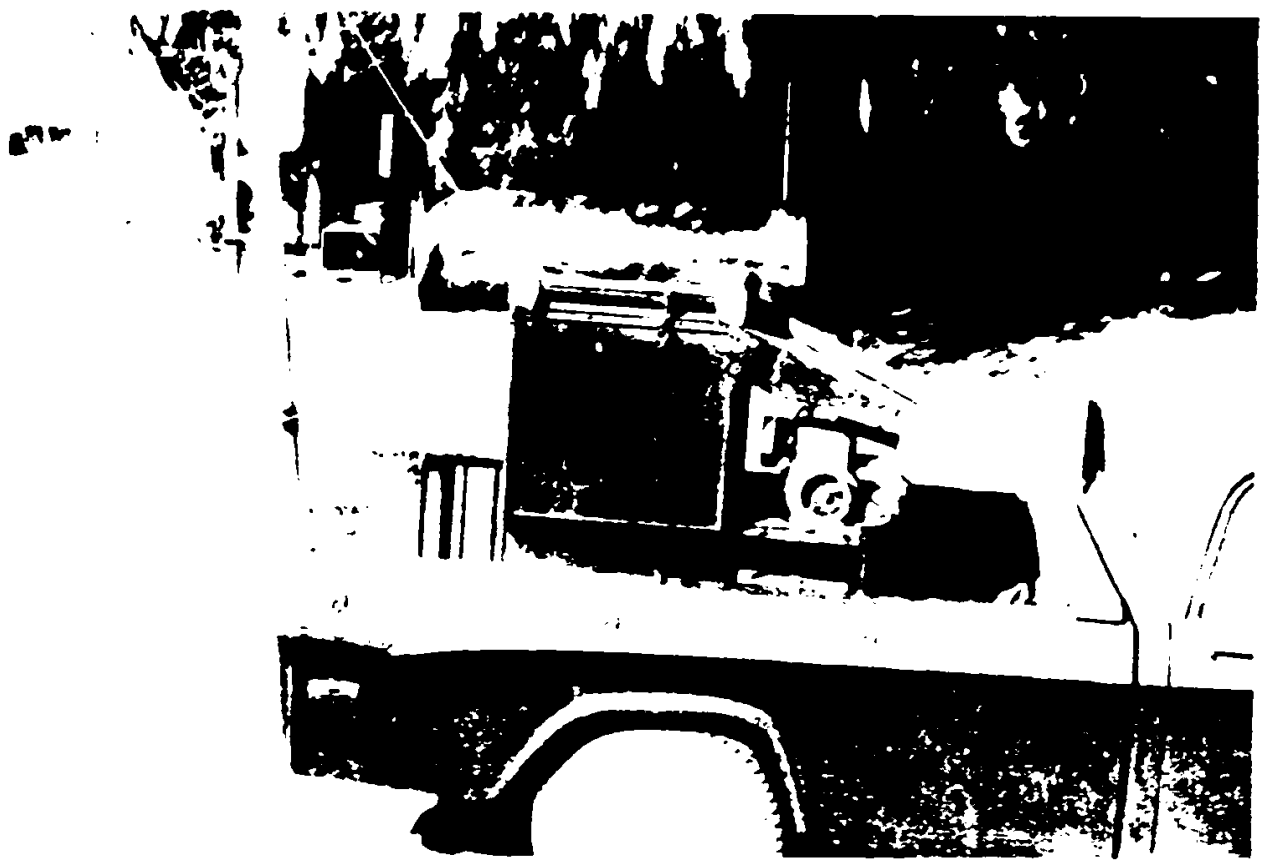

Figure 34. Pickup-mounter blower feeder (IFG).

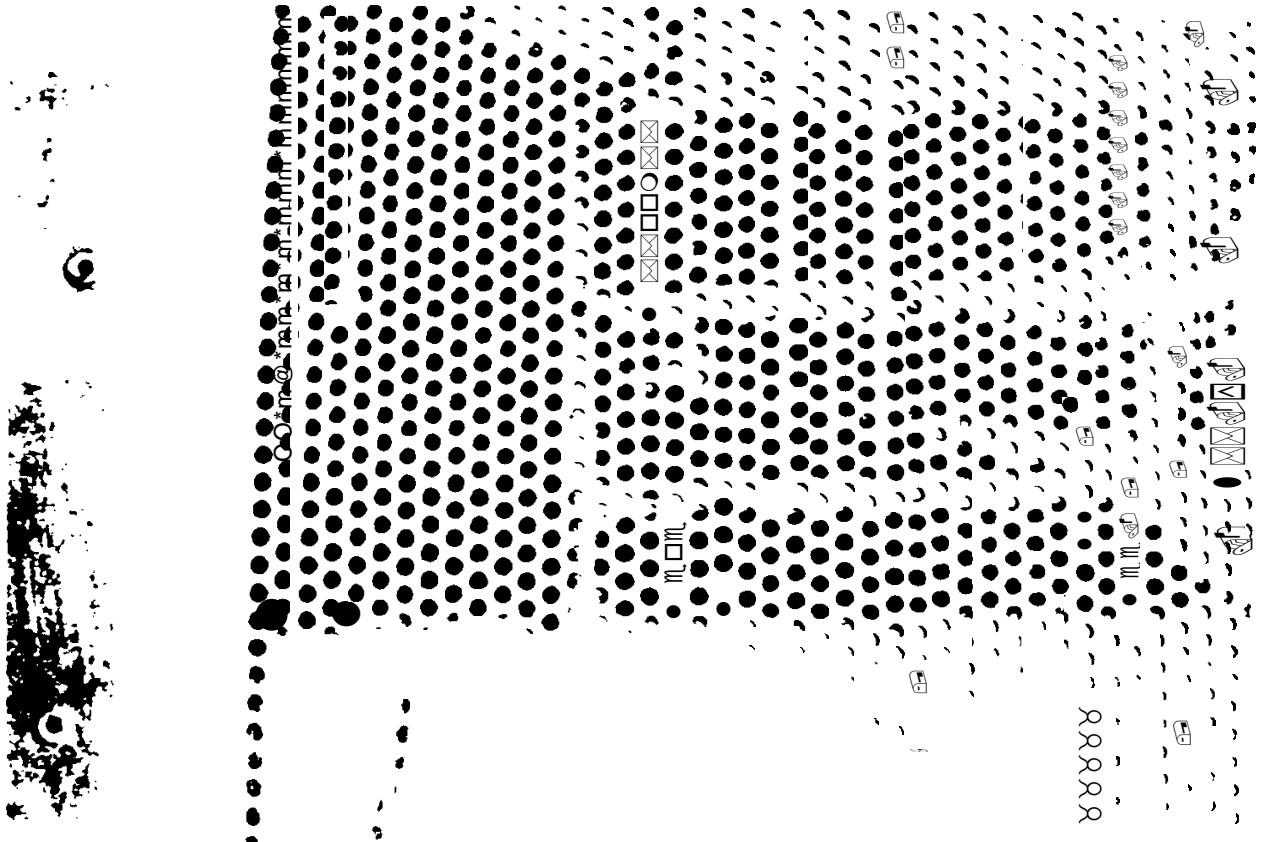

Figure 35 . Typica per Srated plate. 


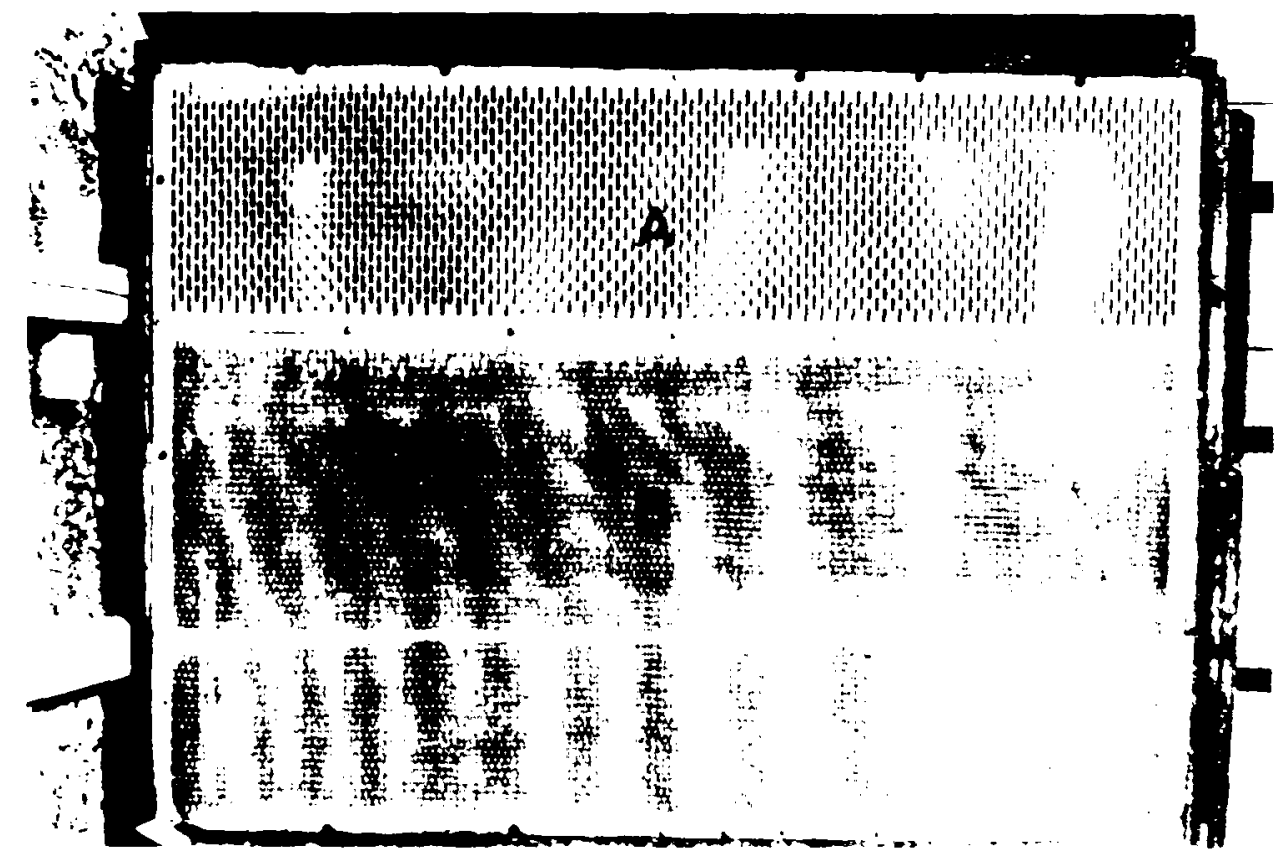

Figure 36. Slotted plate screen for dual purpose use. (A) large slots down when rearing larger fish, (B) small slots down for smaller fish.

Information Sources:

Western Wire Works (Plate)

Pacific Metal Co. (Frame)

3. Hardware Cloth This name is given to wire woven into a mat that has uniform spacing, usually in both directions, and then rolled to flatten and hold the wire spacing. Cloth can be purchased that is galvanized after weaving which firmly locks the wires in their correct original spacings and improves durability. Zinc in the galvanizing can be harmful to fish, but the screen can be treated or aged to minimize this problem. A thin coating of coal tar or asphalt will reduce leaching of the zinc ions and maintain the screen openings. The lightest hardware cloth is 16 gauge and the heavy-duty cloth can go to 11 gauge. Hardware cloth is available in a wide variety of mesh openings and wire sizes. Perhaps the most common mesh sizes used for pond screens have 1/8-1/4 inch square openings, with the wire size dependent upon the amount of wear and strength required. These screens normally have $1 / 8$-inch openings providing $60 \%$ openings $/ \mathrm{ft}^{2}$ for the light wire and 30 \% openings $/ \mathrm{ft}^{2}$ for the heavy-duty wire. Hardware cloth can be stapled to nood frames built to fit guide slots in ponds or intakes. The heavy-duty screen is normally used for intakes and rotary-drum revolving screens, and the lighter wire is used in pond screening. Heavy-duty 1 l-gauge cloth costs $\$ 10.39$ / $\mathrm{ft}^{2}$ and lighter 16 -gauge cloth costs $\$ 6.67 / \mathrm{ft}^{2}$. 
Fuse-bonded vinyl-coated galvanized steel mesh (Fig. 37) is being manufactured for the aquaculture industry. It is available up to 72 inches wide with mesh sizes from 1/4-inch square and larger. Gauges are available from 23 to 10. The plastic covering provides a very smooth surface and is non-abrasive to fish.

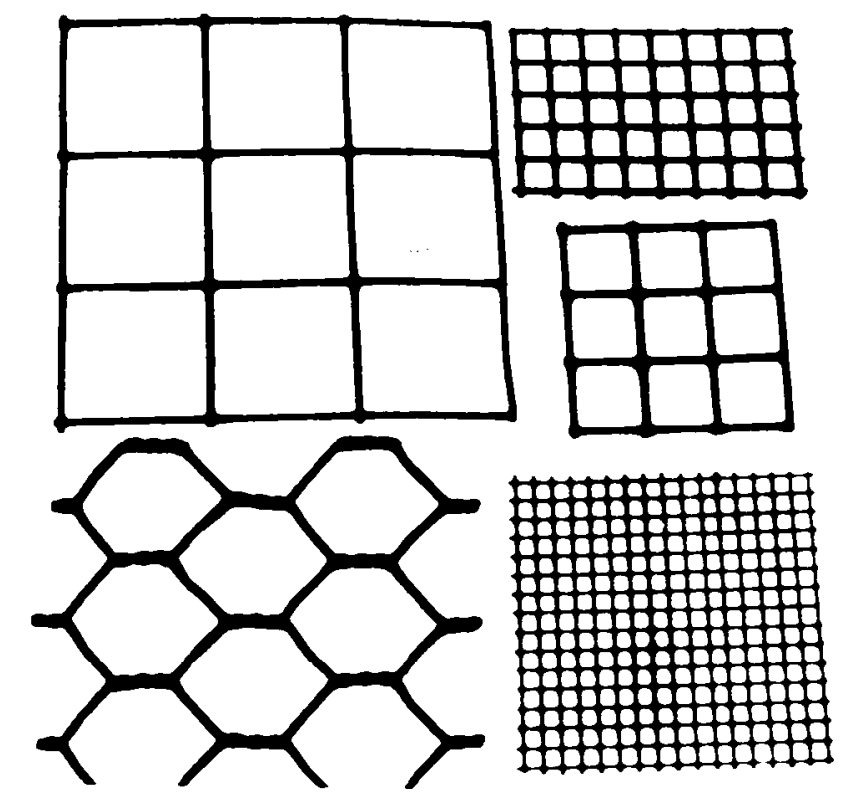

Figure 37. Types of fuse-bonded vinyl-coated hardware cloth.

\section{Cost:}

Screens of 16-gauge hardware cloth galvanized after weaving and stapled to 2-x l-inch treated lumber costs $\$ 7.67 / \mathrm{ft}^{2}$ at the place of manufacture. Life expectancv is seven years. Prices are not available on a ready-to-use screen made of plastic-coated wire, however, a 4-x 150-foot roll (20 gauge) is only $\$ 0.22 / \mathrm{ft}^{2}$.

\section{Information Sources:}

Western Wire Works (Galvanized cloth)

C. E. Shepard Co. (Fuse-bonded vinyl wire)

Nichols Net and Twine Co., Inc.(Fuse-bonded vinyl-coated wire)

4. Aluminum Tube Screens made from aluminum tubing provide an economical method for building station screens (Fig. 38). Construction is as follows: Stiff aluminum tubing, 1/2-inch diameter or larger, is cut to the proper lengths so their ends will fit into a rabbeted groove in the top and bottom inside face of a wood frame. Small aluminum washers can be used as spacers between the bars to obtain the desired opening, or the ends of the tubes can be flattened to provide spacing and attachment. Then hot tar is poured into the bottom groove until filled. After 


\section{Chapter 5}

cooling, the frame is rotated and the other end is also filled with hot tar. The round tubes produce an ideal hydraulic flow pattern thru this type of screen.

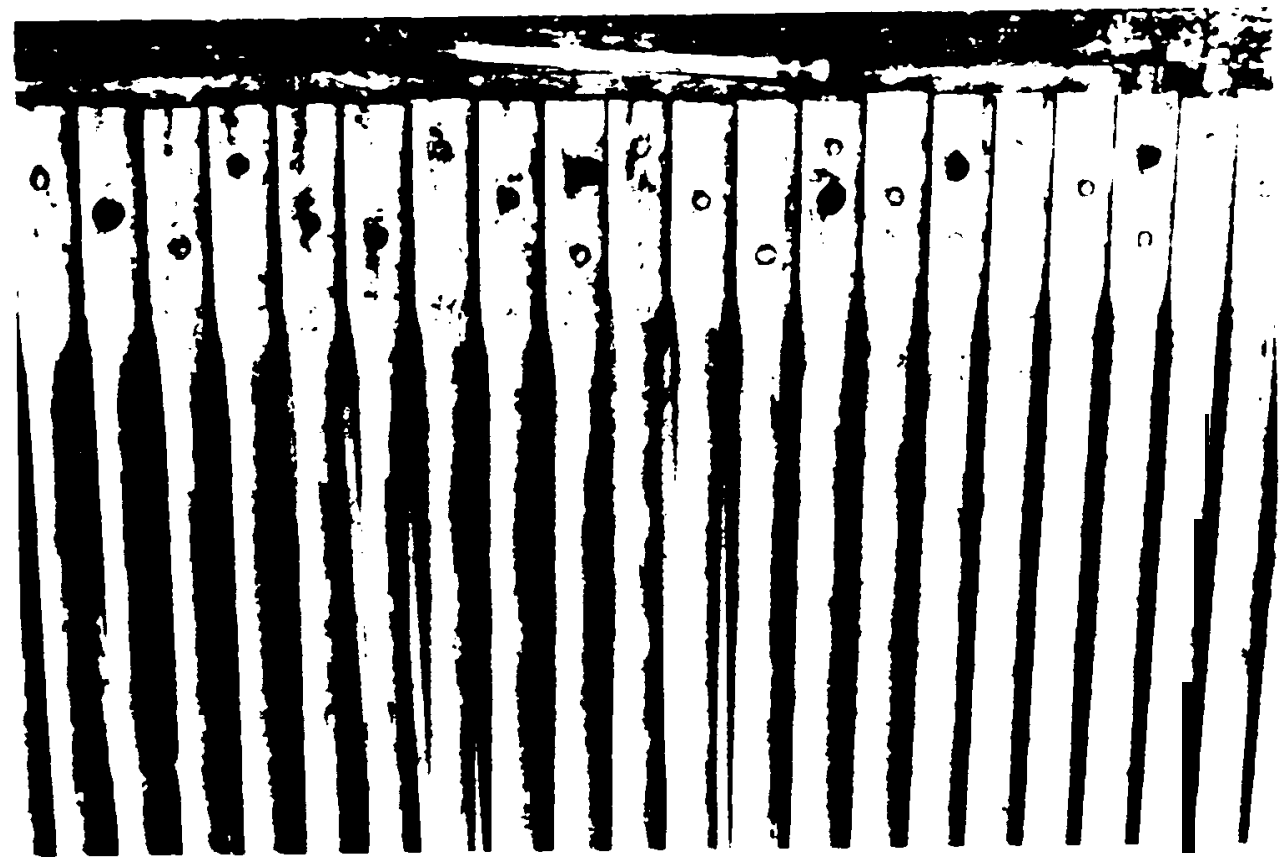

Figure 38. Aluminum tubing screens (IFG).

\section{Advantages:}

- $\quad$ Easily passes stringy matter, leaves and needles

$0 \quad$ Reduces brushing frequency

- Simple to build

- Inexpensive

Disadvantages:

- Tube spacing if on inlet is critical to prevent fish gilling

- Careless screen handling can bend tubes and alter spacing

cost:

Aluminum tubing screens with treated lumber frames cost $\$ 10.00 / \mathrm{ft}^{2}$. Life expectancy is seven years for the frame and 20 years on the tubing.

Information Sources:

Idaho Fish and Game

Washington Department of Game 
5. Rotary Drum Screen The rotary drum fish screen is a metal-framed drum covered with heavy-duty ll-gauge hardware cloth. The drum has a stainless steel center shaft and is secured with pillow block type bearings on both ends. The rotating screen is also sealed on both ends and across the bottom to a fish-tight fit with neophrene rubber material bearing lightly on the drum.

The drum is usually installed with about $2 / 3$ of the screen submerged so that the screen rotation assists in carrying over debris, leaves, needles, etc., and is considered self-cleaning. These screens are usually powered with a one-horsepower electric motor. Other rotary drum screens are rotated with water-powered paddle wheels (Fig. 39) or by internal paddle wheels built to operate inside the drum screen (Fig. 40). Water velocity turns the external paddle wheel and falling water powers the internal paddle wheel. Three or four feet of water drop is required to operate the internal paddle wheel unit.

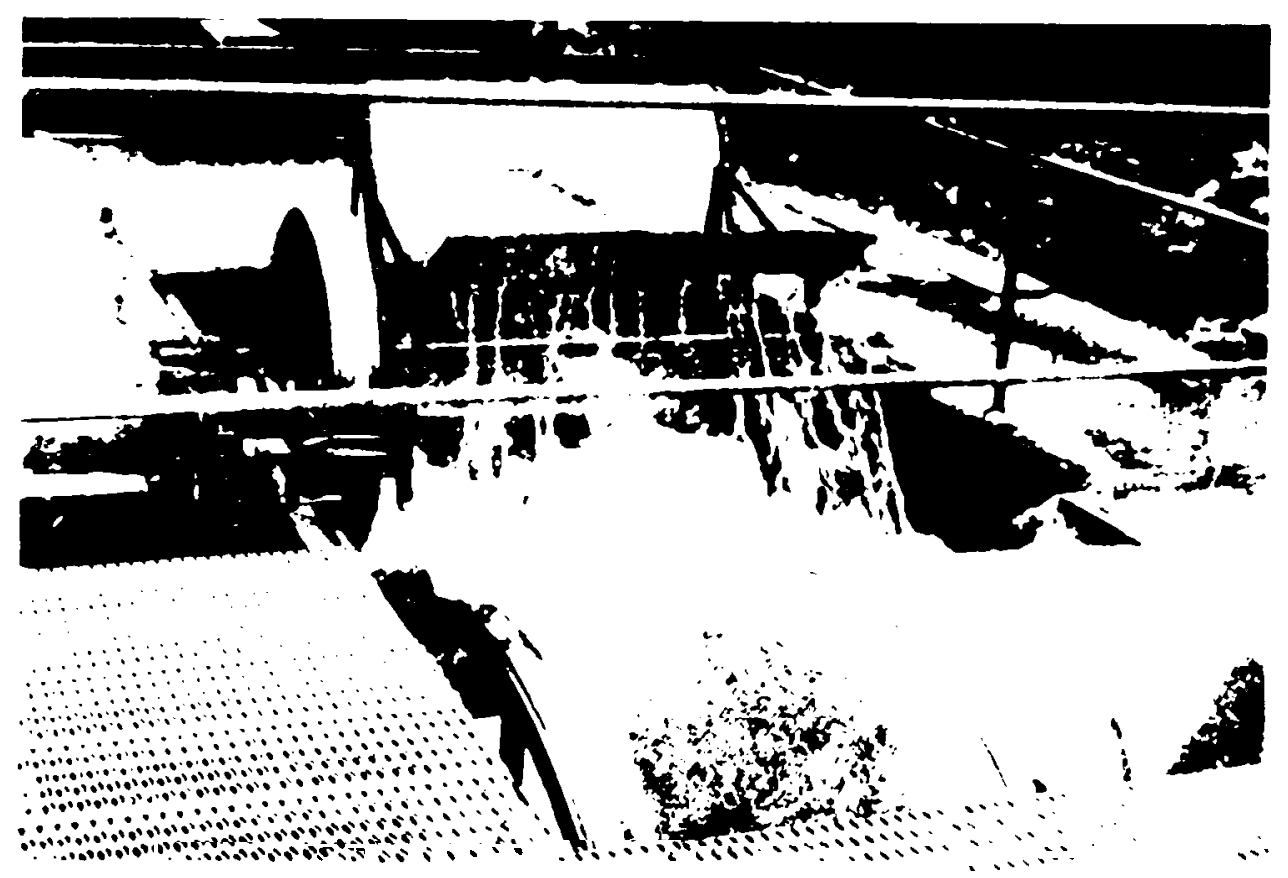

Figure 39. Rotary drum screen powered by an external paddle wheel.

Rotary drum fish screens are installed on the large pond outlet works to retain fish in the pond. The outlet is usually a permanent concrete structure or a temporary wood structure housing the rotary drum and appurtenances. The cost of rotary screens and the necessary appurtenances may preclude their use at a low-cost facility.

Cost:

Costs vary by size and we suggest contacting one of the sources noted below. 


\section{Chapter 5}

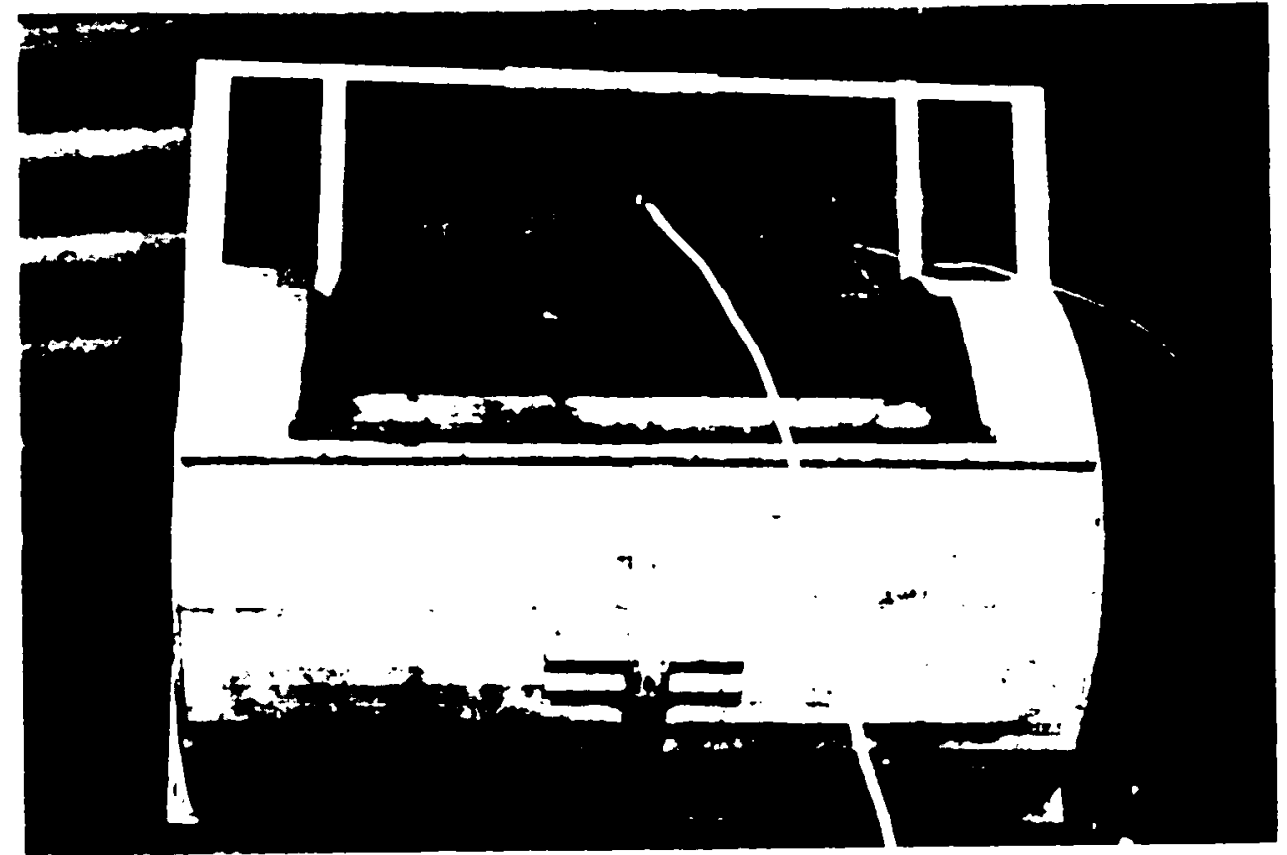

Figure 40. Rotary drum screen powered by internal paddles.

\section{Information Sources:}

Idaho Fish and Game Department's Screen Shop, Salmon, ID

Washington Department of Fisheries' Screen Shop, Yakima, WA

Oregon Department of Fish and Wildlife's Screen Shop, John Day, OR

6. Belt Screens Two types of rotating, power-driven belt screens are used at hatcheries, neither of which is considered applicable to low-cost installations. The Link belt (trade name) screen is a series of flat plate screens, usually made of hardware cloth, that travel an eliptical path at right angle to the water surface. They are sealed fish tight at the sides and bottom and are usually spray cleaned above the water surface as the screen moves up. Debris is caught in a flume in front of the screen at an elevation above the water surface. This unit can be seen at the WDF Cowlitz Salmon Hatchery and WDG Skamania and Beaver Creek Steelhead hatcheries.

The second type of belt screen, often referred to as the WDF belt screen, uses flexible screening as the belt and functions in a sloping position. Like the drum screen, the debris is moved up and over the screen slope. This unit is in use at the WDF Skykomish, Lewis River, and Humptulips River Salmon hatcheries. 


\section{c. PUMPS}

The hatchery operator has uses for special types of pumps in performing various station tasks. In addition to the pumps described in Chapter 2 - Water Delivery, a station needs pumps for cleaning, wash down, water transfer, fish handling, irrigation, and fire suppression.

1. Rash Pump The trash pump (Fig. 41) is designed for handling a limited amount of sediments, including up to 1-1/2-inch gravel. This type of pump is used to clean ponds, intakes, fishways, ditches and water boxes after flood debris has settled on the bottom, or after operations have been curtailed and fish moved out of the system. These pumps are usually gasoline powered, self-priming, portable, and mounted on skids.

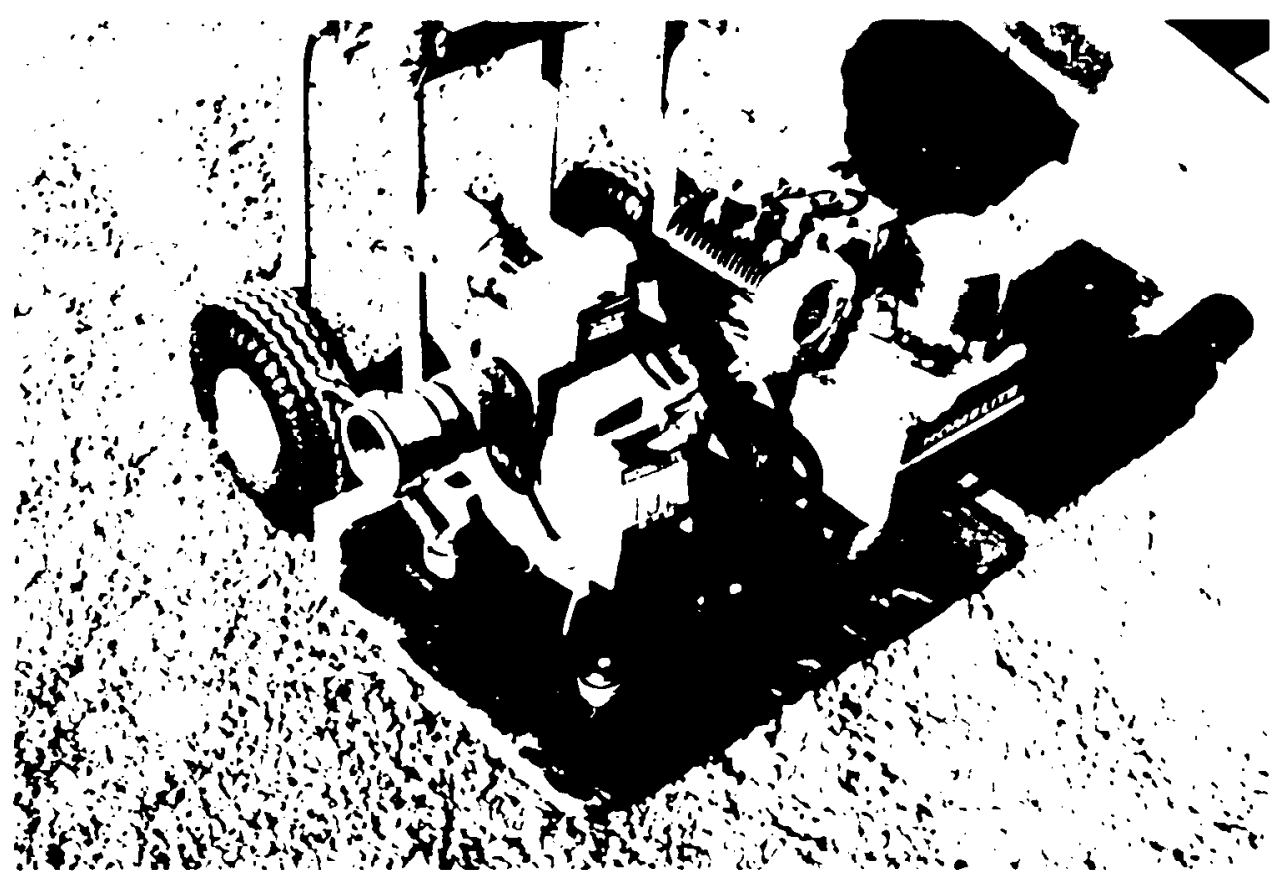

Figure 41. Trash pump at Tulalip Tribal Hatchery, Washington.

\section{Cost:}

A 3- and 4-inch trash pump with accessories costs about $\$ 1,200$ and $\$ 3,000$, respectively. Life expectancy for both pumps is 15 years of intermittent use.

Information Source:

Pace-Pacific Pump Co.

2. High Pressure Pump High pressure pumps are a self-priming type mounted on a wheeled cart, and include a pressure hose and nozzle, and suction hose with a 


\section{Chapter 5}

strainer (Fig. 42). The pump can be of large or small diameter with two or more stages to generate the high pressure. The portable unit is moved to the use location and the suction placed in water. After priming by low pump speed or assisted by a separate priming pump or engine vacuum system, the engine can be speeded up to the water pressure desired. Water pressures of 200 to 400 psi can be developed.

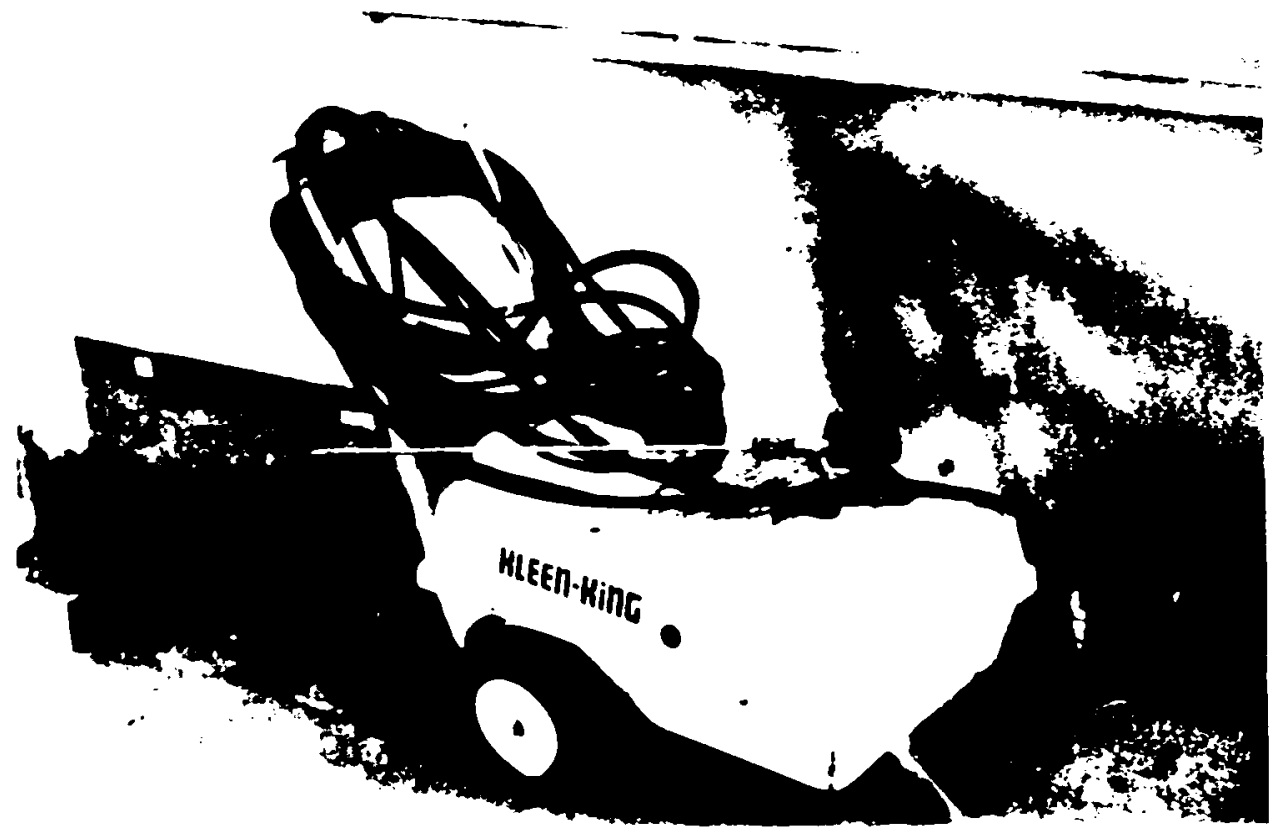

Figure 42. High pressure pump at Big Creek Fish Hatchery (OFW).

This pump can be used to flush out ponds after fish release, treatment, or to assist in pond brushing. Clean-up of the spawning area, general cleaning of walks and drives, vehicle and equipment washing, building wash down, and emergency fire protection are some other uses for this system. Caution is required in operation as the high pressures can be destructive to concrete and wood surfaces.

\section{Cost:}

Purchase cost of this gas driven pump with accessories is about $\$ 2,000$. Life expectancy when used intermittently is about 15 years.

\section{Infor mation Sources:}

Pace-Pacific Pump Co.

Landa, Inc.

3. Vacuum Pump Hatchery personnel use this pump to remove dead fish from ponds and for pond cleaning. This pump operates by using an ejector to develop a vacuum which is piped to a wand used by the operator to reach over the pond area. 
The operator maintains his finger over a vacuum breaker hole near the handle which activates the vacuum to the wand end to pick up dead fish or pond debris. He can quickly break the siphon by moving his finger from the hole to avoid live fish should they school near the end of the wand. The operator also uses the vacuum force in the flexible tube to supply water, assist fish flushing, and move fish from one pond to another by having the water level in the pond being supplied lower than the supplying pond.

This pumping system is very similar to a swimming pool cleaning system and is powered by either a gas or electric pump. The equipment is very cumbersome to use unless the flexible tube to the wand is light and floats on top of the water surface, the wand handle is aluminum, and the wand end is designed with wheels similar to an upright carpet vacuum cleaner.

\section{Cost:}

Purchase cost is about $\$ 2,000$ with accessories. Life expectancy when used intermittently is about 15 years.

Information Sources:

All agencies

Began Equipment

4. Fish Transfer Pump This pump will pass fish through the impeller and case without damage to the fish and is a modification of the pump developed by Pacific Pump Co. to pump whole tomatoes (See Chapter 6). It is now widely used at hatcheries for most fish moving chores, particularly for loading fish from pond to fish planting tanks through a tower that separates the fish and returns the water to the pond (Fig. 6, Chap. 6). At times this pump has been used to lift fish into graders. The speed of the operation must be governed to have the correct numbers of fish passing the grader.

The most practical pump sizes for the fish we propose to culture are 4 to 6 inches; are gasoline engine powered, and usually mounted on a trailer for portability. The pump's priming system should be fully operating before the pump is started and should be run at the lowest speed necessary to lift water and hence minimize damage to fish. The pumping unit should be started, run, and adjusted to lift water to the proper height before the intake screen is opened to move fish. The pump intake usually operates out of a sump which allows pond water levels to be lowered to crowd fish towards the pump suction.

A 4-inch pump is excellent for 1 - to 3 -inch fish, but we suggest a 5 - or 6 -inch pump for 3- to 6-inch fish and a B-inch pump for 6- to 12-inch fish. 
Chapter 5

Infor mat ion Sources:

Neilsen Metal Industries (Pump)

Magic Valley Heli-Arc and Manufacturing (Pump)

\section{DIP-NETS AND SEINES}

All stations require nets to capture or crowd fish. Nets fall into two classes, dip nets and pond seines. Both types are required at a station where fish are handled from the egg to adult stage. Because the units in which fish are reared range from small troughs to large ponds, there can be a multitude of suitable net types; too extensive for individual discussion.

It is recommended that most small nets used for a specific unit be constructed by the culturist. Small dip nets, a pole seine (Fig. 43), or heavy-duty adult dip nets are some examples of nets a culturist can make. Most nets can be purchased from vendors noted in Appendix 2. Heavy-duty dip nets, (Fig. 44) with handles ranging in size from 12-18 inches, cost \$25 each. A heavy-duty, 6-foot deep, knotless, 1/4-inch mesh nylon seine (Fig. 45) costs $\$ 3.00$ per linear foot. A 3-inch mesh knotted-nylon adult seine would approximate one-half this cost.

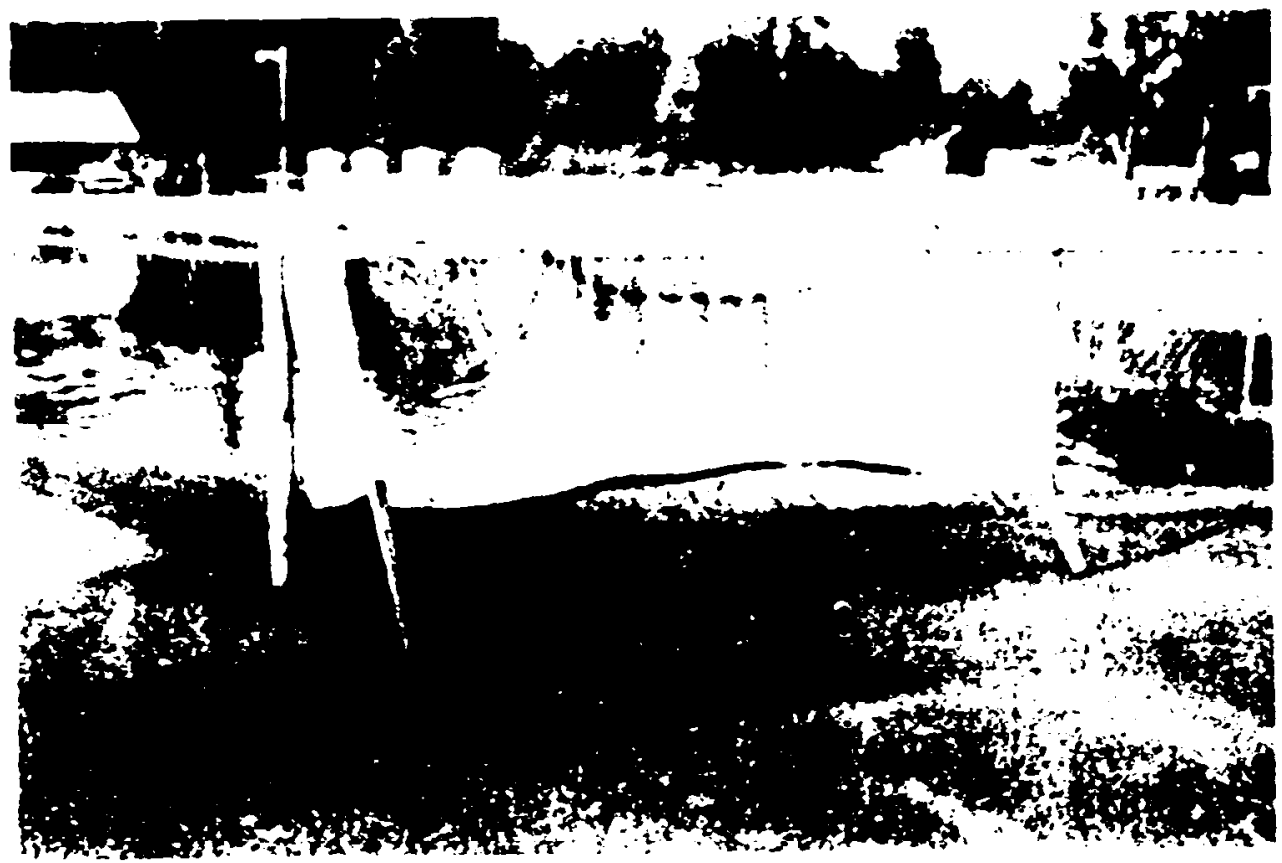

Figure 43. Pole seine for juvenile fish.

In selecting materials for nets and seines of nylon, vinyl or other synthetic plastics, particularly where use will cause exposure to sunlight, we recommend a dark color for longer life. The darker the material the better is its natural protection against the sun's ultra-violet rays. This also applies to all lines and sheeting used around fish facilities. 


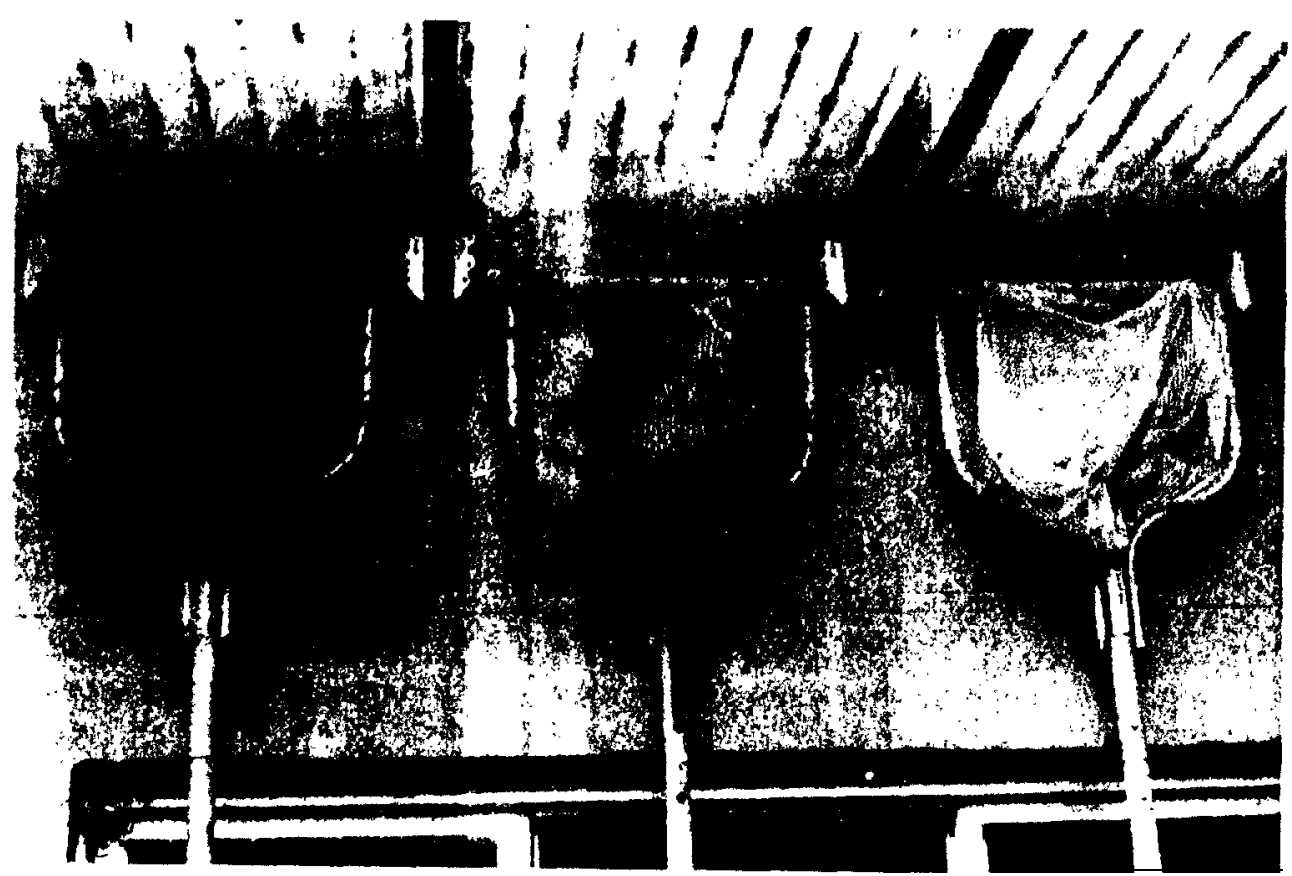

Figure 44. Standard dip nets for juvenile fish.

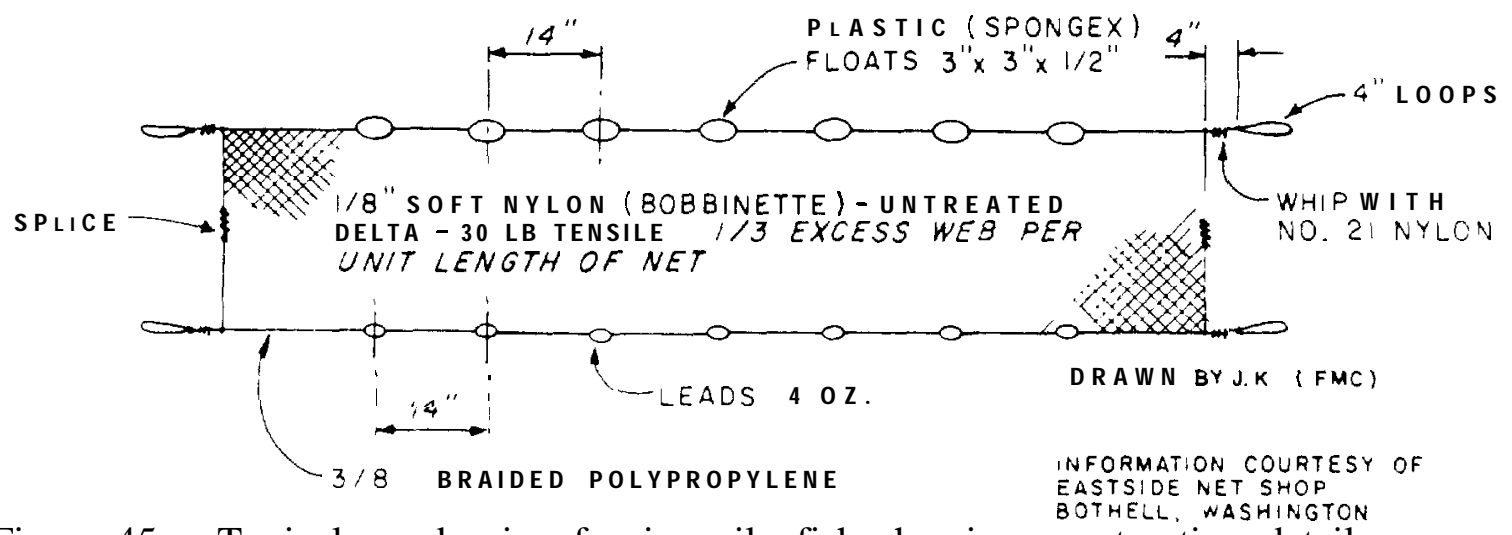

Figure 45. Typical pond seine for juvenile fish showing construction details.

\section{E. POND CARE AND CLEANING}

Several advantageous concepts in the care and cleaning of ponds are included here. These are not universally practiced and the intent is to identify them for others. No attempt is made to be all inclusive of the more commonly used tools or systems,

1. Pond Brooms A new pond broom has been developed which is relatively new to fish culture and appears to save $25 \%$ of the time to brush-clean most ponds. This is the Warren Water Broom (Figs. 46 and 47). The broom is easier to push forward in the water, and on the pull-back stroke current action is minimal. This tends to 
Chapter $\mathbf{5}$
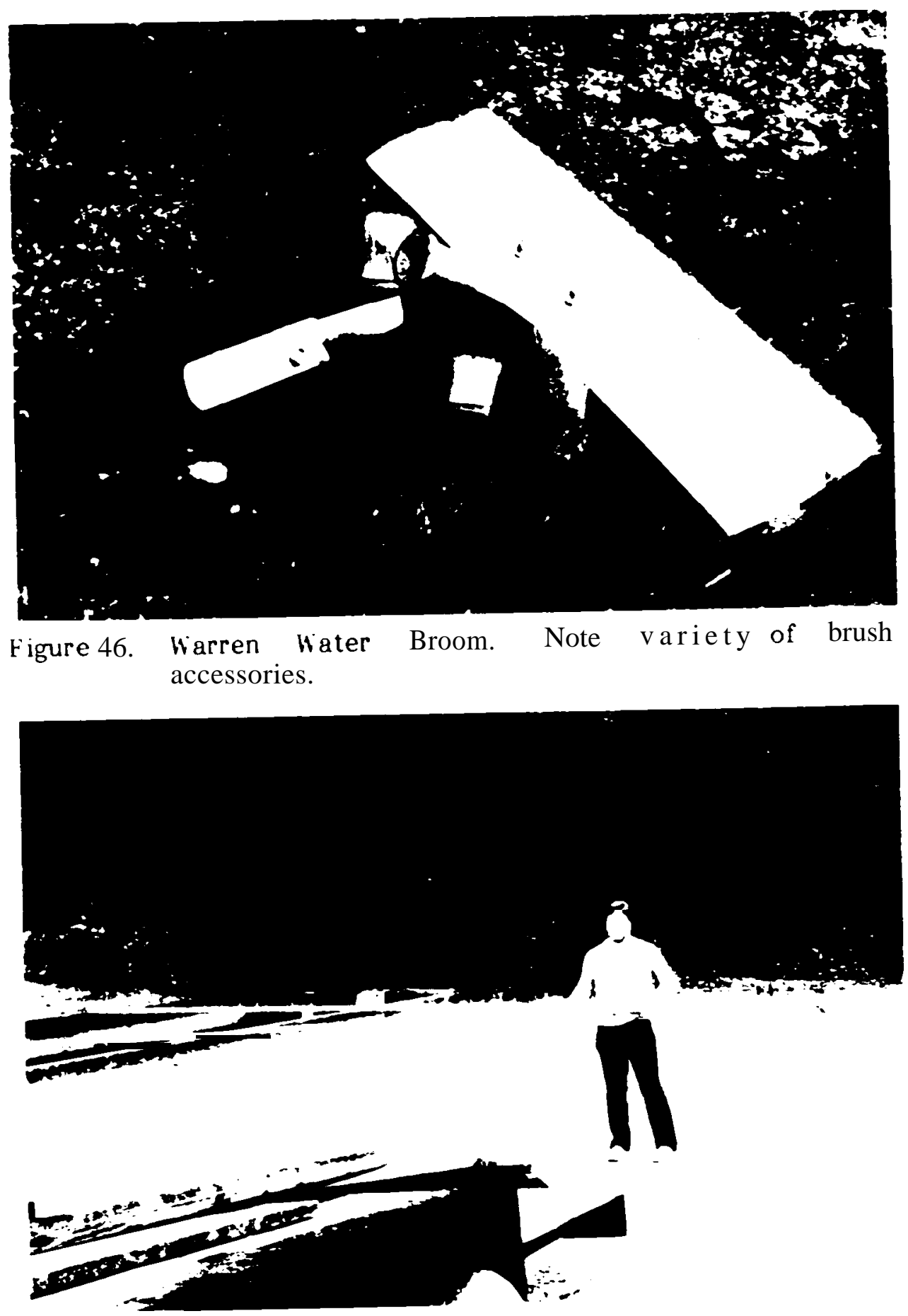

Figure 47. Warren Water Broom with handle. 
move dislodged pond waste only in a forward direction. Besides saving time, the debris in the pond is less disturbed which results in less stress on the fish. The broom is most adaptable where algae is not a major problem. Any length handle and any size brush can be obtained. Costs are comparable to other pond cleaning brooms. Contact Warren water Broom (Appendix 2) for more information.

2. Paint As An Algacide Where algae is a problem, and on surfaces where paint can be applied, consideration should be given to the use of a copper-base paint. This is used at the DFO Puntledge River Hatchery on Vancouver Island and OF w llekenzie, Oakridge, and Marion Forks Fish hatcheries. The manager at Puntledge said that it saves labor by eliminating the algae problem and making the pond surface smooth and easier to clean. One gallon of paint will cover 100-200 square feet and last several years. While a newly painted pond (Fig. 48) has a nice appearance, continual painting is required to maintain this look. Paint costs $\$ 3$ O/gallon. Any use of paint or chemicals in the water should be approved by a pathologist.

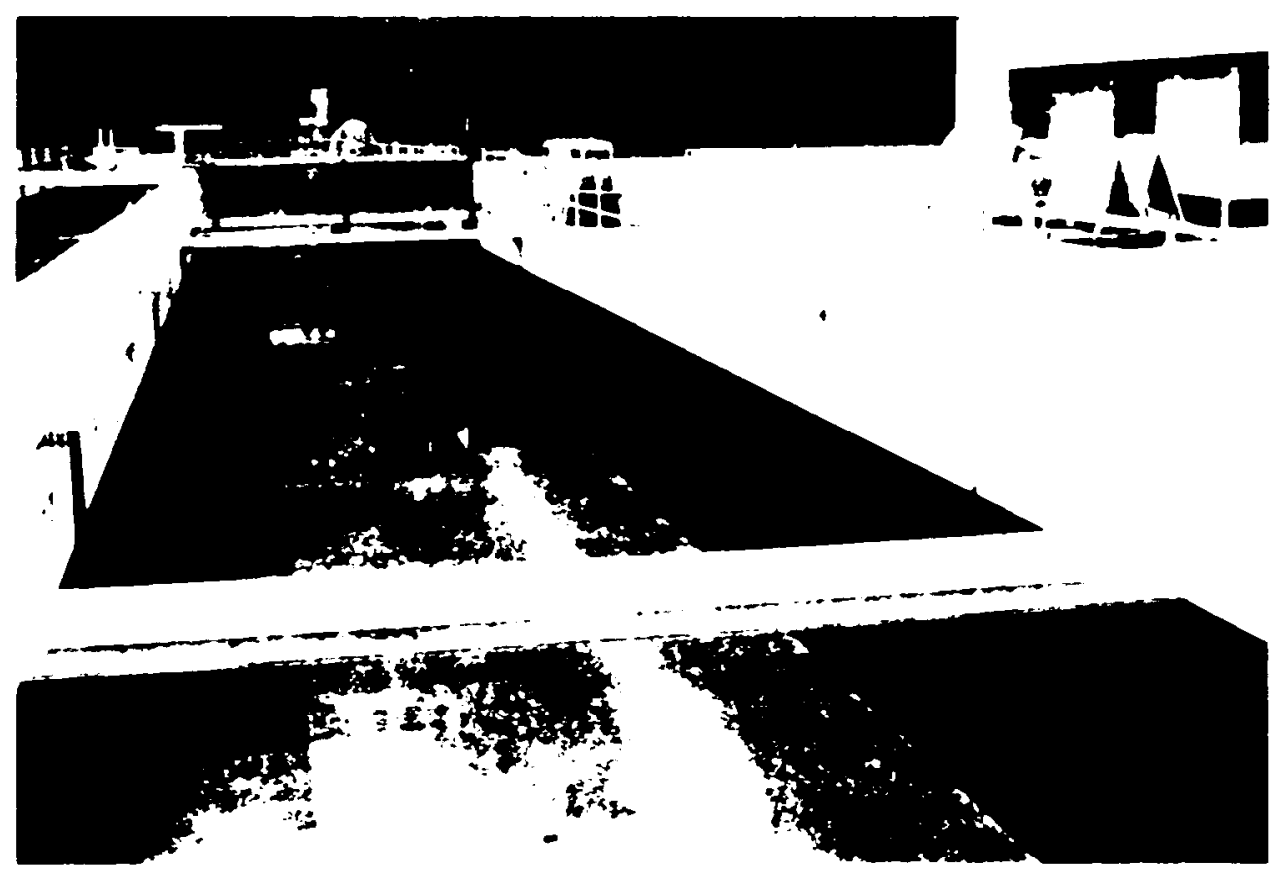

Figure 48. Copper-base paint on pond used to retard algae at the Puntledge River Fish Hatchery (DFO).

3. Herbicides The elimination of unwanted vegetation around ponds can be very effectively and economically controlled with herbicides. Wany chemicals are safe to use around fish ponds and cause no harm even when accidently introduced directly into a pond. Chemicals that are absorbed into the foliage and translocated throughout the entire weed, even below ground, are recommended. Chemicals such as formaldehyde will burn the foliage only to have it shortly reoccur. 


\section{Chapter 5}

The WDF has an active program in the use of chemicals (Peck, 1979). One manager related "that without the aid of chemicals another person would have been required during the spring and summer months." In addition, your county extension agent can provide a list of suitable chemicals.

4. Chemical Applicators Several agency personnei were observec using hand-i,eld chemical dispensers (Fig. iy) that require 50 percent more labor than the newer tye backpack units that are commercially available (Fig. 50). The backpack unit also allows for near perfect spray distribution. The unit illustrated is excellent and can be purchased from most farm stores. (See Appendix 2 for Sprague Sales, Inc.)

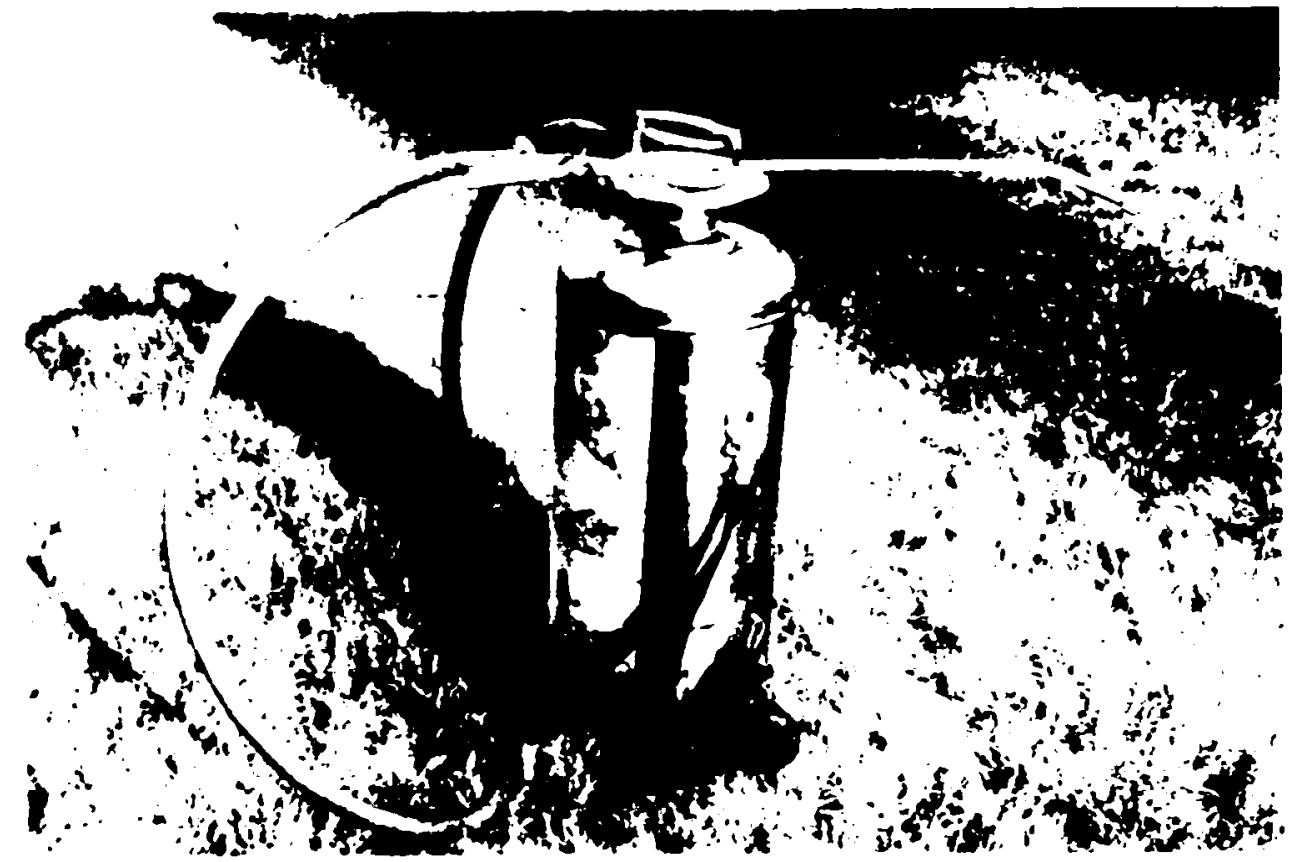

Figure 49. Typical hand-held che mical dispenser.

5. Cleaning Large Ponds Few managers attempt to brush or vacuum-clean ponds when they are larger than $1 / 4$ acre, however, in some cases cleaning them should be considered. For example, the WDF Humptulips Salmon Hatchery manager spends 24 to 48 hours vacuum cleaning a $1 / 2$ acre pond about every three months. This time compares to about 9 hours of accumulated time spent during a 3-month period to clean one concrete raceway. However, the numbers of fish reared is 10-15 times greater in the large pond.

Rearing and pond care measures that reduce the possibility of botulism disease are: (1) remove dead fish routinely, (2) do not allow food or fecal matter to accumulate, (3) feed oxytetracyciine as prescribed by a pathologist, (4) use quick-lime ( $\mathrm{CaOH}$ ) in empty ponds (contact WDG or Dr. Ecklund, N.MFS, Seattle), (5) consider placing scavengers in the ponds such as sturgeon or crayfish, and (6) do not cause excessive mortalities by handling fish improperly. 
Rearing

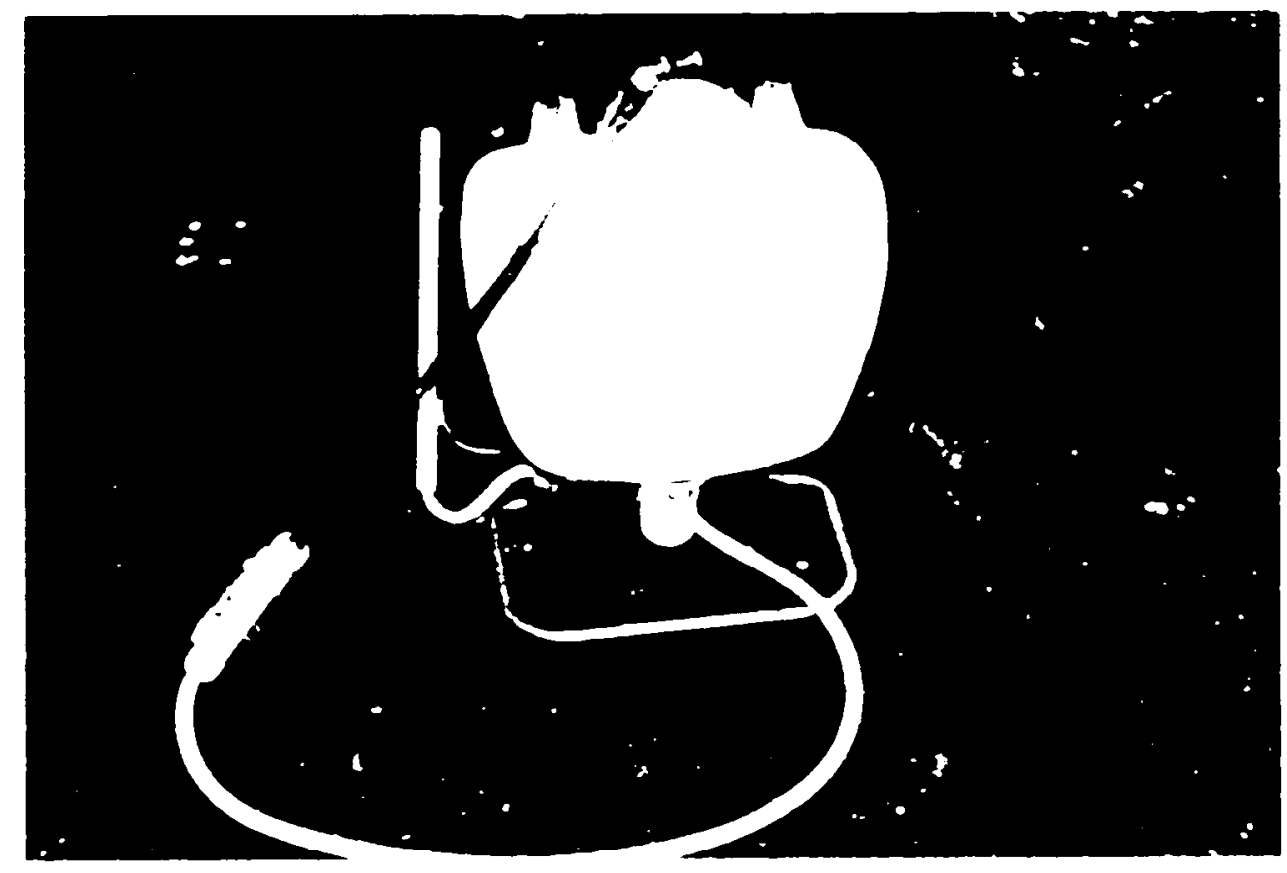

Figure 50. A modern backpack chemical dispenser.

\section{F. POPULATION ENUMERATION}

Tivo methods are recommended at low-cost facilities for estinating live fish populations. These are the total weight and total volume displacement methods. Both involve random sampling, but unlike estimating the number of eggs, live fish have behavioral patterns that can influence the accuracy of sampling. Some behavioral patterns are:

(1) larger fish seek out the more favorable situations, generally near the inflow on the more protected areas of a trough or pond

(2) larger fish move faster and are more difficult to capture

(3) when crowded, larger fish are usually distributed closer to the bottom

(4) when captured in a seine or dip net, large fish wriggle their way to the top of the pile

The most common method for obtaining a total population estimate is to weigh all the fish, and by using random samples to determine the number of fish per unit weight, then calculate the total number of fish.

Another common procedure is the displacement method. Fish are placed in a container such as a transport tank, that is first partially filled with water. The increase in Water level as measured on a gauge or mark on the side of the tank determines the volume of fish. During the process, random samples are taken to determine the number of fish per unit volume. This in turn is used to estimate the total population in the tank. 


\section{Chapter 5}

Electronic fish counters are sometimes used for counting fry as they leave the incubators. These units cost around $\$ 5,000$ and are available through Northwest Marine Technology, Inc. The Alaska Department of Fish and Game should be contacted for further information. The WDG has recently tested these units on larger fish. FMC does not recommend them for low-cost facilities as the two other methods described suffice.

When conducting a research program where a random sample of the fish are desireo in order to represent the entire population, other methods may be used. The WDF has been using a random sampling machine developed in conjunction with Northwest Harine Technology, Inc., which takes a random sample at pre-set intervals while the fish are being transferred by a fish pump. In the past, agencies have also used the pie-sampler (worlund et al., 1969).

We recognize that our brief discussion on enumerating techniques over simplifies this complicated subject, and therefore suggest that for more detailed information several hatchery managers be consulted.

\section{G. SIZING DEVICES}

Several devices, called fish graders, are used to separate the small fish from the larger fish. This is called sizing, and it allows the culturist to adjust feeding rates to produce a more uniform size of all fish at release time. Sizing is usually necessary for steelhead trout as all hatchery-produced steelhead should be larger than 10 fish per pound. Smaller steelhead have generally not returned well as adults. It is of lesser importance with spring chinook and coho salmon because they have a broader size range as smolts. Fall chinook and other salmon species, because of their short rearing period, are not sorted to size.

A typical grader is shown in Fig. 51. A dip net is used to put fish in the grader. The smaller fish fall through the openings between the aluminum or wood bars and the larger fish are retained. Graders or supplies for grader construction are available from a number of vendors and can be ordered with desired bar spacings. The cost of a grader box $20 \times 24 \times 10$ inches with bars is $\$ 130$.

inot her fish grader, used at larger facilities, is the veilsen fish grader (Fig. 52). This all-aluminum or strinless steel unit is $3.25 \times 7.23 \times 3.60$ feet and weighs $\therefore 25$ pounds. Fish may be delivered to the unit by a dip ret or fish pump. The size of the openings in this sider are adjustable for various fish sizes. It is not ine(b)inended for use at low-cost facilities.

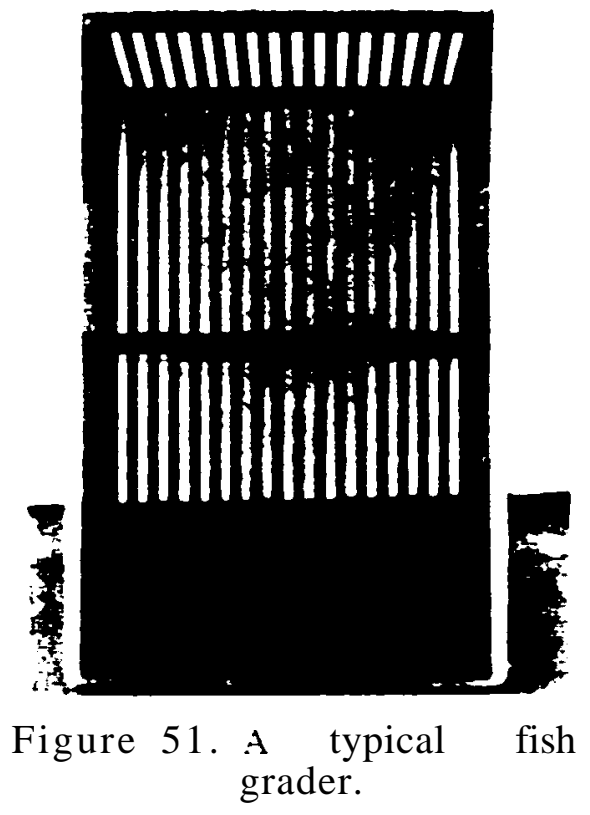




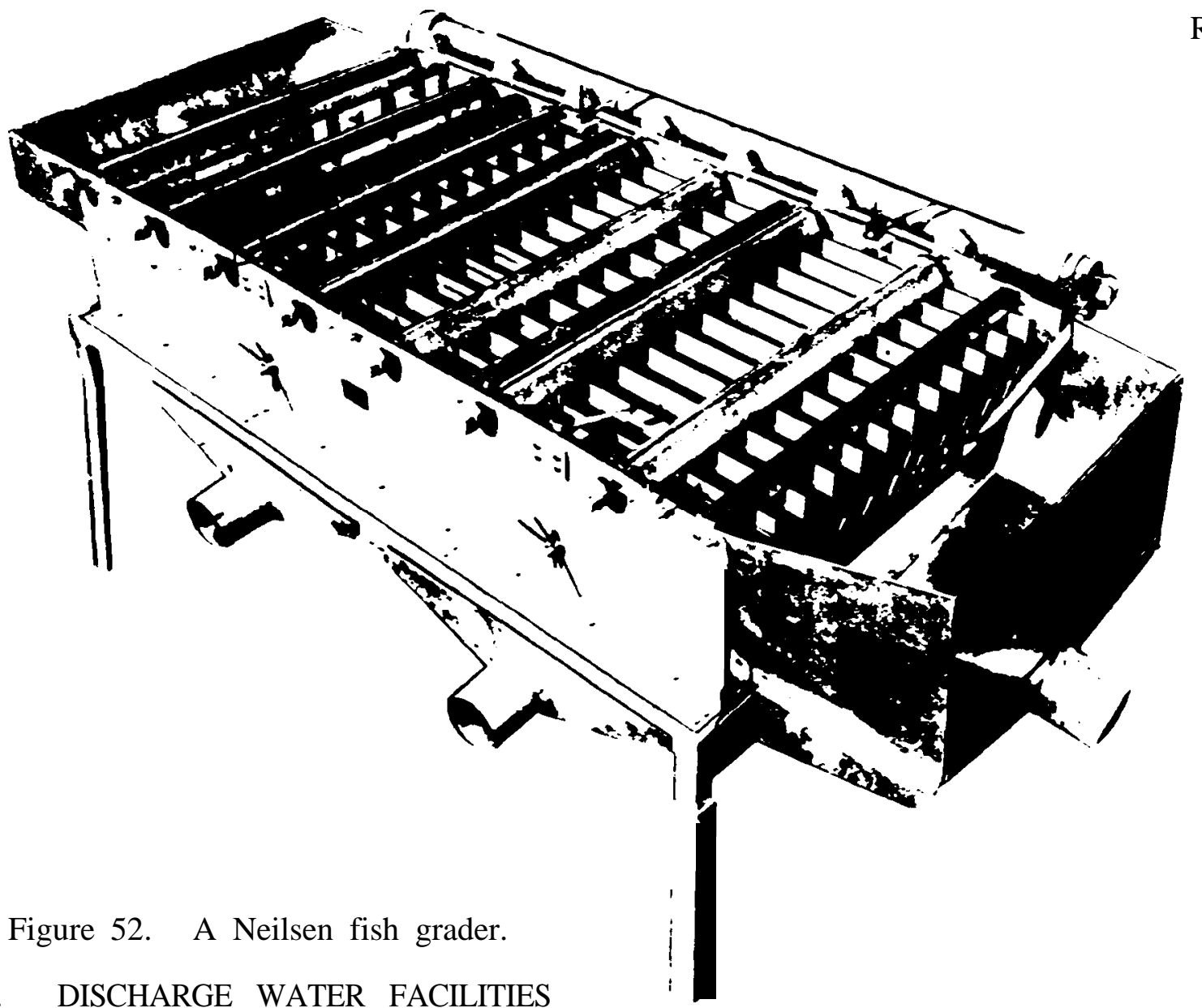

Rearing

\section{H. DISCHARGE WATER FACILITIES}

A National Pollution Discharge Elimination System (NPUES) Permit may be required if fish production from a facility reaches 20,000 pounds (See Chapter 10). In most cases, the requirement can be satisfied by passing pond cleaning wastes through a settling basin (sedimentation basin). We recommend a review of Piper et al., (1982) to obtuill information on hatchery discharge "pollutants". Also, contacts should be made with agency personnel for the latest practices.

Piper (ibid.) states that "generally three types of' pollutants are discharged from hatcheries: (1) pathogenic bacteria and parasites; (2) cheinicals and urugs $\mathrm{f}$ o $\mathrm{r}$ discase control; (3) metabolic products (ammonir, feces) and waste food".

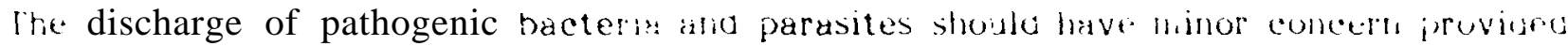
only indigenous stocks are culturea. renerally these pattogens would be found in the watershed. Regarding chemical anc urugs for disease control, a concern hit: oceur alten the concentration is not significantly reduced through immediate dilution: or a hen the

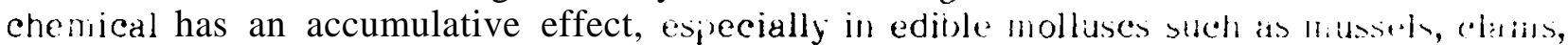
etc. Domestic water supplies, as noted in Chapter 1, arc it major concer'n of course. The discharge of metabolic haste, dead lish, and settleable inorganic alls otlie: organic sulids may require a NPLIS permit. 


\section{Chapter 5}

To mply in it!: NPIDES permit requirements, we recommend an unlined earthen settling

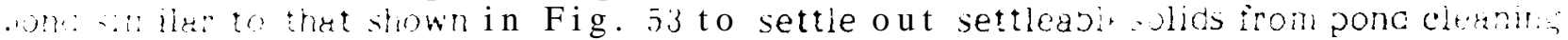

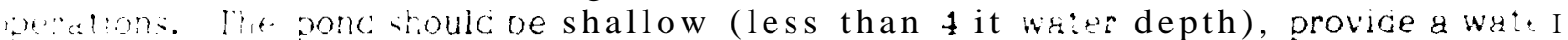

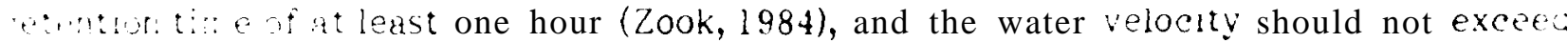

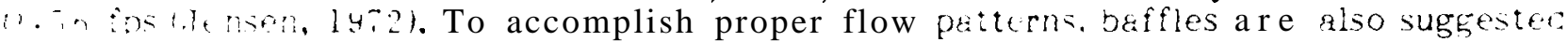

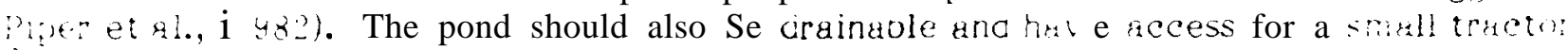
$\therefore$ periocic cleaning.

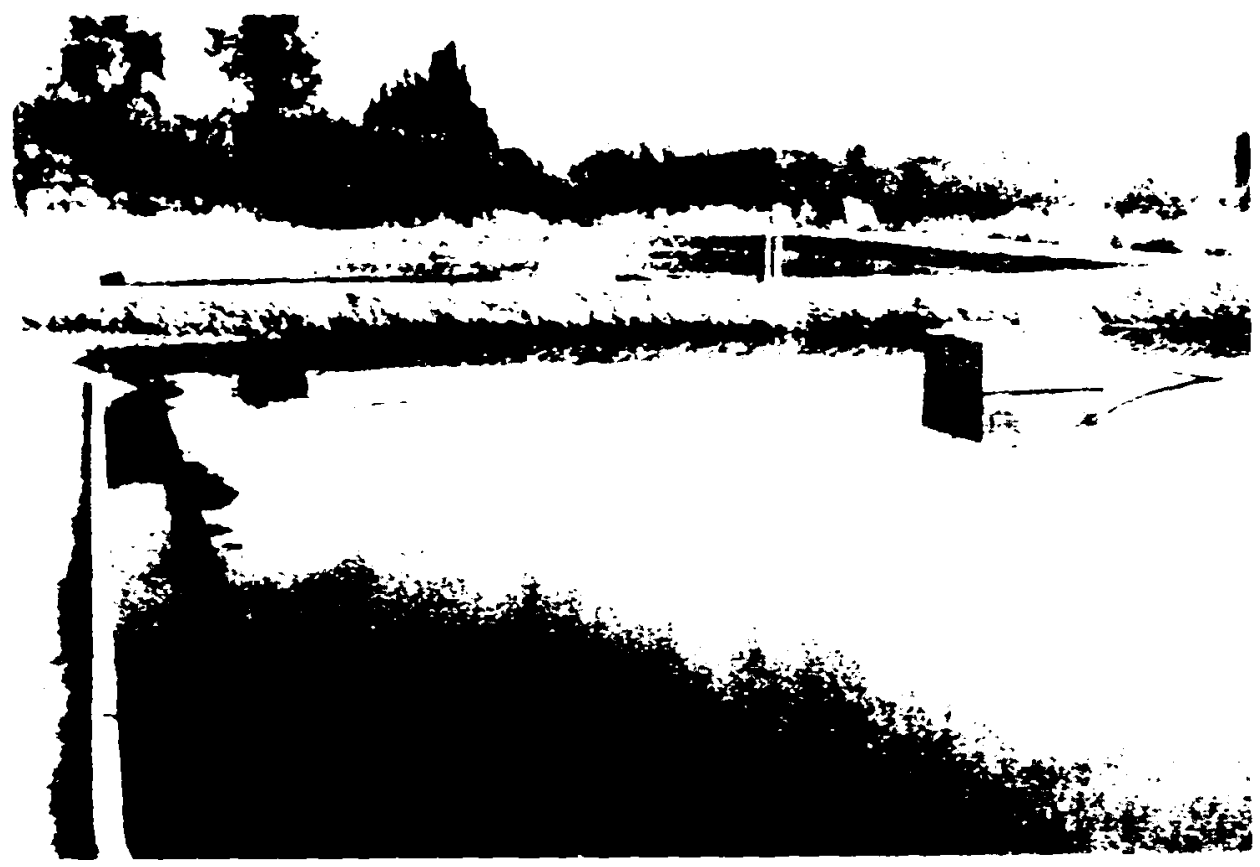

Figure 53. Earthen settling pond at the Chelan Trout Hatchery ( $I$ DDG and Chelan County PUD).

The size of the settling pond required to comply with the above criteria would therefore depend upon the cleaning system practiced, and the rearing pond's discharge-drain pipings ability to isolate individual rearing pond discharges during cleaning. Vacuum cleaning rearing pond wastes generally moves smaller water quantities to the settling basin than a system employing brush cleaning.

The cost of an earthen settling pond is $\$ 1.40 / \mathrm{ft}^{3}$ of water volume and does not include the costs for delivering water to and from this pond. A settling basin for 20,000 lbs of fish production will cost between $\$ 3,000$ and $\$ 20,000$ depending on how the ponds are cleaned and the ability to isolate pond cleaning waters.

NPDES required facilities exist at many Columbia River hatcheries that exceed $1 / 4$ million dollars in capital cost. Most of these are concrete (Fig. 54), have elaborate plumbing systems from the ponds to the basin, and have aeration systems (Fig. 55). 


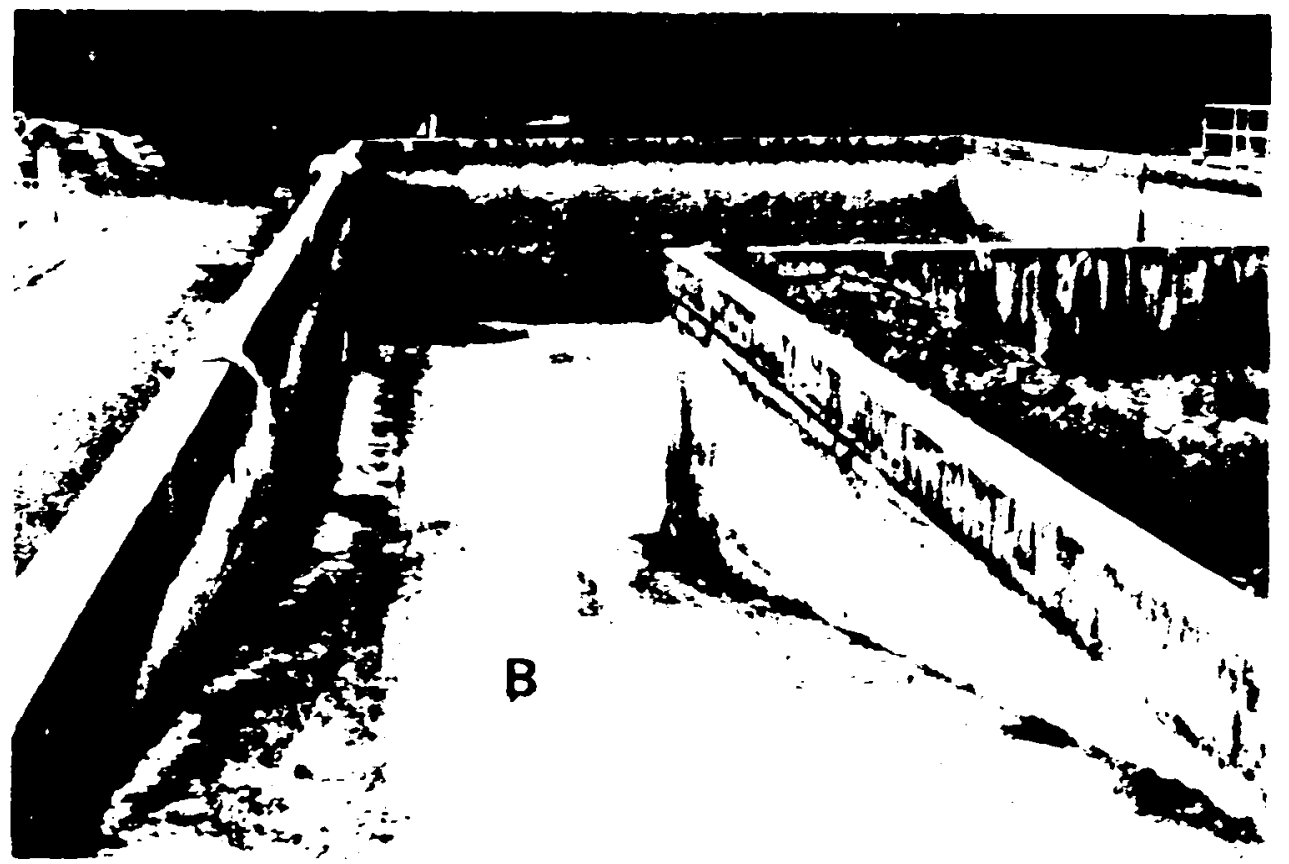

Figure 54. Concrete settling basin at the Big Creek Fish Hatchery (OFW). (A) sludge, (B) ramp.

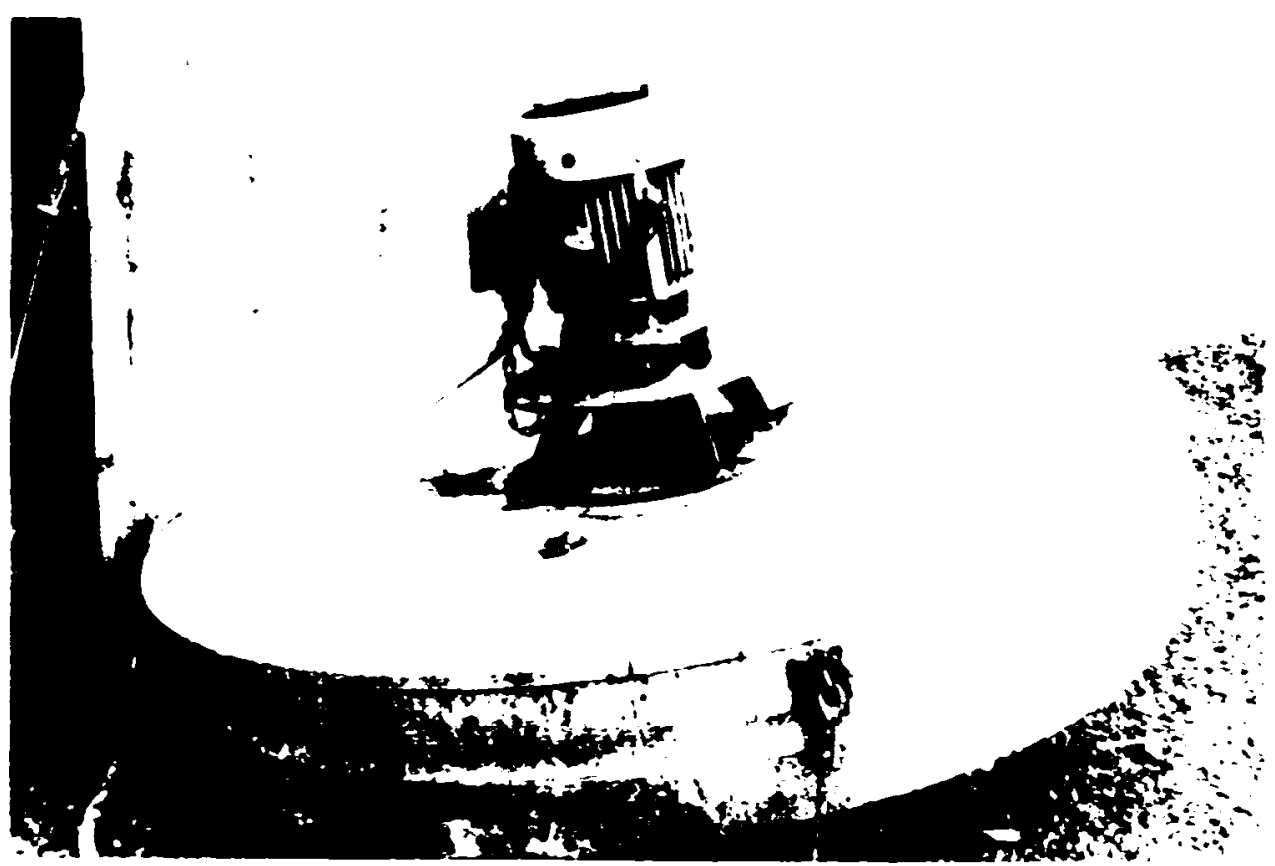

Figure 55. Floating aerator for pollution abatement settling basin at the Big Creek Fish Hatchery $\left(\mathrm{OFW}^{\prime}\right)$. 


\section{Chapter 5}

Aerators are an option for the earthen settling basin to promote aerobic bacterial growth and reduce obnoxious odors.

Large rearing ponds which are cleaned after the fish are removed generally are exempt from permit requirements. Net pens and enclosures would likely have no requirements.

The disposal of sludge from settling basins is described by Piper (ibid.) who suggested it be used as a fertilizer. Eklund (personal communication, NMFS, Seattle, WA), however, warns of the potential dangers from the botulism organism (Clostridium botulinurn). Eklund stated: "The sediments of the ponds in which botulism has occurred contain unusually large numbers of $C$. botulinum type $E$ organisms. These sediments should not be used as fertilizer for home vegetable or flower gardens or for other purposes. Instead the sediments should be buried in the same manner as recommended for dead fish." (omimon practice at Northwest hatcheries is to utilize sludge as fertilizer, however in lignt of I)r. Eklund's concern, we recommend managers first contact a pathologist before it is used. 


\section{CHAPTER6}

\section{TRANSPORTATIONOFSPERM,EGGS,ANDLIVEFISH}

The methods for transporting sperm, eggs and live fish are discussed in this chapter. In addition, we have attempted to provide a realistic cost estimate for hauling live fish to off-station release sites.

\section{PART I. SPERM ANDEGGTRANSPORTATION}

Salmon and steelhead trout eggs may be transportea prior to fertilization, immediately after fertilization, or as eyed eggs. Sperm is sometimes shipped independently and then used to fertilize eggs. The transportation methods are influenced by transit time, size of shipment, temperature conditions, shipping containers and equipment, and the preference of the fish culturist.

\section{A. GAMETESHIPMENT}

Gamete shipment methods practiced in the Pacific Northwest are similar to the procedures used in Alaska and described in the AFG Fish Culture Manual (1983). I his is an excellent reference, and we have used direct quotations here to descrioc gamete shipment methods.

"When shipping gametes separately, place unfertilized eggs into large plastic jars, buckets with lids, aluminum milkcans, or thick-walled plastic bags (double bagged). Ziploc plastic bags are preferred. Never use copper or galvanized containers. Fill the containers completely with eggs. This prevents sloshing and possible damage to the eggs ..." It is very common for fish agencies to ship salmon eggs in garbage cans.

To ship sperm, AFG states, "place sperm into plastic whirl-pack bags [plastic bags with pa tented closure]. During large egg takes, tile sperm from 10-15 inales may be placed into each bag. Do not fill the bag over one-quarter of capacity, however, because viable sperm require air, maintain a 3:1 air-to-sperm ratio." Mashington and Oregon agencies sometimes use bottles to ship sperm. To transport gametes, $A F G$ recommends that fish culturists place full egg containers and sealed sperm bags in a cooler. 'They place the sperm bags so that they lay flat, maximizing the contact of air and sperm. In the Columbia Kiver Basin, the time of shipment likely will be less than 1 or 2 hours, and coolers may not be necessary.

The air temperature is important, and $A F G$ recommends that "if tine gamete storage is up to 10 hours, do not exceed $\mathbf{y}^{\circ} \mathrm{C}\left(48^{\circ} \mathrm{F}\right)$. If storage exceeds 10 hours, then store the gametes at $2^{\circ}$ to $3^{\circ} \mathrm{C}\left(\right.$ never $\left.0^{\circ} \mathrm{C}\right)$. When ice is used, do not allow water from 


\section{Chapter 6}

melting ice to touch the egg containers or sperm bags. Transport should not exceed 24 hours or egg fertilization may be less than $\mathbf{8 0 \%}$."

Ice should be used with care as it can freeze the eggs if it is much colder than $32 \mathrm{~F}$. In such cases, be sure the ice is either warmed in water or that the gametes do not directly touch the ice. Prior to fertilization, most fish culturists warm the chilled gametes for 20-30 minutes so that the temperature is within a few degrees of the incubation water. The shipment of gametes within dead fish is an acceptable procedure if the time of transit is 1 hour or less.

\section{B. EGG SHIPMENT}

The common practice is to ship eyed eggs. Newly fertilized eggs can be transported short distances immediately after they are partially or totally water hardened. However, the eggs become more sensitive to handle as time passes and if the procedure must be conducted we suggest all eggs be transported within a 6-hour period. These eggs should be handled with extreme care, otherwise significant mortalities will occur.

Eyed eggs, on the other hand, are very easy to ship, and standard incubating trays and baskets are commonly used. A good container is a clean, wet burlap bag. As many as 50,000 salmon or steelhead eggs can be shipped per bag on 5-to lo-hour trips. Placing the bags two-deep has proved successful, but it is not preferred. If stacking is necessary, air and moisture must be provided for the eggs. In the Columbia River Basin, eyed salmon egg shipments will occur during the colder months, and an insulated box will prevent freezing. A pickup truck is the most common carrier of eggs, and in extremely cold weather, sawdust on the bed floor will help insulate from the cold. A heat source is permissible if it does not emit excessive toxic gases.

Eggs must be kept moist in transit, and a good method is to wrap the eggs in a water-absorbent material such as cotton diapers, or burlap. If the eggs are in transit longer than 3 to 4 hours, ice should be allowed to slowly melt to replace lost moisture, or water added if necessary. The time in shipment is not critical, since eggs can incubate out of water for more than a week, but the eggs must be kept cool and damp.

It is unlikely that air freight containers will be required for stations in the Columbia River Basin; however, they are available at Skretting and Heath Techna Corp (Appendix 2).

\section{PART II. LIVE FISH TRANSPORTATION}

Live fish transportation is necessary and common at most fish cultural stations, both during on-station rearing and offstation planting. Numerous techniques are available for transporting adult and juvenile salmon and steelhead, but extreme care must be exercised to minimize stress and mortality. Onstation transfers may require only transfer pipes or minor equipment, while off-station transportation systems can include units of any size up to 3,500 gallon tankers and trailers. One of the most dangerous activities for the fish culturist occurs during trucking fish off-station. Driver training and experience are highly recommended regardless of tank size. 
Transportation of Sperm, Eggs, and Live Fish

\section{A. BIOLOGICAL REQUIREMENTS}

The major concern when transporting live fish is to assure that good quality water is maintained, especially the oxygen level. This is true regardless of the method used, and on long hauls water temperature and levels of ammonia, carbon dioxide, and foreign matter are extremely important.

A USFWS publication, "Fish Hatchery Management" by Piper et al., (1982) is a good source of information on water quality for fish transportation. They recommend maintaining oxygen levels in excess of $7 \mathrm{ppm}$ (but accept $6 \mathrm{ppm}$ ), noting that a failure to do so may contribute to delayed fish mortality. They further state that the ammonia level in distribution tanks can reach $10 \mathrm{ppm}$; however, exposure to 11 to $12 \mathrm{ppm}$ total ammonia for 6 hours adversely affects trout. They expressed concern if the $\mathrm{CO} 2$ levels increase rapidly and state that fish become distressed if levels approach $25 \mathrm{ppm}$.

The importance of temperature cannot be over-emphasized. Piper (ibid.) states "for each one degree rise in temperature above $52^{\circ} \mathrm{F}$, the fish load should be decreased by $5.6 \%$; conversely, for each one degree $\mathrm{F}$ decrease in temperature, the load can be increased by $5.6 \%$."

A number of Northwest agencies add sodium chloride to the water and report success in reducing fish mortality during transportation. Piper (ibid.) recommends raising the level of soft water to a total hardness of $50 \mathrm{ppm}$ by adding $0.1-0.3 \%$ sodium chloride and enough calcium chloride to reach the desired level.

Anesthetics as an aid to fish transportation in the Northwest is limited mainly to the use of the drug tricaine methane sulfonate (MS-222); but we found few cases where this was used. The benefits of anesthetics, according to Piper (ibid.), are that payloads two to three times larger may be achieved with less stress and possibly less injury to the fish. He states that 0.1 gram per gallon appears to be useful in transporting fish. In water with a temperature in the mid 40F's or higher, 0.2 gram per gallon is the standard concentration for "completely" immobilizing salmonids for clipping their fins; however, lower temperatures require greater concentrations for the same effects. The main disadvantage to the use of MS-222 is that the Federal Food and Drug Administration prohibits its use on fish that may be consumed by any form of life within several weeks after exposure to the drug. The cost of MS-222 is $\$ 30 / 100$ grams, which is the amount needed for a 1,OOO-gallon tank truck.

There are a number of biologically oriented operational procedures that are important to consider when transporting salmon and steelhead. These are:

(1) Fish should be starved at least 24 hours prior to handling to reduce the amount of fecal matter and vomiting.

(2) Clean oxygenated water must be used.

(3) It is advantageous to flush the tank as it is being loaded, since the greatest deterioration of the transport water occurs during loading and shortly thereafter. 


\section{Chapter 6}

(4) On a long haul, flushing the tank with fresh and cooler water after 6 hours is beneficial.

(5) Water in unrefrigerated fish tanks can often be cooled by filling the tank when air temperatures are reduced, such as during night hours.

(6) Ice can be added to cool tank water.

The payload that can be hauled in a transportation unit depends on so many variables that it is impossible to formulate a figure for all situations. Hatcherymen generalize, however, that you can safely transport 1 pound of 5-to 6-inch salmonids per gallon of water in a tank with an overhead spray system. With increased efficiency in the aeration system, the number of fish safely hauled can increase. If transported fish are smaller, you should haul less poundage, and the reverse is true if they are larger. Chinook do not haul as well as coho or steelhead, and the smolts of all species are more difficult to haul than presmolts.

By understanding the biological requirements of salmonids, the payloads for transportation can be optimized. The proper use of equipment is the other important consideration, and a discussion follows.

\section{B. ON-STATION FISH TRANSPORTATION EQUIPMENT}

On-station fish transportation equipment includes pipes and tubes, flumes, pumps, brails and lifts, crowders, and small containers. The choice for a particular operation often depends on the personal preference of the manager, but all the items described here are useful. Further, some of the items serve a dual use and can be used for off-station fish transfers.

1. Pipes and Tubes The most universal method of on-station fish transfer is through pipes and tubes. All age groups of fish can be transferred in this manner. Common pipe or tube materials are plastics and aluminum. Pipe is sometimes desirable for adult transfer because it is portable, and fish cannot flop out as sometimes happens in flumes.

Aluminum irrigation pipe is most commonly used for the transfer of fish on-station; lo-inch diameter for adults (Fig. 1) and 4-inch for juveniles (Fig. 2). This pipe is light weight, readily available, and stores easily. Its one disadvantage is that it dents easily. The cost of 4-inch aluminum pipe is $\$ 1.50 / \mathbf{f t}$, and IO-inch pipe costs $\$ 5.79$, both with connectors.

Plastic pipe (PVC) can also be used, but, it is not generally used for juveniles unless permanently installed. A disadvantage of PVC pipe is that it is brittle when cold. Four-inch pipe will cost $\$ 0.70 / \mathrm{ft}$ with connectors, while 10 -inch pipe costs $\$ 6.00 / \mathrm{ft}$ with connectors. Transferring fish with pipes that are permanently installed is referred to as a tube transfer. Generally this is seen at large stations, and PVC is usually used. Figs. 3 and 4 show, respectively, a number of tubes and a single plastic pipe used in transporting adults. 


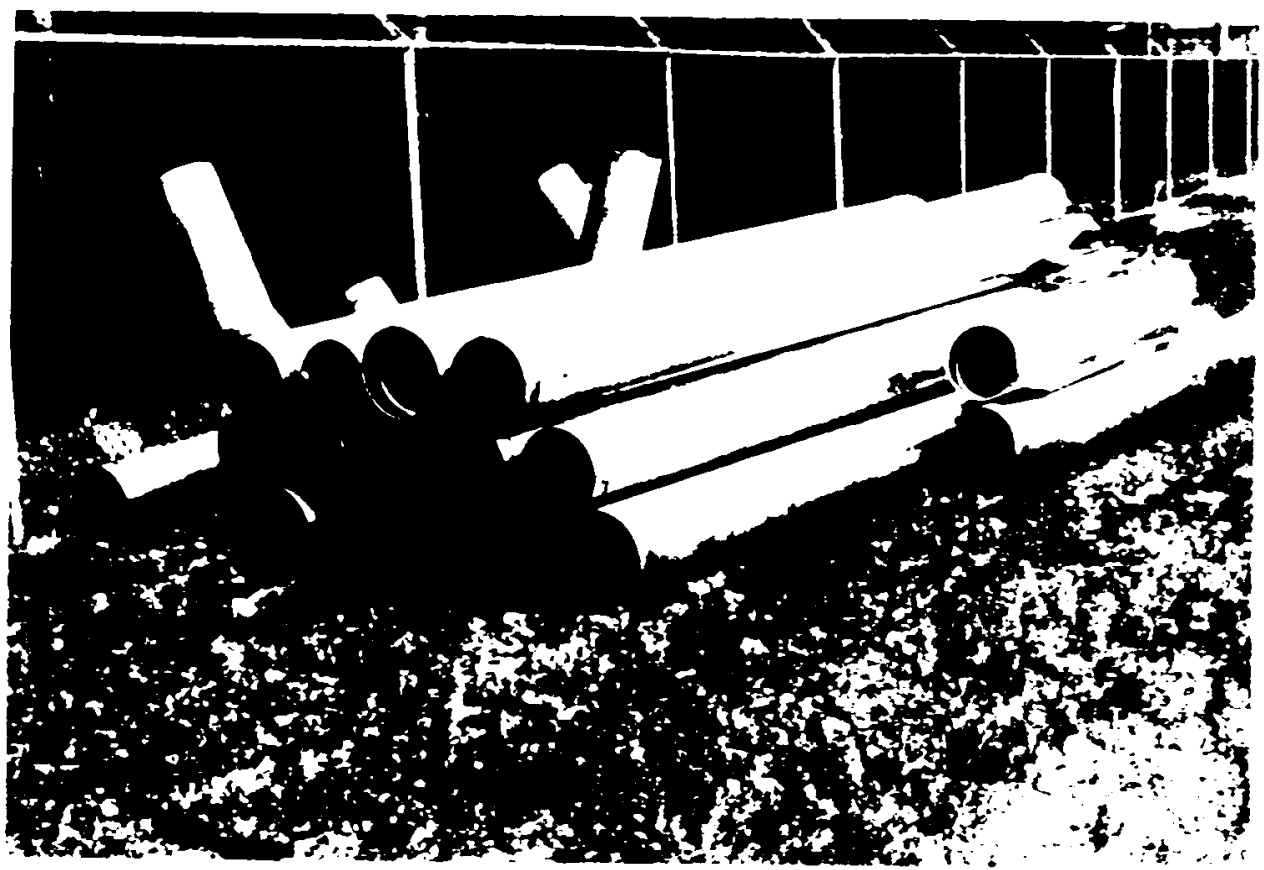

Figure 1. Stored sections of lo-inch aluminum pipe used for fish transfers.

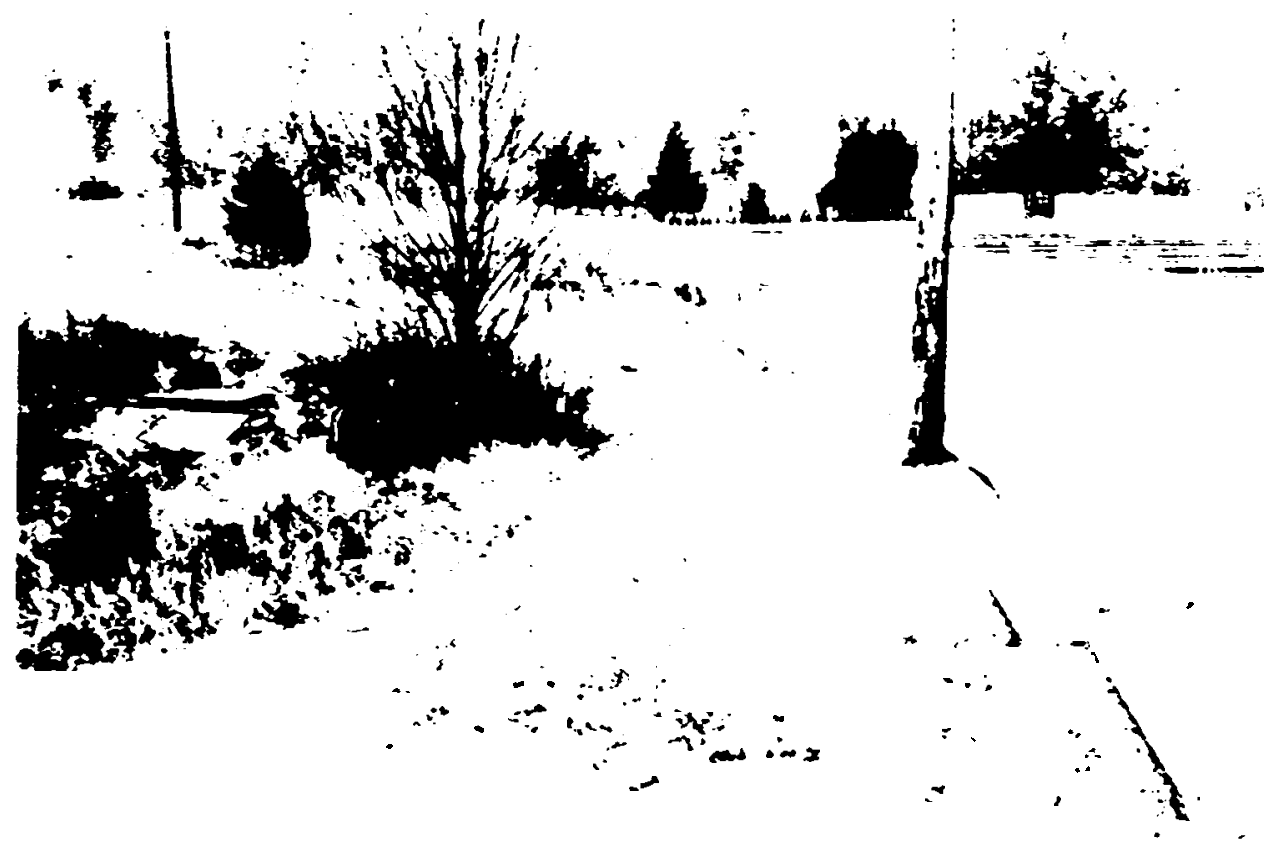

Figure 2. Four-inch aluminum pipe being used to transfer juvenile salmon at the Washougal Salmon Hatchery ( $W D F$ ). 
Chapter 6

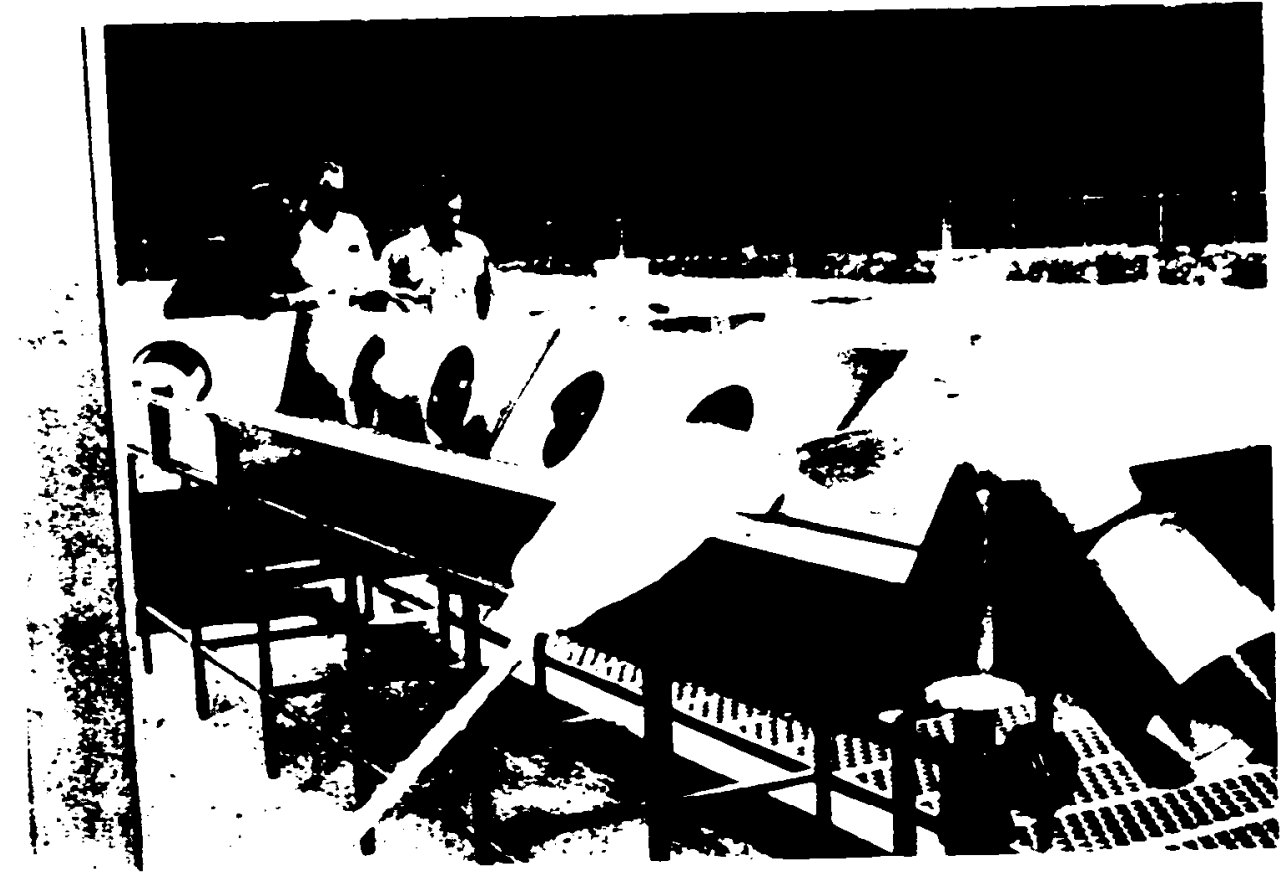

Figure 3. Tube transfers used at the Chehalis River Hatchery in British Columbia, Canada (DFO).

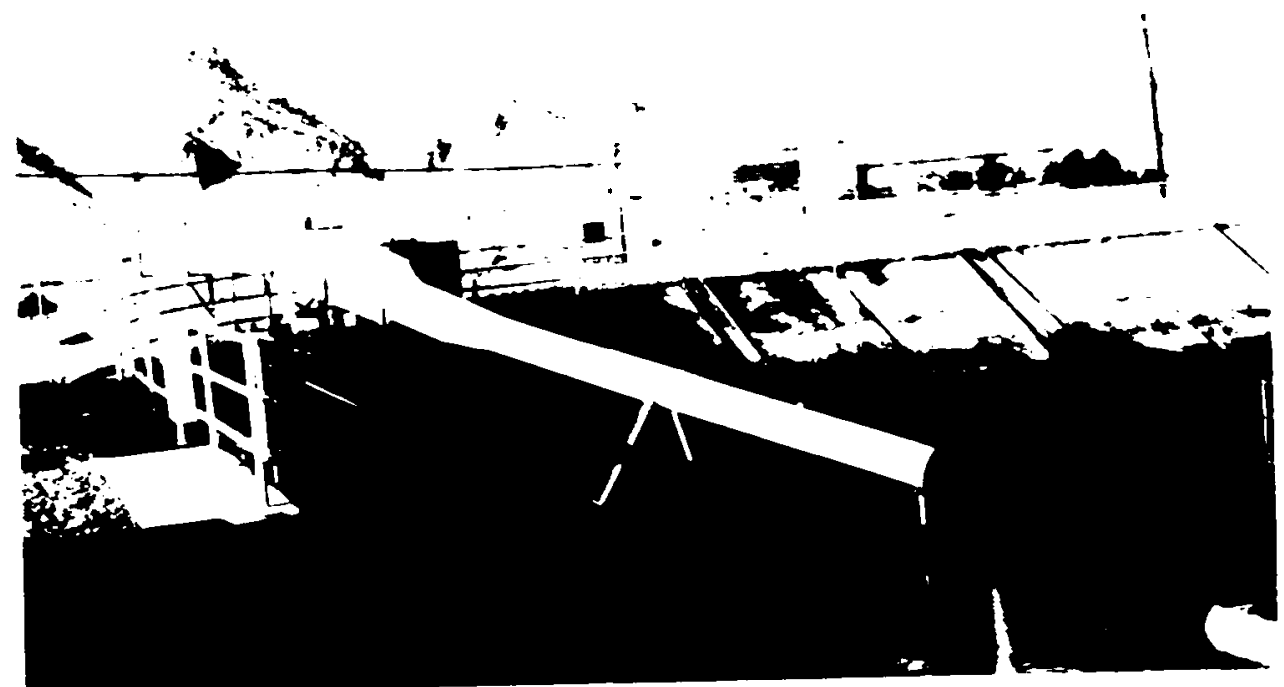

Figure 4. PVC pipe used to transfer adult salmon at Priest Rapids Salmon Hatchery (W DF). 
2. Flumes Flumes are used to transport fish between ponds or between transport tanks and ponds. Their use is common when fish are too large to pass through the discharge hose of a transport tank, or when small fish are being moved between ponds in large volume. In this latter case a portable flume is used and the fish are poured directly into it, thus eliminating the hopper required by pipes.

A flume can be as simple as a steep bank lined with plastic or as illustrated in Fig. 5. A short adapter is usually required between the transport unit and the flume. Foam rubber is used for cushioning wherever required. Any material is satisfactory as long as the surface is smooth and, when lubricated with water, provides a slippery, non-abrasive surface. Plastic film liners are very effective. The side walls on flumes should be high enough to prevent fish from flipping overboard.

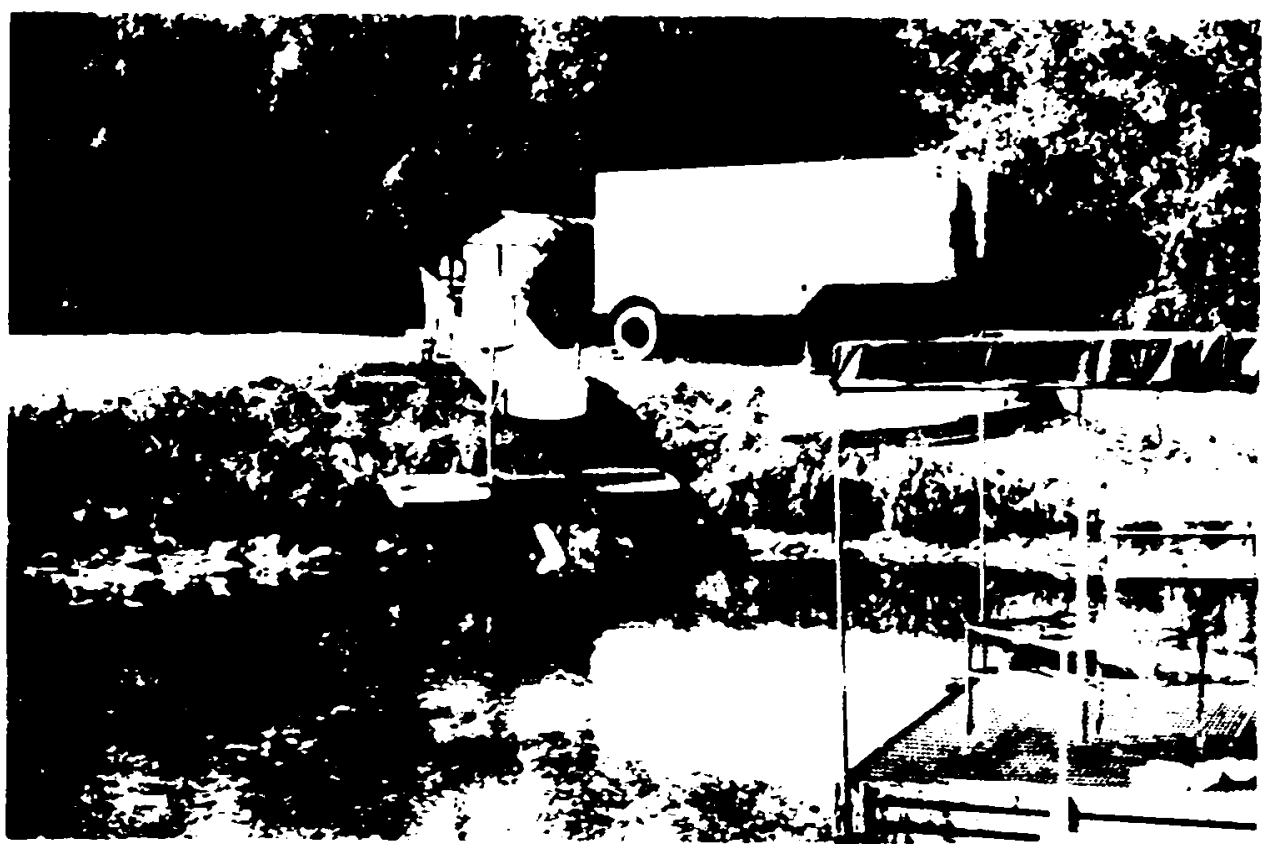

Figure 5. Flume used to transfer salmon and steelhead trout at the Rapid River Hatchery (IFG).

3. Pumps, Brails and Lifts A common method for moving fish is a unit called the "Fish Pump" (Fig. 6). It was developed for use in the agricultural fields, but it is a useful tool in fisheries work. Fish can pass through the "open-style" impellor without harm, provided proper procedures are employed. The 6-inch pump, generally preferred, is powered with a gasoline motor. It can be mounted on a truck or trailer, or as a permanent installation.

The fish pump will handle the smallest fry to fish over 12 inches long. It can be used to deliver fish and water to transfer pipes, to grader boxes, and to dryers on transport tanks. In addition, it is useful in cleaning and transferring plastic substrates, or acting as a $750-\mathrm{gpm}$ pump for an eniergency water supply. The unit 


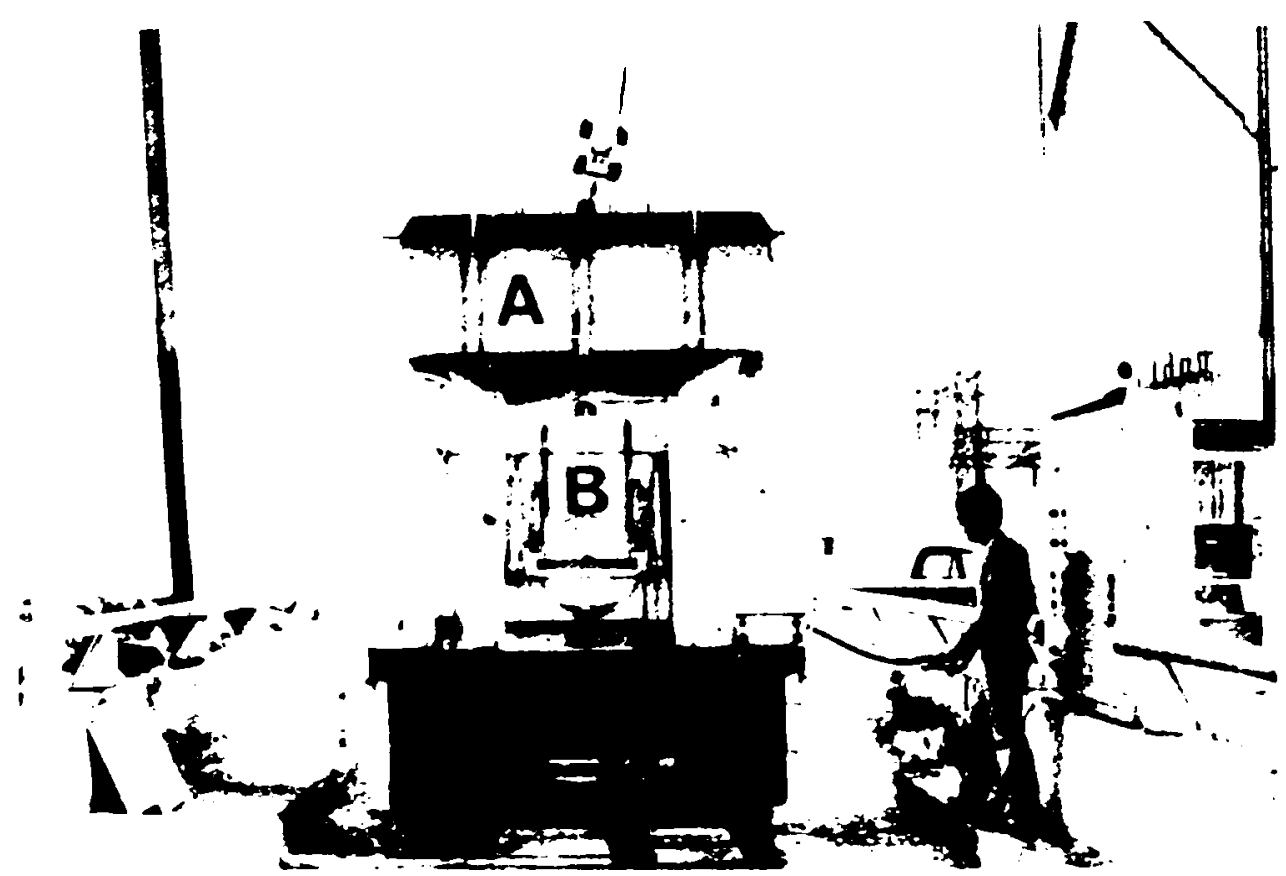

Figure 7. Brail used in an adult salmon and steelhead transfer system at Priest Rapids Salmon Hatchery (WDF); (A) transfer brail, (B) tank on truck.

Power-driven crowders are commonly seen where large numbers of adults are handled for spawning. The one illustrated in Fig. 8 would cost in excess of $\$ 50,000$. Mechanical crowders are not recommended when the number of adults handled is less than 10,000 .

For more information on small low-cost hand crowders, contact any fisheries agency. For crowder screen materials, see Appendix 2.

3. Small Containers Every hatchery uses small containers to transfer fish. Plastic j-gallon buckets and garbage cans are very common. Fifty-gallon drums can be used, but they are very heavy and awkward to handle. A simple larger unit is the bed of a pickup truck lined with heavy reinforced plastic sheet. The truck's bed, once filled with water and fish, can be emptied by dropping the tailgate.

\section{OFF-STATION FISH TRANSPORTATION EQUIPMENT}

Transportation of fish to and from the fish cultural station or collection sites is conducted by a variety of means. Methods discussed include portable fish tanks, tank trucks and trailers, floating live boxes, adult tube transfers, collapsible roll poly, and hand-carried containers. Aircraft and barges are recognized as viable but costly methods, and are not discussed. 
Chapter 6

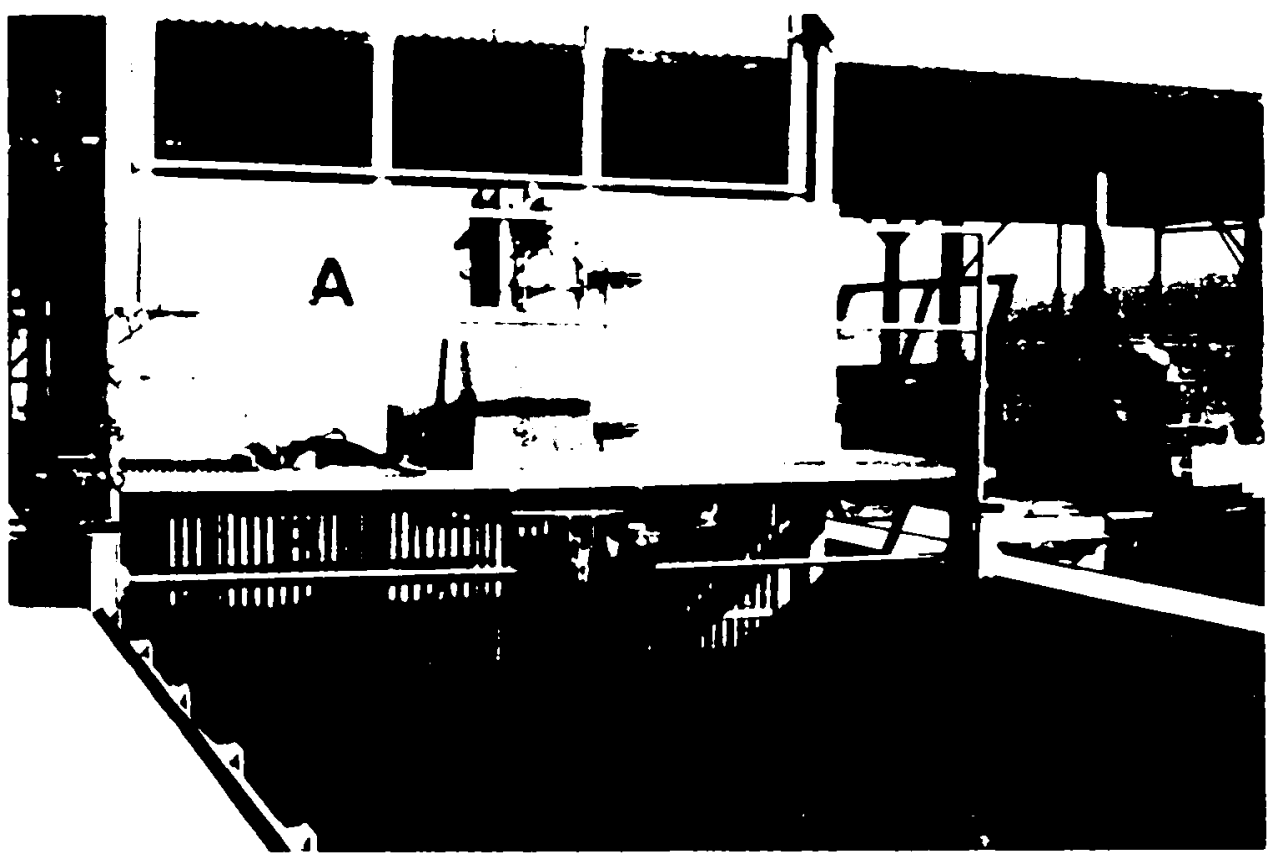

Figure 8. Mechanical fish crowder at the Hoodsport Salmon Hatchery (WDF); (A) crowder, (B) bars on crowder.

As we have emphasized earlier, the two most important factors regulating the efficiency of any transport unit are oxygen and temperature. Aeration systems employ several techniques, including the splash, air scoop, overhead spray, direct insertion of air or oxygen into the circulating water, or air or oxygen passed through air stones. To address temperature concerns, insulated and/or refrigerated tanks can be designed or are available from commercial outlets.

1. Portable Tanks Portable tanks are best suited for low-cost operations. The choice of size ranges from 75 (Fig. 9) to 1,000 gallons or more. They are usually hauled on a truck (Fig. 10) or by truck and trailer, and then removed when the project is completed.

Common materials used in construction include aluminum, steel, and fiberglass. Options in aeration systems include all those previously mentioned, and the choice depends on the program. A low-cost aeration method is a system that adds pure oxygen or air to the water. Provision should also be made in designing the plumbing to allow adaptation of a waterspray system. These usually are powered by a 12-volt DC battery or gasoline motor. A typical portable fish-transport tank is shown in Figure 11 with its water circulation system (Fig. 12) and air/oxygen system (Fig. 13). 
Transportation of Sperm, Eggs, and Live Fish

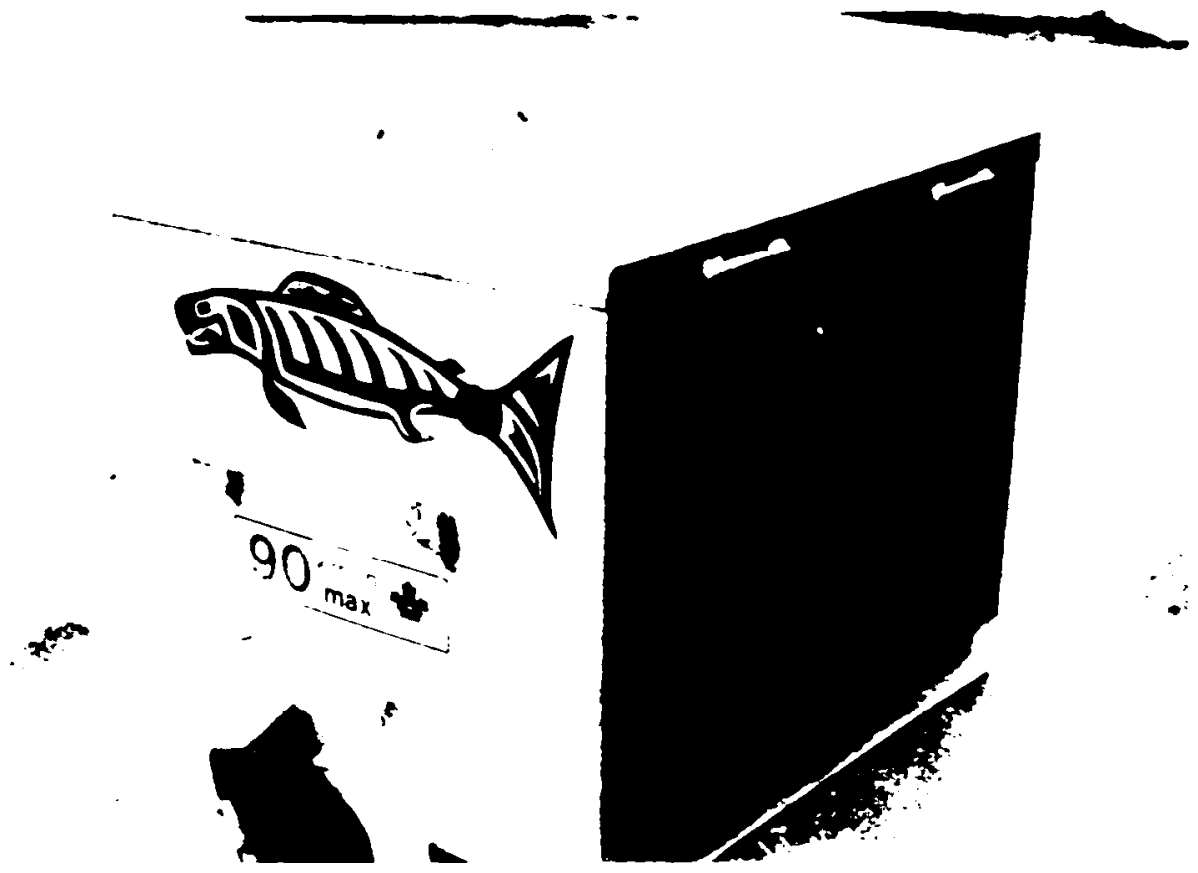

Figure 9. One-hundred gallon portable fish transport tank (DFO).
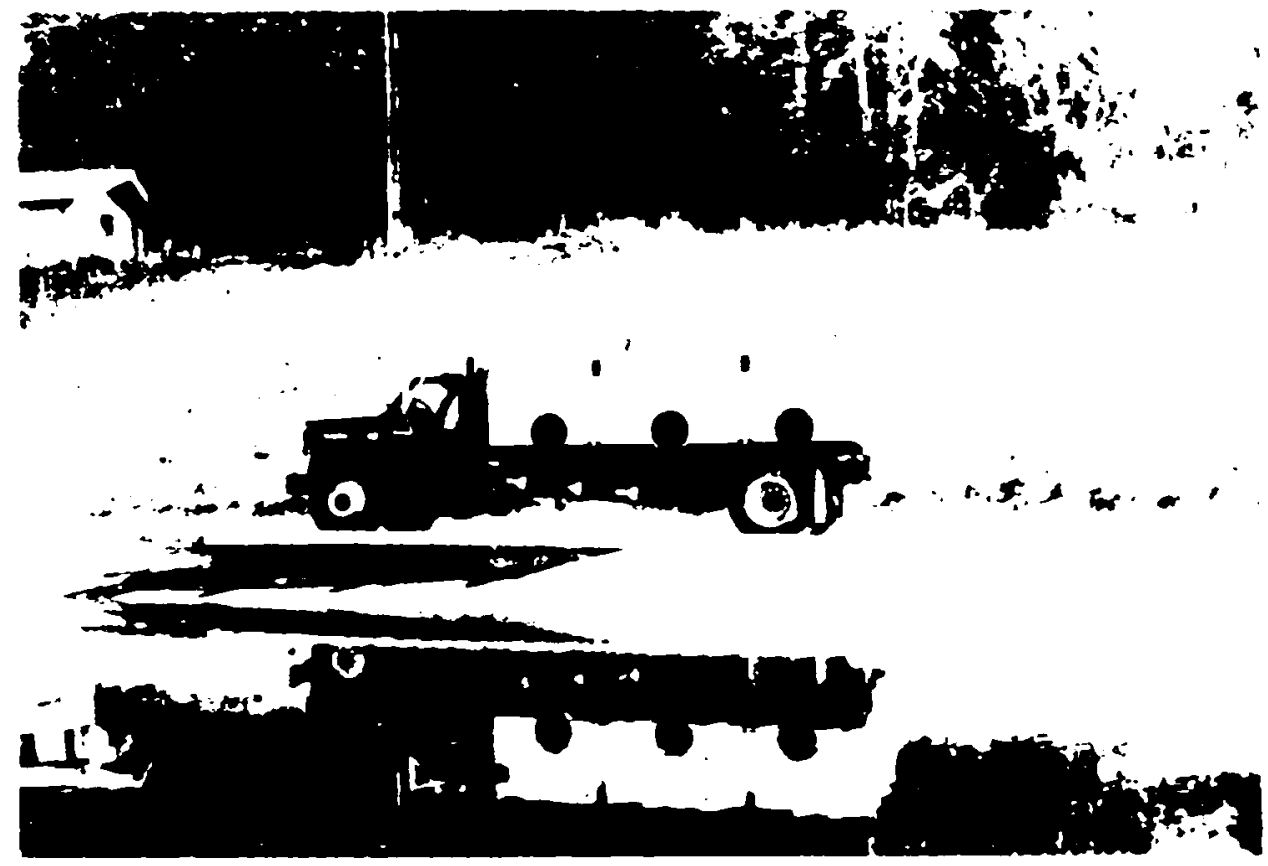

Figure 10. Three 300-gallon fish transport tanks mounted on a flatbed truck (Tulalip Tribal Hatchery). 
Chapter 6

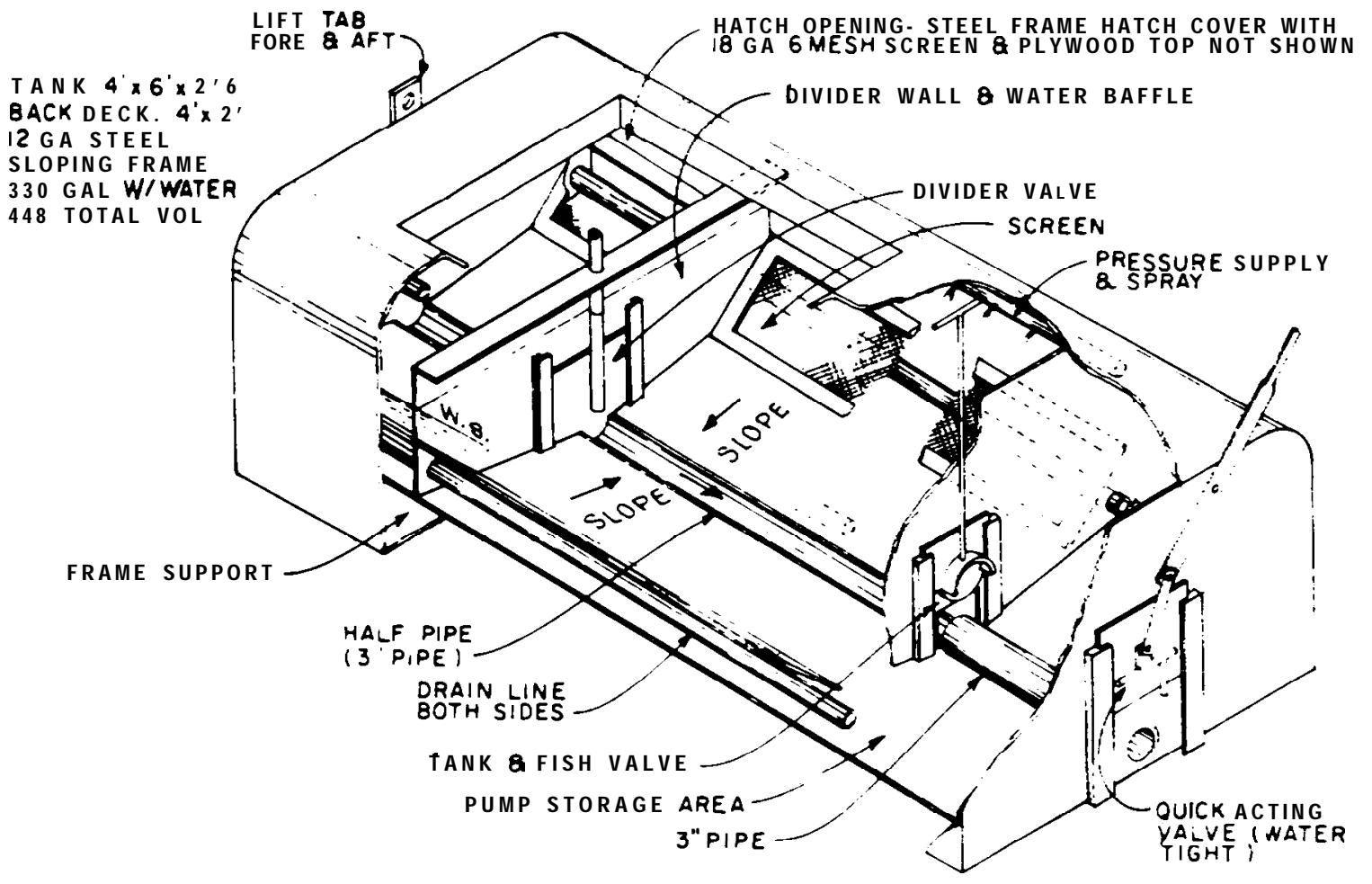

Figure 11. Typical portable fish-transport tank with overhead spray and oxygen injection.

A refrigeration system is not recommended on portable units; however, polyurethane foam sandwiched between fiberglass or metal shells can effectively insulate the unit so that, with the use of ice, water temperature can be properly regulated.

The combination of a trailer and portable tank is a viable option for use at a low-cost facility. A heavy-duty pickup truck, for example, can pull a 4,000 lb unit while the load itself would be too heavy for the truck alone. Trailers can be custom-built for approximately $\$ 1,000$ to accommodate a 400 - to 500-gallon payload. A portable tank is recommended because it can be removed and the trailer used for other purposes. Aquaforms (Appendix 2) has a heavy-duty fifth-wheel trailer for about $\$ 4,000$ that can be ordered complete with tank for approximately $\$ 8,000$.

A major advantage of the portable tank is its mobility, which allows it to be used to traverse back roads and bridges with load limits to reach areas inaccessible to large units. Its greatest disadvantage is inefficiency when handling large numbers of fish over long distances.

Approximate cost of fiberglass tanks (tank only) are: 1,OOO-gallon, four compartments $(\$ 7,000)$; 500-gallon, three compartments $(\$ 4,500) ; 1$ 00-gallon, two compartments $(\$ 2,000)$; and 100-gallon, one compartment $(\$ 1,500)$. 
Transportation of Sperm, Eggs, and Live Fish

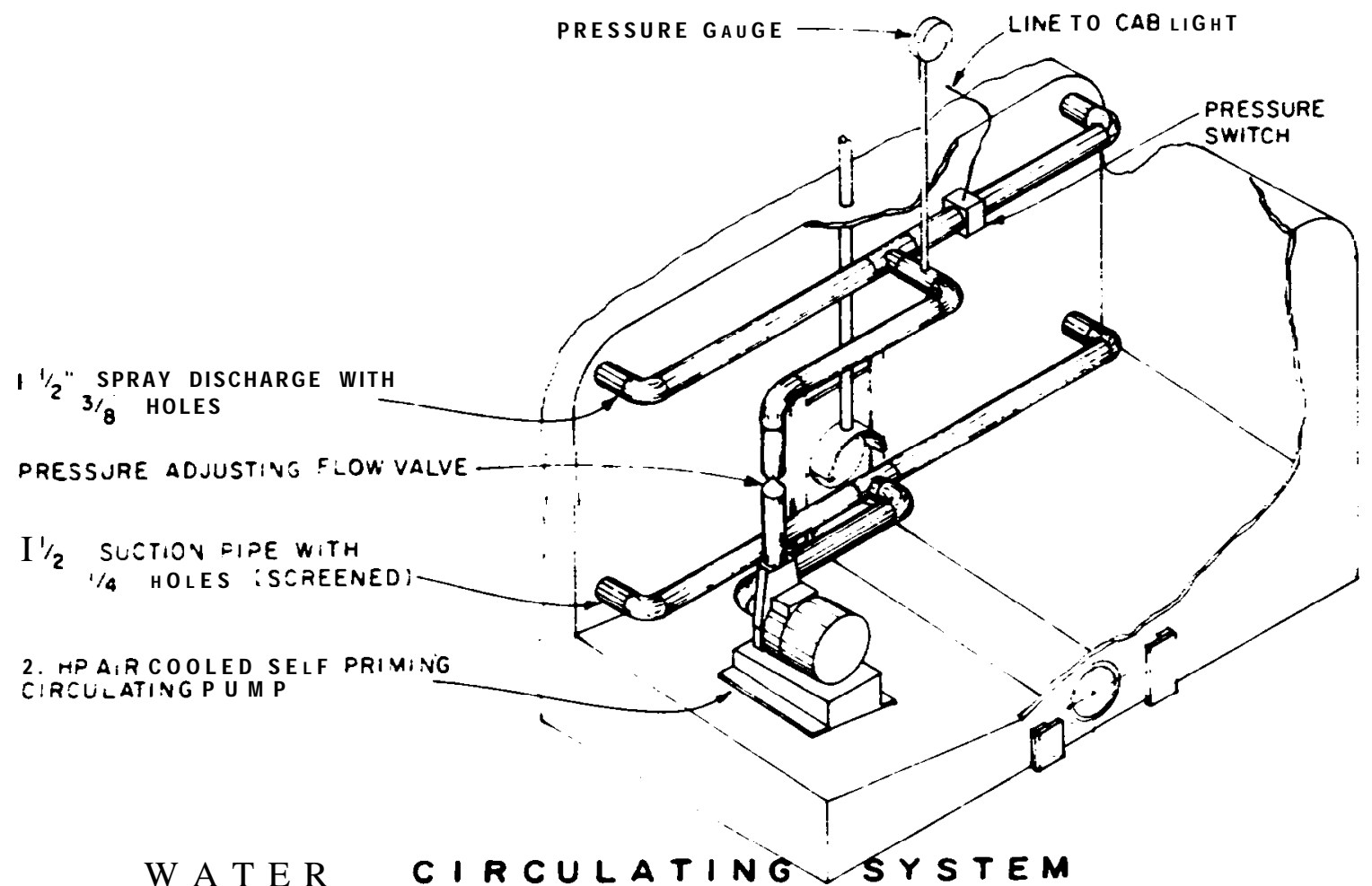

Figure 12. Sketch of a water circulation system for the portable fish-transport tank in Fig. 11.

Information on portable fish tanks is available at most tribal, state and federal hatcheries, and recently the Canada Department of Fisheries and Oceans conducted experiments with low-cost transportation methods. Publication is pending (Bérézay, 1984)

Appendix 2 lists several manufacturers or vendors of portable fish tanks.

2. Tank Trucks and Tank Trailers Tank trucks and tank trailers (Fig. 14) are units used exclusively for hauling fish. Because of their size and cost they are not practical to purchase for use at small or mediumsize stations. The capital cost of a 3,000-gallon unit with the necessary refrigeration and aeration equipment is approximately $\$ 100,000$.

If the occasion arises where it would be advantageous to use large equipment, it may be possible to rent or lease from one of the fish agencies or a private grower. Also, contract hauling is available from LTI, Inc. (Appendix 2), which has two 3,500-gallon transfer tanks that can be used singly or in tandem.

a. Loading capacities for tank units Fig. 15 illustrates approximate tank loading capacities for hauling juvenile salmon and steelhead trout. We are assuming the 


\section{Chapter 6}

water temperature is maintained at $48 \mathrm{~F}$ and the tank has an overhead spray and oxygen aeration system. Data were obtained from WDF, IFG, and WDG personnel. Since information on sockeye salmon was not available, we arbitrarily treated them similar to fall chinook salmon.

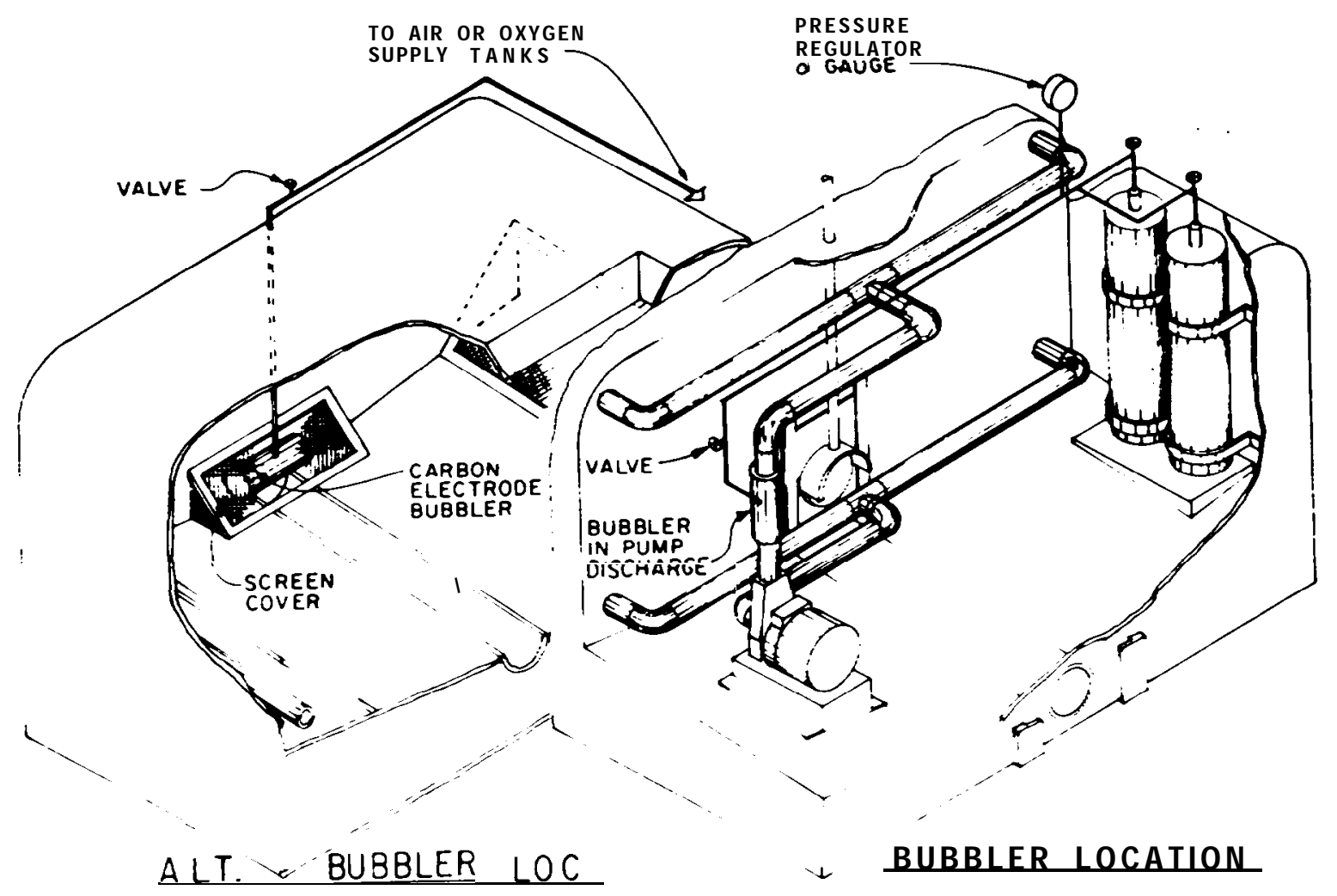

Figure 13. Sketch of an air/oxygen circulation system for the portable fish-transport tank in Fig. 11.

Tank capacities for adult salmon and steelhead trout were often very site specific and lacked adequate temperature data. However, for adults we feel it would be safe to use the upper density limits shown in Fig. 15 for the largest juveniles.

b. Cost of transporting fish Table 1 illustrates the labor and equipment costs per mile of travel for three sizes of fish transport units. Table 2 illustrates the cost per pound of fish transported on a typical SO-mile haul (100 mile round trip) for each of these units. Our estimates have included average equipment operator cost for loading, unloading, and travel (driver only). Operation and maintenance costs include all anticipated repairs and fuel usage over the life of the equipment. The investment cost only included the original purchase price with a $30 \%$ value left after $150,000 .$. miles and 200,000 miles on the gasoline and diesel trucks, respectively. Investment credits were not included, and it was assumed all equipment was located on station. 
Transportation of Sperm, Eggs, and Live Fish

Table 1. Estimated cost per mile of fish transport equipment.

\begin{tabular}{|c|c|c|c|c|c|}
\hline $\begin{array}{l}\text { Tank } \& \\
\text { truck size }\end{array}$ & $\begin{array}{l}\text { Tank \& } \\
\text { truck cost }\end{array}$ & $\begin{array}{l}\text { Driver } \\
\text { cost }^{(3)}\end{array}$ & $\begin{array}{l}\text { Operation \& } \\
\text { maintenance }\end{array}$ & $\begin{array}{l}\text { Amortized } \\
\text { cost }\end{array}$ & $\begin{array}{l}\text { Total } \\
\text { cost }\end{array}$ \\
\hline$\frac{200 \mathrm{gal}}{1 \text { ton }}$ & $\$ 13,000^{(1)}$ & $\$ 0.48$ & $\$ 0.17$ & $\$ 0.07$ & $\$ 0.75$ \\
\hline$\frac{1,000 \mathrm{gal}}{34,000 \mathrm{GVW}}$ & $35,000^{(1)}$ & 0.51 & 0.30 & 0.17 & 0.98 \\
\hline$\frac{3,000 \mathrm{gal}}{\text { Diesel tanker }}$ & $100,000^{(2)}$ & 0.60 & 0.53 & 0.35 & 1.48 \\
\hline
\end{tabular}

(1) Estimated $30 \%$ value at 150,000 miles.

(2) Estimated $30 \%$ value at 200,000 miles.

(3) Includes average equipment-operator salary: \$13.34 per hour for larger tanker and $\$ 12.09$ for one ton or smaller.

(4) Includes all maintenance and fuel at January 1984 prices. Fuel consumption based on 9, 5.25, and $4.5 \mathrm{mpg}$ for small, medium, and large tankers, respectively. Maintenance was estimated at $\$ 0.06$, \$0.10, and $\$ 0.26$ per mile for small, medium, and large tankers, respectively.

(5) These values are based on total unit costs shown in footnotes 1 and 2 and include no added cost for investment. Truck life expectancy in miles and trade-in values are considered.

Table 2. Estimated costs of a SO-mile fish haul (100-mile round-trip) expressed in cost per pound of fish per gallon of tank water for three tank sizes.

\begin{tabular}{rrrrr}
$\begin{array}{c}\text { Tank size } \\
\text { (Gallons) }\end{array}$ & $\underline{4}$ & Pounds of fish per gallon of water & \\
\hline & & $\underline{0.50}$ & $\underline{1.00}$ & 1.50 \\
1,000 & $\$ 1.50$ & $\$ 0.75$ & $\$ 0.37$ & $\$ 0.25$ \\
3,000 & 0.39 & 0.20 & 0.10 & 0.07 \\
& 0.20 & 0.10 & 0.05 & 0.03
\end{tabular}

Source: Calculations based on data shown in Figure 15 and Table 1. Cost amounts are rounded to nearest one cent. 
Chapter 6

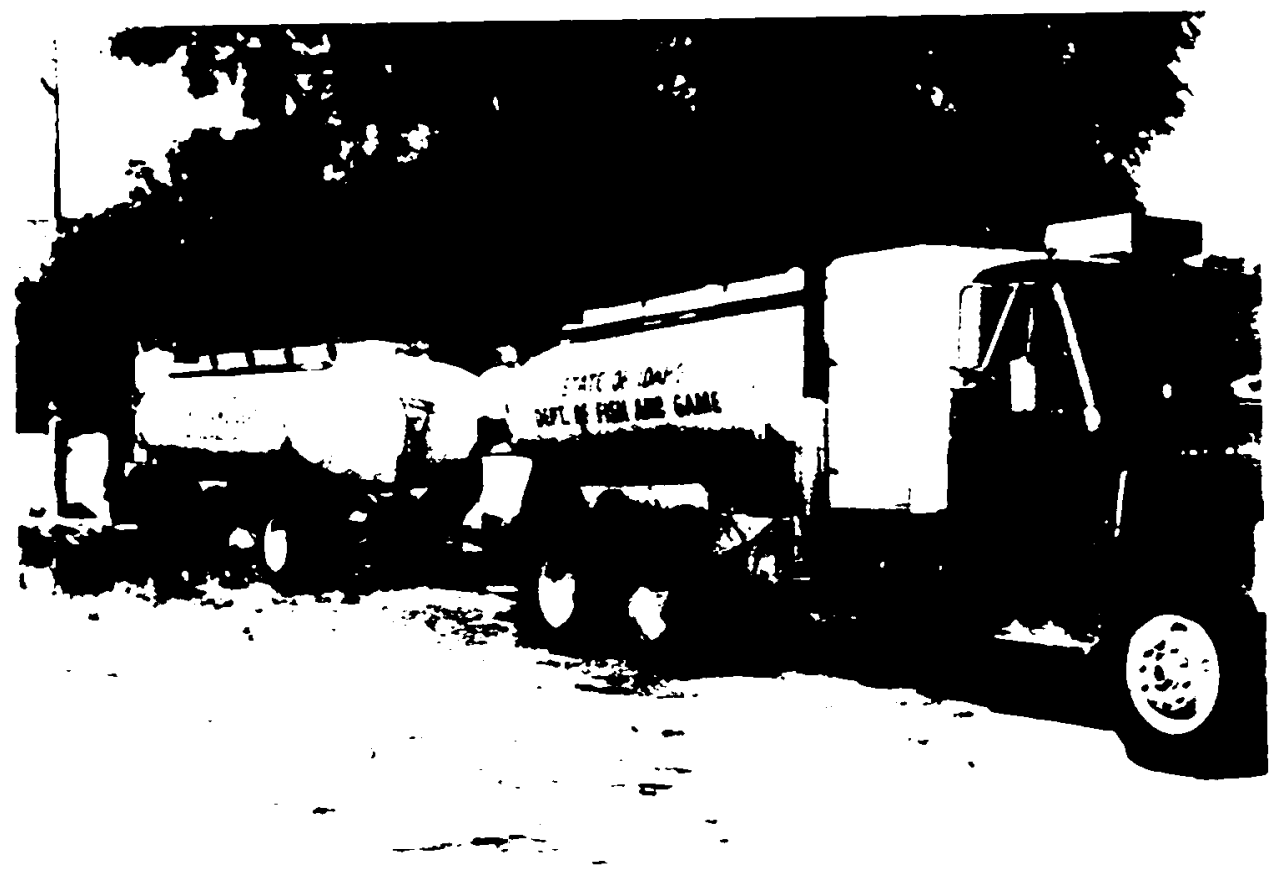

Figure 14. Tank truck and tank trailer fish transport system (IFG).

3. Floating Live Box Transporting fish short distances by water can be done using floating live boxes. The situation dictates the size and shape of the box. The capture of adult steelhead or salmon from streams may require that they be moved downstream to a collection point for subsequent transport to a hatchery. One method is to construct a floating box as illustrated in Fig. 16. In a unit $4 \times 5$ feet in surface area and 3-feet deep, 40 or more lo-pound fish can be transported for several miles. The advantage of this box is that it can be transported over the shallowest of riffles. This method has been used by WDF.

Set pens are also a method of transporting fish short distances across deep water areas such as lakes (see net pens in Chapter 5).

4. Tube Transfers A tube transfer system can be used for loading or releasing adult fish when they must be transferred several hundred feet between the truck and stream. Using this method, one or more adults are placed in a tube (Fig. 15) with water and then hand carried. Naterials used are aluminum or PVC. For information contact Canada Department of Fisheries and Oceans. 
Transportation of Sperm, Eggs, and Live Fish

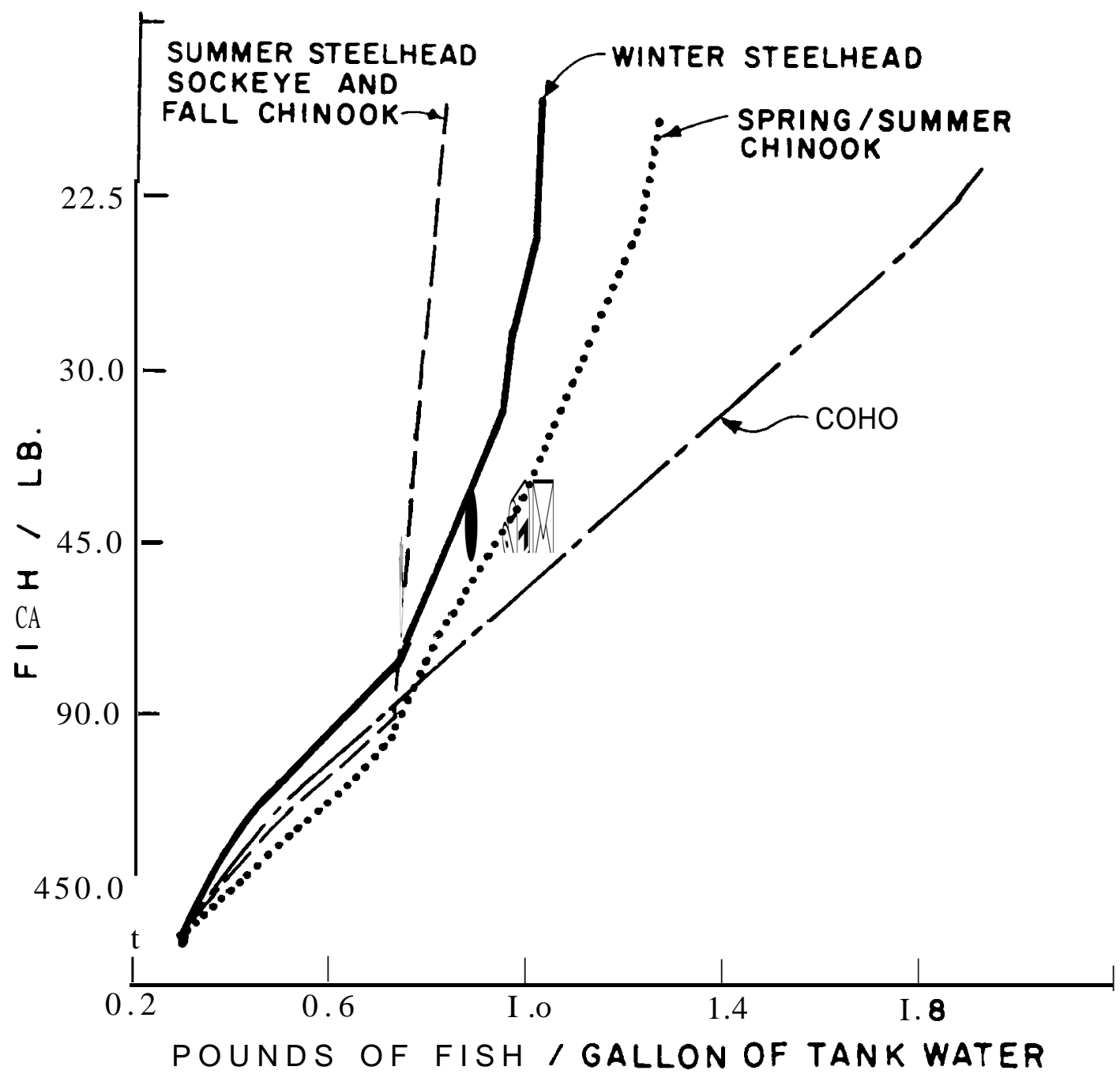

Figure 15. Approximate loading rates of fish-transport tanks in pounds of fish per gallon and by fish size, species, and racial group (with water temperature at constant $48 \mathrm{~F}$ ).

5. Collapsible Roll Poly In British Columbia, an inexpensive technique for transferring juvenile fish involves the use of a collapsible, transparent, 6-mil poiy tube. The plastic is purchased in lengths of up to 1,000 feet and cut to any desired length. One end is attached to the discharge hose of the transport tank and the salance unrolled over the inaccessable area to the stream. When the valve on the tank is opened, the water and fish expand the collapsed tubing to form a 6-inch transparent, flexible release pipe. Upon completion of the release, the poly is collapsed and rolled up for easy storage. The advuntuge of this system is that it allows access to rnany release points not otherwise possible without considerable cost. The cost of the tubing is about $\$ 0.19 /$ inear foot. For information on this 


\section{Chapter 6}

method, contact Canada Department of Fisheries and Oceans. For vendor see Western Concord Mfg. Ltd. in Appendix 2.

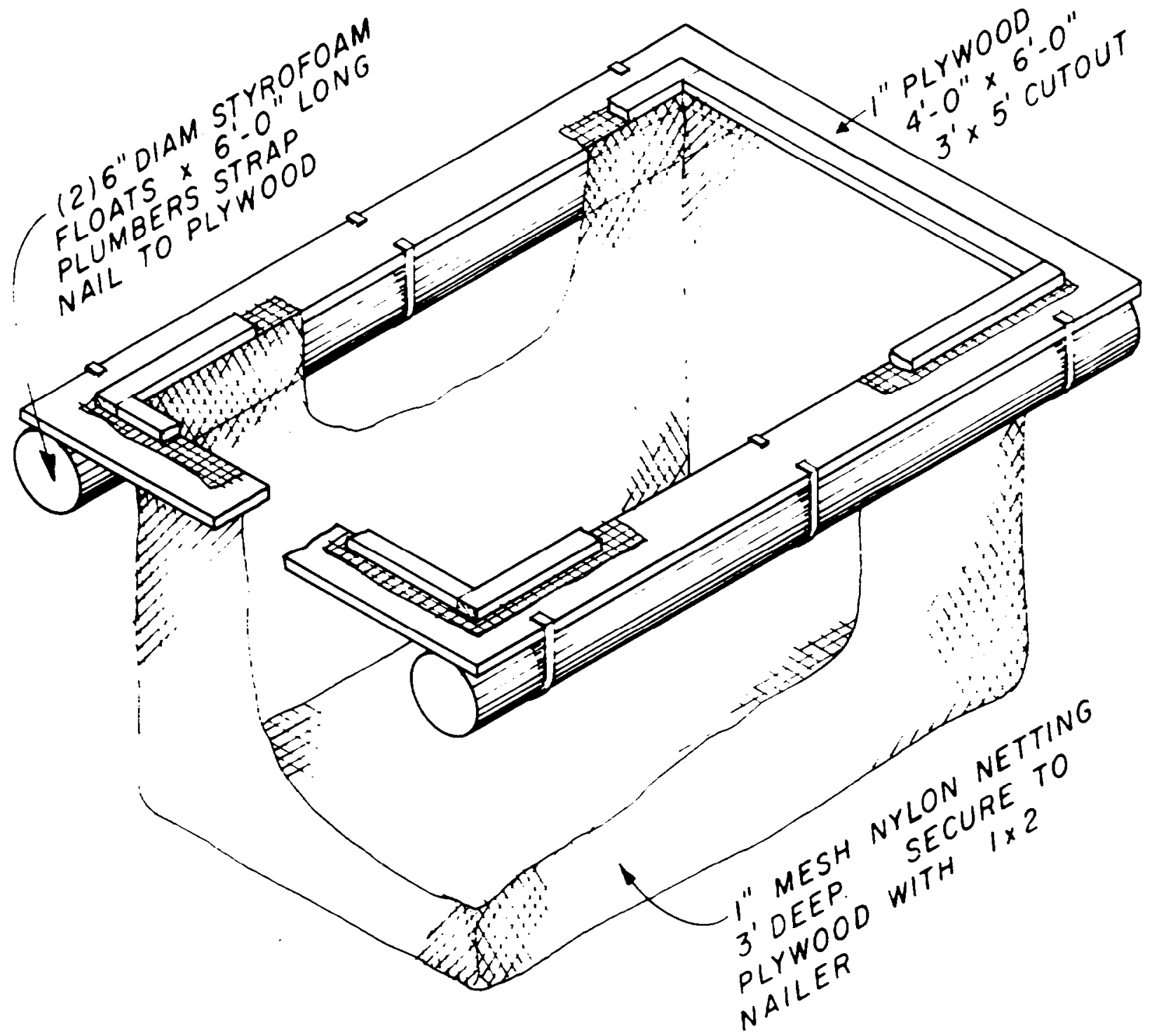

Figure 16. Floating live-box transport system.

6. Cans, Buckets, and Backpacks Many small containers can be used to hand transport fish for short distances. Five-gallon buckets are the most commonly used, especially when randomly distributing fish along a stream. This is referred to as bucket planting. Most managers fill the buckets with $2 / 3$ water and $1 / 3$ fish and keep the maximum time in transit to the stream from 1 to 2 minutes. 
Transportation of Sperm, Eggs, and Live Fish

Backpacking anadromous salmonids is rarely done, but volunteer groups may wish to use this procedure for planting fish in isolated areas. Up to 1,000 salmon or 1,500 steelhead can be carried by a single person in a 4-gallon pack for 1 to 2 hours. The water is aerated by the splashing in the container.

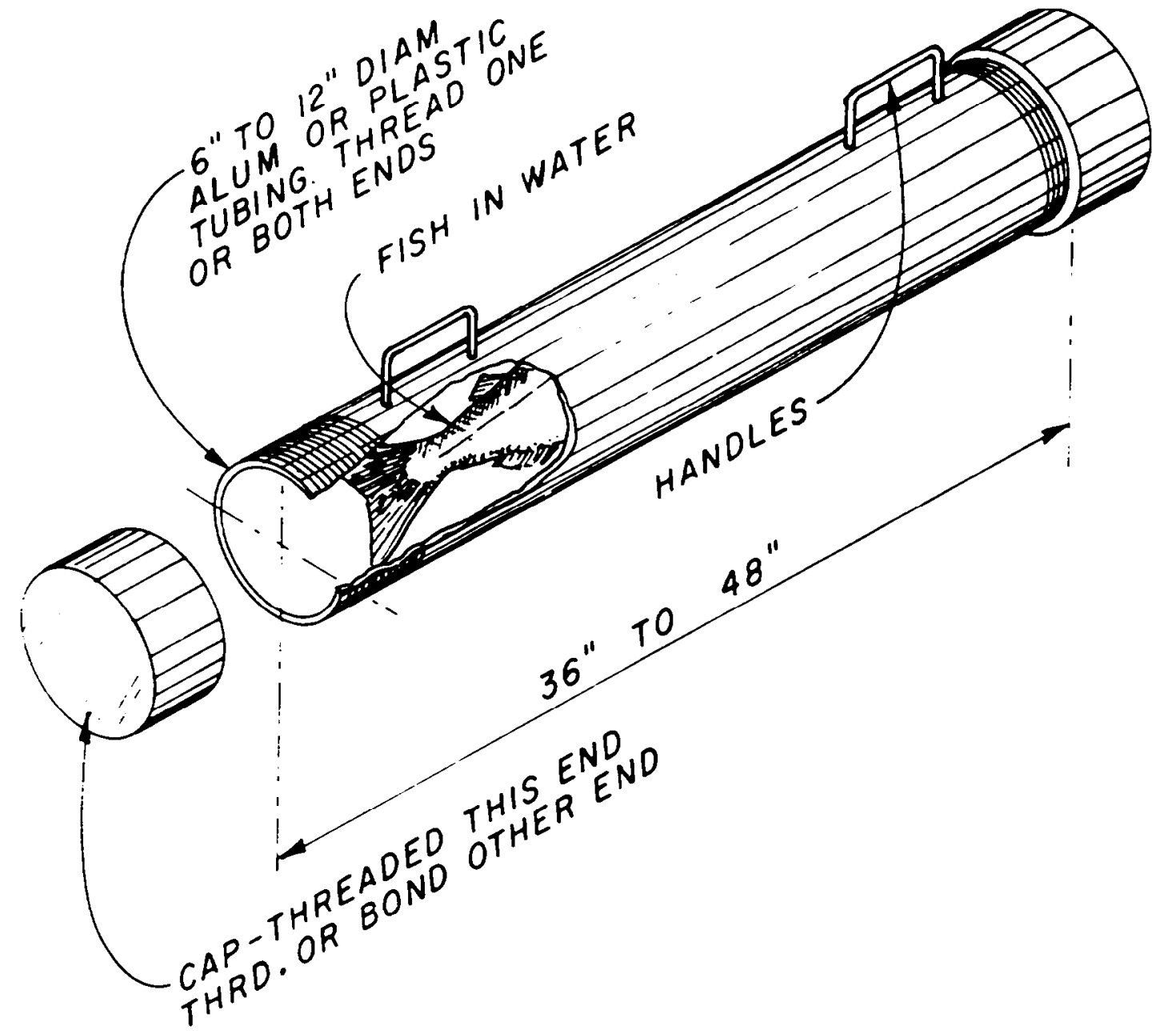

Figure 17. Tube transport system. 


\section{CHAPTER 7}

\section{PRODUCTION SUPPORT FACILITIES AND EQUIPMENT}

\section{PART I. BUILDINGS}

Hatchery building styles (Figs. 1 and 2) and construction materials may vary to suit program goals and budgets without detrimental impact on fish production. However, traditional hatchery facility construction has gone to the most permanent type of construction that budgets will allow. As construction costs increase from metal to wood to masonry, so do the creature comfort parts of the structure, such as locker rooms, crew showers, kitchen facilities, offices, libraries, and display areas. In considering low-cost facility development, it is important that this trend be carefully considered.

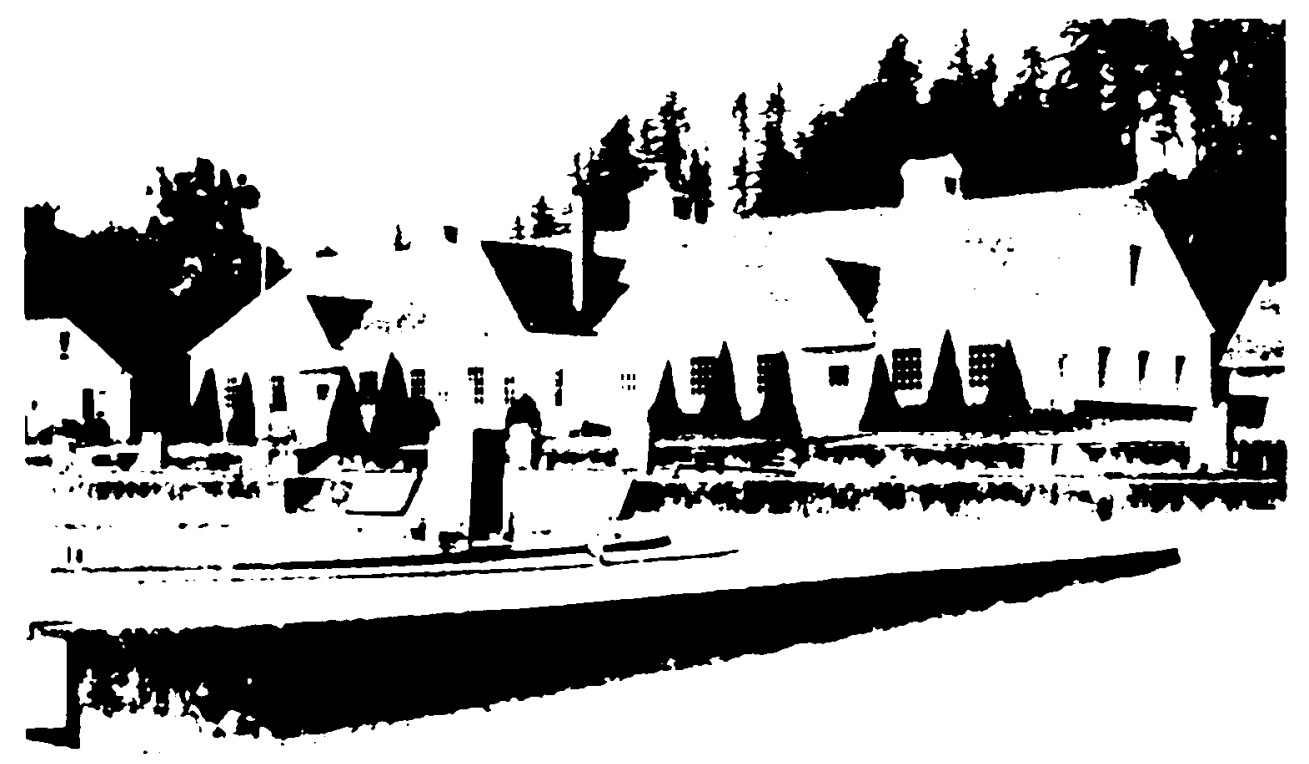

Figure 1. Vancouver Trout Hatchery with majestic multi-purpose wood building (W DG).

The three common construction materials are metal, wood, and masonry and their advantages and disadvantages are shown in Table 1 and costs in Table 2. Pre-buil t buildings offer construction savings compared to on-site construction. Industrial type containers, such as cargo containers and used truck or trailer vans, are suitable for storage or personnel buildings, and offer cost saving options. New or used mobile homes for station personnel housing, and insulated vans or cargo units for adaptation to cold 
Production Support Facilities and Equipment

Table 1. A comparison of metal, wood, and masonry buildings.

$\begin{array}{ll}\text { Metal } & \text { Advantages } \\ \text { Low cost } \\ \text { Erects rapidly } \\ \text { Requires minimal fire protection } \\ \text { Disassembly for relocation less } \\ \text { difficult than wood or masonry } \\ \text { Can be insulated } \\ \text { Pre-painted panels available } \\ \text { 30-year life }\end{array}$

$\underline{\text { Disadvantages }}$

Mastic seal required on all joints

Condensation inside affects insulation and causes rusting of steel parts

Regular maintenance: painting every 8-10 years, roof coating every 5 years.

Wood Lower cost than masonry

Tre-

fabri-

cated)
Full use of newest materials and construction metho-s 40-year life
Size limited to highwy; restrictions or it feet maximum for either fuil or half-width units

Requires leavy syupmeri t o iranspolênr: se t-up

Regular mamtellanee: paunt ing every $8-10$ years, roof replacisinesit every 20 years.

Energy efficiency limited to fuctory designs

Relocation _impractical

Wood Can be sized for intended use

Site- Roof style and materials can be selected for local weather conditions and longer life

Energy efficiency can be designed with minimal extra cost

Custom construct ion at reinote sites is costly

\section{Helocation impractical}

Alteration may be limited

Regular maintenance: painting every I 0 years, roof replacement every 20 years.

SO-year life

Masonry Most durable construction

Size and shape can meet initial operational needs

Requires minimal fire protection 100-year life
Initial construction costly

Regular maintenance: cement and brick require resealing every 20-30 years and surface protection every 5 years.

Replace composition roof every 20 years. Tile roof same life as building.

Alteration limited to nonsupporting areas

Relocation impractical 


\section{Chapter 7}

Table 2. Building costs by material and building types.

$\underline{\text { Building type }}$

1. Hatchery

With some interiors(1)

As presently being built $(2)$

Typical size:

20 x 30 feet; includes

foundation, concrete drain

troughs, and 4-inch

concrete floor.

2. Storage

Typical size:

30 x 40 feet; includes

foundation and 4-inch

concrete floor.

3. Housing
a. Mobile
Typical size:
26 x $50\left(1300 \mathrm{ft}^{2}\right)$
on support blocks
and with skirting.

b. Permanent

Typical size:

$26 \times 50\left(1300 \mathrm{ft}^{2}\right)$

on 6-inch foundation

$2 \mathrm{ft}$ high. $\underline{\text { Metal }}$

$\$ 54.00$

$\$ 54.00$

Construction material

$\left(\operatorname{In} \$ / \mathrm{ft}^{2}\right)^{\text {Wood }}$

$\$ 59.00$

$\$ 96.00$

$\$ 75.00$

$\$ 126.00$

Masonry

$\$ 20.00$

$\$ 25.75$

NA

$\$ 23.50^{(3)}$

$\$ 32.00$

NA

NA

$\$ 50.00$

$\$ 77.00$

4. Cold storage

$\$ 90.00$

$\$ 97.00$

$\$ 125.00$

Typical size:

$12 \times 24$ feet; on

6-inch foundation

$3 \mathrm{ft}$ high.

(1) Represents the same interior with shell cost reflecting the difference.

(2) Building costs reflect "as built" by agencies when materials listed are used.

(3) All metal mobile homes were limited to single width (14 ft) units of various lengths. The unit priced was $14 \times 56$ or $765 \mathrm{ft}^{2}$. Price includes transportation, installation on concrete blocks, and skirting. 
storage needs are other cost saving options for low-cost facilities. Travel trailers are useful and cost effective for temporary or seasonal housing. Regardless of the unit chosen, we recommend that consideration be given to the use of existing agency, tribal, or rental storage space.

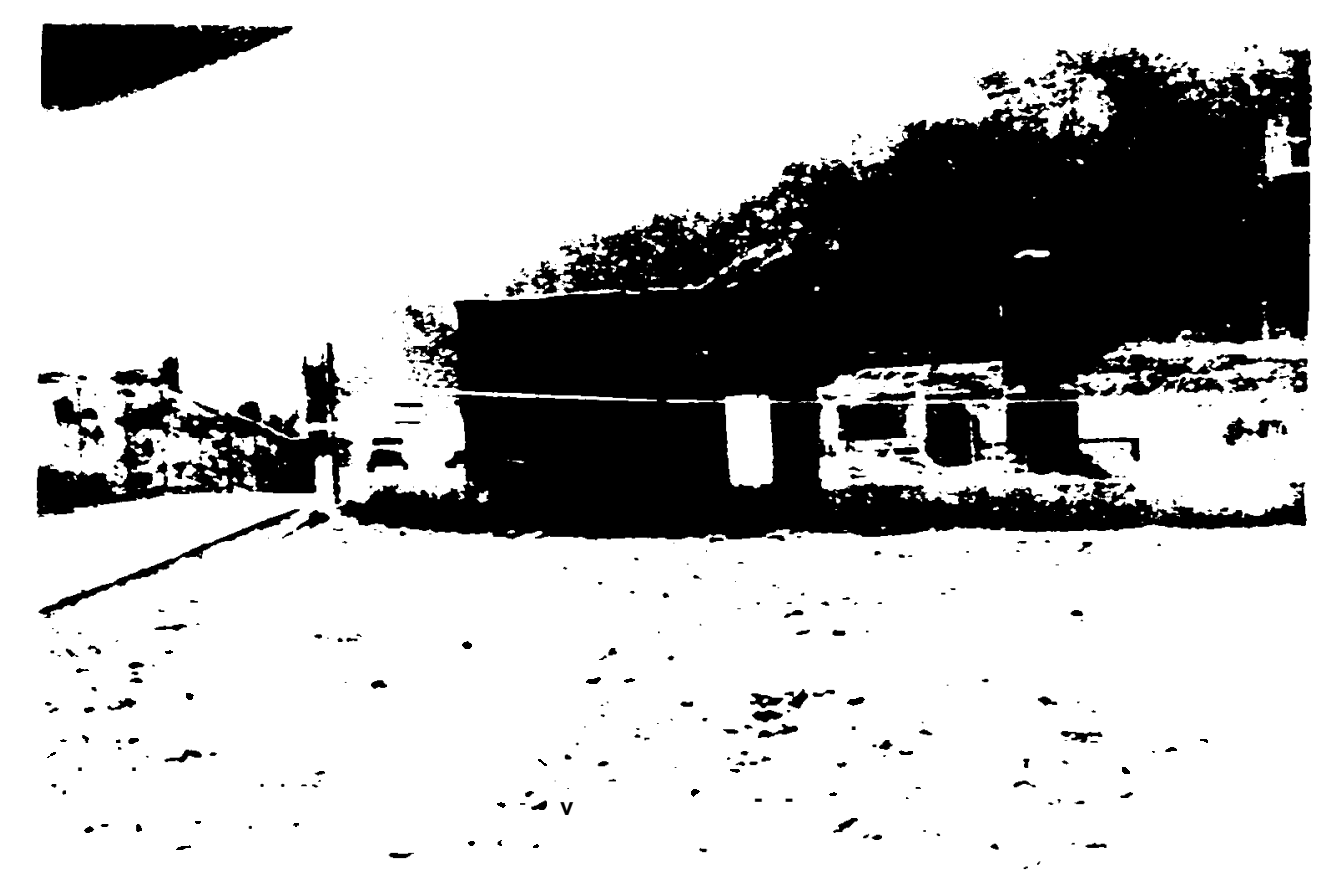

Figure 2. Rocky Reach Hatchery with multi-purpose metal building (Chelan County PUD and WDF). This building has $960 \mathrm{ft}^{2}$ and the construction cost in 1983 was $\$ 29,100.00$. If we assume construction cost at $75 \%$ of total cost, this building costs 38,800 or $\$ 40.42 / \mathrm{ft}^{2}$ (Steve Hays personal communication).

The space requirement and capital cost for a small food storage facility is shown below for a station that produces 20,000 pounds of fish and has an annual moist pellet food requirement of 30,000 pounds. Delivery is assumed to be made three times per year. Thus we recommend a 12,000 pound freezer capacity allowing up to 2,000 pounds carry-over at fill-up time.

The capital cost of the building is estimated at $\$ 28,000$ based on $144 \mathrm{ft}^{2}$ for the freezer area, and $144 \mathrm{ft}^{2}$ for non-refrigerated storage. The area required was estimated as follows:

(1) For 12,000 pounds of food, storage for 240 50-pound bags will be required. The volume per 50 pound bag $=2 \mathrm{ft}^{3}$ when loose stacked on a $4-\mathrm{x}$ 1-foot pallet.

(2) Using two pallets per stack, each pallet is layered with 16 bags or a total height of 


\section{Chapter 7}

about 5 feet for 32 bags. A total of eight pallets is required; four on the floor and four at mid-height. A total of $64 \mathrm{ft}^{2}$ of floor space is needed.

(3) The space for the aisleway is $48 \mathrm{ft}^{2}$, and for the evaporator and minor miscellaneous storage, $32 \mathrm{ft}^{2}$.

(4) For machinery, electrical, and food thawing, a 12- x 12-foot area is planned.

Contacts in 1984 with local cold storage rental outlets provided an annual cost of \$2,000 to provide storage for the program as described. Rental of freezer storage is discussed under Food Storage.

\section{PART II. FOOD STORAGE}

Proper facilities for the storage of fish food is a vital part of any fish production unit. The fact that Oregon moist pellet (OMP) requires refrigeration, and dry feed does not, dictates the type of storage facilities required. Heat and moisture are the two most significant factors causing oxidation and spoilage of the vital elements in fish feeds. For the moist OMP, it is essential that the storage temperature be maintained at OF or below.

Drv feeds, on the other hand, require storage that is dry, well ventilated, and cool. Dry feeds should not be stored in a closed-up or damp building without humidity control. Any sound building with a good roof and plenty of air circulation is satisfactory. In warm locations, metal buildings with open doors and windows are adequate. Always stack dry feed on pallets to avoid moisture penetration from the floor and provide an air space between the stacks. O.IIP should be stacked in the freezer in a similar fashion to provide adequate circulation of cold air, and to prevent any build-up of heat from oxidation or spoilage. Under proper storage, both O.VP and dry feeds will have a 90-day shelf life without significant deterioration.

Freezer units for the storage of O.MP come in a variety of forms, shapes, and sizes; ranging from home freezers to giant commercial units capable of storing millions of pounds. Even a household refrigerator can be used on a temporary basis for short-term storage. Most hatchery freezers are commercially built walk-in, drive-in units that are fabricated separately or as part of the hatchery buildings (Fig. 3). Modern construction, insulation, and refrigeration units keep these types highly cost-effective and trouble-free. A 50,000-pound capacity freezer costs approximately $\$ 75,000$ and has a life expectancy of 30 years.

For small installations and for temporary storage, used refrigerator-trailer units (Fig. 4), usually powered by small diesel motors, are sometimes available at used truck-trailer dealers. They can hold up to 45,000 lbs. While the cost is relatively low, reliability, especially in the diesel powered unit is sometimes questionable and they require careful maintenance. In Alaska it is common to find refrigerated container units parked at various locations, often having the advantage of dual power units, either electric or diesel. The disadvantages of either semi-trailer or container units are difficult accessability to the contents, and lack of space for orderly storage. 
Production Support Facilities and Equipment

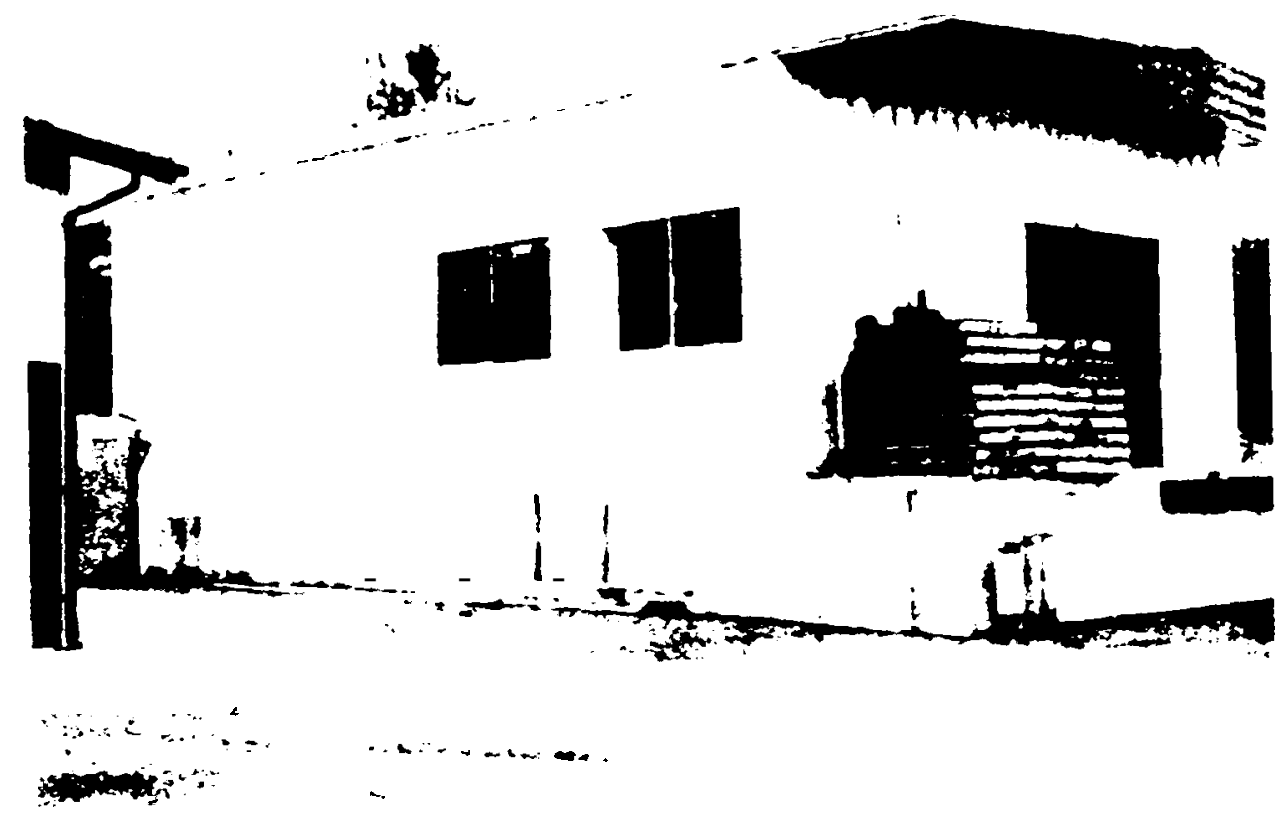

Figure 3. Fifty-thousand pound capacity fabricated freezer at the Puyallup Salmon Hatchery (WDF).

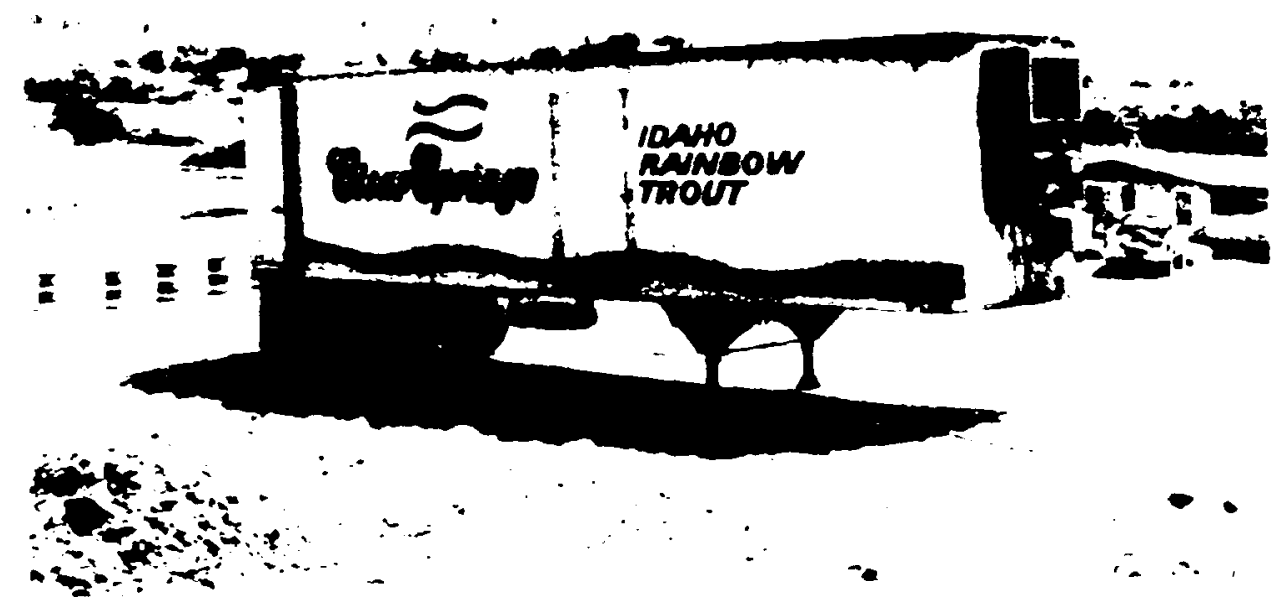

Figure 4. A refrigerated trailer being used for fish food stcrage at the private Clear Springs Fish Hatchery, Idaho. 


\section{Chapter 7}

Types of refrigeration units vary from the older, open ammonia units which are found in large commercial freezers, to modern freon units that are virtually trouble free. Failure in freon systems is most apt to be in the power unit. Fortunately, if a unit fails, the critical temperature of $32 \mathrm{~F}$, or below, can be maintained for a considerable length of time provided the unit is not opened, and if normal operating temperature is at $-10 \mathrm{~F}$, or below. The $-10 F$ operating temperature is a measure of safety that is well to consider.

The rental of freezer space will often be the most economical for low-cost facilities or short-term programs, in which case, a small unit with a three- or four-day supply capacity may also be required at the site. Earlier in this Chapter under Buildings, the capital cost is estimated at $\$ 28,000$ for a food storage facility for a station that produces 20,000 pounds of fish and has an annual OMP requirement of 30,000 pounds. in our contacts with cold storage rental outlets, the estimated cost was $\$ 2,000$ per year to handle food storage for the program as described. Rental of freezer space and dual use of nearby agency cold storage facilities are viable options that should be considered.

\section{PART III. ROADS}

Roads are essential to provide access from a public road to, and around the station grounds. Koad types include concrete, asphalt, and prepared gravel. The width of a road is dependent on useage, and usual station access and onstation road widths are as follows:

Type of road

Two lane access roads

Single lane roads (1)

Operation road around ponds and station

Minimum access width

$\frac{\text { Width }}{\text { (in feet) }}$
$20-24$
$16-18$
12
10

(1) For low-cost developments, a 16-foot single lane road is recommended with turnouts at 500 -foot intervals.

Successful roads, regardless of final topping, should have good drainage and a compacted gravelly base. A good base consists of 8 inches of compacted 2-to 5-inch pit run rock. Recommended surfacing consists of 5 inches of 2 -inch minus crushed rock. This can be oiled or surfaced with cement or asphalt. In low and swampy areas, side ditches should be a minimum of 1 foot below the prepared base and sloped or culverted so water can be drained completely away.

If ground water exists, a plastic fabric mat should be laid down prior to installation of the road base to prevent mud from penetrating the base and damaging the road surface. The advantages and disadvantages of each type of road surfacing are shown in Table 3, and road construction and maintenance costs for 12-and 20-foot road wiaths by surface type are illustrated in Table 4. 
Production Support Facilities and Equipment

Table 3. The advantages and disadvantages of various road surfaces.

$\underline{\text { Surface }}$

Advantages

$\underline{\text { Disadvantages }}$

Gravel Lowest cost

Least damaged by freezing

Minimum cost to reshape

Surface gravel shifts requiring regular grading

Develops chuck holes

Dusty in dry weather

Long life if maintained

Must limit load during a thaw to

Safest surface during adverse protect base. weather

\section{Black top $\quad$ Medium cost}

20-year life if protected during thaws

Can be spray resealed

A smooth surface
Porus surface requires expert installation and maintenance personnel

Slick surface in adverse weather

Must limit loads during a thaw to protect base.
Concrete Longest life

Smooth surface

Minimal hydraulicing
Highest cost

Develops slick surface during icing and winter storm

Nust limit load during thaw to protect base

Develops joint bumps

\section{PART IV. SECURITY AND ALARM SYSTEMS}

The value of the fish resource and the cost of fish production absolutelv necessitates the installation of alarm systems and security measures at every fish rearing facility. The failure of mechanical equipment that stops or interrupts the water supply can be devastating because an entire year's production can be lost in a single incident. Protection from vandalism, including theft and poaching by humans, to predation by birds and mammals, must be designed into any fish facility. Security measures and devices are 


\section{Chapter 7}

described in this section under the general headings of water alarms, adult fish security, and juvenile fish security. Security for the buildings is also required and must be planned for, but we have discussed this very briefly because many good systems are available and choice will depend mainly upon budget restraints. The local law enforcement agency is a primary source of infor mation. All fish alarms are subject to failure, so it is important that all systems protecting a facility be inspected and tested on a regular basis to insure maximum reliability.

Table 4. Estimated road construction and annual maintenance costs by surface type and width for 100 feet of roadway, including 2-foot shoulders.

Surface

$\underline{\text { material }}$

Gravel $^{(1)}$

8-inch base

6-inch topping

Oiled gravel

IIC-250 oil

Blacktop

8-inch base

2-inch blacktop

Concrete

8-inch base

6-inch concrete

Culvert C.MP ea. ${ }^{(3)}$

18 -inch diameter

$x 16$ gauge
Road cost

per 100 feet

Road width in feet

$\underline{20}$

$\$ 1,250$

$\$ 1,800$

$\$ 2,400$

$\$ 1,575$

$\$ 7,950$

$\$ 4,900$

$\$ 50$

Road width in feet

$\underline{20}$

$\$ 150$

$\$ 300^{(2)}$

$\$ 200^{(2)}$

$\$ 120^{(2)}$

(1) For low-cost developments, pit-run base rock is initially recommended followed by a 6 -inch surfacing several years later as necessary.

(2) Cost based on re-oil or oil sealing every three-year interval, or oiling $1 / 3$ of roadway ен ch vear.

(3) Corregated metal pipe. Included here since culverts are an integral part of road construction costs regardless of surface type. Costs include installation. 
Production Support Facilities and Equipment

\section{A. WATER ALARMS}

Table 5 shows four types of alarm switch devices that can be used directly or through relay switches to operate audible alarms. The chart shows where these activating switches are used. Where more than one type is shown for the same location, the site conditions such as pipeline pressure and velocity, and/or individual preference, should determine the selection.

Table 5. Four types of audible water alarm switches and where they are used in a hatchery facility.

Type of switch (described below)

$\begin{array}{llll}(1) & \frac{(2)}{X} & \frac{(3)}{x} & \frac{(4)}{X} \\ & & & x \\ & X & & X \\ & X & & X\end{array}$

$x$
$x$
$x$
$x$
$x$
$x$
$x$

(1)

(3) Water flow operated by depressing an exposed tinged pacide with nercury :ult switch.
Action Where switch is used

S.t

DA

S.A

S.A

SA

SA

DA

I) $A$

DA

S.A

Ponds - flume supply
Gravity intake - still well

Surface water supply pumps

liell supply pumps

Pipelines supply and distribution

Distribution tower

Incubation supply trough

Shallow trays

Deep troughs and tanks

Ponds - single spout drop

Ponds - manifold supply

Ponds - water levels

Holding pond supply and levels

Fishway supply level and auxilary

Recirculating pu mps

(4) Velocity operated paddle set into a pipeline to operate micro-switches.

Water alarms should have an independent power supply, such as a la-volt heav-iut. ceep-cele batter:. If the alarms are on public power und the power inils. the alanil sviste:I. is ae-activated. The batter should be placed near a public power outlet anc nept iully churged. Do not use the facility's auxiliary power generator battel" for the aln?:.. system. If something is defective with the alarm systemii it will cischarge the generitor': battery and two systems are then inoperative. 
inapter 7

1. Water Intakes A float-activated mercury switch at the intake to the hatchery water supply and connected by buried wire to the hatchery building, will activate an alarm when the intake level supplying the pipeline drops to a preset critical level. Since most water flow shut-downs are not instantaneous, the alarm will sound but some flow will continue to keep the pipeline partially full. Immediate response to the alarm will usually prevent any fish loss resulting from water shortage and delays in refilling the pipeline.

On high-head pipelines, a pressure-operated switch located at the hatchery and connected to the alarm system is used. The alarm is activated when the water level in the pipeline drops below the intake operating level.

For intake pipes that run full of water, an internal paddle switch connected to an alarm system at the hatchery is a reliable system. A flow reduction reduces the pressure on the paddle which activates the switch and the alarm. Dual contact units are available that detect a slight decrease in flow as well as a critical shut down.

Alarm costs vary depending on the number of signaling units; wire lengths; type of signal such as a horn, lights, or telephone calls to duty personnel; and if control and indicator boards are required. A simple system could cost $\$ 3,000-\$ 4,000$, while deluxe control systems range from $\$ 30,000-\$ 40,000$.

2. Incubation Units A constant adequate flow of water to the incubation facilities is a top priority when fish are in the alevin stage. Host station water systems are designed to provide incubation facilities first choice of any water in the supply line. The alarm control should be installed at a location in the system that is first affected by any decrease in water flow. Since most operators run the incubation units with a small waste line to the drain at the end of the supply trough or pipe system, the water level at this location is first affected by a flow decrease and is the best location for the float switch that sounds the alarm. For deep and shallow troughs, the end of the supply branch or an end section of the first affected trough can be used as the alarm location.

Individual vertical incubators and the pipes and valves to shallow and deep troughs can become plugged with debris, but an alarm at each of these locations would be cost prohibitive. These sites and the main outlet screens should be inspected and cleaned regularly. If organic debris is present in the incubator water supply, a fine mesh screen can be installed to collect the material at the supply to the overhead trough to prevent individual stacks from plugging. The flow valve to individual units should be kept wide open and the main valve should be adjusted to the flow needed. Then only minor valve adjustments are required to balance the system.

3. Rearing Ponds An alarm system to monitor flows to the rearing ponds can be the internal paddle type located after the valve, if the flow quantity is sufficient to activate the switch, or the external-paddle switch for small flows, which is attached to the discharge end of the supply pipe. The latter unit is designed so the water discharge hits and depresses the paddle. If the flow decreases, the paddle moves, activating a switch which in turn activates an alarm. 
Production Support Facilities and Equipment

If the pond flow is adequate, but the pond stand pipe or stop logs are not tight and the pond level could accidently fall, a pond water-level alarm is used to warn of this condition. This unit is a float operated mercury switch set in a stilling tube at the drain end of the pond behind the screens. Here it warns of a water loss caused by low flow, plugged intake screens, or a defective drain control.

Information Sources:

All Northwest fishery agencies. Phipps Water Alarm Co.

\section{B. ADULT FISH SECURITY}

Whenever adult salmon and steelhead trout are accumulated and held for ripening and spawning, they must be protected since they represent the brood stock for subsequent production. Not only must a hatchery be properly equipped with alarms to signal water supply failures, it must also provide protection from poachers. Various protective techniques are described.

1. Fences Chain-link fences 6 to $\boldsymbol{\gamma}$ feet high with locked gates and barbed wire tops are often used to prevent entry to holding ponds. Poachers sometimes use bolt cutters to effect entry, so additional alarm systems are needed. An alarm wire circuit located in the fence with audible signals, and human proximity alarms are available to deter fence cutters.

A finer mesh fence fastened to the chain-link, or a separate fence at the pond edge and completely encircling the holding area is used to keep out predatory animals.

An 1 l-gauge chain-link security fence 1200 feet long and 8 feet high, with a one-arm threestrand barped wire top, S-inch corner posts, 4-inch gate posts, 2-inch intermeaiate posts, a 1 1/2-inch top rail, and one 16-foot double gate would cost $\$ 6900$, or $\$ 5.75$ per foot. This price assumes that the station is within a $100-$ mile round trip of the supplier.

2. Buildings If fencing is not practical or is cost prohibitive, then a security system for each building may be required. A variety of systems are availaole with different methods of operation and alarm signals. A system that will send a signal from each building and from any window or door that is opened to a master control in the rnain building is availaole from retail catalog such as J. C. Penney or Sears Roebuck Co. A two-building installation system for use on a 20x30-foot incubation building and a $30 \times 40$-foot storage building costs approximately $\$ 1500-\$ 2000$ installed. This system can be adapted to turn on yard lights and/or sound a horn alarm. Another device can be added to the above alarm system that starts a recording system that initiates telephone calls in sequence to three employees that live off station, or calls a local law enforcement agency.

Several alarm systems are available that are activated by noise or the proximity of persons or animals, and these activate signal systems such as lights, sirens, horns, or a phone. The costs vary but generally depend on the sophistication of the system. 


\section{Chapter 7}

3. Lights Yard lights are an additional deterent to protect the station property equipment and adult fish. Mercury vapor yard lights set with daylight-dark controls, or with a timer, provide adequate night visibility. Additional mercury vapor lights, or spot lights activated by the alarm systems mentioned earlier, can be a further deterent to prowlers. The local power company can provide costs for these units.

4. Guards Watchman can be used in place of security and alarm devices, particularly to protect brood stock, but they require special equipment such as spot lights, a look-out shed, phones, proximity alarms, and sometimes dogs. \& good guard dog, particularly within a fenced station, can be an effective deterrent to intruders.

\section{JUVENILE FISH SECURITY}

The concentration of fish in hatchery ponds is a natural attraction for both birds and ma mals. Those birds most damaging to juvenile fish include the mergansers, gulls, terns, and herons. Other birds likely to cause damage are diving ducks, kingfishers, grebes, and cormorants. Damage from loons, water ouzels, ospreys and others is less common. Fish-eating birds can consume fish at a daily rate of $50 \%$ of their body weight. It is not uncommon to lose over $30 \%$ of the fish population from a large rearing pond during the winter months. Alexander, (19:i) estimated that American mergansers eat 1.03 pounds daily when feeding in natural streams. At that rate ten mergansers would have the ability to devour 3,600 2-inch fish at 350/1b per day or 108,000 fish per month. llink normally avoid hatcheries, but land otter can be a problem. The average consumption rate for an adult male otter is 3 lb.'day (.llissett and Parker, 1983).

Permits are not required to scare or mechanically deter predatory birds and inxmmals. With few exceptions, a permit to kill birds must be issued by the USF W. Permits are issued only after one can demonstrate a potential for serious damage. Regulations in eastern Washington and Idaho prohibit otter trapping: however, licensed trappers have a season in western Washington and most of Oregon.

rontrol measures for bird and mammal predators include canopies and covers, fencing, overhead lines, scare and kill devices, or some combination of these. The measures selected will depend upon predator species, type of facility, ant! the work practices of $\therefore$ tition employees.

1. Canopies and Covers A complete enclosure, including A fence and overherd canopy, eliminates all predator problems. This may only be practical, however, ior srnall ponds. Enclosing a $100 \mathrm{ft}^{2}$ rearing area costs approximitely $\$ 10-15.0011$. Generally, an enclosure or canopy should allow access to the rearng areg for routine siaintenance, and must also be sufficiently sturdy to withstand an accuratation of leaves, or snow and ice. The canopy top is made of 2 - or 3-inch wire mesh. For less permanent installations, bird netting can be used (Fig. 5). To support the more permanent cover, strong support posts must be provided.

1 pond-level cover installed 1 to 4 feet above the wuter is un effective control and costs much less. Although direct access to the fish is nore difficult than with elevated canopies, fewer problems with ground maintenunce and snow and ice are 
encountered. The configuration of the pond determines the design of the pond-level canopy. A pond which is $80 \times 270$ feet $(1 / 2$ acre) requires a $1 / 4$-inch stainless steel cable anchored and stretched lengthwise along the centerline of the pond 3 to 5 feet above the water. This cable may require intermediate post supports in several places along its length. A small boat-winch is used to maintain tension on the center line to provide a taut ridge or to lower it into the water in case of snow.

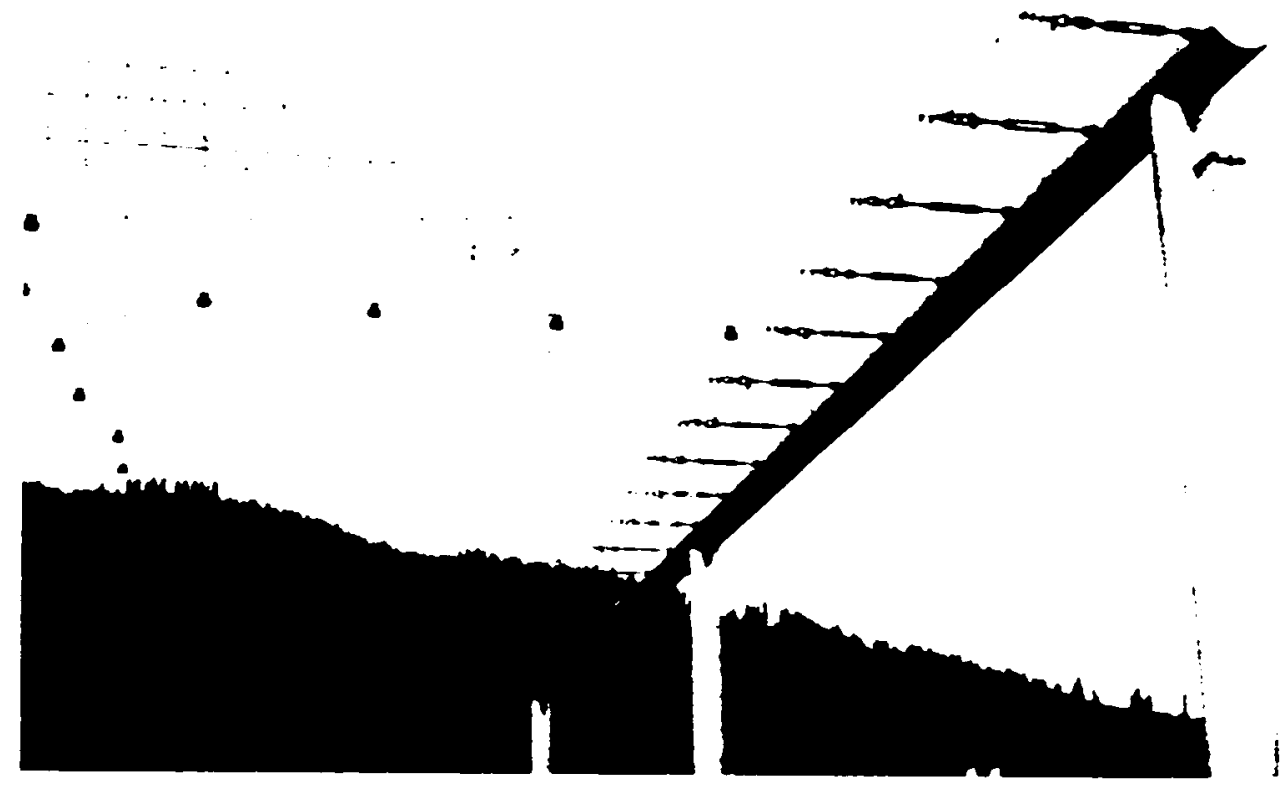

Figure 5. Permanent canopy using netting for predatory bird control at the Dworshak National Fish Hatchery (USFWS).

Steel posts 3-to 4-feet long are driven into the ground around the pond at lo-foot intervals. These should be located 1 foot above the water level but lower than the center line. Braided polyline is attached to each post and stretched across the pond and over the center line to form support for the net. S-shaped hooks are used for connectors (Hager, 198 1). Strips of netting are placed across the pond and then fastened with the "S" hooks to the cross lines. Managers often leave one section loosely attached so employees can work under the netting. Fig. 6 shows a pond-level canopy on a narrow pond without the centerline wire.

The estimated total material cost in 1984 for covering a 1 -acre pond is $\$ 2,500$, and a $1 / 2$-acre pond cover costs about $\$ 1,500$. The life of the netting and string is approximately four years. The netting cost for a l-acre pond is estimated at $\$ 700$ and the braided polyline at $\$ 900$ (Atkins and Kramer, 1979). Managers frequently cover concrete ponds by laying netting across the top of the pond walls. This is effective and the only cost involved is for the netting; about $\$ 0.02 / \mathrm{ft}^{2}$. 
Chapter 7

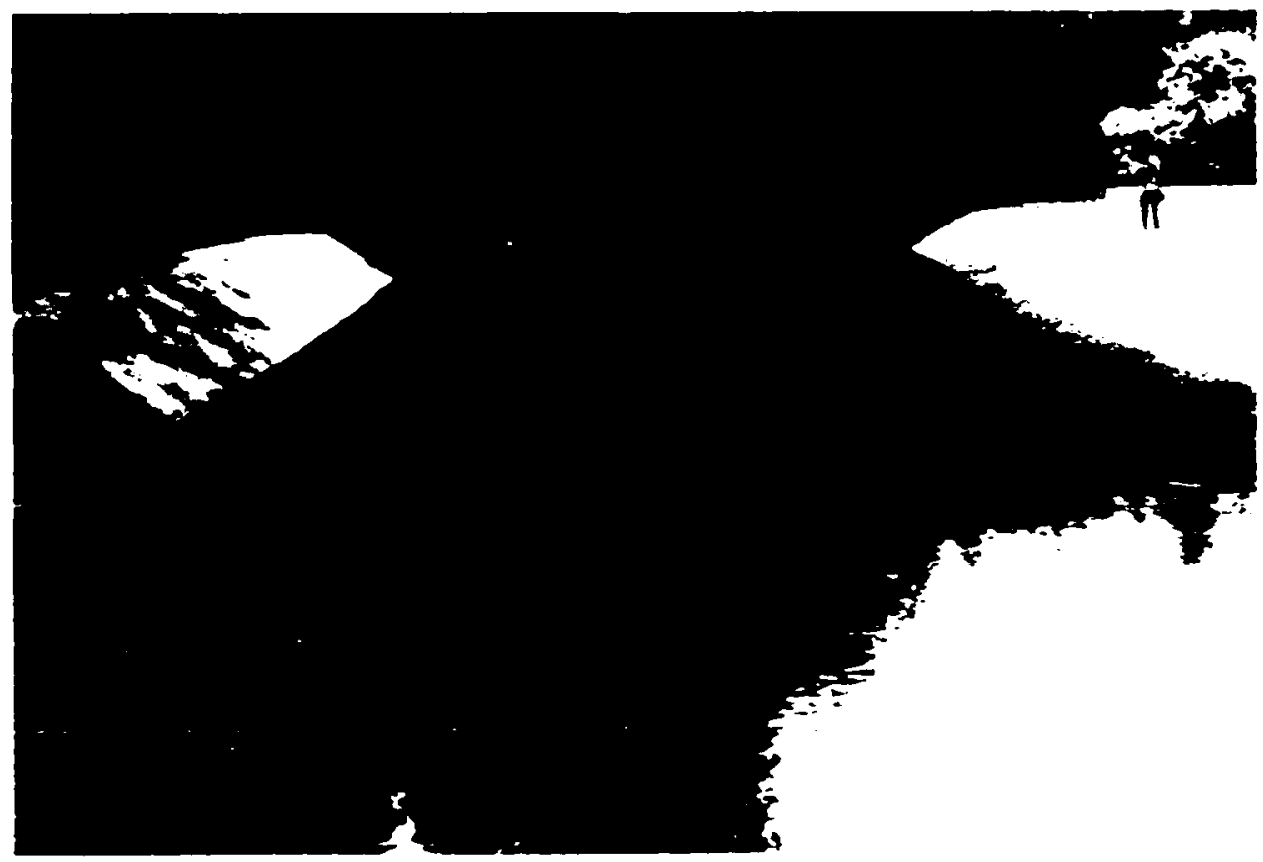

Figure 6. A pond-level canopy without the centerline wire support at the Elokomin Salmon Hatchery (WDF).

The mesh size of bird netting varies from $1 / 16$ to 5 inches, however, a mesh size of 5/8- to 3/4-inch is generally preferred. This size comes in 14- and 17-foot widths and can be ordered in 100-foot lengths or rolls 100- to 5,000-feet long at a cost of approximately $\$ 0.015 / \mathrm{ft}^{2}$. Some birds have been observed to land on 5-inch square netting and wriggle through. One of the biggest advantages of the smaller mesh is that herons find it very difficult to sit on the net and pick fish through the small openings.

\section{Information Sources:}

All Northwest fishery agencies have experience in the use of netting

Internet, Inc.

Memphis Net and Twine Co.

Glitsch, Inc.

Wildlife Control Technology

2. Fencing Various kinds of fences are effective and commonly used to discourage small mammals and wading birds. A perimeter electric fence is very effective for otter, and under certain conditions, wading birds. A 5-acre pond has been fenced at the WDG Cowlitz Trout Hatchery and is reported to work well in controlling the Great Blue Heron. OFW has also controlled heron with electric fences. A single-wire electric fence is often sufficient, but managers usually install two or three wires, one of which serves as a ground (Fig. 7). The cost of an electric fence for a 1-acre pond, including labor, will approximate $\$ 500$ as based on a fence installed at the Tulalip Tribal Hatchery. 
A 30-inch high chicken-wire or plastic-mesh fence is also effective for wading birds when set inside the perimeter of the pond at a water depth of about 1 foot or more (Fig. 8). This combination prevents the wading birds from fishing in the pond.

3. Stringers Stringers or lines set at 2- to 4-foot intervals across a pond either overhead or at pond level, are commonly used. An overhead line system at the IFG Hagerman Fish Hatchery uses wire stringers and requires heavy metal poles and braces for support (Fig. 9). Note the springs (Fig. 10) used to keep the wires taut.

Pond-level lines of synthetic materials are most common. Clear nylon monofiliment fishing line is very inexpensive and used at some hatcheries. Because it deteriorates rapidly in sunlight it has only a one- or two-year life expectancy. Dark-colored materials have a longer life (Fig. 11). Red colored braided polyline is used at the WDF Elokomin Salmon Hatchery (Fig. 12) and is expected to last five or six years. Here the lines are attached to short steel posts and elevated upward from the side of the pond to form a canopy. The cost to cover a 1/2-acre pond using this material would approximate $\$ 1000$.

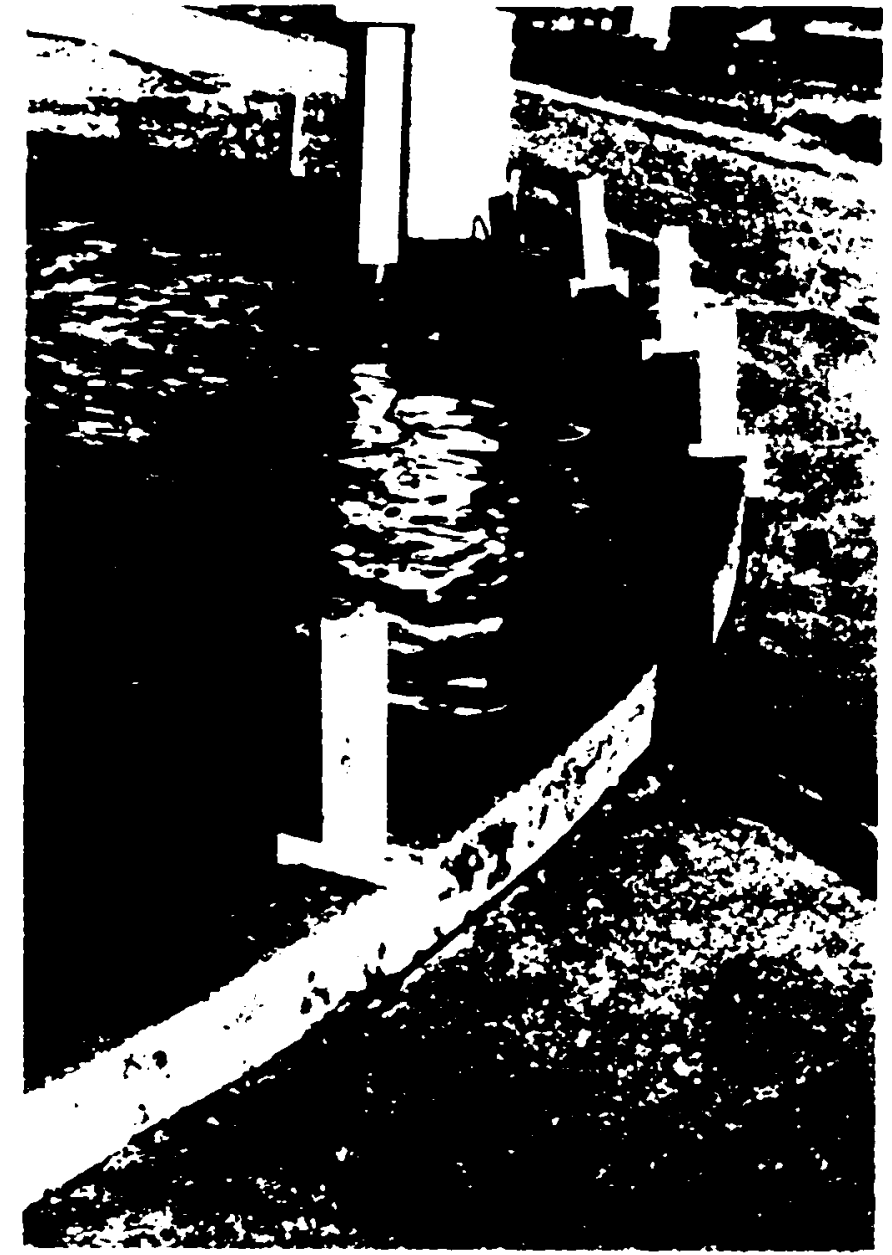

Figure 7. A three-wire electric fence at the Shelton Trout Hatchery (WDG).

A stringer system will deter American mergansers, gulls, and terns, but is not effective with hooded merganser, kingfishers, diving and dabbling ducks, crows, or other miscellaneous small birds.

4. Scare Devices The best scare device is a fish worker; however, for small installations the workers continual presence may not be economically feasible. Therefore, mechanical scare devices are sometimes used. For any scare device to be effective, the predator population should be harassed before they become accustomed to pond feeding. It has not been demonstrated that mechanical scare devices, without the presence of a person, will consistently keep predation under satisfactory control. But these devices, on occasion, may do an adequate job. 


\section{Chapter 7}

Fig. 13 illustrates a flashing colored-light system used at the OF W Big Creek Fish Hatchery. Although various intensities of lights were tried, night-feeding birds become accustomed to their long-term use.

Fig. $\quad 14$ shows an automatic exploder. This device, recently tested at the Dworkshak NFH, and in the 1960's at fish farms operated by WDF, was described as temporarily beneficial by the users. The automatic exploder is controlled by a timer and uses propane or acetylene to power the loud shotgun-like explosion. Used in combination with other techniques, it can be partially effective and would be recommended for intermittent use on large rearing ponds.

Shells that are propelled into the air and explode with a loud noise are also effective for short durations. Cracker shells are available for shotguns; however, if the shells go off in the water, fish can be killed. They can also be potentially dangerous to the culturist if the wad remains in the barrel. Noise-bombs and whistle bombs are available for flare pistols of several sizes. The noise from a shotgun blast can also be helpful.

It should be recognized that loud

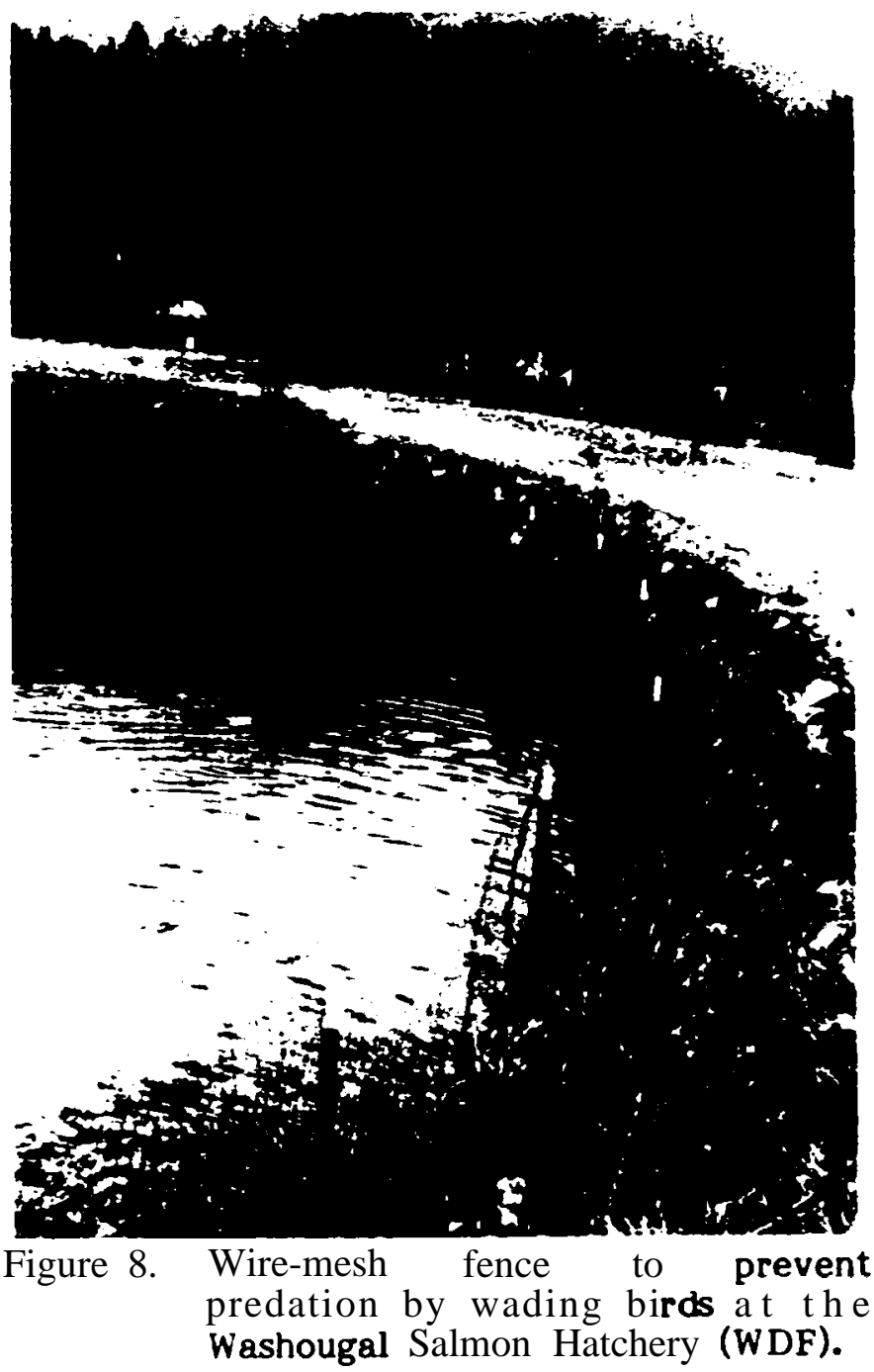

noise devices can become an irritant to nearby neighbors, particularly if used during night or early morning hours. Water sprays, high frequency sound, bird distress calls, scare crows, bird kites, and balloons are other lesser important devices that have a temporary beneficial effect.

5. Kill Devices Firearms, particularly the shotgun, are the most effective devices for destroying predators; however, their use has serious safety and regulatory considerations. Few birds need to be killed if feeding habits in hatchery ponds, as noted previously, are not allowed to get started; immediate harrassment is most important. Traps are used for wading birds, kingfishers, and otter. No. 0 and No. 1 singlespring traps are excellent for small and large sitting or wading birds, 
respectively. A No. 3 or No. 4 doublespring trap is generally used for otter. However, trapping should be done only by experienced individuals, and before any traps are used, permits must be obtained from the appropriate regulatory agency.

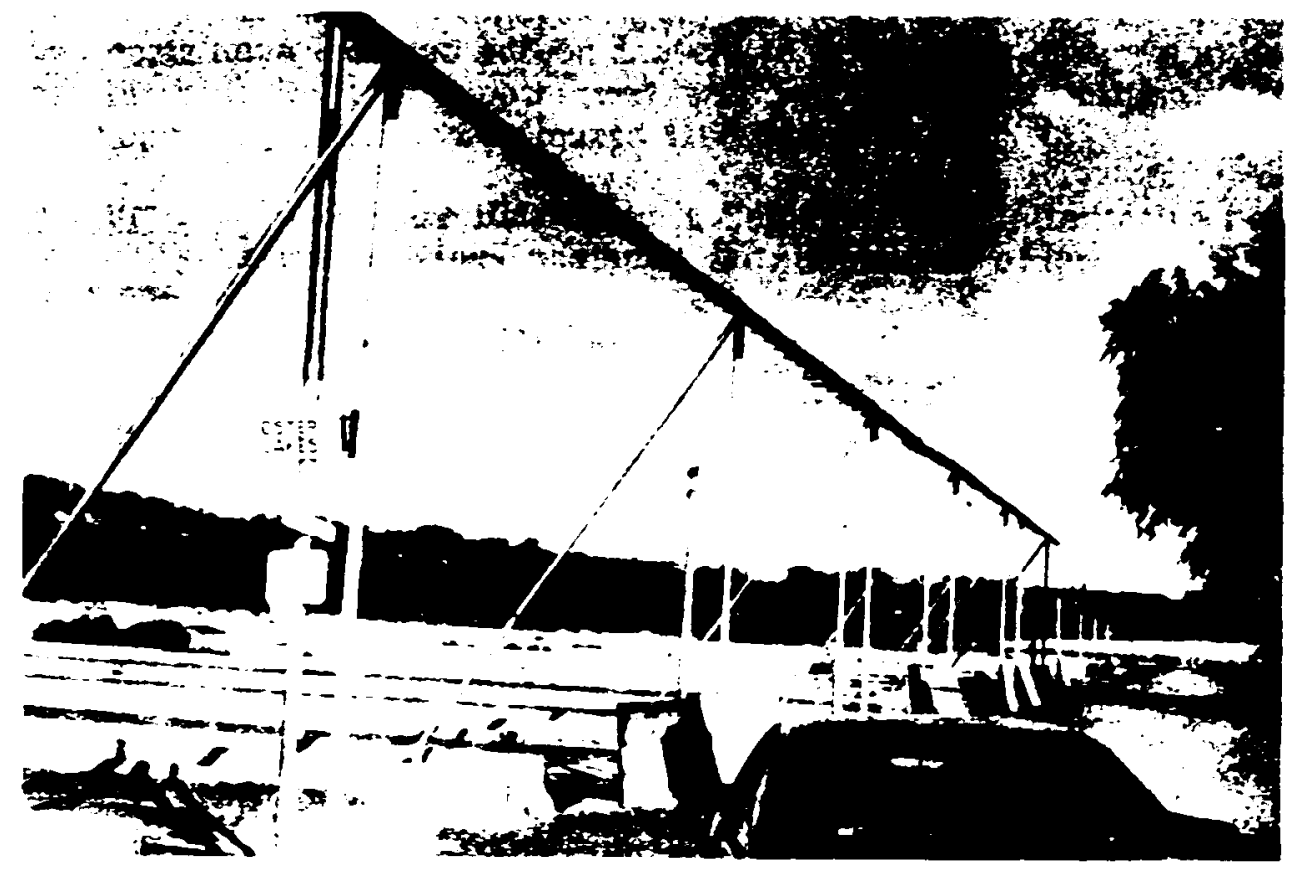

Figure 9. An overhead stringer system for bird control at the Hagerman Fish Hatchery (IFG).

6. Combination A combination of control practices is usually best. For example, the WDF Humptulips Salmon Hatchery manager uses overhead lines on his $1 / \%$-acre pond to deter American merganser. Bird netting is secured to these lines at the pond's edge and stretched over the water 5 or 6 feet to control predation by blue heron. Cracker shells are used to scare the occasional diving duck.

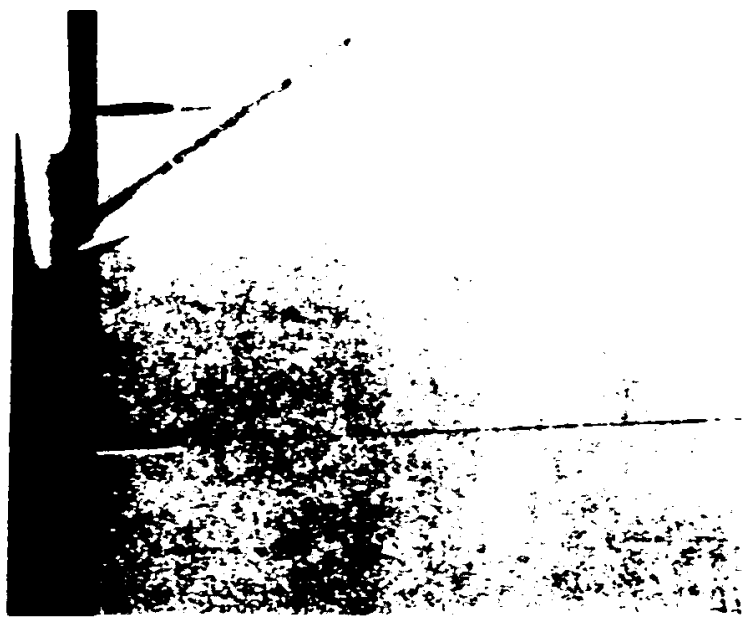

Figure 10. A view from below of the overhead wire stringers in Fig. 7 showing the springs used to keep wires taut. 
Chapter 7

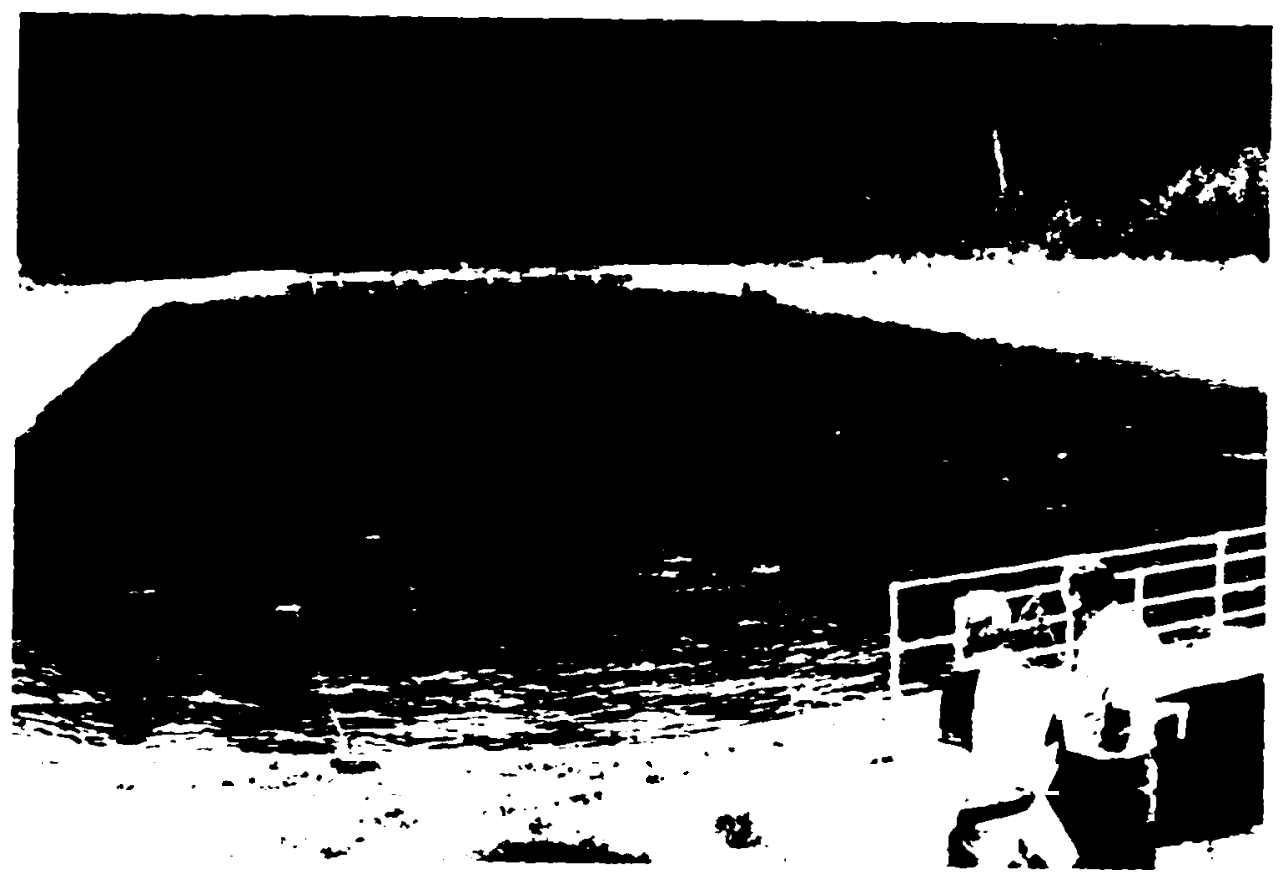

Figure 11. Pond-level stringers to prevent American merganser predation at Klaskanine Fish Hatchery (OFW).

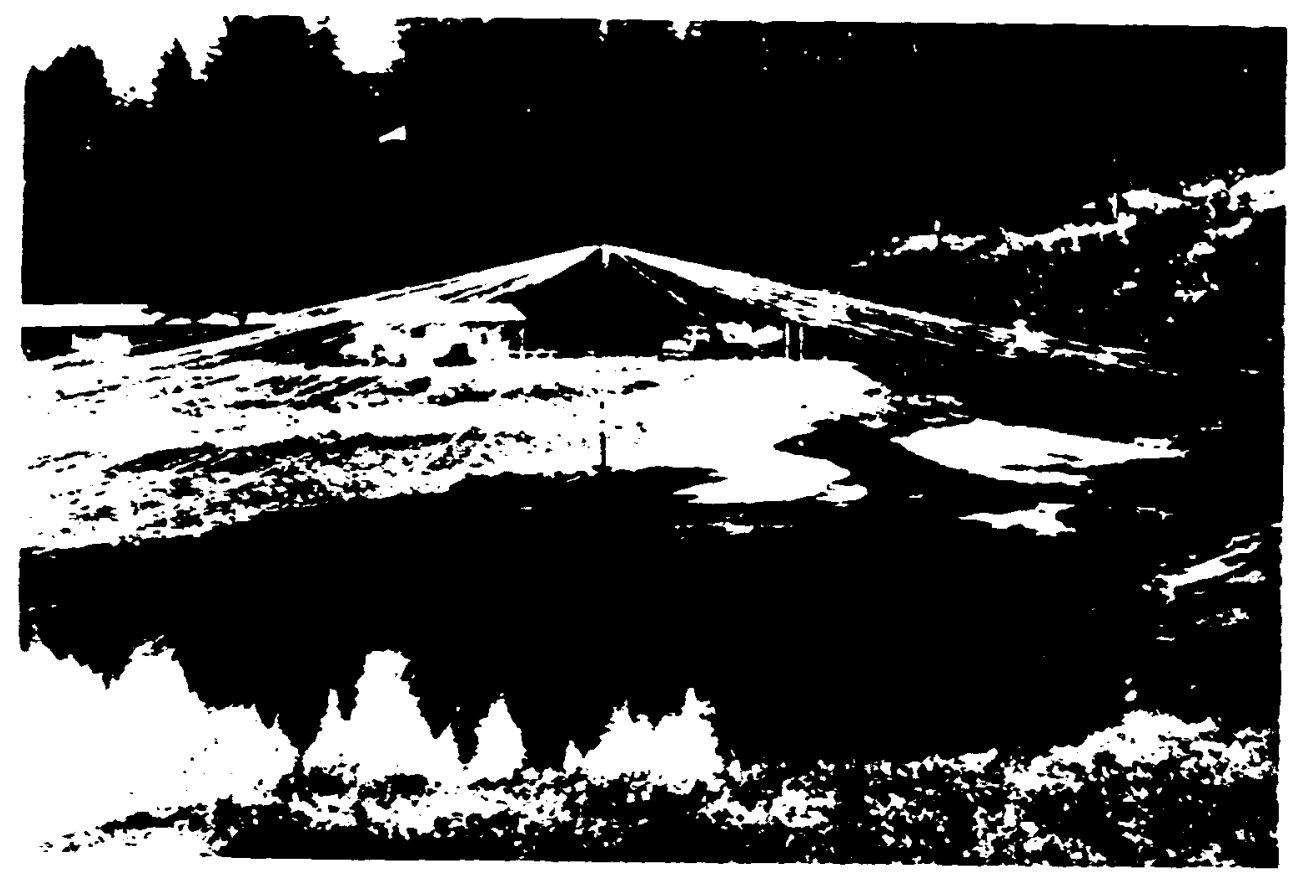

Figure 12. Stringers of red polyline form a canopy to discourage fish predation at the Elokomin Salmon Hatchery (WDF). 


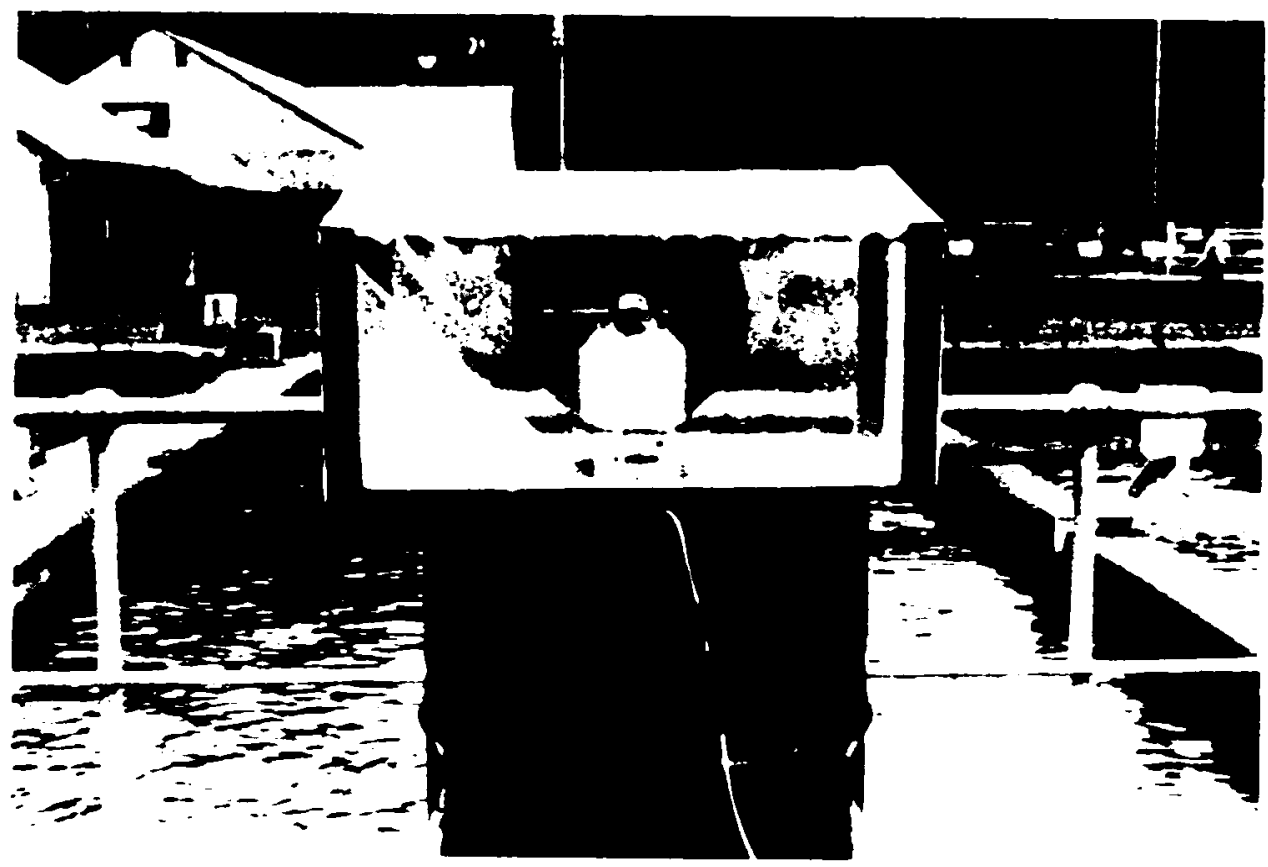

Figure 13. The flashing colored-light setup used to scare fish-eating birds at the Big Creek Fish Hatchery (OFW).

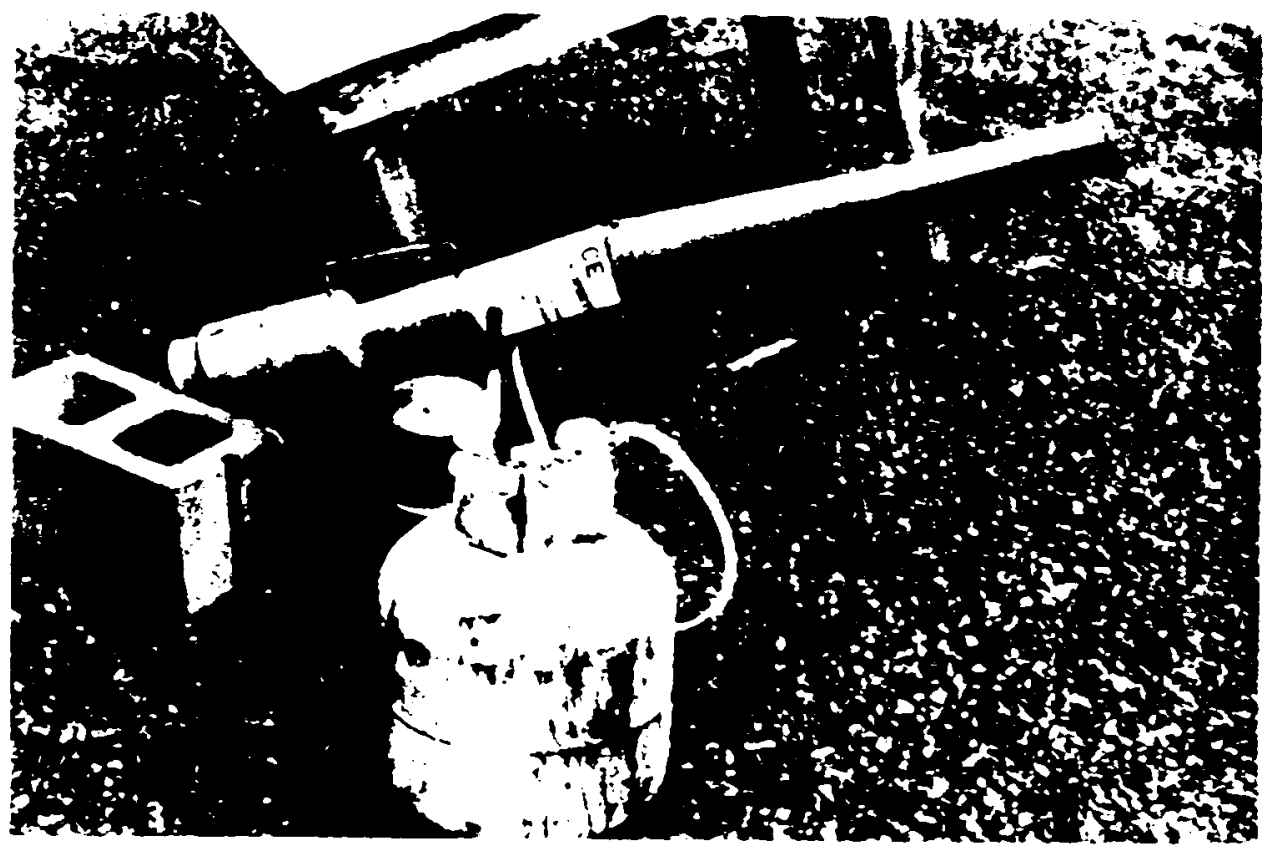

Figure 14. An automatic propane exploder used to scare predatory birds at the Big Creek Fish Hatchery (OFW). 
Chapter 7

\section{PART V. EQUIPMENT LIST}

A necessary part of the fish cultural facility planning process and operation is the equipment. Planners and managers, regardless of the size, cost, or complexity of the station, should not overlook the need for tools and adequate equipment. Most fisheries agencies have developed standard equipment lists for hatcheries (Appendix 4). Although this list includes many items that may not be applicable in a "low-cost facility", it illustrates the type and variety of equipment used in fish cultural operations. Further, the list will serve as a useful shopping guide for developing total project costs. Information sources for many of the smaller items are listed in (Appendix 2). 


\section{CHAPTER 8}

\section{PROJECT SELECTION AND EVALUATION}

In the preceding chapters we have dealt primarily with the technical components that make up a low-cost fish facility such as water requirements of the fish, water delivery systems, adult collection, incubation, and rearing systems, transportation of fish, and production support equipment. In this chapter we deal with some key elements that are necessary to consider in the selection of sites and program alternatives. These include a checklist of mainly site specific factors to be considered, the costs of producing salmonids, personnel skills and salaries, and the use of an economics analysis to evaluate hypothetical hatchery operations and alternatives.

\section{PART I. SITE CONSIDERATIONS}

Table 1 is presented mainly as a checklist to remind the reader of the numerous additional items that should be considered when facility planning begins. Although not listed, we recognize that public relations and political considerations are also real, but comment no further.

Table 1. Considerations in facility site selection.

\section{NATURAL ELEMENTS}

Weather

Flooding

Watershed

Offstation considerations

PHYSICAL SITE

Construction considerations

Land

\section{SUPPORT SERVICES}

Vendors

Tax supported entities
Wind, snow, rain, temperature

Risk factors

Stability, planning program

Migratory obstacles, pollution, predation, diversions

Soil, access, power, remoteness, communications, topography

Ownership, cost, availability, size, future expansion

Access to supplies and materials

Space, rentals, freezers, contract fish rearing.

For labor and equipment exchange, egg and fish transfers, freezer space, security, road repair, etc. 
Chapter 8

AVAILABILITY OF PERSONNEL

Skill required

Temporary help

Volunteer help

Housing

Personnel benefit

LEGAL REQUIREMENTS

MANAGEMENT GOALS
Availability

Availability

Availability

Rental, mobile, on-station, permanent

Schools, hospitals, shopping centers, T.V., safety, etc.

Mitigative, treaty obligations, governmental permit requirements

Are they addressed?

\section{PART IL COST OF SALMONID PRODUCTION}

The cost of producing salmonids is commonly expressed in terms of dollars spent to produce one pound of fish annually. This figure may include (1) the capital cost of the facility, (2) the annual operating cost, or (3) a combination of operating and capital costs. We are presenting the cost of salmonid production using these three categories, and have broken each into its components.

\section{A. CAPITALEXPENDITURES}

The components that make up capital outlays are illustrated in Fig. 1. Construction (75\%) is the largest item, with other costs totalling $25 \%$. Land aquisition coats are not included in the components, but are discussed in detail in Part IV of this chapter. The total capital coat of a hatchery is often expressed in terms of dollars spent to produce a pound of juvenile fish. For example, a $\$ 2$ million hatchery with a 100,000 pound annual production, results in a coat of $\$ 20$ of capital monies for each pound of fish produced annually.

Salmonid stations designed for approximately 100,000 pounds have been constructed for $\$ 20 /$ b while others with similar production programs cost three to four times this amount (1984 dollars). These differences are usually caused by a combination of factors starting with site selection, production unit selection, equipment, the type of program, construction materials, and other considerations such as better facilities for the employees and visitors. In order to assign a portion of the capital cost to the annual production cost we refer you to Part IV of this chapter. Using a simplistic analysis, however, the capital cost of a $\$ 2$ million station pro-rated on an annual basis and producing 100,000 lbs of fish would be $\$ 2.80$ per pound of fish produced, if we used a straight line depreciation of 4\% (25-year life) and assumed an interest rate of $10 \%$ on borrowed monies. 0 \& $\mathrm{M}$ costs are additional. 
Project Selection and Evaluation

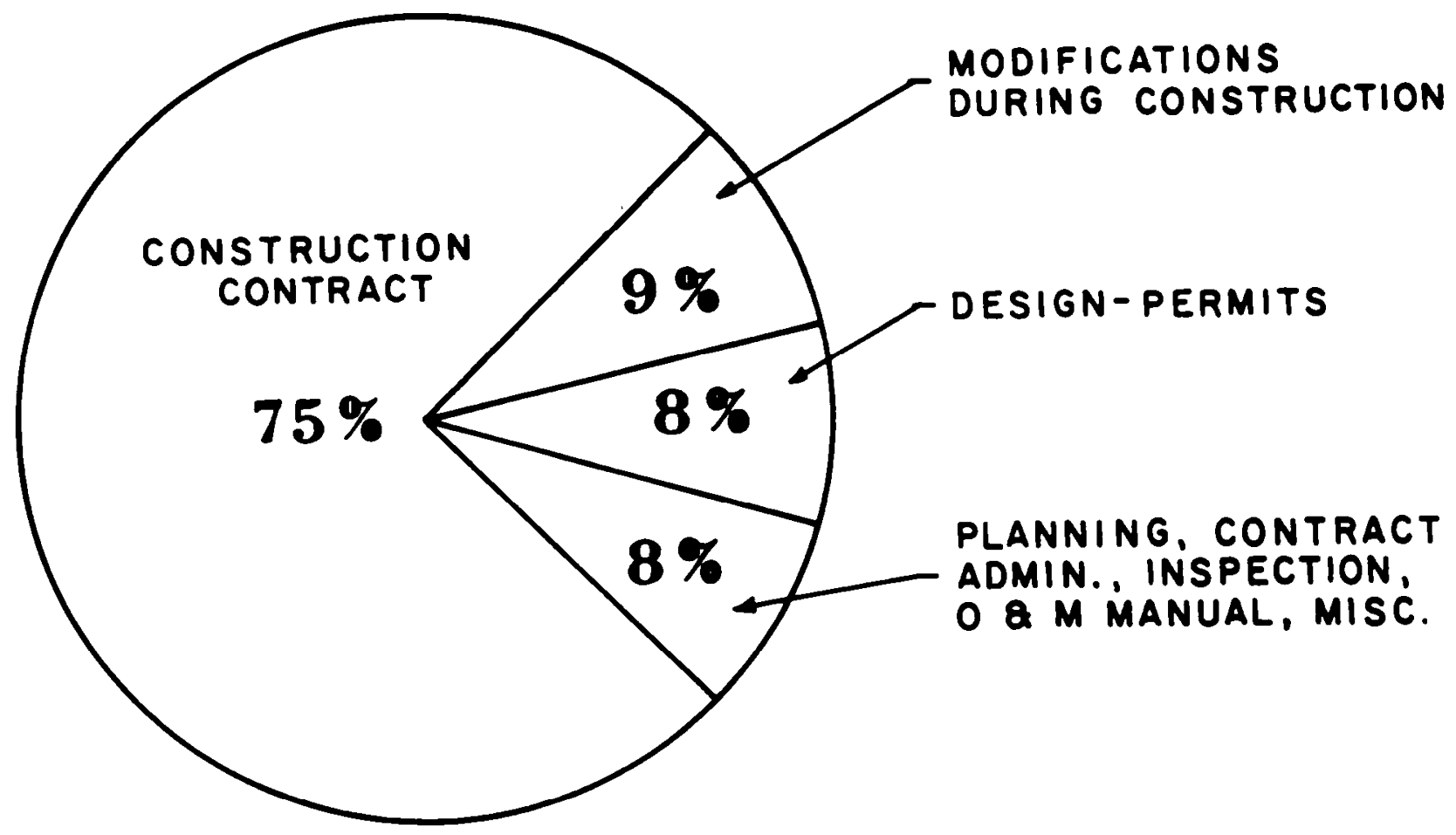

Figure 1. Components of capital expenditures in hatchery construction.

\section{B. OPERATING EXPENDITURES}

When the production at a station is expressed in terms of operating costs, the same measure (fish per pound) is used, and the broad categories are labor, fish food, electrical energy, and miscellaneous supplies.

OFW recently developed an operating budget for fiscal 1984 and 1985 which we believe will be representative of actual costs as conducted at their hatcheries. To illustrate this, we choose hatchery " $\mathbf{A}^{\mathbf{n}}$ with 50 percent pumped water requiring approximately 200 feet of lift (Fig. 2), Hatchery "B" with 100 percent pumped water and requiring 20 feet of lift (Fig. 3); and hatchery "C" is the average of eight hatcheries with gravity flow.

From these illustrations, one can compute the labor and food costs, and readily relate to the added operational outlays if pumps are required to deliver water.

A cost of \$2.52/1b was projected for 1984 for WDF state-funded salmon station\& This figure included agency main office overhead (Flieg, personal communication). During 1983 the cost was $\$ 2.16$ (Table 2) without this overhead included. 
Chapter 8

Hatchery "A"

Total annual cost

Pounds of fish

(50:50 F. chinook, coho)

Cost (fish per pound)

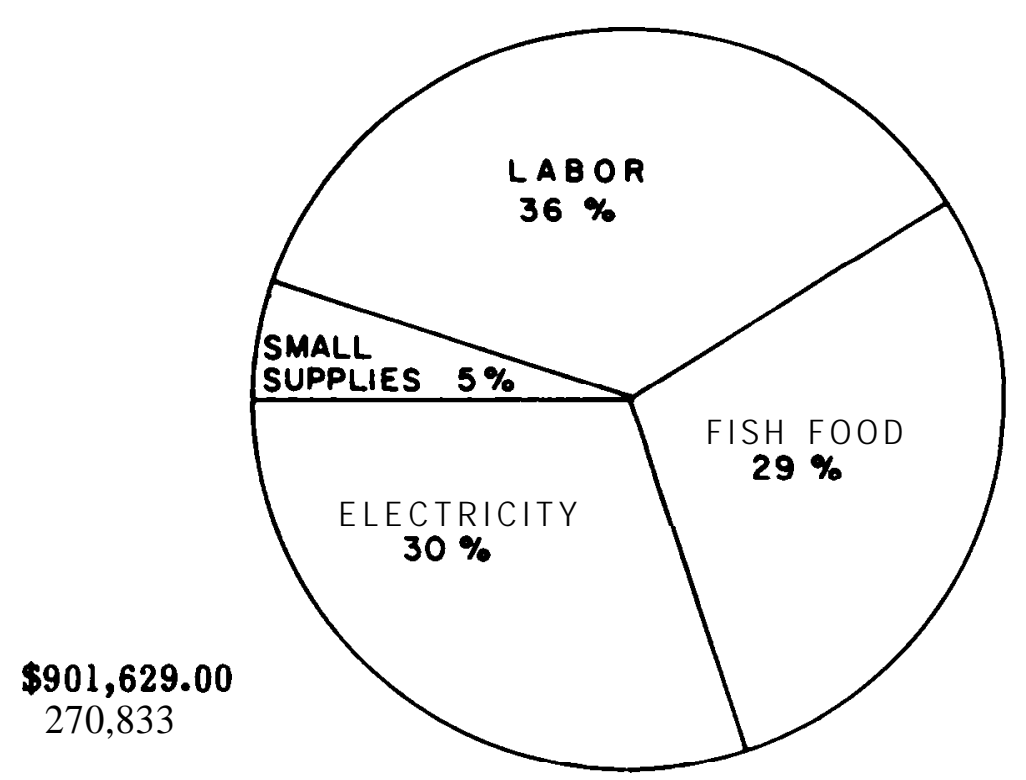

$\$ 3.33$

Figure 2. Composition of the annual operating costs for hatchery "A" (OF W) with 50\% pumped water and $200 \mathrm{ft}$ of lift (average of fiscal 1984 and 1985 budget projections).

Hatchery "B"

Total annual cost

Pounds of fish

(100\% spring chinook)

Cost (fish per pound)
$\$ 280,000.00$ 112,500

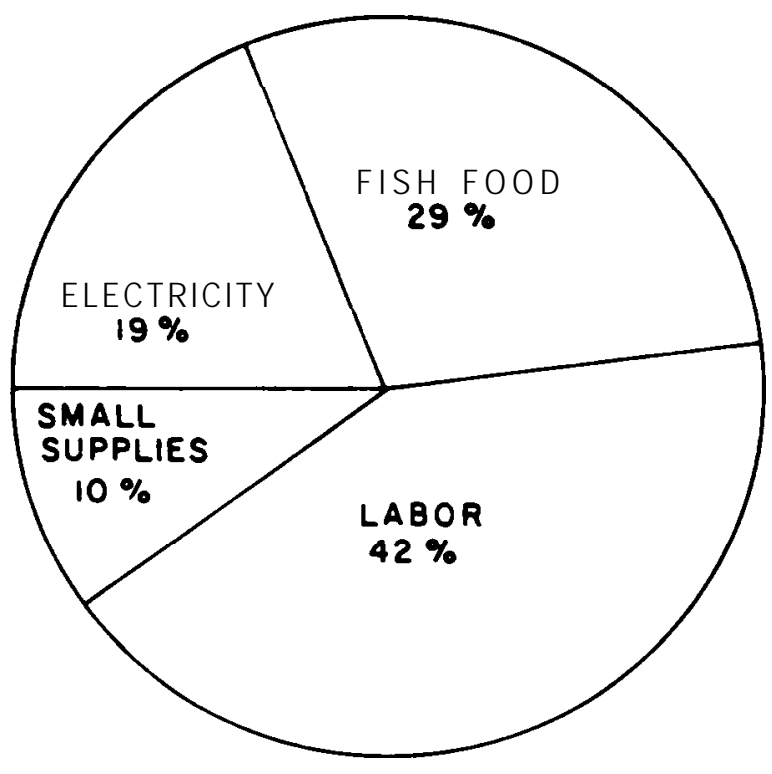

$\$ 2.49$

Figure 3. Composition of the annual operating costs for hatchery "B" (OF W) with $100 \%$ pumped water and $20 \mathrm{ft}$ of lift (average of fiscal 1984 and 1985 budget projections). 
Hatchery "C"

Total annual cost

Pounds of fish

(combination of fall \& spring

chinook, coho, steelhead,

and cutthroat trout)

Cost (fish per pound)

\section{$\$ 2,195,098.00$}

\section{$1,071,535$}

$\$ 2.05$

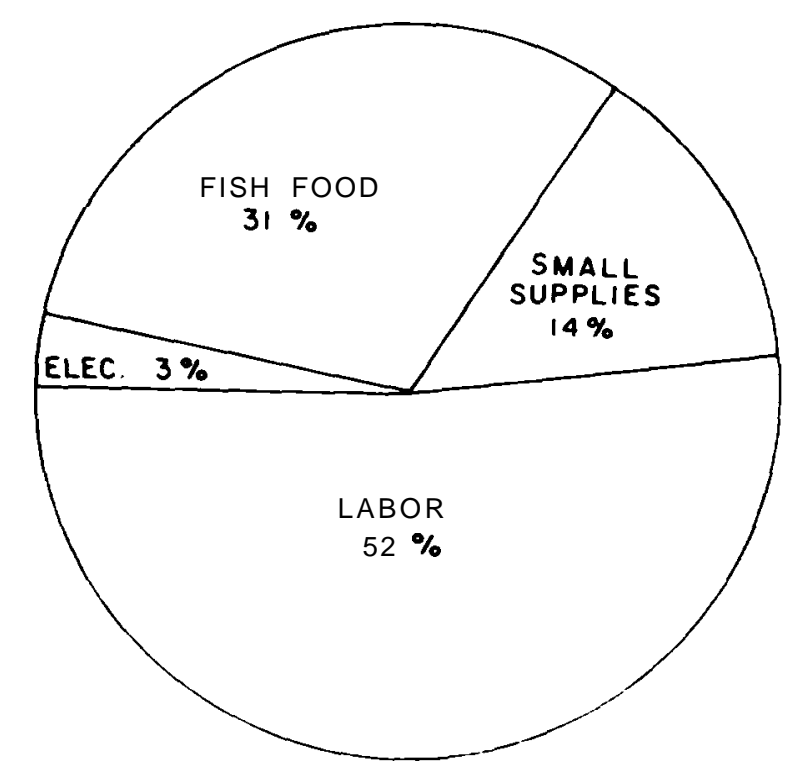

Figure 4. Composition Of the annual operating costs for hatchery " $\mathrm{C}$ " (eight OFW hatcheries) with gravity flow (average of fiscal 1984 and 1985 budget projections).

Table 2. Estimated total cost/lb of producing juvenile salmon at WDF hatcheries in 1983. (From Washington State Senate Natural Resources Committee).(l)

Cost incurred by fish production

For hatchery staff and operations

Maintenance for station repair

Pathology and nutrition

Hatchery supervision and research
$\$ 2.16 / \mathrm{lb}$.

$$
\begin{array}{r}
69 \% \\
13 \% \\
4 \% \\
14 \% \\
\hline 100 \%
\end{array}
$$

(1) Does not include overhead costs of the main office, such as payroll, purchasing, legal support, etc.

While the electrical cost, food cost, and miscellaneous supplies illustrated in Figs. 2, 3, and 4 appear to be self-explanatory, we believe a further analysis of labor costs will aid in facility design and programming. To accomplish this, we selected a study conducted at the WDF Klickitat Salmon Hatchery (Clayton, 1968). During the time of the study, this gravity-supplied, spring-fed station produced $113,701 \mathrm{lbs}$ of salmonids composed of 647,719 spring chinook, 3,716,473 fall chinook, and 1,673,220 coho. Fig. 5 shows the time in hours assigned for (1) paid leave, (2) maintenance, and (3) fish culture; while Table 3 further allots the time spent on maintenance and fish culture (labor). Table 3 also illustrates the typical work tasks conducted, and the hours sperst on each. 


\section{Chapter 8}

We recognize that there can be great variances in work effort, however we believe the level of effort spend at the Klickitat Salmon Hatchery is indicative of many Northwest hatcheries.
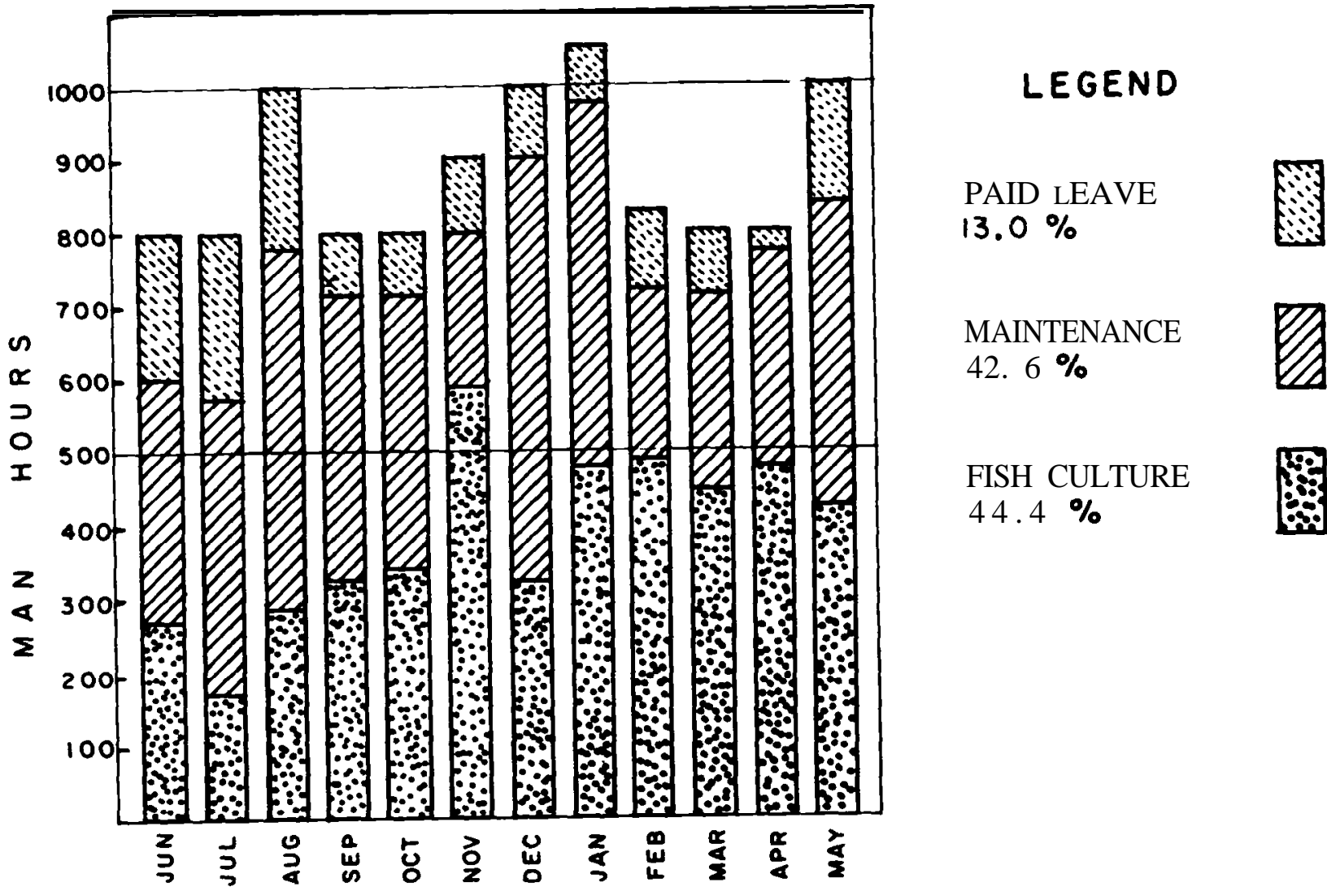

Figure 5. Annual man hours of fish culture, maintenance, and leave by month at the WDF Klickitat Salmon Hatchery. From Clayton, (1968).

The Klickitat Hatchery program did not require security guards for adults nor were all eggs taken at the hatchery. Also, the time employees stand by after working-hours in case of emergency was not included.

In addition to the information in Table 3 we attempted to obtain estimates of time spent on similar specific tasks during our visits to numerous facilities (Appendix 3). We found the answers to be highly variable because of the diversity of the programs and facilities. For example, the normal expected spawning efficiency, or the average numbers of eggs taken by one person in an 8-hour day, ranged from 300,000 - 600,000 for chinook, 200,000 - 400,000 for coho and $150,000-300,000$ for steelhead trout.

During the incubation process, managers generally agreed that egg picking (see Chapter 4) required about half the time spent for egg care. One man could hand-remove in 8 hours 
Project Selection and Evaluation

"all" the dead eggs from a 250,000 shocked egg lot of any species if the losses were in the 5-8 percent range. Heavy egg loss could easily double the time required.

Except for maintenance tasks, the greatest diversity of answers was the hours used per man for the rearing program, and was related to fish size and facility type. We believe that 8 hours of direct daily labor is sufficient to handle 2 million $400 / \mathbf{b}$ fall chinook in ten raceways. These same fish at $\mathbf{1 0} \mathbf{1 b}$ may require 100 raceways and 24 hours of direct attention per day, or one man for 30 raceways. The use of larger rearing units such as 1/2-acre ponds, or large net enclosures would reduce the hours indicated to about one-third.

The average production of juvenile fish per man year of effort at Northwest stations approximates 25,000 lbs (Zook, 1984). While we will tend to use this figure as a guide, most of the prototypes we illustrate are smaller than 25,000 pounds. Also, in our theoretical prototype designs of $\mathbf{5 0 , 0 0 0 - 1 b}$ stations (Chapter 9), we will emphasis smaller but more numerous lots to illustrate a management program to maintain genetic integrity.

Table 3. Annual man hours for fish culture and maintenance activities by the hatchery culturists at the WDF Klickitat Salmon Hatchery. From Clayton, (1968).

\begin{tabular}{lclc} 
Fish culture & Hours & Maintenance & Hours \\
\cline { 2 - 4 } Feed fish & 1325 & Pickup supplies & 772 \\
Transfer/plant fish & 559 & Clerical & 741 \\
Clean/disinfect ponds & 447 & Equipment building & 537 \\
Pick eggs & 407 & Equipment repair & 462 \\
Pick fish & 379 & Miscellaneous & 334 \\
Clerical & 371 & Clean/maintain grounds & 317 \\
Miscellaneous & 263 & Training school & 236 \\
Sample fish & 200 & Snow removal & 175 \\
Spawn fish & 174 & Service equipment & 153 \\
Size fish & 148 & Lawn mowing and care & 134 \\
Clean troughs/trays & 125 & Repair screens & 93 \\
Treat fish & 100 & Road maintenance & 81 \\
Pick fry & 100 & Clean buildings & 75 \\
Fish trap & 60 & Public relations & 70 \\
Unload feed & 43 & Painting & 43 \\
Check intakes & 31 & Repair buildings & 42 \\
Mark fish & 25 & Repair ponds & 36 \\
Treat eggs & 20 & Clean equipment & 27 \\
Total & & Total & 25 \\
\hline
\end{tabular}

\section{c. CAPITAL AND OPERATING EXPENDITURES}

Based on the most current information available from agency projected budgets and recent budget experiences, we believe that the total combined average cost of both capital and operating expenditures to produce a pound of juvenile fish at Northwest 


\section{Chapter 8}

hatcheries will range between $\$ 4.50$ and $\$ 6$. We recognize that this cost will vary with the program, the assignment of interest and depreciation rates on the structure, the efficiency of personnel, the station's electrical energy requirement and numerous other variables.

In the private sector, we find slightly lower cost quoted to FMC by the management of Swecker Salmon Farm (personal communication). Mr. Swecker quoted a price of $\$ \mathbf{3 3 . 0 0 / \mathbf { b }}$ for $\mathbf{1 0 / 1 b}$ fish and $\$ \mathbf{4 . 0 0 / 1 b}$ for $\mathbf{8 0 / 1 b}$ fish, such as fall chinook. All prices were based on eyed eggs being provided free, and included compensation for property and business taxes not required of agencies.

The price quotation by Mr. Swecker shows that for a given species, to purchase a pound of small fish costs considerably more than a pound of large fish. A similar pricesize contrast shows in the quotations presented to FMC by Mr. Russ McLeary of Troutlodge, Tacoma, WA for relatively small lots (5,000 fish). His prices were \$42, \$6.67, and \$2.15 per pound for rainbow trout at the respective sizes of 400, 30, and $5.5 \mathrm{fish} / \mathrm{lb}$. The above price quotations demonstrate that the cost of buying a pound of fish from a private grower is less for large fish than smaller sizes. It is important to understand this difference when evaluating production and capital cost for tribal and agency hatcheries.

\section{PART III. PERSONNEL SKILLS AND SALARIES}

Work in salmon and steelhead trout hatcheries has been standardized over the years so that the work performed is similar wherever the hatchery is located. As a result, job descriptions used by the Northwest fishery agencies listing typical responsibilities' and the knowledge and abilities required are very similar. Therefore, we have included copies of IFG job descriptions for the Culturist and Superintendents I and II in Appendix 5.

The major differences we noticed in the agencies' minimum qualifications were in the amount of education required and the length of time "in grade". The USFWS was the most demanding in its minimum education requirement. Idaho Fish and Game, with a very practical stance, required only that the individual demonstrate competence for the assigned task. Competence being based on any combination of education, training, experience, and ability to manage, if required. No level for educational achievement is specified, but they recognize it as an asset (Dick, personal communication). Probationary periods range from 6 to 12 months. As to differences in the "in grade" requirement, IFG does not require a minimum length of time at a particular level before advancing to a higher grade. However, OFW, WDG, and WDF all require a specific "time in grade" before becoming eligible for promotion to the next level.

We believe that the minimum requirement for the superintendent level position at hatcheries with production ranging between 10,000 to 50,000 pounds, should be one full year of experience as a culturist, or first level superintendent, at a "comparable" station. The "comparable" station to include similar species spawned, incubated, and reared; comparable types of production units and equipment; similar water delivery systems; and comparable production levels. 
Project Selection and Evaluation

The knowledge and skills required for the superintendent's assistant at stations with production from 10,000 to 50,000 pounds is described under a Culturist or Superintendent I in the job descriptions in Appendix 5. Again, we feel that these adequately describe the skills and knowledge required, and the minimum qualifications are satisfactory. For laborers, part-time assistants, and volunteer workers, Northwest agencies do not require fish culture experience.

The accompanying table is an example of approximate 1984 monthly salary levels for hatchery personnel who would be required for the low-cost facilities recommended by this report. Although these data are from WDF, they are reasonably typical of salaries and benefits paid by Northwest regulatory agencies. The column showing the total monthly salary (salary plus benefits) will serve as a guide for estimating labor costs. Other factors to be allowed for are: starting pay, overtime, and paid leave. According to Clayton, (1968), annual leave time at the WDF Klickitat Salmon Hatchery amounted to I3 percent of the workers yearly salary. Standby pay policies vary between agencies and is granted workers for being available onstation in case an emergency situation develops. This duty is usually divided up among the employees living on station so that the station is attended 24 hours each day when fish are on the station. To cover this cost, we have arbitrarily used $10 \%$ of monthly salary of the manager (including benefits) wherever we have applied it.

Tuble 4. Salaries for various nutchery classes. All figures shown have been rounded to some extent. Source: Washington State Department of Fisheries.

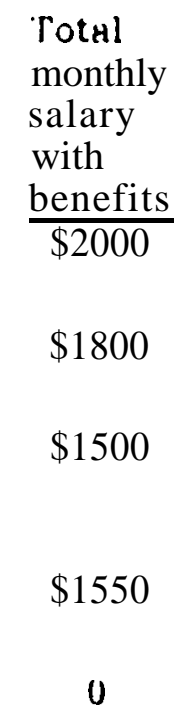

\begin{tabular}{|c|c|c|c|c|}
\hline Job class & Duty & $\begin{array}{ll}\text { salary } & \text { monthly } \\
\text { range } & \text { salary }\end{array}$ & Benefits(1) & $\begin{array}{l}\text { With } \\
\text { benefits }\end{array}$ \\
\hline Super in tenden $t 2$ & $\begin{array}{l}\text { Manages } 20-50,00 n \\
\text { lb. capacity station }\end{array}$ & $\$ 1 \overline{4001-1} 800 \$ \overline{1600}$ & $\$ 368$ & $\$ 2000$ \\
\hline
\end{tabular}

\begin{tabular}{|c|c|c|c|c|c|}
\hline Superintendent 1 & $\begin{array}{l}\text { Manages } 10-20,000 \\
\text { lb. capacity station }\end{array}$ & $\$ 1300-1650$ & $\$ 1475$ & $\$ 339$ & $\$ 1800$ \\
\hline Culturist & $\begin{array}{l}\text { Assistant to } \\
\text { Superintendents } \\
1 \text { and } 2\end{array}$ & $\$ 1000-1450$ & $\$ 1225$ & $\$ 283$ & $\$ 1500$ \\
\hline Laborer & $\begin{array}{l}\text { Labor duties and } \\
\text { security }\end{array}$ & $\$ 1200-1350$ & $\$ 1275$ & $\$ 293$ & $\$ 1550$ \\
\hline Volunteer $(2)$ & As directed & 0 & 0 & 0 & 0 \\
\hline
\end{tabular}

(1) Benefits calculated at $23 \%$ of monthly salary. Includes life and health insurance, retirement and OASI. For part-time workers, the benefits are 14\%. Also $\boldsymbol{A}$ benefit, but not included is standby pay which, when it is required, is added at the rate of $10 \%$ monthly salary including benefits.

(2) Volunteer helpers receive no salary, but agency pays for Industrial Insurance to protect worker in case of injury at rate of $\$ 0.056 / \mathbf{h r}$. 


\section{Chapter 8}

Salmon and steelhead trout rearing programs, staffed with volunteer help, have a long and generally successful record in the Pacific Northwest. Many of these programs are extremely helpful in educating the public to the importance of habitat for fish, and they can reduce the cost of production. Volunteer projects have been formalized in Oregon and British Columbia, while a less formal arrangement exists in Washington State.

The volunteer programs are not without problems, but most negative results, especially in public relations, can be avoided by a carefully planned operation. In talking with agency personnel, we concluded that volunteer projects should be:

(1) of a duration not to tire the volunteer; generally a short program with a clear beginning and ending.

(2) educational to the volunteer.

(3) a relatively pleasant task.

(4) meaningful to the enhancement of fish.

(5) one that allows participation by many members of an organization, not just one or two.

(6) a project with well-defined lines of communications that are maintained.

If the above guides are followed, the program will likely bring satisfaction to all parties involved.

To summarize the personnel requirements for stations where adults are captured and spawned, eggs and alevins incubated, and fish reared and released, we recommend the following:

For a station under 20,000-pound production:

Superintendent 1

Culturist as required

For a station of $\mathbf{2 0 - 5 0 , 0 0 0 - p o u n d ~ p r o d u c t i o n : ~}$

Superintendent 2

1 Culturist

Culturist or Laborer as required (full-time or as required)

(part-time) (full-time)

(full-time or as required)

(part-time)

\section{PART IV. HATCHERY EVALUATION AND SELECTION}

For decades, the value of salmon and steelhead trout hatcheries has been debated and millions of dollars in research funds spent in efforts to provide a proper evaluation. Often this work has been done after the facility was built, when there was no turning back. We 
Project Selection and Evaluation

believe, that given the state of the art of fish culture and fishery management, and the array of modern equipment available, we can start an evaluation of a facility before hard commitments are made; this will allow us to select the best alternatives possible based on a cost-benefit analysis.

The following material was prepared under contract with FMC by Stephen B. Mathews, PhD., University of Washington, Seattle, WA. Dr. Mathews discusses the economists long established Present Value Theory and proceeds to apply this to evaluate potential hatchery subcomponents, such as incubation and rearing systems. He also covers the estimation of expected values of production given some set of components, and where two projects have similar efficiency ratios, provides a sunk cost analysis to assist in a final selection. Finally, Dr. Mathews evaluates six hypothetical hatchery operations with varying production goals, and dollar costs that range broadly from high to low.

\section{A. PRESENT VALUE THEORY AND EXAMPLES}

Present Value Theory has been developed by economists to evaluate and choose among alternative potential strategies for achieving common goals for both private business and government funded projects. So far, such theory has not been utilized for evaluating potential hatchery projects that might be built. There are many ways to achieve similar ends with hatchery projects. Several alternative projects with similar production potentials (quantities of smolts that can be raised) may differ vastly in terms of capital cost, project life, or yearly operating costs. To put several projects in terms of a common denominator, Present Value Theory provides a logical and time tested framework.

The fundamental concept behind this theory is that a unit of cost incurred at some time, $\mathrm{n}$, in the future can be related to the present by a discounting factor, $\$ 1 /(1+r)^{n}$. The term $\mathbf{r}$ is the discounting rate, or what economists sometimes call the marginal time preference rate. This rate measures the indifference of an individual to incurring a unit of cost a year from now versus some cost at present, or to receiving a unit of benefit a year from now versus some benefit at present. Commonly, the discount rate, $\mathbf{r}$, is considered to be the prevailing rate of interest for lending and borrowing since, if an individual chooses to wait a year before making a unit cost purchase, be would need to invest (not spend) only $1 /(1+r)$ today, and that amount would be worth 1 unit in a year at $\mathbf{r}$ rate of interest; if he chooses to wait 2 years to make a unit cost purchase, be could invest $1 /(1+r)^{2}$ today which would grow to a unit value in 2 years. Thus, generally, a unit cost $n$ years in the future has a present value of $1 /(1+r)^{n}$.

The same logic applies to future income benefits received. An individual would be indifferent to receiving a unit value $n$ years in the future as receiving $1 /(1+r)^{n}$ today, since he could invest the latter amount today and it would grow to 1 unit in $n$ years.

The term,

$$
V_{n, r}=\frac{1}{(1+r)} n
$$

is the discount factor to apply to any amount of cost or revenue accruing from a project $n$ years in the future in order to place a present value on such an expenditure or benefit. 


\section{Chapter 8}

Thus, if an annual operating cost of $\mathrm{C}$ were to be incurred for a hatchery $\mathrm{n}$ years in the future, the present value of this cost (P.V.) would be

$$
\text { P.V. }=\frac{C}{(1+r)^{n}}
$$

Similarly, the present value of some future amount of revenue, $\mathbf{B}$, to be received in $n$ years would be

$$
\text { P.V. }=\frac{B}{(1+r)^{n}}
$$

If there is to be a continuing stream over $n$ years of some constant cost (or benefit) resulting from a project, the present value of this sum of costs (or benefits) for years 1, 2, $3,-, \mathrm{n}$ would be:

$$
\begin{aligned}
& \text { P.V. }=\frac{c}{(1+\Gamma)}^{+}{\frac{c}{(1+\Gamma)^{2}}}^{+}-+\frac{c}{(1+\Gamma)^{n}} \\
& =C\left[\begin{array}{ll}
\mathbf{n} & \\
\sum_{\mathbf{j}=1} & \frac{1}{(\mathbf{I}+\mathbf{r})} \mathbf{i}
\end{array}\right]
\end{aligned}
$$

where $\mathrm{C}$ is the annual cost (or benefit) amount.

Economists call the term in brackets in the above expression the annuity factor, $\mathbf{A}_{\mathbf{n}, \mathbf{r}}$. Tables are available in many economics, engineering or financial reference books for both $\mathrm{v}_{\mathrm{n}, \mathbf{r}}$ and $\mathbf{A}_{\mathrm{n}, \mathbf{r} \cdot}$

One other concept, a hybrid of the above concepts, needs to be explained. Consider a stream of benefits $=\mathrm{B}$, that will not start for $\mathrm{m}$ years in the future, but that once started, continues for years, where $\mathrm{n}$ is the number of years from now that the project will end. The present value of such a stream would be:

$$
\text { P.V. }=B A_{n, r} V_{m, r}
$$

With these concepts, we have a framework for hatchery evaluation and planning, given capital cost, annual operating and maintenance costs, project life, yearly production in terms of quantity of smolts or value of adults contributed, and final site value, which includes final land and depreciated facilities value. Although it would be desirable, we do not need to know precisely the value of the fish contributed for purposes of comparing particular projects, as long as we can assume it is proportional to quantity of smolts reared. Evaluating contribution involves knotty problems of estimating contribution rates, estimating unit recreational values, describing which of several choices or values best applies to commercially-caught fish (ex-vessel, wholesale or retail), whether to apply regional income multipliers, how to evaluate fish caught outside of the particular political region of the agency building the hatchery, etc. Thus, for the present purposes, value will be assumed proportional to quantity of smolts reared $(\mathbf{S}=\mathrm{KP})$, where $\mathrm{S}=$ annual dollar value of adults contributed, $\mathrm{P}=$ pounds of smolts produced annually, and $\mathrm{K}=$ an unknown proportionality constant. 
Project Selection and Evaluation

If $\mathrm{S}$ were predictable, then to evaluate a particular project, one would take the difference between the discounted stream of fishery values and the discounted stream of costs over the estimated project life; this would be the present net value of the project. Even with insufficient knowledge to estimate $\mathrm{K}$, the following ratio is a useful statistic for evaluating alternative projects:

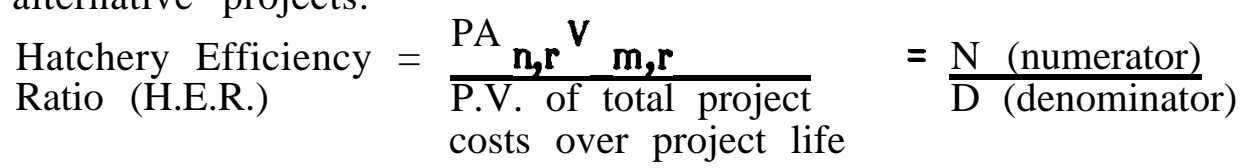

where, $\mathrm{P}=$ the annual pounds of smolts produced

$\mathrm{m}=$ average cycle length of the species reared, in years.

Note several things:

1. The term $\mathrm{m}$ lets value contributed be lagged appropriately behind production (however production would also continue $\mathrm{m}$ years beyond any time the project were ceased). For chinook and coho hatcheries, an appropriate value for $m$ would be 3 years.

2. H.E.K. has the dimensions of pounds of production per dollar of cost. Its denominator is the total fixed and operating costs, net final site and facilities value, with each element of cost over project life discounted to the present accoraing to the time such a cost would be incurred. The numerator is proportional to the present value of the stream of fishery benefits created by the project, i.e., for any year, $\mathrm{S}=\mathrm{KP}$, and

Therefore,

$$
P_{n, r} V_{m, r}=\frac{S}{K} A_{n, r} V_{m}, r
$$

$$
\text { (H.E.R.) }(K)=\frac{\text { Present value of total project benefits }}{\text { Present value of total project costs }}
$$

In other words, H.E.R. is proportional to the ratio of discounted benefits to discounted costs.

3. For purposes of comparing projects with different lives, H.E.R. is independent of project life. This will be shown below with an example.

4. Computation of H.E.R. could include an inflation factor but, for project comparison and choice among alternatives, such is not needed.

For a simple example of H.E.R. computation, consider a hatchery with the following structure (all values and poundages in 000 's):

1. Land acquisition cost $=\$ 200$.

2. Land value appreciates at $\mathbf{r}$ per year.

3. Design and construction cost for facilities $=\$ 800$. 


\section{Chapter 8}

4. Yearly $0+M$ costs $=\$ 100$.

5. Project life $=20$ years.

6. Annual production $=50 \mathrm{lbs}$.

7. Cycle $(m)=3$ years.

8. Depreciated (recovery) value of facilities over 20 years $=100$.

9. $\mathbf{r}=. \mathbf{l}$

On the numerator side:

$$
\begin{aligned}
& P=50 \\
& A_{n, \mathbf{r}}=A_{20, .1}=8.51356 \\
& V_{m, \mathbf{r}}=V_{\mathbf{3}, .1}=.75131 \\
& \text { Thus, } N=\mathbf{P A}_{\mathbf{n}, \mathbf{r}} \mathbf{V}_{\mathbf{m}, \mathbf{r}}=(50)(8.51350)(.75131)=319.82 .
\end{aligned}
$$

On the denominator side:

$$
\begin{aligned}
& \mathrm{D}=\text { land cost }+ \text { facilities cost }+ \text { discounted stream of } 0+M \text { costs }- \text { final land }
\end{aligned}
$$

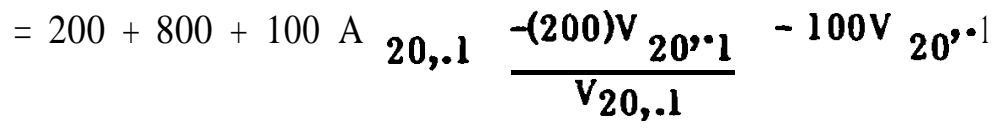

$$
\begin{aligned}
& =200+800+(\mathbf{1 0 0})(8.51356)-200-100(.14864) \\
& =1636.492 \text {. }
\end{aligned}
$$
value discounted to present - recovery value of facilities discounted to

(Note that the discounted final land value equaled the initial cost under the assumption that land appreciated at the rate r). Finally,

$$
\text { H.E.R. }=\frac{\mathrm{N}}{\mathrm{D}}=\frac{319.82}{1636.49}=.1954 \mathrm{lb} / \$
$$

or, reciprocally, the production from this hatchery would cost $\$ 5.12$ per $\mathrm{lb}$.

Let's continue with this example to show that H.E.R. "works" for comparing projects with dissimilar lives. This can be done by comparing two hypothetical hatcheries, one with a 20-year life as above with 50,000 lb production capacity, and the second a 40-year life hatchery costing twice as much to build (land $\$ 400,000$, construction $\$ \mathbf{1 , 6 0 0 , 0 0 0}$ ), but with the same operating costs and production capacity. Conceptually one might desire to compare the two over the same time period, i.e., 40 years, considering that the 20-year hatchery would be replaced precisely at year 20. I will show that H.E.R. for the 20-year hatchery over a 20-year time period is the same as for a 20-year hatchery, with replacement at year 20 and continuance for another 20 years. This is shown in the following computations: 
Project Selection and Evaluation

\begin{tabular}{|c|c|c|c|}
\hline $\begin{array}{l}\mathrm{D}=200 \\
\quad \text { (land) }\end{array}$ & $\begin{array}{l}+800 \\
\text { (original } \\
\text { facilities } \\
\text { cost) }\end{array}$ & $\begin{array}{r}\mathbf{1 0 0} \mathbf{A}_{\mathbf{4 0 ,}, \mathbf{r}} \\
\text { (O+M for } \\
40 \text { years) }\end{array}$ & $\begin{array}{l}+800 \mathbf{V}_{20} \mathbf{r} \\
\quad \text { (facilities } \\
\text { replacement } \\
\text { cost) }\end{array}$ \\
\hline $\begin{array}{l}-100 V_{20, r} \\
\text { (recovery } \\
\text { value of } \\
\text { first set } \\
\text { of facilities) }\end{array}$ & $\begin{array}{l}-100 \mathbf{v}_{\mathbf{4 0 ,}} \mathbf{r} \\
\text { (recovery } \\
\text { value of } \\
\text { second set } \\
\text { of facilities) }\end{array}$ & & $\begin{array}{l}-\frac{200 V_{40, r}}{V_{40, r}} \\
\text { (final land } \\
\text { value discounted } \\
\text { to present) }\end{array}$ \\
\hline
\end{tabular}

$\mathrm{D}=200+800+(\mathbf{1 0 0})(\mathbf{9 . 7 7 9 0 5})+(\mathbf{8 0 0})(.1874)-(\mathbf{1 0 0})(.14874)-(100)(.02289)-200$

$=1879.734$, which represents the discounted costs for a 40-year time period of a 20-year hatchery replaced after 20 years.

Benefits for these two back-to-back 20-year projects would total

$$
\begin{aligned}
& \mathrm{N}=\mathbf{5 0} \mathbf{A}_{\mathbf{4 0}, \mathbf{r}} \mathrm{V}_{\mathbf{3}, \mathbf{r}}=\mathbf{( 5 0 )}(\mathbf{9 . 7 7 9 0 5})(. \mathbf{7 6 1 3 1})=367.3549 . \\
& \text { H.E.R. }=\frac{\mathrm{N}}{\mathrm{D}}=\frac{\mathbf{3 6 7 . 3 5 4 9}}{\mathbf{1 8 7 9 . 7 3 4}}=.1954 \mathrm{lb} / \$
\end{aligned}
$$

This is precisely the same as the H.E.R. for the project over a 20-year life, as shown earlier.

To continue with this example and further demonstrate the power of present value analysis, let us compute H.E.R. for the 40-year project costing originally twice as much as the 20-year project. Which would be preferable, the cheaper hatchery with the shorter life or the more expensive one with the longer life?

For the IO-year hatchery:

\begin{tabular}{|c|c|c|c|c|}
\hline$D=400$ & +1600 & $+100 A_{40, r}$ & & \\
\hline (land) & (facilities) & $(O+M)$ & (final land) & $\begin{array}{l}\text { (recovery of } \\
\text { facilities) }\end{array}$ \\
\hline
\end{tabular}

$\mathrm{N}=50 \mathbf{A}_{\mathbf{4 0 , \mathbf { r }} \mathbf{r}} \mathbf{V}_{\mathbf{3}, \mathbf{r}}=367.3549$.

H.E.R. $=\frac{N}{D}=\frac{307.3549}{.3573 .0^{02}}=.1428 \mathrm{lb} / \$$

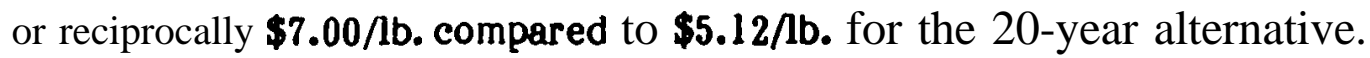

The 40-year project is therefore $27 \%$ less efficient according to the present terms of analysis.

$$
\frac{.1954-.1428}{4}=.27
$$




\section{Chapter 8}

The advantage of the cheaper, shorter-lived hatchery is that, comparatively speaking, it required only half the initial capital of the 40-year hatchery for the first 20-year time period. The present value of the additional 1 million required after 20 years is a lot less than the 1 million additional cost required at present for the 40-year project. Put another way, the extra 1 million could be invested for 20 years at $\mathbf{r}$ interest before it was spent; the interest on this would be additional revenue not available from the 40-year alternative.

This illustrates a basic principle for consideration in hatchery design: all else being equal, cheap, replaceable facilities may be a sensible alternative to expensive long-lived facilities. Clearly there is some practical limit to shortness of life and cost reduction. One could show mathematically, as above, that there would be theoretical increases in efficiency with shorter and shorter-lived hatcheries with construction costs inversely proportional to life. However, practically speaking, this process at some point would lead to a system that would not have the same expected annual production; i.e., in simple terms, would break down too often.

\section{B. COST AND PRODUCTION ESTIMATION}

In applying the foregoing theoretical framework of analysis to any particular project or set of projects, one needs estimates or projections of capital and operating costs, production capabilities, and expected life of each project and/or the separate lives of the components of each project. I will outline a worksheet for organizing such data inputs and illustrate with examples.

First, consider briefly what are the major, necessary items of costs for a hatchery. On the capital cost side, a hatchery requires a physical site which must include a sufficient amount of land of suitable characteristics in terms of space, topography, and substrate, and a sufficient water supply. The latter can come from any one or some combination of surface wells, artesian wells, surface springs, fluvial waters, or lacustrine waters. Fresh water is required for early life stages, but saltwater can work well for later rearing. The major items in hatchery construction are for (1) design and site development, (2) water supply systems, (3) adult collection and holding, (4) incubation, (5) rearing, (6) transportation of reared fish, and (7) production support (shop, food freezers, feeders, stand-by generators, etc.).

The major operating cost items are manpower, fish-food and power. Manpower and power costs are highly dependent upon facilities selected, but fish-food costs tend to be proportional to pounds reared over a broad range of facilities.

The above categories of costs include over $90 \%$ of the capital and operating costs of hatcheries at the present level of technology. Therefore, a simple, straightforward, and meaningful hatchery efficiency analysis of a proposed project can be conducted considering only the above defined costs. If future technology stimulated the need for additional significant cost items (e.g., computers, fish-foodmaking machinery, pathology labs, etc.), these could be incorporated into the present planning and evaluation framework. 
Project Selection and Evaluation

Table 5 illustrates the matrix of input requirements for the denominator of H.E.R. Probably the time period selected for evaluating any particular project would be the estimated length of life for the item with the longest life, perhaps the rearing facilities. Components with shorter lives could be considered replaced as their respective lives were used up within the overall timeframe of the hatchery, and their costs and recovery values would be appropriately treated via present value accounting methodology.

\section{c . FACILITIES RISK}

Risk considerations of this nature can be treated in the development of the H.E.R. numerator. Each hatchery is designed for a certain maximum planned poundage, but the likelihood of achieving this each year depends upon the probabilities of success of each of the separate components. An objective evaluation procedure for planned enhancement projects should involve some procedure for assessing or predicting the expected or average annual production, which would be some fraction of the planned production and depend upon the probabilities of success of each of the major hatchery components. These probabilities depend totally or partially on the type of facilities selected and their costs. For example, the probability of success of a pumped water delivery system would be greater with a back-up power generator system than without. A set of vertical tray incubators to hatch 5 million eggs costs more than a stack of pond trays or gravel boxes with the same capacity, but the probability of partial or total egg or fry loss may be less with the vertical tray system. Dirt rearing ponds are cheaper per unit vclume than concrete raceways, but the dirt ponds coulc have a higher risk of disease than concrete ponds, especially if density levels were the same.

Therefore, item by item, each component should be assessed as to its relative risk in relation to the overall hatchery planned production. Albeit such assessinents may have subjective elements. They could be little more than educated guesses or they could be made from extensive analysis of historical data gleaned from past experience at other hatcheries.

Table 6 illustrates one simple scoring system that could be used to estimate expected value of production given some set of components. A more elaborkte or sophisticated system based on probability assignment could be developed, but such complexity may be unwarranted. Some people might even regard the proposed scheme us unrealistic or requiring too much guesswork.

This proposed system involves the separate rating of each of the major components on a 1 to 10 scale, with 1 being assigned if there is virtually no chance of producing at any significant level of the component capacity in any year, and 10 being assigned it there is a virtual $100 \%$ chance of reaching the capacity goal in all years of component life.

After assigning such scores, each of the 5 major components in Table 6 would be assigned a weighting factor. These would depend upon the evaluator's determination of the importance of that particular component to the attainment of the entire project's planned capacity output. For example, the adult facilities might fail totally in one year, yet the hatchery could get eggs or fry from elsewhere. On the other hand, if the rearing system failed totally, there might be relatively little that could be done to regain production that 


\section{Chapter 8}

year. Consequently adult facilities might be given a lesser weighting score than rearing facilities.

Table 5. An example of worksheet for compiling data inputs for an H.E.R. analysis of a planned salmon enhancement project.

\begin{tabular}{|c|c|c|c|c|c|c|c|c|c|c|c|c|c|c|c|}
\hline $\begin{array}{l}\mathrm{Pr} \\
\mathrm{ca} \\
\text { in } \\
\text { fn } \\
\text { e }\end{array}$ & $\begin{array}{l}\text { Production } \\
\text { capecity } \\
\text { (now, eggs, } \\
\text { fry, pounds, } \\
\text { etc.) }\end{array}$ & $\begin{array}{l}\text { Capital } \\
\text { cost } \\
\$\end{array}$ & $\begin{array}{l}\text { Estimated } \\
\text { life } \\
\text { yr. }\end{array}$ & $\begin{array}{l}\text { Recovery } \\
\text { value at } \\
\text { end of } \\
\text { life } \\
\$\end{array}$ & $\begin{array}{l}\text { A } \\
\text { m } \\
\text { or } \\
\text { m } \\
\text { su } \\
\text { yr }\end{array}$ & $\begin{array}{l}\text { nnual } \\
\text { anpowe } \\
\text { eration } \\
\text { ainten } \\
\text { pervisi } \\
0 \quad \$ / y !\end{array}$ & $\begin{array}{l}\text { for } \\
\text { nce \& } \\
\text { s }\end{array}$ & $\begin{array}{l}\text { Annual } \\
\text { water us } \\
\text { requiren } \\
\text { acre-ft. }\end{array}$ & $\begin{array}{l}\text { Ise } \\
\text { ment }\end{array}$ & $k w$ & $\begin{array}{l}\text { Annu } \\
\text { powe } \\
\text { use } \\
\mathbf{S} / \mathrm{kw}\end{array}$ & $\begin{array}{l}\text { ual } \\
\text { er } \\
5\end{array}$ & & $\begin{array}{l}\text { Annual } \\
\text { fish } \\
\text { food } \\
\quad \$ / 10 .\end{array}$ & $\$$ \\
\hline Land & & $\mathbf{s}$ & & $s$ & - & - & - & - & - & - & - & - & - & - & - \\
\hline $\begin{array}{l}\text { Site } \\
\text { De velopmen }\end{array}$ & $n t$ - & $s$ & ye. & $\boldsymbol{s}$ & yr. & $s$ & $\$$ & $=$ & $=$ & $=$ & . & - & - & - & $=$ \\
\hline Water systems & efs & $s$ & yr. & s & yr. & $\$$ & $s$ & - & - & & - & - & & -- & - \\
\hline $\begin{array}{l}\text { Adult } \\
\text { collection }\end{array}$ & egrs & $\$$ & yr. & $s$ & yr. & $s$ & $s$ & acre-ft. & & kw & $\$$ & s & - & - & - \\
\hline Incubator & iry & $\$$ & yr. & $s$ & yr. & $s$ & $s$ & acre-ft. & $k w$ & & $s$ & $s$ & & - & - \\
\hline Rearing & lbs. & $s$ & yr. & $s$ & yr. & s & $\mathbf{s}$ & acre-ft. & kw & & $s$ & $s$ & lb. & $s$ & $s$ \\
\hline Transportation & lb.-mi. & $\$$ & yr. & $\mathbf{s}$ & yr. & s & $s$ & - & & - & & & -- & & - \\
\hline support & & $\$$ & yr. & $\$$ & yr. & $s$ & s & - & $k w$ & & $s$ & $s$ & - & - & - \\
\hline
\end{tabular}

As an example, the weighting factors might be from 1 to 10 , with 1 being assigned if attainment of the particular component's capacity had no effect on the overall output of the hatchery and $\mathbf{1 0}$ being assigned if that component were absolutely crucial.

The final score for the hatchery would be a weighted average of the scores for the individual components. This divided by 10 would be a factor for reducing $\mathrm{N}$, the numerator in H.E.R.

The process of scoring and weighting depends on many site specific, stock specific, species specific, and agency specific considerations. However, since it is intended to evaluate and compare possible expenditures from some common fund source on some set of two or more potential enhancement projects designed to meet similar fishery goals in some common geographical and a politically defined region, it should improve the rationality of decision making, compared to the present mode of making such choices.

\section{SITE RISK AND SUNK COST}

There is sufficient history with hatchery production and evaluation to demonstrate that even though a hatchery may be producing its goals in terms of poundage of apparently good quality smolts each year, such fish may not be surviving and contributing significantly to fisheries. 
Project Selection and Evaluation

Table 6. Example of a scoring system for hatchery components.

Component systems

Score

assign

$1-10$

Water system Score $1-10$, where 1 is sure to fail totally in providing any of the water needs and 10 is sure to succeed in providing all the water needs.

Adult trapping Score 1-10, where 1 is sure to be totally inadequate for egg requirement needs and 10 is sure to provide egg needs.

Incubation

Score $1-10$, where 1 is sure to provide no viable fry and 10 is sure to provide all fry needed of high quality.

Rearing Score 1-10, where 1 is sure to provide no reared fish of any quality and 10 is sure to release $100 \%$ of planned capacity of high quality individuals.

Transportation Score 1-10, where 1 is sure to inadequately release any of the fish reared and 10 is sure to release $100 \%$ of the reared capacity in excellent condition.

Considering such a hatchery as a private business, it should probably be closed down if and when it is determined to be producing less in value per year than its annual operating costs. Even if its yearly contribution exceeded in value its yearly operating costs, it would be a good business decision, other things being equal, to close it at the time that the present value of the future stream of discounted differences between value of contribution and costs to the end of the project was less than the recovery value of the project at that time.

Presumably such a hatchery would only have been built in the first place had its projected net present value at time of construction been postive. However, living in an uncertain world, actual and projected values may differ. Given such uncertainty, how should a planner regard choices between two opposing cost strategies, one of which may involve high initial capital investment offset by relatively low operating costs, and the other involving a low initial outlay for capital but high operating costs? If a substantial portion of the capital outlay is sunk cost, in the sense that it cannot be recovered either totally or partially by sale of the items constructed or purchased, or by transfer of such items to another site, it may make sense to choose the alternative of low capital outlay but high operating cost.

Consider a simple extreme example: there are two potential programs of enhancement for a stream, each of which is projected to yield the same annual fishery contribution. Alternative 1 consists of a lo-year life capital project costing $\$ 100,000$ having no recoverable portion of the costs, and requiring no operating costs per year (an artificial spawning channel, for instance). Alternative 2 requires no capital costs, but has yearly 
Chapter 8

operating costs (a program of spawning, hatching and planting eyed-eggs from low-cost "throw away" gravel boxes, for instance). Assume the two programs have equal projected net present values. Then the yearly operating costs of alternative $2, \mathrm{C}$, must be such that

$$
\begin{aligned}
& \frac{C}{(1+r)^{1}}+-+\frac{C}{(1+r)^{10}}=\$ 100,000 \\
& \text { or }{C A_{10, r}=100,000}_{\text {or }} C=\frac{100,000}{\mathbf{A}_{10, r}}=\$ 16,274
\end{aligned}
$$

(Note: Total expenditures over the 10 years would equal 162,740 >100,000. But of the two alternatives, both would end up costing the same after 10 years. The fixed cost alternative would leave you $100,000(1+.1)^{10}=\$ 259,000$ poorer than if you did not do it. The operating cost alternatives would cost you the same over ten years, $\mathbf{C}(1+.1)^{9}+$ $\left.C(1+.1)^{8}+\ldots+C(1+.1)^{0}=\$ 259,000.\right)$

Assume, however, that unknown to us, the entire smolt production from either alternative goes through a non-removable pollution block and dies, a fact we determine sometime during the 10 year period. With alternative 2 we can cancel the project once we learn of the pollution problem, thus saving the operating costs from the additional years. The present value of the costs of alternative 1 is $\$ 100,000$ no matter what may be found out about the pollution block and the fishery contribution during the 10 years. The present value of the stream of costs from alternative 2 would always be less than $\$ 100,000$ unless the project was continued for 10 years, in which case costs would be equal. Thus, given some risk of project failure and consequent cessation of the project, the expected value of the net return would be less with the capital intensive alternative. In simple terms, if there are two courses of action which, on the surface, seem to cost the same and potentially seem capable of yielding the same benefits, it makes common sense to choose the strategy that allows greater flexibility-the one that allows disinvestment if the initial projections prove to be faulty.

The above logic would seem to have wide application in hatchery planning where levels of uncertainty are so high. Expensive "labor saving" equipment or facilities may make no sense at all; to the contrary, it may be better to build cheap structures even though they may require lots of labor to maintain and operate. low-cost, short-lived ("throw away") facilities may make sense if they perform the biological functions required as well as high-cost, longer-lived facilities. As a further example, even though the energy conservation implied in a gravity-fed water system compared to one of pumping from a river may be appealing, a high-cost head works and plumbing system to deliver gravity-fed water may not make as much sense as an alternative pumping system even though the latter may have high power costs. Power costs are operating costs which can be stopped given project failure, and pumps can be sold or transferred, unlike most components of a particular in-stream head-works.

Therefore, in addition to calculating H.E.R. for alternative hatchery projects, it may be useful to do a sunk cost analysis of each alternative. Then, of two or more projects with 
Project Selection and Evaluation

similar H.E.R., the additional criteria of minimizing that portion of present value of total costs representing sunk costs may be useful in final project selection.

Such an analysis would be straightforward. Each of the major items of planned capital purchase or construction would be evaluated with the following question: of the total cost at the time of purchase or construction, what portion could be recovered relatively quickly by resale or reassignment to an alternative use or site if an immediate decision were made to close or discontinue the project in question? The remaining values would be summed for all capital items to give total project sunk cost. If expressed as a portion of present value of total cost, including operating costs, this could be a very useful measure for final decision-making among alternatives.

An example of such computations for a hypothetical hatchery follows in Tables $7 \mathrm{a}$ and $7 \mathrm{~b}$. In this example, assume that yearly $\mathrm{O}+\mathrm{M}$ costs are 100 , interest rate is $\mathbf{. 1}$, and project life is 40 years. From Table $\mathbf{7 a}$, total sunk costs are 675; from Table $\mathbf{7 b}$, total discounted operating and capital costs over project life are 1989. Therefore, the sunk cost ratio for this particular project would be $\mathbf{6 7 5 / 1 9 8 9}=\mathbf{. 3 3 9}$, which could be compared with that of some alternative project.

\section{E. INCUBATION SYSTEM ANALYSIS}

Present value analysis can be used to evaluate various potential subcomponents of a hatchery system in exactly the same manner as evaluating a total hatchery. If each of several systems is evaluated in terms of discounted future physical production per dollar of total capital plus discounted operating costs, the resulting efficiency ratio provides a bottom line for comparison.

Such an analysis is presented in Table 8. I assumed that the only benefits of each system would be in alevins produced. Some systems, in addition to producing alevins, can produce some additional quantity of eyed eggs for sale or out-planting, which would represent some additional benefits. Some systems can be used for alternative hatchery operations, such as rearing, adult holding, or marking. I have excluded such additional benefits.

In Chapter 4, Table 4, capital and operating costs for various incubation systems were developed per 100,000 alevins. I assumed that all rearing, from fertilized egg to alevin, would be done in the identified system; however, certain systems may be used in combination, one to eye the eggs and the other to produce final alevins. Cost and floor space requirements are from Chapter 4, Table 4. I assumed that all units except pond trays would have a building, with construction costs equal to $\$ 50$ per square foot. Actually, any of the systems could be placed outside with suitable light covering; however, for working comfort and security reasons most permanent hatchery facilties would have a building of some sort. Plumbing costs were assigned as follows: complex plumbing, \$205/1 00,000 alevins; semi-complex plumbing \$50/1 00,000 alevins; simple plumbing \$24/100,000 alevins (Table $\mathbf{8}$ ). These values were computed by construction specialist Melvin Ebey for vertical incubators (complex plumbing), deep trough (semi-complex) and deepmatrix box (simple). 
Chapter 8

Table 7a. An example of sunk cost computation for hypothetical hatchery.

\begin{tabular}{|c|c|c|c|c|c|}
\hline Item of cost & $\begin{array}{c}\text { Cost } \\
\mathscr{x} \\
\end{array}$ & 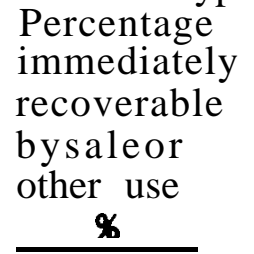 & $\underline{\text { sunk cost }}$ & $\begin{array}{l}\text { Life } \\
\text { yr. }\end{array}$ & $\begin{array}{l}\text { Recovery } \\
\text { value at } \\
\text { end of } \\
\text { life } \\
\$ \\
\end{array}$ \\
\hline Land & 100 & 100 & 0 & 40 & 100 \\
\hline Site development (and design) & 100 & 0 & 100 & 40 & 0 \\
\hline Water system & 100 & 0 & 100 & 20 & 0 \\
\hline Adult collection facility & 100 & 10 & 90 & 40 & 0 \\
\hline Incubation facilities & 150 & 50 & 75 & 20 & 15 \\
\hline Rearing ponds & 300 & 10 & 270 & 40 & 0 \\
\hline Transportation & 50 & 80 & 20 & 10 & 10 \\
\hline Support facilities & 100 & 80 & $\underline{20}$ & 10 & 20 \\
\hline Totals & 1000 & & 675 & & \\
\hline
\end{tabular}

Table 7b. Present value of total costs for hypothetical hatchery in sunk cost example.

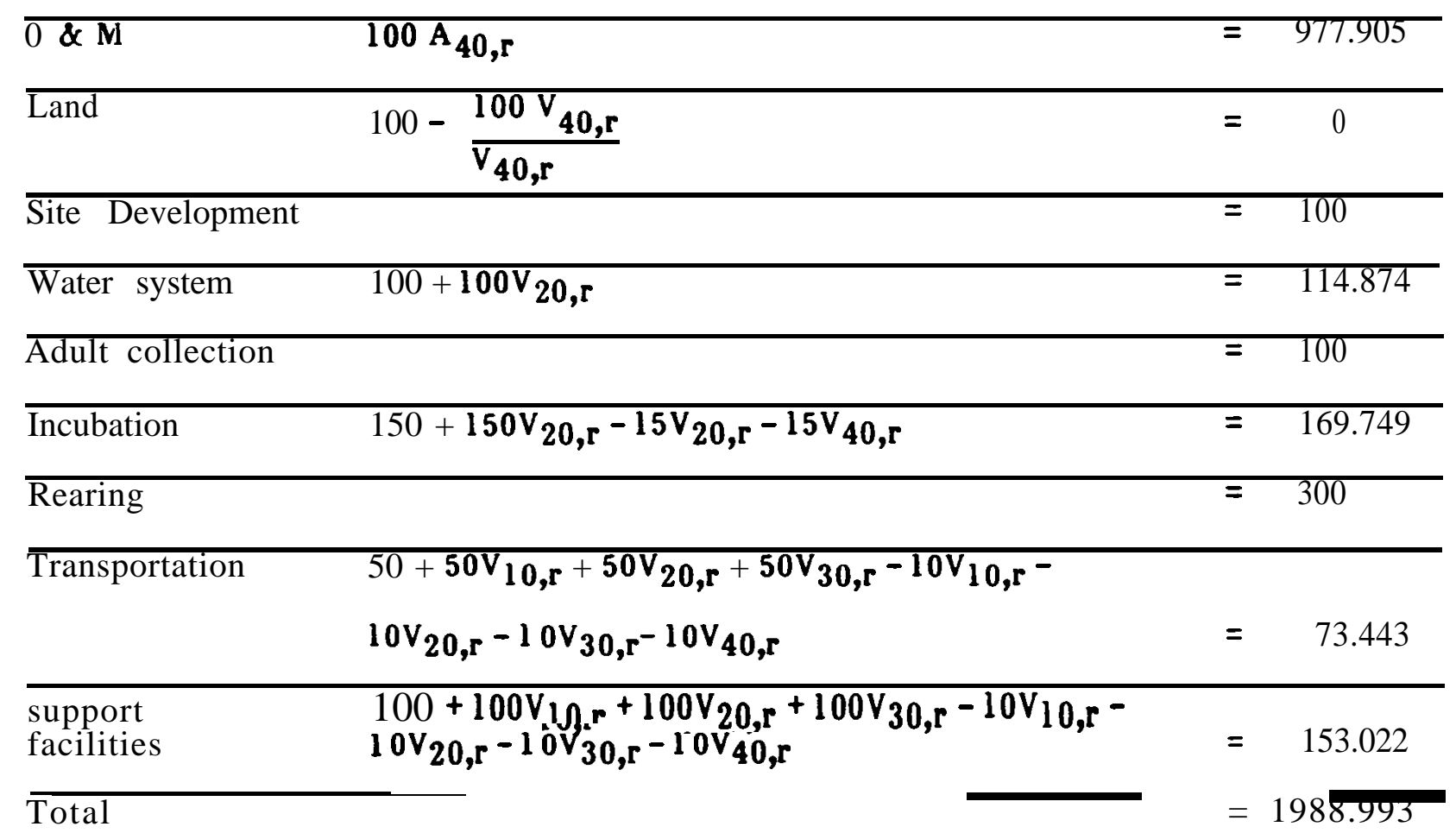


Table 8. Computation of efficiency ratios for alternative fry incubation systems.

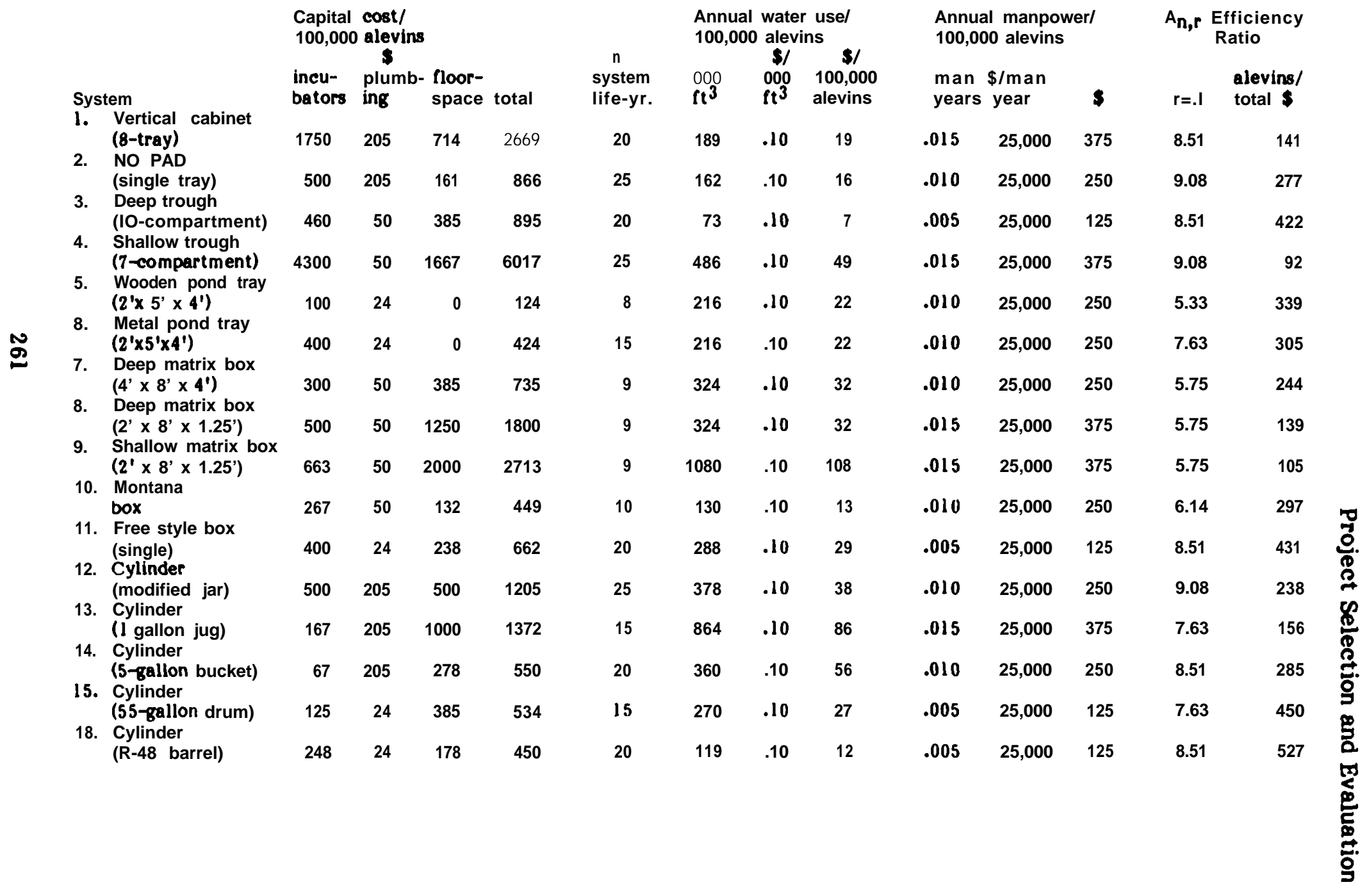




\section{Chapter 8}

Annual manpower costs were estimated on the basis that one man-year is required for incubation of 10 million eggs and alevins at an average large hatchery. Thus, 100,000 eggs would require .010 man-years, for a system of average labor intensity. The factor was arbitrarily scaled upwards to $\mathbf{. 0 1 5}$ man years for 100,000 alevins with a high-intensity system and to $\mathbf{. 0 0 5}$ man years per 100,000 alevins with a low-intensity system. One man year, including overhead and administration, was estimated to cost $\$ 25,000$. Table 8 indicates the required relative labor intensity per system.

Other operating costs would be required, and these were considered proportional to water use requirements. Obviously power costs would be included here for a pumped water system but, even for a gravity system, there would be costs for water line maintenance and monitoring, filtering, de-nitrifying, etc. I calculated an average water cost figure of $\$ .10 / 1000$ cubic feet as follows. The approximate cost of power for pumping at three types of facilities was:

Bonneville hatchery which pumps half of its water requirements from 200' wells (60- cfs available water) Clackamas hatchery which pumps all water (river) from a $20^{\prime}$ head (23 cfs available water) Gravity system

$\$ .14 / 1000 \mathrm{ft}^{3}$

$\$ .07 / 1000 \mathrm{ft}^{3}$ $\$ .00 / 1000 \mathrm{ft}^{3}$

Clackamas might represent an average condition between a heavy pumping facility versus one with no pumping, for comparative use throughout my analysis I arbitrarily added approximately $50 \%$ to the Clackamas hatchery power costs for additional non-power water costs to arrive at the value of $\$ .10 / 1000 \mathrm{ft}^{3}$.

The efficiency ratios in Table 4 were calculated as follows:

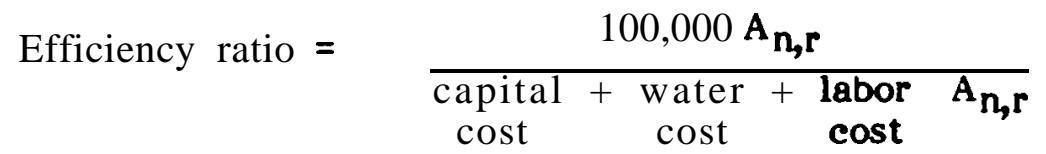

$A_{n, r}$ is the sum of the annuity factors as previously defined, with $\mathbf{r}=. \mathbf{l}$ and $\mathrm{n}$ the system
life.

The numerator, as previously discussed for an entire hatchery, represents the discounted sum of the physical benefits (alevins) over the life of the system. The denominator is the sum of the initial capital cost plus the discounted stream of operating costs over the life of the system.

The efficiency ratio is a good measure for comparing systems with variable life, as can be shown by the following example:

Consider the Montana box system, with a 10-year life. Its efficiency ratio is 297 alevins/dollar. $\mathrm{k}$ this a reasonable value for comparison with, say, the freestyle box with a 20-year life and an efficiency ratio of 431 alevins/dollar? That the answer is yes is best illustrated by considering the efficiency ratio from a Montana box system for 20 years, assuming full replacement after 10 years, the estimated life: 
Project Selection and Evaluation

Efficiency ratio of Montana box system $=$ for 20 years

$$
\frac{100,000 \mathrm{~A}_{\mathbf{2 0 , . 1}}}{449+\mathbf{4 4 9}_{\mathbf{1 0 , . 1}}+263 \mathbf{A}_{\mathbf{2 0}, \mathbf{1}}}=297
$$

Thus the efficiency ratio as defined is independent of the number of lifetimes over which we might wish to evaluate a system.

The last column of Table 8 indicates that, although there has been some artibrary cost assignment in the analysis, there is, nonetheless, a very wide range of efficiency ratios for the alternative means of doing the same job. The range is in the order of $5-1$. The most efficient systems are the deep trough, the freestyle box, and the two barrel type incubators. All four are similarly efficient and substantially better than the remaining systems. The least efficient systems are the shallow trough and the shallow matrix box.

\section{F. REARING SYSTEM ANALYSIS}

A number of rearing systems were evaluated and compared with present value methodology. An efficiency ratio was defined as follows:

$$
\begin{array}{ll}
\text { Efficiency } & \begin{array}{l}
\text { sum of the discounted reared poundages produced } \\
\text { ratio }
\end{array} \\
\begin{array}{l}
\text { over the estimated life of the project } \\
\text { costs over the life of the project }
\end{array}
\end{array}
$$

As previously, this is a good measure for comparing systems with different lengths of life.

Table 9 indicates the 18 separate systems that were evaluated-small pond systems (raceways and circulars), large pond systems, and net pens or enclosures.

Capital costs for the rearing spaces were estimated from the per cubic foot values in Chapter 5, Table 3. Additionally, we made the following assumptions as to pounds of reared salmonids (chinook, coho or steelhead) that can be produced per cubic foot of rearing space:

$$
\begin{aligned}
& \text { small ponds }-1 \mathrm{lb} \text { per } \mathrm{ft}^{\mathbf{3}} \\
& \text { large ponds }-.5 \mathrm{lb} \text { per } \mathrm{ft}^{\mathbf{3}} \\
& \text { net pens or enclosures }-.3 \mathrm{lb} \text { per } \mathbf{f t}^{\mathbf{3}}
\end{aligned}
$$

These differences represent what is generally found in actual rearing useage. They reflect perhaps a better flow (circulation) regime progressing from net pens to raceways, but perhaps, additionally, a tendency or desire towards less dense rearing allowable by cheaper construction modes.

Loading densities vary by species, size, and temperature; but these values were assumed reasonable for illustration.

The plumbing costs in Table 9 reflect estimates for total water delivery systems-intakes, pumps, main lines, feeder lines, valves, and outlets. These are based on average plumbing costs per cfs of rearing water for recently constructed hatcheries. I assumed a full 
Tabl e 9. Computations of efficiency ratios for alternative rearing systems.

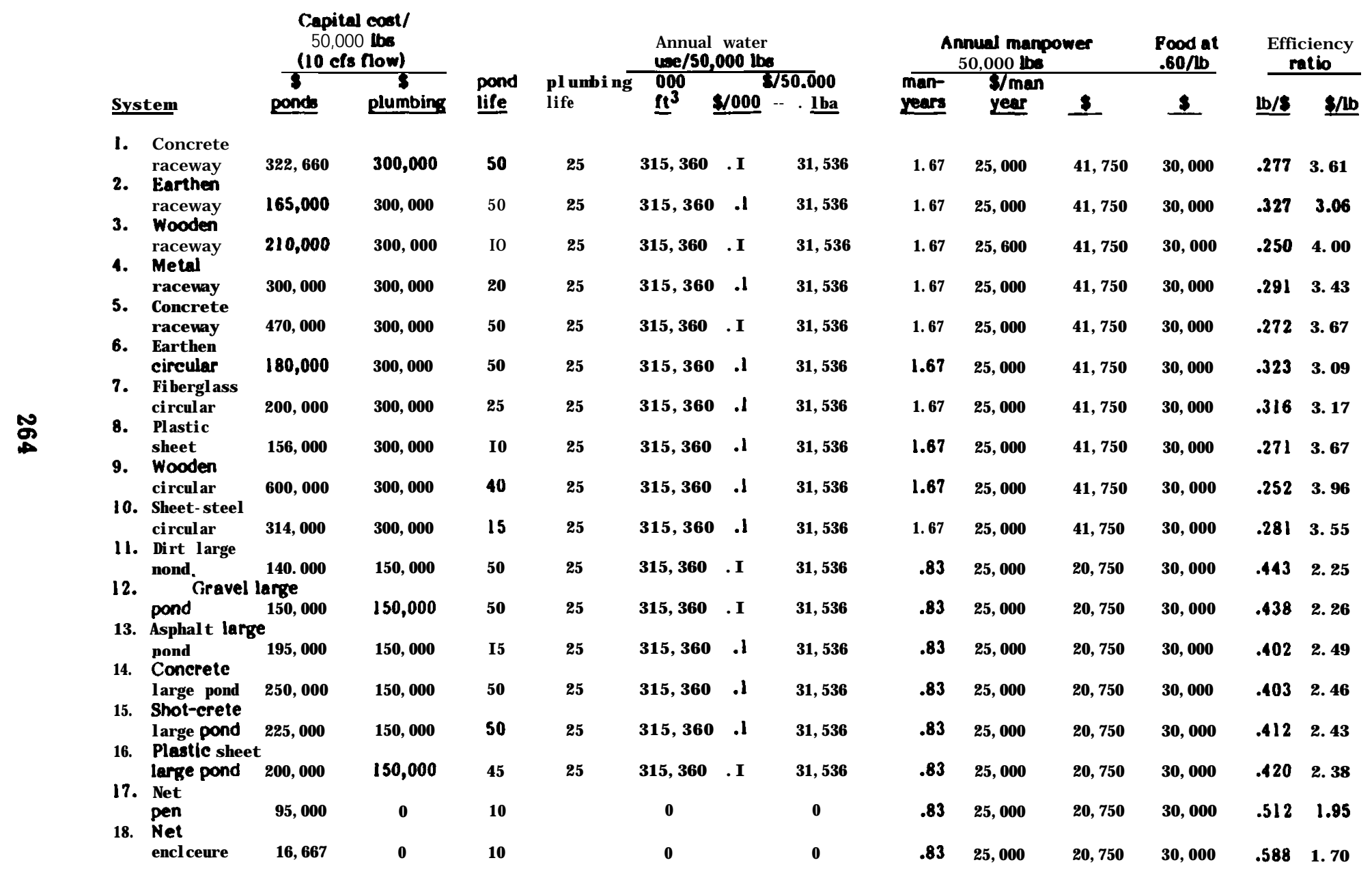


Project Selection and Evaluation

plumbing cost value of $\$ 300,000$ per 10 cfs $(50,000 \mathrm{lba}$ of reared fish at $10 \mathbf{~ b / g a l / m i n ) ~ i n ~ a ~}$ small pond system, $\$ 150,000$ for a large pond system and $\$ 0$ for a net pen or enclosure system.

Pond life estimates were from Chapter 5, Table 3. A 25-year life was assumed for all plumbing systems.

The major operating or variable costs include costs proportional to water use, labor, and feed. Water costs for small and large pond systems were estimated on the basis of \$.10 per $1000 \mathbf{f t}^{3}$, previously derived for incubation system water. Two values for I abor costs were used; one for small ponds in which approximately half of the labor is for pond cleaning, and another for large ponds and net systems for which routine cleaning is a substantially lessor chore. The small pond value was based on an estimate that one man year is required to rear 30,000 lbs., a figure approximating recent experience at public hatcheries. For large ponds or pens it was estimated that one man year could rear 60,000 lbs.

Food costs were based on a 1.5:1 food to fish conversion rate and a food cost per pound of $\$ .40$.

The efficiency ratios were all calculated assuming 50,000 lbs of reared fish per year over a 50-year period. As previously discussed, the comparisons are independent of the time period used, as long as one adheres strictly to the present value model. An example of such computations is given below for a system utilizing wooden circular ponds, according to the data of Table 9 . The interest rate, $\mathbf{r}$, was .1.

Efficiency ratio $=$

$50,000 \mathrm{~A}_{50 . \mathrm{r}}$

\begin{tabular}{|c|c|c|c|c|}
\hline 0,000 & $+600,000 V_{40, r}$ & $0, r+300,000$ & 30 & \\
\hline $\begin{array}{l}\text { initial } \\
\text { pond } \\
\text { cost }\end{array}$ & $\begin{array}{l}\text { replacement } \\
\text { pond cost }\end{array}$ & $\begin{array}{l}\text { unused pond } \\
\text { value at } \\
50 \text { years }\end{array}$ & $\begin{array}{l}\text { replacement } \\
\text { plumbing } \\
\text { cost }\end{array}$ & $\begin{array}{l}\text { variable } \\
\text { rearing } \\
\text { costs }\end{array}$ \\
\hline
\end{tabular}

$=.253$ pounds per $\$$ or $\$ 3.96$ per pound

These ratios ranged from a highest efficiency value of $\mathbf{. 5 8 8}$ pounds per $\$$ for a net enclosure to $\mathbf{. 2 5 0}$ pounds per $\$$ for a wooden raceway system.

\section{G. FULL HATCHERY ANALYSIS}

To demonstrate the use of hatchery efficiency ratio for evaluating projected hatchery designs or comparing several alternative production modes, we "designed" six hypothetical hatchery operations, each producing only coho salmon. The first three combinations were hatcheries producing 50,000 lbs. of fully reared (20/1b coho) and $500 \mathrm{lbs}$ of eyed eggs for out-planting (approximately 500,000 eggs). These three combinations were a high cost alternative typical of recent agency projects, a medium cost alternative designed with 


\section{Chapter 8}

cost-consciousness, and a low cost alternative. The other three combinations were three small hatcheries, each capable of 10,000 lbs of fully reared coho and $500 \mathrm{lbs}$ of eyed eggs. Within this production range, we again hypothesized high, medium and low cost alternatives. Brief discussions of each alternative are given below.

$50,500 \mathrm{lb}$, high cost. Coats are summarized in Table 10. This example had a $10 \mathrm{cfs}$ flow, 10 concrete raceways, a vertical stack of incubators, housing for three people, and a permanent wier or ladder for adult collection. Incubation needs were calculated on the basis of 2 million alevins, sufficient for a 500,000 eyed egg plant, $\mathbf{1 , 0 0 0 , 0 0 0}$ fully reared smolts and the expected egg to alevin mortality losses. Rearing pond needs were

Table 10. A 50,500 pound-2 million egg hatchery with high costs.

\section{Capital Costs}

Item and Description

Pollution pond $-5,000 \mathrm{cu}$. ft. dirt pond dc water system

Roadways $\mathbf{- 1 / 2}$ mi. 20' wide oiled gravel

3 houses -1300 sq. ft. each

Food freezer

Tool shed and office - 1200 sq. ft.

Diesel generator

Concrete raceway rearing ponds - $1020^{\prime} \times \mathbf{8 0}^{\prime}$

Water delivery system and plumbing

Incubator system - 8-tray vertical stacks and plumbing

Incubator shed - 360 sq $\mathrm{ft}$.

Land clearing and grading - 10 acres

Adult trapping and holding - permanent wier or ladder

Landscaping

Pick-up truck

Tools and miscellaneous equipment

Total excluding land

Estimated land cost

Total including estimated land cost

Cost \$

15,000

$\mathbf{4 6 , 8 0 0}$

123,900

75,000

50,000

20,000

300,000

300,000

39,100

18,000

25,000

120,000

25,000

10,000

15,000

$\mathbf{1 , 1 8 2 , 8 0 0}$

300,000

$\overline{1,482,800}$

Annual Operating Costs

Item

Manpower

Water

Food

Misc. supplies

Misc. maint.

Total
Description

3 man years

$3.1536 \times 10^{8} \mathrm{cu}$. ft.

75,000 lbs.

Drugs, telephone, fuel

office supplies, parts, etc.

Equipment repair, roadway \&

building maintenance
Cost \$

75,000

31,536

30,000

8,000

8,000

$\frac{8,000}{152,536}$ 
Project Selection and Evaluation

conservatively calculated on the basis of a holding density of $1 \mathbf{l b} / \mathbf{f t}^{\mathbf{3}}$. Variable water costs were estimated on the basis of $\$ .10 / 1000 \mathrm{ft}^{3}$, a coefficient that has been previously discussed. Other coats were estimated from data given elsewhere in this report. Normally such costs have included add-on factors to cover both design and contingency. The total capital cost for this hypothetical unit was about 1.2 million $\mathbf{( \$ 2 4 / p o u n d ~ o f ~}$ production) and operating costs approximated \$150,000/year.

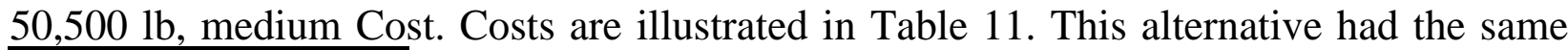
production capacity as the previous example, but its means of production differed in

Table 11. A 50,500 pound-2 million egg hatchery with medium costs.

Capital Costs

Item and Description

Pollution pond $-5,000 \mathrm{cu}$. ft. dirt pond \& water system

Roadways $-1 / 2$ mi. 12 ' wide gravel

2 houses -1100 sq. ft. each

Tool shed and office - 1200 sq. ft.

Diesel generator

Concrete raceway $-420^{\prime} \times \mathbf{8 0}^{\prime}$

Dirt rearing pond $-34,600 \mathrm{cu} . \mathrm{ft}$

Water delivery system and plumbing

Incubator system - 10 comp. deep trough \& plumbing

Incubator shed - 192 sq. ft.

Land clearing and grading - 10 acres

Adult trapping - temporary rack

Adult hauling - flat bed truck and tank

Adult holding - dirt pond modifications

Landscaping

Tools and miscellaneous equipment

Total excluding land

Estimated land cost

Total including estimated land cost

\begin{tabular}{rr} 
Cost $\$$ & $\begin{array}{r}\text { Life } \\
\text { (yr) }\end{array}$ \\
\hline 15,000 & $\begin{array}{r}\mathbf{5 0} \\
22,750\end{array}$ \\
69,900 & 50 \\
50,000 & 50 \\
20,000 & 15 \\
120,000 & 50 \\
48,400 & 50 \\
150,000 & 25 \\
10,200 & 20 \\
9,600 & 50 \\
25,000 & 50 \\
10,000 & 10 \\
20,000 & 10 \\
10,000 & 50 \\
15.000 & 50 \\
$15 ; 000$ & 10 \\
610,850 & \\
300,000 & \\
\hline 910,850 &
\end{tabular}

\section{Annual Operating Costs}

Item

Manpower

Water

Food

Misc. supplies

Misc. maint.

Freezer rental

Total
Description

2 man years

$3.1536 \times 10^{8} \mathrm{cu} . \mathrm{ft}$.

75,000 lbs.

Drugs, telephone, fuel

office supplies, parts, etc.

Equipment repair, roadway \&

building maintenance
Cost

50,000

31,536

30,000

8,000

6,000

1,200 


\section{Chapter 8}

several regards. It had 4 raceways and a large dirt pond to take up the bulk of the production. With less raceway cleaning, it could be operated with two men. The incubation system was the cheaper deep trough type. Adult trapping was with a temporary wier; adult holding was in the large dirt pond, suitably modified. Other costs not strictly related to production were scaled down, such as roadways, landscaping and freezer space. The latter function was considered to be accomplished by rental of freezer space. Plumbing costs were less than the high-cost alternative since there were less ponds overall. The capital cost was about .6 million or one-half those of the first example. Operating costs were less because of the elimination of the one man-year.

50,500 lb., low cost. Costs are summarized in Table 12. This alternative represents the approximate bottom level for which 50,000 lbs. of reared coho and 500,000 eyed eggs for

Table 12. A 50,500 pound-2 million egg hatchery with low costs.

\section{Capital Costs}

Item and Description

Roadways $-1 / 2$ mi. 12 ' wide gravel

2 houses -1160 sq. ft. each

Tool shed and office -600 sq. ft.

Incubator system - R-48 barrels and plumbing

Water system - intake and lines

Net pen rearing system - netting, floats, lines

Land clearing and grading -4 acres

Landscaping

Pick-up truck

Outboard skiff and motor

Tools and miscellaneous equipment

Total excluding land

Estimated land cost

Total including estimated land cost

\begin{tabular}{rr} 
Cost $\$$ & $\begin{array}{c}\text { Life } \\
\mathbf{( y \mathbf { r } )}\end{array}$ \\
\hline 22,750 & $\mathbf{2 5}$ \\
$\mathbf{6 9 , 9 0 0}$ & 50 \\
25,000 & 50 \\
5,400 & 20 \\
6,000 & 20 \\
100,000 & 10 \\
10,000 & 50 \\
5,000 & 50 \\
10,000 & 10 \\
3,000 & 10 \\
$\mathbf{1 0 , 0 0 0}$ & 10
\end{tabular}

\section{Annual Operating Costs}

Item

Mandower

Water

Food

Misc. supplies

Misc. maint.

Eyed egg purchase

Freezer rental

Total
Description

2 man years

Incubation only

75,000 lbs.

Drugs, telephone, fuel

office supplies, parts, etc.

Equipment repair, roadway \&

building maintenance

$2 \times 10^{6}$ at $\$ 8 / 1000$
Cost \$

50,000

$-240$

30,000

5,000

5,000

16,000

1,200

107,440 
planting could be sensibly and safely produced. It utilized outdoor, barrel-type Incubators and net pens for rearing, both of which have been proven. It assumes, of course, the availablity of a suitable body of laucustrine water. No adult collection facilities were included. This hatchery would rely upon fertilized eggs from other sources. A cost of $\$ \mathbf{\$ 8 0 0 0}$ for fertilized eggs was assumed, which would represent an annual operating cost. Operating costs did not include the water proportional costs of the previous two examples since there would be no pumping or line service costs with floating pens. This low cost system costs less than half the previous one but, of course, the pens and floats would have to be replaced regularly, unlike ponds,

10,500 lbs: high, medium and low cost. Similar production and cost-scaling assumptions were made as for the previous three examples. All three examples assumed a coho production of 10,000 lbs. of fully reared fish and 500,000 eyed eggs for planting. Incubators were costed on the basis of $\mathbf{1 , 0 0 0 , 0 0 0}$ alevins. The high-cost unit had two concrete raceways, a dirt rearing-adult pond, a vertical tray incubator system, and a wooden ladder for fish collection. The medium-cost unit had one large dirt rearing pond, a deep trough incubator system, and a wooden ladder. Roth units were assumed operable by one man. The low cost unit had barrel incubators, floating pens, and no adult collection facilities. It was assumed operable with .75 man years. Costs for three of these units are summarized in Tables 13,14 and 15 respectively.

An example of hatchery efficiency ratio (H.E.R.) computations for the 50,500 $\mathrm{lb}$, high-cost unit is given in Table 16. The ratios for all units are given in Table 17. They vary from a low of $\$ 3.17$ per pound of production for a $50,500 \mathrm{lb}$ low-cost unit to $\$ 18.10$ for a $10,500 \mathrm{lbs}$, high-cost unit. In all cases an interest rate of $\mathbf{r}=.1$ was assumed.

Although these examples are hypothetical, they illustrate that there is a substantial range of efficiencies of operation within the bounds of standard hatchery designs and production modes. These examples also indicate potential efficiencies of scale may exist with size. Efficiencies tended to be greater for producing the larger poundage values than the smaller ones. Further analysis would be needed to more fully define the production values at which efficiencies are greatest.

In the previous examples, land costs were added to each table only for completeness and as a reminder that these are important up-front cost considerations. However, since land tends to appreciate in value roughly in proportion to the going interest rate, land may not be a true cost at all. This point was previously discussed in the section on present value theory. 
Chapter 8

Table 13. A 10,500 pound-1 million egg hatchery with high costs.

\section{Capital Costs}

Item and Description

Roadways $-1 / 2$ mi. 12 ' wide gravel

House --1300 sq. ft.

Tool shed and office - portable 400 sq. ft.

Concrete raceways $-2 \mathbf{2 0}^{\prime} \times 80^{\prime}$

Dirt rearing-adult holding pond $-5000 \mathrm{cu}$. ft.

Water delivery system and plumbing

Incubator system - 8-tray vertical and plumbing

Incubation shed $-200 \mathrm{sq}$. $\mathrm{ft}$.

Land clearing and grading -4 acres

Adult trapping and holding - wooden ladder and pond modification

Landscaping

Pick-up truck

Tools and miscellaneous equipment Total excluding land

Estimated land cost

Total including estimated land cost

Life

Cost \$

22.750

41,300

12,000

60,000

15,000

75,000

19,550

10,000

10,000

28,000

12,000

10,000

7,500

$3 \frac{7,500}{23,100}$

120,000

$\frac{120,000}{443,100}$

\section{Annual Operating Costs}

Item

Manpower

Water

Food

Misc. supplies

Misc. maint.

Freezer rental Total
Description

1 man year

$6.307 \times 10^{7} \mathrm{cu} . \mathrm{ft}$.

20,250 lbs.

Drugs, telephone, fuel

office supplies, parts, etc.

Equipment repair, roadway \&

building maintenance
Cost \$

25,000

6,307

8,100

2,000

4,000

1,200 
Table 14. A 10,500 pound-1 million egg hatchery with medium costs.

\section{Capital Coats}

Item and Description

Roadways - 1/2 mi. 12' wide gravel

House -1100 sq. ft.

Tool shed and office - portable $\mathbf{4 0 0}$ sq. ft.

Dirt rearing pond $-13,000 \mathrm{cu} . \mathrm{ft}$.

Water delivery system and plumbing

Incubator system - IO comp. deep trough and plumbing

Incubation shed - 150 sq. ft.

Land clearing and grading - 4 acres

Adult trapping and holding - wooden ladder and pond modification

Landscaping

Pick-up truck

Tools and miscellaneous equipment

Total excluding land

Estimated land cost

Total including estimated land cost

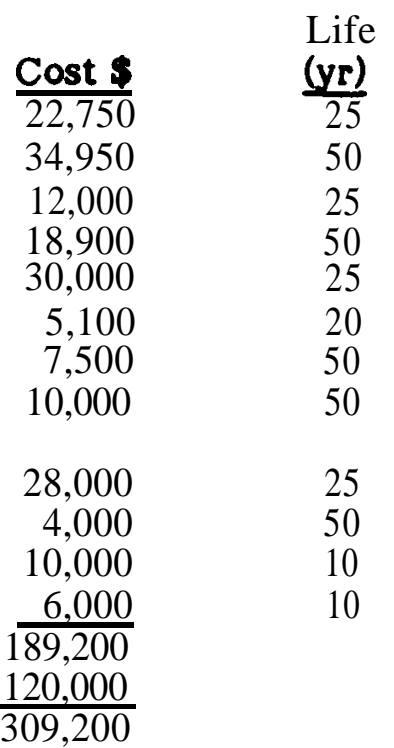

Annual Operating Costs

$\underline{\text { Item }}$ $\underline{\text { Description }}$

\section{Cost}

1 man year

$6.307 \times 10^{7} \mathrm{cu} . \mathrm{ft}$.

25,000

6,307

8,100

20,250 lbs.

Drugs, telephone, fuel

office supplies, parts, etc.

Misc. maint.

Equipment repair, roadway \&

2,000

building maintenance 
Chapter 8

Table 15. A 10,500 pound-1 million egg hatchery with low costs.

\section{Capital Costs}

Item and Description

House - 1100 sq. ft.

Tool shed - portable 200 sq. ft.

Incubator system R-48 barrels and plumbing

Water system - intake and lines

Net pen rearing system - net and floats

Land clearing and grading - 2 acres

Landscaping

Pick-up truck

Tools and miscellaneous equipment

Total excluding land

Estimated land cost

Total including estimated land cost

\begin{tabular}{rr} 
Cost $\$$ & $\begin{array}{l}\text { Life } \\
\text { (yr) }\end{array}$ \\
\hline 34,950 & $\mathbf{5 0}$ \\
$\mathbf{6 , 0 0 0}$ & 25 \\
2,700 & 20 \\
6,000 & 20 \\
23,750 & 10 \\
5,000 & 50 \\
2,000 & 50 \\
10,000 & 10 \\
5,000 & 10
\end{tabular}

Annual Operating Costs

Item

Manpower

Water

Misc. supplies

Food

Misc. maint.

Egg purchase

Freezer rental

Total
Description

.75 man years

Incubation only

Drugs, telephone, fuel

office supplies, parts, etc.

20,250 lbs.

Equipment repair, roadway \&

buildingmaintenance

$1 \times 10^{6}$ at $\$ 8 / 1000$
Cost $\$$

18,750

2,000

8,000

2,000

8,000

1,200 
Project Selection and Evaluation

Table 16. An example of computations of hatchery efficiency ratio for a 50,500 $\mathrm{lb}$. high cost unit.

H.E.R. $=\quad \mathbf{5 0 , 5 0 0 ~} \mathbf{A}_{\mathbf{5 0}, \mathbf{r}}$

Total discounted costs over

hatchery life of 50 years

The separate elements of the denominator are as follows:

$\underline{\text { Item }}$

1. 723,700

2. $375,500\left(\mathbf{1}+\mathrm{V}_{\mathbf{2 5}, \mathbf{r}}\right)$

3. $20,000\left(1+V_{15, r}+V_{30, r}+V_{45, r}\right)$

4. $\quad-69667 \mathbf{V}_{\mathbf{5 0 , \mathbf { r }}}$

5. $39,100\left(1+V_{20, r}+V_{40, r}\right)$

6. $-19,550 \mathrm{~V}_{\mathbf{5 0}}, \mathbf{r}$

7. $25,000\left(1+V_{10, r}+V_{20, r} V_{30, r}+V_{40, r}\right)$

8. $152,536 \mathrm{~A}_{50, \mathrm{r}}$ $\underline{\text { Explanation }}$

cost of SO-year items

cost of 25-year items

cost of 15-year items

salvage value of 15-year items

cost of 20-year items

salvage value of 20-year items

cost of 10-year items

operating costs

For simplicity, no recovery values are assumed for any items at end of their lives. The salvage values above represent the fractional values for certain replacement items at the SO-year point.

Table 17. Hatchery efficiency ratios for six hypothetical production combinations.

$50,500 \mathrm{lbs}-2$ million eggs

high cost

medium cost

low cost $\underline{\mathrm{lb} / \$}$

.178

.252

.316

.123
.150
.181
$\$ / 1 b$

5.61

3.96

3.17

10,500 lbs-1 million eggs

high cost

medium cost

low cost

.181

8.10

6.67

5.52 


\section{CHAPTER 9}

\section{THEORETICAL HATCHERIES}

Within this Chapter, 20 theoretical low-cost hatcheries have been conceived that produce $10,000 \mathrm{lbs}, 20,000 \mathrm{lbs}$, or 50,000 lbs of juvenile salmon and steelhead trout annually. They have the capability of adult capture and spawning, egg and alevin incubation, and rearing and releasing. Prototype designs have been developed for each along with the estimated operational and capital costs. Special consideration has been given to both physical and biological conditions that are likely to be encountered in areas east of the Cascade range.

\section{PART I. METHODS USED IN DEVELOPING 20 THEORETICAL HATCHERIES}

The steps we took for the theoretical physical development of each hatchery were:

(1) Clearly define the goal of juvenile fish production.

(2) Develop the biological criteria for the life phase of each species needed to meet these goals.

(3) Identify operational considerations.

(4) Develop theoretical site conditions.

(5) Design the physical components of the facility with consideration for alternatives.

(6) Compute the capital operating and maintenance costs, and define the manpower required to manage each facility.

Each of these steps listed is further explained as it applies in general to all 20 hatcheries. A discussion will be included with each conceptional plan.

\section{A. DEVELOPMENT OF GOALS}

The ultimate goal of a hatchery is to economically produce adults by releasing juvenile fish. In this report, the goal is to produce given numbers and sizes of certain species of juvenile fish in low-cost life facilities with components designed to last 10 years or longer; however, because all hatcheries are theoretical and the intent is to compare developmental options, we will forgo any analysis of adult production.

We were provided specific hatchery goals for 12 stations where all production occurs at a single site. The other eight facilities include off-station production (Table 1). For the latter eight facilities, more specific goals were developed with emphasis on aiding natural 
production and local fishery harvest. Specific programs are presented with each facility concept later in this chapter.

Table 1. Broad production goals for 20 theoretical hatcheries.

\section{Species \\ Fall chinook}

Spring chinook

Fall chinook and coho

Coho

Steelhead
With on-station production

\begin{tabular}{lll} 
& only (pounds) & \\
\cline { 2 - 3 } 10,000 & 20,000 & 50,000 \\
10,000 & 20,000 & 50,000 \\
10,000 & 20,000 & 50,000 \\
0 & 0 & 0 \\
10,000 & 20,000 & 50,000
\end{tabular}

$\begin{array}{lc}\begin{array}{l}\text { With on and offstation } \\ \text { production }\end{array} & \text { (pounds) } \\ 20,000 & 50,000 \\ 20,000 & 50,000 \\ 0 & 0 \\ 20,000 & 50,000 \\ 20,000 & 50,000\end{array}$

$\begin{array}{ll}20,000 & 50,000 \\ 20,000 & 50,000 \\ 0 & 0 \\ 20,000 & 50,000 \\ 20,000 & 50,000\end{array}$

(1) Offstation production includes adult holding, incubation, and/or rearing as satellites to the main station.

\section{B. BIOLOGICAL CRITERIA}

The biological criteria used to develop the physics1 concept for each facility was previously presented in this report and is primarily documented in:

Chapter 3, Table 2 "Space and flow criteria for long-term holding of adult salmon and steelhead trout ...";

Chapter 4, Table 1 through 3 for incubation temperature requiremenis, incubation water requirements, and incubation density by unit types, respectively;

Chapter 5, Table 1, 2 and 4 on water flow, rearing space, and food requirements, respectively; and

Chapter 6, Table 2 on transportation densities.

While these tables assisted our design team in developiring the physical hatcher; encept, further criteria were developed from which we based the proauction program. This mainly relates to adult timing and the survival rates for each lifc phase (fuolc 2). This table was developed after conferring with agency personnel. It will be used as a standuru for all 20 hatcheries; recognizing, however, that managers and existing facilities can experience different results.

Table 3 was developed from Table 2 to provide a standard system in which to obtain the required numbers of adults, eggs, and fish for a 10,0OO-lb smolt program. The needs of a larger smolt program is a direct multiple of these figures (i.e., a 50,001)-lb smolt statioli requires a multiple of 5 ).

The temperature and feeding levels are the two most comnion fuctors tfecing gruwtil, and are used exclusively in this report. Using $50-52 \mathrm{~F}$ rearing water, our visertatun was that it takes salmon about 120 days to reach 80 fish per pound, aits llus is liac buiserit! rizle of growth we will use. If we pegin with fish et $1100 \%$ (1) (1.41 incless sta ill:y biow ic 80/1b (3.45 inches), the gain in inches per month is slightly slower thin siecllest. 
Chapter 9

Table 2. General biological criteria used to program theoretical salmonid hatcheries in the Columbia River Basin.

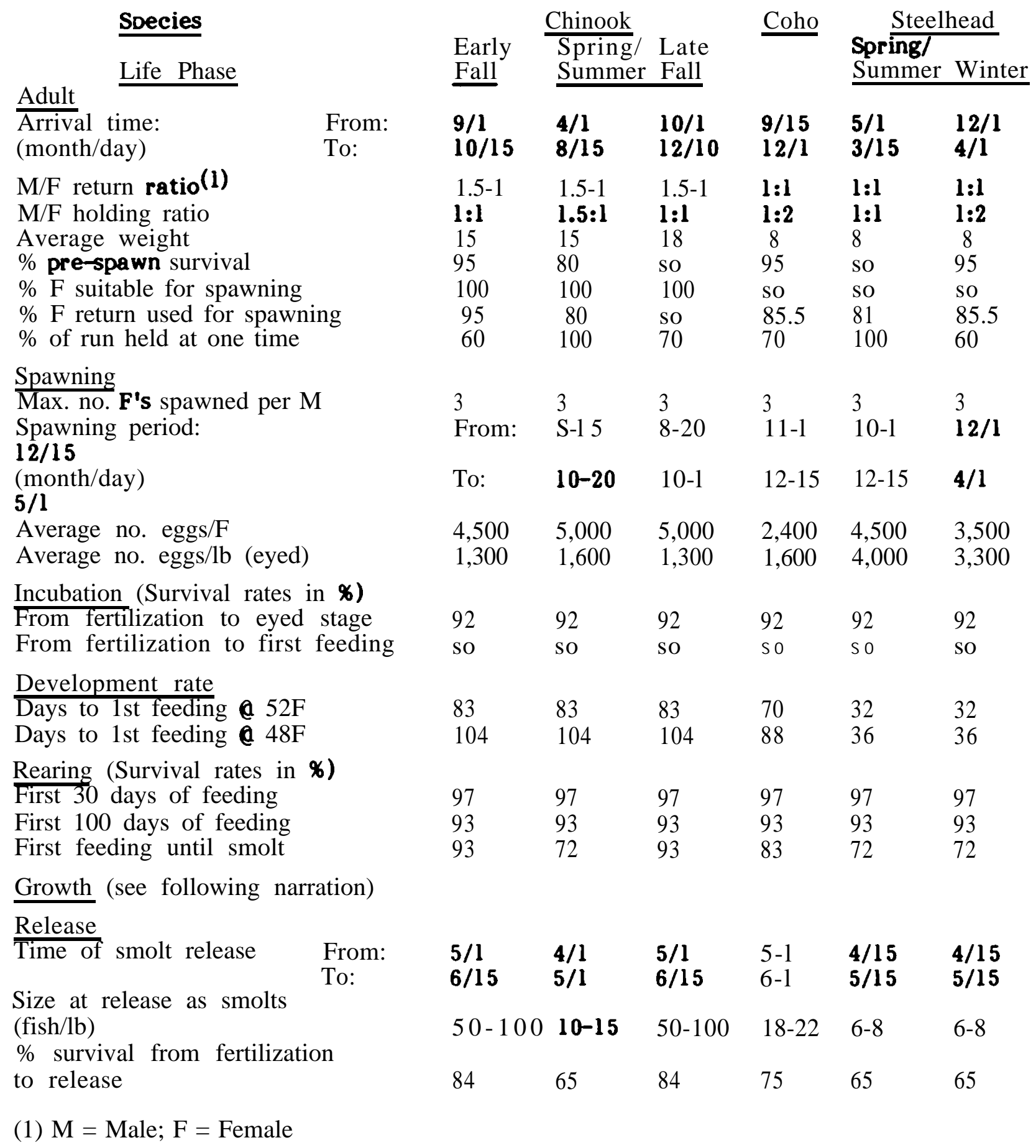


Theoretical Hatcheries

Table 3. Numbers of adults, eggs, and juveniles needed for a 10,OOO-lb smolt release.

\begin{tabular}{|c|c|c|c|c|c|c|}
\hline Species & & Chinook & & Coho & & head \\
\hline & Early & Spring/ & Late & & Spring/ & \\
\hline Life Phase & Fall & $\underline{\text { Summer }}$ & Fall & & Summer & Winter \\
\hline $\begin{array}{l}\text { Adult (numbers) } \\
\text { Total F return }\end{array}$ & & & & & 30 & \\
\hline Snawned F & 223 & 46 & 211 & 130 & 30 & 36 \\
\hline $\begin{array}{l}\text { Spawned F } \\
\text { Return }\end{array}$ & 212 & 37 & 191 & 111 & 24 & 31 \\
\hline Return total $\mathrm{M} \& \mathrm{~F}$ & 552 & 70 & 528 & 260 & 60 & 78 \\
\hline Ratio of $\mathrm{M}$ to $\mathrm{F}$ holding & $1: 1$ & $1.5: 1$ & $1: 1$ & $1: 2$ & $1: 1$ & $1: 2$ \\
\hline $\begin{array}{l}\text { No. M \& F held } \\
\text { at one time }\end{array}$ & 26 & 115 & 297 & 137 & 60 & 36 \\
\hline Incubation (numbers) & & & & & & \\
\hline New fertilized eggs & 952,000 & 185,000 & 952,000 & 267,000 & 108,000 & 108,000 \\
\hline Eyed eggs & 876,000 & 179,000 & 876,000 & 245,000 & 99,000 & 99,000 \\
\hline Rearing (numbers) & & & & & & \\
\hline Fry Donded & 857,000 & 166,000 & 857,000 & 240,000 & 97,000 & 97,000 \\
\hline At 30 days & $831 ; 000$ & 161,000 & 831,000 & 233,000 & 94,000 & 94,000 \\
\hline At 100 days & 797,000 & 155,000 & 797,000 & 223,000 & 90,000 & 90,000 \\
\hline At smolt stage & 800,000 & 120,000 & 800,000 & 200,000 & 70,000 & 70,000 \\
\hline
\end{tabular}

Gearheard (personal communication) related that steelhead trout grow at the approximate rate of 0.5 inches per month in rearing water with a temperature of $\mathbf{4 7 - 5 3 F}$, and this is the basis for our programming growth rates for steelhead trout. Starting with a one-inch trout at $2857 / \mathbf{l b}$, we calculate that at the end of 13 months the fish will reach 7.5 inches, or about 7 fish/lb. We suggest you refer to Piper et al., (1982) for tables converting fish in inches to fish per pound.

As previously mentioned, the survival of steelhead trout from juveniles to adults appears to be enhanced if they are reared in water cooler than $\mathbf{5 0 F}$ during the winter and early spring period prior to release. We have programmed this as a biological requirement. In addition, we used the option of accelerating maturation and incubation to provide more rearing for a steelhead trout rearing program (see Chapters 3 \& 4).

We have developed Table 4 to show the approximate anticipated size of juvenile fall chinook and steelhead trout by month that a culturist could expect in a rearing program given the above situation.

Most often the growth rates for spring chinook and coho salmon juveniles either should be slowed and/or the number of days for rearing reduced. Generally, the times of the year that space and water are usually in greatest need for spring chinook and coho is at the time of smolt release, during low warm summer flows, and during the fall of the year when low flows persist and adults are being held. In Chapter 4 we documented that fish size can be regulated by using cool incubation water, cool winter rearing water, reduced feeding rates, or a combination of these. These options will be used to give the culturist considerable latitude to manipulate fish size. All these options will result in a more suitable hatchery environment for the juveniles and adults. 


\section{Chapter 9}

Table 4. Anticipated growth for fall chinook salmon and steelhead trout in water temperatures approximating SOP.

\begin{tabular}{|c|c|c|c|c|}
\hline \multirow[b]{2}{*}{ Days of rearing } & \multicolumn{2}{|c|}{ Fall chinook } & \multicolumn{2}{|c|}{ Steelhead trout } \\
\hline & Fish/lb & $\overline{\text { Length (Inches) }}$ & Fish $\overline{\mathbf{l b}}$ & 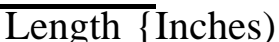 \\
\hline 0 & 1100 & 1.4 & 2857 & 1.0 \\
\hline 30 & 500 & 1.9 & 862 & 1.5 \\
\hline 60 & 250 & 2.4 & 352 & 2.0 \\
\hline so & 125 & 3.0 & 185 & 2.5 \\
\hline 120 & 80 & 3.4 & 102 & 3.0 \\
\hline 150 & & & 67 & 3.5 \\
\hline 180 & & & 44 & 4.0 \\
\hline 210 & & & 31 & 4.5 \\
\hline 240 & & & 23 & 5.0 \\
\hline 270 & & & 17 & 5.5 \\
\hline 300 & & & 13 & 6.0 \\
\hline 330 & & & 10 & 6.5 \\
\hline 360 & & & 8 & 7.0 \\
\hline 390 & & & 7 & 7.5 \\
\hline 420 & & & 5 & 8.0 \\
\hline
\end{tabular}

With the theoretical spring chinook and coho stations that follow, the fish sizes that we feel are achievable by time are shown in Table 5 .

Table 5. Programmed growth rates for juvenile spring chinook and coho salmon by time for theoretical hatcheries.

Spring chinook

Date

April 15

June 1

October 1

For fall release

Held for spring release

As smolts

$$
\text { (April } 15 \text { - May 1) }
$$

$\begin{array}{rc}\frac{\text { Fish/lb }}{100-150} & \text { Grams/fish } \\ 65-70 & <\mathbf{4 . 5} \\ & <\mathbf{7 . 0}\end{array}$

15
$25-30$
30.0

$<18.0$

38.0
Species

\begin{tabular}{cc} 
& \multicolumn{2}{c}{ Coho } \\
$\frac{\text { Fish/lb }}{250-300}$ & $\frac{\text { Grams/fish }}{<\mathbf{1 . 5}}$ \\
$1 \mathrm{SO}-200$ & $<\mathbf{3 . 0}$
\end{tabular}

not conducted

$35-40<13.0$

$20 \quad 23.0$

Water sources used in the theoretical hatcheries have a temperature profile abitrarily chosen, but they are based on recorded temperatures of typical Columbia River Basin streams and ground water sources east of the Cascade range. Fig. 1 (upper) is the surface water temperature curve used to rear fall chinook salmon and steelhead trout, while Fig. 1 (lower) is the surface water temperature curve we will use at the spring chinook and coho salmon hatcheries.

The ground water temperatures programmed are 53F for fall chinook, $48 \mathrm{~F}$ for spring chinook and coho, and 50F for steelhead trout. 
Theoretical Hatcheries

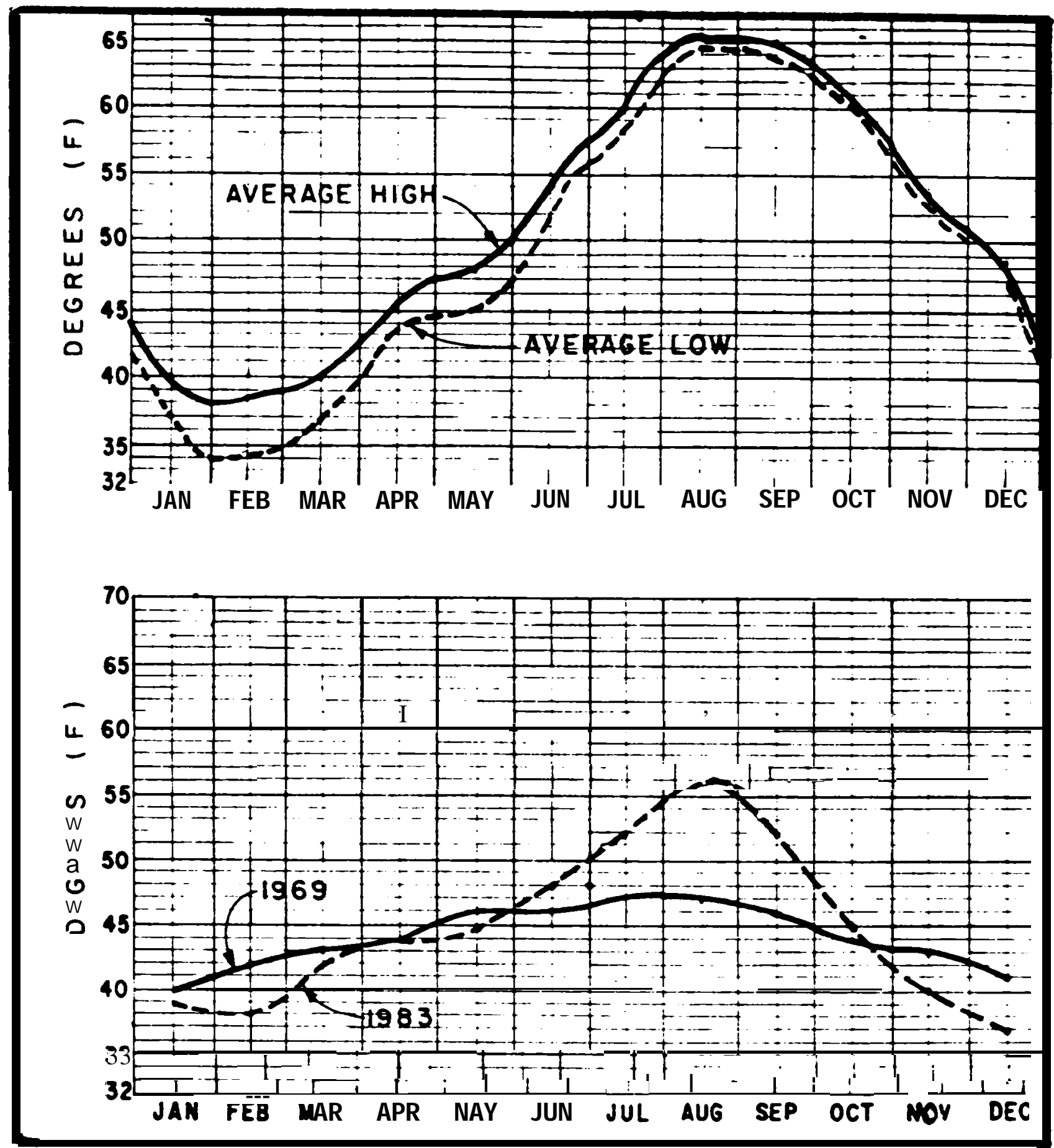

Figure 1. Surface water temperature curves for rearing fall chinook salmon and steelhead trout (upper), and spring chinook and coho salmon (lower), at theoretical hatcheries. Source: S-year average at wells Salmon Hatchery, WDF (upper), and two years of records at Entiat $\mathrm{NFH}$, USFWS (lower). 


\section{Chapter 9}

\section{c. OPERATIONAL CONSIDERATIONS}

The facilities and personnel needed to handle the adult holding and spawning, incubation and rearing is based on information from previous chapters. To briefly review, we present the following:

1. General Consideration First and foremost, quality fish are predictable; the cost of the facility is comparatively low; portability is a consideration; rapid installation is an advantage; and single life-phase use of any unit is avoided if feasible, etc.

3. Adult Holding and Spawning Small groups will require similar security costs as large groups; spawning of adults, as steelhead, over long periods of time will tie up space so individual holding will be used for efficiency; for small programs, such as 10,000-20,000 pounds production of steelhead, coho, or spring chinook, a spawn shed will not be necessary; etc.

3. Incubation Provisions will be required to isolate the steelhead trout eggs because of disease considerations; large and small egg lots will be considered units with multi-purpose use will be preferred, such as ones which can conveniently eye eggs, incubate alevins, rear fry, hold adults, or be used for miscellaneous programs, such as marking fish.

4. Rearing Small units will be used where many small lots of fish begin feeding over a long period of time; ponds that can be readily sectioned to accomodate this concern, or for segregation for other reasons, will be preferred. Large ponds are less costly per $\mathrm{ft}^{3}$ of space and more manpower efficient than smaller ponds and will be used where possible. Net enclosures and net pens will be used where possible because they require no costly inlet or outlet structure, are portable, low cost, and provide rapid installation; rearing ponds will be designed to handle adults; etc.

5. Personnel and Other Considerations In the theoretical hatcheries that follow, we have assumed the operations of each facility is located east of the Cascade range, where most natural elements are extreme. Other assumptions are (see Chapter 8, Table 1): support services are within 20 miles; skilled personnel is available; temporary and volunteer helpers exist; no support is available from nearby tax supported entities; some housing onstation is require o the schools, hospitals, and shopping centers are available; work assignments other than at the fish culture station can be made for any employee; and once given the hatchery production goal, it is assumed that the legal requirements and management goals are properly addressed.

\section{THEORETICAL SITE SELECTION}

Most quality hatchery sites for developing large salmonid hatcheries $(100,000 \mathrm{lbs}$ or more annual production) in the Columbia River Basin have been developed. We believe, however, that good numbers of potential sites are still available for developing smaller hatcheries producing smaller quantities of fish. Most of our low-capital propagation facilities and techniques illustrated in this chapter have been successfully utilized or are 
being utilized in salmon and steelhead trout programs These facilities are particularly efficient and cost effective for smaller hatchery installations where rearing programs are designed to operate for a given length of time.

It is recognized that no two hatchery sites are identical, however, we have chosen to use an onstation production hatchery site that is similar to all 20 stations. The site has about 5 acres of relatively flat ground and is supplied with gravity flow surface water and ground water obtained from a single source or a combination of springs, wells, or infiltration galleries. It is also recognized that ground water is not essential provided that surface water flows and quality adequately meet the criteria for all phases of fish life involved in hatchery operations.

\section{E. DESIGN}

The following engineering guidelines were established by the Department of Energy's (BPA) work statement for "Prototype Designs".

0 Flexibility in design to allow accomodation to various sites and to permit future modification at relatively low cost;

0 Water supplied, ideally, by gravity from a spring source, although flexibility in design to accomodate other water sources is require 4

0 Low capital cost;

0 Construction will minimize the use of concrete or other permanent structural material in favor of wood, fiberglass, preformed components, or other relatively low-cost construction;

0 Design must be applicable to environmental conditions in the Columbia River Basin; and

0 Operation and maintenance ( $\mathrm{O} \& \mathrm{M}$ ) costs should be minimized.

To develop the "Prototype Designs", the following criteria were established to meet the above guidelines, and to provide for general cost comparisons for the various low-cost salmon production systems previously identified in this publication.

\section{$\underline{\text { Site Preparation }}$}

(1) Average clearing and grubbing work effort.

(2) Minimal cut and fill for site development.

(3) Site drainage utilizing culverts and ditches.

(4) Roads - surfacing, widths and lengths all standardized. 
Chapter 9

(5) Electrical and phone service transmission lines to site are not included in Project costs.

\section{Water Supply \& Drains}

(1) Stream width at surface water intake and fishway location standardized.

(2) Stream and spring intakes - Concrete construction for stability against washouts. Stream intake sized to permit future expansion and provide a safety factor against water shutdowns caused by icing, debris, or stream sedimentation.

(3) Surface and spring water supplies are gravity flow.

(4) Pipelines, water supply canals, and drains are all standardized for materials and lengths. Pipes are sized not to exceed 2 feet of head loss per 1,000 feet of pipe length for gravity flow, and drainpipes are sized to provide increased drainage capacity to allow for rapid lowering of pond waterlevels without diminishing incoming water supplies.

(5) Groundwater aerated with packed column aerators.

(6) Well pumps are submersible types for security against vandalism.

(7) Multi-well systems are each located at least 1,000 feet apart to minimize interference.

(8) Diesel generators are provided for back-up power during power outages to supply electricity to wells and/or infiltration gallery ground-water pumps.

(9) All outside pipelines and valves are buried for protection against vandalism and extreme air temperatures.

(10) After once being used, no reconditioning of the water is considered. Used water will have the option to gravitate to downstream ponds or new pond development, 'space permitting, or be pumped back upstream where space is available for pond development. The general criteria for re-use of water is that rearing densities should be reduced by one-third with each re-use, provided dissolved oxygen is maintained near optimum in the rearing-pond water.

Fish Production Systems

(1) Egg incubation systems utilize aerated ground water. Incubation equipment is housed in the hatchery building's tank room for light control, protection from vandalism and extreme climatic conditions. Double stack incubation equipment is used to minimize floor space and reduce piping needs. 


\section{Theoretical Hatcheries}

(2) Ground water surplus to the incubation systems is piped to rearing and adult holding facilities for tempering surface water supplies, as necessary, and to imprint smolts for adult return to hatchery waters

(3) Use of dirt ponds is optimized because of lowest unit cost and ease of future expansion.

(4) Fishways require a 6-foot fish lift, and dimensions are standardized to utilize full 4-x 8-foot sheets of plywood.

(5) Pollution control pond is sized for 1 hour detention time. Pond cleaning by vacuum system on facilities producing over $20,000 \mathrm{lb}$ of fish annually.

(6) Net covering is provided over rearing ponds for protection against fish-eating birds.

(7) Electrified fencing around large rearing ponds is provided for protection against wading birds and swimming fish-eating mammals

(8) Low-water alarms are provided for incubation and pond water supplies. Mobile phone-call systems are provided for low-water alarms on remote large ponds with no on-site operator.

\section{Buildings}

(1) All buildings, except for the storage building, utilize concrete foundations.

(2) All large buildings utilize a 12- or 24-foot wide modular dimension for ease of procurement, erection, and future expansion.

(3) All buildings maintain a 40-foot clear distance between buildings to minimize fire damages.

(4) Housing - Provide one quality three-bedroom prefabricated wood frame residence of $1,100 \mathrm{ft}^{2}$ with attached garage for the manager.

(5) Hatchery - Metal frame, siding, and roof: heated, and insulated: partitioned for tank, crew lockers, office, mechanical, and rest rooms.

(6) Storage Building - Pole supported, metal siding and roof, with minimal lighting and gravel floor. Cabinets and storage bins to be installed later by owner.

(7) Cold Storage Building - Freon system capable of -loF O.MP holding temperature. Small capacity units (to $16,000 \mathrm{lb} / \mathrm{OMP}$ storage), use $66 \mathrm{lb} / \mathrm{ft}^{2}$ for sizing the building. Over $16,000 \mathrm{lb}$ capacity units use $83 \mathrm{lb} / \mathrm{ft}^{2}$ for building size. Provide additional work space for thawing and handling feed. 
Chapter 9

\section{F. CAPITAL AND OPERATIONS AND MAINTENANCE}

The capital and operations ( 0 \& $\mathbf{M})$ costs, including 0 \& $\mathbf{M}$ manpower effort and experience required, are listed in the write-up of each prototype facility later in this report. The general approach used is included below.

Capital Costs: Capital costs are all costs associated with facility developments. The capital cost estimates for constructing the "Prototype Designs" are in 1983 dollars and are summarized in Table No. 70 at the end of this Chapter. This table also provides individual estimates for the following hatchery elements for each "Prototype Design".

Site development

Water supply and drains

Fish production facilities

Buildings

Equipment, furnishings, and supplies

These estimates include costs for site-specific planning, design, contract administration, construction, construction contingencies, and facility start-up instructions. Because of highly variable costs that could require substantial funding, the above estimates do not include property (land and water rights) acquisition, environmental documents (assessments, statements, permits, and archaeologic investigations), and permanent electrical or telephone services into the site.

Operations and Maintenance $(0$ \& $M$ ) Costs: 0 \& $M$ costs, as the name implies, are those associated with operating and maintaining the facility to meet management production goals. In the operation of the theoretical hatcheries presented in this chapter, we assume approximately $90 \%$ of the total 0 \& $\mathrm{M}$ cost is spent for fish food, labor, and electricity (see Chapter 8, p 241-243). Of the 90\%, labor cost approximates $50 \%$ (Fig. 5, p 244). In a breakdown of labor costs, we assume 45\%-50\% will be alloted for such maintenance items as equipment and building repair, road and ground maintenance, screen and pond repair, painting, et al or as documented in Chapter 8, Table 3 (p 245). The remaining 10\% of the 0 \& $\mathbf{M}$ expenditures is programmed to be utilized for routine expenses, supplies, vehicle operations, specialized facility and equipment maintenance, rental equipment, and contract services. For a 50,000 lb production station, the dollars programmed will approximate $\$ 9,000$ to $\$ 1 \mathrm{O}, \mathrm{OO} 0$. Utilities on housing will be paid by the tenant and dollars accumulated from rental charges will not be considered. As the facilities and equipment age, the dollar amount may require an increase. Major repairs or rehabilitation work, and major equipment replacements should also be programmed well in advance of need, to minimize emergencies that could severely impact the 0 \& $M$ funds

A few of the specific operating cost items used in our 0 \& $\mathrm{M}$ estimates are as follows:

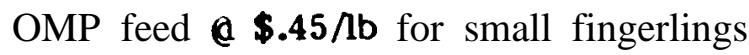

OMP feed @ \$.40/lb for larger fingerlings to smolt-sized fish

Electrical costs for hatcheries without water pumps $3 \%$ of 0 \& $\mathrm{M}$ budget and

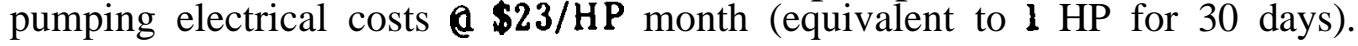




\section{PART II. CONCEPTS OF 20 THEORETICAL HATCHERIES}

Following the methods described in Part I., we have summarized for all 20 hatcheries the space $\left(\mathrm{ft}^{3}\right.$ ) requirements for adult holding (Table 6 ), the recommended type and numbers of incubation units (Table 7), the recommended rearing space and numbers of units (Table 8), and the recommended water supply (Table 9).

Following these tables the 20 hatcheries are individually described and include:

\section{Identification}

Goals

Biological requirements

Facilities and equipment

Operational strategies

costs

The hatcheries are grouped by species in the same order as shown in Table 1., then followed with a general discussion.

Table 6. Minimum recommended space $\left(\mathrm{ft}^{3}\right)$ for adult holding by station capacity.

\begin{tabular}{|c|c|c|c|c|c|}
\hline \multirow[b]{2}{*}{ Species } & \multicolumn{3}{|c|}{ Onstation production } & \multicolumn{2}{|c|}{$\begin{array}{c}\text { On- and off-station production } \\
\text { (pounds) }\end{array}$} \\
\hline & 10,000 & 20,000 & 50,000 & 20,000 & 50,000 \\
\hline$\overline{\text { Fall chinook }}$ & 1876 & $\overline{3752}$ & $\overline{9380}$ & 4252 & $\overline{12,000}$ \\
\hline Spring chinook & 920 & 1840 & 4600 & 3960 & 4952 \\
\hline $\begin{array}{l}\text { Fall chinook/coho } \\
\text { Coho }\end{array}$ & 1022 & 2044 & 5110 & 4324 & 10,800 \\
\hline Steelhead & 85 & 170 & 425 & 545 & 500 \\
\hline
\end{tabular}

Table 7. Recommended number and type of incubation units by station capacity. (Deeps and shallow refer to trough incubators, see Chapter 4.)

\begin{tabular}{|c|c|c|c|c|c|}
\hline \multirow[b]{2}{*}{ Species } & \multicolumn{3}{|c|}{$\begin{array}{l}\text { Onstation production } \\
\text { (pounds) }\end{array}$} & \multicolumn{2}{|c|}{$\begin{array}{c}\text { On- and off-station production } \\
\text { (pounds) }\end{array}$} \\
\hline & $\underline{10,000}$ & $\underline{20,000}$ & $\underline{50,000}$ & 20,000 & $\underline{50,000}$ \\
\hline $\begin{array}{l}\text { Fall } \\
\text { chinook }\end{array}$ & $\begin{array}{l}5 \text { deeps } \\
1 \text { shallow }\end{array}$ & $\begin{array}{l}9 \text { deeps } \\
1 \text { shallow }\end{array}$ & $\begin{array}{l}22 \text { deeps } \\
1 \text { shallow }\end{array}$ & $\begin{array}{l}9 \text { deeps } \\
1 \text { shallow }\end{array}$ & $\begin{array}{l}22 \text { deeps } \\
1 \text { shallow }\end{array}$ \\
\hline $\begin{array}{l}\text { Spring } \\
\text { chinook }\end{array}$ & $\begin{array}{l}1 \text { deep } \\
1 \text { shallow }\end{array}$ & $\begin{array}{l}2 \text { deeps } \\
1 \text { shallow }\end{array}$ & $\begin{array}{l}5 \text { deeps } \\
1 \text { shallow }\end{array}$ & $\begin{array}{l}4 \text { deeps } \\
1 \text { shallow }\end{array}$ & $\begin{array}{l}6 \text { deeps } \\
1 \text { shallow }\end{array}$ \\
\hline $\begin{array}{l}\text { Fall } \\
\text { chinook/ } \\
\text { coho }\end{array}$ & $\begin{array}{l}4 \text { deeps } \\
1 \text { shallow }\end{array}$ & $\begin{array}{l}4 \text { deeps } \\
1 \text { shallow } \\
3 \text { barrels }\end{array}$ & $\begin{array}{l}10 \text { deeps } \\
1 \text { shallow } \\
8 \text { barrels }\end{array}$ & & \\
\hline Coho & & & & $\begin{array}{l}7 \text { deeps } \\
1 \text { shallow }\end{array}$ & $\begin{array}{l}16 \text { deeps } \\
1 \text { shallow }\end{array}$ \\
\hline Steelhead & $\begin{array}{l}27 \text {, 1-gal jugs } \\
1 \text { shallow } \\
14,5-\text { gal jugs }\end{array}$ & $\begin{array}{l}27,5 \text {-gal jugs } \\
1 \text { shallow }\end{array}$ & $\begin{array}{l}77, \mathbf{5} \text {-gal jugs } \\
1 \text { shallow }\end{array}$ & $\begin{array}{l}47,5-\text { gal jugs } \\
1 \text { shallow }\end{array}$ & $\begin{array}{l}85,5 \text {-gal incb. } \\
1 \text { shallow }\end{array}$ \\
\hline
\end{tabular}


Chapter 9

Table 8. Minimum recommended rearing space $\left(\mathrm{ft}^{3}\right)$ by rearing unit size by station capacity.

\begin{tabular}{|c|c|c|c|c|c|c|c|c|}
\hline \multirow{3}{*}{$\begin{array}{l}\text { Species } \\
\text { Fall } \\
\text { chinook }\end{array}$} & \multicolumn{3}{|c|}{$\begin{array}{l}\text { On-station production } \\
\text { (pounds) }\end{array}$} & \multicolumn{5}{|c|}{$\begin{array}{l}\text { On- and off-station production } \\
\text { (pounds) }\end{array}$} \\
\hline & $\underline{10,000}$ & 20,000 & $\underline{50,000}$ & & 20,000 & 50,0 & 000 & \\
\hline & $\begin{array}{l}2 \text { a } 2,000 \\
1 \text { a } 6,200\end{array}$ & $\begin{array}{ll}4 \text { e } & 2,000 \\
1 \text { a } & 13,270\end{array}$ & $\begin{array}{l}6 \text { @ } 2,000 \\
2 \text { @ } 23,650\end{array}$ & $\begin{array}{ll} & \text { On } \\
2 \text { @ } & 2,000 \\
1 \text { @ } & 6,200\end{array}$ & $\begin{array}{l}\text { Off } \\
1 @ 10,500\end{array}$ & $6 @ \mathrm{On}-\mathrm{O} 2,000$ & 10 & $\begin{array}{l}\text { Off } \\
77,000\end{array}$ \\
\hline $\begin{array}{l}\text { Spring } \\
\text { chinook }\end{array}$ & $\begin{array}{l}2 \text { @ } 2,000 \\
1 \text { @ } 3,500\end{array}$ & $\begin{array}{ll}4 \text { @ } & 2,000 \\
1 \text { @ } & 6,200\end{array}$ & $\begin{array}{ll}44 & 2,000 \\
20 & 15,800\end{array}$ & $\begin{array}{l}3 \text { a } 2,000 \\
1 \text { e } 4,000\end{array}$ & 1 e 3,360 & $\begin{array}{l}6 \text { @ } 2,000 \\
1 \text { @ } 8,000\end{array}$ & $\begin{array}{l}6 \mathrm{a} \\
1 \mathrm{a}\end{array}$ & $\begin{array}{l}15 \times 18 \times 6^{(1)} \\
11,000\end{array}$ \\
\hline $\begin{array}{l}\text { Fall } \\
\text { chinook/ } \\
\text { coho }\end{array}$ & $\begin{array}{ll}4 @ & 1,000 \\
1 @ 3,069\end{array}$ & $\begin{array}{l}4 @ 2,000 \\
1 @ 6,200\end{array}$ & $\begin{array}{ll}6 \text { @ } & 2,000 \\
\text { l @ } & 17,400 \\
1 \text { a } & 14,920\end{array}$ & & & & & \\
\hline Coho & & & & 4 e 2,000 & 1 a 4,776 & $\begin{array}{ll}7 \text { @ } & 2,000 \\
1 @ & 10,880\end{array}$ & 10 & 13,140 \\
\hline (1) Net pel & $\begin{array}{l}2 \text { @ } 1,000 \\
1 \text { a } 5,000 \\
3 \text { @ } 50^{(2)}\end{array}$ & $\begin{array}{ll}2 & 2,000 \\
1 & 10,000 \\
6 & 0\end{array}$ & $\begin{array}{ll}4 \text { a } & 2,000 \\
1 & 24,500 \\
2 & 50(2)\end{array}$ & $\begin{array}{l}402.0 n(2) \\
8 @ 50(2)\end{array}$ & $\begin{array}{c}2 @ 15^{\prime} x^{(1)} \\
18^{\prime} \times 6^{\prime} \\
3 @ 15^{\prime} x^{(1)} \\
15^{\prime} \times 10^{\prime} \\
\text { Enclosure } \\
100^{\prime} \times 50^{\prime} \times 4^{\prime}\end{array}$ & $\begin{array}{ll}8 @ 2,0 \cap 0 \\
8 @ 50\end{array}$ & $\begin{array}{l}30 \\
10 \\
20\end{array}$ & $\begin{array}{l}15^{\prime} \times 18^{\prime}(1) \\
\times 6 \\
8920 \\
15^{\prime} \times 18^{\prime}(1) \\
\times 8^{\prime}\end{array}$ \\
\hline
\end{tabular}

Table 9. Minimum recommended water flows (gpm) by water type and station capacity.

\begin{tabular}{|c|c|c|c|c|c|c|c|}
\hline \multirow[b]{3}{*}{ Species } & \multicolumn{3}{|c|}{$\begin{array}{c}\text { On-station production } \\
\text { (pounds) }\end{array}$} & \multicolumn{4}{|c|}{$\begin{array}{l}\text { On-and } \mathrm{g} f \mathrm{f}-\mathrm{station} \\
\text { production }(1) \text { (pounds) }\end{array}$} \\
\hline & 10,000 & 20,000 & 50,000 & 20,0 & & 50,0 & 000 \\
\hline & Ground River & Ground River & Ground River & Ground & River & Ground & River \\
\hline Fall chinook & $\begin{array}{ll}343 & 1740\end{array}$ & 6863480 & $\begin{array}{ll}17158700 \\
\end{array}$ & 343 & 1760 & 1715 & 787 \\
\hline Spring chinook & 2161095 & 4322190 & 10805475 & 432 & 1119 & 1080 & 2445 \\
\hline Fall chinook/coho & 1719946 & 3421891 & $855 \quad 4727$ & & & & \\
\hline Coho & & & & 90 & 770 & 225 & 1924 \\
\hline Steelhead & 214 & $428 \quad 1868$ & $1070 \quad 4670$ & 428 & 1422 & 1070 & 2070 \\
\hline
\end{tabular}

(1) Only includes water used for on-station production. 
Theoretical Hatcheries

\section{A. THEORETICAL FALL CHINOOK SALMON HATCHERIES}

The conceptual plans, operations, and costs of five theoretical hatcheries follow,

1. Fall Chinook Salmon Hatchery No. 1

Goals:

Produce 800,000 fall chinook smolts at $80 \mathrm{fish} / \mathrm{lb}(10,000 \mathrm{lbs})$ from an early spawning adult stock for annual on-station releases in stream " $A$ " between "May 15 and June 10.

Summary of Biological Requirements:

Smolt production (no./size)

Fertilized eggs (no. spawned)

Females to spawn (no.)

Adults held at one time (no.)

$800,000 @ 80 / 1 b$

Recommended minimum water (gpm)

ground and or spring surface

Recommended minimum pond space or equivalent

952,000

212

268

$343 @ 53 \mathrm{~F}$

1,740 (see Fig. 1)

$10,000 \mathrm{ft} 3$

Facilities Development:

Table 10 lists the facilities and the associated requirements of Fall Chinook Salmon Hatchery No. 1 and Fig. 2 illustrates the physical plan for the hatchery.

Operational Strategies:

The water and space as related to the percentage of the total biological requirements are shown by time in Figs. 3 and 4, respectively. Comments follow on the operational strategies for each life phase of husbandry.

(1) Adults All adult fall chinook salmon will be captured at the head of the fishway and held until mature in the adult/rearing pond in y wrter temperature of $53 \mathrm{~F}$ or colder. (see Fig. 2)

(2) Incubation All newly fertilized eggs will be incubated in one (or more) lo-compartment deep trough(s) until the eggs are well eyed. Dead egg removal (egg picking) will then be conducted, and the live eggs (approximately 875,000) placed on trays with plastic substrates in five deep troughs. In all cases, the first eggs to hatch will be placed in the lower sections of each trough. Incubation water will be $53 \mathrm{~F}$.

(3) Rearing For rearing, the fish will be transfered from the incubation units to the two 2,000 $\mathrm{ft}^{3}$ raceways. The raceways will be sectioned and the five deep troughs used as required during the early feeding phases. A tut al of 480,000 smolts will be programmed for release from the $6,200 \mathrm{ft}^{3}$ pond. anc. 160,000 from each of the raceways. 


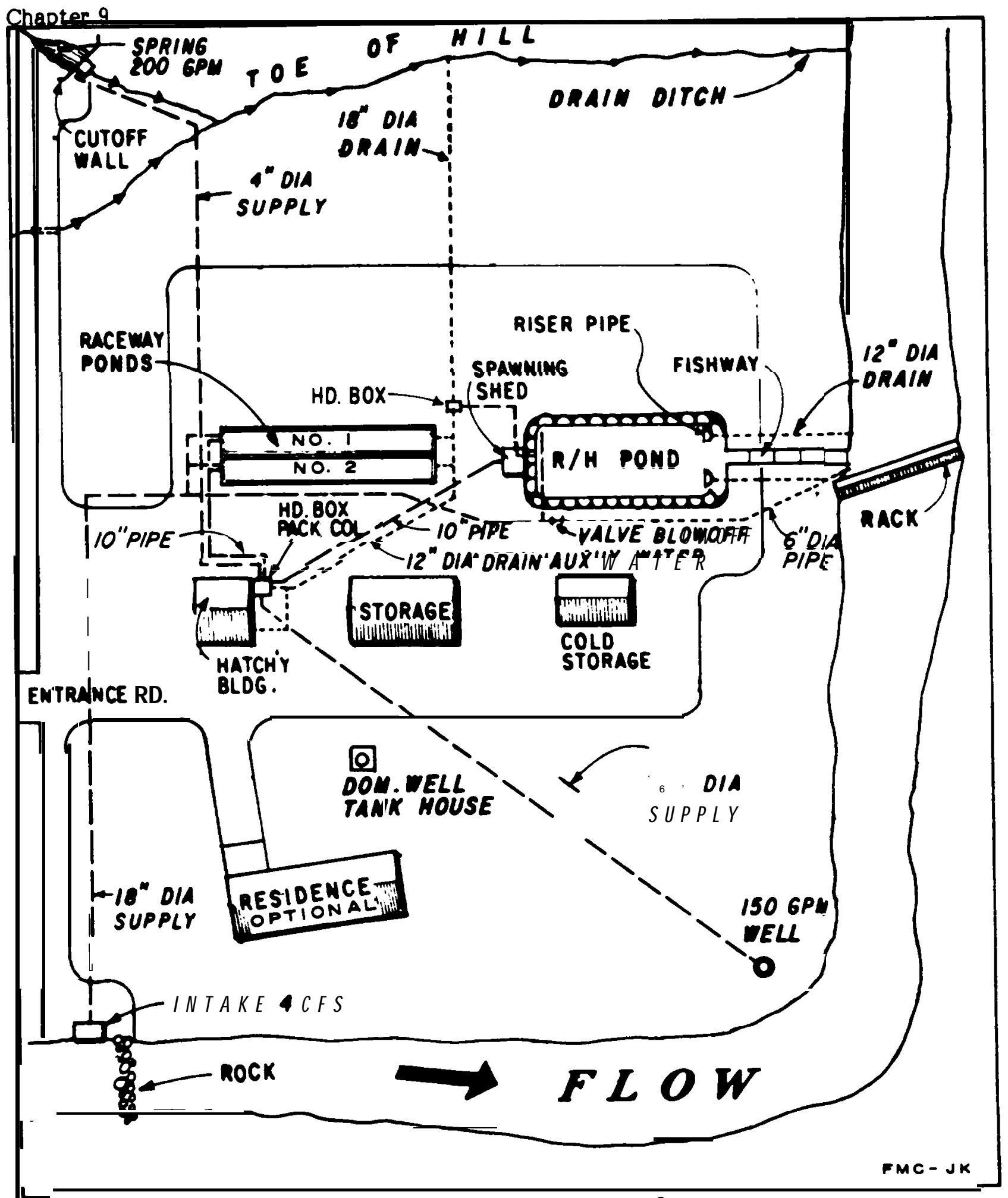

Figure 2. Schematic of Fall Chinook Salmon Hatchery No. l. 
Theoretical Hatcheries

Water-use strategies will be to start all fish on the spring and well water; then use the surface water as required. The water from the raceways will be passed through the $6,200 \mathrm{ft}^{3}$ pond; however, no value for added production will be assigned. A warming effect will occur, however, providing a more rapid growth.

(4) Release All fall chinook smolts will be released through the outlet drain. As theapproach $90 / \mathrm{lb}$ the screens will be pulled to allow a volitional emigration. Feeding will continue for several weeks, at which time the ponds will be drained, forcing the remaining fish into stream " $\mathbf{A}$ ".

\section{Costs:}

Table 11 shows the estimated capital cost for Fall Chinook Salmon Hatchery No. 1, and Table 12 shows the estimated annual operational costs and manpower requirements.

Table 10. Facility development for Fall Chinook Salmon Hatchery No. 1 (10,000 lbs, on-station release.)

\begin{tabular}{|c|c|c|c|}
\hline Facilities & No. & Size & Description \\
\hline \multicolumn{4}{|c|}{ Site Development } \\
\hline $\begin{array}{l}\text { Clearing } \\
\text { \& Grubbing }\end{array}$ & 4 & Acres & $\begin{array}{l}\text { Clearing \& grubbing of hatchery site, } \\
\text { entrance road \& pipeline } R / W \text {. }\end{array}$ \\
\hline Entrance Road & $1 / 2$ & Mile & $\begin{array}{l}\text { 16' wiae, 8" pit run base over ave. 2' fill } \\
\text { ht. Turnouts a } 500^{\prime} \text { intervals. }\end{array}$ \\
\hline $\begin{array}{l}\text { On Site Road } \\
\text { \& Drives }\end{array}$ & 3,600 & $y d^{2}$ & $8 "$ base \& $2 "$ crushed rock topping. \\
\hline \multicolumn{4}{|c|}{ Water Supply \& Drains } \\
\hline Stream Intake & T & $10^{\prime} \times 4$ & $\begin{array}{l}\text { Coarse \& fine screen reinforced concrete } \\
\text { with rock check }\end{array}$ \\
\hline Supply Lines & & & $\begin{array}{l}\text { 12" diameter \& larger - C.VP, under } 12 " \\
\text { PVC }\end{array}$ \\
\hline Drain Lines & & & $\begin{array}{l}12 " \text { diameter \& larger - C.VIP, under } 12 " \\
\text { PVC }\end{array}$ \\
\hline Production Well & 1 & $150 \mathrm{gpm}$ & $\begin{array}{l}\text { 8" diameter x 200' deep with } 10 \mathrm{HP} \\
\text { submersible pump }\end{array}$ \\
\hline Domestic Well & 1 & $5 \mathrm{gpm}$ & $\begin{array}{l}6^{\prime \prime} \text { diameter } \times 120^{\prime} \text { deep with } 1 / 2 \mathrm{HP} \\
\text { submersible pump. Pressure tank with } \\
\text { wood frame house - PVC underground } \\
\text { piping to buildings \& spawning shed. }\end{array}$ \\
\hline Spring Intake & 1 & 16' long & $\begin{array}{l}\text { Concrete cut-off wall X } 5^{\prime} \text { high with } 2^{\prime} \times \\
4^{\prime} \text { concrete screened intake box }-200 \mathrm{gpm} \text {. }\end{array}$ \\
\hline Aeration Head Box & 1 & $4^{\prime} \times 4^{\prime}$ & $\begin{array}{l}\text { Plywood construction/compartments for } \\
\text { spring and well water aeration through } \\
\text { two } 2 \text { packed column aerator units. }\end{array}$ \\
\hline Stream Rock Check & 1 & $20 \mathrm{yd}^{3}$ & Heavy rock rip $\operatorname{rap}\left(30^{\prime} \times 6^{\prime} \times 3^{\prime}\right)$ \\
\hline
\end{tabular}


Chapter 9

\begin{tabular}{|c|c|c|c|}
\hline Facilities & No. & Size & Description \\
\hline \multicolumn{4}{|c|}{ Fish } \\
\hline Raceways & 2 & $83^{\prime} \times 8^{\prime}$ & $\begin{array}{l}2,000 \mathrm{ft}^{3} \text { water } \\
\text { steel/plastic sh. lining. }\end{array}$ \\
\hline Pond & 1 & $80^{\prime} \times 36^{\prime}$ & $\begin{array}{l}\text { Combination rearing \& adult holding } 6,000 \\
\mathrm{ft}^{3} \text { water, dirt sides \& bottom } / 3: 1 \text { bank } \\
\text { slopes. Pen fencing utilized for adult } \\
\text { holding separation. }\end{array}$ \\
\hline Hatching Tanks & 5 & $16^{\prime} \times 18^{\prime \prime}$ & $\begin{array}{l}5 \text { deep tanks for egg incubation \& } 1 \\
\text { shallow tank for egg picking. }\end{array}$ \\
\hline Adult Fish Rack & 1 & 40 lin $\mathrm{ft}$ & Wood constr - annual installation \\
\hline Fishway & 1 & 6' lift & $\begin{array}{l}\text { Plywood constr } / 4^{\prime} W \times 4^{\prime} H \times 48^{\prime} L / s i x \\
\text { pools with cyclone fencing on top of } \\
\text { fishway for fish containment. }\end{array}$ \\
\hline \multicolumn{4}{|r|}{ Buildings } \\
\hline Hatchery & 1 & $18^{\prime} \times 24^{\prime}$ & $\begin{array}{l}\text { Metal building with tank, office, crew } \\
\text { locker, mechanical' and rest rooms. }\end{array}$ \\
\hline Storage & 1 & $36^{\prime} \times 24^{\prime}$ & $\begin{array}{l}\text { Metal building with gravel floor, three 12' } \\
\text { bays for equipment and supply storage and } \\
\text { diesel generator housing. }\end{array}$ \\
\hline $\begin{array}{l}\text { Cold Storage } \\
\text { Fish Feed }\end{array}$ & 1 & $16^{\prime} \times 12^{\prime}$ & $\begin{array}{l}\text { Prefab } 10^{\prime} \times 12^{\prime} \text { freon cold storage } \\
\text { unit } / 8,000 \text { lb capacity with a } 12^{\prime} \times 6^{\prime} \text { add } \\
\text { on for food handling and thawing OMP } \\
\text { feed delivery } 2 \times \text { per year. }\end{array}$ \\
\hline Residence & 1 & $46^{\prime} \times 24^{\prime}$ & $\begin{array}{l}3 \text { BR. wood frame prefab unit/attached } \\
\text { garage (residence would be marketable if } \\
\text { facility closed). }\end{array}$ \\
\hline Spawning Shed & 1 & $10^{\prime} \times 10^{\prime}$ & $\begin{array}{l}\text { Open sides \& ends with roof for spawning } \\
\text { at head end of holding pond. }\end{array}$ \\
\hline
\end{tabular}

Equipment

General List

l pick-up, nets, pumps' misc. tools \& cleaning equip. $(\$ 24,000)$

Table 11. Facility development costs for Fall Chinook Salmon Hatchery No. 1.

Facility
Site development
Water supply and drains
Fish production facilities
Buildings
Equipment

Total

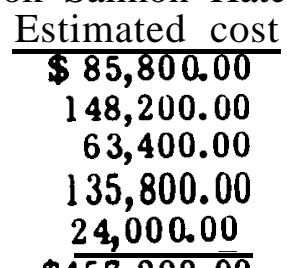

$\$ \overline{457,200.00}$ 
Table 12. Estimated annual operational costs and labor requirements for Fall Chinook Salmon Hatchery No. 1.

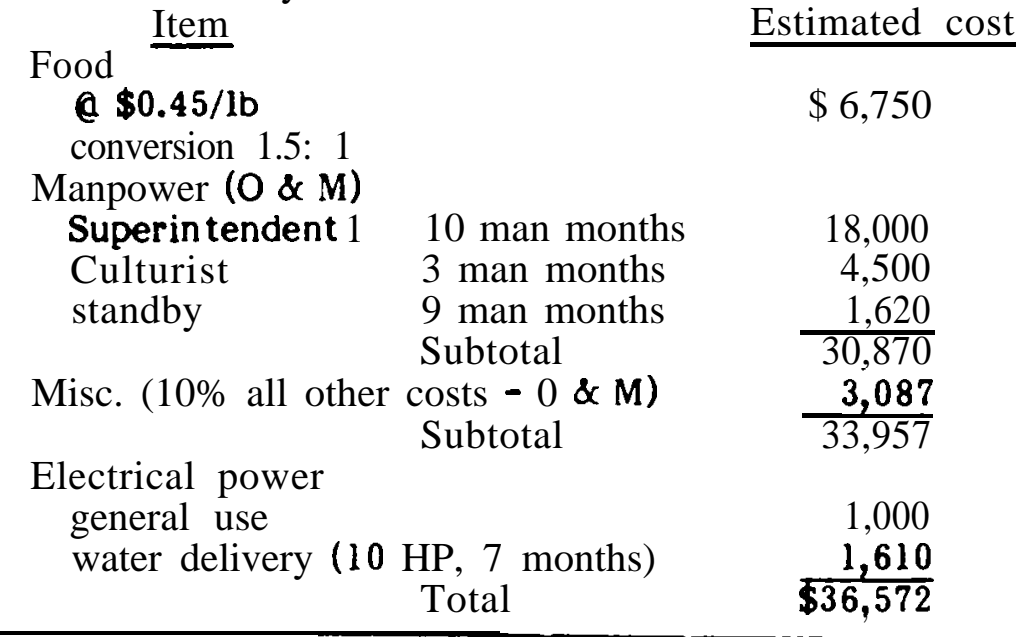
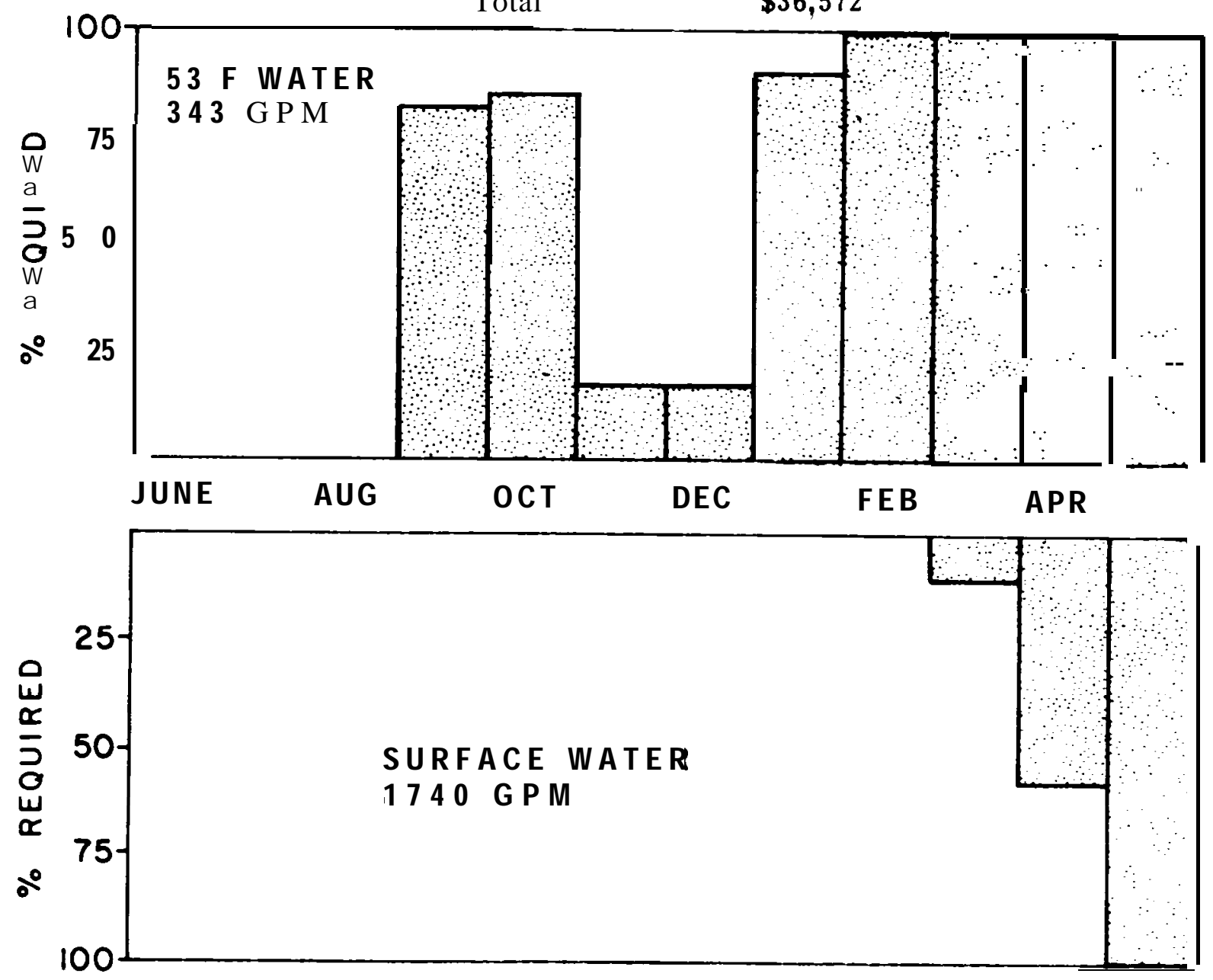

Figure 3. Water-use strategies fir Fall Chinook Salmon Ilatchery Nio. 1. 


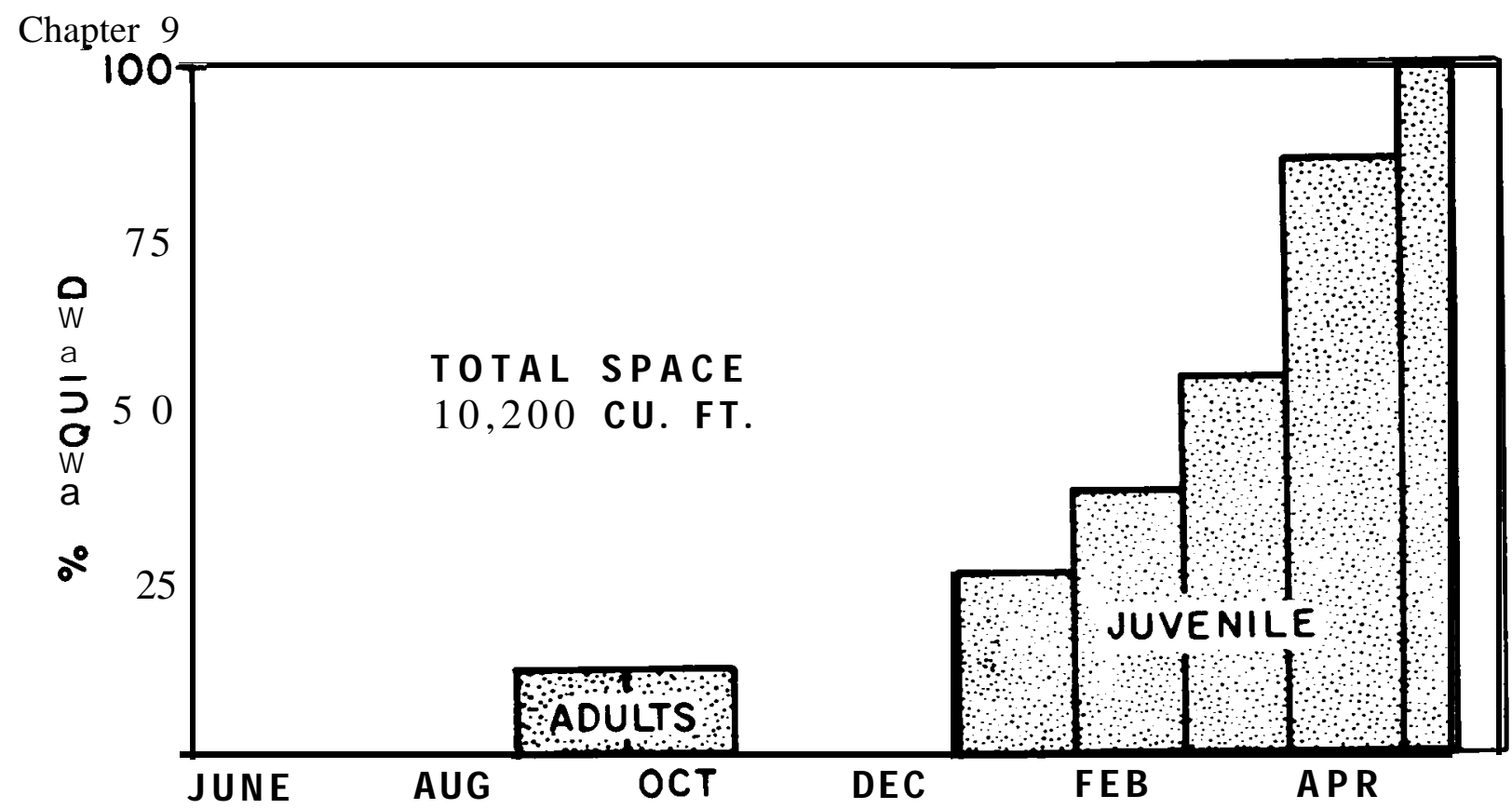

Figure 4. Space-use requirements for Fall Chinook Salmon Hatchery No. 1.

2. Fall Chinook Salmon Hatchery No. 2

Goals:

Produce 1,600,000 fall chinook smolts at 80 fish/lb (20,000 lbs) from an early spawning adult stock for annual on-station releases in stream " $\mathrm{A}$ " between May 15 and June 10.

Summary of Biological Requirements:

Smolt production (no./size)

Fertilized eggs (no. spawned)

Females to spawn (no.)

Adults held at one time (no.)

Recommended minimum water (gpm)

ground and or spring surface

Recommended minimum pond space

or equivalent.

$$
\begin{gathered}
1,600,000 @ 80 / 1 b \\
1,905,000 \\
424 \\
536
\end{gathered}
$$

686 a $53 \mathrm{~F}$

3,480 (see Fig. 1)

$20,000 \mathrm{ft}^{3}$

Facilities Development:

Table 13 lists the facilities and the associated requirements of Fall Chinook Salmon Hatchery No. 2, and Fig. 5 illustrates the physical plan for the hatchery.

\section{Operational Strategies:}

The water and space as related to the percentage of the total biological requirements are shown by time in Figs. 3 and 4, for Fall Chinook Salmon Hatchery No. 1 and are typical for this station. The husbandry for each life phase is identical to Fall Chinook Salmon Hatchery No. 1, including that we 
Theoretical Hatcheries

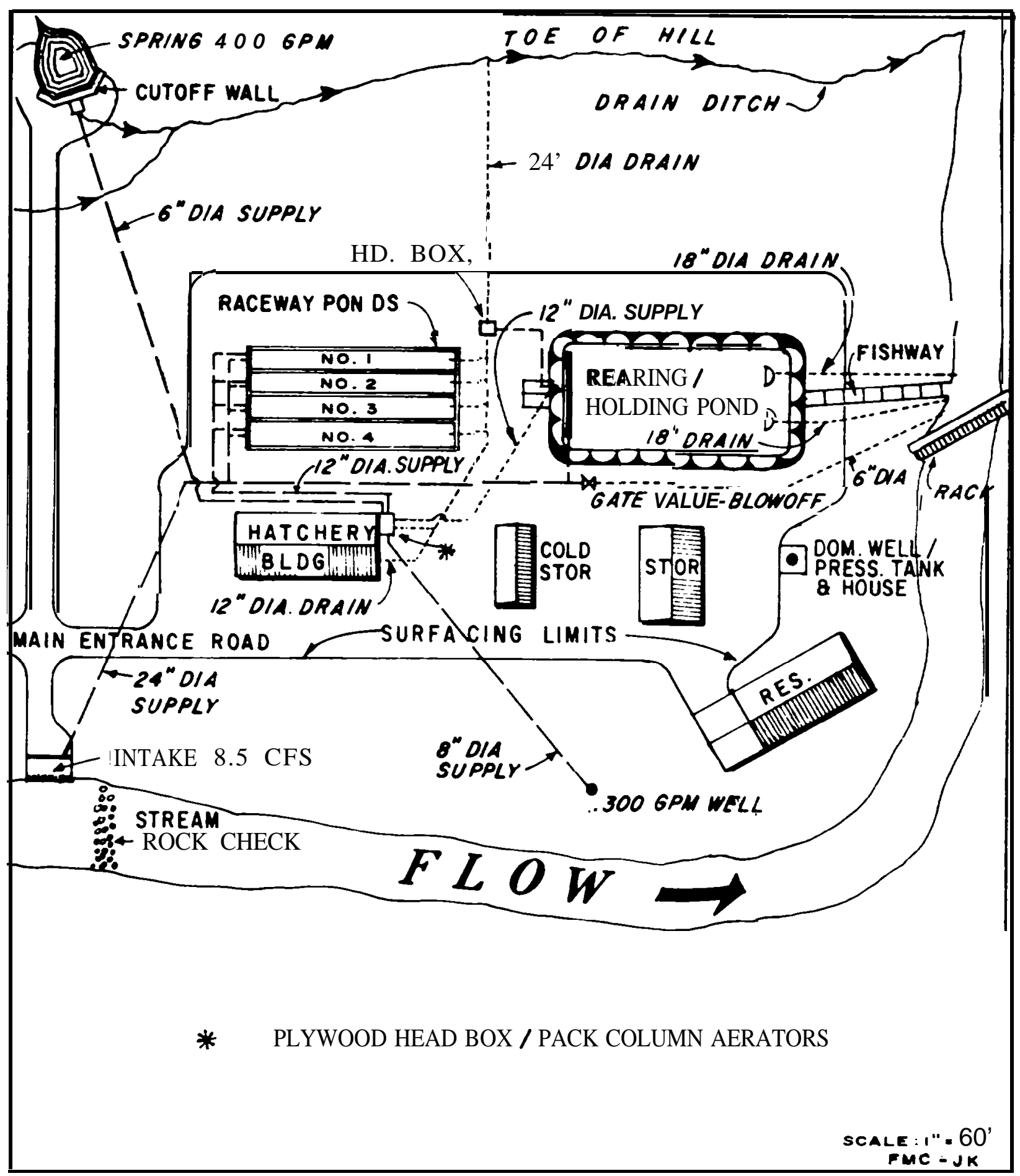

Figure 5. Schematic of Fall Chinook Salmon Hatchery No. 2. 
Chapter 9

have chosen to provide a fishway to capture the adults. All adults will be held in the large rearing/holding pond shown in Fig. 5.

\section{Costs:}

Table 14 shows the estimated capital cost for Fall Chinook Salmon Hatchery No. 2, and Table 15 shows the estimated annual operational costs and manpower requirements.

Table 13. Facility development for Fall Chinook Salmon Hatchery No. 2 (20,000 lbs, onstation release.)

\begin{tabular}{|c|c|c|c|}
\hline Facilities & No. & Size & Description \\
\hline \multicolumn{4}{|c|}{ Site Development } \\
\hline $\begin{array}{l}\text { Clearing } \\
\text { \& Grubbing }\end{array}$ & $41 / 2$ & Acres & $\begin{array}{l}\text { Clearing \& grubbing of hatchery site, } \\
\text { entrance road \& pipeline R/W. }\end{array}$ \\
\hline Entrance Road & $1 / 2$ & Mile & $\begin{array}{l}\text { 16' wide, 8" pit run base over ave. 2' fill } \\
\text { ht. Turnouts a } 500^{\prime} \text { intervals. }\end{array}$ \\
\hline $\begin{array}{l}\text { On Site Road } \\
\text { \& Drives }\end{array}$ & 3,600 & $\mathrm{yd}^{2}$ & $8 "$ base \& $2 "$ crushed rock topping. \\
\hline \multicolumn{4}{|c|}{ Water Supply \& Drains } \\
\hline Stream Intake & 1 & $14^{\prime} \times 4^{\prime}$ & $\begin{array}{l}\text { Coarse \& fine screen reinforced concrete } \\
\text { with rock check }\end{array}$ \\
\hline Supply Lines & & & $\begin{array}{l}\text { 12" diameter \& larger - CMP, under 12" - } \\
\text { PVC }\end{array}$ \\
\hline Drain Lines & & & $\begin{array}{l}\text { 12" diameter \& larger - CMP, under 12" - } \\
\text { PVC }\end{array}$ \\
\hline Production Well & 1 & $300 \mathrm{gpm}$ & $\begin{array}{l}\text { 12" diameter } x \text { 200' deep with } 20 \mathrm{HP} \\
\text { submersible pump }(170 \text { ' lift } x \quad 0.75 \text { eff. })\end{array}$ \\
\hline Domestic Well & 1 & $5 \mathrm{gpm}$ & $\begin{array}{l}\text { 6" diameter } \times 120 \text { ' deep with } 1 / 2 \text { HP } \\
\text { submersible pump. Pressure tank with } \\
\text { wood frame house - PVC underground } \\
\text { piping to buildings \& spawning shed. (240' } \\
\text { lift } x 0.6 \text { eff.) }\end{array}$ \\
\hline Spring Intake & 1 & 16 ' long & $\begin{array}{l}\text { Concrete cut-off wall x 5' high with } 2^{\prime} \text { x } \\
\text { 4' concrete screened intake box. }\end{array}$ \\
\hline Aeration Head Box & 1 & $4^{\prime} \times 4^{\prime}$ & $\begin{array}{l}\text { Plywood construction/compartments for } \\
\text { spring and well water aeration through } \\
\text { four packed column aerator units. }\end{array}$ \\
\hline Stream Rock Check & 1 & $20 \mathrm{yd}^{3}$ & Heavy rock rip rap $\left(30^{\prime} \times 6^{\prime} \times 3^{\prime}\right)$ \\
\hline
\end{tabular}




\begin{tabular}{|c|c|c|c|}
\hline Facilities & No. & Size & Description \\
\hline \multicolumn{4}{|c|}{ Fish Production Facilities } \\
\hline Raceways & 4 & $83^{\prime} \times 8^{\prime}$ & 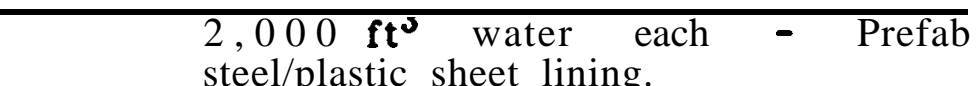 \\
\hline Pond & 1 & $100^{\prime} \times 52^{\prime}$ & $\begin{array}{l}\text { Combination rearing \& adult holding } \\
13^{\prime} 000 \mathrm{ft}^{3} \text { water, dirt sides \& bottom } / 3: 1 \\
\text { bank slopes. Pen fencing utilized for } \\
\text { adult holding separation' }\end{array}$ \\
\hline Hatching Tanks & 9 & $16^{\prime} \times 18^{\prime \prime}$ & $\begin{array}{l}9 \text { deep tanks for egg incubation \& } 1 \\
\text { shallow tank for egg picking. }\end{array}$ \\
\hline Adult Fish Rack & 1 & $40 \operatorname{lin} \mathrm{ft}$ & Wood constr - annual installation \\
\hline Fishway & 1 & 6' lift & $\begin{array}{l}\text { Plywood constr/4'W } \times 4^{\prime} \mathrm{H} \times \mathbf{4 8}^{\prime} \mathrm{L} / \mathrm{six} 8^{\prime} \\
\text { pools with cyclone fencing on top of } \\
\text { fishway for fish containment. }\end{array}$ \\
\hline \multicolumn{4}{|r|}{ Buildings } \\
\hline Hatchery & T & $24^{\prime} \times 24^{\prime}$ & $\begin{array}{l}\text { Metal building with tank, office, crew } \\
\text { locker, mechanical, and rest rooms. }\end{array}$ \\
\hline Storage & 1 & $36^{\prime} \times 24^{\prime}$ & $\begin{array}{l}\text { Metal building with gravel floor, three } 12 \\
\text { bays for equipment and supply storage and } \\
\text { diesel generator housing. }\end{array}$ \\
\hline Cold Storage & 1 & $6^{\prime} \times 12^{\prime}$ & Prefab $20^{\prime} \times 12^{\prime}$ freon cold storage \\
\hline Fish Feed & & & $\begin{array}{l}\text { unit/ } 16,000 \text { lb capacity with a } 66^{\prime} \times 12^{\prime} \text { add } \\
\text { on for food handling and thawing. }\end{array}$ \\
\hline Residence & 1 & $46^{\prime} \times 24^{\prime}$ & $\begin{array}{l}3 \mathrm{BH} \text {. wood frame prefab unit/attached } \\
\text { garage (residence would be marketable if } \\
\text { facility closed). }\end{array}$ \\
\hline Spawning Shed & 1 & $10^{\prime} \times 10^{\prime}$ & $\begin{array}{l}\text { Open sides \& ends with roof for spawning } \\
\text { at head end of holding pond. }\end{array}$ \\
\hline
\end{tabular}

Equipment

General List

1 pick-up, nets, pumps' misc. tools \& cleaning equip. $(\$ 2 \mathbf{\$}, 000)$

Table 14. Facility development costs for Fall Chinook Salmon Hatchery No. 2.

Facility

Site development

Water supply and drains

Fish production facilities

Buildings

Equipment

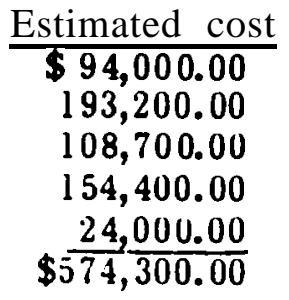

Estimated cost

$193,200.00$

$108,700.00$

$54,400.00$

$\frac{24}{574}, \frac{00000}{300.00}$ 


\section{Chapter 9}

Table 15. Estimated annual operational costs and labor requirements for Fall Chinook Salmon Hatchery No. 2.

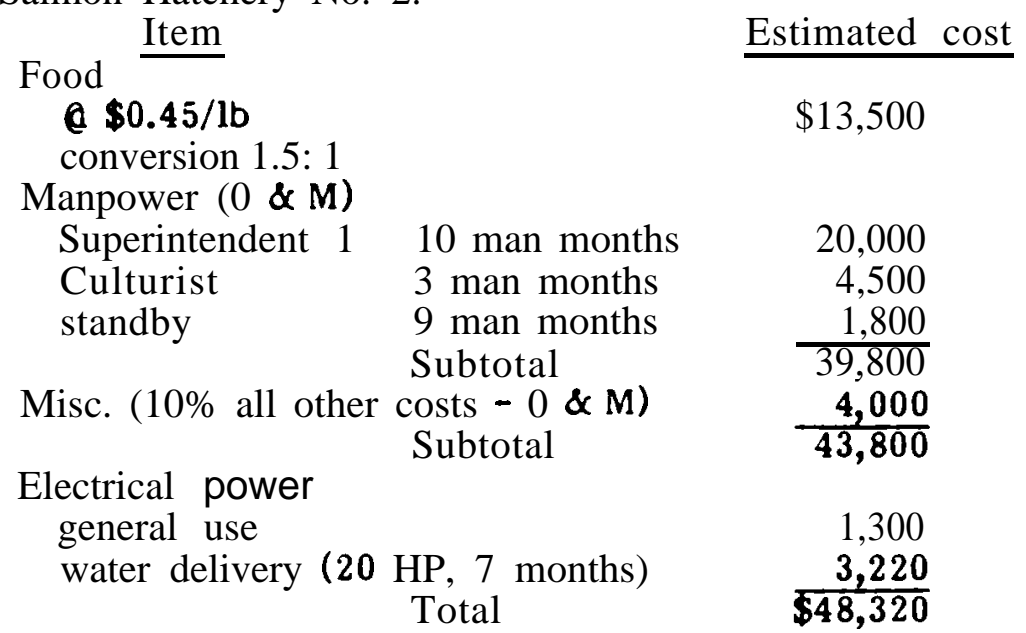

3. Fall Chinook Salmon Hatchery No. 3

Goals:

Produce 4,000,000 fall chinook smolts at $80 \mathrm{fish} / \mathrm{lb}(50,000 \mathrm{lbs})$ from an early spawning adult stock for annual onstation releases in stream "A" between May 15 and June 10.

Summary of Biological Requirements:

Smolt production (no./size)

Fertilized eggs (no. spawned)

Females to spawn (no.)

Adults held at one time (no.)

Recommended minimum (gpm)

ground and or spring water surface water

Recommended minimum pond space or equivalent.

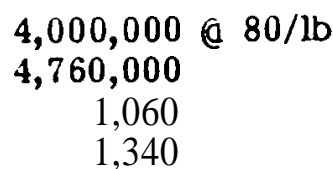

1,715 @ $53 \mathrm{~F}$

8,700 (see Fig. 1) $50,000 \mathrm{ft}^{3}$

Facilities Development:

Table 16 lists the facilities and the associated requirements of Fall Chinook Salmon Hatchery No. 3 and Fig. 6 illustrates the physical plan for the hatchery.

Operational Strategies:

Water and space utilization and all fish husbandry would be similar to the Fall Chinook Salmon Hatchery No. 2 previously described. The programming of the 12 man months for the fish culturist would be conducted as work level required. During the summer months, no culturist would be employed, but during fall and spring months two culturists would often be required. 
Theoretical Hatcheries

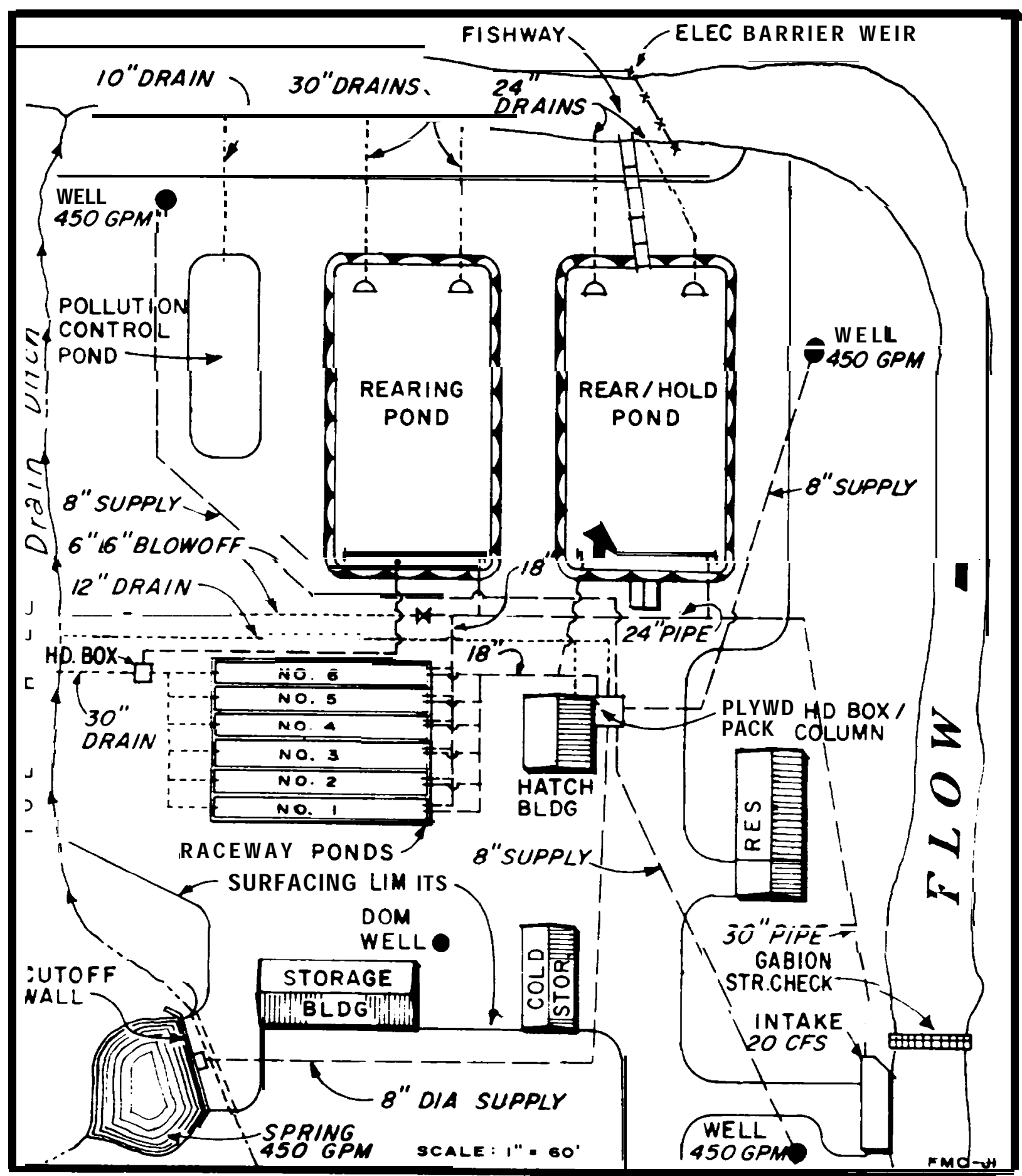

Figure 6. Schematic of Fall Chinook Salmon Hatchery No. 3. 
Chapter 9

\section{Costs:}

Table 17 shows the estimated capital cost for Fall Chinook Salmon Hatchery No. 3 and Table 18 shows the estimated annual operational costs and manpower requirements.

Table 16. Facility development for Fall Chinook Salmon Hatchery No. 3 (50,000 lbs, on-station releases).

\begin{tabular}{|c|c|c|c|}
\hline Facilities & No. & Size & Description \\
\hline \multicolumn{4}{|c|}{ Site Development } \\
\hline $\begin{array}{l}\text { Clearing } \\
\text { \& Grubbing }\end{array}$ & $\overline{7}$ & Acres & $\begin{array}{l}\text { Clearing \& grubbing of hatchery site, } \\
\text { entrance road \& pipeline R/Ws. }\end{array}$ \\
\hline Entrance Road & $1 / 2$ & Mile & $\begin{array}{l}\text { 16' wide, 8" pit run base over ave. 2' fill } \\
\text { ht. Turnouts @ } 500^{\prime} \text { intervals. }\end{array}$ \\
\hline $\begin{array}{l}\text { On Site Road } \\
\text { \& Drives }\end{array}$ & 4,500 & $\mathrm{yd}^{2}$ & $8^{\prime \prime}$ base $\& 2^{n}$ crushed rock topping. \\
\hline \multicolumn{4}{|c|}{ Water Supply \& Drains } \\
\hline Stream Intake & T & $22^{\prime} \times 4^{\prime}$ & $\begin{array}{l}\text { Coarse \& fine screen reinforced concrete } \\
\text { with gabion stream check }\end{array}$ \\
\hline Supply Lines & & & $\begin{array}{l}12 " \text { diameter \& larger - CMP, under } 12^{n} \text { - } \\
\text { PVC }\end{array}$ \\
\hline Drain Lines & & & $\begin{array}{l}12 " \text { diameter \& larger - CMP, under } 12^{\prime \prime} \text { - } \\
\text { PVC }\end{array}$ \\
\hline Production Well & 3 & $450 \mathrm{gpm}$ & $\begin{array}{l}\text { 12" diameter } x \text { 200' deep with } 25 \text { HP } \\
\text { submersible pump. }\end{array}$ \\
\hline Domestic Well & 1 & $5 \mathrm{gpm}$ & $\begin{array}{l}\text { 6" diameter } \times 120 \text {, deep with } 1 / 2 \mathrm{HP} \\
\text { submersible pump. Pressure tank in } \\
\text { storage building - PVC underground piping } \\
\text { to buildings and spawning shed. }\end{array}$ \\
\hline Spring Intake & 1 & $16^{\prime}$ long & $\begin{array}{l}\text { Concrete cut-off wall } x 5^{\prime} \text { high with } 2 \text { ' } x \\
4^{\prime} \text { concrete screened intake box } 450 \mathrm{gpm} \text {. }\end{array}$ \\
\hline Aeration Head Box & 1 & $4^{\prime} \times 8^{\prime}$ & $\begin{array}{l}\text { Plywood construction/compartments for } \\
\text { spring \& well water aeration through } \\
\text { eight packed column aerator units. }\end{array}$ \\
\hline Stream Gabion & 1 & $20 \mathrm{yd}^{3}$ & Gabion rock-filled wire baskets \\
\hline Checks & & & $\left(30^{\prime} \times 6^{\prime} \times 3^{\prime}\right)$ \\
\hline
\end{tabular}


Theoretical Hatcheries

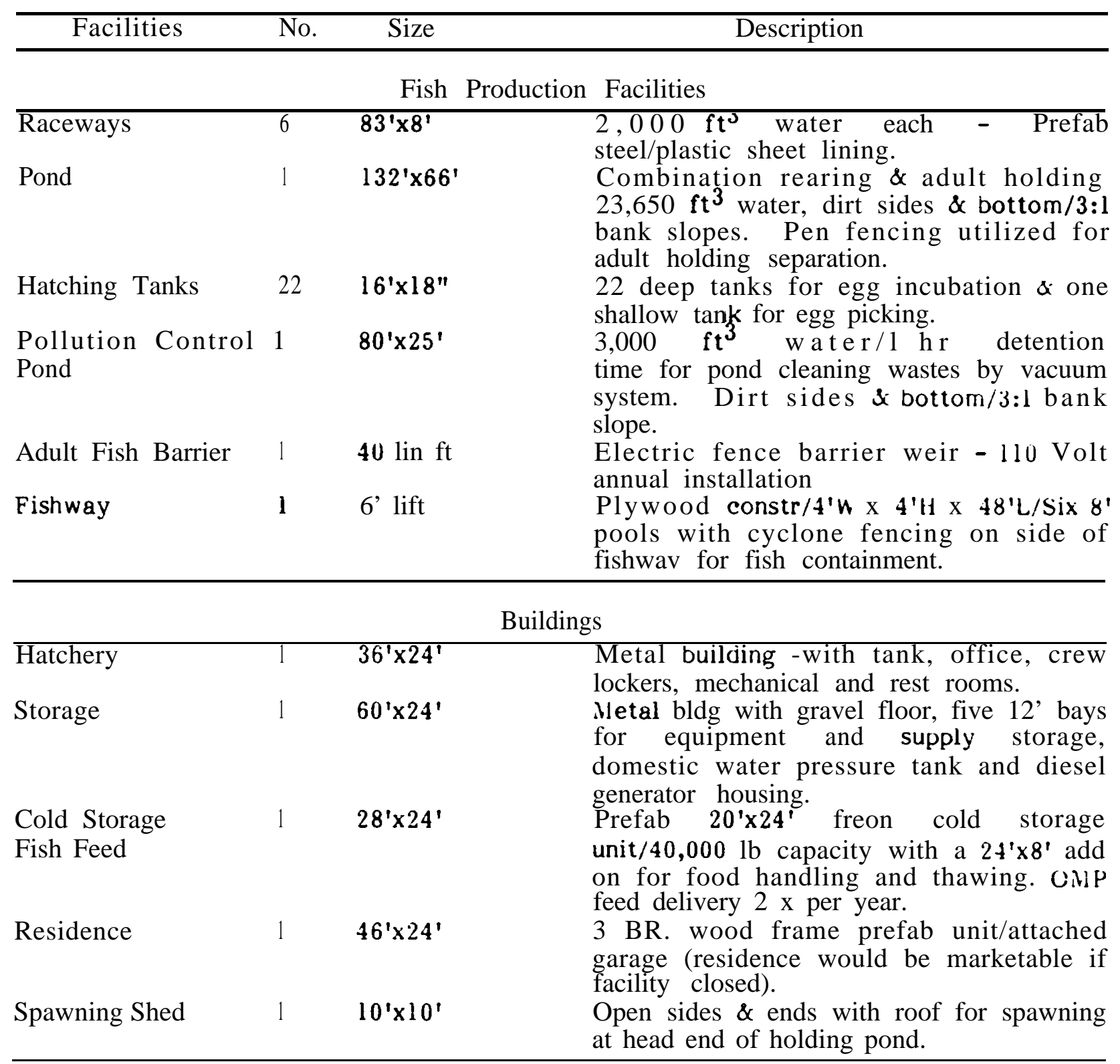

Equipment

General List

1 pick-up, nets, pumps, misc. tools \& cleaning equip. $(\$ 26,000)$ 


\section{Chapter 9}

Table 17. Facility development costs for Fall Chinook Salmon Hatchery No. 3.

\begin{tabular}{|c|c|}
\hline Facility & Estimated $\cos$ \\
\hline Site development & $\$ \$ 137.000 .00$ \\
\hline Water supply and drains & $387,400.00$ \\
\hline Fish production facilities & $235,300.00$ \\
\hline Buildings & $204,4 \cup 0.00$ \\
\hline Equipment & $\frac{26,000.00}{\$ 990,100.00}$ \\
\hline
\end{tabular}

Table 18. Estimated annual operational cost and labor requirements for Fall Chinook Salmon Hatchery No. 3.

\begin{tabular}{|c|c|c|}
\hline Item & & Estimated \\
\hline Food & & $\$ 33,750$ \\
\hline \multicolumn{3}{|l|}{ Manpower $(0$ \& $\mathbf{M})$} \\
\hline Superintendent 1 & 12 man months & 24,000 \\
\hline Culturist & 12 man months & 18,000 \\
\hline standby & months & 1,800 \\
\hline & Subtotal & 77,550 \\
\hline Misc. $(10 \%$ all other & costs -0 \& M) & 7,750 \\
\hline & Subtotal & 85,300 \\
\hline \multicolumn{3}{|l|}{ Electrical power } \\
\hline water delivery ( 25 & $\begin{array}{l}\text { HP, } 6 \text { months) } \\
\text { Total }\end{array}$ & $\begin{array}{r}3,450 \\
\$ 91,250\end{array}$ \\
\hline
\end{tabular}

4. $\quad$ Fall Chinook Salmon Hatchery No. 4

\section{Goals:}

Produce 1,600,000 (20,000 lbs) fall chinook smolts at $80 \mathrm{fish} / \mathrm{lb}$. This production is comprised of 800,000 smolts each from early and late spawning stocks for annual releases between May 13 and June 10 . The early stock will be released off-station from a satellite facility located in another watershed.

Summary of Biological Requirements:

Smolt production (no./size) early spawning fall chinook late spawning fall chinook

Fertilized eggs (no. spawned) early spawning fall chinook $\quad 952,000$ late spawning fall chinook $\quad 952,000$

Females to spawn (no.) early spawning fall chinook late spawning fall chinook

Adults held at one time (no.)

early spawning fall chinook 268

late spawning fall chinook

Total at one time 
Theoretical Hatcheries

\author{
Recommended minimum water (gpm) \\ Onstation: \\ ground and/or spring \\ surface \\ 343 a $53 \mathrm{~F}$ \\ Offstation: \\ surface \\ Recommended minimum pond space \\ $1,760 @$ (see Fig. 1) \\ 2,083 a (see Fig. 1) \\ Onstation \\ or equivalent \\ Offstation \\ $10,000 \mathrm{ft}^{3}$ \\ $10,000 \mathrm{ft}^{3}$
}

(Note: We recognize that it is unlikely that the two racial groups will overlap the holding period to the extent indicated in Fig. 8 for space requirements)

Facilities Development:

Table 19 lists the facilities and the associated requirements of Fall Chinook Salmon Hatchery No. 4 and Figs. $7 \mathrm{a}$ and $7 \mathrm{~b}$ illustrate the physical plan for the hatchery and satellite, respectively.

Operational Strategies:

Early spawning fall chinook salmon will be programmed for space and water requirements for adult holding and spawning, incubation, and rearing and release as conducted by time with Fall Chinook Salmon Hatcheries Nos. 1, 2, and 3. However, after 30-40 days of rearing, all fish will be transferred 25 miles to a rearing and release pond located immediately below an irrigation diversion dam in another watershed. Upon return to the pond, the adults will be captured at the existing fish ladder and hauled to the onstation adult holding facility where water temperatures are suitable.

The late spawning fall chinook, which spawn 40 days after the early spawning fall chinook are cultured as documented for the 10,000 lb Fall Chinook Salmon Hatchery No. 1.

Provisions will be made within the adult pond to segregate early and late stocks to prevent excessive handling. Fig. 8 illustrates the strategies in fish husbandry within the rearing and adult holding ponds by time.

\title{
Costs:
}

Table 20 shows the estimated capital cost for Fall Chinook Salmon Hatchery No. 4 and Table 21 shows the estimated annual operational costs and manpower requirements. 


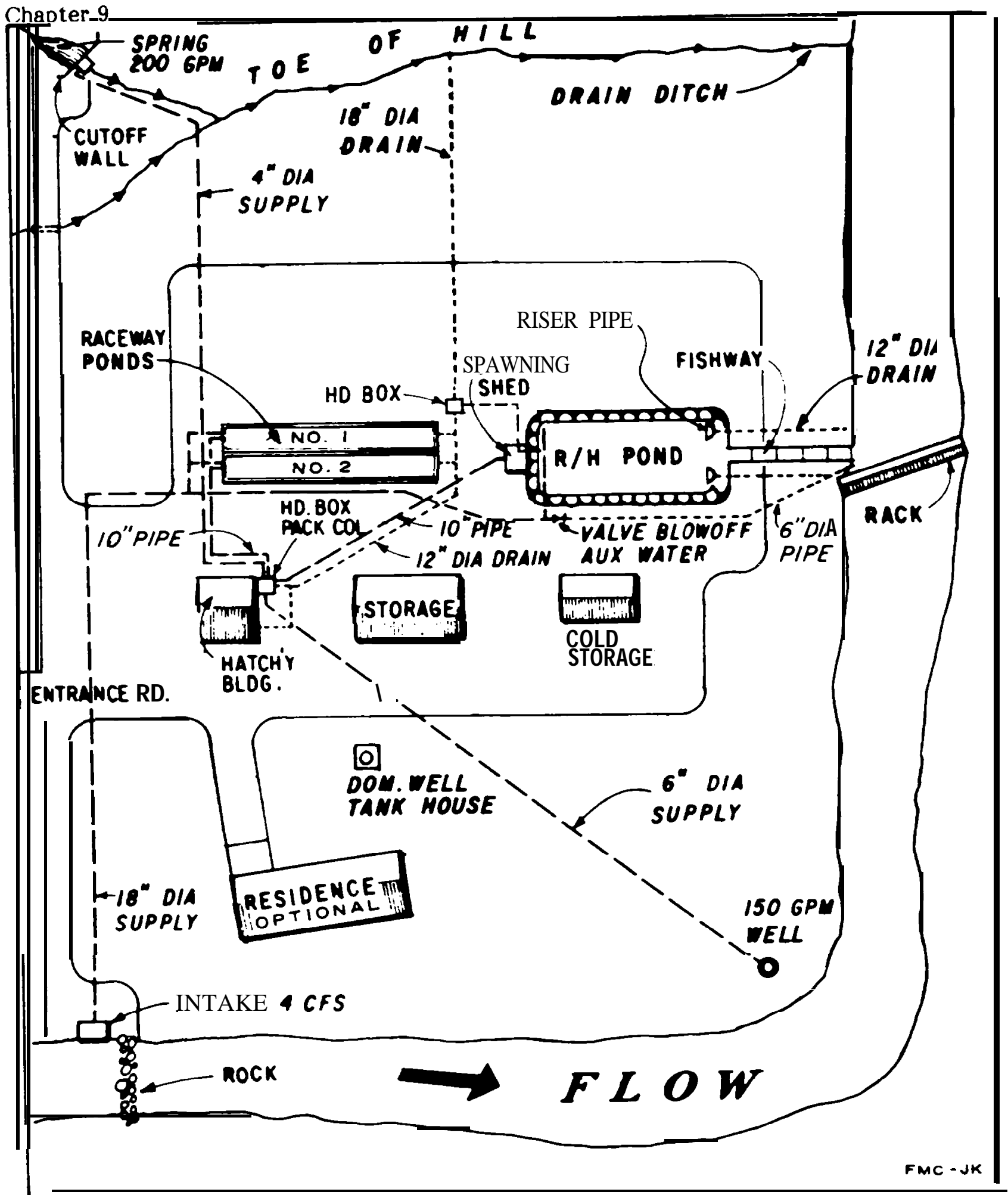

Figure 7a. Schematıc of rall Cnınook Salmon Hatchery No. 4 - On-station facilities. 
Theoretical Hatcheries

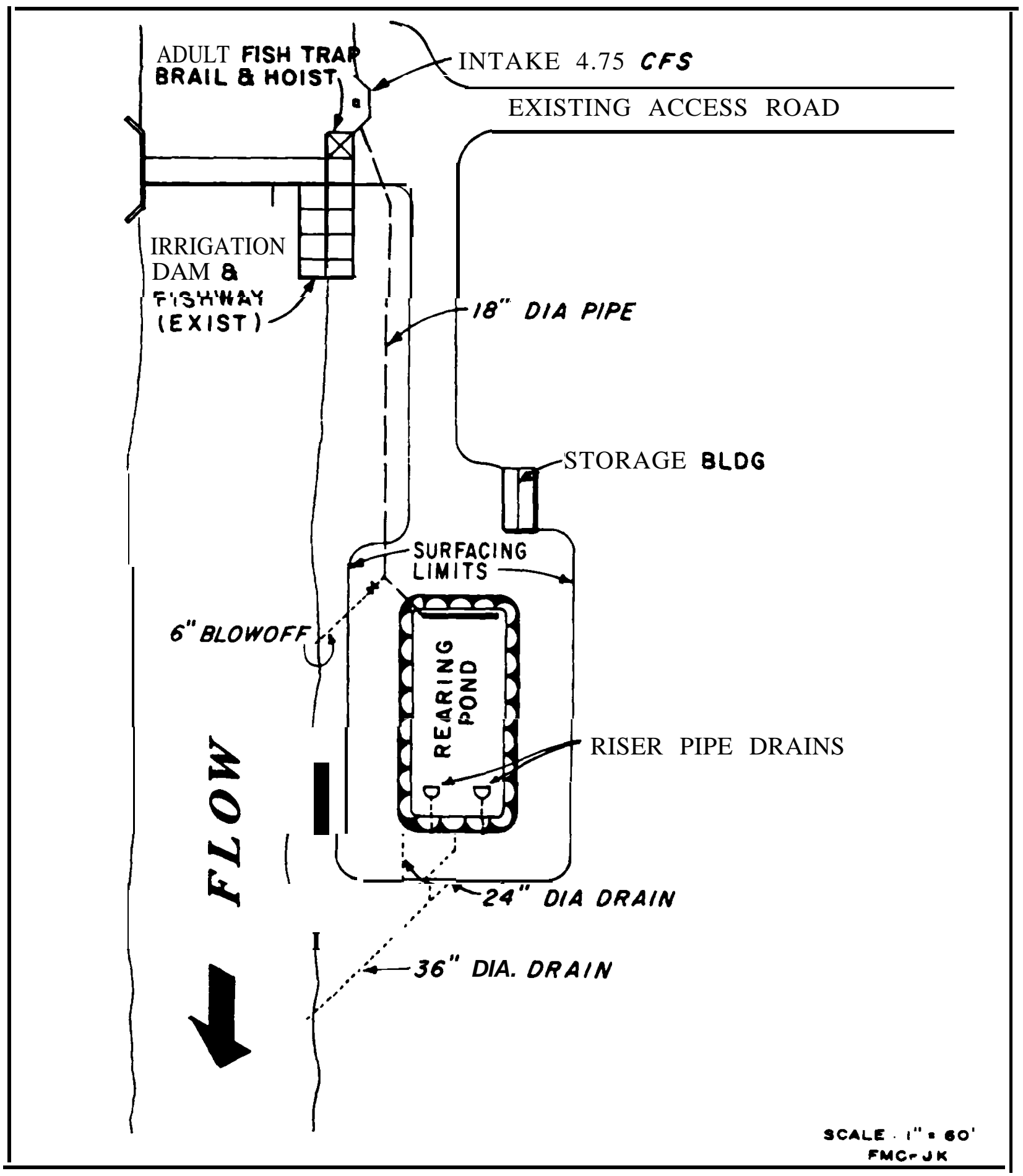

Figure 7b. Schematic of Fall Chinook Salmon Hatchery No. 4 - Satellite facilities. 


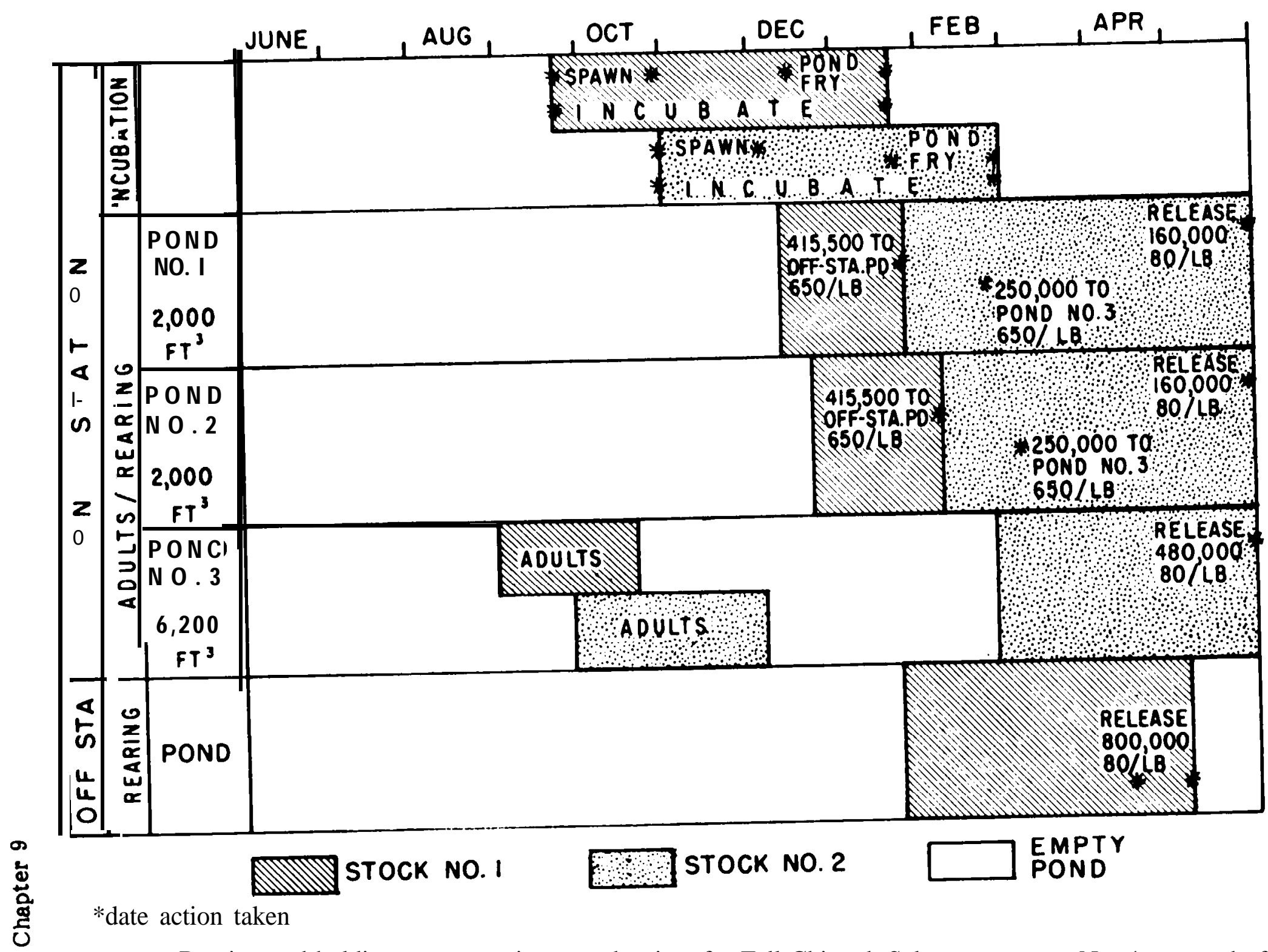

Figure 8. Rearing and holding space requirements by time for Fall Chinook Salmon Hatchery No. 4 - on and off-station. 
Theoretical Hatcheries

Table 19.

Facility development for Fall Chinook Salmon Hatchery No. 4 $(20,000 \mathrm{lbs}$, on- and off-station releases).

\begin{tabular}{|c|c|c|c|}
\hline Facilities & No. & Size & Describtion \\
\hline \multicolumn{4}{|c|}{ Site Development - On Station } \\
\hline $\begin{array}{l}\text { Clearing } \\
\& \text { Grubbing }\end{array}$ & 4 & Acres & $\begin{array}{l}\text { Clearing \& grubbing of hatchery site, } \\
\text { entrance road \& pipeline } \mathrm{R} / \mathrm{W} \text {. }\end{array}$ \\
\hline Entrance Road & $1 / 2$ & Mile & $\begin{array}{l}\text { 16' wide, 8" pit run base over ave. } 2 \text { ' fill } \\
\text { ht. Turnouts } 500^{\prime} \text { intervals. }\end{array}$ \\
\hline $\begin{array}{l}\text { On Site Road } \\
\& \text { Drives }\end{array}$ & 3,600 & $y d^{2}$ & $8^{\prime \prime}$ base \& $2 "$ crushed rock topping. \\
\hline
\end{tabular}

Water Supply \& Drains - On Station

\begin{tabular}{|c|c|c|c|}
\hline Stream Intake & & $10^{\prime} \times 4^{\prime}$ & $\begin{array}{l}\text { Coarse \& fine screen reinforced concrete } \\
\text { with rock check }\end{array}$ \\
\hline Supply Lines & & & $\begin{array}{l}12 " \text { diameter \& larger - CMP, under } 12 " \text { - } \\
\text { PVC }\end{array}$ \\
\hline Drain Lines & & & $\begin{array}{l}\text { 12" diameter \& larger - CMP, under 12" - } \\
\text { PVC }\end{array}$ \\
\hline Production Well & 1 & $150 \mathrm{gpm}$ & $\begin{array}{l}8 \text { " diameter x 200' deep with } 10 \mathrm{HP} \\
\text { submersible pump. }\end{array}$ \\
\hline Domestic Well & 1 & $5 \mathrm{gpm}$ & $\begin{array}{l}\text { 6" diameter x } 120 \text { ' deep with } 1 / 2 \text { HP } \\
\text { submersible pump. Pressure tank in } \\
\text { storage building - PVC underground piping } \\
\text { to buildings \& spawning shed. }\end{array}$ \\
\hline Spring Intake & 1 & 16' long & $\begin{array}{l}\text { Concrete cut-off wall x } 5 \text { ' high with } 2^{\prime} \times 4^{\prime} \text {. } \\
\text { Concrete screened intake box }-200 \mathrm{gpm} \text {. }\end{array}$ \\
\hline Aeration Head Box & 1 & $4^{\prime} \times 4^{\prime}$ & $\begin{array}{l}\text { Plywood construction/compartments for } \\
\text { spring \& well water aeration through two } \\
\text { packed column aerator units. }\end{array}$ \\
\hline Stream Rock Check & 1 & $20 \mathrm{yd}^{3}$ & Heavy rock rip rap $\left(30^{\prime} \times 6^{\prime} \times 3^{\prime}\right)$ \\
\hline
\end{tabular}

Fish Production Facilities - On-Station

\begin{tabular}{|c|c|c|c|}
\hline Raceways & 2 & $83^{\prime} \times 8^{\prime}$ & $\begin{array}{l}2,000 \quad \mathrm{ft}^{\mathbf{3}} \text { water each } \\
\text { steel/plastic sheet lining. }\end{array}$ \\
\hline Pond & 1 & $80^{\prime} \times 36^{\prime}$ & $\begin{array}{l}\text { Combination rearing and adult holding. } \\
6,200 \mathrm{ft}^{3} \text { water, dirt sides \& bottom } / 3: 1 \\
\text { bank slopes. Pen fencing utilized for } \\
\text { adult holding separation. }\end{array}$ \\
\hline Hatching Tanks & 9 & $16^{\prime} \times 18^{\prime \prime}$ & $\begin{array}{l}9 \text { deep tanks for egg incubation \& one } \\
\text { shallow tank for egg picking. }\end{array}$ \\
\hline $\begin{array}{l}\text { Adult Fish Rack } \\
\text { Fishway }\end{array}$ & $\begin{array}{l}1 \\
1\end{array}$ & $\begin{array}{l}40 \text { lin } \mathrm{ft} \\
\text { 6' lift }\end{array}$ & $\begin{array}{l}\text { Wood constr. - annual installation. } \\
\text { Plywood constr/4'W } \mathrm{W} 4{ }^{\prime} \mathrm{H} \times 48^{\prime} \mathrm{L} / \mathrm{six} 8 \\
\text { pools with cyclone fencing on sides of } \\
\text { fishway for fish containment. }\end{array}$ \\
\hline
\end{tabular}


Chapter 9

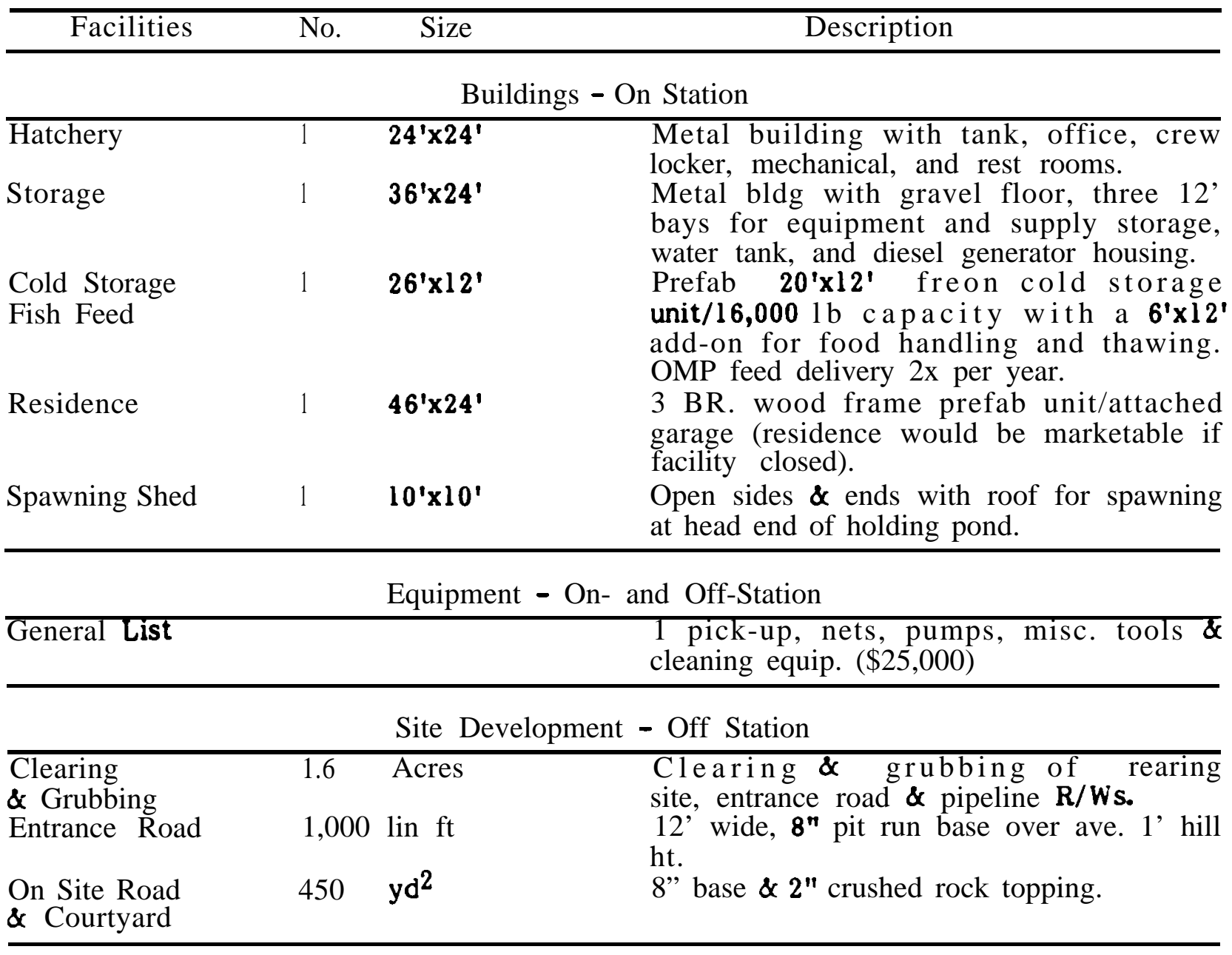

Water Supply \& Drains - Off Station

Stream Intake $1 \quad 10^{\prime}$ x $4^{\prime}$

Supply Lines

Coarse \& fine screen reinforced concrete

Drain Lines 12 " diameter \& larger - CMP, under 12" PVC

$12^{n}$ diameter \& larger - CMP, under 12" PVC

Fish Production Facilities - Off Station

\begin{tabular}{llll}
\hline Pond & 1 & $\mathbf{9 4}^{\prime} \times \mathbf{4 8}^{\prime}$ & $\begin{array}{l}10, \mathbf{7 0 0} \mathbf{f t}^{\mathbf{J}} \text { water. Dirt rearing pond sides } \\
\text { with } 3: 1 \text { slope. } \\
\text { Metal construction for separating }\end{array}$ \\
$\begin{array}{l}\text { Adult Fish Trap, } \\
\text { Brail \& Hoist }\end{array}$ & 1 & $\mathbf{8}^{\prime} \times \mathbf{8}^{\prime}$ & $\begin{array}{l}\text { adults from water for hauling to holding } \\
\text { facility. }\end{array}$
\end{tabular}


Theoretical Hatcheries

\begin{tabular}{|c|c|c|c|}
\hline Facilities & No. & Size & Description \\
\hline \multicolumn{4}{|c|}{ Buildings - Off Station } \\
\hline Storage & 1 & $12^{\prime} \times 24^{\prime}$ & $\begin{array}{l}\text { Metal building with gravel floor for } \\
\text { equipment and supply, security, and } \\
\text { refrigerator housing. }\end{array}$ \\
\hline Cold Storage & 1 & $36 \mathrm{ft}^{3}$ & Liquid gas or propane refrigerator. \\
\hline
\end{tabular}

Table 20. Facility development costs for Fall Chinook Salmon Hatchery . No. 4.

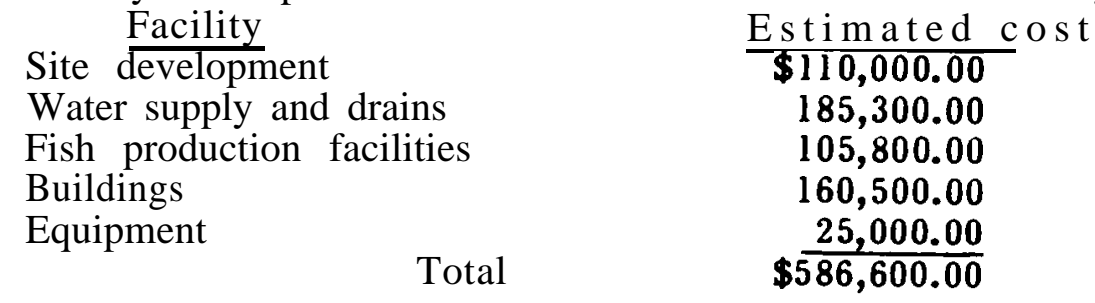

Table 2 1. Estimated annual operational costs and labor requirements for Fall Chinook Salmon Hatchery No. 4.

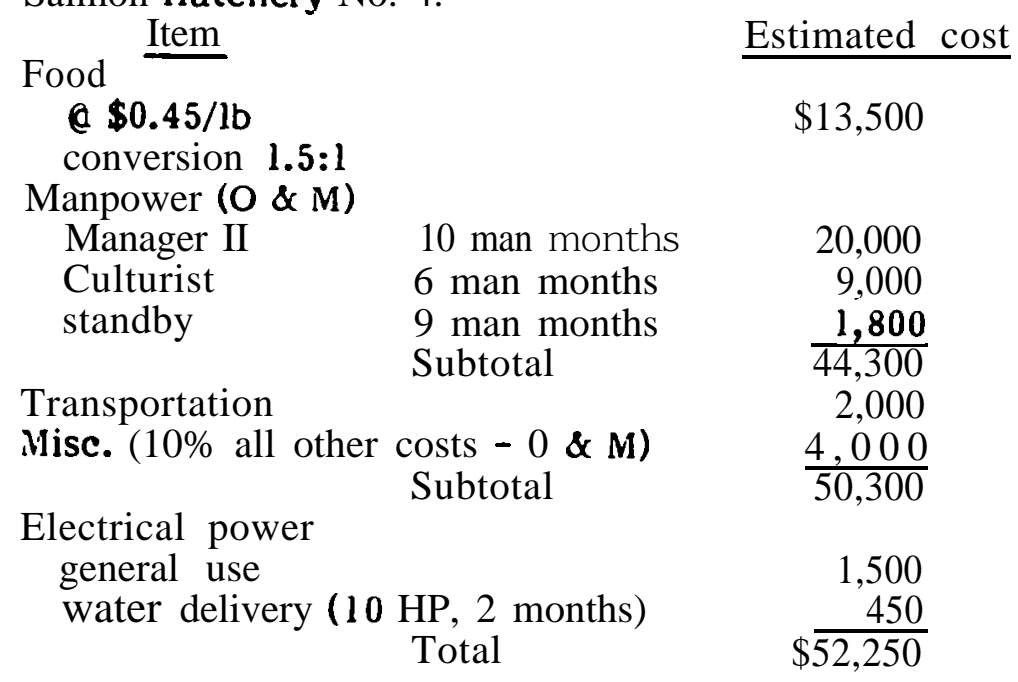

5. Fall Chinook Salmon Hatchery No. 5

Gods:

Produce 4 million fall chinook smolts a 80 fish/lb (50,000 lbs) from a late spawning adult fall chinook stock for annual release between May 15 and June 10.

A total of $38,000 \mathrm{lbs}$ will be released from an off-station production facility, and 12,000 $\mathrm{lbs}$ will be released at the station. 
Summary of Biological Requirements:

Smolt production (no./size)

Fertilized eggs (no. spawned)

Females to spawn (no.)

Adults held at one time (no.)

Recommended minimum water (gpm)

Onstation ground and/or spring surface

Off-station surf ace

Recommended minimum pond space or equivalent

On-station

Of f-station

\author{
$4,000,000 @ 80 \mathrm{lb}$ \\ $4,760,000$ \\ 955 \\ 1,485
}

$1,715 @ 53 \mathrm{~F}$

787 (see Fig. 1)

7,917 @ (see Fig. 1)

$12,000 \mathrm{ft}^{3}$

Facilities Development:

Table 22 lists the facilities and the associated requirements of Fall Chinook Salmon Hatchery No. 5 and Figs. 9a and $\mathbf{9 b}$ illustrate the physical plan for the hatchery and satellite, respectively.

Operational Strategies:

All incubation and rearing will be programmed for space and water requirements as conducted with Fall Chinook Salmon Hatcheries No. 1-4; however, adult holding and spawning will occur at the off-station release pond, and the eggs transported to the hatchery.

\section{Costs:}

Table 23 shows the estimated capital cost for Fall Chinook Salmon Hatchery No. 5 and Table 24 shows the estimated annual operational costs and manpower requirements.

Table 22. Facility development for Fall Chinook Salmon Hatchery No. 5 (50,000 lbs, onand of $\mathbf{f}$-station releases).

\begin{tabular}{|c|c|c|c|}
\hline Facilities & No. & Size & Description \\
\hline \multicolumn{4}{|c|}{ Site Development - On Station } \\
\hline $\begin{array}{l}\text { Clearing } \\
\text { \& Grubbing }\end{array}$ & 6 & Acres & \multirow{3}{*}{$\begin{array}{l}\text { Clearing \& grubbing of hatchery site, } \\
\text { entrance road \& pipeline R/Ws. } \\
16^{\prime} \text { wide, } \mathbf{8}^{\prime \prime} \text { pit run base over ave. } \mathbf{2}^{\prime} \text { fill } \\
\text { ht. Turnouts } 2500^{\prime} \text { intervals. } \\
\mathbf{8}^{\prime \prime} \text { base \& } 2^{\prime \prime} \text { crushed rock topping. }\end{array}$} \\
\hline Entrance Road & & Mile & \\
\hline $\begin{array}{l}\text { On Site Road } \\
\text { \& Drives }\end{array}$ & 3,000 & $y d^{2}$ & \\
\hline
\end{tabular}


Theoretical Hatcheries

\begin{tabular}{|c|c|c|c|}
\hline Facilities & No. & Size & Description \\
\hline \multicolumn{4}{|c|}{ Water Supply \& Drains - On-Station } \\
\hline Stream Intake & 1 & $14^{\prime} \times 4^{\prime}$ & $\begin{array}{l}\text { Coarse \& fine screen reinforced concrete } \\
\text { with rock check }\end{array}$ \\
\hline Supply Lines & & & $\begin{array}{l}12^{\prime \prime} \text { diameter \& larger - CMP, under } 12 " \text { - } \\
\text { PVC }\end{array}$ \\
\hline Drain Lines & & & $\begin{array}{l}12 " \text { diameter \& larger - CMP, under } 12 " \text { - } \\
\text { PVC }\end{array}$ \\
\hline Production Well & 3 & $450 \mathrm{gpm}$ & $\begin{array}{l}\text { 12" diameter x 200' deep with } 25 \mathrm{HP} \\
\text { submersible pump. }\end{array}$ \\
\hline Domestic Well & 1 & $5 \mathrm{gpm}$ & $\begin{array}{l}\text { 6" diameter x } 120 \text { ' deep with } 1 / 2 \mathrm{HP} \\
\text { submersible pump. Pressure tank in } \\
\text { storage building - PVC underground piping } \\
\text { to buildings. }\end{array}$ \\
\hline Spring Intake & 1 & 16' long & $\begin{array}{l}\text { Concrete cut-off wall } \mathrm{x} 5^{\prime} \text { high with } 2^{\prime} \mathrm{x} \\
4^{\prime} \text { concrete screened intake box. }\end{array}$ \\
\hline Aeration Head Box & 1 & $4^{\prime} \times 8^{\prime}$ & $\begin{array}{l}\text { Plywood construction/compartments for } \\
\text { spring \& well water aeration through } \\
\text { eight packed column aerator units. }\end{array}$ \\
\hline Stream Rock Check & 1 & $20 \mathrm{yd}^{3}$ & Heavy rock rip rap $\left(30^{\prime} \times 6^{\prime} \times 3^{\prime}\right)$ \\
\hline
\end{tabular}

Fish Production Facilities - On Station

\begin{tabular}{|c|c|c|c|}
\hline Raceways & 6 & $83^{\prime} \times 8^{\prime}$ & $\begin{array}{l}2,000 \mathrm{ft}^{3} \text { water each } \\
\text { steel/plastic sheet lining. }\end{array}$ \\
\hline Hatching Tanks & 22 & $16^{\prime} \times 18^{\prime \prime}$ & $\begin{array}{l}22 \text { deep tanks for egg incubation \& } 1 \\
\text { shallow } \\
\text { tank for egg picking. }\end{array}$ \\
\hline
\end{tabular}

Buildings - On-Station

\begin{tabular}{|c|c|c|c|}
\hline Hatchery & 1 & $36^{\prime} \times 24^{\prime}$ & $\begin{array}{l}\text { Metal building with tank, office, crew } \\
\text { locker, toilet, and storage rooms. }\end{array}$ \\
\hline Storage & 1 & $48^{\prime} \times 24^{\prime}$ & $\begin{array}{l}\text { Metal building with gravel floor four } 12^{\prime} \\
\text { bays for equipment and supply storage, } \\
\text { domestic water pressure tank, and diesel } \\
\text { generator housing. }\end{array}$ \\
\hline Cold Storage & 1 & $20^{\prime} \times 12^{\prime}$ & Prefab $15^{\prime} \times 12^{\prime}$ freon cold storage \\
\hline Fish Feed & & & $\begin{array}{l}\text { unit } / 12,000 \mathrm{lb} \text { capacity with a } 5^{\prime} \times 12^{\prime} \\
\text { add-on for food handling and thawing. } \\
\text { OMP feed delivery } 2 \times \text { per year. }\end{array}$ \\
\hline Residence & 1 & $46^{\prime} \times 24^{\prime}$ & $\begin{array}{l}3 \text { BR. wood frame prefab unit/attached } \\
\text { garage (residence would be marketable } \\
\text { if facility closed). }\end{array}$ \\
\hline
\end{tabular}


Chapter 9

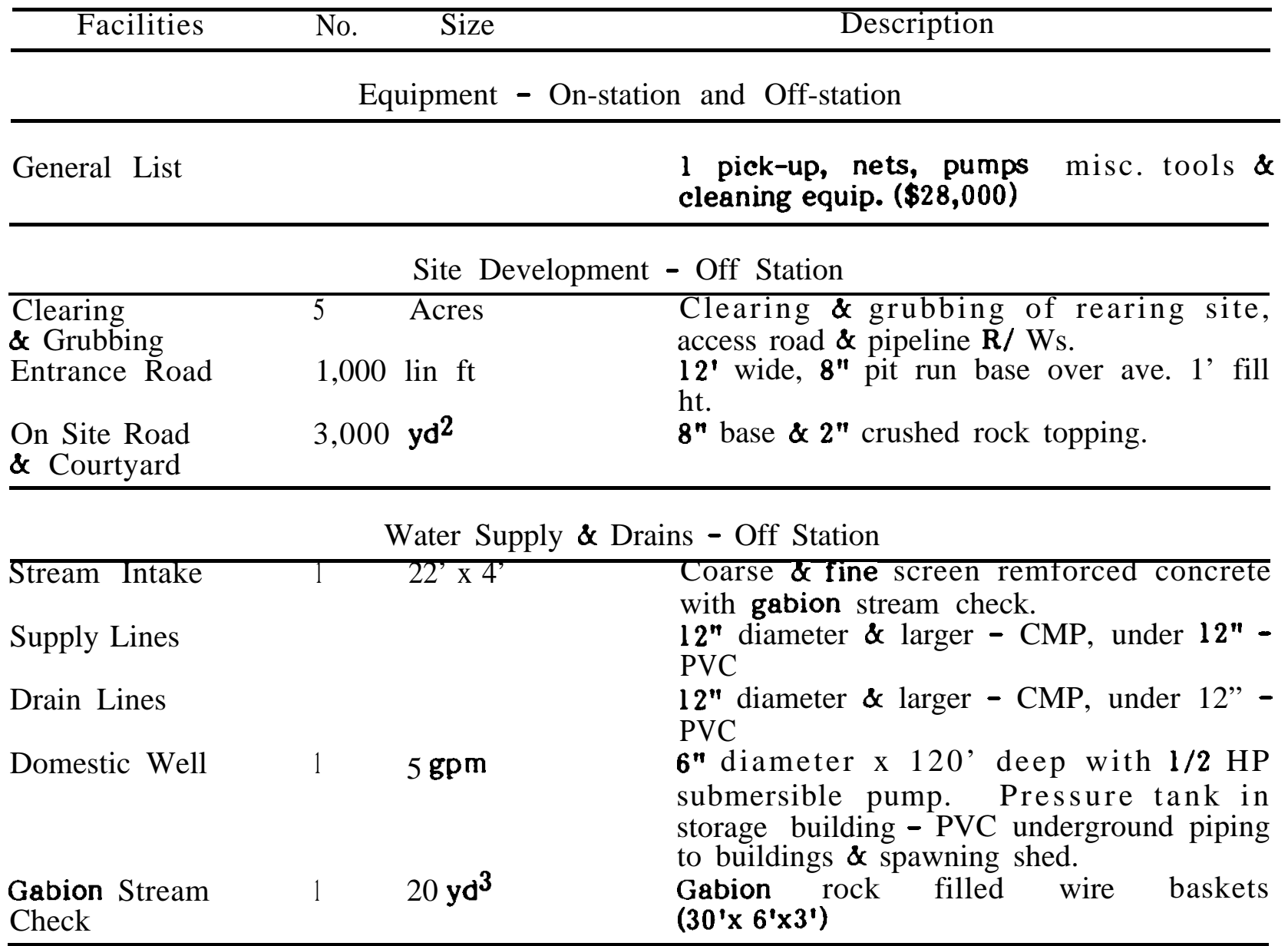

Fish Production Facilities - Off-Station

\begin{tabular}{|c|c|c|c|c|}
\hline$\overline{\text { Pond }}$ & & 2 & $132^{\prime} \times 66^{\prime}$ & $\begin{array}{l}23,650 \mathrm{ft}^{3} \text { water each. Dirt sides \& } \\
\text { bottom/3: l bank slope - One pond dual use } \\
\text { for rearing \& adult holding with pen, } \\
\text { fencing utilized for adult holding } \\
\text { separation }\end{array}$ \\
\hline Adult Fish & Barrier & 1 & $40 \operatorname{lin} \mathrm{ft}$ & $\begin{array}{l}\text { Electric fence barrier weir }-\quad 110 \\
\text { volts/portable electric generator. Annual } \\
\text { installation. }\end{array}$ \\
\hline Fishway & & 1 & $6^{\prime}$ lift & $\begin{array}{l}\text { Plywood const/4'W } 4^{\prime} 4^{\prime} \mathrm{H} \times 48^{\prime} \mathrm{L} / \mathrm{six} 8^{\prime} \\
\text { pools with cyclone fencing on sides of } \\
\text { fishway for fish containment. }\end{array}$ \\
\hline $\begin{array}{l}\text { Pollution } \\
\text { Pond }\end{array}$ & Control & 1 & $80^{\prime} \times 25^{\prime}$ & $\begin{array}{l}3,000 \text { ft } \mathrm{ft}^{3} \text { ater/l } \mathrm{hr} \text {. detention } \\
\text { time for pond cleaning wastes by vacuum } \\
\text { system. Dirt sides \& bottom } / 3: 1 \\
\text { bank slope. }\end{array}$ \\
\hline
\end{tabular}




\begin{tabular}{|c|c|c|c|}
\hline Facilities & No. & Size & Description \\
\hline \multicolumn{4}{|c|}{ Buildings - Off Station } \\
\hline Storage & 1 & $36^{\prime} \times 24^{1}$ & $\begin{array}{l}\text { Metal building with gravel floor three 12 } \\
\text { bays for equipment and supply, storage } \\
\text { and domestic water pressure tank housing. }\end{array}$ \\
\hline $\begin{array}{l}\text { Cold Storage } \\
\text { Fish Feed }\end{array}$ & 1 & $24^{\prime} \times 24^{\prime}$ & $\begin{array}{l}\text { Prefab } 18^{\prime} \times 24^{\prime} \text { freon - cold storage } \\
\text { unit/38,000 lb capacity with a } 6^{\prime} \times 24^{\prime} \\
\text { add-on for food handling \& thawing. OMP } \\
\text { feed delivery } 2 \times \text { per year. }\end{array}$ \\
\hline Trailer House/Pad & 1 & $24^{\prime} \times 12^{\prime}$ & $\begin{array}{l}\text { Concrete } \mathrm{pad} / \mathrm{move} \text { on-move off housing } \\
\text { unit and drainfield installation }\end{array}$ \\
\hline Spawning Shed & 1 & $10^{\prime} \times 10^{\prime}$ & $\begin{array}{l}\text { Open sides \& ends with roof for spawning } \\
\text { at head end of holding pond. }\end{array}$ \\
\hline
\end{tabular}

Table 23. Facility development costs for Fall Chinook Salmon Hatchery No. 5.

\begin{tabular}{|c|c|}
\hline Facility & Estimated cost \\
\hline Site development & $\$ 179,900.00$ \\
\hline Water supply and drains & $448,900.00$ \\
\hline Fish production facilities & $235,400.00$ \\
\hline Buildings & $246,400.00$ \\
\hline Equipment & $\$ 1, \frac{28,000.00}{138,600.00}$ \\
\hline
\end{tabular}

Table 24. Estimated annual operational cost and labor requirements for Fall Chinook Salmon Hatchery No. 5.

Food $\stackrel{\text { Item }}{ }$

\section{a $\$ 0.45 / 1 b$}

conversion 1.5:1

Manpower (O \& $M$ )

Manager II

Culturist

standby

Subtotal
Misc. $(10 \%$ all other costs -0 \& )

(including transportation

Electrical power

Subtotal

general use

water delivery (25 HP, 6 months)

Total $\underline{\text { Estimated cost }}$

$\$ 33,750$

24,000

21,000

1,800

80,550

8,055

88,605

5,000

3,450

$\$ \overline{\$ 97,055}$ 


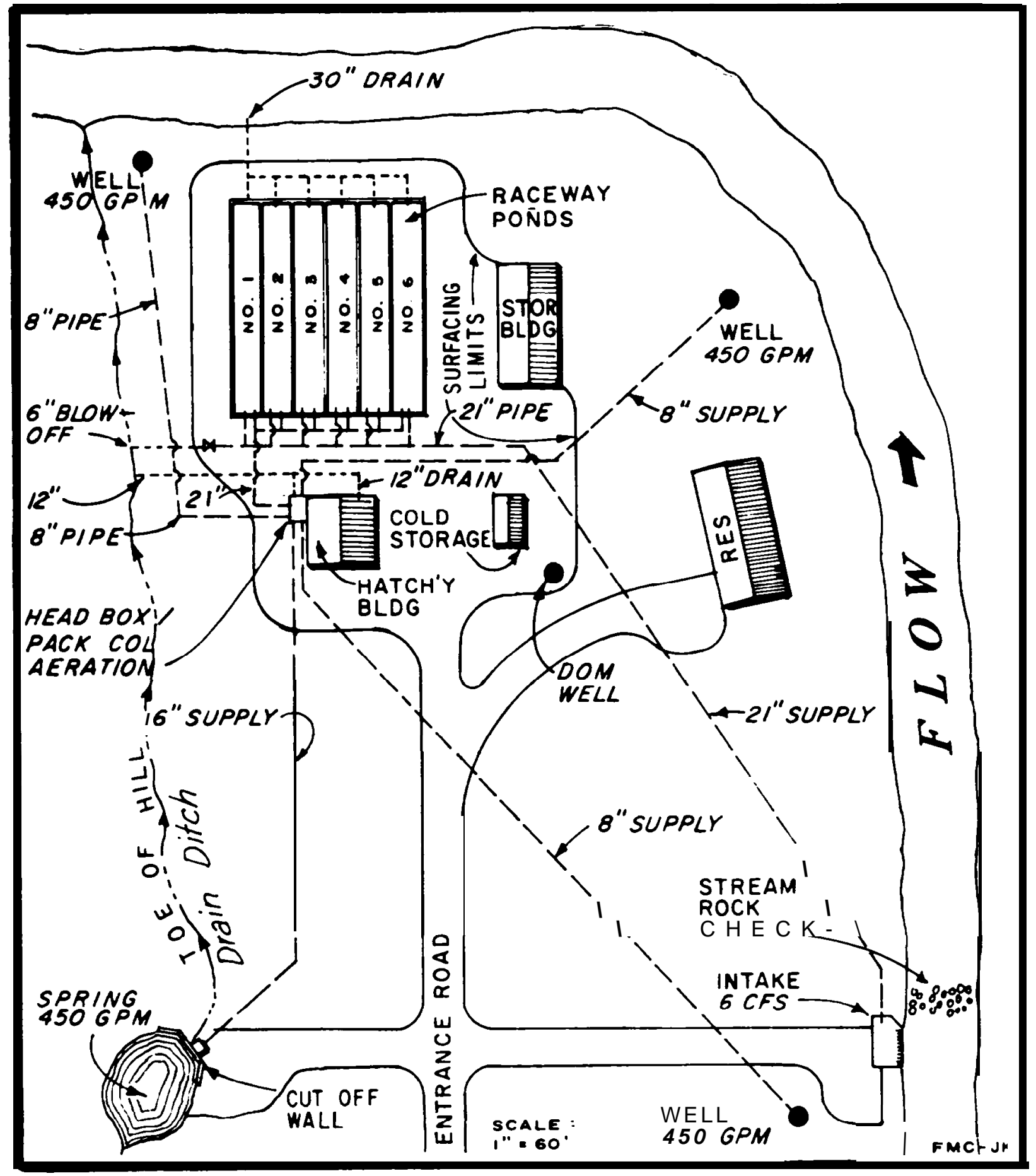

Figure 9a. Schematic of Fall Chinook Salmon Hatchery No. 5 - On-Station Facilities. 
Theoretical Hatcheries

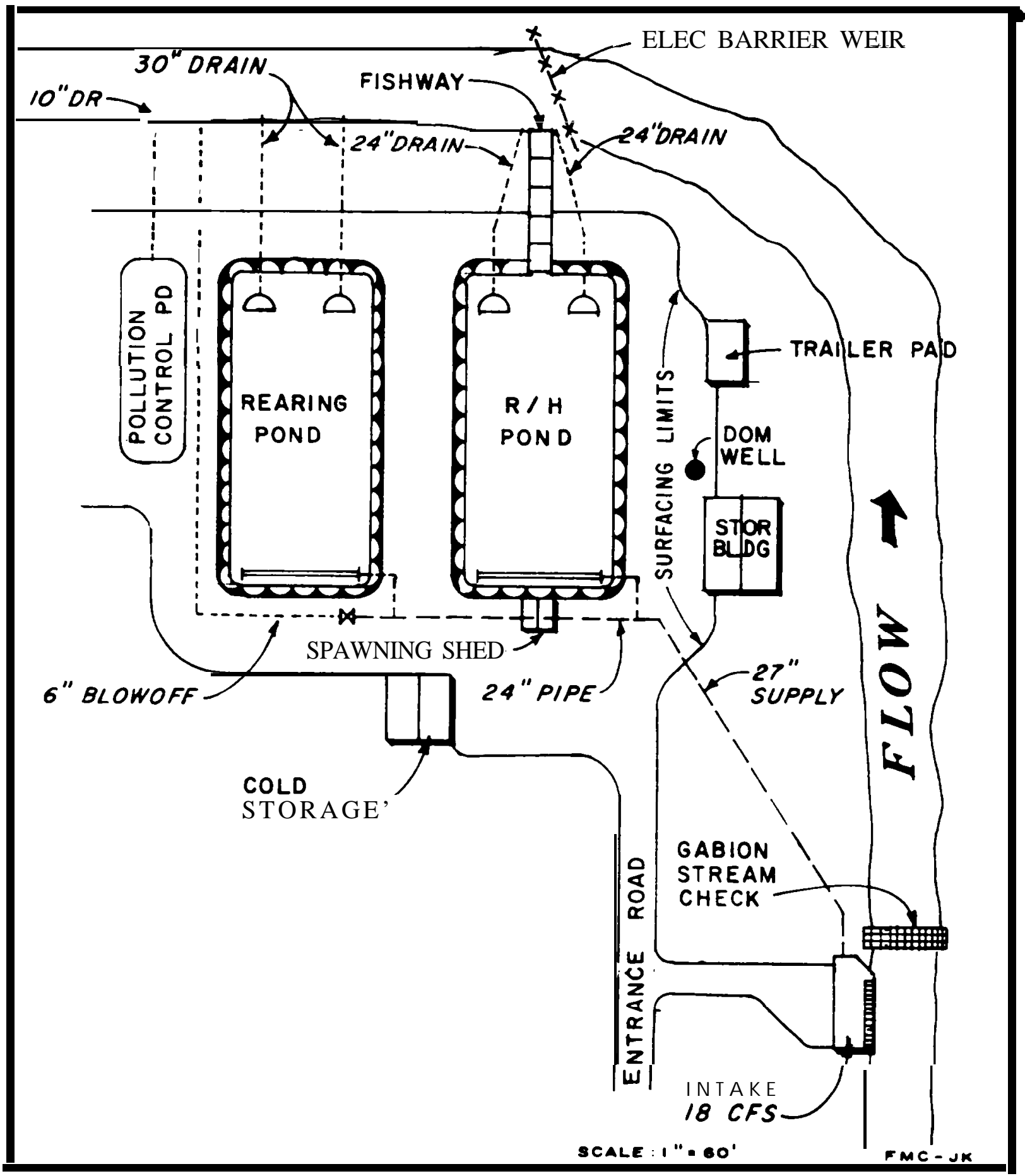

Figure 9b. Schematic of Fall Chinook Salmon Hatchery No. 5 - Satellite Facilities. 


\section{Chapter 9}

\section{B. THEORETICAL SPRING CHINO'JK SALMON HATCHERIES}

The conceptual plans, operations, and costs of five theoretical spring chinook salmon hatcheries follow.

1. Spring Chinook Salmon Hatchery No. 1

\section{Goals:}

Produce 120,000 spring chinook smolts at 12 fish/lb (10,000 lbs) for annual release in stream " $A$ " in April.

Summary of Biological Requirements:

Smolt production (no./size)

120,000 a $12 / \mathrm{b}$

Fertilized eggs (no. spawned)

Females to spawn (no.) 185,000

Adults held at one time (no.)

Recommended minimum water (gpm)

\section{ground and/or spring} surface

Recommended minimum pond space or equivalent

Facilities Development:

Table 25 lists the facilities and the associated requirements of Spring Chinook Salmon Hatchery No. 1 and Fig. 10 illustrates the physical plan for the hatchery.

\section{Operational Strategies:}

The water and space requirements as related to the percentage of the total biological requirements by time are shown in Figs. 11 and 12, respectively. Comments follow on each life phase of husbandry.

(1) Adults The adult fish will ascend the fishway leading to the adult holding/rearing pond $\left(3,500 \mathrm{ft}^{3}\right)$; where provisions are made to hold all fish until spawning has been completed (September 20). A minimum of $115 \mathrm{gpm}$ of water from the $48 \mathrm{~F}$ spring will be used, or reused from the juveniles being reared in the raceways.

(2) Incubation (See Fall Chinook Hatchery No. 1 regarding incubation units) Because there is a tendency for the spring chinook to grow faster than necessary, we will program the coolest clear water that is available. Generally, this will be the $48 \mathrm{~F}$ gravity supply in the early fall, then cooler surface water when available during late fall and winter.

(3) Rearing Initial rearing will begin in two sectioned $2,000 \mathrm{ft}^{3}$ raceways ond deep troughs as required. The older age group of juveniles will utilize the third $2,000 \mathrm{ft}^{3}$ raceway and the 3,500 $\mathrm{ft}^{3}$ earthen pond. The need for the latter pond will occur about October 15 . In order to prevent sun-burn (see Chapter 1), the raceways will be oriented in a north/south direction to provide shade, water 
Theoretical Hatcheries

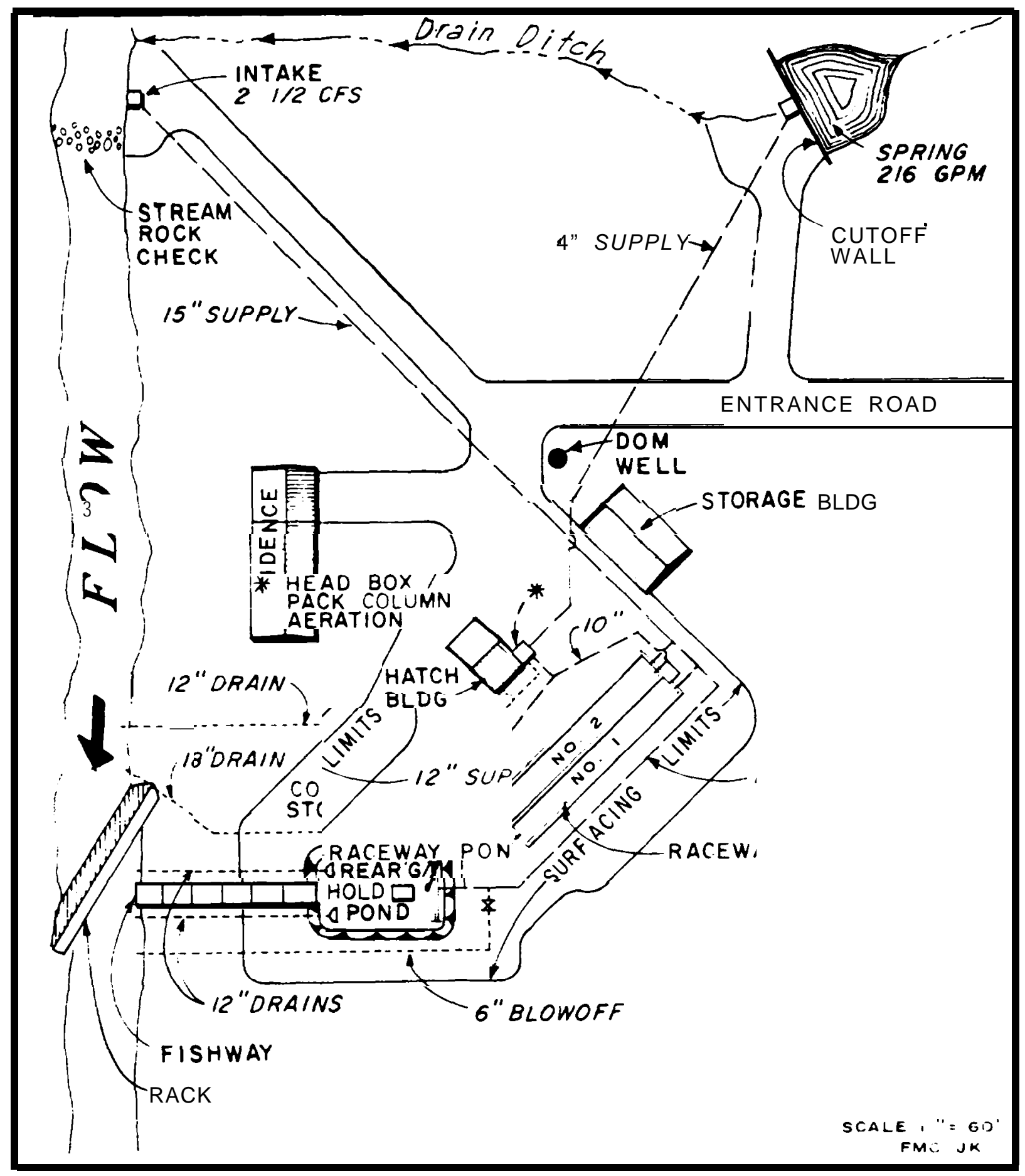

Figure 10. Schematic of Spring Chinrok Salmon Ilatchery No. 1. 


\section{Chapter 9}

sprinklers will be used for refraction of the direct light rays, and dark-colored liners will be used on the raceways.

The fish will be fed by hand, and if their growth progresses too rapidly, feeding levels will be reduced through less frequent feedings.

(4) Release All fish will be allowed to emigrate through the pond drain systems to the river between March 30 and April 15. Those that do not leave will be forced into the river by draining the ponds.

\section{Costs:}

Table 26 shows the estimated capital cost for Fall Chinook Salmon Hatchery No. 1 and Table 27 shows the estimated annual operational costs and manpower requirements.

Table 25. Facility development for Spring Chinook Salmon Hatchery No. 1 (10,000 lbs, on-station release).

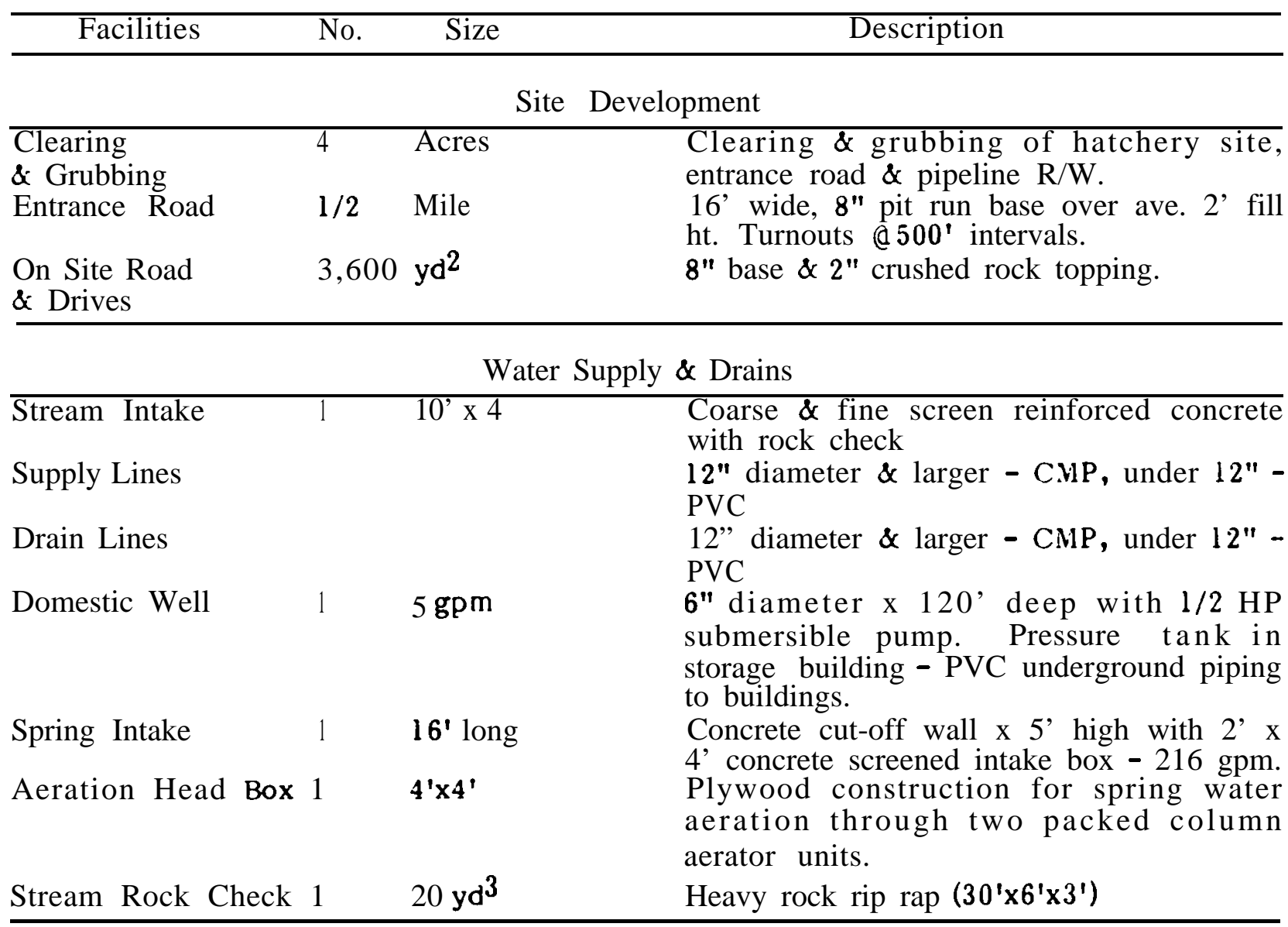


Theoretical Hatcheries

\begin{tabular}{|c|c|c|c|}
\hline Facilities & No. & Size & Description \\
\hline \multicolumn{4}{|c|}{ Fish Production Facilities } \\
\hline Raceways & 2 & $83^{\prime} \times 8^{\prime}$ & $\begin{array}{l}2.000 \mathrm{ft}^{3} \text { water each }- \\
\text { steel/plastic sheet lining. }\end{array}$ \\
\hline Pond & 1 & $52^{\prime} \times 36^{\prime}$ & $\begin{array}{l}\text { Combination rearing \& adult holding } 3,500 \\
\mathrm{ft}^{3} \text { water, dirt sides \& bottcm } / 3: 1 \text { bank } \\
\text { slopes Upwelling W.S. on pond bottom } \\
\text { for adult holding. }\end{array}$ \\
\hline Hatching Tanks & 1 & $16^{\prime} \times 18^{\prime \prime}$ & $\begin{array}{l}1 \text { deep tank for egg incubation \& } 1 \\
\text { shallow tank for egg picking. }\end{array}$ \\
\hline Adult Fish Rack & 1 & $40 \operatorname{lin} \mathrm{ft}$ & Wood constr. - annual installation \\
\hline Fishway & 1 & 6' lift & $\begin{array}{l}\text { Plywood constr/4'W } 4^{\prime} 4^{\prime} \times 48^{\prime} \mathrm{L} / \mathrm{six} 8^{\prime} \\
\text { pools with canvas fencing on top of } \\
\text { fishway for fish containment. }\end{array}$ \\
\hline \multicolumn{4}{|r|}{ Buildings } \\
\hline Hatchery & 1 & $18^{1} \times 24^{\prime}$ & $\begin{array}{l}\text { Metal building with tank, office, crew } \\
\text { locker, mechanical, and rest rooms. }\end{array}$ \\
\hline Storage & 1 & $36^{\prime} \times 24^{\prime}$ & $\begin{array}{l}\text { Metal bldg with gravel floor, three } 12 \text { ' } \\
\text { bays for equipment and supply storage and } \\
\text { domestic water pressure tank housing. }\end{array}$ \\
\hline Cold Storage & 1 & $16^{\prime} \times 12^{\prime}$ & Prefab $10^{\prime} \times 12^{\prime}$ freon cold storage \\
\hline Fish Feed & & & $\begin{array}{l}\text { unit } / 8,000 \mathrm{lb} \text { capacity with a } 12^{\prime} \times 6^{\prime} \text { add } \\
\text { on for food handling and thawing. Oivi } \mathrm{P} \\
\text { feed delivery } 3 \times \text { per year. }\end{array}$ \\
\hline Residence & 1 & $46^{\prime} \times 24^{\prime}$ & $\begin{array}{l}3 \text { BR. wood frame prefab unit/attached } \\
\text { garage (residence woula be marketable } \\
\text { if facility closed). }\end{array}$ \\
\hline
\end{tabular}

Equipment

General List

1 pick-up, nets' pumps' misc. tools \& cleaning equip. $(\$ 24,000)$

Table 26. Facility development costs for Spring Chinook Salmon Hatchery No. 1.

\section{Facility}

Site development

Water supply and drains

Fish production facilities

Buildings

Equipment

$$
\begin{gathered}
\text { Estimated cost } \\
\hline \$ 81,700.00 \\
83,000.00 \\
54,604.00 \\
134,600.00 \\
24,004.00 \\
\$ 377,900.00
\end{gathered}
$$




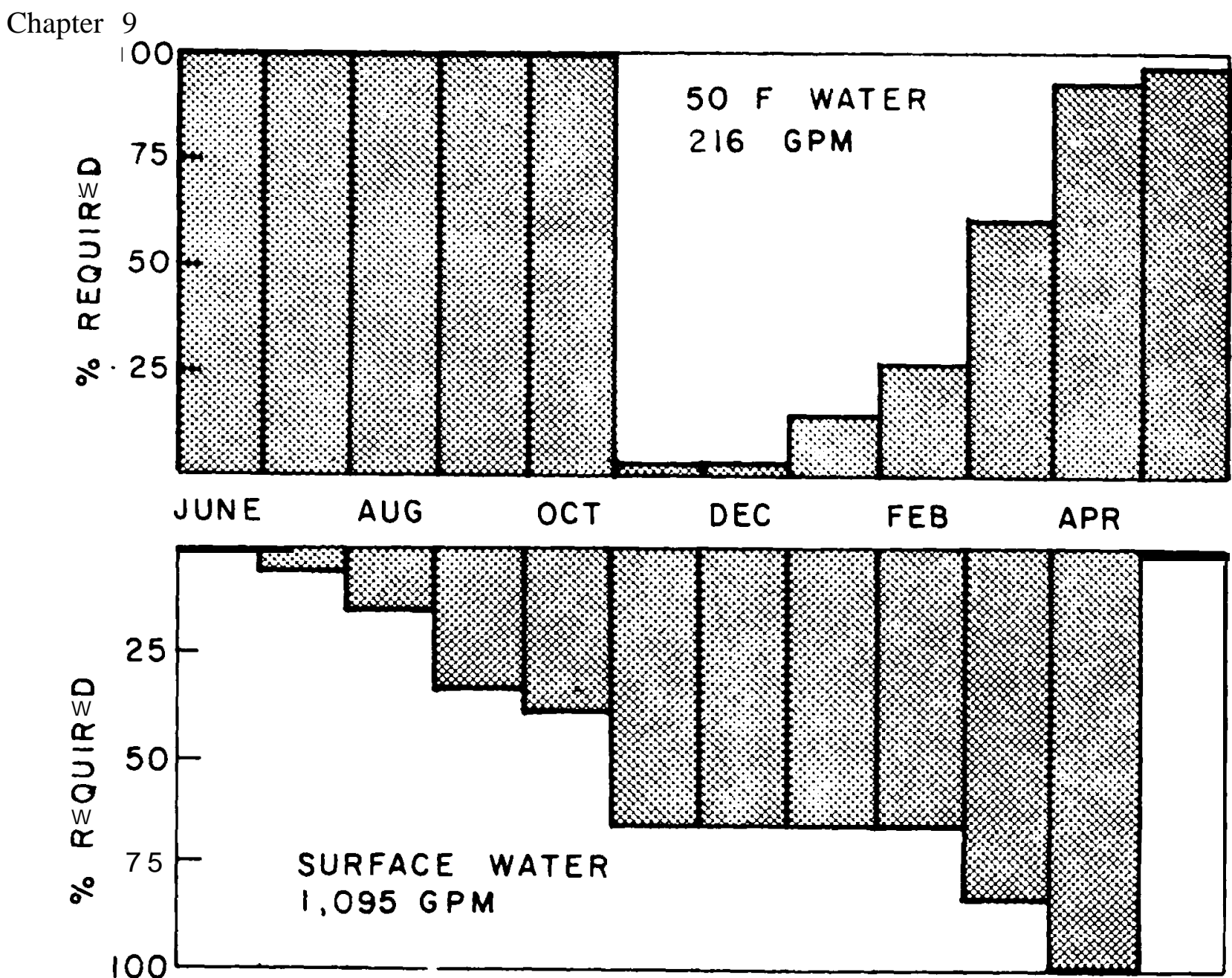

Fisure 11. Water-use strategies for Spring Chinook Salmon tlatcnery No. 1.

Ta:le 2\%. Estimated annual operational costs and labor requirements for Spring Chinook Salmon Hatchery No. 1.

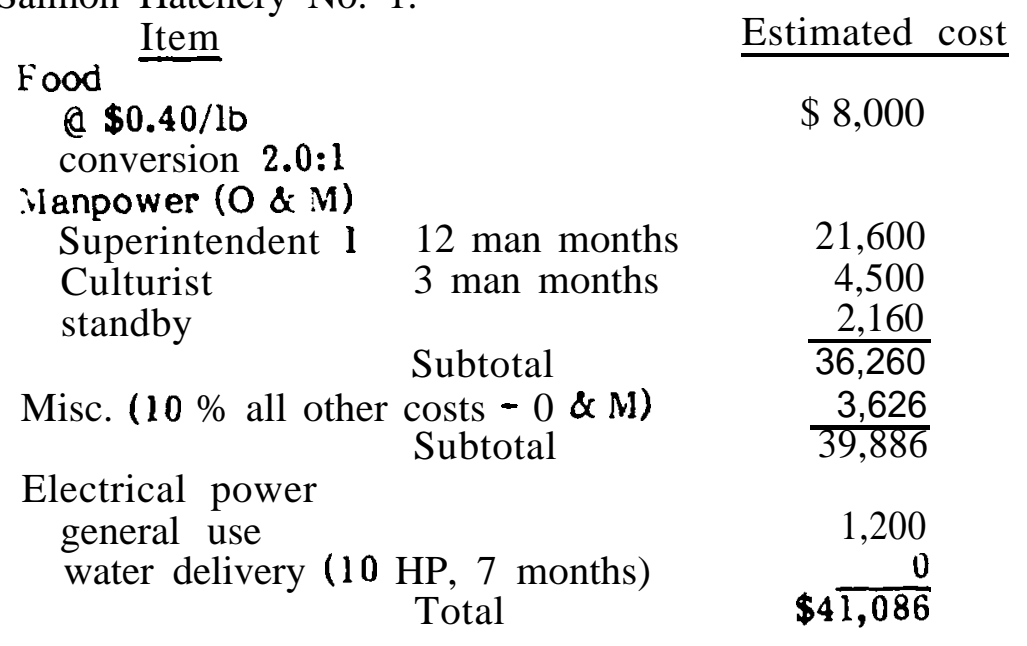


Theoretical Hatcheries

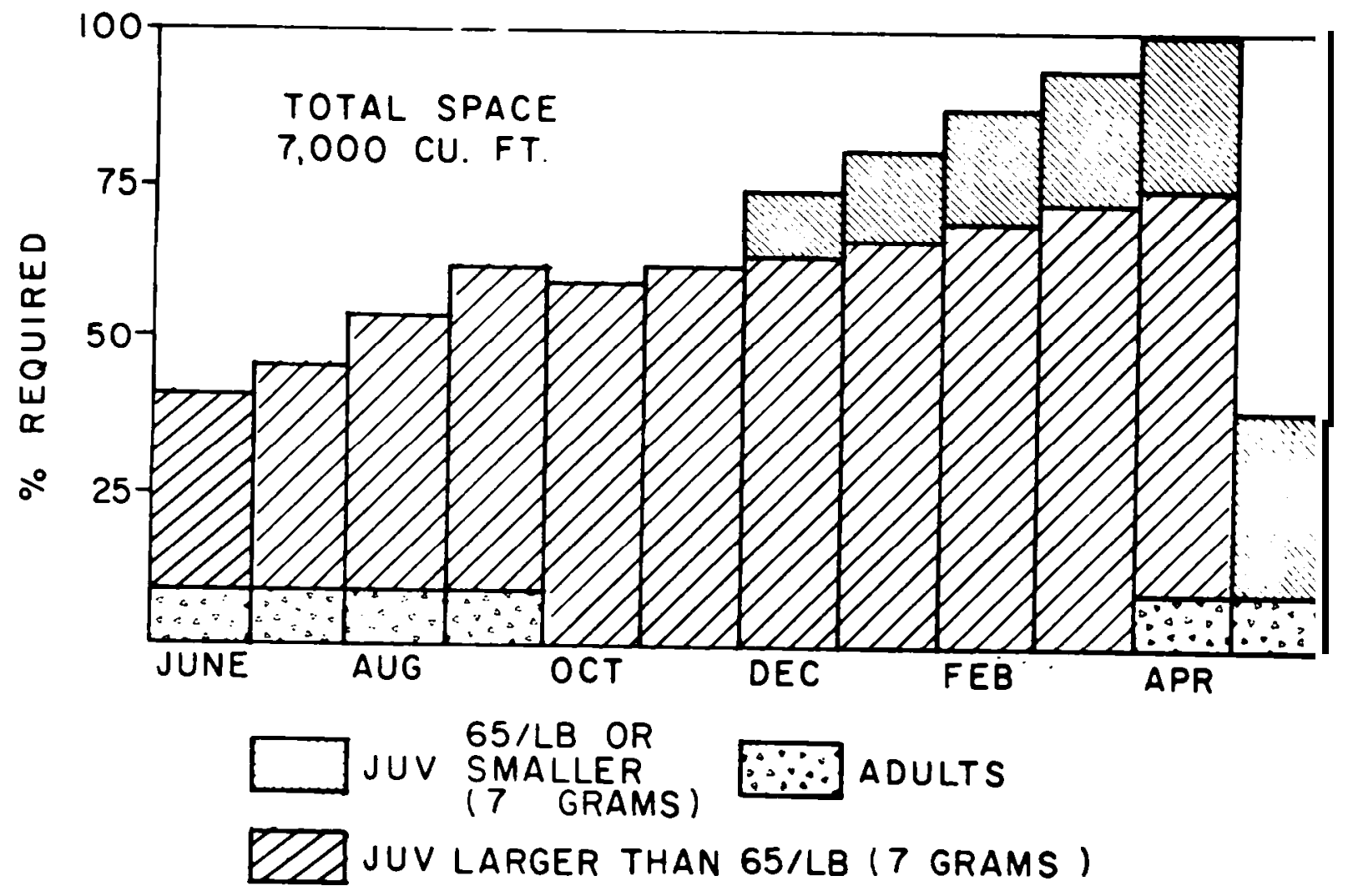

Figure 12. Space-use requirements for Spring Chinook Salmon Hatchery No. 1.

2. Spring Chinook Salmon Hatchery No. 2

Goals:

Produce 240,000 spring chinook smolts at 12 fish/lb (20,000 lbs) for annual onstation release in April.

Summary of Biological Requirements:

Smolt production (no./size)

Fertilized eggs (no. spawned)

Females to spawn (no.)

Adults held at one time (no.)

Recommended minimum water (gpm)

ground and/or spring surface

Recommended minimum pond space or equivalent

$240,000 @ 12 / 1 b$
370,000
74
230

432 @ $48 \mathrm{~F}$

2,190@ (see Fig. 1)

$14,000 \mathrm{ft}^{3}$

Facilities Development:

Table 28 lists the facilities and the associated requirements of Spring Chinook Salmon Hatchery No. 2 and Fig. 13 illustrates the physical plan for the hatchery. 
Chapter 9

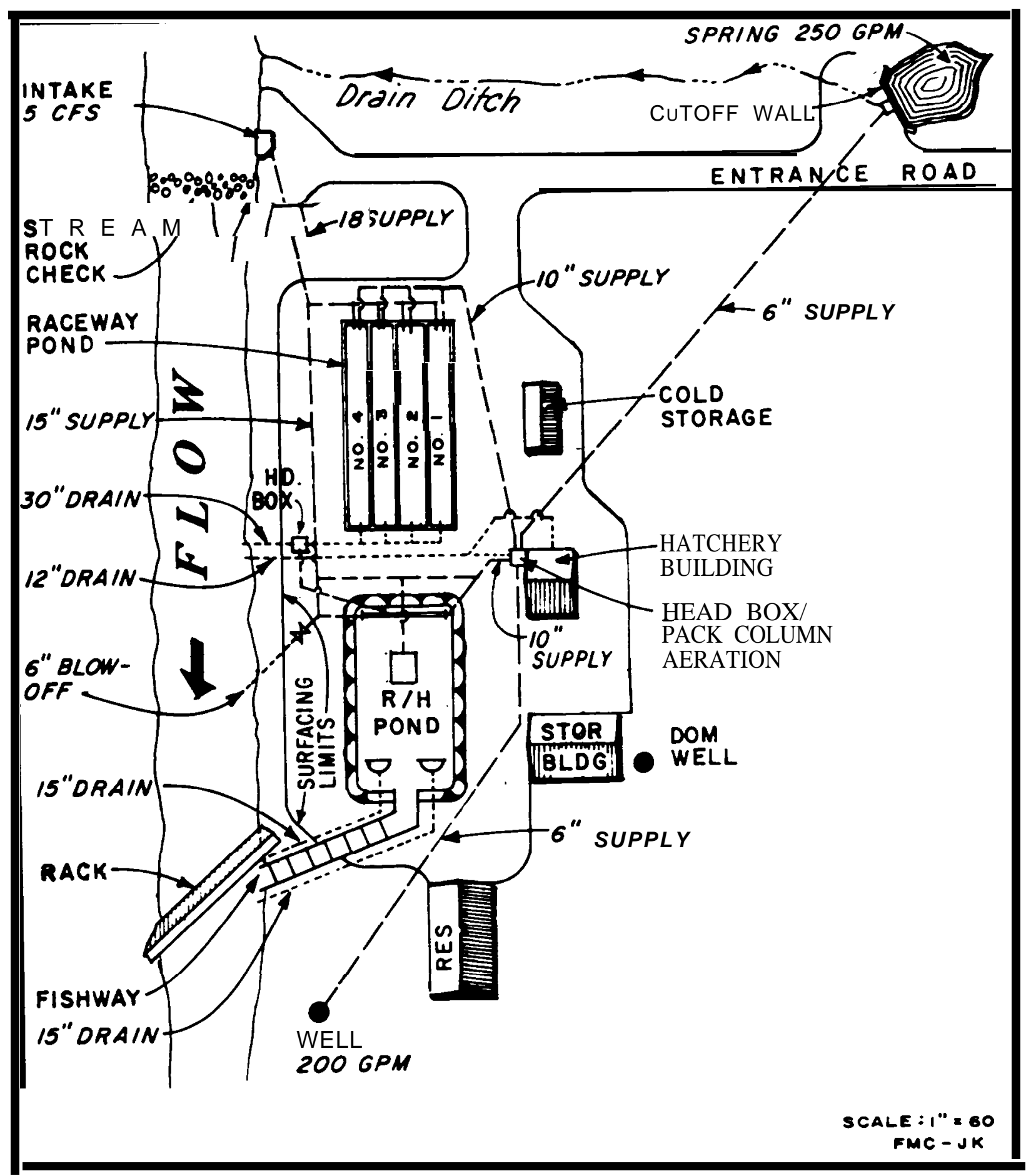

Figure 13. Schematic of Spring Chinook Salmon Hatchery No. 2. 
Theoretical Hatcheries

Operational Strategies:

The water and space requirements and operational procedures are as documented previously for Spring Chinook Salmon Hatchery No. 1.

\section{Costs:}

Table 29 shows the estimated capital cost for Spring Chinook Salmon Hatchery No. 2 and Table 30 shows the estimated annual operational costs and manpower requirements.

Table 28. Facility development for Spring Chinook Salmon Hatchery No. 2 (20,000 lbs, on-station release).

\begin{tabular}{|c|c|c|c|}
\hline Facilities & No. & Size & Description \\
\hline \multicolumn{4}{|c|}{ Site Development } \\
\hline $\begin{array}{l}\text { Clearing } \\
\text { \& Grubbing }\end{array}$ & $41 / 2$ & Acres & $\begin{array}{l}\text { Clearing \& grubbing of hatchery site, } \\
\text { entrance road \& pipeline } \mathrm{K} / \mathrm{W} \text {. }\end{array}$ \\
\hline Entrance Road & $1 / 2$ & Mile & $\begin{array}{l}\text { 16' wide, } 8 " \text { pit run base over ave. } 2 \text { ' fill } \\
\text { ht. Turnouts a } 500^{\prime} \text { intervals. }\end{array}$ \\
\hline $\begin{array}{l}\text { Cn Site Road } \\
\& \text { Drives }\end{array}$ & 3,600 & $\mathrm{yd}^{2}$ & $8 "$ base \& $2 "$ crushed rock topping. \\
\hline \multicolumn{4}{|c|}{ Water Supply \& Drains } \\
\hline Stream Intake & 1 & $10^{\prime} \times 4$ & $\begin{array}{l}\text { Coarse \& fine screen reinforced concrete } \\
\text { with rock check }\end{array}$ \\
\hline Supply Lines & & & $\begin{array}{l}12^{\prime \prime} \text { diameter \& larger - C.MP, under } 12^{\prime \prime}= \\
\text { PVC }\end{array}$ \\
\hline Drain Lines & & & $\begin{array}{l}\text { 12" diameter \& larger - C.YIP, under } 12 " \text { - } \\
\text { PVC }\end{array}$ \\
\hline Domestic Well & 1 & $5 \mathrm{gpm}$ & $\begin{array}{l}6^{\prime \prime} \text { diameter } \mathrm{x} 120^{\prime} \text { deep with } 1 / 2 \mathrm{HP} \\
\text { submersible pump. Pressure tank in } \\
\text { storage ouilding - PVC underground piping } \\
\text { to buildings. }\end{array}$ \\
\hline Production Well & 1 & 200 gpm & $\begin{array}{l}\text { 8" diameter } x \text { 200' deep with lo HP } \\
\text { submersible pump. }\end{array}$ \\
\hline Spring Intake & 1 & $16^{\prime}$ long & $\begin{array}{l}\text { Concrete cut-off wall } x 5^{\prime} \text { high with } 2^{\prime} \times \\
4^{\prime} \text { concrete screened intake box }-250 \mathrm{gpm} \text {. }\end{array}$ \\
\hline Aeration Head Box & 1 & $4^{\prime} \times 4^{\prime}$ & $\begin{array}{l}\text { Plywood construction/compartments for } \\
\text { spring \& well water aeration through two } \\
\text { packed column aerator units. }\end{array}$ \\
\hline Stream Rock Check & 1 & $20 \mathrm{yd}^{3}$ & Heavy rock rip rap $\left(30^{\prime} \times 6^{\prime} \times 3^{\prime}\right)$ \\
\hline
\end{tabular}


Chapter 9

\begin{tabular}{|c|c|c|c|}
\hline Facilities & No. & Size & Description \\
\hline \multicolumn{4}{|c|}{ Fish Production Facilities } \\
\hline Raceways & 4 & $83^{\prime} \times 8^{\prime}$ & $\begin{array}{l}2,000 \mathrm{ft}^{3} \text { water each } \\
\text { steel/plastic sheet lining. }\end{array}$ \\
\hline Pond & 1 & $80^{\prime} \times 42^{\prime}$ & $\begin{array}{l}\text { Combination rearing \& adult holding } 7,400 \\
\mathrm{ft}^{3} \text { water, dirt sides \& bottom } / 3: 1 \text { bank } \\
\text { slopes. Upwelling W.S. on pond bottom } \\
\text { for adult holding. }\end{array}$ \\
\hline Hatching Tanks & 2 & $16^{\prime} \times 18^{\prime \prime}$ & $\begin{array}{l}2 \text { deep tanks for egg incubation } \& 1 \\
\text { shallow tank for egg picking. }\end{array}$ \\
\hline Adult Fish Rack & 1 & $40 \operatorname{lin} \mathrm{ft}$ & Wood constr. - annual installation \\
\hline Fishway & 1 & 6' lift & $\begin{array}{l}\text { Plywood constr } / 4^{\prime} W \times 4^{\prime} \mathrm{H} \times 48^{\prime} \mathrm{L} / \mathrm{six} 8^{\prime} \\
\text { pools with canvas fencing on top of } \\
\text { fishway for fish containment. }\end{array}$ \\
\hline \multicolumn{4}{|c|}{ Buildings } \\
\hline Hatchery & 1 & $18^{\prime} \times 24^{\prime}$ & $\begin{array}{l}\text { Metal building with tank, office, crew } \\
\text { locker, mechanical, and rest rooms. }\end{array}$ \\
\hline Storage & 1 & $36^{\prime} \times 24^{\prime}$ & $\begin{array}{l}\text { Metal bldg with gravel floor, three } 12 \text { ' } \\
\text { bays for equipment and supply storage and } \\
\text { domestic water pressure tank housing. }\end{array}$ \\
\hline Cold Storage & 1 & $26^{\prime} \times 12^{\prime}$ & Prefab $20^{\prime} \times 12^{\prime}$ freon cold storage \\
\hline Fish Feed & & & $\begin{array}{l}\text { unit/ } 16,000 \text { lo c a pacity with a } 12^{\prime} \times 6^{\prime} \\
\text { add-on for food handling and thawing. } \\
\text { OMP feed delivery } 3 \times \text { per year. }\end{array}$ \\
\hline Residence & 1 & $46^{\prime} \times 24^{\prime}$ & $\begin{array}{l}3 \text { BR. wood frame prefab unit/attached } \\
\text { garage (residence would be marketable } \\
\text { if facility closed). }\end{array}$ \\
\hline
\end{tabular}

Equipment

General List 1 pick-up, nets, pumps' misc. tools $\&$
cleaning equip. $(\$ 2 \$ 000)$

Table 29. Facility development costs for Spring Chinook Salmon Hatchery No. 2.

\section{Facility}

Site develooment

Water supply and drains

Fish production facilities

Buildings

Equipment
Estimated cost

$\$ y 0,600.00$

$152,700.00$

$90,304.00$

$145,500.00$

$24,000.00$

$\$ 504,100.00$ 
Taole 30. Estimated annual operational costs and labor requirements for Spring Chinook Salmon Hatchery No. 2.

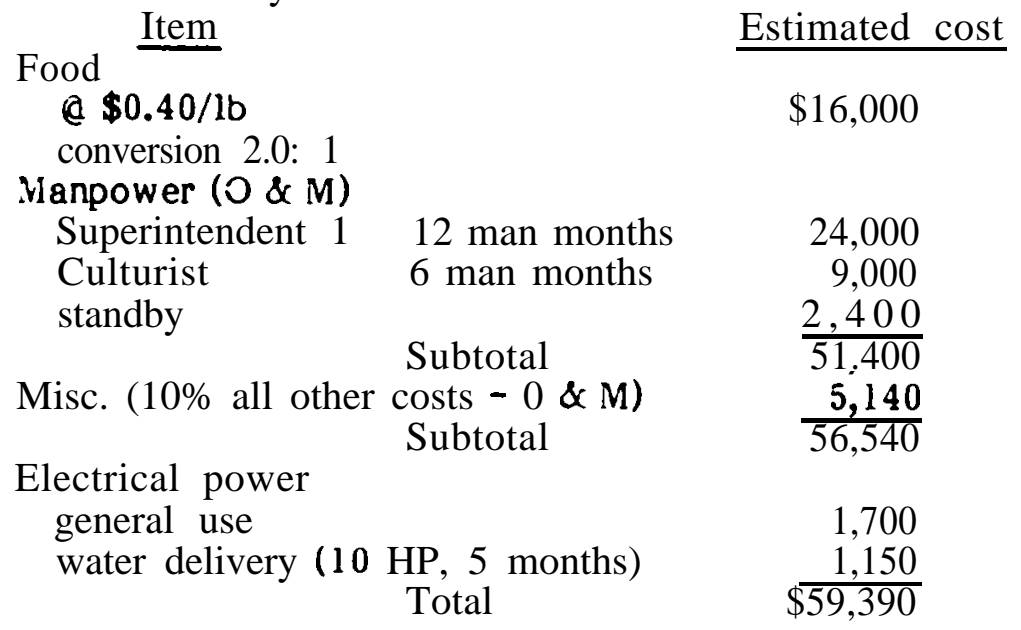

3. Soring Chinook Salmon Hatcherv No. 3

Goals:

Produce 600,006 spring chinook smolts at 12 fish/lb (50,000 lbs) for annual on-station release in April.

Summary of Biological Requirements:

Smolt production (no./size)

Fertilized eggs (no. spawned)

Females to spawn (no.)

Adults held at one time (no.)

Recommended minimum water (gprn) ground and/or spring surface

Recommended minimum pond space or equivalent

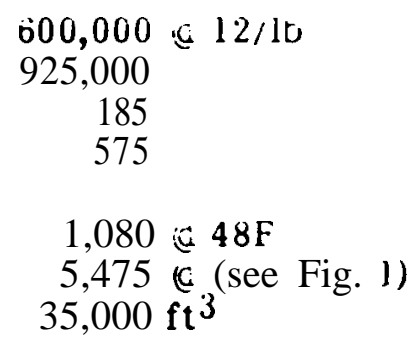

Facilities Development:

Table 31 lists the facilities and the associated requirements of Spring Chinook Salmon Hatchery No. 3, and Fig. 14 illustrates the physical plan for the hatchery.

Operational Strategies:

X11 water and space requirements and operational procedures are as documented previously for Spring Chinook Salmon Hatcheries Nos. 1 and 2.

This station does not have a spring water supply, but depends upon a pumped shallow ground water supply (infiltration gallery). The $7.511 \mathrm{P}$ pump will be used as needed, or about 150 days. 
Chapter 9

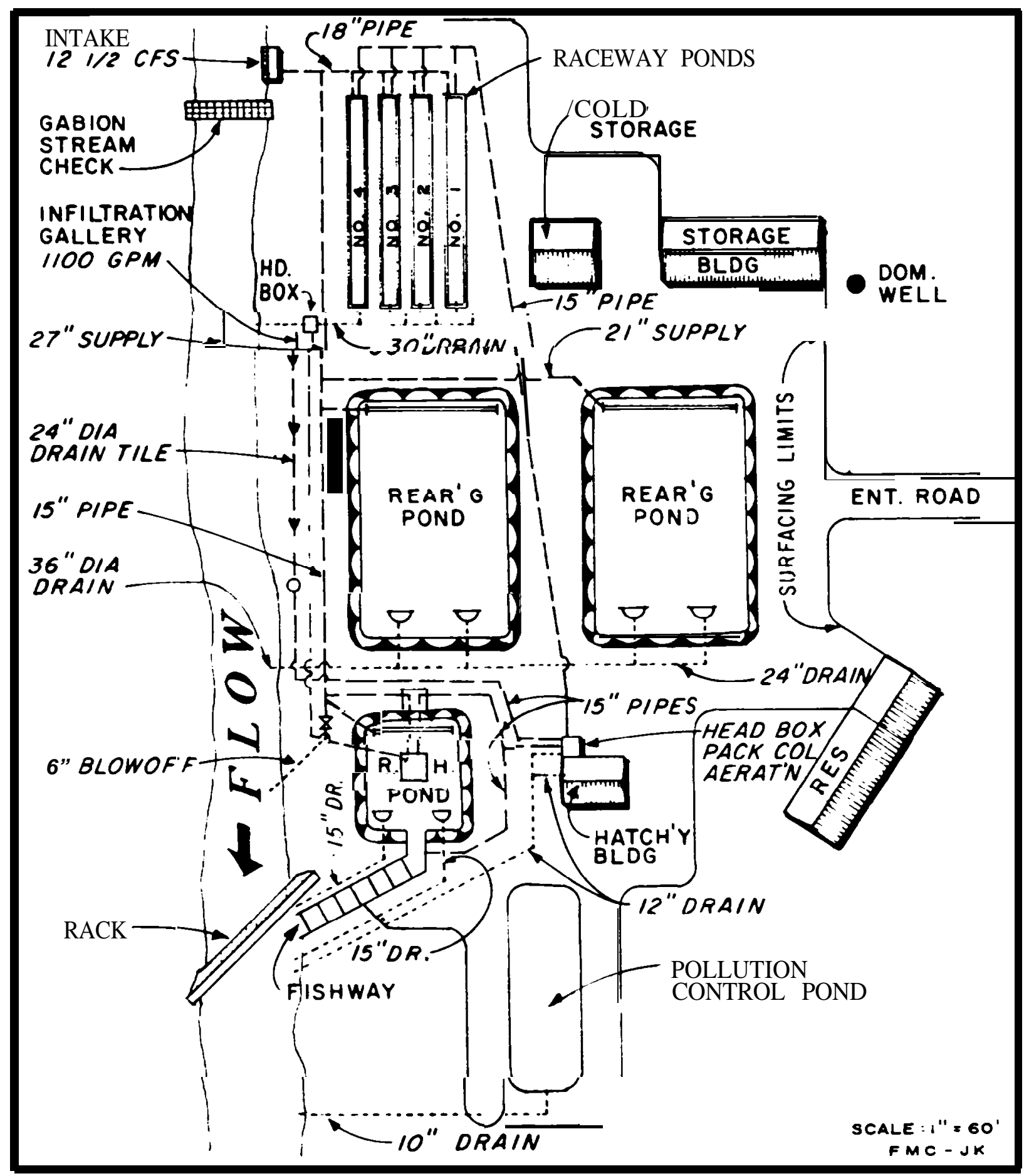

Figure 14.Schematic of Spring Chinook Salmon Hatchery No. 3. 
Theoretical Hatcheries

Costs:

Table 32 shows the estimated capital cost for Spring Chinook Salmon Hatchery No. 3 and Table 33 shows the estimated annual operational costs and manpower requirements.

Table 31. Facility development for Spring Chinook Salmon Hatchery No. 3 (50,000 lbs, on-station release).

\begin{tabular}{|c|c|c|c|}
\hline Facilities & No. & Size & Description \\
\hline \multicolumn{4}{|c|}{ Site Development } \\
\hline $\begin{array}{l}\text { Clearing } \\
\text { \& Grubbing }\end{array}$ & 6.5 & Acres & $\begin{array}{l}\text { Clearing \& grubbing of hatchery site, } \\
\text { entrance road \& pipeline } \mathrm{R} / \mathrm{W} \text {. }\end{array}$ \\
\hline Entrance Road & $1 / 2$ & Mile & $\begin{array}{l}\text { 16' wide, } \mathbf{8}^{\prime \prime} \text { pit run base over ave. } 2^{\prime} \text { fill } \\
\text { ht. Turnouts @ } 500^{\prime} \text { intervals. }\end{array}$ \\
\hline $\begin{array}{l}\text { On Site Road } \\
\& \text { Drives }\end{array}$ & 4,000 & $\mathrm{yd}^{2}$ & $8 "$ base \& $2 "$ crushed rock topping. \\
\hline \multicolumn{4}{|c|}{ Water Supply \& Drains } \\
\hline Stream Intake & 1 & $18^{\prime} \times 4^{\prime}$ & $\begin{array}{l}\text { Coarse \& fine screening, reinforced } \\
\text { concrete with gabion stream check }\end{array}$ \\
\hline Supply Lines & & & $\begin{array}{l}\text { 12" diameter \& larger - CilP, under } 12 " \text { - } \\
\text { PVC }\end{array}$ \\
\hline Drain Lines & & & $\begin{array}{l}12 " \text { diameter \& larger - C.MP, under } 12^{\prime \prime}- \\
\text { PVC }\end{array}$ \\
\hline Domestic Well & 1 & $5 \mathrm{gpm}$ & $\begin{array}{l}6^{\prime \prime} \text { diameter } \times 120^{\prime} \text { deep with } 1 / 2 \text { HP } \\
\text { submersible pump. Pressure tank in } \\
\text { storage building - PVC underground piping } \\
\text { to buildings \& spawning shed. }\end{array}$ \\
\hline $\begin{array}{l}\text { Infiltration } \\
\text { Gallery/Pump }\end{array}$ & 150 & $\operatorname{lin} \mathrm{ft}$ & $\begin{array}{l}4^{\prime} \mathbf{W} \text { trench gallery excavated to } \\
\text { below stream bed. } 24^{\prime \prime} \text { perforated drain } \\
\text { tile backfilled with washed river gravel. } \\
\text { Pump sump with } 7.5 \text { HP submersible pump } \\
-1100 \text { gpm }\end{array}$ \\
\hline Aeration Head Box & 1 & $4^{\prime} \times 6^{\prime}$ & $\begin{array}{l}\text { Plywood construction/compartments for } \\
\text { water aeration through three packed } \\
\text { column aerator units. }\end{array}$ \\
\hline $\begin{array}{l}\text { Stream Gabion } \\
\text { Check }\end{array}$ & 1 & $20 \mathrm{yd}^{3}$ & $\begin{array}{l}\text { Gabion rock-filled wire } \quad \text { baskets } \\
\left(30^{\prime} \times 6^{\prime} \times 3^{\prime}\right)\end{array}$ \\
\hline
\end{tabular}


Chapter 9

\begin{tabular}{|c|c|c|c|}
\hline Facilities & No. & Size & Description \\
\hline & & Fish & Production \\
\hline Raceways & 4 & $83^{\prime} \times 8^{\prime}$ & $\begin{array}{lllll}2,000 \quad \mathrm{ft}^{3} & \text { water each } & - & \text { Prefab } \\
\text { steel/plastic } & \text { sheet lining. }\end{array}$ \\
\hline Ponds & 2 & $96^{\prime} \times 55^{\prime}$ & $\begin{array}{l}13,200 \mathrm{ft}^{3} \text { water each - Dirt sides } \& \\
\text { bottom/3: } 1 \text { bank slopes. Average pond } \\
\text { water depth, } 3-1 / 2^{\prime} \text {. }\end{array}$ \\
\hline $\begin{array}{l}\text { Comb. Rearing } \\
\text { Holding Pond }\end{array}$ & 1 & $50^{\prime} \times 40^{\prime}$ & $\begin{array}{l}5,200 \mathrm{ft}^{3} \text { wate } \mathrm{r} \text { - Dirt sides \& } \\
\text { bottom with 2.5:1 bank slopes. Average } \\
\text { pond water depth, 5-1/2. Upwelling W.S. } \\
\text { on pond bottom for adult holding. }\end{array}$ \\
\hline Electric Fence & 1 & $40 \operatorname{lin} \mathrm{ft}$ & $\begin{array}{l}\text { Electric fence barrier weir }-110 \text { volts. } \\
\text { Annual installation. }\end{array}$ \\
\hline Fishway & 1 & 6' lift & $\begin{array}{l}\text { Plywood constr } / 4^{\prime} \mathrm{W} \times 4^{\prime} \mathrm{H} \times 48^{\prime} \mathrm{L} / \mathrm{six} 8^{\prime} \\
\text { pools with canvas fencing on sides of } \\
\text { fishway for fish containment. Auxilliary } \\
\text { water added at top of ladder to provide } \\
\text { for min. operational flow. }\end{array}$ \\
\hline Hatching Tanks & 5 & $16^{\prime} \times 18^{\prime \prime}$ & $\begin{array}{l}5 \text { deep tanks for egg incubation \& } 1 \\
\text { shallow tank for egg picking. }\end{array}$ \\
\hline $\begin{array}{l}\text { Pollution Control } \\
\text { Pond }\end{array}$ & 1 & $80^{\prime} \times 25^{\prime}$ & $\begin{array}{l}3,000 \mathrm{ft}^{3} \text { water/l hour detention time } \\
\text { for pond cleaning wastes by vacuum } \\
\text { system. Dirt sides \& bottom } / 3: 1 \text { bank } \\
\text { slopes. Average water depth, 3-1/2'. }\end{array}$ \\
\hline \multicolumn{4}{|r|}{ Buildings } \\
\hline Hatchery & 1 & $18^{\prime} \times 24^{\prime}$ & $\begin{array}{l}\text { Hetal building with tank, office, crew } \\
\text { locker, mechanical, and rest rooms. }\end{array}$ \\
\hline Storage & 1 & $60^{\prime} \times 24^{\prime}$ & $\begin{array}{l}\text { Metal bldg with gravel floor, five } 12^{\prime} \text { bays } \\
\text { for equipment and supply storage, } \\
\text { domestic water pressure tank, and diesel } \\
\text { generator housing. }\end{array}$ \\
\hline Cold Storage & 1 & $24^{\prime} \times 24^{\prime}$ & Prefab $18^{\prime} \times 24^{\prime}$ freon cold storage \\
\hline Fish Feed & & & $\begin{array}{l}\text { unit } / 38,000 \text { lb capacity with a } 6^{\prime} \times 24^{\prime} \\
\text { add-on for food handling and thawing. } \\
\text { OMP feed delivery } 3 \times \text { per year }\end{array}$ \\
\hline Spawning Shed & 1 & $10^{\prime} \times 10^{\prime}$ & $\begin{array}{l}\text { Open sides ends with roof for spawning } \\
\text { at head end of holding pond. }\end{array}$ \\
\hline Residence & 1 & $46^{\prime} \times 24^{\prime}$ & $\begin{array}{l}3 \mathrm{BH} \text {. wood frame prefab unit/attached } \\
\text { garage (residence would be maristable } \\
\text { if facility closed). }\end{array}$ \\
\hline
\end{tabular}

Equipment

General List

1 pick-up, nets, pumps, misc. tools \& cleaning equip. $(\$ 26,000)$ 
Theoretical Hatcheries

Table 32. Facility development costs for Spring Chinook Salmon Hatcherv No. 3.

\begin{tabular}{|c|c|}
\hline Facility & Estimated \\
\hline Site development & $\overline{\$ 111,900.00}$ \\
\hline Water supply and drains & $215,400.00$ \\
\hline Fish production facilities & $150,800.00$ \\
\hline Buildings & $175,500.00$ \\
\hline Equipment & $\$ \frac{26,000.00}{\$ 779,600.00}$ \\
\hline
\end{tabular}

Table 33. Estimated annual operational costs and labor requirements for Spring Chinook Salmon Hatchery No. 3.

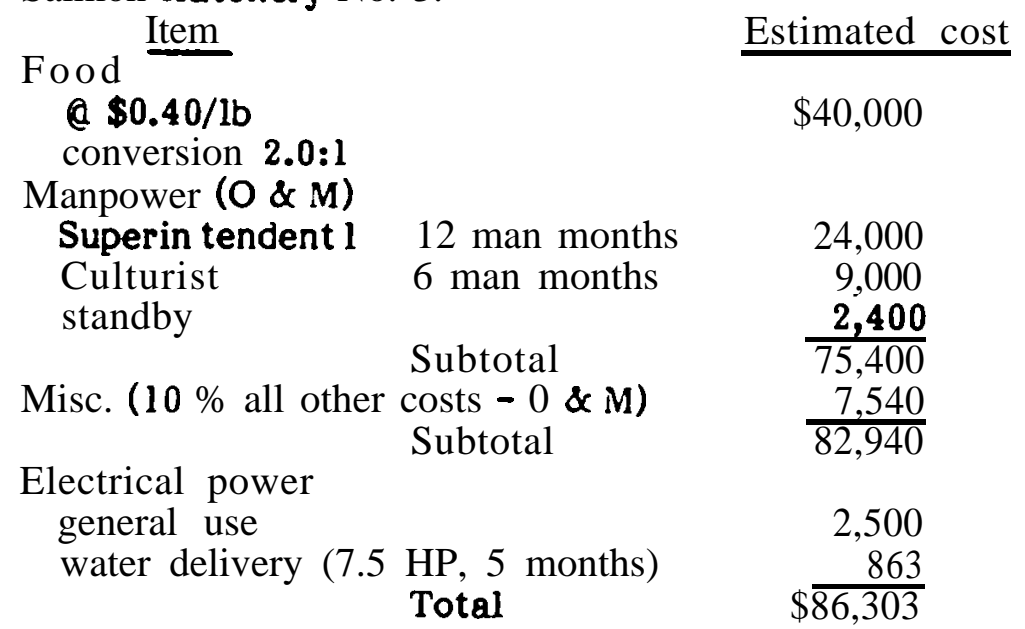

\section{4. $\quad$ Spring Chinook Salmon Hatchery No. 4}

\section{Goals:}

Produce 20,000 spring chinook juveniles of various sizes from a single racial stock for on-station and off-station production and releases as follows:

\begin{tabular}{|c|c|c|c|c|}
\hline *Nos. & No./lb & Lbs & Date & Stream release site \\
\hline 86,400 & 12 & 7.200 & April & A (on-station) \\
\hline 21,600 & 12 & 1,800 & April & B 1 \\
\hline 21,600 & 12 & 1,800 & April & B 2 \\
\hline 160,000 & 1,600 (eyed eggs) & 100 & November & B3 \\
\hline 80,000 & 1,600 (eyed eggs) & 50 & November & Hatchery Transfer \\
\hline 180,000 & 60 & 3,000 & June & B 4,5 \\
\hline 72,600 & 12 & 6,050 & April & $\mathrm{C}$ \\
\hline
\end{tabular}

The goals of these releases are as follows:

Stream A - For brood stock and all fisheries

Stream B, 1-5 - To rebuild a very depressed stream and its tributaries for an eventual fishery. 
Stream C - To develop a tribal net fishery on Stream C which has very limited natural production capabilities.

Summary of Biological Requirements:

\section{Smolt \\ Fingerling \\ Eyed-egg plants/transfers}

Fertilized eggs (no. spawned)

Smolt

Fingerling

Eyed-egrs

Females to spawn (no.)

Adults held at one time (no.)

Recommended minimum water (gpm)

On-station ground and/or spring

Offstation surface
surface

Recommended minimum pond space

Onstation or equivalent

Offstation

$$
\begin{aligned}
& 202,200 \text { 12/1b } \\
& 180,000 \div 60 / 1 b \\
& 240,000 @ 1,600 / 1 b
\end{aligned}
$$

217,000

267,000

795,000

$-159$

495

\section{5 a $48 \mathrm{~F}$ \\ 1,326 (see Fig. 1) \\ 672 (see Fig. 1)}

$10,000 \mathrm{ft}^{3}$
$3,360 \mathrm{ft}^{3}$

Facilities Development:

Table 34 lists the facilities and the associated requirements of Spring Chinook Salmon Hatchery No. 4, Fig. 15 is a vicinity map of the production- facilities and release sites, and Figs. $16 \mathrm{a}$ and $16 \mathrm{~b}$ illustrate the physical plan for the hatchery.

Operational Strategies:

The water and space requirements as related to the total biological requirements are shown for on station production in Figs. 17 and- 18, respectively The programming of the fish within the rearing units is illustrated in Fig. 19.

On-station fish husbandry is similar to the previously described Spring Chinook Salmon Hatcheries Nos. 1, 2, and 3; however, brief comments follow for each life phase because of the off-station production.

(1) Adults The number of females required to be spawned for the smolt production, fingerling plants at $60 / \mathrm{b}$, and eyed-egg plants and transfers are 62, 43 , and 54, respectively; or a total of 159. Because these adults are of a single racial group they will be held together in the large on-station pond (Fig. 16a).

(2) Incubation The incubation program conducted is identical to Spring Chinook Salmon Hatchery No. 1. Eyed-egg plants will be made in the appropriate manner as described in Chapter 4. Also, see Steelhead Trout Hatchery No. 4 in this Chapter. Special care will be given to prevent freezing. 


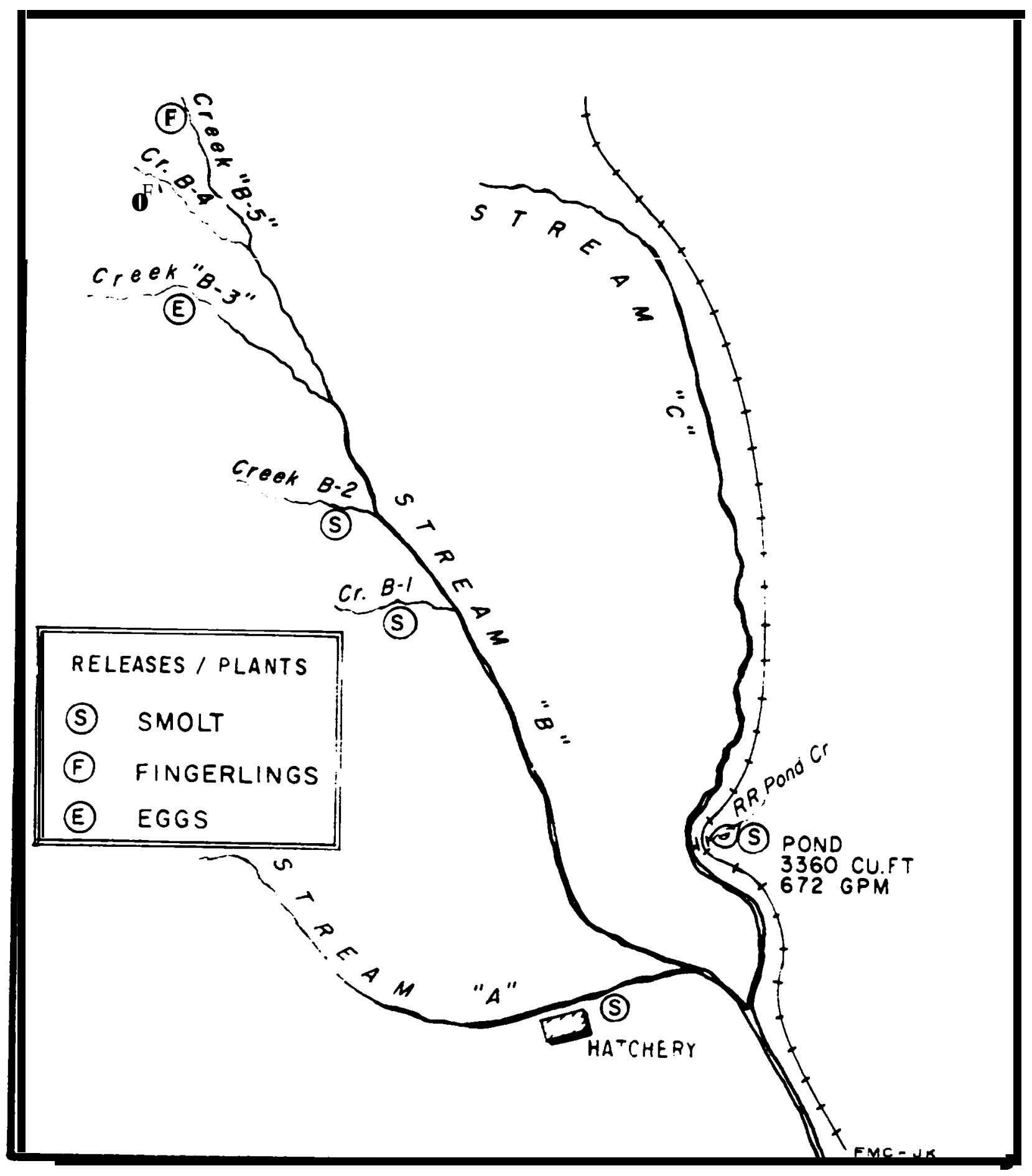

Figure 15. Vicinity map of the production facilities and release sites for Spring Chinoo: Salmon Hatchery No. 4. 
Chapter 9

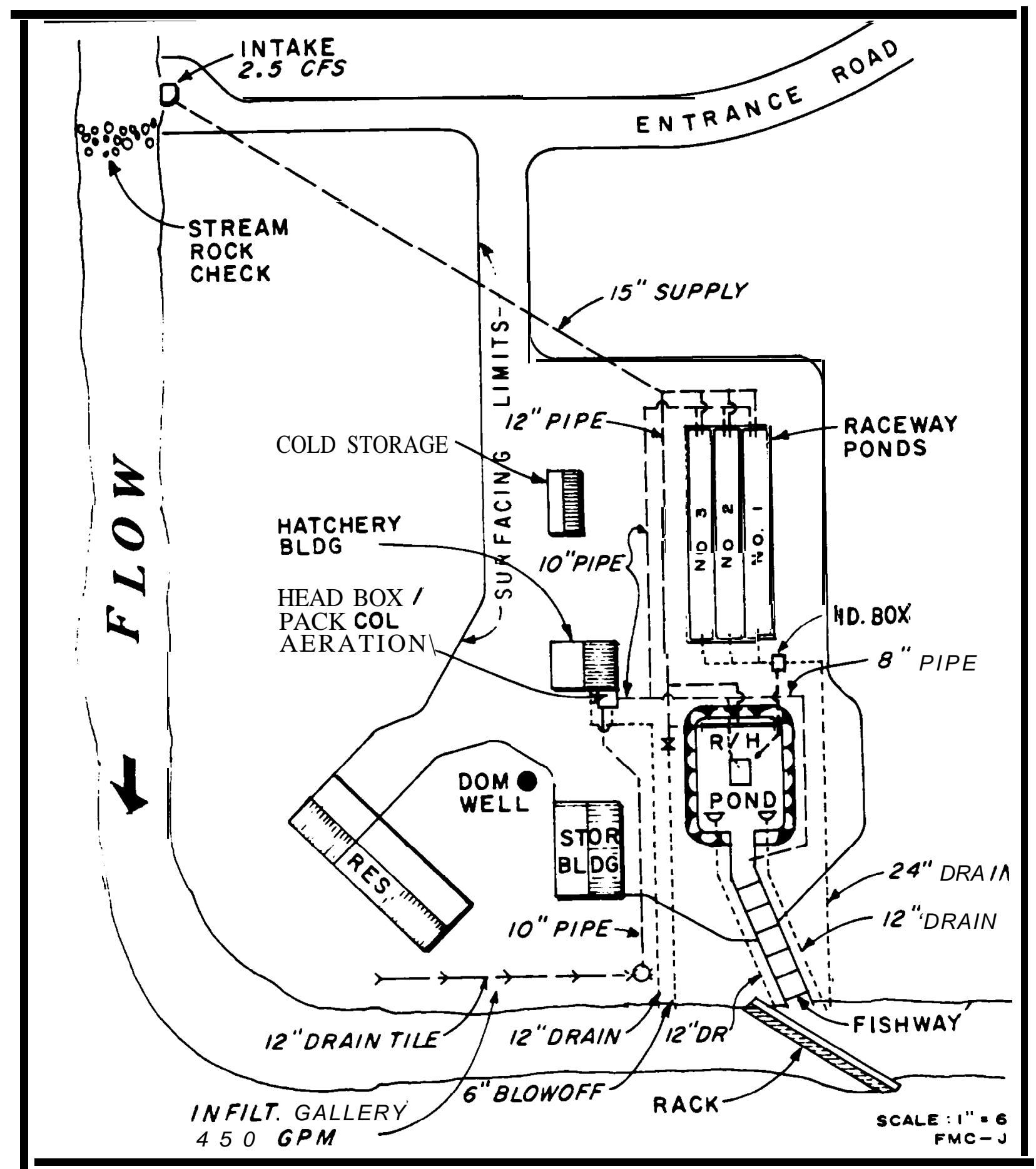

Figure 168. Schematic of Spring Chinook Salmon Hatchery No. 4 - On-station facilities. 


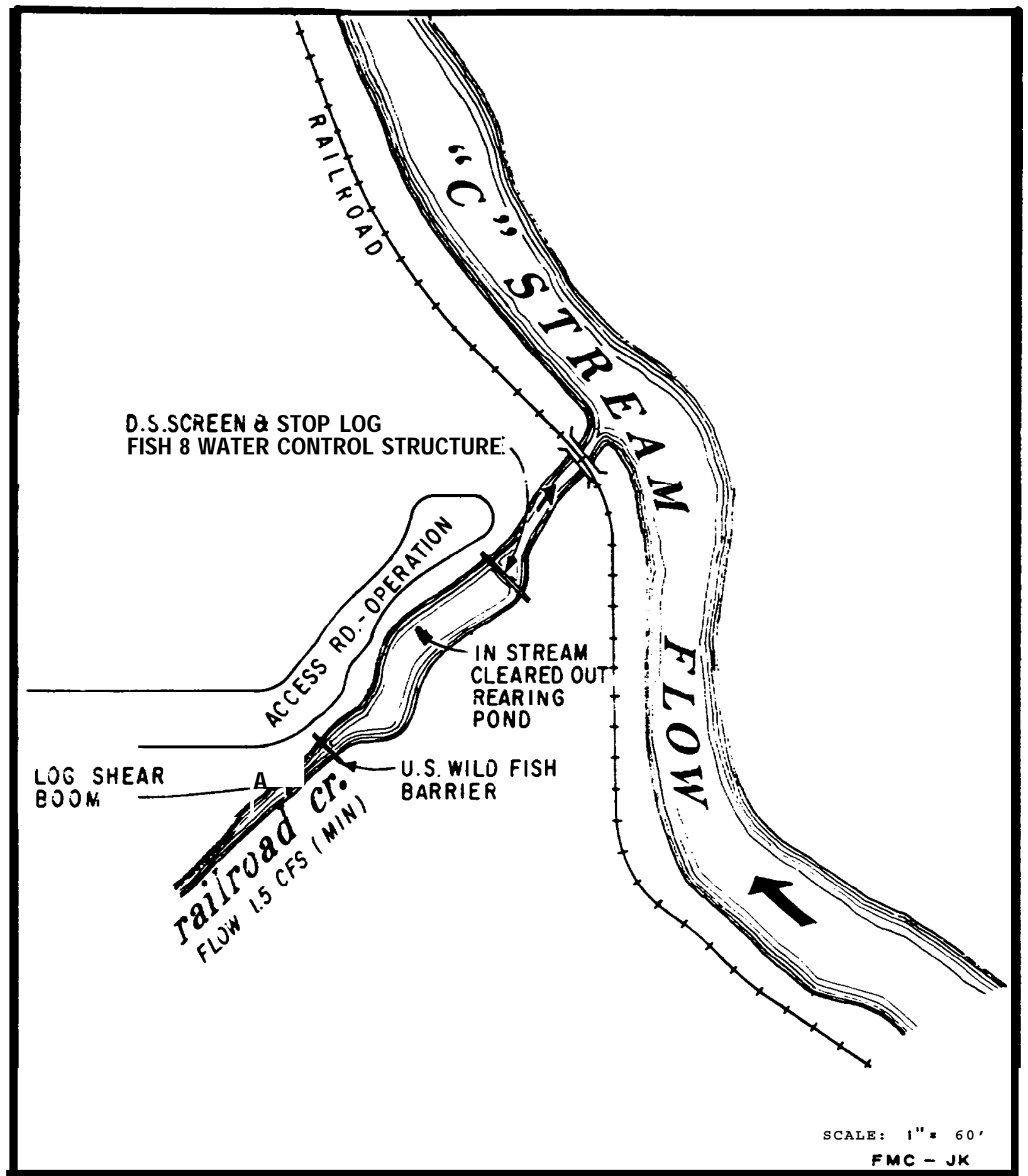

Figure 16b. Schematic of Spring Chinook Salmon Hatchery No. 4 - Satellite facilities. 
Chapter 9

(3) Rlelarintgaftiegs the on-station and off-station production plan for each rearing unit by time. The off-station $3,360 \mathrm{ft}^{3}$ pond will require 672 gpm and extra predator control measures. The fish will be fed by students as a high school class science project.

(4) Releases On-station smolt releases will follow the program described under Spring Chinook Salmon Hatchery No. 1 and the off-station smolt transportation and release will be conducted as described in Chapter 6 Transportation.

\section{Costs:}

Table 35 shows the estimated capital cost for Spring Chinook Salmon Hatchery No. 4 and Table 36 shows the estimated annual operational costs and manpower requirements.

Table 34. Facility development for Spring Chinook Salmon Hatchery No. 4 (20,000 lbs, on- and off-station release).

\begin{tabular}{|c|c|c|c|}
\hline Facilities & No. & Size & Description \\
\hline \multicolumn{4}{|c|}{ Site Development - On-Station } \\
\hline $\begin{array}{l}\text { Clearing } \\
\& \text { Grubbing }\end{array}$ & 4 & Acres & $\begin{array}{l}\text { Clearing \& grubbing of hatchery site, } \\
\text { entrance road \& pipeline } \mathrm{R} / \mathrm{W} .\end{array}$ \\
\hline Entrance Road & $1 / 2$ & Mile & $\begin{array}{l}\text { 16' wide, 8" pit run base over ave. 2' fill } \\
\text { ht. Turnouts a } 500^{\prime} \text { intervals. }\end{array}$ \\
\hline $\begin{array}{l}\text { On Site Road } \\
\& \text { Drives }\end{array}$ & 2,100 & $\mathrm{yd}^{2}$ & 8" base \& $2 "$ crushed rock topping. \\
\hline
\end{tabular}

Water Supply \& Drains - On-Station

\begin{tabular}{|c|c|c|c|}
\hline Stream Intake & & $10^{\prime} \times 4$ & $\begin{array}{l}\text { Coarse \& fine screening, reinforced } \\
\text { concrete with rock check }\end{array}$ \\
\hline Supply Lines & & & $\begin{array}{l}\text { 12" diameter \& larger - CMP, under 12" - } \\
\text { PVC }\end{array}$ \\
\hline Drain Lines & & & $\begin{array}{l}12 " \text { diameter \& larger - CMP, under } 12 "- \\
\text { PVC }\end{array}$ \\
\hline Domestic Well & 1 & $5 \mathrm{gpm}$ & $\begin{array}{l}6^{\prime \prime} \text { diameter } \mathrm{x} 120^{\prime} \text { deep with } 1 / 2 \mathrm{HP} \\
\text { submersible pump. Pressure tank in } \\
\text { storage building - PVC underground piping } \\
\text { to buildings. }\end{array}$ \\
\hline $\begin{array}{l}\text { Infiltration } \\
\text { Gallery with Pump }\end{array}$ & 150 & $\operatorname{lin} \mathrm{ft}$ & $\begin{array}{l}4^{\prime} \text { w trench gallery excavated to } 6 \text {, } \\
\text { below stream bed. } 12^{\prime \prime} \text { perforated drain } \\
\text { tile backfilled with washed river gravel, } \\
\text { Pump sump with } 3 \mathrm{HP} \text { submersible pump - } \\
450 \mathrm{gpm} \text { and a } 150 \mathrm{gpm} \text { respectively. }\end{array}$ \\
\hline Aeration Head Box & 1 & $4^{\prime} \times 4^{\prime}$ & $\begin{array}{l}\text { Plywood construction/compartments for } \\
\text { water aeration through two packed } \\
\text { column aerator units. }\end{array}$ \\
\hline Stream Rock Check & 1 & $20 \mathrm{yd}^{3}$ & Heavy rock rip rap $\left(30^{\prime} \times 6^{\prime} \times 3^{\prime \prime}\right)$ \\
\hline
\end{tabular}


Theoretical Hatcheries

\begin{tabular}{|c|c|c|c|}
\hline Facilities & No. & Size & Description \\
\hline \multicolumn{4}{|c|}{ Fish Production Facilities - On-Station } \\
\hline Raceways & $\overline{3}$ & $83^{9} \times 8^{1}$ & $\begin{array}{l}2,000 \quad \mathbf{f t}^{\mathbf{J}} \text { water each } \quad-\quad \text { Prefab } \\
\text { steel/plastic sheet lining. }\end{array}$ \\
\hline $\begin{array}{l}\text { Corn b. Rearing } \\
\text { Holding Pond }\end{array}$ & 1 & $52^{\prime} \times 40^{\prime}$ & $\begin{array}{l}4,000 \mathrm{ft}^{3} \text { wate }- \text { Dirt sides \& } \\
\text { bottom with } 3: 1 \text { bank slopes. Average } \\
\text { pond water depth, } 3-1 / 2 \text {. Upwelling W.S. } \\
\text { on pond bottom for adult holding. }\end{array}$ \\
\hline Hatching Tanks & 4 & $16^{\prime} \times 18^{\prime \prime}$ & $\begin{array}{l}4 \text { deep tanks for egg incubation \& } 1 \\
\text { shallow tank for egg picking. }\end{array}$ \\
\hline Adult Fish Rack & 1 & $40 \operatorname{lin} \mathrm{ft}$ & Wood constr. - annual installation \\
\hline Fishway & 1 & 6' lift & $\begin{array}{l}\text { Plywood constr/six } 8^{\prime} \text { pools } \times 4^{\prime} \mathbf{W}^{\prime} \times 4^{\prime} \mathrm{H} \times \\
48^{\prime} \mathrm{L} \text { with canvas fencing on sides of } \\
\text { fishway for fish containment. Auxilliary } \\
\text { water added at top of ladder to provide } \\
\text { for min oderational flow. }\end{array}$ \\
\hline
\end{tabular}

\begin{tabular}{|c|c|c|}
\hline \multicolumn{3}{|c|}{ Buildings - On-Station } \\
\hline Hatchery & $18^{\prime} \times 24^{\prime}$ & $\begin{array}{l}\text { Metal building with tank, office, crew } \\
\text { locker, mechanical, and rest rooms. }\end{array}$ \\
\hline Storage & $36^{\prime} \times 24^{\prime}$ & $\begin{array}{l}\text { Metal building with gravel floor, three } 12 \text { ' } \\
\text { bays for equipment and supply storage, } \\
\text { domestic water pressure tank, and diesel } \\
\text { generator housing. }\end{array}$ \\
\hline Cold Storage & $12^{\prime} \times 24^{\prime}$ & Prefab 12'x18' freon cold storage \\
\hline Fish Feed & & $\begin{array}{l}\text { unit/ } 14,000 \text { lb capacity with a } 6^{\prime} \times 12^{\prime} \text { add } \\
\text { on for food handling and thawing. }\end{array}$ \\
\hline Residence & $46^{\prime} \times 24^{\prime}$ & $\begin{array}{l}3 \text { BR. wood frame prefab unit/attached } \\
\text { garage (residence would be marketable } \\
\text { if facility closed). }\end{array}$ \\
\hline \multicolumn{3}{|c|}{ Equipment - On-Station and Off-station } \\
\hline $\begin{array}{l}\text { General List } \\
(\$ 29,000)\end{array}$ & & $\begin{array}{l}1 \text { pick-up, nets, pumps, misc. tools, } \\
\text { cleaning equip., \& s mall fish-tank } \\
\end{array}$ \\
\hline \multicolumn{3}{|c|}{ Site Development - Off-Station Stream "C" } \\
\hline $\begin{array}{l}\text { Clearing } \\
\text { \& Grubbing }\end{array}$ & $1 \quad$ Acre & $\begin{array}{l}\text { Clearing \& grubbing of rearing } \\
\text { site \& access road. }\end{array}$ \\
\hline Entrance Road & $1,000 \operatorname{lin} \mathbf{f t}$ & $\begin{array}{l}\text { 12' wide, } \mathbf{8}^{\prime \prime} \text { pit run base over ave. } 1 \text { ' fill } \\
\text { ht. }\end{array}$ \\
\hline $\begin{array}{l}\text { On Site Operations } \\
\text { Road }\end{array}$ & $\mathrm{yd}^{2}$ & $8^{\prime \prime}$ base \& $2 "$ crushed rock topping. \\
\hline
\end{tabular}


Chapter 9

\begin{tabular}{|c|c|c|}
\hline Facilities & Size & Description \\
\hline Fish & Production & - Off-Station, Stream "C" \\
\hline R.R. Cr. Pond & $84^{\prime} \times 20^{\prime}$ & $\begin{array}{l}3,360 \mathrm{ft}^{3} \text { water. 2' average pond bottom } \\
\text { water depth. In stream development } \\
6,000 \mathrm{lb} \text { production. }\end{array}$ \\
\hline $\begin{array}{l}\text { Upstream Wild Fish } \mathbf{I} \\
\text { Barrier }\end{array}$ & & $\begin{array}{l}\mathbf{4}^{\prime} \mathbf{H} \text { screen structure to prevent } \\
\text { wild fish migration into rearing pond. }\end{array}$ \\
\hline $\begin{array}{l}\text { Downstream Water } 1 \\
\text { Control }\end{array}$ & $24 \operatorname{lin} \mathrm{ft}$ & $\begin{array}{l}\text { 4'H screen \& stop log structure to } \\
\text { contain fish and maintain pond water } \\
\text { elevation. }\end{array}$ \\
\hline
\end{tabular}

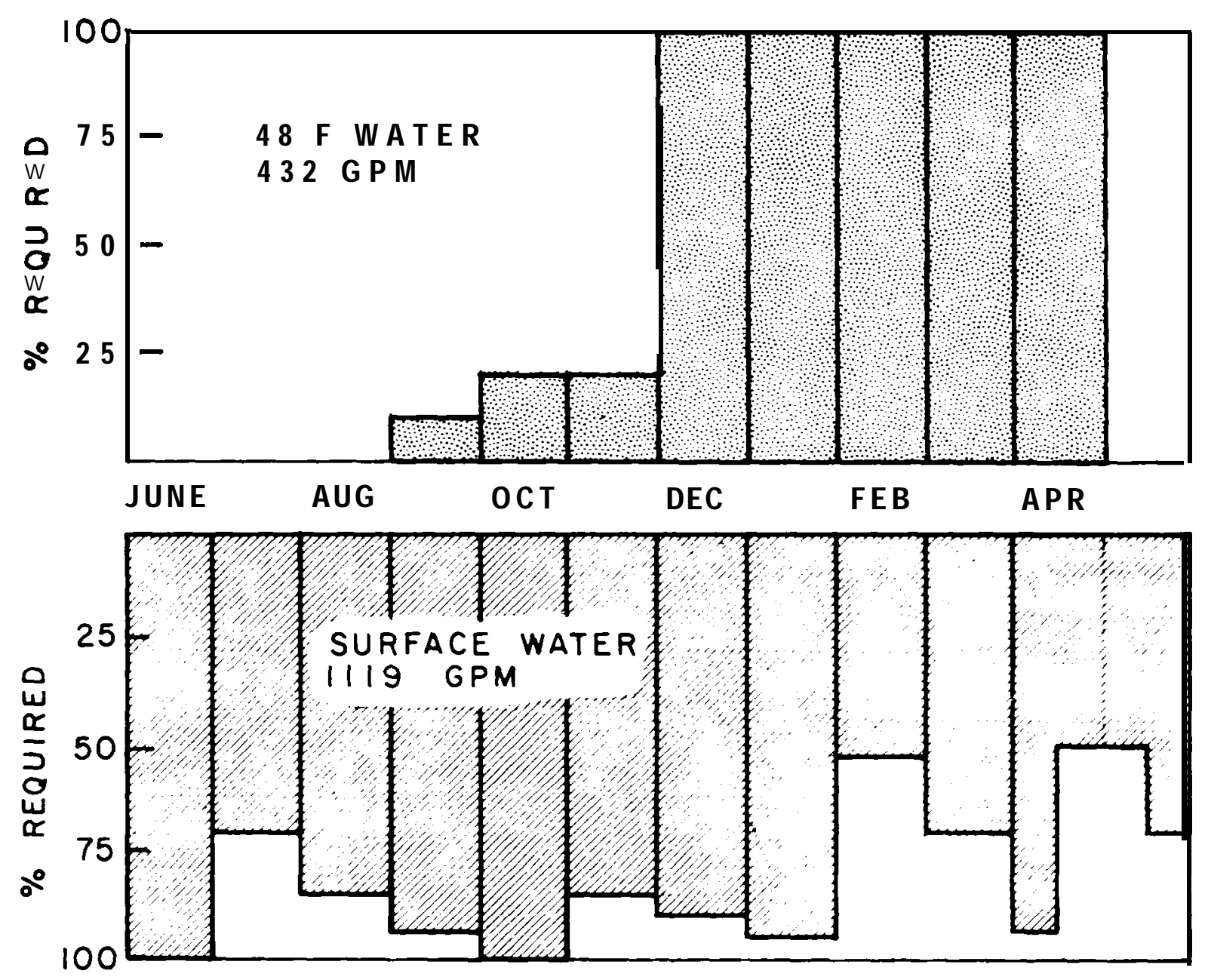

Figure 17. Water-use strategies for Spring Chinook Hatchery No. 4 - On-station. 
Theoretical Hatcheries

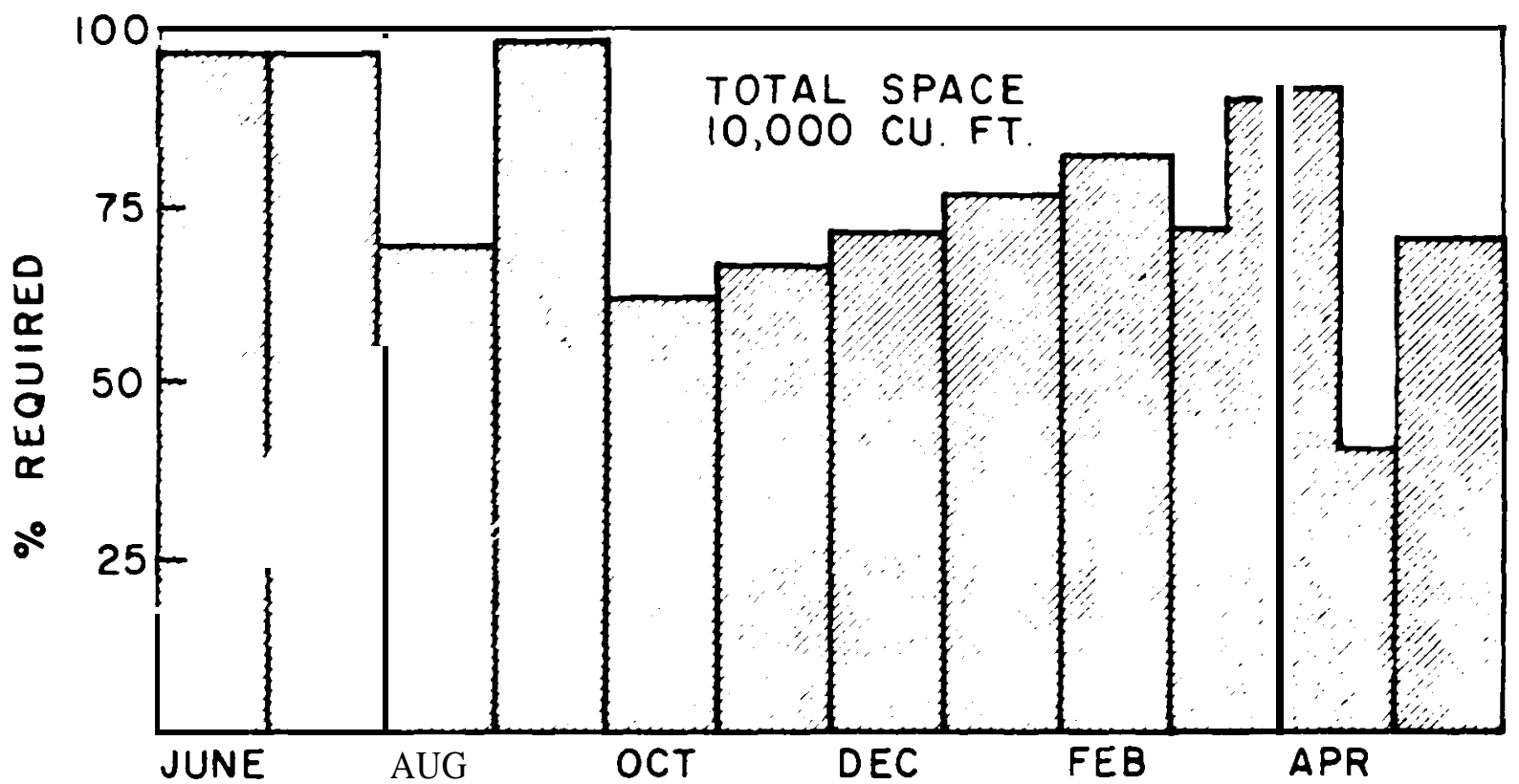

Figure 18. Space-use requirements for Spring Chinook Hatchery No. 4 - On-station.

Table 35. Facility development costs for Spring Chinook Salmon Hatchery No. 4.

\begin{tabular}{|c|c|}
\hline Facility & Estimated cost \\
\hline & $\$ 99,500.00$ \\
\hline Water supply and drains & $134,600.00$ \\
\hline Fish production facilities & $92,000.00$ \\
\hline Buildings & $143,200.00$ \\
\hline Equipment & $\frac{29,000.00}{\$ 498.300 .00}$ \\
\hline
\end{tabular}

Table 36. Estimated annual operational costs and labor requirements for Spring Chinook Salmon Hatchery No. 4.

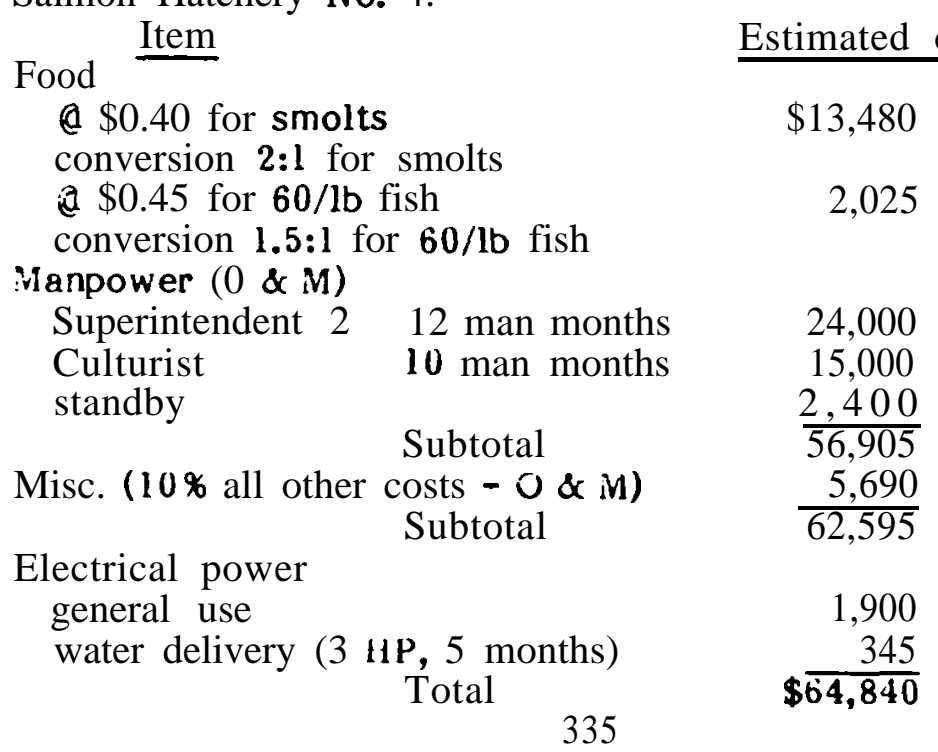



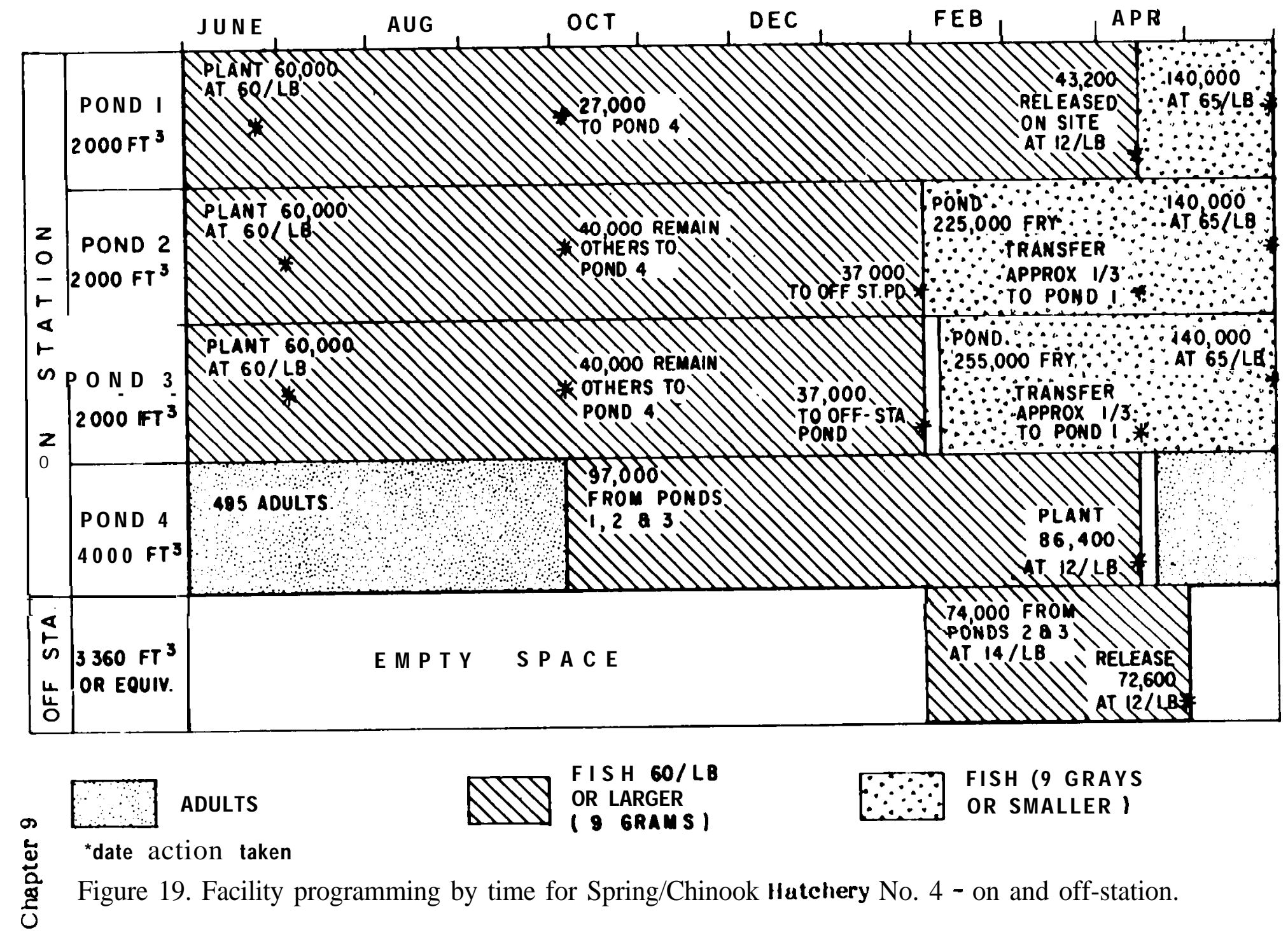
5. Spring Chinook Salmon Hatchery No. 5

Goals:

Produce 50,000 spring chinook juveniles of various sizes from a single racial stock for on-station and off-station production and releases as follows:

\begin{tabular}{cccll} 
Nos. & No./1b & Lbs & $\begin{array}{l}\text { Release } \\
\text { date }\end{array}$ & Stream release site \\
\cline { 2 - 3 } 2900 & 12 & 24,300 & April 15 & A (on-station) \\
300,000 (Oct.) & 15 & 20,000 & September 30 & B \\
60,000 & 12 & 5,000 & April 15 & C 1 \\
42,000 & 60 & 700 & June & C 2-3
\end{tabular}

The goals of these releases are as follows:

Stream A - For brood stock and all fisheries.

Stream B, 1-5 - For all fisheries ano to rebuild natural production.

Stream C, 1-3 - To rebuild depressed stream.

Summary of Biological Requirements:

\section{Production (no./size)}

Smolt

Fingerling

Eyed - egg plants/transfers

Fertilized eggs (no. spawned)

Smolt

Fingerling

Eyed-eggs

Females to spawn (no.)

Adults held at one time (no.)

Recommended minimum water (gpm)

On-sta tion ground and/or spring surface

Offstation

surf ace

or equivalent

Recommended minimum pond space

On-station or equivalent

Off-station

(Site No. 1) Outlet Creek pens

(Site No. 2)

$$
\begin{array}{r}
331,600 @ 12 / 10 \\
300,000 @ 15 / 10 \\
42,000 @ 60 / 10
\end{array}
$$

541,000

400,000

$\mathbf{5 2 , 0 0 0}$

$\overline{993.000}$

'199

619

225 a $48 \mathrm{~F}$

1,326 (see Fig. 1)

6,412 (see Fig. 1)

$20,000 \mathrm{ft}^{3}$

$9,720 \mathrm{ft}^{3}$

$11,000 \mathrm{ft}^{3}$

Facilities Development:

Table 37 lists the facilities and the associated requirements of Spring Chinook Salmon Hatchery No. 5, Fig. 20 is a vicinity map of the production- facilities and release sites; and Figs. 2la, 2lb, and $21 \mathrm{c}$ illustrate the physical plan for the hatchery. 
Chapter 9

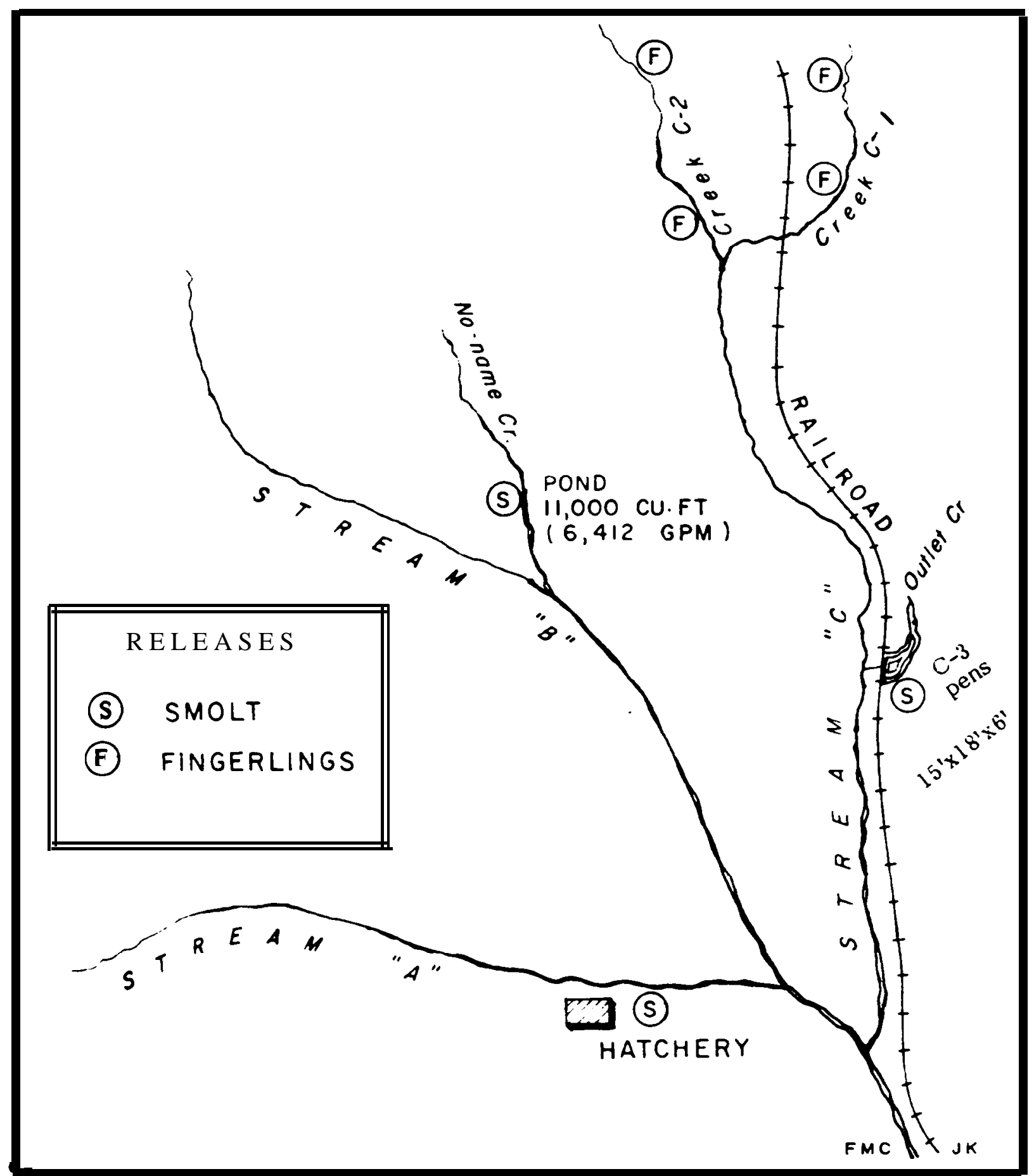

Figure 20. Vicinity map of the production facilities and release sites for Spring Chinook Salmon Hatchery No. 5. 
Theoretical Hatcheries

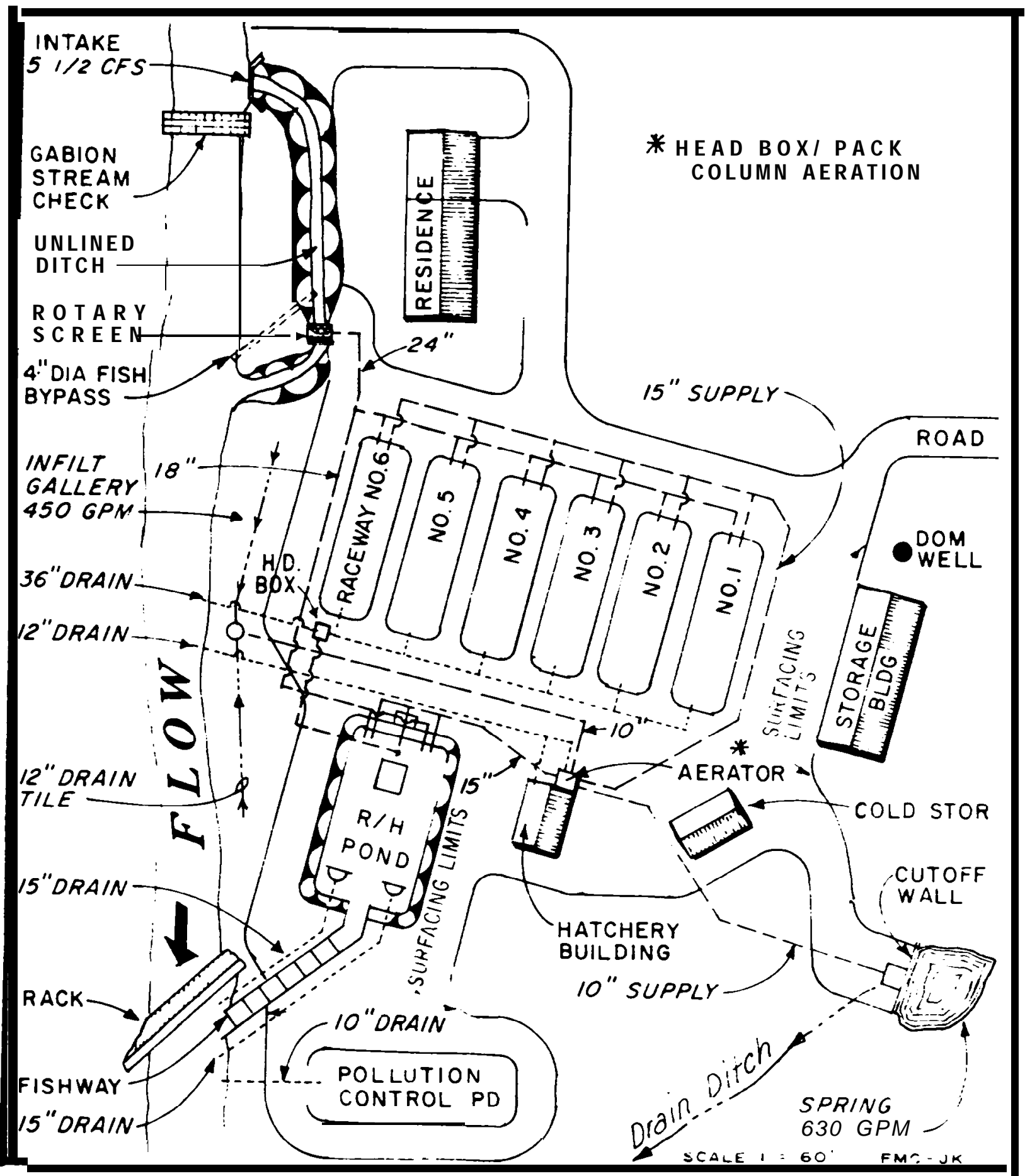

Figure 21a. Schematic of Spring Chinook Salmon llatchery No. 5-Cn-stiatioil ficcilitit s. 


\section{Chapter 9}

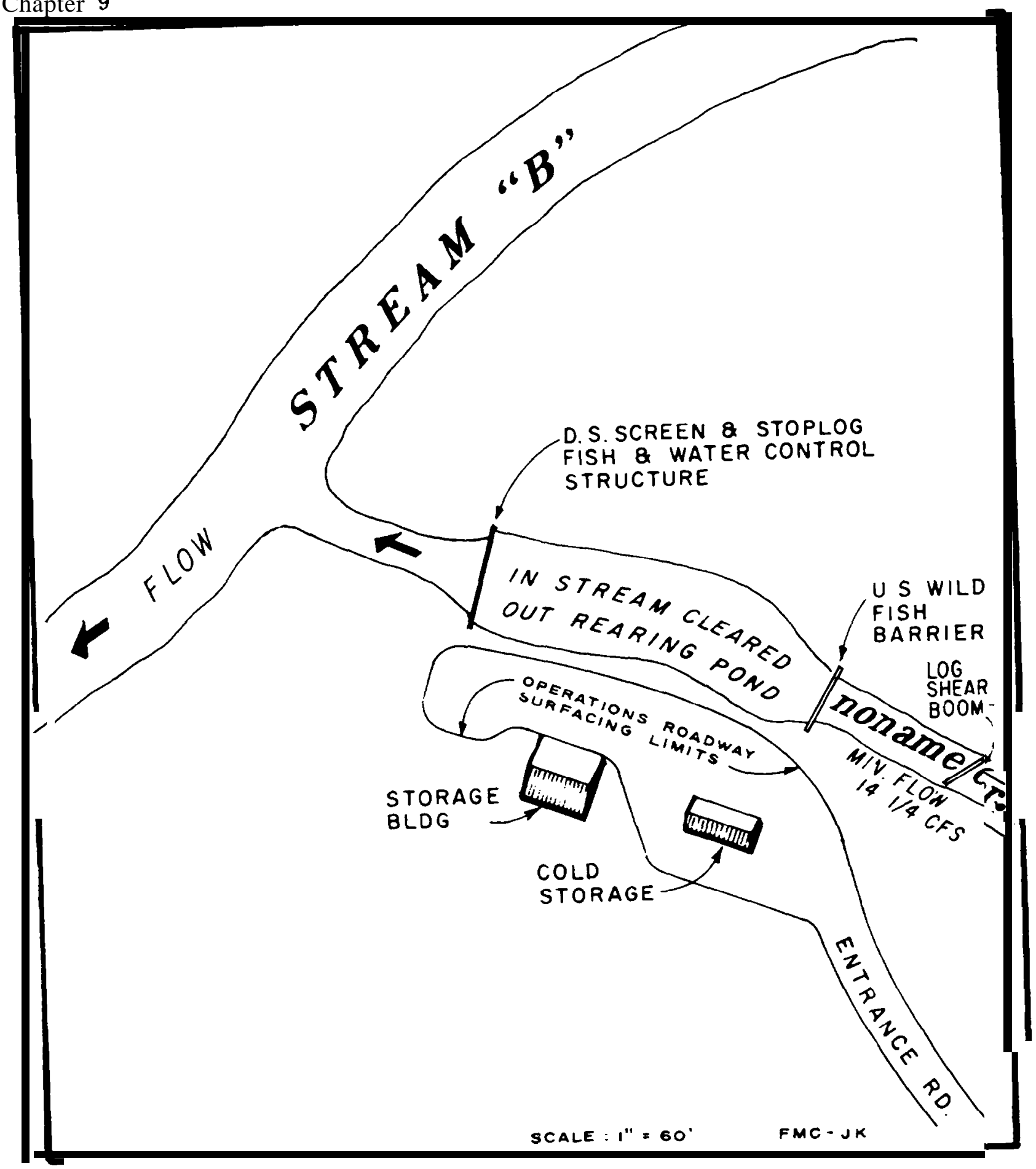

Figure 21b. Schematic of Spring Chinook Salmon Hatchery No. 5 - Off-station rearıng pond at stream "C" (Note: Pond at stream "B" not shown.) 
Theoretical Hatcheries

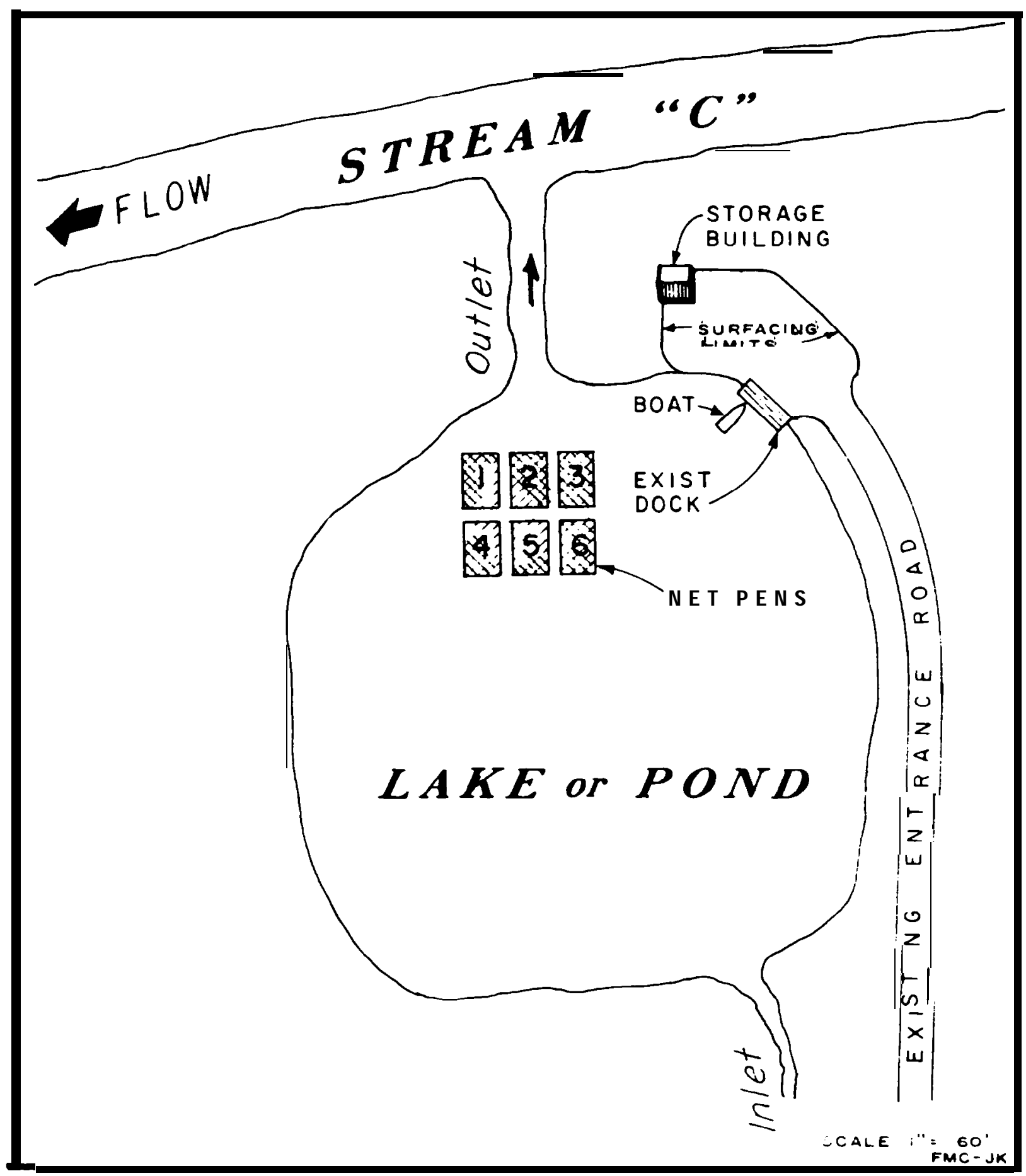

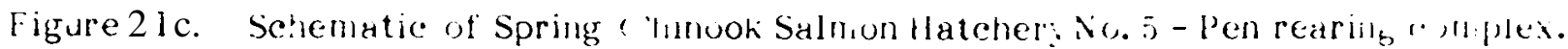




\section{Chapter 9}

Operational Strategies:

Water and space needs as related to the total biological requirements by time are shown in Figs. 22 and ' 23 respectively. Spring Chinook No. 1-4 are typical of the program for this hatchery. Comments on brief deviations follow.

(1) Adults A total of 199 adult female spring chinook are required for spawning and will be held in the large adult/rearing pond.

(2) Incubation The only deviation in the incubation program (see Spring Chinook Salmon Hatcheries No. 1-4) calls for the $48 \mathrm{~F}$ water to be used for the eggs and alevins programmed for the off-station September release (Stream "B"). This will accelerate development, and allow the fish more time to reach $15 /$ lb (30 grams each) by late September.

(3) Rearing Rearing is conducted as with other spring chinook hatcheries with the exception of a pen-rearing program for the smolts for stream "C". Station personnel will care for these fish. The off-station pond (fish for stream " $\mathrm{B}$ ") will be cared for by a part-time culturist.

(4) Releases The release program will be similar to other spring chinook hatcheries. The exception is a "smolt" release in September.

costs:

Table 38 shows the estimated capital cost for Spring Chinook Salmon Hatcher> No. 5 and Table 39 shows the estimated annual operational costs ano manpower requirements.

Taule 37. Facility development for Spring Chinook Salmon Hatchery No. 5 (50,000 lbs, onand off-station releases).

\begin{tabular}{|c|c|c|c|}
\hline Facilities & No. & Size & Description \\
\hline \multicolumn{4}{|c|}{ Site Development - On-Station } \\
\hline $\begin{array}{l}\text { Clearing } \\
\& \text { Grubbing }\end{array}$ & 5 & Acres & \multirow{3}{*}{$\begin{array}{l}\text { Clearing \& gruboing of hatchery site, } \\
\text { entrance road, water ditch \& pipeline } \\
\text { R/Ws. } \\
16 \text { ' wide, } 8 " \text { pit run base over ave. } 2 \text { ' fill } \\
\text { ht. Tul nouts @ } 500^{\prime} \text { intervals. } \\
8 \text { " base \& } 2^{\prime \prime} \text { crushed rock topping. }\end{array}$} \\
\hline Entrance Road & $1 / 2$ & Mile & \\
\hline $\begin{array}{l}\text { On Site Road } \\
\& \text { Drives }\end{array}$ & 4,000 & $\mathrm{yd}^{2}$ & \\
\hline
\end{tabular}


Theoretical Hatcheries

\begin{tabular}{|c|c|c|c|}
\hline Facilities & NO. & Size & Description \\
\hline \multicolumn{4}{|c|}{ Water Supply \& Drains - On-Station } \\
\hline Stream Intake & 1 & $10^{\prime} \times 4^{\prime}$ & $\begin{array}{l}\text { Coarse screen, reinforced concrete with } \\
\text { Gabion screen check }\end{array}$ \\
\hline $\begin{array}{l}\text { Water supply open } \\
\text { ditch }\end{array}$ & 1,000 & $\operatorname{lin} \mathrm{ft}$ & $\begin{array}{l}\text { Unlined canal } / 3^{\prime} \text { depth } x 3^{\prime} \text { bottom width } \\
\& 21 / 2: 1 \text { side slopes - grade of } 0.03 \% \\
\text { max. }\end{array}$ \\
\hline Rotary Drum Screen & 1 & $3^{\prime}$ dia.x $4^{\prime} \mathrm{L}$ & $\begin{array}{l}\text { Electric power - fine screen/fish bypass } \\
\text { pipe. }\end{array}$ \\
\hline Supply Lines & - & & $\begin{array}{l}\text { 12" diameter \& larger - CMP, under } 12^{\prime \prime} \text { - } \\
\text { PVC }\end{array}$ \\
\hline Drain Lines & - & & $\begin{array}{l}\text { 12" diameter \& larger - C.MP, under 12" - } \\
\text { PVC }\end{array}$ \\
\hline Spring Intake & 1 & 16' long & $\begin{array}{l}\text { Concrete cut-off wall } \mathrm{x} j^{\prime} \mathrm{H} \text { with } 2^{\prime} \mathrm{x}{ }^{\prime}{ }^{\prime} \\
\text { concrete screened intake box }-630 \mathrm{gpm} \text {. }\end{array}$ \\
\hline Domestic Well & 1 & $5 \mathrm{gpm}$ & $\begin{array}{l}\text { b" diameter } \mathrm{x} 120 \text { deep/1 /2 HP } \\
\text { submersible pump. Pressure tank in } \\
\text { storage building - PVC underground piping } \\
\text { to buildings and spawning shed. }\end{array}$ \\
\hline $\begin{array}{l}\text { Infiltration } \\
\text { Gallery with Pump }\end{array}$ & 150 & $\operatorname{lin} \mathrm{ft}$ & $\begin{array}{l}\text { 4'W trench gallery excavated to 6' below } \\
\text { stream bed. 12" perforated drain tile } \\
\text { backfilled with washed river gravel. } \\
\text { Pump sump with } 3 \text { HP submersible pump - } \\
450 \text { gpm. }\end{array}$ \\
\hline $\begin{array}{l}\text { Stream Gabion } \\
\text { Check }\end{array}$ & 1 & $20 \mathrm{yd}^{3}$ & $\begin{array}{l}\text { Gabion } \\
\left(30^{\prime} \times 6^{\prime} \times 3^{\prime}\right)\end{array}$ rock-filled wire $\quad$ baskets \\
\hline $\begin{array}{l}\text { Aeration Head } \\
\text { BOX }\end{array}$ & 1 & $4^{\prime} \times 6{ }^{\prime}$ & $\begin{array}{l}\text { Plywood construction/compartments for } \\
\text { spring and infiltration water aeration } \\
\text { through three packed column units. }\end{array}$ \\
\hline
\end{tabular}

Fish Production Facilities - On-Station

\begin{tabular}{|c|c|c|c|}
\hline Raceways & 6 & $70^{\prime} \times 20^{\prime}$ & $\begin{array}{l}2,000 \mathrm{ft}^{3} \text { water each with 3' average } \\
\text { water depth. Dirt sides \& bottoms with } \\
3: 1 \text { bank slopes. }\end{array}$ \\
\hline $\begin{array}{l}\text { Corn b. Rearing } \\
\text { Holding Pond }\end{array}$ & 1 & $75^{\prime} \times 46^{\prime}$ & $\begin{array}{l}8,000 \mathrm{ft}^{3} \text { water }- \text { Dirt sides \& } \\
\text { bottom with } 3: 1 \text { bank slopes. Average } \\
\text { water depth, } 3-1 / 2 \text {. Upwelling } \boldsymbol{W . S .} \text { on } \\
\text { pond bottom for adult holding. }\end{array}$ \\
\hline Hatching Tanks & 6 & $16^{\prime} \times 18^{\prime \prime}$ & $\begin{array}{l}6 \text { deep tanks for egg inaubation \& } \mathbf{1} \\
\text { shallow tank for egg picking. }\end{array}$ \\
\hline $\begin{array}{l}\text { Electric Fence } \\
\text { Rack }\end{array}$ & 1 & $40 \operatorname{lin} \mathrm{ft}$ & $\begin{array}{l}\text { Electric fence barrier weir }-110 \\
\text { volts. Annual installation. }\end{array}$ \\
\hline F ishway & 1 & 6' lift & $\begin{array}{l}\text { Plywood constr } / 4^{\prime} W \times 4^{\prime} \mathrm{H} \times 48^{\prime} \mathrm{L} / \mathrm{six} 8^{\prime} \\
\text { pools with canvas fencing on sides of } \\
\text { fishway for fish containment. }\end{array}$ \\
\hline
\end{tabular}


Chapter $\mathbf{9}$

\begin{tabular}{|c|c|c|}
\hline Facilities & Size & Description \\
\hline & Fish Production & Facilities - On-Station (cont.) \\
\hline $\begin{array}{l}\text { Pollution Control } \\
\text { Pond }\end{array}$ & $80^{\prime} \times 25^{\prime}$ & $\begin{array}{l}3,000 \mathrm{ft}^{3} \text { water/l hour detention } \\
\text { time for pond cleaning wastes by vacuum } \\
\text { system. Dirt sides and bottom } / 3: 1 \text { bank } \\
\text { slopes. Average pond bottom } \\
\text { water depth } 3-1 / 2^{\prime} \text {. }\end{array}$ \\
\hline \multicolumn{3}{|c|}{ Buildings - On-Station } \\
\hline Hatchery & $18^{\prime} \times 24^{\prime}$ & $\begin{array}{l}\text { Metal building with tank, office, crew } \\
\text { locker, mechanical, and rest rooms. }\end{array}$ \\
\hline Storage & $60^{\prime} \times 24^{\prime}$ & $\begin{array}{l}\text { hetal building with gravel floor, five 12' } \\
\text { bays for equipment and supply storage, } \\
\text { domestic water pressure tank, and diesel } \\
\text { generator housing. }\end{array}$ \\
\hline Cold Storage & $26^{\prime} \times 12^{\prime}$ & Prefab $20^{\prime} \times 12^{\prime}$ freon cold storage \\
\hline Fish Feed & & $\begin{array}{l}\text { unit/ } 16,000 \mathrm{lb} \text { capacity with a } 66^{\prime} \times 12^{\prime} \text { add } \\
\text { on for fooa handling and thawing. O.MP } \\
\text { feed deliveries } 3 \times \text { per year. }\end{array}$ \\
\hline Spawning Shed & $10^{\prime} \times 10^{\prime}$ & $\begin{array}{l}\text { Open sides and ends with roof for } \\
\text { spawning at head end of holding pond. }\end{array}$ \\
\hline Residence & $46^{\prime} \times 24^{\prime}$ & $\begin{array}{l}3 \text { BR. wood frame prefab unit/attached } \\
\text { garage. (residence would be marketable } \\
\text { if facility closed). }\end{array}$ \\
\hline \multicolumn{3}{|c|}{ Equipment - On-Station and Off-Station } \\
\hline General List & & $\begin{array}{l}\text { 1 pick-up, nets, pumps, misc. tools, } \\
\text { cleaning } \\
(\$ 32,000)\end{array}$ \\
\hline \multicolumn{3}{|r|}{ ff-Station, Stream "B" Tributary } \\
\hline $\begin{array}{l}\text { Clearing } \\
\& \text { Grubbing }\end{array}$ & $1 \quad$ Acre & $\begin{array}{l}\text { Clearing \& grubbing of pona site } \\
\text { operations and entrance road. }\end{array}$ \\
\hline Entrance Road & 1,000 lin $\mathrm{ft}$ & $\begin{array}{l}\text { 12' wide, 8" pit run base over ave. l' fill } \\
\text { ht. }\end{array}$ \\
\hline $\begin{array}{l}\text { On Site Road } \\
\& \text { Courtyard }\end{array}$ & $\mathrm{yd}^{2}$ & $8 "$ base $\& 2 "$ crushed rock topping. \\
\hline
\end{tabular}


Theoretical Hatcheries

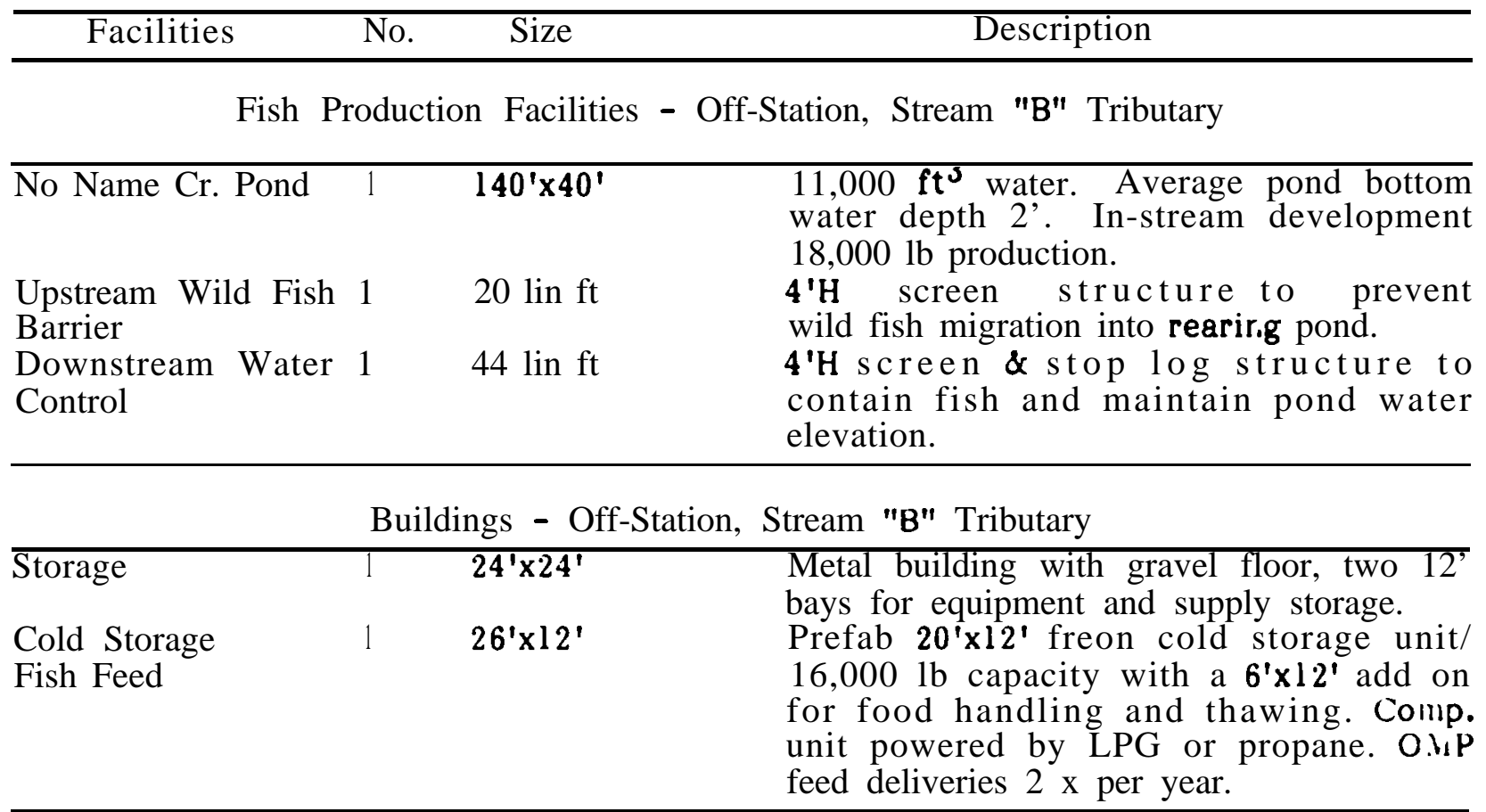

Site Development - Off-Station, Stream "C" Tributary

\begin{tabular}{|c|c|c|c|c|}
\hline \multirow{2}{*}{\multicolumn{2}{|c|}{$\begin{array}{l}\text { Clearing } \\
\text { \& Grubbing } \\
\text { Net Pen Lake } \\
\text { Bottom Clearing }\end{array}$}} & $1 / 20$ & Acre & Clearing \& grubbing of courtyard. \\
\hline & & $2 / 10$ & Acre & $\begin{array}{l}\text { Inspection \& clearing of lake bottom } \\
\text { for net pen snag prevention. }\end{array}$ \\
\hline Entrance & Road & - & - & 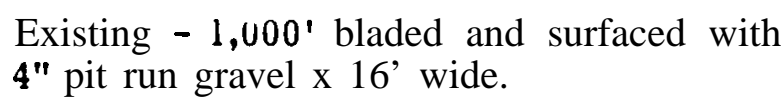 \\
\hline Cn Site & Courtyard & 250 & $y d^{2}$ & $4 "$ base $\& 2 "$ crushed rock topping. \\
\hline
\end{tabular}

Fish Production Facilities - Off-Station Stream "C" Tributary

Existing dock Rehabilitate as required.

\begin{tabular}{llll} 
Net Pens & 6 & $1^{\prime} \times 18^{\prime} \times 6^{\prime}$ & $6^{\prime}$ water depth pens $-6,000 \mathrm{lb}$ production. \\
\hline
\end{tabular}

Buildings - Off-Station, Stream "C" Tributary

\begin{tabular}{|c|c|c|}
\hline$\overline{\text { Storage }}$ & $1 \quad 12^{1} \times 12^{1}$ & $\begin{array}{l}\text { Wetal building with gravel floor, one } 12 \text { ' } \\
\text { bay for equipment and supply storage. }\end{array}$ \\
\hline Cold Storage & $12^{\prime} \times 12^{\prime}$ & Prefab $7^{\prime} \times 12^{\prime}$ freon cold storage \\
\hline Fish Feed & & 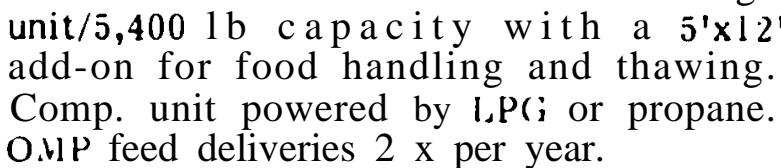 \\
\hline
\end{tabular}


Chapter $\mathbf{9}$
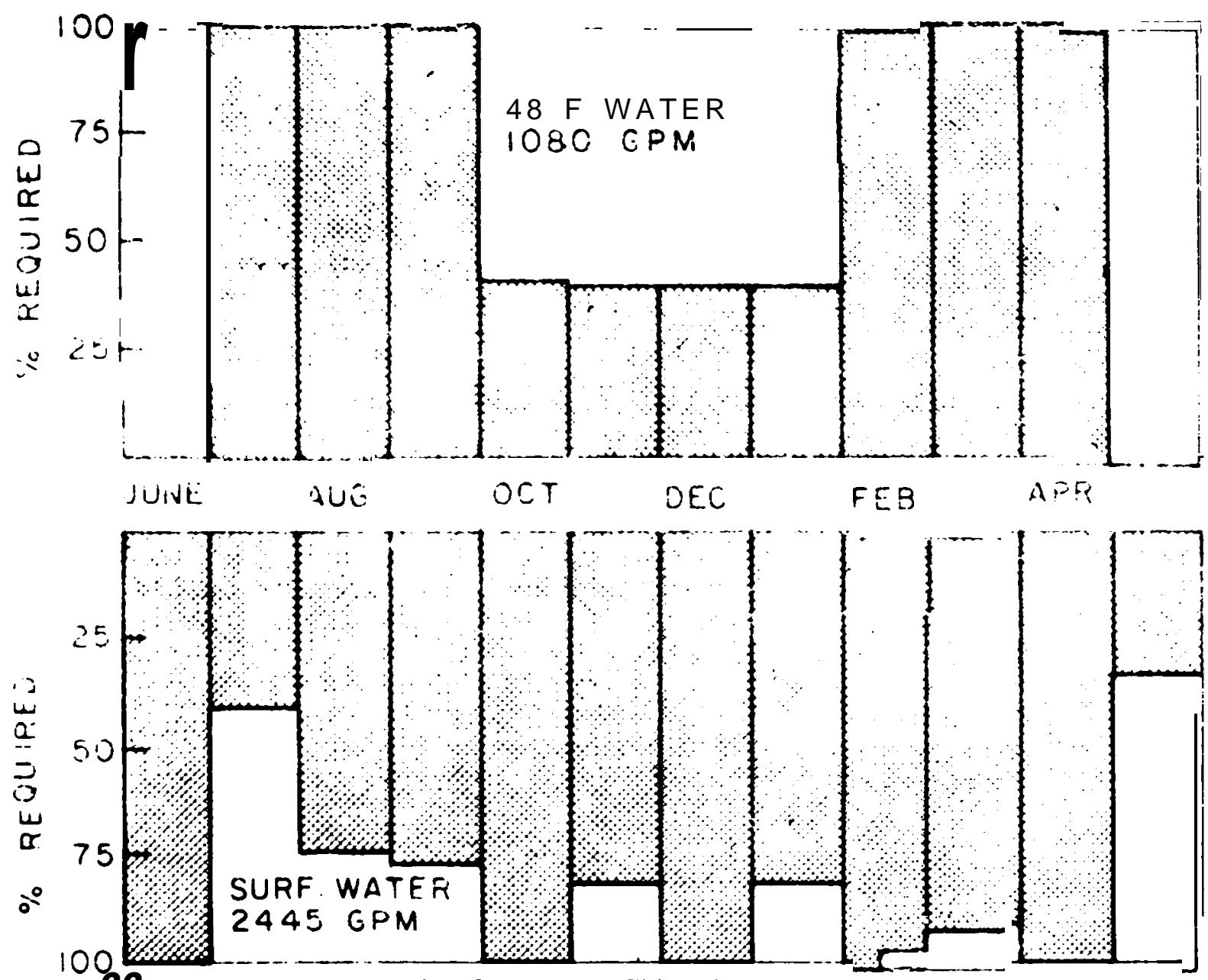

ligure22. Water-use strategies for Spring Chinook Salmon Hatchery No. 5 - On-station.

[y|ble 38. Facility development costs for Spring Chinook Salmon Hatchery ho. 5. Facility

Site development

Water supply and drains

Fish production facilities

Buildings

Equipment

\begin{tabular}{c} 
Estimated cost \\
\hline$\$ 132,000.00$ \\
$156,100.00$ \\
$153,400.00$ \\
$201,100.00$ \\
$32,000.00$ \\
$\$ 674,600.00$
\end{tabular}


Theoretical Hatcheries

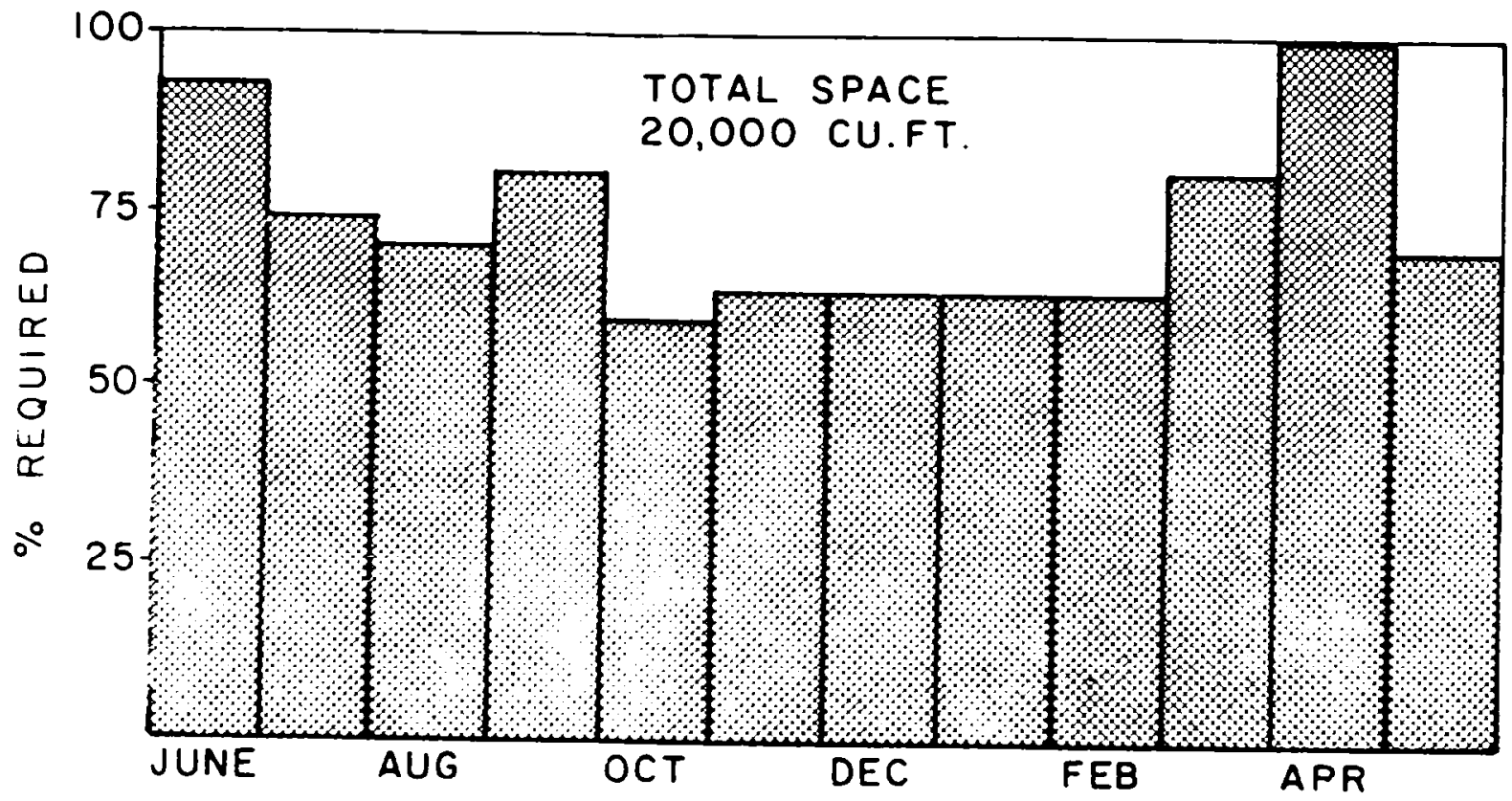

Figure 23. Space-use requirernents for Spring Chinook Salınon Hatchery No. jOn-station.

Table 39. Estimated annual operational costs and labor requirements for Spring ( hinook: Salmon Hatchery No. 5.

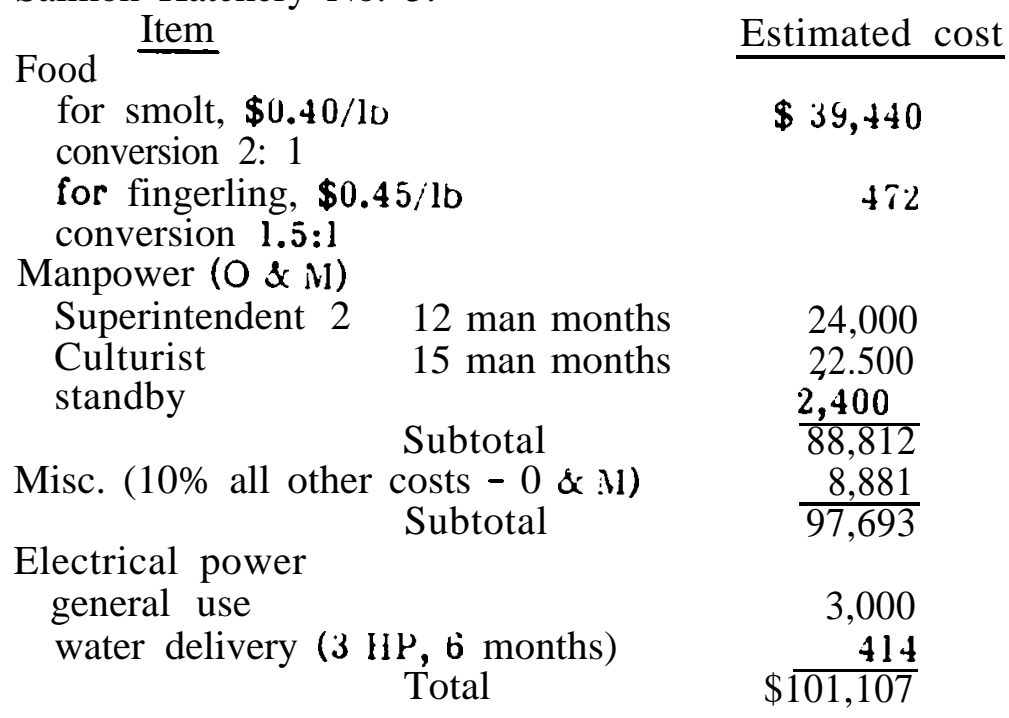




\section{Chapter 9}

\section{THEORETICAL FALL CHINOOK/COHO SALMON HATCHERIES}

The conceptual plans, operations, and costs of three theoretical hatcheries that culture both fall chinook and coho salmon follow.

1. Fall Chinook/Coho Salmon Hatchery No. 1

Goals:

Produce 5,000 lbs each of fall chinook and coho salmon smolts at 80 fish/lb ana $20 / \mathrm{b}$ respectively, for onstation releases.

Summary of Biological Requirements:

Smolt production (no./size)

$\begin{array}{ll}\text { chinook } & 400,000 @ 80 / 1 \mathrm{D} \\ \text { coho } & 100,000 @ 20 / 1 \mathrm{D}\end{array}$

Fertilized Eggs (no. spawned)

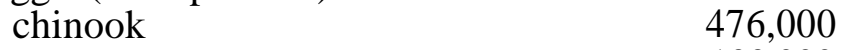

476,000

coho

133,000

Females to spawn (no.)

chinook

106

coho

Adults held at one time (no.)

chinook

coho

(Est. 21 on hand when 134 chinook are being heid)

Recommended minimum water (gpm) ground and/or spring surface

Recommended minimum pond space

Facilities Development:

Taole 40 lists the facilities and the associated requirements of Fall Chinook/Coho Salmon Hatchery No. 1 and Fig. 24 illustrates the physical plan for the hatchery.

Operational Strategies:

For the water and space requirements as related to the percentage of the total biological requirements by time, respectively, refer to Fall Cninook/Cono Salmon Hatchery No. 2 which follows. The two hatcheries only differ in the magnitude of production.

costs:

The facility development costs for Fall Chinook/Cono Salmon Hutchery So. i are documented in Table 41 and the estimated annual operational costs ano manpower requirements in Table 42 . 
Theoretical Hatcheries

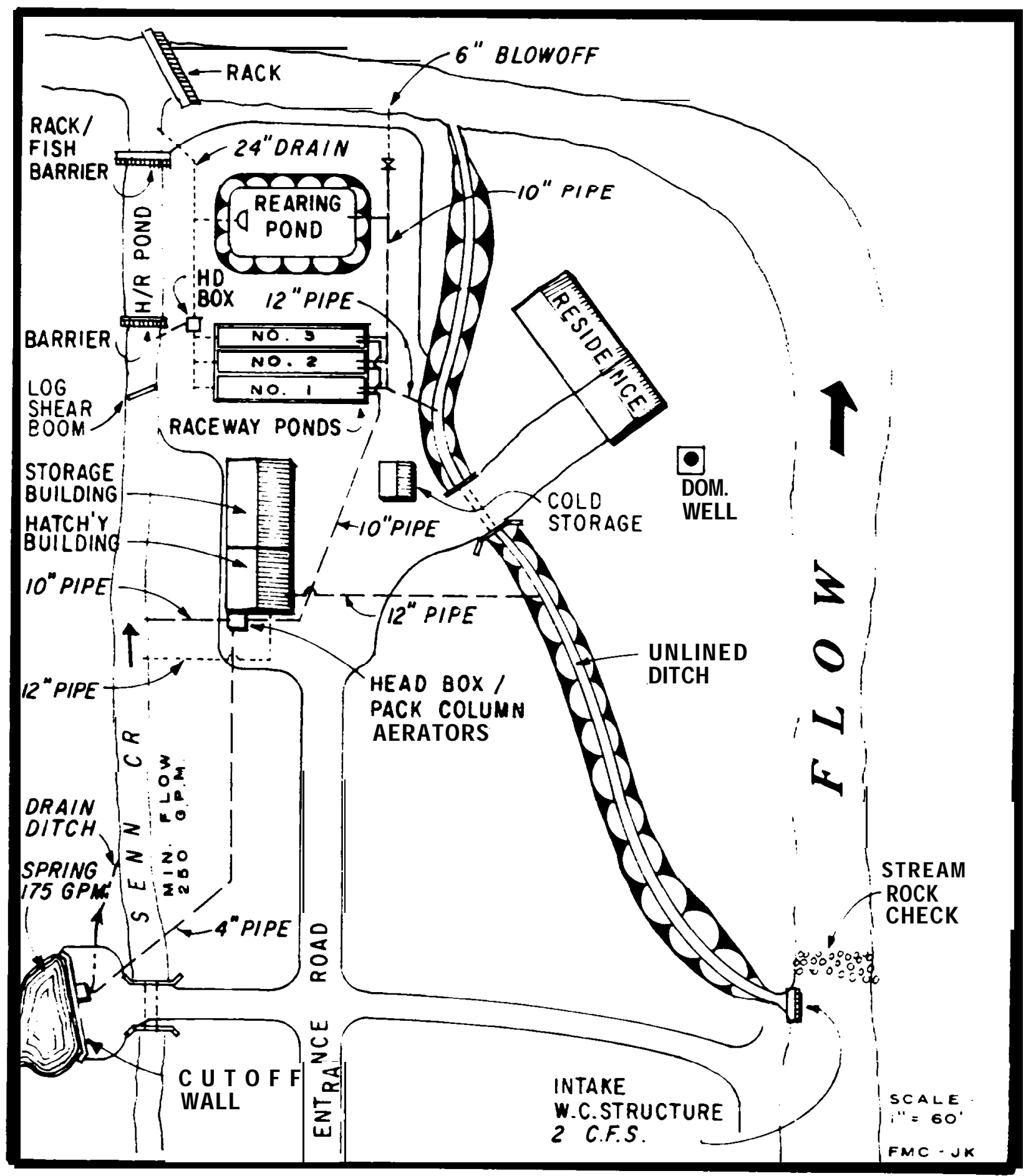

Figure 24. Schematic of Fall chinowh/ Coho Salmon Hatchery No. 1. 


\section{Chapter Y}

Table 40. Facility development for Fall Chinook/Coho Salmon Hutchery ho. 1 (10,00u lbs, onstation releases).

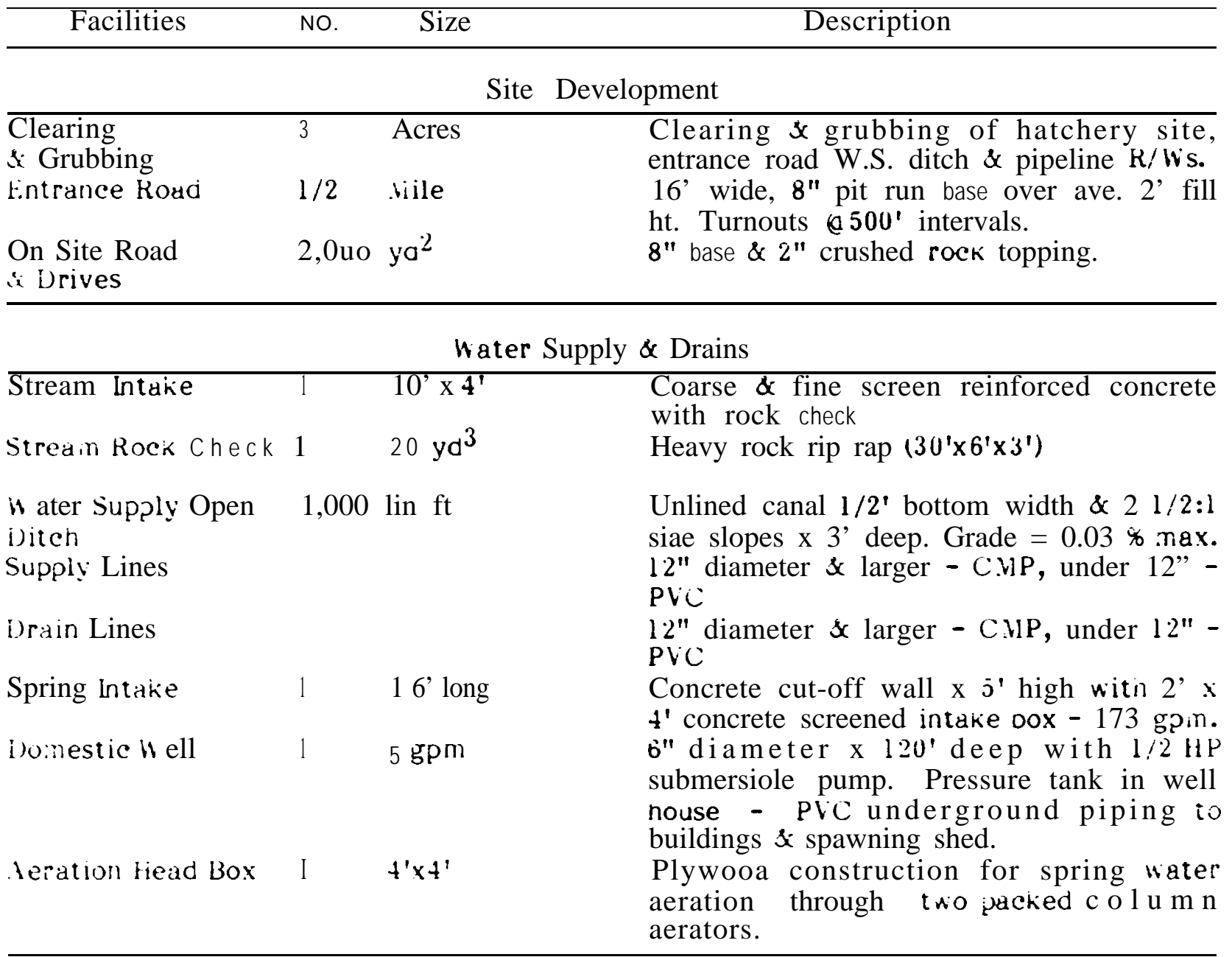

Fisn Production Facilities

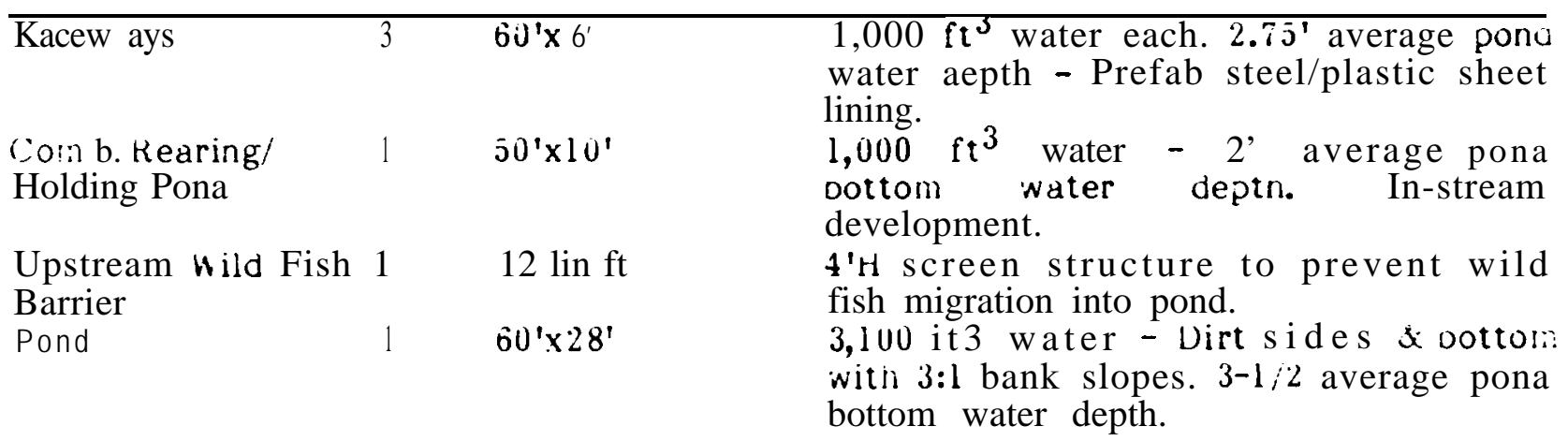


Theoretical Hatcheries

\begin{tabular}{|c|c|c|c|}
\hline Facilities & No. & Size & Description \\
\hline \multicolumn{4}{|c|}{ Fish Production Facilities (cont.) } \\
\hline Hatching Tanks & 4 & $16^{\prime} \times 18^{\prime \prime}$ & $\begin{array}{l}4 \text { deep tanks for egg incubation \& } 1 \\
\text { shallow tank for eg picking. }\end{array}$ \\
\hline Adult Fish Rack & 1 & 40 lin $\mathrm{ft}$ & $\begin{array}{l}\text { Wood constr., annual installation to divert } \\
\text { adults into side creek. }\end{array}$ \\
\hline $\begin{array}{l}\text { Uownstresm Rack \& } \\
\text { Fish Barrier }\end{array}$ & & $12 \operatorname{lin} \mathrm{ft}$ & $\begin{array}{l}\text { 4'H screen \& stop log structure to } \\
\text { contain fish, maintain pond water elev. } \\
\text { \& finger weir for adult entrance. }\end{array}$ \\
\hline
\end{tabular}

Buildings

\begin{tabular}{|c|c|c|}
\hline Hatchery \& Storage & $54^{\prime} \times 24^{\prime}$ & $\begin{array}{l}\text { Metal building combination for equipment } \\
\& \text { supply storage and hatcnery. Three 12' } \\
\text { bays for storage/gravel floor. Hatchery } \\
\text { with tank, office, crew lockers, } \\
\text { mechanical, \& rest rooms. Hatchery }=\text { la' } \\
\times 24^{\prime} \& \text { Storage }=24^{\prime} \times 36^{\prime} \text {. }\end{array}$ \\
\hline$\therefore$ sid Storage & $10^{\prime} \times 12^{\prime}$ & Prefab 10$)^{\prime} \times 12^{\prime}$ freon colc storage \\
\hline 1 is: Feed & & $\begin{array}{l}\text { unit/8, vifu lo erpacily with a } 12^{\prime} \times 6^{\prime} \\
\text { add-on for food handing o thawing. U }{ }^{\prime} \\
\text { feed delivery } 3 \times \text { per yeur. }\end{array}$ \\
\hline Residence & $46^{\prime} \times 24^{\prime}$ & $\begin{array}{l}3 \text { B.R. wood frame prefut) unilattached } \\
\text { garage (residence would de inarketaole } \\
\text { if facility closed.) }\end{array}$ \\
\hline
\end{tabular}

Equipment

Generdl list

1 pick-up, nets, pumps, misc. tools s clenning equip. $(\$ 24,000)$

Tasle 41. Facility developirent costs for Fall Chinook/Coho Salmon ilatcrery So. I. Facility

Site development

ivater supply and aruins

Fish production facilities

Buildings

Estimated cost

$\$ 72,600.00$

$71,400 \mathrm{UU}$

$56,200.00$

$132,900.00$

Equipment

Total

$24,000.00$

$\$ 357,100.00$ 


\section{Chapter 9}

Table 42. Estimated annual operational costs and labor requirements for Fall Chinook/Coho Salmon Hatchery No. 1.

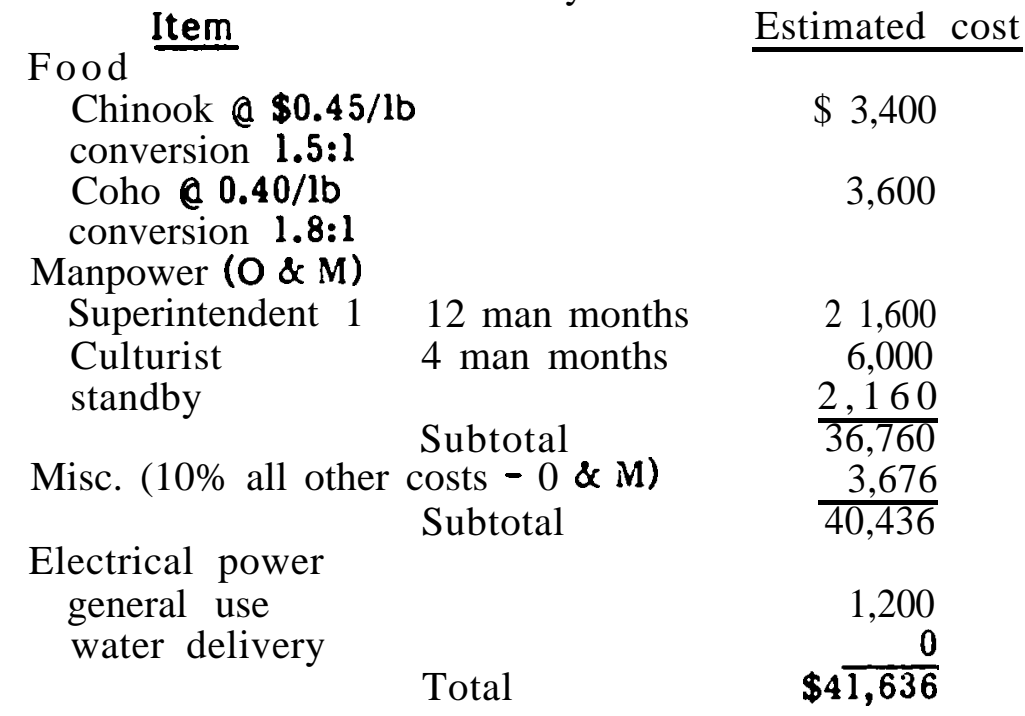

2. Fall Chinook/Coho Salmon Hatchery No. 2

\section{Goals:}

Produce 10,000 $\mathrm{lbs}$ each of fall chinook and coho salmon smolts at $80 \mathrm{fish} / \mathrm{lb}$ and $20 \mathrm{fish} / \mathrm{lb}$ respectively, for on-station releases.

Summary of Biological Requirements:

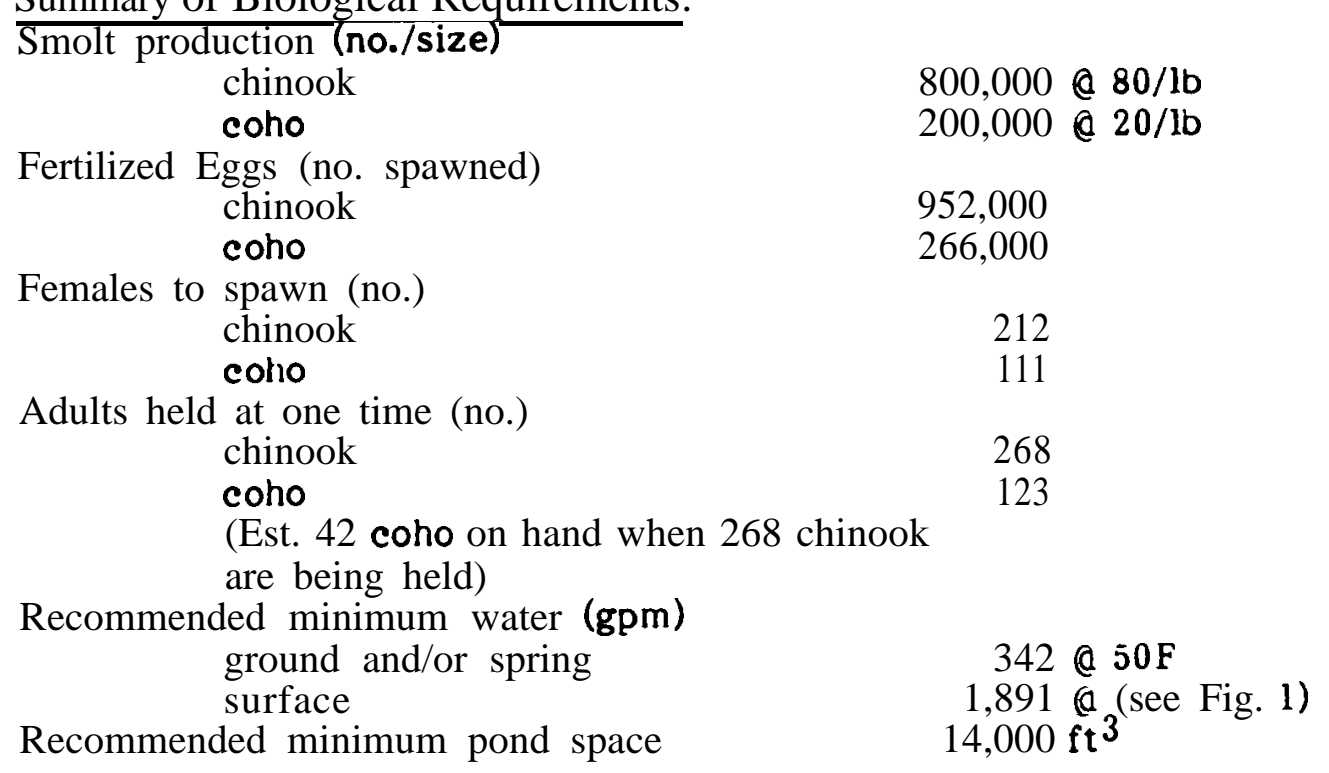


Theoretical Hatcheries

Facilities Development:

Table 43 lists the facilities and the associated requirements of Fall Chinook/Coho Salmon Hatchery No. 2 and Fig. 25 illustrates the physical plan for the hatchery.

Operational Strategies:

Water and space requirements as related to the percentage of the total biological requirements by time are shown in Figs. 26 and 27 respectively. Fig. 28 shows the programming of each rearing unit by time. Brief comments follow for each life phase.

(1) Adults All of the returning adults will be held in the large $6,000 \mathrm{ft}^{3}$ pond. Because the early portion of the coho return will arrive while the chinook are being held provisions are made for segregation. Water from the juvenile coho being reared in the raceways will be re-used for the adults. Cool water (50F) will be requied to cool the surface water during the early part of the fall chinook holding and spawning period.

(2) Incubation All eggs will be eyed in deep troughs and all fall chinook eggs will be hatched and alevins incubated in deep troughs using artifcial substrate. Coho eggs will be hatched in barrel incubators and the alevins incubated using artficial substrate. The densities of chinook alevins in the five deeps is 175,000 each, and in the barrel incubators the cono density is 80,000 each. If slight overages occur, pond trays will be used to hatch eggs and incubation will occur in the ponds.

All chinook will oe incubated in warm water to accelerate development while coho will be incubated in the coolest water available. This will accelerate chinook development, provide more rearing time, and retard coho development so that fewer pounds will be on hand during the chinook rearing progrem ana during the warm summer period.

(3) Rearing Fall chinook will be transferred from the hatchery to the 2,000 $\mathrm{ft}^{3}$ raceways (Nos. 2, 3, and 4, Fig. 28) and reared until May 2. At this time the smolt coho will have been planted from the $6,000 \mathrm{ft}^{3}$ pond (No. 5) ano all fish from pond No. 2 and portions of ponds 3 \& 4 will be transferred to Pond No. 5. The chinook will be programmed to provide a release of 2,000 lbs each from ponds 3 and 4, and 6,000 $\mathrm{lbs}$ from pond No. 5. Coho will receive their initial rearing in the four deep troughs and pond No. 1. They will be split into ponds Nos. 2 and 3 as the chinook are removed (Fig. 28). Pond No. 4 will remain unused or available until the next cycle of chinook requires its use. After the adults are spawned from pond No. 5 (November 15), juvenile coho at $30 / 1 \mathrm{~b}$ will be transferred in from ponds Nos. 1, 2, and 3 providing 200,000 smolts until release the following May (Fig. 28). Water used for the younger coho and fall chinook will be reused as required for the smolt coho. The latter will receive only reused water. 


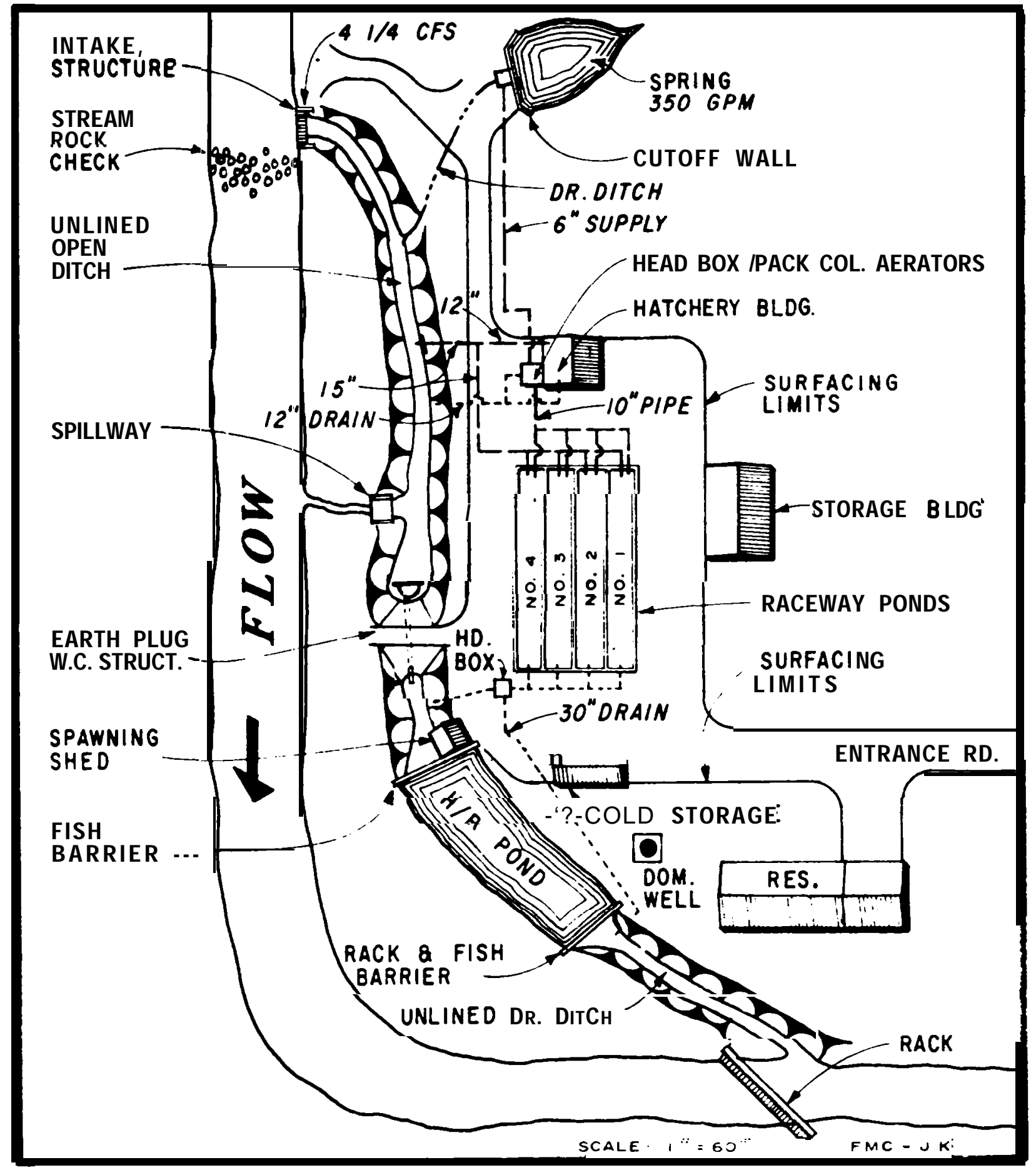

Figure 25. Schematic of Fall Chinook/Cono Salmon Hatchery No. 2. 
Theoretical Hatcheries

(4) Release All fish will be allowed to emigrate from the ponds two weeks prior to the final release. Tne final release will require completely draining fish and water from the ponds.

\section{Costs:}

Tne facility development costs for Fall Chinook/Coho Salmon Hatchery No. 2 are documented in Table 44, and the estimated annual operational costs and manpower requirements in Table 45.

Taole 43. Facility development for Fall Chinook/Coho Hatchery No. 2 (20,000 lbs, onstation release).

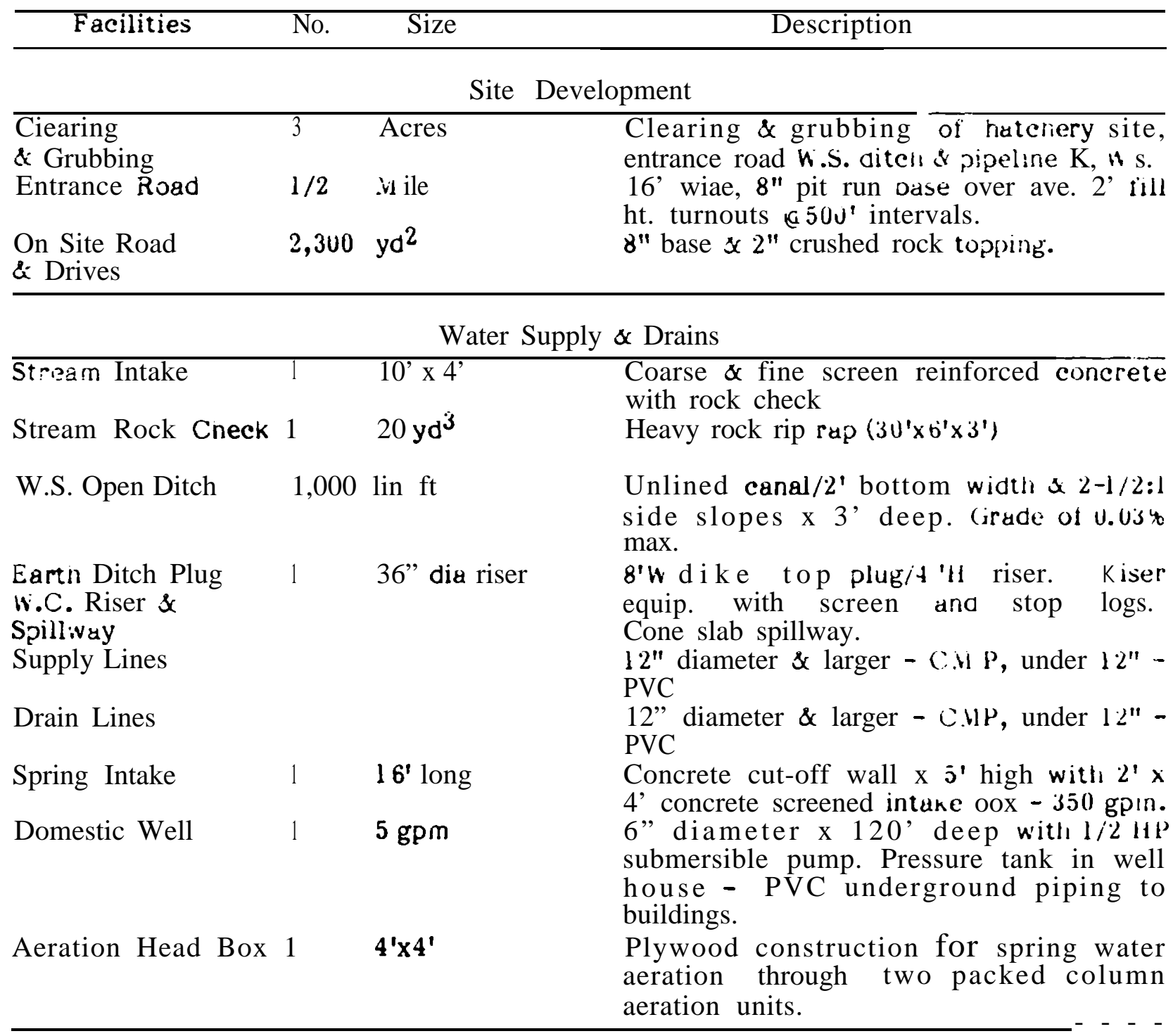


Chapter 9

\begin{tabular}{|c|c|c|c|}
\hline Facilities & No. & Size & Description \\
\hline \multicolumn{4}{|c|}{ Fish Production Facilities } \\
\hline Raceways & 4 & $83^{\prime} \times 8^{\prime}$ & 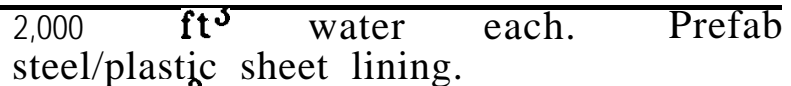 \\
\hline $\begin{array}{l}\text { Comb. Rearing/ } \\
\text { Holding Pond }\end{array}$ & 1 & $110^{\prime} \times 20^{\prime}$ & $\begin{array}{l}6,200 \text { ft water }-3^{3} \text { average pond } \\
\text { water depth. Un-lined dirt pond/pen } \\
\text { fencing utilized for adult holding } \\
\text { separation. }\end{array}$ \\
\hline $\begin{array}{l}\text { Upstream Wild Fish } \\
\text { Barrier }\end{array}$ & 1 & $24 \operatorname{lin} \mathrm{ft}$ & $\begin{array}{l}6^{\prime} \mathrm{H} \text { screen and stop-log structure to } \\
\text { prevent fish movement. }\end{array}$ \\
\hline $\begin{array}{l}\text { Downstream Rack } \\
\text { \& Fish Barrier }\end{array}$ & 1 & $2-\mathrm{t} \operatorname{lin} \mathrm{ft}$ & $\begin{array}{l}\text { 6'H screen and stop log structure to } \\
\text { contain fish, maintain pond water elev. } \\
\text { and finger weir for adult entrance. }\end{array}$ \\
\hline Hatching Tanks & 4 & $16^{\prime} \times 18^{\prime \prime}$ & $\begin{array}{l}4 \text { deep tanks for egg incubation } \& \text { one } \\
\text { shallow tank for egg picking. }\end{array}$ \\
\hline Barrell Incubators & 3 & 55 gals. ea. & Incubators for coho egs. \\
\hline Adult Fish Rack & 1 & $40 \operatorname{lin} \mathrm{ft}$ & $\begin{array}{l}\text { Wood constr. - annual installation to } \\
\text { divert adults into side channel. }\end{array}$ \\
\hline \multicolumn{4}{|c|}{ Buildings } \\
\hline Hatchery & 1 & $18^{\prime} \times 24^{\prime}$ & $\begin{array}{l}\text { Metal building with tank, office, crew } \\
\text { locker, mechanical and restrooms. }\end{array}$ \\
\hline Storage & 1 & $36^{\prime} \times 24^{\prime}$ & $\begin{array}{l}\text { Wetal building with gravel floor, three } 12 \text { ' } \\
\text { bays for equipment and supply storage. }\end{array}$ \\
\hline Cold Storage & 1 & $26^{\prime} \times 12^{\prime}$ & Prefab $20^{\prime} \times 12^{\prime}$ freon cold storage \\
\hline Fish Feed & & & $\begin{array}{l}\text { unit/ } 16,000 \# \text { capacity with a } 12^{\prime} \times 6^{\prime} \text { add } \\
\text { on for food handling \& thawing. O.MP } \\
\text { feed delivery } 3 \times \text { per year. }\end{array}$ \\
\hline Residence & 1 & $46^{\prime} \times 24^{\prime}$ & $\begin{array}{l}3 \text { B.R. wood frame prefab unit/attached } \\
\text { garage (residence would be marketable if } \\
\text { facility closed.) }\end{array}$ \\
\hline Spawning Shed & 1 & $10^{\prime} \times 10^{\prime}$ & $\begin{array}{l}\text { Open sides and ends with roof for } \\
\text { spawning at head end of holding pond. }\end{array}$ \\
\hline
\end{tabular}

Equipment

General List

1 pick-up, nets, pumps, misc. tools \& cleaning equip. $(\$ 24,000)$ 
Theoretical Hatcheries

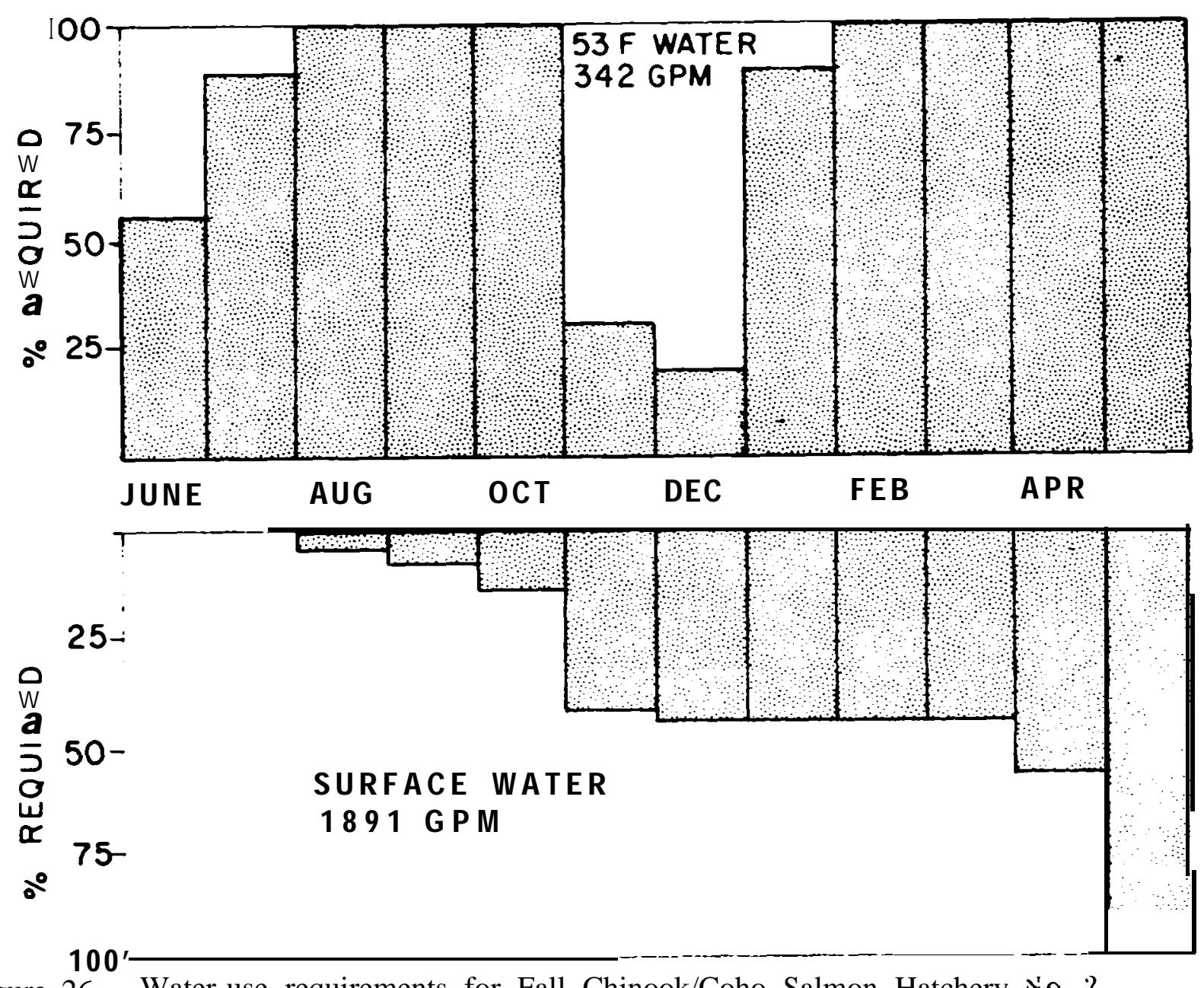

Figure 26. Water-use requirements for Fall Chinook/Coho Salmon Hatchery No. 2.

Taple 44. Facility development costs for Fall Chinook/Coho Salmon Hatchery No. 2. Facility

Site development

Water supply and drains

Fish production facilities

Buildings

Equipment

Total

\author{
Estimated cost \\ $\$ 72,400.00$ \\ $69,704.00$ \\ $81,100.00$ \\ $148,800.00$ \\ $24,000.00$ \\ $\$ 396,000.00$
}


Chapter 9

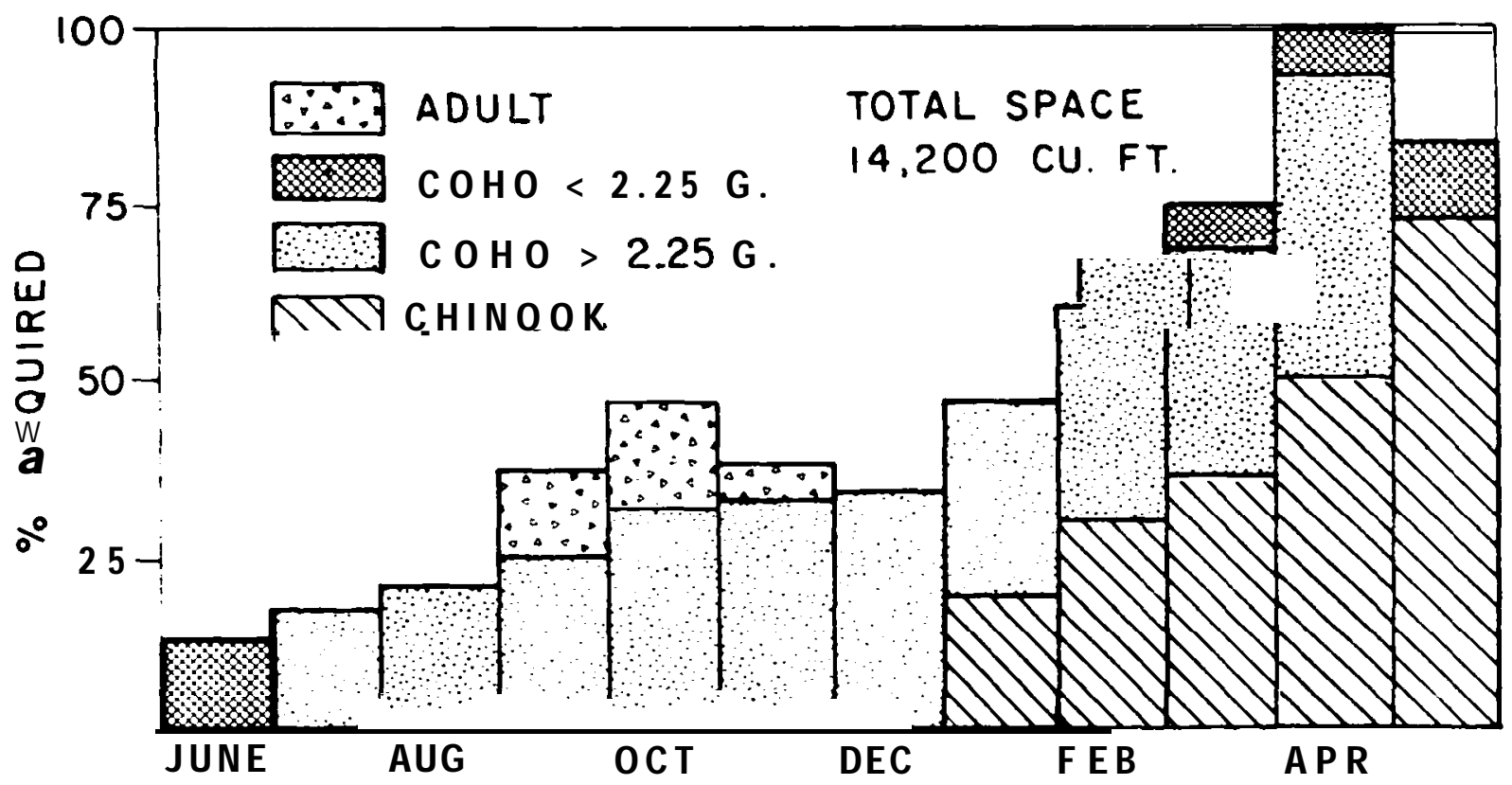

Figure 27. Space-use requirements for Fall Chinook/Coho Salmon Ilatchery No. 2.

Table 45. Estimated annual operational costs and labor requirements for Fall Chinook/Coho Salmon Hatchery No. 2.

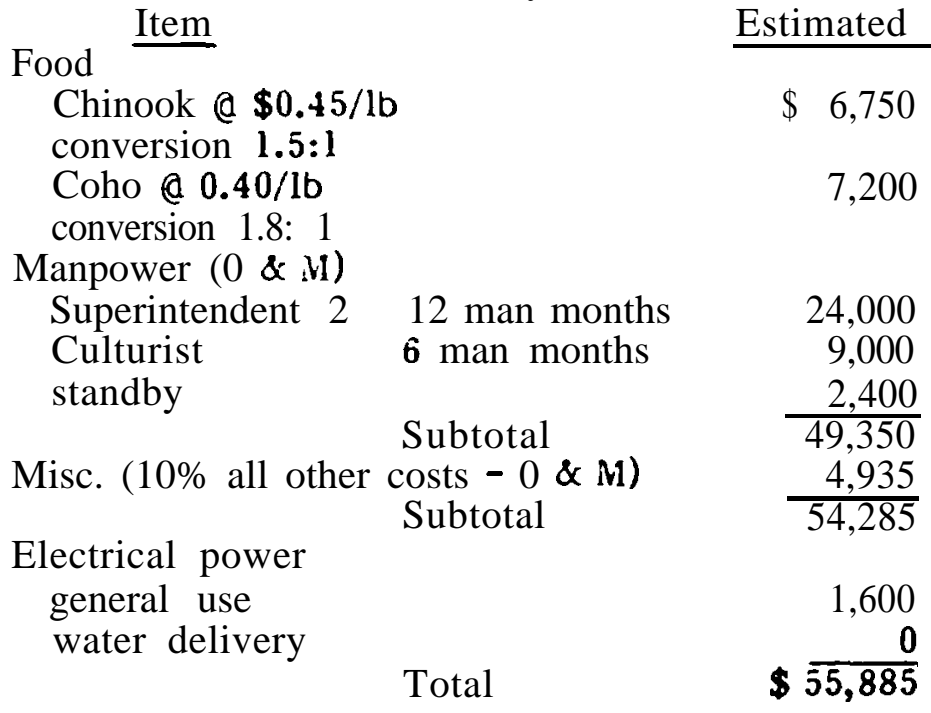




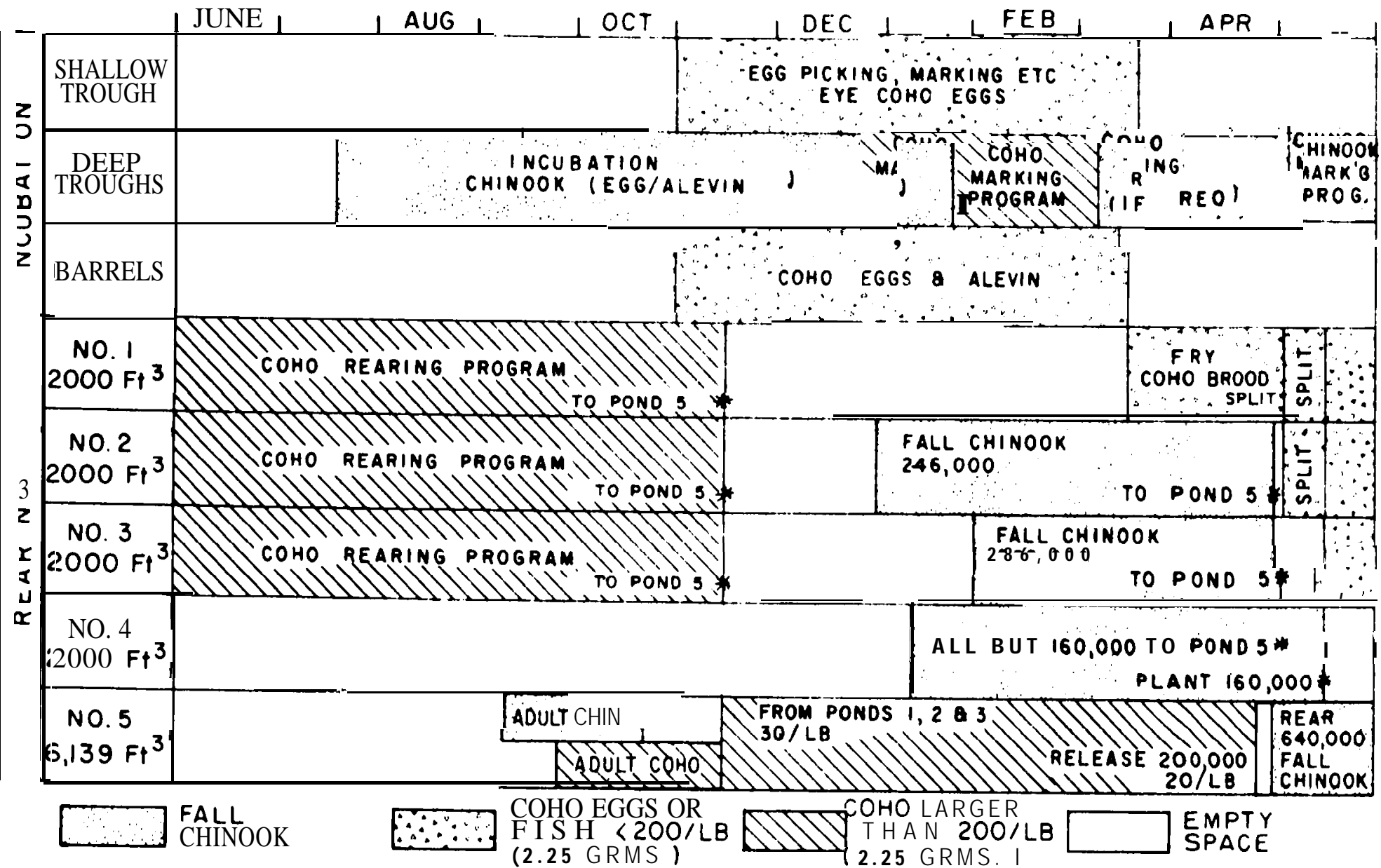

*date action taken

Figure 28. Facility production programming by time for Fall Chinook/Coho Salmon Hatchery No. 2. 
Chapter 9

3. Fall Chinook/Coho Salmon Hatchery No. 3

Goals:

Produce $25,000 \mathrm{lbs}$ each of early fall chinook and coho salmon smolts at 80 fish/lb and 20/lb respectively, for on-station releases.

Summary of Biological Requirements:

Smolt production (no./size)

$$
\begin{aligned}
& \text { chinook } \\
& \text { coho }
\end{aligned}
$$$$
2,000,000 @ 80 / 1 b
$$

Fertilized Eggs (no. spawned)

chinook

coho

Females to spawn (no.)

chinook

$2,380,000$

665,000

coho

530

280

Adults held at one tìme (no.)

chinook

670

coho

310

(Est. 105 coho on hand when chinook are being held)

Recommended minimum water (gpm) ground and/or spring surface

Recommended minimum pond space

$855 @ 50 \mathrm{~F}$

4,727 (see Fig. 1)

$44,300 \mathrm{ft} 3$

Facilities Development:

Table 46 lists the facilities and the associated requirements of Fall Chinook/Coho Salmon Hatchery No. 3 and Fig. 29 illustratks the physical plan for the hatchery.

Operational Strategies:

The operational strategies for this station only differ from Fall Chinook/Coho Salmon Hatchery No. 2 by the magnitude in size. Thus we refer you to the illustrations and details provided previously.

costs:

The facility development costs for Fall Chinook/Coho Salmon Hatchery No. 3 are documented in Table 47 and the estimated annual operational costs and manpower requirements in Table 48. 


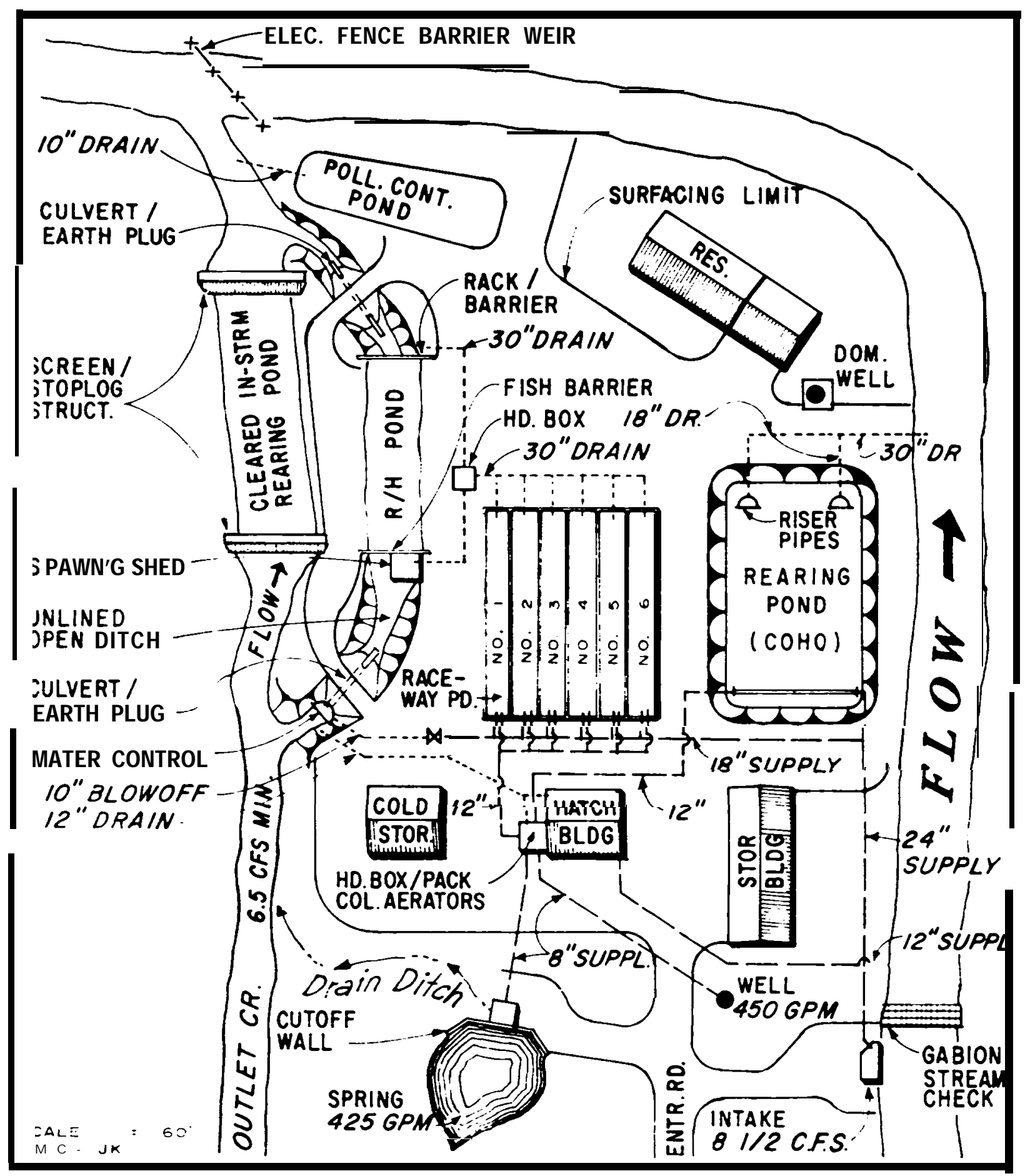

Figure 29. Schematic of Fall Chinook/Coho Salmon Hatchery No. 3. 
Chapter 9

Table 46. Facility development for Fall Chinook/Coho Hatchery No. 3 (50,000 lbs, onstation release).

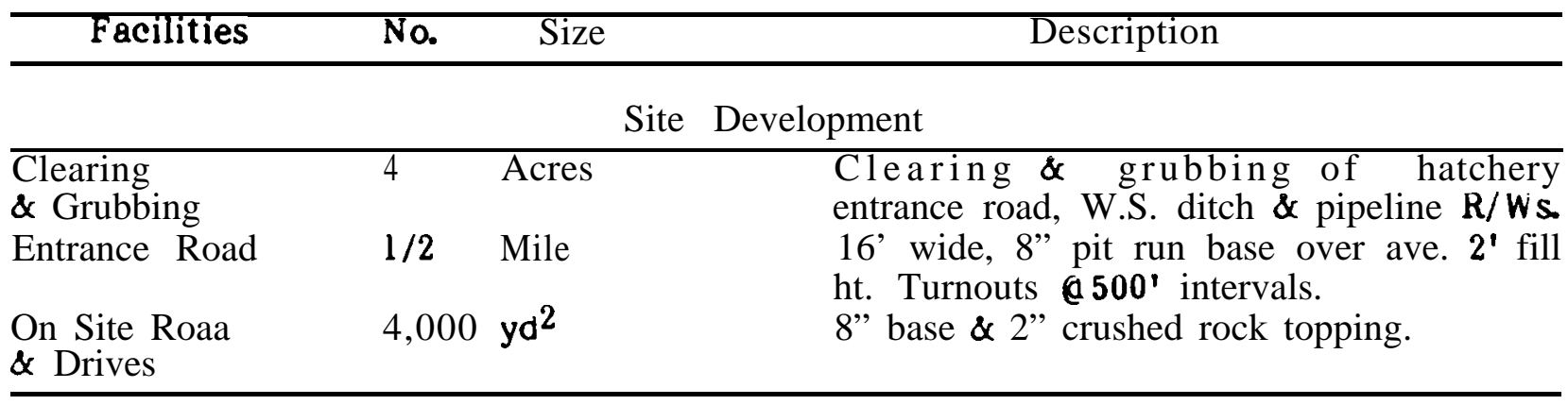

Water Supply \& Drains

\begin{tabular}{|c|c|c|c|}
\hline Stream Intake & 1 & $14^{\prime} \times 4^{\prime}$ & $\begin{array}{l}\text { Coarse \& fine screen reinforced concrete } \\
\text { intake with stop log water control }\end{array}$ \\
\hline $\begin{array}{l}\text { Gabion Stream } \\
\text { Check }\end{array}$ & 1 & $20 \mathrm{yd}^{3}$ & $\begin{array}{l}\text { Gabion rock-filled wire baskets } \\
\left(30^{\prime} \times 6^{\prime} \times 3^{\prime}\right)\end{array}$ \\
\hline $\begin{array}{l}\text { Water Supply Open } \\
\text { Ditch }\end{array}$ & 1,000 & $\operatorname{lin} \mathrm{ft}$ & $\begin{array}{l}\text { Unlined canal/3' bottom width \& } 21 / 2: 1 \\
\text { side slopes } \times 3 \text { ' deep. Grade of } 0.03 \% \\
\text { max. }\end{array}$ \\
\hline $\begin{array}{l}\text { Earth Ditch Plug/ } \\
\text { Water Control Riser }\end{array}$ & 1 & $36^{\prime}$ dia riser & $\begin{array}{l}8^{\prime} W \text { dike to p plug/4'H rise } \mathrm{r} \text {. } \\
\text { equipped with screen and stop logs. }\end{array}$ \\
\hline $\begin{array}{l}\text { Drain Ditch Plug } \\
\text { Open culvert }\end{array}$ & 1 & 24" dia culv. & $8^{\prime} W$ dike top plug/28' long culvert \\
\hline Supply Lines & & & $\begin{array}{l}\text { 12" diameter \& larger - CMP, under } 12^{\prime \prime} \text { - } \\
\text { PVC }\end{array}$ \\
\hline Drain Lines & & & $\begin{array}{l}\text { 12" diameter \& larger - C.MP, under 12" - } \\
\text { PVC }\end{array}$ \\
\hline Spring Intake & 1 & 16’ long & $\begin{array}{l}\text { Concrete cut-off wall x 5' high with } 2^{\prime} \times \\
4^{\prime} \text { concrete screened intake box }-425 \mathrm{gpm} \text {. }\end{array}$ \\
\hline Production Well & 1 & g p m & 12" dia x 200' gpm with 25 HP sub. pump. \\
\hline Domestic Hell & 1 & $5 \mathrm{gpm}$ & $\begin{array}{l}\text { 6" dia. X 120' deep with } 1 / 2 \text { HP } \\
\text { submersible pump. Pressure tank in well } \\
\text { house - PVC underground piping to } \\
\text { buildings \& spawning shed. }\end{array}$ \\
\hline Aeration Head Box & 1 & $4^{\prime} \times 6^{\prime}$ & $\begin{array}{l}\text { Plywood construction for spring water } \\
\text { aeration through three packed column } \\
\text { units. }\end{array}$ \\
\hline
\end{tabular}


Theoretical Hatcheries

\begin{tabular}{|c|c|c|c|}
\hline Facilities & No. & Size & Description \\
\hline \multicolumn{4}{|c|}{ Fish Production Facilities } \\
\hline$\overline{\text { Raceways }}$ & 6 & $83^{\prime} \times 8^{\prime}$ & $\begin{array}{l}2,000 \mathrm{ft}^{3} \text { water ea. Prefab steel/plastic } \\
\text { sheet lining }\end{array}$ \\
\hline $\begin{array}{l}\text { Com b. Rearing/ } \\
\text { Holding Pond }\end{array}$ & 1 & $86^{\prime} \times 20^{\prime}$ & $\begin{array}{l}5,160 \mathrm{ft}^{3} \text { water }-3^{\prime} \text { ave. pond } \\
\text { water depth. Unlined dirt pond }-3: 1 \text { bank } \\
\text { slopes with pen fencing utilized for adult } \\
\text { holding separation. }\end{array}$ \\
\hline $\begin{array}{l}\text { Outlet Cr. Pond } \\
\text { Barrier }\end{array}$ & 1 & $110^{\prime} \times 30^{\prime}$ & 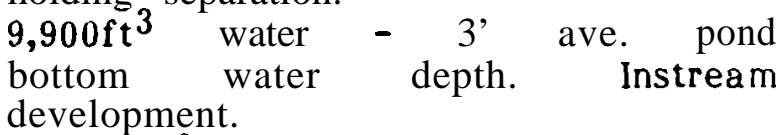 \\
\hline Coho Pond & 1 & $120^{\prime} \times 56^{\prime}$ & $\begin{array}{l}17,500 \mathrm{ft}^{3} \text { water }-3-1 / 2 \text { ave. pond bottom } \\
\text { water depth. Dirt pond } 3: 1 \text { side slopes. }\end{array}$ \\
\hline Hatching Tanks & 10 & $16^{\prime} \times 18^{\prime \prime}$ & $\begin{array}{l}10 \text { deep tanks for egg incubation \& } 1 \\
\text { shallow tank for egg picking. }\end{array}$ \\
\hline Barrel Incubators & 8 & gals. ea. & Incubators for coho eggs. \\
\hline Adult Fish Barrier & 1 & $40 \operatorname{lin} \mathrm{ft}$ & $\begin{array}{l}\text { Electric fence barrier weir }-110 \mathrm{~V} \text {. } \\
\text { Annual inst. to divert adults into side } \\
\text { creek. }\end{array}$ \\
\hline $\begin{array}{l}\text { Pollution Control } \\
\text { Pond }\end{array}$ & 1 & $80^{\prime} \times 25^{\prime}$ & $\begin{array}{l}3,000 \quad \mathrm{ft}^{3} \text { water with one-hour } \\
\text { detention time by cleaning wastes by } \\
\text { vacuum system. Dirt sides \& bottom with } \\
3: 1 \text { bank slopes - 3-1/2' average pond } \\
\text { bottom water depth. }\end{array}$ \\
\hline
\end{tabular}

\begin{tabular}{|c|c|c|c|}
\hline \multicolumn{4}{|c|}{ Buildings } \\
\hline Hatchery & 1 & $30^{\prime} \times 24^{\prime}$ & $\begin{array}{l}\text { Metal bldg. with tank, office, crew } \\
\text { locker, toilet, and mechanical roonıs. }\end{array}$ \\
\hline Storage & 1 & $600^{\prime} \times 24^{\prime}$ & $\begin{array}{l}\text { Metal bldg with gravel floors, five } 12 \text { ' } \\
\text { bays for equipment, supply storage, and } \\
\text { diesel generator housing. }\end{array}$ \\
\hline $\begin{array}{l}\text { Cold Storage } \\
\text { Fish Feed }\end{array}$ & 1 & $28^{\prime} \times 24^{\prime}$ & $\begin{array}{l}\text { Prefab } 20^{\prime} \times 24^{\prime} \text { freon cola storage } \\
\text { unit/40,000 lb capacity with } \& 24^{\prime} \times 8^{\prime} \text { aaa } \\
\text { on for food handling \& thawing. O.MP } \\
\text { feed delivery } 3 \times \text { per year. }\end{array}$ \\
\hline Spawning Shed & 1 & $10^{\prime} \times 10^{\prime}$ & $\begin{array}{l}\text { Open sides and enas with roof for } \\
\text { spawning at head end of holding pond. }\end{array}$ \\
\hline Residence & 1 & $46^{\prime} \times 24^{\prime}$ & $\begin{array}{l}3 \text { BR wood frame prefab unit/attached } \\
\text { garage (residence would be marketable } \\
\text { if facility closed.) }\end{array}$ \\
\hline
\end{tabular}

Equipment

General List

1 pick-up, nets, pumps, misc. tools \& cleaning equip. $(\$ 26,000)$ 
Chapter 9

Table 47. Facility development costs for Fall Chinook/Coho Salmon Hatchery No. 3.

\begin{tabular}{|c|c|}
\hline Facility & Estimated cost \\
\hline Site development & $\$ 108,100.00$ \\
\hline Water supply and drains & $228,100.00$ \\
\hline Fish production facilities & $197,100.00$ \\
\hline Buildings & $198,800.00$ \\
\hline Equipment & $\frac{26,000.00}{\$ 758,100.00}$ \\
\hline
\end{tabular}

Table 48. Estimated annual operational costs and labor requirements for Fall Chinook/Coho Salmon 'Hatchery No. 3.

\begin{tabular}{|c|c|c|}
\hline Item & & Estimated \\
\hline Food & & \\
\hline $\begin{array}{l}\text { Chinook @ } \$ 0.45 / 1 \mathrm{t} \\
\text { conversion } 1.5: 1\end{array}$ & & $\$ 16,875$ \\
\hline $\begin{array}{l}\text { Coho } 0.40 / \mathrm{lb} \\
\text { conversion } 1.8: 1\end{array}$ & & 18,000 \\
\hline Manpower $(\mathrm{O} \& \mathrm{M})$ & & \\
\hline Superintendent 2 & 12 man months & 24,000 \\
\hline $\begin{array}{l}\text { Culturist } \\
\text { standby }\end{array}$ & 15 man months & $\begin{array}{r}22,500 \\
2,400\end{array}$ \\
\hline & Subtotal & 83,775 \\
\hline Misc. ( $10 \%$ all other & costs $-0 \& M)$ & 8,377 \\
\hline & Subtotal & $\$ \overline{92,152}$ \\
\hline $\begin{array}{l}\text { Electrical power } \\
\text { general use } \\
\text { water delivery }\end{array}$ & $\begin{array}{l}\text { ( } 25 \mathrm{HP}, 6 \text { months) } \\
\text { Total }\end{array}$ & $\begin{array}{r}2,800 \\
3,450 \\
\$ 98,402\end{array}$ \\
\hline
\end{tabular}

\section{THEORETICAL COHO HATCHERIES}

The conceptual plans, operations, and costs of two theoretical coho salmon hatcheries follow.

1. Coho Salmon Hatchery No. 1

Goals:

Produce 20,000 coho juveniles of various sizes from a single racial stock with on-station and off-station production and releases as follows:

$\begin{array}{rrrll}\text { Nos. } & \text { No./lb } & \text { Lbs } & \begin{array}{l}\text { Release } \\ \text { date }\end{array} & \text { Stream release site } \\ 137,600 & 20 & 6.880 & \text { May } & \text { A (on-station) } \\ 162,400 & 20 & \mathbf{8 , 1 2 0} & \text { Slay } & \text { B } 1-10 \\ 800,000 & 180 & 4,444 & \text { June } & \text { C } 11-16 \\ 890,000 & 1,600 & 556 & \text { February } & \end{array}$


The goals of these releases are:

Stream A - For brood stock and all fisheries.

Stream B - For tribal and other fisheries.

Stream C, 1-16 - To rebuild a very depressed stream system.

Summary of Biological Requirements:

Production (no./size)

Smolt

Fingerling

Eyed - egg plants/transfers

Fertilized eggs (no. spawned)

Smolt

Fingerling

Eyed-eggs

Females to spawn (no.)

Adults held at one time (no.)

Recommended minimum water (gpm)

Onstation ground and or spring surface

Offstation surface

Recommended minimum pond space

onstation or equivalent

of fstation
300,000

800,000

890,000

d 20/lb

a $180 / 1 b$

400,000

955,800

989,000

$2, \overline{344,800}$

977

1,081

90 @ 48F

770 @ (see Fig. 1)

634 \& (see Fig. 1)

$8,000 \mathrm{ft}^{3}$

$4,776 \mathrm{ft}^{3}$

Facilities Development:

Table 49 lists the facilities and the associated requirements of Cono Salmon Hatchery No. 1, Fig. 30 is a vicinity map of all production and release sites, and Fig. 31a and 3lb, illustrate the facilities.

Operational Strategies:

For the water and space requirements as related to the total biological requirements by time, we refer you to the Coho Salmon Hatchery No. 2 which follows immediately. The two hatcheries only differ in the magnitude of production. (Note: We have illustrated dirt raceways in order to show they are a viable option.)

\section{Costs}

The facility development costs for Cono Salmon Hatchery No. 1 is documented in Table 50, and the annual operational costs and labor requirements in Table 51. 


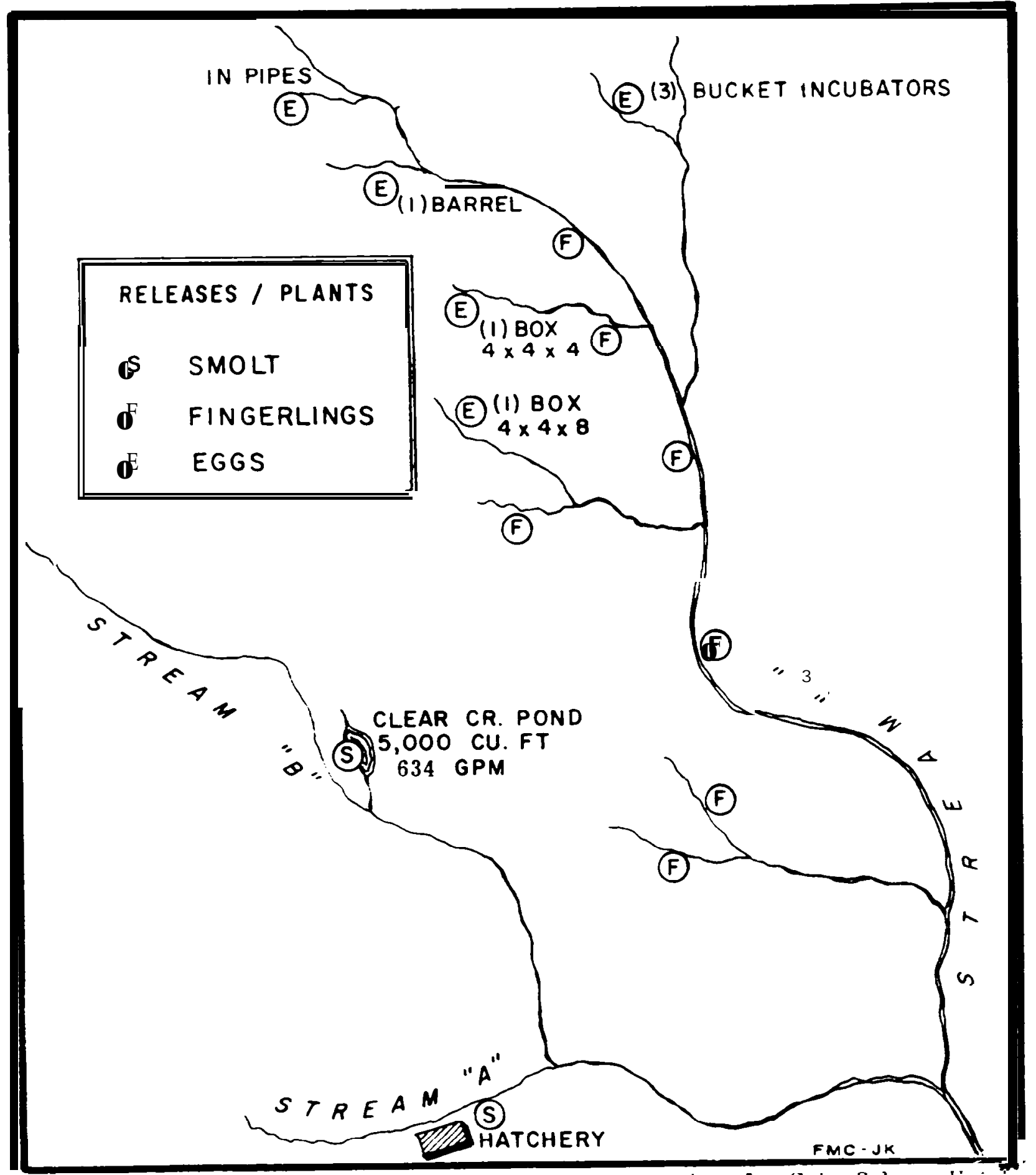

Figure 30. Vicinity map of the production and release sites for Cono saimon Hatcrery No. 1. - on and off-station facilities. 
Theoretical Hatcheries

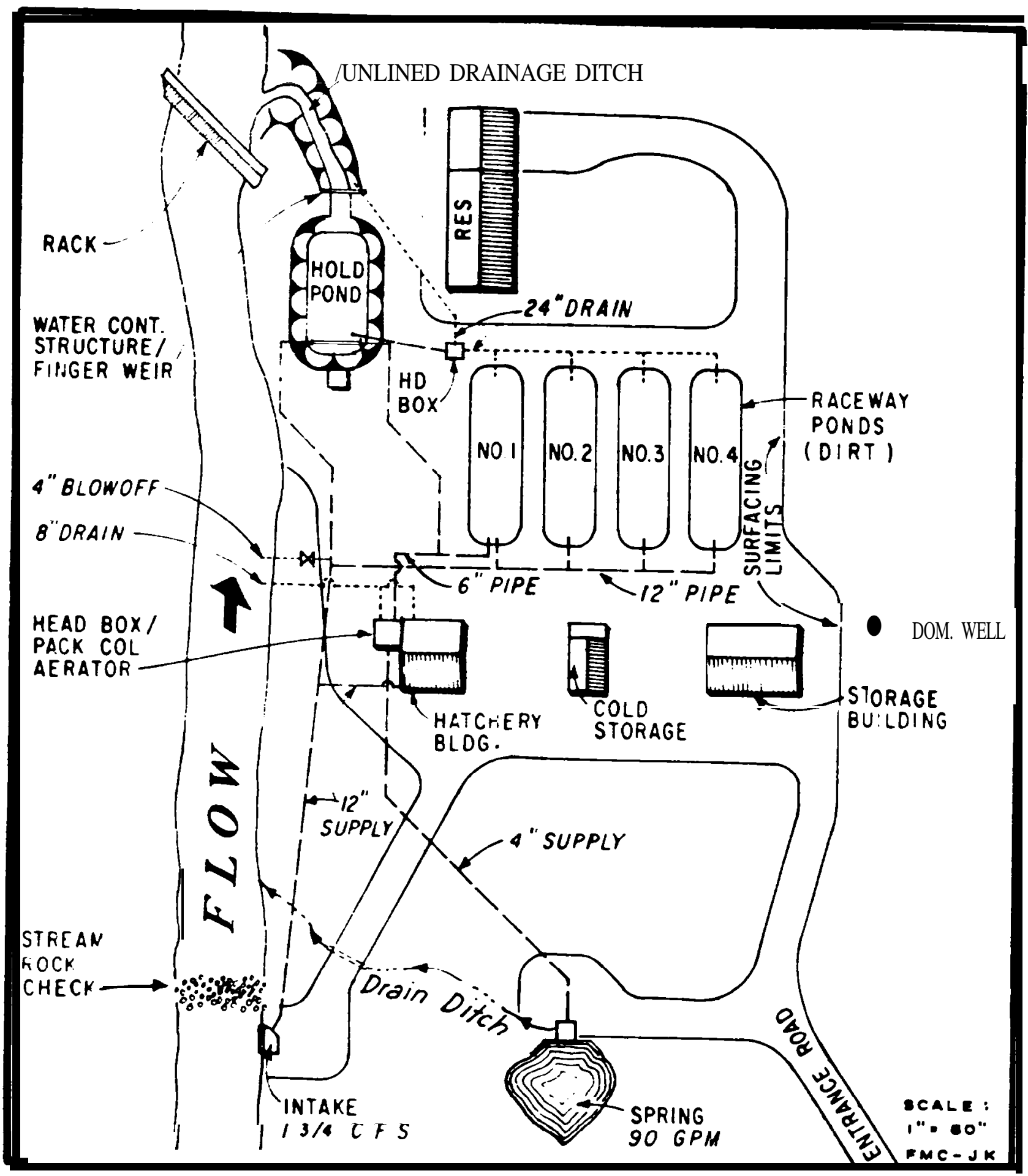

$\mathrm{t}$ igure 31 a. Schematic of Coho Salmon Hatchery No. 1 - On-station facilities. 
chapter 9

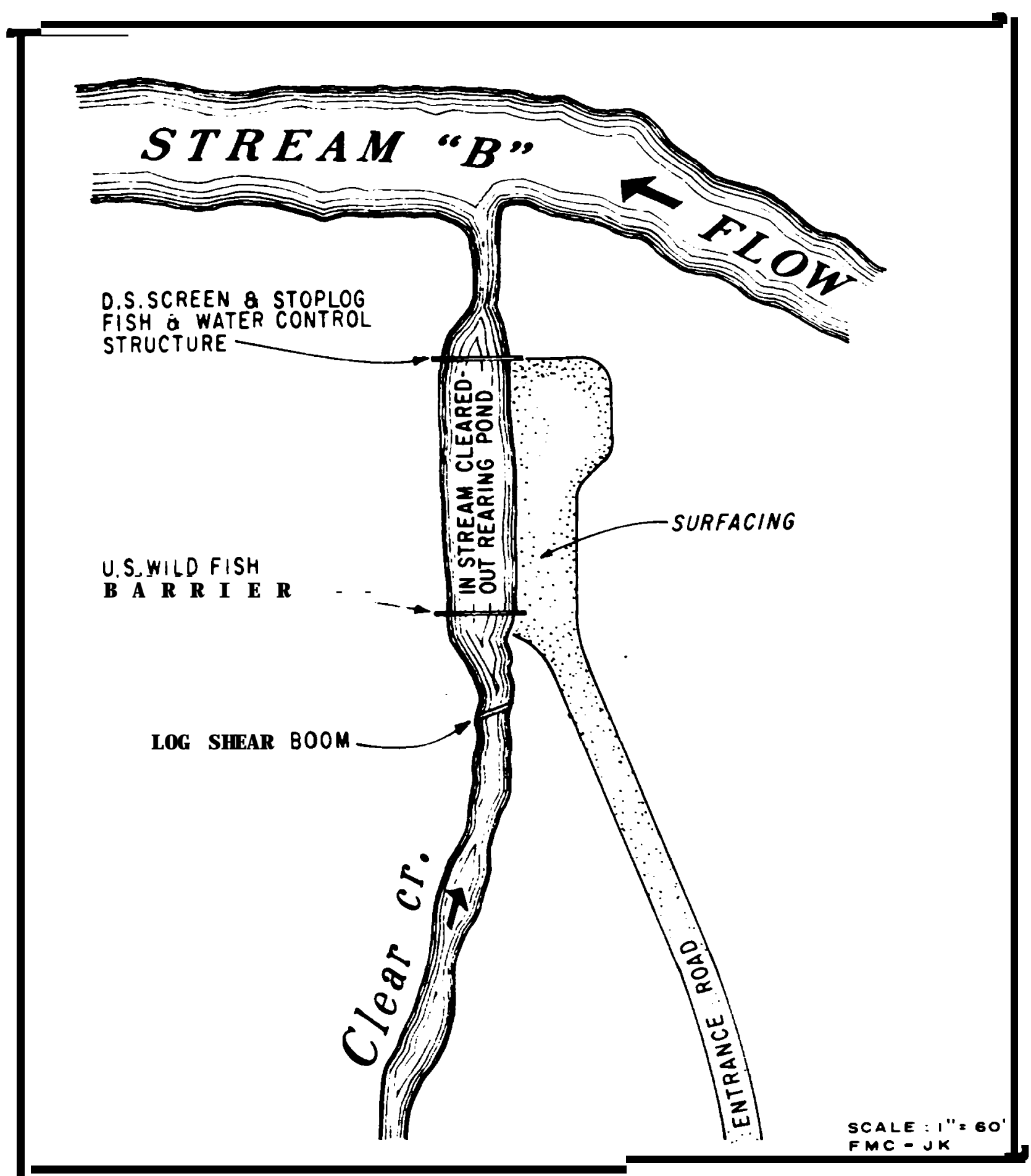

Figure 31b. Schematic of Coho Salmon Hatchery No. 1 - Ott-station pona. 
Theoretical Hatcheries

Table 49. Facility development for Coho Salmon Hatchery No. 1. (20,000 lbs, on- and off-station releases).

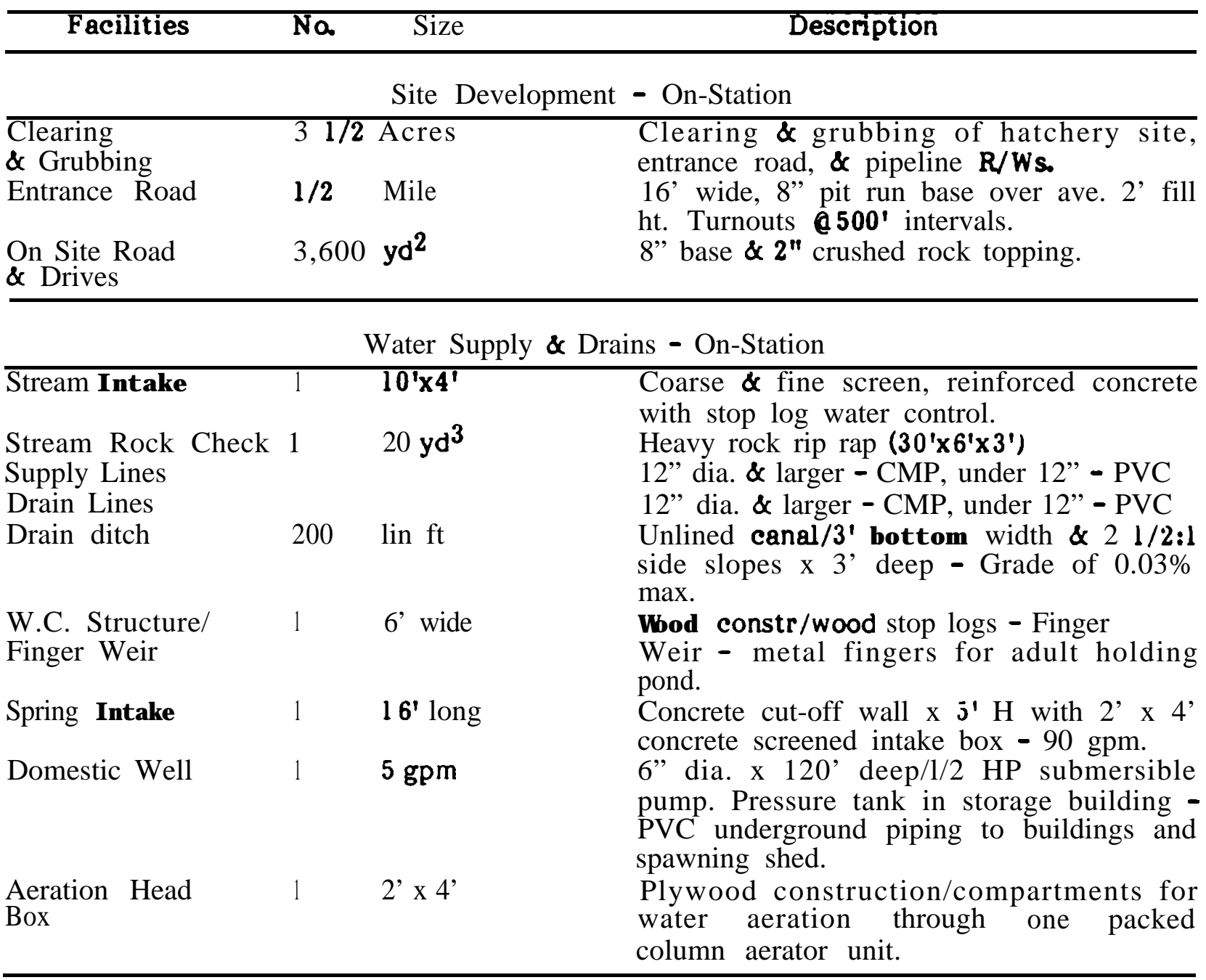

Fish Production Facilities - On-Station

\begin{tabular}{|c|c|c|c|}
\hline Race ways & 4 & $70^{\prime} \times 20^{\prime}$ & $\begin{array}{l}\text { 2,000 } \mathrm{ft}^{\mathbf{s}} \text { water each - 3' average pond } \\
\text { water depth. Dirt sides } \& \text { bottoms with } \\
\text { 3:1 bank slopes. }\end{array}$ \\
\hline Holding Pond & 1 & $65^{\prime} \times 34^{\prime}$ & $\begin{array}{l}4 ' 324 \mathrm{ft}^{3} \text { water }-31 / 2^{\prime} \text { average pond } \\
\text { bottom water depth. Dirt sides \& bottom } \\
\text { with } 3: 1 \text { bank slopes. Pen fencing utilized } \\
\text { for adult holding separation. }\end{array}$ \\
\hline Hatching Tanks & 7 & $16^{\prime} \times 18^{\prime \prime}$ & $\begin{array}{l}7 \text { deep tanks for egg incubation \& } 1 \\
\text { shallow tank for egg picking. }\end{array}$ \\
\hline Adult Fish Rack & 1 & $40 \operatorname{lin} \mathrm{ft}$ & $\begin{array}{l}\text { Wood constr. - annual installation to } \\
\text { divert adults into side ditch. }\end{array}$ \\
\hline
\end{tabular}


Chapter 9

\begin{tabular}{|c|c|c|}
\hline Facilities & Size & Description \\
\hline \multicolumn{3}{|c|}{ Equipment - On-Station and Off-Station } \\
\hline General List & & $\begin{array}{l}1 \text { pick-up, nets, pumps, misc. tools, } \\
\text { cleaning equip., \& small fish-tank } \\
(\mathbf{\$ 2 9 , 0 0 0 )}\end{array}$ \\
\hline
\end{tabular}

\begin{tabular}{|c|c|c|c|}
\hline \multicolumn{4}{|c|}{ Buildings - On-Station } \\
\hline Hatchery & 1 & $22^{\prime} \times 24^{\prime}$ & $\begin{array}{l}\text { Metal bldg with tank, office, crew locker, } \\
\text { toilet, and mechanical rooms. }\end{array}$ \\
\hline Storage & 1 & $36^{\prime} \times 24^{\prime}$ & $\begin{array}{l}\text { Metal bldg with gravel floors, three } 12 \text { ' } \\
\text { bays for equipment and supply storage } \\
\text { domestic water pressure tank housing. }\end{array}$ \\
\hline Spawning Shed & 1 & $10^{\prime} \times 10^{\prime}$ & $\begin{array}{l}\text { Open sides and ends with roof for } \\
\text { spawning at head end of holding pond. }\end{array}$ \\
\hline $\begin{array}{l}\text { Cold Storage } \\
\text { Fish Feed }\end{array}$ & 1 & $12^{\prime} \times 24^{\prime}$ & $\begin{array}{l}\text { Prefab } 18^{\prime} \times 12^{\prime} \text { freon cold storage } \\
\text { unit/ } 14,000 \mathrm{lb} \text { capacity with a } 6^{\prime} \times 12^{\prime} \text { add } \\
\text { on for food handling and thawing. OMP } \\
\text { feed deliveries } 3 \times \text { per year. }\end{array}$ \\
\hline Residence & 1 & $46^{\prime} \times 24^{\prime}$ & $\begin{array}{l}3 \text { BR wood frame prefab unit/attached } \\
\text { garage. (residence would be marketable } \\
\text { if facility closed). }\end{array}$ \\
\hline
\end{tabular}

Site Development - Off-Station "Clear Cr."

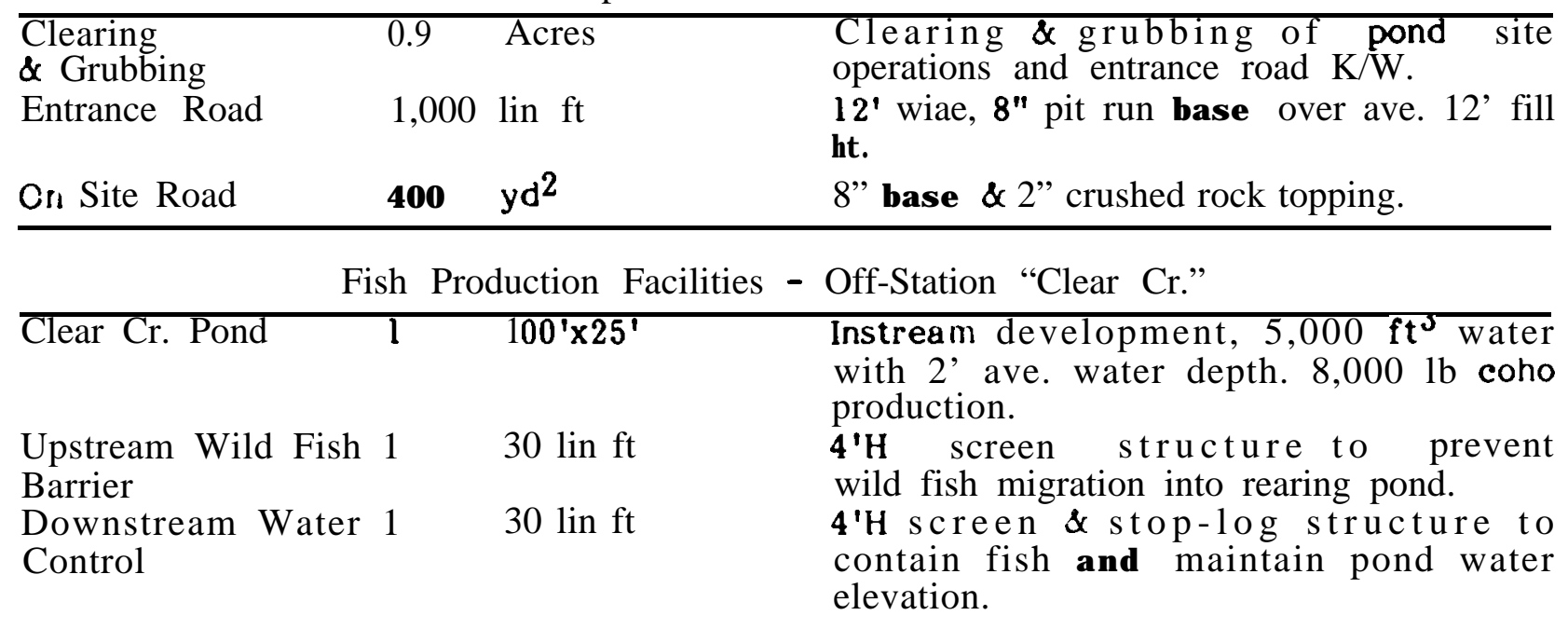


Theoretical Hatcheries

Table 50. Facility development capital costs for Coho Salmon Hatchery No. 1.

\begin{tabular}{|c|c|}
\hline Facility & Estimated cost \\
\hline Site development & $\$ 98,300.00$ \\
\hline Water supply and drains & $85,500.00$ \\
\hline Fish production facilities & $88,000.00$ \\
\hline Buildings & $149,600.00$ \\
\hline Equipment & $\frac{29,000.00}{\$ 450,40000}$ \\
\hline
\end{tabular}

Tasle 51. Estimated annual operational costs and labor requirements for Coho Salmon Hatchery No. 1 with on-station and off-station production.

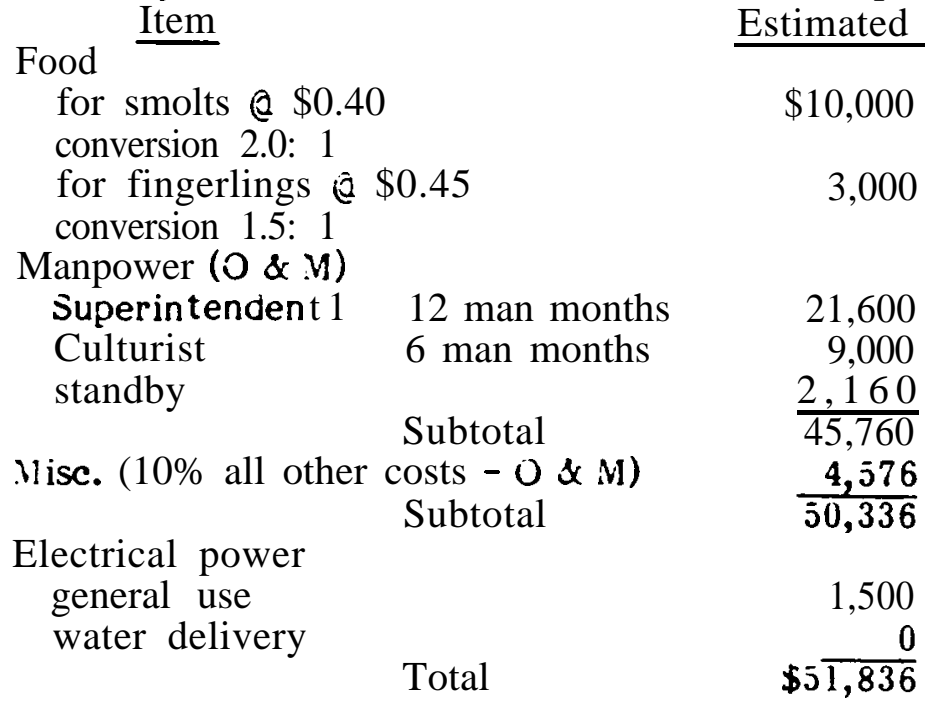

2. Coho Salmon Hatchery No. 2

Goals:

Produce 50,000 lbs of coho juveniles of various sizes from a single racial stock with on-station and off-station production and releases as follows:

\begin{tabular}{|c|c|c|c|c|}
\hline Nos. & No./10 & $\begin{array}{l}\text { Release } \\
\text { Lbs }\end{array}$ & Date & Stream release site \\
\hline 344,000 & 20 & 17,200 & Miay & A (on-station) \\
\hline 406,000 & 20 & 20,300 & May & B \\
\hline $2^{\prime} 000,000$ & 180 & 11,110 & June & $c^{\prime} 1-10$ \\
\hline $2,225,000$ & 1,600 & 1,390 & February & C $11-16$ \\
\hline
\end{tabular}

The goals of these releases are:

Stream A - For brood stock and all fisheries.

Stream B - For tribal and other fisheries.

Stream C, 1-1 6 - To rebuild \& very depressed stream sisten. 
Summary of Biological Requirements:

Production (no./size)

Smolt

Fingerling

Eyed - egg plants/transfers

Fertilized eggs (no. spawned)

Smolt

Fingerlings

Eyed-eggs

Females to spawn (no.)

Adults held at one time (no.)

Recommended minimum water (gpm)

Onstation ground and/or spring surface

$750,000 @ 20 / 1 b$

$2,000,000 @ 180 / 1 \mathrm{~b}$

$2,225,000 @ 1,600 / \mathrm{lb}$

$1,000,000$

$2,390,000$

$2,475,000$

$5,865,000$

2,443

2,703

Of f-station surf ace

Recommended minimum pond space or equivalent

Onstation

Of fstation

$225 @ 48 \mathrm{~F}$

1,924 (see Fig. 1)

1,586 (see Fig. 1)

$24,880 \mathrm{ft}^{3}$

$13,140 \mathrm{ft} 3$

Facilities Development:

Table 52 lists the facilities and the associated requirements of Coho Salmon Hatchery No. 2, Fig. 32 is a vicinity map of all production and release sites, and Fig. 33a and 33b illustrate the station's facilities.

Operational Strategies:

Water and space requirements as related to the percentage of the total biological requirements by time are shown in Figs. 34 and 35, respectively. Brief comments follow on each life phase.

(1) Adults All adults will be held in the large rearing/adult pond. Their space requirement is equal to the total $\mathrm{ft}^{3}$ space within the pond, and the water requirements are $1,351 \mathrm{gpm}$ of new water. Water from the juveniles being reared in the raceways $(2,149 \mathrm{gpm})$ will be passed through the adult pond.

(2) Incubation All eggs $(5,865,000)$ will be eyed in six or seven of the 16 deep troughs. A total of $2,225,000$ eyed eggs will be transfered to the stream for planting or final incubation in stream-side box incubators as described in Chapter 4. Protection from the extreme cold weather will be required. Either burial in the ground or earth insulation will generally be used. This latter program will be conducted largely with volunteer assistance.

The remaining eyed eggs $(3.0$ million) will be incubated in the 16 deep troughs with artificial substrate for hatching and alevin incubation. The coolest clear water available will be utilized for incubation. This will slow development 
Theoretical Hatcheries

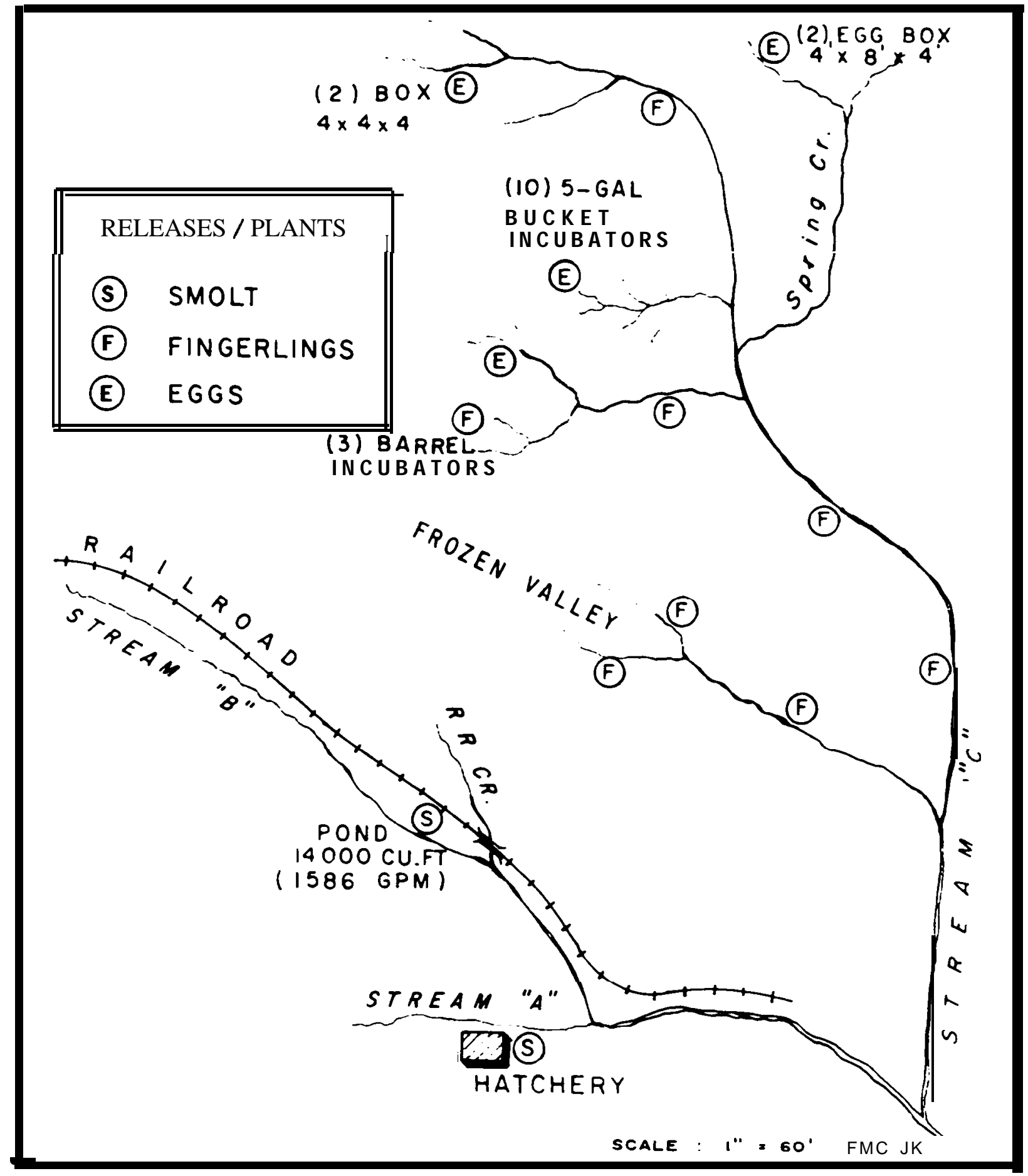

Figure 32. Vicinity map of the production and release sites for Coho Salmon Hatchery No. 2. 


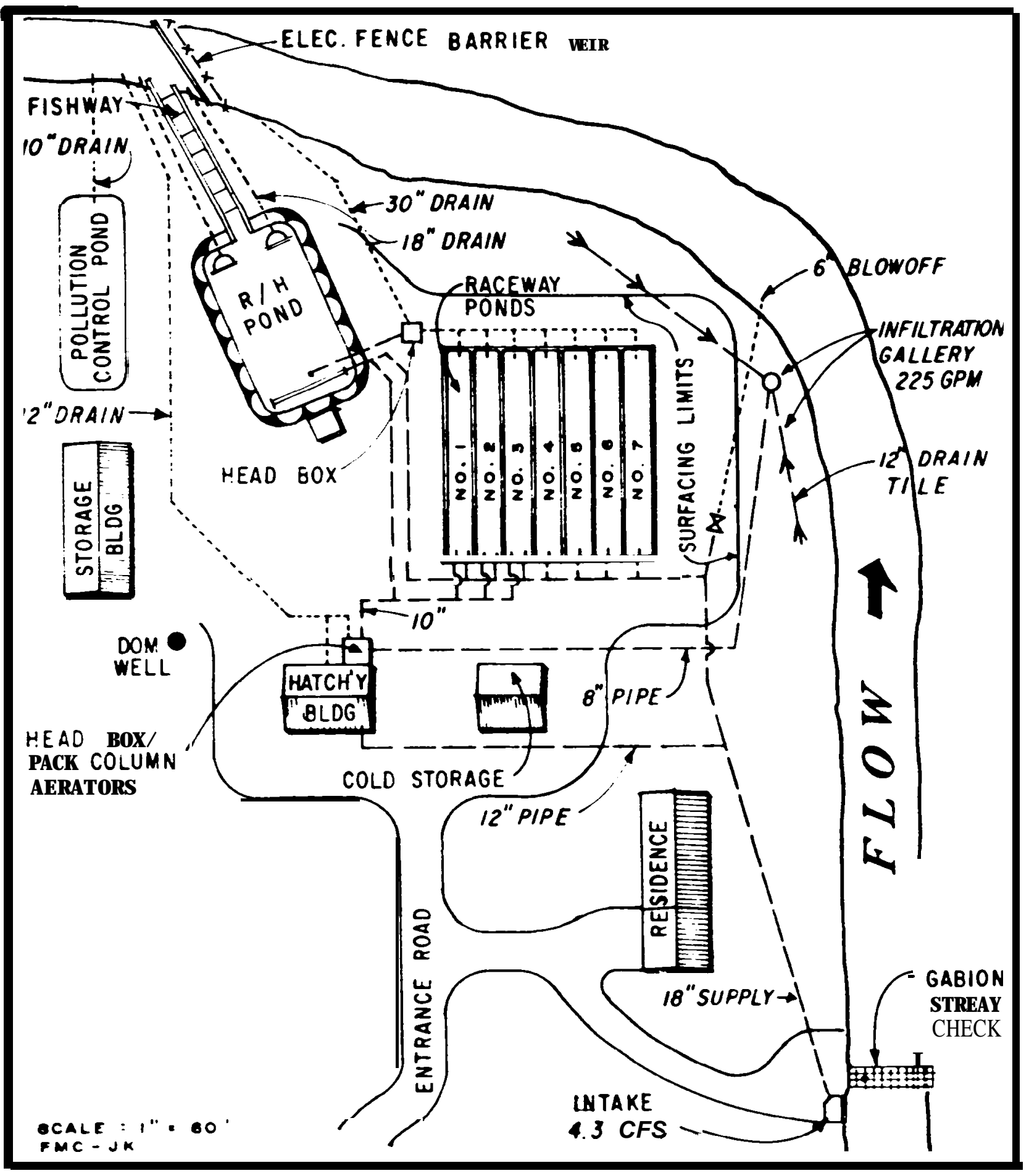

Figure 33a. Schematic of Coho Salmon Hatchery No. 2 - Onstation facilities. 
Theoretical Hatcheries

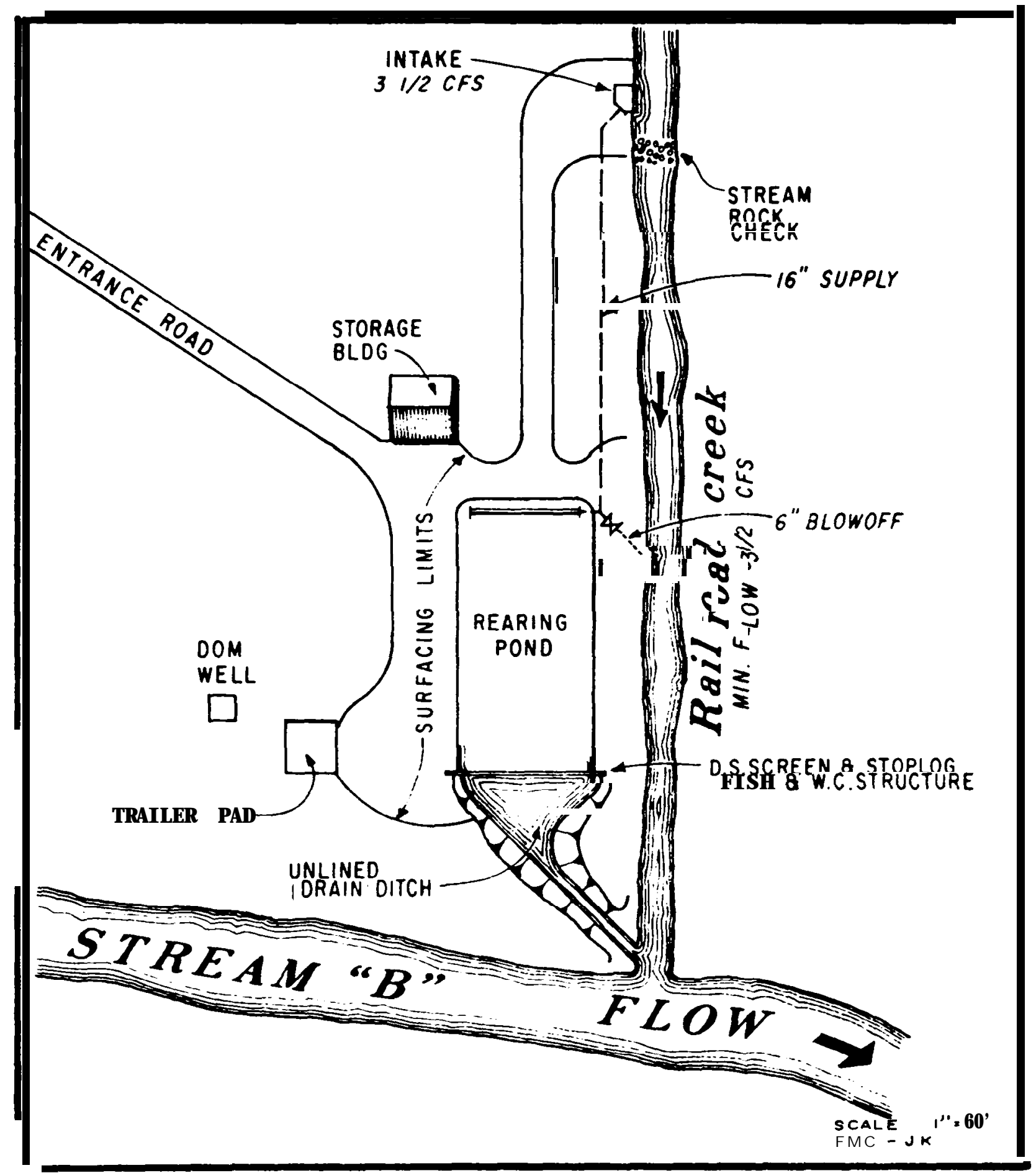

Fi gure 33b. Schenatic of Coho Salmon Hatchery No. 2 - Off-stution pond. 
Chapter 9

rates and result in less poundage of fry and fingerlings during the spring, summer, and fall months. For the egg plants, slower development will allow the fry to emerge at a time that is most favorable to their survival.

(3) Rearing Sixteen deep troughs are available (if needed) for fry rearing once the incubation of the alevins is completed. All fingerling coho for smolt on-station releases will be in the large pond (see Fig. 33a), thus the seven 2,000 $\mathrm{ft}^{3}$ raceways will also be ulitized for starting fry and continued rearing until mid-November when the adults no longer utilized the rearing and holding pond. At this time the maximum densities of fish will exist in all ponds. Programming the feeding levels so the juvenile coho are smaller than 30 fish/lb (15 grams each) at this time will be conducted. When appropriate, the $48 \mathrm{~F}$ water will be used to cool surface water and help prevent icing problems during the winter. The off-station rearing program will be conducted by a paid hourly employee.

(4) Releases Fry from stream-side incubators will be provided direct access to the stream. Fingerling plantings will be conducted by the various means documented in Chapter 6. For on-station smolt releases, the fish will be allowed to exit the rearing units beginning in mid-April, and all fish will be forced to leave during the first week in May.

\section{Costs}

The facility development costs for Coho Salmon Hatchery No. 2 is documented in Table 53, and the annual operational costs and labor requirements in Table 54.

Table 52. Facility development for Coho Salmon Hatchery No. 2 (50,000 lbs, on- and off-station releases).

\begin{tabular}{|c|c|c|c|}
\hline Facilities & No. & Size & Description \\
\hline \multicolumn{4}{|c|}{ Site Development - On-Station } \\
\hline $\begin{array}{l}\text { Clearing } \\
\text { \& Grubbing }\end{array}$ & 5 & Acres & $\begin{array}{l}\text { Clearing \& grubbing of hatchery site, } \\
\text { entrance road, \& pipeline } \mathrm{k} / \mathrm{hs} \text {. }\end{array}$ \\
\hline Entrance Road & $1 / 2$ & M ile & $\begin{array}{l}\text { 16' wide, 8" pit run base over ave. 2' fill } \\
\text { ht. Turnouts @ } 500 \text { ' intervals. }\end{array}$ \\
\hline $\begin{array}{l}\text { On Site Road } \\
\text { \& Drives }\end{array}$ & 4,000 & $y d^{2}$ & 8" base \& 2" crushed rock topping. \\
\hline
\end{tabular}


Theoretical Hatcheries

\begin{tabular}{|c|c|c|c|}
\hline Facilities & No. & Size & Description \\
\hline \multicolumn{4}{|c|}{ Water Supply \& Drains - On-Station } \\
\hline Stream Intake & 1 & $10^{\prime} \times 4^{\prime}$ & Coarse \& fine screen, reinforced concrete \\
\hline $\begin{array}{l}\text { Stream Gabion } \\
\text { Check } \\
\text { Supply Lines }\end{array}$ & 1 & $20 \mathrm{yd}^{3}$ & $\begin{array}{l}\text { Gabion rock-filled baskets } \\
(30 \text { 'x6'x3') } \\
12 \text { " diameter \& larger - CMP, under } 12 \text { " - } \\
\text { PVC }\end{array}$ \\
\hline Drain Lines & & & $\begin{array}{l}\text { 12" diameter \& larger - C.MP, under 12" - } \\
\text { PVC }\end{array}$ \\
\hline $\begin{array}{l}\text { Infiltration } \\
\text { Gallery with Pump }\end{array}$ & 1 & $120 \operatorname{lin} \mathrm{ft}$ & $\begin{array}{l}4^{\prime} \text { ' trench gallery excavated to } 6 \text { ' } \\
\text { below stream bed. } 12^{\prime \prime} \text { perforated drain } \\
\text { tile backfilled with washed river gravel. } \\
\text { Pump sump with } 11 / 2 \mathrm{HP} \text { submersible } \\
\text { pump }=225 \mathrm{gpm} \text {. }\end{array}$ \\
\hline Domestic Well & 1 & $5 \mathrm{gpm}$ & $\begin{array}{l}\text { 6" diameter } \mathrm{x} 120 \text { dee } / 1 / 2 \mathrm{HP} \\
\text { submersible pump. Pressure tank in } \\
\text { storage building - PVC underground piping } \\
\text { to buildings and spawning shed. }\end{array}$ \\
\hline $\begin{array}{l}\text { Aeration Head } \\
\text { Box }\end{array}$ & 1 & $2^{\prime} \times 4^{\prime}$ & $\begin{array}{l}\text { Plywood construction/compartments for } \\
\text { water aeration through one packed } \\
\text { column } \\
\text { aerator unit. }\end{array}$ \\
\hline \multicolumn{4}{|c|}{ Fish Production Facilities - On-Station } \\
\hline Raceways & 7 & $83^{\prime} \times 8^{\prime}$ & $\begin{array}{l}2,000 \mathrm{ft}^{3} \text { water each. Prefab steel with } \\
\text { plastic sheet lining. }\end{array}$ \\
\hline $\begin{array}{l}\text { Com b. Rearing } \\
\text { Holding Pond }\end{array}$ & 1 & $96^{\prime} \times 48^{\prime}$ & $\begin{array}{l}10,880 \mathrm{ft} 3 \text { water }-3-1 / 2 \text { average pond } \\
\text { water depth. Dirt sides \& bottom } / 3: 1 \\
\text { bank slopes. Pen fencing utilized for } \\
\text { adult holding separation. }\end{array}$ \\
\hline Hatching Tanks & 16 & $16^{\prime} \times 18^{\prime \prime}$ & $\begin{array}{l}16 \text { deep tanks for egg incubation \& } 1 \\
\text { shallow tank for egg picking. }\end{array}$ \\
\hline Adult Fish Barrier & 1 & $40 \operatorname{lin} \mathrm{ft}$ & $\begin{array}{l}\text { Electric fence barrier weir }-110 \text { volt. } \\
\text { Annual installation. }\end{array}$ \\
\hline Fishway & 1 & 6' lift & $\begin{array}{l}\text { Plywood constr/4'W } \times 4^{\prime} \mathrm{H} \times 4^{\prime} \mathrm{L} / \mathrm{six} 8^{\prime} \\
\text { pools with canvas fencing on sides of } \\
\text { fishway for fish containment. }\end{array}$ \\
\hline $\begin{array}{l}\text { Pollution Control } \\
\text { Pond }\end{array}$ & 1 & $80^{\prime} \times 25^{\prime}$ & $\begin{array}{l}3,000 \mathrm{ft}^{3} \text { water/l hr detention time } \\
\text { for pond cleaning wastes by vacuum } \\
\text { system. Dirt sides and bottom } / 3: \text { I bank } \\
\text { slopes. } 31 / 2^{\prime} \text { average pond bottom } \\
\text { water depth. }\end{array}$ \\
\hline
\end{tabular}


Chapter 9

\begin{tabular}{|c|c|c|c|}
\hline Facilities & Na. & Size & Description \\
\hline \multicolumn{4}{|c|}{ Buildings - On-Station } \\
\hline Hatchery & 1 & $32^{\prime} \times 24^{\prime}$ & $\begin{array}{l}\text { Metal bldg with tank, office, crew locker, } \\
\text { toilet, and mechanical rooms. }\end{array}$ \\
\hline Storage & 1 & $60^{\prime} \times 24^{\prime}$ & $\begin{array}{l}\text { Metal building with gravel floor, five } 12 \text { ' } \\
\text { bays for equipment and supply storage, } \\
\text { domestic water pressure tank, and diesel } \\
\text { generator housing. }\end{array}$ \\
\hline Cold Storage & 1 & $24^{\prime} \times 24^{\prime}$ & $\begin{array}{l}\text { Prefab } 18^{\prime} \times 24^{\prime} \text { freon cold storage } \\
\text { unit } / 34,500 \text { lb capacity with a } 6^{\prime} \times 24^{\prime} \text { add } \\
\text { on for food handling and thawing. OMP } \\
\text { feed deliveries } 3 \times \text { per year. }\end{array}$ \\
\hline Spawning Shed & 1 & $10^{\prime} \times 10^{\prime}$ & $\begin{array}{l}\text { Open sides and ends with roof for } \\
\text { spawning at head end of holding pond. }\end{array}$ \\
\hline Residence & 1 & $46^{\prime} \times 24^{\prime}$ & $\begin{array}{l}3 \text { BR wood frame prefab unit/attached } \\
\text { garage. (residence would be marketable } \\
\text { if facility closed). }\end{array}$ \\
\hline
\end{tabular}

Equipment

\begin{tabular}{ll}
\hline General List & 1 pick-up, nets, pumps, misc. tools' \\
& cleaning equip., \&s small ffish-tank \\
& $(\$ 32,000)$ \\
\hline
\end{tabular}

Site Development - Of f-Station Stream (Railroad Cr.)

\begin{tabular}{|c|c|c|}
\hline $\begin{array}{l}\text { Clearing } \\
\& \text { Grubbing }\end{array}$ & $21 / 2$ Acres & $\begin{array}{l}\text { Clearing \& grubbing of pond site } \\
\text { operations and entrance road \& pipeline } \\
\text { R/Ws. }\end{array}$ \\
\hline Entrance Road & $1,000 \operatorname{lin} \mathrm{ft}$ & $\begin{array}{l}12 \text { ' wide, } 8 \text { " pit run base over ave. } 12 \text { ' fill } \\
\text { ht. }\end{array}$ \\
\hline On Site Road & $2,000 y^{2}{ }^{2}$ & 8" base \& 2" crushed rock topping. \\
\hline
\end{tabular}

Water Supply \& Drains - Off-Station Stream (Railroad Cr.)

\begin{tabular}{|c|c|c|c|}
\hline Stream Intake & I & $10^{\prime} \times 4^{\prime}$ & $\begin{array}{l}\text { Coarse \& fine screen reinf. concrete with } \\
\text { stop log water control. }\end{array}$ \\
\hline Stream Rock Check & 1 & $10 \mathrm{yd}^{3}$ & Heavy rock rip $\operatorname{rap}\left(15^{\prime} \times 6^{\prime} \times 3^{\prime}\right)$ \\
\hline Supply Lines & & & 12" dia and larger - CMP, under 12" PVC. \\
\hline Drain Ditch & 200 & $\operatorname{lin} \mathrm{ft}$ & $\begin{array}{l}\text { Unlined canal } / 3^{\prime} \text {, bottom width and } 21 / 2: 1 \\
\text { side slopes } \times 3 \text { ' deep. Grade of } 0.03 \% \\
\text { max }\end{array}$ \\
\hline Domestic Well & 1 & $5 \mathrm{gpm}$ & $\begin{array}{l}\text { 6" dia. } 120^{\prime} \text { deep with } 1 / 2 \mathrm{HP} \text { submersible } \\
\text { pump. Press. tank with wood frame house } \\
\text { - PVC underground piping to storage } \\
\text { bldg. and trailer pad. }\end{array}$ \\
\hline
\end{tabular}


Theoretical Hatcheries

\begin{tabular}{lcccc}
\hline Facilities & No. & Size & Description \\
\hline & Fish Production Facilities & - Off-Station Stream (Railroad Creek) & \\
\hline Pond & 1 & $\mathbf{1 0 6}^{\prime} \times 52^{\prime}$ & $\begin{array}{l}14,000 \mathrm{ft}^{3} \text { water. Dirt sides and } \\
\text { bottom/3:1 bank slopes. 3 1/2' average } \\
\text { pond water depth. }\end{array}$ \\
\hline
\end{tabular}

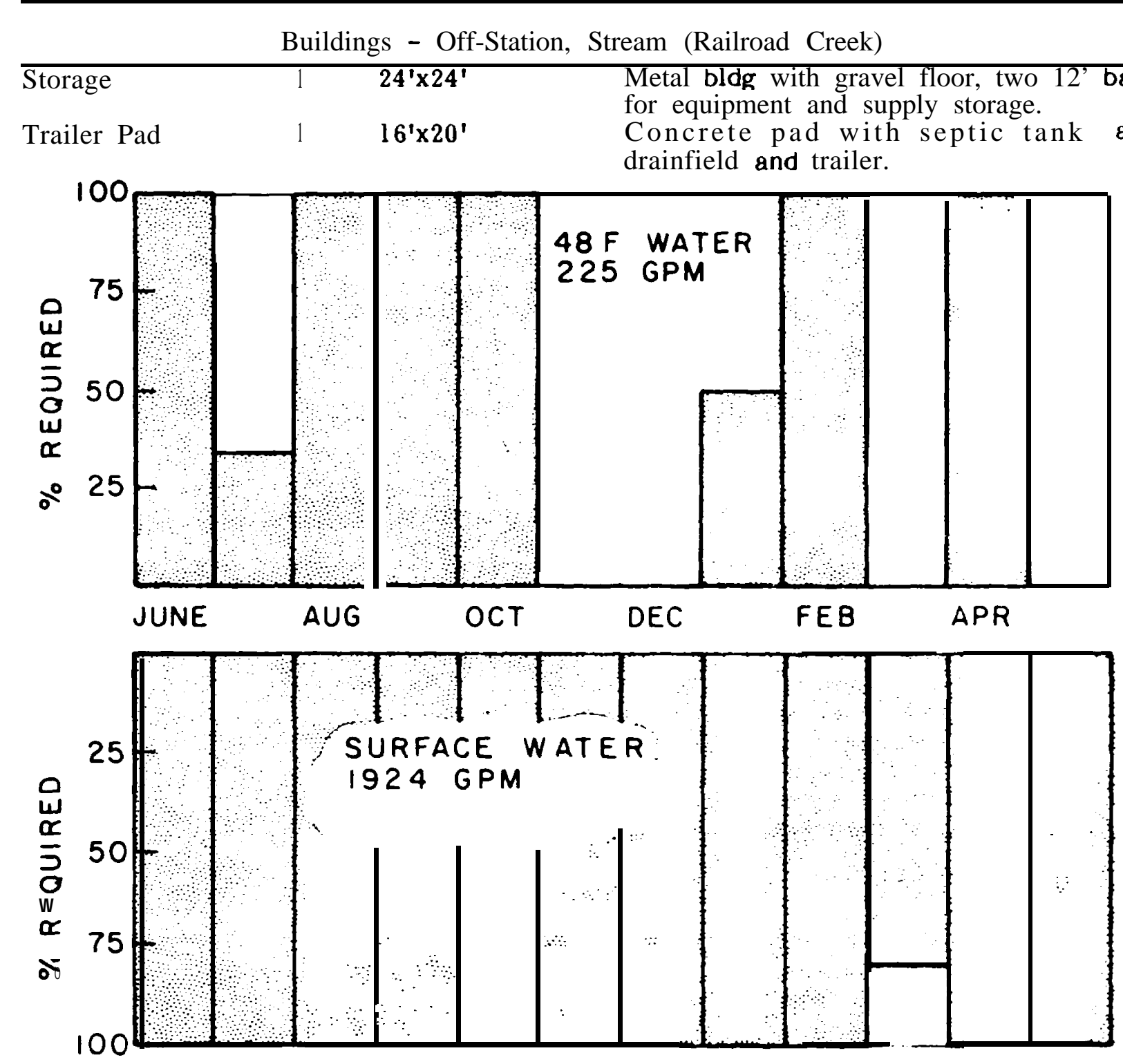

Figure 34. Water-use strategies for coho Salmon llatci; 2 ivo. 2 - M-stitlw. 


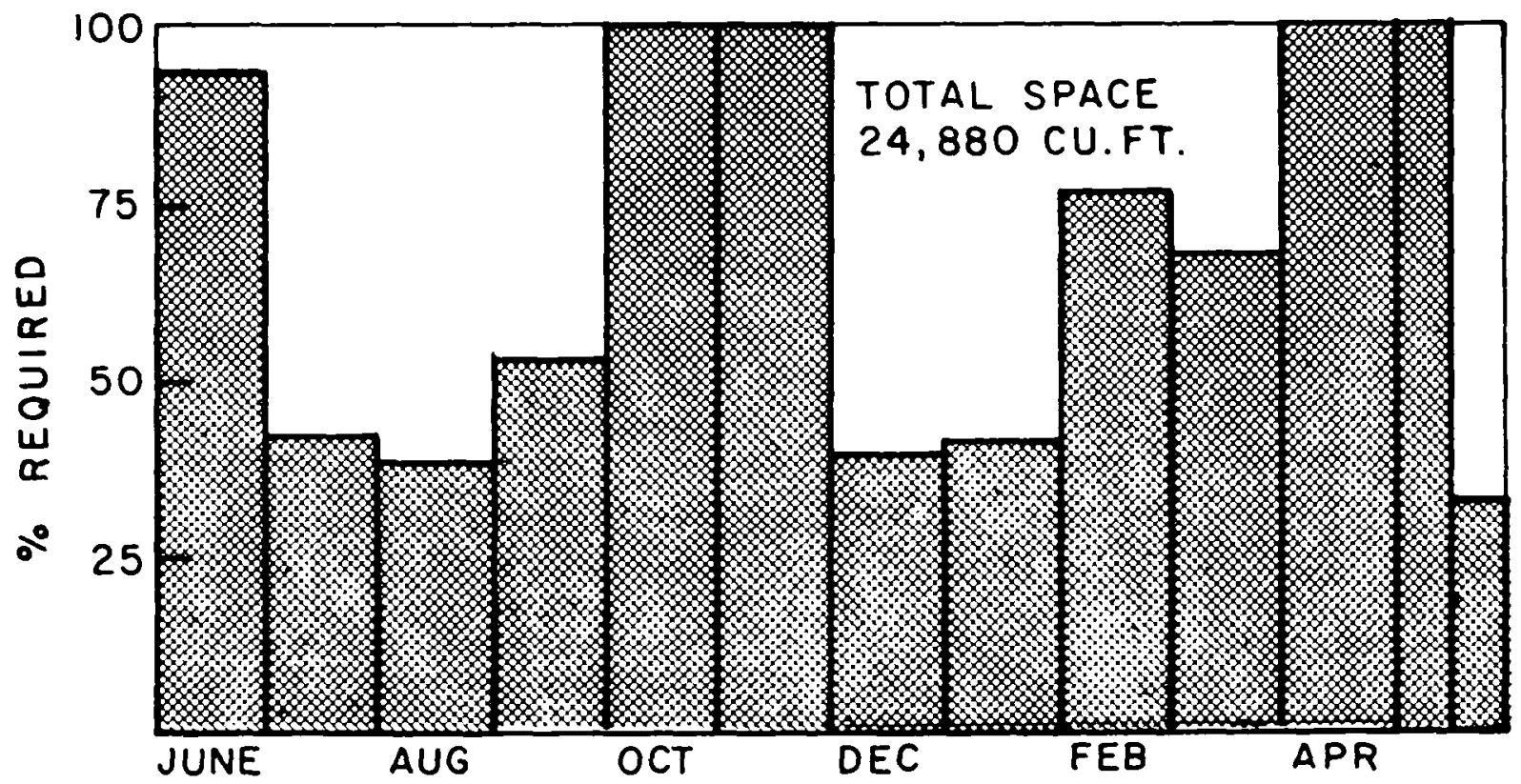

Figure 35. Space-use requirements for Coho Salmon Hatchery No. 2 - on-station.

Table 53. Facility development capital costs for Coho Salmon Hatchery No. 2.

Site $\frac{\text { Facility }}{\text { development }}$

Water supply and drains

Fish production facilities

Buildings

Equipment

$$
\begin{array}{r}
\text { Estimated cost } \\
\hline \$ 146,400.00 \\
\cdot 212,600.00 \\
201,400.00 \\
216,600.00 \\
32,000.00 \\
\$ 809,000.00
\end{array}
$$

\begin{tabular}{|c|c|c|}
\hline \multicolumn{2}{|l|}{$\underline{\text { Item }}$} & Estimated \\
\hline \multicolumn{2}{|c|}{ Food $=$} & \\
\hline \multicolumn{2}{|c|}{$\begin{array}{l}\text { for smolts @ } \$ 0.40 / 1 b \\
\text { conversion } 2.0: 1\end{array}$} & $\$ 27,000$ \\
\hline \multicolumn{2}{|c|}{$\begin{array}{l}\text { for fingerlings } @ . \$ 45 / 1 b \\
\text { conversion 1.5: } 1\end{array}$} & 7,500 \\
\hline \multicolumn{3}{|c|}{ Manpower $(\mathrm{O} \& \mathrm{M})$} \\
\hline \multirow{2}{*}{$\begin{array}{l}\text { Superintendent } 2 \\
\text { Culturist } \\
\text { st andby }\end{array}$} & 12 man months & 24,000 \\
\hline & 15 man months & $\begin{array}{r}22,500 \\
2,400 \\
\end{array}$ \\
\hline & Subt ot al & $\$ \overline{83,400}$ \\
\hline \multicolumn{2}{|c|}{$\begin{array}{c}\text { Misc. }(10 \% \text { all other costs }-0 \& \mathbf{M}) \\
\text { Subtotal }\end{array}$} & $\frac{\mathbf{8 , 3 4 0}}{\$ 91,740}$ \\
\hline \multicolumn{2}{|c|}{$\begin{array}{l}\text { Electrical power } \\
\text { general use } \\
\text { water delivery (1.5 If P, } \mathbf{5} \text { mont hs) } \\
\quad \text { Total }\end{array}$} & $\begin{array}{r}\mathbf{2 , 7 5 0} \\
\quad \mathbf{1 7 3} \\
94,663\end{array}$ \\
\hline
\end{tabular}

Table 54. Estimated annual operational costs and labor requirements for Coho Salmon Hatchery No. 2 with on-station and off-station production. 
Theoretical Hatcheries

\section{E. THEORETICAL STEELHEAD TROUT HATCHERIES}

To illustrate that salmon and steelhead trout rearing programs are feasible using numerous types of facilities, we show some of these here. It is recognized that where fish, as steelhead, are to be handled numerous times, pond-type is more critical. The units illustrated were observed in use during our facility review process.

\section{Steelhead Trout Hatchery No. 1}

Goals:

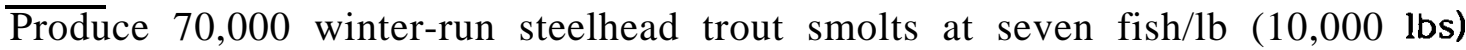
for annual on-station releases between April 15 and May 10.

Summary of Biological Requirements:

Production (no./size)

Fertilized eggs (no. spawned)

Females to spawn (no.)

Adults held at one time (no.)

Recommended minimum water (gpm) ground and/or spring surface

Recommended minimum pond space on-station

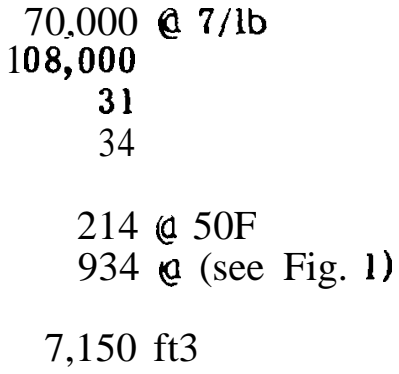

$7,150 \mathrm{ft} 3$

Facilities Development:

Table 55 lists the facilities and the associated requirements of steelnead 1 rout Hatchery No. 1, and Fig. 36 illustrates the physical plan for the hatchery.

Operational Strategies:

Water and space requirements as related to the percentage of the total biological requirements by time are shown in Figs. 37 and 38 respectively. Brief comments follow on each life phase of husbandry.

(1) Adults All adults will be placed in the appropriate size acrulic tubes and held in $50 \mathrm{ft}^{3}$ Capilano troughs located inside the hatchery building. Up to 15 fish per trough will be held. To accelerate maturation, lights and hormone injection will be used, especially on late spawners. Water shall de from the $50 \mathrm{H}$ gravity source and will not be re-used for reuring. Minimum labor for Security is programmed as all fish will be held inside a locked building.

(2) Incubation In consideration of IHN disease, the eggs from each fenıale will be isolated by using l-gallon jug incubators, a minimum of 27. Assuming no $111 \mathrm{~N}$ virus is detected prior to hatching, the eggs for alevin incubation will be placed in $11 \mathrm{j}$-gallon bucket incubators with substrate (see Chapter 4). Fry for rearing will be collected in Capilano troughs as they leave the incubators.

The water supply will be obtained from the $50 \mathrm{~F}$ gravity source und supplied separately to each incubation unit. 
Chapter 9

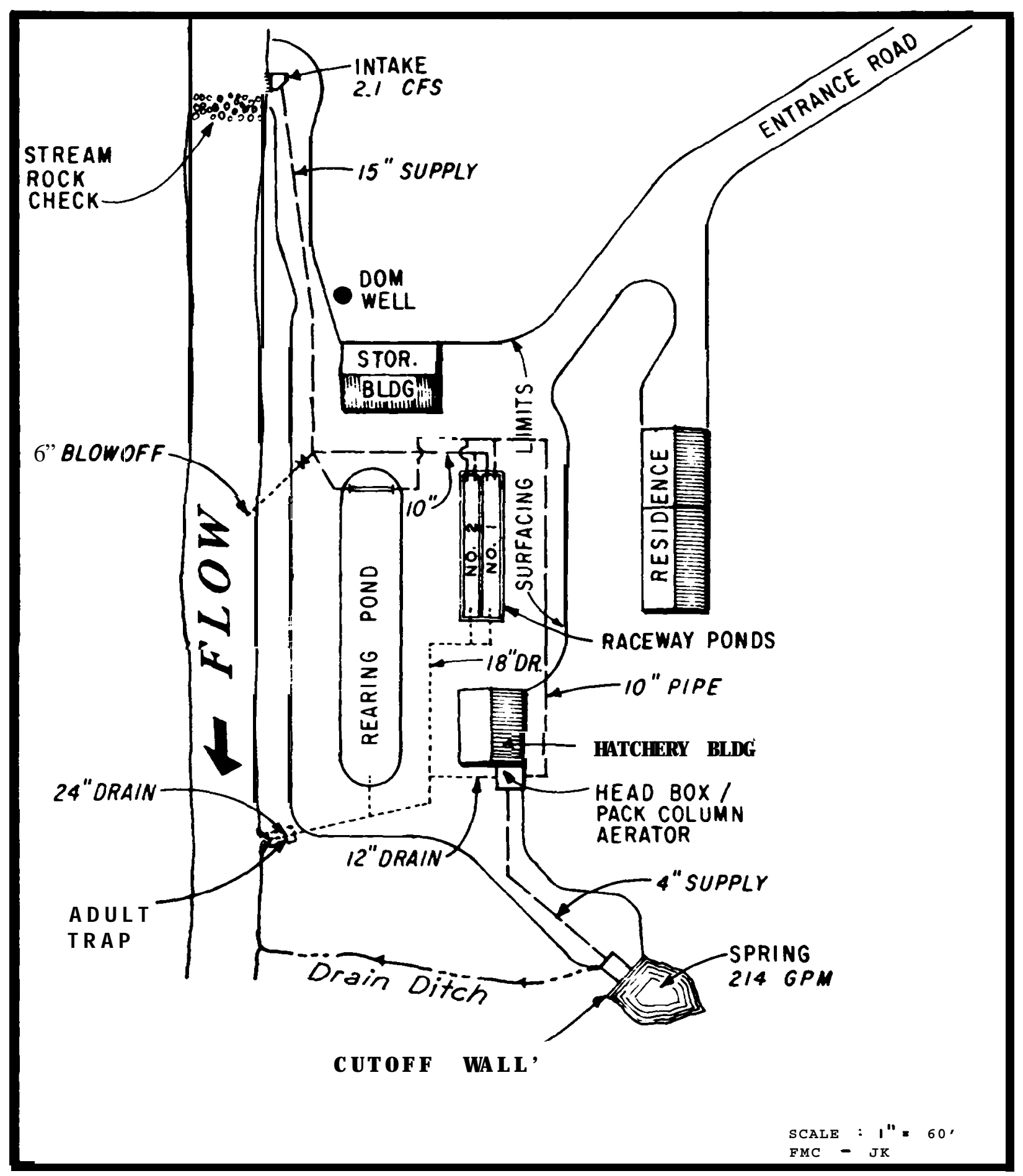

Figure 36. Schematic of Steelhead Trout Hatchery No. 1. 
Theoretical Hatcheries
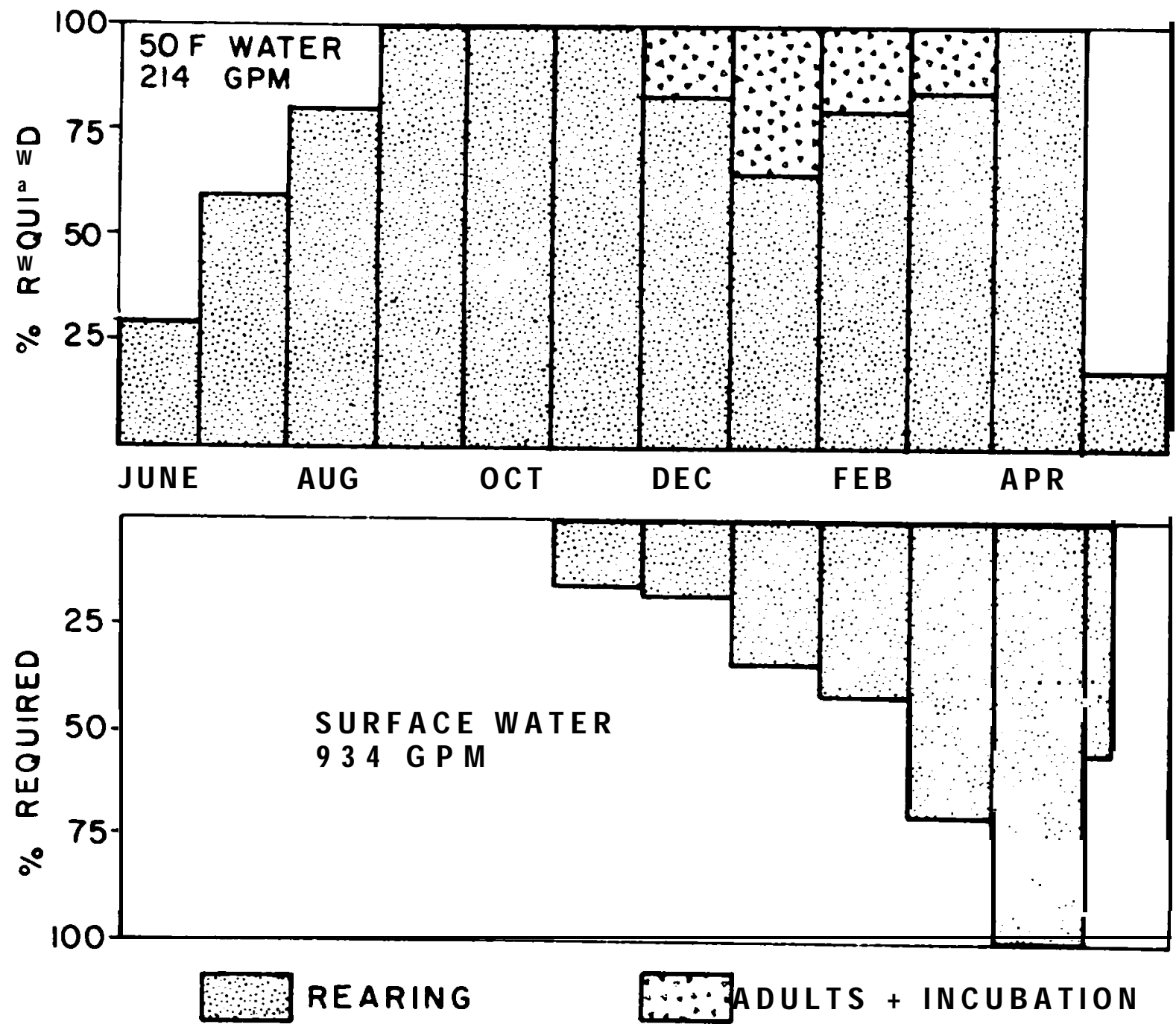

Figure 37. Water-use strategies for Steelhead Trout Hatchery No. 1.

(3) Rearing The 97,000 fry that survive the incubation of 108,000 fertilized eggs will receive their first 3 to 4 weeks of feeding within the three Capilano troughs, sectioned as required. When they reach about twice their original size by weight, or about $1,400 \mathrm{fish} / \mathrm{lb}$, they will be transferred into the two $6^{\prime} \times 60^{\prime} \times 3.0^{\prime}$ ponds, again sectioned as necessary with the older fry positionea downstream.

Grading or sizing of the steelhead trout fingerlings will be required about three times. All fish will eventually be joined into one population in the $5,000 \mathrm{ft}^{3}$ pond prior to release. We anticipated the final transfer to occur in March.

The gravity spring water at $\mathbf{5 0 F}$ will be used for trough rearing. On Way 1 , with 94,000 fry $1,400 / 1 b$ on hand, these will have a water demand of $30-40$ 


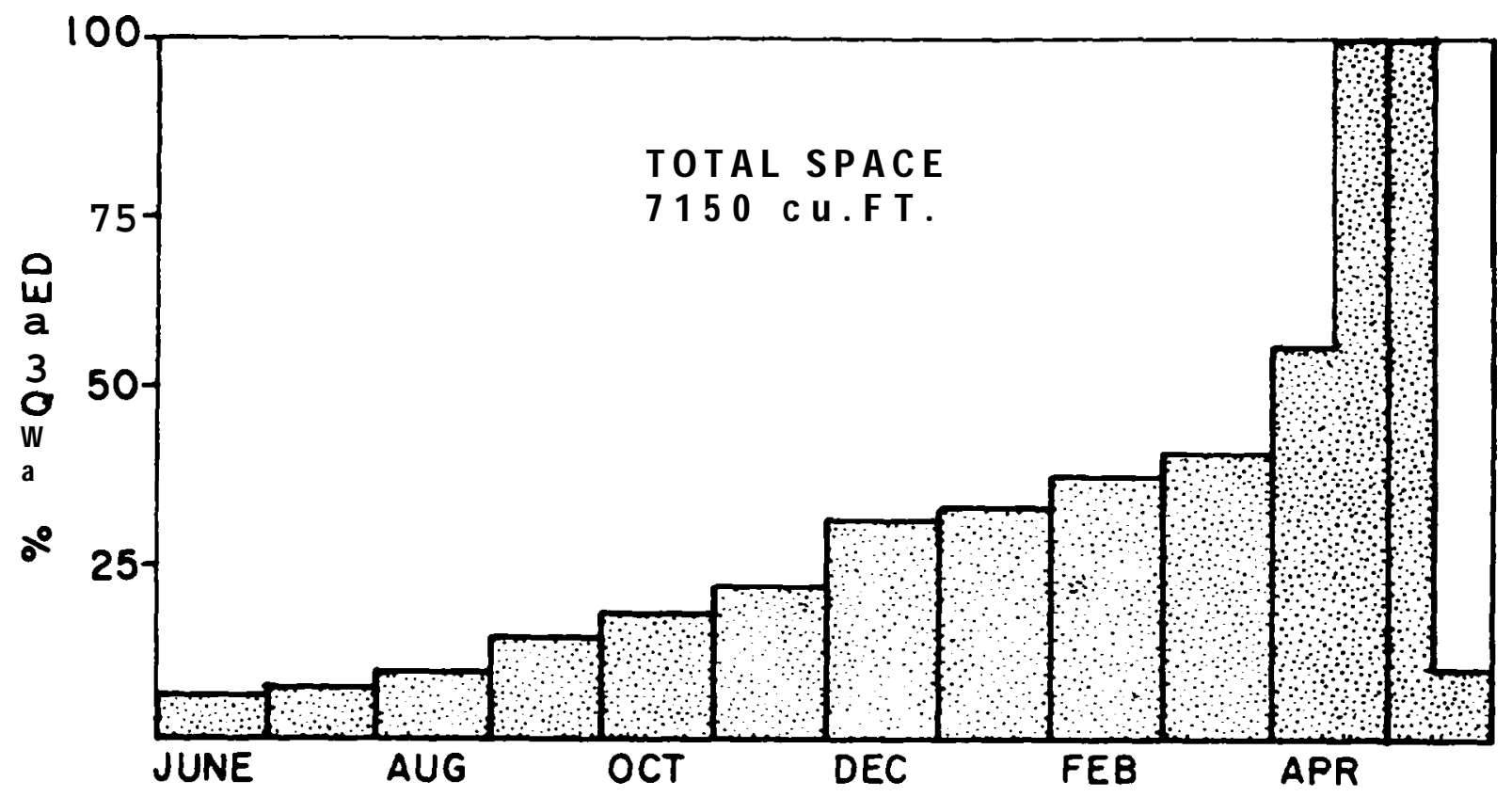

Figure 38. Space-use requirements for Steelhead Trout Hatchery $\mathrm{Na} 1$.

gpm and the smolts will require 1,111 gpm. Because of the small amount of water used for the adults, incubation, and fry rearing, none of the water is programmed to be used a second time for the large fingerling fish. The option could be made available, however, with minimal cost.

In summary, the 50F water will be used for adult holding, incubation, early rearing, to cool surface water during the summer, and during the winter to advance the smallest fish and prevent the icing of ponds The surface water will be used during a shortage of $50 \mathrm{~F}$ spring water, or when temperatures are appropriate for its use. It will be used to acclimatize fish during the winter and spring for late April and early May sınolt releases.

(4)

Releases Screens in the pond where smolts are being reared will be removed April 15 to allow a natural out-migration. On May 10, all fish will be drained into the river. As an option to the final release, we would evaluate the "smolt" population remaining and determine if a high percentage of the fish are nonsmolts. If so, and depending on their size, the use of these fish for a resident trout fishery would be proposed.

\section{Costs}

Table 56 shows the estimated capital costs for Steelhead Trout Hatchery No. 1, and Table 57 shows the estimated annual operational costs and manpower requirements. 
Theoretical Hatcheries

Table 55. Facility development for Steelhead Trout Hatchery No. 1 (10,000 lbs, onstation releases).

\begin{tabular}{|c|c|c|c|}
\hline Facilities & Na. & Size & Description \\
\hline \multicolumn{4}{|c|}{ Site Development } \\
\hline $\begin{array}{l}\text { Clearing } \\
\text { \& Grubbing }\end{array}$ & 3 & Acres & $\begin{array}{l}\text { Clearing \& grubbing of hatchery site, } \\
\text { entrance road' } \& \text { pipeline } R / W \text { s. }\end{array}$ \\
\hline Entrance Road & $1 / 2$ & Mile & $\begin{array}{l}\text { 16' wide, 8' pit run base over ave. 2' fill } \\
\text { ht. Turnouts a 500' intervals. }\end{array}$ \\
\hline $\begin{array}{l}\text { On Site Road } \\
\text { \& Drives }\end{array}$ & 2,500 & $y d^{2}$ & $8 "$ base \& $2 "$ crushed rock topping. \\
\hline \multicolumn{4}{|c|}{ Water Supply \& Drains } \\
\hline Stream Intake & T & $10^{\prime} \times 4{ }^{\prime}$ & $\begin{array}{l}\text { Coarse \& fine screen, reinforced concrete } \\
\text { with stop log water control. }\end{array}$ \\
\hline $\begin{array}{l}\text { Stream Rock Check } \\
\text { Supply Lines }\end{array}$ & 1 & $20 \mathrm{yd}^{3}$ & $\begin{array}{l}\text { Heavy rock rip rap }\left(30^{\prime} \times 6^{\prime} \times 3^{\prime}\right) \\
12^{\prime \prime} \text { diameter \& larger }-\mathrm{CMP} \text {, under } 12^{\prime \prime} \\
\text { PVC }\end{array}$ \\
\hline Drain Lines & & & $\begin{array}{l}12 " \text { diameter \& larger - CMP, under } 12 " \text { - } \\
\text { PVC }\end{array}$ \\
\hline Spring Intake & 1 & 16 ' long & $\begin{array}{l}\text { Concrete cut-off wall x } 5^{\prime} \mathrm{H} \text { with } 2^{\prime} \mathrm{x} \mathbf{4}^{\prime} \\
\text { concrete screened intake box }-214 \mathrm{gpm} .\end{array}$ \\
\hline Domestic Well & 1 & $5 \mathrm{gpm}$ & $\begin{array}{l}\text { 6" dia. } \times 120 \text { deep/l/2 HP submersible } \\
\text { pump. Pressure tank in storage building } \\
\text { PVC underground piping to buildings. }\end{array}$ \\
\hline $\begin{array}{l}\text { Aeration Head } \\
\text { Box }\end{array}$ & 1 & $2^{\prime} \times 4^{\prime}$ & $\begin{array}{l}\text { Plywood construction/compartments for } \\
\text { water aeration through one packed } \\
\text { column aerator unit. }\end{array}$ \\
\hline \multicolumn{4}{|c|}{ Fish Production Facilities } \\
\hline Raceways & 2 & $60^{\prime} \times 6$ & $\begin{array}{l}1,000 \mathrm{ft}^{3} \text { water each }-2.75 \text { average pond } \\
\text { water depth. Prefab steel/plastic sheet } \\
\text { lining. }\end{array}$ \\
\hline Pond & 1 & $124^{\prime} \times 22^{\prime}$ & $\begin{array}{l}5,000 \mathrm{ft}^{3} \text { water }-3 \text { average pond water } \\
\text { depth. Dirt sides \& bottom/2-1/2:1 bank } \\
\text { slopes }\end{array}$ \\
\hline Hatching Jars & 41 & Units & 27 l-gallon \& 14 5-gallon jars, \\
\hline Egg Picking Tank & 1 & $12^{\prime} \times 18^{\prime}$ & Shallow tank for egg picking. \\
\hline Capilano Tanks & 3 & Units & $50 \mathrm{ft}^{3}$ water each - housed in building \\
\hline Adult Trap & 1 & $100 \mathrm{ft}^{3}$ & $\begin{array}{l}\text { fank room. } \\
\text { psi ream and downstream broom handle } \\
\text { picket rack with V-trap entrance weir. }\end{array}$ \\
\hline
\end{tabular}


Chapter 9

\begin{tabular}{|c|c|c|c|}
\hline Facilities & No. & Size & Description \\
\hline \multicolumn{4}{|c|}{ Buildings } \\
\hline hatchery & $T$ & $30^{\prime} \times 24^{1}$ & $\begin{array}{l}\text { Metal bldg with tank, office, crew locker, } \\
\text { toilet, and mechanical rooms. } 36 \mathrm{ft}^{3} \\
\text { freezer in tank room for OMP starter } \\
\text { feed. }\end{array}$ \\
\hline Storage & 1 & $36^{\prime} \times 24^{\prime}$ & $\begin{array}{l}\text { Metal bldg with gravel floors, three } 12 \text { ' } \\
\text { bays for equipment and supply storage, } \\
\text { domestic water pressure tank housing and } \\
8,000 \text { lbs of dry fish feed storage and } \\
\mathbf{3 6 \mathbf { f t } ^ { 3 }} \text { chest freezer. }\end{array}$ \\
\hline Residence & 1 & $46^{\prime} \times 24^{\prime}$ & $\begin{array}{l}3 \text { BR wood frame prefab unit/attached } \\
\text { garage. (residence would be marketable } \\
\text { if facility closed). }\end{array}$ \\
\hline
\end{tabular}

Equipment

\begin{tabular}{lll}
\hline General List & $\begin{array}{l}1 \text { pick-up, nets, pumps’ misc. tools \& } \\
\text { cleaning equip. }(\$ 24,000)\end{array}$
\end{tabular}

Table 56. Facility development costs for Steelhead Trout Hatchery. No. 1.

\begin{tabular}{|c|c|}
\hline Facility & Estimated cost \\
\hline Site development & $\$ 72,000.00$ \\
\hline Water supply and drains & $89,200.00$ \\
\hline Fish production facilities & $35,500.00$ \\
\hline Buildings & $.140,000.00$ \\
\hline Equipment & $\frac{24,000.00}{\$ 360,700.00}$ \\
\hline
\end{tabular}

Table 57. Estimated annual operational. costs and labor requirements for Steelhead Trout Hatchery. No. 1. Item

\section{(a $\$ 0.40 / 1 b$}

conversion 2.0:1

Manpower (O \& $M$ )

Superintendent 1

Culturist

12 man months

Estimated cost standby

4 man months

21,600

6,000

standby

Subtotal

$\frac{2,160}{37,760}$

Misc. (10\% all other costs - 0 \& $\mathbf{M}$ )

Subtotal

$\frac{3,776}{41,536}$

Electrical power

$$
\text { general use }
$$
water delivery

1,200
Total $\quad \$ \frac{0}{2,736}$


Theoretical Hatcheries

2. $\quad$ Steelhead Trout Hatchery No. 2

Goals:

Produce 140,000 winter-run steelhead trout smolts at seven fish/lb $(20,000 \mathrm{lbs})$ for annual on-station releases between April 15 and May 10.

Summary of Biological Requirements:

Production (no./size)

Fertilized eggs (no. spawned)

Females to spawn (no.)

Adults held at one time (no.)

Recommended minimum water (gpm) ground and/or spring surface

Recommended minimum pond space

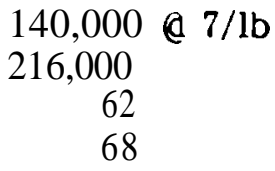

$428 @ \mathbf{5 0 F}$

1,868 @ (see Fig. 1)

$14,300 \mathrm{ft} 3$

Facilities Development:

Table 58 lists the facilities and the associated requirements of Steelinead Trout Hatchery No. 2, Fig. 39 illustrates the physical plan for the hatchery.

Operational Strategies:

Water and space requirements are directly proportional as for the Steelhead Trout Hatchery No. 1. Also, procedures for fish husbandry will be followed according to Steelhead Trout Hatchery No. 1. It snould be noted that this station does not have a spring-water supply but relies on is deep well as a source of $50 \mathrm{~F}$ water. In addition, we have chosen to illustrate the use of four circular swimming pools for rearing. We consider these an option for small low-cost rearing units.

\section{Costs}

Table 59 shows the estimated capitol costs for Steelhead Trout Hatchery v.n. 2, and Table 60 shows the estimated annual operational costs and inanpower requirements.

Table 58. Facility development for Steelhead Trout Hatchery No. 2 (20,000 Ibs, on-station releases).

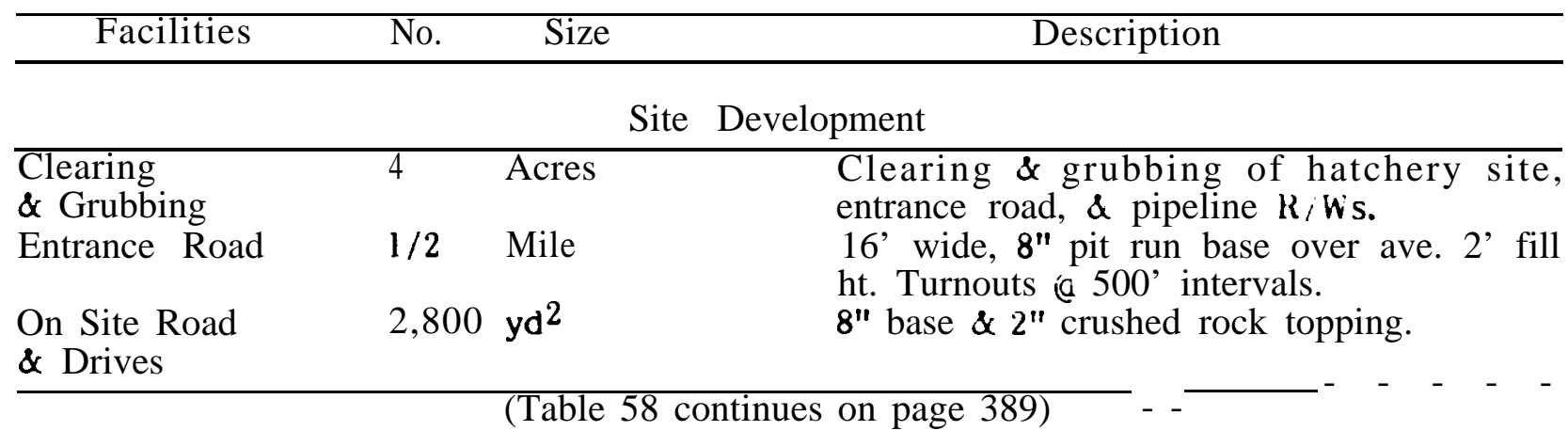




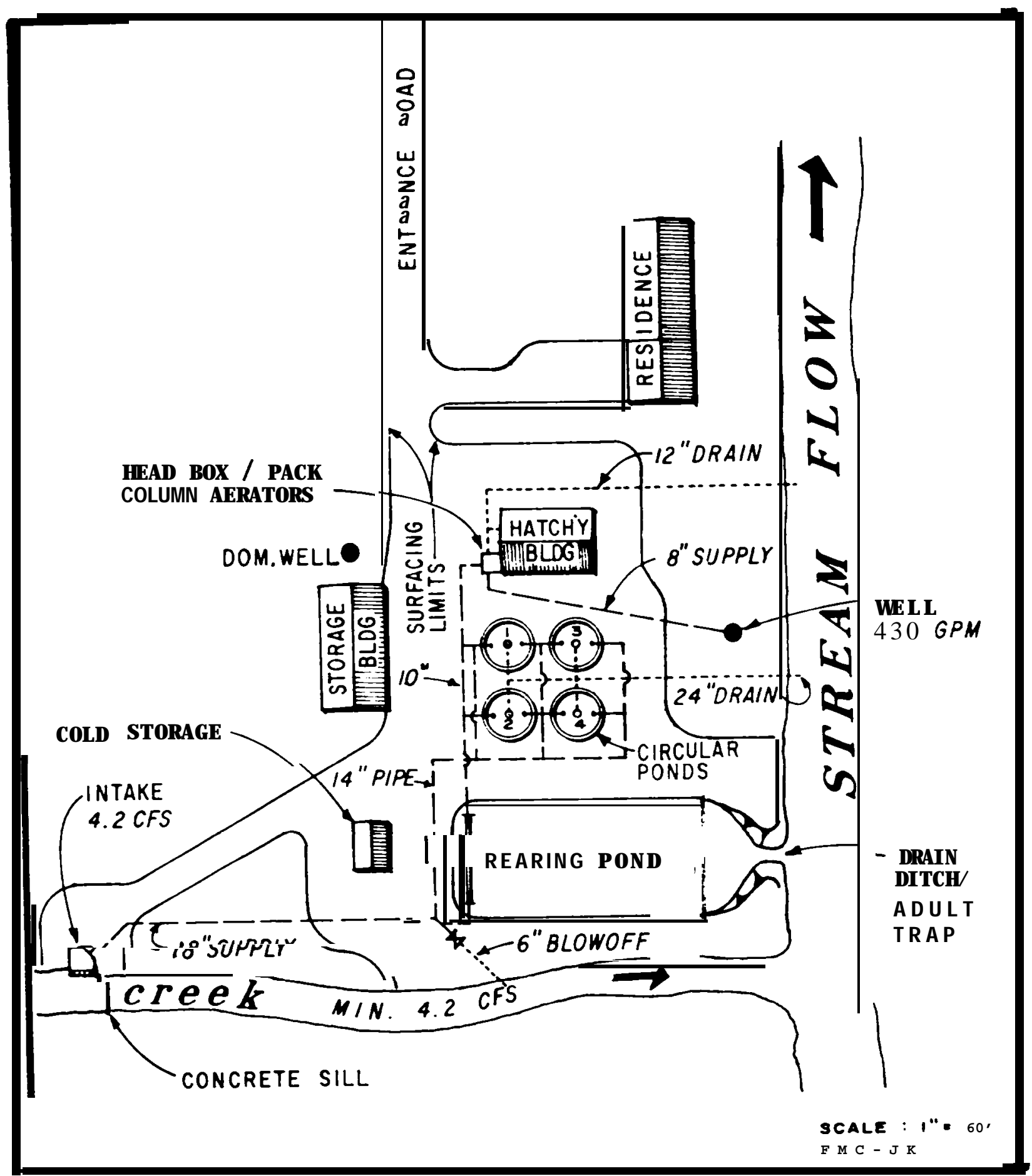

Figure 39. Schematics of Steelhead Trout Hatchery No. 2. 
Theoretical Hatcheries

(Continued from page 387)

\begin{tabular}{|c|c|c|c|}
\hline Facilities & No. & Size & Description \\
\hline \multicolumn{4}{|c|}{ Water Supply \& Drains } \\
\hline Stream I nt ake & 1 & $10^{\prime} \times 4^{\prime}$ & $\begin{array}{l}\text { Coarse \& fine screen, reinforced concrete } \\
\text { with stop log water control. }\end{array}$ \\
\hline Stream Sill Check & 1 & $12 \operatorname{lin} \mathrm{ft}$ & $\begin{array}{l}\text { Concrete sill with } 3^{\prime} \text { cut-off depth } \times 5^{\prime} \\
\text { total ht. } \times 8^{\prime \prime} \text { thick. }\end{array}$ \\
\hline Supply Lines & & & $\begin{array}{l}\text { 12" diameter \& larger - CMP, under } 12 " \text { - } \\
\text { PVC }\end{array}$ \\
\hline Drain Lines & & & $\begin{array}{l}\text { 12" diameter \& larger - CMP, under } 12 " \text { - } \\
\text { PVC }\end{array}$ \\
\hline Drain Ditch & 100 & $\operatorname{lin} \mathrm{ft}$ & $\begin{array}{l}\text { Unlined canal } / 3^{\prime} \text { bottom width and } 2-1 / 2: 1 \\
\text { side slopes } \times 3 \text { ' deep - Grade } 0.0003 / \text {. }\end{array}$ \\
\hline Product ion Well & 1 & $430 \mathrm{gpm}$ & 2" dia x 200’ deep with 25HP sub. pump. \\
\hline Domestic Well & 1 & $5 \mathrm{gpm}$ & $\begin{array}{l}\text { " dia } \times 120 \text { ' deep/l/2 HP submersible } \\
\text { pump. Pressure tank in storage building } \\
\text { PVC underground piping to buildings. }\end{array}$ \\
\hline Aeration Head Box & 1 & $4^{\prime} \times 4^{\prime}$ & $\begin{array}{l}\text { Plywood construction/compartments or } \\
\text { water aeration through two packed } \\
\text { column aeration units. }\end{array}$ \\
\hline
\end{tabular}

Fish Production Facilities

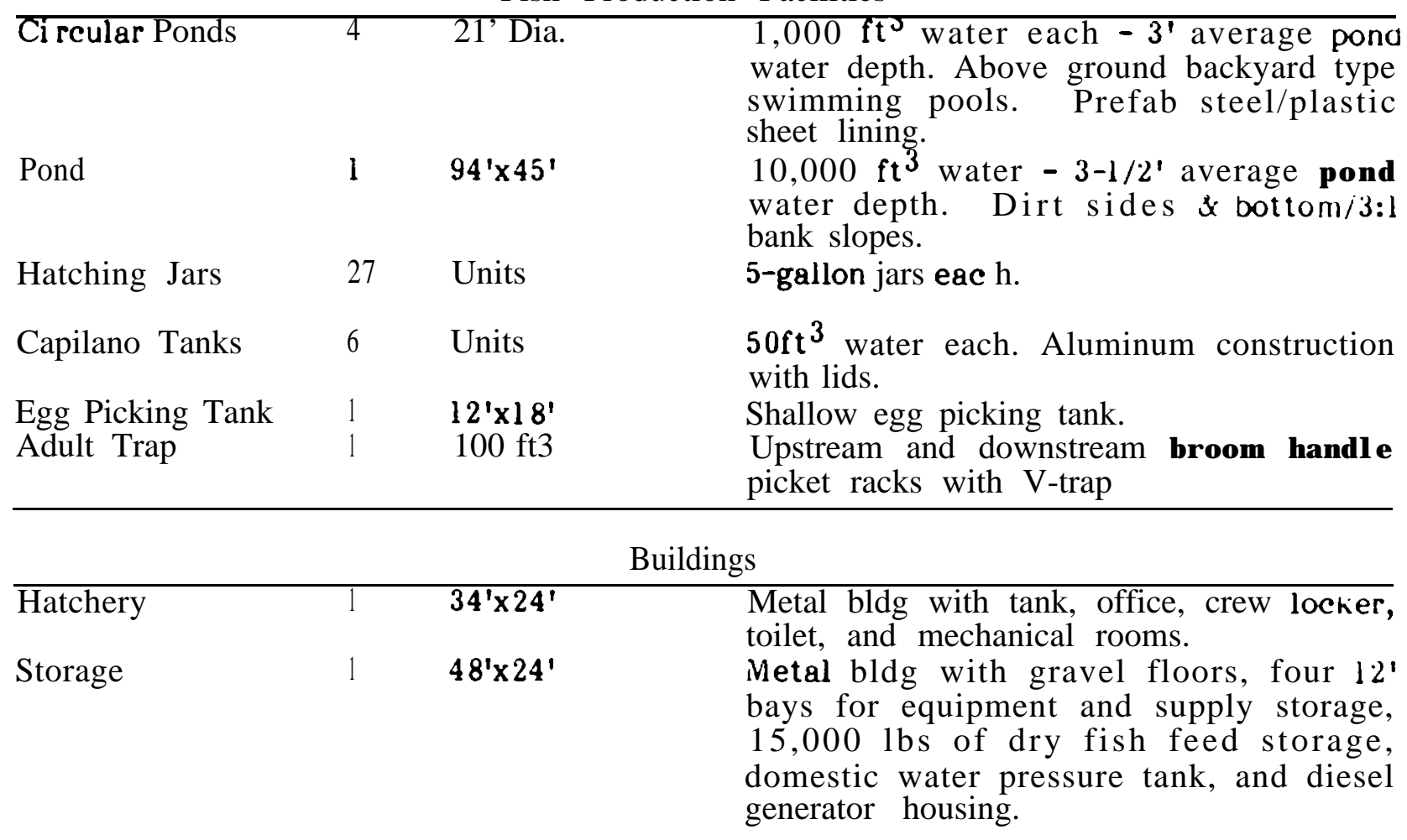


Chapter 9

\begin{tabular}{|c|c|c|c|}
\hline Facilities & No. & Size & Description \\
\hline \multicolumn{4}{|c|}{ Buildings (cont.) } \\
\hline Residence & 1 & $46^{\prime} \times 24^{\prime}$ & $\begin{array}{l}3 \text { BR wood frame prefab unit/attached } \\
\text { garage. (residence would be marketable } \\
\text { if facility closed). }\end{array}$ \\
\hline $\begin{array}{l}\text { Cold Storage } \\
\text { Fish Feed }\end{array}$ & 1 & $18^{\prime} \times 12^{\prime}$ & $\begin{array}{l}\text { Prefab } 12^{\prime} \times 12^{\prime} \text { freon cold storage } \\
\text { unit/10,000 lb capacity, with a } \mathbf{6}^{\prime} \times 12^{\prime} \\
\text { add-on for food handling \& thawing. } \\
\text { OMP feed delivery } 2 \times \text { per year. }\end{array}$ \\
\hline
\end{tabular}

Equipment

General List

1 pick-up, nets, pumps, misc. tools \& cleaning equip. (\$24,000)

Table 59. Facility development capital costs for Steelhead Trout Hatchery No. 2.

Site $\frac{\text { Facility }}{\text { development }}$

Water supply and drains

Fish production facilities

Buildings

Equipment

Total

\begin{tabular}{c} 
Estimated cost \\
\hline$\$ 84,500.00$ \\
$179,300.00$ \\
$30,300.00$ \\
$168,200.00$ \\
$24,000.00$ \\
$\$ 486,300.00$
\end{tabular}

Table 60. Estimated annual operational costs and labor requirements for Steelhead Trout Hatchery No. 2.

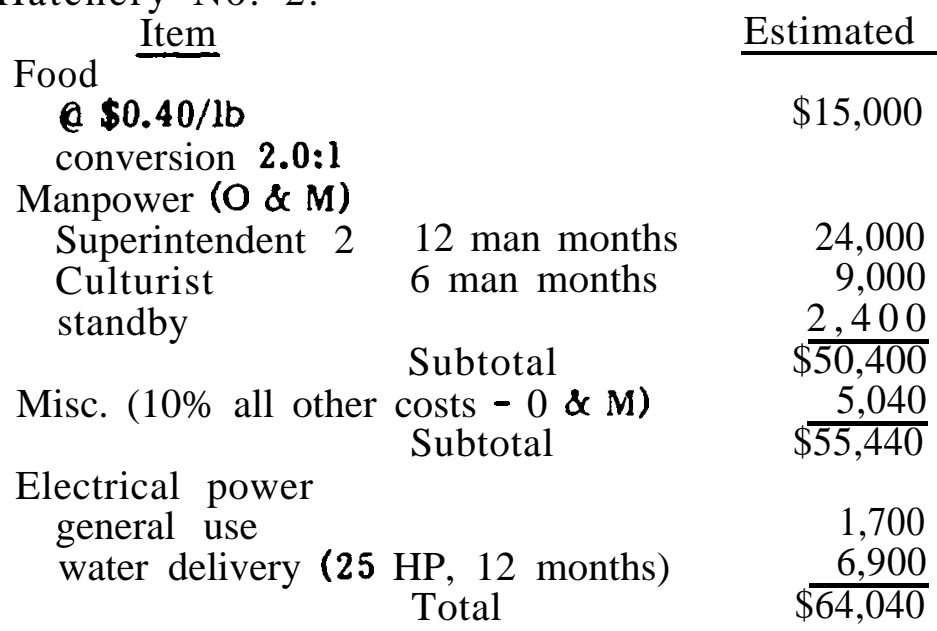

3. Steelhead Trout Hatchery No. 3

Goals:

Produce 350,000 winter-run steelhead trout smolts at seven fish/lb (50,000 lbs) for annual on-station releases between April 15 and May 10. 
Theoretical Hatcheries

Summary of Biological Requirements:

Production (no./size)

Fertilized eggs (no. spawned)

Females to spawn (no.)

Adults held at one time (no.)

Recommended minimum water (gpm) ground and/or spring surface

Recommended minimum pond space

$$
\begin{aligned}
& 4 \text { units @ 2,000 } \mathrm{ft}^{3} \\
& 1 \text { unit @ } 24,400 \mathrm{ft}^{3}
\end{aligned}
$$$$
2 \text { units } 50 \mathrm{ft}^{3}
$$

350,000 ? $7 / 1 \mathrm{~b}$

540,000

155

170

1,070 a $50 \mathrm{~F}$

4,670 (see Fig. 1)

$32,500 \mathrm{ft} 3$

$8,000 \mathrm{ft} 3$

$24,400 \mathrm{ft}^{3}$

$100 \mathrm{ft}^{3}$

Facilities Development:

Table 61 lists the facilities and the associated requirements of Steelhead Trout Hatchery No. 3, Fig. 40 illustrates the physical plan for the hatchery.

Operational Strategies:

Water and space requirements are directly proportional to Steclnead Trout Hatchery No. 1, previously described. Procedures for fish husbandry are also the same with minor deviations. The adult holding program at this hatchery calls for all adult fish to be held in \& $2,000 \mathrm{ft}^{3}$ sectioned raceway, however, when the numbers of fish left to spawn is less than 25, holding in acrylic tubes within Capilano troughs inside the hatchery will be conducted if deemed advantageous.

For the rearing program, two of the $2,000 \mathrm{ft}^{3}$ raceways will be usrd to rear fish until they are 7 fish/lb or smolt size. All four will then bo used for fry and fingerling rearing.

\section{Costs}

Table 62 shows the estimated capital costs for Steclieid Trout Hutchery No. 3, and Table 63 shows the estimated annual operational costs and manpower requirements.

Table 61. Facility development for Steelhead Trout Hatchery No. 3 (50,000 lbs,

\begin{tabular}{|c|c|c|c|}
\hline Facilities & No. & Size & Description \\
\hline \multicolumn{4}{|c|}{ Site Development } \\
\hline $\begin{array}{l}\text { Clearing } \\
\& \text { Grubbing }\end{array}$ & $61 / 2$ & Acres & $\begin{array}{l}\text { Clearing \& grubbing of htitchery site } \\
\text { entrance road, w.s ditch \& pipeline } R, \text { Ws. }\end{array}$ \\
\hline Entrance Road & & H ile & $\begin{array}{l}\text { 16' wide, 8" pit run base uver ave. 2' hill } \\
\text { ht. Turnouts @ } ₫ 00 \text { ' intervals. }\end{array}$ \\
\hline $\begin{array}{l}\text { On Site Road } \\
\& \text { Drives }\end{array}$ & 4,100 & $y d^{2}$ & $8 "$ base \& $2 "$ crushed rock to!pling. \\
\hline
\end{tabular}
onstation releases).

(Table $\mathbf{b} \mathbf{l}$ continues on page 393) 


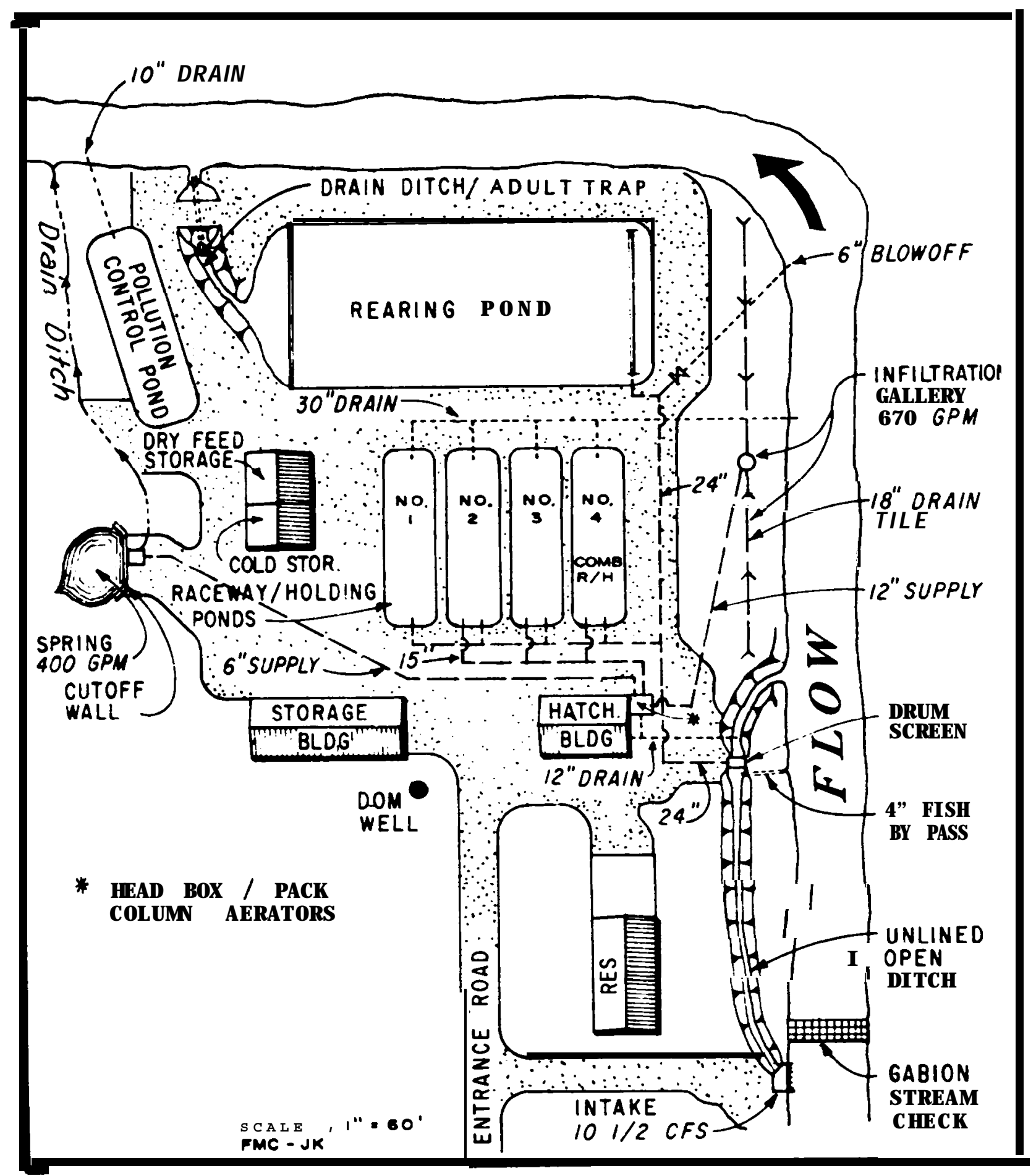

Figure 40. Schematics of Steelhead Trout Hatchery No. 3. 
Theoretical Hatcheries

(Continued from page 39l)

\begin{tabular}{|c|c|c|c|}
\hline Facilities & No. & Size & Description \\
\hline \multicolumn{4}{|c|}{ Water Supply \& Drains } \\
\hline Stream In take & 1 & $18^{\prime} \times 4^{\prime}$ & $\begin{array}{l}\text { Coarse screen reinforced concrete with } \\
\text { stop log water control. }\end{array}$ \\
\hline $\begin{array}{l}\text { Stream Gabion } \\
\text { Check }\end{array}$ & 1 & $20 y^{3}{ }^{3}$ & $\begin{array}{l}\text { Gabion rock-filled wire baskets } \\
\left(30^{\prime} \times 6^{\prime} \times 3^{\prime}\right)\end{array}$ \\
\hline $\begin{array}{l}\text { Water supply \& } \\
\text { Drain Ditches }\end{array}$ & 2 & $1,200 \operatorname{lin} \mathrm{ft}$ & $\begin{array}{l}\text { Unlined canal/3' bottom width \& } 2-1 / 2: 1 \\
\text { side slopes } \times 3 \text {, deep. Grade of } 0.03 \%\end{array}$ \\
\hline & & & max. \\
\hline Rotary Drum Screen & 1 & 3' diax6'L & $\begin{array}{l}\text { Electric power - fine screen/fish bypass } \\
\text { pipe. }\end{array}$ \\
\hline $\begin{array}{l}\text { Drain ditch plug/ } \\
\text { Open culvert }\end{array}$ & 1 & $36 "$ dia culv. & $\mathbf{8}^{\prime} \mathbf{W}$ dike top plug/28' long culvert. \\
\hline Supply Lines & - & & $\begin{array}{l}\text { 12" diameter \& larger - CMP, under 12" - } \\
\text { PVC }\end{array}$ \\
\hline Drain Lines & - & & $\begin{array}{l}12 " \text { diameter \& larger - CMP, under } 12 "- \\
\text { PVC }\end{array}$ \\
\hline Spring I ntake & 1 & 16’ long & $\begin{array}{l}\text { Concrete cut-off wall } \mathrm{x} 5^{\prime} \text { high with } \mathbf{4}^{\prime} \times \mathbf{4}^{\prime} \\
\text { concrete screened intake box }-400 \mathrm{gpm} \text {. }\end{array}$ \\
\hline $\begin{array}{l}\text { Infiltration } \\
\text { Gallery with Pump }\end{array}$ & 1 & $160 \operatorname{lin} \mathrm{ft}$ & $\begin{array}{l}4^{\prime} W \text { trench gallery excavated to } 6 \text { ' below } \\
\text { stream bed - } 18^{\prime \prime} \text { perforated drain tile } \\
\text { backfilled with washed river gravel. } \\
\text { Pump sump with } 5 \mathrm{HP} \text { sub. pump. }\end{array}$ \\
\hline Domestic Well & 1 & $5 \mathrm{gpm}$ & $\begin{array}{l}\text { 6" diameter } x \text { 120' deep with } 1 / 2 \text { HP } \\
\text { submersible pump. Pressure tank in } \\
\text { storage building - PVC underground piping } \\
\text { to buildings \& holding pond. }\end{array}$ \\
\hline \multirow[t]{2}{*}{ Aeration Head Box } & 1 & $4^{\prime} \times 4^{\prime}$ & $\begin{array}{l}\text { Plywood constr./compartments for spring } \\
\& \text { infiltration gallery water aeration } \\
\text { through four packed column units. }\end{array}$ \\
\hline & \multicolumn{3}{|c|}{ Fish Production Facilities } \\
\hline $\begin{array}{l}\text { Raceways/Adult } \\
\text { Holding }\end{array}$ & 4 & $70^{\prime} \times 20^{\prime}$ & $\begin{array}{l}2,000 \mathrm{ft}^{3} \text { water each. } 3^{\prime} \text { average pond } \\
\text { water depth. Dirt sides and bottom with } \\
3: 1 \text { bank slopes. One raceway for dual } \\
\text { adult holding/rearing. }\end{array}$ \\
\hline Pond & 1 & $140^{\prime} \times 65^{\prime}$ & $\begin{array}{l}24^{\prime} 500 \mathrm{ft}^{3} \text { water } 3-1 / 2^{\prime} \text { average depth. } \\
\text { Dirt sides \& bottom } / 3: 1 \text { bank slope. }\end{array}$ \\
\hline Hatching Jars & 77 & Units & 5-gallon jars each. \\
\hline $\begin{array}{l}\text { Capilano Tank } \\
\text { Egg Picking Tank }\end{array}$ & 2 & Units & $50 \mathrm{ft}^{3}$ each. Aluminum constr./lids. \\
\hline $\begin{array}{l}\text { Egg Picking Tank } \\
\text { Pollution Control }\end{array}$ & 1 & $12^{\prime} \times 18^{\prime}$ & Shallow egg picking tank. \\
\hline Pollution Control & 1 & $80^{\prime} \times 25^{\prime}$ & $\begin{array}{l}3,000 \mathrm{ft}^{3} \text { water/one hour detention time } \\
\text { for pond cleaning wastes with vacuum } \\
\text { system. Dirt sides \& Dottom/3:1 average } \\
\text { pond bottom water depth. }\end{array}$ \\
\hline Adult Trap & 1 & $100 \mathrm{ft} 3$ & $\begin{array}{l}\text { Upstream and downstream broom handle } \\
\text { picket racks with V-trap. }\end{array}$ \\
\hline
\end{tabular}


Chapter 9

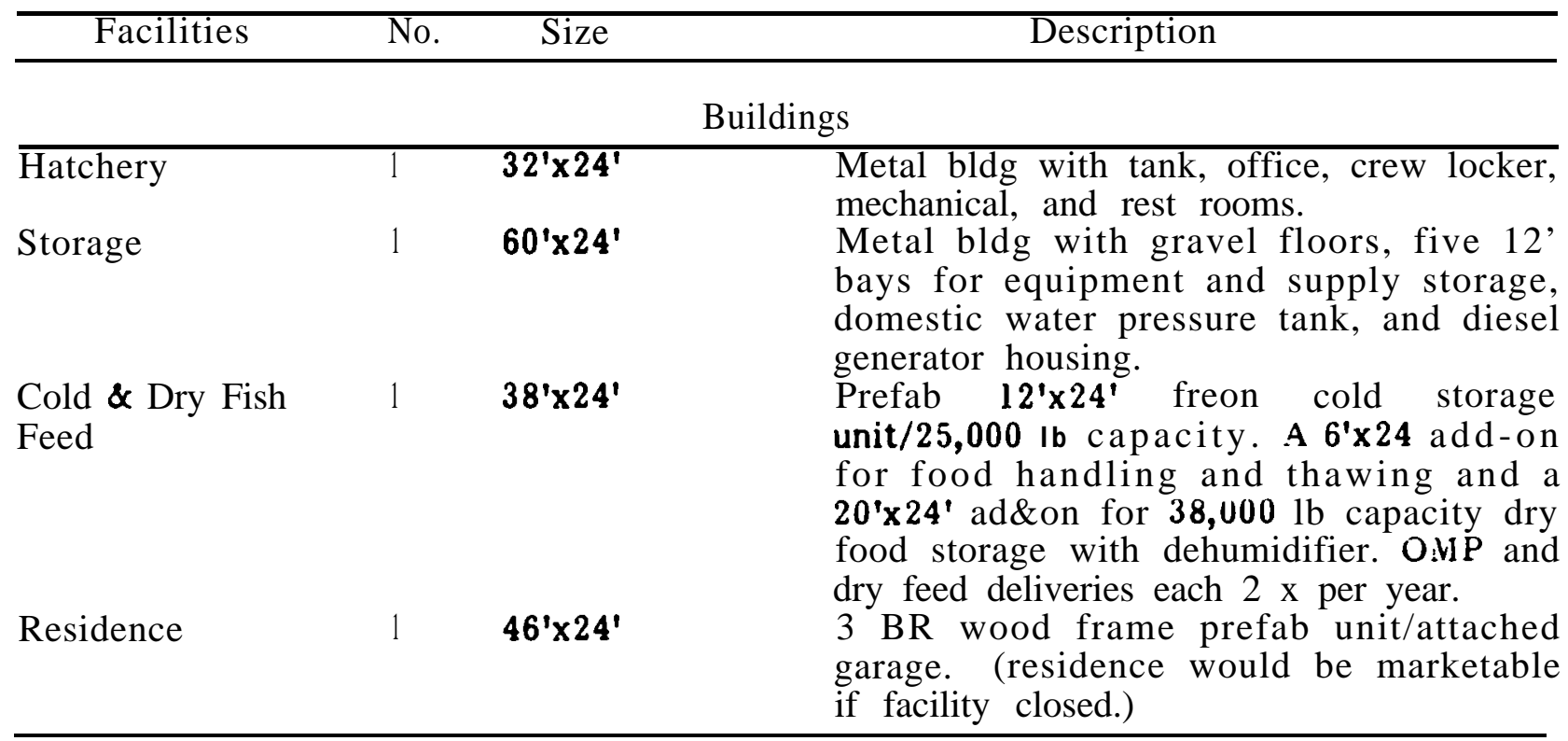

Equipment

General List

1 pick-up, nets, pumps, misc. tools \& cleaning equip. $(\$ 26,000)$

Table 62. Facility development capital costs for Steelhead Trout Hatchery No. 3.

\begin{tabular}{|c|c|}
\hline Facility & Estimated cost \\
\hline Site development & $\$ 112,300.00$ \\
\hline Water supply and drains & $134,000.00$ \\
\hline Fish production facilities & $89,300.00$ \\
\hline Buildings & $205,400.00$ \\
\hline Equipment & $\frac{26,000.00}{\$ 567,000.00}$ \\
\hline
\end{tabular}

Table 63. Estimated annual operational costs and labor requirements for Steelhead Trout Hatchery No. 3.

\begin{tabular}{|c|c|c|}
\hline \multicolumn{2}{|l|}{ Food $\stackrel{\text { Item }}{=}$} & Estimated \\
\hline \multicolumn{2}{|l|}{$\begin{array}{l}\text { @ } \$ 0.40 / \mathbf{l b} \\
\text { conversion } 2.0: 1\end{array}$} & $\$ 40,000$ \\
\hline \multicolumn{3}{|l|}{ Manpower $(0 \&$ \& $)$} \\
\hline Superintendent 2 & 12 man months & 24,000 \\
\hline $\begin{array}{l}\text { Culturist } \\
\text { standby }\end{array}$ & 12 man months & $\begin{array}{r}18,000 \\
2,400\end{array}$ \\
\hline & Subtotal & 84,400 \\
\hline Misc. $(10 \%$ all other & $\begin{array}{l}\text { costs }-0 \& M) \\
\text { Subtotal }\end{array}$ & $\frac{8,440}{92,840}$ \\
\hline $\begin{array}{l}\text { Electrical power } \\
\text { general use } \\
\text { water delivery }\end{array}$ & $\begin{array}{l}\text { HP, } 7 \text { months) } \\
\text { Total }\end{array}$ & $\begin{array}{r}2,800 \\
\quad 805 \\
\$ 96,445\end{array}$ \\
\hline
\end{tabular}


Theoretical Hatcheries

4. Steelhead Trout Hatchery No. 4

Goals:

Produce 20,000 lbs of winter-run steelhead trout juveniles of various sizes from three racial stocks for on-station and off-station releases as follows:

\begin{tabular}{|c|c|c|c|c|c|}
\hline Stock No. & Nos. & No./lb & Lbs & $\begin{array}{l}\text { Release } \\
\text { date }\end{array}$ & Stream release \\
\hline 1 & 56,000 & $\frac{1}{7}$ & 8,000 & May 1 & A (on-station) \\
\hline 1 & 42,000 & 7 & 6,000 & May 1 & B (enclosure) \\
\hline 1 & 14,000 & 7 & 2,000 & May 1 & B pens ( 2 each) \\
\hline 2 & 26,600 & 7 & 3,800 & May 1 & C per(s each) \\
\hline 3 & 300,000 & 1667 & 180 & July & D 2, 3 \\
\hline 3 & 63,000 & $\begin{array}{r}\text { 3,150 (eyed } \\
\text { eggs) }\end{array}$ & 20 & Mar. & D 4 \\
\hline
\end{tabular}

The goals of these releases are:

Stream A - For brood stock and all local sport fisheries.

Stream B - For tribal harvest, sport fishery, and spawner recruitment.

Stream C - For snort fisherv and spawner recruitment.

Stream D - To rebuild depressed runs in all tributaries of stream D for an eventual fisheries.

Summary of Biological Requirements

Production (no./size)

smolt stock No. 1

smolt stock No. 2

fingerlings No. 3

eyed-eggs No. 3

Fertilized eggs (no. spawned) smolt stock No. 1 smolt stock No. 2

fingerlings No. 3

eyed-eggs No. 3

$$
\begin{array}{rll}
112,000 & @ 7 / 1 b \\
26,600 & @ 7 / 1 b \\
300,000 & @ 167 / 1 b \\
63,000 & @ 3,150
\end{array}
$$

172,000

41,000

375,000

$\frac{69 ; 000}{657,000}$

Females to spawn (no.)

stock No. 1

stock No. 2

stock No. 3

Adults held at one time (no.)

Recommended minimum water (gpm) ground and or spring surface

(Note: Pens and enclosures used off-station)

Recommended minimum pond space

Onstation raceway!

(plus 8 units (a $50 \mathrm{ft}^{3}$ )
657,000

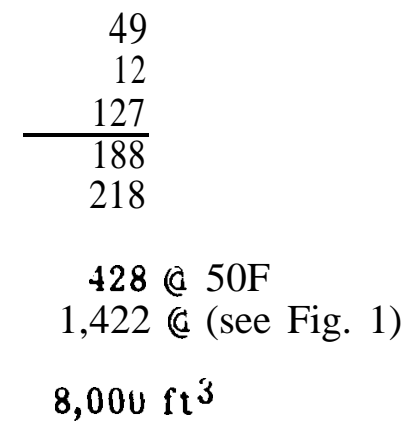




$$
\begin{array}{lr}
\text { Off-station } & \\
5 \text { pens } & 9,720 \mathrm{ft}^{3} \\
1 \text { enclosure } & 20,000 \mathrm{ft}^{3}
\end{array}
$$

Facilities Development:

Table 64 lists the facilities and the associated requirements of Steelhead Trout Hatchery No. 4, Fig. 41 is a vicinity map illustrating the production units and release sites, and Fig. 42 is a schematic of on-station facilities.

\section{Operational Strategies:}

Water and space requirements as related to the total biological requirements by time are shown in Figs. 43 and 44, respectively. On-station husbandry is illustrated for onstation production units (Fig. 45) and is similar to previously described steelhead hatcheries (see Steelhead Trout Hatchery No. 1); however, because of the complexity of the program brief explanations for on- and offstation activities of each life phase follow.

(1) Adults St ock No. 1: A total of 49 females are required for spawning purpose-with 57 fish (males \& females) held at one time. All fish will be captured at the hatchery and held inside the hatchery in acrylic tubes within Capilano troughs.

Stock No. 2: A total of 12 females are required for spawning purposes with 15 fish (males \& females) held at one time. All fish will be captured by volunteer sports fishermen and transported and held for maturation as with Steelhead Trout Hatchery No. 1.

Stock No. 3: A total of 127 females are required for spawning purposes with 147 fish (males \& females) held at one time. Fish will be captured in tributary streams by seining, electro shocking, and from a trap on an existing dam. Volunteer help will be used. All fish will be transported to the hatchery for holding and spawning, and held in the lower $1 / 3$ of a $2,000 \mathrm{ft}^{3}$ rearing pond until only a few remain. At this time they can be transferred to troughs inside the hatchery if outside rearing space is needed.

(2) Incubation Incubation will be conducted as with Steelhead Trout Hatchery No. 1 with the exception of st ock No. 3. On this latter group, 63,000 eyed eggs will be transported to incubation systems in remote areas of stream " $D$ " to complete their incubation in gravel-filled S-gallon bucket incubators, perforated boxes, drainfield pipe, or hand dug redds as appropriate (See Chapter 4). Volunteer help will be ulitized as a continuation of their efforts. Freezing will not be a problem at this time of year.

(3) Rearing Fig. 45 illustates the rearing program by the units included for on- and off-station production. Also refer to Steelhead Trout Hatchery No. 1 for onstation procedures. 
Theoretical Hatcheries

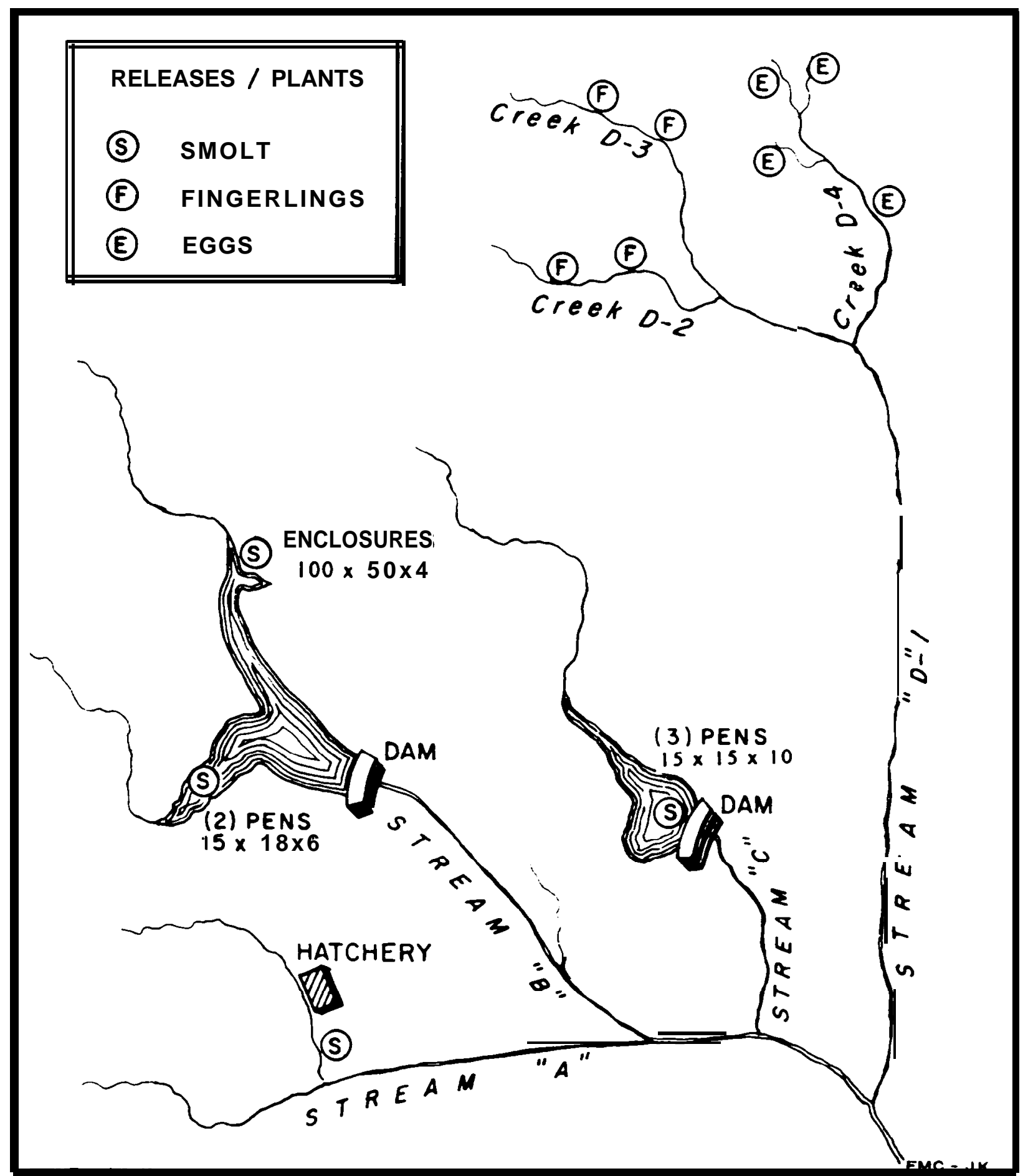

Figure 4 1. Vicinity map of production and release sites for Steelhead Trout Hatchery No. 4. 
Chapter 9

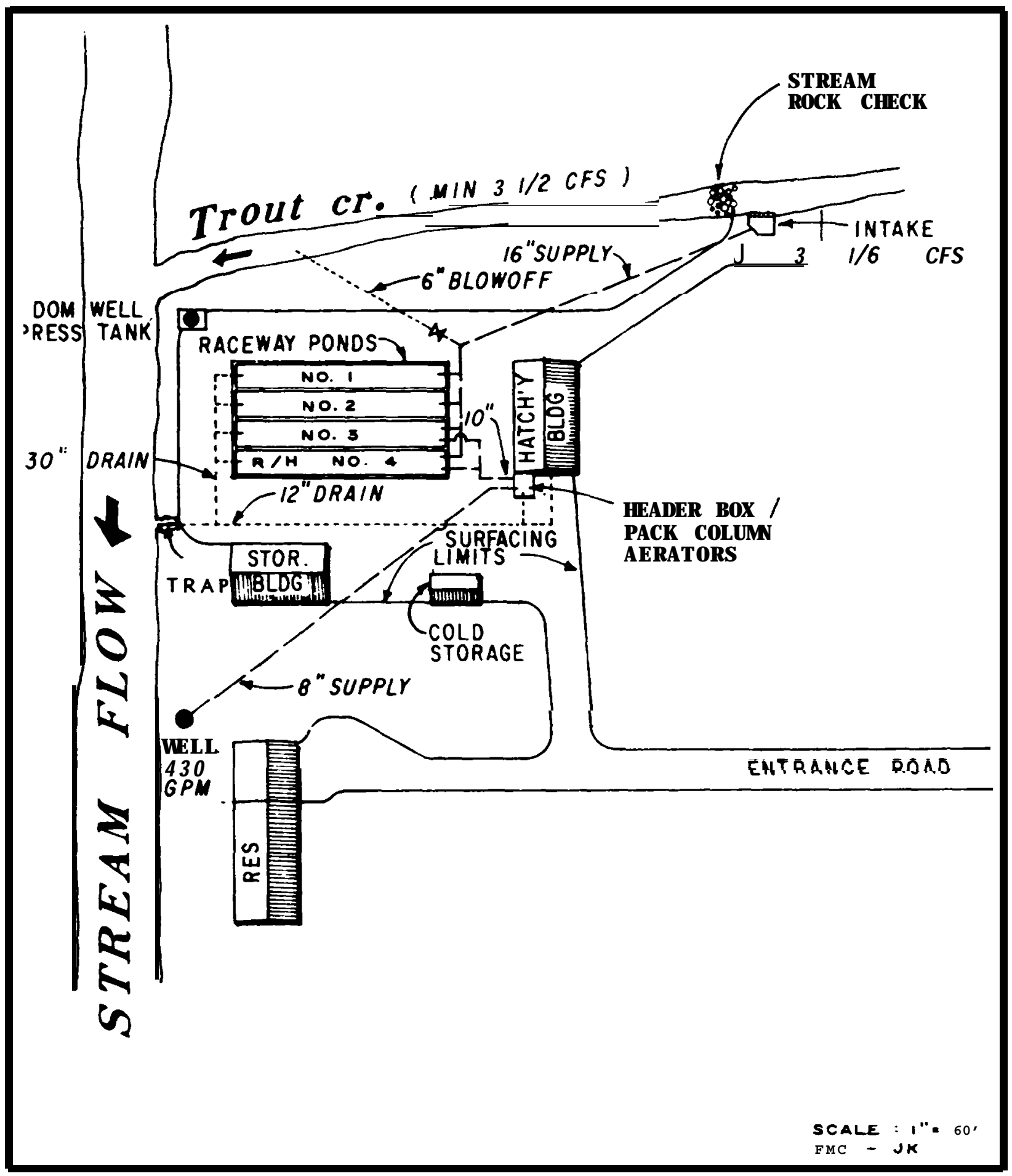

Figure 42. Schematic of Steelhead Trout Hatchery No. 4 - on-station. 
Theoretical Hatcheries

As noted in Fig. 45, the fish for the net-pens and enclosures will be transferred during mid-February after serious icing problems are reduced. This $\mathbf{7 5 - d a y}$ rearing program will require an hourly culturist to assist the on-station personnel. Volunteer help will be used especially for week-end duties at all off-station sites. Predation control will be conducted using techniques described in Chapter 7.

(4) Releases All smolt releases are similar to Steelhead Trout Hatchery No. 1. Fry releases shall be scatter planted to each identified site using techniques as described in Chapter 6, II-C (TRANSPORTATION).

\section{Costs}

Table 65 shows the estimated capital costs for Steelhead Trout Hatchery No. 4, and Table 66 shows the estimated annual operational costs and manpower requirements.

Table 64. Facility development for Steelhead Trout Hatchery No. \& (20,000 lbs, on- and off-station relerses).

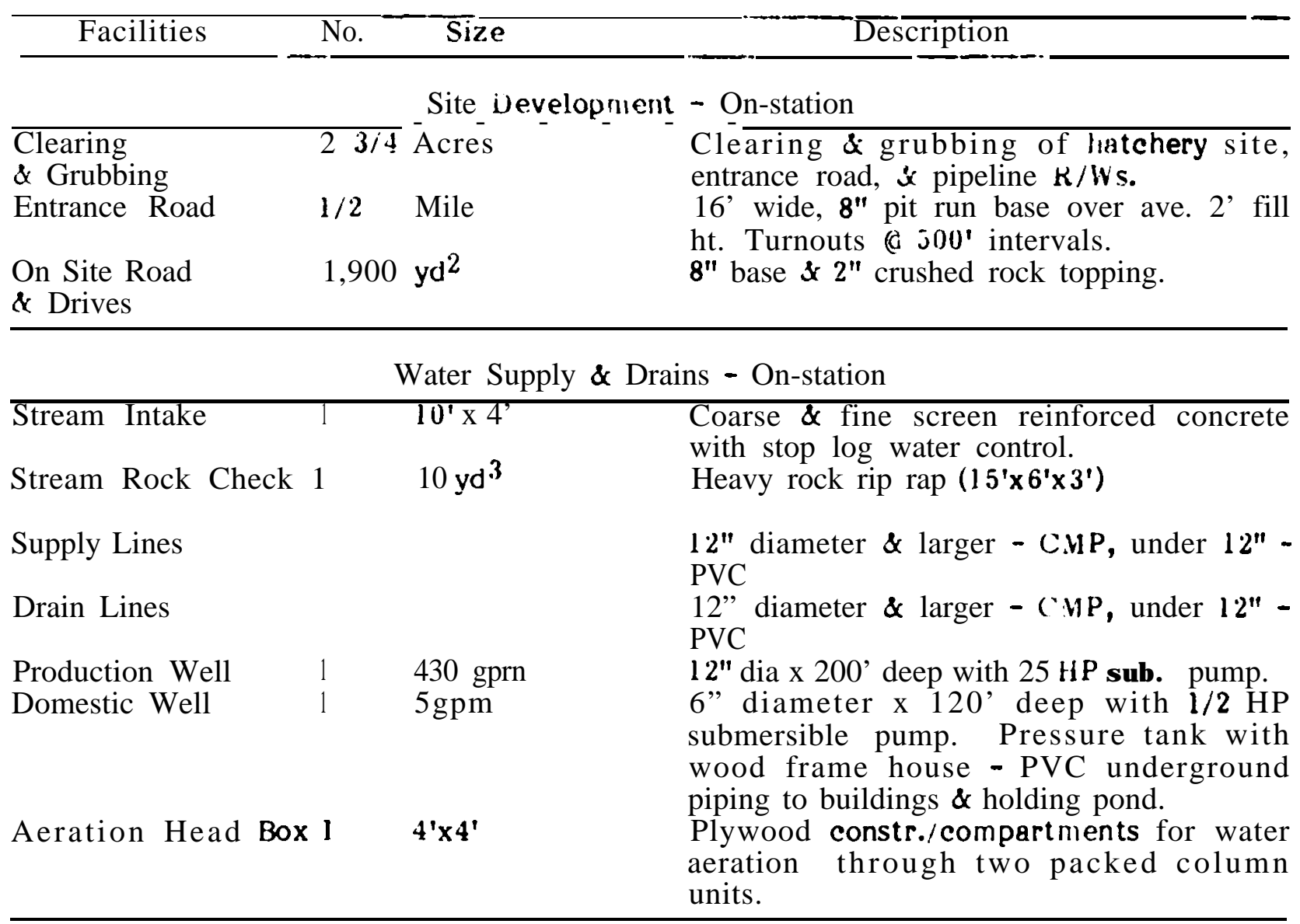


Chapter 9

\begin{tabular}{|c|c|c|c|}
\hline Facilities & Na. & Size & Description \\
\hline \multicolumn{4}{|c|}{ Fish Production Facilities - Onstation } \\
\hline Raceways & 4 & 83 'x 8' & $\begin{array}{l}2,000 \mathrm{ft}^{\mathrm{S}} \text { water each. Prefab steel with } \\
\text { plastic sheet lining. One raceway } \mathrm{R} / \mathrm{H} \text {. }\end{array}$ \\
\hline Adult Trap & 1 & $100 \mathrm{ft} 3$ & $\begin{array}{l}\text { Upstream and downstream broom handle } \\
\text { picket racks with V-trap. }\end{array}$ \\
\hline Hatching Jars & 47 & units & Five gal jars each. \\
\hline Capilano Tanks & 8 & units & $50 \mathrm{ft}^{3}$ water each. Aluminum constr. /ids. \\
\hline Egg Picking Tank & 1 & $12^{\prime} \times 18^{\prime \prime}$ & Shallow egg-picking tank. \\
\hline \multicolumn{4}{|c|}{ Buildings - On-Station } \\
\hline Hatchery & 1 & $42^{\prime} \times 24^{\prime}$ & $\begin{array}{l}\text { Metal bldg, with tank, office, crew locker, } \\
\text { mechanical' and restrooms. }\end{array}$ \\
\hline Storage & 1 & $36^{\prime} \times 24^{\prime}$ & $\begin{array}{l}\text { Metal bldg with gravel floor - three } 12 \text { ' } \\
\text { bays for equip. \& supply storage, } 15,000 \\
\text { lbs of dry fish feed storage, and diesel } \\
\text { generator housing. }\end{array}$ \\
\hline $\begin{array}{l}\text { Cold Storage Fish } \\
\text { Feed }\end{array}$ & 1 & $18^{\prime} \times 12^{\prime}$ & $\begin{array}{l}\text { Prefab } 12^{\prime} \times 12^{\prime} \text { freon cold storage } \\
\text { unit with } 10,000 \text { lb capacity. A } 6^{\prime} \times 12 \\
\text { add-on for food handling \& thawing. OMP } \\
\text { feed deliveries } 2 \times \text { per year. }\end{array}$ \\
\hline Residence & 1 & $46^{\prime} \times 24^{\prime}$ & 3 BR wood frame prefab unit/garage. \\
\hline
\end{tabular}

Equipment

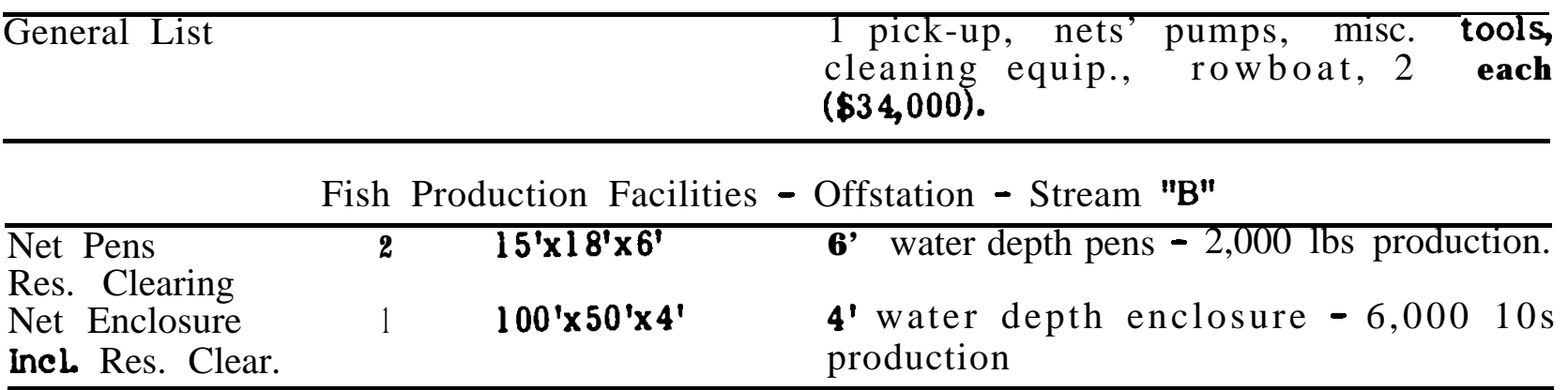

Fish Production Facilities - Off-station - Stream "C"

\begin{tabular}{lllllll}
\hline $\begin{array}{l}\text { Net Pens } \\
\text { Res. Clearing }\end{array}$ & 3 & $\mathbf{1 5}^{\prime} \times \mathbf{l 5}^{\prime} \times 10^{\prime}$ & $\begin{array}{l}10 \text { water depth pens } \\
\text { production. }\end{array}$ & 4,000 & lbs \\
\hline
\end{tabular}

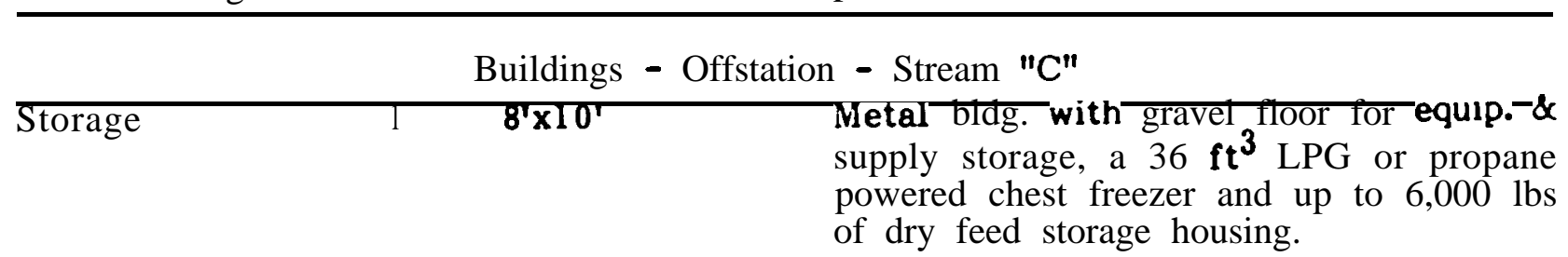



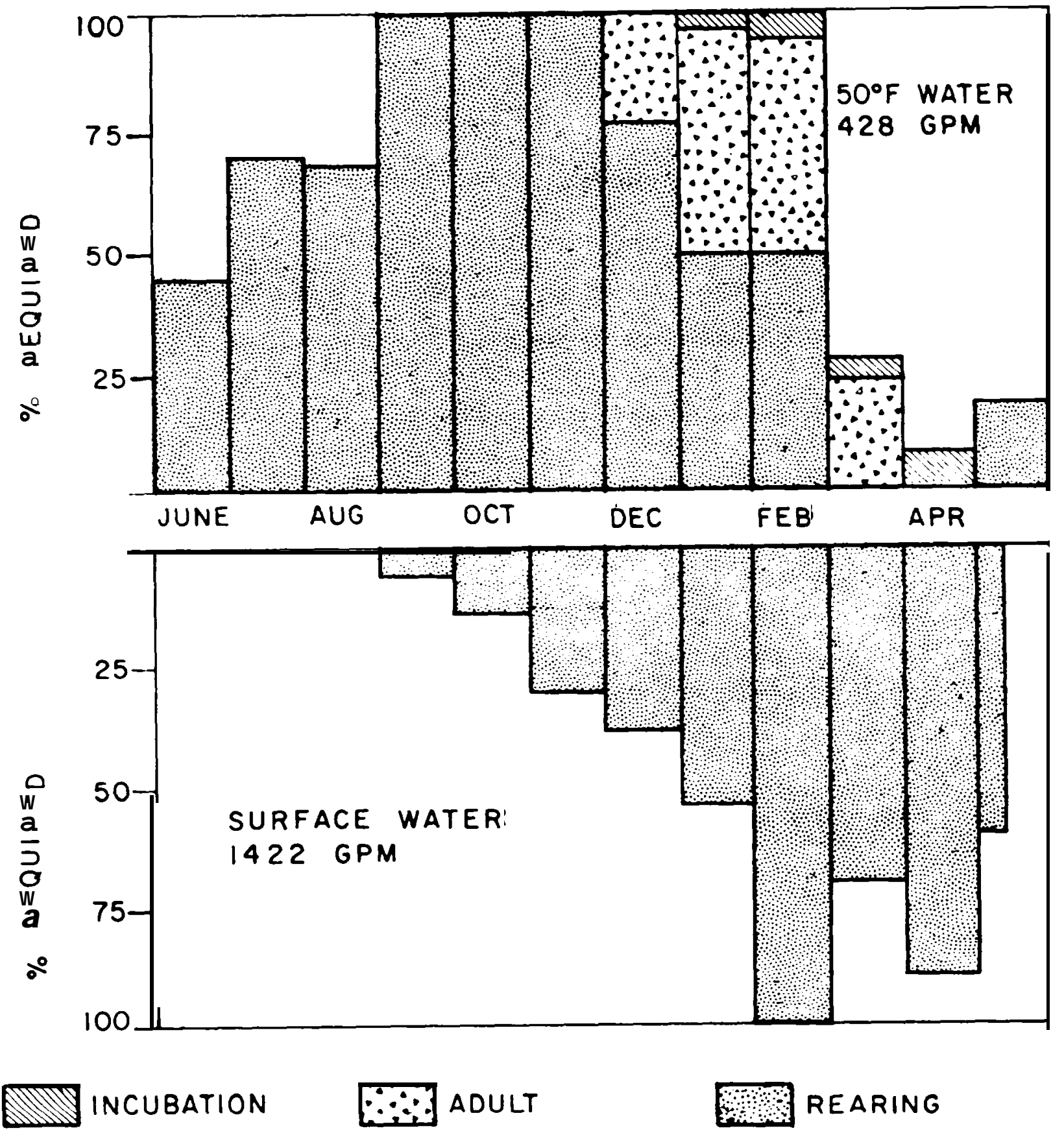

Figure 43. Water-use strategies for Steelhead Trout Hatchery No. 4 - on-station. 


\section{Chapter 9}

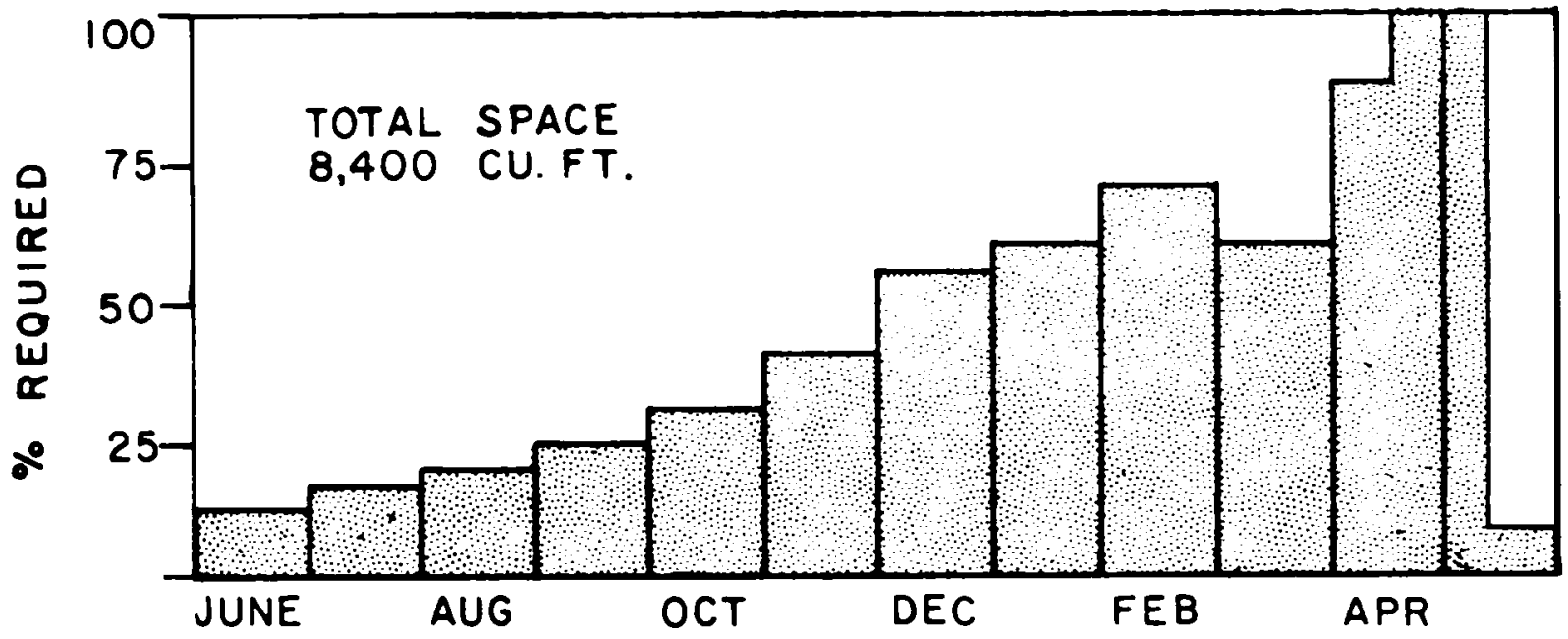

Figure 44. Space-use requirements for Steelhead Trout Hatchery No. 4 - on-station.

Table 65. Facility. development costs for Steelhead Trout Hatchery No. 4.

Site $\frac{\text { Facility }}{\text { development }}$

Water supply and drains

Fish production facilities

Buildings

Equipment

Total

$$
\begin{gathered}
\text { Estimated cost } \\
\hline \$ 78,400.00 \\
154,900.00 \\
90,800.00 \\
174,800.00 \\
34,000.00 \\
\$ 532,900.00
\end{gathered}
$$

Table 66. Estimated annual operational costs and labor requirements for Steelhead Trout Hatchery No. 4.

Food $\underline{\text { Item }}$

a $\$ 0.40 / 1 b$

conversion 2.0: 1

Manpower ( $O \&$ M)

Superintendent 2

Culturist

standby

12 man months

10 man months

Subtotal

Misc. (10\% all other costs - 0 \& $\mathrm{M})$

Subtotal

Electrical power general use water delivery (25 HP, 12 months) Total $\underline{\text { Estimated cost }}$

$\$ 16,000$

24, 000

15,000

2, 400

57,400

5,740

$\overline{63,140}$

1,900

6,900

$\$ 71,940$ 


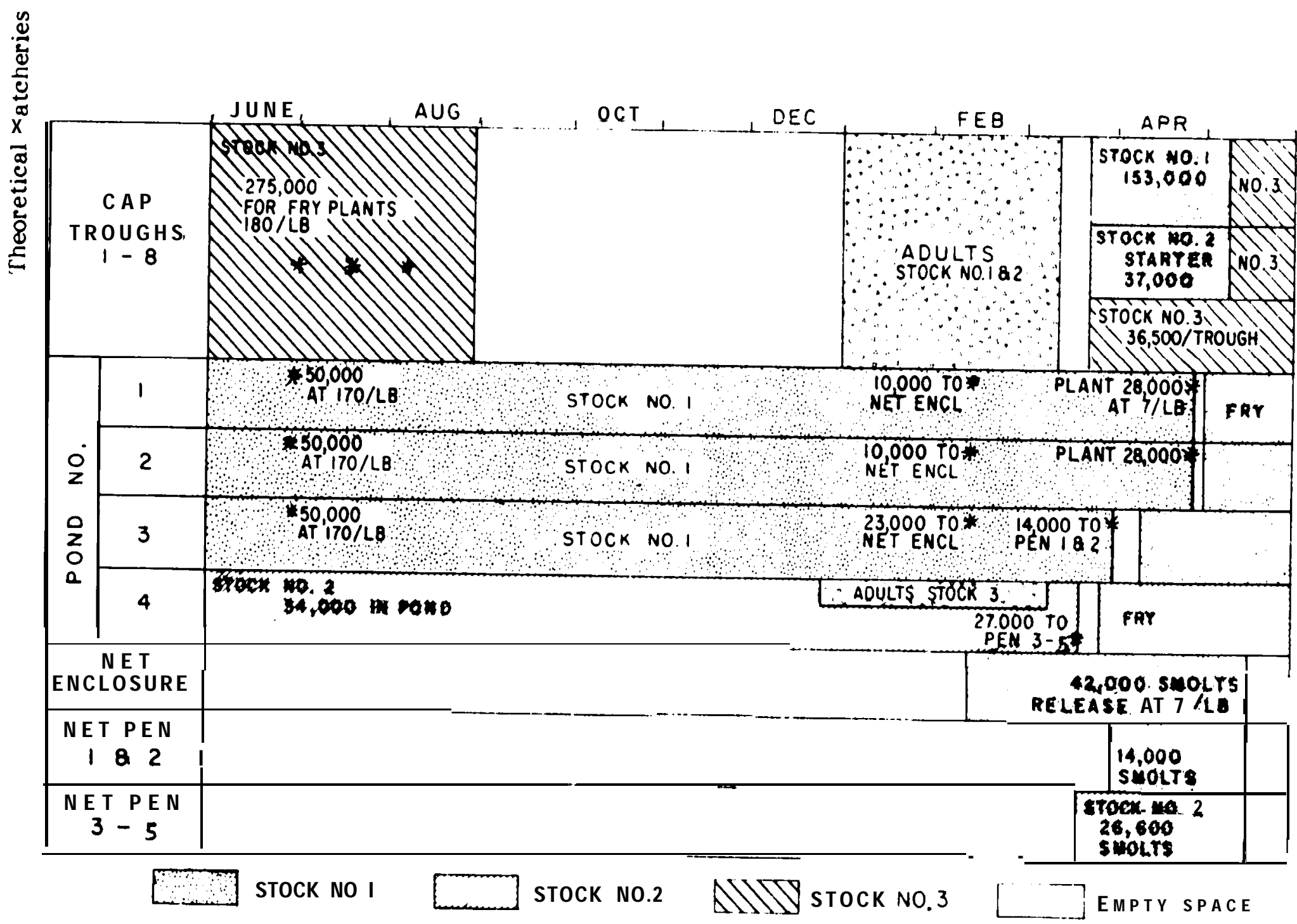

*date action taken

Figure 45. Facility production programming by time for Steelheed Trout Hatchery No. 4 - on and off-station. 
Chapter 9

5. Steelhead Trout Hatchery No. 5

Goals:

Produce 50,000 lbs of winter-run steelhead trout juveniles of various sizes from three racial stocks for onstation and offstation releases as follows:

The goals of these releases are:

Stream A - For brood stock recruitment.

Stream A/B - For sport fisheries

Stream B - To return for a tribal harvest and natural production.

Stock No. 2, Stream C - For a sport fishery and spawning recruitment.

Stock No. 3, Stream D - For a very limited sport fishery and spawning recruitment.

Stream D, 2, 3, 4 - Improve depressed stocks in tributaries of stream D.

Summary of Biological Requirements:

Production (no./size)
Stock No. 1
Stock No. 2
Stock No. 3

Fingerling production

Stock No. 3

Fertilized eggs (no. spawned)

Stack No. 1

St ock Nb. 2

St ock No. 3 (smolt)

Stock No. 3 (fingerling)

Females to spawn (no.)

Stock Na 1

Stock No. 2

Stock No. 3

Adults held at one time (no.)

Recommended minimum water (gpm)

onstation

ground and or spring

surface

of fstation

surf ace

$$
\begin{aligned}
& 282,310 @ 7 / 1 b \\
& 46,200 @ 7 / 1 b \\
& 20,000 @ 7 / 1 b \\
& 50,000 @ 250 / 1 b \\
& 434,000 \\
& 71,000 \\
& 31,000 \\
& 61,000 \\
& 597,000
\end{aligned}
$$

124

20

27

199

1,070 d $50 \mathrm{~F}$

2,070 (see Fig. 1)

2, 260 (see Fig. 1) 
Theoretical Hatcheries

Recommended minimum pond space

Onstation raceways at.? $000 \mathrm{ft}^{3}$ each

Of fstation (plus 8 a $50 \mathrm{ft}^{3}$ each)

$$
\begin{array}{r}
16,000 \mathrm{ft}^{3} \\
\mathbf{4 0 0} \mathrm{ft}^{3} \\
9,180 \mathrm{ft}^{3}
\end{array}
$$$$
5 \text { pens }
$$

1 pond (minimum)

Facilities Development:

Table 67 lists the facilities and the associated requirements of Steelhead Trout Hatchery No. 5, Fig. 46 is a vicinity map, and Figs. 47a and 47b are schematics of on- and off-station facilities.

\section{Operational Strategies:}

Water requirements as related to the total biological requirements by time are shown in Fig. 48. General fish husbandry is similar to the previously described steelhead trout hatcheries (See Steelhead Trout Hatchery No. 4 for a smaller but comparable operation). A brief summary follows.

(1) Adults St ock No. 1 will be held in the lower half of a 2,000 $\mathrm{ft}^{3}$ raceway and stock No.'s 2 and 3 inside the hatchery (see Steelhead Trout Hatchery No. 1 for holding and Hatchery No. 4 for capture methods).

(2) Incubation See Steelhead Trout Hatchery No. 1 and No. 4 for operations.

(3) Rearing See Fig. 49 for the production programming by pond (See Steelhead Trout Hatchery No. 4 for volunteer help program).

(4) Releases All fish will be released as described earlier with the exception of 28,000 from stock No. 2, and 20,000 smolt and 250,000 fingerlings from stock No. 3 which will be trucked from onstation pond No. 8 on May 1 and during June, respectively.

A 1,000 gallon tank truck will be rented from a fishery agency.

\section{Costs}

Table 68 shows the estimated capital costs for Steelhead Trout Hatchery No. 5, and Table 69 shows the estimated annual operational costs and manpower requirements. 


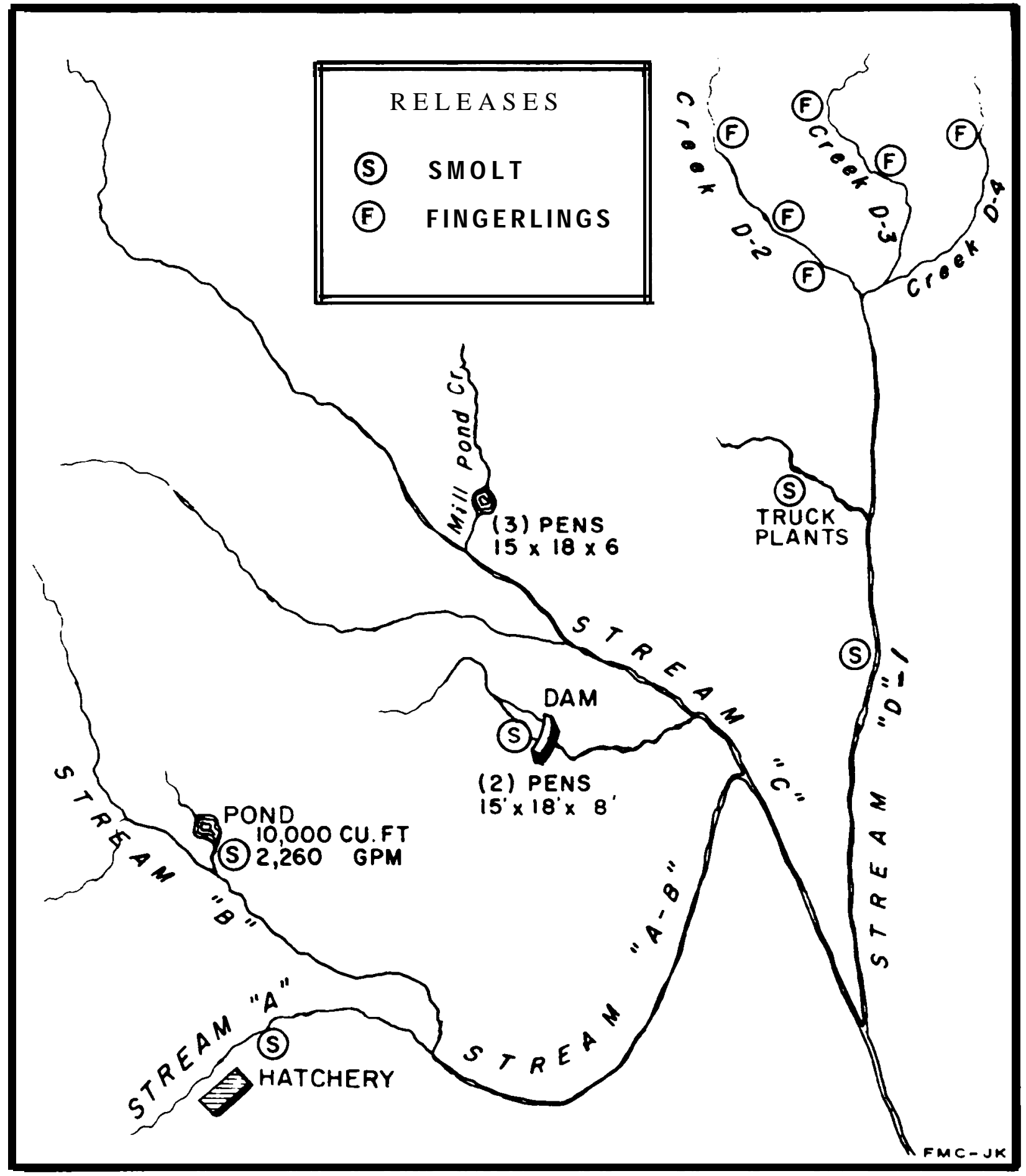

Figure 46. Vicinity map of production and release sites for Steelhead Trout Hatchery No. 5. 
Theoretical Hatcheries

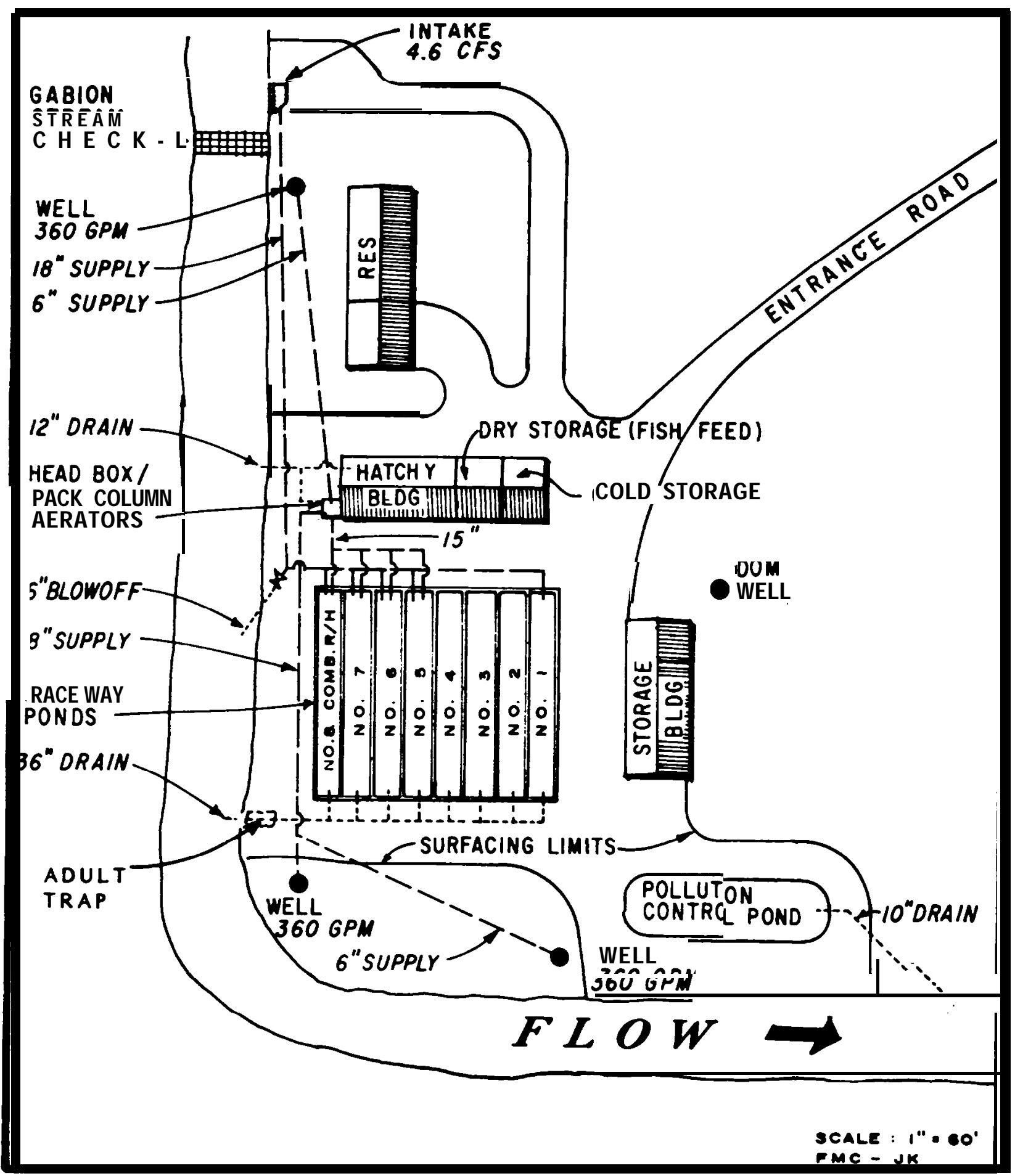

Figure 47a. Schematic of Steelhead Trout Hatchery No. 5 - On-station facilities. 
Chapter 9

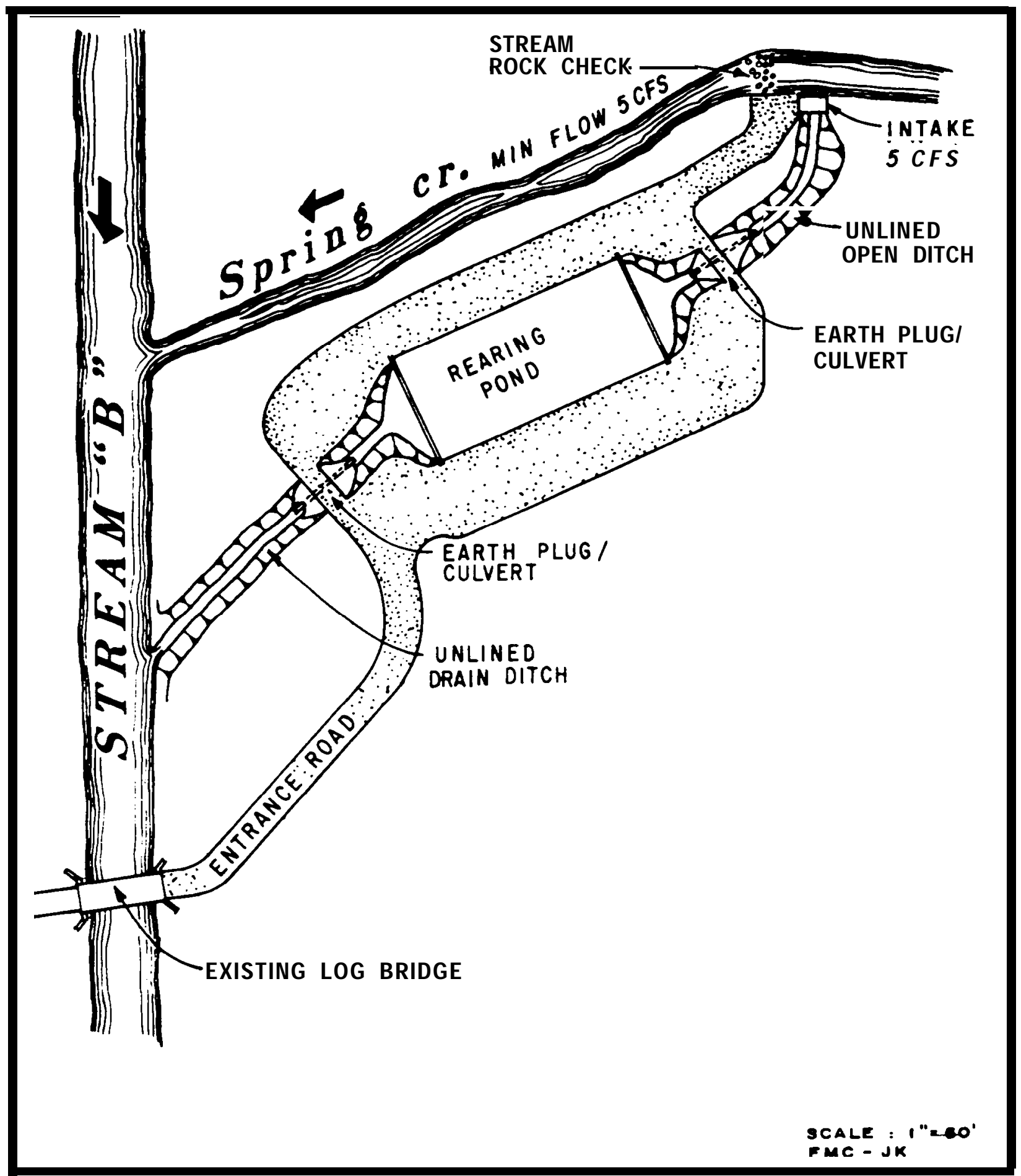

Figure 47b. Schematic of Steelhead Trout Hatchery No. 5 - Off-station pond. 
Theoretical Hatcheries

Table 67. Facility development for Steelhead 'Trout Hatchery No. 5 (50,000 lbs, on- and off-station releases).

\begin{tabular}{|c|c|c|c|}
\hline Facilities & $\sqrt{\mathrm{Na}}$ & $\overline{\text { Size }}$ & Description \\
\hline \multicolumn{4}{|c|}{ Site Development - Onstation } \\
\hline $\begin{array}{l}\text { Clearing } \\
\text { \& Grubbing }\end{array}$ & $41 / 2$ & Acres & \multirow{3}{*}{ 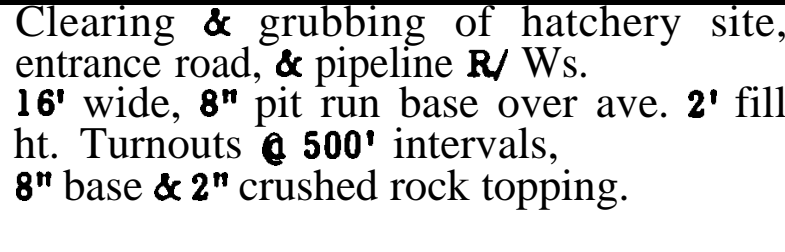 } \\
\hline Entrance Road & & Mile & \\
\hline $\begin{array}{l}\text { On Site Road } \\
\text { \& Drives }\end{array}$ & 3,600 & $\mathrm{yd}^{2}$ & \\
\hline
\end{tabular}

Water Supply \& Drains - On-station

\begin{tabular}{|c|c|c|c|}
\hline Stream Intake & $T$ & $10^{\prime} \times 4^{\prime}$ & $\begin{array}{l}\text { Coarse \& fine Screen reinforced concrete } \\
\text { with stop log water control. }\end{array}$ \\
\hline $\begin{array}{l}\text { Gabion Stream } \\
\text { Check }\end{array}$ & 1 & $20 y_{d^{3}}$ & $\begin{array}{l}\text { Gabion rock-filled wire baskets } \\
\left(30^{\prime} \times 6^{\prime} \times 3^{\prime}\right)\end{array}$ \\
\hline Supply Lines & & & $\begin{array}{l}12^{n} \text { diameter \& larger - CMP, under } 12^{\prime \prime}- \\
\text { PVC }\end{array}$ \\
\hline Drain Lines & & & $\begin{array}{l}12^{n} \text { diameter \& larger - CMP, under } 12^{n} \text { - } \\
\text { PVC }\end{array}$ \\
\hline $\begin{array}{l}\text { Production Wells } \\
\text { Domestic Well }\end{array}$ & $\begin{array}{l}3 \\
1\end{array}$ & $\begin{array}{l}360 \mathrm{gpm} \text { ea } \\
\mathbf{5} \mathbf{~ g p m}\end{array}$ & $\begin{array}{l}\text { 12" dia } \times 200^{\prime} \text { deep with } 20 \text { HP sub. pump. } \\
6^{n} \text { diameter x } 120^{\prime} \text { deep with } 1 / 2 \text { HP } \\
\text { submersible pump. Pressure tank in } \\
\text { storage building - PVC underground piping } \\
\text { to buildings \& holding pond. }\end{array}$ \\
\hline Aeration Head Box & 1 & $4^{\prime} \times 6^{\prime}$ & $\begin{array}{l}\text { Plywood constr./compartments for spring } \\
\text { dc infiltration gallery water aeration } \\
\text { through three packed column units, }\end{array}$ \\
\hline Pollution Control & 1 & $80^{\prime} \times 25^{\prime}$ & $\begin{array}{l}3,000 \mathrm{ft}^{3} \text { water/l hr. detention time for } \\
\text { pond cleaning wastes/vacuum system. } \\
\text { Dirt sides \& bottom with } 3: 1 \text { bank slopes } \\
31 / \mathbf{2}^{\prime} \text { ave. pond bottom water depth. }\end{array}$ \\
\hline
\end{tabular}

Fish Production Facilities - Onstation

\begin{tabular}{|c|c|c|c|}
\hline Raceways & 8 & $83^{\prime} \times 8^{\prime}$ & $\begin{array}{l}2,000 \mathbf{f t}^{\mathbf{S}} \text { water ea. Prefab steel with } \\
\text { plastic sheet lining. One racewav } \mathrm{R} / \mathrm{H}\end{array}$ \\
\hline Hatching Jars & 85 & Units & S-gallon jars each \\
\hline Capilano Tank & 8 & Units & $50 \mathrm{ft}^{3}$ each Aluminum constr./ids. \\
\hline Egg Picking Tank & 1 & $12^{\prime} \times 18^{\prime \prime}$ & Shallow egg picking tank. \\
\hline Adult Trap & 1 & $100 \mathrm{ft}^{3}$ & $\begin{array}{l}\text { Upstream and downstream broom handle } \\
\text { picket racks with V-trap. }\end{array}$ \\
\hline
\end{tabular}


Chapter 9

\begin{tabular}{|c|c|c|c|}
\hline Facilities & $\overline{\mathbf{N a}}$ & Size & Description \\
\hline \multicolumn{4}{|c|}{ Buildings - On-Station } \\
\hline $\begin{array}{l}\text { Combination } \\
\text { Hatchery \& Fish } \\
\text { Feed Storage }\end{array}$ & $T$ & $80^{\prime} \times 24^{\prime}$ & 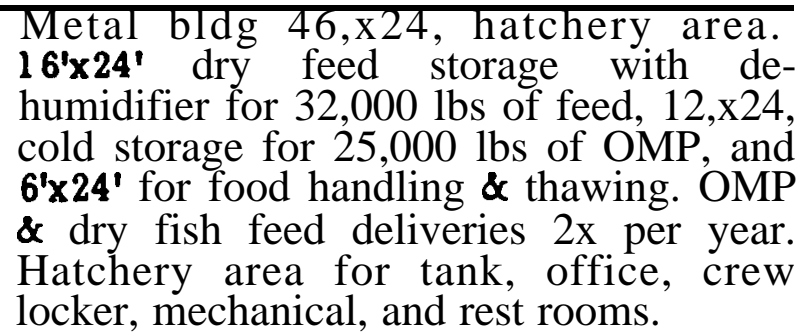 \\
\hline Storage & 1 & $60 ' \times 24 '$ & $\begin{array}{l}\text { Metal bldg with gravel floor. Five } 12 \\
\text { bays for equip. and supply storage, } \\
\text { domestic water pressure tank and diesel } \\
\text { generator housing. }\end{array}$ \\
\hline Residence & 1 & $46^{\prime} \times 24^{\prime}$ & $\begin{array}{l}3 \mathrm{BR} \text { wood frame prefab unit/attached } \\
\text { garage. (residence would be marketable } \\
\text { if facility closed.) }\end{array}$ \\
\hline
\end{tabular}

Equipment - Onstation and Off-Station

General List 1 pick-up, nets, pumps, misc. tools, cleaning equip., small fish-tank, \& one rowboat $(\mathbf{\$ 3 4 , 0 0 0 )}$

Site Development - Offstation - Stream "B"

\begin{tabular}{|c|c|c|}
\hline $\begin{array}{l}\text { Clearing } \\
\text { \& Grubbing }\end{array}$ & & $\begin{array}{l}\text { Clearing \& grubbing of intake, water } \\
\text { transportation ditches \& pond sites }\end{array}$ \\
\hline Entrance Road & $1,000 \operatorname{lin} \mathrm{ft}$ & $\begin{array}{l}\text { Blade existing entr. road \& gravel } \\
\text { road/ } 6^{\prime} w \times 4^{\prime \prime} \text { thick pit run base. }\end{array}$ \\
\hline $\begin{array}{l}\text { On Site Road } \\
\& \text { Drives }\end{array}$ & $2,000 \mathrm{yd}^{2}$ & $4^{\prime \prime}$ base $\& 2^{\prime \prime}$ crushed rock topping. \\
\hline
\end{tabular}

\begin{tabular}{|c|c|c|}
\hline \multicolumn{3}{|c|}{ Water Supply \& Drains - Off-station - Stream "B" } \\
\hline Intake-Creek & $1 \quad 10^{\prime} \times 4$ & $\begin{array}{l}\text { Coarse \& fine screen reinforced concrete } \\
\text { intake with stop log water control }\end{array}$ \\
\hline Stream Rock Check & $10 \mathrm{yd}^{3}$ & Heavy rock rip rap $\left(155^{\prime} \times 6^{\prime} \times 3^{\prime}\right)$ \\
\hline $\begin{array}{l}\text { Water Supply Open } \\
\text { Ditch \& Drain Ditch }\end{array}$ & $1,000 \operatorname{lin} \mathrm{ft}$ & $\begin{array}{l}\text { Unlined can al/3 }{ }^{\prime} \text { bottom width } \\
21 / 2: 1 \text { side slopes } \times 3^{\prime} \text { deep. Grade of } \\
0.03 \% \text { max. }\end{array}$ \\
\hline $\begin{array}{l}\text { Ditch plug/open } \\
\text { culvert }\end{array}$ & $24^{\prime \prime}$ dia culverts & $\mathbf{8}^{\prime} \mathbf{W}$ dike top plug/28' long culverts. \\
\hline
\end{tabular}




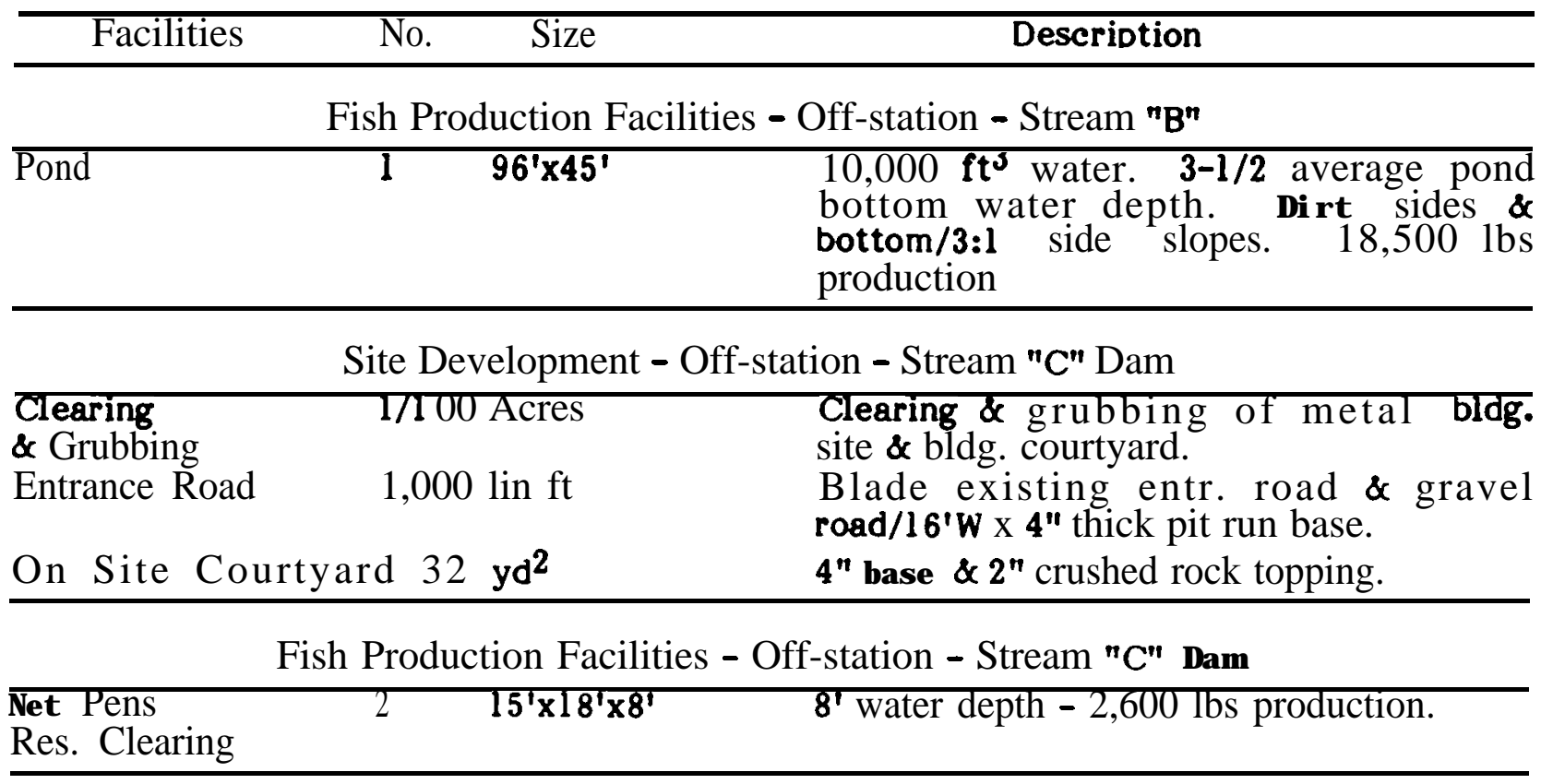

Fish Production Facilities - Off-station - Mill Creek Pond

\begin{tabular}{|c|c|c|c|}
\hline $\begin{array}{l}\text { Net Pens } \\
\text { Res. Clearing }\end{array}$ & 3 & $15^{\prime} \times 18^{\prime} \times 6^{\prime}$ & $\mathbf{6}^{\prime}$ water depth $-2,900 \mathrm{lbs}$ production. \\
\hline \multicolumn{4}{|c|}{ Buildings - Off-station - Stream "C" Dam } \\
\hline Storage & $T$ & $8^{\prime} \times 10^{1}$ & $\begin{array}{l}\text { Metal bidg with gravel floor for equip. \& } \\
\text { supply storage, } 36 \mathrm{cu} \text {. ft LPG or propane } \\
\text { powered chest freezer housing and up to } \\
6,000 \text { lbs of dry feed storage. }\end{array}$ \\
\hline Trailer Pad & 1 & $16^{\prime} \times 20^{\prime}$ & $\begin{array}{l}\text { Conc. pad with septic tank \& drainfield. } \\
\text { Water supplied from facilities dev. for } \\
\text { dam requirements. }\end{array}$ \\
\hline
\end{tabular}

Table 68. Facility development costs for Steelhead Trout Hatchery No. 5.

Facility

Site development

Water supply and drains

Fish production facilities

Buildings

Equipment
Estimated cost

$\$ 131,000.00$

$301,300.00$

$166,000.00$

$232,800.00$

$34,000.00$

Tot al
$\$ 865,100.00$ 
Chapter 9
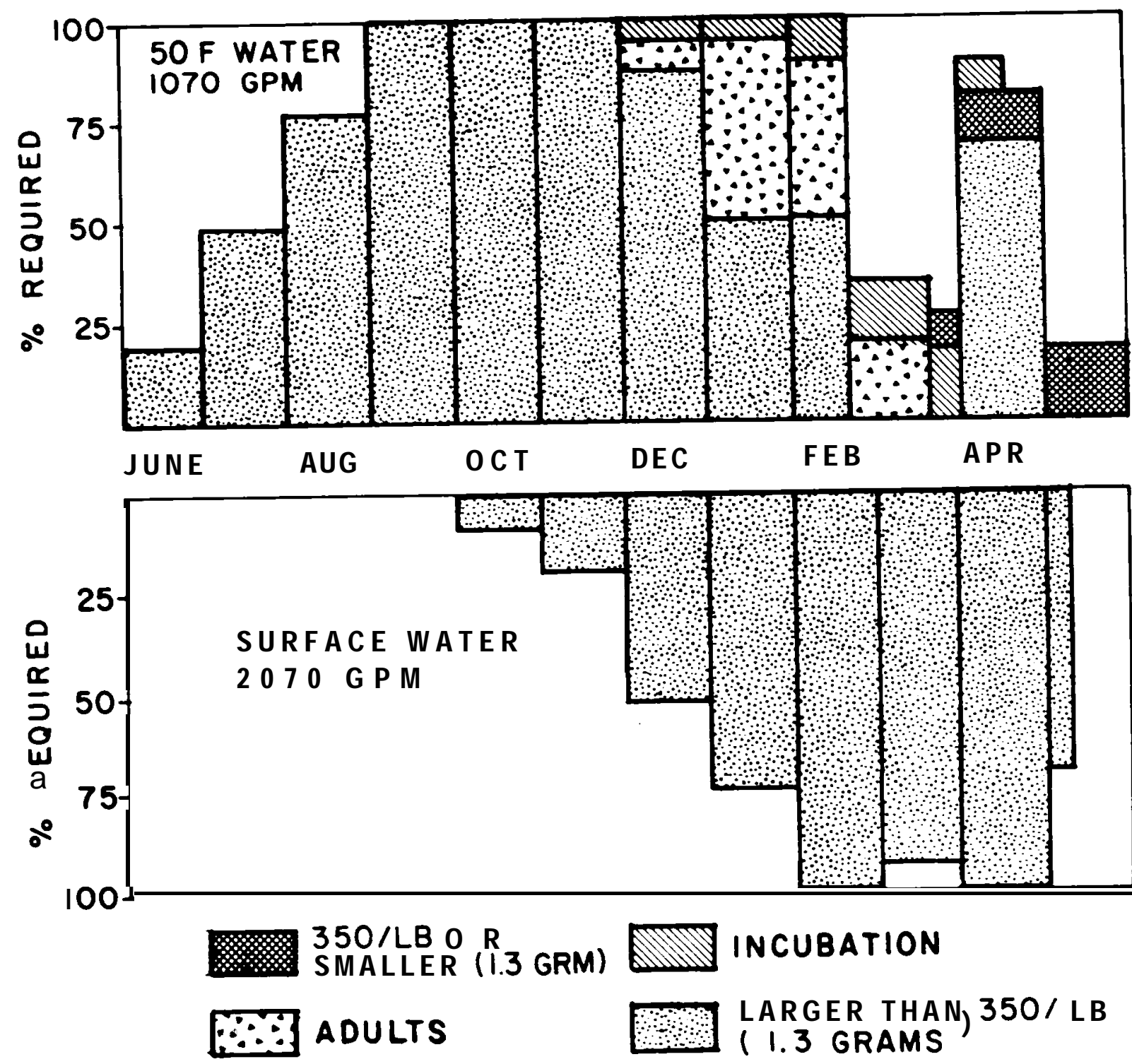

Figure 48. Water-use strategies for Steelhead Trout Hatchery No. 5 - onstation. 


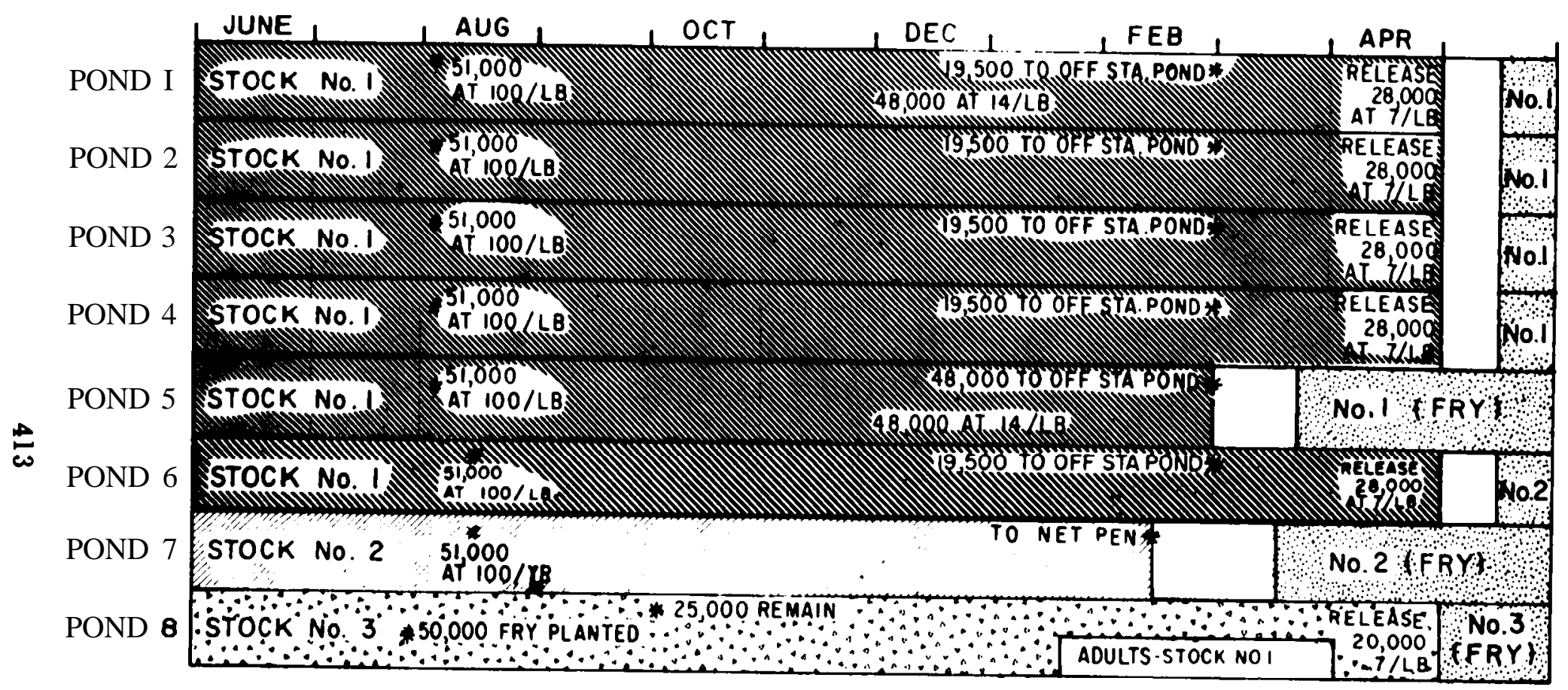

FRY OF STOCK NO'S I, 2 \& 3

FINGERLING OR SMOLT OF STOCK NO'S I, 2 a 3

FINGERLING OR SMOLT OF STOCK NO. I

$\because \because \because$ FINGERLING OR SMOLT OF STOCK NO. 3 EMPTY SPACE

* DATE OF ACTION

Figure 49. Facility production programming by time for Steelhead Trout Hatchery No. 5 - on-station. 


\section{Chapter 9}

Table 69. Estimated annual operational costs and labor requirements for Steelhead Trout Hatchery No. 5.

\begin{tabular}{|c|c|c|}
\hline Item & & Estimated \\
\hline $\begin{array}{l}\text { Food }- \\
\text { a \$0.40/1b } \\
\text { conversion } 2.0: 1\end{array}$ & & $\$ 40,000$ \\
\hline Manpower (O \& M) & & \\
\hline Superintendent 2 & 12 man months & 24,000 \\
\hline $\begin{array}{l}\text { Culturist } \\
\text { standby }\end{array}$ & 15 man months & $\begin{array}{r}22,500 \\
2,400\end{array}$ \\
\hline & Subtotal & 88,900 \\
\hline Misc. (10\% all other c & costs $-0 \& \mathrm{M})$ & 8,890 \\
\hline smolt transportatio & & 500 \\
\hline & Subtotal & 98,290 \\
\hline $\begin{array}{l}\text { Electrical power } \\
\text { general use }\end{array}$ & & 3,000 \\
\hline water delivery $\mathbf{2 0 ~}$ & $\begin{array}{l}\text { HP } 20 \text { months) } \\
\text { Total }\end{array}$ & $\begin{array}{r}9,200 \\
\$ 110,490\end{array}$ \\
\hline
\end{tabular}

\section{SUMMARY AND DISCUSSION}

The 20 theoretical low-cost salmon and steelhead trout hatcheries presented in this Chapter are based on an average developmental situation expected to exist within the Columbia River Basin. The hatcheries are all small, ranging from 10,000 to 50,000 pounds of production; and to a large extent are programmed to enhance natural production. We believe that these facilities, while neither the least nor the most expensive, are adequate for the job intended, and would be accepted by most fish culturists.

An analysis of the costs of these facilties, as summarized for the 20 hatcheries (Tables 70 and 71 ), reveals:

(1) Based on the cost of producing one pound of juvenile fish, the capital and $0 \& M$ cost decreases for all hatcheries as the production levels increase.

(2) The capital and 0 \& $\mathbf{M}$ costs are similar for all hatcheries of equal size regardless of the targeted species.

(3) The capital and 0 \& $M$ costs required for the 10,000 pound facilities are sufficiently high to justify purchasing fish from private operators.

(4) The 0 \& $M$ cost to produce a pound of fish (Table 71) for the 20,000 and 50,000 pound hatcheries is comparable to the average production cost of state-operated hatcheries, where the average pounds of production per station is greater.

(5) The estimated capital dollar expenditure required to produce one pound of fish (Table 70) is considerably less than the dollar now being spent for the new Columbia River Basin hatcheries. 
In Chapter 8 three concepts for developing a 50,000 lb and a 10,000 lb coho hatchery were made (a total of six hatcheries). The concepts for development were based on hatcheries: (1) similar to the new Columbia River Basin hatcheries; (2) similar to concepts presented in this Chapter; and (3) that embrace the concept of very low cost and higher risk, The analysis shows that for a given production goal, a wide range of capital expenditures exists depending upon the selection of facilities for the hatchery.

Because of these many options that are available to save costs in hatchery development and operations, we strongly recommend that each developer be challenged to minimize capital and 0 \& $M$ cost by analysing "all" the options available prior to construction.

Examples of alternatives for cost reductions beyond those we have illustrated so far in this Chapter are:

(1) For the Site

Develop an intake from existing instream structure; develop a site where a road exists (we chose to develop $1 / 2$ mile of road); select a larger spring water supply or obtain water from very shallow aquifers; consider building the facilities at sites far removed from the point of release, then transporting the fish to release ponds.

(2) For Adults

Use existing facilities as a site of adult collection (as a dam or hatchery); obtain eggs from other hatcheries.

(3) For Incubation

Utilize existing facilities (excess incubation water is often available).

(4) For Rearing

Utilize more net pens, net-enclosures, and in-stream ponds (costly intakes and water supply systems will be saved). Use quality dry food when feasible (dry food costs less to use and saves freezer cost).

(5) For Buildings

Use surplus travel trailers or truck vans (acceptable for short programs and suitable-for work areas, storage, or as an incubation room); utilize rental units (especially freezer space for a Fall Chinook program); eliminate concrete floors and flumes in hatchery buildings where short-lived programs are in order; eliminate the incubation room of the hatchery building for short-term programs (where a spring water supply prevents freezing, outside incubation is possible).

(6) Labor considerations

At the 10,000 pound stations, other daily work activities should be assigned to personnel (as a creel census, law enforcement, special studies); develop a low-capital and low-maintenance landscape surrounding the hatchery. 


\section{Chapter 9}

In addition to all the alternatives mentioned for saving costs, we believe that the most important single factor needed is to have a firm directive from the controlling authorities requiring that "all" developmental cost-saving options be explored to reduce the capital and 0 \& $\mathbf{M}$ costs while maintaining quality fish. Unless this is done, significant cost-saving options may not be properly explored, especially where public or mitigative funding is provided.

Table 70. Summary of the estimated facility development cost for 20 theoretical salmon and steelhead trout hatcheries for-the Columbia River Basin.

\begin{tabular}{|c|c|c|c|c|c|c|c|}
\hline cility & $\begin{array}{l}\text { Prod. } \\
\text { lbs in } \\
1,000 \text { 's } \\
\text { lbs }\end{array}$ & $\begin{array}{l}\text { Site } \\
\text { Dev. } \\
\$\end{array}$ & $\begin{array}{c}\text { Water } \\
\text { Supply } \\
\& \text { \& } \\
\text { D r a i n }\end{array}$ & $\begin{array}{l}\text { Fish } \\
\text { Production } \\
\text { S Facilities } \\
\$\end{array}$ & $\frac{\text { Bldgs. }}{\$}$ & $\begin{array}{l}\text { Equip. } \\
\& \& \\
\text { Supplies } \\
\$\end{array}$ & $\begin{array}{l}\text { Dev. } \\
\text { cost } \\
\text { Per lb } \\
\text { prod. } \\
\mathbf{\$ / l b}\end{array}$ \\
\hline Chinook No. 1 & 10 & 85.8 & 148.2 & 63.4 & 135.8 & 24.0 & 45.72 \\
\hline Chinook No. 2 & 20 & 994.0 & 193.2 & 108.7 & 154.4 & 24.0 & 28.72 \\
\hline Chinook No. 3 & 50 & 137.0 & 387.4 & 235.3 & 204.4 & 26.0 & 19.80 \\
\hline Chinook/Satellite No. 4 & 20 & 110.0 & 185.3 & 105.8 & 160.5 & 25.0 & 29.33 \\
\hline Chinook/Satellite No. 5 & 50 & 179.9 & 448.9 & 235.4 & 246.4 & 28.0 & 22.77 \\
\hline ng Chinook No. 1 & 10 & 81.7 & 83.0 & 54.6 & 134.6 & 24.0 & 37.79 \\
\hline Chinook No. 2 & 20 & 90.6 & 152.7 & 90.3 & 145.4 & 24.0 & 25.15 \\
\hline ing Chinook No. 3 & 50 & 111.9 & 215.4 & 150.8 & 175.5 & 26.0 & 13.59 \\
\hline ing Chinook/Satellite No. & 420 & 99.5 & 134.6 & 92.0 & 143.2 & 29.0 & 24.92 \\
\hline ing Chinook/Satellite No. & 550 & 132.0 & 156.1 & 153.4 & 201.1 & 32.0 & 13.49 \\
\hline Chinook/Coho No. 1 & 10 & 72.6 & 71.4 & 56.2 & 132.9 & 24.0 & 35.71 \\
\hline $0 ?$ & 20 & 72.4 & 69.7 & 81.1 & 148.8 & 24.0 & 19.80 \\
\hline Chinook/Coho No. 3 & 50 & 108.1 & 228.1 & 197.1 & 198.8 & 26.0 & 15.16 \\
\hline No. 1 & 20 & 98.3 & 85.5 & 88.0 & 149.6 & 29.0 & 22.52 \\
\hline & 50 & 146.4 & 212.6 & 201.4 & 216.6 & 32.0 & 16.18 \\
\hline ad No. 1 & 10 & 72.0 & 89.2 & 35.5 & 140.0 & 24.0 & 36.07 \\
\hline No. 2 & 20 & 84.5 & 179.3 & 30.3 & 168.2 & 24.0 & 24.32 \\
\hline & 50 & 112.3 & 134.0 & 89.3 & 205.4 & 26.0 & 11.34 \\
\hline //Satellite & 20 & 78.4 & 154.9 & 90.8 & 174.8 & 34.0 & 26.65 \\
\hline lhead/Satellite I & 50 & 131.0 & 301.3 & 166.0 & 232.8 & 34.0 & 17.30 \\
\hline
\end{tabular}


Theoretical Hatcheries

Table 71. Summary of the estimated annual operational and maintenance cost for 20 theoretical salmon and steelhead trout hatcheries for the Columbia River Basin.

$\underline{\text { Facility }}$

Fall Chinook No. 1

Fall Chinook No. 2

Fall Chinook No. 3

Fall Chinook/Satellite No. 4

Fall Chinook/Satellite No. 5

Spring Chinook No. 1

Spring Chinook No. 2

Spring Chinook No. 3

Spring Chinook Satellite No. 4

Spring Chinook Satellite No. 5

Fall Chinook/Coho No. 1

Fall Chinook/Coho No. 2

Fall Chinook/Coho No. 3

Coho No. 1

Coho No. 2

Steelhead No. 1

Steelhead No. 2

Steelhead No. 3

Steelhead/Satellite No. 4

Steelhead/Satellite No. 5
Prod. lbs

in 1,000's

lbs

10

20

50

20

50

10

20

50

20

50

10

20

50

20

50

10

20

50

20

50
Production

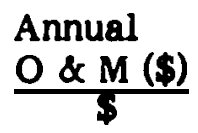

$\$ 36,572$

48,320

91,250

52,250

97,055

41,086

59,390

86,303

64,840

101,107

41,636

55,885

98,402

51,836

94,663

41,536

64,040

96,445

71,940

110,490 cost per lb

of prod.

$\$ 716$

3.66

2.42

1.83

2.61

1.94

4.11

2.97

1.73

3.24

2.02

4.16

2.79

1.97

2.60

1.89

4.15

3.20

1.93

3.60

2.21 
CHAPTER 10

\title{
PERMITS: FISH FACILITY DEVELOPMENT AND OPERATION
}

\begin{abstract}
All projects that require land development and construction work adjacent to surface waters are regulated by various permits from State and Federal agencies. On Indian tribal lands, the tribal regulations apply. In this chapter we identify and describe the required permits, and name the agencies issuing them, for (1) project development, and (2) fish culture operations. Local government permits are not described, but project developers should be aware that county and city governments have regulations that may apply. Agency addresses and telephone numbers are provided.
\end{abstract}

\section{PART I. FACILITY DEVELOPMENT PERMITS}

Permits that are required, or may be required, for the construction of a fish cultural facility are identified in this section. The permit requirements generally provide for the protection of the natural environment, including the salmonid resources.

\section{A. FEDERAL GOVERNMENT}

\section{U.S. Army Corps of Engineers Section 10 Permit \\ - Section 404 Permit}

Section 10 of the Rivers and Harbors Act of 1899 gives authority to the U.S. Army Corps of Engineers to regulate development in navigable waters. The Corps also requires a permit for disposal of dredge and/or fill material in "waters of the United States" under Section 404 of the Clean Waters Act. The Corps circulates permit applications to other agencies for review, including the Environmental Protection Agency, Fish and Wildlife Service, National Marine Fisheries Service, state resource agencies, and local governments.

Any Federal government action, including decisions on permit applications, requires compliance with the National Environmental Policy Act. This is commonly satisfied by preparation of an environmental assessment by the responsible agency, but major developments may require an environmental impact statement (EIS) to identify areas of environmental concern.

For developments in coastal portions of the basin, the Federal permits must consider the Coastal Zone Management Act. Under this law, the states developed coastal management programs that received Federal approval. Projects must be consistent with the guidelines set forth in these programs. 
Permits: Fish Facility Development and Operation

The U. S. Fish and Wildlife Service administers the Endangered Species Act of 1973. If a proposed facility is expected to propogate or impact an endangered species in any way, the USFWS must be consulted as required under Section 7 of the Act.

If a proposed fish culture facility is to be located on federal lands, involve federal funds or federal land, the USFWS should be consulted as required under the Fish and Wildlife Coordination Act as amended.

Federal regulatory agencies:

U.S. Army Corps of Engineers

Seattle District

P.O. Box 3-3755

Seattle, WA 98134

(206) 764-3495

Walla Walla District

Building 602

City-County Airport

Walla Walla, WA 99362

(509) 525-5500

Portland District

P.O. Box 2946

Portland, OR 97208

(503) 221-6997
National Marine Fisheries Service Environmental \& Tech. Sves. Div. 847 NE 19th Avenue

Portland, OR 97232

(503) 230-5400

Environmental Protection Agency

Mail Stop 423

1200 Sixth Avenue

Seattle, WA 98101

(206) 442-1096

U.S. Fish and Wildlife Service

Division of Ecological Services

727 NE 24th

Portland, OR 97232

(503) 231-6179

\section{B. STATE GOVERNMENT}

In addition to participating in the review of Corps of Engineer permits, the states have other permit or approval requirements. These are summarized in Tables 1, 2, and 3 for Oregon, Washington and Idaho, respectively. Addresses for all regulatory agencies in each state are also provided.

Oregon

Oregon law requires that a permit, or "water right", must be obtained from the Oregon Water Resources Department for the appropriation of either surface water or ground water.

The Division of State Lands (DSL) requires a permit for dredging or filling any waters of the state, when 50 cubic yards or more of material is involved. Riprap permits are also issued under this law. DSL uses a joint permit application with the Corps of Engineers, since many activities also require a federal permit. Other state agencies, including the Department of Fish and Wildlife and the Department of Land Conservation and Development, submit recommendations during the permit review process. 


\section{CHAPTER 10}

Table 1. Facility development permits required and regulating agencies for fish hatcheries in the State of Oregon.

Type of permit or instrument

Water Right Permit

Removal and Fill Permit

Riprap Permit

Lease (Navigable Waters)

Archaeological/Historical Consultation

Water Quality Approval

Forestry Notification

Road Access Permit
Regulating agency

Water Resource Department

Division of State Lands

Division of State Lands

Division of State Lands

State Historic Preservation Office

Department of Environmental Quality

Department of Forestry

Department of Transportation

Consultation is required with the State Historic Preservation Office, Oregon State Parks, to determine if the project site has potential historical or archaeological value.

Other Oregon developmental permits that may be required:

1) The state owns most lands under navigable waters, and a state lease may be required from the Division of State Lands.

2) The Department of Environmental Quality regulates water quality and may require approval if there will be sedimentation.

3) If timber is to be removed from the site, a Notification of Operation must be filed with the Department of Forestry.

4) A state road access permit may be required from the Transportation Department regional engineer.

General information regarding permit requirements in Oregon may be obtained from the Department of Fish and 'Wildlife.

Oregon regulatory agencies

Department of Environmental Quality 522 SW Fifth Ave.

P.O. Box 1760

Portland, OR 97204

(503) $229-5696$

Division of State Lands

Permit Coordinator

1445 State St.

Salem, OR 97310

(503) 378-3805
Department of Fish and Wildlife

Environmental Management Section

506 SW Mill St.

P.O. Box 3503

Portland, OR 97204

State Historic Preservation Office

Oregon State Parks

525 Rade St. SE

Salem, OR 97310

(503) 378-5023 
Permits: Fish Facility Development and Operation

Oregon Water Resources Department

555 13th St. NE

Salem, OR 97310

Department of Forestry

2600 State St.

Salem, OR 97310

(503) $378-3671$

(503) $378-2560$

Department of Transportation

Transportation Building

Salem, OR 97310

(503) $378-6388$

Washington

Table 2. Facility development permits required and regulating agencies for fish hatcheries in the State of Washington.

Type of permit or instrument

State Environmental Policy Act

Water Right Permit

Flood Control Zone Permit

Water Quality Exception or Certification

Wastewater Facility Plan Approval

Hydraulic Project Approval

Archaeological/Historical Consultation

Forest Practices Act Permit

Surface Mining Permit

State Leases or Easements
Regulating agency

Department of Ecology

Department of Ecology

Department of Ecology

Department of Ecology

Department of Ecology

Departments of Game or Fisheries

Office of Archaeological and

Historical Preservation

Department of Natural Resources

Department of Natural Resources

Department of Natural Resources

Most hatchery projects in Washington will involve activities covered by the State Environmental Policy Act (SEPA). This Act requires that, before certain permits or approvals are issued, consideration is given to environmental impacts. SEPA guidelines are available upon request from the Washington Department of Ecology.

The Washington Department of Ecology (WDOE) regulations require a Permit to Appropriate Public Water (Water Right) for the withdrawal of surface water or more than 5,000 gallons per day of ground water.

Other permits that may be required by WDOE include:

(1) A Flood Control Zone Permit, if any portion of the project is located in a designated Flood Control Zone.

(2) A Water Quality Exception or Certification, for any construction activity that may result in a temporary violation of state water quality standards.

(3) A Wastewater Facilities Plan Approval, if it is determined that the project involves a production level sufficient to require waste treatment. 


\section{CHAPTER 10}

(4) A Reservoir Permit may be required for any man-made reservoir with a surface area greater than 10 acres or greater than 10 feet in depth.

The Department of Fisheries and the Department of Game jointly issue Hydraulic Project Approvals for any work in waters of the state. Construction provisions are included for protection of fish and their habitat.

The Office of Archaeology and Historic Preservation is responsible for the protection of cultural sites and resources, and should be contacted before construction starts.

The Department of Natural Resources (DNR) should be contacted if construction is planned on forested land, or if surface disruption covers more than 2 acres or involves more than 10,000 tons of material. A Forest Practices Application or Surface Mining Permit may be required. DNR also requires a lease for development on state lands and an easement or road right-of-way may also be necessary.

Information regarding permit requirements in Washington may be obtained at the Environmental Permit Information Center, Department of Ecology, Olympia.

Washington regulatory agencies

Department of Ecology

Mailstop PV-11

Olympia, WA 98504

(206) $753-2800$

Department of Game

600 North Capitol Way

Olympia, WA 98504

(206) 753-6600

Office of Archaeology

and Historic Preservation

11121 st Avenue West

Olympia, WA 98504

(206) 754-1625
Department of Fisheries

Habitat Management Division

115 General Administration Bldg.

Olympia, WA 98504

(206) 753-6650

Department of Natural Resources

Public Lands Building

Olympia, WA 98504

(206) $753-5327$

\section{Idaho}

Table 3. Facility development permits required and regulating agencies for fish hatcheries in the State of Idaho.

Type of permit or instrument

Water Right Permit

Stream Channel Alteration Permit

Encroachment on Navigable Waters

Surface Mining Permit

State Lease, Easement or Purchase

Archaeological/Historical Consultation
Regulating agency

Department of Water Resources

Department of Water Resources

Department of Lands

Department of Lands

Department of Lands

Historic Preservation Office 


\section{Permits: Fish Facility Development and Operation}

Regulations governing water right permits in Idaho are similar to those of Oregon and Washington. An Application for Permit form is submitted to the Department of Water Resources for either surface or ground water.

The Department of Water Resources also regulates work in streams, and requires a Stream Alteration Permit that may include conditions for the protection of environmental quality. A "Joint Application for Permit" form is used in conjunction with the Corps of Engineers and the Idaho Department of Lands. Application review considers the recommendations of other state resource agencies, including the Department of Fish and Game.

The Department of Lands requires a state permit for any encroachment on navigable waters, a surface mining permit if more than one acre is involved, and issues leases and easements for state lands.

The Department of Health and Welfare examines project impacts on water quality and provides a state water quality certification on Corps of Engineers permits. They may also respond to applications for a Stream Channel Alteration permit. If a project is likely to cause siltation or temporary water quality impairment during construction, contact should be made with this agency.

The State Historic Preservation Office maintains a register of potential archaeological and historical sites, and should be contacted when planning new projects.

Idaho regulatory agencies

Department of Water Resources

Statehouse

Boise, ID 83720

(208) $334-2190$

Department of Fish and Game

P.O. Box 25

Boise, ID 83707

(208) $334-3700$

State Historic Preservation Office

610 North Julia Davis Drive

Boise, ID 83702

(208) $334-3847$
Department of Lands

Statehouse

Boise, ID 83720

(208) $334-3280$

Department of Health and Welfare

Division of Environment

450 West State

Boise, ID 83720

(208) 334-4059

\section{INDIAN TRIBAL GOVERNMENT}

Any fish cultural development on Indian reservation land should be closely coordinated with the tribal government and the U. S. Bureau of Indian Affairs office in Portland.

The Confederated Tribes of the Umatilla Reservation list the following permit requirements for orderly land use and development: 
CHAPTER 10

(1) Water Use Permit, for diversion of either ground or surface water, with terms and conditions pertaining to pollution and maintenance of water quality.

(2) Stream Zone Alteration Permit

(3) Zoning Permit

(4) Conditional Use Permit

The Confederated Tribes of the Warm Springs Reservation of Oregon list these requirements before construction can begin:

(1) Approval of site, from the Land Use Committee

(2) Approval of water source, from the Water Control Board

(3) Lease agreement for land, from the Bureau of Indian Affairs Realty

(4) Building Permit, from the Tribal Building Inspector\% Office

The Yakima and Nez Perce tribes do not have formal regulation or permit requirements pertaining to fish cultural facilities at this time. They do require, however, that Tribal Realty and Zoning offices be contacted to assure proper and non-conflicting usage of the land.

Indian tribal agencies

Confederated Tribes of the

Umatilla Reservation

P.O. Box 638

Pendleton, OR 97801

(503) 276-8221

Nez Perce Tribe

P.O. Box 365

Lapwai, ID 83540

(208) $843-2253$
Confederated Tribes and Bands

Yakima Indian Nation

P.O.Box 151

Yakima, WA 98948

(509) 865-5121

Confederated Tribes of the

Warm Springs Reservation of Oregon

Box C

Warm Springs, OR 97761

(503) 553-1 161

\section{PART II. FACILITY OPERATIONS PERMITS}

Regulations governing salmon and steelhead trout culture are less complex than the numerous laws covering construction and development. The states implement most of the laws or policies that regulate important phases of salmon and steelhead culture, and these are similar in Oregon, Washington and Idaho. Federal permits, when required, are identical throughout the basin. Tribal and local government requirements are likely to be minor, but should not be disregarded. 
Permits: Fish Facility Development and Operation

Details of the required permits and approvals follow. Agency addresses are also provided.

\title{
A. FEDERALGOVERNMENT
}

Federal permits may be required for discharge of pollutants, predatory bird and mammal control, or for fish imported from outside the United States. A National Pollution Discharge Elimination System (NPDES) Permit may be required if fish production from a facility reaches 20,000 pounds. Determination of the need for this permit is normally made on a case-by-case basis. The U.S. Environmental Protection Agency (EPA) has final responsibility for this permit, but in Oregon and Washington they have delegated the task of issuing it to the Oregon Department of Environmental Quality and the Washington Department of Ecology, respectively. The Idaho Department of Health and Welfare has not been so delegated, however EPA requires their review and certification before a permit is issued.

If migratory predator birds are to be destroyed, a permit is required from the U.S. Fish and Wildlife Service. This agency must also be consulted when any live fish or fish parts are imported from outside the United States.

Federal regulatory agencies

Environmental Protection Agency

1200 Sixth Avenue

Seattle, WA 98101

(206) 442-1200

\author{
U.S. Fish and Wildlife Service \\ Division of Hatcheries and Fisheries \\ Resource Management \\ 500 NE Multnomah St. \\ Portland, OR 97232 \\ (503) $230-6216$
}

Delegated state regulatory agencies for NPDES permit

Oregon Department of Environmental Quality

522 SW Fifth Avenue

P.O. Box 1760

Portland, OR 97204

Washington Department of Ecology

Mail Stop PV-11

Olympia, WA 98504

(503) $229-5256$

(206) 753-2800

Idaho Department of Health and Welfare (Reviews and certifies only)

Division of Environment

450 West State

Boise, ID 83720

(208) $334-4059$

\section{B. STATE GOVERNMENT}

The state fish and game agencies of Idaho, Oregon and Washington all implement regulations or policies for the control of salmon and steelhead propagation. Their purpose is to ensure orderly development, compatability with existing stocks, and disease control. All have regulations dealing with transfer of fish into and out of the state, including the 


\section{CHAPTER 10}

requirement of health inspection reports by an approved pathologist. Washington and Oregon also have strict regulations for transfer and release of salmonids within the state and both require and maintain records of disease history for all facilities.

Due to the occurrence of the virus diseases, infectious hematopoetic necrosis and infectious pancreatic necrosis in the Columbia River system, Oregon discourages the movement of these fish into coastal streams and Washington does not permit transplants of Columbia River stock into other watersheds. Roth states will consider exceptions on a case-by-case basis. In Idaho, a fish health program is presently being developed that will identify specific requirements governing the movement of fish and fish products.

Addresses for the fish and game agencies of Idaho, Oregon, and Washington are listed earlier in this chapter in the discussion of facility development permits required by each of the three states.

\section{c. INDIAN TRIBAL GOVERNMENT}

Only the Confederated Tribes of the Warm Springs Reservation of Oregon listed necessary fish cultural permits. Their Fish and Wildlife Committee must approve release sites, species, and numbers of fish. 


\section{BIBLIOGRAPHY AND LITERATURE CITED}

Alaska Department of Fish and Game. 1983. Fish Cultural Manual Fisheries Resource Enhancement Division. 85p.

Alexander, Gaylord R. 1977. Food of vertebrate predators on trout waters in North Central Lower Michigan. Papers of the Michigan Academy of Science, Arts and Letters, X(2): 181-194.

Allen, Richard L., K. Bauersfeld, L. R. Cowan, T. Burns, and D. A. Wilson, 1980. Salmon natural production enhancement program, 1976-1978. Washington Department of Fisheries Progress Report No. 105. 62 p.

Amend, D. F. 1976. Prevention and control of viral diseases of salmonids. Journal of the Fisheries Research Board of Canada 33 (4, 2): 1059-1066.

Anderson, A. R. 1982. The use of ozone in fish culture: A brief review. U.S. Fish and Wildlife Service, Longview, WA. Technology Transfer Series No. 82-2. 32 p.

Anderson, Richard 0. 1964. A sugar-flotation method of picking trout eggs. Progressive Fish-Culturist 26 (3): 124-126.

Antipe, Ross. 1982. Mini-modular hatchery. Component Analysis. Washington Department of Fisheries (Unpublished manuscript). 1 Op.

Atkin, L. and R. Kramer. 1979. Predator control by use of netting materials. Washington State Department of Fisheries (Unpublished manuscript). 3p.

Barns, R. A. 1979. Evaluation of gravel incubators on the third cycle of Tsolum River pink salmon, 1972-74. Fisheries and Marine Service Technical Report No 871. Canada Department of Fisheries and Oceans, Nanaimo, B.C. 31 p.

Barns, R. A. 1982. Experimental incubation of chum salmon (Oncorhynchus keta) in a Japanese-style hatchery system. Canadian Technical Report of Fisheries and Aquatic Sciences No 1101. Canada Department of Fisheries and Oceans, Nanaimo, B.C. $65 \mathrm{p}$.

Banks, J. L. 1983. Artificial substrates in vertical incubators: A method for controlling coagulated yolk disease in chinook salmon Oneorhynchus tshawytscha (Walbaum). U.S. Fish and Wildlife Service Technology Transfer Series, No. 83-1. 16 p.

Banks, J. L. and Warner G. Taylor and Steve L. Leek. July 1979. Carrying capacity recommendations for Olympia Area National Fish Hatcheries. Abernathy Salmon Cultural Development Center, Longview, WA. (working document). 44 p. 
Bibliography

Bell, Milo C. 1973. Fisheries Handbook of Engineering Requirements and Biological Criteria. Fisheries Engineering Research Program. Corps of Engineers, North Pacific Division, Portland, OR.

Bérézay, Gordon. Publication pending. Experiments with low-cost fish transportation methods. Canada Department of Fisheries and Oceans.

Bouck, G. R. 1980. Etiology of gas bubble disease. Transactions of the American Fisheries Society 109: 703-707.

Bouck, G. R. 1980. Air supersaturation in surface water: A continuing engineering and biological problem. Symposium on surface water inpoundments. ASCE/June 2-5, 1980/Minneapolis, MN. Paper No. 7-32. 1542-1551.

Bouck, G. R. 1982. Gasometer: An inexpensive device for continuous monitoring of dissolved gases and saturation. Transactions of the American Fisheries Society 111: 505-516.

Bouck, G. R. and King, R. E. 1983. Tolerance to gas supersaturation in fresh water and sea water by steelhead trout, Salmo gairdneri, Richardson. Journal of Fisheries Biology 23: 293-300.

Brannon, E. L. 1965. The influence of physical factors on the development and weight of sockeye salmon embryos and alevins. International Pacific Salmon Fisheries Commission Progress Report 12, 26 p.

Bullock, G. L. and H. M. Stuckey. 1977. Ultraviolet treatment of water for destruction of five gram-negative bacteria pathogenic to fishes. Journal of the Fisheries Research Board of Canada 34 (8): 1244-1249.

Burrows, R. E. and D. D. Palmer. 1955. A vertical egg and fry incubator. Progressive Fish-Culturist 17: 147-155.

Burrows, R. E. 1957. Diversion of adult salmon by an electrical field. U.S. Fish and Wildlife Service, Special Scientific Report - Fisheries No. 246.

Burrows, R. E. and B. D. Combs. 1968. Controlled environments for salmon propagation. Progressive Fish-Culturist 30(3): 123-136.

Burrows, R. E. and H. H. Chenowith. 1970. The rectangular-circulating rearing pond. Progressive Fish-Culturist 32 (2): 67-80.

Canada Department of Fisheries and Oceans (undated). Loading Criteria. Working Document DFO small projects, Vancouver, B.C. p 12.

Cannady, Bruce B. 1970. Loading factors as related to water temperature and altitude for trout and salmon to estimate weight of fish per GPM inflow. U.S. Fish and Wildlife Service, Portland, OR. (Unpublished manuscript). 1 p. 
Bibliography

Clay, C. H. 1961. Design of fishways and other facilities. Department of Fisheries, Ottawa, Ontario. 301 p.

Clayton, John G. 1968. Klickitat time study. Washington State Department of Fisheries. Hatchery Division, Inter-department report (unpublished manuscript). 7p.

Colt, John E. and George Tchobanoglous. 1979. Design of aeration systems for aquaculture. Proceedings of the Bio-Engineering Symposium for fish culture. American Fisheries Society. p. 138-148.

Combs, Bobby D. 1965. Effect of temperature on the development of salmon eggs. Progressive Fish Culturist 27 (3): 134-137.

Combs, Bobby D. 1968. An electrical grid for controlling trematode cercariae in hatchery water supplies. Progressive Fish-Culturist 30 (2): 67-75.

Combs, Bobby D. and Roger E. Burrows. 1957. Threshold temperatures for the normal development of chinook salmon eggs. Progressive Fish-Culturist 19 (1): 3-6.

Dailey, D. D. 1979. An evaluation of the Japanese-style Thorton Creek Pilot Chum Hatchery. 1976 Brood. Canadian Manuscript Report of Fisheries and Aquatic Service No. 1542. Canada Department of Fisheries and Oceans, Vancouver, B.C. 65 p.

Demaris, A. J. 1982. Some recent methods of predation control at Oregon Fish Hatcheries. Proceedings of the Northwest Fish Culture Conference: 51-58.

Dwyer, William P. and Howard R. Tisher. 1975. A method for settleable solids removal in fish hatcheries. Bozeman Information Leaflet Number 5, US Fish and Wildlife Service, Bozeman, Montana. 6 p.

Fagerlund, U. H. M., J. R. McBride and E. T. Stone. 1981. Stress-related effects of hatchery rearing density on coho salmon. Transactions of the American Fisheries Society 110 (5): 644-649.

Fitzpatrick, M. S., D. M. Oberbillig, B. K. Suzumoto, and C. B. Schreck. 1983. The use of des-gly 10 [d-ALA ${ }^{6}$ LH-RH-Ethylamide to induce precocious ovulation in adult female coho salmon (Onchorhynchus kisutch). In International Symposium for Salmon Reproduction, University of Washington Sea Grant Program. October, 1983. Seattle, WA.

Fulton, Leonard, Harold Gangmark and Bair, 1951. Trial of Denil-type fish ladder on Pacific salmon. U.S. Fish and Wildlife Service, Special Scientific Report Fisheries No. 99.

Fuss, H. J. and Charles Johnson. 1983. The effects of artificial substrate on growth and survival of hatchery coho salmon. Proceedings of the Northwest Fish Culture Conference: 8 . 


\section{Bibliography}

Fuss, H. J. and Charles Johnson. 1982. Quality of chum salmon fry improved by incubation over artifical substrates. Progressive Fish-Culturist (44) 4: 170-1 72.

Fuss, H. J. 1982. The use of substrate in the reduction of coagulated yolk disease in chinook salmon (Oncorhynchus tshawytscha). Proceedings of the Northwest Fish Culture Conference: 175-186.

Garlick, Lewis R. 1950. The helicopter in fish-planting operations in Olympic National Park. Progressive Fish-Culturist 12 (2): 73-76.

Glover, Maxine. 1980. (Editor) Salmonid enhancement program. Annual Report Summary. Canada Department of Fisheries and Oceans and Province of B.C. Ministry of Environment. 20 p.

Hager, Robert. 1981. Use of physical barriers to address bird predation problems at salmon hatcheries and rearing ponds operated by WDF. Proceedings of the Northwest Fish Culture Conference: 41-45.

Hager, Robert. 1980. Chum salmon production in Washington State Department of Fisheries Hatcheries. (Unpublished manuscript). $10 \mathrm{p}$.

Haskell, D. C. 1955. Weight of fish per cubic foot of water in hatchery troughs and ponds. Progressive Fish-Culturist (17) 3: 117-1 18.

Hoskins, John. 1982. Flow control and alarms. Proceedings of the Northwest Fish Culture Conference: 35-40.

Hourston, W. R. and D. Mackinnon. 1956. Use of artificial spawning channel by salmon. Transactions of the American Fisheries Society 86: 220-230.

Idaho, State of,/Corps of Engineers. 1984. General Information and Instructions for completion of joint applications for permit. Revised January 1984. $21 \mathrm{p}$.

Jensen, Raymond. 1972. Taking care of wastes from the trout farm. American Fishes and U.S. Trout News 16(5): 4-6, 21.

Johnson, W. S. 1983. Photoperiod induced delayed spawning of freshwater reared salmon. Salmonid Reproduction Symposium. Univ. of Wash. Sea Grant Program, Seattle, WA. 1 p.

Kerr, Wood and Leidal and Assoc. and D. B. Lister and Assoc., 1980. Stream enhancement guide. Canada Department of Fisheries and Oceans and B.C. 82 p.

Klontz, George W., Irvin R. Brock and John A. McNair. 1978. Aquaculture Techniques: Water Use and Discharge Quality. Idaho Water Resource Research Institute, Univ. of Idaho, Moscow, ID. 114 p. 
Koch, David and Gilbert F. Cochran. 1977. Feasibility report on a fish hatchery on the Colville Indian Reservation at Chief Joseph DAm, Bridgeport, WA. 44 p.

Kuhn, Gary E. 1982. Demand feeders. Document U.S. Fisheries Academy, Kearneysville, West Virginia. $24 \mathrm{p}$.

Lannan, J. E. 1975. The Netarts Bay chum salmon hatchery: An experiment in ocean ranching. Oregon State University., Corvallis, OR.

Leavens, Kathy. February 1983. An overview of net pen rearing as an enhancement technique. Canada Department of Fisheries and Oceans, Vancouver, B.C. p. 109.

Leitritz, Earl and Robert C. Lewis. 1980. Trout and Salmon Culture (hatchery methods). California Department of Fish and Game, Fish Bulletin 164. 1 y7 p.

Lister, D. B., D. E. Marshall and D. G. Hickey. 1980. Chum salmon survival and production at seven improved groundwater-fed spawning areas. Canada Department of Fisheries and Oceans - Report of Fisheries and Aquatic Science, No. 159558 p.

Mace, P. M. 1983. Bird predation on juvenile salmonids in the Big Qualicum estuary, Vancouver Island. Canadian Technical Report of Fisheries and Aquatic Sciences, No. 1176. Canada Department of Fisheries and Oceans, Vancouver, B.C. 79 p.

Mathews, Stephen B. and H. G. Senn. 1975. Chum salmon rearing in Japan, in Washington. Univ. of Wash. Sea Grant Program, Seattle, WA. WSG-TA 75-3. 24 p.

McClary, Denny. 1967. Development and use of an egg counter. Proceedings of the Northwest Fish Culture Conference: 22

McCraren, J. P. and R. M. Jones, 1974. Restoration of sock filters used to prevent entry of wild fish into ponds. Progressive Fish-Culturist 36, (4): 222.

McFarland, W. N. 1960. The use of anesthetics for the handling and the transport of fishes. California Fish and Game 46 (4): 407-431.

McIvor, Earl and Michael McMahon. 1983. Preliminary ideas catalog. Canada Department of Fisheries and Oceans, Special Projects Division, Vancouver, B.C. 69 p.

McLean, W. E. and A. Boreham. 1980. Aeration of hatchery water supplies. Proceedings of the Northwest Fish Culture Conference, Courtenay, British Columbia: 115-1 23.

MeMahon, Leonard A. 1984. A Guide To Public Works and Heavy Construction Costs. Magraw and Hill. Princeton, New Jersey. 206 p.

McNeil, William J. and Jack E. Bailey. 1975. Salmon Rancher's Manual National Marine Fisheries Service, Northwest Fisheries Center, Auke Bay Fisheries Laboratory, Auke Bay, Alaska, Processed Report. 95 p. 
Bibliography

Meehan, W. R. and L. Revet. 1962. The effect of tricane methane sulfonate (MS-2221 and/or chiied water on oxygen consumption of sockeye salmon fry. Progressive Fish-Culturist 24 (4): p. 185-1 87.

Mighell, James L. 1977. Device for rapid separation and removal of dead salmon eggs. Progressive Fish-Culturist 39 (3): 151-1 52.

Miller, Jack G. 1965. Advances in the use of air in taking eggs from trout. Progressive Fish-Culturist 27 (4): 234-237.

Missett, Kate and LuRay Parker. December 1983. Playboy of the Western World. Wyoming Wildlife, Wyoming Game and Fish Commission. p. 10-18.

Morberly, Stanley A. and Robert Lium. 1977. Japan salmon hatchery review. Alaska Department of Fish and Game. 124 p.

Mott, D. F. 1978. Control of wading bird predation at fish-earing facilities. Wading Birds, Research Report X7. Audubon Society. p. 131-132.

Northwest Power Planning Council. 1982. Recommendations for fish and wildlife program under the Pacific Northwest Electric Power Planning and Conservation Act, Vol II. Northwest Power Planning Council, Portland, OR: 416-723.

Nosho, Terry, Editor. 1981. Salmonid broodstock maturation. Proceedings by Northwest and Alaska Fisheries Center. National Marine Fisheries Service. Univ. of Wash. Sea Grant Program, Seattle, WA. 92 p.

Olson, Wayne. 1982. Demand feeders replace hand feeding at Dworshak NFH. Proceedings of the Northwest Fish Culture Conference: 73-78.

Oregon State University Extension Service. 1982. Obtaining permits for waterway development. SG 72/October 1982. 12 p. Prepared by James W. Good, Extension coastal resource specialist.

Owsley, David E. 1982. Control of bird predation at Dworshak NFH. Proceedings of the Northwest Fish Culture Conference: 56-62.

Owsley, David E. 1979. Nitrogen gas removal using packed columns, U.S. Fish and Wildlife Service, Dworshak NFH. Proceedings of the Bio-Engineering Symposium for fish culture. American Fisheries Society. p. 71-82.

Peck, Larry. 1979. Herbicide usage. Field memorandum Washington State Department of Fisheries (Unpublished manuscript). 5p.

Pflug, David E., H. Lee Fortier and Walter Larrick. 1983. Remote location hatchery development, R.W. Beck and Associates, Seattle. 11 p. 
Bibliography

Piper, Robert G. 1972. Managing hatcheries by the numbers. Fish Cultural Development Center. Bureau of Sport Fisheries and Wildlife. Bozeman, Montana. Published in American Fishes and U.S. Rout News (Sept. - Oct.). 3 p.

Piper, Robert G., Ivan B. McElwain, Leo E. Orme, Joseph P. McCraren, Laurie G. Fowler and John R. Leonard. 1982. Fish Hatchery management U.S. Department of the Interior, Fish and Wildlife Service. Washington D.C.5l7p.

Poon, D. C. and A. K. Johnson. 1970. The effect of delayed fertilization on transported salmon eggs. Progressive Fish-Culturist 32 (2): 81-84.

Roberts, R. J. and C. J. Shepherd. 1974. The Handbook of Trout and Salmon Diseases. Unit of Pathobiology, Univ. of Stirling, Great Britain. 168 p.

Salmon, Terrell P. and Fred S. Conte. Control of bird damage at Aquaculture Facilities. U.S. Fish and Wildlife Service Wildlife Management Leaflet No. 475. 11 p.

Sams, Roy E. 1983. A review of Oregon's experience in rearing salmon in earthen ponds, Oregon Fish and Wildlife Department (unpublished manuscript). 14 p.

Scholtz, A. T., R. M. Horrall, J. C. Cooper, A. D. Hasler, D. M. Madison, R. Poff and R. I. Daly. 1975. Artificial imprinting of salmon and trout in Lake Michigan. Wisconsin Department of Natural Resources, Fish Management Report 80. 45 p.

Sedgwick, Stephen D. 1982. The Salmon Handbook. Distributed by: Scholium International, Inc., Great Neck, New York. 242 p.

Senn, Harry G. and Andrew Jensen. 1968. Salmon egg incubation and Columbia River emigration studies. Phase II. - Temperature incubation analysis at Ringold study area. Contract \# 14-17-0001-1674. Bur. Corn. Fish, Portland, Oregon. p. S-20.

Senn, Harry G., Jack H. Pattie and John Clayton. 1973. Washington pond trays as a method for incubating salmon eggs and fry. Progressive Fish-Culturist 35 (3): 132-137.

Smith, Charlie E. 1978. Transportation of salmonid fishes. Pages 9-41 in Manual of Fish Culture, Secton G. U.S. Fish and Wildlife Service, Washington D.C.

Snyder, B. P. 1979. Use of artificial substrates for incubation of chum salmon. 1978 Research in Fisheries, Annual Report, College of Fisheries, Univ. of Wash., Seattle. Contribution 500. 33p.

Svoboda, Paul. 1984. Nisqually Tribal egg box site (unpublished manuscript). lp.

Swan, George A., Tommy G. Winthrow and Donn L. Park. 1980. Survey of fish protective facilities at water withdrawals on the Snake and Columbia rivers. National Oceanic and Atmospheric Administration Coastal Zone and Estuarine Studies Division, Seattle, WA and Environmental and Technical Services Division, Portland, OR. 15 p. plus Appendices. 
Bibliography

Thomas, Allan E. 1975. Effect of egg concentration in an incubation channel on survival of chinook salmon fry. Transactions of the American Fisheries Society 104 (2): 335-337.

Thomas, Allan E. 1975. Effect of egg development at planting on chinook salmon survival. Progressive Fish-Culturist 37 (4): 231-233.

Tipping, Jack. 1982. Evaluation of predator control attempts at the Cowlitz Trout Hatchery. Proceedings of the Northwest Fish Culture Conference: 47-50.

Trussel, R. P. 1972. The percent unionized ammonia in aqueous ammonia solutions at different $\mathbf{p H}$ levels and temperatures. Journal of the Fisheries Resources Board of Canada 29 (10): 1505-1507.

Wahle, R. J. and R. Z. Smith. 1979. A historical and descriptive account of Pacific coast anadromous selmonid rearing facilities and a summary of their releases by region, 1960-76. NOAA Technical Report, National Marine Fisheries Service, SSRF-736, 4op.

Washington State Department of Ecology. 1980. Operating a business in Washington State. Resource protection requirements. Second Edition, June 1980. Olympia, WA. 6 p.

Washington State Department of Ecology. 198 1. Developing hydropower in Washington State; a guide to permits, licenses and incentives. Office of Water Programs in cooperation with Washington State Energy Office, U.S. Department of Energy, Region X. January 1981. Olympia, WA. 50 p.

Wedemeyer, Gary A. and James W. Wood. 1974. Stress as a predisposing factor in fish diseases. Fish Disease Leaflet 38, U.S. Department of Interior, Fish and Wildlife Service, Washington, D.C. 8 p.

Weithman, A. Stephen and Richard 0. Anderson. 1977. Evaluation of flotation solutions for sorting trout eggs. Progressive Fish-Culturist 39 (2): p. 76-78.

Westers, H. 1970. Carrying capacities of salmonid hatcheries. Progressive Fish-Culturist 32 (1): 43-46.

Westers, H. and Keith M. Pratt. 1977. Rational design of hatcheries for intensive salmonid culture based on metabolic characteristics. Progressive Fish-Culturist 39 (4): $157-165$.

Wood, J. W. 1979. Diseases of Pacific Salmon: their prevention and treatment. Washington State Department of Fisheries, Olympia, WA. 82 p.

Worlund, D. D., R. J. Wahle and P. D. Zimmer. 1969. Contribution of Columbia River hatcheries to harvest of fall chinook salmon (Oncohynchus tshawytscha). U.S. Fish and Wildlife Service, Fisheries Bulletin. 67(2): 361-391. 
Bibliography

Zimmer, Paul D. 1964. A salmon and steelhead egg incubation box. Progressive Fish-Culturist 26 (3): 139-142.

Zirges, Malcolm H. and Lyle D. Curtis. 1972. Viability of fall chinook salmon eggs spawned and fertilized 24 hours after death of female. Progressive Fish-Culturist: 34 (4): 190.

Zook, William. Coordinator. 1984. Facility design work group report to the enhancement planning team for implementation of the Salmon and Steelhead Conservation and Enhancement Act of 1980. Final Draft, April 20, 1984. (Unpublished Manuscript). $73 \mathrm{p}$. 


\section{APPENDIX 1}

\section{TERMINOLOGY AND AGENCY ABBREVIATIONS}

\section{TERMINOLOGY}

Acclimatization - the adaptation of fishes to a new environment or habitat.

Adult - a sexually mature fish, In salmon species, precocious individuals that mature sexually before reaching full size are called jacks

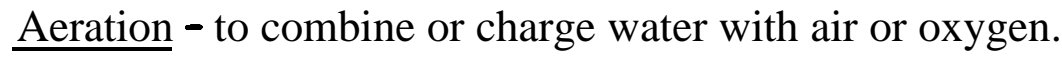

Alevin - larval salmon from the time of hatching to resorption of the yolk sac.

Artificial Substrate - a medium, other than gravel, in which eggs or alevins are incubated.

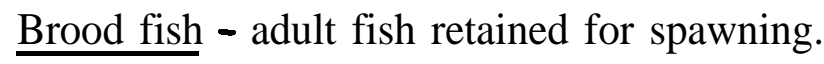

Capital costs - funds used for açauisition or construction of major capital facilities as opposed to operational costs

$\underline{\text { Carcass }}$ - the dead spawned out salmon or steelhead trout.

Conversion rate - the growth of fish relative to the amount of feed used.

Degassing - the process of removing gases from water; usually nitrogen, but applies to all supersaturated gases. Sometimes called deaeration.

Egg - the matured female germ cell, ovum.

Eyed egg - the stage where pigmentation of the eyes of the embryo becomes visible through the egg shell.

Feeder - usually refers to mechanical devices to distribute fish food.

Fingerling - juvenile fish from 15 days after beginning of feeding to one year after egg fertilization.

Fry - juvenile salmon at the time of yolk absorption, or the initiation of feeding in rearing units.

Gametes - sexual cells which conjugate and form a fertilized ovum.

Gene pool - the total genetic information possessed by the reproductive members of a population of sexually reproducing organisms. 
Genetic integrity - a fish population with an unimpaired gene pool.

Green egg - female germ cell prior to the eyed-egg stage.

Hatchery efficiency ratio (H.E.R.) - a measure to compare economic efficiency of several alternative subsystems one might use in a hatchery. The ratio of present value of total project (or subsystem) benefits divided by present value of total project (or subsystem) cost.

Incubation period - period from fertilization of the egg until beginning of active feeding by fry.

Incubator - device for artificial incubation of eggs and alevins from fertilization of the

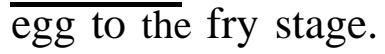

Infertile egg - egg that failed to fertilize.

Interchange rate - the number of times the water in a pond is completely replaced during one hour.

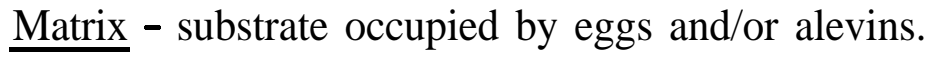

Maturation - the process of becoming mature.

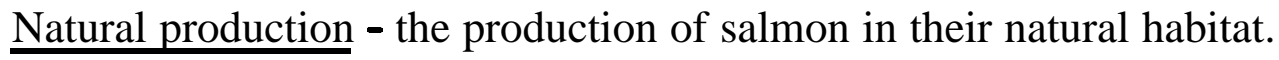

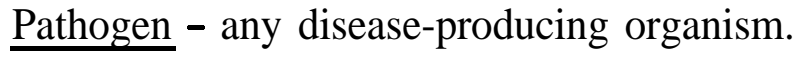

Predatory birds - birds that prey on hatchery fish.

Present value - the value of a benefit derived or a cost incurred, or used in the future, divided by a discount rate.

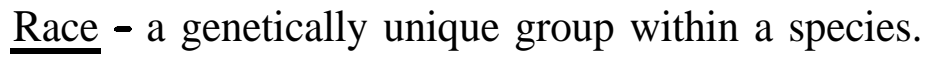

Rearing - the husbandry of fish from first feeding to time of release.

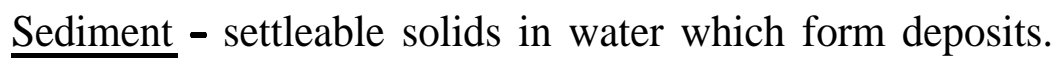

Shocking eggs - rough handling of eyed eggs, causing infertile eggs to turn white so they can be identified and removed.

Sizing - the use of grading devices to separate fish into uniform size groups.

Smolt - juvenile salmon at the time of initial physiological adaptation to life in the marine environment.

Smoltification - the process of a fish smolting. 
Appendix 1

Spawning - the process whereby the sex products are stripped from mature (or ripe) male and female fish and mixed to achieve fertilization. This is often referred to as the artificial spawning process.

Sperm - male sex cell.

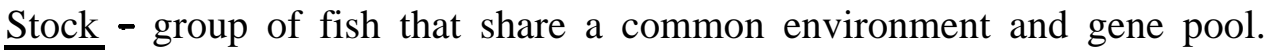

Substrate - gravel or plastic materials placed in an incubator to provide a medium for incubation of eggs or alevins.

Suspended particles - solids retained in suspension in the water column.

Temperature unit (TU) - defined as one degree of temperature above freezing for 24 hours.

Tender stage - period of early development during which the embryo is highly sensitive to shock, from a few hours after fertilization to the time pigmentation of the eyes becomes evident. Often called green eggs.

Turbidity - the extent of cloudiness of water, including both suspended and settleable particles.

Upwelling - water passing upward.

Water hardening - process where an egg absorbs water, generally at the time of fertilization.

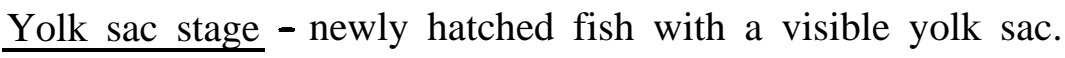

\section{AGENCY ABBREVIATIONS}

$\underline{\mathrm{AFG}}$ - Alaska Department of Fish and Game

$\underline{B I A}$ - Bureau of Indian Affairs

BPA - Bonneville Power Administration

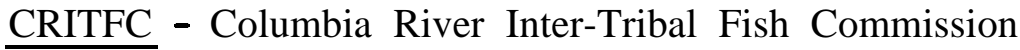

DFO - Canada Department of Fisheries and Oceans

$\underline{\text { FMC }}$ - Fish Management Consultants

IFG - Idaho Department of Fish and Game

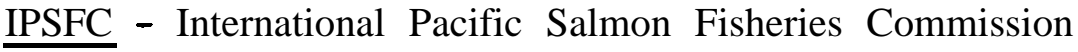

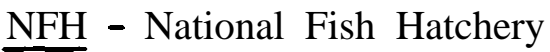




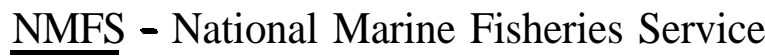

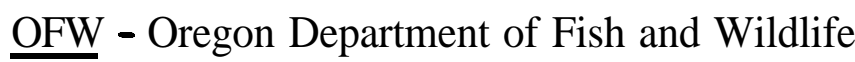

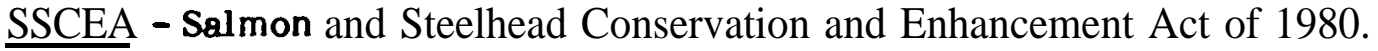

USFWS - U.S. Fish and Wildlife Service

WDF - State of Washington Department of Fisheries

WDG - State of Washington Department of Game 


\section{APPENDIX 2}

\section{VENDORS}

Disclaimer: The manufacturers, distributors and their products mentioned herein are for informational purposes only and do not imply endorsement by the authors. Further, it is not intended to be a complete list of products or vendors.

NAME OF FIRM

Air-Oil Products, Corp.

2400 E. Burnside

Portland, OR 97214

(also Seattle WA \& Eugene, OR)

Agri-Glass

P.O. Box 4474

Greenville, MS 38701

American Plastics

P.O. Box 238

Cheshire, OR 97419

American Scientific Products

3660 148th Ave. NE

Redmond, WA 98052

Ameron Pipe Division, NW

750 NE Columbia Blvd.

Portland, OR 97211

Aquaculture Research

Environmental Associates

P.O. Box 1303

Homestead, FL 33090

Aquadyne, Inc.

1440 Rollins Rd.

Burlingame, CA 94010

Aquafarms Canada Limited

RR 1

Feversham, Ontario

Canada NOC $1 \mathrm{CO}$

\section{PARTIAL SUPPLY LISTING}

Compressors, vacuum pumps, animators

Fiberglass tanks, troughs, and planting tanks, fish farming supplier, seines, diffusers and agitators, flow meters

Pond liners

Scientific testing equipment, microscopes, water analysis, small pumps, balances, etc.

Concrete cylinder pipe, tanks.

Aeration equipment, immersion heaters, low/ highwater alarm, compressors

Water powered screen

Demand and automatic feeders, timers, transport tanks, degassers, small rearing tanks, shallow and deep troughs, fish graders, fiberglass tanks, etc. 
$\underline{\text { NAME OF FIRM }}$

Aquafine Corp. 1869 Victory Place

Burbank, CA 91504

Aquashade

P.O. Box 198

Eldred, NY 12732

Aquatic Ecosystems, Inc.

P.O. Box 1446

Apopka, FL 32703

Argent Chemical Labs

14929 NE 40th St.

Redmond, WA 98052

Armco Construction

Products Division

P.O. Box 517

Hillsboro, OR 97123

Atco Metal Buildings

5115 Crowchild Trail SW

Calgary, Alberta

Canada T3E IT9

Babington Enterprises

Rt. 1 Box 264

Hagerman, ID 83332

Beal Pipe and Tank Corp.

5320 SW Macadum Ave.

Portland, OR 97201

Becker Industries

Rt. 3 Box 3272A

Clatskanie, OR 97016

Began Equipment

100 NE 11th Ave.

Portland, OR 97232

Biomed Research Labs, Inc.

1115 E. Pike St.

Seattle, WA 98122 $\underline{\text { PARTIAL SUPPLY LISTING }}$

Ultraviolet water sterilizers

Aquatic weed control

Gauges, spray nozzles, polyethylene fittings, air diffusers, air blowers, air compressor, 02 meter, tubing

Chemicals for aqua culture, including fish eradication, induced spawning, algae control

Steel pipe and pipe arch, aluminized steel pipe, risers, flumes

Metal buildings (Fold-A-Way)

Demand feeders, fish tanks, fiberglass products

Pipe and tanks.

Air and water treatment equipment, waste treatment, drum screens, other

Electronic vacuum pond cleaning unit, petroleum, liquid handling equipment

Fish health care products 
Appendix 2

NAME OF FIRM

Bioproducts, Inc.

P.O. Box 429

Warrenton, OR 97146

Boatcycle Co.

P.O. Box 494

Henderson, TX 75653-0495

Borden Metal Products Co.

P.O. Box 172

Elizabeth, NJ 07207

Burke Concrete Accessories

5750 NE Hassalo St.

Portland, OR 97213

Byron Jackson Pumps

1920 116th NE

Bellevue, WA 98005

Capilano Plastic

300 120th Ave. NE, Bldg. 5

Bellevue, WA 98005

Carolina Biological Supply, Co.

Box 187

Gladstone, OR 97027

Carus Chemical Co. 1500 8th St.

LaSalle, IL 61301

C. E. Shepard Co.

P.O. Box 9445

Houston, TX 7726 1-9445

Cessco, Inc.

740 SE Oak St.

Portland, OR 97214

Che $\mathbf{m}$-Tainer Industries

361 Neptune Ave.

N. Babylon, NY 11704

\section{$\underline{\text { PARTIAL SUPPLY LISTING }}$}

Dry and moist fish food

Agitators and chemicals, general fish culture equipment, seines, tanks, 12-volt car battery submersible pumps, feeders

Metal grating all types, slip resistant surface material

Pond sealing strips

Pumps including submersibles

Small shipping containers, buckets and

Aids, space saver rectangular containers, square salmon roe containers, others

Biological supplies, displays, apparatus, diagnostics, media, chemicals

Potassium permanganate

Vinyl coated wire mesh

Construction equipment, pumps, generators, pressure washers

Small plastic tanks (all types), stainless steel tanks and custom processing equipment 
NAME OF FIRM

Chemical Proof Corp.

19205 144th Ave. NE

Woodinville, WA 98072

Classic Pool and Spa Distributors, Inc.

5558 SE International Way

Milwaukie, OR 97222

Colossus-Multi-Tainer Corp.

P.O. Box 2004

Wenatchee, WA 98801

Concrete Products of Moses Lake

Moses Lake, WA

Common Sensing

7595 Finch Rd. NE

Bainbridge Island, WA 98110

Conde Milking Machine Co.

Box 99

Sherrill, NY 13461

Construction Materials, Inc.

2603 151st Place NE

Redmond, WA 98052

Corrosion Controls, Inc., 2930 Ford St.

Washougal, WA 98671

Crescent Research Chem.

5301 N. 37th Place

Paradise Valley, AZ 85253

Crestline Supply Corp.

Salt Lake City, UT

Daco Co.

P.O. Box 4

Bellevue, WA 98009

\section{PARTIAL SUPPLY LISTING}

Fiberglass tanks, piping, rearing units, fishways, tower shell.

Pools

Rigid structural foam, polyethelene containers - carcass holding, egg boxes, etc.

Pipe

Total dissolved gas pressure instrument

Aeration pumps

Engineering fabrics

Fiberglass fishways, large and small plastic-reinforced pipes, tanks, raceways, tower shell.

Anesthetics, foam, antifoaming agents, malachite green

Rubber sheet pond liners

Barrels, eggbaskets, aluminum processing tables, hand trucks, wire mesh containers, pallets, insect electrocutors, lifting equipment, etc. 
Appendix 2

\section{NAME OF FIRM}

Delta Net and Twine Co.

P.O. Box 356

Greenville, MS 38701

Demorest, H. Al

10912 Tempo Lake Drive SE

Olympia, WA 98503

Design Space International

27457 Pacific Hwy. S.

Kent, WA 98031

Don Sprague Sales, Inc.

2660 Progress Way

Woodburn, OR 97071

Duraframe Dipnet

Route 2 Box 166

Viola, WI 54664

Eastside Net Shop

14207 100th NE

Bothell, WA 98011

Environmental Marketing Associates 5065 SW Nash Rd.

Corvallis, OR 97333

Ershigs, Inc.

Bellingham, WA

FAL Products, Inc.

P.O. Box 9416

Tacoma, W.4 98409

Fisheries Supply Co.

1900 N. Northlake Way

Seattle, WA 98103

Floy Tag and Mfg., Inc.

P.O. Box 5357

Seattle, WA 98105

\section{PARTIAL SUPPLY LISTING}

Plastic containers, fish and egg transport equipment, seines, cages, rope and twine, scales, dip nets, algecide, rain gear, other

Paddle egg counter

Buildings, office and job trailers

Chemical sprayers and repairs

Dipnets, aerators, balances, netting, $\mathrm{PH} \& 02$ meters

Seines, net construction

Fish screens, micro screens, rotary screens, volclay pond sealing, fiberglass raceways, aeration, UVT, hydro generators, water treatment systems

Plastic tower shell.

Vertical cabinet incubator

Plumbing fittings, all types of marine hardware, ropes, twine, nets, clothing, paints, fishing gear and safety gear

Fish tags - spaghetti, disc and oval, streamers 
Appendix 2

\section{NAME OF FIRM}

Flurocarbon Fab. Div.

3711 S. Hudson St.

Seattle, WA 98118

Fresh-Flow Corp.

Rt. 1 - Hwy. 28 SW

Cascade, WI 53011

Gaco Western

6108 Highway 99

Vancouver, WA 98665

Garon

915 W. 12th St.

P.O. Box 114

Vancouver, WA 98666

Gator Dock and Marine

865 N. Dixie Highway

Lantana, FL 33465-3318

Gator Gates

P.O. Box 3318

Lantana, FL 33464-33 18

Glitsch, Inc.

P.O. Box 226227

Dallas, TX 75266

Great Western Chem. Co.

N. 1402 Thierman Rd.

Spokane, WA 98206

or

808 SW 15th

Portland, OR 97205

Hach Co.

P.O. Box 389

Loveland, CO 80537

H. D. Fowler Co., Inc.

13440 SE 30th St.

P.O. Box 160

Bellevue, WA 98009

\section{PARTIAL SUPPLY LISTING}

Free-style incubators

Aerators

Liquid rubber

Automatic fish feeder

Docks and aluminum water gates

Aluminum gates

Tower packings, tower internals, substrates saddles, bio-rings

Specialty cleaning and sanitation products, defoamers, many other products

Test kits, laboratory instruments, dissolved oxygen meters, chemicals, reagents, labware, technical information, service

Aerators and pumps 
Appendix 2

$\underline{\text { NAMEOFFIRM }}$

Heath Tecna Corp.

Structures, Inc.

19819 84th Ave. S.

Kent, WA 98031

Helnie Manufacturing Co., Inc.

8174 Berry Ave.

Sacremento, CA 95828

Herrington Manufacturing Co.

Twin Falls, Idaho

Hinds Supply Co.

4000 SW Hoken

Beaverton, OR 97005

Hydrolab Corp.

P.O. Box 50116

Austin, TX 78763

Industrial Fiberglass

Rt. 1 Box 34L

Cheney, WA 99004

Industrial Plastics, Inc.

680 S. 28th St.

Washougal, WA 98671-2597

Infilco Degremont, Inc.

Koger Executive Center

Box K-7

Richmond, VA 23288

Inqua Corp.

P.O. Box 86

Dobbs Ferry, NY 10522

Internet, Inc.

2730 Nevada Ave. N.

Minneapolis, MN 55427

J. L. Eagar, Inc.

P.O. Box 476

N. Salt Lake, UT 84054

\section{$\underline{\text { PARTIALSUPPLY LISTING }}$}

Fiberglass tanks, vertical incubator, tanks, troughs, live egg shipping cases

Feeders

Blower-feeder

Pipe and plumbing supplies

Water quality systems - surface or ground

Egg sorter

Machining/fabrication all plast ics, polyethylene piping (large)

Aerators

Cage culture

Heavy and light plastic netting, many varieties, predator netting, live box netting

Fish culture supplies of all types, rainwear, foot wear, gloves, hatching containers, nylon mesh, nets, plastic netting, livehaul tanks, twine, other 
NAME OF FIRM

Jensorter

Greg K. Jensen

18934 River wood Drive

Bend, OR 97701

Jon B. or Jolly Inc.

5416 California SW

Seattle, WA 98136

Johnson Screens Division

P.O. Box 3118

St. Paul, MN 55165

Justin Enterprises, Inc.

Westminister, CA

Keir and Sons, Ltd.

715 W. 16th Ave.

Vancouver, BC v5Z 158 Canada

Kelly Klosure Systems

P.O. Box 1058

Fremont, NE 68025

Ken's Fish Hatchery

P.O. Box 449

Alapana, GA 3 1622-0449

Kinney Spring Steel Broom Co.

Topsf ield, M A 01983

Koch Engineering Co., Inc.

4111 E. 37th St. N

Wichita, KN 67220

Landa, Inc.

4920 NE 122nd

Portland, OR 97230

Larry Harrington Co., Inc.

515 116th Ave. NE

Suite 260

Bellevue, WA 98004

\section{PARTIAL SUPPLY LISTING}

Jensorter - egg sorter and other makes of egg sorters

Fish counter (adult), temp printer, feeder control system

Well and intake screens, well development information

Plastic shell towers

Fin clipping scissors

Temporary modular buildings, semi-permanent modular buildings

Fish cultural equipment of all kinds, demand feeders, chemicals in fish culture, plastic mesh

Steel brooms

Tower packir:gs and in' ernals, substrates, bio-rings.

Pressure Washer

Hydronic specialties, centrifugal pumps. Heat transfer products, plumbing. 
Appendix 2

NAME OF FIRM

LTI, Inc.

P.O. Box 433

Lynden, WA 98264

Magic Valley Ileli-Arc

and Manufacturing

Twin Falls, ID

Mariculture Northwest

Rochester, WA 98579

Markson Science

7815 S. 46th St.

Phoenix, AZ 85040

MeCrary's Farm Supply

114 Park St.

Lonoke, AR 72086

Memphis Net and Twine Co., Inc.

P.O. Box 8331

Memphis, TN $3810^{8}$

Micro-Por, Inc.

P.O. Box 12218

Wichita, KS 67277

Mirafi, Inc.

P.O. Box 240967

Charlotte, NC 28224

(also Redmond, WA)

Modutank, Inc.

29-24 40th Ave.

Long Island City, NY 11101

Moore-Clark., Inc.

P.O. Box in

LaConner, WA 98257

Muskin

14545 S. Sunnyside Ave.

San Bernadino, CA 92408

\section{PARTIAL SUPPLY LISTING}

Contract fish hauling

Fish transfer pipe and tower

Contract rearing

Scientific testing equipment and supplies

Fish farm supplies, chemical, netting, nets, graders, agitators, pumps, many fish culture needs

Netting, nets, bird netting, ropes, twine, numerous small items for aquaculture needs

Air and fluid dispersers

Geotextiles

Pond liners, round steel tanks

Oregon moist pellets. Abernathy dry salmon feeds. New age dry salmon and trout feeds

Swimming pools 


\section{NAME OF FIRM}

M \& W Fabricators

717 E. Hastings St.

Vancouver, B.C. Canada

VGA1 R3

National Tank \& Pipe Co.

P.O. Box 7

Clackamas, OR 97015

Neilsen Metal Industries 3501 Portland Rd. NE

Salem, OR 97303

Nichols Net \& Twine

RR 3 - Bend Rd.

E. St. Louis, IL 62201

NOPAD Co.

P.O. Box 3029

Juneau, AK 99803

The Northstar Co.

Rt. 1 Box 229

Gaston, OR 97119

Northwest Linings

\& Geotextile Products

20222 87th Ave. S.

Kent, WA 98032

Northwest Marine Technology

Shaw Island, WA 98286

Norton Company

Chem. Prod. Division

Worchester, MA 01606

Novatech Designs Ltd.

830 - C Pembroke St.

Victoria, BC Canada V8T l H9

Nylon Net Co.

P.O. Box 592

Memphis, TN 38101

\section{PARTIAL SUPPLY LISTING}

Capilano rearing trough

Wood tanks, pipe, and flumes

Fish feeders, grader, fish pump and tower, aluminum trough

Hatchery seines (heavy and light), rope and twines, dip nets, netting

Fish incubators

Automatic fish feeder

Geotextile products

Binary-coded tagging machines, fry and egg counters

Substrate - plastic, plastic bio-rings, bio-saddles

Tensionometer (to check gas pressure)

Ropes, twines, nets, netting, commercial fishing supplies 
Appendix 2

NAME OF FIRM

Otterbine Barebo, Inc.

P.O. Box 217 R.D. \# 1

Emmaus, PA 18049

Oregon Aqua Foods

Springfield, OR

OVA, Incorporated

P.O. Box 1288

Wrangell, AK 99929

Pacific Metal Co.

P.O. Box C 88440

Tukwilla, WA 98188

(also Portland, OR)

Pacific States Cast Iron Pipe Co.

9450 SW Barnes Road

Portland, OR 97225

Pacific Water Works Supply Co.

P.O. Box 3515

Seattle, WA 98124

(also Portland, OR)

Pacific Wire Works, Inc.

2743 13th SW

P.O. Box 3824

Seattle, WA 98134

Pace-Pacific Pump Co.

2551 NW 30th Ave.

Portland, OR 97210

Peterson Fiberglass Laminates, Inc.

P.O. Box 158

Shell Lake, WI 54871

Phipps Water Alarm Co.

3529 NE 121st

Portland, OR 97220

Pro-Line

P.O. Box 1348

Crystal River, FL 32629

\section{$\underline{\text { PARTIAL SUPPLY LISTING }}$}

Aerators, including paddlewheel aerators, oxygen monitors

Contract rearing

Egg planting device

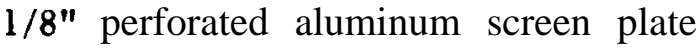

Pipe, valves and hydrants

Aerators

Wire screens, wire eggbaskets

High pressure and trash pumps

Pump systems, fish pumps

Transport tanks (fiberglass)

(complete line)

Water alarm

Fiberglass tanks, all shapes and sizes 
NAME OF FIRM

Prometco

P.O. Box 119

Kenmore, WA 98028

Queen Pump Co.

305 NE Russell

Portland, OR 97227

Rangen, Inc.

P.O. Box 706

Buhl, ID 83316

Ranger Boat

25802 Pacific Hwy. S.

Kent, WA 98031

Red Ewald, Inc.

P.O. Box 519

Karnes City, TX 78118-0519

Redden Net, Inc.

2626 Harbor Loop

Bellingham, WA 98225

Reiff Fiberglass Co.

Rt. 4 Box 183

City Co. Airport

Walla Walla, WA 99362

Roe, Inc.

Rt. 1 Box 240

Paymyra, WI 53156

\section{Roescan}

Rt. 1 Box 34L

Cheney, WA 99004

Scientific Supply \&

Equipment, Inc.

1818 E. Madison St.

Seattle, WA 98122

Shelter Shed 2200 South 144th St.

Seattle, WA 98168

\section{PARTIAL SUPPLY LISTING}

Aluminum prefabrication tanks, raceways \& fish tanks transport

Pumps

Rangen dry salmon and trout feeds

Fiberglass incubation tank

Fiberglass fish culture tanks

Seine and net building, marine supplies

Aqua culture tanks, hatchery tanks

Roe egg counter and sorter, hand tweezers for egg picking

Roescan egg sorter

Complete line of scientific equipment and supplies including respirators ans safety gear.

Ocean cargo containers 
Appendix 2

$\underline{\text { NAME OF FIRM }}$

Sims Fiberglass Co.

P.O. Box 36

Jefferson, OR 97352

SIR Mail Order

1869 Burrows Ave.

Winnipeg, Manitoba

R2X 2V6 Canada

Skane Fish Farm

Rt. 4 Box 137

Stratford Rd.

Moses Lake, WA 98837

Skretting

P.O. Box 319

4001 Stavanger, Norway

Quentin Smith

Claskanine Fish Hatchery

Rt. 1 Box 764

Astoria, OR 97013

Smith-Root, Inc.

14014 NE Salmon Creek Ave.

Vancouver, WA 98665

Soule Buildings

P.O. Box 6222

Carson, CA 90749

Spencer Turbine Co.

600 Day Hill Rd.

Windsor, CT 06095

Staff Industries

P.O. Box 759

78 Dryden Rd.

Upper Montclair, NJ 07043

Sterling H. Nelson \& Sons

118 W. 4800 S.

Murray, UT 84107

\section{PARTIAL SUPPLY LISTING}

Fiberglass tanks, incubation and rearing

Camping supplies

Contract rearing

Dry food and technical equipment for fish farming, hatching trough, hatching cylinder, fish feeders, transport boxes, net pens, other

Fish killing clubs

Boats and work barges, electro-fishing

equipment (battery and gas powered)

Buildings

Vortex blowers

Pond liners (flexible impermeable membranes)

Silver cup dry salmon and trout feeds 


\section{NAMEOFFIRM}

Sterling Net \& Twine Co., Inc. 18 Label St.

Montclair, NJ 07042

Swecker Salmon Farm

Rochester, WA

Sweeney Enterprises, Inc.

Rt. 2 Box 2452

Boerne, TX 78006

Syndel Laboratories Ltd. 8879 Selkirk St.

Vancouver, BC Canada V6P 4J6

Temcor

P.O. Box 3039

Torrance, CA 90510

Terra Aqua Conservation Co.

Reno, NV

Tetko, Inc.

420 Saw Mill Rd.

Elmsford, NY 10523

Topper Industries, Inc.

P.O. Box 1587

Vancouver, WA 98668

Tri-Core Plastics Ltd.

702 W. 59th Ave.

Vancouver, BC Canada V6P 1 X6

Trout Springs, Inc.

P.O. Box 11

McMillan, WA 98352

Valentine Equipment Co.

P.O. Box 53

Hinsdale, IL 60521

VWR Scientific, Inc.

P.O. Box 3551

Seattle, WA 98124

or

P.O. Box 14070

Portland, OR 97214

\section{PARTIALSUPPLY LISTING}

Nylon netting material, nets, live boxes,

Contract rearing

Automatic feeding systems

Hormones for inducing maturation, steroids for sex control, UV-chemicals

All aluminum dome building

Gabion wire

Screening and filtration media, synthetic fabrics, wire cloth, (all types)

Full line of floating structures for rearing pens, including aluminum frame net pen, marina docks

Vertical incubators, plastic

Sustaf egg sorter, contract rearing

Wire netting all kinds, poultry water and chemical dispensers, farm supplies

Very large line of scientific instruments, equipment and supplies, including safety gear 
Appendix 2

NAME OF FIRM

Warner Fish Ways WPM Corp.

P.O. Box 370

Point Roberts, WA 98281

or

St. Tsawwassen, Delta, B.C.

Warren Water Broom

Rt. 1 Box 764

Astoria, OR 97103

Western Concord Mfg. Ltd.

880 Cliveden Ave.

New Westminster, B.C. V3M 5V9

Western Farmers Association

201 Elliott Ave. W

Seattle, WA 98119

Western Wire Works

4025 NW Express Ave.

Portland, OR 97210

Wildlife Control Technology

6408 S. Fig

Fresno, CA 93706

Worcester Brush Co.

P.O. Box 658

Worcester, MA 01601

Yellow Springs Instrument Co., Inc.

Scientific Division, Box 279

Yellow Springs, OH 45387

Zak Tackle Mfg. Co. 2321 104th St. S.

Tacoma, WA 98444
PARTIAL SUPPLY LISTING

Adult fish lift

Pond brooms

Collapsable roll poly

Many farm supplies, plastic netting for birds

Screens, cloth, perforated metals, baskets

Bird netting, chemical protectors of birdnets

Pond brushes (stainless steel and nylon), fiberglass extension rods

Environmental study equipment, including oxygen monitor, thermometers, other

Spawning knife 


\section{APPENDIX 3}

\section{SALMON - STEELHEAD TROUT PRODUCTION FACILITIES VISITED}

$\underline{\text { Alaska }}$

Medvejie Central Incubation Facility - Private cooperative - Sitka

$\underline{\text { Canada (B.C.) - (DFO, Cooperatives and Tribes) }}$

Alouette River Cooperative

The Bell-Irving Hatchery - Kanacka Creek

Big Qualicum Salmon Hatchery

Chehalis Salmon Hatchery

Courtney Rod and Gun Club Side Channel

Ed Leon Side Channel of the Chehulis Indian Reservation

French Creek Fish and Game Club Facility

Little Mt. Side Channel of the Chehalis River

North Vancouver Outdoor School Mini Hatchery

Puntledge River Fish Hatchery

Quinsam River Salmon Hatchery

Railroad Creek Side Channel

Tenderfoot Salmon and Steelhead Hatchery

Upper Paradise Side Channel - Cheakamus River

Worth Creek Side Channel

$\underline{\text { Idaho }}$

Clear Springs Fish Hatchery - Private

Dworshak National Fish Hatchery - USFWS

Hagerman Fish Hatchery - IFG

Hngerman National Fish Hatchery - USFWS

Hayden Creek Research Station - U of Idaho/IF(j

Niagara Springs Steelhead Hatchery - IFG

Pahsimeroi Chinook Salmon Facility - IFG

Pahsimeroi Steelhead Collection Facility - IFG

Rapid River Fish Hatchery - IFG

Red River Rearing/Holding Area - IFG

\section{Oregon}

Big Creek Fish Hatchery - OFW

Bonneville Fish Hatchery - OFW

Cascade Fish Hatchery - OFW

Clatsop Co. Economic Development Project - County

Eagle Creek National Fish Hatchery - USFWS 
Appendix 3

Gnat Creek Fish Hatchery - OFW

Klaskanine Fish Hatchery - OFW

Leabury Fish Hatchery - OFW

McKenzie Fish Hatchery - OFW

Oakridge Fish Hatchery - OFW

Oregon Aqua Foods (Springfield, Oregon) - Private

Oxbow Fish Hatchery - OFW

Washington

Aberdeen Trout Hatchery - WDG

Abernathy Salmon Cultural Development Center - USFWS

Allison Springs Salmon Rearing Area - WDF

Beaver Creek Steelhead Hatchery - WDG

Bumping River Paddle Wheel Screen - Irrigation District

Chelan Trout Hatchery - WDG

Cowlitz Trout Hatchery - WDG

Elokomin Salmon Hatchery - WDF

Elsen Creek Hatchery - Squaxin Tribe

Enetai Creek Hatchery - Skokomish Tribe

Garrison Springs Salmon Hatchery - WDF

George Adams Salmon Hatchery - WDF

Goldendale Trout Hatchery - WDG

Hoodsport Salmon Hatchery - WDF

Humptulips Salmon Hatchery - WDF

Kennedy ( reek Egg Box Program - WDF

Klickitat Salmon Hatchery - WDF

Little White Salmon National Fish Hatchery - USFWS

Mariculture Northwest - Private

McKernan Salmon Hatchery - WDF

Moore-Clarke Company (Food Processing)`- Private

Naches Fish Hatchery - WDG

Naselle Salmon Hatchery - WDF

Nelson Springs (Coop.) - WDG

Pacific Power and Light Co. Intake, Naches - PP \& L

Priest Kapids Salmon Hatchery - WDF

Puyallup Salmon Hatchery - WDF

Quilcene National Fish Hatchery - USFWS

Quineult National Fish Hatchery - USFWS

Quinault Tribal Fish Hatchery - Quinault Tribe

Ringold Springs Rearing Pond - WDF

Ringold Springs Steelhead Pond - WDG

Rocky Reach Hatchery - WDF

Semish River Adult Holding Facility - WDF

Setsop Springs Rearing Area - WDF

Sequalechew Lake - WDF

Shelton Trout Hatchery - WDG

Skuinania Steelheed Hatchery - I DGi 
South Tacoma Steelhead Hatchery - WDG

Spring Creek National Fish Hatchery - USFWS

Swecker's Salmon Hatchery - Private

Tulalip Tribal Salmon Hatchery - Tulalip Tribe

Vancouver Fish Hatchery - WDG

Washougal Salmon Hatchery - WDF

Wells Salmon and Trout Hatchery - WDG/WDF

Yakima City Water Diversion - City of Yakima

Yakima Trout Hatchery - WDG 


\section{APPENDIX4}

\section{HATCHERY EQUIPMENT LIST BY FUNCTION}

\section{A. TRANSPORTATION, FISH ANDPERSONNEL}

1. Pickup Truck, 1/2 Ton

2. Pickup Truck, 3/4 Ton

3. Feed and Fish Tank Flat-Bed, 2-1/2 Ton

4. Fingerling and/or Adult Fish Transport Tanks With Accessories

5. $\quad \mathrm{CB}$ Mobile Units

6. Boat Suitable for Need

7. Tractor/Hoe, Broom, Louder and Hower

8. Forklift

9. Mini-Motor Powered Carts

10. Fish Pump With 'Tower

11. CB Base Station

12. CB Antenna

\section{B. MAINTENANCEOF GROUNDS-FACILITIES}

1. Sludge Pump

2. Ladders, Step and Extension

3. Push Brooms

\section{MAINTENANCEOFGROUNDS-EQUIPMENT}

1. Hydraulic Jack, 12 Ton

2. Battery Charger, $8 \mathrm{Amp}, 6$ and 12 volts

3. Booster Cables, 12 Volt x $20 \mathrm{ft}$. long

4. Grease Gun

5. Au to Creeper

6. Oil and (iasoline containers

7. Funnels (Various Size's)

\section{MAINTENANCE OF GROUNDS - GENERAL}

1. $\quad$ oodworking Hand Tools

R. Vetalworking Hand Tools

3. Welding Equipment and clothing

4. Portable Finergency Generator

$\therefore \quad$ Portable tinergency lighting

6. riss $w$ elder 
MAINTENANCE OF GROUNDS - GENERAL (cont'd.)

7. Arc Welder

8. Wood Vise

9. Drill Press and Vise

10. Band Saw

11. Wood Lathe

12. Metal Vise with Cinch

13. Table Saw

14. Flammable Storage Cabinet

15. Guns and Gun Safe

16. Small Hand and Power Tool Cabinets/Lock

17. Sawdust Vacuum

18. Electric Air Compressor

19. Portable Electric Circle Srw

20. Radial Arm Sew

21. Mitre Box/Back Saw

22. Hand Truck, 300 lb. Capacity

23. Bench Grinder, 3/4 HP

24. Electric Drill and Bits

25. Solder Gun Kit

26. Heavy Duty Staple Gun Set

27. Pop Rivet Gun Set

28. Hand Saws

29. Hack Saw

30. Come-A-Long

31. Hand Truck

32. Pipe Cutter

33. Wrecking Prybar (Small and Large)

34. Cloth end Metal Measuring Tapes

35. Wire and Paint Brushes

36. Tap and Die Set

37. Power Sanders

38. Pipe Threader

39. Rubber Mallet

40. Hemmers, Sledges and Axes

41. Pickaroon

42. Bolt Cutter

43. Extension Cord with Trouble Lite

44. Garbage Cans

45. Face Shield

\section{MAINTENANCE OF GROUNDS - GHOUNDS}

1. Shovels, Snow and ciardening

2. Weed Eater - Gas

3. Lawn Hower - Cias 
Appendix 4

\section{MAINTENANCE OF GROUNDS - GROUNDS (cont'd.)}

4. Wheelbarrow - Industrial

5. Garden and Leaf Rake and Hoe

6. Stainless Steel Weed Sprayer

7. Brush and Limb Trimmers

8. Garden Hose, Spray Nozzles (Pistol Grip), and Sprinklers

\section{HATCHERY BUILDING - OFFICE}

1. Typewriter

2. Calculator with Tape

3. Desks

4. Chairs

5. Filing Cabinets

6. Waste Baskets

7. Table

8. Book Case and Credenzas

9. Clock

10. Plain Paper Copy machine

\section{HATCHERY BUILDING - LAB}

1. Laboratory Fume Hood

2. Laboratory Refrigerator

3. Laboratory Stools

4. Laboratory Table Top with Cabinets

5. Glassware

6. Chemicals

7. Microscopes

8. Dissecting Microscope Lite

9. Balance Scales

10. Spectrophotometer

11. PH Meter

12. DO Meter

13. Maximum - Minimum Thermometers

14. Calibrating Thermometers

15. Dissecting Tools

16. Propane Torch with Holder

17. Bench Top Autoclave

18. Stir Hotplates

\section{HATCHERY BUILDING - CREW ROOM}

1. Microwave Oven

2. Brooms, Mops and Dust Pans 


\title{
HATCHERY BUILDING - CREW ROOM (cont'd.)
}

\author{
3. Lunch Table \\ 4. Chairs \\ 5. Refrigerator \\ 6. Stove or Hot Plate \\ 7. $\cot$ \\ 8. Lockers \\ 9. Large Bulletin Board
}

D. SPAWNING - HOLDING POND

1. Bleeding Racks

2. Egg Pails and Stands

3. Work Table

4. Carcass Boxes

5. Portable 12 cubic feet Temporary Holding Tank

6. Adult Dip Nets

7. Adult Fish Crowder or Seine

8. Spawning Knives

9. Spawning Club

10. Cooler Insulated Chests

11. House Trailer for Security during Adult Holding and Spawning

12. Spawning Clothing, Gloves and Boots

13. Boom Hoist

\section{E. INCUBATION}
1. Egg Weighing Scoop
2. Egg Tongs
3. Burlap Bags
4. Egg-Picking Machine
5. Egg-Picking Table
6. Low-Water Alarm

F. REARING - INTAKE

1. Screen and Pond Brushes

2. Pike Poles

3. Rack and Screen Rakes

REARING - POND

1. Screen end Pond Brushes

2. Fish Weighing Scale/Holder 
Appendix 4

REARING - POND (cont'd.)

3. Prams for Pond Feeding

4. Hand Cart

5. Dip Nets - Small Fish

6. Seine - Small Fish

7. Rack and Screen Rakes

8. Pond Cleaning Vacuum Pump/Accessories

9. Pump/Standpipe for Filling Fish Hauling Tanks

10. Coded Wire Tagging Machine

11. Trailer Mounted Blower Feeder

12. Pond Crowder

13. Fish Feeders (Uemand and or Automatic)

14. Hatcheryman's Raingear

15. Low-Water Alarms

\section{REARING - FEED ROOM}

1. $\quad$ Feed Weighing Scales

2. Hand Cart

3. Feed Buckets (5 gal.)

4. Feed Room Scoops

\section{REARING - GENERAL}

1. Wash Down Pump/Suction and Discharge Hose

2. Portable High Pressure Washer Pump with Accessories

\section{G. SAFETY-FIRST AID - GENERAL}

1. First Aid Kits (Shop \& Trucks)

2. Stretcher/Wool Blanket

3. Safety Goggles

4. Respirator Mask/Filters

5. Air Splint Set

6. Hard Hats

7. Hazard Signs (Keep Out, No Tresspassing, Danger, Detour, etc.)

8. Fire Pump/Hose and Nozzle

9. Fire Extinguishers (Buildings \& Trucks)

10. Life Vests

11. Ear Cover - Noise Suppression

12. Bulletin Board 


\section{APPENDIX 5}

\section{HATCHERY PERSONNEL JOB DESCRIPTIONS}

The following job descriptions were furnished courtesy of the Idaho Department of Fish and Game end are reproduced without change except for an addition to the Fish Hatchery Superintendent 2 minimum qualifications (in brackets).

\section{FISII HATCHERY SUPERINTENDENT 2}

Class code: 00784

\section{CLASS PURPOSE}

To direct the operation of a fish hatchery for the production of fish to be planted in Idaho waters; and perform related duties.

\section{PRINCIPAL ACCOUNTABILITIES}

1. Hatchery management. Typical responsibilities: directs the operation of a fish hatchery; supervises and trains staff; develops and monitors budget; maintains records and prepares reports on hatchery operation; is rcsponsible for inventory and maintenance of equipment and capital improverients; coordinates the hatchery operation with other department functions.

2. Aquaculture. Typical responsibilities: spawns fish and monitors the development of eggs and fry; develops and implements feeding schedules required for specific growth rates; cleans hatching tanks and raceways; observes fish behavior for signs of stress or disease; develops and implements water end feed treatments and prophylactic measures; grades and sorts fish by size and species; distributes, transports, and plants fish.

3. Public relationships. Typical responsibilities; conducts hatchery tours end answers questions; speaks to interested groups.

\section{GENERAL INFORMATION}

Incumbents in this classification direct the operation of a tirade 2 fish hatchery.

\section{MINIMUM QUALIFICATIONS}

[FMC recommends one full year of experience at a comparable station. See text.]

Any combination of education, training, and experience that demonstrates competence in each of the following: 
Appendix 5

Considerable knowledge of: department rules and regulations related to fish hatcheries; identifying characteristics, nutritional requirements, and behaviors of various fish species; spawning techniques; fish development; water quality relating to hatchery operation and fish planting; fish planting techniques.

Good knowledge of other department programs that relate to fish hatcheries.

Ability to: supervise a technical staff; provide training in hatchery operations; recognize abnormal behavior and disease symptoms of various fish species; develop and implement prophylactic and control measures; calculate feeding rates; develop and monitor a budget; interpret rules and regulations; establish policies and procedures; write narrative reports; give oral presentations; establish and maintain effective working relationships.

\section{PROBATIONARY PERIOD:}

Entrance: 2080 hours (12 months)

Promotion: 1040 hours (6 months)

Adopted: $7 / 70$; revised: $4-73 ; 7 / 78 ; 2 / 83$

JOB CONTENT EVALUATION: D12 175/D3(29)50/D1 P 87/B3II: $14=326$

Overtime code: $S$

\section{FISH HATCHERY SUPERINTENDENT 1}

Class code: 00786

\section{CLASS PURPOSE}

To direct the operation of a hatchery for the production of fish to be planted in Idaho waters; and perform related duties.

\section{PRINCIPAL ACCOUNTABILITIES}

1. Aquaculture. Typical responsibilities: spawns fish and monitors the development of eggs and fry; develops and implements feeding schedules required for specific growth rates; cleans hatching tanks and raceways; observes fish behavior for signs of stress or disease; develops and implements water and feed treatments and prophylactic measures; grades and sorts fish by size and species; distributes, transports, and plants fish.

2. Hatchery management. Typical responsibilities: directs the operation of a fish hatchery: supervises and trains staff; develops and monitors budget; maintains records and prepares reports on hatchery operation; is responsible for inventory and maintenance of equipment and capital improvements; coordinates the hatchery operation with other department functions. 
Appendix 5

\section{GENERAL INFORMATION}

3. Public relations. Typical responsibilities; conducts hatchery tours and answers questions; speaks to interested groups.

Incumbents in this classification either direct a Grade 1 hatchery or serve on the staff of a Grade 2 or 3 hatchery.

\section{MINIMUM QUALIFICATIONS}

Any combination of education, training, and experience that demonstrates competence in each of the following:

Considerable knowledge of: identifying characteristics, nutritional requirements, and behaviors of various fish species; spawning techniques; fish development; water and feed treatments and prophylactic measures.

Good knowledge of: department rules and regulations related to fish hatcheries; water quality relating to hatchery operation and fish planting; fish planting techniques.

Ability to: recognize abnormal behavior and disease symptoms of various fish species; write narrative reports; give oral presentations; establish and maintain effective working relationships.

PROBATIONARY PERIOD:

En trance: 2080 hours (12 months)

Promotion: 1040 hours (6 months)

Adopted: 7/70; revised: 4-73; $2 / 83$

JOB CONTENT EVALUATION: D12 152/C3(25)38/C IP 57/B3II:14 = 261

Overtime code: $\mathrm{S}$

FISH CULTURIST

Class code: 00810

\section{CLASS PURPOSE}

To perform technical duties at spawning stations or fish hatcheries for the production of fish to be planted in Idaho waters; and perform related duties. 
Appendix 5

\section{PRINCIPAL ACCOUNTABILITY}

Aquaculture. Typical responsibilities: spawns fish and monitors the development of eggs and fry; calculates growth gains; implementing feeding schedules required for specific growth rates; cleans hatching tanks and raceways; observes fish behavior for signs of stress or disease; implements water and feed treatments and prophylactic measures; grades and sorts fish by size and species; records amounts and types of feed given to fish, numbers of fish of various sizes and species, and daily fish mortality; transports and plants fish; writes narrative reports on feeding experiments and fish diseases and plantings; conducts tours of hatchery and explains hatchery operation; assists in maintenance of hatchery buildings and grounds.

\section{MINIMLM QUALIFICATIONS}

Any combination of education, training, and experience that demonstrates competence in each of the following:

Good knowledge of: identifying characteristics, nutritional requirements, and behaviors of various fish species; spawning techniques; egg development; common fish diseases and prophylactic measures.

Some knowledge of: water quality relating to hatchery operation and fish planting, first aid; basic carpentry and hernd tools.

Ability to: Calculate percentage, proportion, and volume; read ana apply technical terminology related to fish medications; write narrative reports concerning feeding experiments and fish diseases; give oral presentations; drive a one-ton truck; diagnose and repair minor mechanical problems.

Physical ability to: lift 50-pound bags.

\section{PROBATIONARY PERIOD:}

Entrance: 1040 hours ( 6 months)

Promotion: 520 hours (3 months)

Adopted: $2 / 83$

JOBB CONTENT EVAIUATION: CII $115 /(C 2(22) 25 /$ CXR $29 ; B 311: 14=183$

Overtime code: Y 


\section{APPENDIX 6}

\section{METHODS USED TO DETERMINE FISH COMPLEMENT AND REARING SPACE FOR PROTOTYPE STATIONS}

\section{PART I. METHODS OF ESTIMATING THE NUMBERS OF ADULTS, EGGS, OR ALEVINS REQUIRED TO ACHIEVE PRODUCTION GOALS}

In order to achieve the program production goals set out for the hatchery, the required number of adult fish, eggs, or alevins to be handled must be determined. The example which follows illustrates the procedures we used in this report.

Goal: Produce 200,000 coho smolts at 20 fish per pound and 200,000 coho fingerlings at 200 fish per pound.

Procedure: Using Table 2 in Chapter 9 we find that coho smolts survived from fertilized eggs to release at the rate of $75 \%$. Thus, to calculate the number of eggs required, we used a direct proportion:

$$
\left.\frac{75 \%}{200,000} \text { (Smolts) }=\quad \frac{100 \%}{X} ; \text { or } x=266,667 \text { (or } 267,000\right)
$$

Thus 267,000 fertilized eggs are required to produce 200,000 smolts.

To determine the fertilized egg requirement for the fingerling release at 200 coho/pound, we again use Table 2 which shows that 90 percent survive from fertilization to feeding, and 93 percent of the fish survive the first 100 days of feeding. Thus to find the survival level from fertilization to the end of 100 days of feeding, we multiply 90 (percent survival from fertilization to first feeding) $\mathrm{x} 93$ (percent survival for first 100 days of feeding), or 83.7 percent. Again using direct proportion:

$$
\left.\frac{83.7 \%}{200,000} \text { (fingerlings) } \quad \frac{100 \%}{X} ; \quad \text { or } \mathrm{x}=238,949 \text { (or } 240,000\right)
$$

Thus 240,000 eggs are required to produce 200,000 fingerlings.

When we add the two egg requirements together, the result is a total requirement of 507,000 eggs. Since there are an estimated 2,400 eggs per coho female (Table 2), we need 211 females for spawning. Either Table 2 or Table 3 in Chapter 9 can be used to make percentage calculations using the number of eggs or number of females as a base.

We used Table 3 and determined that the number of coho adults needed to be held at one time is 137 for 267,000 eggs. Thus, for 507,000 eggs (our total egg requirement), we need to hold 260 adults. Again using the direct ratio:

$$
\frac{137 \text { (adults) }}{267,000(\text { eggs })}=\frac{x \text { (rdults); }}{507,000 \text { (eggs) }}=260 \text { (male and females) }
$$


Appendix 6

Another method, using proportion, would have been to observe from Table 3 in a program that requires $111 \mathrm{females}$ for spawning. For this, 137 are projected to be held at one time. Thus:

$$
\frac{111}{137}=\frac{211}{X} ; \quad \text { or } x=260
$$

Thus 260 adult fish must be projected for holding at one time for spawning purposes.

\section{PART II. METHODS USED TO DETERMINE REARING SPACE REQUIRED IN LARGE PONDS TO MEET PRODUCTION GOALS}

The maximum rearing densities for salmonids in ponds less than $4,000 \mathrm{ft}^{3}$ capacity can be read directly from Table 2, Chapter 5. For ponds exceeding 4,000 $\mathrm{ft}^{3}$ capacity, we reduced the density factor (pounds $/ \mathrm{ft}^{3}$ ) shown in the table by $1 \%$ for each $1,000 \mathrm{ft}^{3}$ above 4,000 , up to a $50 \%$ reduction.

To determine the rearing space requirement, given the maximum rearing density allowed from Table 2, and the pounds to be reared, we used the following steps, where:

$$
\begin{array}{lll}
\mathrm{X} & = & \text { pond space in 000's of } \mathrm{ft}^{3} \\
\mathrm{P} & = & \text { pounds of fish in 000's } \\
\mathrm{d} & = & \text { maximum rearing density allowed (Table 2, Chapter 5) by size } \\
& \text { and species (e.g. } 2 \mathrm{lbs} / \mathrm{ft}^{3}, 1 \mathrm{lb} / \mathrm{ft}^{3} \text { ) } \\
\mathrm{P}^{\prime} & =\begin{array}{l}
\text { a value beyond which pond space } \mathrm{x} \text { increases linearly with } \\
\text { desired poundage } \mathrm{P} .
\end{array}
\end{array}
$$

1) Solve for

$$
\mathrm{p}^{\prime}=\frac{(1.04)^{2} \mathrm{~d}}{.04}
$$

2) If $\mathbf{P}>\mathbf{P}^{\prime}$, Solve for $\mathrm{X}$ using this formula:

$$
\mathrm{X}=\underset{\mathrm{d} / 2}{\mathrm{P}} \text { or } \frac{2 \mathrm{P}}{\mathrm{d}}
$$

3) If $\mathrm{P}<\mathrm{P}^{\prime}$, solve for $\mathrm{X}$ using this formula:

$$
\frac{X=1.04 d-\sqrt{(1.04 d)^{2}-(4)(.01 d)(P)}}{.02 d}
$$

Example: Using steps 1 and 2.

$$
\begin{aligned}
& \mathbf{x}=\text { pond space in 000's of } \mathrm{ft}^{3} \\
& \left.\mathbf{d}=1.0 \mathrm{lbs} / \mathrm{ft}^{3} \text { (Table } 2, \text { Chapter } 5\right) \\
& \mathbf{P}=38,500 \text { pounds of fall chinook } 100 / \mathrm{lb}
\end{aligned}
$$


Appendix 6

\$tep : Solve for $\mathbf{P}^{\prime}$

$$
\begin{aligned}
P^{\prime} & ={\frac{(1.04)^{2}}{.04}}^{\frac{d}{4}} \\
& ={\frac{(1.04)^{2}}{.04}}^{.04 .0)} \\
& =27.04 \mathrm{lbs}
\end{aligned}
$$

$\underline{\text { Btep }:} \quad$ Since $\mathbf{P}>\mathbf{P}^{\prime}$

$$
\begin{aligned}
& 38.5>27.04 \\
& \mathrm{X}=\frac{2 \mathrm{P}}{\mathrm{d}}=\frac{(\mathbf{2})(\mathbf{3 8 . 5})}{\mathbf{l}}=77 \text {, or } \\
& \mathrm{X}=77,000 \mathrm{ft}^{3} \quad \begin{array}{c}
\text { (pond space required for a } 38,500-\mathrm{lb} \text { fall chinook population } \\
100 / \mathrm{b})
\end{array}
\end{aligned}
$$

Example: Using steps 1 and 3.

$\mathrm{X}=$ pond space in $000 \%$ of $\mathrm{ft}^{3}$

$\mathrm{d}=1.7 \mathrm{lbs} / \mathrm{ft}^{3}$ (Table 2, Chapter 5)

$\mathrm{P}=20,300$ pounds of coho $20 / \mathrm{b}$

step 1: Solve for $\mathbf{P}^{\prime}$

$$
\mathrm{P}^{\prime}=\frac{(1.04)^{2} \mathrm{~d}=(1.04)^{2}(1.7)}{.04}=45.96 \mathrm{lbs}
$$

Btep : $\quad$ Since $\mathrm{P}<\mathrm{P}^{\prime}$

$20.30<45.969$

$$
\begin{aligned}
X & =\frac{(1.04)(1.7)-\sqrt{(1.04 \times 1.7)^{2}-(4)(.01)(1.7)(20.3)}}{(.02)(1.7)} \\
& =\frac{1.768-\sqrt{3.1258-1.3804}}{.034} \\
& =\frac{1.768-1.321}{.034}=13.14, \text { or }
\end{aligned}
$$

$\mathrm{x}=13,140 \mathrm{ft} 3$ (space required) for a 20,000-lb coho population $\mathrm{a} 20 / \mathrm{lb}$. 


\section{INDEX}

Abbreviations of agencies-Appendix 1, 438-439

Acidity 8

Adults 49-86

building security 229

guards 230

collection 49-68

artificial imprinting 67-68

barriers 49-58

fishlift (Warner) 206

fish ways $58-63$

hand methods 63-68 artificial imprinting 67-68

electro-shocking 67,68

hook and line capture $6 \tau$

nets $64-65$

snagging and gaffing 64-67

crowders $72,74,80$

fish security (see Security)

holding 68-78, 275-276

biological requirement. $<69-70$;

compartment holding 76-77 (see also Hatcheries (theoretiral) (condominiums))

holding ponds 70-75, 80

asphalt holding pond 73

concrete holding pond 73-74

dirt holding pond 72

design criteria 70-72

gravel holding pond 73

five boxes 75-76

pond sketch 70-75, 80;

shot-crete holding pond 74-75

informal holding 75-78

jumping 70-74

net pens 75

pen 75

portable tanks, adult 75

racks 49-53

rearing pond 76

space and flow for 69-70

space, hatcheries (t heoretical) 285

spawning 78-85, 461

survival $13.5,275-27 \hbar$

tanks 75
Adults (continued)

tethering 78

traps 76

tube 76-78, 214, 217, 381, 390, 396

security fences 229

spawning 78-85, 461

anesthetics 82

channels 114-I 17

efficiency 244

equipment list 461

facilities, 78-79, 80-81

handling 7 8-7 9

maturation rontrol 78-81

methods $81-82$

racks $49-53,79$

tools $8.3-85$

survival

effects from rearing 13.

in ponds $27.3-? 7 t j$

Ieration: of gase: $36-46$

lerstors $411-4$ !

Airlift pumps 24

-11arms, security 225-297, 230-237, 381

building 229

fence $229,232-234$

guards 230

guard dog 230

juvenile fish, kill alarm devices, scare devices 233-235, 237

juvenile fish, stringer lines 233, 235-236

telephone alarm 229

yard lights 229-230

water 227-229

water switch

location 227-229

type $227-229$

Alaskun Step pass fishwav $58, \mathbf{f 0 0} \mathbf{6}$ I

Algacides 191
lluminum raceways (se inetal raceways) 
Aluminum tube screen 18 1-1 82

Amberson dam 56-58

Anesthetics 82

Artificial imprinting of adults 67-68

Asphalt ponds (large) 159-160

Backpacks for fish transfer 2 16-2 17

Barriers, fish 44-58

electric fence 53-55

racks, 49-53

single and double 49-53

spacing 50, 69

trap $49,51,53,76$

picket spacing 69

velocity barrier 55-56

vertical dam 56-58

V-trap, V-tunnel 49, 51, 59

Basins, settling 33-34

Behavioral pat terns of fish $\mathbf{1 9 ?}$

lielt screens 34, 184

Bibliography 427-435

Bio-Rings (plastic) 128-129

Biological requirements of adult

holding 69-70, 275-277

numbers needed 276-277

oxygen 70

picket size 69

space and flow 69-70

survival 135, 275-276

Biological rearing requirements-criteria $133-136$

biological factors 133-I 36

fish per gpm 133-134

growth rates $275-278$

hatcheries (theoretical) 275-279

interchange rate $\mathbf{1 3 j - 1 3 6}$

net pens, net enclosures 163

numbers needed 276-278
Biological rearing... (continued)

pounds of fish $\mathrm{ft}^{3}$ 133-135, 468-469

raceways vs. circular 136

release time 276

rearing 133-198, 275, 278 (see also

Hatcheries, theoretical)

fish food 168-171

numbers required (calculations of) 467-469

rearing facilities 136-169

support equipment 171-198

unit cost summary 168-169

space requirements (calculations) 468-469

survival

effects to adults during rearing 135

temperature 134

temperature units $86-87$

Bird kill permits 230, 4 19, 425

Bleeding (adul ts) rack 83-84

Botulism (clostridium botulinum)

in large ponds 155

in sludge 198

Bounce egg picking method 123-124

Box incubators 99-109, 130

baffled or shallow-matrix 104-I OS

false bottom or deep-matrix 101-104

free-style 107-1 09

Montana 106-107

Brails, fish transfer 206207

Broomstick weirs 50-51, 53

Bucket incubators $1111-14$

Buckets for fish transfer 2 16-2 17

Budgets

costs of operating 241, 243 (see also

Theoretical hatcheries, Chapter 9)

at theoretical hatcheries 285-4 17

summary at theoretical hatcheries 416-417 
Index

Buildings 2 18-22 1

capital costs, theoretical hatcheries 284,416

cold feed storage criteria, 221-222

design criteria, hatcheries (theoretical) 281-283

material costs 220

material comparisons 219

security alarms 229

Butyl rubber lined ponds 161

Buzzell egg sorter 123-1 24

Cage culture (see pens)

Canopies and covers, juvenile fish security $230-232,235$

Cans for fish transfer 2 16-2 17

Capilano trough 138-139, 169

Capital costs (see also Cost) capital and operating costs 245-246 component costs 240-241, 284 hatcheries (theoretical) 284, 416 rearing units 89, 136, 169 summary by functions 416

Centrifugal pumps 24-25

Channel and stream incubation 114-120 egg planting 119-120 incubation channels 117-I 18 keeper-Japanese channels 118-1 19 spawning channels 114-1 17

Chemical applications 191-193

Chlorine, wa ter sterilizatior. 46

Circular ponds 147-155 concrete 149-1 50 cost summary 169 earthen 150-151 fiberglass 15 1-1 52 general characteristics of $147-149$ life expectancy 169 plastic $151-152$

Circular ponds (continued) plastic-sheet 152-153 swimming pool 152-153 wooden 153-154

\section{Cleaning}

large ponds 192

raceways $139-140$

Coarse screens 31

Coho hatcheries/satellites (theoretical) 364-380, 416-417

20,000 lb. capacity $364-371,416-417$ $50,000 \mathrm{lb}$. capacity $371-380,416-417$

Collection of adults 49-68 artificial imprinting 67-68 barriers $49-58$

fishlift (Warner) 206

fishways $58-63$

hand methods 63-68 artificial imprinting 67-68 electro-shocking 67, 68 hook and line capture 67 nets $64-65$ snagging and gaffing 64-67

Collection systems, water, 12-23

Comparisons of building materials 219

Compartment holding-adults 76-77

Concrete ponds

adult holding 74

circular ponds 153-154

cost 169

large 160

life expectancy 169

rearing (see also raceways, circular ponds, large rearing pond 14 1-1 42) raceways 141-142 summary 169

Concrete pool-and-weir fishway 59, 61

Condominium holding, adults 76-77

Construction, general 
Construction . . . (continued)

costs, capital 241

modification costs 241

Construction permits

federal 418-419, 425

state $\mathbf{4 1 9 - 4 2 3}, 425-426$

tribal 423-424, 426

Controls

water temperature $47-48$

Costs

(see also within each chapter individual unit costs)

analysis 4 14-4 17

building material 220

capital 240-241, 245-246, 284, 416

components 240-241, 284

construction 241

per pound of production 416

summary by functions 416

combined capital and operating 245-246

construction

capital 241

modifications 241

component costs 240-241, 284

cost and production estimation 254-255

electricity 284

engineering 241,284

fish production manpower standards 245

food costs 171, 284

food storage 220-222, 224

hatcheries (theoretical) 284, 416-417

heating water 47-48

incubation egg picking efficiency 244-245

land acquisition 240, 284

landscaping 415

manpower standards 245

operating 241-246, 254-255, 284, 416-417

budgets 241, 243

operations manpower analysis 243-245

per pound of fish production, summary, hatchery $416-417$

private sector fish production 246, 414

production estimation 89, 254-255

pump operating 25-26, 241-243, 284

ratio, sunk 259-260
Costs (continued)

reduction alternatives 415-416

road construction and maintenance 226

rearing units 89, 136, 169

salmonid production 240-246, 284

spawning efficiency 244

summary by functions 416

sunk, ratio, 259, 260

theoretical hatcheries

buildings, capital costs 284, 416

equipment, furnishings and supplies, capital 284, 416

fish production facilities 284, 416

site development, capital costs 284, 416

water supply and drains, capital, 284,416

water heating 47-48

water temperature control $47-48$

Counters (fish) 194

Crew room equipment list 460-461

Crowders

adult $72,74,80,206-208$

Cylindrical incubators 109-1 14, 130

barrel 113-1 14

bucket 111, 113

jar 109-112

jug 111-113

typical unit illustrated 110

Dam, toe drain 23

Data worksheet, hatchery, efficiency ratio 256

Deaeration of gases 37

Degassing of gases 37

Deep trough incubators 93-94, 137

Delivery open channels, water 28

pipelines, water $26-28$

siphons, water 29-30 
Index

Demand feeders 175-177

Earthen circular ponds 149-150, 169

Denil fishway 58, 60, 61

Earthen raceways 142-144, 169

Design criteria

building 283

fish production system 282-283

provisions (considera tions) for rearing 136

site preparation 281-282

water supply and drains 282

Development

goals, hatcheries (theoretical) 274-275

methods, hatcheries (theoretical) 274

permits

federal 4 18-4 19, 425

state $419-423,425-426$

tribal 423-424, 426

site, capital costs of hatcheries (theoretical) 284, 416

Dip-nets 188- 189

Dirt Ponds adult holding 72

circular ponds 150 - I5 1, 1 iis

large 157-158, 169

raceway.5 142-144, 189

Discharge wa tcr facilities for 196-198

permits requirements $195,196,425$

pollutants 195

rearing facilities $13 \mathbf{6}, 282$

sludge, usı? of 198

Dissolved gases 7 (see also Bıological requirements, adults, incubation, rearing, transporta tion)

in water 7

limitation of 37

Drains and water supply systems 24-30 capital costs, hatcheries (t heoretical) 284,416

Irum incubator; (see Incuinators, barrel)

Iry feed (see food)

Efficiency ratios

hatchery (HER) 251-253, 255-256, 258-259, 265-273, 415

data worksheet 256

incubation systems 259, 261-263

rearing systems $263-265$

\section{Egg}

baskets, wire 96

counters 124-I 25

estimation methods 124-125

mechanical 124

paddle 124

development 86-88

estimating numbers 124-126

planting channels 119-120

sorting 120-I 24

bounce method 123-I 24

flotation method 122-I 23

hand picking 12 1-1 22

mechanical pickers 123

transportation of 199-200

pre-fertilized 199-F-200

fertilized 200

water absorption 86

Electronic counters 194

Electric fence 53-55

Electric grids for water sterilization 46

Electricity in hatcheries

costs 24 1-243, 284

Electroshocking 66, 68, 396

Enclosure (see net)

Endnngered Species Act 419

Equipment

crew room 460-461

furnishings and supplies, capital costs, hatchery (theoretical) 284, 416 incubation 120-129, \$61 
Equipment (continued)

laboratory 460

list of $238,458-462$

maintenance $458-460$

office 460

replacement, major, hatcheries (theoretical) 284

rearing $461-462$

safety 462

spawning 83-85, 461

transportation 202-217, 458

Engineering costs 241, 284

Evaluation, theoretical site risk 257-258

Facilities 455-457 (see also facilities by name)

design provisions (considerations) 136

risk 255-256

risk scoring system 255-257

visited $455-457$

Fall chinook/coho hatcheries (theoretica!) 348-364, 416-417

$10,000 \mathrm{lb}$. capacity $348-352,416-41 \pi$

20,000 lb. capacity $352-359,416-417$

$50,000 \mathrm{lb}$. capacity 360-364, 4 16-417

Fall chinook hatcheries (theoretical)

287-313, 416-417

$10,000 \mathrm{lb}$. capacity $287-292,416-417$

$20,000 \mathrm{lb}$. capacity $292-296,416-417$

$50,000 \mathrm{lb}$. capacity 296-300, 416-417

Fall chinook hatcheries'sa tclli tes

(theoretical) 300-313, 416-417

20,000 lb. capacity 300-307, 4 16-41 ?

$50,000 \mathrm{lb}$. capacity $307-313,416-417$

False bottom or deep-matrix box incubators $101 \cdot-104$

Feeders

demand feeders $175-177$

fry feeders (mechanical) 172-I ?3

hand feeding $171-173$

mobile feeders 175-175, 178-1 79

pond feeders 174-175

stationary blower feeders 171
Feeders (continued) stationary mechanical fry 172-173 stationary pond $174-175$

Federal permits $418-419,425$

federal agencies for 4 18-4 19

Fences

adult fish security 229

electric 53-55

predator fences 232-234

security alarms 229

Fiberglass circular ponds 15 i-1 52

Fiberglass raceways 147-148, 169

Fine screens 31

Finger weirs 59

Fish food 168, 170-171

concepts 285-286

conversion 170-17 1

cost of 170

feeders (see Feeders)

feed types 168, 170-171

Oregon Moist Pellet (OMP) costs 284

Fishlifts, transfer 206

Fish predator control methods 2.30 $2: \therefore 7$

(see also Predation)

kill permits 230, 425

rish predators 230. 332

Fish production facilities theoretical hatcheries capital costs 284,4 I $\dot{b}$

Fish tanks (see Transportation, equipment:

Fish transfer puinp 18: -18r ?0:-3:0

Fishways 58-63

Alaskar Step j,asis 38, (il)-6!

-hararteristic comparisor of 61

lenil $58,60,61$ 
Index

Fishways (continued)

life expectancy 61

pool-and-weir 58-63

concrete 59,61

plastic $61-62$

rock 61-63

wood 61-63

salvage value 61

vertical baffle 59

vertical slot 59

Flotation of eggs 122-123

Flumes (fish transfer) 205

Food, fish 168, 170-171

cold feed storage building criteria 221-222

conversion 170-1 71

cost of 170

feeders (see Feeders)

demand feeders 175-177

fry feeders (mechanical) 172-1 73

hand feeding 171-173

mobile feeders 175-176, 178-179

pond feeders 174-1 75

stationary blower feeders 171

stationary mechanical fry $172-173$

stationary pond 174-175

feed types 168, 170-171

storage 222-224, 382, 386, 388-389,

392,394

cold feed storage building criteria $22 \quad 1-222$

cost 220-222, 224

dry feed 222, 382, 386, 388-389, 392,394

housing 222-224

Oregon Moist Pellet (OMP) 222

Free-style incubators 107-109

Fry feeders (mechanical) 172-I 73

Gabion screens 35

Gaffing adults 64-67

Gallery, infiltration 323-325, 330, 332, $339,343,374,377,392-393$
Gamete transportation 199-200

Gas, atmospheric (see Gases)

Gases (see also Water quality, Incubation) aeration 36-46 aerators (see Gases, stabilization)

degassing (deaera t ion) 36

dissolved limitations 37

gas bubble disease 35-37, 46

gas measurementation (oxygen, nitrogen) 45-46

gasometer, nitrogen 45

saturometer, nitrogen 45

stabilization 35-46

aerators

floating 42-43, 197-198

multicone 44-45

paddle $40-41$

spray 41

aspirators $39-40$

equipment $37-46$

in nature 35

tower/media (pack column) 36, 37-39

vacuum degassing 42,44

supersaturation $35-37,46,48$

(iear pumps 24

Groundwater 35-36

Growth rates steelhead trout 275-278

salmon $275-278$

Grading, graders (see sizing)

Gravel box incubators (see Box incuba tors)

Gravel ponds adult holding 73

large 158-159

raceways 142-143, 169

Gravel substrate 126-128

Guard dogs, security 230

Guards, security 230 
Index

Hand feeding 17 1-1 73

Hand picking of eggs 121-122

Handling during spawning 78-79

Hardware cloth screen 180-181

Hatcheries, theoretical (see also Theoretical hatcheries)

analysis $265-273$

concepts, 285-286

efficiency ratio (HER) 251-253, 255-256, 258-259, 265-273, 415

evaluation and selection 248-273 (see Water quality)

site considerations (see Water quality 239-240)

theoretical 274-417 (see also Coho,

Fall chinook, Fall chinook/coho, Spring chinook, Steelhead hatcheries, theoretical)

adult holding space 285

biological criteria 275-279

capital costs 284,416

buildings 283

design criteria 283

design 28 1-283

design criteria 281-283

design guidelines 281

development goals 274-275

development methods 274

equipment, furnishing and supplies 284,416

equipment replacement, major 284

fish production facilities 284, 416

fish production systems, design criteria 282-283

housing 284

incubation types 285

incubation units 285

operational considerations 280

operations and maintenace (O\& $\mathrm{M}$ ) costs 24 1-246, 284, 4 1 6-4 17

programs of 280-4 15

rearing types and space 286

repairs (rehabilitation), major, 284

site development 284, 416

site preparation, design criteria $28 \quad 1-282$
Hatcheries, theoretical (continued)

site selection 280-281

water requirements 286

water supply and drains 284, 416

water supply and drain design 282

water temperatures 278-279

theoretical types of hatcheries

coho 364-380, 416-417

fall chinook 387-3 13, 416-4 17

fall chinook/coho 348-364, 4 16-417

spring chinook 3 14-347, 4 16-4 17

steelhead 381-414, 416-417

Hatchery efficiency ratio (HER) 25 1-253, 255-256, 258-259, 265-273, 415

Hatching eggs (see eggs)

Heating costs, water $47-48$

Heath incubator (see incubator, vertical)

Heavy metals 8

Herbicides 19 1-1 92

High pressure pump 185-1 86

History of Columbia River hatcheries 1-2

Holding, adult 68-78, 275-276

biological requirements $69-70$

compartment holding 76-77 (see also

Hatcheries (theoretical)

(condominiums))

holding ponds $70-75,80$

asphalt holding pond 73

concrete holding pond 73-74

dirt holding pond 72

design criteria 70-72

gravel holding pond 73

live boxes $75-76$

pond sketch 70-75, 80;

shot-crete holding pond $i \$-i j$

informal holding 75-78

jumping 70-74

net pens 75

pen 75

portable tanks, adult 75

racks 49-53 
Holding, adult (continued)

rearing pond 76

space and flow for 69-70

space, hatcheries (theoretical) 285

spawning 78-85, 461

survival 135, 275-276

tanks $\mathbf{7 5}$

tethering 78

traps 76

tube $76-78,214,217,381,390,396$

Hole size of screen 177

Hormone injection, maturation, steelhead trout, 381

Housing

cold feed storage building criteria $22 \quad 1-222$

food storage 222-224

dry feed storage $222,382,386,398-389$, 392, 394

hatcheries (theoretical) 284

Oregon Moist Pellet (O.MP) storage 222

residential 283

Idaho permits (see State permit?)

Incubation 86-1 32, 244-245, 259, 261-263, 275-278, 285, 461

biological requirements/criteria $\mathbf{9 6 - 8}$, 275-278

channels 117-1 18

channel and stream incubation 114-120

spawning channels 114-1 17

incubation channels 117-I 18

keeper-Japanese channels 118-1 19

egg planting 119-120

egg picking efficiency costs 244-245

equipment 120 -I 29

floor space 131-132

substrates 125-129

gravel 126-1 27

plastic netting 127-1 28

plastic saddles 128

plastic bio-rings 128-1 29

summary 129 -I 32

summary of unit features 131

systems analysis $259,26 \quad \mathbf{l - 2 6 . 3}$

tools 120-I 29
Incubation (eontinueri)

types for hatcheries (theoretical) 285

unit cost comparison 130

unit type 88-120

units, in hatcheries (theoretical) 285

Incubators 86-1 31

box incubators 99-109, 130

baffled or shallow-matrix 104-105

false bottom or deep-matrix 101-104

free-style 107-109

Montana 106-1 07

cylindrical incubators 109-1 14, 130

barrel 113-1 14

bucket 111, 113

jar 109-112

jug 111-113

typical unit illustrated 110

egg baskets, wire 96

equipment list 120-I 29, 461

gravel box incubators (see box incubators)

pond incubation 97-100, 130

st rea mside incubators (see box incube tors, cylindrical incubs I ors)

trough incubators 93-97, 130

deep trough 93-94

shallow trough 95-97

vertical incubators 88-9.3, 130

No pad 91-92

vertical cabinet 88-9 I

Inclined plane screens 14, 32-33

Indian tribal permits 423-424, 426

Infiltration gallery $323-325,330,332,339$, $343,374,377,392-393$

Infiltration, water, 22-23

trenching for 22

IIIN, steelhead trout 381

Injection, hormone, steelhead trout maturation 381

Inlets, water 12-20, 139-140 (see also Intakes)

instream dam water intakes 15 
Index

Inlets, water (continued)

instream rock filter water intakes 15

Intakes $12-20$

submerged screen 1 S-1 8

lake bank 12-14

stream bank 12-14

spring $19-20$

instrea in rock filter 15

instream dam 14-15

inlet $12-20$

Interchange rate (water) 135-136

Introduction 1-4

general procedures used 3-4

history of Columbia River hatcheries $1-2$

management efforts 2

purpose of compendium 1

Japanese channels (keeper) 118-1 19

Job description (see also Perscnncl job descriptions; 246-247, 46.3-467

Jug incubator $111-113$

.lumping of adults in-i4

Juvenile fish predation (see predation)

Kecper-.Japanese channels 1 18-119

I. Aivoratory equipment list 4 t?

Lake bank water intakes 12-1 4

I andscaping costs 415

Large rearing ponds 154-16 I

asphalt 159-160

butyl rubber 161

characteristics of 154-1 57

cleaning 192

concrete 160

cost summary 169

dirt ponds $157-158$

gravel 158-159

life expectancy 169
Large rearing ponds (continued) plastic lined 161

shot-crete 160-1 61

Land acquisition costs 240, 284

Light (see also Ma tura tion) effects on nets 188 refraction for adult holding 70 steelhead trout 381

sunburn 10

Limitations dissolved gases 37

Literature cited, 4?7-435

I rve boxes adults $75-76$

(floating), transportation 214, 216

l.je fish transportation 200-217

biological criteria of 20 I-202

biological requirements of 201-202

cost per pound 212-213

live boxes

Hdults $75-76$

off-station equipment 207-217

on-station equipinent 202-207

personnel dangers 200

Maintengines and supplies (see Equipment list i

Manpiwer (see tersonnel)

In terial costs of buildings (see Buildings)

Naturation

rontrol 79-P I

lights 381

hormone injection 381

Mechanical egg counter It 1

Inechanicai e g pichers 1?j-124

Hetqis, toxic $8,41,48$

Hetul ry.rongs 146-i 4; 
Index

Microfilter screens 34-35

Mobile feeders 175-176, 178-179

Montana incubators 106-107

Morpholine 6 8-69

Netarts incubator 104

Netting (see nets)

Net pens and net enclosures 161-169, 337-338, 34 1-342, 345, 395-397, 399-400, 403, 405-406, 411, 413, 415 adult holding 75

characteristics of 162-1 68

locations of 165-166

net enclosures 164-169, 395-397, 399-400, 403-415

net pens $162-169$

Nets

dip-nets 188-189

effects from light 188

for adults 64-65, 396

for juvenile fish 188-189

materials for (Vendors) 440-454

pole seine, 188

pond seine, 188-189

Nitrogen

dissolved 35-37, 45-46

dissolved measurementation 45-46 gasometer 45 saturometer 45

Non-smolt, steelhead trout 384

Office equipment list 460

Off-station transportation equipment portable tanks 208-211 tank trucks and tank trailers 211 cans, buckets and backpacks 2 16-217 collapsible roll poly 215

floating live boxes 2 14, 216 tube transfer 202-204
On-station fish transfer equipment 202-208

pipes and tubes 202-204

flumes 205

pumps, brails and lifts 205-206

crowders 206208

small containers 207

Open channels, water delivery 28

Operating costs $241-245,284,417$

Operating pumps, costs of 25-26, 284

Operation budget (see hatcheries, theoretical 241-245, 284, 417)

Operation considerations, hatchery (theoretical) 280

Operations and maintenance costs, hatcheries (theoretical) 284, 416-417

O\&M (operations and maintenance) costs, hatcheries (theoretical) 284, 416417

Operations list, equipment 238

Operations permits $418-426$

federal 425

state $425-426$

tribal 426

Optical density egg pickers 123-124

Oregon permits (see State permits)

Outlets, sizing 141

Oxygen

Dissolved measurementa tion 45

Dissolved 35-37, 45

see Biological requirements rearing

adults

incubation

transportation

in water $7-8$ 
Ozone, water sterilization 46

Paddle egg counter 124

Paddlewheel screen drive 183

Pathogens 5, 9-1 1 (see also Biological) adults 69

botulism (clostridium botulinum)

in large ponds 155

in sludge 198

require men ts, adults; incubation;

rearing; see also Botulism)

Pens, net and net enclosures 161-169, 337-338, 341-342, 345, 395-397, 399-400, 403, 405, 406, 411, 413, 415 adult holding 75

characteristics of 162-1 68

locations of 165-166

net enclosures 164-169, 395-397, 399-400, 403-415

net pens $162-165,169,337-338$, $341-342,345,395-397,399-400,403$, 405-406, 411, 413, 415

Perforated plate 177,179

Permits $418-427$

discharge water 195,196

facility development $418-424$

facility operations $418,424-426$

predators (fish) 230, 425

Personnel

fish culturist $465-466$

job descriptions 246-247, 463-467

policies $246-247$

qualifications $246-247$

salaries 247

skills and salaries $246-248$

standby time 247

superintendent 1, 464-465

superintendent 2, 463-464

station requirements 248

volunteer 247-248, 332, 396, 399, 405

volunteer program guides 248
Picket spacing (see screening adults) 50, 69

Picking eggs (see hand picking)

Pipelines 26-28

Pipes, fish transfer 202-204

Piston pumps 24

Pit incubator 103

Planting tanks off-station, portable 208-211

Plastic Bio-Rings 128-129

Plastic circular ponds 151-152, 169

Plastic lined ponds 161, 169

Plastic pool-and-weir fishway 61-62, 169

Plastic sheet circular ponds 151-152, 169

Plastic raceways 147, 169 (see also metal, wooden)

Plastic saddle substrate 128-1 29

Pole seine, 188

Pollutants in discharge water 195

Pollution abatement ponds 196-198

Pond seine, 188-189

Pond

brooms in pond care (see Pond care)

care 189-1 93 algacides 191

chemical applications 192, 193

cleaning 192

herbicides 191-1 92

large pond cleaning 192

painting 191

pond brooms 189-191

feeders 174-1 75

incubation 97-100, 130

screen 176-1 84 
Index

Pond (continued)

aluminum tube 181-182

belt 184

hardware cloth 180, 181

hole size 177

paddlewheel screen drive 183

perforated plate 177,179

rotary drum 33, 183-184

slotted plate 178,180

vinyl-coated hardware cloth 181

settling basins 196-I 98

space

adults $69-70$

rearing 133-136

Ponds (see also Adult holding, Rearing

facilities, Pond care)

holding ponds $69-75,80$

pollution abatement 196-198

Pool-and-weir fishway 58-63

concrete 59, 61

plastic $61-62$

ruck 61-63

wood $61-63$

Population enumeration (live fish) 193-194

behavioral pat terns of fish 193

elrctronic counters 194

inethods 193-194

random samplers 194

Population estimation methods 467-469

eggs, fish 457-468

live fish 467-469

Portable tanks

adult 75

planting tanks for off-station

transportation, 208-21 I

Pounds of fish

per cubic foot 133-1 35, 468-469

per gpm 5, 7, 133-134

Predation control, juvenile fish 230-237

canopies and covers 230-232, 235

fencing 232-234

kill devices 234-235

scare devices 233-234, 237

Predation control (continued)

security 233-235, 237

stringer lines 235-236

Predator kill permits (see Security)

Predators, fish (control methods) 236-237

Preface xxiv

Present value theory 249-254

(examples) 25 1-253

Pressure pump 185-1 86

Private sector fish costs 246, 414

Procedures used in report 1-4, 467-469

(see also individual chapters, Appendix 6)

estimating egg/fish for production $467-468$

Introduction 1-4

space required in large ponds 468-469

Production

costs 240-246, 284, 4 16-4 17

estimation, and cost, 254-255

facilities visited $\mathbf{4 5 5}-\mathbf{4 5 7}$

Propeller pumps 24-25

Pumps 24-26

airlift 24

centrifugal 24-25

characteristics of 25

costs for energy 25-26, 241-243, 284

fish transfer 187-188, 205-206

gear 24

high pressure 185- 186

operating costs 25-26, 254-255, 284

piston 24

propeller 24-25

rubber vane 24

toma to pump $187-188,205-206$

trash pump 185

vacuum 186-1 87

Purpose of compendium 1 
Index

Raceways 139-147, 169

cleaning 139-140

concrete 141-142, 169

earthen 142-143, 169

fiberglass 147-148, 169

inlets 139-140 (see Individual units)

metal 146-147

outlets 141-143 (see Individual units)

pond incubation 97-100, 130

screening (see individual rearing units)

wooden 144-146, 169

Racks 49-53, 69, 79

single and double 49-53

spacing 50, 69

spawning 79

Ratio

data worksheet (hatchery efficiency) ratio 256

efficiency 251-253, 255-256, 258-259, 265-273, 415

Rearing 133-1 98, 46 1-462

biological requirements 133-136, 163

channels 168

criteria 133-1 36

equipment list 46 1-462

facilities 136-169

circular ponds 147-155, 169

cost of (see Individual unit) 89, 136, 169

design provisions (considerations) 136

large ponds 154-161, 169

net pens and net enclosures 161-169

raceways 139-147, 169

trough and tanks 137-139, 169

fish food, 168-17 1

growth 133-136, 275-278

life expectancy summary 169

numbers required 467-469

ponds-adult holding 76

support equipment 17 1-I 98

systems

analysis 263-265

efficiency ratio 263-265

types and space, hatcheries

(theoretical) 286

unit cost summary 168-169
Redds, 396

Repairs, major, hatcheries (theoretical) 284

Requirements

biological, hatcheries (theoretical) 275-279

water hatcheries (theoretical) 286

Risk, facilities and scoring system 255-257

Roads 224-226

construction and maintenance 226

construction materials 225

construction criteria 224

costs, construction and maintenance 226 widths 224

Rock pool-and-weir fishway 6 1-63

Rotary drum screens 33, 183-181, 339, 343, 392-393

Rubber vane pumps 24

Saddles, plastic, as substrate 128

Safety

dangers in fish transportation 200

equipment list 462

personnel 200

Salaries and skiils, personnel 246-248, 46.3-467

Salt dipping of $\in 605 \div 1 ? \lambda-123$

Salt in fish transportation 201

Salmon

growth rates $275-278$

Salmonid production costs 240-246, 284, 416-417

Samplers (fish! i 94

San: filter s.retns 31

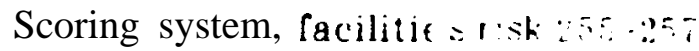


Index

Screening 3 1-35 (see also screens and individual rearing units within chapters)

Screens 12-17, 20, 31-35

belt 34

coarse 31

drum 16

fine 31

gabion 35

hole size 177

incline plane 14, 20, 32-33

infiltration 22-23

intake (low cost) 18

microfilter 34-35

rock filter 15

rotary drum 33, 339, 343, 392-393

sand filter 34

stream and lake bank 12-14

water velocity 31

well screens for intakes 16

Security alarms 225-237, 239-237, 381

building 229

fence $229,232-234$

guards 230

guard dog 230

juvenile fish, kill alarm devices, scare devices 233-35, 237

juvenile fish, stringer lines 233, 235-236

telephone alarm 229

yard lights 229-230

water 227-229

water switch

location 227-229

type $227-229$

Seining (see Nets)

Seins (see Nets)

Settling basins 33-34, 196-198

Shallow trough incubators 95-97

Shipment (see Transportation)

Shocking eggs $86,120-121$

Shocking, electric 67-68, 396

Shot-crete ponds

adult holding 74-75

large 160-161, 169

rearing 160-161, 169

Silt in water 8

Single and double racks 49-53

Siphon 2 9-30

Site

considerations 239-240)

development capital costs, hatcheries (theoretical) 284, 416

housing 284

operational considerations 280

operations and maintenance (O\& M1) costs, 284, 416-417

repairs, (rehabilitation), major, 284

risk and sunk cost 256-259

risk evaluation, theoretical 257-258

selection, hatcheries (theoretical) 280-281

water

quality 5-1 1

temperatures 278-279

Sizing

devices 194-1 95

fish graders 194-1 95

steelhead trout 383

Slotted plate screen 178, 180

Sludge, use of 198

Smoltification 7, 384

steelhead trout 7,384 (see also

biological requirements-rearing)

Snagging adults 64-67

Sodium chloride in fish transportation 201

Spawning of adults 78-85, 461

anesthetics 82

channels 114-I 17

efficiency 244

equipment list 461 
Spawning of adults (continued) facilities, 78-79, 80-81

handling 7 8-7 9

maturation control 79-81

methods 8 1-82

racks 49-53, 79

tools $83-85$

Sperm and egg transportation 199-200

Spring chinook hatcheries (theoretical) 314-347, 416-417

$10,000 \mathrm{lb}$. capacity $314-319,416-417$

$20,000 \mathrm{lb}$. capacity $319-323,416-417$

50,000 lb. capacity 323-327, 416417

Spring chinook hatcheries/salellite

(theoretical) 327-347, 416-417

$20,000 \mathrm{lb}$. capacity $327-336,416-417$

$50,000 \mathrm{lb}$. capacity $337-347,416-417$

Spring water intakes 19-20

Stabilization of gasses 35-46

aerators

floating 42-43, 197-198

multicone $44-45$

paddle $40-41$

spray 41

aspirators $\quad 39-40$

in nature 35

tower/media (pack column) 36, 37-39

vacuum degassing 42,44

Standby time, personnel 247

State permits

Idaho 422-423, 425-426

Oregon 419-421, 425-426

Washington 42 1-422, 425-426

Stationary blower feeders 171

Stationary mechanical fry feeders 172-1 73

Stationary pond feeders 174-175

Steelhead trout hatcheries (theoretical) 381-414, 416-417

$10,000 \mathrm{lb}$. capacity $381-386,416-417$
Steelhead trout hatcheries (continued) $20,000 \mathrm{lb}$. capacity $387-390,416-417$

50,000 lb. capacity 390-394, 416-417

Steelhead trout hatcheries/satellite (theoretical) 395-414, 416-417

$20,000 \mathrm{lb}$. capacity $395-403,416-417$

$50,000 \mathrm{lb}$. capacity 404-414, 416-417

IHN 381

maturation

lights 381

hormone injection 381

non-smolt 384

Sterilization

water $46-47$

chlorine 46

electric grids 46

ozone 46

sand filter 34

ultraviolet light (UV) 46-47

Storage (see also Buildings)

area for tools 82

dry feed

housing, 222-224

food, costs of 220-222, 224

Oregon Moist Pellet (OMP) storage 222

food 222-224, 382, 386, 388-389, 392, 394

cold feed storage building criteria 221-222

Stream bank water intakes $12-14$

Streamside incubators 99-1 14, 130 (see box incubators, cylindrical incube tors)

Submerged screen water intakes 15-18

Substrates 125-129 (see also individual incubation units)

gravel 126-127

plastic netting 127-1 28

plastic saddles 128

plastic bio-rings 128-129

Sunburn

from water quality 10

spring chinook 314,316 
Index

Sunk cost site risk 256-259

Supersaturation of gases 7, 35-37, 46, 48

Suppliers, materials 440-454

Supplies and maintenance 440-454

Swimming pools (rearing) 151-153, 387-389

Switch type water security alarms 227-229

Tanks for adults 75

Tank trucks and trailers, for transportation 211

payload $211-2$ 12, 215

hauling cost $212-213$

loading rates 215

Telephone security alarms 229

Temperature (see also Biological requirements: adults, incubation, rearing, transportation)

control, water, costs 47-48 egg transportation 199-200

fish transportation 20 I-202 incubation 86-87

transportation of fish 201-202

units, incubation 86-87

water 5,7

water supply for 5-7, 276-279

water temperature control 47-48

Terminology-Appendix 1, 436-438

Tethering of adults 78

Theoretical hatcheries 274-4 17

adult holding space 285

biological criteria 275-279

buildings

capital costs 284, 416

design criteria 283

capital costs 284,416

cost reduction alternatives 4 15-416

design 28 1-283

design criteria 281-283

design guidelines 281
Theoretical hatcheries (continued)

development goals 274-275

development methods 274

equipment, furnishing and supplies 284, 416

equipment replacement, major 284

fish production facilities 284, 416

fish production systems, design criteria 282-283

housing 284

incubation types 285

incubation units 285

operational considerations 280

operations and maintenace (O\&MI) costs 284, 416-417

rearing types and space 286

repairs (rehabilitation), major, 284

site development 284, 416

site preparation, design criteria 281-282

site selection 280-281

temperature units $86-87$

theoretical types

fall chinook 287-3 13, 416-4 17

spring chinook 314-347, 416-417

coho 364-380, 416-417

fall chinook/coho 348-364, 4 16-4 17

steelhead 38 1-4 14, 4 16-4 17

Theory

present value (examples) 251-253

present value 249-254

Time, personnel standby 247

Toe Drain, Dam 23

Tools (see Equipment)

Tomato pump (see Pumps, fish transfer)

Toxic materials 8

Toxic metals 41,48

Transportation anesthetics, use of 201

biological criteria of $201-202$

cost per pound $212-213$

eggs 199-200

pre-fertilized 199-200 


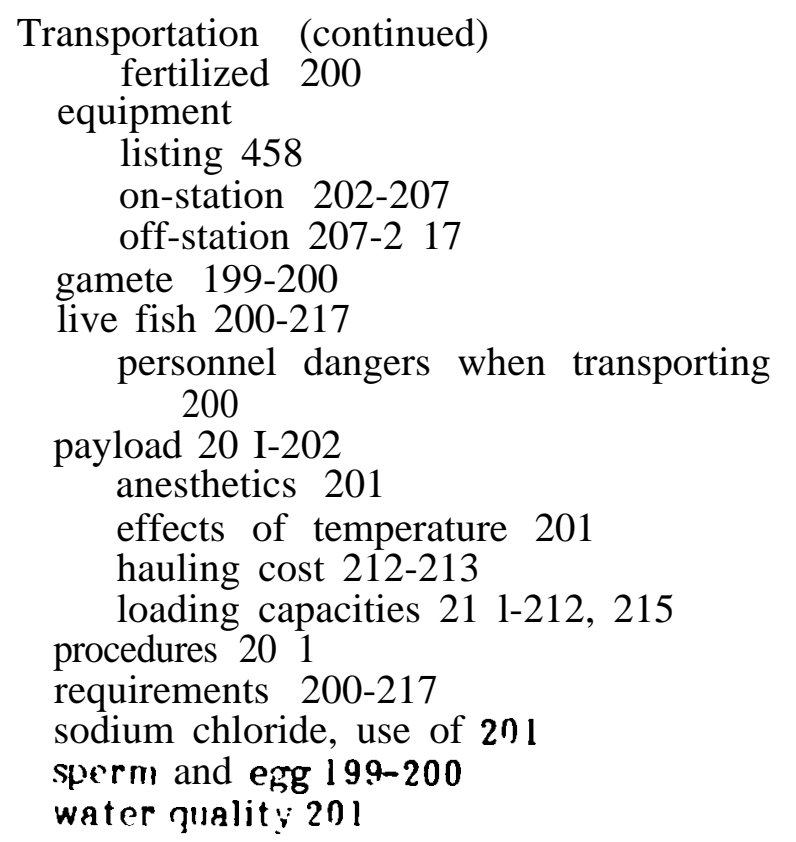

Trap 49, 51, 5.3, 69, 76 adults 76

picket spacing 69

1 rash pump 185

Trunching, for water infi!tration 22

Tribql permits $42.3-424,426$

Truugh and tank rearing $89, ! 37-139,169$

rapilano trough 138-139, 169

cost of (see Trough incubators)

derp trough 93-94, 137

shallow trough 95-97

types of 89,137

Trough incubators 93-97, 130

deep trough 93-94

shallow trough 95-97

Tube

adult 76-78, 214, 217, 381, 390, 396

collapsible roll poly 215

fish transfer 202-204

Turbidity 8

U'traviolet light, water sterilization 46-4
Vacuum degassing 42, 44 (see also gas stabilization)

Vacuum pump 186-187

Value theory, present 249-254 examples $251-253$

Velocity barrier 55-56

Velocity of water (screening) 31

Vendors 440-454

Vertical baffle fishway 59

Vertical barrier dam 56-58

Vertical cabinet incubators 88-9 I

Vertical incubators 88.9.93, 130 No pad 91-92

Vertical slot fishwry 59

V-trap, V-tunnn! 19, 51, 59

Vihert box 120

Vinyl-coated hardware sloth 181

l'inyl raceways (ser fiberglass; metal, wooden)

Volunteer personnel 247-248, 332, 396, 399,405

Warner fishlift 206

Washington permits (see State permits)

Water

alarms (see Alarms; Security)

collection systems 12-2.3

dam toe drain 23

delivery systems 24-30

open channels 28

pipelines 26-28

siphons 2y-30

discharge prrinit 425 